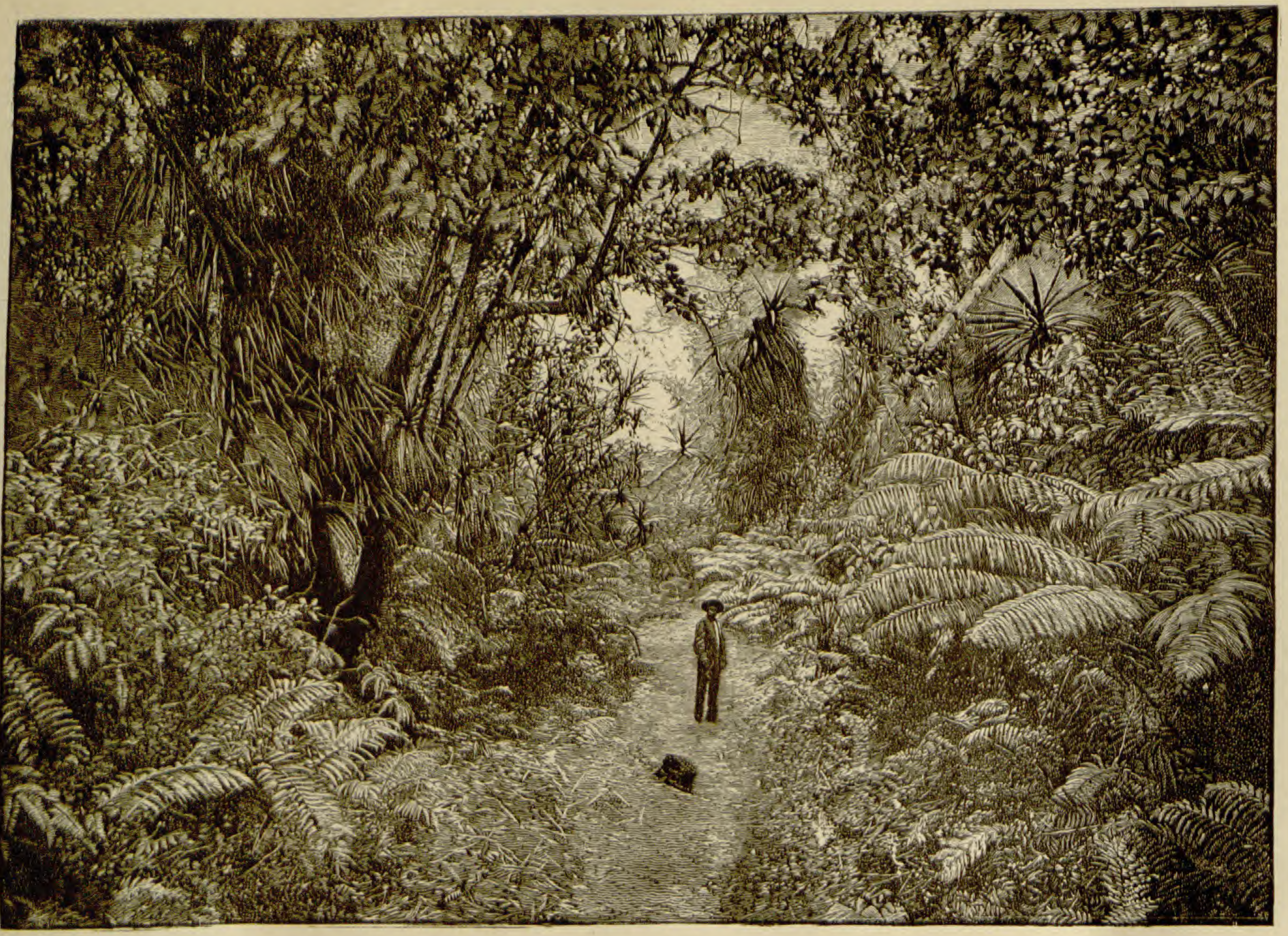




\section{FLOR A}

OF THE

\section{HAWAIIAN ISLANDS:}

A DESCRIPTION

OF THEIR

PHANEROGAMS AND VASCULAR CRYPTOGAMS.

BY

WILLIAM HILLEBRAND, M.D.

ANNOTATED AND PUBLISHED AFTER THE AUTHOR'S DEATH

BY

W. F. HILLEBRAND.

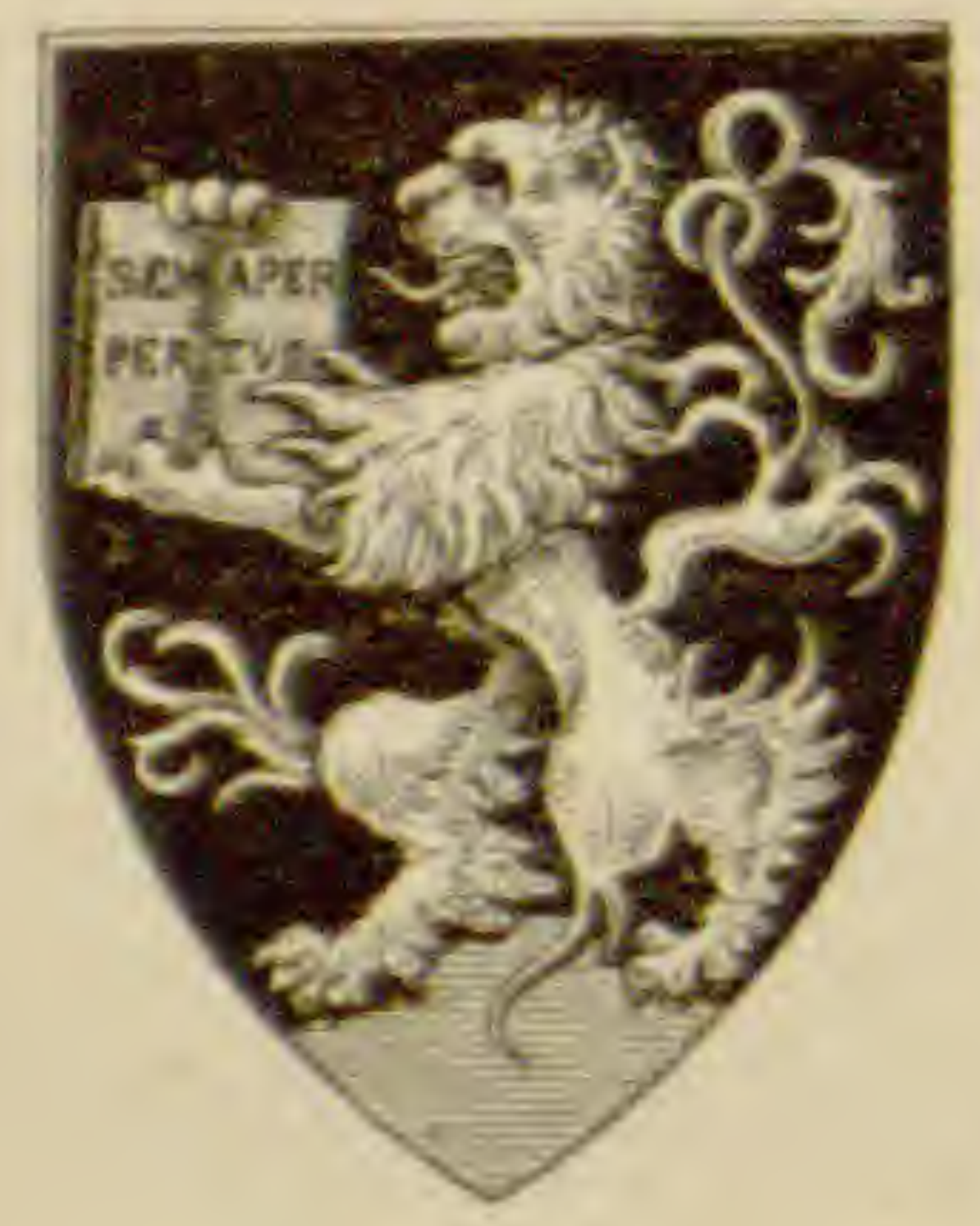

LONDON:

NEW-YORK :

WILLIAMS \& NORGATE. B. WESTERMANN \& CO. I4 HENRIETTA STREET, COVENT GARDEN.

Sas BROADWAY.

HEIDELBERG:

CARL WINTER, UNIVERSITY-BOOKSELLER. 
All rights reserved.

$x$ 


\section{DEDICATED}

BY

\section{THE FAMILY OF THE AUTHOR}

IN AFFECTIONATE REMEMBRANCE OF HIM

TO THE

\section{HAWAIIAN PEOPLE,}

WHOSE KINDLY TRATTS OF CHARACTER HE WARMLY APPRECIATED AND TO WHOSE WELFARE DURING A SOJOURN OF TWENTY YEARS HIS BEST ENERGIES WERE UNSELFISHLY DEVOTED. 


\section{CONTENTS.}

Frostibpiece (Forest Scenery, Puxa).

Page.

Dedication

Mr. Bextham's Outzines of Botany:

Chap. 1. Definttons and Descriptive Botany...... XXXII

$\$$ 1. The Plant in General . . . . . . . . . . . .

XXXIII

s 2. The Root.

XXXV

s 3. The Stock

XXXVI

$\$$ 4. The Stem.

XXXVI

$\$$ 5. The Leaves

XXXVIII

\& 6. Scales, Bracts, and stipules

XLII

\$ 7. Inflorescence and its Bracts

XLIII

$\$$ 8. The Flower in General

XLV

\$ 9. The Calyx and Corolla, or Perianth

XLVIII

\& 10. The Stamens

\$ 11. The Pistil

LI

$\$ 12$. The Receptacle and Relative Attachment of the Floral Whorls ...............

$\$$ 13. The Fruit . . . . . . . . . . . . .

$\$ 14$. The Seed.

\$ 15. Accessory Organs

LVIII

Chap, II, Classification, or Sxstematio Botany . . . . .

LIX

Chap. III. Vegetable Axatomy axd Physiology:

8 1. Structure and Growth of the Elementary Tissues..

$\$ 2$, Arrangement of the Elementary Tissues, or Structure of the Organs of Plants ............

\$ 3. Growth of the Organs

LXI

s 4. Functions of the Organs

LXIII

Chap. IV, Colaechos, Preservation, and Determisation or Plasts.

INDEx of Tetars, or Glossary

LXV

LXVIII

LXX

Explaxatioss of ABввEviations and Sigss 


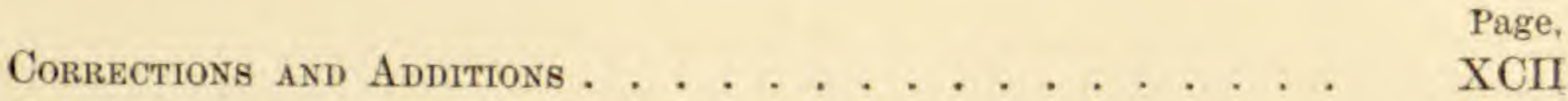
FLORA :

Phanerogamous or Flowering Plants:

Dicotyledonous or Exogenous Plants ... . . . . . . 1

Monocotyledonous or Endogenous Plants . . . . . . . 428

Cryptogamous or Acotyledonous Plants:

Vascular Cryptogams . . . . . . . . . . 539

General Index . . . . . . . . . . . . . . . . 652 MaPs:

General Map of the Hawaiian Islands.

Map of Hawaii.

Map of Maui, Molokai, Lanai, and Kahoolawe.

Map of Oahu, Kauai, and Niihau. 


\section{P R E F A C E.}

Shortly before his death, which occurred unexpectedly in Heidelberg, Germany, on the $13^{\text {th }}$ of July, 1886, Dr. Hillebrand had placed part of the manuscript of his Flora of the Hawaiian Islands in the hands of the printer, and the first few pages of proof had already been corrected.

No directions having been left it devolved upon his family to decide how best to continue the publication. The manuscript of the descriptive portion of the Flora was supposed to be complete, and as Professor E. Askenasy, of Heidelberg, had most kindly expressed a willingness to assist in the correction of the proof-sheets from the point of view of the botanist it was decided that the task of seeing the work through the press should devolve upon myself. This responsibility I assumed with many misgivings, feeling far from competent to carry the work to a successful issue; and that these misgivings were well founded was soon made manifest when, fairly entered upon the work, the true nature of the task became fully apparent. The difficulty was increased by the impossibility of communicating satisfactorily with the publishers in regard to many matters of detail, owing to the length of time required for the transmittal of letters twice across the Atlantic. To this fact is due likewise, in great measure, the delay in publication.

To no one who may study the volume can there be cause for greater regret than to myself that the author did not live to correct the proof-sheets. The tortures of a painful illness during the last two years of his life necessarily produced results which 
showed themselves in various ways in portions of the manuscript. The literal reading of the text has been scrupulously adhered to, except in certain minor points where I felt justified in using an editorial discretion, and in certain other cases where, mainly owing to ambiguity of expression, changes seemed imperatively demanded. Where these were of a nature to require the advice of a professional botanist they have been made only after meeting with the full approval of Professor Askenasy, to whose vigilance, in fact, the chief corrections of this character are due.

It is believed that every error of consequence overlooked in the proof has been noted in the list of Corrections and Additions, That these errors are so numerous as they appear arises in part from the fact that only one proof could be examined by myself, in part from certain inconsistencies in the manuscript which were not apparent in correcting the proof-sheets as they arrived from time to time.

The present work comprises descriptions of all indigenous and well naturalized Phanerogams and Vascular Cryptogams known to have been collected on the Hawaiian Islands*. Among them are 180 species and 6 genera which are considered new. The author had also made considerable collections of mosses, lichens, etc., and it is probable that these may be entrusted for examination to some authority upon the subject, in which case the results will doubtless be given to the world at some future time.

In giving the habitat of a plant the name of the island is printed in spaced letters, that of a district or place in italics. The sign $\dagger$ appearing before a specific name indicates that the species is of recent introduction into the Hawaiian Islands, i. e., since the discovery of the group by Capt. Cook. The conventional sign! placed after a name denoting habitat signifies that a specimen or specimens of the species described are to be

* Including those reported by other botanists and not observed by the author. Only in eases where the assignment of a species to the Hawaiian Islands was known by him to be founded on error has such species been omitted. 
found in the author's herbarium, which, according to a verbal wish expressed a few hours before his death, has been presented to the Royal Botanical Museum of Berlin*. In view of the great value of the gift the Prussian Government has granted the sum of one thousand Marks towards defraying the expenses of the present publication.

Among the papers left by Dr. Hillebrand were several pages, numbered consecutively, of what was evidently the rough draft of the commencement of an Introduction to the present work. A portion of it bore evidence of having been written at an earlier period than the rest, and there was want of connection between parts. There were besides a few pages devoted to a discussion of the origin and development of the Hawaiian flora as revealed by a study of the Ferns, and a number of fragmentary notes and observations. Notwithstanding their incompleteness and the uncertainty as to whether they fairly represent throughout the views held by the author up to the time of his death it has been deemed advisable to publish both the Introduction and notes as found, with only such slight emendations as were absolutely necessary. It is probable that the Introduction, had the author lived to complete and elaborate it, would have been a very important feature of his book and of high scientific value, for his long residence on the Islands fitted him preeminently to discuss in their greatest breath the interesting questions of the origin and development of the Hawaiian flora.

It was known to be the author's intention that the Flora should contain some elementary outline of botany, for the convenience chiefly of amateurs in the Hawaiian Islands. No arrangements had been made, however, in regard to this, and it is uncertain that any would have been made. I felt that such an addition to the work would be of value in certain directions, and therefore endeavored to meet his wish in this respect by acquiring from Messrs. L. Reeve \& Co., of London, the right to

- The Royal Herbarium at Kew likewise possesses numerous speeimens sent thither by Dr. Hillebrand previous to the year 1870. 
republish Mr. Bentham's invaluable Outlines of Botany, and Glossary.

Following this I have introduced a kind of bibliographical index, giving in sufficient fullness to allow of ready identification the titles, with cross references, of all botanical works cited in abbreviated form in the Flora. This feature will, I trust, be of value to many.

The maps at the close of the book were prepared with special reference to immediate location of the habitat of a given species. With very few exceptions all names of habitat mentioned in the Flora are to be found upon the maps. The orthography differs in a few cases from that employed by the author, but generally so slightly as to offer little or no difficulty in identification. No claim is made to the highest degree of topographical accuracy, especially in the cases of the islands of Kauai, Molokai, and Lanai, of which no recent maps were available for use in compilation, the Hawaiian Government Survey not having as yet completed its work.

Dr. Hillebrand was indebted since his departure from Honolulu in especial to Mr. John Lydgate, of Laupahoehoe, Hawaii, and to Mr. Valdemar Knudsen, of Waiawa, Kauai, for frequent remittances of dried plants to aid in the preparation of this work. The first named gentleman is generally quoted as authority throughout the text by the abbreviation Lydg., the latter by $K n$. Specimens were also received, I believe, from $\mathrm{Mr}$. D. Baldwin (Baldw.), Mr. Edward Bailey, and from the late Messrs. Edward Bishop and E. Johnson.

To all who may have been of assistance to the author in his labors, whether living in the Hawaiian Islands or elsewhere, his family express in his name their sincere thanks.

The use of the original plate for the frontispiece, which is taken from Capt. C. E. Dutton's paper on Hawaiian Volcanoes, in the Fourth Annual Report of the United States Geologieal Survey, was kindly allowed by the Hon. G. W. Powell, Director of the Survey, for the purpose of making an electrotype copy. To 
Prof. W. D. Alexander, Surveyor General of the Hawaiian Islands, my thanks are due for maps of recent government surveys, and to Prof. Lester F. Ward, of the United States Geological Survey, Mr. Frank H. Knowlton, of the Smithsonian Institute, Dr. George Vasey, of the Agricultural Department, Washington, and Prof. W. G. Farlow, of Cambridge, Mass., for advice and favors in the prosecution of my own task. Above all to Prof. E. Askenasy, of Heidelberg, is the expression of my deepest gratitude fitting for his untiring interest in the production of the life-work of his friend, the author of the present volume, without whose invaluable advice and assistance my labors would have been far less successful than it is hoped the result will prove them to have been.

In conclusion a few words biographical may be in place.

William Hillebrand was born at Nieheim, Westphalia, on the $13^{\text {th }}$ Nov., 1821. At the close of his university career at Göttingen, Heidelberg, and Berlin he practised his profession, medicine, in Paderborn, near his birthplace. On account of an affection of the lungs he was soon forced to leave his native country, and set sail for Australia. Thence he passed to Manila, in the Philippine Islands. While engaged here in practice his health again obliged him to wander. At death's door, as supposed, he boarded a brig bound for San Francisco. The voyage was of benefit to him, and after arrival in California he sought by advice the Sandwich or Hawaiian Islands, where in course of time his health became fully restored.

During a residence of twenty years in Honolulu he prosecuted unremittingly the study of the Hawaiian flora, visiting all the larger islands, penetrating to the inmost recesses of their deepest and darkest ravines, and climbing to the summits of their loftiest mountains. He gradually formed about his home an extensive garden, crowded with the greatest variety of shrubs and trees gathered from all parts of the world at great expense. The cultivation of this garden, full of its native and foreign plants, was his chief recreation and delight. 
He mastered the language, and soon, by his skill in his profession and unselfish efforts to mitigate the effects of disease upon the aboriginal race, won a lasting reputation both among the native and foreign population. He filled at different times various responsible positions, such as those of Physician of the Queen's Hospital and of the Insane Asylum. He was an active member of the Board of Health and of the Royal Hawaiian Agricultural Society, and was a member of the Privy Council of king Kamehameha V., besides being his private physician.

In 1865 and 1866, while on a voyage as Commissioner of Immigration for the Hawaiian Government to China and the East Indies, he made collections of plants in Hongkong and its neighborhood and in Java. A great number of living plants and birds were brought by him from the Asiatic countries visited, many of which are now more or less distributed, some even naturalized, in the Islands. Previous to this he had collected largely in certain parts of California.

Since leaving the Islands in 1871 he had resided in different parts of Germany and Switzerland, and was for some years in Madeira and Teneriffe, where he also collected extensively. For two years or more previous to his death he had been afflicted with an excruciating illness, in consequence of which progress upon the Flora was much delayed and sometimes altogether suspended. It was not more than two months before the end that the manuscript was declared complete.

His remains lie in the burial place overlooking the fertile valley of the Rhine on the outskirts of the beautiful town of Heidelberg, so endeared to him by the recollections of his student days and the associations of several years of residence during the later years of his life.

Washington, D.C., Sept. 1887.

W. F. Hullebrand. 


\section{INTRODUCTION.}

The Hawaiian Islands, lying between $18^{\circ} 55^{\prime}$ and $22^{\circ} 15^{\prime}$ N. lat. and $154^{\circ} 50^{\prime}$ and $160^{\circ} 30^{\prime} \mathrm{W}$. long. from Greenwich, are more remote from any continent or high land of considerable extent than any group of similar dimensions on our globe. The shortest distance to the American Continent is 2040 geographical miles; to the Marquesas, the nearest high islands in the Pacific Ocean, it is only 180 miles less (1860), and to Tahiti 150 miles more (2190). Of other large islands which can serve for comparison, New Caledonia, with an area nearly equal to that of our group, is at a distance of 660 miles from Australia, and the Vitis or Fijis, with an area only little larger, are 1410 miles from the same continent; but both are connected by an almost continuous series of high islands with New Guinea and the Malay Archipelago. New Zealand, with an area sixteen times as large, is 1080 miles distant from the nearest point of Australia. Madagascar and the Mascarene Islands are only 300 miles apart, and St. Helena, although 1120 miles from the African coast, is too small to be placed in comparison.

There is no ground for supposing that in past geological ages this isolation of the Hawaiian group has been less complete. It is true that in a northwesterly direction a succession of reefs and low uninhabited islets extends for a distance of thirty degrees of longitude about halfway to Japan, revealing a narrow band of raised sea-bottom, with an average depth of less than 1000 fathoms. This line of reefs and islets follows exactly the trend of the fissure in the globe's crust on which the Hawaiian volcanoes have been built up, and, as there is abundant evidence that the age of the different islands of the group increases from east to west, it is fair to conclude that these islets, rocks, and reefs lie on the same fissure and are only the coral covered peaks of submerged older volcanoes, or, in other words, that the 
volcanic action commenced at the northwest extremity, thirty degrees of longitude northwest from the island of Kauai, and gradually moved on to the island of Hawaii, with subsidence of the older formations while it progressed. But the western extremity of this raised sea-bottom land is separated by a great distance and enormous depths of sounding from the nearest high land, Japan, and the circumstance that the present flora of the Hawaiian Islands has less affinity to that of Japan than to any other warm or temperate country on the borders of the Pacific Ocean forbids altogether the assumption that this submerged chain of islands can at any time have formed a road for the migration of plants.

The soundings hitherto made between the Hawaiian Islands and California have given uniform depths of 3000 fathoms, and only a couple of degrees to the south commences one of the greatest depressions in the ocean, with depths of more than 3000 fathoms, extending nearly to the next group of low islands Palmyra, Fanning, Christmas, Jarvis, and others - which trend in the direction of the Society group. The supposition of a terrestrial immigration of plants in former times finds no support in our actual knowledge.

Not much better stands the case with regard to ocean currents. The Hawaiian group lies entirely within the domain of the Northeasterly Current of the Pacific, a direct continuation of the great Kuro Siwo or North Pacific Drift, which, like the Atlantic Gulf Stream, deflects southward on reaching the opposite continent and returns upon its course to deposit driftwood of pine logs from the northwest coast of America on the shores of our islands and those of the Marshall and Caroline groups much farther on. As a review of the Hawaiian flora shows that the northwest coast of America, including California, has until quite recent times only contributed one or two inhabitants of the highest mountains, and has besides few so-called representative species, the influence of this current in supplying the islands could hardly come into account if it were not for a feeder which it receives on its southern boundary, while deflecting westward, from the coast of Mexico and Central America, and perhaps from still farther south. This accessory stream may or may not account for the important American element of the Andine regions which is apparent in the Hawaiian flora.

Of greater importance must have been the Equatorial CounterCurrent. Originating north of the equator, in the neighborhood 
of the Molucca Islands, it runs in a nearly straight course south of the Caroline and Marshall Islands toward the Bay of Panama. Although separated ordinarily by a narrow strip of neutral water from the North Equatorial Current - the continuation of the North Pacific Drift running in a direction opposite to it - still there can be no doubt that during the long continued prevalence of southwesterly gales, which prevail in winter, it will be pushed farther north, so as to intermingle to the east of our longitude with the North Equatorial Current and thus deposit drift on the shores of the Hawaiian Islands.

As may be inferred from this isolation the flora of the Hawaiian Islands is very peculiar, and contains a much larger proportion of endemic plants than that of any other country. The great elevation of the mountains contributes to bring about this result and to increase the variety of forms. A single day's march will carry the traveller from the tropical heat of the coast to the region of perpetual snow, and in crossing the breadth of an island he may pass from a climate with an annual average of 180 inches of rainfall to one of 30 inches or less. In contrast to this diversity in temperature, moisture, and barometric pressure stands the uniformity of soil, which is derived almost entirely from the decomposition of basaltic rock, there being but a narrow band along the coast in some regions formed from coral limestone. The ground is generally pervious, so that the rainfall is soon absorbed. Only in the lowest and broadest valleys and the adjacent flat coast, and on some of the tablelands of the oldest formation, where denudation has long been active, is the water retained. In the valleys a heavy retentive clay forms the surface and affords a suitable bed for the cultivation of taro and rice. On the high tablelands of Kauai and West Maui, and also in one or two parts of Molokai, a thick layer of mosses, liverworts, and sedges covers the moderately heavy soil; being within the reach of perpetual clouds and continually dripping with moisture it has increased to beds of turf, and forms extensive bogs, the habitation of many of the rarest plants. The present work describes $844^{*}$ species of phanerogamic

* The figures given on this and the following pages are mainly my own, as it was found by a careful enumeration that the number of species described in the Flora did not quite accord with the author's total nor with allotments to the different subdivisions. This, with other evidence in my possession, renders it almost certain that this portion at least of the Introduction was written some time before the completion of the Flora, and that the author subsequently altered his mind as to the validity of a few species and as to whether a plant had been introduced since the discovery of the Islands or was original. W. F. H. 
plants, distributed over 335 genera, and 155 vascular cryptogamio plants, distributed over 30 genera, making a total of 999 species and 365 genera. Of these it is believed that 115 species have been introduced since the discovery by Captain Cook in 1779 . These are distributed over 101 genera, 22 of which also contain indigenous species. They are weeds of cultivation, escapes from gardens, accidental arrivals, but all well established, and many: are counted among the most common wayside weeds. Others have invaded the forests, and some are found on mountain tops. Their number is increasing from year to year, and undoubtedly even now exceeds that given above, which refers to a period fifteen years ago. Only few trees figure anong them, although several, as the Algaroba, Pride of India, Tamarind, and several species of Acacia and Eucalyptus might well claim a place. Besides these the following 24 species are considered to have been introduced by natives in prehistorical times*: Calophyllum Inophyllum, L., Paritium titiaceum, St. Hil., Thespesia populnea, Corr., Eugenia (Jambosa) Malaccensis, L., Lagenaria vulgaris, Ser., Cucurbita maxima, Duch., Cordia subcordata, Lam., Ipomaea Batatas, Lam., Broussonettia papyrifera, Vent., Artocarpus incisa, L. f., ?Boehmeria stipularis, Wedd., ?Aleurites Moluccana, Willd., Piper' methysticum, Forst., Cocos nucifera, L., Colocasia antiquorum, Schott, Alocasia macrorrhiza, Schott, Musa sapientum, L., ?Zingiber: Zerumbet, Rosc., Curcuma longa, L., Tacca pinnatifida, Forst., Dioscorea pentaphylla, L., Dioscorea sativa, L., Cordyline terminalis, Kth., Saccharum officinarum, L.

They all extend through the whole of Polynesia into Malaysia, and have accompanied the Maoli race in their migrations, yielding them food, intoxicating beverage, and material for eloth, rope, and other domestic uses, while some were associated with religious worship or esteemed as littoral shade trees. The seedless breadfruit tree, the sugar-cane, banana, taro, etc., could not possibly have reached the islands by any other than human agency. That the natives in remote times made voyages to southern island groups is abundantly established by their old meles or songs, In them the names Kahiki, Raiatea, Bolobola - islands of the Society group - are mentioned, as also the headland on the island from which they used to start; and the time of the year or constellation. When one reflects on the enormous distances thus traversed, without compass, in open canoes, one is struck * This list did not aceompany the manuscript, but was copied from a memorandum
found among the author's papers. W. F. H. 
with amazement at their daring and cannot help assuming that they then had a greater knowledge of astronomy than they were found to possess at the time of the discovery of the group. It is not unlikely that the number of plants thus introduced is in reality much greater than has been assumed here.

Deducting now the 115 species introduced by man since the discovery and the 24 before that period there remain 860 species of Phanerogams and Vascular Cryptogams as original inhabitants of the Hawaiian Islands, distributed over 265 genera, or 3.25 species to one genus. Of these 860 species no less than 653 are endemic, i. e., peculiar to the Islands, or 75.93 per cent., and of this number 250 species belong to 40 endemic or peculiar genera, with an average of 6.25 species to one genus. The proportion of endemic Phanerogams to original Hawaiian Phanerogams is 574: 705 , or 81.42 per cent. Restricting the computation to Dicotyledons alone we arrive at the extraordinary proportion of $500: 584$, or 85.62 per cent. of endemic Dicotyledons*.

s:

The great majority of endemic species inhabit a limited area, are confined to a single island or portion of it. In some of the larger genera there are one or a few leading species which extend over the whole or greater part of the group, with only slight

* Here occurs an evident hiatus, and the page of the manuscript following, relating to geographical distribution and to the affinities of endemic genera, shows so little connection with what precedes or follows and is so incomplete in itself that it has been deemed neeessary to exclude it.

The subjoined table has been prepared to show at a glance the proportions of endemic and original plants, as well as those of recent and aboriginal introduction, in the different Series and Classes.

\begin{tabular}{|c|c|c|c|c|c|}
\hline & $\begin{array}{l}\text { Of Aboriginal } \\
\text { Introduction }\end{array}$ & $\begin{array}{l}\text { Of Recent } \\
\text { Introduction }\end{array}$ & Endemic & Original & Total \\
\hline $\begin{array}{l}\text { Dicotyledons } \\
\text { Monocotyledons }\end{array}$ & $\begin{array}{l}13 \\
11\end{array}$ & $\begin{array}{l}92 \\
23\end{array}$ & $\begin{array}{r}500 \\
74\end{array}$ & $\begin{array}{l}584 \\
121\end{array}$ & $\begin{array}{l}689 \\
155\end{array}$ \\
\hline Phanerogams & 24 & 115 & 574 & 705 & 844 \\
\hline Vascular Cryptogams & 0 & 0 & 79 & 155 & 155 \\
\hline $\begin{array}{l}\text { Phanerogams and } \\
\text { Vascular Cryptogams }\end{array}$ & 24 & 115 & 653 & 860 & 999 \\
\hline
\end{tabular}

Hillebrand, Flora of the Hawaiian Islands. 
modifications; others, again, have only been found in quite limited localities. One reason for this circumstance may be found in the regular currents which pass through the various channels from northeast to southwest and effectually prevent communication by sea.

As the age of the various islands increases in progression from east to west it may be inferred that the richness in endemic species will stand in the same ratio. Kauai, although in point of extent only fourth in the list, is not only richest in species but has them also on the whole more differentiated. In several genera, as Schiedea, Raillardia, Dubautia, the Kauai species are more individualized than the rest.

The southwest or Kaala range of Oahu would seem to be of the same age as Kauai, and perhaps is not inferior to it in number of peculiar species. The character of this range differs from that of the main range of the same island, inasmuch as it is more disintegrated and broken up, and, lying under the lee, has a drier climate and no permanent watercourses of any importance. It extends in length about twenty miles; its highest mountain, Kaala, has an elevation of $4000 \mathrm{ft}$., the next in height, Puakea, being nearly $1000 \mathrm{ft}$. lower. The main range of Oahu, which runs through the whole length of the island, has a rather gentle slope on the leeward side, and is there furrowed by broad and deep valleys, each with a stream, except those of the rather low eastern extremity. This southern or lee side is, or rather was, fairly covered with forest. At the head of Nuuanu valley, on each side of it, stand the highest peaks of the range, Konahuanui and Waiolani, with elevations of about $3000 \mathrm{ft}$., from which point the range gradually lowers to its eastern and western ends. It forms a slight curve, approaching close to the northern shore at the extremities while the middle portion recedes from it and falls of in an almost perpendicular, unbroken rock wall into the low lying district of Koolau, which is in part surrounded by it as by an amphitheater, and produces the impression of having been a vast crater, the northern wall of which had been submerged in the sea. This rock wall presents sharp knife-like ridges at the head of each valley running toward the south. Between the main and the western or Kaala range extends a somewhat elevated, bare tableland furrowed by streams issuing from the adjacent ranges.

The island of Molokai is probably of the same age as the main range of Oahu, but of a different character, since the 
mountain range has a larger bulk, is not intersected by cuts, and therefore intercepts the greater portion of its rainfall on the northern side, which is deeply furrowed by a succession of large valleys, Pelekunu, Wailau, and others, cut off from each other on the sea side by steep, projecting headlands. The southern slope of the range is gentle and mostly continuous, with only a very narrow strip of flat land at its foot. Low hills occupy the western end of the island. The highest peak probably reaches a height of $3600 \mathrm{ft}$.

The island of Maui consists of two very distinct divisions, which are united by a broad and sandy isthmus having a maximum elevation of $160 \mathrm{ft}$. The smaller western half, a bulky mountain mass of about $6000 \mathrm{ft}$. height, is surrounded by a very narrow strip of flat land, and its flanks are cut on all sides nearly to the center into deep and precipitous ravines, each carrying a copious stream of water. The flat top, wrapt in a cloud of mist nearly the whole year, is boggy, and harbors a number of rare plants, many of which are altogether confined to this narrow area. No bare lava streams are anywhere to be seen; a thick layer of detritus or arable soil covers the entire surface. All evidence of a central crater has been effaced, but the valley of Oloalu presents a broad and deep, circular valley with a narrow outlet for its stream, similar to the well known Caldera of the island of Palma, or rather like the Grand Curral of Madeira, to which island West Maui bears also otherwise a considerable resemblance. Tufa cones are likewise almost absent.

Of much more recent origin is East Maui, built up entirely by the vast mountain mass of Haleakala. Its height exceeds $10,000 \mathrm{ft}$., and a vast triangular pit-crater with steep sides of 1000 to $2000 \mathrm{ft}$. in height occupies the summit. Its slopes, studded with numerous tufa cones, slope to the sea without a belt of flat land intervening, and three bare lava fields lie exposed in glistening blackness on the southern flank. Still, the subterranean fires have been quiet for ages; there is no steamvent or hot spring anywhere on the island, and no tradition of volcanic activity is preserved in native lore. The great height of the island forees the clouds to deposit their moisture on the northern or windward side. Here, consequently, a considerable number of gullies are worn in the lower portion of the flank, but they are neither so deep nor so long as those in the western division of the island. The southern slope is continuous, unbroken, and rainless to such a degree that the three lava 
streams spoken of before, although certainly hundreds of years old, are quite bare of vegetation and reflect, when seen from a distance above, mirror-like the rays of the sun from the smooth surface. Yet they are covered with shrub and forest in their upper course, as far as this touches the region of clouds.

The island of Hawaii, separated from Maui by a strait twenty miles in width, is made up of mountain stocks of very different ages. The oldest is undoubtedly the most western, the Kohala range. It occupies the north angle of the island in a direction from nortbwest to southeast, and rises to a height of about $6000 \mathrm{ft}$. No trace of a crater is left, and the few tufa cones on the southwest side are much worn down. On the northern extremity it is fringed by the plain of Kohala, the only level land with deep soil to be found on the island, and eminently adapted to the cultivation of the sugar-cane. The windward side is deeply cut into broad valleys which penetrate to the core of the mountain and enclose level bottoms with steep, often precipitous, walls 1500 to $2000 \mathrm{ft}$. in height. The valley of Waipio has a waterfall of considerable size (1500 ft. high), which it is dangerous to approach on account of the stones and rocks which are frequently detached and hurled down by the force of the water. The dividing ridges fall off in precipitous cliffs toward the sea. Intercommunication between these valleys otherwise than by canoe is exceedingly difficult, in some cases impossible, and the people living in them are as much cut off from the rest of the world as those in the valleys of Pelekunu and Wailau on the north side of Molokai. The valleys are all noted for the abundance of taro raised. The basalt of this range is more compact, heavier, and blacker than that of any other formation of the Islands, and the preponderance of iron is indicated by the strongly magnetic property of the black sand carried to the sea by the streams.

Next in age comes Mauna Kea, the highest mountain of the whole group $(13,805 \mathrm{ft}$.). It is an extinct volcano without central crater, and has an almost unbroken mantle of eroded rock in its upper half, here and there covered with argillaceous soil. Bare lava streams appear only near the broad top, which is generally wrapt in clouds and is crowned by seven cones of 600 to $1000 \mathrm{ft}$. height, built up of lapilli and tufa. The small crater of one of these cones is usually filled with water. In its lower half the windward side of the mountain is furrowed by a great number of more or less deep, narrow gulches, each carrying a copious 
stream which in its course forms many cascades. Between Hamakua and Hilo the traveler has to cross more than forty of these gulches, the largest of them, that of Hakalau, almost $2000 \mathrm{ft}$. deep, while others do not exceed $100 \mathrm{ft}$. in depth.

Hualalai, $8200 \mathrm{ft}$. high, has experienced several eruptions in the beginning of the present century, but none since. Probably it had formerly a pit-crater at its summit like Kilauea and Mokuaweoweo; at present the depression of its extensive summit is surrounded on three sides or more by a rim of moderate elevation, which recalls on a smaller scale the Circus of the Peak of Teneriffe without the central Pico de Teyde. In place of this both the bottom of the small caldera and its rim are studded by a multitude of small cones; some with a truncate top at once recognizable as tufa cones, others pointed and giving vent at the sharp top to a narrow chimney, often of unfathomable depth, so that the reverberation of a stone strown down will be heard for a quarter of a minute. The lava at the bottom of the caldera is concealed by a very porous and light scoria covering, through which the foot breaks at every step.

Finally, Mauna Loa, the only active volcano at the present time, with its two great pit-craters, Kilauea and Mokuaweoweo, concludes the series of Hawaiian formations. With a base of nearly 60 miles from west to east and a height of $13,675 \mathrm{ft}$. it has a uniform and gentle slope of $5^{\circ}$, unbroken on all sides and bare of vegetation in its upper half, which is entirely covered by recent lava streams. No ravine or gully breaks the uniformity of its mantle, although the lower half is covered by dense forest - only here and there broken by recent lava streams - which causes large precipitation of rain, not only on the windward side, but, owing to a deflection of the trade-winds at the southwest end, also in the middle zone on the lee side. All the rain which falls, the annual average at Hilo being 180 inches, is absorbed by the porous rock and runs underground, to well forth in springs along the shore or farther out under the sea.

The area between the three mountains, Mauna Kea, Mauna Loa, and Hualalai, is a triangular plateau of 5000 to $6000 \mathrm{ft}$. elevation above the sea, covered by broken lava and a stunted scrub vegetation.

We have thus the following groups of formation: 1. Mauna Loa; 2. Hualalai; 3. Haleakala; 4. Mauna Kea; 5. Kohala range and West Maui; 6. Molokai and main range of Oahu; 7. Kaala range of Oahu, and Kauai. 
The preceding digression establishes one indisputable fact, viz., that volcanic action in the fissure of the earth's crust over which the Hawaiian group has been built up proceeded gradually, some irregularities excepted, from west to east. Geologists might hesitate to infer from this the absolutely greater age of the western islands, for geological evidence alone would not exclude the supposition that all the islands of the chain were elevated at the same time and that the volcanic activity only died out sooner in the western than in the eastern islands. But here botanical evidence steps in to furnish the proof that in reality the age of the different islands rises in progression from east to west. It may be stated simply in these few words, that the flora of Mauna Loa is the poorest and most uniform, and that of Kauai the richest and most individualized in species, and that on the whole the intervening islands follow the same ratio when allowance is made for difference in heights; for high mountains offer a greater diversity of climate, and, therefore, suitable conditions for many plants which cannot live in lower zones.

The monotony of the forests of Puna, Kau, and South Kona, on Hawaii, will strike every attentive visitor and disappoint the botanical collector by the scarcity of the harvest. This can hardly be ascribed to the periodical destruction of forests by lava streams, for these follow with long intermissions, affect only limited areas at a time, descend mostly down the northeast slope, and it is surprising to see how quickly the ruin is repaired, how speedily decomposition takes place in the lava when exposed to the influence of copious rains and the trade-winds. In 1862 I visited the lower end of the lava stream which in 1856 had cut its way through the forests toward Hilo. A belt of thirty feet in width on each side of it was covered with a shrubby vegetation which had already attained a height of three to five feet. In the break of the pali of Oahu at the head of Nuuanu valley, through which the trade-winds sweep with intense force nearly the entire year, one could observe hard, compact basalt gradually softening until it could be eut with a pocket knife. And with how little soil plants are content when favored by copious rains is exemplified by the fact that the natives of Puna, Hawaii, raise good crops of sweet-potatoes in the hollows and cracks of bare lava by simply covering the budding sprigs with decayed leaves and herbs. In the same region I once saw a cocoanut lying on smooth pahoehoe lava which had germinated there and sent off a root for a distance of eight inches until it met a 
crack down which it descended. On the other hand the same kind of lava when not affected by rain and wind will remain unchanged for centuries, as may be seen under the lee of East Maui. Nowhere else have the forests, although extensive, so gregarious a character as within the area of Mauna Loa, and the species which compose them show hardly any variation from those forms which are met with more to the east. The forests of Hilo and Hamakua, which belong to the region of Mauna Kea, are already more diversified, and still more those of the Kohala range.

In great contrast stands the vegetation both of Kauai and of the Kaala range of Oahu. Most of Mann's and Wawra's new species come from Kauai, and Mr. Knudsen's collections have added still more to them. Even the species which that island has in common with others generally vary from them in one or more particulars. The Kauai species of the leading Hawaiian genera are in all instances the most specialized, to be distinguished by more striking characters than the others. Examples are: Schiedea, Raillardia, Dubautia, Campylotheca, Lipochaeta, Pittosporum, Pelea. The proportion of species peculiar to Kauai with species peculiar to all the other islands is about $67: 382$, or $17.5: 100$.

For the sake of convenience the Hawaiian flora may be divided into groups occupying different zones of elevation, as follows.

1. The lowland zone. Open country, grass-covered after the rains, with isolated trees or clumps of trees represented by Paritium tiliaceum, Erythrina, Reynoldsia, Pandanus, Capparis, Gossypium, Abutilon incanum. It also includes the littoral species.

2. The lower forest-zone. Tropical in character, its upper limit between 1000 and $2000 \mathrm{ft}$. above the sea. Its physiognomy is marked distinctly by Aleurites Moluccana, the pale foliage of which in contrast with the green color around attracts at once the eye of the beholder. The woods are rather open. Zingiber Zerumbet covers the ground. Cordyline, Eugenia domestica, Zingiber Zerumbet, and other plants are strictly confined to it. Pandanus odoratissimus and Paritium tiliaceum do not pass beyond it, but Freycinetia does. To its upper portion, but extending into the lower portion of the next zone, belong also most Sapotaceae, Apocynaceae, Gardenia, Psychotria, Maba, most Urticaceae, Pisonia, Elaeocarpus, Aurantiaceae, and others.

3. The middle forest-zone. This lies within the region of clouds, and develops the greatest luxuriance in trees and jungle. 
As representatives may be designated the Alani and Olapa in Pelea and Cheirodendron. The prevailing trees are indeed Metrosideros polymorpha and Acacia Koa, but although they reach here their greatest development in size and number they are not confined to this zone, but extend above and descend below it. It is the home of all Rutaceous and most Araliaceous trees, the ubiquitous Dodonaea viscosa, Alphitonia, and Coprosma. The ferns luxuriate in it, and tree-ferns attain only here their full dimensions. Old trunks are wrapped in creeping ferns, mosses, and lichens. Here also the Lobeliaceae, the peculiar pride of our flora, exhibit their most striking forms, but invariably in isolated individuals. The upper limit of this zone may be drawn at an elevation of 5000 to $6000 \mathrm{ft}$. It then passes gradually into the next.

4. The upper forest-zone. This extends as high as 8000 or $9000 \mathrm{ft}$. and is characterized by stunted trees, chiefly the Mamani (Sophora chrysophylla), Cyathodes, the Naeo (Myoporum), arborescent Raillardiae, Wikstroemiae, and Coprosma Menziesii. Between them luxuriate shrubby Compositae, Raillardiae, Dubautia, Campylotheca, and Artemisia, Strawberries, Brambles, and the Ohelo, Vaccinium. Ferns are scarce and mostly belong to widely spread species or stand near them, as Asplenium Trichomanes, $A$. Adiantum nigrum, Polypodium pellucidum, Aspidium aculeatum, Cystopteris. Shrubby Geranium and silvery leaved Argyroxiphium extend beyond the zone, at least on Mauna Kea, to the upper limit of vegetation, which may be placed at $11,000 \mathrm{ft}$. for that mountain. Santalum belongs to this zone and to the upper belts of the middle forests.

5. A place apart must be assigned to the bog-flora of the high table-land of Kauai and of the broad top of Mt. Eeka, on West-Maui. The turfy soil is covered with tussock-like Graminaceae and Cyperaceae, all quite peculiar species, with Sphagnum, creeping forms of woody Metrosideros, Cyathodes, Geranium, Lysimachia, and a number of rare, mostly single, representatives of genera which have their home in the Antarctic regions, New Zealand, the Falkland Islands, southern Andes, etc.

The breadth of these zones, partieularly of the first and second, varies considerably with their exposure; thus, under the lee of Haleakala and Mauna Loa the second zone rises to a height of $2500 \mathrm{ft}$.

Another peculiarity in the physiognomy of the vegetation has to be noticed. Under the lee of the high mountains of Hawaii 
and Maui the vegetation of the lower and part of the middle forest-zones is dwarfed; there are no trees properly speaking, everything is low shrub, stunted and gnarled, with stiff branches, the leaves crowded at their ends or in distant whorls, coriaceous, and generally tomentose underneath. The great heat and dryness of the air, the scanty soil — often undecomposed lava - check life. Short seasons of growth follow the rare rainfalls, to be succeeded by long periods of repose. As a rule the trees growing here have some peculiarity of their own which distinguishes them as varieties from the species of the same genus growing in the forests above. These regions look like the Australian Scrub or Californian Chaparal. In the following pages I have adopted the Australian name to designate it. There is a good deal of it also on Lanai, which lies under the cover of Eeka, and much less on Molokai. The vegetation of the third forest-zone on the high central plateau of Hawaii is of the same character, but composed of different species.

$* \quad * \quad \% \quad \%$

A comparison of the Hawaiian flora with that of any other country brings out at once a striking difference in the great number of varieties in all the species of leading genera. Some of these varieties are limited to narrow localities, and many of them might claim to rank as species. Others are spread over several islands and seem to be the product of climatal peculiarities, the same condition calling forth similar deviation from the normal type. Thus, in the scrub vegetations of the lee sides, the arid rocky soil, intense light and rare rainfalls, and rest of growth during many months of the year, modify a species in the same direction. Difference in temperature seems to be of less importance, for not rarely the same variety occurs above and below the dense forest-zone. The species are in consequence not well defined, and their description will be found to suffer from want of brevity, of terseness, which the student is inclined to expect in a work of this kind. As an apology I can only plead that my constant endeavor has been to be faithful to nature, that I have thought necessary in order to bring out the general transitions from one form to another to enter upon characters which often are considered of small importance.

Nature here luxuriates in formative energy. Is it because the Islands offer a great range of conditions of life? Or is it because the leading genera are in their age of manhood, of 
greatest vigor? Or is it because the number of types which here come into play is limited, and therefore the area offered to their development comparatively great and varied?

: $:$

$\therefore$

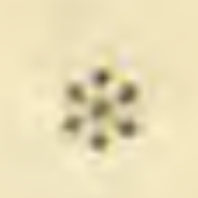

:

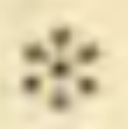

*On the contrary, a review of the Ferns of our flora may suggest the idea that it has been the center of formative power. In the genus Asplenium, which figures with 39 species and more than that number of good varieties, there exist three series or groups of species which show a gradual development of highly compound forms from simple pinnate ones. No one who saw only the extreme forms would think of associating them without knowing the intermediate grades; but having before me all links of the group I cannot resist the impression that all are intimately connected, that the more highly developed forms are the children or descendants of the next lower ones and have been developed on the Islands. The series have been named from the simplest form or first link of the chain: Group of Asplenium pseudofalcatum, with 4 species, Group of $A$. contiguum, with 8 species, and Group of $A$. Kaulfussii, with 6 species. The characters common to each group have been shortly noticed at the head of it, characters often considered of small importance by pteridologists but of undoubted value in the present case, because general. Now it happens that of each group one or another species, or at least a fern much like it, is reported from far distant countries, but not its other relatives in the family. Thus the A. affine $\rightarrow$ of the group pseudofalcatum exists in various islands of the Indian and Pacific Oceans, but not A. pseudofalcatum, A. lobulatum, or A. sphenotomum. Of the second group A. contigurm and A. caudatum have a wide range over one set of islands and continents and

* The leaves of the manuseript containing the present remarks upon ferus were not numbered, this portion of the Introduction therefore eannot be considered as a continuation of what has here preceded, and it is certain that it would not have been incorporated witls the Introduction without great alteration, possibly not at all. The reasons for this belief are based on evidence furnished by the manuscript, which shows that this discussion was written long prior to the completion of the author's labors on the Florn. 1. The omission of the gromp Asplenium polyphyllum in the enumeration of the groups into which a large portion of the Asplenia are divided. (The figures indicating number of species in each group were wanting in the manuscript and have been supplied by myself.) 2. The repeated use of the name Asplenium affine to designate the plant described in the Flora as A. insititium, Brack. (Shown by the erasure of the former name, in that portion of the Flora manuscript descriptive of the species, and the substitution of the latter.) For these reasons I hesitated to publish these remarks, but deem it best to do so in view of the importance of the subject and of the fact that no other opportunity is afforded for learning the author's views upon it. W. F. H.

+ A. insititium, Brack, of the descriptive portion of the Flora. W. F. F. 
A. furcatum over another, A. horridum in Tahiti, but they seldom go together, and are never accompanied by the other related members of their group, which in fact have not thus far been found anywhere else. Shall we conclude from this that the Hawaiian Islands are the original home of A. affine, A. contiguum, $A$. caudatum, etc., and that only the spores of these species have been carried by the aid of birds, or whatever other agency, to distant countries? This would be little probable and not consonant with the conclusions we are driven to by the study of the other Orders of plants which constitute the Hawaiian flora. But if these species as such - ready made - were conveyed to the Islands, how does it happen that they fit so exactly in the frame of affinity with other species which already existed before their arrival in the new home? Perhaps the group of A. Kaulfussii will help us in overcoming the difficulty. Here we have in the lowest species of the series (and here I comprehend for the sake of convenience the form $\alpha$ of the three first species under one head, for they are collateral, all three must be considered as parallel first links in the chain of similar development) a fern which has great affinity to many other so-called species, as is attested by the great number of synonyms it has received from pteridologists who saw only one or few species. Its peculiarities are of apparently trifling importance: thus it differs from the New Zealand and Australian A. obtusatum or A. lucidum in the character of the scales, the width of the angle at which the veins leave the midrib, and the degree of curvature in the latter. In the simple form the second and third differences are so slight that they barely attract attention. Now it happens that both the New Zealand fern and the Hawaiian have parallel lines of evolution, a dareoid and a pinnate. But while the simple forms are only to be distinguished with difficulty by the slight characters indicated above, the higher forms diverge more and more. Our dareoid varieties are already sufficiently distinct from $A$. flaccidum, Forst., and our A. Lydgatei and A. meiotomum cannot be mistaken for A. difforme, R. Br., A. bulbiferum, Forst., or the S. Polynesian A. multifidum, Br., which all belong to the group of A. obtusatum. And then our A. bipinnatum is a fern which has no counterpart in that group. In fact, the higher evolutions of these two groups, although running parallel, are all unlike each other, and only the first links are very similar.

It is otherwise in our groups of $A$. pseudofalcatum and $A$. contiguum. Both are amply represented in the S. Polynesian 
islands, Australia, and India, nay even in the New World; for A. serra, L. \& R., and its relatives belong to the latter, $A$. cuneatum, Lam., to the former. Here one or another of the middle forms of our Hawaiian and corresponding Indian and S. Polynesian species approach each other, so as to show no specific difference, while those next below or above in the series may diverge. Thus, New Zealand and Hawaii have A. caudatum, but $A$. falcatum, Lam., of the former island is replaced in the Hawaiian flora by my A. nitidulum; the lowest links, though, appear to be identical. What species in the other group corresponds to our first link pseudofalcatum elsewhere I have not been able to make out, but it is certain that its next higher neighbor, A. sphenotomum, has not been observed yet elsewhere, nor to my knowledge the next lower, A. lobulatum, Metten.

Now the answer to the questions raised by the preceding considerations is this, that the $A$. affine of the Hawaiian Islands neither derives from Mauritius, Ceylon, or any part of India, nor vice versa has been sent there, that the presence of $A$. caudatum and $A$. horridum in countries where they are associated with $A$. contiguum does not need to be explained by the agency of birds, wind, or other conveyance, but that is has been evolved in loco; that originally spores of a few simple species have been diffused by known agencies over various countries, there have undergone slight modifications in character and evolved a series of higher forms; that in the evolution of these higher forms the latest modifications gained in prominence from generation to generation, but that on the whole the form of the new generations was predetermined by the structure of the original immigrant, consequently they run parallel in the different countries whither the original species drifted; that therefore a gradual divergence took place in the offshoots of the original species, which divergence increased with the higher grades of development; that nevertheless according to the law of atavism exceptionally rapprochement occurred even in the higher forms.

This theory would not be incompatible with the supposition that spores of a higher order of development reached a new country and the species pursuing its evolution upward reverted also to the lower forms.

The most interesting group of closely connected species is that of our Lindsayae, which stands unique, and, fortunately, has not been vitiated by wrong synonyms. 


\section{Fragmentary Notes and Observations.}

I have abstained as much as possible from generalizing, in describing a species have selected the most common form by which it is represented, or, where previous accurate descriptions existed, have adopted this as the typical form, to which the deviating ones are appended as varieties, each circumscribed by its geographical limits. Only in this way it seemed to me that confusion could be avoided in determining species which are separated by comparatively light characters and have a tendency to vary extraordinarily within this narrow range. That thus different species will closely touch each-other with their most outlying varieties cannot surprise us and is quite in harmony with the prevailing views of our times; and, in fact, with many forms it must appear in a measure arbitrary to which of the contiguous species they shall be referred. In fact, the evolution theory could hardly find a more favorable field for observation than an isolated island-group in mid-ocean, large enough to have produced a number of original forms and at the same time so diversified in conditions of temperature, humidity, and atmospheric currents as to admit an extraordinary development in nearly every direction of vegetable morphology, uninfluenced by intercrossing with foreign elements.

Systematic science does not mean to separate what was originally distinct, but to find the most logical terms by which to separate, and thereby render acceptable to the understanding, a mass of facts or products originally one or few. In Nature exists unity; but the mind requires division to comprehend, dividing lines to combine in units what lies between.

$\$$

$\star$

$*$

*

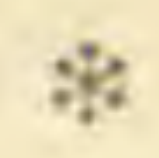

Hawaiian Islands the only Polynesian Island group which contain a large proportion of indigenous plants with American affinities. Compositae of Tahiti allied to Malaysian types.

* $* \quad * \quad * \quad *$

Australian genera or types which are wanting or very scantily represented in the intermediate island groups: Scaevola, Isotoma, Pittosporum. 
Species of Austral-Asiatic genera mostly single or few, constant on all islands with little variation. Many of them probably carried over by aborigines, as they served for food or for some purpose of domestic economy.

$\% \quad \% \quad \% \quad \%$

Absence of Gymnosperms militates for the view that the islands were formed subsequent to the age in which these were universally distributed, Ferns having been prevalent in all periods.

$* \quad * \quad * \quad \%$

Importance of the tropic bird (Phaëton phoenicurus) in the distribution of species; [also of] another migratory bird, the plover, which is known also on the coast of N. America.

$\%$ :

The silvery white tomentum a character of high mountain plants: Argyroxiphium, Geranium, Raillardia struthioloides.

The presence of resin in plants seems to be associated mostly with narrow and stiff nervate leaves.

6* $\% * 2 \%$

Low size of trees. None, excepting the Cocoanut palm, exceeding $100 \mathrm{ft}$. On Oahu trees are seldom over $50 \mathrm{ft}$., except in deep valleys of Kaala, where Kukui and Koa are seen of 60 - $80 \mathrm{ft}$. height. Knudsen reports the Alphitonia ponderosa as the highest (60 ft.) from Kauai. On Maui (Ulupalakua) and Hawaii high trees only on the leeward sides.

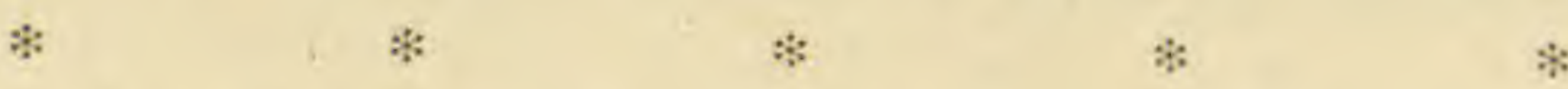

Nearly all native plants perennial and woody.

Few water plants; mistake of Engler in marking all Cyperaceae as such.

Ohia lehua - Ohia ai - Ohia.

Is this indication of a beginning of generalization or classification in the native mind - the word ohia being the general appellation for nearly related species? Or is the recurrence of the word ohia in ohia ai owing to the circumstance that the latter tree was imported after the first settlement by men and after the indigenous trees had already received special names, 
the later arrival in that case receiving a name from a native tree with which it bore the greatest resemblance, just as the Spanish and English colonists in America and elsewhere named the new fruit trees and tuber or cereal plants after those known to them in their mother countries?

It is possible that in early times the Metrosideros polymorpha had different names in different islands, it being called ohia in the windward islands and lehua in the leeward islands Oahu and Kauai, where this name was principally given, as it is still now, to the narrow leaved varieties. The arrival of a new tree with flowers and foliage resembling the indigenous kinds probably induced the natives to combine the two existing names as a specific appellation for the native tree, and to distinguish the new arrival by its then most distinctive quality - the fleshy fruit - which is indicated by the word ai (edible). 


\section{OUTLINES OF BOTANY.}

FROM MR. BENTHAM'S BRITISH AND COLONIAL FLORAS.

\section{Chap. I. Definttions and Descriptive Botany.}

1. The principal object of a Flora of a country, is to afford the means of determining (i. e. ascertaining the name of) any plant growing in it, whether for the purpose of ulterior study or of intellectual exercise.

2 . With this view, a Flora consists of descriptions of all the wild or native plants contained in the country in question, so drawn up and arranged that the student may identify with the corresponding description any individual speeimen which he may gather.

3 . These descriptions should be clear, concise, accurate, and characteristic, so as that each one should be readily adapted to the plant it relates to, and to no other one; they should be as nearly as possible arranged under natural (184) divisions, so as to faciliate the comparison of each plant with those nearest allied to it; and they should be accompanied by an artificial key or index, by means of which the student may be guided step by step in the observation of such peculiarities or characters in his plant, as may lead him, with the least delay, to the individual description belonging to it.

4. For descriptions to be clear and readily intelligible, they should be expressed as much as possible in ordinary well-established language. But, for the purpose of accuracy, it is necessary not only to give a more precise technical meaning to many terms used more or less vaguely in common conversation, but also to introduce purely technical names for such parts of plants or forms as are of little importance except to the botanist. In the present chapter it is proposed to define such technical or technically limited terms as are made use of in these Floras.

5. At the same time mathematical accuracy must not be expected. The forms and appearances assumed by plants and their parts are infinite. Names cannot be invented for all; those even that have been proposed are too numerous for ordinary memories. Many are derived from supposed resemblances to well-known forms or objects. These resemblances are differently appreciated by different persons, and the same term is not only differently applied by two different botanists, but it frequently happens that the same writer is led on different occasions to give somewhat different meanings to the same word. The botanist's endeavours should always be, on the one hand, to make as near an approach to precision as circumstances will allow, and, on the other hand, to avoid that prolixity of detail and 
overloading with technical terms which tends rather to confusion than clearness. In this he will be more or less successful. The aptness of a botanical description, like the beauty of a work of imagination, will always vary with the style and genius of the author.

\section{$\S$ 1. The Plant in General.}

6. The Plant, in its botanical sense, includes every being which has vegetable life, from the loftiest tree which adorns our landscapes, to the humblest moss which grows on its stem, to the mould or fungus which attacks our provisions, or the green scum that floats on our ponds.

7. Every portion of a plant which has a distinct part or function to perform in the operations or phenomena of vegetable life is called an Organ.

8. What constitutes vegetable life, and what are the functions of each organ, belong to Vegetable Physiology; the microscopical structure of the tissues composing the organs, to Vegetable Anatomy; the composition of the substances of which they are formed, to Vegetable Chemistry; under Descriptive and Systematic Botany we have chiefly to consider the forms of organs, that is, their Morphology, in the proper sense of the term, and their general structure so far as it affects classification and specific resemblances and differences. The terms we shall now define belong chiefly to the latter branch of Botany, as being that which is essential for the investigation of the Flora of a country. We shall add, however, a short chapter on Vegetable Anatomy and Physiology, as a general knowledge of both imparts an additional interest to and facilitates the comparison of the characters and affinities of the plants examined.

9. In the more perfect plants, the organs are comprised in the general terms Root, Stem, Leaves, Flowers, and Fruit. Of these the first three, whose function is to assist in the growth of the plant, are Organs of Vegetation; the flower and fruit, whose office is the formation of the seed, are the Organs of Reproduction.

10. All these organs exist, in one shape or another, at some period of the life of most, if not all, flowering plants, technically called phaenogamous or phanerogamous plants; which all bear some kind of flower and fruit in the botanical sense of the term. In the lower classes, the ferns, mosses, fungi, moulds or mildews, seaweeds, etc., called by botanists cryptogamous plants, the flowers, the fruit, and not unfrequently one or more of the organs of vegetation, are either wanting, or replaced by organs so different as to be hardly capable of bearing the same name.

11. The observations comprised in the following pages refer exclusively to the flowering or phaenogamous plants. The study of the cryptogamous classes has now become so complicated as to form almost a separate science. They are therefore not included in these introductory observations, nor, with the exception of ferns and their allies, in the present Flora.

\section{Plants are}

Monocarpic, if they die after one flowering-season. These include Annuals, which flower in the same year in which they are raised from seed; and Biennials, which only flower in the year following that in which they are sown.

Caulocarpic, if, after flowering, the whole or part of the plant lives through the winter and produces fresh flowers another season. These include Herbaceous perennials, in which the greater part of the plant dies 
after flowering, leaving only a small perennial portion called the Stock or Caudex, close to or within the earth; Undershrubs, suffruticose or suffrutescent plants, in which the flowering branches, forming a considerable portion of the plant, die down after flowering, but leave a more or less prominent perennial and woody base; Shrubs (frutescent or fruticose plants), in which the perennial woody part forms the greater part of the plant, but branches near the base, and does not much exceed a man's height; and Trees (arboreous or arborescent plants) when the height is greater and forms a woody trunk, scarcely branching from the base. Bushes are low, much branched shrubs.

13. The terms Monocarpic and Caulocarpic are but little used, but the other distinctions enumerated above are universally attended to, although more useful to the gardener than to the botanist, who cannot always assign to them any precise character. Monocarpic plants, which require more than two or three years to produce their flowers, will often, under certain circumstances, become herbaceous perennials, and are generally confounded with them. Truly perennial herbs will often commence flowering the first year, and have then all the appearance of annuals. Many tall shrubs and trees lose annually their flowering branches like undershrubs. And the same botanical species may be an annual or a perennial, an herbaceous perennial or an undershrub, an undershrub or a shrub, a shrub or tree, according to elimate, treatment, or variety.

14. Plants are usually terrestrial, that is, growing on earth; or aquatic, $i$. e. growing in water; but sometimes they may be found attached by their roots to other plants, in which case they are epiphytes when simply growing upon other plants without penetrating into their tissue, parasites when their roots penetrate into and derive more or less nutriment from the plant to which they are attached.

15. The simplest form of the perfect plant, the annual, consists of-

(1) The Root, or descending axis, which grows downwards from the stem, divides and spreads in the earth or water, and absorbs food for the plant through the extremities of its branches.

(2) The Stem, or ascending axis, which grows upwards from the root, branches and bears first one or more leaves in succession, then one or more flowers, and finally one or more fruits. It contains the tissues or other channels (217) by which the nutriment absorbed by the roots is conveyed in the form of sap (192) to the leaves or other points of the surface of the plant, to be elaborated or digested (218), and afterwards redistributed over different parts of the plant for its support and growth.

(3) The Leaves, usually flat, green, and horizontal, are variously arranged on the stem and its branches. They elaborate or digest (218) the nutriment brought to them through the stem, absorb carbonic acid gas from the air, exhaling the superfluous oxygen, and returning the assimilated sap to the stem.

(4) The Flowers, nsually placed at or towards the extremities of the branches. They are destined to form the future seed. When perfect and complete they consist:-1st, of a pistil in the centre, consisting of one or more carpels, each containing the germ of one or more seeds; 2 nd, of one or more stamens outside the pistil, whose action is necessary to fertitize the pistil or enable it to ripen its seed; $3 \mathrm{rd}$, of a perianth or floral envelope, which usually encloses the stamens and pistil when young, and expands and exposes them to view when fully formed. This complete perianth is double; the outer one, called Calyx, is usually more green and leaf-like; 
the inner one, called the Corolla, more conspicuous, and variously coloured. It is the perianth, and especially the corolla, as the most showy part, that is generally called the flower in popular language.

(5) The Fruit, consisting of the pistil or its lower portion, which persists or remains attached to the plant after the remainder of the flower has withered and fallen off. It enlarges and alters more or less in shape or consistence, becomes a seed-ressel, enclosing the seed until it is ripe, when it either opens to discharge the seed or falls to the ground with the-seed. In popular language the term fruit is often limited to such seed-vessels as are or look juicy and eatable. Botanists give that name to all seed-vessels.

16. The herbaceous perennial resembles the annual during the first year of its growth; but it also forms (usually towards the close of the season), on its stock (the portion of the stem and root which does not die), one or more buds, either exposed, and then popularly called eyes, or concealed among leaves. These buds, called leaf-buds, to distinguish them from flower-buds or unopened flowers, are future branches as yet undeveloped; they remain dormant through the winter, and the following spring grow out into new stems bearing leaves and flowers like those of the preceding year, whilst the lower part of the stock emits fresh roots to replace those which had perished at the same time as the stems.

17. Shrubs and trees form similar leaf-buds either at the extremity of their branches, or along the branches of the year. In the latter case these buds are usually axillary, that is, they appear in the axil of each leaf, i. e. in the angle formed by the leaf and the branch. When they appear at any other part of the plant they are called adventitious. If these buds by producing roots (19) become distinct plants before separating from the parent, or if adventitious leaf-buds are produced in the place of flowers or seeds, the plant is said to be viviparous or proliferous.

\section{§ 2. The Root.}

18. Roots ordinarily produce neither buds, leaves, nor flowers. Their branches, called fibres, when slender and long, proceed irregularly from any part of their surface.

19. Although roots proceed usually from the base of the stem or stock, they may also be produced from the base of any bud, especially if the bud lie along the ground, or is otherwise placed by nature or art in circumstances favourable for their development, or indeed occasionally from almost any part of the plant. They are then often distinguished as adventitious, but this term is by some applied to all roots which are not in prolongation of the original radicle.

\section{Roots are}

fibrous, when they consist chiefly of slender fibres.

tuberous, when either the main root or its branches are thickened into one or more short fleshy or woody masses ealled tubers (25).

taproots, when the main root descends perpendicularly into the earth, emitting only very small fibrous branches.

21. The stock of a herbaceous perennial, or the lower part of the stem of an annual or perennial, or the lowest branches of a plant, are sometimes underground and assume the appearance of a root. They then take the 
name of rhizome. The rhizome may always be distinguished from the true root by the presence or production of one or more buds, or leaves, or scales.

\section{§ 3. The Stock.}

22. The Stock of an herbaceous perennial, in its most complete state, includes a small portion of the summits of the previous year's roots, as well as of the base of the previous year's stems. Such stocks will increase yearly, so as at length to form dense tufts. They will often preserve through the winter a few leaves, amongst which are placed the buds which grow out into stems the following year, whilst the under side of the stock emits new roots from or amongst the remains of the old ones. These perennial stocks only differ from the permanent base of an undershrub in the shortness of the perennial part of the stems and in their texture, usually less woody.

23. In some perennials, however, the stock consists merely of a branch which proceeds in autumn from the base of the stem either aboveground or underground, and produces one or more buds. This branch, or a portion of it, alone survives the winter. In the following year its buds produce the new stem and roots, whilst the rest of the plant, even the branch on which these buds were formed, has died away. These annual stocks, called sometimes hybernacula, offsets, or stolons, keep up the communication between the annual stem and root of one year and those of the following year, thus forming altogether a perennial plant.

24 . The stock, whether annual or perennial, is often entirely underground, or root-like. This is the rootstock, to which some botanists limit the meaning of the term rhizome. When the stock is entirely root-like, it is popularly called the crown of the root.

25. The term tuber is applied to a short, thick, more or less succulent rootstock or rhizome, as well as to a root of that shape (20), although some botanists propose to restrict its meaning to the one or to the other. An Orchis tuber, called by some a knob, is an annual tuberous rootstock with one bud at the top. A potato is an annual tuberous rootstock with several buds.

26. A bulb is a stock of a shape approaching to globular, usually rather conical above and flattened underneath, in which the bud or buds are concealed, or nearly so, under scales. These scales are the more or less thickened bases of the decayed leaves of the preceding year, or of the undeveloped leaves of the future year, or of both. Bulbs are annual or perennial, usually underground or close to the ground, but occasionally buds in the axils of the upper leaves become transformed into bulbs. Bulbs are said to be scaly when their scales are thick and loosely imbricated, tunicated when the scales are thinner, broader, and closely rolled round each other in concentric layers.

27. A corm is a tuberous rootstock, usually annual, shaped like a bulb, but in which the bud or buds are not covered by scales, or of which the scales are very thin and membranous.

\section{Stems are}

\section{§ 4. The Stem.}

erect, when they ascend perpendicularly from the root or stock; twiggy or virgate, when at the same time they are slender, stiff, and scarcely branched. 
decumbent or ascending, when they spread horizontally, or nearly so, at the base, and then turn upwards and become erect.

procumbent, when they spread along the ground the whole or the greater portion of their length; diffuse, when at the same time very much and rather loosely branched.

prostrate, when they lie still closer to the ground.

creeping, when they emit roots at their nodes. This term is also frequently applied to any rhizomes or roots which spread horizontally.

tufted or caespitose, when very short, close, and many together from the same stock.

29. Weak climbing stems are said to twine, when they support themselves by winding spirally round any object; such stems are also called voluble. When they simply climb without twining, they support themselves by their leaves, or by special clasping organs called tendrits (169), or sometimes, like the Ivy, by small root-like excrescences.

30. Suckers are young plants formed at the end of creeping, underground rootstocks. Scions, runners, and stolons or stoles, are names given to young plants formed at the end or at the nodes (31) of branches or stocks creeping wholly or partially aboveground, or sometimes to the creeping stocks themselves.

31. A node is a point of the stem or its branches at which one or more leaves, branches, or leaf-buds (16) are given off. An internode is the portion of the stem comprised between two nodes.

\section{Branches or leaves are}

opposite, when two proceed from the same node on opposite sides of the stem.

whorled or verticillate (in a whorl or verticil), when several proceed from the same node, arranged regularly around the stem; geminate, ternate, fascicled or fasciculate when two, three, or more proceed from the same node on the same side of the stem. A tuft of fasciculate leaves is usually in fact an axillary leafy branch, so short that the leaves appear to proceed all from the same point.

alternate, when only one proceeds from each node, one on one side and the next, above or below on the opposite side of the stem.

decussate, when opposite, but each pair placed at right angles to the next pair above or below it; distichous, when regularly arranged one above another in two opposite rows, one on each side of the stem; tristichous, when in three rows, etc. (92).

scattered, when irregularly arranged round the stem; frequently, however, botanists apply the term alternate to all branches or leaves that are neither opposite nor whorled.

secund, when all start from or are turned to one side of the stem.

33. Branches are dichotomous, when several times forked, the two branches of each fork being nearly equal; trichotomous, when there are three nearly equal branches at each division instead of two; but when the middle branch is evidently the principal one, the stem is usually said to have two opposite branches; umbellate, when divided in the same manner into several nearly equal branches proceeding from the same point. If however the central branch is larger than the two or more lateral ones, the stem is said to have opposite or whorled branches, as the case may be.

34. A culm is a name sometimes given to the stem of Grasses, Sedges, and some other Monocotyledonous plants. 


\section{$\S$ 5. The Leaves.}

35. The ordinary or perfect Leaf consists of a flat blade or lamina, usually green, and more or less horizontal, attached to the stem by a stalk called a footstalk or petiole. When the form or dimensions of a leaf are spoken of, it is generally the blade that is meant, without the petiole or stalk.

36. The end by which a leaf, a part of the flower, a seed, or any other organ, is attached to the stem or other organ, is called its base, the opposite end is its apex or summit, excepting sometimes in the case of anther-cells (115).

\section{Leaves are}

sessile, when the blade rests on the stem without the intervention of a petiole.

amplexicaul or stem-clasping, when the sessile base of the blade clasps the stem horizontally.

perfoliate, when the base of the blade not only clasps the stem, but closes round it on the opposite side, so that the stem appears to pierce through the blade.

decurrent, when the edges of the leaf are continued down the stem so as to form raised lines or narrow appendages, called wings.

sheathing, when the base of the blade, or of the more or less expanded petiole, forms a vertical sheath round the stem for some distance above the node.

38. Leaves and flowers are called radical, when inserted on a rhizome or stock, or so close to the base of the stem as to appear to proceed from the root, rhizome, or stock; cauline, when inserted on a distinct stem. Radical leaves are rosulate when they are spread in a circle on the ground,

\section{Leaves are}

simple and entire, when the blade consists of a single piece, with the margin nowhere indented, simple being used in opposition to compound, entire in opposition to dentate, lobed, or divided.

ciliate, when bordered with thick hairs or fine hair-like teeth.

dentate or toothed, when the margin is only cut a little way in, into what have been compared to teeth. Such leaves are serrate, when the teeth are regular and pointed like the teeth of a saw; crenate, when regular and blunt or rounded (compared to the battlement of a tower); serrulate, and crenulate, when the serratures or crenatures are small; sinuate, when the teeth are broad, not deep, and irregular (compared to bays of the coast); wavy or undulate, when the edges are not flat, but bent up and down (compared to the waves of the sea).

lobed or eleft, when more deeply indented or divided, but so that the incisions do not reach the midrib or petiole. The portions thus divided take the name of lobes. When the lobes are narrow and very irregular, the leaves are said to be laciniate. The spaces between the teeth or lobes are called sinuses.

divided or dissected, when the incisions reach the midrib or petiole; but the parts so divided off, called segments, do not separate from the petiole, even when the leaf falls, without tearing.

compound, when divided to the midrib or petiole, and the parts so divided off, called leaflets, separate, at least at the fall of the leaf, from the petiole, as the whole leaf does from the stem, without tearing. The 
common stalk upon which the leaflets are inserted is called the common petiole or the rachis; the separate stalk of each leaflet is a petiolule.

40. Leaves are more or less marked by veins, which, starting from the stalk, diverge or branch as the blade widens, and spread all over it more or less visibly. The principal ones, when prominent, are often called ribs or nerves, the smaller branches only then retaining the name of veins, or the latter are termed veinlets. The smaller veins are often connected together like the meshes of a net, they are then said to anastomose, and the leaf is said to be reticulate or net-veined. When one principal vein runs direct from the stalk towards the summit of the leaf, it is called the midrib. When several start from the stalk, diverge slightly without branching, and converge again towards the summit, they are said to be parallel, although not mathematically so. When 3 or 5 or more ribs or nerves diverge from the base, the leaf is said to be 3-nerved, 5-nerved, etc., but if the lateral ones diverge from the midrib a little above the base, the leaf is triplinerved, quintuplinerved, ete. The arrangement of the veins of a leaf is called their venation.

\section{The Leaflets, Segments, Lobes, Veins of leaves are}

pinnate (feathered), when there are several succeeding each other on each side of the midrib or petiole, compared to the branches of a feather. A pinnately lobed or divided leaf is called lyrate when the terminal lobe or segment is much larger and broader than the lateral ones, compared, by a stretch of imagination, to a lyre; runcinate, when the lateral lobes are curved backwards towards the base of the leaf; pectinate, when the lateral lobes are numerous, narrow, and regular, like the teeth of a comb.

palmate or digitate, when several diverge from the same point, compared to the fingers of the hand.

ternate, when three only start from the same point, in which case the distinction between the palmate and pinnate arrangement often ceases, or can only be determined by analogy with allied plants. A leaf with ternate lobes is called trifid. A leaf with three leaflets is sometimes improperly called a ternate leaf; it is the leaflets that are ternate; the whole leaf is trifoliolate. Ternate leaves are leaves growing three together.

pedate, when the division is at first ternate, but the two outer branches are forked, the outer ones of each fork again forked, and so on, and all the branches are near together at the base, compared vaguely to the foot of a bird.

42. Leaves with pinnate, palmate, pedate, ete., leaflets, are usually for shortness called pinnate, palmate, pedate, etc., leaves. If they are so cut into segments only, they are usually said to be pinnatisect, palmatisect, pedatisect, etc., although the distinction between segments and leaflets is often unheeded in description, and cannot indeed always be ascertained. If the leaves are so cut only into lobes, they are said to be pinnatifid, palmatifid, pedatifid, etc.

43. The teeth, lobes, segments, or leaflets, may be again toothed, lobed, divided, or compounded. Some leaves are even three or more times divided or compounded. In the latter case they are termed decompound. When twice or thrice pinnate (bipinnate or tripinnate), each primary or secondary division, with the leaflets it comprises, is called a pinna. When the pinnae of a leaf or the leaflets of a pinna are in pairs, without an odd terminal finna or leaflet, the leaf or pinna so divided is said to be abruptly pinnate; if there is an odd terminal pinna or leaflet, the leaf or pinna is unequally pinnate (imparipinnate). 
44. The number of leaves or their parts is expressed adjectively by the following numerals, derived from the Latin:-

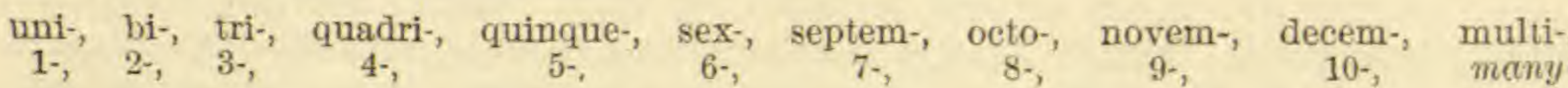

prefixed to a termination, indicating the particular kind of part referred to. Thus:-

unidentate, bidentate, multidentate, mean one-toothed, two-toothed, many-toothed, etc.

bifid, trifid, multifid, mean two-lobed, three-lobed, many-lobed, etc.

unifoliolate, bifoliolate, multifoliolate, mean having one leaflet, two leaflets, many leaflets, etc.

unifoliate, bifoliate, multifoliate, mean having one leaf, two leaves, many leaves, etc.

biternate, and triternate, mean twice or thrice ternately divided.

unijugate, bijugate, multijugate, ete., pinnae or leaflets, mean that they are in one, two, many, etc. pairs (juga).

45. Leaves or their parts, when flat, or any other flat organs in plants, are

linear, when long and narrow, at least four or five times as long as broad, falsely compared to a mathematical line, for a linear leaf has always a perceptible breadth.

lanceolate, when about three or more times as long as broad, broadest below the middle, and tapering towards the summit, compared to the head of a lance.

cuneate, when broadest above the middle, and tapering towards the base, compared to a wedge with the point downwards; when very broadly cuneate and rounded at the top, it is often called flabelliform or fanshaped.

spathulate, when the broad part near the top is short, and the narrow tapering part long, compared to a spatula or flat ladle.

ovate, when scarcely twice as long as broad, and rather broader below the middle, compared to the longitudinal section of an egg; obovate is the same form, with the broadest part above the middle.

orbicular, oval, oblong, elliptical, rhomboidal, etc., when compared to the corresponding mathematical figures,

transversely oblong, or oblate, when conspicuously broader than long. falcate, when curved like the blade of a scythe.

46. Intermediate forms between any two of the above are expressed by combining two terms. Thus, a linear-lanceolate leaf is long and narrow, yet broader below the middle, and tapering to a point; a tinear-oblong one is scarcely narrow enough to be called linear, yet too narrow to be strictly oblong, and does not conspicuously taper either towards the summit or towards the base.

47. The apex or summit of a leaf is

acute or pointed, when it forms an acute angle or tapers to a point. obtuse or blunt, when it forms a very obtuse angle, or more generally when it is more or less rounded at the top.

acuminate or cuspidate, when suddenly narrowed at the top, and then more or less prolonged into an acumen or point, which may be acute or obtuse, linear or tapering. Some botanists make a slight difference between the acuminate and cuspidate apex, the acumen being more distinct from the rest of the leaf in the latter case than in the former; but in general 
the two terms are used in the same sense, some preferring the one and some the other.

truncate, when the end is cut off square.

retuse, when very obtuse or truncate, and slightly indented.

emarginate or notched, when more decidedly indented at the end of the midrib; obcordate, if at the same time approaching the shape of a heart with its point downwards.

mucronate, when the midrib is produced beyond the apex in the form of a small point.

aristate, when the point is fine like a hair.

48. The base of the leaf is liable to the same variations of form as the apex, but the terms more commonly used are tapering or narrowed for acute and acuminate, rounded for obtuse, and cordate for emarginate. In all cases the petiole or point of attachment prevents any such absolute termination at the base as at the apex.

49. A leaf may be cordate at the base whatever be its length or breadth, or whatever the shape of the two lateral lobes, called auricles (or little ears) formed by the indenture or notch; but the term cordiform or heartshaped leaf is restricted to an ovate and acute leaf, cordate at the base, with rounded auricles. The word 'auricles' is more particularly used as applied to sessile and stem-clasping leaves.

50. If the auricles are pointed, the leaf is more particularly called auriculate; it is moreover said to be sagittate, when the points are directed downwards, compared to an arrow-head; hastate, when the points diverge horizontally, compared to a halbert.

51. A reniform leaf is broader than long, slightly but broadly cordate at the base, with rounded auricles, compared to a kidney.

52. In a peltate leaf, the stalk, instead of proceeding from the lower edge of the blade, is attached to the under surface, usually near the lower edge, but sometimes in the very centre of the blade. The peltate leaf has usually several principal nerves radiating from the point of attachment, being, in fact, a cordate leaf with the auricles united.

53. All these modifications of division and form in the leaf pass so gradually one into the other that it is often difficult to say which term is the most applicable-whether the leaf be toothed or lobed, divided or compound, oblong or lanceolate, obtuse or acute, etc. The choice of the most apt expression will depend on the skill of the describer.

54. Leaves, when solid, Stems, Fruits, Tubers, and other parts of plants, when not flattened like ordinary leaves, are

setaceous or capillary, when very slender like bristles or hairs.

acicular, when very slender, but stiff and pointed like needles.

subulate, when rather thicker and firmer like awls.

linear, when at least four times as long as thick; oblong, when from about two to about four times as long as thick, the terms having the same sense as when applied to flat surfaces.

ovoid, when egg-shaped, with the broad end downwards; obovoid, if the broad end is upwards: these terms corresponding to ovate and obovate shapes in flat surfaces.

globular or spherical, when corresponding to orbicular in a flat surface. Round applies to both.

turbinate, when shaped like a top.

conical, when tapering upwards; obconical, when tapering downwards if in both cases a transverse section shows a circle. 
pyramidal, when tapering upwards; obpyramidal, when tapering downwards; if in both cases a transverse section shows a triangle or polygon.

fusiform, or spindle-shaped, when tapering at both ends; cylindrical, when not tapering at either end; if in both cases the transverse section shows a circle, or sometimes irrespective of the transverse shape.

terete, when the transverse section is not angular; trigonous, triquetrous, if the transverse section shows a triangle, irrespective in both cases of longitudinal form.

compressed, when more or less flattened laterally; depressed, when more or less flattened vertically, or at any rate at the top; obcompressed. (in the achenes of Compositae), when flattened from front to back.

articulate or jointed, if at any period of their growth (usually when fully formed and approaching their decay, or in the case of fruits when quite ripe) they separate, without tearing, into two or more pieces placed end to end. The joints where they separate are called articulations, each separate piece an article. The name of joint is, in common language, given both to the articulation and the article, but more especially to the former. Some modern botanists, however, propose to restrict it to the article, giving the name of joining to the articulation.

didymous, when slightly two-lobed, with rounded obtuse lobes.

monitiform, or beaded, when much contracted at regular intervals, but not separating spontaneously into articles.

55. In their consistence Leaves or other organs are

fleshy, when thick and soft; succulent is generally used in the same sense, but implies the presence of more juice. leather.

coriaceous, when firm and dry, or very tough, of the consistence of

membranous, when thin and not stiff.

scarious or scariose, when very thin, more or less transparent and not green, yet rather stiff.

56. The terms applied botanically to the consistence of solids are those generally used in common language.

57. The mode in which unexpanded leaves are disposed in the leaf-bud is called their vernation or praefoliation; it varies considerably, and technical terms have been proposed to express some of its varieties, but it has been hitherto rarely noticed in Descriptive Botany.

\section{§ 6. Scales, Bracts and Stipules.}

58. Scales (Squamae) are leaves very much reduced in size, usually sessile, seldom green or capable of performing the respiratory functions of leaves. In other words, they are organs resembling leaves in their position on the plant, but differing in size, colour, texture, and functions. They are most frequent on the stock of perennial plants, or at the base of annual branches, especially on the buds of future shoots, when they serve apparently to protect the dormant living germ from the rigour of winter. In the latter case they are usually short, broad, close together, and more or less imbricated, that is, overlapping each other like the tiles of a roof. It is this arrangement as well as their usual shape that has suggested the name of scales, borrowed from the scales of a fish. Imbricated scales, bracts, or leaves, are said to be squarrose, when their tips are pointed, and very spreading or recurved. 
59. Sometimes, however, most or all the leaves of the plant are reduced to small scales, in which case they do not appear to perform any particular function. The name of scales is also given to any small broad scale-like appendages or reduced organs, whether in the flower or any other part of the plant.

60. Bracts (Bracteae) are the upper leaves of a plant in flower (either all those of the flowering branches, or only one or two immediately under the flower), when different from the stem-leaves in size, shape, colour, or arrangement. They are generally much smaller and more sessile. They often partake of the colour of the flower, although they very frequently also retain the green colour of the leaves. When small they are often called scales.

61. Floral leaves or leafy bracts are generally the lower bracts or the upper leaves at the base of the flowering branches, intermediate in size, shape, or arrangement, between the stem-leaves and the upper bracts.

62. Bracteoles are the one or two last bracts under each flower, when they differ materially in size, shape, or arrangement from the other bracts.

63. Stipules are leaf-like or scale-like appendages at the base of the leaf-stalk, or on the node of the stem. When present there are generally two, one on each side of the leaf, and they sometimes appear to protect the young leaf before it is developed. They are, however, exceedingly variable in size and appearance, sometimes exactly like the true leaves except that they have no buds in their axils, or looking like the leaflets of a compound leaf, sometimes apparently the only leaves of the plant; generally small and narrow, sometimes reduced to minute scales, spots, or scars, sometimes united into one opposite the leaf, or more or less united with, or adnate to the petiole, or quite detached from the leaf, and forming a ring or sheath round the stem in the axil of the leaf. In a great number of plants they are entirely wanting.

64. Stipellae, or secondary stipules, are similar organs, sometimes found on compound leaves at the points where the leaflets are inserted.

65. When seales, bracts, or stipules, or almost any part of the plant besides leaves and flowers, are stalked, they are said to be stipitate, from stipes, a stalk.

\section{\$ 7. Inflorescence and its Bracts.}

66. The Inflorescence of a plant is the arrangement of the flowering branches, and of the flowers upon them. An Inflorescence is a flowering branch, or the flowering summit of a plant above the last stem-leaves, with its branches, bracts, and flowers.

67. A single flower, or an inflorescence, is terminal when at the summit of a stem or leafy branch, axillary when in the axil of a stem-leaf, leafopposed when opposite to a stem-leaf. The inflorescence of a plant is said to be terminal or determinate when the main stem and principal branches end in a flower or inflorescence (not in a leaf-bud), axillary or indeterminate when all the flowers or inflorescences are axillary, the stem or branches ending in leaf-buds.

68. A Peduncle is the stalk of a solitary flower, or of an inflorescence; that is to say, the portion of the flowering branch from the last stem-leaf to the flower, or to the first ramification of the inflorescence, or even up to its last ramifications; but the portion extending from the first to the 
last ramification or the axis of inflorescence is often distinguished under the name of rachis.

69. A Scape or radical Peduncle is a leafless peduncle proceeding from the stock, or from near the base of the stem, or apparently from the root itself.

70. A Pedicel is the last branch of an inflorescence, supporting a single flower.

71. The branches of inflorescences may be like those of stems, opposite, alternate, etc. $(32,33)$, but very often their arrangement is different from that of the leafy branches of the same plant.

\section{Inflorescence is}

centrifugal, when the terminal flower opens first, and those on the lateral branches are successively developed.

centripetal, when the lowest flowers open first, and the main stem continues to elongate, developing fresh flowers.

73. Determinate inflorescence is usually centrifugal. Indeterminate inflorescence is always centripetal. Both inflorescences may be combined on one plant, for it often happens that the main branches of an inflorescence are centripetal, whilst the flowers on the lateral branches are centrifugal; or vice versa.

\section{An Inflorescence is}

a Spike, or spicate, when the flowers are sessile along a simple undivided axis or rachis.

a Raceme, or racemose, when the flowers are borne on pedicels along a single undivided axis or rachis.

a Panicle, or paniculate, when the axis is divided into branches bearing two or more flowers.

a Head, or capitate, when several sessile or nearly sessile flowers are collected into a compact head-like cluster. The short, flat, convex or conical axis on which the flowers are seated, is called the Receptacle, a term also used for the torus of a single flower (135). The very compact flower-heads of Compositae are often termed compound flowers.

an Umbel, or umbellate, when several branches or pedicels appear to start from the same point and are nearly of the same length. It differs from the head, like the raceme from the spike, in that the flowers are not sessile. An umbel is said to be simple, when each of its branches or rays bears a single flower; compound, when each ray bears a partial
umbel or umbellule.

a Corymb, or corymbose, when the branches and pedicels, although starting from different points, all attain the same level, the lower ones being much longer than the upper. It is a flat-topped or fastigiate
paniele.

a Cyme, or cymose, when branched and centrifugal. It is a centrifugal panicle, and is often corymbose. The central flower opens first. The lateral branches sucessively developed are usually forked or opposite (dichotomous or trichotomous), but sometimes after the first forking the branches are no longer divided, but produce a succession of pedicels on their upper side forming apparently unilateral centripetal racemes; whereas, if attentively examined, it will be found that each pedicel is at first terminal, but becomes lateral by the development of one outer branch only, immediately under the pedicel. Such branches, when in bud, are generally rolled back at the top, like the tail of a scorpion, and are thence called
scorpioid. 
a Thyrsus, or thyrsoid, when cymes, usually opposite, are arranged in a narrow pyramidal panicle.

75. There are numerous cases where inflorescences are intermediate between some two of the above, and are called by different botanists by one or the other name, according as they are guided by apparent or by theoretical similarity. A spike-like panicle, where the axis is divided into very short branches forming a cylindrical compact inflorescence is called sometimes a spike, sometimes a panicle. If the flowers are in distinct clusters along a simple axis, the inflorescence is described as an interrupted spike or raceme, according as the flowers are nearly sessile or distinctly pedicellate; although when closely examined the flowers will be found to be inserted not on the main axis, but on a very short branch, thus, strictly speaking, constituting a panicle.

76. The Catkins (Amenta) of Amentaceae, the Spadices of several Monocotyledons, the Ears and Spikelets of Grasses, are forms of the spike.

77. Bracts are generally placed singly under each branch of the inflorescence, and under each pedicel; bracteoles are usually two, one on each side, on the pedicel or close under the flower, or even upon the calyx itself; but braets are also frequently scattered along the branches without axillary pedicels; and when the differences between the bracts and bracteoles are trifling or immaterial, they are usually all called bracts.

78. When three bracts appear to proceed from the same point, they will, on examination, be found to be really either one bract and two stipules, or one bract with two bracteoles in its axil. When two bracts appear to proceed from the same point, they will usually be found to be the stipules of an undeveloped bract, unless the branches of the inflorescence are opposite, when the bracts will of course be opposite also.

79. When several bracts are collected in a whorl, or are so close together as to appear whorled, or are closely imbricated round the base of a head or umbel, they are collectively called an Involucre. The bracts composing an involucre are described under the name of leaves, leaflets, bracts or scales, according to their appearance. Ployllaries is a useless term, lately introduced, for the bracts or scales of the involucre of Compositae. An Involucel is the involucre of a partial umbel.

80 . When several very small bracts are placed round the base of a calyx or of an involucre, they have been termed a Calycule, and the calyx or involucre said to be calyculate; but these terms are now falling into disuse, as conveying a false impression.

81. A Spatha is a bract or floral leaf enclosing the inflorescence of some Monocotyledons.

82. Paleae, Pales, or Chaff, are the inner bracts or scales in Compositae, Gramineae, and some other plants, when of a thin yet stiff consistence, usually narrow and of a pale colour.

83. Glumes are the bracts enclosing the flowers of Cyperaceae and Gramineae.

\section{\$ 8. The Flower in General.}

84. A complete Flower (15) is one in which the calyx, corolla, stamens, and pistils are all present; a perfect flower, one in which all these organs, or such of them as are present, are capable of performing their several functions. Therefore, properly speaking, an incomplete flower is one in which any one or more of these organs is wanting; and an imperfect flower, 
one in which any one or more of these organs is so altered as to be incapable of properly performing its functions. These imperfect organs are said to be abortive if much reduced in size or efficiency, rudimentary if so much so as to be scarcely perceptible. But, in many works, the term incomplete is specially applied to those flowers in which the perianth is simple or wanting, and imperfect to those in which either the stamens or pistil are imperfect or wanting.

\section{A Flower is}

dichlamydeous, when the perianth is double, both calyx and corolla being present and distinct.

monochlamydeous, when the perianth is single, whether by the union of the calyx and corolla, or the defieiency of either.

asepalous, when there is no calyx.

apetalous, when there is no corolla.

naked, when there is no perianth at all.

hermaphrodite or bisexual, when both stamens and pistil are present
and perfect.

male or staminate, when there are one or more stamens, but either no pistil at all or an imperfect one.

female or pistillate, when there is a pistil, but either no stamens at all, or only imperfect ones.

neuter, when both stamens and pistil are imperfect or wanting.

barren or sterile, when from any cause it produces no seed. fertile, when it does produce seed. In some works the terms barren,
fertile, and perfect are also used respectively as synonyms of male, female,
and hermaphrodite.

86. The flowers of a plant or species are said collectively to be unisexual or diclinous when the flowers are all either male or female. same plant.

dioecious, when the male and female flowers are on distinct plants. polygamous, when there are male, female, and hermaphrodite flowers
on the same or on distinct plants.

87. A head of flowers is heterogamous when male, female, hermaphrodite, and neuter flowers, or any two or three of them, are included in one head; homogamous, when all the flowers included in one head are alike in this respect. A spike or head of flowers is androgynous when male and female flowers are mixed in it. These terms are only used in the
case of very few Natural Orders.

88. As the scales of buds are leaves undeveloped or reduced in size and altered in shape and consistence, and bracts are leaves likewise reduced in size, and occasionally altered in colour; so the parts of the flower are considered as leaves still further altered in shape, colour, and arrangement round the axis, and often more or less combined with each other. The details of this theory constitute the comparatively modern improperly termed Morphology (8).

89. To understand the arrangement of the floral parts, let us take a complete flower, in which moreover all the parts are free from each other, definite in number, $i$. $e$. always the same in the same species, and number of parts. 
90. Such a complete symmetrical flower consists usually of either four or five whorls of altered leaves (88), placed immediately one within the other.

The Calyx forms the outer whorl. Its parts are called sepals.

The Corolla forms the next whorl. Its parts, called petals, usually alternate with the sepals; that is to say, the centre of each petal is immediately over or within the interval between two sepals.

The Stamens form one or two whorls within the petals. If in two whorls, those of the outer one (the outer stamens) alternate with the petals, and are consequently opposite to, or over the centre of the sepals; those of the inner whorl (the inner stamens) alternate with the outer ones, and are therefore opposite to the petals. If there is only one whorl of stamens, they most frequently alternate with the petals; but sometimes they are opposite the petals and alternate with the sepals.

The Pistil forms the inner whorl; its carpels usually alternate with the inner row of stamens.

91. In an axillary or lateral flower the upper parts of each whorl (sepals, petals, stamens, or carpels) are those which are next to the main axis of the stems or branch, the lover parts those which are furthest from it; the intermediate ones are said to be lateral. The words anterior (front) and posterior (back) are often used for lower and upper respectively, but their meaning is sometimes reversed if the writer supposes himself in the centre of the flower instead of outside of it.

92. The number of parts in each whorl of a flower is expressed adjectively by the following numerals derived from the Greek:-

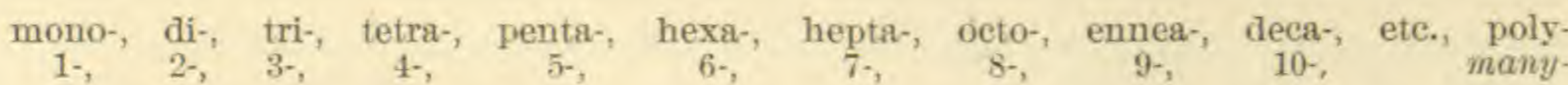

prefixed to a termination indicating the whorl referred to.

93. Thus, a Flower is

disepalous, trisepalous, tetrasepalous, polysepalous, etc., according as there are $2,3,4$, or many (or an indefinite number of) sepals.

dipetalous, tripetalous, polypetalous, ete., according as there are 2, 3, or many petals.

diandrous, triandrous, polyandrous, etc., according as there are 2, 3, or many stamens.

digynous, trigynous, polygynous, ete., according as there are 2, 3, or many carpels.

And generally (if symmetrical), dimerous, trimerous, polymerous, etc., according as there are 2, 3, or many (or an indefinite number of) parts to each whorl.

94. Flowers are unsymmetrical or anisomerous, strictly speaking, when any one of the whorls has a different number of parts from any other; but when the pistils alone are reduced in number, the flower is still frequently called symmetrical or isomerous, if the calyx, corolla, and staminal whorls have all the same number of parts.

95. Flowers are irregular when the parts of any one of the whorls are unequal in size, dissimilar in shape, or do not spread regularly round the axis at equal distances. It is, however, more especially irregularity of the corolla that is referred to in descriptions. A slight inequality in size or direction in the other whorls does not prevent the flower being elassed as regular, if the corolla or perianth is conspicuous and regular. 


\section{§ 9. The Calyx and Corolla, or Perianth.}

96. The Calyx (90) is usually green, and smaller than the corolla; sometimes very minute, rudimentary, or wanting, sometimes very indistinctly whorled, or not whorled at all, or in two whorls, or composed of a large number of sepals, of which the outer ones pass gradually into bracts, and the inner ones into petals.

97. The Corolla (90) is usually coloured, and of a more delicate texture than the calyx, and in popular language is often more specially meant by the flower. Its petals are more rarely in two whorls, or indefinite in number, and the whorl more rarely broken than in the case of the calyx, at least when the plant is in a natural state. Double flowers are in most cases an accidental deformity or monster in which the ordinary number of petals is multiplied by the conversion of stamens, sepals, or even carpels, into petals, by the division of ordinary petals, or simply by the addition of supernumerary ones. Petals are also sometimes very small, rudimentary, or entirely deficient.

98. In very many cases, a so-called simple perianth (15) (of which the parts are usually called leaves or segments) is one in which the sepals and petals are similar in form and texture, and present apparently a single whorl. But if examined in the young bud, one half of the parts will generally be found to be placed outside the other balf, and there will frequently be some slight difference in texture, size, and colour, indicating to the close observer the presence of both calyx and corolla. Hence much discrepancy in descriptive works. Where one botanist describes a simple perianth of six segments, another will speak of a double perianth of three sepals and three petals.

99. The following terms and prefixes, expressive of the modifications of form and arrangement of the corolla and its petals, are equally applicable to the calyx and its sepals, and to the simple perianth and its segments.

100. The Corolla is said to be monopetalous when the petals are united, either entirely or at the base only, into a cup, tube, or ring; polypetalous when they are all free from the base. These expressions, established by a long usage, are not strictly correct, for monopetalous (consisting of a single petal) should apply rather to a corolla really reduced to a single petal, which would then be on one side of the axis; and polypetalous is sometimes used more appropriately for a corolla with an indefinite number of petals. Some modern botanists have, therefore, proposed the term gamopetalous for the corolla with united petals, and dialypetalous for that with free petals; but the old-established expressions are still the most
generally used.

101. When the petals are partially united, the lower entire portion of the corolla is ealled the tube, whatever be its shape, and the free portions of the petals are called the teeth, lobes, or segments (39), according as they are short or long in proportion to the whole length of the corolla. When the tube is excessively short, the petals appear at first sight free, but

102. The Aestivation of a corolla is the arrangement of the petals, or of such portion of them as is free, in the unexpanded bud. It is valvate, when they are strictly whorled in their whole length, their edges being placed against each other without overlapping. If the edges 
are much inflexed, the aestivation is at the same time induplicate; involute, if the margins are rolled inwards; reduplicate, if the margins project outwards into salient angles; revolute, if the margins are rolled outwards; plicate, if the petals are folded in longitudinal plaits.

imbricate, when the whorl is more or less broken by some of the petals being outside the others, or by their overlapping each other at least at the top. Five-petaled imbricate corollas are quincuncially imbricate when one petal is outside, and an adjoining one wholly inside, the three others intermediate and overlapping on one side; bilabiate, when two adjoining ones are inside or outside the three others. Imbricate petals are described as crumpled (corrugate) when puckered irregularly in the bud.

twisted, contorted, or convolute, when each petal overlaps an adjoining one on one side, and is overlapped by the other adjoining one on the other side. Some botanists include the twisted aestivation in the general term imbricate: others carefully distinguish the one from the other.

103. In a few cases the overlapping is so slight that the three aestivations cannot easily be distinguished one from the other; in a few others the aestivation is variable, even in the same species, but, in general, it supplies a constant character in species, in genera, or even in Natural Orders.

104. In general shape the Corolla is

tubular, when the whole or the greater part of it is in the form of a tube or cylinder. or bell. campanulate, when approaching in some measure the shape of a cup

urceolate, when the tube is swollen or nearly globular, contracted at the top, and slightly expanded again in a narrow rim.

rotate or stellate, when the petals or lobes are spread out horizontally from the hase, or nearly so, like a wheel or star.

hypocrateriform or salver-shaped, when the lower part is cylindrical and the upper portion expanded horizontally. In this case the name of tube is restricted to the cylindrical part, and the horizontal portion is called the limb, whether it be divided to the base or not. The orifice of the tube is called its mouth or throat.

infundibuliform or funnel-shaped, when the tube is cylindrical at the base, but enlarged at the top into a more or less campanulate limb, of which the lobes often spread horizontally. In this case the campanulate part, up to the commencement of the lobes, is sometimes considered as a portion of the tube, sometimes as a portion of the limb, and by some botanists again described as independent of either, under the name of throat (fauces). Generally speaking, however, in campanulate, infundibuliform, or other corollas, where the lower entire part passes gradually into the upper divided and more spreading part, the distinction between the tube and the limb is drawn either at the point where the lobes separate, or at the part where the corolla first expands, according to which is the most marked.

105. Irregular corollas have received various names according to the more familiar forms they have been compared to. Some of the most
important are the

bilabiate, or two-lipped corolla, when, in a four- or five-lobed corolla, the two or three upper lobes stand obviously apart, like an upper lip, from the two or three lower ones or under lip. In Orchideae and some 
other families the name of lip, or labellum, is given to one of the divisions or lobes of the perianth.

personate, when two-lipped, and the orifice of the tube closed by a projection from the base of the upper or lower lip, called a palate.

ringent, when very strongly two-lipped, and the orifice of the tube very open.

spurred, when the tube or the lower part of a petal has a conical hollow projection, compared to the spur of a cock; saccate, when the spur is short and round like a little bag; gibbous, when projecting at any part into a slight swelling.

resupinate or reversed, when a lip, spur, etc., which in allied species is usually lowest, lies uppermost, and vice versa.

106. The above terms are mostly applied to the forms of monopetalous corollas, but several are also applicable to those of polypetalous ones. Terms descriptive of the special forms of corolla in certain Natural Orders, will be explained under those Orders respectively.

107. Most of the terms used for describing the forms of leaves $(39,45)$ are also applicable to those of individual petals; but the flat expanded portion of a petal, corresponding to the blade of the leaf, is called its lamina, and the stalk, corresponding to the petiole, its claw (unguis). The stalked petal is said to be unguiculate.

\section{§ 10. The Stamens.}

108. Although in a few cases the outer stamens may gradually pass into petals, yet, in general, Stamens are very different in shape and aspect from leaves, sepals, or petals. It is only in a theoretical point of view (not the less important in the study of the physiologieal eeonomy of the plant) that they can be called altered leaves.

109. This usual form is a stalk, called the filament, bearing at the top an anther divided into two pouches or cells. These anther-cells are filled with pollen, consisting of minute grains, usually forming a yellow dust, which, when the flower expands, is seattered from an opening in each cell. When the two cells are not closely contiguous, the portion of the anther that unites them is called the connectivum.

110. The filament is often wanting, and the anther sessile, yet still the stamen is perfect; but if the anther, which is the essential part of the stamen, is wanting, or does not contain pollen, the stamen is imperfect, and is then said to be barren or sterile (without pollen), abortive or rudimentary (84), according to the degree to which the imperfection is carried. Imperfect stamens are often called staminodia.

111. In unsymmetrical flowers, the stamens of each whorl are sometimes reduced in number below that of the petals, even to a single one, and in several Natural Orders they are multiplied indefinitely.

112. The terms monandrous and polyandrous are restricted to flowers which have really but one stamen, or an indefinite number respectively. Where several stamens are united into one, the flower is said to be
synandrous.

\section{Stamens are}

monadelphous, when united by their filaments into one cluster. This cluster either forms a tube round the pistil, or, if the pistil is wanting,
occupies the centre of the flower. 
diadelphous, when so united into two clusters. The term is more especially applied to certain Leguminosae, in which nine stamens are united in a tube slit open on the upper side, and a tenth, placed in the slit, is free. In some other plants the stamens are equally distributed in the two clusters.

triadelphous, pentadelphous, polyadelphous, when so united into three, five, or many elusters.

syngenesious, when united by their anthers in a ring round the pistil, the filaments usually remaining free.

didynamous, when (usually in a bilabiate flower) there are four stamens in two pairs, those of one pair longer than those of the other.

tedradynamous, when (in Cruciferae) there are six, four of them longer than the two others.

exserted, when longer than the corolla, or even when longer than its tube, if the limb be very spreading.

114. An Anther (109) is

adnate, when continuous with the filament, the anther-cells appearing to lie their whole length along the upper part of the filament.

innate, when firmly attached by their base to the filament. This is an adnate anther when rather more distinct from the filament.

versatile, when attached by their back to the very point of the filament, so as to swing loosely.

115. Anther-cells may be parallel or diverging at a less or greater angle; or divaricate, when placed end to end so as to form one straight line. The end of each anther-cell placed nearest to the other cell is generally called its apex or summit, and the other end its base (36); but some botanists reverse the sense of these terms.

116. Anthers have often, on their connectivum or cells, appendages termed bristles (setae), spurs, crests, points, glands, etc., according to their appearance.

117. Anthers have occasionally only one cell: this may take place either by the disappearance of the partition between two closely contiguous cells, when these cells are said to be confluent; or by the abortion or total deficiency of one of the cells, when the anther is said to be dimidiate.

118. Anthers will open or dehisce to let out the pollen, like capsules, in valves, pores, or slits. Their dehiscence is introrse, when the opening faces the pistil; extrorse, when towards the eircumference of the flower.

119. Pollen (109) is not always in the form of dust. It is sometimes collected in each cell into one or two little wax-like masses. Special terms used in describing these masses or other modifications of the pollen will be explained under the Orders where they occur.

\section{\$ 11. The Pistil.}

120. The carpels (91) of the Pistil, although they may oecasionally assume, rather more than stamens, the appearance and colour of leaves, are still more different in shape and strueture. They are usually sessile; if stalked, their stalk is called a podocarp. This stalk, upon which each separate carpel is supported above the receptacle, must not be confounded with the gymobasis (143), upon which the whole pistil is sometimes raised.

121. Each carpel consists of three parts: 
(1) the Ovary, or enlarged base, which includes one or more cavities or cells, containing one or more small bodies called ovules. These are the earliest condition of the future seeds. porting-

(2) the Style, proceeding from the summit of the ovary and sup-

(3) the Stigma, which is sometimes a point (or punctiform stigma) or small head (a capitate stigma) at the top of the style or ovary, sometimes a portion of its surface more or less lateral and variously shaped, distinguished by a looser texture, and covered with minute protuberances called papillae.

122. The style is often wanting, and the stigma is then sessile on the ovary, but in the perfect pistil there is always at least one ovule in the ovary, and some portion of stigmatic surface. Without these the pistil is imperfect, and said to be barren (not setting seed), abortive, or rudimentary (84), according to the degree of imperfection.

123. The ovary being the essential part of the pistil, most of the terms relating to the number, arrangement, etc., of the carpels, apply specially to their ovaries. In some works each separate carpel is called a pistil, all those of a flower constituting together the gynaecium; but this term is in little use, and the word pistil is more generally applied in a collective sense. When the ovaries are at all united, they are commonly termed collectively a compound ovary.

124. The number of carpels or ovaries in a flower is frequently reduced below that of the parts of the other floral whorls, even in flowers otherwise symmetrical. In a very few genera, however, the ovaries are more numerous than the petals, or indefinite. They are in that case either arranged in a single whorl, or form a head or spike in the centre of the flower.

125. The terms monogynous, digynous, polygynous, etc. (with a pistil of one, two, or more parts), are vaguely used, applying sometimes to the whole pistil, sometimes to the ovaries alone, or to the styles or stigmas only. Where a more precise nomenclature is adopted, the flower is monocarpellary, when the pistil consists of a single simple carpel.

bi-, tri-, etc., to poly-carpellary, when the pistil consists of two, three, or an indefinite number of carpels, whether separated or united,

syncarpous, when the carpels or their ovaries are more or less united into one compound ovary.

apocarpous, when the carpels or ovaries are all free and distinct.

126. A compound ovary is

unilocular or one-celled, when there are no partitions between the ovules, or when these partitions do not meet in the centre so as to divide the cavity into several cells.

plurilocular or several-celled, when completely divided into two or more cells by partitions called dissepiments (septa), usually vertical and radiating from the centre or axis of the ovary to its circumference.

bi-, tri-, etc., to multi-locular, according to the number of these cells, two, three, etc., or many.

127. In general the number of cells or of dissepiments, complete or partial, or of rows of ovules, corresponds with that of the carpels, of which the pistil is composed. But sometimes each carpel is divided completely or partially into two cells, or has two rows of ovules, so that the carpels are so completely combined and reduced as to form a single cell, with a single ovule, although it really consists of several carpels, 
But in these cases the ovary is usually described as it appears, as well as such as it is theoretically supposed to be.

128. In apocarpous pistils the styles are usually free, each bearing its own stigma. Very rarely the greater part of the styles, or the stigmas alone, are united, whilst the ovaries remain distinct.

129. Synearpous flowers are said to have

several styles, when the styles are free from the base.

one style, with several branches, when the styles are connected at the base, but separate below the point where the stigmas or stigmatic surfaces commence.

one simple style, with several stigmas, when united up to the point where the stigmas or stigmatic surfaces commence, and then separating. one simple style with a branched, lobed, toothed, notched, or entire stigma (as the case may be), when the stigmas also are more or less united. In many works, however, this precise nomenclature is not strictly adhered to, and considerable confusion is often the result.

130. In general the number of styles, or branches of the style or stigma, is the same as that of the carpels, but sometimes that number is doubled, especially in the stigmas, and sometimes the stigmas are dichotomously or pinnately branched, or penicillate, that is, divided into a tuft of hair-like branches. All these variations sometimes make it a difficult task to determine the number of carpels forming a compound ovary, but the point is of considerable importance in fixing the affinities of plants, and, by careful consideration, the real as well as the apparent number has now in most cases been agreed upon.

131. The Placenta is the part of the inside of the ovary to which the ovules are attached, sometimes a mere point or line on the inner surface often more or less thickened or raised. Placentation is therefore the indication of the part of the ovary to which the ovules are attached.

\section{Placentas are}

axile, when the ovules are attached to the axis or centre, that is, in plurilocular ovaries, when they are attached to the inner angle of each cell; in unilocular simple ovaries, which have almost always an excentrical style or stigma, when the ovules are attached to the side of the ovary nearest to the style; in unilocular compound ovaries, when the ovules are attached to a central protuberance, column, or axis rising up from the base of the cavity. If this column does not reach the top of the cavity, the placenta is said to be free and central.

parietal, when the ovules are attached to the inner surface of the cavity of a one-celled compound ovary. Parietal placentas are usually slightly thickened or raised lines, sometimes broad surfaces nearly covering the inner surface of the cavity, sometimes projecting far into the cavity, and constituting partial dissepiments, or even meeting in the centre, but without cohering there. In the latter case the distinction between the one-celled and the several-celled ovary sometimes almost disappears.

133. Each Ovule (121), when fully formed, usually consists of a central mass or mucleus, enclosed in two bag-like coats, the outer one called primine, the inner one secundine. The chalaza is the point of the ovule at which the base of the nucleus is confluent with the coats. The foramen is a minute aperture in the coats over the apex of the nucleus.

134. Ovules are

orthotropous or straight, when the chalaza coincides with the base (36) of the ovule, and the foramen is at the opposite extremity, the axis of the ovule being straight. 
campylotropous or incurved, when the chalaza still coinciding with the base of the ovule, the axis of the ovule is curved, bringing the foramen down more or less towards that base.

anatropous or inverted, when the chalaza is at the apex of the ovule, and the foramen next to its base, the axis remaining straight. In this, one of the most frequent forms of the ovule, the chalaza is connected with the base by a cord, called the raphe, adhering to one side of the ovule, and becoming more or less incorporated with its coats, as the ovule enlarges into a seed.

amphitropous or half-inverted, when the ovule being as it were at. tached laterally, the chalaza and foramen at opposite ends of its straight or curved axis are about equally distant from the base or point of attachment.

\section{$\S$ 12. The Receptacle and Relative Attachment of the Floral Whorls.}

135. The Receptacle or torus is the extremity of the peduncle (above the calyx), upon which the corolla, stamens, and ovary are inserted. It is sometimes little more than a mere point or minute hemisphere, but it is often also more or less elongated, thickened, or otherwise enlarged. It must not be confounded with the receptacle of inflorescence (74).

136. A Disk, or disc, is a circular enlargement of the receptacle, usually in the form of a cup (cupular), of a flat disk or quoit, or of a cushion (pulvinate). It is either immediately at the base of the ovary within the stamens, or between the petals and stamens, or bears the petals or sta. mens or both on its margin, or is quite at the extremity of the receptacle, with the ovaries arranged in a ring round it or under it.

137. The disk may be entire, or toothed or lobed, or divided into a number of parts, usually equal to or twice that of the stamens or carpels, When the parts of the disk are quite separate and short, they are often called glands.

138. Nectaries, are either the disk, or small deformed petals, or abortive stamens, or appendages at the base of petals or stamens, or any small bodies within the flower which do not look like petals, stamens, or ovaries. They were formerly supposed to supply bees with their honey, and the term is frequently to be met with in the older Floras, but is now deservedly going out of use.

139. When the disk bears the petals and stamens, it is frequently adherent to, and apparently forms part of, the tube of the calyx, or it is adherent to, and apparently forms part of, the ovary, or of both calyx. tube and ovary. Hence the three following important distinctions in the relative insertion of the floral whorls.

140. Petals or, as it is frequently expressed, flowers, are hypogynous (i. e. under the ovary), when they or the disk that bears
them are entirely free both from the calyx and ovary. The ovary is then
described as free or superior, the eal described as free or superior, the calyx as free or inferior, the petals as being inserted on the receptacle.

perigynous ( $i$. $e$. round the ovary), when the disk bearing the petals is quite free from the ovary, but is more or less combined with the base of the calyx-tube. The ovary is then still described as free or superior, even though the combined disk and calyx-tube may form a deep cup with the ovary lying in the bottom; the calyx is said to be free or inferior, and the petals are described as inserted on the calyx. 
epigynous (i.e. upon the ovary), when the disk bearing the petals is combined both with the base of the calyx-tube and the base outside of the ovary; either closing over the ovary so as only to leave a passage for the style, or leaving more or less of the top of the ovary free, but always adhering to it above the level of the insertion of the lowest ovule (except in a very few cases where the ovules are absolutely suspended from the top of the cell). In epigynous flowers the ovary is described as adherent or inferior, the calyx as adherent or superior, the petals as inserted on or above the ovary. In some works, however, most epigynous flowers are included in the perigynous ones, and a very different meaning is given to the term epigynous (144), and there are a few cases where no positive distinction can be drawn between the epigynous and perigynous flowers, or again between the perigynous and hypogynous flowers.

141. When there are no petals, it is the insertion of the stamens that determines the difference between the hypogynous, perigynous, and epigynous flowers.

142. When there are both petals and stamens,

in hypogynous flowers, the petals and stamens are usually free from each other, but sometimes they are combined at the base. In that case, if the petals are distinct from each other, and the stamens are monadelphous, the petals are often said to be inserted on or combined with the staminal tube; if the corolla is gamopetalous and the stamens distinct from each other, the latter are said to be inserted in the tube of the corolla.

in perigynous flowers, the stamens are usually inserted immediately within the petals, or alternating with them on the edge of the disk, but occasionally much lower down within the disk, or even on the unenlarged part of the receptacle.

in epigynous flowers, when the petals are distinct, the stamens are usually inserted as in perigynous flowers; when the corolla is gamopetalous, the stamens are either free, or combined at the base with (inserted in) the tube of the corolla.

143. When the receptacle is distinctly elongated below the ovary, it is often called a gynobasis, gynophore, or stalk of the ovary. If the elongation takes place below the stamens or below the petals, these stamens or petals are then said to be inserted on the stalk of the ovary, and are occasionally, but falsely, described as epigynous. Really epigynous stamens (i. e. when the filaments are combined with the ofary) are very rare, unless the rest of the flower is epigynous.

144. An epigynous disk is a name given either to the thickened summit of the ovary in epigynous flowers, or very rarely to a real disk or enlargement of the receptacle closing over the ovary.

145. In the relative position of any two or more parts of the flower, whether in the same or in different whorls, they are

connivent, when nearer together at the summit than at the base.

divergent, when further apart at the summit than at the base.

coherent, when united together, but so slightly that they can be separated with little or no laceration; and one of the two coherent parts (usually the smallest or least important) is said to be adherent to the other. Grammatically speaking, these two terms convey nearly the same meaning, but require a different form of phrase; practically, however, it has been found more convenient to restrict cohesion to the union of parts of the same whorl, and adhesion to the union of parts of different whorls. 
connate, when so closely united that they cannot be separated without laceration. Each of the two connate parts, and especially that one which is considered the smaller or of the least importance, is said to be adnate to the other.

free, when neither coherent nor connate.

distinct is also used in the same sense, but is also applied to parts distinctly visible or distinctly limited.

\section{§.13. The Fruit.}

146. The Fruit (15) consists of the ovary and whatever other parts of the flower are persistent (i.e. persist at the time the seed is ripe), usually enlarged, and more or less altered in shape and consistence. It encloses or covers the seed or seeds till the period of maturity, when it either opens for the seed to escape, or falls to the ground with the seed. When stalked, its stalk has been termed a carpophore.

147. Fruits are, in elementary works, said to be simple when the result of a single flower, compound when they proceed from several flowers closely packed or combined in a head. But as a fruit resulting from a single flower, with several distinct carpels, is compound in the sense in which that term is applied to the ovary, the terms single and aggregate, proposed for the fruit resulting from one or several flowers, may be more appropriately adopted. In descriptive Botany a fruit is always supposed to result from a single flower unless the contrary be stated. It may, like the pistil, be syncarpous or apocarpous (125); and as in many cases carpels united in the flower may become separate as they ripen, an apocarpous fruit may result from a syncarpous pistil.

148. The involucre or bracts often persist and form part of aggregate fruits, but very seldom so in single ones.

149. The receptacle becomes occasionally enlarged and succulent; if when ripe it falls off with the fruit, it is considered as forming part of it.

150. The adherent part of the calyx of epigynous flowers always persists and forms part of the fruit; the free part of the calyx of epigynous flowers or the calyx of perigynous flowers, either persists entirely at the top of or round the fruit, or the lobes alone fall off, or the lobes fall off with whatever part of the calyx is above the insertion of the petals, or the whole of what is free from the ovary falls off, including the disk bearing the petals. The calyx of hypogynous flowers usually falls off entirely or persists entirely. In general a calyx is called deciduous if any part falls off. When it persists it is either enlarged round or under the fruit, or it withers and dries up.

151. The corolla usually falls off entirely; when it persists, it is usually withered and dry (marcescent), or very seldom enlarges round the fruit.

152. The stamens either fall off, or more or less of their filaments persists, usually withered and dry.

153. The style sometimes falls off or dries up and disappears; sometimes persists, forming a point to the fruit, or becomes enlarged into a wing or other appendage to the fruit.

154. The Pericarp is the portion of the fruit formed of the ovary, and whatever adheres to it exclusive of and outside of the seed or seeds, exclusive also of the persistent receptacle, or of whatever portion of the calyx persists round the ovary without adhering to it. 
155. Fruits have often external appendages called wings (alae), beaks, crests, awns, etc., according to their appearance. They are either formed by persistent parts of the flower more or less altered, or grow out of the ovary or the persistent part of the calyx. If the appendage be a ring of hairs or scales round the top of the fruit, it is called a pappus.

156. Fruits are generally divided into succulent (including fleshy, pulpy, and juicy fruits) and dry. They are dehiscent when they open at maturity to let out the seeds, indehiscent when they do not open spontaneously but fall off with the seeds. Succulent fruits are usually indehiscent.

157. The principal kinds of succulent fruits are

the Berry, in which the whole substance of the pericarp is fleshy or pulpy, with the exception of the outer skin or rind, called the Epicarp. The seeds themselves are usually immersed in the pulp; but in some berries the seeds are separated from the pulp by the walls of the cavity or cells of the ovary, which form as it were a thin inner skin or rind, called the Endocarp.

the Drupe, in which the pericarp, when ripe, consists of two distinct portions, an outer succulent one called the Sarcocarp (covered like the berry by a skin or epicarp), and an inner dry endocarp called the Putamen, which is either cartilaginous (of the consistence of parchment) or hard and woody. In the latter ease it is commonly called a stone, and the drupe a stone-fruit.

158. The principal kinds of dry fruits are

the Capsule or Pod*, which is dehiscent. When ripe the pericarp tusually splits longitudinally into as many or twice as many pieces, called valves, as it contains cells or placentas. If these valves separate at the line of junction of the carpels, that is, along the line of the placentas or dissepiments, either splitting them or leaving them attached to the axis, the dehiscence is termed septicidal; if the valves separate between the placentas or dissepiment, the dehiscence is loculicidal, and the valves either bear the placentas or dissepiments along their middle line, or leave them attached to the axis. Sometimes also the capsule discharges its seeds by slits, chinks, or pores, more or less regularly arranged, or bursts irregularly, or separates into two parts by a horizontal line; in the latter case it is said to be circumsciss.

the Nut or Achene, which is indehiscent and contains but a single seed. When the pericarp is thin in proportion to the seed it encloses, the whole fruit (or each of its lobes) has the appearance of a single seed, and is so called in popular language. If the pericarp is thin and rather loose, it is often called a Utricle. A Samara is a nut with a wing at its upper end.

159. When the carpels of the ovary are distinet (125), they may severally become as many distinct berries, drupes, capsules, or achenes. Separate carpels are usually more or less compressed laterally, with more or less prominent inner and outer edges, called sutures, and, if dehiscent, the carpel ustally opens at these sutures. A Follicle is a carpel opening at the inner suture only. In some cases where the carpels are united in the ovary, they will separate when ripe; they are then called Cocci if one-seeded.

160. The peculiar fruits of some of the large Orders have received special names, which will be explained under each Order. Such are the

- In English descriptions, pod is more frequently used when it is long and narrow; capsule, or sometimes pouch, when it is short and thick or broad. 
Siliqua and Siticule of Cruciferae, the Legume of Leguminosae, the Pome of Pyrus and its allies, the Pepo of Cucurbitaceae, the Cone of Coniferae, the Grain or Caryopsis of Gramineae, ete.

\section{§ 14. The Seed.}

161. The Seed is enclosed in the pericarp in the great majority of flowering plants, called therefore Angiosperms or angiospermous plants. In Coniferae and a very few allied genera, called Gymnosperms or gymnospermous plants, the seed is naked, without any real pericarp. These truly gymnospermous plants must not be confounded with Labiatae, Boragineae, etc., which have also been falsely called gymnospermous, their small nuts having the appearance of seeds (158).

162. The seed when ripe contains an embryo or young plant, either filling or nearly filling the cavity, but not attached to the outer skin or the seed, or more or less immersed in a mealy, oily, fleshy, or horn-like substance, called the albumen, or perisperm. The presence or absence of this albumen, that is, the distinction between albuminous and exalbuminous seeds, is one of great importance. The embryo or albumen can often only be found or distinguished when the seed is quite ripe, or sometimes only when it begins to germinate.

163. The shell of the seed consists usually of two separable coats. The outer coat, called the testa, is usually the principal one, and in most eases the only one attended to in descriptions. It may be hard and crustaceous, woody or bony, or thin and membranous (skin-like), dry or rarely succulent. It is sometimes expanded into wings, or bears a tuft of hair, cotton, or wool, called a coma. The inner coat is called the tegmen,

164. The funicle is the stalk by which the seed is attached to the placenta. It is occasionally enlarged into a membranous, pulpy, or fleshy appendage, sometimes spreading over a considerable part of the seed, or nearly enelosing it, called an aril. A strophiole or caruncle is a similar appendage, proceeding from the testa, by the side of or near the funicle.

165. The hilum is the scar left on the seed where it separates from the funicle. The micropyle is a mark indicating the position of the foramen of the ovule (133).

166. The Embryo (162) consists of the Radicle or base of the future root, one or two Cotyledons or future seed-leaves, and the Plumule, or future bud within the base of the cotyledons. In some seeds, especially where there is no albumen, these several parts are very conspicuous, in others they are very difficult to distinguish until the seed begins to germinate, Their observation, however, is of the greatest importance, for it is chiefly upon the distinction between the embryo with one or with two cotyledons that are founded the two great classes of phaenogamous
plants, Monocotyledons and Dicotyledons.

167. Although the embryo lies loose (unattached) within the seed, it is generally in some determinate position with respect to the seed or to the whole fruit. This position is described by stating the direction of the radicle next to or more or less remote from the hilum, or it is said to be superior if pointing towards the summit of the fruit, inferior if pointing 


\section{$\S 15$. Accessory Organs.}

168. Under this name are included, in many elementary works, various external parts of plants which do not appear to act any essential part either in the vegetation or reproduction of the plant. They may be classed under four heads: Tendrils and Hooks, Thorns and Prickles, Hairs and Glands.

169. Tendrils (cirrhi) are usually abortive petioles, or abortive peduncles, or sometimes abortive ends of branches. They are simple or more or less branched, flexible, and, coil more or less firmly round any objects within their reach, in order to support the plant to which they belong. Hooks are similar holdfasts, but of a firmer consistence, not branched, and less coiled.

170. Thorns and Prickles have been fancifully called the weapons of plants. A Thorn or Spine is the strongly pointed extremity of a branch, or abortive petiole, or abortive peduncle. A Prickle is a sharply pointed excrescence from the epidermis, and is usually produced on a branch, on the petiole or veins of a leaf, or on a peduncle, or even on the calyx or corolla. When the teeth of a leaf or the stipules are pungent, they are also called prickles, not thorns. A plant is spinous if it has thorns, aculeate if it has prickles.

171. Hairs, in the general sense, or the indumentum (or clothing) of a plant, include all those productions of the epidermis which have, by a more or less appropriate comparison, been termed bristles, hairs, down, cotton, or wool.

172. Hairs are often branched. They are said to be attached by the centre, if parted from the base, and the forks spread along the surface in opposite directions; plumose if the branches are arranged along a common axis, as in a feather; stellate, if several branches radiate horizontally. These stellate hairs have sometimes their rays connected together at the base, forming little flat circular disks attached by the centre, and are then called scales, and the surface is said to be scaly or lepidote.

173. The Epidermis, or outer skin, of an organ, as to its surface and indumentum, is

smooth, when without any protuberance whatever.

glabrous, when without hairs of any kind.

striate, when marked with parallel longitudinal lines, either slightly raised or merely discoloured.

furrowed (sulcate) or ribbed (costate) when the parallel lines are more distinctly raised.

rugose, when wrinkled or marked with irregular raised or depressed lines.

umbilicate, when marked with a small round depression.

umbonate, when bearing a small boss like that of a shield.

viscous, viscid, or glutinous, when covered with a sticky or clammy exudation.

scabrous, when rough to the touch.

tuberculate or warted, when covered with small, obtuse, wart-like protuberances.

muricate, when the protuberances are more raised and pointed but yet short and level. 

prickly.

echinate, when the protuberances are longer and sharper, almost setose or bristly, when bearing very stiff erect straight hairs.

glandular-setose, when the setae or bristles terminate in a minute resinous head or drop. In some works, especially in the case of Roses and Rubus, the meaning of setae has been restricted to such as are glandular.

glochidiate, when the setae are hooked at the top. hairs.

pilose, when the surface is thinly sprinkled with rather long simple

hispid, when more thickly covered with rather stiff hairs.

hirsute, when the hairs are dense and not so stiff.

downy or pubescent, when the hairs are short and soft; puberulent, when slightly pubescent.

strigose, when the hairs are rather short and soft, and lie close along the surface all in the same direction; strigillose, when slightly strigose. tomentose or cottony, when the hairs are very short and soft, rather dense and more or less intricate, and usually white or whitish.

woolly (lanate), when the hairs are long and loosely intricate, like wool. The wool or tomentum is said to be floccose when closely intricate and readily detached, like fleece

mealy (farinose), when the hairs are excessively short, intricate and white, and come off readily, having the appearance of meal or dust. canescent or hoary, when the hairs are so short as not readily to be distinguished by the naked eye, and yet give a general whitish hue to the epidermis. bloom.

glaucous, when of a pale bluish-green, often covered with a fine

174. The meanings here attached to the above terms are such as appear to have been most generally adopted, but there is much vagueness in the use practically made of many of them by different botanists. This is especially the case with the terms pilose, hispid, hirsute, pubescent, and tomentose.

175. The name of Glands is given to several different productions, and principally to the four following:-

1. Small wart-like or shield-like bodies, either sessile or sometimes stalked, of a fungous or somewhat fleshy consistence, occasionally secreting a small quantity of oily or resinous matter, but more frequently dry. They are generally few in number, often definite in their position and form, and occur chiefly on the petiole or principal veins of leaves, on the branches of inflorescences, or on the stalks or principal veins of bracts, sepals, or petals.

2. Minute raised dots, usually black, red, or dark-coloured, of a resinous or oily nature, always superfieial, and apparently exudations from the epidermis. They are often numerous on leaves, bracts, sepals, and green branches, and occur even on petals and stamens, more rarely on pistils. When raised upon slender stalks they are called pedicellate (or stipitate) glands, or glandular hairs, according to the thickness of the stalk.

3. Small, globular, oblong or even linear vesicles, filled with oil, imbedded in the substance itself of leaves, bracts, floral organs, or fruits. They are often very numerous, like transparent dots, sometimes few and 
determinate in form and position. In the pericarp of Umbellifercae they are remarkably regular and conspicuous, and take the name of vittae.

4. Lobes of the disk (137), or other small fleshy excrescences within the flower, whether from the receptacle, calyx, corolla, stamens or pistil.

\section{Chap. II. Classification, or Systematic Botany.}

176. It has already been observed (3) that descriptions of plants should, as nearly as possible, be arranged under natural divisions, so as to facilitate the comparison of each plant with those most nearly allied to it. The descriptions of plants here alluded to are descriptions of species; the natural divisions of the Flora refer to natural groups of species.

177. A Species comprises all the individual plants which resemble each other suffieiently to make us conclude that they are all, or may have been all, descended from a common parent. These individuals may often differ from each other in many striking particulars, such as the colour of the flower, size of the leaf, etc., but these particulars are such as experience teaches us are liable to vary in the seedlings raised from one individual.

178. When a large number of the individuals of a species differ from the others in any striking particular they constitute a Variety. If the variety generally comes true from seed, it is often called a Race.

179. A Variety can only be propagated with certainty by grafts, cuttings, bulbs, tubers, or any other method which produces a new plant by the development of one or more buds taken from the old one. A Race may with care be propagated by seed, although seedlings will always be liable, under certain circumstances, to lose those particulars which distinguish it from the rest of the species. A real Species will always come true from seed.

180. The known species of plants (now near 100,000) are far too numerous for the human mind to study without classification, or even to give distinct single names to. To facilitate these objects, an admirable system, invented by Linnaeus, has been universally adopted, viz. one common substantive name is given to a number of species which resemble each other more than they do any other species; the species so collected under one name are collectively called a Genus, the common name being the generic name. Each species is then distinguished from the others of the same genus by the addition of an adjective epithet or specific name. Every species has thus a botanical name of two words. In Latin, the language usually used for the purpose, the first word is a substantive and designates the genus; the second, an adjective, indicates the species. In English, the adjective or specific name comes before the substantive or generic one.

181. The genera thus formed being still too numerous (above 6000) for study without further arrangement, they have been classed upon the same principles; viz. genera which resemble each other more than they do any other genera, have been collected together into groups of a higher degree called Families or Natural Orders, to each of which a common name has been given. This name is in Latin an adjective plural, usually taken from the name of some one typical genus, generally the best known, 
the first discovered, or the most marked (e. g. Ranunculaceae from Rananculus). It is rendered in English by the addition of the word plants to a plural adjective, or by adding the word family or order to the name of the typical genus taken adjectively, as Ranunculaceous Plants, or the Ranunculus Family (or Order). This is, however, for the purpose of study and comparison. To speak of a species, to refer to it and identify it, all that is necessary is to give the generic and specific names.

182. Natural Orders themselves (of which we reckon near 200) are often in the same manner collected into Classes; and where Orders contain a large number of genera, or genera a large number of species, they require further classification. The genera of an Order are then collected into minor groups called Tribes, the species of a genus into Sections, and in a few cases this intermediate classification is carried still further. The names of these several groups the most generally adopted are as follows, beginning with the most comprehensive or highest:-

Classes.

Subclasses or Alliances.

Natural Orders or Families.

Suborders.

Tribes.

Subtribes.

Divisions.

Subdivisions.
Genera.

Subgenera.

Sections.

Subsections.

Species.

Varieties.

183. The characters (3) by which a species is distinguished from all other species of the same genus are collectively called the specific character of the plant; those by which its genus is distinguished from other genera of the Order, or its Order from other Orders, are respectively called the generic or ordinal characters, as the case may be. The habit of a plant, of a species, a genus, etc., consists of such general characters as strike the eye at first sight, such as size, colour, ramification, arrangement of the leaves, inflorescence, etc., and are chiefly derived from the organs of

184. Classes, Orders, Genera, and their several subdivisions, are called natural when, in forming them, all resemblances and differences are taken into aceount, valuing them according to their evident or presumed importance; artificial, when resemblances and differences in some one or very few particulars only are taken into account independently of all others.

185. The number of species included in a genus, or the number of genera in an Order, is very variable. Sometimes two or three or even a single species may be so different from all others as to constitute the entire genus; in others, several hundred species may resemble each other so much as to be all included in one genus; and there is the same discrepancy in the number of genera to a Family. There is, moreover, unfortunately, in a number of instances, great difference of opinion as to whether certain plants differing from each other in certain particulars are varieties of one species or belong to distinct species; and again, whether two or more groups of species should constitute as many sections of one genus, or distinct genera, or tribes of one Order, or even distinct Natural Orders. In the former case, if a species is supposed to have a real existence in nature, the question may be susceptible of argument, and sometimes of absolute proof. But the place a group should occupy 
in the scale of degree is very arbitrary, being often a mere question of convenience. The more subdivisions upon correct principles are multiplied, the more they facilitate the study of plants, provided always the main resting-points for constant use, the Order and the Genus, are comprehensive and distinct. But if every group into which a genus can be divided be erected into a distinct genus, with a substantive name to be remembered whenever a species is spoken of, all the advantages derived from the beautiful simplicity of the Linnaean nomenclature are gone.

The definitions above given of Varieties, Races, Species, Sections, etc., must be taken in a general sense, as the distinctions between them are not always so absolute as they were once thought to be.

\section{Chap. III. Vegetable Anatomy and Physiology.}

\section{\$ 1. Structure and Growth of the Elementary Tissues.}

186. If a very thin slice of any part of a plant be placed under a microscope of high magnifying power, it will be found to be made up of variously shaped and arranged ultimate parts, forming a sort of honeycombed structure. These ultimate parts are called cells, and form by their combination the elementary tissues of which the entire plant is composed.

187. A cell in its simplest state is a closed membranous sac, formed of a substance permeable by fluids, though usually destitute of visible pores. Each cell is a distinct individual, separately formed and separately acting, though cohering with the cells with which it is in contact, and partaking of the common life and action of the tissue of which it forms a part. The membranes separating or enclosing the cells are also called their walls.

188. Botanists usually distinguish the following tissues:-

(1) Cellular tissue, or parenchyma, consists usually of thin-walled cells, more or less round in form, or with their length not much exceeding their breadth, and not tapering at the ends. All the soft parts of the leaves, the pith of stems, the pulp of fruits, and all young growing parts, are formed of it. It is the first tissue produced, and continues to be formed while growth continues, and when it ceases to be active the plant dies.

(2) Woody tissue, or prosenchyma, differs in having its cells considerably longer than broad, usually tapering at each end into points and overlapping each other. The cells are commonly thick-walled; the tissue is firm, tenacious, and elastic, and constitutes the principal part of wood, of the inner bark, and of the nerves and veins of leaves, forming, in short, the framework of the plant.

(3) Vascular tissue, or the vessels or ducts of plants, so called from the mistaken notion that their functions are analogous to those of the vessels (veins and arteries) of animals. A vessel in plants consists of a vertical row of cells, which have their transverse partition walls obliterated, so as to form a continuous tube. All phaenogamous plants, as well as ferns and a few other cryptogamous plants, have vessels, and are therefore called vascular plants; so the majority of cryptogams having only cellular 
tissue are termed cellular plants. Vessels have their sides very variously marked; some, called spiral vessels, have a spiral fibre coiled up their inside, which unrolls when the vessel is broken; others are marked with longitudinal slits, cross bars, minute dots or pits, or with transverse rings. The size of vessels is also very variable in different plants; in some they are of considerable size and visible to the naked eye in cross: sections of the stem, in others they are almost absent or can only be traced under a strong magnifier.

189. Various modifications of the above tissues are distinguished by vegetable anatomists under names which need not be enumerated here as not being in general practical use. Air-vessels, cysts, turpentine-vessels, oil-reservoirs, etc., are either cavities left between the cells, or large cells filled with peculiar secretions.

190. When tissues are once formed, they increase, not by the general enlargement of the whole of the cells already formed, but by cell-division, that is, by the division of young and vitally active cells, and the enlargement of their portions. In the formation of the embryo, the first cell of the new plant is formed, not by division, but around a segregate por: tion of the contents of a previously existing cell, the embryo-sac. This is termed free cell-formation, in contradistinction to cell-division.

191. A young and vitally active cell consists of the outer wall, formed of a more or less transparent substance called cellulose, permeable by fluids, and of ternary chemical composition (carbon, hydrogen, and oxygen); and of the cell-contents, usually viscid or mucilaginous, consisting of pro= toplasm, a substance of quaternary chemical composition (carbon, hydrogen, oxygen, and nitrogen), which fills an important part in cell-division and growth. Within the cell (either in the centre or excentrical) is usually a minute, soft, subgelatinous body called the nucleus, whose functions appear to be intimately connected with the first formation of the new cell. As this cell increases in size, and its walls in thickness, the proto: plasm and watery cell-sap become absorbed or dried up, the firm cellu= lose wall alone remaining as a permanent fabric, either empty or filled with various organized substances produced or secreted within it.

192. The principal organized contents of cells are

sap, the first product of the digestion of the food of plants; it contains the elements of vegetable growth in a dissolved condition.

sugar, of which there are two kinds, ealled cane-sugar and grapesugar. It usually exists dissolved in the sap. It is found abundantly in growing parts, in fruits, and in germinating seeds. and starch.

dextrine, or vegetable mucilage, a gummy substance, between mucilage

starch or fecula, one of the most universal and conspicuous of cellcontents, and often so abundant in farinaceous roots and seeds as to fill the cell-cavity. It consists of minute grains called starch-granules, which vary in size and are marked with more or less conspicuous concentrio lines of growth. The chemical constitution of starch is the same as that water, and turns blue when by cold water, but forms a jelly with boiling no longer starch, but dextrine. cher starch, but dextrine.

green under the very minute granules, containing nitrogen, and coloured in the layers of cells immediatelyht. These granules are most abundant in the layers of cells immediately below the surface or epidermis of leaves 
and young bark. The green colouring matter is soluble in alcohol, and may thus be removed from the granules.

chromule, a name given to a similar colouring matter when not green.

wax, oits, camphor, and resinous matter, are common in cells or in cavities in the tissues between the cells, also various mineral substances, either in an amorphous state or as microscopic crystals, when they are called Raphides.

\section{$\S$ 2. Arrangement of the Elementary Tissues, or Structure of the Organs of Plants.}

193. Leaves, young stems, and branches, and most parts of phaenogamous plants, during the first year of their existence consist anatomically of

(1) a cellular-system, or continuous mass of cellular tissue, which is developed both vertically as the stem or other parts increase in length, and horizontally or laterally as they increase in thickness or breadth. It surrounds or is intermixed with the fibro-vascular system, or it may exist alone in some parts of phaenogamous plants, as well as in cryptogamous ones.

(2) a fibro-vascular system, or continuous mass of woody and vascular tissue, which is gradually introduced vertically into, and serves to bind together, the cellular system. It is continued from the stem into the petioles and veins of the leaves, and into the pedicels and parts of the flowers, and is never wholly wanting in any phaenogamous plant.

(3) an epidermis, or outer skin, formed of one or more layers of flattened (horizontal), firmly coherent, and usually empty cells, with either thin and transparent or thick and opaque walls. It covers almost all parts of plants exposed to the outward air, protecting their tissues from its immediate action, but is wanting in those parts of aquatic plants which are constantly submerged.

194. The epidermis is frequently pierced by minute spaces between the cells, called Stomates. They are oval or mouth-shaped, bordered by lips, formed of two or more elastic cells so disposed as to cause the stomate to open in a moist, and to close up in a dry state of the atmosphere. They communicate with intercellular cavities, and are obviously designed to regulate evaporation and respiration. They are chiefly found upon leaves, especially on the under surface.

195. When a phaenogamous plant has outlived the first season of its growth, the anatomical structure of its stem or other perennial parts becomes more complicated and very different in the two great classes of phaenogamous plants called Exogens and Endogens, which correspond with very few exceptions to the two classes Dicotyledons and Monocotyledons (167), founded on the structure of the embryo. In Exogens (Dicotyledons) the woody system is placed in concentric layers between a central pith $(198,1)$, and an external separable bark $(198,5)$. In Endogens (Monocotyledons) the woody system is in separate small bundles or fibres running through the cellular system without apparent order, and there is usually no distinct central pith, nor outer separable bark.

196. The anatomical structure is also somewhat different in the different organs of plants. In the Root, although it is constructed generally on the same plan as the stem, yet the regular organization, and the difference between Exogens and Endogens, is often disguised or obliterated by irre- 
gularities of growth, or by the production of large quantities of cellular tissue filled with starch or other substances (192). There is seldom, if ever, any distinct pith, the concentric circles of fibro-vascular tissue in Exogens are often very indistinct or have no relations to seasons of growth, and the epidermis has no stomates.

197. In the Stem or branches, during the first year or season of their growth, the difference between Exogens and Endogens is not always very conspicuous. In both there is a tendency to a circular arrangement of the fibro-vascular system, leaving the centre either vacant or filled with cellular tissue (pith) only, and a more or less distinct outer rind is observable even in several Endogens. More frequently, however, the distinction is already very apparent the first season, especially towards its close. The fibro-vascular bundles in Endogens usually anastomose but little, passing continuously into the branches and leaves. In Exogens the circle of fibro-vascular bundles forms a more continuous cylinder of network emitting lateral offsets into the branches and leaves.

198. The Exogenous stem, after the first year of its growth, consists of

1. the pith, a eylinder of cellular tissue, occupying the centre or longitudinal axis of the stem. It is active only in young stems or branches, becomes dried up and compressed as the wood hardens, and often finally disappears, or is scarcely distinguishable in old trees.

2. the medullary sheath, which surrounds and encases the pith. It abounds in spiral vessels $(188,3)$, and is in direct connection, when young, with the leaf-buds and branches, with the petioles and veins of leaves, and other ramifications of the system. Like the pith, it gradually disappears
in old wood.

3. the wood, which lies immediately outside the medullary sheath. It is formed of woody tissue $(188,2)$, through which, in most cases, vessels $(188,3)$ variously disposed are interspersed. It is arranged in annual concentric circles (211), which usually remain active during several years, but in older stems the central and older layers become hard, dense, comparatively inactive, and usually deeper coloured, forming what is called heartwood or duramen, the outer, younger, and usually paler-coloured living layers constituting the sapwood or alburnum.

4. the medullary rays, which form vertical plates, originating in the pith, and, radiating from thence, traverse the wood and terminate in the bark. They are formed of cellular tissue, keeping up a communication between the living portion of the centre of the stem and its outer surface. As the heart-wood is formed, the inner portion of the medullary rays ceases to be active, but they usually may still be seen in old wood, forming what carpenters call the silver grain.

5. the bark, which lies outside the wood, within the epidermis. It is, like the wood, arranged in annual concentric circles (211), of which the bark, older ones become dry and hard, forming the corky layer or outer or is cast off with thended by the thickening of the stem, either cracks Within the corky layer is the cellu, which is no longer distinguishable. of loose thin-walled pulpy cells cellular, or green, or middle bark, formed is usually the laver of thy cells containing, chlorophyll (192); and which circle, next the young preceding season. The innermost and youngest tough woody tissue called bast-cells.

199. The Endogenous stem, as it grows old, is not marked by the concentric circles of Exogens. The wood consists of a matrix of cellular tissue 
irregularly traversed by vertical cords or bundles of woody and vascular tissue, which are in connection with the leaves. These vascular bundles change in structure and direction as they pass down the stem, losing their vessels, they retain only their bast- or long wood-cells, usually curving outwards towards the rind. The old wood becomes more compact and harder towards the circumference than in the centre. The epidermis or rind either hardens so as to prevent any increase of diameter in the stem, or it distends, without increasing in thickness or splitting or casting off any outer layers.

200. In the Leaf, the structure of the petioles and principal ribs or veins is the same as that of the young branches of which they are ramifications. In the expanded portion of the leaf the fibro-vascular system becomes usually very much ramified, forming the smaller veins. These are surrounded and the interstices filled up by a copious and very active cellular tissue. The majority of leaves are horizontal, having a differently constructed upper and under surface. The cellular stratum forming the upper surface consists of closely set cells, placed vertically, with their smallest ends next the surface, and with few or no stomates in the epidermis. In the stratum forming the under surface, the cells are more or less horizontal, more loosely placed, and have generally empty spaces between them, with stomates in the epidermis communicating with these intercellular spaces. In vertical leaves (as in a large number of Australian plants) the two surfaces are nearly similar in structure.

201. When leaves are reduced to scales, acting only as protectors of young buds, or without taking any apparent part in the economy of vegetable life, their structure, though still on the same plan, is more simple; their fibro-vascular system is less ramified, their cellular system more uniform, and there are few or no stomates.

202. Bracts and floral envelopes, when green and much developed, resemble leaves in their anatomical structure, but in proportion as they are reduced to scales or transformed into petals, they lose their stomates, and their systems, both fibro-vascular and cellular, become more simple and uniform, or more slender and delicate.

203. In the stamens and pistils the structure is still nearly the same. The fibro-vascular system, surrounded by and intermixed with the cellular tissue, is usually simple in the filaments and style, more or less ramified in the flattened or expanded parts, such as the anther-cases, the walls of the ovary, or carpellary leaves, etc. The pollen consists of granular cells variously shaped, marked, or combined, peculiar forms being constant in the same species, or often in large genera, or even Orders. The stigmatic portion of the pistil is a mass of loosely cellular substance, destitute of epidermis, and usually is in communication with the ovary by a channel running down the centre of the style.

204. Tubers, fleshy thickenings of the stem or other parts of the plants, succulent leaves or branches, the fleshy, woody, or bony parts of fruits, the albumen, and the thick fleshy parts of embryos, consist chiefly of largely developed cellular tissue, replete with starch or other substances (192), deposited apparently in most cases for the eventual future use of the plant or its parts when recalled into activity at the approach of a new season.

205. Hairs (171) are usually expansions or processes of the epidermis, and consist of one or more cells placed end to end. When thick or hardened into prickles, they still consist usually of cellular tissue only, 
Thorns (170) contain more or less of a fibro-vascular system, according to their degree of development.

206. Glands, in the primary sense of the word $(175,1)$, consist usually of a rather loose cellular tissue without epidermis, and often replete with resinous or other substances.

\section{§ 3. Growth of the Organs.}

207. Roots grow in length constantly and regularly at the extremities only of their fibres, in proportion as they find the requisite nutriment, They form no buds containing the germ of future branches, but their fibres proceed irregularly from any part of their surface without previous indication, and when their growth has been stopped for a time, either wholly by the close of the season, or partially by a deficiency of nutriment at any particular spot, it will, on the return of favourable circumstances, be resumed at the same point, if the growing extremities be uninjured. If during the dead season, or at any other time, the growing extremity is cut off, dried up, or otherwise injured, or stopped by a rock or other obstacle opposing its progress, lateral fibres will be formed on the still living portion; thus enabling the root as a whole to diverge in any direction, and travel far and wide when lured on by appropriate nutriment.

208. This growth is not however by the successive formation of terminal cells attaining at once their full size. The cells first formed on a fibre commencing or renewing its growth, will often dry up and form a kind of terminal cap, which is pushed on as cells are formed immediately under it; and the new cells, constituting a greater or lesser portion of the ends of the fibres, remain some time in a growing state before they have attained their full size.

209. The roots of Exogens, when perennial, increase in thickness like stems by the addition of concentric layers, but these are usually much less distinctly marked; and in a large number of perennial Exogens and most Endogens the roots are annual, perishing at the close of the season, fresh adventitious roots springing from the stock when vegetation commences the following season.

210. The Stem, including its branches and appendages (leaves, floral organs, etc.), grows in length by additions to its extremity, but a much greater proportion of the extremity and branches remains in a growing and expanding state for a much longer time than in the case of the root. At the close of one season, leaf-buds or seeds are formed, each containing the germ of a branch or young plant to be produced the following season. At a very early stage of the development of these buds or seeds, a commencement may be found of many of the leaves it is to bear; and before a leaf unfolds, every leaflet of which it is to consist, every lobe or tooth which is to mark its margin, may often be traced in miniature, and thenceforth till it attains its full size, the branch grows and expands in every part. In some cases however the lower part of a branch and more rarely (e. $g$. in some Meliaceae) the lower part of a compound leaf attains its full size before the young leaves or leaflets of the extremity are yet formed.

211. The perennial stem, if exogenous (198), grows in thickness by the addition every season of a new layer or ring of wood between the outer. most preceding layer and the inner surface of the bark, and by the 
formation of a new layer or ring of bark within the innermost preceding layer and outside the new ring of wood, thus forming a succession of concentric circles. The sap elaborated by the leaves finds its way, in a manner not as yet absolutely ascertained, into the cambium-region, a zone of tender thin-walled cells connecting the wood with the bark, by the division and enlargement of which new cells (190) are formed. These cells separate in layers, the inner ones constituting the new ring of wood, and the outer ones the new bark or liber. In most exogenous trees, in temperate climates, the seasons of growth correspond with the years, and the rings of wood remain sufficiently distinct to indicate the age of the tree; but in many tropical and some evergreen trees, two or more rings of wood are formed in one year.

212. In endogenous perennial stems (199), the new wood or woody fibre is formed towards the end of the stem, or irregularly mingled with the old. The stem consequently either only becomes more dense without increasing in thickness, or only increases by gradual distention, which is never very considerable. It affords therefore no certain criterion for judging of the age of the tree.

213. Flowers have generally all their parts formed, or indicated by protuberances or growing cells at a very early stage of the bud. These parts are then usually more regularly placed than in the fully developed flower. Parts which afterwards unite are then distinct, many are present in this rudimentary state which are never further developed, and parts which are afterwaris very unequal or dissimilar are perfectly alike at this early period. On this account flowers in this very early stage are supposed by some modern botanists to be more normal, that is, more in conformity to a supposed type; and the study of the early formation and growth of the floral organs, called Organogenesis, has been considered essential for the correct appreciation of the affinities of plants. In some cases, however, it would appear that modifications of development, not to be detected in the very young bud, are yet of great importance in the distinction of large groups of plants, and that Organogenesis, although it may often assist in clearing up a doubtful point of affinity, cannot nevertheless be exclusively relied on in estimating the real value of peculiarities of structure.

214. The flower is considered as a bud (flower-bud, alabastrum) until the perianth expands, the period of flowering (anthesis) is that which elapses from the first expanding of the perianth, till the pistil is set or begins to enlarge, or, when it does not set, until the stamens and pistil wither or fall. After that, the enlarged ovary takes the name of young fruit.

215. At the close of the season of growth, at the same time as the leaf-buds or seeds are formed containing the germ of future branches or plants, many plants form also, at or near the bud or seed, large deposits, chiefly of starch. In many cases - such as the tubers of a potato or other rootstock, the scales or thickened base of a bulb, the albumen or the thick cotyledons of a seed-this deposit appears to be a store of nutriment, which is partially absorbed by the young branch or plant during its first stage of growth, before the roots are sufficiently developed to supply it from without. In some cases, however, such as the fleshy thickening of some stems or peduncles, the pericarps of fruit which perish long before germination (the first growth of the seed), neither the use nor the cause of these deposits has as yet been clearly explained. 


\section{\& 4. Functions of the Organs.}

216. The functions of the root are: -1 . To fix the plant in or to the soil or other substance on which it grows. 2. To absorb nourishment from the soil, water, or air, into which the fibres have penetrated (or from other plants in the case of parasites), and to transmit it rapidly to the stem. The absorption takes place through the young growing extremities of the fibres, and through a peculiar kind of hairs or absorb. ing organs which are formed at or near those growing extremities. The transmission to the stem is through the tissues of the root itself. The nutriment absorbed consists chiefly of carbonic acid and nitrogen or nitrogenous compounds dissolved in water. 3. In some cases roots secrete or exude small quantities of matter in a manner and with a purpose not satisfactorily ascertained.

217. The Stem and its branches support the leaves, flowers, and fruit, transmit the crude sap, or nutriment absorbed by the roots and mixed with previously organized matter, to the leaves, and re-transmit the assimilated or elaborated sap from the leaves to the growing parts of the plant, to be there used up, or to form deposits for future use (204), The transmission of the ascending crude sap appears to take place chiefly through the elongated cells associated with the vascular tissues, passing from one cell to another by a process but little understood, but known by the name of endosmose.

218. Leaves are functionally the most active of the organs of vegetation, In them is chiefly conducted digestion or Assimilation, a name given to the process which accomplishes the following results:-1. The chemical decomposition of the oxygenated matter of the sap, the absorption of carbonic acid, and the liberation of pure oxygen at the ordinary temperature of the air. 2. A counter-operation by which oxygen is absorbed from the atmosphere and carbonic acid is exhaled. 3. The transformation of the residue of the crude sap into the organized substances which enter into the composition of the plant. The exhalation of oxygen appears to take place under the influence of solar heat and light, chiefly from the under surface of the leaf, and to be in some measure regulated by the stomates; the absorption of oxygen goes on always in the dark, and in the daytime also in certain cases. The transformation of the sap is effected within the tissues of the leaf, and continues probably more or less throughout the active parts of the whole plant.

219. The floral organs seldom contribute to the growth of the plant on which they are produced; their functions are wholly concentrated on the formation of the seed with the germ of a future plant.

220. The perianth (calyx and corolla) acts in the first instance in pro. tecting the stamens and pistils during the early stages of their development. of the sweet or strong odours they emit, has not been adequately explained. Perhaps they may have great influence in attracting those insects whose concurrence has been shown in many cases to be necessary for the due transmission of the pollen from the anther to the stigma.

221. The pistil, when stimulated by the action of the pollen, forms and nourishes the young seed. The varied and complicated contrivances by which the pollen is conveyed to the stigma, whether by elastic action of the organs themselves, or with the assistance of wind, of insects, or other 
extraneous agents, have been the subject of numerous observations and experiments of the most distinguished naturalists, and are yet far from being fully investigated. Their details, however, as far as known, would be far too long for the present ontline.

222. The fruit nourishes and protects the seed until its maturity, and then often promotes its dispersion by a great variety of contrivances or apparently collateral circumstances, $e \cdot g$. by an elastic dehiscence which casts the seed off to a distance; by the development of a pappus, wings, hooked or other appendages, which allows them to be carried off by winds, or by animals, etc., to which they may adhere; by their small specific gravity, which enables them to float down streams; by their attractions to birds, etc., who taking them for food drop them often at great distances, etc. Appendages to the seeds themselves also often promote dispersion.

223. Hairs have various functions. The ordinary indumentum (171) of stems and leaves indeed seems to take little part in the economy of the plant besides perhaps some occasional protection against injurious atmospheric influences, but the root-hairs (216) are active absorbents, the hairs on styles and other parts of flowers appear often materially to assist the transmission of pollen, and the exudations of glandular hairs $(175,2)$ are often too copious not to exereise some influence on the phenomena of vegetation. The whole question, however, of vegetable exudations and their influence on the economy of vegetable life, is as yet but imperfectly understood.

\section{Chap. IV. Collection, Preservation, and Determination of Plants.}

224. Plants can undoubtedly be most easily and satisfactorily examined when freshly gathered. But time will rarely admit of this being done, and it is moreover desirable to compare them with other plants previously observed or collected. Specimens must, therefore, be selected for leisurely observation at home, and preserved for future reference. A collection of such specimens constitutes a Herbarium.

225. A botanical Specimen, to be perfect, should have root, stem, leaves, flowers (both open and in bud) and fruit (both young and mature). It is not, however, always possible to gather such complete specimens, but the collector should aim at completeness. Fragments, such as leaves without flowers, or flowers without leaves, are of little or no use.

226. If the plant is small (not exceeding $15 \mathrm{in.}$ ), or can be reduced to that length by folding, the specimen should consist of the whole plant, including the principal part of the root. If it be too large to preserve the whole, a good flowering branch should be selected, with the foliage as low down as can be gathered with it; and one or two of the lower stem-leaves or radieal leaves, if any, should be added, so as to preserve as much as possible of the peculiar aspect of the plant.

227. The specimen should be taken from healthy uninjured plants of a medium size. Or if a specimen be gathered because it looks a little different from the majority of those around it, apparently belonging to the same species, a specimen of the more prevalent form should be taken from the same locality for comparison.

228. For bringing the specimens home, a light portfolio of pasteboard, covered with calico or leather, furnished with straps and buckles for 
elosing, and another for slinging on the shoulder, and containing a few sheets of stout coarse paper, is better than the old-fashioned tin box (except, perhaps, for stiff, prickly plants, and a few others). The specimens as gathered are placed between the leaves of paper, and may be crowded together if not left long without sorting.

229. If the specimen brought home be not immediately determined when fresh, but dried for future examination, a note should be taken of the time, place, and situation in which it was gathered; of the stature, habit, and other particulars relating to any tree, shrub, or herb of which the specimen is only a portion; of the kind of root it has; of the colour of the flower; or of any other particulars which the specimen itself cannot supply, or which may be lost in the process of drying. These memoranda, whether taken down in the field, or from the living specimen when brought bome, should be written on a label attached to the specimen or preserved with it.

230. To dry specimens, they are laid flat between several sheets of bibulous paper, and subjected to pressure. The paper is subsequently changed at intervals, until they are dry.

231. In laying out the specimen, care should be taken to preserve the natural position of the parts as far as consistent with the laying flat. In general, if the specimen is fresh and not very slender, it may be simply laid on the lower sheet holding it by the stalk and drawing it slightly downwards; then, as the upper sheet is laid over, if it be slightly drawn downwards as it is pressed down, it will be found, after a few trials, that the specimen will have retained a natural form with very little trouble. If the specinuen has been gathered long enough to have become flaccid, it will require more care in laying the leaves flat and giving the parts their proper direction. Specimens kept in tin boxes, will also often have taken unnatural bends which will require to be corrected.

232. If the specimen is very bushy, some branches must be thinned out, but always so as to show where they have been. If any part, such as the head of a Thistle, the stem of an Orobanche, or the bulb of a Lily, be very thick, a portion of what is to be the under side of the specimen may be sliced off. Some thick specimens may be split from top to bottom before drying.

233. If the specimen be succulent or tenacious of life, such as a Sedum or an Orchis, it may be dipped in boiling water all but the flowers. This will kill the plant at once, and enable it to be dried rapidly, losing less of its colour or foliage than would otherwise be the case. Dipping in boiling water is also useful in the case of Heaths and other plants which are apt to shed their leaves during the process of drying.

234. Plants with very delicate corollas may be placed between single leaves of very thin unglazed tissue-paper. In shifting these plants into dry paper the tissue-paper is not to be removed, but lifted with its contents on to the dry paper.

235. The number of sheets of paper to be placed between each specimen or sheet of specimens, will depend, on the one hand, on the thickness and humidity of the specimens; on the other hand, on the quantity and quality of the paper one has at command. The more and the better the paper, the less frequently will it be necessary to change it, and the sooner the plants will dry. The paper ought to be coarse, stout, and unsized. Common blotting-paper is much too tender.

236. Care must be taken that the paper used is well-dried. If it be likewise hot, all the better; but it must then be very dry; and wet plants 
put into hot paper will require changing very soon, to prevent their turning black, for hot damp without ventilation produces fermentation, and spoils the specimens.

237. For pressing plants, various more or less complicated and costly presses are made. None is better than a pair of boards the size of the paper, and a stone or other heavy weight upon them if at home, or a pair of strong leather straps round them if travelling. Each of these boards should be double, that is, made of two layers of thin boards, the opposite way of the grain, and joined together by a row of clenched brads round the edge, without glue. Such boards, in deal, rather less than half an inch thick (each layer about $2^{1 /} / 2$ lines) will be found light and durable.

238. It is useful also to have extra boards or pasteboards the size of the paper, to separate thick plants from thin ones, wet ones from those nearly dry, ete. Open wooden frames with cross-bars, or frames of strong wirework lattice, are still better than boards for this purpose, as accelerating the drying by promoting ventilation.

239. The more frequently the plants are shifted into dry paper the better. Excepting for very stiff or woody plants, the first pressure should be light, and the first shifting, if possible, after a few hours. Then, or at the second shifting, when the specimens will have lost their elasticity, will be the time for putting right any part of a specimen which may have taken a wrong fold or a bad direction. After this the pressure may be gradually increased, and the plants left from one to several days without shifting. The exact amount of pressure to be given will depend on the consistence of the specimens, and the amount of paper. It must only be borne in mind that too much pressure crushes the delicate parts, too little allows them to shrivel, in both cases interfering with their future examination.

240. The most convenient specimens will be made, if the drying-paper is the same size as that of the herbarium in which they are to be kept. That of writing demy, rather more than 16 inches by $10^{1 / 2}$ inches, is a common and very convenient size. A small size reduces the specimens too much, a large size is both costly and inconvenient for use.

241. When the specimens are quite dry and stiff, they may be packed up in bundles with a single sheet of paper between each layer, and this paper need not be bibulous. The specimens may be placed very closely on the sheets, but not in more than one layer on each sheet, and care must be taken to protect the bundles by sufficient covering from the effects of external moisture or the attacks of insects.

242. In laying the specimens into the herbarium, no more than one species should ever be fastened on one sheet of paper, although several specimens of the same species may be laid side by side. And throughout the process of drying, packing, and laying in, great eare must be taken that the labels be not separated from the specimens they belong to.

243. To examine or dissect flowers or fruits in dried specimens it is necessary to soften them. If the parts are very delicate, this is best done by gradually moistening them in cold water; in most cases, steeping them in boiling water or in-steam is much quicker. Very hard fruits and seeds will require boiling to be able to dissect them easily.

244. For dissecting and examining flowers in the field, all that is necessary is a pen-knife and a pocket lens of two or three glasses from 1 to 2 inches focus. At home it is more convenient to have a mounted lens 
or simple microscope, with a stage holding a glass plate, upon which the flowers may be laid; and a pair of dissectors, one of which should be narrow and pointed, or a mere point, like a thick needle, in a handle; the other should have a pointed blade, with a sharp edge, to make clean sections across the ovary. A compound microscope is rarely necessary, except in cryptogamic botany and regetable anatomy. For the simple microscope, lenses of $1 / 4,{ }^{1} / 2,1$, and $1^{1 / 2}$ inches focus are sufficient.

245. To assist the student in determining or ascertaining the name of a plant belonging to a Flora, analytical tables should be prefixed to the Orders, Genera, and Species. These tables should be so constructed as to contain, under each bracket, or equally indented, two (rarely three or more) alternatives as nearly as possible contradictory or incompatible with each other, each alternative referring to another bracket, or having under it another pair of alternatives further indented. The student having a plant to determine, will first take the general table of Natural Orders, and examining his plant at each step to see which alternative agrees with it, will be led on to the Order to which it belongs, he will then compare it with the detailed character of the Order given in the text. If it agrees, he will follow the same course with the table of the genera of that Order, and again with the table of species of the genus. But in each case, it he finds that his plant does not agree with the detailed description of the genus or species to which he has thus been referred, he must revert to the beginning and carefully go through every step of the investigation before he can be satisfied. A fresh examination of his specimen, or of others of the same plant, a critical consideration of the meaning of every expression in the characters given, may lead him to detect some minute point overlooked or mistaken, and put him into the right way. Species vary within limits which it is often very difficult to express in words, and it proves often impossible, in framing these analytical tables, so to divide the genera and species, that those which come under one alternative should absolutely exclude the others. In such doubtful cases both alternatives must be tried before the student can come to the conclusion that his plant is not contained in the Flora, or that it is erroneously described.

246. In those Floras where analytical tables are not given, the student is usually guided to the most important or prominent characters of each genus or species, either by a general summary prefixed to the genera of an Order or to the species of the genus, for all such genera or species; or by a special summary immediately preceding the detailed description of each genus or species. In the latter case this summary is called a diagnosis. Or sometimes the important characters are only indicated by italicizing them in the detailed description.

247. It may also happen that the specimen gathered may present some occasional or accidental anomalies peculiar to that single one, or to a very few individuals, which may prevent the species from being at once recognized by its technical characters. It may be useful here to point out a few of these anomalies which the botanist will be most likely to meet with. For this purpose we may divide them into two classes, viz.:

(1) Aberrations from the ordinary type or appearance of a species for which some general cause may be assigned.

A bright, light, and open situation, particularly at considerable eleva. tions above the sea, or at high latitudes, without too much wet or drought, 
tends to increase the size and heighten the colour of flowers, in proportion to the stature and foliage of the plant.

Shade, on the contrary, especially if accompanied by richness of soil and sufficient moisture, tends to increase the foliage and draw up the stem, but to diminish the number, size, and colour of the flowers.

A hot climate and dry situation tend to increase the hairs, prickles, and other productions of the epidermis, to shorten and stiffen the branches, rendering thorny plants yet more spinous. Moisture in a rich soil has a contrary effect.

The neighbourhood of the sea, or a saline soil or atmosphere, imparts a thicker and more succulent consistence to the foliage and almost every part of the plant, and appears not unfrequently to enable plants usually annual to live through the winter. Flowers in a maritime variety are often much fewer, but not smaller.

The luxuriance of plants growing in a rich soil, and the dwarf stunted character of those crowded in poor soils, are too well known to need particularizing. It is also an everyday observation how gradually the specimens of a species become dwarf and stunted as we advance into the cold damp regions of the summits of high mountain ranges, or into high northern latitudes; and yet it is frequently from the want of attention to these circumstances that numbers of false species have been added to our Enumerations and Floras. Luxuriance entails not only an increase in the size of the whole plant, or of particular parts, but often also an increase of number in branches, in leaves, or leaflets of a compound leaf; or it may diminish the hairiness of the plant, induce thorns to grow out into branches, etc.

Capsules which, while growing, lie close upon the ground, will often become larger, more succulent, and less readily dehiscent, than those which are not so exposed to the moisture of the soil.

Herbs eaten down by sheep or cattle, or erushed underfoot, or otherwise checked in their growth, or trees or shrubs cut down to the ground, if then exposed to favourable circumstances of soil and climate, will send up luxuriant side-shoots, often so different in the form of their leaves, in their ramification and inflorescence, as to be searcely recognizable for the same species.

Annuals which have germinated in spring, and flowered without check, will often be very different in aspect from individuals of the same speeies, which, having germinated later, are stopped by summer droughts or the approach of winter, and only flower the following season upon a second growth. The latter have often been mistaken for perennials.

Hybrids, or crosses between two distinct species, come under the same category of anomalous specimens from a known cause. Frequent as they are in gardens, where they are artificially produced, they are probably rare in nature, although on this subject there is much diversity of opinion, some believing them to be very frequent, others almost denying their existence. A bsolute proof of the origin of a plant found wild, is of course impossible; but it is pretty generally agreed that the following particulars must always co-exist in a wild hybrid. It partakes of the characters of its two parents; it is to be found isolated, or almost isolated, in places where the two parents are abundant; if there are two or three, they will generally be dissimilar from each other, one partaking more of one parent, another of the other; it seldom ripens good seed; it will never be found where one of the parents grows alone, 
Where two supposed species grow together, intermixed with numerous intermediates bearing good seed, and passing more or less gradually from the one to the other, it may generally be concluded that the whole are mere varieties of one species. The beginner, however, must be very cautious not to set down a specimen as intermediate between two species, because it appears to be so in some, even the most striking characters, such as stature and foliage. Extreme varieties of one species are connected together by transitions in all their characters, but these transitions are not all observable in the same specimens. The observation of a single intermediate is therefore of little value, unless it be one link in a long series of intermediate forms, and, when met with, should lead to the search for the other connecting links.

(2) Accidental aberrations from the ordinary type, that is, those of which the cause is unknown.

These require the more attention, as they may sometimes lead the beginner far astray in his search for the genus, whilst the aberrations above-mentioned as reducible more or less to general laws, affect chiefly the distinction of species.

Almost all species with coloured flowers are liable to occur occasionally with them all white.

Many may be found even in a wild state with double flowers, that is, with a multiplication of petals.

Plants which have usually conspicuous petals will occasionally appear without any at all, either to the flowers produced at particular seasons, or to all the flowers of individual plants, or the petals may be reduced to narrow slips.

Flowers usually very irregular, may, on certain individuals, lose more or less of their irregularity, or appear in some very different shape. Spurs, for instance, may disappear, or be produced on all instead of one only of the petals.

One part may be occasionally added to, or subtracted from, the usual number of parts in each floral whorl, more especially in regular polypetalous flowers.

Plants usually monoecious or dioecious may become occasionally hermaphrodite, or hermaphrodite plants may produce occasionally unisexual flowers by the abortion of the stamens or of the pistils.

Leaves cut or divided where they are usually entire, variegated or spotted where they are usually of one colour, or the reverse, must also be elassed amongst those accidental aberrations which the botanist must always be on his guard against mistaking for specific distinctions. 


\section{INDEX OF TERMS, OR GLOSSARY.}

\section{The figures refer to the Paragraphs of the Outlines.}

Aberrations, 247.

Abortive, 84.

Abruptly pinnate, 43.

Accessory organs, 168.

Acienlar, 54.

Achene, 158.

Aculeate, 170 .

Acuminate, acumen, 47.

Acute, 47.

Adherent, 140, 145 .

Adnate, 63,145 .

Adnate anther, 114.

Adventitious, $17,19$.

Aerial $=$ growing in the air.

Aestivation, 102.

Aggregate fruit, 147.

Alabastrum (bud), 214.

Alae (wings), 37, 155.

Alate $=$ having wings.

Albumen, albuminous, 162.

Albarnom, 198.

Alliances, 182.

Alternate, 32, 90.

Amentum $=$ catkin, 76 .

Amphitropous, 134.

Amplexicaul, 37.

Amygdaloid $=$ almond-like.

Amyloid, 192.

Anastomose, 40.

Anatropons, 134 .

Androgynons, 87.

Angiospermons, 161.

Anisomerous, 94 .

Annuals, 12.

Anterior, 91.

Anther, 109, 114.

Anthesis (flowering period), 214 .

Apetalons, 85 .

Apex, 36, 47, 115.

Apiculate $=$ with a little point.

Apocarpons, 125.

Aquatie $=$ growing in water, 14.

Arboreous or arborescent plant, 12.

Aril, arillns, 164.

Arillate (having an aril), 164.

Aristate, 47.
Article, articulate, articulation, 54.

Artifieial divisions and eharacters, 184.

Ascending, 28.

Asepalous, 85.

Assimilation, 218.

Auricle, 49.

Aurienlate $=$ having auricles, 50.

Axil, axillary, 17.

Axile (in the axis), 132.

Bark, 198.

Barren, 85, 110.

Base, 36, 48, 115.

Bast-cells, 198.

Berry, 157.

Bi- (2 in composition), 44.

Bicarpellary, 125.

Bidentate, 44.

Biennials, 12.

Bifid, 44.

Bifoliolate, 44.

Bijugate, 44.

Bilabiate (two-lipped), 102, 105.

Bilocular, 126.

Bipinnate, 43.

Bisexnal, 85.

Biternate, 44.

Blade, 35.

Bracts, bracteae, 60, 77, 202.

Bracteate $=$ having bracts.

Bracteoles, 62 .

Bristles, bristly, 173.

Bud, 16.

Bulb, 26.

Bush, 12.

Caespitose $=$ tufted, 28.

Callous $=$ hardened and ustally thickened.

Calyeule, ealyeulate, 80 .

Calyx, 15, 90, 96.

Cambium-region, 211.

Campanulate, 104.

Campylotropous, 134.
Canescent, 173.

Capillary = hair-like, 54 .

Capitate, 74.

Capsule, 158

Carpel, 15, 123.

Carpophore, 146.

Cartilaginous $=$ of the consistence of cartilage or of parchment.

Carnnele, carunenlate, 164.

Caryopsis, 160.

Catkins, 76.

Canline (on the stem), 39.

Canlocarpic, 12.

Cells (elementary), 186.

Cells (of anthers), 109.

Cells (of the ovary), 121.

Cellular system, 193.

Cellular tissne, 188.

Cellulose, 191.

Centrifugal, 72.

Centripetal, 72.

Chaff, 82.

Chalaza, 133.

Character, 183.

Chlorophyll, 192.

Chromule, 192.

Ciliate, 39.

Circumsciss, 158.

Cirrhus = tendril, 169.

Class, 182.

Claw (of a petal), 107.

Climbing stem, 29.

Coats of the ovule, 133.

Coats of the seed, 163.

Coceus, 159.

Coherent, 145.

Collateral $=$ inserted one by

the side of the other.

Collection of specimens, 224.

Coma, 163.

Common petiole, 39.

Complete flower, 89.

Compound leaf, 39.

Compoand flower, 74 .

Componnd fruit, 147.

Compound ovary, 126. 
Compound ambel, 74.

Compressed, 54.

Cone, 160.

Confluent, 117.

Conieal, 54.

Connate, 145.

Connective, connectivum, 109.

Connivent, 145.

Contorted, convolate, 102.

Cordate, 49.

Cordiform, 49.

Coriaceons, 55.

Corky layer, 198.

Corm, 27.

Corolla, 15, 90, 97.

Corrngate (erampled), 102.

Corymb, eorymbose, 74 .

Costate, 173.

Cotton, eottony, 173.

Cotyledons, 166.

Creeping, 28.

Crenate, erenulate, 39.

Cristate $=$ having a crest-like appendage.

Crown of the root, 24.

Crumpled, 102.

Cryptogamous plants, 10.

Cnlm, 34.

Cnneate, 45.

Copular (eap-shaped), 136.

Cuspidate, 47.

Cylindrical, 54.

Cyme, cymose, 74.

Deca - or decem - (10 in composition), 44, 92.

Deciduous ealyx, 152.

Decompound, 43.

Decumbent, 28.

Deeturrent, 37.

Decussate, 32.

Definite, 89 .

Definitions (p. XXXII).

Dehiscenee, debiscent, 118, 160.

Dentate, 39.

Depressed, 54 .

Descriptive Botany (p. XXXII).

Determinate, 67 .

Determination of plants, 245.

Dextrine, 192.

Di- (2 in eomposition), 92.

Diadelphons, 118.

Diagnosis, 246.

Dialypetalons, 100.

Diandrons, 93.

Diehlamydeons, 85.

Diehotomons, 33.

Dielinons, 86.

Dicotyledonous plants, 167.

Didymons, 54.
Didynamons, 113.

Diffase, 28.

Digitate, 41.

Digynous, 93, 125,

Dimerons, 93.

Dimidiate, 117.

Dioecions, 86.

Dipetalous, 93.

Disepalons, 93.

Disk, 136.

Dissepiment, 126.

Dissected, 32.

Distichous, 32.

Distinct, 145.

Divaricate, 115 .

Diverging, divergent, 115,145 .

Divided, 39.

Dorsal $=$ the back.

Double flowers, 97 .

Bown, downy, 173.

Drupe, 157.

Dry fruits, 158.

Duets, 188.

Dnramen, 198.

Ear, 76.

Echinate, 173.

Elaborated kap, 217.

Elementary cells and tissues, 186.

Elliptieal, 45.

Emarginate, 47.

Embryo, 162, 166.

Endocarp, 157.

Endogens, endogenons plants. 195.

Endogenons stem, 199.

Endosmose, 217.

Ennea- (9 in eomposition), 92.

Entire, 39.

Epiearp, 157.

Epidermis, 173, 193.

Epigynons, 140.

Epigynons disk, 144.

Epiphyte, 14.

Erect, 28.

Exalbuminons (withont a)bumen), 162.

Examization of plants, 243.

Exogens, exogenons plant $\kappa_{,} 195$.

Exogenons stem, 198.

Exserted, 113.

Extrorse, 118.

Faleate, 45.

Families, 181.

Parinose, 173.

Fascicled, fascionlate, 32.

Fastigiate, 74.

Fecula, 192.
Female, 85

Fertile, 85.

Fibre, 18.

Fibrons root, 20.

Fibro-rascular system, 193.

Filament, 108.

Filiform $=$ thread-liks.

Fimbriate $=$ fringed.

Flabelliform $=$ fan-shaped, 45 .

Fleshy, 55.

Floecose, 173.

Floral envelope, 15.

Floral leaves, 61.

Flowers, 15, 84, 218, 219 .

Flowering plants, 10.

Polisceous $=$ leaf-like.

Follielo, 159.

Foramen, 133

Forked, 33

Free, 89, 132, 140, 145.

Pruit, 15, 146, 222.

Fratescent, fruticone, 12.

Function, 7 .

Funicle (funienins), 164.

Funnel-haped, 104.

Furrowed, 178.

Fusiform = spindle-shaped, 54.

Gamopetalous, 100.

Geminater, 32.

Geans, genera, 180.

Germ, germinatiou, 215.

Gibbous, 105.

Glabrons, 173.

Gland8, 175, 206.

Glandular-setose, 178.

Glancons, 173.

Globose, globular, 54.

Glochidiate, 173.

Glume, 83.

Gintineas, 173.

Grain, 160.

Gymnospermons, 161.

Gynobasis, gynophore, 148.

Habit, 188.

Hiairs, 171, 205, 223.

Hastate, 50 .

Head, 74.

Heart-wood, 198.

Hepta- 17 in eomposition), 92.

Herbaceous perennials, 12.

Herbaritum, 224.

Hermaphrodite, 85.

Heterogamous, 87.

Hexa - 16 in composition), 92.

Hilum, 165.

Hinnte, 178.

Hispid, 173.

Hoary, 173. 
Homogamous, 87.

Hooks, 169.

Hybernaenlum, 23.

Hybrids, 247.

Hypocrateriform (salvershaped), 104.

Hypogynous, 140.

Imbricate, imbricated, 58, 102.

Impari-pinnate, 43.

Imperfeet, 84.

Incomplete, 84.

Indefinite, 92.

Indehiscent, 156.

Indeterminate, 67 .

Indumentum, 171.

Induplicate, 102.

Inferior, 140.

Inferior radicle, 167 .

Inflorescence, 66.

Infundibuliform (funne)shaped), 104.

Innate anther, 114.

Insertion, 140.

Internode, 31.

Interrapted spike or raceme, 75 .

Introrse, 118.

Involncre, involucel, 79.

Involnte, 102.

Irregular, 95 .

Isomerous, 89.

Joint, joining, 54.

Jugum, juga = pairs, 44.

Kernel, 157.

Knob, 25.

Labellnm, 105.

Laciniate, 39.

Lamina, 35, 107.

Lanate $=$ woolly, 173.

Lanceolate, 45.

Lateral, 91.

Leaf, leaves $15,35,200,218$.

Leaf-bad, 16.

Leaflet, 39.

Leaf-opposed, 67.

Legume, 160 .

Lepidote, 172.

Líber, 198, 211.

Lignlate = strap-shaped.

Limb, 104.

Linear, 45, 54.

Lip, lipped, 105.

Lobe, lobed, 39.

Loenlicidal, 158.

Lower, 91.

Lunate $=$ crescent-shaped.

Lyrate, 41.

Male, 85.
Marcescent, 151.

Mealy, 173.

Medullary rays and sheath, 198.

Membranons, 5็.

Mieropyle, 165.

Midrib, 40.

Monadelphons, 113.

Monandrons, 112.

Moniliform, 54 .

Mono- (1 in composition), 92.

Monocarpellary, 125.

Monocarpic, 12.

Monochlamydeous, 85.

Monocotyledonous plants, 167 .

Mronoecions, 86.

Monogynous, 125.

Monopetalons, 100.

Morphology, 8, 88.

Mucronate, 47.

Mnlti- (many, or an indefinite number in composition), 44 .

Muricate, 173.

Naked, 85, 161.

Natural divisions and characters, 184.

Natural Order, 181.

Navieular $=$ boat-shaped.

Nectary, 138.

Nerve, 40.

Net-veined, 40.

Nenter, 85.

Node, 31 .

Novem- (9 in composition), 44.

Nuclens of a cell, 191.

Nncleus of the ovule, 133.

Nut, 158.

Obcompressed, ธั4.

Obeonical, 54.

Obeordate, 47.

Oblate, 45.

Oblong, 45, 54.

Obovate, 45 .

Obevoid, 54.

Obpyramidal, 54.

Obtuse, 47.

Oct- or oeto- (8 in composition), 44, 92.

Offset, 23.

opposite, 32.

Orbienlar, 45 .

Order, 181.

Organ, 7.

Organogenesis, 213.

Organs of vegetation and reproduetion, 9.

Orthotropous, 134.

Oval, 45.

Ovary, 121.
Ovate, 45.

Ovoid, 54.

Ovule, 121, 133.

Palate, 105.

Palea, paleae, 82.

Paleaceots $=$ of a chaffy consistence.

Palmate, 41, 42.

Palmatifid, palmatisect, 42.

Panicle, paniculate, 74 .

Papillae, 122.

Pappus, 155.

Parallel veins, 40 .

Parasite, 14.

Parenehyma, 188.

Parietal, 132.

Pectinate, 41.

Pedate, 41, 42.

Pedatifid, pedatisect, 42.

Pedicel, 70.

Pedicellate $=$ on a pedicel.

Peduncle, 68.

Pednnculate $=$ on a peduncle.

Peltate, 52.

Penicillate, 130.

Penta - (5 in composition), 92.

Pepo, 160.

Perennial, 12.

Perfect flower, 84.

Perfoliate, 37.

Perennials, 12.

Perianth, 15, 98, 202, 220.

Pericarp, 154.

Perigynous, 140.

Perisperm, 162.

Persistent, 146.

Personate, 105.

Petal, 90.

Petiole, 35.

Petiolule, 39.

Phaenogamous, phanerogamous, 10.

Phyllaries, 79.

Phyllodium $=$ a flat petiole with no blade.

Pilose, 173.

Pinna, 43,

Pinnate, 41, 42.

Pinnatifid, pinnatisect, 42.

Pistil, 15, 90, 120, 203, 221.

Pistillate, $8 \tilde{5}$.

Pith, 198.

Placenta, placentation, 131.

Plant, 6.

Plicate, 102.

Plumose, 172.

Plumule, 166.

Pluri = several, in composition.

Pluriloenlar, 126. 
Pod, 158.

Podocarp, 120.

Pollen, 109, 119.

Poly- (many, or an indefinite number in eomposition), 92.

Polyadelphons, 113.

Polyandrous, 92, 112.

Polygamons, 86.

Polygynous, 92, 125.

Polypetalons, 100.

Pome, 160.

Posterior, 91.

Praefoliation, 57.

Preservation of specimens, 224.

Prickles, 170.

Primine, 139.

Proeumbent, 28.

Proliferons, 17.

Prosenehyma, 188.

Prostrate, 28.

Protoplasm, 191.

Pobescent, puberulent, 173.

Pulvinate (eushion-shaped), $13 \%$.

Punctiform = like a point or dot.

Patamen, 157.

Pyramidal, 54.

Quadri- (4 in composition), 44. Quinenneial, 102.

Quinque- (5 in eompesition), 44.

Quintuplinerved, 40.

Race, 178.

Baceme, racemose, 74 .

Rachis, 39, 68.

Radieal, 38.

Radicle, 166.

Raphe, 194.

Raphides, 192.

Receptacle, 74, 135.

Bedoplieate, 102.

Regular, 95.

Reniform, 51 .

Besupinate, 105.

Reticulate, 40.

Retuse, 47.

Revolute, 102.

Rhachis $=$ rachis, 39,68 .

Rhaphe $=$ raphe, 194.

Rhizome, 21, 24 .

Rhomboidal, 45.

Ribs, 40.

Ribbed, 173.

Ringent, 105.

Koot, 15, 18, 196, 207, 216.

Rootstock, 24.

Rostrate = beaked.

Rosnlate, 38.
Rotate, 104.

Redimentary, 84.

Rugose, 173.

Rancinate, 41.

Runner, 30.

Saceate, 105.

Sagittate, 50.

Balver-shaped, 104.

Bamara, 158.

Sap, 192.

Sapwood, 198.

Sarcoearp, 157.

seabrous, 173.

Seales, 58, 59, 172, 201.

Sealy balb, 26.

Sealy surface, 172 .

Seape, 69.

Seariose, scarions, 55.

Scattered, 32.

Beion, 30.

Beorpioid eyme, 74.

section, 182.

Seeund, 32.

Becundine, 139.

Seed, 161.

Segment, 89.

Sepals, 90.

Septem- (7 in composition). 44.

Septicidal, 158.

Septum = partition, 126.

Serrate, serrulate, 39.

Sessile, 37.

Seta, setae (bristles), 173.

Setaceous (bristle-like), 54.

Setose (bearing bristles), 173.

Sex- $(6$ in composition), 44.

Sheathing, 37.

Shribs, 12.

Silicule, siliqua, 180.

Silver grain, 198.

Simple, 39.

Sinnate, 39.

Simus, 39.

Amooth, 173.

Spadix, 76.

Spatha, 81.

Spatulate, 45.

Species, 177.

Bpecimen, 225.

Bpherieal, 54.

Bpike, spieate, 74

Spikelet, $7 €$.

Spinous, 170.

Spiral vesgels, 188.

Spar, spurred, 105.

Squamae = scales, 58 .

Squarrose, 58.

Stamens, 15, 90, 108, 203.
Staminate, 85.

Staminodia, 110.

Starch, 192.

Stellate, 104.

Stellate hairs, 172.

Stem, 15, 28, 197, 210, 217.

Stem-clasping, 37.

Sturile, 85.

8tigma, 121.

Btipella, 64.

Stipes, stipitate, 65.

Btipnles, 68.

Stoek, 16, 22.

Stole, stolon, 23, 30

Stomates, 194.

Btone, stone-fruit, 157.

Btriate, 173.

Strigone, strigillose, 173.

Btrophiole, strophiolate, 164.

Style, 121.

gub = almont, or under, in eomposition.

Bubclask, noboriter, 182.

Bubmerged = nndor water.

Subulate, 54.

Sneculent, 56.

Bucculent fruits, 157.

Sucker, 80.

Suffrutescent, suffraticose, 12.

Bugar, 192.

Buleate, 178.

Superior, 140.

Snperior radieale, 167.

Saperposed z= inserted one above the other.

Suture, 159.

Symmetrical, 89.

Bynandrous, 112.

Synearpons, 125.

Syagenesions, 113.

Bystematic Botany (p. LXI).

Taproot, 20.

Teeth, 39, 101.

Tegmen, 163.

Tendril, 29, 169.

Terete, 54.

Ternate, 82, 41.

Torreatrial = growing on the earth, 14.

'Teata, 163.

Tetra - (4 in eamposition), 92,

Tetradynamons, 118.

Thorns, 170.

Throat, 104.

Thyruss, thyruoid, 74.

Tissnes (elementary), 186.

Tomentose, 178.

Toothed, 39.

Torus, 135. 
Trees, 12.

Tri- ( 3 in composition), 44, 92.

Tribe, 182.

Trichotomous, 34.

Trifid, 43.

Trifoliolate, 41.

Trigonous, 54.

Tripinnate, 43.

Triplinerved, 40 .

Triquetrons, 54.

Tristichous, 32.

Truneate, 47.

Trank, 12.

Tube, 101, 104.

Tuber, taberous 20, 25, 204.

Tuberenlate, 173.

Tabular, 104.

Tufted, 28.

Tnnicated bulb, 27.

Turbinate $=$ top-shaped, 54 .

Twiner, 29

Twisted, 102.

Type, typical, 181.
Umbel, nmbellate, umbellule, 33,74 .

Umbilicate, 173.

Umbonate, 173.

Uneinate $=$ hooked.

Undershrubs, 12.

Undulate, 39.

Unequally pinnate, 43.

Unguienlate, 107.

Unguis (claw), 107.

Uni- (1 in eomposition), 44.

Unilateral (one-sided) racemes, 74.

Unilocular, 126.

Unisexual, 86.

Unsymmetrical, 94.

Upper, 91.

Urceolate, 104.

Utricle, 158.

Valvate, 102.

Valves, 158.

Variety, 178.

Vascular tissue, 188.
Vegetable Anatomy, 8, 186.

Vegetable Chemistry, 8.

Vegetable Homology or Metamorphosis, 88.

Vegetable Physiology, 8, 207.

Veins, veinlets, venation, 40.

Vernation, 57.

Versatile anther, 114.

Verticil, verticillate, 32 .

Vessels, 188.

Virgate $=$ twiggy, 28.

Viscid, viscous, 173.

Vitta, vittae, 175.

Viviparons, 17.

Voluble, 29.

Wart, warted, 173

Wavy, 39

Whorl, whorled, 32.

Wing, winged, 37, 155 .

Wood, 198.

Woody tissue, 188 .

Wool, woolly, 173 . 


\section{EXPLANATIONS OF ABBREVIATIONS AND SIGNS*.}

\section{Boolis and Periodicals cited.}

Whenever it could be ascertained with certainty that a work cited was originally published in a scientific periodical the title and, where possible, the volume or year of
the latter are here added. Acrost. . . . . . See Fée, Acrost.

Act. Nat. Cur. . . Acta physico-medica Academiae Caesareae LeoAct. Petropol. poldino-Carolinae Naturae Curiosorum.

Acta Academiae Scientiarum imperialis Petropo-
litanae. Adumbrat. Fil. Cap. . See Schlecht. Adumbrat. Fil. Cap.

Agardh, Pterid. . . . J. G. Agardh. Recensio Specierum Generis PteAmer. Pict. . . . . See Jacq. Amer. Pict.

Ann. See Walp. Ann.

Ann. and Mag. Nat.

Hist.
Ann. Mus. Paris. . . Annals and Magazine of Natural History. London. Ann. Sc. Nat. . . : Annales du Museum d'Histoire Naturelle. Paris. Ann. Wien. Mus. . Annales des Sciences Naturelles. Paris.

Asiat. Res. . . . A nnalen des Wiener Museums der Naturgeschichte. Asiatic Researches; or Transactions of the Society instituted in Bengal for inquiring into the $\mathrm{Hi}$ story, Arts, Sciences, and Literature of Asia.

Aspid. Calcutta, 1788-1836.

Asplen. . . . . . . . See Metten. Farngattungen.

Aster. . . . See Metten. Farngattungen.

Atakta Bot. . . See Nees, Aster.

Baker, Fl. Maur. . . See Endlicher, Atakta Bot.

Baker, Synops. Fil. . See Hook. \& Bak. Synops. Fil.

- Abbreviated names of botanical authorities are not here considered unless they occur in the text prefixed to the title of some one of their publications; nor are the
ordinary abbreviations of botanieal terms noticed. 
Baner, Ill. Pl. Norf. Ferd. Bauer. Illustrations of Norfolk Island Plants (unpublished).

Beech. Voy. . . . . . See Hook. \& Arn. Bot. Beech.

Benth. Fl. Austral. . G. Bentham and F. von Mueller. Flora Australiensis.

Benth. Fl. Hongk. . . G. Bentham. Flora Hongkongensis.

Benth. Lab. . . . . . G. Bentham. Labiatarum Genera et Species.

Benth. \& Hook.Gen.Pl. G. Bentham and J. D. Hooker. Genera Plan-

Ber. d. k. Akad. d.

Wiss. in Berl. . . . Berichte der königlichen Akademie der Wissenschaften. Berlin.

Ber. d. k. Akad. d. Wissensch. in Wien.

Ber. d. k. Bayer. Akad. d. Wiss.

Blume, Fl. Jav. . . .

Boissier, Ic. Euphorb. Bomplandia ....

Boott, III. Gen. Car. . Bot. Beech. . . . . Bot. Bon. . . . . .

Bot. Calif.

Bot. Freye.

Bot. Mag. tarum .....

Berichte der kaiserlichen Akademie der Wissenschaften. Vienna.

Sitzungsberichte der königl. Bayerischen Akademie der Wissenschaften. Munich.

C. L. Blume and J. B. Fischer. Flora Javae... Filices.

E. Boissier. Icones Euphorbiarum .....

Bonplandia; Zeitschrift für die gesammte Botanik. Hanover, 1853-1862.

F. Boott. Illustrations of the Genus Carex.

See Hook. \& Arn. Bot. Beech.

See Gaud. Bot. Bon.

A. Gray, S. Watson, and W. H. Brewer. Botany of California.

See Gaud. Bot. Freye.

Curtis's Botanical Magazine. London.

Bot. Reg. . . . . . . The Botanical Register. London.

Bot. U. S. E. E. . S See Gray, Bot. U. S. E. E.

Bot. U. S. E. Exp. . See Gray, Bot. U. S. E. E.

Bot. Voy. Bon. .. . See Gaud. Bot. Bon.

Bot. Voy. Freyc. : See Gaud. Bot. Freyc.

Bull. Torrey Club. NiY. Bulletin of the Torrey Botanical Club. New-York. Br. Fl. Gard. . . . . See Sweet, Br. Fl. Gard.

Brack. Fil. U.S.E.E. W. D. Brackenridge. Botany of the United States Exploring Expedition under Captain Wilkes. Filices.

Brongn. Voy. de la Coq. A. T. Brongniart. Botanique du Voyage autour du Monde sur la Corvette La Coquille.... publié par L. J. Duperrey.

Brongn. \& Gr. Fragm. Fl. N. Cal.

Calcutta Journ. Nat.
Hist.

Ad. Brongniart and A. Gris. Fragments d'une Flore de la Nouvelle Calédonie; ou Observations sur diverses Plantes nouvelles ou peu connues de cette Contrée. (Annales des Sciences Naturelles, París, Sér. II., 1864). 
Cavan. Icon.

Chlor. And.

Chois. Cuscut.

Comp. Bot. Mag. Contrib. to Bot.

Crypt. Fl.

Crypt. Fl. Germ.

Cyclop.

DC. Mem. Comp.

DC. Prod.

De Cand. Monogr. .

De Vriese, Gooden.

De Vriese, Monogr. Mar.

Deless. Ic. . . . . . .

Desv. Prod. Fil. . .

Diss.

Don, Gen. Syst.

Don, Prod. Fl. Nepal. Enchirid. . . . . Endl. Fl. Ins. Austral.

Endl. Gen. Pl.

Endl. Prod. Fl. Norf. Endlicher, Atakta Bot.

Endlicher, Gen. Plant. Suppl.

Enum.

Enum. Fil.

Enum. Pl.

Enum. Pl. Tah. .

Epimel.

Ettingshausen, Skelete der Farnkr.

Exot. $F$

Farngattungen.
A. J. Cavanilles. Icones et Descriptiones Plantarum .... in Hispania . ... .

See Wedd. Chlor. And.

J. D. Choisy. Convolvulaceae orientales. De Convolvulaceis Dissertatio tertia. Cuscutarum Enumeratio.

See Hook. Comp. Bot. Mag.

See Miers, Contrib. to Bot.

See Luerssen, Crypt. Fl. Germ.

See Luerssen, Crypt. Fl..Germ.

See Rees, Cyclop.

A. P. de Candolle. Collection de dix Mémoires. IX: Observations sur la Structure et la Classification de la Famille des Composées.

A. P. and A. de Candolle. Prodromus systematis naturalis Regni vegetabilis.

A. and C. de Candolle. Monographiae Phanerogamarum ....

W. H. de Vriese. Goodenovieae. (Naturkundige Verhandlingen van de Hollaudsche Maatschappij de Wetenschappen te Haarlem, X, 1854).

W. H. de Vriese and P. Harting. Monographie des Marattiacées.

B. Delessert. Icones selectae Plantarum ....

N. A. Desvaux. Prodrome de la Famille des Fougères. (Mémoires de la Société Linnéenne de Paris, VI., 1827).

See Trin. Diss. or Thunb. Diss.

G. Don. General System of Gardening and Botany (Don's Gardeners' Dictionary).

G. Don. Prodromus Florae Nepalensis ....

See Pers. Enchirid.

S. L. Endlicher. Bemerkungen über die Flora der Südsee-Inseln. (Annalen des Wiener Museums der Naturgeschichte, I., 1836).

S. L. Endlicher, Genera Plantarum ....

S, L. Endlicher. Prodromus Florae Norfolkicae....

S. L. Endlicher, Atakta botanica. Nova Genera et Species Plantarum.

S.L.Endlicher. Genera Plantarum. SupplementumII. See Mann, Enum.

See Kaulf. Enum. Fil. or Hook. \& Grev, Enum. Fil.

See Kunth, Enum. Pl.

See Nad. Enum. Pl. Tah.

See Presl, Epimel.

C. von Ettingshausen. Beiträge zur Kenntniss der Flächen-Skelete der Farnkräuter. (Denkschriften der mathematisch-naturwissensehaftlichen Classe der kaiserlichen Akademie der Wissenschaften. Vienna. XXII., 1862, XXIII., 1864).

See Hook. Exot. F'.

See Metten. Farngattungen. 
Fée, Acrost. . . . .

A. L. A. Fée. Mémoires sur la Famille des Fougères. Histoire des Acrostichées.

Fée, Gen. Fil. . . . . A. L. A. Fée. Genera Filicum.

Fil. Afric. . . . . . See Kuhn, Fil. Afric.

Fil. Eur. et. Atlant. . See Milde, Fil. Eur. et Atlant.

Fil. Exot. . . . . . . See Hook. Fil. Exot.

Fil. Germ. . . . . . See Schkuhr, Fil. Germ.

Fil. Graeff. . . . . . See Luerssen, Fil. Graeff.

Fil. Hort. Lips. . . . See Metten. Fil. Hort. Lips.

Fil. U. S. E. E. . . See Brack. Fïl. U. S. E. E.

Fl. . . . . . . See Pursh, Fl.

Fl. Am. . . . . . See Torr. \& Gray, Fl. N. Am.

Fl. Austral. . . . . . See Benth. Fl. Austral.

Fl. Bor. Amer. . . . See Michx. Fl. Bor. Amer.

Fl. Bras. . . . . . . See Mart. Fl. Bras.

Fl. Bras. Mer. . . . See St. Hil. Fl. Bras. Mer.

Fl. Calif. . . . . . . See Bot. Calif.

Fl. Haw. Islds. . . . See Mann, Fl. Haw. Islds.

Fl. Hongk. . . . . . See Benth. Fl. Hongk.

Fl. Ind. Bat. . . . . See Miq. Fl. Ned. Ind.

Fl. Ins. Austral. . . . See Endl. Fl. Ins. Austral.

Fl. Japon. . . . . See Thunb. Fl. Japon.

Fil. Jav. . . . . . See Blume, Fil. Jav.

Fl. Maur. . . . . . See Baker, Fl. Maur.

Fl. N. Am. . . . . . See Torr, \& Gray. Fl. N. Am.

Fl. N. Zeal. . . . . See Hook. Fl. N. Zeal.

Fl. Ned. Ind. . . . . See Miq. Fl. Ned. Ind.

Fl. Vit. . . . . . . S See Seem. Fl. Vit.

Fl. W. Ind. . . . . . See Griseb. Fl. W. Ind.

Fl. Zeyl. . . . . . . See L. Fl. Zeyl.

Flora. . . . . . Flora, oder allgemeine botanische Zeitung. Regensburg.

Flora Deutschlands. . See Mert. \& Koch, Flora Deutschlands.

Forst. Prod. . . .

G. Forster. Florulae Insularum australium Prodromus.

Forster, Pl. Escul. . . G. Forster. De Plantis esculentis Insularum Oceani australis Commentatio botanica.

Fragm. Fl. N. Cal. . See Brongn. \& Gr. Fragm. Fl. N. Cal.

Fundam. . . . See Trin. Fundam.

Gaud. Bot. Bon. . . . C. Gaudichaud-Beaupré. Botanique du Voyage autour du Monde.... sur la Bonite.

Gaud. Bot. Voy. Bon.

Gaud. Bot. Freyc. . .

Gaud. Bot. Voy. Freyc. Gaud. Général.

See Gaud. Bot. Bon.

C. Gaudichaud-Beaupré. Botanique du Voyage autour du Monde.... sur l'Uranie et la Physicienne par Freycinet.

See Gaud. Bot. Freye.

See Gaud. Bot. Freyc. Undoubtedly a citation taken from Kunth's Enumeratio Plantarum, I., 98, referring to the Observations Génerales of the text of Gaudichand's Botany of Freycinet's Voyage.

Gen. Aroid. . . . . . See Schott, Gen. Aroid.

Gen. Fil. . . . . . See Fée, Gen. Fil. or Hook. Gen. Fil.

Gen. Ill. . . . . . See Gray, Gen. Ill. 
Gen. Pl. or Gen. Plant. Gen. Plant. Suppl. . Gen. Syst.

Gen. \& Spec. Orchid. . Général .

Gooden.

Gray, Bot. U. S. E. E.

Gray, Bot.U.S.E.Exp. Gray, Gen. Ill. . .

Gray, Man. Bot. . .

Gray, Pl. Fendl. . .

Gray, Pl. Wright. .

Griseb. Fl. W. Ind.

Guillem. Zephyr. Taitens.

H. B. K. Nova Gen. Amer.

Hook. Comp. Bot. Mag.

Hook. Exot. Fl. Hook. f. Icon. plant. .

Hook. Fil. Exot. Hook. Fl. N. Zeal. Hook. Gen. Fil. Hook. Ic. Pl.

Hook. Journ. Bot. Hook. Lond. Journ. Bot. Hook. Second Cent. . Hook. Sp. Fil. . . . Hook. Synops. Fil. . . Hook. \& Arn. Bot. Beech.

Hook. \& Bak. Synops, Fil.

Hook, \& Grev. Ic. Fit.
See Endl. Gen. Pl. or Benth. \& Hook. Gen. Pl. See Endlicher, Gen. Plant. Suppl.

See Dom, Gen. Syst.

See Lindl. Gen. \& Spec. Orchid.

See Gaud. Général.

See De Vriese, Gooden.

A. Gray. Botany of the United States Exploring Expedition under Captain Wilkes. Phanerogamia. See Gray, Bot. U. S. E. E.

A. Gray. Genera Florae Americae boreali-orientalis illustrata.

A. Gray. Manual of Botany of the northern United States. Revised Ed., 1859.

A. Fendler and A. Gray. Plantae Fendlerianae Novae-Mexicanae ..... (Memoirs of the American Academy of Arts and Sciences, IV., 1849).

A. Gray. Plantae Wrightianae Texano-Neo-Mexicanae.... (Smithsonian Contributions, III., V).

A. H. R. Grisebach. Flora of the British West Indian Islands.

J. A. Guillemin. Zephyritis Taitensis. Enumération des Plantes .... dans les Mles de la Société. (Annales des Sciences Naturelles, Paris, VI., 1836, VII., 1837).

F. H. A. von Humboldt, A. Bonpland, and C. S. Kunth. Nova Genera et Species Plantarum.... orbis novi ....

Companion to the Botanical Magazine, by W. J. Hooker. London.

W. J. Hooker. Exotic Flora.

J. D. Hooker. Third Series of the Icones Plantarum of W. J. Hooker.

W. J. Hooker. Filices exoticae ....

J. D. Hooker. New Zealand Flora.

W. J. Hooker. Genera Filicum ....

W. J. Hooker. Icones Plantarum ....

The Journal of Botany, by W. J. Hooker.

The London Journal of Botany, by W. J. Hooker.

W. J. Hooker. A Second Century of Ferns....

W. J. Hooker. Species Filicum...

See Hook. \& Bak. Synops. Fil.

W. J. Hooker and G. A. Walker-Arnott. Botany of Captain Beechey's Voyage .... to the Pacific and Behring's Strait.

W. J. Hooker and J. G. Baker. Synopsis Filieum; or a Synopsis of all known Ferns. Unless otherwise indicated references are to the first edition, 1868.

W. J. Hooker and R. K. Greville. Icones Filieum .... 
Hook. \& Grev. Enum. Fil.

Hort. Monac.

Ic.

Ic. Euptorb. - .

Ic Fit

Ic Pl. . * * *

Icon. . . . . .

Icon. Pl. Ind. Or. . .

Icon. plant.

Icon. Rar.

IIl. Gen. Car.

III. Pip.

Ill. Pl. Norf

Jacq. Amer. Pict.

Jacq. Icon. Rar. . . . Journ. Bot. . . . . Kaulf. Enum. Fil. . .

Koch,Synops. Fl.Germ.

Kruidl. Arch.

Kuhn, Fil. Afric.

Kunth, Enum. Pl.

Kunth, Rev. Gram.

L. F. Suppl.

L. Fl. Zeyl. .

L. $S p . P l$. .

I. spec.

Lab.

Lindl. Gen. \& Spec. Orchid.

Linn. Transact.

Linnaea.

Lobel.

Luerssen, Crypt. Fl.

Germ.

Luerssen, Fil. Graeff.

Man. Bot.

Mann, Enum.
W. J. Hooker and R. K. Greville. Enumeratio

Filicum. (Hooker's Botanical Miscellany, II,, 1831).

See Schrank, Pl. Rar. Hort. Monac.

See Deless. Ic.

See Boissier, Ic. Euphorb.

See Hook, \& Grev. Ic. Fit.

See Hook. Ic. Pl.

See Cavan. Icon. or Trin. Icon.

See Wight, Icon. $\mathrm{Pl}$. Ind. Or.

See Hook. f. Icon. plant.

See Jacq. Icon. Rar.

See Boott, Ill. Gen. Car.

See Miq. Ill. Pip.

See Bauer, Ill. Pl. Norf.

N. J. von Jacquin. Selectarum Stirpium Amerieanarum Historia ... pietis .... Vienna (about 1780).

N. J. von Jacquin. Icones Plantarum rariorum.

See Hook. Journ. Bot. or Seem. Journ. Bot.

G. F. Kaulfuss, Enumeratio Filicum quas .... legit A. de Chamisso....

W. D. J. Koch. Synopsis Florae Germanicae et Helveticae ....

Nederlandsch kruidkundig Archief.

M. Kuhn, Filices Africanae....

C. S. Kunth. Enumeratio Plantarum ...

C. S. Kunth. Revision des Graminées. (Published also in the Nova Genera et Species Plantarmm of Humboldt, Bonpland, and Kunth).

Supplementum Plantarum Systematis Vegetabilium Editionis XIII, Generum Plantarum Editionis II (editum a Carolo Linnaeo filio, 1781).

C. von Linné. Flora Zeylanica... .

C. von Linné. Species Plantarum .... .

C. von Linné. Species Plantarum ....

See Benth. Lab.

J. Lindley. The Genera and Species of Orchidaceous Plants.

See Transact. Linn. Soc.

Linnaea, Journal für die Botanik.

See Presl, Lobel.

Deutschlands Kryptogamenflora, by L. Rabenhorst. Vol. III: Gefasskryptogamen, by C. Luerssen.

C. Luerssen. Filices Graeffanae .... (Mittheilungen aus dem Gesammtgebiete der Botanik, I).

See Gray, Man. Bot.

Horace Mann. Enumeration of Hawaiian Plants. (Proceedings of the American Academy of Arts and Sciences, VII., 1868). 
Mann, Fl. Haw. Islds. Horace Mann. Flora of the Hawaiian Islands. (Communications Essex Institute, Salem, Mass., V., 1868, VI, 1871).

Mart. Fl. Bras. . . . Mart. Palm. . . . . . Melet.

C. F. P. von Martius. Flora Brasiliensis....

C. F. P. von Martius. Historia naturalis Palmarum. See Schott, Melet.

Mem. Acad. St. Petersh.

Mem. Bost. Soc. Nat. Hist.

Mem. Comp. . . . . . Mert. \& Koch, Flora Deutschlands.

Melten. Aspid. Metten. Asplen. Metten. Farngattungen

Metten. Fil. Hort. Lips. Metten. Phegopt. . . . Metten. Polyp. . . . . Meyen, Reise . . . Michx. Fl. Bor. Am. . Miers, Contrib to Bot. Milde, Fil. Eur. et Atlant.

Miq. Fl. Ned. Ind. . .

Miq. Ill. Pip. . . .

Miq. Syst. Pip

Monatsber. T. Akad. Wiss. Berl. . . . .

Monogr.

Monogr Amer. Oxal. Monogr. Lycop. Monogr. Mar. Monogr: Urt Mose. Bull. Mrs. Sinclair.

Nad. Enum, Pl. Tah.

Mémoires de l'Academie impériale des Sciences. St. Petersburg.

Memoirs of the Boston Society of Natural History.

See DC. Mem. Comp.

Deutschlands Flora, by J. C. Roehling. Edition III: revised and enlarged by Mertens and Koch. See Metten. Farngattungen.

See Metten. Farngattungen.

G. H. Mettenius. Ueber einige Farngattungen: I. Polypodium; II. Plagyogyria; III. Pteris; IV. Phegopteris and Aspidium; V. Cheilanthes; VI. Asplenium. (Abhandlungen der Senkenberg'schen naturforschenden Gesellschaft, Frankfort, I., II., III).

G. H. Mettenius. Filices Horti botanici Lipsiensis. See Metten. Farngattungen.

See Metten. Farngattungen.

F. J. F. Meyen. Reise um die Erde...

A. Michaux. Flora boreali-Americana....

J. Miers. Contributions to Botany ....

J. Milde. Filices Europae et Atlantidis, Asiae Minoris et Sibiriae.

F. A. W. Miquel. Flora van Nederlandsch Indië (Flora Indiae Batavae).

F. A. W. Miquel. Illustrationes Piperacearum. (Nova Acta ... Naturae Curiosorum, XXI., Suppl.).

F. A. W. Miquel. Systema Piperacearum.

Monatsberichte der königlich Preussischen Akademie der Wissenschaften. Berlin.

See De Cand. Monogr.

See Zuccar. Monogr. Amer. Oxal.

See Spring, Monogr. Lycop.

See De Vriese, Monogr. Mar.

See Wedd, Monogr. Urt.

Bulletin de la Société impériale des Naturalistes de Moscou.

Mrs. Francis Sinclair, Jr. Indigenous Flowers of the Hawaiian Islands. London, 1885. Sampson Low, Marston, Searle, and Rivington. Water
color plates.

J. Nadeaud. Enumération des Plantes indigènes de l'Tle de Tahiti.

Nees von Esenbeck. Genera et Species Asterearum.

See Steud. Nomencl. 
Nova Act. Nat. Cur.

Nova Act. Petropol.

Nova Gen. Amer. .

Oestr. Bot. Wochenbl. .

Palm.

Parlat. Sp. Coton. .

Pers. Enchirid.

Phegopt

Pl. As. Rar.

Pl Rar Hort Monac.

Pl. Us Bras.

Pl. Wright. . . . . .

Polyp.

Presl, Epimel. . . . .

Presl, Lobel.

Presl, Rel. Haenk. . . Presl, Suppl. Epimel. Presl, Tent. Pterid.

Proc. Am. Ac....

Proc.Bost.Soc.Nat.Hist.

Prod.

Prod. Fil.

Prod. Fl. Ind Or.

Prod. Fl. Nepal.

Prod. Fl. Norf. . .

Prod. Nov. Holl.

Pterid.

Pursh, Fl.

R. Br. Prod. Nov. Holl.

Rees, Cyclop.

Reise

Rel. Haenk.

Rep.

Repert.

Rev. Gram.

Roem. and Sch. Syst.

Roth, Tent. Fl. Germ.
Nova Acta physico-medica Academiae Caesareae Leopoldino-Carolinae Naturae Curiosorum.

Nova Acta Academiae Scientiarum imperialis Petropolitanae.

See H. B. K. Nova Gen. Amer.

Oesterreichisches botanisches Wochenblatt. Vienna.

See Mart. Palm.

F. Parlatore. Le Specie dei Cotoni ....

C. H. Persoon. Synopsis Plantarum, seu Enchiridium botanicum ....

See Metten. Farngattungen.

See Wall. Pl. As. Rar.

See Forster, Pl. Escul.

See Gray, Pl. Fendl.

See Schrank, Pl. Rar. Hort. Monac.

See St. Hil. Pl. Us. Bras.

See Gray, Pl. Wright.

See Metten. Farngattungen.

C. B. Presl. Epimeliae botanicae. (Abhandlungen der königlich Böhmischen Gesellschaft der Wissenschaften, VI., 1851).

C. B. Presl. Prodromus Monographiae Lobeliacearum. (Abhandlungen der königlich Böhmischen Gesellschaft der Wissenschaften, 1836).

C. B. Presl. Reliquiae Haenkeanae ....

C. B. Presl. Supplementum Epimeliae botanicae.

C. B. Presl. Tentamen Pteridographiae. (Abhandlungen der königlich Böhmischen Gesellschaft der Wissenschaften, 1836).

Proceedings of the American Academy of Arts and Sciences.

Proceedings of the Boston Society of Natural History.

See DC. Prod. or Forst. Prod.

See Desv. Prod. Fil.

See Wight \& Arn. Prod. Fl. Ind. Or.

See Don, Prod. Fl. Nepal.

See Endl. Prod. Fl. Norf.

See R. Br. Prod. Nov. Holl.

See Agardh, Pterid.

F. T. Pursh, Flora Americae septentrionalis.

R. Brown. Prodromus Florae Novae Hollandiae et Insulae Van Diemen . . . (Oken, Isis, 1819, Jena).

A. Rees. The Cyclopedia or Universal Dietionary of Arts, Sciences, and Literature.

See Meyen, Reise.

See Presl, Rel. Haenk.

See Walp. Rel. Meyen.

See Walp. Repert.

See Walp. Repert.

See Kunth, Rev. Gram.

J. J. Roemer and J. A. Schultes. Caroli a Linné Systema Vegetabilium ....

A. W. Roth. Tentamen Florae Germanicae. 
Schkuhr, Car. . . .

Schkuhr, Fil. Germ.

Schlecht. Adumbrat.

Fil. Cap. . . . .

Schott, Gen. Aroid. Schott, Melet.

Schott, Synops. Aroid. Second Cent. .... Seem. Fl. Vit.... .

Seem. Journ. Bot.

Skelete der Farnkr.

Sp. Coton.

Sp. Fil.

Sp. Pl.

Spreng. Syst. Veget.

Spring, Monogr. Lycop.

St. Hil. Fl. Bras. Mer.

St. Hil. Pl. Us. Bras. Steud. Nomencl.

Steud.Synops.Pl. Glum. Suppl. Epimel.

Su. Syn. Fil.

Sweet, Br. Fl. Gard. Syn. Fil.

Synops. Aroid.

Synops. Cass.

Synops. Fil. .

Synops. Fl. Germ.

Synops. Pl. Glum. .

Syst.

Syst. Pip.

Syst. Veget.

Tent Fl. Ger...

Tent. Pterid.

Thunb. Diss.

Thunb. F7. Japon. . .

Torr. \& Gray, Fl.N.Am.

Trans. Am. Phil. Soc.

Trans. St. Louis Ac. Sc,
C. Schkuhr. Beschreibung und Abbildung von .... Riedgräsern (Carices).... .

C. Schkuhr. Vierundzwanzigste Klasse des Linnéschen Pflanzensystems, oder kryptogamische Gewächse. Vol. I.: Die Farnkräuter (Species Filicum Germaniarum .....).

D. F. L. von Schlechtendahl. Plantarum (Filices Capenses).

Adumbrationes

H. W. Schott. Genera Aroidearum exposita.

H. W. Schott and S. L. Endlicher. Meletemata botanica.

H. W. Schott. Synopsis Aroidearum ....

See Hook. Second Cent.

B. Seeman. Flora Vitiensis.

The Journal of Botany, British and Foreign, by B. Seeman,

See Ettingshausen, Skelete der Farnkr.

See Parlat. Sp. Coton.

See Hook. Sp. Fil.

See L. Sp. Pl. or Willd. Sp. Pl.

Caroli Linnaei Systema Vegetabilium Ed. XVI., by C. Sprengel.

A. Spring. Monographie de la Famille des Lycopodiacées. (Mémoires de l'Académie Royale de Belgique, XV., 1842, XXIV., 1850).

A. de St. Hilaire, A. de Jussieu, and J. Cambessèdees. Flora Brasiliae meridionalis.

A. de St. Hilaire. Plantes usuelles des Brasiliens.

E. G. Steudel. Nomenclator botanicus, seu Synonymia Plantarum universalis....

E. G. Steudel. Synopsis Plantarum Glumacearum.

See Presl, Suppl. Epimel.

O. Swartz. Synopsis Filicum ....

R. Sweet. British Flower Garden.

See Sw. Syn. Fil.

See Schott, Synops. Aroid.

See Vogel, Synops. Cass.

See Hook. \& Bak. Synops. Fil.

See Koch, Synops. Fl. Germ.

See Steud. Synops. Pl. Glum.

See Roem. and Sch. Syst.

See Miq. Syst. Pip.

See Spreng. Syst. Veget.

See Koth, Tent. F7. Germ.

See Presl, Tent. Pterid.

C. P. Thunberg. Dissertationes Academicae Upsaliae....

C. P. Thunberg. Flora Japonica ...

J. Torrey and A. Gray. Flora of North America.

Transactions of the American Philosophical society (New Series).

Transactions of the St. Louis Academy of Science. 
Transact. Linn. Soc. . Transactions of the Linnaean Society of London. Trin. Diss. . . . . . C. B. Trinius. De Graminibus unifloris et sesquifloris Dissertatio botanica. . . .

Trin. Fundam. . . . C. B. Trinius. Fundamenta Agrostographiae ... .

Trin. Icon. . . . . . C. B. Trinius. Species Graminum Iconibus et Descriptionibus . . .

Wall. Pl. As. Rar. . N. Wallich. Plantae Asiaticae rariores. . .

Walp. Ann. . . . . . W. G. Walpers. Annales botanices systematicae.

Walp. Rel. Meyen. . . W. G. Walpers. Reliquiae Meyenianae....

Walp. Rep...... See Walp. Repert.

Walp. Repert. . . . . W. G. Walpers. Repertorium botanices systematicae.

Wedd. Chlor. And.

Wedd. Monogr. Urt. .

H. A. Weddell. Chloris Andina . . .

H. A. Weddell. Monographie de la Famille des Urticées. (Archives du Museum d'Histoire Naturelle, Paris, IX., 1856-1857).

Wight, Icon. Pl.Ind.Or. R. Wight. Icones Plantarum Indiae orientalis.

Wight \& Arn. Prod. Fl. Ind. Or. . . .

Willd. Sp. $\mathrm{Pl}$.

Vogel, Synops. Cass. .

Voy. de la Coq. . . .

Zuecar. Monogr. Amer. Oxal. . . . . . .

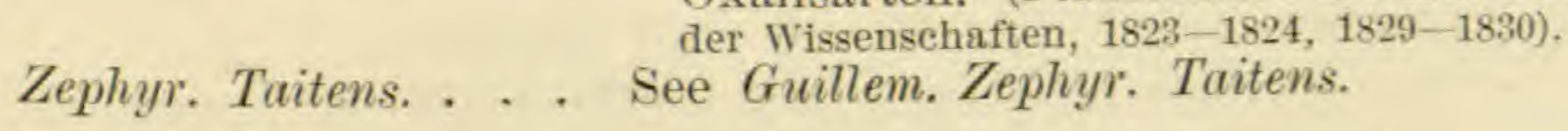

R. Wight and G. A. Walker-Arnott. Prodromus Florae Peninsulae Indiae orientalis...

C. L. Willdenow. Edition IV. of the Species Plantarum of Linné.

T. Vogel. Generis Cassiae Synopsis, (Linnaea, XI., 1837, XV., 1841).

See Brongn. Voy. de la Coq.

J. G. Zuccarini. Monographie der amerikanischen Oxalisarten. (Denkschriften der Münchener Akademie

\section{Botanical Collectors, local and foreign.}

Baldw, Mr. D. Baldwin, of Wailuku, Maui.

Cham. Adalbert v. Chamisso. 1816, 1817.

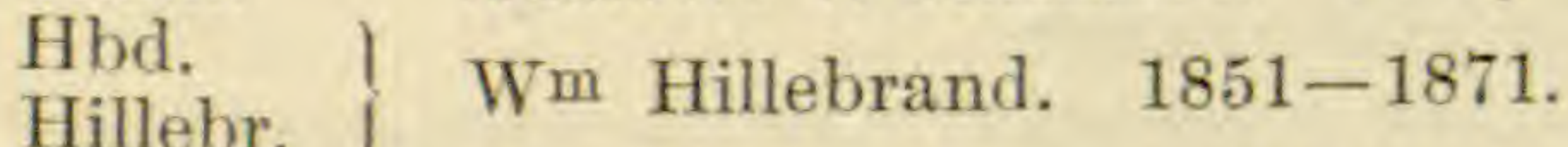

Kn. Mr. V. Knudsen, of Waiawa, Kauai.

Lydg. Mr. J. Lydgate, of Laupahoehoe, Hawaii.

M. \& B. Messrs. Horace Mann and Wm T. Brigham. 1864-1865.

U. S. E. E. The botanists of Captain Wilkes Expedition, 1840.

\section{Conventional Signs.}

+ before a specific name, indicates that the species is supposed to have been introduced before the discovery of the Islands by Captain Cook. ! after a name indieating habitat, signifies that a specimen or specimens are in the author's herbarium, now deposited in the Royal Botanical Museum of Berlin. 


\section{CORRECTIONS AND ADDITIONS.}

Page 100, line 4, for anc read can, and omit comma after doubt.

»101, » 4 from below, for Koolaupapa read Kalaupapa.

》 $111, \gg 6$, for fore hills read fore-hills.

» 114, » 21, for Journ. Bot. read Hook. Journ. Bot.

》 122 , \# 8 from below, for Roots-tock read Root-stock.

» $126,127,128$, page heading, for Mytraceae read Myrtaceae.

» 126, line 11, for Nunanu read Nuuanu.

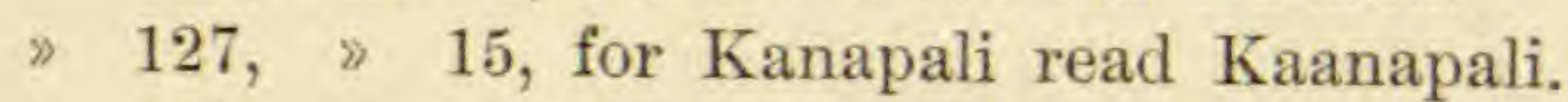

» 129, » 19, for Journ. Bot. read Hook. Journ. Bot.

»131, 》 10 , for quadrangularbranches read quadrangular branches.

》 135, , 18 from below, for bea ked read beaked.

» 137, » 7 , for Olualu read Oloalu, and for Kanapali read Kaanapali.

»137, 》 11, for Kamaloo read Kamalo.

》142, 》 17, for Kanapali read Kaanapali.

» 145 , „ 7 , for Koolaupapa read Kalaupapa.

》 $150, \gg 12$, after characters insert a comma.

»150, »16, after character omit comma.

$\gg 155$, $\gg$ 8, for Kanapali read Kaanapali, and for Kalauwau read Kalawao.

» 159 , » 14 from below, for Olualu read Oloalu, and for Kanapali read Kaanapali.

" 159 , » 15 from below, for Kanapali read Kaanapali.

\# 160 , „ 1 , for Koolaupapa read Kalaupapa.

》161, » 20, for Kalauwau read Kalawao.

" 162, » 7 , for flat read flattish.

\ 165 , \& 18 from below, for Kanapali read Kaanapali.

» 166, „19, for Kalawau read Kalawao.

》 167, » 22, for Romanzoffiana read Romanzoffiensis.

") 168, \# 5 from below, for Olualu read Oloalu,

" 168, \% 11, for G. coriacea read G. coriacea, Hitlebr.

* 169 , 5, for G. terminalis read G. terminalis, Hitlebr. 
Page 169, line 10 from below, for G. hirtella read G. hirtella, Hillebr.

» 170 , " 17 from below, for $6-8$ read $6-8$ ".

》171, lines 21 and 22 , for glutinose read glutinous.

》 171, line 1 from below, for fore hills read fore-hills.

»172, » 16, for Halemanu read Halemano.

»172, » 1 from below, after genera omit period.

» 174, „ 7 from below, for Olualu read Oloalu.

»189, 》 16, for R. scabra read R. scabra, St. Hit., and line 24 add as synonym Richardia scabra, L.

» $190, \gg 31$. It is here stated that the number of species introduced since the discovery of the group amounts to 14 , whereas there were but 11 marked in the manuscript with the sign ( $\dagger$ ) indicative of this. Those pages of the manuscript bearing that part of the description of the Order Compositae which is printed in nonpareil type show unmistakable evidence of having been written at a different and apparently earlier time than those descriptive of the species. It is possible that maturer reflection may have convinced the author that certain species (Ageratum conyzoides, Verbesina encelioides, Centaurea Melitensis) at first held to have been introduced since the discovery, and so marked in a list of introduced plants found among his papers, may in reality have been of earlier introduction; and that after making the final revision of the specific descriptions he forgot to alter this portion to correspond. If this view is correct the number of species introduced since the discovery should read 11 , and for lines 27 to 30 should be substituted the following: Of a non-endemic species which existed before the discovery, 1, Adenostemma viscosum, is cosmopolitan in the tropics, 6, one Ageratum (now diffused over most tropical countries), one Aster, two species of Erigeron, one Verbesina, and one Gnaphalium, are American, and 2, Gnaphatium luteo-album and Centaurea, are of old World origin, but found in some remote countries.

》) 192 , lines 18 and 19 from below, for $1 / 21^{\prime}$ read ${ }^{1 / 2}-1^{1}$.

» 193 , line 13 from below, for 536 read 1231 .

» 197, » 9 from below, for T. Remyi, Gray, Proe. Am. Ac. V, 119 (sub Vittadinia) read T. Remyi, Hillebr.

»198, » 4, add as synonym Vittadinia Remyi, Gray, in Proc. Am. Ac. $\mathrm{V}, 119$. 
Page 199, line 5, for T. Chamissonis, Gray, l. c. (sub Vittadinia) read T. Chamissonis, Hillebr., and line 15, after 1-serial, insert as synonym Vittadinia Chamissonis, Gray, l. c. p.119.

»199, »13 from below, for T. consanguineum, Gray, l.c. (Vittadinia) read T. consanguineum, Hillebr., and line 6 from below add as synonym Vittadinia consanguinea, Gray, l. c. p. 120 .

» 199, » 4 from below, for T. arenarium, Gray, l.c. (Vittadinia) read $\mathbf{T}$. arenarium, Hillebr.

》200, » 7 , add as synonym Vittadinia arenaria, Gray, 1. c.

"200, " 12, for T. conyzoides, Gray, l. c. (Vittadinia) read T. cony. zoides, Hillebr., and line 22 add as synonym Vittadinia conyzoides, Gray, 1. c.

» 208, » 19, for Puloa read Puuloa.

» 213, 》 14 from below, for C. cosmoides (Coreopsis), Gray, in Proc. Am. Ac. V, 126 read C. cosmoides, Hillebr.

"214, " 2, after awns add as synonym Coreopsis cosmoides, Gray, in Proc. Am. Ac. V, 126.

»214, » 9 from below, for C. macrocarpa (Coreopsis), Gray, l. c. p. 126 read C. macrocarpa, Hillebr.

1) 215, 》 4, after barbs add as synonym Coreopsis macrocarpa, Gray, 1. c. p. 126.

》) 215, » 13 , after var. insert ovatifolia.

» 216, \& 13 , omit V.

» 216, » 17 from below, for C. Menziesii, (Coreopsis), Gray, l.c. read C. Menziesii, Hillebr., and line 11 from below add as synonym Coreopsis Menziesii, Gray, l. c. p. 127.

» 216, » 7 from below, for Kohola read Kohala.

» $217, \geqslant 9$ from below, for Kanai read Kauai,

» 229, after line 14 insert the following key:

Leaves elliptico-oblong, heads in a panicle

Leaves linear-capillary, peduncles single headed
1. S. Sandwicensis.

2. S. capillaris.

Page 232, line 6 from below, for Makaleka read Makaleha.

» 235, , 9 from below, for Koolaupapa read Kalaupapa.

» 239, , 3 , for Wailua read Waialua.

» 241, » 6, for Halemanu read Halemano.

๖ 245, „ 24, for Halemanu read Halemano.

* 246, 》 7 from below, for Halemanu read Halemano.

» 247, $\varnothing$ from below, for Halemanu read Halemano.

》248, »10, for Halemanu read Halemano.

» 249, \# 17 from below, for Wailua read Waialua, and line 13 from below for Halemanu read Halemano. 
Page 253, lines 14 and 18 from below, for Halemanu read Halemano.

\255, line 12 from below, for C. recta. (Delissea), Wawra, in Flora, $1873, p .47$ read C. recta, Hillebr., and line 4 from below add as synonym Delissea recta, Wawra, in Flora, 1873 , p. 47.

» 257, » 14 from below, for Honokahau read Honokahua.

" 261 , lines 15 and 16 , for $8-10^{\prime \prime} 5-6^{\prime \prime} \mathrm{read} 8-10^{\prime \prime} \times 5-6^{\prime \prime}$, and line 15 from below for $8 \times 4^{\prime \prime}$ read $8^{\prime \prime} \times 4^{\prime \prime}$.

》) 263 , line 16 , for $10 \times 8^{\prime \prime}$ read $10^{\prime \prime} \times 8^{\prime \prime}$, and line 18 for Honokahau read Honokahua.

»266, » 14, for Kolaupapa read Kalaupapa.

》267, 》 14 , for $1 \times^{1 / 2^{\prime}}$ read $1^{\prime} \times{ }^{1} / 2^{\prime}$, and line 5 from below for Menziesii read Menziesiana.

》 271 , » 1 from below, for Je. read Ic.

» 276, „17, for S. Sandwicense. - Benth. \& Hook. read S. Sandwicense, Benth. \& Hook.

$\gg 284, \gg 7$, for $4 \times 2^{\prime}$ read $4^{\prime} \times 2^{\prime}$.

» 285, » 21, for L. spathulata. - Benth. \& Hook. read L. spathulata, Benth. \& Hook.

》287, » 11, for Puloa read Puuloa.

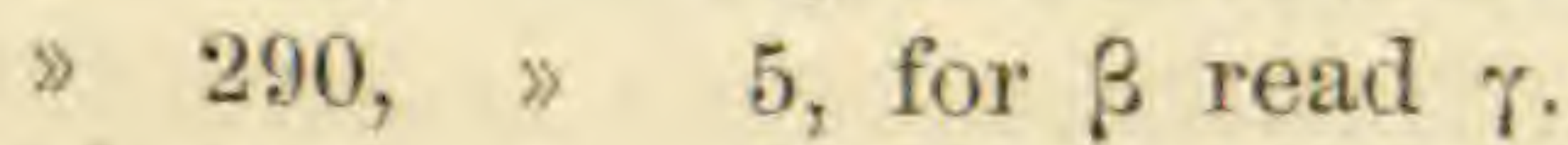

» 294, \$ 7 from below, for Catharanthus rosea read Catharanthus roseus.

302 , 》 11 , for turice read twice.

314 , » 15 , for $2-3^{\prime \prime}$ read $2-3^{\prime}$.

315, » 21 from below, for DC. Prod. IX, 386, var. trichosperma, read DC. Prod. IX, 386. - Var. trichosperma, Hillebr.

»316, » 7 from below, for Haulu read Hauulu.

\$) 322, 》23, for Puloa read Puuloa.

» 329, $7 \quad 7$ from below, after lobes omit comma.

»330, $\gg$ 8, for C. lysiosepala. read C. lysiosepala, Hillebr.

$» 331, \gg 17$, for 531 read 351 .

» 347, » 14 from below, for Kamolo read Kamalo.

» 366 , » 1 , after XIII insert Sect. I, p.

» 380 , " 3, for Maunakea read Mauna Kea.

¿ 396, „ 12 from below, for var. $\alpha$ and $\gamma$ read var. $\gamma$.

1) 416, after line 7 insert the following key:

Leaves appressedly gray - pubescent or silvery or glabrous underneath Leaves gray-tomentose underneath, the hairlets not appressed 2 2. N. Kahoolawensis. Page 420, line 10 from below, for $V, 4$, read IV.

» 421 , » 5, after Pelekunu insert a semicolon.

$\gg 423$, $\gg 20$, for $V, 4$ read $\mathrm{IV}$. 
Page 429, line 15, for Najadaceae read Naiadaceae.

$\gg 435, \gg 15$ from below, before 1. C. Indica, insert the sign $(\dagger)$ indicative of recent introduction.

》 $492, \gg 6$, for 18 read 19 .

》 495, \ 21, for Büne read Büse.

》519, » 2 , for R. \& L. read R. \& S.

» 573 , 》 12 , for colletion read collection.

» 580, \ 19 from below, for C. fragitis read C. fragilis, Bernh.

»604, » 7, A. spathulinum, Hook. Sp. Fil. III, 170 (not J. Smith?). Very grave doubt exists as to the correctness of this name. In the manuscript stood originally A. insititium, Brack. Fil. U. S. E. E. p. 261, tab. 22. This had been crossed out, and in pencil above appeared A. spathulinum, followed by a mark of interrogation. The original synonym in place of $A$. insititium, Carruthers and Metten. (line 23), was A. spathulinum, Hook. Sp. Fil. III, 170 (not J. Smith?). This had likewise been erased and the synonym as printed substituted. It should here be remarked that in the key to the genus (page 586, line 3) the manuscript name A. spathulinum had been substituted in pencil for A. insititium. It is evident that the author had not reached a final decision as to the name to be given to No. 24. It therefore seemed best after deliberation to print the specific name with citation as it appears, although in so doing the difficulty was encountered that this name elsewhere (p. 598) appears as a synonym for $\mathrm{A}$. insititium, Brack. The remarks at the foot of page 598 and the head of page 599 should be consulted in this connection. It is possible that the mark of interrogation (line 7, page 604) should not apply to J. Smith alone, but to what precedes as well. 


\section{SERIES I. PHANEROGAMOUS OR FLOWERING PLANTS.}

Plants bearing true flowers, that is, having stamens and pistils, and producing seeds which contain an embryo.

\section{Class I. DICOTYLEDONOUS OR EXOGENOUS PLANTS.}

Stems consisting of a pith in the center, of bark on the outside, and these separated by one or more layers of fibro-vasal or woody tissue, which, when the stem lives from year to year, increases by the addition of new layers to the outside next the bark. Embryo usually with two opposite cotyledons, or rarely with several in a whorl.

SUbctass I. Thalamiflorae. Petals free from the calyx and from each other, wanting in Xylosma. Stamens hypogynous.

\section{§ 1 . Ovary apocarpous.}

I. Ranunculaceat. Sepals 5. Stamens indefinite; carpels many.

II. Menispermaceae. Flowers small, unisexual; sepals and petals each in 2 series; stamens definite, opposite the petals; carpels 1,3 or 6 . Trailing plants or climbers.

\section{\$ 2. Ovary syncarpous; placentas parietal.}

III. PAPAVEraceae. Sepals 2 ; petals 4 ; stamens indefinite; albumen copious.

IV. Cructrerae. Sepals 4 ; petals 4 ; stamens 6 (exceptionally only 2 ), of which 2 are longer than the others; albumen none.

V. CAPPARIDACEAE. Sepals 4; petals 4; stamens indefinite; placentas 2; albumen none.

VI. VrolackaE. Sepals, petals and stamens 5 ; anthers cohering or conniving round the ovary; placentas 3 ; fruit a 3-valved capsule with the placentas along the midale of the valves.

VII. Brxaceaz. Petals as many as sepals or none; stamens indefinite; placentas 3 or more.

VIII. Pittosporacrae. Sepals, petals and stamens isomerous, 5 each; anthers free, erect; placentas 2 , along the midale of the valves of a woody capsule.

\section{\$ 3. Ovary syncarpous, 1-celled; placenta central and free; embryo curved round albumen.}

IX. Caryophyluaceat. Sepals and petals isomerous, 5 or 4 each; or the petals wanting; stamens twice as many, or as many and opposite the sepals.

X. Portulacaceat. Sepals 2 ; petals 5 ; stamens as many as petals and opposite to them, or indefinite. Suceulent herbs.

Hillebrand, Flora of the Hawaiian Islands. 


\section{\$ 4. Ovary syncarpous; placentas axile. \\ * Disk wanting; sepals imbricate.}

XI. Guttiferae. Sepals and petals tetramerous (2, 4 or 6$)$; stamens indefinite; ovary 1-celled and with a single ovule in our genus; leaves opposite.

XII. Ternstroemadeeae. Sepals and petals pentamerous (5), the latter often cohering at the base; stamens indefinite; leaves alternate.

XVIII. OXaLIDACEAE. Sepals and petals 5 ; stamens 10 , monadelphous; leaves of 3 folioles.

\section{* Disk wanting; sepals valvate.}

XIII. Maldaceae. Stamens indefinite, monadelphous; anthers 1-celled.

XIV. Buettaneriadean. Stamens mostly definite, monadelphous; anthers 2-celled.

XV. Tiliaceae. Stamens indefinite, free or polyadelphous; anthers 2-celled.

$$
\text { *** Disk redueed to } 5 \text { glands, rarely wanting. }
$$

XVI. Gerantaceae. Stamens definite; ovary 3-5-lobed, the carpels seceding at maturity from a central axis; leaves stipulate, alternate.

\section{\#** Disk annular, inside the stamens.}

XVII. ZYGOPHYLLACEAE. Leaves abruptly pinnate, stipulate; fruit spinescent.

XIX, a. RutaceaE. Leaves entire and opposite, or impari-pinnate and alternate, not stipulate; stamens as many or twice as many as petals, sometimes monadelphous; ovary 4-celled and in fruit 4-lobed, or of a single carpel.

XIX, b. Meltaceat. Leaves pinnate or compound, alternate, not stipulate; stamens twice as many as petals, and monadelphous. Ovary several-celled, entire in fruit.

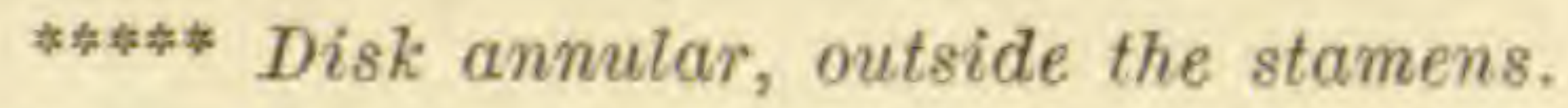

XXIII. SAPINDACEAE. Leaves entire, impari-pinnate or dissected, alternate, not stipulate; stamens not isomerous with the petals, or the flowers irregular, the petals sometimes wanting; ovary 3-celled.

Subcrass II. Calyciflorae. Petals free. Stamens perigynous or epigynous. Petals wanting in Acaena and Sesuvium.

\section{\& 1. Disk conspicuous, perigynous or hypogynous; flowers small, regular.}

XXI. Celastraceae. Stamens alternate with the petals; seeds albuminous; leaves entire.

XXII. RHamaceaE. Stamens opposite the small petals; seeds usually albuminous; leaves entire.

XXIV. Anacardiceae. Stamens alternate with the petals or twice as many; no albumen; leaves impari-pinnate.

\section{\$2. Carpels free, or connate only at the base (or in some Rosaceae syncarpous and adnate to the calyx); the ovules ascending, or affixed to the inner angle.}

XXV. LegumrosaE. Flowers irregular and imbricate, or (in Mimoseae) regular and valvate; stamens definite and mostly connate, or almost hypogynous, free and sometimes indefinite; carpels 1 ; fruit a 2-valved pod.

XXVI. RosaCEAE. Flowers regular; petals imbricate when present; stamens mostly indefinite, very perigynous.

XXVII. Crassulacear. Flowers regular, isomerous, the stamens in 1 or 2 series; carpels connate at the base; ovules many in each carpel; petals united in our genus.
A fleshy herb.

\section{\$ 3. Ovary syncarpous, superior, with axile placentas; ovules pendulous, 1 or few} in each cell.

XX. ILICINEAE, Corolla monopetalous in our genus; ovary many-celled; stigma sessile.

\$ 4. Ovary syncarpous, with axile placentas and many seeds on each placenta.

XXXI. Mrrtacean. Ovary inferior; style entire; lobes of calyx imbricate or gaping; stamens generally indefinite.

XXXII. LythraceaE. Ovary superior, 2-celled; style entire; lobes of calyx valvate; petals generally crumpled. 
XXXIII. ONagraceae. Ovary inferior, 4-celled; style entire; lobes of calyx valvate; stamens definite.

XXXVI. Frcordeat. Ovary superior, 3-5-celled, with 3-5-cleft style; petals wanting and capsule circumscissile in our genus.

\$ 5. Ovary syncarpous, with parietal placentas and many ovules on each placenta.

XXIX. Droseraceak. Ovary superior, 1-celled, with simple parietal placentas and distinct styles. Herb with glandular leaves.

XXVII. SAXIfRAGACEAE. Ovary partly aduate to the calyx, spuriously several-celled, the placentas introflexed, bilamellate, not n.eeting in the center. Leaves opposite.

XXXIV. Cucurbitaceaf. Flowers unisexual, 3- or 5-merous, the petals confluent with the calyx, and the generally flexuose anthers adnate to the outside of the filaments, one anther mostly 1-celled; ovary inferior, fruit fleshy. Climbing herbs with tendrils.

XXXV. PAPAYACEaE. Flowers unisexual; ovary superior; corolla of male flowers tubular, that of the female flowers of 5 distinet small petals; stamens 10 ; fruit fleshy.

XXXVII. CACTACEAE. Flowers hermaphrodite; ovary inferior; sepals, petals and stamens numerous; fruit fleshy. Fleshy plants with spines and generally without leaves.

XXXVIII, Begontaceae. Flowers unisexual; sepals or calyx-lobes 2 or 5 ; stamens numerous; ovary inferior, fruit a capsule. Herbs with uneven-sided leaves.

\section{\$ 6. Ovary inferior, with an epigynous disk, 2-to several-celled, with a single pendulous} ovule in each cell.

XXXIX. Umbelliferae. Ovary 2-celled, with 2 distinct styles; petals generally imbrieate; pericarp with oil-bearing ducts; fruit separating into 2 dry indehiscent carpels.

XL. Araliaceae. Ovary 2- to many-celled, the styles often connate; petals generally valvate; fruit mostly drupaceous, with distinct pyrenae.

XXX. Haloragaceae, Ovary 1-4-celled, with as many sessile stigmas; lobes of calyx, petals and stamens 2 or 4 , the latter opposite the petals; fruit dry, indehiscent.

SUbclass III. Monopetalae. Petals united, at least at the base.

\section{§1. Corolla epigynous, regular.}

XLI. Rublaceat. Stamens adnate to the corolla, as many as lobes of the corolla; ovary 2- or more-celled; leaves opposite, with stipules.

XLII. Compositae. Stamens adnate to the corolla, as many as lobes of the corolla; flowers in involucrate heads; anthers nnited in a ring round the style; ovary 1-celled, 1-ovulate; no stipules.

XLV. VACCINIACEAE. Stamens free from the corolla, generally twice as many as lobes of the corolla; the anthers opening by terminal pores; leaves alternate, without stipules.

\section{\$ 2. Corolla epigynous, irregular.}

XIIII. Lobeliaceak. Stamens 5, the filaments and anthers connate, some of the latter always bearded at the top. Milksap present.

XLIV. Goodeniaceae. Stamens free; stigma surrounded by a hairy indusium.

\section{\$3. Corolla hypogynous or perigynous, bearing the stamens, regular.}

* Ovary 3-or more-celled; 1 or 2 ovules in each cell.

XLVI. EpaCridaceae. Stamens 5, alternate with the lobes of the corolla; a single pendulous ovule in each cell.

XLVII. EBenaceat. Flowers unisexual; stamens indefinite.

XIVIII. SAPOTACEAE. Stamens opposite the lobes of the corolla when of the same number, often alternating with staminodia. Milksap present.

\section{** Ovary 1-celled, with a free central placenta.}

XIIX. MrrsinaceaE. Stamens opposite the corolla-lobes; style simple; drupe with a single basilar seed.

L. Prrnulacear. Stamens opposite the corolla-lobes; style simple; capsule with many seeds.

LI. Plumbaginaceae. Stamens alternate with the corolla-1obes; style 5-cleft; ovary with 1 basilar ovule. 
*** Ovary 2- or incompletely 4-celled; corolla 5-or 4-lobed; stamens as many as lobes of the corolla and alternate with them.

+ Corolla contorted in the bud; leaves generally opposite.

LiI. Gentianaceat. Capsule spuriously 2-celled, the two parietal placentas meeting in the center; style bifid; leaves entire.

LIII. LoganiaceaE. Capsule 2- or 3-celled, with axile placentas; style 2- or 3-lamellate, the lobes cohering; leaves stipulate.

LIV. ApocrnaceaE. Carpels 2, more or less distinct, the single stigma annular below the entire apex of the style; filaments distinct; milksap often present.

LV. Asclepiadaceate. Carpels 2, distinct; stigma single, entire, 5-angled; filaments connate into a short tube; pollen-masses attached in pairs or in fours to processes of the stigma.

\section{†† Corolla not contorted; leaves generally alternate.}

LXVI. Plantaginaceat. Corolla searious, tubular, 4-lobed, the lobes imbricate; stamens versatile on long filaments; style simple; capsule circumscissile, 2-celled, with few superposed seeds; leaves parallel-nerved.

LVI. Hydrophyldaceae. Corolla 5-lobed, imbricate; capsule spuriously 2-celled, the parietal placentas meeting in the eenter; styles 2, distinct; seeds many.

LVII, Oleacear. Corolla colored, 4-lobed, imbricate; stamens 2 or 4 ; ovary 2-celled, with $1-3$ ovules in each cell; style short; drupe generally 1 -seeded; leaves opposite.

LVIII. Solanacean. Corolla plaited or imbricate, 5- or 4-lobed; ovary 2-celled, with many ovules in each cell.

LiX. Convolvolaceat. Corolla plaited, 5-lobed; ovary 2- or 4-celled, with 2 or 1 erect ovules in each cell. Twining herbs or undershrubs, or parasites.

LX. Boraginaceat. Corolla 5-lobed, imbricate; fruit either a 4-seeded drupe or consisting of 2 or 4 distinct nuts; flowers in one-sided spikes or racemes, which are rolled back (scorpioid) before the flowers expand; leaves rough.

\section{§ 4. Corolla perigynous, bearing the stamens, irregular; stamens 1 less or 3 less} than the corolla-lobes.

LXI. Scrophulartaceae. Ovary 2-celled, with many ovules in each cell.

LXII. Gesneriacean. Ovary 1-celled, with 2 bilamellate parietal placentas and many ovules to each; leaves opposite.

LXIII. Mroporaceae. Ovary 2-10-celled, with 1 pendulous ovule in each cell; radicle of embryo superior; corolla in our species with 5-7 lobes and as many stamens; sometimes all stamens antheriferous; stigma entire; leaves alternate.

LXIV. Verbenackae. Ovary 2- or 4-celled, not lobed, with 1 ovule in each cell; radicle of embryo inferior; style terminal; leaves mostly opposite.

LXV. LaBtatat. Ovary 4-lobed, with 1 erect ovule in each lobe; style between the lobes; leaves opposite.

Subchass IV. Monochlamydeae. Perianth really or apparently simple or none (except in some Euphorbiaceae). An artificial Subclass, built upon a character of minor importance, but retained here for practical purposes. The first six Orders are by most recent systematists united with Caryophyllaceae and Portulacaceae into a family ealled Centrospermeas and characterized by a free central placenta and an embryo curved round albumen. The Euphorbiacede are nearest related to Sapindacede and Rhamnaceae.

\$1. Embryo curved round mealy albumen; a single ovule in the ovary or in each carpel or cell.

LXVII. Nyotaginaceae. Tube of perianth persistent round the fruit; ovary 1-celled, with simple style; stamens hypogynous, not of the same number as the lobes of the perianth, sometimes many.

LXVIII. Amarantackae. Perianth dry, supported by 3 bractlets; ovary 1-celled; style simple or 2-3-cleft; stamens connate at the base, as many as segments of perianth; capsule often eircumscissile.

LXIX. Phytolaccaceae. Perianth herbaceous; carpels many, connate in a ring; styles distinct; stamens hypogynous.

LXX. Polygonaceae. Perianth small; ovary 1-celled, with 2 or more styles or stigmas, stamens perigynous; stipules sheathing. 
LXXI. Chenopodiaceae. Lobes of perianth herbaceous or membranous; stamens free; ovary 1-celled, with several stigmas or a 2-3-cleft style; fruit an indehiscent utricle.

LXXII. BATIDEAE. Flowers dioecious, in axillary catkins; ovary 4-celled. A succulent salt-water herb.

§ 2. Embryo not curved; ovary 1-celled, free, with a single ovule; stamens perigynous, as many or twice as many as segments of the perianth.

LXXIII. Lauracear. Perianth-segments 6 in 2 circles; anther-cells opening into valves turned upwards.

LXXIV. Thymelafaceae, Perianth segments 4 ; stamens twice as many.

§ 3. Ovary 1-celled, with few ovules; seed single, without integument, or connate with the pericarp.

LXXV. Santalaceae. Perianth partly adnate to the maturing ovary, its lobes valvate; stamens opposite the lobes; ovules $1-3$.

LXXVI. Loranthaceae. A leafless parasite with articulate branches.

\section{§ 4. Flowers always unisexual (see also Batideae).}

LXXVII. EtPhorbiaceae. Ovary of 3 , or rarely of 2 or more than 3 , united carpels with 1 or 2 pendulous ovules in each, and usually separating into cocci; seeds albuminous. Milksap generally present.

LXXVIII. URTICACEAk. Male flowers small, green; stamens opposite the perianthsegments; ovary free, with 1 ovule; styles 2 , or rarely 1 , the stigma lateral; albumen scanty; leaves stipulate. Milksap sometimes present.

\section{\$ 5. Perianth wanting.}

LXXIX. PiPeraceat. Flowers in catkins, minute; stamens free from the ovary; ovule 1, erect. Succulent herbs.

\section{ORDER I. RANUNCULACEAE.}

Sepals 3 or more, usually 5 , free, often petaloid, caducous. Petals as many or more, sometimes none. Stamens indefinite, hypogynous, free; anthers short, erect, opening by lateral or extrorse slits. Carpels many or rarely solitary, usually free, with 1 or more ovules in each, becoming, when ripe, indehiscent achenes or berries or follicular capsules. Seeds without arillus. Embryo minute, near the base of a copious albumen. Herbs, or woody vines, with a colorless acrid juice, the leaves generally alternate and variously dissected, with petioles dilated and clasping at the base. Stipules none.

\section{RANUNCULUS, L.}

Sepals $3-5$, petals $5-15$, both imbricate in the bud, the petals with a nectariferous scale or pit at the base. Achenes numerous in a head, mostly flattened and beaked, with 1 erect seed. - Annual or perennial herbs, with alternate stem-leaves. Flowers solitary or paniculate, yellow or white, rarely red.

A large genus, belonging to the temperate and cold regions chiefly of the northern hemisphere, a few species inhabiting the higher mountains of the tropical zone. Spreading, pubescent; flowers small, in diffuse open panicles; leaves trisect 1 . R. Mauiensis. Erect, hirsute; flowers larger, in close corymbs; leaves twice trisect . 2. R. Hawaiiensis. 
1. R. Mauiensis, Gray, Bot. U. S. E. Exp. p. 11. - A spreading, much branching perennial, $2-3 \mathrm{ft}$. long, pubescent, the branches fistular, but the stem solid. Lowest cauline leaves on long petioles of $1 \mathrm{ft}$. or more, ovate to deltoid in outline, $4-6^{\prime}$ in each diameter, trisected, the segments stipitate or not, deeply 2-3-lobed, the lobes obovate-acute, irregularly cut and serrate; the uppermost leaves sessile, trisected and at last ovate, subentire. Flowers small, single in the axils of the ultimate reduced leaves, on faintly grooved slender peduncles of about $1^{\prime}$ in length. Sepals ovate, $2^{\prime \prime}$ long, hyaline, pubescent. Petals scarcely longer, obovate, yellow, with a 2-cleft scale at the base. Achenes in globose heads, ovate, compressed, $1-1^{1 / 2} 2^{\prime \prime}$, shortly tipped with a suberect style, smooth and margined.

On the higher lands of the whole group, from $2000 \mathrm{ft}$. upward; in Oahu on Mt. Kaala only. Forms with stipitate and sessile segments oceur on all islands, the former probably growing at lower elevations. Speeimens from East Maui and Kauai are almost hirsute. In leaf and fruit resembling forms of $R$. repens, but the flower much smaller. Native name: "Makou».

2. R. Hawaiiensis, Gray, l. c. p. 10. - Stout, erect, hirsute throughout, $2-4 \mathrm{ft}$. high, with a fistulous stem. Lowest cauline leaves on long petioles of about $1 \mathrm{ft}$, twice ternately or subpinnately compound, all leaflets stalked, these again cut into cuneately oblong, irregularly cut and serrate leaflets or segments, the ultimate floral leaves lanceolate and sharply cut-lobed. Flowers larger than in the preceding species, numerous, on grooved peduncles of $1-2^{4}$, crowded at the end of the stem or branches in a subcorymbose inflorescence with bract-like leaves. Sepals $2-3^{\prime \prime}$, colored. Petals 5-10, each $4-5^{\prime \prime}$ long, with a 2 -cleft scale on the short claw. Achenes in ovoid heads, $1^{1 / 2}-2^{\prime \prime}$ long, smooth, not margined, ending in a rather curved beak.

Hawail! and East Maui! from $4000 \mathrm{ft}$. upward.

\section{ORDER II. MENISPERMACEAE.}

Flowers unisexual. Sepals usually 6 in 2 series, rarely 5 or fewer, or 9 or 12 in 3 or 4 series, the inner ones largest. Petals usually 6 , nearly equal, and smaller than the inner sepals, imbricate in 2 series, rarely none or less than 6. Male $\mathrm{fl}$. Stamens usually as many as petals and opposite to them, free, or united into a central column. Female fl. Stamens rudimentary. Carpels distinct and free, usually 3 , sometimes 6 or more, rarely a single one; 1-ovulate, at first nearly straight, with the stigma subterminal, but often incurved when mature, so that seed and embryo are bent into a crescent or ring. Fruit a drupe, with the endocarp projecting on the ventral side. Seed peltately attached to the projection, either albuminous, with a central embryo, or almost without albumen, the embryo then thick and fleshy, with almond-like cotyledons. Radicle 
superior. - Climbers. Leaves alternate, undivided, usually with palmate nerves, or peltate. No stipules. Flowers usually small, in cymes, racemes or panicles.

A considerable tropical Order, both in the New and the Old World, a few species extending into North America and northern Asia and a rather greater number into southern Africa and Australia.

\section{COCCULUS, DC.}

Flowers dioecious. Sepals 6 or 9. Petals 6, generally auricled and embracing the stamens. Male $f l$. Stamens 6, free, the anthers terminal, globular, 4-lobed, opening by transverse slits. Fem. fl. Carpels 3 or 6, with excentric erect or recurved styles. Drupes curved, obovate or rounded, laterally compressed, the scar of the style near the base. Putamen fragile, crescent- or ring-shaped and often perforated laterally. Embryo much curved, with albumen, the cotyledons linear, flat, much exceeding the short radicle. - Flowers in axillary cymes or panicles, the female inflorescence generally 3 -flowered.

A small genus, chiefly Indo-Chinese, but extending also into Africa and Australia, with two N. American species.

The Hawaiian species are peculiar in having typically 3 eycles of sepals, of which, however, one or the other is often defective, and 6 carpels. The differences between male and female plants are not limited to the generative organs, but extend to the sepals, mode of inflorescence, and, it would seem, sometimes even to the shape of the leaves - eircumstances which render the limitation of the different species exceedingly difficult. Nat. name: "Huehues or "Hueie".

Petals entire:

1. C. integer.

Petals bifid or bidentate:

Drupe annular:

Petals auriculate at the base.

Petals cuneate at the base

Drupe horseshoe-shaped, not carinate

2. C. Ferrandianus.

3. C. lonehophyllus.

4. C. virgatus.

1. C. integer, $s p . n$. - Stem twining, sparingly pubescent, with a hairy cushion in the axillas between the petioles and supraaxillary peduncles. Leaves membranous, nearly glabrous, ovate, acute, with $3-5$ basal nerves, $2-3^{\prime} \times 1^{1 / 4}-1^{1 / 2^{t}}$, on petioles of $6-8^{\prime \prime}$. Male $\mathrm{fl}$. in a compound subpaniculate cyme which does not exceed the petiole, the peduncle $3-4^{\prime \prime}$. Sepals $9-7$ in 3 cycles, those of the outer very minute, the inner obovate or rounded, $1^{1} / 2^{\prime \prime}$. Petals narrow lanceolate, auriculate near the base and drawn out into a long entire apex.

Lanai! on the highest ridge.

2. C.Ferrandianus, Gaud. Bot.Voy. Freyc. p. 4ir, tab.101. - Stem twining, retrorsely hispid or pubescent, most so in the axillas. Leaves ovatoor elliptico-lanceolate, acute, rarely subcordate at the base, with 3 basal nerves, the nerves and veins puberulous underneath, $2-3^{\prime} \times 10$ $-12^{\prime \prime}$, on petioles of $4-6^{\prime \prime}$. Male $f l$. many in a compound cyme not exceeding the petiole. Sepals generally 6 in 2 cycles, but sometimes $7-8$, 
pubescent. Petals bifid or sharply bidentate, auriculate at the base. Fem. $f$ l. Cymes 3 -flowered, all pedicels of even length, $1-1^{1} / 2^{\prime \prime}$. Drupe fleshy, bluish, the putamen annular and perforate, the styliferous apex touching the base, with a dorsal keel and 2 lateral furrows, transversely rugose. - Walp. Rel. Meyen. p. 268. - Nephroica Ferrandiana, Miers, in Contrib. to Bot. III. - Gray, Bot. U. S. E. E. p. 39.

Oahu! Hawaii! and probably other islands. M. \& B.'s no. 429 (without indication of locality) has larger, broad-oblong and obtuse mucronate leaves with $3-5$ basal nerves, the flowers with 6 sepals. In plants from Puna! Hawaii, the leaves are mucronate, while there are 3 full cycles of sepals.

3. C. lonchophyllus, Hillebr. - Stem twining, pubescent. Leaves glabrous, ovate-lanceolate, but generally contracted at the base, even cuneate, in female specimens occasionally cordate, mucronate, $2-2^{1 /} 2^{\prime}$ $\times 10-12^{\prime \prime}$, on petioles of $3-6^{\prime \prime}$. Male $f l$. many in a compound cyme. Sepals ciliate, 6 in 2 cycles, those of the outer minute, $1 / 3$ or $1 / 4$ as large as the inner ones, which measure $1^{\prime \prime}$. Petals with a cuneate base, dilated below the middle and shortly bidentate, rarely entire. Fem. $f$. Cyme 3 -flowered. Sepals $6-9$, besides 2 bractlets, in 3 cycles, although often one sepal wanting in any or all cycles. Stamens 6 , abortive. Carpels 6 , stipitate, with recurved styles, often all maturing. Drupes fleshy, the putamen annular, laterally perforated, tuberculate at the back, not keeled. - Holopeira lonchophylla, Miers, in Ann. and Mag. Nat. Hist. XIX, no. 109, and Contrib. to Bot. III.

Maui! Kula and Honuaula.

4. C. virgatus, $s p . n$. - Stems rather stiff and trailing, pubescent, as is the inflorescence. Leaves subcoriaceous, ovate to cordate, obtuse and mucronate or subacute, with $3-5$ basal nerves, pubescent underneath, $1^{1 / 2}-2^{1} / 2^{\prime} \times 1-1^{1} / 4^{\prime}$, on petioles of $6^{\prime \prime}$. Male $f l$. many in compound cymes, often crowded at the ends of short lateral branches with reduced leaves, appearing like foliose panicles. Sepals $5-8$ in 2 or 3 cycles. Petals bidentate, auriculate at the base. Fem. $f l$. Cyme simple, longer than the petiole. Sepals 6 in 2 cycles, of nearly even shape and size. Stamens abortive. Carpels 6, with recurved styles. Drupes dryish, stipitate horseshoe-shaped, the styliferous apex at some distance from the base, not keeled at the back, transversely rugose.

Lanai or Molokai! In a similar specimen from Ka uai the leaves are ovate mucronate, the female flower has $8-9$ sepals and the petals are shortly and obtusely bidentate.

Here must also be mentioned the Order Anonaceae, to which belong the Custard-Apples, Anona Cherimolia, Mill., from the Ecuadorian Andes, A. squamosa, L., from the W. Indies, and the Soursop, A. muricata, L., also from the W. Indies, fruit trees in general eultivation, the first one occasionally found as an escape.

To the Order Nelumbiaceae belongs the Lotus flower, Nelumbium speciosum, Willd, which covers some ponds in the neighborhood of Honolulu, a native of China and the East. 


\section{ORDER III. PAPAVERACEAE.}

Sepals 2 , rarely 3 , deciduous. Petals 4 , rarely 6 , usually folded in the bud. Stamens indefinite, free, hypogynous. Anthers versatile, opening with longitudinal slits. Ovary free, 1-celled, with 2 or more parietal placentas sometimes projecting into the cavity so as nearly to divide it into as many cells. Style simple or none. Stigmas as many as placentas, usually radiating on the top of the ovary or style. Fruit capsular, or rarely a berry. Seeds albuminous, with a small embryo next the hilum. - Herbs, with milky juice and mostly alternate leaves.

A small Order, spread over the temperate zones principally of the northern hemisphere; a few species also diffused as weeds over tropical countries.

\section{ARGEMONE, L.}

Stigmas $4-6$, nearly sessile on the top of the ovary. Capsule obovate or oblong, opening at the top into short valves between the parietal placentas. Seeds pitted. - Leaves usually prickly. Juice yellow.

A small American genus.

$\dagger$ 1. A. Mexicana, L. - DC. Prod. I, 120. - An erect, stiff, glaucous and glabrous annual, $3-4 \mathrm{ft}$. high. Leaves alternate, half-stem-clasping, sinuately pinnatifid and bordered with prickly teeth, spotted with white along the primary veins. Flowers terminal, white, $2-3^{\prime}$ in diameter. Capsule about $1^{\prime}$ long, priekly. - Mrs. Sinclair, Indigenous Flowers of the Haw. Islds. pl. 17.

Common in dry rocky situations on the leeward side of various islands, particularly o ahu. Originally a native of the warmer parts of $\mathrm{N}$. America, it has found its way to many tropical countries. Varies also with smaller and yellow flowers. In the Hawaiian Islands it has been found by the earliest collectors. The natives employ the acrid juice as a local application to ehronic ulcers. Nat, name: "Puakala".

\section{ORdER IV. CRUCIFERAE.}

Sepals 4. Petals 4. Stamens 6 , of which 2 are usually shorter, hypogynous. Ovary 2-celled, with 2 or more ovules in each cell. Style single, often very short, or almost none, with a capitate or 2-lobed stigma. Fruit a siliqua or silicule, that is, a pod divided into 2 cells by a thin partition from which the valves separate at maturity, or in a few genera the pod is 1-celled or indehiscent or separates transversely into several joints. Seeds without albumen, attached in each cell alternately to the right and left edges of the partition. Embryo curved, the radicle either accumbent - folded against the edge of the cotyledons - or incumbent - folded over the back of one of them. - Herbs or rarely undershrubs. Leaves alternate, without stipules. Flowers in terminal centripetal racemes usually very short and reduced to a corymb when flowering commences, but lengthening out as it advances, 
A large and widely diffused Order, most abundant in the temperate regions of the northern hemisphere.

Pods short, pouch-like. Siliculosae:

Carpels opening when mature

Carpels falling off as closed nutlets

Pods elongate. Siliquosae:

Flowers yellow; radicle incumbent

Flowers white; radicle accumbent:

Pods and seeds turgid

Pods and seeds flat

1. Lepidium.
2. Senebiera.

5. Brassica.

4. Nasturtium.

3. Cardamine.

\section{LEPIDIUM, L.}

Sepals short, equal at the base. Petals small or wanting. Stamens sometimes only two. Silicule suborbicular, much flattened contrary to the narrow partition, usually notched at the apex, the valves boat-shaped and keeled, dehiscent. Seeds 1 in each cell, pendulous. Radicle incumbent or accumbent. - Herbs or undershrubs, with bractless racemes of small whitish flowers.

About 80 species, spread over the temperate and warm regions of the whole globe one species in the islands of the southern Pacific.

Stamens 6:

Silicule emarginate; leaves obovate, eut; suffruticose.

Silicule not emarginate; shrubs:

1. L. Oahuense.

Leaves spathulate, obtuse, entire or denticulate; racemes single or few, the flowers at the end of a long naked rhachis

Leaves lanceolate acute, serrate; racemes many, united into Stamens 2 a foliose panicle

2. L. arbuscula.

3. L. serra.

4. L.Virginicum.

1.L. Oahuense (0 wahiense), Cham. \& Schl.in Linnaea, I, 32. - Suffruticose, the, branches freely dividing towards the top, $1-1^{1} / 2 \mathrm{ft}$. high, glabrous. Leaves membranous, those of the stem obovate, obtuse, coarsely serrate or cut, $1^{1 / 2}-3^{\prime} \times{ }^{3} / 4^{4}$, tapering into a short petiole, the upper and floral ones spathulate, subentire. Racemes simple, one terminating each branch, when mature $5-7^{*}$ long, bearing fruit from the very base on horizontal pedicels of about $3^{\prime \prime}$. Flowers small. Sepals ciliate, conchoid or oblong. Petals twice as long, unguiculate, with a round lamina. Stamens 6 , shorter than the petals. Five glands. Silicule $3^{\prime \prime}$, obovate, narrowly emarginate and slightly crested at the top, the very short style not exceeding the notch. Cotyledons thick fleshy, accumbent! - Bot. Beech. p. 78. - Walp. Rel. Meyen. p. 250. - Walp. Repert. I, 177. - Gray, Bot. U. S. E. E. p. 63. - Mann, Enum. no. 5.

In the lower zone of all islands, from the seashore up to $2000 \mathrm{ft}$. Nat. name: "Anounou". Approaches near to $L$. piscidium, Forst., from the southern Pacific.

2. L. arbuscula, sp. n. - A shrub, 2-4 ft. high, tortuous, gnarled, woody to the last ramifications, which are closely covered with leaf-scars. Leaves crowded at the ends of the branches, spathulate, narrowing into short petioles, $1^{1 / 2}-2^{\prime} \times{ }^{1 / 4}-{ }^{1 / 3^{\prime}}$, faintly denticulate, subcoriaceous, glabrous. Racemes simple, erect, one to three from the apex of a branch, 
3-6' long when full grown, with a filiform rhachis which is naked below, the flowers crowded toward its end. Petals less distinetly clawed than before. Silicule $2^{\prime \prime}$, ovate, entire, very flat, the style very short, less than ${ }^{1} / 2^{\prime \prime}$. Cotyledons apparently incumbent.

Oahu! dry open ridges of the Waianae Mts. (Makaha). The innovations rise from the apex of the last year's growth, close under the raceme, the new branches strongly deflected from the axis of the last one.

3. L. serra, Mann, Enum. no. 6. - A straggling, much branched shrub, $2-3 \mathrm{ft}$. high, nearly glabrous. Leaves crowded at the ends of the branches, lanceolate, acute, closely and sharply laciniato-serrate, chartaceous, $2-3^{\prime} \times 4-5^{\prime \prime}$, on petioles of about half their length. Inflorescence a branching panicle, spreading in a corymbose manner, the racemose branches subtended by linear entire bract-like leaves. Flowers along the greater part of the branch on pedicels of $3^{\prime \prime}$. Stamens 6, longer than the petals. Style slender, $1 / 2-1^{\prime \prime}$ long. Silicule flat, suborbicular, not emarginate. Cotyledons accumbent (according to Mann).

Kauai! Hanapepe to Waimea (M. \& B. Wawra, Kn,).

$\doteqdot 4$. L. Virginicum, L. - DC. Prod. I, 205. - Herbaceous, about $1 \mathrm{ft}$. high, freely branching, glabrous. Lower leaves pinnatifid, the upper lanceolatedentate or incised. Stamens 2. Silicule orbicular, wingless, shortly emar, ginate. Cotyledons accumbent. - Gray, Man. Bot. p. 38.

East Maui! First appeared in canefields of Ulupalakua, but has spread now over the southern slope of Haleakala.

\section{SENEBIERA, Poir.}

Sepals short, patent, equal at the base. Stamens often only 2. Silicule small, compressed contrary to the narrow partition, the two carpels indehiscent, falling away as closed nutlets, wrinkled or tuberculate, 1-seeded. Stigma sessile. Embryo curved, the cotyledons incumbent and folded, gradually tapering into the radicle. - Low and diffuse herbs, with minute whitish flowers on racemes which are opposite to the leaves.

About 6 species, inhabiting the temperate and warm regions of both hemispheres.

$\dagger$ 1. S. didyma, Pers. - A prostrate annual, branching from the base, hispidulous or glabrate. Leaves once or twice pinnatisect. Silicule shorter than the pedicel, transversely wrinkled, notched at both ends. $-S$. pinnatifida, DC. - Lepidium didymum, L.

The Peppergrass, a common weed in gardens, a native of the warmer parts of $\mathrm{N}$. America, but widely spread over many other countries.

\section{CARDAMINE, L.}

Pods linear, the valves flat, without a conspicuous midrib, and opening from the base by elasticity. Seeds apparently in a single row in each cell, not margined. Radicle accumbent. Flowers white or purple. 
A large genus of herbaceous plants, widely spread over the temperate and cold regions of both hemispheres. C. sarmentosa, Forst., is a common plant in many islands of the southern Pacific.

†1. C. hirsuta, L. - DC. Prod. I, 152. - An annual, $1 / 2-1 \mathrm{ft}$. high, erect, branching at the base, generally glabrous in the Hawaiian plants. Lower leaves pinnate with 5-9 rounded, angular or lobed, stalked leaflets, the terminal one larger and generally subcordate; the leaflets of the upper leaves with a cuneate base. Flowers small, the white petals twice as long as the calyx. Pedicels and pods ascending, suberect, the latter $1 / 2-1^{\prime}$ long. Style shorter than the width of the pod.

A common weed in gardens, and carried into open woods wherever cattle penetrate. A native of Europe, but now widely dispersed.

The plant probably arrived within the first decades of the present century, for it was collected for the first time (in Waimea, $\mathrm{Haw}$ aii) by the botanists of the U. S. E. E. ; yet it presents itself under three distinct forms. The above given description, which agrees tolerably well with the common European form, applies to the garden weed as it appears in early spring. From the woods of Kona! Haw a ii (about $3000 \mathrm{ft}$. above the sea), we have spreading plants, $1^{1 / 2} \mathrm{ft}$. and more in length, with ereet and flagelliform branches (as in C. sarmentosa), the latter dividing again into ascending branchlets; all leaflets generally cordate, the terminal one $1^{\prime}$ in diam.; pedicels and pods of the elongate open raceme spreading as in C. sylvatica, Lk. In plants again from Haleakala, Mauj (6000 ft. above the sea), the stem is quite leafy, the leaflets even of the lower leaves are all cuneate at the base, while those of the middle and upper leaves are oblong and decurrent.

\section{NASTURTIUM, R.Br.}

Pod a short silique, oblong-linear, often curved, the valves convex, with the midrib scarcely visible, dehiscent. Seeds turgid, not margined, in 2 regular rows in each cell. Radicle accumbent. - Aquatic or marsh plants, with white or yellow flowers and pinnate or pinnatifid leaves, usually glabrous.

A small, widely spread genus.

$\dagger 1$. N. officinale, R.Br. - Perennial. Stems spreading and rooting. Leaves pinnate with $3-11$ roundish or oblong, nearly entire pinnas. Petals small, white, twice the length of the calyx. Anthers yellow. Pods linear, 6-8" long, on slender spreading pedicels.

The common Water-Cress, of European origin, fills watercourses in the neighborhood of Honolulu and elsewhere, but flowers rarely.

\section{BRASSICA, L.}

Silique linear, terete or quadrangular, the valves 1-nerved, with anastomosing veins, dehiscent. Seeds globose, in one row. Cotyledons incumbent, folded round the radicle. - Annual or biennial herbs, with mostly yellow flowers.

A considerable genus of the Old World, chiefly Mediterranean.

$\uparrow 1$. B. nigra, Koch. - An erect annual, $1-2 \mathrm{ft}$. high, rough-hispid below. Leaves petiolate, the lower lyrate or lobed, the upper entire. Inflorescence flat corymbose at first. Sepals spreading. Petals yellow. Pedicels and 
pods erect, appressed, the latter 4-cornered and beaked, 6-12" long. Seeds black. - Sinapis nigra, L.

The Black Mustard, naturalized in some places of Hawai and E. Maui! where it was cultivated in former times.

Knudsen's collection also contains a scrap of Raphanus sativus, the common Radish, but $I$ doubt if it be more than an accidental escape.

\section{ORDER V. CAPPARID ACEAE.}

Sepals 4, free or partly united. Petals 4 , rarely 8 or none. Stamens usually indefinite, or, if definite, 6 or more, often unequal. Anthers oblong, erect. Ovary superior, 1-celled, with 2 or rarely more parietal placentas, each bearing several or many ovules. Style single, often very short or almost wanting, the stigma generally round. Fruit either a dehiscent pod or an indehiscent berry. Seeds generally reniform, without albumen, the embryo coiled. - Herbs, shrubs or climbers, rarely trees, with alternate simple or digitate leaves. Stipules usually none, rarely spinescent or small. Flowers in terminal racemes, or axillary and solitary. The ovary in several genera, and sometimes the stamens also, are raised on a stalk or elongate receptacle within the flower.

A considerable Order, found chiefly within the tropics, a few species stretching northward into more temperate regions.

Fruit a dehiscent capsule; leaves 5-foliolate:

Stamens free, inserted on the torus.

Stamens in part connate with the elongate gynophore

1. Cleome.

Fruit indehiscent, fleshy; leaves simple

2. Gynandropsis.

3. Capparis.

\section{CLEOME, L.}

Calyx 4-parted or of 4 sepals. Petals 4, imbricate or open in the bud. Stamens 6 or 4 , free, inserted on a short conical disk or torus, all or at least two antheriferous, the filaments generally unequal and declinate. Ovary sessile or stipitate, many-ovuled, with mostly a sessile stigma. Capsule silique-shaped, 2-valved, separating from the intervalvular placenta. Seeds rough or hairy. Radicle conical. - Herbs, with digitate leaves and terminal racemes.

About 70 species, most numerous in America, Egypt and Arabia.

1. C. Sandwicensis, Gray, Bot. U. S. E. Exp. p. 65. - Erect, about $2 \mathrm{ft}$. high, clothed with a viscous pubescence, the stem, petiole and ribs of leaflets sparsely aculeate with small prickles, the stipular ones strongest. Leaflets 5, oblong-lanceolate, $2-2^{1} / 2^{2}$ long, gray-pubescent on both faces. Floral leaves or bracts ovate or oblong, often subcordate, $3-2^{\prime \prime}$ long, on short petioles. Pedicels $1^{\prime}$. Calyx of 4 sepals $1^{1 /} / 2^{\prime \prime}$ long, viscous-hairy. Petals $3^{\prime \prime}$, obovate, on short claws, pale rose-colored. Stamens 6, long exserted, all equal and antheriferous, the linear anthers $2^{\prime \prime}$ long. Pod $1^{1 / 2}-2^{\prime}$ long, $2^{\prime \prime}$ thick, terete, smooth, with subsessile stigma, raised on 
a stalk or gynophore of nearly $1^{1 / 2}$. Seeds obovoid, coiled, tuberculate. C. spinosa, Hook. \& Arn. Bot. Beech. p. 78. - Walp. Rel. Meyen. p. 251.

In the low lands of all islands here and there, but by no means common, generally in the neighborhood of "taros ponds - Oahu! Manoa, Kalihi!. Nat. names: "Miohu" and eHonohinos.

\section{GYNANDROPSIS, DC.}

Sepals 4, deciduous. Petals 4, unguiculate, imbricate or open in the bud. Torus prolonged into a filiform gynophore or stalk which carries the ovary. Stamens 6, all antheriferous and equal, the filaments in their lower half connate around the gynophore in a monadelphous column, but free above. Ovary many-ovuled, with 2 placentas. Style short or elongate, with a 2-lobed stigma. Capsule and seeds, leaves and inflorescence as in Cleome.

About 10 species, chiefly of $\mathrm{S}$. America and Africa.

†1. G. pentaphylla, DC. Prod. I, 238. - A fetid, viscous-hairy annual, about $1 \mathrm{ft}$. high. Leaflets 5 , on a petiole of $2-3^{\prime}$, obovate, acuminate, entire, the terminal one $1^{1} / 2-2^{1} / 2^{\prime}$ long, ciliate at the margins. Floral leaves or bracts small, $6-2^{n}$, trifoliolate with obtuse leaflets. Pedicels $9-12^{\prime \prime}$. Sepals $1^{1} / 2^{\prime \prime}$, acute. Petals $4-5^{\prime \prime}$, with long claws, open in the bud, pale purple. Staminal column about $6^{\prime \prime}$, the gynophore lengthening to $9-10^{\prime \prime}$. Stigma subsessile. Capsule linear-compressed, 3-4' long. Seeds cyclical, tuberculate.

Common on roadsides near Honolulu, also in parts of Ka uai! Made its first appearance in 1857. - A native of Africa, but naturalized in many tropical countries.

\section{CAPPARIS, I,}

Sepals 4. Petals 4, imbricate in the bud. Stamens 8 to many, free, inserted on the torus, filiform. Ovary stalked, many-ovuled, with 2 placentas. Stigma sessile. Fruit pulpy, indehiscent. - Shrubs or climbers, rarely trees. Leaves undivided. Stipules subulate or spinous.

About 120 species, distributed over the warm regions of both Worlds, but absent from N. America.

1. C. Sandwichiana, DC. Prod. I, 245. - A straggling shrub, 2-3 ft. high, glabrous, unarmed. Stipules none. Leaves oblong, entire, rounded at both ends or sometimes subcordate at the base, $1^{1 / 2}-2^{\prime} \times 1-1^{1} / 2^{\prime}$, on petioles of $6-8^{n}$. Flowers large and white, axillary, single, the stout peduncle about $2^{\prime}$ long, without bracts. Sepals imbricate, ovate, concave, unequal, the inner ones saccate, $1^{\prime}$ long. Petals about $2^{x}$ long, obovate, unequal. Stamens indefinite, exserted. Berry oblong, $1^{1 / 2}-2^{1} / 2^{t}$ long by ${ }^{1} / 2^{\prime}$ in width, raised on a curved stalk of $2-3^{\prime}$. Seeds reniform, imbedded in an orange-colored fetid pulp. - Bot. Beech. p. 59. - Gaud. Bot. Bon. tab. 55. - Gray, Bot. U. S. E. E. p. 69. - Mrs. Sinclair, pl. 42. 
Common along the seashore and on dry lava-fields. Flowers fragrant. Nat. names: "Maiapilo", "Puapilo" in Kauai. - The species oceurs also on the Low or Paumotu Islands and on Matia near Tahiti.

\section{ORdER VI. VIOLACEAE.}

Sepals 5, imbricate, persistent. Petals 5, imbricate in the bud, generally unequal, the lowest one larger and often spurred, or subequal. Stamens 5, hypogynous, alternate with the petals, on short filaments, the introrse anthers erect, often coherent round the ovary. Ovary free, sessile, 1-celled, with generally 3 parietal placentas. Style usually clavate, the simple stigma hollow and turned to one side. Fruit generally a capsule separating into as many valves as there are placentas; the seeds inserted along the center of the valves, anatropous, with a hard testa and copious albumen. Embryo straight, axile; cotyledons flat. - Herbs or shrubs, with alternate stipulate leaves and axillary flowers.

The Order, distributed over the whole globe, is represented in Polynesia by Agatea, Gray, and perhaps Alsodeia, Thouars, besides the two following genera.

Lowest petal spurred or saccate at the base; anthers appendienlate at the apex

Petals equal, not spurred; anthers not appendiculate

1. Viola.

2. Isodendrion.

\section{VIOLA, L.}

Sepals generally produced at the base below their insertion. Petals unequal, the lowest one spurred at the base. Anthers subsessile, closely surrounding the ovary, their connective prolonged beyond the apex, and in the 2 lowest generally spurred at the back. Capsule 3-valved. Seeds ovoid-globose. - Herbs or shrubs, with persistent stipules. Peduncles axillary, 1-, rarely 2-4-flowered. - Most species produce 2 sets of flowers, viz., early ones with large petals, but mostly sterile, and later ones with small or no petals, and generally fertile.

A large genus, scattered over the temperate regions of the whole world, with a few tropical species.

Rhizome subterranean, leafless, with herbaceous leafy scapes

1. V. Kauaiensis.

Stems erect, woody and leafy:

Peduncle 1-4-flowered:

Flowers in an umbel; stem deeumbent, simple, or dividing at the base

Flowers single or in irregular fascicles; stem erect, simple, or dividing above

2. V. Mauiensis.

3. V. rabusta.

Peduncle 1-flowered; branching shrubs:

Leaves cordate; sepals gibbous at the base; petals spathulate, pale blue or purple

Leaves ovate, smaller; sepals drawn out at the base; petals clawed, broad oblong or orbieular, large, pure white

4. V. Chamissoniana.

5. V. helioscopia.

1. V. Kauaiensis, Gray, Bot. U. S. E. Exp. p. 85. - Rhizome creeping, rather thick $\left(2-3^{\prime \prime}\right)$, scaly near the apex with obtuse stipules, and bearing (besides the remnants of older ones) one or two slender scapes $4-8^{\prime}$ in length, with 1 internode and a single leaf and flower, or with 2 internodes 
and a second leaf and flower. Leaves on slender petioles of $2-6^{\prime}$, broadly ovate, orbicular or reniform, with a cuneate base, less than $1^{\prime}$ in diameter, rather thick with prominent subflabellate nerves, crenate, glabrate. Stipules deltoid, 2-3", with a few short teeth. Flowers dimorphous, the larger ones on peduncles of $2-4^{1} / 2^{\prime}$, which bear a pair of short subulate bracts in the upper portion. Sepals $3^{1} / 2^{\prime \prime}$, narrow lanceolate, the base produced into a short appendage. Petals twice as long, pale blue, not bearded, oblong-spathulate, the lowest one slightly saccate. Anthers free, half as long as the sepals, attached to the anterior face of a broad connective which fringes them and extends above in the shape of a hood, the 2 lowest with a short dorsal keel near the base. Style curved and clavate above, with anterior stigma. The shorter flowers (described by Gray) have petals not exceeding the calyx, and stamens with distinct filaments nearly equalling the petals, while the style is thicker and hooked. Capsule acute, 5-6", with $8-10$ seeds to each placenta.

Kauai! in the bogs of the high plateau of Lehua makanui (U. S. E. E. and Kn.) and of Waialeate (Wawra). Knudsen writes that the stem is neither creeping nor trailing, but always erect.

2. V. Mauiensis, Mann, Enum. no. 11. - Stem simple, or dividing at the base, prostrate or ascending, woody below, a few inches to $1^{1 / 2} \mathrm{ft}$. long, covered in its upper portion with dark brown, sharply cut, long acuminate stipules, and foliose near the apex. Leaves on petioles of $1^{\prime}$, coriaceous, glabrous, broadly ovate and obtuse or rounded, $1-1^{1 / 1} 2^{4}$ in diameter, truncate or cuneate at the base, serrulate with callous teeth. Seapes or peduncles $1-3$ on a stem, $2-6^{\prime}$ long, with 2 narrow acute bracts about the middle, bearing an umbel of $2-4$ flowers on pedicels of $1^{\prime}$, which are again bracteolate. Sepals narrow lanceolate, $4^{\prime \prime}$, purplish, scarcely produced at the base. Petals twice as long, unguiculate, obovate, dark blue, the lowest saccate. Anthers oblong, $1-1^{1 / 2}$ ", not margined, tipped with a short papilla, the 2 lowest broadly spurred. Style curved, thickening toward the stigma. Capsule $6^{\prime \prime}$, with $8-10$ seeds to the placenta.

Maui! in the bogs on the top of Eeka.

3. V. robusta, sp. $n$. - Stem $3-5 \mathrm{ft}$. high, light-wooded, pale, nearly $1 / 2^{t}$ thick at the base, simple, or sparingly branching in the upper portion, the ascending branches hollow, herbaceous at the extremities, carrying many old and dry flowerstalks; the long persistent stipules dark, broadly lanceolate, long pointed, denticulate, nearly ${ }^{1} / 2^{\prime}$ long. Leaves membranous, puberulous underneath, ovate, acute, serrulate, $3-4^{1} / 2^{\prime} \times 1^{3} / 4-2^{1} / 2^{\prime}$, the truncate or cuneate base on a petiole of $1-1^{1 / 2}$. Flowers nodding, numerous (an inflorescence rising from nearly every axil), generally single, or $2-4$ irregularly disposed on a peduncle of very variable length, the pedicels $2^{\prime}$, bibracteolate about the middle, the bracts long subulate from a broad base, but often foliaceous. Sepals gibbous at the base, but not 
produced, narrow lanceolate, $3-4^{\prime \prime}$. Petals twice as long, pale purple, oblong, the lowest saccate, the 4 upper ones converging, assurgent. Anthers shortly apiculate, the 2 lowest with a narrow dorsal wing along their whole length which does not run out into a spur. Style as before. Capsule 8-10" long, with 8-14 pale seeds on each placenta.

Molokai! in boggy clearings on the heights of Kamato, $2500 \mathrm{ft}$. above the sea, also at Kalae. Remy's no. 532, with smaller, elliptjeo-oblong leaves, colleeted on Lanai, probably belongs here, as does also a plant collected on Kauai by Knudsen.

4. V. Chamissoniana, Gingins, in Linnaea, I, 408. - An upright, branching shrub, 3-5 ft. high, the woody, close-grained stem often ${ }^{1} / 2^{\prime}$ thick or more, the branches diffusely foliose. Stipules dark, scarious, 2-4", broadly deltoid, entire and long acuminate or glandular-dentate. Leaves on petioles of $1-2^{\prime}$, cordate, rarely the upper ones ovate, $3-6^{\prime} \times 1-2^{1} / 2^{\prime}$, dentate with appressed callous teeth, chartaceous, glabrous. Peduncles 1 or 2 to a branch, $1 / 2-1^{1 / 2^{\prime}}$ long, with 2 subulate bracts above the middle, single-flowered. Sepals narrow-lanceolate, $2-4^{\prime \prime}$, shortly pointed at the base. Petals pale purplish, twice as long and more, oblongspathulate, the lowest one deeply saccate. Anthers $1^{\prime \prime}$, with narrow connective and short but broad terminal appendage, the 2 lowest with a long and broad obtuse spur. Capsule $6^{\prime \prime}$, with 6-8 obovoid blackish seeds to each placenta. - Gray, 1. c. p. 86. - Walp. Repert. I, 216. Includes V. trachelifolia, Ging. 1. c. p. 409. - Dimorphism is indicated by the occasional occurrence of well developed diminutive flowers not exceeding $3^{\prime \prime}$ in length, with petals scarcely longer than the sepals.

On all islands at altitudes of 1000 to $3000 \mathrm{ft}$.

$\beta$ var. - Young shoots and inflorescence puberulous. Leaves serrate with uncinate teeth, puberulous underneath. Stipules large, $6^{\prime \prime}$. Flowers whitish.

Kauai! (Kn.).

5. V. helioscopia, $s p . n$. - An erect shrub, $2-3 \mathrm{ft}$. high, with few slender virgate branches foliose at the apex. Stipules deltoid-subulate, fringed with long glandular fimbria. Leaves coriaceous, glabrous, ovate, $1-1^{1} / 2^{\prime} \times 1^{\prime}$, acuminate, serrulate, the truncate base passing abruptly or cuneately into a petiole of $2-4^{\prime \prime}$. Peduncles generally 2 to a branch, ascending, $1^{1 / 2}-2^{4}$, long, each bearing a single large erect flower, and bibracteolate a short distance from the calyx. Sepals narrow lanceolate. $4^{\prime \prime}$, drawn out at the base into a short appendage. Petals 8-14", broad oblong or orbicular, on long claws, pure white, waxy, the lowest saccate. Anthers and style as before. Capsule $6^{\prime \prime}$. Seeds dark.

$\mathrm{Oahu}$ ! on dry open ridges of Makaha in the Waianae district. The large snow-white flowers which project beyond the foliage will recommend the plant for cultivation.

Hillebrand, Flora of the Hawaiian Islands. 


\section{ISODENDRION, Gray.}

Sepals equal, persistent. Petals nearly equal, linear-spathulate, the long claws erect and contiguous, the broader blades spreading, imbricate. Filaments short, distinct, the anthers connivent round the ovary, their connective neither spurred nor prolonged above. Style elongate, slightly curved and thickened near the apex, with anterior stigma. Capsule coriaceous, surrounded by the withered corolla, 3-valved, the placentas along the middle of the conduplicate valves, with $2-4$ seeds. Seeds horizontal, obovoid, with smooth crustaceous testa, and a broad circular umbonate chalaza at the free end. Embryo straight, in the middle of a farinaceous albumen and as long, with orbicular cotyledons, the terete radicle as long as these. - Shrubs, with entire leaves and persistent, rather intrapetiolar, keeled stipules. Flowers small, axillary, solitary, shortly pedicellate.

A Hawaiian genus, with a place in the system between Paypayrola, Aubl, and Alsodeia, Thouars, of which the former is exclasively American and the latter preponderatingly so, with a doubtful representative in the Viti Islands.

Leaves membranous, pubescent, ovate-oblong, small; stipules silkyhaired

1. I. pyrifolium.

Leaves chartaceous, glabrous, oblong, with cuneate base, large; stipules glabrous, triangular or lanceolate

\section{I. longifolium.}

Leaves chartaceous, glabrous, oblong, with rounded base; stipules glabrous, subulate.

3. I. laurifolium.

1. I. pyrifolium, Gray, Bot. U. S. E. Exp. p. 93, pl. 8. - A spreading shrub, 2-3 ft. long, the virgate branches with short branchlets, foliose near the apex and covered for some distance below with narrow lanceolate or subulate, silky-haired, converging stipules of $1^{1 / 2}-2^{\prime \prime}$ in length. Leaves membranous, pubescent when young, ovato- or ellipticooblong, obtuse, crenate, $1^{1 / 2}-2^{\prime} \times{ }^{3} / 4-1^{\prime}$, on petioles of $3-5^{\prime \prime}$. Pedicels single, $2-4$ ", pubescent, with a pair of rather broad scarious bractlets at the middle. Sepals connected at the base, $2^{1} / 2-3^{\prime \prime}$, lanceolate, silky, scarious with thin margins. Petals $5-6^{\prime \prime}$, rather thick, greenish-white. Stamens nearly half the length of the sepals, the anthers as long as the filaments. Style almost straight, of even height with the petals. Capsule $6^{\prime \prime}$, each placenta with $2-5$ obovoid pale seeds. - The flowers are sweet-scented.

In the scrub of the fore-hills and on open ridges. Oahu! in Waiande and on the siopes of Kaald; Lanai! Mani! Oloalu and Wailuku. The specimens from the latter regions, which I refer here, have larger leaves, $3^{\prime} \times 1^{1} / 2^{\prime}$, and agree with forms collected by Remy on Hawaii (no, 539) and on Niihau (no. 534). Nat. name: Aupakas.

2. I. longifolium, Gray, l. c. p. 95, pl. 9. - A glabrous shrub, $6 \mathrm{ft}$. high or more, with rather stout branches and scattering leaves. Stipules erect, triangular or lanceolate, $1^{1 / 2}-2^{\prime \prime}$. Leaves chartaceous, pale, shining, obovate-oblong, obtuse or shortly acuminate, gradually narrowing to the 
base, repandly crenate or subentire, $6-8^{\prime} \times 2-2^{1} / 2^{\prime}$, on short petioles of $1 / 4-1^{\prime}$. Flowers single, from short and thick bracteate spurs, the naked pedicel $1^{1 /} 2^{\prime \prime}$. Sepals $2^{\prime \prime}$, glabrous. Petals twice as long, strapshaped, scarcely dilated above, purplish-white. Stamens as before, the filaments curved. Capsule $3-5^{\prime \prime}$.

Oahu, Kaala (U. S. E. E.); Kauai! (Kn.).

3. I. laurifolium, Gray, l. c. p. 96. - Glabrous, the stipules subulate, brownish. Leaves oblong, acute, rounded at the base, repandly crenate 'or subentire, pale below, chartaceous, shining, $3^{1} 2^{i} \times 1^{\prime}$ ', on petioles of $1-2^{u}$. Flowers single, bibracteolate, on pedicels of $1-2^{\prime \prime}$, or the pedicels on bracteate spurs and naked. Petals expanded at the end into a roundish lamella.

Ridges of Wailupe! at the eastern end of $\mathrm{Oahu}$.

\section{Order VII. BIXACEAE.}

Flowers regular, hermaphrodite or unisexual. Sepals $2-6$, usually 4 or 5 , imbricate or rarely almost valvate in the bud. Petals as many or more, imbricate or twisted, or more frequently none. Stamens usually indefinite, rarely equal in number to the petals and alternate with them. Ovary 1-celled, or incompletely divided. Placentas 2-12, parietal, with several or many anatropous ovules to each. Styles or sessile stigmas as many as placentas, free, or combined into a single one. Fruit an indehiscent berry, or a capsule opening into as many valves as placentas. Seeds albuminous, with a straight or curved embryo in the axis. - Trees or shrubs. Leaves alternate, undivided, usually toothed. Stipules minute or none. Flowers axillary or lateral, rarely terminal.

Natives of the tropical and subtropical regions of the whole world.

\section{BIXA, L.}

Flowers hermaphrodite. Sepals 5, imbricate, deciduous, alternating with 5 exterior glands. Petals 5, large, contorted. Stamens indefinite, inserted on a thick torus; anthers oblong, opening at the apex by 2 short slits which unite in a single pore. Placentas 2, many-ovuled. Style elongate, recurved in the bud, with a 2-lobed stigma. Capsule 2-valved, with placentas in the middle of the valves and a soluble endocarp. Seeds obovoid, their loose, somewhat fleshy testa furrowed along the rhaphe. Cotyledons broad. - Small trees, with large entire palmato-nerved leaves, and showy pinkish flowers in terminal panicles.

Only 2 species, natives of tropical America.

†1. B. Orellana, L. - DC. Prod. I, 259. - A low tree, 10-12 ft. high. Leaves glabrous, cordate or ovate, acuminate. Capsule covered with setose prickles.

The Arnotto or Rocou tree, formeriy cultivated on account of the red dye which is gained by macerating the seed-pulp, now naturalized here and there on Ka uai and elsewhere. 


\section{XYLOSMA, Forst.}

Flowers dioecious. Sepals $4-5$, scale-like, distinct, or coherent at the base, imbricate. Petals none. Stamens indefinite, often surrounded by a glandular disk; anthers short, versatile. Ovary upon an annular disk, with $2-3-6$ few-ovuled parietal placentas. Style entire or more or less divided, or the stigma subsessile, peltately lobed. Berry small, 2-8seeded. Seeds obovoid, with a smooth crustaceous or coriaceous testa. Cotyedons broad. - Trees, often with axillary thorns. Leaves dentate or entire. Flowers in axillary fascicles or short racemes. - Myroxylon, Forst.

A genus of about 27 species, with the general range of the Order. Leaves entire; stigmas sessile, generally 3

1. X. Hawaiiense. Leaves crenate or sinuate, pitted; stigmas raised on astyle, generally 2 2. X. Hillebrandii.

1. X. Hawaiiense, Seem. in Fl. Vit. p. \%. - An unarmed tree, 20-30 ft. high, with stiff branches. Leaves distichous, on petioles of ${ }^{1} / 2^{\prime}$, ovate or rounded, $3-4^{\prime} \times 2^{1 / 2}-3^{\prime}$, shortly acuminate, entire, thick coriaceous, prominently reticulate, glabrous. Flowers small, greenish, about 8 in racemes of $4-6^{\prime \prime}$ in length, often several racemes from one gemma, the pedicels of about the same length, bracteolate below the middle. Male $f l$. Sepals 4 , connected at the base, ovate, obtuse, $1^{1 / 2}$, externally puberulous or glabrous, hairy inside, with eiliate margins. Stamens 2 or 3 times as long, on a raised torus and surrounded by a crenulate (glandular?) disk. Fem. $f$. Sepals 5, quincuncial. Ovary surrounded by a crenulate disk and some rudimentary stamens. Stigma sessile, peltately 3-(4-)lobed, the lobes reflexed. Placentas 3(-4), with 3 pendulous anatropous ovules to each. Berry dry, 4-6" long, ovoid. Seeds $2^{1} / 2^{\prime \prime}$. Embryo straight in copious albumen, but shorter, the radicle in elose proximity to the micropyle and shorter than the broad foliaceous cotyledons.

Oahu! Kauai! in forests up to $2000 \mathrm{ft}$. above the sea. Nat. name: "Maua*. - The fruit of the Kauai specimens has a 2-lobed stigma; Seemann found it 4-lobed in those eollected by Barclay on Oahu. - The species approaches very closely to $X$. orbiculatum, Forst., which is found in the Marquesas, Tonga and Viti Islds., the latter differing only in the clustered or corymbose inflorescence and the less deeply divided calyx.

2. X. Hillebrandii, Wawra, in Flora, 1873, p. 171. - A smaller tree. Leaves on petioles of ${ }^{1} / 2^{\prime}$, ovate-oblong, $2^{1 / 2}-4^{t} \times 1^{1 / 2}-3^{\prime}$, somewhat obtuse, or acute, contracted at the base or rounded, repandly crenate, even sinuate, the teeth tipped with a callous gland, membranous or chartaceous, distinctly pitted, glabrous and shining. Racemes puberulous, $6-9^{\prime \prime}$ long, with $10-12$ flowers on pedicels of $1-3^{\prime \prime}$, which are bracteolate above the base and articulate. Male $f l$. Sepals 4, broadly ovate or triangular, with a white pubescence on both faces, ciliate. Disk 4-lobed. Fem. fl. Sepals 4, occasionally 5. Stigma 2-lobed, on a short style. Placentas 
(2, rarely 3$)$ each with 3 pendulous ovules. Fruit globose, beaked with the permanent style.

Lanai! (sepals acute) Hawail! (sepals obtuse). This species differs from the Tahitian $X$. suaveolens exactly in the same manner as $X$. Hawaiiense does from $X$. orbiculatum. It does not appear, however, that the wood is sweet-scented.

\section{ORdER VIII. PITTOSPORACEAE.}

Sepals 4 or 5 , free or partially combined, imbricate in the bud. Petals as many, imbricate. Stamens as many, distinct, hypogynous, alternating with the petals. Ovary single, with 2 or more parietal placentas, or divided into as many cells by the meeting of the placentas in the axis. Ovules several to each placenta, anatropous. Style simple, with as many stigmas or stigmatic lobes as placentas. - Fruit a capsule or berry. Seeds often covered with pulp. Embryo minute, in fleshy albumen close to the hilum, the cotyledons short or indistinct. - Trees, shrubs or climbers, with alternate, mostly entire leaves and no stipules.

A small Order, chiefly Australian, with a few tropical or subtropical African and Asiatic species, represented in Polynesia by our genus only.

\section{PITTOSPORUM, Banks.}

Sepals 5, distinct, or united at the base. Petals 5, their claws erect and sometimes united. Filaments subulate; anthers erect, ovato-oblong, opening by two lateral slits. Ovary sessile or shortly stipitate, with 2 or rarely $3-5$ placentas or as many cells with 8 or more ovules to each. Stigma faintly lobed. Capsule opening into thick valves which bear the placentas along their middle. Seeds large, angular, smooth, black, with hard testa, covered with a resinous viscid pulp. - Evergreen shrubs or trees, the entire leaves often crowded in spurious whorls. Flowers in terminal or axillary racemes, panicles or clusters.

Natives of Africa and Atlantic islands, tropical Asia, Japan, Australia, New Zealand, Viti Islands, Tahiti and the Hawailan group.

The Hawaiian species have bivalvular capsules, distinet sepals, and the petals slightly cohering beyond their miadle, while their blades are reflexed or expanded in salver-shape. The flowers in all of them are dimorphous, that is, they are of two kinds: fertile or pistillate (with a fully developed round ovary, easily distinguishable from the style, which equals or exceeds the tube of the corolla and bears a capitate 2-lobed stigma, while the stamens are only about half the length of the tube, and their slender barren sagittate anthers converge around the ovary) and sterile or staminate (the corolla is generally larger, the slender ovary passes gradually into the style, which, although of the same length as in the fertile flowers, ends in a truncate or bidentate stigma, while the stamens are as long as the tube of the corolla, or even longer, and bear full-sized oblong anthers). With this dimorphism would seem to run parallel a diclinism in some species, inasmuch as individual trees are found with only fertile or sterile flowers. In species where both sexes are combined on one plant the sterile inflorescences mostly oceupy the apex or upper leaf-whoris, and the fertile ones the lower whorls or the bare branch; but there are species in which flowers of both sexes appear intermixed and without an appreciable difference in the size of the corollas. Furthermore, it may fairly be assumed that in a set of so closely related species the fertilization of which depends altogether on the concurrence of insects, bybrids will not be wanting. From all these cireumstances 
results a complexity of characters which renders the exact limitation of each species very difficult, and it is to be hoped that a closer attention to them by future collectors will result in a more satisfactory arrangement of a genus of plants which until now has shown itself very refractory in the hands of systematists.

A good principle of distribution may possibly be afforded by the capsules, which are either ovoid or subquadrangular and deeply wrinkled or furrowed, or compressed and smooth; but, as the mature fruits of many forms are not known yet, division can, for the present, not be based upon them. It happens, however, that the characters relied upon in the following synopsis, although apparently irrelevant, coincide to some extent with those afforded by the eapsules and also with the color of the flowers. - Hawaiian name of the genus: "Hoawa".

Inflorescence axillary or cauline:

Leaves glabrous; flowers white, the raceme generally pedunculate; seeds smooth: Flowers pedicellate:

Sepals ovate, $1 / 6-1 / 3$ the length of the corolla-tube : capsule smooth

Sepals lanceolate acute or subulate,.$^{1 / 2}$ the length of the corolla-tube or more; capsule rough:

Pedicels long $\left(6^{\prime \prime}\right)$, on long peduncles; leaves acuminate Pedicels short $\left(3^{\prime \prime}\right)$, on short peduneles; leaves rounded

Flowers sessile and glomerate at the end of a long peduncle

2. P. glabrum.

eaves tomentose, obtuse; flowers cream-colored, subsessile; seeds often rough at the back or notched:

Flowers small, in a sessile cluster; a shrub.

Flowers larger, on a distinct peduncle; a tree

Inflorescence terminal and in the axils of the last leaf-whorls:

Flowers subsessíle, on pedicels less than $2^{\prime \prime}$ :

Leaves pale strigose underneath; corolla short

Leaves ferruginous underneath or glabrate; corolla larger

Flowers on pedicels of $3-6^{\prime \prime}$ :

Corolla white, its tube $4-5$ times as long as the calyx

Corolla cream-colored, the tube twice as long as the calyx

1. P. acuminatum.

4. P. spathulatum.

3. P. glomeratum.

5. P. terminaloides.

6. $P$. cauliflorum.

1. P. acuminatum, Mann, Emum. no. 22. - A small tree, $15-20 \mathrm{ft}$. high, with slender branches, the youngest shoots pale-pubescent. Leaves thin chartaceous, glabrous, spathulate, shortly acuminate to acute, gradually merging in a short petiole, $4-6^{t}<1-1^{1} / 2^{t}$. Inflorescence axillary. Sterile fl. from the uppermost leaf-whorl, in corymbose racemes of $10-20$ " in length, or (in some specimens) on long foliose axes, with the flowers single in the axils of reduced leaves; pedicels $12^{\prime \prime}$, pubescent; bracts and sepals subulate, $3^{1} / 2^{\prime \prime}$; corolla white, with a tube of $5^{1} / 2^{\prime \prime}$ and long acute lobes. Fertile $f l$. from the lower whorls, on peduncles of $8^{\prime \prime}$, which bear flowers along their entire length; the subulate bracts $2^{\prime \prime}$; pedicels $4-6^{\prime \prime}$; sepals narrow lanceolate, acute, $2^{\prime \prime}$; tube of corolla $3^{1} / 2^{\prime \prime}$. Ovary tomentose with a brownish wool. Capsule subquadrate, deeply tuberculate or wrinkled.

Kauai! mountaius of Waimea (M. \& B., Wawra, Kn.). The male fl, are fragrant. It is barely possible that the specimens with sterile fl. (Kn. 207), in which the sepals are nearly twice the length of those in the fertile fl. (Kn, 60, M. \& B., and Wawra), represent a different variety, but the leaves are exactly alike in both.-On Molo k a I collected a suite of specimens which well agree with those from $\mathrm{Ka} u \mathrm{u}$. The fertile flowers, quite similar to those described above, stand in the second and third leaf-whorl, the immature capsules still lower or on the bare branch. These are ovato-quadrate and pointed, deeply runcinate or tubereulate, with pedicels of $6-9^{\prime \prime}$, on peduncles of variable length, $1^{1 / 2}-2^{1 / 2^{\prime}}$ in specimens from Kamalo and Mopulehu, but only ${ }^{1 / 2^{\prime}}$ in those from Halava. 
Of the form from this last locality I only hold twigs with advanced capsules similar to those from the other localities, bnt their leaves are larger, broader, somewhat obtuse, and of a dark brownish tinge when dry, not olivaceous as in the other forms; in all these respects like the leaves of $P$. insigne from W. Ma ui, of which I posses only sterile terminal flowers.

2. P. glabrum, Hook. \& Arn. in Bot. Beech. p. 110. - A small tree, $10-15 \mathrm{ft}$. high, glabrous throughout, the grayish pubescence of the young shoots soon deciduous. Leaves on slender branches, in loose whorls, chartaceous, spathulate or lanceolate, acuminate, gradually merging in a short petiole, $5-6^{\prime} \times 1^{\prime}$. Inflorescence quite glabrous, in axillary corymbose racemes of $6-12$ flowers, those of the sterile $\mathrm{fl}$. on the latest whorls near the apex, with an axis of $6-8^{\prime \prime}$, the fertile ones lower down, often cauline, with an axis of $3-6^{\prime \prime}$. Pedicels $3^{\prime \prime}$. Sepals $1 / 2-3 / 4^{\prime \prime}$, glabrous, obtuse. Corolla pure white, with a tube of $4^{1} / 2^{\prime \prime}$ in the staminate, of $3^{1} / 2^{\prime \prime}$ in the pistillate flowers. Ovary glabrous. Capsule at first ovoid and pointed, rather rough, but compressed at maturity with transverse shallow waves or wrinkles, the valves after dehiscence quite flat, about $1^{\prime}$ each way. Seeds black, shining, compressed, angular, smooth at the back, $2-3^{\prime \prime}$ broad. - Gray, Bot. U. S. E. E. p. 229. - Mann, Enum. no. 21.

Forests of Oahu! from Manoa to Ewa.

\& var. - Leaves somewhat larger. The nodding peduncle $\left(18^{\prime \prime}\right)$ and pedicels $\left(3-6^{\prime \prime}\right)$ covered with a pale pubescence. Sepals $1-1^{1 / 2} 2^{\prime \prime}$, ovate, obtuse or acuminate, pubescent but soon glabrate. Ovary tomentose. P. spathulatum, Mann, in part. - P. terminaloides, var. $\gamma$, Gray.

Oahu! Kaala range. A similar form with acuter and more tomentose sepals is common on Molokai!

3. P. glomeratum, sp. n. - A small tree with slender virgate branches, their leaf-whorls at intervals of $2-4^{\prime}$, the young shoots cinereouspubescent. Leares spathulate, elongate, $6-9^{\prime} \times 1-2^{1} / 4^{\prime}$, acuminate or obtuse, gradually narrowing into a petiole of $1^{\prime}$ or less, chartaceous, glabrous. Peduncles axillary, $1-1^{1} / 2^{\prime}$ long, bracteate, with a dense cluster of almost sessile flowers at the apex, pubescent, the lanceolate bracts $1^{1 / 2}-3^{n}$. Sepals ovate, obtuse, $1-1^{1 / 4^{\prime \prime}}$, tomentose. Corolla white, with a tube of 5 ". Ovary tomentose. Fertile fl. shorter on shorter peduncles. Capsule and seeds as in no. 2, the latter $4^{\prime \prime}$ broad, smooth at the back.

Eastern end of Oahu, Wailupe!

$\beta$ var. acutisepala. - Sepals and bracts narrow lanceolate, even subulate, the former $1 / 2$ the length of the corolla, the latter about $3^{\prime \prime}$. Sterile $f$. clustered at the ends of long bracteate peduncles, the fertile ones few, often single in the axils, with short pedicels on reduced peduncles of $1^{\prime \prime}$ or less.

Same region, Palolo to Niu! 
4. P. spathulatum, Mann, Enum. no. 20. - A taller tree than the preceding species, the stiff branches densely foliose, with leaves scattering or in close whorls. Leaves subcoriaceous, glabrous, cuneate or obovate, gradually narrowing from an obtuse or rounded apex into a short petiole, $3^{1 / 2}-5^{\prime} \times 1-1^{1 / 2^{\prime}}$. Inflorescence axillary, and similar for both sexes, faintly pubescent with dusky hairlets. Peduncle very short, 3-4", with $5-8$ flowers. Pedicels of same length. Sepals $2-2^{1} / 2^{\prime \prime}$, broadly ovate, acute, sparingly pubescent, or glabrate. Corolla white, with a tube of $4-5^{\prime \prime}$. Ovary faintly pubescent. Capsule subquadrangular, pointed, $12^{\prime \prime} \times 6-8^{\prime \prime}$, the suberiform epicarp deeply furrower or runcinate. Seeds as before.

$\mathrm{O}$ a hu! in forests between Kalihi and Ewa (Remy 572). Differs from var. $\beta$ of $P$. glabrum in the eapsule and the size of the tree. Mann's description applies to fertile flowers of the former, but as he included Remy's number his name may stand. Leaves as in the next species, but glabrous.

5. P. terminaloides, Planch. - Gray, Bot. U. S. E. Exp. p. 231. A stiff shrub, 6-10 ft. high, the young shoots eovered with a brick- or rust-colored tomentum. Leaves crowded near the ends of the branches, coriaceous, the upper side wrinkled with a close areolar network, the lower side woolly, but glahrate with age, obovate rounded or bluntly acuminate, gradually tapering into a short petiole, $3-4^{\prime} \times 1-1^{1 /} / 2^{\prime}$. Inflor. axillary or cauline, short, tomentose, the thick peduncle ${ }^{1 / 2}-1^{\prime \prime}$ long, the flowers almost sessile. No difference as regards sexes, fertile flowers being as often found near the end of the branch as on the bare stem. Sepals ovate, $1-2^{\prime \prime}$, tomentose. Corolla creamy, the tube short, $2^{1 / 2}-3^{\prime \prime}$, its lobes half as long. Ovary tomentose. Capsule tomentose, flattened, the valves $1^{\prime}$ high and equally broad, with a longitudinal median groove and transverse waves. Seeds rugose, dull. - Mann, Enum. no. 19.

Hawaii, coast of Puna, and Mauna Loa at an elevation of $7000 \mathrm{ft}$. (U. S. E. E.), Hualalai (M. \& B.); Lanai! A similar form from the low and dry hills of the east end of Oahu! Generally only one, or at most two eapsules mature in an inflorescence, and often appear sessile. The species is characteristic of the scrub below and above the forest zone.

6. P. caulifiorum, Mann, Enum. no. 18. - A tree, $30 \mathrm{ft}$. high, the trunk a foot in diameter, loosely branched. Leaves crowded at the ends of the stout and stiff branches, coriaceous, closely areolate above, elongateobovate or cuneate, $6-8^{\prime} \times 2-3^{\prime}$, ronnded or shortly apiculate, gradually narrowing into a petiole of ${ }^{1} / 2^{\prime}$, pale green, densely covered underneath with a soft fawn- or pale lemon-colored tomentum. Fertile fl. eauline on the bare branches below the leaves. Peduncle $2-4^{\prime \prime}$, bearing at the end $8-12$ subsessile flowers; bracts $2^{1} / 2^{\prime \prime}$; sepals $1^{1} / 2^{\prime \prime}$, ovate, obtuse, tomentose. Corolla cream-colored, with a tube of $4-5^{\mu}$. Stamens ${ }^{1 / 2}$ as long, with sagittate anthers. Ovary tomentose, the stigma capitate, 2-lobed. Capsule thick woody, the flattened valves with a median furrow and transverse waves, $14^{\prime \prime} \times 12^{\prime \prime}$, with the endocarp pale orange. Seeds 
flat angular, crenulate or tuberculate at the back and edges. - Hairlets flat, long-attenuate at both ends, 1 -celled, but much longer than in $P$. Kauaiense, and curled.

Oahu! Makaleha, Kaala range (M. \& B. 601, and Lydg.).

$\beta$ var. fulvum. - Tomentum of a deep yellow-brownish or golden color. Peduncle of fertile $\mathrm{fl}$. cauline, $4-10^{\prime \prime}$, bearing at the end a cluster of numerous subsessile flowers. Sepals ${ }^{1 / 2}-1^{\prime \prime}$. Tube of corolla $3^{\prime \prime}$. No capsule.

Oahu! Ewa to Waialua.

$\gamma$ var. - Leaves obovate-oblong, $4-6^{\prime} \times 2-2^{1} / 2^{\prime}$, obtuse or slightly acuminate, with a more distinct petiole of $1^{\prime}$, brownish-tomentose as in $\beta$, but strongly nerved underneath. Staminate fl. cauline in subsessile clusters. Sepals ovate, $2^{\prime \prime}$; tube of corolla $5^{\prime \prime}$. $-P$. terminaloides, var. $\beta$, Gray.

Oahu! Mt. Kaala, and Kauai (U. S. E. E.).

¿ var. flocculosum. - Leaves obovate-oblong, bluntly acuminate, the pale strigose pubescence in flakes or patches. Flowers of both sexes axillary or cauline, subsessile and crowded in close heads at the ends of peduncles of $1 / 2-1^{\prime}$. Bracts $2^{1 / 2}-3^{\prime \prime}$. Sepals $1^{1 / 2} 2^{\prime \prime}$, ovate, obtuse, tomentose. Corolla-tube $5-6^{\prime \prime}$ in the sterile and $4^{\prime \prime}$ in the fertile flowers. Ovary thickly tomentose.

Oahu! Kaala.

7. P. Kauaiense, $s p . n$. - A tree, $30 \mathrm{ft}$. high or more, with spreading branches, the young shoots pubescent with coarse strigose whitish hairlets. Leaves chartaceous, with prominent nerves, obovate-oblong, $6-10^{4} \times 2-3^{1} / 2^{2}$, shortly acuminate, with a distinct petiole of $1-1^{1 / 2^{2}}$, dark-green, pubescent underneath. Sterile fl. chiefly terminal, the fertile ones axillary or cauline, both in clusters. Axis of inflorescence short, $3-4^{\prime \prime}$, many-flowered, the linear bracts $2^{1 / 2^{\prime \prime}}$, the pedicels $1-1^{1 / 2^{u}}$. Sepals lanceolate acute, tomentose, $1^{\prime \prime}$. Corolla small in both sexes, the slender tube $2^{1} / 2-3^{1} / 2^{\prime \prime}$. Ovary tomentose. Closed capsules with apparently mature seeds small subglobose, about $6^{\text {" }}$ each way, with 4 deep longitudinal furrows, tomentose and roughish, but not tubereulate. Seeds few, 3-4" long, with smooth back. Flowers fragrant. Hairlets 1-celled.

Kauai! mountains of Waimea (Kn.). A singular form is Knndsen's no. 157, marked "stemless, with creeping branches". The latter are slender and straggiing, the leaves glabrate. It probably grew on the swampy high plateau, and offers an analogon to the varieties $\beta$ and $\varepsilon$ of Metrosideros polymorpha.

8. P. insigne, sp. n. - A tall shrub or tree, $10-20 \mathrm{ft}$. high, with stiff ascending branches. Leaves in distant whorls, thick chartaceous, brownish when dry, glabrous, obovate-oblong, acuminate, contracting into 
a short petiole, $3-4^{1} / 2^{\prime} \times 1^{1 / 4}-1^{3} / 4^{\prime}$. Flowers both terminal and axillary in the uppermost leaf-whorls, in dense corymbose racemes; the rhachis tomentose, surrounded at the base with numerous linear bracts of $3-4^{\prime \prime}$, and bearing 15-25 flowers on pedicels of $4^{\prime \prime}$. Sepals fulvo-tomentose, ovate, acuminate, $1-1^{1} / 2^{\prime \prime}$. Corolla white, with a tube of $6^{\prime \prime}$. Ovary tomentose.

West Maui! at elevations of $4000-6000 \mathrm{ft}$; ; very handsome species.

$\beta$ var. - Leaves glossy, paler. The corymbose racemes as densely and many-flowered as before, but those of the whorls raised on long bracteate peduncles of $2-4^{4}$. Sepals faintly pubescent, or glabrate. Ovary tomentose. Capsule less than $1^{\prime}$ high and broad, deeply wrinkled. Seeds compressed, smooth.

E. Maui! Hamakua (Lydg.).

9. P. confertiflorum, Gray, Bot. U. S. E. Exp. p. 232, pl. 19. - A tree, 20-30 ft. high, with stout and stiff branches. Leaves whorled near the ends of the branches, otherwise scattering, coriaceous, with prominent nerves, obovate-oblong, $3-7^{\prime} \times 1^{1 / 2}-2^{1} / 2^{\prime}$, shortly acuminate, contracting into a distinct petiole of $1^{\prime}$, pale fulvo-tomentose underneath. Inflorescence of both sexes terminal, the numerous flowers densely packed in a corymbose raceme with an axis of $6-12^{\prime \prime}$. Pedicels $3-6^{\prime \prime}$; bracts linear-oblong, $8^{\prime \prime}$. Sepals $3^{\prime \prime}$, broadly ovate, somewhat obtuse, tomentose. Corolla cream-colored, with a tube of $5-6^{\prime \prime}$. Ovary tomentose. Style short. Capsule globose-ovoid, somewhat flattened, the thick woody valves $1^{\prime}$ both ways, wrinkled and rough. Seeds tuberculate and crenate at the back. Flowers fragrant. - Mann, Enum. no. 17.

South side of Haleakala! Maui, at an elevation of $4000-5000 \mathrm{ft}$.

$\beta$ var. - Tomentum rust-colored. Leaves smaller. Inflorescence of both sexes terminal at first, but the fruiting ones axillary at last by the development of a terminal shoot. Sepals lanceolate.

Hawaii! Kau and Kona; Lanai (M. \& B. 337).

10. P. Hawaiiense, sp. n. - A small tree, $12-15 \mathrm{ft}$. high, sparingly branching. Leaves scattering or in distant whorls, large obovate-oblong, acute, $7-10^{\prime} \times 2-3^{\prime}$, suddenly contracting into petioles of $1-1^{1} / 2^{\prime}$, thick chartaceous, with prominent nerves, slightly tomentose underneath or glabrate, brownish when dry. Flowers subsessile and clustered on terminal and axillary or cauline peduncles of $4-8^{\prime \prime}$. Bracts ovate-lanceolate, $4^{\prime \prime}$. Sepals ovate, $1^{1 / 2}-2^{\prime \prime}$, glabrate or pubescent. Corolla cream-colored, with a tube of $3-4^{\prime \prime}$, the lobes slightly pubescent in the bud. Ovary tomentose. Capsule 1' high and broad, compressed, deeply rugose.

Forests of Kona and Kohala, Hawaii! A leaf-specimen picked in a gulch of the Kohala range has the largest leaves in the genus, $14^{\prime} \times 4^{\prime}$. 
$\beta$ var.? argenteum. - Leaves whitish underneath with a closely appressed tomentum. Inflorescences mostly in cauline whorls, subsessile, their axes $4-6^{\prime \prime}$, the pedicels $1-2^{\prime \prime}$. Sepals white-tomentose, $2^{\prime \prime}$. Tube of corolla $3^{\prime \prime}$. Ovary and young capsules whitish-tomentose.

Collected by Lydgate on the south side of Haleakala! Maui.

\section{ORDER IX. CARYOPHYLLACEAE.}

Sepals 4-5, persistent, free, or united into a toothed calyx. Petals as many, imbricate or contorted in the bud, sometimes minute or wanting. Stamens free, twice as many as the petals, or fewer, hypogynous or very slightly perigynous, filiform, the anthers 2-celled, opening lengthwise. Torus sometimes drawn out into a stalked gynophore supporting petals, stamens and ovary, or expanded into an annular disk which invests the calyx and continues between or outside the stamens in short glands or staminodia. Ovary free, 1-celled, or rarely at the base 2-5-celled. Ovules 2 to many, campylotropous, affixed to the bottom of the ovary or to a free central columella. Styles 2-5, stigmatose along their whole length, free, or united in part. Capsule 1-celled, opening at the top into as many or twice as many teeth or valves as there are styles. Embryo coiled or curved round mealy albumen. - Herbs or undershrubs, with opposite entire leaves. Stipules none, or small and scarious. Flowers in cymes, paniculate or corymbose.

A considerable Order, widely spread, chiefly over the temperate regions of the northern hemisphere.

Calyx tubular; petals, stamens and ovary raised on a gynophore . 1. Silene.

Sepals distinct, or nearly so; torus not elongate:

Petals wanting:

Sepals and staminodia 5; stamens free . . 2. Schiedea.

Sepals $4-5$; staminodia $8-10$; stamens connected at the base 3. Alsinidendron.

Petals present:

Stipules absent:

Petals bifid; capsule opening at the top into 10 teeth 4 . Cerastium.

Petals entire; capsule splitting to the base into 5 valves.5. Sagina.

Stipules present . . . . . . . . 6. Spergula.

\section{SILENE, L.}

Calyx 5-toothed, 10-or many-nerved. Petals, stamens and ovary raised on a gynophore. Petals 5, generally unguiculate, with an entire or bifid blade, which often bears 2 scales at the base. Stamens 10. Ovary 1-celled, with a central columella. Styles 3 , discreet. Capsule opening at the top into 6 or rarely 3 teeth or valves. Seeds tuberculate, affixed by marginal funicles. - Herbs or rarely undershrubs, with alternating pairs of opposite leaves, without stipules. Flowers solitary or cymose, often forming one-sided racemes or terminal panicles.

Over 200 species, spread over the temperate regions chiefly of the old World. 
Flowers in corymbose or paniculate eymes:

Leaves subulate

Leaves lanceolate:

1. S. struthioloides.

Petals exserted from the calyx:

Calyx campanulate; gynophore short; claws of petals included

Calyx elavate elongate; gynophore much longer; claws of petals protruding from the calyx

Petals enclosed in the calyx, very small Flowers in a simple raceme; a hispid annual
2. S. lanceolata.
3. S. Alexandri.
4. S. cryptopetala.
5. S. Gallica.

1. S. struthioloides, Gray, Bot. U. S. E. Exp. p. 109, pl. 10. - A much branching shrub, $1-3 \mathrm{ft}$. high, the branches woody and foliose to the top. Barren branches short, with crowded leaves, the fertile ones with internodes of $1 / 2-1^{\prime}$ and axillary shoots at every node. Leaves stiff subulate, at length recurved, $1 / 2-1^{1} / 2^{\prime}$ long, channelled above, clasping with a broad base, glabrous or faintly viscous-pubescent. Panicle elongate, sometimes subracemose, or even the flowers single in the axils of leaves, the foliaceous bracts subulate from a broad base. Pedicels $3-4^{\prime \prime}$, the lateral ones bibracteolate at the middle. Calyx $6-8^{\prime \prime}$, thin, tubular, clavate at last, 5-toothed, faintly 10-nerved. Gynophore 3". Claws of petals scarcely exserted, the oblong blades $3^{n}$, bifid, with 2 oblong scales at the base. Capsule 5", more or less exserted, 1-chambered below, opening into 6 small teeth. Seeds rough-pubescent.

Mauna Loa, Mauna Kea and Hualalai, Hawaii; Haleakala, Maui! at elevations of $5000-9000 \mathrm{ft}$. In the Maui plants the branch passes gradually into the inflorescence, while in those from $\mathrm{Ha}$ waii the two are rather distinct.

2. S. lanceolata, Gray, l. c. p. 111, pl 10. - Suffruticose, erect, $1-1^{1 / 2} \mathrm{ft}$. high, woody below, glabrous, the leaves crowded above, but the internodes lengthening to $1^{\prime}$ or more as the axis passes into the corymb. Leaves chartaceous, ciliate near the base, 1-nerved, lanceolate, $2-2^{1} / 2^{\prime}$ $\times 3-6 "$, acuminate at both ends, on short petioles. Inflorescence a terminal corymb, 5-6' long, with small lanceolate bracts; pedicels $4^{\prime \prime}$, bracteolate below the middle. Calyx campanulate, $4^{\prime \prime}$, ovoid with fruit, 5-toothed, 10-nerved. Petals dingy-white, their claws not exserted beyond the calyx, the cuneate blade $3^{\prime \prime}$, emarginate, with 2 small scales at the base. Stamens enclosed, the 5 opposite the petals adnate with their bases. Gynophore 1-1 $1 / 2^{\prime \prime}$. Capsule not exserted, 3-chambered below, opening into 6 teeth, 3 slits extending deeper than the others. Seeds reniform, muricate.

Kauai and Maui (U. S. E. E.); Central Plateau of Hawail! (Hbd.); Lanai! (Lydg.); at elevations of $300-500 \mathrm{ft}$.

$\beta$ var, angustifolia. - Leaves linear, $1^{\prime \prime}$ broad.

3. S. Alexandri, sp. n. - Habit, size and leaves of the preceding species. Inflorescence subpaniculate, less compound, with linear or subulate bracts. Pedicels $9^{\prime \prime}$, bracteolate below the middle. Calyx long clavate, $9^{\prime \prime}$. Gynophore very long, $6-7^{\prime \prime}$. Claws of petals and stamens 
exserted to about 3 " beyond the calyx. Capsule 3-chambered below, entirely protruded beyond the calyx when mature.

Molokai! Kamalo, about $2000 \mathrm{ft}$, above the sea.

4. S. cryptopetala, $s p . n$. - Subherbaceous, decumbent, the elongate stems or branches $1-2 \mathrm{ft}$. long, distantly foliose, with internodes of $2^{1 / 2}-4^{\prime}$. Leaves glabrous, linear-lanceolate, $3-4^{\prime} \times 3-5^{\prime \prime}$, acute at both ends, 1-nerved, very shortly petiolate. Cymes axillary, subpaniculate, rather dense, with foliaceous bracts, the peduncle 6 ", the pedicels $2-3$ ", the whole inflorescence often forming a long thyrsoid panicle. Calyx viscopuberulous, $3 "$, clavate, 10-nerved, very shortly 5 -toothed at the contracted mouth. Corolla and stamens included in the calyx, the petals pale, obovate-oblong, slightly and obtusely emarginate, scarcely more than $1^{\prime \prime}$ long, without claws or scales, on a gynophore of about $11^{1 / 2}$. Stamens 10 , as long as the petals, the alternate ones shorter; anthers ovoid, obtuse, bifid at the base. Styles 3 , very short, $1 / 4-1 / 3^{\prime \prime}$. Capsule coriaceous, ovoid, $5^{\prime \prime}$ long, on a gynophore of $4-5^{\prime \prime}$, opening into 6 obtuse teeth, with 3 slits deeper than the others. Seeds reniform, tuberculate-aculeate.

Maui! Haleakala (Lydg.).

$\dagger 5$. S. Gallica, L. - DC. Prod. I, 3r1. - An annual, ${ }^{1 / 2-1} \mathrm{ft}$. high, erect, hirsute. Leaves obovate-oblong, $1-1^{1} / 2^{\prime}$ long, mucronate, subsessile, the upper ones spathulate, feather-veined. Inflorescence a terminal raceme, the flowers single in the axils of bracteiform leaves, on pedicels of $1-2^{\prime \prime}$. Calyx 4-5", tubular, at length ovoid, 10-nerved, with 5 subulate teeth,

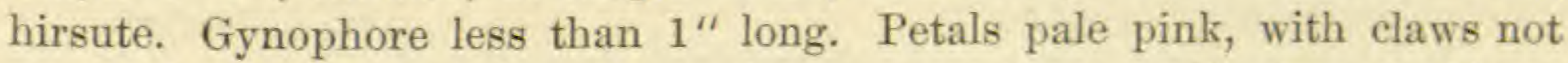
exserted, the blades obovate, entire or emarginate, with 2 or 3 oblong emarginate scales of half their length. Filaments hispid. Styles very short. Capsule 3-chambered below.

Northern slope of Kaala! Oahu; Waimea! Kauai. A weed from southern Europe.

\section{SCHIEDEA, Cham. \& Schlecht.}

Sepals 5, imbricate. Petals none. Staminodia 5, hyaline, opposite the petals. Stamens 10 , the 5 opposite the sepals adhering to the base of the staminodia; anthers short oblong, versatile. Ovary 1 -celled, the numerous ovules affixed to a short central placenta. Styles 3, or less commonly 4, 5, 7 or 10, filiform, stigmatose all round at the clavate apices. Capsule opening into as many valves as there are styles. Seeds reniform or orbicular, subglobose or laterally compressed, with a coriaceous, generally rugose or muricate testa. Embryo annular, surrounding a mealy albumen. - Undershrubs or perennial herbs, with opposite entire leaves and clasping petioles. Stipules none. Flowers in paniculate, open or contracted, rarely in simple or corymbose cymes. 
An exclusively Hawaiian genus. The rhachis and rays of even the largest panicles end in a cymose trichotomy, the lateral branches of the terminal cyme again repeatedly trichotomous in the most developed forms. The two last species, with large flowers and short and broad scale-like staminodia, lead into the following genus.

Flowers small, in panicles; sepals narrow; staminodia linear or lanceolate; stamens filiform; (Euschiedea, Mann):

Leaves 1-nerved or costate:

Panicle large, with long spreading filiform subhorizontal rays :

Staminodia linear, bidentate or bifid:

Seeds rugose or muricate:

Leaves broad, obovate-oblong, somewhat obtuse, subsessile; stem short

Leaves lanceolate or oblong, acuminate at both ends; stem elongate

Seeds smooth; flowers larger

Staminodia linear, entire:

Leaves ovate or ovate-oblong ; panicle clammy-pubescent

Leaves linear-oblong, clasping with a broad auriculate base.

Leaves linear-spathulate or euneate, tapering into a short petiole.

\section{S. Kaalae.}

1. S. Nuttallii.

2. S. diffusa.

3. S. pubescens.

6. S. amplexicaulis.

5. S. stellarioides.

Panicle short, not exceeding 6 inches, but open, with suberect short branches; staminodia linear, entire:

Leaves broadly oblong or ovate

7. S. Hawaiiensis.

Leaves narrow-lanceolate or linear.

8. S. salicaria.

Panicle contracted and interrupted, thyrsoid; staminodia about $1 / 2$ the length of the sepals:

Thyrsus rather open, of $3-5$ pairs of contracted cymes :

Leaves narrow-lanceolate

Leaves linear or filiform, with axillary leaf-shoots

Thyrsus of 1 or 2 dense glomerules; filaments not exserted; leaves linear-lanceolate

Leaves $3-5$-nerved:

Panicle open, with long filiform horizontally spreading rays;

leaves narrow-lanceolate

Panicle open, but shorter, with suberect rays; leaves broad

elliptico-oblong

12. S. Hookeri.

Panicle contracted, thyrsoid:

Glomerules or pairs of cymes 1 or 2 ; staminodia and stamens

$1 / 2$ the length of the sepals; leaves obovate-lanceolate 14. S. globosa.

Glomerules or pairs of eymes generally 2 or 3 ; staminodia and stamens as long as the sepals, or longer; leaves linear or lanceolate

9. S. ligustrina.

10. S. spergutinat.

11. S. Remyi.

13. S. Lydgatei.

15. S, Menziesii.

Flowers large, in simple or compound corymbose cymes; sepals

broad, overlapping; staminodia short and broad; filaments complanate, euclosed; leaves 3-5-nerved; (Nothosehiedea, Mann):

Leaves elliptico-oblong, 3-nerved; eymes 3-9-flowered

Leaves broadly ovate, 5-nerved; cymes many-flowered

16. S. viscosa.

17. S. Tychnoides.

1. S. Nuttallii, Hook. Ic. Pl. tab. 649, 650. - Suffrutescent, $2-4$ ft. long, branching near the base, the branches straggling, distantly foliose, glabrous throughout. Leaves chartaceous, oblong, $3-4^{\prime} \times 3 / 4-1^{\prime}$, on petioles of $1-3^{\prime \prime}$, acuminate at both ends or rarely somewhat rounded at the base, pale, smooth, 1-nerved or costate with veins effaced, the margins reflexed. Panicle ample and spreading, glabrons, ${ }^{1 / 2}-1^{1 / 4} \mathrm{ft}$. long, the rhachis with $4-6$ nodes, the lowest internodes $3-2^{\prime}$ long, the lowest 
rays $6-12^{\prime}$, most branches dividing from the base, with the lowest branchlets deflected. Median pedicels 4-5"; bractlets short subulate. Sepals $1^{1 / 2}$ ", narrow lanceolate, acute, glabrous, green, with scarious edges. Staminodia nearly as long, linear from an orbicular base, bifid. Stamens exserted, filiform. Styles 3, long exserted. Capsule generally not exceeding the sepals. Seeds few, subcompressed, much curved, transversely muricate or rugose. - Walp. Repert. V, 789. - Gray, Bot. U. S. E. E. p. 137. - Mann, Fl. Haw. Islds. p. 16. - Eucladus suffruticosus, Nutt. in herb. Hook. - S. Oahuensis, Wawra.

Oahu! from Niu to Kaala; Molokai! Stem short, leaves thin and crowded; paniele stramineous: capsules mostly exserted. Ka uai! leaves obovate-oblong; panicle smaller, with fewer divisions, the flowers larger, approaching those of $S$. diffusa; immature seeds only rugose.

B var. implexa. - Leaves narrow-lanceolate, acute at both ends. Panicle short, with filiform rays spreading in every direction, the median pedicels $6-9^{\prime \prime}$. Capsule elliptical, almost twice as long as the calyx.

East and West Maui! In W. Maui specimens the branches of the panicle are hispid with short whitish, not glandular hairlets.

$\gamma$ var. intermedia. - Subherbaceous, about $1^{1 / 2} \mathrm{ft}$. long, dichotomously branching. Leaves ovate-lanceolate, thin and dull. Panicle short, about $6^{\prime}$ long, quite open, the rays not dividing at the base, rather few-flowered. Sepals and capsules $2^{\prime \prime}$. Seeds tuberculate.

Western end of Molokai! Habit of S. diffusa, but the seeds not smooth.

2. S. diffusa, Gray, Bot. U. S. E. Exp. p. 138, pl. 11. - Subherbaceous, the stems $1-1^{1 / 2} \mathrm{ft}$. long, quite glabrous. Leaves thin membranous, pale, oblong or lanceolate, $2-4^{\prime} \times{ }^{3 / 4}-1^{1} / 4^{\prime}$, on petioles of $2-3^{\prime \prime}$, acute, contracting or rounded at the base, 1-nerved, with evanescent veins, Panicle $6-12^{\prime}$ long, with $6-7$ pairs of spreading rays, the rays faintly pubertulous or glabrate, sparingly divided and few-flowered, the median pedicels $12-18^{\prime \prime}$ long. Bracts setaceous, those of the main rhachis sometimes foliaceous. Sepals $2-3$ ", ovate, actue, prominently several-nerved at the base. Staminodia gradually contracting from a broad base, linear, bifid. Capsule not exceeding the calyx, 3-5-valved. Seeds numerous, smooth.

H a wa ii! forests of Kohala, Mauna Kea and Mauna Loa; West Ma ui! flowers smaller.

3. S. pubescens, sp. $n$. - Suffrutescent, the straggling stems several feet long, purplish. Leaves distant, broadly ovate or ovate-oblong, 1-nerved, $2-4^{1} / 2^{\prime} \times 1^{1}{ }^{4}-2^{1 /} / 2^{\prime}$, on petioles of $4-12^{\prime \prime}$, somewhat obtuse, mucronate, thick chartaceous, dark green and dull. Panicle very large, occasionally reaching $5 \mathrm{ft}$., foliose along the main rhachis, with $6-10$ nodes, clammypuberulous throughout, the internodes $8-6^{\prime}$, the lowest rays $12-18^{\prime}$. Median pedicels $4-7^{\prime \prime}$. Bracts linear-lanceolate, $1-1^{1} / 2^{\prime \prime}$. Sepals $1^{1} / 2^{\prime \prime}$, puberulous, caudato-acuminate, purplish. Staminodia nearly as long, filiform entire from an orbicular or deltoid base. Styles 3-4, long exserted, as 
are the stamens. Capsule as long as the sepals. Seeds transversely rugose. - S. Nuttallii, Gray, in part.

East and West Maui! Hamakua, Waihee, Kaanapali.

$\beta$ var. - Leaves ovate-lanceolate, acute.

Molokai!

\% var. - Leaves ovate-lanceolate, acute, thicker and dusky-purple, as is the entire panicle.

Oahu! Mt. Kaala.

4. S. Kaalae, Wawra, in Flora, 1873, p. 175. - Stem short and tortuous, $3-6^{\prime}$ long, woody below, with crowded leaves. Leaves glabrous, spathulate or obovate-oblong, $6-10^{\prime} \times 1^{1 / 2}-2^{1 / 2^{\prime}}$, subsessile, somewhat obtuse, shortly acuminate or mucronate, gradually narrowing toward the base, pale, thick chartaceous, rather fleshy, distinctly feather-veined, the ultimate veinlets ending free in the meshes of an areolar network. Panicle stramineous when dry, quite loose and open, $1^{1 / 2}-2 \mathrm{ft}$. long, with $4-5$ nodes only, the lowest internode $6-10^{\prime}$, the lowest rays $9-12^{\prime \prime}$. Median pedicels $6 "$. Bracts subulate, $2^{\prime \prime}$. Sepals $2^{\prime \prime}$, narrow-lanceolate. Staminodia nearly as long, linear from a suborbicular base, bifid. Stamens long exserted. Styles 3-4. Capsule not exserted. Seeds transversely rugose. - S. plantaginea, Hbd. in herb.

Oahu! IIt. Kaala. Inaptly compared by Wawra with $S$. Remyi, a speeies which he does not seem to have known, for no two species could be more unlike.

5. S. stellarioides, Mann, Enum. no. 28; Fl. Haw. Islds. p. 16. - Suffruticose, prostrate, several ft. long, much branched. Leaves linear or linearspathulate, $1^{1 / 2}-1^{3 / 4^{\prime}} \times 1-2^{\prime \prime}$, acuminate or obtuse and mucronate, 1-nerved, tapering into a very short petiole, ciliate-pubescent along the margins, the hairlets longest near the base. Panicle open and loose, $6-10^{\prime}$ long, the lowest internodes $2^{\prime}$, the lowest rays $3-5^{\prime}$. Pedicels $6^{\prime \prime}$, puberulous. Bractlets $1^{1 / 2} 2^{\prime \prime}$. Sepals $2^{\prime \prime}$, lanceolate acute, puberulous. Staminodia little shorter, linear-lanceolate from a broad base, entire. Stamens scarcely exserted. Styles 3. Capsule as long as the calyx. Seeds few, rugulose.

Kauai! mountains of Waimea (M. \& B. 595, and Kn. 53).

$\beta$ var. - Leaves spathulate or obovate, ${ }^{3} / 4-1^{\prime} \times 3-4^{\prime \prime}$, broadly rounded and mucronate at the apex, thence suddenly narrowing into a slender margined petiole, ciliolate at the base and in the axils. Sepals and staminodia as above.

Same region (Kn. 52).

6. S. amplexicaulis, Mann, Enum. no. 27; Fl. Haw. Islds. p. 16. Suffruticose. Leaves linear-oblong, with a broad auriculate and clasping base, 1-nerved, obtuse, mucronate, $2^{\prime} \times 5-6^{\prime \prime}$. Panicle open and diffusely spreading, about $1 \mathrm{ft}$. long, its younger portions and the calyx minutely hirsute. Pedicels capillary, $4-8^{\prime \prime}$. Sepals $2^{\prime \prime}$, ovate-lanceolate, with 
scarious fibrillose margins. Staminodia lanceolate entire. Stamens not exserted. Capsule 3-valved, nearly equalling the calyx, few-seeded. Seeds smooth. (Descr. according to Mann).

Niihau (or Kauai). Only collected by Remy (548).

7. S. Hawaiiensis, sp. $n$. - Stem weak, decumbent, rather herbaceous, about $1 \mathrm{ft}$. long. Leaves oblong and mucronate or ovate, $1-1^{1} / 2^{\prime} \times 6-8^{\prime \prime}$, membrano-chartaceous, 1-nerved. Panicle open and short, 2-4' long, with $3-5$ nodes, the rays elongate, branching from the middle, fewflowered. Bracts short, linear. Sepals $2^{\prime \prime}$ long, shorter than their pedicels, ovate-lanceolate, long-acuminate, scarcely puberulous. Staminodes linear entire from a broad ovate base, somewhat shorter than the sepals. Capsule 3-4-valved, shorter than the calyx. Seeds tuberculate.

Hawaii! Waimea (Lydg.).

8. S. salicaria, sp. $n$. - Erect, suffruticose, $1-2 \mathrm{ft}$. high, sparingly branched, distantly foliose, with internodes of $1-{ }^{1} / 2^{\prime}$. Leaves narrow lanceolate, $2-3^{\prime} \times 2-4^{\prime \prime}$, very acute at both ends, with a subulate point, chartaceous, pale, with a transparent costa. Panicle short, but open and continuous, $3-4^{\prime}$ long, with $4-5$ nodes, the lowest rays about $2^{\prime}$ long, dividing from the middle, the pedicels $4-6^{\prime \prime}$, the acute and scarious bracts $2-1$ ". Sepals 2", lanceolate-acute and strigose. Staminodia nearly as long, linear, entire. Stamens shortly exserted. Capsule 3-5-valved, about as long as the sepals. Seeds transversely rugose.

W. Maui! Gulches back of Lahaina and Oloalu (a form with narrow linear leaves of thicker texture, with revolute margins, the two lowest veins running parallel with the midrib and rather prominent), Maalaea.

9. S. ligustrina, Cham. \& Schl. in Linnaea, I, 46. - Suffrutescent, erect, dichotomously branching, $1-2 \mathrm{ft}$. high, with internodes of $3 / 4-1 / 2^{\prime}$. Leaves narrow lanceolate, $1^{1 / 2-2} \times 2-3^{\prime \prime}$, acuminate at both ends, with thickish or revolute margins, subsessile, or the short petioles margined, membranous, glabrous, costate with indistinct pinnate veins. Panicle contracted and rather interrupted, 2-4' long, with $4-5$ nodes, the lowest rays $1-2^{\prime}$, ascending, glabrous, dividing from the base. Pedicels $1^{1 / 2} "$. Sepals occasionally 4 or 6 , ovate, obtuse, obsoletely 3 -nerved, $1^{1 / 2}-2^{\prime \prime}$ long. Staminodia half as long, lanceolate, with 2 subulate points. Stamens exserted. Styles 3 or 4. Capsule exceeding the calyx. Seeds muricate. - Fenzl, in Endlicher, Atakta Bot. tab. 14, and in Ann. Wien. Mus. II, 273. - Portulacacea, Hook. \& Arn. in Bot. Beech. p. 188. - Gray, 1. c. p. 133. - Mann, Fl. Haw. Islds. p. 17.

Oahu! Kaala range and Waianae, on dry fore-hills.

10. S. spergulina, Gray, l. c. p. 135, pl. 11. - Ereet, 1-2 ft. high, shrubby at the base, much branched and very foliose, with internodes Hillebrand, Flora of the Hawaiian Islands. 
of $1-^{1} / 4^{d}$, and leaf-fascicles in most axillas. Leaves spreading, filiform, $2^{\prime} \times 1 / 2^{\prime \prime}, 1$-nerved, channelled above, mucronate. Panicle contracted and interrupted, thyrsoid, consisting of 3-5 short fascicles or glomerules, the lowest rays $1-3 / 4^{\prime}$ long, supported by leaf-like bracts; the bractlets short ovate-subulate. Pedicels 1-2". Sepals 1", ovate, obtuse, pubescent, nearly nerveless. Staminodia nearly as long, linear-subulate from a thickened base. Stamens exserted. Styles 3. Capsule a little longer than the calyx. Seeds minute, almost smooth. - Some flowers tetramerous and octandrous. (Descr. according to Gray).

K a uai! Waimea (U. S. E. E.). - M. \& B.'s no. 342, collected on Lanai, belongs to S. Menziesii.

11. S. Remyi, Mann, Enum. no. 33; Fl. Haw. Islds. p. 18. - Subherbaceous, low, $1 / 2-1 \mathrm{ft}$. high, the short nodose and naked stems prostrate, with branches ascending, these densely foliose below, with axillary fascicles, suddenly passing into scapes of $3-6^{4}$ in length, which bear only 1-3 distant pairs of leaves and a dense globose head of flowers at the end, mostly with another smaller one at the next lower node at a distance of $1-2^{\prime}$. Leaves linear-lanceolate, $2-3^{\prime} \times 1-3^{\prime \prime}$, acute, broadly sessile and clasping, 1-nerved, membranous, glabrate. The terminal glomerule, ${ }^{3 / 4}-1^{1 /} / 4^{t}$ in diam., consists of 2 or 3 closely approximate nodes, the short cymes dividing from near the base, the pubescent pedicels $1-3^{\prime \prime}$. Sepals $2^{\prime \prime}$, pubescent, ovate, blunt, thin, nerveless, soon withering. Staminodia ligulate, ${ }^{1 / 2}$ as long as the sepals, truncate or bifid, not dilated at the base. Stamens scarely exserted. Styles oftener 4 than 3 or 5. Capsule not exserted. Seeds numerous, transversely rugose (almost smooth according to Mann).

Molokai! Waikolu, Kaluaaha, near the seashore; Oahu! Waimanalo (the glomerules looser, more open and fewer-flowered).

12. S. Hookeri, Gray, 7. c. p. 133. - Weak, decumbent, 1-2 ft. high, distantly foliose, most branches ending in a panicle. Leaves membranous, narrow lanceolate, $1^{1 / 2}-2^{1} / 2^{\prime} \times 3-6^{\prime \prime}$, acute at both ends, with a petiole of $1-2^{\prime \prime}$, 3-nerved, glabrous. Panicle open, $4-8^{\prime}$ long, with $4-6$ pairs of filiform, horizontally spreading, inultibracteate rays, often dividing near the base. Bracts lanceolate, gradually diminishing from 6 " below to $2^{\prime \prime}$ at the extremities. Pedicels and sepals puberulous, the former $4-6^{\prime \prime}$, the latter $2^{\prime \prime}$, narrow lanceolate. Staminodia longer than the sepals, linear, bifid, dilated at the base. Stamens slightly exserted. Styles 3. Capsule as long as sepals. Seeds almost smooth, - L. ligustrina, Hook. Ic. Pl. fol. 649, adnot.

Oahu! Kaala range, Makaha and Makateha.

13. S. Lydgatei, $s p . n$. - Erect, subherbaceous, $3 / 4-1^{1 / 2} \mathrm{ft}$. high, brownish when dry, distantly foliose, with internodes of $1-2^{4}$. Leaves 
elliptico-oblong, broadest at the middle, almost rhomboidal, $1-1^{1} / 2^{\prime} \times 6-8^{\prime \prime}$, shortly acuminate, suddenly contracting into a margined petiole of $2-3^{\prime \prime}$, fleshy-membranous, glabrous, dull, faintly 3-nerved, the lowest lateral veins converging with the costa at the apex. Panicle open and continuous, $4-6^{\prime}$ long, with $3-4$ pairs of suberect rays, the lowest $1-2^{\prime}$, dividing at the middle. Bractlets ovate, acute, $1^{\prime \prime}$. Pedicels $4^{\prime \prime}$. Sepals ovatelanceolate, 3-nerved, $2^{1 / 2^{\prime \prime}}$, ciliate. Staminodia about as Iong, linear from a roundish base, bifid. Stamens little exserted. Styles 3, seldom 4. Capsule as long as sepals. Seeds transversely rugose.

Molokai! Kalawao, near the seashore. Excepting the leaves, like S. salicaria.

14. S. globosa, Mann, Enum. no. 34; Fl. Haw. Islds. p. 18. - Low herbaceous, hoary-pubescent in the upper portions of the stem and inflorescence, otherwise glabrous, the simple branches rising from the base, $1 / 2-1 \mathrm{ft}$. high, with $4-5$ pairs of leaves. Lower leaves obovate-lanceolate from a narrow sessile base, rather fleshy, $4^{\prime} \times 1^{\prime}$, or less, 3-5-nerved, the upper ones reduced to subulate foliaceous 3 -nerved bracts of $9^{\prime \prime} \times 11^{1 / 2}$. Flowers in a terminal compact head of $1^{\prime}$ in diameter, sometimes with a second pair of globose cymes at the next lower node. Sepals ovateobtuse, $1^{1 / 2} 2^{\prime}$, nerved below the middle, shorter than the 4-valved capsule. Staminodia $1 / 2$ or $1 / 3$ as long, entire, obtuse. Stamens as short. Seeds few, larger than in the other species, tubereulate (Descr. according to Mann).

Oahu, near Koko Head (M. \& B. 580, Remy 552).

15. S. Menziesii, Hook. Ic. Pl. fol. 649, adnot. - Straggling, 1--3 ft. long, woody at the base, the branches hispid, densely foliose below, soon passing into a rather naked few-leaved scape. Leaves linear, $1^{1 / 2}-2^{\prime} \times 1-2^{\prime \prime}$, acuminate at both ends, or subsessile with clasping base, membranous, prominently 3-(5-)nerved. Panicle pubescent, contracted, thyrsoid, consisting of 2 or 3 , rarely 1 or 4 glomerules of less than $1^{\prime}$ in diam., or of pairs of globose cymes at distances of $1 / 2-1^{1 / 2} 2^{\prime}$, the terminal globule made up of $2-3$ nodes. Pedicels $1-2^{\prime \prime}$. Sepals pubescent, $2^{1 / 2}$ ", lanceolate, bluntish, faintly 1-nerved. Staminodia as long or longer, linear, bifid, dilated at the base. Stamens exserted. Styles 3. Capsule as long as the calyx. Seeds transversely rugose.

Lanai! W, Maui! (leaves pubescent underneath). In the open scrub of the forehills. The glomerate cymes are neither so large nor so dense as in S. Remyi.

$\beta$ var. spergulacea. - Leaves filiform, less than $1^{\prime \prime}$ broad, but distinctly 3-nerved, and pubescent, often with axillary shoots. Cymes as in $\alpha$.

Lanai! (M. \& B. 342).

Cymes more open, with pedicels of $2-3^{\prime \prime}$, and few-flowered.

W. Maui! Differs from $S$. spergulina only in the 3-nerved leaves. 
16. S. viscosa, Mann, Enum. no. 35; Fl. Haw. Islds. p. 18. - Suffruticose, decumbent and spreading, with branches $2-3 \mathrm{ft}$. long, the internodes $1-2^{1} / 2^{\prime}$, the whole plant, especially the inflorescence, covered with a viscous pubescence. Leaves elliptico-oblong, $1^{1 / 2}-2^{\prime} \times 1 / 3-1 / 2^{\prime}$, acute, the base contracted into a short petiole, 3-nerved, membranous, the upper face glabrate with age. Flowers in cymes of $3-9$, at the ends of short lateral "branches, with leaf-like bracts. Pedicels $4-6$ ". Sepals ovate-oblong, $4-6^{\prime \prime} \times 2^{\prime \prime}$, much overlapping ( 1 being internal and 1 external in the bud), bluntish, thin, many-nerved. Staminodia short and broad, scale-like, bicuspidate, ${ }^{1 / 4}$ the length of the sepals. Stamens ${ }^{1 / 3}$ shorter than the sepals with complanate filaments. Styles $5-7$, stigmatose all round in the upper half or third. Capsule ovoid, 4", enclosed by the connivent sepals. Seeds numerous, compressed, smooth (tuberculate according to Mann).

Kauai! mountains above Waimea, Halemanu (M. \& B. 579, Kn. 79).

17. S. lychnoides, sp. $n$. - Habit of the preceding species, but larger and stouter, visco-pubescent. Leaves broadly ovate, $1^{1 / 2}-2^{\prime} \times 1-1^{1 / 4^{\prime}}$, acuminate or mucronate, rounded at the base or suddenly contracting into a petiole of $1-2^{\prime \prime}, 5$-nerved, chartaceous, glabrate with age. Flowers $18-21$, in compound cymes with foliaceous bracts, on lateral branches of $6-10^{\prime}$. Pedicels $6-7{ }^{\prime \prime}$. Sepals overlapping as before, obovate, $6^{\mu \prime} \times 3-4^{\prime \prime}$, thin, many nerved, obtuse or rounded. Staminodia $1 / 3-^{-1 / 4}$ the size of the sepals, almost as broad as high, bi- or tri-cuspid, the one opposite the largest sepal with 3 points. Stamens $1 / 3$ shorter than the sepals, the anthers affixed near the base. Styles $8-10-11$, stigmatose all round down to the lower third. Capsule $4^{\prime \prime}$, enclosed by the calyx. Seeds smooth.

Kauai! above Waimea (Kn. 89).

\section{ALSINIDENDRON, Mann, char. emend.}

Sepals large, persistent, fleshy at last, free to near the base, 5, unequal, imbricate, the 2 largest ones sub-opposite and external, or oftener by reduction 4, and then decussate, viz., 2 external and 2 internal. Petals none. Staminodia broad and short, thin hyaline, connate in a 10 - to 8-cleft ring or cup, with the base of which the stamens are connate. Stamens 10 or 8 , equal, alternating with the lobes of the staminodial cup; the filaments complanate, the anthers linear-oblong, affixed above the base. Styles $4-7$, filiform, stigmatiferous all round in the upper clavate half. Capsule ovoid, 1-celled, with a free central placenta, splitting at maturity into $4-7$ valves. Seeds numerous, orbicular-reniform, compressed, with a crustaceous testa. Embryo coiled around a scanty albumen, the cotyledons elongate. - An erect undershrub, with entire palmately 
nerved opposite leaves. No stipules. Cymes compound, in the axils of the uppermost pair of leaves.

A Hawaiian genus with a single species.

The staminodia were overlooked by Mann, but are certainly present in the manner given above. In the dried plant they adhere to the sepals, from which on account of their transparency they can hardiy be distinguished; only careful preparation after due maceration will bring them into view. In this operation the thin filmy border is apt to tear from the continuous base as far as it is connate with the stamens, which then will present the appearance described and figured by Mann, "stamina margini disci tenuissimi inserta". The height of the staminodial cup varies from ${ }^{1 / 3}$ to more than $1 / 2$ the length of the sepals, and as variable is the extent of its division, which in some flowers is carried to near the base, forming 8 or 10 apparently free lobes or scales alternating with the stamens. Sometimes the alternate clefts appear deeper, suggesting the idea of 4 or 5 bifid or bicuspidate seales connate with their bases. On this view the close relationship of the genus with the two last species of the preceding one comes out in the clearest light. Indeed the concrescence of the staminodia and the fleshiness of the calyx form the only distinctive characters not subject to variation, and there might be good reasons for combining S. viscosa and S. lychnoides with Alsinidendron, which, thus constituted, would form a genus limited to our oldest geological province.

1. A. trinerve, Mann, Enum. no. 36; Mem. Bost. Soc. Nat. Hist. I, 529, $p l$. 21. - Erect, $2-6 \mathrm{ft}$. high, glabrous, woody below, the branches herbaceous. Leaves ovate- or elliptico-oblong, $3-4^{1 / 2^{\prime}} \times 1^{1 / 2}-2^{1} / 4^{\prime}$, on petioles of ${ }^{1 / 2}-1^{\prime}$, acuminate at both ends, prominently 3 -nerved, thin chartaceous. Cyme terminal corymbose, not projecting beyond the leaves, $4-5$ times compound, the peduncle $1-1^{1 / 2} 2^{4}$, its short branches divaricate, the filiform pedicels ${ }^{1 / 2}-3 / 4$, the lanceolate bractlets half as long. Sepals broadly oblong or obovate, $3^{1} / 2^{\prime \prime}$, many-nerved, with a thick base, greenishred. Staminodial eup as above. Stamens shorter than the sepals. Styles short. Capsule ovoid or globose, enclosed by the persistent fleshy calyx, which assumes a dark bluish, almost black hue. Seeds crustaceous, black, compressed, with smooth faces, the convex margin rugulose.

Oa h u! summit and western slope of Mt. Kaala, from 4000 to $2000 \mathrm{ft}$. First discovered by the writer in 1860; collected by Mann in 1865. - The cyme, although terminal at first, becomes axillary in many instances by the development of an innovation from the axil of one of the last leaves.

\section{CERASTIUM, L.}

Sepals 5, rarely 4, distinct. Petals as many, 2-cleft, rarely entire. Stamens twice as many or fewer. Styles as many as sepals and opposite to them. Capsule 1-celled, cylindrical, membranous, opening at the top into twice as many teeth as there were styles. Seeds many, rough. Herbs. Flowers white, in terminal dichotomous cymes.

A large genus, spread over the temperate and cold regions of the entire globe.

† 1. C. triviale, Link. - Koch, Synops. Fl. Germ. - A decumbent weed, the stems ${ }^{1 / 2}-1^{1 / 2} \mathrm{ft}$. long, clammy-pubescent. Leaves ovate-oblong, $1 / 2-1$ ' long, obtuse, the lower ones contracting into a short petiole. Lower bracts herbaceous, hairy, the upper and the sepals with a scarious 
margin. Fruiting pedicels about twice as long as the calyx. Sepals 5, lanceolate, $2^{1 / 1}-3^{\prime \prime}$. Petals as long or shorter, deeply bifid. Capsule nearly twice as long as the calyx. - C. viscosum, herb. Linn.

Pastures and open woods of E. and W. Maui! A common weed of Europe.

\section{SAGINA, L.}

Sepals 4 or 5. Petals as many, entire, often obsolete or none. Stamens as many as petals or twice as many. Styles 4 or 5 . Capsule 1 -celled, splitting to the base into 4 or 5 valves. Seeds numerous, reniform, generally smooth. - Little matted herbs, with subulate leaves and small flowers. No stipules.

A small genus, confined to the temperate and frigid zones of the northern hemisphere.

† 1. S. subulata, Wimm. - Koch, Synops. Fl. Germ. - Stems, nodose, glabrate. Leaves linear and awned, clasping, 1-nerved, 4-6" long. Flowers single in the axils of the upper leaves. Pedicels erect, $6-9^{\prime \prime}$ long, glandular-hispid like the sepals, which are ovate, obtuse, $1^{1 /} 2^{\prime \prime}$ long. Petals 5, shorter, hyaline. Stamens 10, a little longer than the sepals. Valves of the capsule 5, opposite the sepals. Seeds minutely dotted, not margined.

Pastures of Ulupalakua! Maui. A native of Europe.

\section{SPERGULA, L.}

Sepals 5. Petals 5, entire. Stamens 10, rarely 5. Styles 5. Capsule 1 -celled, 5-valved, the valves opposite the sepals. Seeds laterally compressed, margined or winged. Embryo annular. - Annual weeds. Leaves subulate, apparently whorled by short many-leaved axillary shoots. Stipules small, scarious. Flowers in terminal cymes.

Geographical range of Sagina.

$\dagger$ 1. S. arvensis, L. - DC. Prod. I, 394. - Leaves 1-2'long, channelled on the under side. Flowers white. Sepals puberulous, $1^{1 / 2}$ ". Petals as long. Stamens 10, shorter. Seeds globose-lenticular, rough, with a narrow sharp margin.

Kauai! Waimea. A European weed, naturalized in the United states.

\section{Order X. PORTULACACEAE.}

Sepals 2 or rarely 3 , free, or connate with the base of the ovary, imbricate. Petals 4 or 5, rarely more, free, or connate at the base, imbricate, hypogynous or rarely perigynous. Stamens as many as petals, or fewer, opposite to them and adnate, or indefinite and hypogynous. Ovary 1-celled, with a free central placenta; style simple, with $3-8$ branches, these stigmatose along the inner side. Capsule splitting into as many valves as there are styles, or opening transversely-circumscissile. Seeds 
campylotropous, rising on slender stalks from the bottom of the capsule or from a central placenta. Embryo curved round a mealy albumen. Succulent herbs, with opposite or alternate entire leaves.

\section{PORTULACA, Tourn.}

Calyx 2-cleft, with deciduous limb, the tube cohering with the ovary. Petals 5, with the $7-20$ stamens inserted on the calyx, thin, fugacious. Style short, with $7-8$ branches. Capsule globose, eircumscissile with the free portion. - Fleshy herbs, with scattering leaves, the uppermost forming an involucre round the yellow, white or purplish flowers.

About 16 species, chiefly belonging to tropical America.

Stamens $7-12$.

Stamens indefinite:

Petals purple

Petals whitish

1. P. oleracea, L. -DC. Prod. III, 353. - A low prostate annual, fleshy and quite glabrous, without any hairs. Leaves obovate or spathulate. Flowers small, yellow, sessile above the last leaves or bracts. Sepals keeled. Petals very fugacious and scarcely exceeding the calyx. Stamens 7-12. Style 5-cleft. Seeds minutely granulose.

The Pigweed of gardens and cultivated grounds, common on all islands. Nat. name: "Thi". Found in nearly all warm countries. - In dry rocky situations near the sea (Kailud and Kaena, Oahu) a very similar plant is found with a thick lignescent stem, evidently a perennial, of which no specimen has been preserved in my herbarium, but I suspect that it is the P. lutea, Sol., spoken of in the Flora Vitiensis, p. 9.

2. P. villosa, Cham. in Linnaea, VI, 565. - "Low diffuse, with a fleshy root. Leaves lanceolate or linear, obtuse or subulate, with tufts of silky hair in the axils. Flowers sessile at the ends of the branches in a dense tuft of hairs. Petals purple, $5-6 "$, rather exceeding the keelless sepals. Stamens indefinite. Seeds areolate» («smooth», Gray). - Walp. Repert. II, 234. Gray, Bot. U. S. E. E. p. 140. - Nearly allied to the American P. pilosa, L.

In dry rocky places, Diamond Hill and Ewa, Oahu (Cham. and U. S. E. E.). Unknown to me, if really distinet from the following.

3. P. sclerocarpa, Gray, Bot. U. S. E. Exp. p. 141. - Root fleshy and tuberous, woody when old. Stems rather straight, thickened at the base, $2-5^{\prime}$ high, much branched. Leaves terete subulate, $4-6^{\prime \prime}$ long, crowded, longer than the copious hairs which occupy their axils and sides. Flowers sessile and crowded at the ends of the branches. Calyx $2^{1} / 2^{\prime \prime}$, with a short tube and ovate-obtuse scarious lobes. Petals twice as long, whitish. Stamens indefinite. Style short, with 8 divisions. Capsule globose, hard, coriaceous, $2-3$ " in diameter, adherent only a short distance above the base and tardily dehiscent at the line of adhesion. Placenta basal, dividing into 8 rays or branches. Seeds reniform, smooth, not compressed. - Mann, Fl. Haw. Islds. p. 22. - The capsules resemble 
the seed of a Scleria, and generally do not open until some time after they have fallen from the plant.

Haw ai1! and Maui! on dry lava fields $2000-5000 \mathrm{ft}$. above the sea; Lanai (M. \& B.); Kahoolawe (Lydg.). Nat. name: "Thimakole".

\section{ORDER XI. GUTTIFERAE.}

Sepals 2, 4 or 6, rarely more, imbricate in pairs. Petals 4 or more, contorted in the bud. Stamens indefinite, hypogynous, free, or variously united. Ovary sessile, usually several-celled, with 1 or more ovules in each cell, or reduced to a single cell and ovum. Style simple or none. Stigma broad, usually with as many lobes as cells to the ovary. Fruit either a capsule with as many valves as cells, or a berry, or drupe. Seeds often arillate, without albumen. Embryo thick with minute cotyledons. - Trees or shrubs, exuding a yellow juice. Leaves opposite, entire, coriaceous, without stipules.

A large tropical Order, common to the New and old World. To it belongs the Mammee-Apple, Mammea Americana, L, now in common cultivation.

\section{CALOPHYLLUM, L.}

Sepals 2-4. Petals 4, rarely 2,6 or 8 . Stamens numerous, free, or united into several bundles at the base. Ovary 1-celled, with a single erect ovule. Style filiform, with a peltate stigma. Fruit a drupe. - Trees, with parallel- and straight-veined leaves. Flowers in terminal or axillary racemes, sometimes branching into panicles.

About 25 species, mostly of tropical Asia, only 3 or 4 belonging to America.

1. C. Inophyllum, L.-DC. Prod. I, 562. - A tree, 40-60 ft. high, glabrous throughout. Leaves coriaceous, shining, broadly oblong or obovate, $8^{\prime} \times 4^{\prime}$, rounded or emarginate, on petioles of nearly $1^{\prime}$. Racemes axillary, $2-7^{\prime}$ long, the pedicels $1-1^{1 / 2} 2^{\prime}$, with short, soon deciduous bracts at the base. Sepals 4 , rounded, $4-5$ "long. Petals 4 , rarely $6-8$, white, oblong, $7-8^{\prime \prime}$. Style $2-3^{\prime \prime}$. Fruit globose, $1^{\prime}$ or more thick.

- The flowers are fragant.

A littoral tree, common and well known through all tropical Asia and Polynesia, generally planted near habitations and valued for its timber, which furnishes an excellent eabinet wood. In southern Polynesia and India the oil expressed from the nuts enjoys a great reputation as an external remedy against rheumatic pains and bruises. The yellow juice of the stem - Tacamahaca resin of commeree - is esteemed as a scent by the Tahitians. The tree, which is ealled "Kamani or "Kamanus by the Hawailans as well as by the other Polynesians of the Maoli race, is certainly of ancient aboriginal introduction, for the name occurs in oid meles, and a large grove of it which formerly existed in the valley of Halawa on Moloka has been referred to by early navigators. Of this only a few old trees remained in 1870 . More are to be found along the coast in Puna, Hawaii.

\section{ORdER XII. TERNSTROEMIACEAE.}

Sepals generally 5, imbricate. Petals as many, hypogynous, often united into a ring or short tube at the base, contorted or imbricate in the 
bud. Stamens indefinite, rarely equal in number to the petals and alternate with them, hypogynous, often shortly united at the base with each other or with the base of the petals. Ovary superior, completely or almost completely divided into 3 or more cells with 2 or more ovules in each. Styles either as many and free from the base, or more or less united into a single style, sometimes very short, with as many stigmatic lobes as ovary-cells. Seeds with or without albumen. Embryo straight or inflected, the radicle next the hilum. - Trees or shrubs, with mostly alternate toothed leaves, without stipules.

A considerable Order of the tropics of both Worlds, only a few genera extending to temperate zones, among which the Tea-plant and Camellia,

\section{EURYA, Thunb.}

Flowers mostly unisexual. Sepals and petals 5, much imbricate, the latter united at the base. Stamens seldom above 15; anthers adnate. Ovary 3-(rarely 2-, 4- or 5-)eelled, with several ovules in each cell. Styles almost free, or united to near the top. Fruit a berry. Embryo much curved in a somewhat granular albumen. - Flowers small, axillary, usually fascicled, supported by permanent bracteoles.

A small genus of southern and eastern Asia, with a few species in the Samoa and Viti Islands.

1. E. Sandwicensis, Gray, Bot. U. S. E. Exp. p. 209. - A low, much branching tree, the ultimate branchlets with appressed hairs. Leaves chartaceous, glabrous, oblong or obovate-oblong, $2-3^{\prime} \times 1-1^{1 / 4^{\prime}}$, on petioles of $1-1^{1} / 2^{\prime \prime}$, obtuse or shortly acuminate, serrulate, subcordate. Flowers polygamous, solitary, on nodding pedicels of $3-4^{\prime \prime}$. Bracteoles at the base of the calyx small, rounded. Sepals $2-3^{\prime \prime}$, dark purplish, coriaceous, suborbicular, persistent. Petals (early deciduous in the fertile flowers) ovate or obovate, 3-4", rather thick, yellowish. Stamens 10-15, free, very short, $1^{1 / 2^{\prime \prime}}$, the filaments half as long as the oblong mucronate anthers. Styles 3 or 2 , distinct, short, with capitate stigmas. Berry dryish, globose, 3 " or more in diam. Seeds many, reniform, with a thin testa. Albumen scanty. Cotyledons thick and broad, folded upon the radicle, which is of about the same length and partly overlapped by them.

Not uncommon in forests of the entire group.

$\beta$ var. - Leaves larger, rounded or acute at the base.

Kauai, Kealia (Wawra).

\section{ORdER XIII. MALVACEAE.}

Sepals united into a 5-(rarely 4- or 3-)lobed calyx, the lobes valvate in the bud. Petals as many, hypogynous, convolute in the bud, usually adhering at their base to the staminal tube. Stamens indefinite, united into a tube or column round the ovary, free at their ends. Anthers 
1-celled; pollen-grains hispid. Several carpels around the central axis, free, or united into a several-celled ovary. Style single, with as many or twice as many lobes as carpels, rarely entire. Ovules 1 or more in each carpel or cell. Fruit usually capsular, or separating into closed cocci or dehiscent carpids. Seeds usually reniform. Albumen little or none. Embryo with twisted cotyledons, curved in the reniform seeds. - Herbs, shrubs or soft-wooded trees, with stellate down. Leaves alternate, stipulate, usually palmately veined or lobed. Peduncles 1-flowered, axillary and solitary, or arranged in axillary fascicles or short racemes or in terminal racemes. Bracteoles often 3 or more close under or upon the calyx, free, or united into an involucre or outer calyx.

A large Order, dispersed over the whole globe, except the arctic regions.

Besides the following, Urena lobata has to be mentioned, a few plants of which have appeared in the neighborhood of Honolulu, having been accidentally introduced with foreign plants from China. 'It is readily recognized by the hooked prickles which eover the carpels - a hispid plant with angular leaves and small pinkish flowers in clusters forming an irregular raceme, the calyx surrounded by a 5-leaved involucre.

Carpels 1-ovulate, at last free and seceding from the axis; staminal

column ending in filaments:

Style-branches stigmatose along the inner side

1. Malva.

Style-branches with terminal stigmas:

Involucral bracts $3-1$; ovule ascending

Involucral bracts none; ovule pendulous or horizontal

2. Malvastrum.

3. Sida.

Carpels generally with 2 or more ovules, more or less united into a capsule:

No involucral bracts; staminal column ending in filaments; carpels discreet near the top

Calyx involucrate; staminal column 5-toothed or truncate at the top; carpels united to the top:

Calyx 5-lobed; style divided into 5 branches with capitate stigmas: Involueral bracts free Involucral bracts united.

Calyx truneate; style simple, with clavate stigma:

Involueral bracts caducous, lanceolate

Involucral bracts permanent, generally broad and cordate

\section{Abutilon.}

\section{MALVA, L.}

Involucre of 3 distinct bracts. Calyx 5-cleft. Petals obcordate. Staminal column ending in filaments. Style-branches as many as carpels, stigmatose along the inner side. Carpels many, forming a depressed ring round the short axis, breaking away from it at maturity as closed nutlets, each containing 1 ascending seed. - Herbs, with palmately nerved, mostly lobed or dissected leaves and axillary white or red flowers.

Natives of Europe, northern Africa and Asia.

$\dagger$ 1. M. rotundifolia, $L$. - A decumbent hairy biennial or perennial. Leaves orbicular, cordate or reniform, obscurely 5-7-lobed and crenate, on long petioles. Flowers in axillary fascicles, on pedicels of $3-6^{\prime \prime}$. Involucral bracts, linear, shorter than the calyx. Calyx hairy, $2^{\prime \prime}$. Petals twice as long, white. Carpels 8 , faintly rugose. $-M$. vulgaris, Fries. 
A common weed along roadsides and in cultivated fields, of European origin, but naturalized in the United States.

\section{MALVASTRUM, Gray.}

Involucral bracts $3-1$, or none. Staminal tube ending in filaments. Carpels 5 or more, separating from the axis as closed nuts or 2-valved carpids. Style-branches as many as carpels, with terminal stigmas. Seed single, ascending. - Herbs or undershrubs. Flowers small, yellow or red.

About 60 species, belonging to the American continent and to South Africa.

† 1. M. tricuspidatum, Gray, Pl. Wright. I, 16, and Bot. U. S. E. Exp. p. 148. - An erect annual or perennial, $2-3 \mathrm{ft}$. high, the branches sprinkled with appressed coarse hairs. Leaves ovate to lanceolate, penninerved, $1^{1 / 2}-2^{\prime} \times^{1 / 2}-1^{1 / 2^{\prime}}$, on petioles of ${ }^{1 / 2}-1^{\prime}$, bluntly serrate, hairy. Flowers few, in fascicles, on pedicels of $2-3^{\prime \prime}$, crowded toward the ends of the branches. Involucral bracts 3, subulate to lanceolate, nearly as long as the calyx. Calyx $4^{\prime \prime}$, its lobes ovate, long acuminate. Petals exserted, orange. Carpels $8-12$, opening by a narrow slit, bristle-haired, reniform, with a subterminal and 2 dorsal projections. - Malva tricuspidata, Ait. - M. Coromandeliana, L. - M. Americana and subhastata, Cav. - Sida carpinoides, DC.

The most common of all weeds, of American origin, but widely scattered over the warmer regions of the globe.

\section{SIDA, L.}

Calyx without involucre, 5-lobed or toothed. Staminal column ending in filaments. Carpels 5 or more, seceding from the axis when ripe, indehiscent, or opening into 2 short valves at the top. Style-branches with capitate stigmas. Seed solitary, pendulous. - Herbs or shrubs, more or less tomentose. Flowers usually yellow, single or fascicled, often in terminal racemes.

A large genus, distributed over the warmer regions of the entire globe. - Nat. name of all species: "Ilima».

Leaves unarmed:

Leaves cuneate at the base; carpids mostly awnless
Leaves rounded at the base; carpids more or less awned when

mature:

Leaves tomentose; calyx-lobes ovate, not sharp-pointed, the median nerve thickened at the base:

Carpids with short and broad diverging teeth

1. S. rhombifolia.

Carpids with Iong and straight subulate teeth; leaves cordate

Leaves glabrous or with seattering stellate hairs; ealyx-lobes long acuminate, with subulate points

Leaves with $1-3$ spinescent tubereles at the base of the petiole;

carpids with 2 long subulate beaks and 2 dorsal tubercles

2. S. fallax.

3. S. cordifolia.

4. S. Meyeniana.

5. S. spinosa.

1. S. rhombifolia, L. - DC. Prod. I, 462. - A low shrub, 2-4 ft. high, tomentose. Leaves rhomboidal or obovate-oblong, $1-2^{\prime} \times 4-8^{\prime \prime}$, 
acute or obtuse, crenulate or serrate except at the cuneate base, green above, hoary or pale underneath, on petioles of $2-3 "$. Pedicels mostly solitary, ${ }^{3} / 4-1^{1} / 4^{\prime}$, jointed above the middle. Calyx $2^{1} / 2-3^{\prime \prime}$, puberulous, with acute lobes, and 10 short prominent ridges at the base. Petals not much longer, pale yellow (not spotted). Carpids $8-10$, short $\left(1-1^{1 / / 2}{ }^{\prime \prime}\right.$, with or without terminal awns. In our specimens they appear awnless by coalescence of the short teeth, as in the var. $\beta$ of Gray, in Bot. U. S. E. E. p. 158.

A common weed, but also growing in out of the way places, and apparently indigenous. The species is diffused over most island groups of Polynesia and many parts of tropical America, Africa and Asia.

2. S. fallax, Walp. Repert. V, 94. - A low shrub, 3-4 ft. high, covered in all parts with a whitish velvety tomentum. Leaves ovate or ovate-oblong, acuminate or obtuse, even rounded, sometimes subcordate, deeply crenate, hoary on both sides, rather thick, with prominent straight veins, ${ }^{3} / 4-1^{1 /} / 2^{\prime} \times 1 / 3-1^{\prime}$, on petioles of $3-9^{\prime \prime}$. Stipules setaceous. Pedicels solitary, rarely 2 or 3 together, crowded toward the ends of the branches, longer than their leaves, $1-2$ ', articulate about the middle. Calyx tomentose, coriaceous, angular, 10-ribbed at the base, about $3^{\prime \prime}$, with lobes acute or bluntish. Petals often twice the length of the calyx, yellow. Carpids $7-12$, hard and pale, $1^{1 / 2}$ "long, wrinkled at the back, their short and broad teeth approximate at first but diverging after dehiscence, pubescent with stellate hairlets. - Gray, 1. c. p. 161. - Anoda ovata, Meyen.

Common on all islands, particularly on ancient lava beds on the leeward side of the islands Maui and Hawaii! up to $2000 \mathrm{ft}$. and more. - Occurs also in the islands of the South Pacifie and in southern China.

$\beta$ var. - Low decumbent, with small ovate, mostly acute leaves of $6-14$ " in length. Flowers crowded on short branches or leafy shoots, with mostly shorter pedicels. Calyx-lobes somewhat obtuse. $-S$. Diellii, Gray, l. c. p. 162 .

Near the sea-coast in Puna and Kau, Hawaii! and on the isthmus of Maui

' var. - Leaves thinner, broadly oblong, $1-1^{1} / 2^{\prime}$, obtuse or rounded at both ends, slightly cordate at the base, glabrate and greenish on the upper face. Calycine lobes obtuse. Flowers large, twice as long as the calyx. Carpids glabrous, with short and sharp diverging beaks. $-S$. Sertum, Nutt. in Gray, 1. c. p. 163. - S. rotundifolia, Gaud., and Hook. \& Arn. in Bot. Beech. p. 79.

A variety really much resembling S. rotundifolia, Cav., and not separable by good charaeters from the following species. It is cultivated, together with S. Meyeniana, for the sake of its flowers, which, strung together in wreaths or garlands called "leis, are worn as ornaments by the native women.

3. S. cordifolia, L. - DC. Prod. I, 464. - A stouter shrub, 3-5 ft. high, tomentose in all parts like S. fallax. Leaves ovate, generally 
cordate, $1^{1 / 2}-3^{1} / 2^{\prime} \times 1-2^{\prime}$, acuminate or obtuse, with bluntish serratures, thick with prominent nerves, tomentose below, greenish above, on petioles of $1 / 4-1 / 3$ of their own length. Pedicels crowded on short branches, either single, with a short accessory glomerule, or 2 or 3 together, $1-2$, long. Calyx $3^{\prime \prime}$, tomentose, thick, angular, with deltoid lobes, the base of the median nerve thickened. Corolla as in no. 2. Carpids 8-9, slender, $2-3$ " long, terminating in 2 erect subulate beaks of more than half their own length, with appressed hairlets, - Benth. Fl. Hongk, Griseb. Fl. W. Ind, p. 76.

Our form corresponds with $\alpha$ of Grisebach, as reported from S. America and India.

On lava fields of Maui and Hawail! with S. fallax. Common in the tropies of both hemispheres, and generally associated with $S$, fallax or $S$. rotundifolia. The three species seem to pass into each other where they occur together.

4. S. Meyeniana, Walp. Rel. Meyen. p. 307; Repert. V, 94. - A shrub, 4-6 ft. high, the young shoots sparingly covered with a scattered stellate pubescence, otherwise glabrous and green. Leaves broadly ovate, $1-3^{\prime} \times{ }^{3} / 4-2^{\prime}$, on petioles of $1 / 2$ their length, acute, deeply serrate, mostly cordate, thin membranous, glabrous on both sides. Stipules setaceous, minutely pubescent, $3^{\prime \prime}$. Pedicels ${ }^{1 / 2}-1^{1} / 2^{\prime}$, articulate in the upper third, single, or 2 or 3 together and then generally connate above the base. Calyx $3-5^{\prime \prime}$, thin, subglabrate, with broad caudato-acuminate lobes. Petals twice as long or more, deep yellow. Carpids $7-9$, short and thick, with 2 subulate teeth which diverge after dehiscence and are as long as the bodies of the carpids or longer. - Gray, 1. c. p. 164. S. ulmifolia, Hook. \& Arn. 1. c. p. 79. - Some plants are sprinkled with pubescence and have a hoary calyx.

In open forests of all islands. Not reported from elsewhere, but nearly allied to S. ulmifolia, Cav., from tropical America.

† 5. S. spinosa, L. - DC. Prod. I, 460. - Subherbaceous, 1-2 ft. high, erect, minutely pubescent. Leaves oblong- or linear-lanceolate, bluntish, serrate except at the rounded base, pale underneath and puberulous, $1-2^{\prime} \times 1 / 4-1 / 2^{\prime}$. Petioles $4-8^{\prime \prime}$, with a spinescent tubercle at the base besides 2 lateral ones at the base of the filiform stipules. Pedicels axillary, single, or 2 or 3 together, $4-8$ "long, articulate above the middle. Calyx membranous, $3^{\prime \prime}$ long, the ovate-acute lobes $1 / 3$ of its length. Petals a little longer, pale yellow. Carpids $5-8,2^{\prime \prime}$ long, with two dorsal tubercles, the subulate beaks as long as their bodies, pubescent. S. angustifolia, Lam. - Griseb. Fl. W. Ind. p. 74.

Near Honolulu at the base of Punchbowl! hill. A late arrival from tropical America, which has also found its way to parts of Afriea and adjacent islands.

\section{ABUTILON, Gaertn.}

Calyx without involucre. Staminal column ending in filaments. Carpels 5 or more, each with several ovules, and when ripe united below, but 
divergent at the top and opening into 2 valves. Style-branches with terminal stigmas. - Herbs or shrubs, with the habit of Sida and the same geographical range, but most common in America.

In cultivation A. Indicum, Don., A. (Wissadula) periplocifolium and A. venosum, the two former bidding fair to become naturalized.

Calyx ${ }^{1 / 3}$ the length of the capsule, deeply 5-parted; petals small, $3-4^{\prime \prime}$ long Calyx longer than the capsule, 5-toothed, 2-3-lobed; petals large, $10-12^{\prime \prime}$

1. A. ineanum.

2. A. Menziesii.

1. A. incanum, G. Don. - A low decumbent undershrub, $1-2 \mathrm{ft}$. high, covered with a soft and close gray pubescence. Stipules filiform, short. Leaves cordate-ovate, acuminate, crenate or serrate, canescent on both sides, gradually decreasing in size upward, the lowest $2^{\prime} \times 1^{3 / 4^{\prime}}$, on petioles of $1-1^{1 /} / 4^{\prime}$. Flowers axillary and solitary, or by reduction of the upper leaves sometimes subracemose, on pedicels of $1 / 2-1^{1} / 2^{\prime}$, which are articulate near their ends. Calyx canescent, $1^{1 / 2}-2^{\prime \prime}$, deeply 5-cleft into ovate- or lanceolate-acute lobes. Petals of a pale red or flesh color, 3-4", obovate. Carpels 5, canescent, 4-5" high, connate about $3 / 4$ their length into a columnar subtruncate capsule, dehiscent at the apex and along the dorsal sutures. Seeds 3 in each carpel, superposed, globose, pubescent. - Gray, Bot. U. S. E. E. p. 168. - Sida incana, Link in DC. Prod. I, 468.

Common on dry plains and rocky slopes of the lower regions. Nat. name: "Mao".

2. A. Menziesii, Seem. Fl. Vit. p. 15 (in adnotat.). - A hoary shrub. Leaves ovate-cordate, $1^{1 / 2}-3^{\prime}$ long and nearly as broad, on petioles of $1-2^{\prime}$, hoary on both faces or subglabrate above, deeply crenate or coarsely and obtusely serrate, sometimes angular, acute with a produced apex. Pedicels axillary, solitary, $1-1^{1 /} / 2^{\prime}$, articulate in the upper third. Calyx hoary outside and silky inside, $7-8^{\prime \prime}$ long, minutely 5 -toothed, but cleft in anthesi to one third of its length into 2 or 3 broad reflexed lobes which finally break away from the maturing fruit. Petals deep red, 10-12", unguiculate, the broad obovate, often emarginate lobes spreading or reflexed. Staminal column $10-12^{\prime \prime}$. Capsule 5 " high, tomentose, columnar, 7-8-celled, the carpels externally connate to near the acute apex, which shelves considerably toward the shorter axis, splitting at the top and along the upper third; each cell with 3 puberulous seeds. Stigmatic branches $2^{\prime \prime}$, capitate.

Ha waii! on the Waimea side of the Kohala range, and probably also on Lanai (Lydg.). - Notwithstanding some discrepancy in the description I have hardly any doubt that my plants are to be referred to the above species. Seeman attributes to it broad ovateacute calyx-lobes, without indicating their number or stating the relative length of the calyx. The eapsule is said to be 5-celled in the specimens of the British Musenm colleeted by Menzies in the Sandwich Islands.

$\beta$ var. - Leaves finely crenate, not at all angular. Flowers light fleshcolored.

Lanai! (Lydg.). 


\section{HIBISCUS, L.}

Involucre of several free bracts. Calyx 5-lobed or toothed. Staminal column ending in 5 teeth, antheriferous outside. Carpels 5, with several ovules in each, united into a single 5-celled ovary. Style 5-lobed at the top, or nearly entire, with terminal stigmas, Capsule loculicidal. Seeds reniform or globose, glabrous or tomentose. - Herbs, shrubs or trees. Flowers often large and showy.

A large genus, widely spread over the warmer regions of the globe.

In general cultivation: $H$. Rosa sinensis, H. mutabilis, H. esculentus (Ochra or Gombo), H. Manihot, H. moschatus, H. Sabdariffa, H. vitifolius, H. cannabinus, H. phoeniceus.

Leaves lobed:

Flowers pink; involucral bracts bifid

Flowers yellow; involucral bracts entire Leaves entire:

Flowers white; style-branches erect .

Flowers red; style-branches horizontal
1. H. Youngianus.

2. H. Brackenridgei.

3. H. Arnottianus.

4. H. Kokio.

1. H. Youngianus, Gaud. Bot. Voy. Freyc. p. 91. - Hook. \& Am. in Bot. Beech. p. 79. - An erect, sparingly branching undershrub, $2-3 \mathrm{ft}$. high, with a light pithy stem, tomentose, and covered throughout with short spinescent bristles which fall away from a papillose base. Leaves cordate-ovate, almost entire, or obtusely 3 - to 5-lobed, the middle lobe longest, dentate with broad patent teeth, palmately 7-nerved, scabrouspubescent on both faces, most so underneath and along the nerves, $3-4^{1 / 2^{\prime}} \times 2-4^{\prime}$, on petioles of $1 / 2-2^{\prime}$. Pedicels single in the axils of the upper leaves, about ${ }^{1 / 2}{ }_{2}$ long, sometimes bearing 2 or more flowers. Invol, bracts 10, linear, bidentate at the apex, 6-8" long. Calyx 9-18", thick, densely setose, strongly 10-ribbed, cleft to near the middle into lanceolate-acute lobes which close over the mature capsule, their median nerves with a gland in the upper half. Petals puberulous, pink, obovate, emarginate, $2-3^{\prime}$. Staminal columm half as long, with short $\left(1 / 2^{\prime \prime}\right)$ filaments along its entire length. Style-branches $1^{\prime \prime}$. Capsule $9-15^{\prime \prime}$, covered with appressed hairs. Seeds $11^{1 / 2} 2^{\prime \prime}$, numerous, globose-reniform, pale, glabrous. - Gray, Bot. U. S. E. E. p. 174. - Mrs. Sinclair, pl. 11.

In marshes and abandoned taro-patehes here and there on all islands, as in Kapalama near Honotulu. Nat. name: :Akiohalav. Is nearly related to the American H. bifurcatus, Cav.

2. H. Brackenridgei, Gray, Bot. U. S. E. Exp. p. 175, pl. 12. - An erect, light-wooded shrub, $4-5 \mathrm{ft}$. high, with spreading stiff branches tomentose at the ends and beset with short patent spines which are articulate on papillary bases and soon deciduous. Leaves on long petioles of $3-5^{\prime}$, rounded in outline, $3^{1 / 2}-4^{\prime}$ each way, cordate, $5-7$-lobed, with sharp and narrow sinuses, and besides coarsely toothed or cut, membranous, glabrate, of a lively green. Stipules setaceous. Peduncles solitary in the axils of the uppermost leaves, $6^{\prime \prime}$ or less, articulate at the base. 
Invol. bracts $9-10$, linear, entire, stiff, $6-10^{\prime \prime}$ long. Calyx ${ }^{3} / 4-1$ ', very hispid, cleft to below the middle, the tube 10-ribbed, the narrow lanceolate lobes often with a gland at their base. Petals $2-3$ ', spreading, yellow, pubescent outside. Staminal column not longer, bearing subsessile anthers down to the lowest third. Style-branches hirsute, less than $2^{\prime \prime}$; capsule $7-10^{\prime \prime}$, ovoid, densely hispid, enclosed by the calyx. Seeds 5 in each cell, angular, studded with the papillar bases of evanescent hairlets. The corolla turns green after drying.

Rather rare, in the serub vegetation of the lee-side chiefly; Oahu! Makaleha; W. and E. Maui! Lanai! Worthy of cultivation on account of the showy flowers, as are also the two following species.

3. H. Arnottianus, Gray, l. c. p. 176. - A tall shrub, but often a small tree, $10-25 \mathrm{ft}$. high, with a dense crown, glabrous throughout. Leaves ovate, $2-3^{1 / 2} 2^{\prime} \times 11^{1 / 2}-2^{\prime}$, bluntly acuminate, repandly crenulate or entire, 3-nerved, chartaceous, on petioles of $1-1^{1 / 2}$. Stipules subulate caducous. Flowers solitary in the axils of the one or two uppermost leaves, on pedicels of 6-20", which are articulate near the end. Invol. bracts $5-7$, triangular to lanceolate, $2-3^{\prime \prime}$ long. Calyx $8-12 "$, thin, tubular, 5-toothed, splitting laterally when with fruit. Petals white, obovate-oblong, with long claws, $3-4^{\prime}$, pubescent below. Staminal column long exserted, $4-6^{\prime}$, red, sending off filaments of $6-8^{\prime \prime}$ from its upper half or third. Style-branches $3-4$ ", erect. Capsule elongate, as long as the calyx, chartaceous. Seeds $2^{i} / 2^{\prime \prime}$, reniform, covered with a short brownish wool. - H. Boryanus, Hook. \& Arn. 1. c. (non DC). - Mrs. Sinclair, pl. 11.

In forests between 1500 and $3000 \mathrm{ft}$. above the sea, probably on all islands; Kauai! Oahu! Maui! Hawaii! On Oahn in Pauoa, Manoa, and on Puakea of the Waianae range. Ka uai specimens have the leaves slightly puberulous. Nat. names: "Hauhele", -Kokio keokeos.

4. H. Kokio, Hillebr. in Flora, 1873, p. 173. - A tall shrub, 8-14 ft. high, dividing from the base into long straggling branches, the young shoots with discreet stellar pubescence. Leaves ovate- or elliptico-oblong, $3-4^{i} \times 1^{1 / 2}-2^{i}$, rather long-acuminate, sinuately crenate, scarcely palmatenerved, the lateral nerves not extending beyond the middle, chartaceous, glabrous, on petioles of $3-9^{\prime \prime}$. Flowers axillary, solitary, few near the ends of short lateral branches. Pedicels $9-15^{\prime \prime}$, pubescent, articulate in the upper third. Invol. bracts $6-7$, linear, $4-6^{\prime \prime}$ long. Calyx tubular or subcampanulate, $9-15^{\prime \prime}$, cleft to the middle into 5 acute lobes, glabrate. Petals $2-2^{1} / 2^{4}$, entire, red. Staminal column shorter, red, the short filaments crowded near the 5-toothed apex. Style-branches $4-5^{\prime \prime}$ long, spreading horizontally, ciliate. Capsule glabrous, $9^{\prime \prime}$. Seeds $2^{1 / 2} 2^{\prime \prime}$, reniform, covered with a coarse brownish pubescence. - Mrs. Sinclair, pl. 9 (the horizontal style-branches not well brought into view). 
Oahu, Nuuanu (Remy); Molokai! Halawa (Hbd.); Kauai Haena and Waimea? (Mrs. Sinclair). Very rare, and probably is the Hibiscus with red flowers from "Byron's bay" referred to by Hook. \& Arn. under H. Boryanus, 1. c. - Nat. names: "Pualoalo" and Kokio". Wawra's specimens came from the writer's garden, where it has been in eultivation for many years. Its next congener is $H$. Rosa sinensis, from which it differs in the habit, the smaller flowers with suberect petals, shorter involucre, and the horizontal style-branches.

\section{PARITIUM, St. Hil.}

Bracts of involucre united into an 8-10-lobed cup. Cells of capsule incompletely partitioned by a protrusion of the endocarp. Otherwise as in Hibiscus.

1. P. tiliaceum, St. Hil. Fl. Bras. Mer. 1, 295. - A small freely branching tree. Leaves on long petioles, orbicular-cordate, about 5 ' each way, shortly acuminate, entire, hoary underneath with a short close tomentum, nearly glabrous above, palmately 7-9-nerved, the 3 middle nerves with a gland near the base. Stipules large ovate, caducous. Peduncles short, in the upper axils or at the ends of the branches, with 1 to several flowers. Involucre campanulate, about half the length of the calyx, divided to the middle into $10-12$ acute lobes. Calyx tomentose, nearly $1^{\prime}$ long, with lanceolate lobes. Petals large, yellow, often with a brown center. Capsule about $1^{\prime}$ in diameter, opening into 5 valves; 3 naked seeds to a cell. - Hibiscus titiaceus, L. - Some trees bear yellow flowers with yellow stigmas, others have them spotted in the center and with dark brown or reddish stigmas. Double flowers are occasionally seen near the sea shore. - Mrs. Sinclair, pl. 1.

Very common along the coast, extending up to elevations of $1500 \mathrm{ft}$. and more, where it becomes bushy, with smaller leaves. Occurs in nearly all tropical countries and is abundant in all Pacific islands. Nat. name: "Haus; "Faus in Tahiti and Viti. This useful tree is generally planted near native habitations on account of its dense shade, and trained into lanais or arbors. The light wood serves for outriggers of canoes, the bark furnishes a tough and pliable bast for ropes, and a decoction of the flowers is a useful emollient in bronchial and intestinal catarrhs.

In cultivation: $P$. elatum, a tree with a tough flexible wood valuable to cart makers.

\section{THESPESIA, Correa.}

Involucral bracts $3-5$, free. Calyx truncate, 5-toothed or 5-cleft. Staminal column ending in a 5 -toothed apex, antheriferous outside. Ovary 5-celled, each cell with several ovules. Style club-shaped, 5-grooved, or divided into 5 short erect clavate branches. Capsule coriaceous, loculicidal or almost indehiscent. Seeds large obovoid. Cotyledons much plaited, enclosing the short erect radicle, generally dotted with black specks. Trees or tall herbs, with entire or lobed leaves and large showy, generally yellow flowers.

About 6 species, ranging from Madagascar to the Hawailan Islands.

1. T. populnea, Correa, in Ann. Mus. Paris, IX, 290, tab. 8. - A tree, 25-40 ft. high. Leaves roundish, cordate, acuminate, entire, $4-5^{\prime}$ in Hillebrand, Flora of the Hawaiian Islands. 
diameter, glabrous. Peduncles as long as the petioles. Involucral bracts lanceolate, equalling the calyx, soon deciduous. Calyx truncate, 6 "long and as broad at the top. Petals obovate-oblong, 2', yellow, turning dark during the day. Capsule globose, $12-15^{\prime \prime}$ in diameter, almost woody and very tardily dehiscent. Seeds 4", villous at the base and angles. - Hibiscus populneus, L. - H. bacciferus, Forst. - Mrs. Sinclair, pl. 10.

Along the seacoast in and near villages. Hawailan name: "Milo", the same as in Tahiti, Samoa and Tonga; "Mulon in the Viti Islands. The tree ranges from Madagascar to the Hawaiian Islands, being a favorite with the inhabitants of all intervening countries. In Tahiti it was regarded as sacred, used to be planted in morais or temples, and its leaves were employed in religious ceremonies - a circumstance which would account for the wide distribution. Although I am not aware that the Hawaiians held it in religious veneration, yet from the circumstance that a number of the trees surrounded the house of Kamehameha I. at Waikiki, one may fairly infer that it was held in high esteem.

\section{GOSSYPIUM, L.}

Involucral bracts 3 , large, generally cordate, free. Calyx truncate or shortly 5-cleft. Staminal column naked at the truncate apex, antheriferous outside. Ovary 3-5-celled, each cell with 1 or more ovules. Style undivided, clavate, 3-5-grooved. Capsule loculicidal. Seeds subglobose or angular, woolly or tomentose. Albumen thin or none. Cotyledons much folded, enclosing with their auricles the erect radicle. - Tall herbs or shrubs, or trees. Leaves lobed, rarely entire. Flowers large, yellow or reddish. Leaves, flowers and cotyledons generally dotted with black specks.

A genus of few species, several of which, subject to great variation, have been cultivated since early historical times for the sake of the cotton-wool which envelopes the seeds. The two following are truly indigenous to the Hawailan Islands, but besides there are or have been in cultivation $G$. Barbadense, L., with its smooth-seeded variety, the Sea-Island Cotton, and G. Peruvianum, Cav.

A spreading shrub, petals sulphur-colored, $1^{1 / 2^{\prime}}$ long

A small tree, petals brick-red, 3-4' long.

1. G. tomentosum.

1. G. tomentosum, Nuttall, in Seem. Fl. Vit. p. 22. - A spreading shrub, 4-6 ft. high, hoary with a soft white tomentum. Leaves thick, orbicular in outline, cut about half way into $3-5$ ovate-acute lobes, cordate, with narrow sinus and round sweeping base, tomentose on both faces and faintly speckled with black dots, 2-4' each way, on petioles of $1-2^{\prime}$. Flowers axillary on a peduncle of $1-2^{\prime}$, which bears at its end a reduced leaf and a pedicel of $1 / 2-1$. Invol. bracts ovate and slightly cordate, $10-12^{\prime \prime}$, cut into 5-11 sharp serratures or lobes. Calyx truncate, $3^{\prime \prime}$ long, with 10-12 longitudinal nerves, tomentose and dotted, as are the bracts. Petals obovate, $1^{1} / 2^{4}$, sulphur-colored, puberulous outside, minutely dotted, connected at the base. Staminal column enclosed, antheriferous from base to apex. Style as long as the petals, with a 3-grooved stigma. Capsule ovoid, 8-10", coriaceous, pitted, 3valved, each cell holding $3-4$ separable seeds which are enveloped in a firmly adhering short tawny wool, the fibres of which measure $3-6^{\prime \prime}$ 
in length. - G. religiosum, Roxb., also of Gray, Bot. U. S. E. E. p. 179. - G. Sandwicense, Parlat. Sp. Coton. p. 37, tab. 6. - Varies with leaves glabrate above and distinctly punctate, - Mrs. Sinclair, pl. 23.

Along the seacoast here and there on all islands. Nat. names: "Maos and *Huluhuln. Oceurs also on the Viti Islands. In plants from Kaunakakai! Molokai, the peduncle elongates in the axis of a branch, with the flowers opposite to the leaves. The species is unfit for cultivation on account of the short staple.

G. religiosum, L., which grows on the islands of the Soeiety group, differs in glabrate and larger leaves with a gland on the middle nerve, involucral bracts $1^{1 / 2}-2^{\prime}$ high and eut into linear-lanceolate lobes, an urceolate ealyx with subulate teeth, a 4-valved capsule, and seeds which are easily separable from a yellowish wool. This form (G. Tahitense, Parlat.) has not, to my knowledge, been found on our group, although Mann (Enum. no. 43) enumerates it, besides $G$. tomentosum.

2. G. drynarioides, Seem. in Fl. Vit. p. 22, adnot. - A small tree, 12-15 ft. high, with a thick gnarled trunk, resembling Erythrina monosperma in habit, woody in its last ramifications. Leaves on long petioles of 3-4', membranous, glabrous, pitted, but destitute of black dots, cordate and $7-5$-lobed, about $5^{\prime}$ in diameter, the deltoid lobes $11^{1 / 2}$ deep, the basal sinus quite open. Flowers single in the axils of the uppermost leaves, on stout peduncles of $1-2^{\prime}$, which bear at the middle a broadly sessile and obliquely clasping caducous ovate bract of $4-5^{\prime \prime}$ in length. Invol. bracts broadly ovate to subcordate, obtuse, entire, 7-13-nerved, $1-1^{1} / 2^{\prime}$ long and $1^{\prime}$ or more broad, glabrous, coriaceous. Calyx urceolate, truncate (the upper half carried away by the rising corolla?), 6-9" high, thin scarious, distinctly punctate with black dots. Petals brick-red, obovate-oblong, entire, 3-4'long, silky outside, eminently reticulate, with a black dot in each areole. Staminal column of same length, truncate or obsoletely $2-3$-toothed at the apex, antheriferous in the upper third with short filaments. Style shortly exserted, clavate, 5-grooved. Ovary 5-celled, each cell with 1 ascending ovum. Capsule ovoid, 1', thick woody, opening tardily near the apex. Seeds obovoid, covered with a short brownish tomentum.

Imperfectly described by Seeman from a specimen in the British Museum collected by Nelson, the companion of Capt. Cook. My specimens of this form I owe to the kindness of Mr. R. Meyer, who discovered three trees on the western end of Molok ai which could not be found again on a subsequent visit a few years later. Nat. name: Kokios.

\section{$\beta$ var. - Bracts of involucre lanceolate, $1^{1 / 2}-2^{\prime} \times 1 / 2-1^{\prime}$.}

Eastern end of $\mathrm{Oahu}$ ! on the hills of Makaku and Koko Head. Two trees seen.

The species is remarkable in the genus for its entire bracts, red flowers, the woody capsule, and single, shortly tomentose seed. It is much to be feared that this rare and interesting tree is doomed to extinction, as it grows in regions accessible to cattle. The ripe seeds are mostly spoiled by worms, for in consequence of the imperfect dehiscence of the eapsule they are retained an undue length of time.

To the nearly related Order Bombaceae belong Ochroma Lagopus, Sw., and Bombax Ceiba, L., tall trees of cultivation. 


\section{ORDER XIV. BUETTNERIACEAE (STERCULIACEAE).}

Stamens monadelphous, generally definite, the column often divided into alternate staminiferous and naked lobes, the former opposite the petals. Anthers 2-celled, with smooth pollen-grains. Carpels 5-1, united when more than one. Petals often wanting. Otherwise as Malvaceae.

A large tropical Order, extending also into southern Africa and Australia.

To it belong the Cacao tree, Theobroma Cacao, Abroma augusta, Guazuma tomentosa, Commersonia echinata. Kleinhovia hospita, Pentapetes Phoenicea, Visenia Indica, and other introduced species.

\section{WALTHERIA, L.}

Calyx 5-lobed. Petals oblong-spathulate, flat. Stamens 5, opposite the petals, united at the base, with 2 parallel anther-cells. Ovary sessile, of a single carpel with 2 erect ovules. Style excentrical, with fringed stigma. Capsule opening at the back into 2 valves. Seed usually solitary, with albumen. Embryo straight; cotyledons foliaceous. - Herbs or shrubs, with stellate tomentum mixed with simple hairs. Leaves toothed. Stipules narrow, deciduous. Flowers axillary, clustered.

About 16 species, mostly American, a few in Africa.

Leaves ovate-oblong, tomentose on both faces

Leaves obovate or orbicular, glabrous on the upper face; flowers larger

1. W. Americana.

2. W. pyrolaefolia.

1. W. Americana, L.-DC. Prod. I, 492. - A perennial with a woody base, $1-2 \mathrm{ft}$. high, densely tomentose or softly villous in every part. Leaves ovate-oblong, $1-2^{\prime} \times{ }^{3} / 4-1^{1} / 4^{\prime}$, on petioles of $6^{\prime \prime}$, obtuse, dentate, feather-veined. Flowers small, sessile in close clusters along axillary peduncles of $1-1^{1} / 2^{\prime}$. Bracts linear. Calyx $2^{\prime \prime}$, villous, with acute lobes. Petals little longer, unguiculate, orange-colored. Ovary and style villous. - W. Indica, L. - Mrs. Sinclair, pl. 38.

A common weed, occuring also in most tropical countries and in many Polynesian island groups. Nat, name: "Hialoa».

2. W. pyrolaefolia, Gray, Bot. U. S. E. Exp. p. 190. - An undershrub, $3 \mathrm{ft}$. high, gray-villous. Stipules setaceous. Leaves coriaceous, obovate to orbicular, $8-15^{\prime \prime}$ in diameter, on petioles of $3-6^{\prime \prime}$, usually retuse at both ends, finely toothed, glabrous above, or slightly pubescent when young, gray below with a fine and close pubescence which disappears with age. Flowers crowded in subsessile axillary heads or rarely on a short peduncle. Bracts somewhat obtuse, $3^{\prime \prime}$. Calyx $3^{\prime \prime}$, silkyvillous, cleft to the middle into obtuse lobes. Petals ${ }^{1 / 3}$ longer, glabrous, narrow-spathulate. Filaments $1 / 3$ the length of the petals, monadelphous at the base. Ovary and style villous. Stigma truncate. dition,

On sandhills near Wailuku, Ma ui. Only found by the members of the U. S. E. Expe- 


\section{Order XV. TILIACEAE.}

Sepals 5 or 4 , free, or united into a lobed calyx, valvate. Petals as many, imbricate or valvate, sometimes none. Stamens indefinite, or rarely twice as many as petals, hypogynous, free, or united into several bundles. Anthers 2-celled. Ovary free, 2-10-celled, with several ovules or rarely a single ovule in each cell. Style entire, or divided at the top into as many lobes as cells of the ovary, or sometimes the stigma is sessile on the ovary. Fruit dry or succulent, indehiscent or with a loculicidal dehiscence, or rarely separating into cocci. Seeds usually albuminous. Cotyledons broad, the radicle next the hilum. - Trees, shrubs or rarely herbs. Leaves alternate, entire, with pinnate or palmate nerves. Stipules small and deciduous, rarely wanting.

A considerable Order, chiefly tropical, with a few species in the temperate regions of the northern hemisphere; represented in Polynesia by 6 genera.

\section{ELAEOCARPUS, L.}

Sepals 4 or 5 . Petals as many, toothed, lobed or fringed, induplicatevalvate. Stamens mostly numerous, inserted on a glandular disk. Anthers with adnate cells opening at the top into transverse valves, often ciliate on the edges. Ovary $3-5$-celled, with $2-6$ ovules in each cell. Style subulate. Fruit drupaceous, the putamen usually $3-5$-celled. Seeds solitary in each cell, pendulous. - Trees, with flowers in axillary racemes.

A considerable genus, extending from the Mascarene Islands through tropical Asia and Australia to New Zealand and Polynesia, with 6 species in the Viti group.

1. E. bifidus, Hook. \& Arn. in Bot. Beech. p. 110, tab. 24. - A glabrous tree, $30 \mathrm{ft}$. or more high, the twigs gummy at their ends. Leaves ovate or ovate-oblong, $4-7^{\prime} \times 2-3^{1} / 2^{4}$, on petioles of $2^{\prime}$, acuminate, crenate or bluntly serrate, often almost entire, chartaceous. Stipules lanceolate, $1^{\prime \prime}$ long, caducous. Racemes $1-2^{\prime}$ long, with $5-8$ flowers on pedicels of $1 / 2^{\prime}$. Sepals narrow-lanceolate, $3-4^{\prime \prime}$ long, pubescent on the inner side. Petals as long, greenish, linear-oblong, shortly bifid or scarcely emarginate, pubescent on both faces. Torus discoid, glandular. Stamens 13-16, one third the length of the sepals, with short pubescent filaments; anthers obtuse or emarginate, transversely gaping at the top and dehiscing to the middle. Ovary ovoid, 2-3-celled, tapering into the simple $2-3$ grooved-style. Ovules $3-6$ in each cell. Drupe subglobose or oliveshaped, $12-15^{\prime \prime}$ long, the putamen thick woody, sending numerous stiff fibres into the scanty flesh of the mesocarp. Seeds generally solitary, rarely two, with a thin testa. Embryo central in a thin layer of albumen, the short radicle bent on large foliaceous cotyledons. - Gray, Bot. U. S. E. E. p. 205. - Beythea bifida, Endl, in Gen. Pl. - Walp. Repert. I, 365 , and $\mathrm{V}, 121$. 
Very common in the lower and middle woods of $\mathrm{Oahu}$ ! and Kauai! but scarce, if not altogether wanting, in $\mathrm{Maui}$ and $\mathrm{Hawaii}$. Nat. name: "Kalia". The bast of the tree used to be made into cordage. The inflorescence of this tree is often found monstrously deformed by oviposition of some dipterous insect.

\section{ORDER XVI. GERANIACEAE.}

Sepals 5, mostly distinct, regular or irregular, imbricate. Petals as many or less, imbricate or contorted. Mostly 5 glands alternating with the petals. Stamens 10, united or distinct, those opposite the petals sometimes sterile. Carpels 5 or 3 , their styles adnate to the prolonged axis, from which they separate at maturity together with the carpels, their free ends stigmatose along the inner side. Ovules 2 or 1 in each carpel. Albumen scanty or none. Cotyledons convolute-plaited and bent on the short radicle. - Herbs or shrubs, with opposite or alternate stipulate leaves.

Inhabitants of the temperate regions; in the tropics confined to high elevations.

Flowers regular; glands alternating with the petals:

Fertile stamens 10 ; style naked on the inner side, curled up, not twisting when separated from the axis

\section{Geranium.}

Fertile stamens 5 ; styles bearded inside, curling and twisting when detached

Flowers irregular, the calyx spurred: no glands:

Spur adnate to the pedicel; carpels beaked, dehiscent . . 3. Pelargonium.

Spur free; carpels not beaked, indehiscent

4. Tropaeolum.

\section{GERANIUM, L.}

Flowers regular. Stamens 10, all with anthers, free, or connate at the base, a gland at the back of each alternating one. Ovary 5-lobed, each carpel with 2 superposed ovules, of which one only matures. Styles adnate to the prolonged torus or axis, ending in 5 free stigmatic branches, the adnate portions thickening into carpellary beaks and curling up from below when ripe, not twisting, each carrying with it its carpel. - Herbs or shrubs, with opposite or alternate, entire or dissected, stipulate leaves. Peduncles axillary or terminal, 1- to many-flowered.

About 100 species, with the range of the Order. The Hawaifian species constitnte a distinet section, Neurophyllodes, Gray, eharacterized by alternate entire parallel-nerved leaves, many-flowered cymes and distinct stamens. The cymes, at first terminal, become lateral by prolongation of the axis of the branch. The peduncle divides at the first node into a median leading and two fewer-flowered lateral branches, one of which commonly is replaced by a leaf.

Leaves dentate; shrubs or undershrubs:

Flowers white and regular; styles discreet beyond the adnate beaked portions :

Stem erect:

Leaves cuneate:

Leaves 5-7-toothed, with prominent nerves; eymes projected beyond the leaves; branches reddish

Leaves 3 -toothed, with hidden nerves; cymes scarcely protruding; branches blackish

1. G. cuneatum.

2. G. tridens. 
Leaves obovate, serrate in the upper half; cymes many flowered

4. G. multiflorum.

Leaves ovate, serrulate to near the base; cymes few-flowered 5. G. ovatifolium. Stem or branches prostrate, rooting

3. G. humile.

Flowers red, subirregular; styles united beyond the adnate beaked portions

Leaves palmately lobed; an herb

6. G. arboreum.

7. G. Carolinianum.

1. G. cuneatum, Hook. Ic. Pl. tab. 198. - An erect undershrub, about $2 \mathrm{ft}$. high, the numerous slender and reddish branches rather distantly foliose and covered below with the permanent stipules, which are subulate from a broad clasping base, $1^{1 /} / 2-2^{\prime \prime}$ long. Leaves alternate, thin chartaceous, green on both sides, pubescent when young, cuneate or cuneate-obovate, $1-1^{1 / 2^{4}} \times{ }^{1 / 2}-3 / 4^{4}$, on petioles of $1 / 2^{\prime}, 5-7$, rarely 3 -toothed at the truncate or slightly rounded apex, otherwise entire, the 5 or 7 nerves prominent underneath, bifurcating near the end (except the median one) and occasionally anastomosing. Cymes compound, 9-30-flowered, one from every branch, forming large corymbose inflorescences which project $1-3$ inches beyond the leaves. Bracts linear, 1". Pedicels 6-9", pubescent. Sepals $3^{\prime \prime}$, ovate-lanceolate, mucronate, pubescent. Petals 5", obovate, entire, white, with greenish veins. Glands pubescent. Stamens free to the base and equal, as long as the sepals, the filaments dilated below, pubescent. Carpels and their backs canescent, the latter $6-7$ ", their free stigmatiferous ends $1-1^{1 / 2}$ "long and revolute, Seeds glabrous, minutely reticulate. - Var. $\alpha$, Menziesii, Gray, Bot. U. S. E. E. p. 312 , pl. 29, B.

Haw aii! on Hualalai and the Central Plateau.

$\beta$ var. - Leaves silvery-canescent below or on both faces. - Var. $\beta$, hypoleucum, and $\gamma$, hololeucum, Gray, 1. c. and pl. 29, D.

Mauna Loa, from Kilauea upward, and Manna Kea.

Y var. pauciflorum. - Branches thick and stiff. Leaves coriaceous, broad-obovate, $10-12^{\prime \prime} \times 6-8^{\prime \prime}$, with $5-7$ teeth, canescent on both faces. Cymes few-(3-9-)flowered, not projecting.

Mauna Kea, at an elevation of $11000 \mathrm{ft}$., where it grows with Argyroxiphium. Gray, 1. c. pl. 29 , C.

2. G. tridens, sp. $n$. - Shrubby, erect, about $3 \mathrm{ft}$. high, the repeatedly forking branches stiff and gnarled, blackish, densely foliose above, scarcely stipulaceous below the leaves. Leaves narrow cuneate, $10-20^{\mu} \times 4-5^{\mu}$, on petioles of $3-6^{\prime \prime}$, thick coriaceous, silvery-tomentose on both faces with appressed silky hairs, sharply 3-, rarely 5-toothed at the narrow contracted apex, the $3-5$ nerves sunk, scarcely perceptible, and simple, Cymes 7-12-flowered, scarcely projected beyond the leaves, often shorter, white-silky throughout. Pedicels $2^{\prime \prime}$. Sepals $4^{\prime \prime}$, lanceolate, not mucronate, silky. Petals 7-8", obovate, white, with greenish veins. Carpellary beaks $6^{\prime \prime}$, silvery, the discreet stigmatic branches $2^{\prime \prime}$. $-G$. euneatum, var. 
$\gamma$, hololeucum, Gray, in part. - In 5-nerved leaves 2 nerves run out into the sinus between the teeth.

M aui! Haleakala, from 4000-8000 ft, common on the north and east slope. Called "Hinahina" (silver-gray) by the natives, as is the Argyroxiphium.

3. G. humile, sp. n. - A low trailing shrub, the slender blackish branches running to the length of 2 or $3 \mathrm{ft}$. and rooting, foliose at the ends and covered for some distance below with subulate stipules of $4-5^{\prime \prime}$. Leaves obovate-obtuse, $8-12^{\prime \prime} \times 4-6$ ", on petioles of $3 "$, $5-9$-toothed near the apex, thick coriaceous, silvery-tomentose underneath, dark-green above, but with a silvery pubescence along the $5-9$ simple nerves. Cymes few-(1-5-)flowered, projecting beyond the leaves, about $3^{\prime}$ long, the peduncle over $1^{\prime}$, the bracteolate pedicels $1 / 2^{\prime}$. Sepals silvery, ovate, $2-3 "$. Petals white, obovate, entire, $5-6 "$.

Summit of Eeka! Ma ui; and a similar plant in the swamps of Lehua makanui, Ka uai. Mrs. Sinclair, pl. 35 (leaves toothed, cymes single-flowered). Nat. name: "Nohuanu".

4. G. multiflorum, Gray, Bot. U. S. E. Exp. p. 311, pl. 29. - An undershrub with branches softly pubescent. Leaves membranous, green on both faces, roundish-obovate, $1^{1 / 2^{\prime}} \times 1^{\prime}$, on petioles of ${ }^{1 / 2^{\prime}}, 7$-9-nerved, with most nerves forking and anastomosing, deeply serrate in the upper half or two thirds into $13-17$ broad teeth. Stipules subulate, $4-5^{\prime \prime}$. Cyme compound, on a peduncle of $2-3^{\prime}$, bearing 30 or more flowers. Bracts subulate, scarious, $1^{\prime \prime}$. Pedicels $3^{\prime \prime}$. Sepals $3-4^{\prime \prime}$, mucronate, pubescent. Petals a little longer. Carpels pubescent, their beaks $8-9^{\prime \prime}$. Seeds smooth.

Hawaii, Waimea (U. S. E. E.).

$\beta$ var. canum, - Leaves silvery-tomentose on both faces, but glabrate with age, 7-9-nerved, with 9-11 serratures in the upper half. Stigmatic branches discreet, $1^{1 / 2} 2^{\prime \prime}$, glabrous.

N. edge of the crater of Haleakala! Maui.

5: G. ovatifolium, Gray, l. c. p. 314, pl. 30. - A shrub, several feet high, with spreading branches, which are covered with connate subulatepointed stipules. Leaves thin chartaceous, green on the upper, whitesilky on the lower face, ovate, $1-2^{1 / 2^{t}} \times{ }^{1 / 2}-1^{1} / 2^{1}$, on petioles of $1-1^{1} / 2^{\prime}$, acute, serrulate with numerous appressed toothlets, except at the obtuse or rounded base, 7-11-nerved, the nerves forking at the end and sparingly anastomosing. Cymes few-(3-7-)flowered, on short pluri-bracteate peduncles. Flowers rather large, the sepals purplish, ovate-oblong, mucronulate, the petals white, with purple veins. Seeds minutely reticulate. (Descr. according to Gray).

North bank of the crater of Haleakala, Maui (U. S. E. E.). No mention is made of the stigmatic branches, which are entirely wanting in the figure. Mr. Lydion is made of the specimens in the same region and labelled with the above name. In these the leaves agree in shape with the description, but are green underneath, although hispid. The 
dried petals are darker than in the several preceding species, but lighter than in the following one, and the stigmatic branches beyond the beaked portion are united into a long style exactly as in $G$. arboreum. Probably the species stands nearer to the last named than to preceding ones.

6. G. arboreum, Gray, 7. c. p. 315, pl. 31. - A tall arborescent shrub, $6-12 \mathrm{ft}$. high, with a trunk of often 4 inches in thickness, the long branches stipulate, distantly foliose toward the ends, and hispid with soft spreading hairlets, as are also the leaves and inflorescence. Stipules long-subulate from a broad base, $4-5^{\prime \prime}$. Leaves membranous, green on both faces, ovate-cordate, $1^{1 / 2}-2^{\prime} \times 1-1^{1 / 2^{\prime}}$, on petioles of $1 / 2-1^{\prime}$, pointed, sharply serrulate almost to the base with 8-14 teeth on each side, 7-nerved, the nerves freely forking and anastomosing. Cymes short, 3-4-flowered, on short lateral shoots, the peduncle and pedicels about ${ }^{1 / 2^{\prime}}$. Sepals lanceolate, abruptly awned, hairy, $6^{\prime \prime}$. Petals $9-10^{\prime \prime}$, dull red, obovate, entire, the 3 upper suberect, the 2 lower spreading. Glands minute. Stamens 10", hairy at the dilated bases. Carpels villous, their beaks as long as the stamens, but uniting beyond the axis into a simple glabrous style of nearly their own length which ends in 5 filiform branches. Seeds glabrous, minutely reticulate.

Southern stope of Haleakala! Maui, at an elevation of about $6000 \mathrm{ft}$. (near the path which leads from Ulupalakua to the crater).

$\dagger 7$. G. Carolinianum, L. - An annual or biennial herb, diffusely branching, pubescent. Stipules broad, scarious. Leaves on long petioles, palmately 5-cleft, the divisions cut again into oblong lobes. Peduncles axillary, $1-2^{\prime}$ long, 2-flowered, the pedicels $8^{\prime \prime}$. Bracts ovate-subulate. Sepals 2-3", mucronate. Petals scarcely longer, emarginate, pale red. Carpels hairy. Seeds reticulate. - Gray, Man. Bot. p. 73.

A native of North America which has become established in the open woods and pastures of Waimea! H a waii. In the Flora of New Zealand it is referred as a variety to G. dissectum, L., and its range stated to extend over the American continent from Canada to Cape Horn, also New Zealand.

\section{ERODIUM, L'Herit.}

Only 5 stamens antheriferous, those opposite the petals scale-like. Styles or carpellary beaks twisting spirally at maturity, bearded inside. Otherwise as in Geranium.

$\dagger$ 1. E. cicutarium, L'Herit. - A hairy annual, branching from the base, spreading. Leaves pinnate, the leaflets sessile, once or twice pinnatifid. Peduncle axillary, bearing an umbel of $2-8$ flowers, the pedicels $6^{\prime \prime}$. Sepals $2^{\prime \prime}$, acute, Petals a little longer, red.

A European weed, now common in California; is spreading in Waimeal Ka uai.

\section{PELARGONIUM, L'Herit.}

Calyx 5-parted, the uppermost lobe spurred, the spur adnate to the pedicel. Petals irregular, the 2 upper ones approximate at the sides or 
the back of the spur. No glands. Stamens 10, connate at the base, unequal, 3 generally without anthers. Carpels and styles as in Geranium. - Tall herbs or shrubs, mostly belonging to South Africa.

$\dagger$ 1. P. zonale, Willd. - Stem fleshy-frutescent. Leaves orbicular, cordate, shortly and obtusely lobed. Flowers in umbels on long peduncles, the pedicels glandular-pubescent. Petals bright red, the 2 upper shorter and narrower.

An occasional escape from cultivation.

\section{TROPAEOLUM, L.}

Calyx spurred, the spur free. Two upper petals larger and inserted near the spur, the 3 lower on claws. No glands. Stamens 8, free, unequal, all antheriferous. Ovary 3 -lobed. Carpels fleshy and rugose when mature, seceding from the short axis without opening. - Diffuse or climbing herbs, all South American.

$\dagger$ 1. T. majus, L. - A fleshy climbing herb with orbicular peltate leaves and large yellow or orange flowers.

The Nasturtium of the gardens, runs wild in Kula! Maui.

\section{ORDER XVII. ZYGOPHYLLACEAE.}

Sepals 5(-4), generally imbricate. Petals 5(-4), hypogynous, imbricate or contorted. Stamens of the same number or 2 or 3 times as many. Ovary sessile or raised, generally 5-4-celled, each cell with 1 or few pendulous or ascending ovules. Styles united into one. Fruit never a berry, often separating into several cocci or combined into a septicidal capsule. Embryo straight, with plane cotyledons; albumen corneous or none. - Herbs, shrubs or small trees, with stipulate, usually pinnate and opposite leaves, devoid of pellucid dots.

An Order chiefly tropical, occupying both hemispheres, but wanting in eastern Asia
dalaysia.

\section{TRIBULUS, I,}

Sepals and petals 5, both imbricate. Stamens 10 , inserted at the base of a 10-lobed annular disk, those opposite the petals a little longer, the alternate ones with a gland on the outside of the base. Ovary sessile, $5-12$-lobed, with an equal number of stigmas on a short style, the cells often partitioned by horizontal dissepiments. Ovules $1-5$ superposed in each cell. Fruit of 5-12 indehiscent cocei, which are hard and spinescent. Albumen none. - Herbs, with abruptly pinnate leaves and solitary
axillary flowers.

About 15 species, distributed over the warm regions of the globe. 
1. T. cistoides, L-DC. Prod. I, r03. - A perennial trailing herb, pubescent. Stipules $2-3{ }^{\prime \prime}$, linear. Leaves $2-3^{\prime}$ long, with generally 8 pairs of oblong leaflets, $6-8^{\prime \prime}$ long, somewhat obtuse, entire, with soft silky hairs on both faces, whitish underneath. Pedicels $1^{\prime}$ or more. Petals twice as long, pale yellow, oblong or obovate. Stamens $1 / 3$ the length of the petals, with capillary filaments and short ovoid anthers. Ovary surrounded by erect bristles. Style thick, elongate, with a clavate angular stigma. Cocci generally 5 or 6 , almost woody, tuberculate and hairy, with 2 divergent lateral spines about the middle, partitioned internally into four 1-seeded compartments. - Gray, Gen. Ill. II, pl. 145. Griseb. Fl. W. Ind, p. 134. - Mrs. Sinclair, pl. 30.

Along the seashore and in the lower plains here and there on all islands. Nat. name: "Nohu". A widely distributed plant of American origin. Found on most low coral-islands of the northern Pacific (Midway Isld.).

\section{ORDER XVIII. OXALIDACEAE.}

Sepals 5, imbricate. Petals 5, convolute. Stamens 10, slightly united at the base. No glands. Styles 5, distinct or united. Stigmas eapitate. Fruit a 5-celled capsule or berry, each cell with several seeds. Embryo straight; cotyledons plane; albumen thin. - Herbs, shrubs or small trees, with compound leaves, generally abounding in oxalic acid.

\section{OXALIS, L.}

Stamens all antheriferous. Ovary 5-lobed, 5-celled, each cell with one or several ovules. Styles distinct, dividing into 2 or more stigmatic branches. Capsule loculicidal, its valves remaining united with the short axis. Seeds crustaceous, with a loose fleshy coat or aril, which at length splits and turns back on the rhaphe. Albumen fleshy. - Herbs or rarely shrubs. Leaves radical or cauline, stipulate, alternate, 3- or manyfoliolate. Peduncles axillary or radical, bearing one flower or several in a cymose umbel.

A large genus, belonging chiefly to $\mathrm{S}$. America and S. Africa.

Peduncles axillary; flowers yellow

Peduneles radical; flowers red

1. 0. corniculata.

2. O. Martiana.

† 1. O. corniculata, L.-DC. Prod. I, 692. - A prostrate, much branching, delicate perennial, the hispid branches from a few inches to a foot and more long. Stipules adnate to the petioles, these about 1 ' long. Leaflets 3 , obcordate, sessile, 3-4". Peduncles axillary, about the length of the petioles, bearing an umbel of $2-6$ small yellow flowers on reflexed pedicels of $3-4^{\prime \prime}$. Stamens nearly as long as the styles. Capsule columnar, $1 / 2^{2}$ or more long, pubescent, many-seeded.

Probably of early introduction, but found everywhere in woods and waste places. A common weed in many parts of the globe. 
† 2. 0. Martiana, Zuccar. in Monogr. Amer. Oxal. p. 20. - Stemless, with a compound bulbous rhizome which is covered with brown 3-ribbed scales. Leaves radical, slightly hairy, the petioles $4-6 "$. Leaflets 3 , broadly obovate, emarginate, $8-10$ " long. Peduncles radical, longer than the petioles, bearing one or several umbels of flowers on branches of different lengths. Sepals obtuse, with 2 small glands at the tip, $2-2^{1} / 2^{\prime \prime}$. Petals 3 or 4 times as long, purplish or red, with green veins. Stamens hairy, the longer ones exceeding the hairy styles. - Bot. Mag. tab. 3938. - Benth, Fl. Hongk. p. 56. Brazil.

of more recent importation, but already found in woods and pastures. A native of

\section{ORDER XIX, a. RUTACEAE.}

Flowers usually regular. Sepals and petals $4-5$, rarely 3 or 2 , imbricate or valvate, the former usually small and often united at the base. Stamens as many or twice as many, free, or rarely united at the base, inserted with the petals round a hypogynous or slightly perigynous disk; anthers 2-celled. Carpels $1-5$, sessile or on a raised torus or short stalk, free at the top or combined into a several-celled ovary. Styles often free at the base, but usually combined upward with a capitate or lobed stigma which is sometimes sessile. Ovules 2, rarely 4-8 in each cell. Fruit either entire and indehiscent, or capsular with loculicidal dehiscence, or separating into distinct two-valved cocci, the outer coat generally separating from the inner, which is chartaceous, dry and elastic. Seeds smooth, with or without albumen. Cotyledons flat or crumpled. Trees or shrubs, rarely herbs. Leaves without stipules, entire or compound, generally marked with glandular dots.

A large Order of the tropical and temperate zones, represented in Polynesia by the genera Evodia; Acronychia, Melicope and the following:

Leaves simple, opposite or whorled:

Stamens free, petals valvate.

Stamens united; petals imbricate.

Leaves compound alternate; flowers unisexual

1. Pelea.

2. Platydesma.

3. Zanthoxylum.

\section{PELEA, GRAY.}

Flowers polygamous. Sepals 4, imbricate. Petals 4 , valvate. Stamens 8 , not exserted, those opposite the petals shorter than the alternate ones; filaments flattened; anthers short ovoid or sagittate, introrse. Hypogynous disk slightly 8 -lobed. Ovary 4 -celled, 4-lobed, with a single terminal 4 -lobed style. Ovules 2 in each cell, collateral, hemitropous, one ascending. Capsule quadrangular, subentire or more or less deeply 4-parted or 4-coccous, its cells or cocci divaricate, loculicidal. Seeds crustaceous with a black shining testa, partly adnate to a short and broad funis. Embryo straight in a fleshy albumen, with a short radicle and broadly ovate complanate 
cotyledons. - Unarmed trees. Leaves simple, entire, opposite or whorled, with a more or less defined intramarginal nerve, dotted underneath with minute oil-glands and emitting a spicy odor. Flowers in axillary, simple or compound, mostly paniculate cymes.

A Hawaiian genus, probably also represented in the Samoa and Society Islands. Nat. name: "Alani».

It seems inadmissible to separate the Hawaiian Alanis into two genera. The reason which induced Gray to divide them between Pelea and Melicope, viz., the supposed imbricate aestivation of the petals in some species with distinct cocei, is untenable, for in these the petals are not imbricate in the early bud, but always valvate, with induplicate margins, and cohere firmly with their uncinate tips, as is also the case in those species with united cocci or carpels. In $P$. cinerea and perhaps also in $P$. barbigera, which have rather broad petals, the resistance offered by the coherent apex forces one or more margins of the growing petals outward before expansion, but only near the base, while the apices remain valvate to the last. As regards the syncarpous or apocarpous character of the fruit, there is a gradual transition from almost complete union to entire separation.

The nearest affinity of our trees is, in my opinion, not with Melicope, a New Zealand genus from which they are also widely separated geographically*, but with Acronychia, a genus which ranges from Malaysia far into the Polynesian island world. With the latter they have in common the valvate petals and the terminal style, while the syncarpous capsules of $P$. sapotaefolia and $P$. anisata are scareely different from those of $A$. heterophylla and $A$. Richii, as figured in Gray's plates. In the fruit with distinct cocei the endocarp detaches itself completely from the pericarp at maturity, while in the syncarpous ones it remains adherent to the axis. From Melicope, on the other hand, they are distinguished, aside from the valvate aestivation of the petals, by the terminal style, not basal or lateral as in that genus (from between the lobes, Hooker, in Fl. N. Zeal.), and by the stigma, which is capitate in Melicope but divides into 4 filiform branches in Pelea. The embryo also is straight in Pelea, but slightly curved in Melicope.

The genus Pelea has polygamous flowers. The sterile flowers are larger than the fertile ones and have the aiternate stamens of about the length of the petals, while their style is very short, with convergent lobes. In the fertile flowers, on the contrary, the 4-cleft style with spreading lobes is nearly of the length of the petals, while the stamens are much reduced in size. Hermaphrodite flowers have been observed in $P$. clusiaefolia and $P$. Sandwicensis, and probably oecur in others, but would appear to be rare. The four carpels are united in the ovary with a single terminal style. As soon however as this has fallen, the apices, recognizable by the scars of the styles, begin to separate in consequence of increased growth of their axial side, and are gradually carried outward, so as at last to become lateral. The placentiferons portion follows this elongation, so that the seeds at length become pendulous from the horizontal upper side of each cell or coccus.

Capsule syncarpous, the carpels more or less united:

Flowers fasciculate on a short axis:

Leaves whorled; capsule deeply parted:

Leaves obovate; eapsule thick woody

Leaves lanceolate-acute; eapsule thin

1. P. clusiaefolia.

2. P. Waialealae.

Leaves opposite, sometimes whorled in no. 3:

Capsule cuboid, scarcely lobed, subentire:

Capsule broader than high, large, $12^{\prime \prime}$ transversely

Capsule as high as broad, small, about $6^{\prime \prime}$ in each diam.

Capsule deeply 4-parted; leaves cobwebby underneath .

3. P. sapotaefolia.

4. P. anisata.

5. P. Kauaiensis.

Flowers single or eymosely 3 , rarely 5 , on a slender peduncle and

long terete, often thickened pedicels; capsule deeply fourparted :

* I am aware that Nadéaud describes three new species of Melicope in his Enum. P1. Tah., but in the deseriptions he fails to give the very characters on which the correctness of the diagnosis depends. 
Leaves small ovate, less than $2^{\prime}$ long; flowers mostly 2 . Leaves larger, mostly obovate:

Leaves sessile

Leaves petiolate; pedicels $6-15^{\prime \prime} \mathrm{long}$, clavately thickened

Leaves petiolate; pedicels shorter, $3-4^{\prime \prime}$ long beyond the bracts :

Flowers 1-3; leaves oblong .

Flowers $3-5$; leaves suborbicular .
9. P. parvifolia.

8. P. Lydgatei.

7. P. macropus.

6. $P$, oblongifolia.

10. P. Molokaiensis.

Flowers paniculate, more than 5 , the peduncles and pedicels stiff angular:

Flowers very numerous, the panicle branching from the base 11. P. Mannii.

Flowers 5-18 on a pedunculate panicle:

Capsule moderately 4-lobed, its carpels connate about $1 / 2$

of their length.

12. P. Sandwicensis.

Capsule deeply 4-parted, the carpels stellately divaricate or recurred:

Leaves sessile

Leaves petiolate:

Petals glabrous

15. $P$, rotundifolia.

Petals hairy; leaves orbicular, emarginate at both ends 14 . $P$. orbicularis.

Capsules apocarpous, the carpels or follicles discreet, often one or more abortive; petals puberulous.

Leaves 3 in a whorl

16. P. pallida.

Leaves 2, opposite:

Inflorescence short, with an angular peduncle of less than $6^{\prime \prime}$ :

Leaves thin, glabrous, or with a sparse and pale pubescence; calyx and corolla persistent; capsule thin papery; endocarp glabrous

18. P. elliptica.

Leaves thick, mostly tomentose underneath when young; calyx aud corolla deciduous; capsule thick, endocarp pubescent

17. $P$. cinerea.

Inflorescence elongate, the peduncle $9-12^{\prime \prime}$ long:

Leaves cobwebby underneath; peduncle angular, with rather large bracts:

Leaves elliptico-oblong

Leaves broad cordate

19. P. barbigera.

20. P. Knudsenii.

Leaves glabrous; peduncle terete, with small bracts . 18. P. elliptica,var.ô.

1. P. clusiaefolia, Gray, Bot. U. S. E. Exp. p. 340, p7. 35. - A tree, about $20 \mathrm{ft}$. high, glabrous throughout. Leaves in whorls of 4 or 3 , rarely 2 , obovate or obovate-oblong, $2^{1 / 2}-4^{\prime} \times 1^{1 / 2}-2^{\prime}$, rounded or emarginate, with contracted base, thick coriaceous, with a continuous marginal nerve close to the edge, shining above, on petioles of ${ }^{1 / 2}-1^{\prime}$. Flowers in axillary clusters, often cauline, the thick peduncle scarcely $1^{\prime \prime}$ long, the pedicels $1-2^{\prime \prime}$, minutely bracteate at the base. Sepals triangular, $2^{\prime \prime}$. Petals $4 "$, whitish. Ovary glabrous. Capsule thick woody, about $8^{\prime \prime}$ transversely, 4-lobed, the carpels united to the middle, obtuse or obovate, keeled, and prominently marked with concentric wrinkles. - Mann, in Proc. Bost. Soe. Nat. Hist. X, 312. - Wawra, in Flora, 1873, p. 107. - Clusia sessitis, Hook. \& Arn. in Bot. Beech. p. 80. Oahu! on both ranges, those from Kaala with emarginate leaves; Ka uail the costa pubescent underneath.

$\beta$ var. - Leaves narrow, $3-4^{\prime} \times 1-1^{1} / 4^{\prime}$, on long petioles of $1^{1} / 4^{\prime}$. Capsules very sniall, only $4-6^{\prime \prime}$ transversely.

Oahu! Halemano. 
$\gamma$ var. - Leaves as in $\alpha$, but on short petioles, capsules small as in $\beta$.

Molokai! Maui! Hawaii!

In Mopulehu, Molokai, a specimen was collected from a straggling shrub which had neither flower nor fruit, with leaves whorled, subsessile, oblanceolate and acuminate, thin chartaceous. Probabiy identical with the var. $\gamma$ of Gray from Hawaii, but likely to be specifically distinct.

2. P. Waialealae, Wawra, in Flora, 1873, p. 108. - "A low shrub with slender straight branches, $3 \mathrm{ft}$. high, the young shoots puberulous, otherwise glabrous. Leaves quaternate, lanceolate, $3^{\prime} \times 1^{1 / 2} 2^{4}$, rather oblique, acute, thin coriaceous, gradually narrowing into a margined petiole. Flowers fasciculate, shortly stalked, the pedicels bibracteolate near the case and puberulous. Fem. $\mathrm{fl}$. Sepals broader than high, penni-nerved. Petals more than 3 times as long, puberulous at the base. Ovary glabrous. Capsule scarcely measuring ${ }^{1 / 2^{\prime}}$, deeply parted, thin chartaceous, green, the cocci globose and minutely reticulate, keeled along the sutures.»

Kauai, on the high plateau of Waialeale, $6000 \mathrm{ft}$. (Wawra).

3. P. sapotaefolia, Mann, in Proc. Bost. Soc. Nat. Hist. X, 312. - «A small tree, about $20 \mathrm{ft}$. high, much branched, the young leaf-buds hirsute. Leaves large, 4 or 3 in a whorl, elongate-oblong or spathulate, pale chartaceous, with almost horizontal parallel nerves, the marginal nerve rather close to the edge and subcontinuous, $4-9^{\prime} \times 2-3^{\prime}$, obtuse or emarginate, narrowing but rounded at the base, on petioles of $1^{1 / 2}-2^{\prime}$, villous-pubescent beneath, at least along the rib, quite glabrous above. Flowers in axillary clusters, the peduncle less than $1^{\prime \prime}$, the pedicels $2-3^{\prime \prime}$, bracteolate at the base. Sepals ovate, $1^{1 / 2^{\prime \prime}}$. Petals ovate, $2-2^{1 /} / 2^{\prime \prime}$. Ovary glabrous. Style as long as the petals, 4-parted nearly to the base, the divisions clavate and stigmatic near the summit.»

Kauai! Kealia and Hanalei (M. \& B., and Wawra).

$\beta$ var. - Leaves opposite, coriaceous, the nerves prominent beneath and cobwebby. Capsule chartaceous, quadrangular, $10-12^{\prime \prime}$ in the transverse diameter, 6 " high, subentire, only slightly notched at the middle of each side, the carpels cohering with their axis even after dehiscence which affects the upper and lower suture.

Kauai! Waimea (Kn.).

$\gamma$ var.? procumbens. - Low shrubby, with trailing, distantly foliose, subherbaceous branches. Leares opposite, elliptico-oblong, acuminate, contracted at the base, the marginal nerve quite near to the edge, glabrous underneath. Flowers $9-15$, in a short compound cyme or binodose cymose panicle which branches from the base, the slender rhachis 2-4", the slender pedicels $3-4^{\prime \prime}$, the lateral ones nodose at the middle. Sepals $1^{1 / 2} 2^{\prime \prime}$, petals $2^{\prime \prime}$. No capsules seen.

Kauai, on the high plateau back of Waimea (Kn, 165). 
4. P. anisata, Mann, l. c. p. 314. - A slender tree, $15-20 \mathrm{ft}$. high. Leaves opposite, oblong, $3-7^{\prime} \times 1^{1 / 2}-2^{1} / 4^{\prime}$, on petioles of $1^{\prime}$, obtuse or rounded at both ends, or emarginate with an attenuute base, chartaceous, the sinuate marginal nerve distant from the edge, with smaller secondary meshes intervening. Flowers small, $1-3$ or more on a common axis of less than $1 / 2^{\prime \prime}$, the pedicels $2^{\prime \prime}$, nodose at the middle. Sepals obtuse, $1^{\prime \prime}$ or less. Petals 2-3". Ovary glabrous. Capsule thick coriaceous, small, cuboid, not exceeding $6^{\prime \prime}$ in each diameter, subentire, the outer faces notched only by a shallow sulcus, the axis remaining entire after dehiscence. - Wawra, 1. c. p. 109.

Kauai! in various parts, but most abundant in Hanalei. Nat. name: "Mrokehana". - All parts of the tree, but particularly the capsules, when bruised, emit a strong spicy odor of anise.

5. P. Kauaiensis, Mann, l. c. p. 313. - A small tree, about $15 \mathrm{ft}$. high, with rambling branches. Leaves opposite, ovate or elliptico-oblong, $4-5^{\prime} \times 2-2^{1 / 2} 2^{\prime}$ on petioles of ${ }^{1 / 2}-1^{\prime}$, moderately acuminate, chartaceous, the marginal nerve remote from the edge, with one or two sets of meshes between, shining above, clothed underneath, especially along the midrib, with a dense velvety or cobwebby villosity. Flowers small, 1 or more in a cluster, on filiform pedicels of $2-3^{\prime \prime}$, which are bracteolate at the base. Sepals ovate, $1-1^{1 / 2}{ }^{\prime \prime}$. Petals thin, $1^{1 / 2}-2^{1 / 2} 2^{\prime \prime}$. Capsule (full grown, but with seeds not matured) rather thin, deeply 4-parted to near the base, the elongate cocci divaricate and recurved, about 6 "long and less than $3^{\prime \prime}$ high, keeled at the upper suture, one or more often abortive.

The leaves bear a suspicious resemblance to $P$. (Melicope) barbigera from the same region.

Kauai! Waimea, at elevations of $2000-3000 \mathrm{ft}$. (M. \& B., and Kn. 64).

$\beta$ var. glabra. - Leaves ovate, broader, subemarginate at the base, on longer petioles, quite glabrous underneath. Flowers in clusters of $3-6$, glabrous, with whitish petals. A low tree, rather shrubby.

Same region (Kn, 200).

6. P. oblongifolia, Gray, l. c. p. 343. - A tall spreading shrub, 8-12 ft. high, with slender branches, glabrous almost throughout. Leaves opposite, rarely ternate, elliptico- or obovately-oblong, $2^{1 / 2}-4^{1} / 2^{\prime} \times 1-2^{\prime}$, on petioles of $4-6^{\prime \prime}$, bluntly acuminate or rounded, even emarginate at the apex, contracted but truncate and subemarginate at the base, chartaceous, shining on both sides, the marginal nerve almost straight and near the edge. Flowers quite glabrous, generally single on a filiform $2-3$-nodose peduncle of $4-12^{\prime \prime}$, the filiform pedicel $6-9^{\prime \prime}$, minutely bracteolate at the middle, rarely 2 flowers in a cyme. Sepals $1-1^{1 / 2} 2^{\prime \prime}$. Petals 3-4", greenish-white, triangular or lanceolate-acute. Capsule chartaceous, with thin endocarp, about $1^{\prime}$ across and $2-3^{\prime \prime}$ high; its carpels parted to at least $3 / 4$ of their length, keeled above, horizontally divaricate, at length recurved, one or more often abortive. Seeds 
large, 3-4". Cotyledons thin, and flat on both sides. - Mann, l. c. p. 315 (in part). - Wawra, 1. c. p. 137.

On all islands, but rare, oceurring only in isolated individuals. Oahu! Hatemano; Molokai! Mopulehu and Halawa; Kauai! Kealia; Maui! Hamakua; Lanai!

$\beta$ var.? - Ovary and capsule fulvo-tomentose, the carpels or cocci of the latter cohering only at the base. Endocarp pubescent. Flowers 1-3 on a long and slender peduncle. Leaves large, $4-6^{\prime} \times 2-3^{\prime}$.

Hawaii! S. Kona.

7. P. macropus, $s p . n$. - A small tree, about $15 \mathrm{ft}$. high, quite glabrous. Leaves as in the broad-leaved forms of the preceding species, but contracted and not emarginate at the base. Flowers single, on a short peduncle of $1-2 "$, which bears 1 or 2 pairs of minute bractlets, the pedicels beyond them clavately thickened to the length of $12-15^{\prime \prime}$. Petals greenish. Capsule nearly $1^{1 / 2^{\prime}}$ transversely and $4^{\prime \prime}$ high, its earpels parted more than 1/2 their length (one-seeded in my specimens, and therefore pointed).

Kauai! Waimea (Kn. 189). The thickening of the pedicel, already considerable in the bud, increases after the lapse of the flowers, and attains a diameter of $1^{1 / 2} 2^{\prime \prime}$ when the capsule matures.

8. P. Lydgatei, sp. n. - Shrubby, quite glabrous. Leaves sessile, cordate and auriculate at the base, obovately-oblong, chartaceous, 4-5. $\times 2-2^{1} / 2^{1}$. Inflorescence and flowers as in P. oblongifolia.

Oahu! Paloto (Lydg.).

9. P. parvifolia, $s p . n$. - Shrubby, 5-8 ft. high, with closely foliose, short and stiff, crowded branches, glabrous. Leaves small ovate or ovateoblong, $1^{1 / 2}-2^{\prime} \times 1-1^{1 / 2^{\prime}}$, on short petioles of $1-3^{\prime \prime}$, acute, subemarginate at the base, rather coriaceous, dull, darkgreen, the marginal nerve near the edge. Flowers 2, less commonly 1 or 3 , on a short peduncle of $1 / 2-2^{\prime \prime}$, the slender pedicels $8-10 "$, nodose below the middle. Sterile fl. large, quite glabrous, the acute petals $4-5^{\prime \prime}$, three times as long as the triangular sepals. Ovary faintly pubescent.

Ma ui! Eeka, at an elevation of $5000 \mathrm{ft}$., and doubtfully Hawaii. A specimen from the latter island with larger leaves bears a deeply parted, capsule like that of $P$. oblongifolia.

10. P. Molokaiensis, $s p . u$. - A small tree, about $20 \mathrm{ft}$. high, the young shoots slightly puberulous. Leaves $4-5^{4} \times 2^{3 / 4}-3^{1 / 4^{\prime}}$, on petioles of $6-12^{\prime \prime}$, chartaceous, with nerves little prominent, quite glabrous even on the reddish midrib, obovate, with retuse base and rounded or emarginate apex, the marginal nerve at some distance from the edge, with one or two sets of meshes intervening. Flowers glabrous, $2-5$ in a cyme or pseudo-raceme of $9-18^{\prime \prime}$ in length, the terete slender rhachis with $2-3$ nodes, the pedicels $5-6^{\prime \prime}$, nodose near the middle and thickened beyond. Sepals triangular, $1^{1 / 2}-2^{\prime \prime}$. Petals reddish, $2^{1 / 2}-3^{\prime \prime}$. Capsule as in $P$. volcanica, $10-18^{\prime \prime}$ transversely.

The prevailing form on Molokai! also on W. Maui!

Hillebrand, Flora of the Hawaiian Islands. 
$\beta$ var.? - Leaves smaller, suborbicular, emarginate at the base, thick coriaceous, with prominent nerves, the marginal one nearer the edge, quite glabrous and shining, $2-2^{1} / 2^{\prime} \times 1^{1 /} / 2-2^{\prime}$. Inflorescence $3-7$-flowered, with shorter pedicels which are little thickened beyond the nodes, and the rhachis rather stiff angular, nearly as in P. Sandwicensis. Flowers smaller than in $\alpha$. Capsule not seen.

Oahu! Niu. Leaves as in P. orbicularis, all on long petioles. Collected also by the U. S. E. E.

11. P. Mannii, sp. n. - A small tree. Leaves opposite, obovate, $2^{1 / 2}-3^{\prime} \times 1^{1 / 2}-2^{\prime}$, on petioles of $6-9^{\prime \prime}$, rounded, emarginate, coriaceous, the marginal vein separated from the edge by one set of meshes, the midrib pubescent. Flowers numerons, $20-50$, on a panicle of $1-1^{1 / 2}$ in length with 3-4 nodes, divaricately branching from the base and at every node, the branches again repeatedly cymose or paniculate, the ultimate pedicels $1-2^{\prime \prime}$ long and thickened. Petals of sterile fl. $2^{\prime \prime}$, twice as long as the somewhat obtuse sepals. Stamens as long as the petals. Ovary glabrate.

E. Maui! Hamakua (M. \& B. 376, and Lydg.). The specific value of the copious inflorescence is not free of doubt, for a few specimens from the same region with similar leaves exhibit only $7-9$ flowerbuds with thickened pedicels of the same length. Smallleaved and rather glabrous forms of $P$. volcanica grow in the same part of that island.

12. P. Sandwicensis, Gray, l. c. p. 345, pl. 37. - A tree, 20-30 ft. high, the young shoots and inflorescence covered with a coarse gray pubescence. Leaves opposite, elliptico- or obovato-oblong, $3-6^{\prime} \times 1^{1 / 4}-3^{\prime}$, on petioles of $1-1^{1} / 2^{4}$, bluntly pointed or rounded, thick coriaceous, with prominent nerves, the marginal nerve near the edge, petioles and midrib furfuraceous, occasionally hirsute. Flowers $9-18$, on a cymose erect panicle of $9-18^{\prime \prime}$ in length with 3 (rarely 4 or 5 ) nodes, the stiff angular peduncle $3-9^{\prime \prime}$, the lowest branches with $1-2$ nodes and the ultimate pedicels only ${ }^{1} / 2-1^{\prime \prime}$. Bractlets dentiform. Sepals puberulous, $1-1^{1} / 2^{\prime \prime}$. Petals glabrous, greenish-white, $2^{1 / 2}-3^{\prime \prime}$ in the sterile flowers, about ${ }^{1 / 3}$ shorter in the fertile ones. Ovary puberulous. Capsule glabrate, coriaceous, $4-8^{\prime \prime}$ in the transverse, $3-5^{\prime \prime}$ in the vertical diameter, its carpels parted less than halfway. Endoearp glabrous in all my specimens (pubescent according to Gray). Seeds $3^{\prime \prime}$. Cotyledons rather thick, planoconvex. - Mann, 1. c. p. 315. - Brunellia Sandwicensis, Gaud. in Bot. Freye., and Hook. \& Arn. in Bot. Beech. p. 80.

Oa hu! common in the main range, particularly its western division. In the woods of Waialua I collected a speeimen with extraordinarily large leaves, $11^{\prime} \times 3^{1 / 2}$. In Gray's figure the capsule is not correetly given, in fact it hardly differs there from that of $P$. voleanica on the next plate.

$\beta$ var. - Leaves thinner, chartaceous, quite glabrous, even on the midrib and the shorter petiole. Oil-dots very conspicuous. Capsule larger, 9-12" transversely.

Oahu! with the form $\alpha$; Kauai! (Kn.), and doubtful forms with obtuse leaves on Molokai (Kalae)! and Maui (Oloalu and Hamakua)! 
$\gamma$ var. - Leaves 3 in a whorl, otherwise as in $\beta$.

Oahu! Halemano.

ò var. lucens. - Leaves small, elliptical, $2-3^{\prime} \times 1-1^{1 / 2^{\prime}}$, on petioles of $3-6^{\prime \prime}$, bluntly acuminate, pale, glabrous and shining on both sides, densely dotted, the marginal nerve close to the edge and straight. Inflorescence 3-7-11-flowered, glabrous and short, not exceeding $6^{\prime \prime}$, the ultimate pedicels short and angular as above. Petals of fertile fl. $2^{\mu}$, of sterile fl. $2-3^{\prime \prime}$. Capsule as in $\beta$.

Oahu! Kaala range (Makaleha). Here belongs M. \& B's 208.

13. P. volcanica, Gray, l. c. p. 346, pl. 38. - A tall tree, 20-40 ft. or more in height, the young shoots and inflorescence coarsely pubescent. Leaves opposite, obovate-oblong, $3-6^{\prime} \times 2-3^{1 / 2^{\prime}}$, on petioles of ${ }^{1 / 2}-2^{\prime}$, rounded, even emarginate and mucronulate at the apex, little contracting below, pale and thick coriaceous, with prominent reddish rib and nerves, the marginal nerve rather near the edge, the midrib generally, at least in the early stage, pubescent or hairy. Inflorescence paniculate as in no. 12, but the flowers larger and reddish and their ultimate pedicels longer, $1-1^{1} / 2^{\prime \prime}$, and slightly thickened. Bracts $1^{1 /} / 2^{\prime \prime}$. Sepals pubescent, $1^{1 / 2}-2^{\prime \prime}$. Petals of sterile fl. 4", glabrous. Ovary pubescent. Capsule glabrous, large, $1-1^{1} / 2^{\prime}$ transversely and $4-5^{\prime \prime}$ high, the carpels parted to $3 / 4$ their Iength, horizontally spreading, stellate, even recurved. Cotyledons planoconvex. - Mann, 1. c. p. 315.

Upper regions of Hawail! and Maui! also Lanai! (leaves smaller and glabrous).

$\beta$ var. grandifolia. - Leaves very large and dark, obovate-oblong or suborbicular, often attaining a size of $9^{4} \times 5^{1} / 2^{\prime}$, chartaceous, with prominent areoles, the marginal nerve quite distant from the edge, sinuate, with several meshes intervening. Infl. tomentose, in my specimens shorter than in $\%$, but the flowers large. Capsule $1^{\prime}$ across, parted more than halfway.

Hawaii! in woods near Hilo,

$\gamma$ var. ovalifolia. - A tall tree as before. Leaves ovate-oblong, 4-54 $\times 2-2^{1 / 2} 2^{\prime}$, emarginate or subcordate at the base and generally pointed at the apex, coriaceous, the marginal nerve near the edge, midrib and nerves at first hairy, but glabrate at last. Infl. as in $\alpha$, tomentose, a single panicle $1^{1 / 2}-2^{\prime}$ long with $5-9$ flowers, or 2 shorter and fewerflowered racemes from a common short axis. Pedicels $1^{\prime \prime}$, not thickened. Sepals tomentose, $1^{1 / 2}-2^{\prime \prime}$. Petals twice as long in the sterile flowers, glabrate or puberulous. Capsule as above.

Maui! Waihee and southeru slope of Haleakala. One of my specimens exhibits both ovate and elliptico-oblong, another ovate and obovate leaves on the same branch.

14. P. orbicularis, $s p \cdot n$. - A small stunted tree, the young shoots coarsely hirsute. Leaves opposite, almost orbicular, $2^{1 / 2-3^{4}}$ in each 
diameter, on petioles of $6-9^{\prime \prime}$, emarginate at both ends, mucronate, thick coriaceous, with prominent reddish nerves, the marginal nerve continuous and close to the edge, the midrib underneath hirsute and the lower face covered with a scattering pubescence, but glabrate at a later time. Oildots copious. Panicle as in the two preceding species, $12-15$-flowered, hirsute. Sepals and petals hairy, the latter in the fertile fl. about $3^{\prime \prime}$ long, the sepals not much shorter, the stamens less than $1 / 2$ the length and narrow sagittate, the lobes of the style short and thick. Ovary tomentose.

Ma ui! summit of Mt. Eeka, $6000 \mathrm{ft}$; a similar form on the top of Mt. Kaala, O a hu (M. \& B. in herb. Cornell Univers. without number).

15. P. rotundifolia, Gray, l. c. p. 344, pl.37. - A small tree. Leaves sessile or subsessile, round or very shortly pointed, $2^{1 / 2}-3^{1 / 2^{\prime}}$ in each diameter or a little less in the transverse one, cordate at the base, thick coriaceous and prominently nerved below, the marginal nerve arcuate and distant from the edge, with intervening meshes, entirely glabrous. Flowers $3-7$ in a puberulous cyme or pseudo-raceme, the angular peduncle 4 ", the pedicels $2-3$ ", bracteolate above the middle; bractlets $1^{1 / 2} / 2^{\prime \prime}$. Sepals $1^{1 / 2} 2^{\prime \prime}$, the reddish petals $3^{\prime \prime}$. Capsule as in $P$. volcanica. - Mann, 1. c. p. 315. - Wawra, 1. c. p. 137.

$\mathrm{Oahu}$, eastern division of the main range.

16. P. pallida, $s p$. $n$. - Leaves ternate, ovate-oblong, $5-7^{4} \times 2^{1 / 4}-2^{3 / 4}$, shortly acuminate, truncate and emarginate at the base, thin chartaceous, pale, glabrous, on petioles of $1^{1 / 2}-2^{\prime}$. Flowers numerous, $15-35$, in a glabrate compound panicle of $2^{\prime}$ in length, the peduncle $6-9^{\prime \prime}$, the subulate bracts $1^{1} / 2^{\prime \prime}$. Sepals and petals puberulous, the former rather acutely ovate, $1^{1} / 2^{\prime \prime}$, the latter valvate. Ovary glabrous.

Oa hu! Kaala range.

17. P. cinerea, Hillebr. - A small tree, $15-20 \mathrm{ft}$. high, the young shoots covered with a grayish or ochraceous tomentum. Leaves opposite, ovate-oblong, $3-4^{\prime} \times 1^{1 / 2}-2^{\prime}$ on petioles of $8-12^{\prime \prime}$, shortly acuminate, subcoriaceous, with faint nerves, the marginal nerve distant and arcuate, tomentulose underneath, but soon glabrate. Flowers $3-5$ in a short cyme or raceme, the angular peduncle $3-6^{\prime \prime}$, the pedicels $2-4^{\prime \prime}$, bibracteolate at the middle, the bractlets about $1^{1} 2^{\prime \prime}$. Petals $2^{\prime \prime}$, valvate in the bud, but some edges forced out before expansion, gray-puberulous. Ovary tomentose. Capsule $10-12^{\prime \prime}$ transversely, the follicles cohering slightly at the base only, soon glabrate, thick-coriaceous, opening only along the ventral suture, generally all maturing; the thick endocarp pubescent! Seeds 1 or 2 in each follicle, $2-3^{\prime \prime}$ in diam. Cotyledons plano-convex, extending the whole length and breadth of the albumen. - Melicope cinerea, Gray, l. c. p. 350 ; pl. $39 .-$ Mann, l. c. p. 316.

$\mathrm{O}$ a $\mathrm{u}$ ! main range, ehiefly in the western division. 
$\beta$ var. - Tomentum olivaceous. Leaves thick coriaceous, sometimes emarginate at the base, tomentose below or glabrate. Inflor. and follicles tomentose, these not $10^{\prime \prime}$ thick as in a. Petals of sterile fl. $3^{\prime \prime}$ or more. Cymes of various length, some very short and 3 -flowered, others 6 "long and 5-flowered. Capsule $6-10^{\prime \prime}$ in diam.

Lanai! Maui! Makawao (M. \& B. 371). On the dry fore-hills of the first named island the leaves are much smaller.

$\gamma$ var. - Tomentum fulvous. Leaves as in $\alpha$, somewhat obtuse, tomentose underneath or glabrate, rather dark. Capsule thickly tomentose, the follicles $6-8^{\prime \prime}$. - P. Hawaiiensis, Wawra, 1. c. p. 110.

Hawaii! Kohala range.

o var. - A shrub with long rambling branches. Leaves as in $\gamma$, but larger, thinner and quite glabrate and shining, $5-6^{\prime} \times 2-3^{\prime}$. Peduncle about 6 "long and 5 -flowered, the coriaceous capsule fulvo-tomentose, with mostly all follicles developed.

Hawail! Kau and S. Kona. In all these varieties the endocarp is pubescent.

18. P. elliptica, Hillebr. - A small tree. Leaves thin chartaceous, with pellucid dots, elliptico-oblong, $3-5^{\prime} \times 1-2^{1 /} / 2^{\prime}$, on petioles of $4-8^{\prime \prime}$, broadly obtuse or rounded, even emarginate at both ends, faintly nerved, with the sinuous marginal nerve rather distant from the edge, sparsely dotted underneath with a pale pubescence, but soon glabrous and pale. Flowers $1-3$ on a short angular peduncle of $1-3^{\prime \prime}$, the pedicels $3^{\prime \prime}$, bracteolate below the middle with dentiform bractlets; sometimes several cymes in one axilla. Sepals and petals coriaceous, persistent below the capsule, both canescent in the bud, but subglabrate at a later period. Sepals $1^{\prime \prime}$, obtuse, petals valvate in the bud, oblong, $1^{1 / 2}-2^{1 / 2} 2^{\prime}$. Style obscurely 4 -lobed, almost capitate in the sterile flowers. Follicles discreet to the base, gray-puberulous, $4-5^{\prime \prime}$, thin papery, dehiscent in both sutures, one or more abortive. Endocarp glabrous. - Melicope elliptica, Gray, 1. c. p. 353. - Mann, 1. c. p. 317. - P. Kaalae, Wawra, 1. c. p. 110.

Oahu! Kaala range.

$\beta$ var. - Leaves broad and emarginate at both ends, the midrib and principal nerves softly pubescent below. Sepals and petals gray puberulous, as above, and persistent.

Maui! Oloalu.

7 var. - Leaves elongate, subacuminate, $4-6^{\prime} \times 1^{1 / 2}-2^{\prime}$, on petioles of 1 ', softly pubescent underneath. Flowers $3-7$ on a short axis. Sepals and petals eanescent, persistent. Endocarp glabrous.

Mauil Hamakua and Ulupalakua.

o var. elongata. - Shrubby, quite glabrous. Leaves elongate and subacuminate. Peduncle elongate and slender, 6-12" long, 3-flowered, 
with pedicels $3-4^{\prime \prime}$ and bracteolate as before. Sepals and petals canescent. Ovary glabrous.

Oahu! Niu.

$\varepsilon$ var. - Leaves pubescent underneath, elongate and often acuminate. Flowers $3-5$ on an elongate peduncle of $4-9^{\prime \prime}$. Sepals $1^{1 / 2} 2^{\prime \prime}$, petals $2-3^{\prime \prime}$, both canescent and persistent. Follicles $4^{\prime \prime}$, chartaceous and pale-tomentose, transversely rugose. Endocarp pubescent.

Molokai! Kalae and Maunaloa.

19. P. barbigera, Hillebr. - A small tree. Leaves elliptico-oblong, $4-5^{\prime} \times 2-2^{1} \gamma_{2}^{\prime}$, on petioles of $1-2^{\prime}$, contracting but obtuse at both ends, green and shining above, beneath densely clothed, especially along the midrib, with a long cobwebby wool, which however disappears with age, chartaceous, with faint nerves. Flowers $3-5$ on a stiff angular graytomentose peduncle or rhachis of $8-16^{\prime \prime}$, the pedicels $1-3^{\prime \prime}$ long and bracteolate at the middle, the bracts and bractlets unusually large for the genus, 4-3". Sepals and petals gray-tomentose, the former ovate-acute, $1^{1 / 2}-2^{\prime \prime}$, the latter $2^{1 / 2}-3^{\prime \prime}$. Ovary sparingly pubescent. Follicles discreet, one or another abortive, obovoid, $4-6^{\prime}$ long, almost glabrate and dark, rather thin, concentrically striate (1-seeded in my specimens). Endocarp glabrous. - Melicope barbigera, Gray, 1. c. p. 351, pl. 39. - Mann, 1. c. p. 316 .

Ka ua i! Waimea, at an elevation of $3000 \mathrm{ft}$. In some specimens the peculiar pubescence is quite searce and confined to the midrib. To this species or to $P$, cinerea probably belongs also a form from the same locality (Kn. 59) which has the underside of the leaves covered with a uniform short and dense olivaceous tomentum.

20. P. Knudsenii, $s p . n$. - A tree, about $30 \mathrm{ft}$. high, the young shoots and inflorescence covered with a gray tomentum. Leaves opposite, $5-6^{\prime} \times 3-4^{\prime}$, on petioles of $2-2^{1} / 2^{2}$, ovate or ovate-oblong, cordate at the base, or the basal lobes connate, with the petiole subpeltately inserted above the base, bluntish, glabrous above, pubescent underneath, the midrib and nerves densely villous with a soft grayish wool, thin chartaceous, with the marginal nerve in deep arches. Flowers numerous, 20-40, in a large pyramidal panicle of $2-2^{1 / 2}$ in length with $3-4$ pairs of divaricate branches, the stiff angular peduncle about $12^{\prime \prime}$, the ultimate pedicels very short, with the last bractlets close to the calyx. Bracts $4-3^{\prime \prime}$. Calyx and corolla villous externally, the sepals $3^{\prime \prime}$, the oblong petals scarcely longer. Disk 8-lobed, hairy. Ovary sparsely pubescent.

Kauai! Waimea (Kn. 210), at an elevation of $1500 \mathrm{ft}$.

\section{Platydesma, Mann; char. auct.}

Flowers hermaphrodite. Sepals 4 , persistent, strongly imbricate (2 exterior and 2 interior), rounded. Petals 4 , imbricate (either convolute, all petals with one margin overlapping, or one petal external and a contiguous one internal, the two others with one margin each overlapping). 
Disk plane, slightly 4-8-lobed. Stamens 8 , inserted outside the disk, the filaments united into a wide tube, the anther-cells elongate, attached to each side of protruding lobes of the staminal tube, introrse, converging at the top. Ovary 4-lobed. Style terminal, undivided, truncate, the stigmas indicated by 4 lines. Ovules $5-8$ in each cell, suspended from a short and broad flat funis, hemitropous. Capsule dry, 4-lobed, loculicidal (or indehiscent), with a thin endocarp, several-seeded. Seeds crustaceous, angular-convex, with a black shining testa. Embryo straight, in the middle of a fleshy albumen, equalling it in length and width, the cotyledons thin, broad and rounded, the radicle short, terete. Small trees or shrubs, with a heavy turpentiny odor. Leaves opposite or whorled, with copious oil-dots, simple, entire. Flowers in axillary cymes, rather large. - H. Mann, in Mem. Bost. Soc. Nat. Hist. I, 529.

A peculiarly Hawaiian genus, remarkable in the Order for its monadelphous stamens. The principal nerves of the leaves divide at about $2 / 3$ the distance from the midrib into two main branches which form prominent anastomoses with the corresponding ones of the next nerves, thus constituting a sinuate intramarginal nerve which is separated from the edge by several series of secondary areoles.

Leaves opposite:

Leaves petiolate; carpels connate to the apex.

Leaves subsessile; carpels discreet at the top:

Carpels ending in a short point

Carpels ending in a subulate beak

Leaves ternate; carpels deeply parted

1. P. campanulata.

2. P. cornuta.

3. P. rostrata.

4. $P$. auriculaefolia.

1. P. companulata, Mann, in Mem. Bost. Soc. Nat. Hist. I, 529, pl. 22. - A small tree, $15-20 \mathrm{ft}$. high. Leaves opposite, spathulate or obovate-oblong, $4-8^{i} \times 2-3^{i}$, on petioles of $1-2^{i}$, bluntly acuminate or rounded at the apex, narrowing but rounded at the base, thin chartaceous, with transparent dots, glabrous, the nerves not prominent. Flowers $3-9$ in a cyme or cymose panicle, the peduncle $5-15^{\prime \prime}$, the pedicels $3-5^{4 \prime}$, bibracteolate above the middle with small dentiform bractlets. Sepals round, $3-4^{\prime \prime}$ in diameter, coriaceous, glabrous. Petals obovate or oblong, $7-9^{\prime \prime}$, white, thick, puberulent in the bud. Staminal tube nearly as long as the petals. Ovary puberulous, with $5-6$ ovules in each cell. Style $2-3^{\prime \prime}$, terminal and central. Capsule chartaceous, subglobose, $7-9^{\prime \prime}$ high, deeply 4-lobed, but the carpels cohering at the axis from the base to the top, erect, not divaricate.

Oahu! Pauoa and Manoa; Ka uai! Waimea (Kn,), Kealia (Wawra), the leaves cuneate at the base, not rounded.

$\beta$ var. pallida. - Leaves smaller and thicker, pale, pubescent or tomentose underneath and minutely dotted. Peduncle, sepals and petals pubescent, the latter smaller, 4-5".

Oahu! Kaala; E. Maui! Hamakua (Lydg.).

$\gamma$ var. macrophylla. - Leaves large, $9-12^{\prime} \times 3-4^{\prime}$, on petioles of $3-4^{\prime \prime}$, thin, almost membranous, quite glabrous and dark green on 
both sides. Flowers as in $\alpha$. Style $4-5^{\prime \prime}$ long. Capsule nearly 12 " high.

Kauai! (Kn.),

I have little doubt that to $\alpha$ belongs Melicope spathulata, Gray, Bot. U. S. E. E. p. 352 , of which a single imperfect specimen was collected on Kauai by the naturalists of the U. S. E. Exp., but which is not preserved in herb. Gray. "Shrubby, the leaves coriaceous, spathulate-oblong or oblanceolate, obtuse, tapering to an acute base, $3-6^{\prime} \times$ $1-2$, pale and dull, with copious black dots, on petioles of $6-8^{\prime \prime}$. Peduncle short, $2^{\prime \prime}$, bibracteolate, 3 -flowered, the pedicels $3-4^{\prime \prime}$, bracteolate at the middle. Sepals large, $3^{\prime \prime}$, glabrous and orbicular, thickish, with thin margins, and strongly imbricate. Petals orbicular and glabrous, strongly imbricate in the young bud. Connective of anthers glandular. Ovary glabrous, its carpels apparently distinct, or nearly son.

2. P. cornuta, sp. n. - Shrubby, quite glabrous, the stiff erect branches closely foliose near the ends, light-wooded. Leaves opposite, subsessile or on short petioles of $1-2^{\prime \prime}$, obovate or lanceolate, $8-16^{\prime} \times 3-5^{\prime}$, gradually narrowing toward the base but rounded off at last, chartaceous, with copious pellucid dots. Flowers $9-15$ in axillary subsessile cymose clusters, the pedicels $3^{\prime \prime}$, minutely bibracteolate below the middle. Sepals rounded, $1^{1 / 2}-2^{\prime \prime}$. Petals 3 times as long, broadly lanceolate, slightly connate at the base, white. Staminal tube as long as the petals and at the base connate with them. Disk 8-lobed. Ovary glabrous, 4lobed above, with $7-8$ ovules in each cell. Styles united into a single one with 4 stigmatic lines, but splitting at maturity with the separation of the apices of the carpels. Capsule thin papery, $6^{\prime \prime}$ long, its carpels united in the lower half, only divided by shallow grooves, but their upper halves discreet and diverging, each ending in a sharp point. - Melicope grandifolia, Wawra (but hardly of Gray).

Oahu! Halemano, Wailupe, Pauoa. - Wawra's specimens derived from my collection. Gray's Melicope? grandifolia, Bot. U. S. E. Exp. p. 354, came from the forests of Mauna Kea, Hawaii. Only leaf-shoots were collected from a tree the trunk of which measured $8-10^{\prime}$ in diam. The description of the leaves agrees in the main with those of the present species, but they had a cuneate base and a pubescence of sparse hairs on the lower face. No specimen exists in Herb. Gray.

3. P. rostrata, sp. n. - Shrubby as before. Leaves opposite, subsessile, linear-oblong, $12-16^{\prime} \times 2-3^{\prime}$, of nearly even width from the suddenly rounded base to the bluntly acuminate apex, dark green, glabrous. Flowers $12-20$ in shortly pedunculate cymose clusters. Sepals $2^{\prime \prime}$, puberulous. Petals $5^{\prime \prime}$. Capsule 6 "long, ovoid, indehiscent (?), the carpels connate nearly their entire length, but the apices diverging and ending in subulate beaks of $4^{\prime \prime}$ in length, the permanent styles; 8 seeds in each cell.

Kauail (Kn. 68).

4. P.auriculaefolia, Hillebr. - An upright, light-wooded, sparingly branched shrub of about $6 \mathrm{ft}$, in height, the subherbaceous branches distantly foliose. Leaves 3 in a whorl, subsessile, oblanceolate or spathulate, $6-10^{\prime} \times 2-4^{\prime}$, bluntly acuminate, rounded and somewhat auricled at 
the narrowing base, chartaceous, puberulous underneath. Flowers in axillary or cauline clusters, the peduncle very short. Sepals $3^{1} / 2^{n}$, rounded, pubescent. Petals $4^{1} / 2^{\prime \prime}$, white, imbricate, puberulous. Stamens monadelphous. Style short and thick truncate. Capsule deeply 4-parted, with obtuse lobes, the carpels 2-seeded. - Pelea auriculaefolia, Gray, Bot. U. S. E. E. p. 343, pl. 36. - Mann, in Proc. Bost. Soc. Nat. Hist. X, 313.

H awaii! forests of Mauna Kea (U. S. E. E.); Kohala range above Waimea (Hbd.); woods of Laupahoehoe (Lydg.), leaves glabrous underneath. The description of the fruit according to Gray.

\section{ZANTHOXYLUM, L.}

Flowers unisexual. Calyx 5-3-cleft, with imbricate Iobes. Petals 5, 4 , or rarely 3 or 2 or none, imbricate in the bud, rarely valvate. Stamens as many, rudimentary or wanting in the female flowers. Carpels oblique, $5-1$ on a raised torus or short stalk, free, or united at the base, with 2 collateral ovules in each, rudimentary in the male flower. Styles somewhat lateral, distinct, or united at the top, with capitate stigmas. Follicles distinct, opening into 2 valves. Seeds ovoid or globular, with a black shining crustaceous testa. Embryo straight or slightly curved, in a fleshy albumen. - Trees or shrubs, often prickly. Leaves alternate, impari-pinnate or ternate, rarely unifoliolate, mostly dotted with pellucid oil-glands. Flowers small, in axillary or terminal cymes or panicles.

A considerable genus, common to the New and old World, chiefly tropical, not found in Polynesia outside the Hawaiian group.

The Hawaiian species are all unarmed and have tetramerous flowers and enclosed stamens, with a single biovulate carpel, a thick adherent endocarp, and generally a single almost exalbuminous seed with thick orbicular cotyledons and a short papillaeform radicle. The leaflets are entire, and the petiolule of the terminal one often exhibits in its upper portion a thickening or articulation. Native name of all species: "Heaë, (trisyllabic).

Petals 4, thin and slightly imbricate. Flowering panicles appear before the leaves in the axils of large scales:

Lenflets pinnately $9-3$-foliolate, the lateral leaflets sessile or on short petiolules: $\begin{array}{ll}\text { Leaflets } 9-7 \text {, lanceolate, with copious transparent oil-dots } & \text { 2. Z. glandulosum. }\end{array}$

Leaflets 5 , rarely 3 , ovate or ovate-oblong, opaque . 1. Z. Kauaiense.

Leaflets 3 , rarely 5 , thick and tomentose, truncate at the base, the lateral ones very unsymmetrical, rhomboidal

Leaflets pedately ternate, the lateral ones on long petiolules:

All petiolules articulate at the midale.

All petiolules without articulation or thickening

3. Z. Mautense.

4. Z. Oahuense.

5. Z. Hawailense.

Petals 4 or 2 , thick coriaceous and valvate. Flowering panicles terminal and oppositifolious. Small stipelliform leaflets at the base of the lowest leaflets or of the single leaflet

6. Z. dipetalum.

1. Z. Kauaiense, Gray, Bot. U. S. E. Exp. p. 354. - A graceful small tree, about $20 \mathrm{ft}$. high, with a straight undivided trunk and a dense round crown. Leaves 5- or rarely 3 -foliolate, on petioles of $10-15^{\prime \prime}$; the leaflets ovate or oblong, $1^{1 / 2}-2^{\prime} \times^{3 / 4}-1^{\prime}$, subacuminate, coriaceous and quite opaque, or with a few transparent dots along the margin, glabrous, the petiolule of the terminal one articulate near the blade, $6^{\prime \prime}$, those of the lateral ones $1-1^{1 / 2} 2^{\prime}$. Panicles $1-4$ near the base of the 
short branchlets, $1-1^{1 / 2^{\prime}}$ long, the compressed peduncle ${ }^{1 / 2}-1^{\prime}$, the pedicels $1-2^{\prime \prime}$, the bractlets minute, subnlate and soon deciduous. Flowers tetramerous. Sepals ${ }^{3} / 4^{\prime \prime}$, somewhat acute; petals $2-3^{\prime \prime}$. Stamens in the sterile fl. 1" long, with ovoid anthers; wanting in the fertile fl. Carpel single, with a globose subsessile stigma; rudimentary in the sterile fl. Follicle on a stipes of 2 ", obovate, glabrous, faintly pitted and concentrically striate. Seed solitary, 4-5". - Mann, in Proc. Bost. Soc. Nat. Hist. X, 318; Enum. no. 80.

Kauai! Waimea. In my specimens (Kn. 113) the follicles are not stipitate.

$\beta$ var. - Leaflets 5, chartaceous to membranous, strongly pubescent underneath and smaller, ovate-acute. Follicles distinctly pitted; the thick woody testa of the seed deeply runcinate under the shining black epidermis. Albumen very scanty or wanting. Embryo erect; radicle small, papillaeform; cotyledons fleshy, plano-convex.

Hawaii! Kawaihae iuka; and a form with thin, quite glabrous leaves, probably from E. Maui.

$\gamma$ var. - Leaflets 5 or 3 , ovate or ovate-oblong, $2-3^{1} / 2^{1} \times 1^{1 / 2}-1^{3} / 4^{4}$, bluntly acuminate, or obtuse, membranous, dark, almost black when dry and opaque, quite dotless, faintly pubescent underneath, the common petiole $2-3^{\prime}$, that of the terminal leaflet ${ }^{1} / 2-1^{\prime}$, often articulate with the blade, the lateral leaflets subsessile. Panicles 1-3' long, supported by scales of $3-4 "$ in length, with a broadly flattened peduncle and divaricate branches, the flowers crowded near their ends. Female $f$. Sepals 4 , rarely 3 , acute, $1 / 2^{\prime \prime}$ long; petals $2^{\prime \prime}$ long, thin and slightly imbricate, pinkish-white. Stamens none. Carpel 1, rarely 2, on a thick annular disk; stigma globose and subsessile or subpeltate on a short and thick curved style. Ovules 2, collateral, pendulous. Male $f$. smaller and more numerous in larger panicles. Stamens nearly as long as the petals, of which not rarely 2 are found connate; anthers ovoid, erect, obtuse.

Kauai! Waimea (Kn. 146); Oahu! Makaleha.

2. Z. glandulosum, sp. $n$. - Leaves $9-7$-foliolate, 7-8' long, the leaflets lanceolate, $3-3^{1} / 2^{\prime} \times 1-1^{1 / 4^{\prime}}$, acute, contracting at the base, membranous, glabrous, copiously punctate with large transparent oil-dots, the common petiole about $1^{\prime}$, that of the terminal leaflet $3 / 4^{\prime}$, the lateral leaflets subsessile.

W. Maui! gulch of Lahainaluna. Only a leaf-branch gathered from a low shrub.

$\beta$ var. - Leaflets $7-5$, large oblong, $5^{\prime} \times 2-3^{\prime}$, caudato-acuminate, rounded at the base and dotted as before.

Hawail! woods of Hilo. A panicle with immature fruit at the base of the latest growth; earpel single.

3. Z. Mauiense, Mann, l. c. p. 319, and Enum. no. 81. - A small tree, 10-15 ft. high, with a gnarled trunk and few short stiff branches, 
Leaflets 3 on a common petiole of $1-1^{1 / 2}$, ovate or ovate-oblong, $2-3^{\prime}$ $\times 15-20^{\prime}$, acuminate or somewhat obtuse, pale, coriaceous, quite opaque, puberulent above, gray-tomentose underneath, the lateral ones subtruncate at the base, more or less cut in the upper half, on petiolules of $2-3^{\prime \prime}$, that of the median leaflet $9^{\prime \prime}$ and often articulate near the blade. Panicles $2-3^{\prime}$ long, many-flowered, the common peduncle $1 / 2-1^{1 / 2^{\prime}}$, the pedicels $2^{\prime \prime}$, tomentose. Follicles $4-5^{\prime \prime}$, not stipitate, lunulate-obovoid, the apex almost lateral, after dehiscence recurved, rugose and pitted. Seems to be dioecious.

W. Maui! (Remy and Lydg.).

$\beta$ var. - Petioles very long, $2-4^{\prime}$. Leaflets 3 , glabrous above, coarsely pubescent underneath along the rib, thick chartaceous, with pellucid dots along the margin, $3^{1}{ }_{1}{ }_{2}-4^{\prime} \times 2-2^{1} / 2^{\prime}$, acute, the lateral ones with the lower half much larger, almost rhomboidal, lozenge-shaped; the petiole of the median one rarely articulate. Panicles $2-4$ at the base of the short branches, supported by scales of $5-6^{\prime \prime}$ in length, simple, almost racemose, 3-4' long, the common peduncle 2-3'. Fem. $f$ l. Sepals 4, acute and coarsely pubescent, $1^{\prime \prime}$. Petals lanceolate, $2^{1 / 2}$, pubescent below. Ovary on a small disk, pubescent, with a short and thick excentric style and a globose or subpeltate stigma. Follicles rugose, slightly pitted.

Molokai! Mannahui.

$\gamma$ var. - Leaflets thick coriaceous and quite opaque, obtuse or rounded, the lateral ones subsessile, $3-4^{\prime} \times 2^{1 / 2}-3^{\prime}$, truncate at the base, rhomboidal, the lower half much produced, almost auriculate, the rib puberulous or glabrate underneath, the common petiole $1-1^{1 /} / 2^{\prime}$, that of the median leaflet rarely articulate with its blade. Panicle simple or compound. Male $\mathrm{fl}$. Sepals ${ }^{1} / 2^{\prime \prime}$, pubescent, obtuse; petals $2-2^{1} / 2^{\prime \prime}$; stamens a little shorter, with broadish filaments and short ovoid anthers. Fem. $f l$. as in $\beta$. Follicles strongly pitted. Seed and embryo as in no. 1.

Lanai!

o var. - Leaflets $3-5$, ovate-oblong, $4-4^{1 / 2^{\prime}} \times 2^{1 / 2}-3^{\prime}$, coriaceous, obtuse or acuminate, the lateral ones a little unsymmetrical. Sepals acute. Follicles pitted.

Oahu! Kaala.

4. Z. Oahuense, $s p . n$. - A small tree, in size and habit like the preceding, glabrous. Leaves pedately 3 -foliolate, on long petioles of $3-3^{1} / 2^{x}$, their leaflets on petioles of nearly even length, $1^{1 / 4}-2^{1} / 2^{4}$, which are all articulate or thickened above the middle, ovate or orbicular, $2-2^{1} / 2^{\prime}$ in length and as much or more in width, caudato-acuminate, the lateral ones unsymmetrical at the base, excised in the upper half, glabrous, coriaceous, opaque, or with a few and distant pellucid dots along 
the edge. Panicles at the base of the branch $3-4^{\prime}$ long, loosely- and few-flowered. Follicle 5-6, pitted and concentrically rugose.

$\mathrm{O}$ a hu! on high ridges of Konahuanui and Niu. The articulation, or rather the thickening of all the petioles (for they are not apt to break there), seems to be constant in this species, which is by no means the case in the first and third, where it is confined to the terminal petiolule.

5. Z. Hawaiiense, sp. $n$. - Size and habit of the preceding species. Leaves pedately 3 -foliolate, on petioles of $1 / 2-2^{\prime}$, the leaflets on not articulate stalks of nearly even length $\left(1-1^{1} / 2^{\prime}\right)$, ovate, suddenly acuminate, the lateral ones unsymmetrical with an oblique base (the lower half larger and subcordate, the upper half excised), $1^{1 / 2}-2^{\prime}$ in each diameter. Panicles at the base of the branches, but some in the axils of true leaves. Follicles curved, almost smooth, $3-4^{\prime \prime}$.

Hawaii! Central Plateau, 5000-6000 ft. above the sea.

ק var. - Petiolules 9-15" long. Leaflets almost deltoid, subacute. Follicles eminently pitted. Seeds $4^{\prime \prime}$, with a rhaphe of ${ }^{1 /} / 2$ its length, almost exalbuminous. Embryo as before.

Lanai!

6. Z. dipetalum, Mann, l. c. p. 319, and Enum. no. 82. - A handsome tree, about $30 \mathrm{ft}$. high, quite glabrous. Leaves $6-7$ ' long including a petiole of $1-1^{1 / 2^{\prime}}$, pinnately $5-7$-foliolate, the lowest pair of leaflets generally with a pair of smaller stipelliform or auricular folioles close to its base. Lateral petiolules 3 ", the terminal one $6-9$ ", often articulate. Leaflets oblong, $3-3^{1} / 2^{\prime} \times 1^{1 / 2}-1^{3} / 4^{\prime}$, obtuse, all contracting and nearly symmetrical at the base, coriaceous, with faint nerves and many pellucid dots, glossy. Panicles terminal and oppositifolious, $3-4^{\prime}$ long, with a peduncle of $1-1^{1 / 2}$ and suberect branches, the ternate flowers on pedicels of $3^{\prime \prime}$, the lateral pedicels minutely bracteate below the middle. Male $f l$. Sepals 4, rounded, less than 1 " high. Petals 2 , lanceolate, thick coriaceous and valvate, 5 " long. Stamens 4, scarcely half the length of the petals, placed on the edge of the disk, with long apiculate anthers of $1-1^{1 / 2}{ }^{\prime \prime}$. Ovary rudimentary.

Oahu! slopes of Waiotani in Nuuanu valley.

$\beta$ var. - Leaves generally 3 -foliolate, with the rarely wanting reduced leaflets close to the outer folioles, thus appearing pedately 5 -foliolate, the median or terminal petiolule $10-12^{\prime \prime}$ and articulate. Leaflets smaller and thicker than in $\alpha$, with pellucid dots along the margin only, $1^{3 / 4}-2^{\prime} \times 1-1^{1} / 2^{2}$. Inflorescence of undeveloped buds pubescent. Petals 4, firmly cohering. Anthers acute, much longer than their filaments.

Hawail! Kawaihae iuka of the Kohala range.

$\gamma$ var. -- Leaves on short petioles of ${ }^{1} / 2^{\prime}$ or less, 3-1-foliolate, with the supplementary pair of stipelliform leaflets besides, obovate-oblong, 
$3-5^{\prime} \times 1^{3} / 4-3^{\prime}$, thick coriaceous and quite opaque, with prominent veins and a distinct intramarginal nerve. Panicles as before, but shorter, the fruiting pedicels $9^{\prime \prime}$. Follicle single, substipulate, $1^{\prime}$ long and $9^{\prime \prime}$ broad, pitted and concentrically rugose, almost woody, with a coriaceous, partly detached endocarp. Seed ovoid, 9-10", the hard woody and smooth testa covered with a black, shining, thin and brittle epidermis, the rhaphe extending along its entire length. Cotyledons thick fleshy, plano-convex, the radicle very short and enclosed. - Wawra, in Flora, 1873, p. 139. - Connarus? Kauaiensis, Mann, Enum. no. 94.

Kauai! Waimea, at an elevation of $2000 \mathrm{ft}$. (Kn. 82).

Mann has referred this interesting species, of which the first form was communicated to him by the writer, to the imperfeetly known genus or subgenus Blackburnia, Forst. (united by Hooker \& Bentham with Zanthoxylum), on account of the valvate petals; but the Norfolk Island tree has abruptly pinnate leaves and an axillary inflorescence. The overlapping of the thin petals in the several preeeding species is very light indeed and would become impossible with such a development in thickness as obtains in the present one. The reduced number of the petals in $\alpha$ is owing not to a suppression of a pair, but to coalescence of two contiguous petals, as has been observed also exceptionally in $Z$. Kauaiense. It is not so much therefore on the strength of these characters that the present species must claim a place distinet from the preceding ones within the genus, as for its mode of inflorescence and the presence of the supplementary pair of reduced leaflets in such an extraordinary position, where they appear like appendages of the lowest folioles. An analogous strueture is found in some Araliads and among Sapindaceae in the genera Capara, Pometia, and in Nephelium stipulaceum (vid. Hook. \& Benth. Gen. Pl. I, 405-407).

Nearly allied to the Order Rutaceae are the Aurantiaceae, which differ chiefly in the entire indehiscent juicy or pulpy fruit with pendulous exalbuminous seeds on an axial placenta, the cells separable from the thickened rind.

\section{CITRUS, L.}

Calyx urceolate or cupular, 3-5-cleft. Petals 4-8. Stamens indefinite, their filaments compressed and variously united at the base. Ovary many-celled, with $4--8$ ovules in each cell. Leaves simple, articulate, with a mostly winged petiole.

C. Aurantium, the Orange, C. Limetta, the Lime, C. medica, the Citron, C. Japonica, the Comquat, C. Decumana, the Shaddock, have been long in eultivation and are often found in recesses of the deeper valleys, so that they might almost claim a place in the flora, - Murraya exotica, L., is common in gardens.

\section{ORDER XIX, b. MELIACEAE.}

Calyx 4-5-cleft. Petals 4-5. Stamens as many or several times as many, inserted in a hypogynous disk, monadelphous, the anthers usually sessile on the top of the staminal tube or on its inner side. Ovary $3-5$-celled, with simple style and generally 2 ovules in each cell. - Trees or shrubs, with alternate pinnate leaves without stipules.

\section{MELIA, L.}

Calyx 5-cleft. Petals oblong-linear, convolute. Staminal tube with 10 sessile anthers and twice as many teeth. Ovary 3-6-celled, with 2 superposed ovules in each cell. Fruit a drylsh drupe with long putamen and 1 pendulous seed in each cell. - Trees or shrubs, with pinnate or compound leaves and mostly purple flowers in large axillary panicles.

Here belongs Melia Azedarach, L., the Pride of India, spread over all islands by cultivation. M, sempervirens Sw., a tall shrub, is not uncommon. 


\section{ORDER XX. ILICINEAE.}

Flowers regular, often polygamous. Calyx of $3-6$ sepals or lobes. Petals 4-10 (generally 5), hypogynous, mostly united into a lobed corolla, imbricate in the bud. Stamens as many, inserted on the base of the corolla and alternate with its lobes, or rarely free and hypogynous, usually short. Ovary 2- or several-celled. Ovules usually solitary in each cell and suspended, anatropous. Stigma sessile, or nearly so, entire or divided. Fruit a berry or drupe enclosing 2 or more 1-seeded kernels. Embryo small, near the top of fleshy albumen. - Shrubs or trees. Leaves alternate or rarely opposite, without stipules. Flowers usually small, white, axillary.

Only 3 genera, distributed over the temperate and warmer regions of the globe.

\section{BYRONIA, Endl.}

Flowers polygamous. Calyx small, 3-4-lobed; corolla 5-10-parted, the lobes of both imbricate. Stamens as many or twice as many as lobes of the corolla and inserted on its tube, the filaments subulate, the anthers short oblong, introrse. Ovary globose, 10-20-celled, each cell with 1 pendulous ovule, the stigma sessile, discoid, with $10-20$ rays. Fruit a drupe with $10-20$ cartilaginous kernels. - Trees, with alternate simple leaves. Flowers in trichotomous cymes.

A genus of 3 species, one in Australia, one in Tahiti, and the following.

1. B. Sandwicensis, Endl. in Ann. Wien. Mus. I, 184. - A handsome tree, $20-40 \mathrm{ft}$. high, quite glabrous. Leaves elliptico-oblong or obovate, $2-4^{\prime} \times 1-2^{1} / 2^{\prime}$, on petioles of $6-15^{\prime \prime}$, obtuse, narrowing toward the base, entire or rarely serrulate, coriaceous, dark-green, glossy, with impressed nerves. Flowers numerous in cymose panicles of $2-4^{\prime}$ in length, the naked and compressed peduncle ${ }^{1 / 2}-2^{\prime}$, the pedicels $3^{\prime \prime}$, bibracteolate below the middle, the bractlets $1-1^{1 / 2}{ }^{\prime \prime}$. Calyx $1^{\prime \prime}$, coriaceous, 4 -lobed, the lobes rounded. Corolla $2^{\prime \prime}$, rotate, white, deeply 6-10-cleft. Stamens $6-10$, half the Jength of the corolla, with short ovoid anthers. Stigma of $12-20$ rays. Drupe black, fleshy, globose, compressed, $3-4^{\prime \prime}$ in diameter, many-ribbed when dry, containing $10-20$ separable pyrenas. Gray, Bot. U. S. E. E. p. 296 , pl. 26. - Ilex anomala, Hook, \& Arn. in Bot. Beech. p. 111, tab. 25.

Not uncommon in the middle woods of all islands. In the mountains of Ka uai there is a very small-leaved form with panicles in every axil. Nat. name: -Kaawaus.

\section{ORder XXI. CELASTRACEAE.}

Sepals 5 or 4 , small, united at the base, imbricate in the bud. Petals as many, inserted on the margin of a perigynous disk. Stamens as many, alternate with the petals, or 3 only, inserted on the margin of the disk or upon it. Ovary more or less immersed in the disk, 2-5-celled, with 
2 or rarely 1 or more erect ovules in each cell. Styles as many as cells, free or combined into one. Fruit free from the calyx, 2-5-celled or rarely 1-celled, indehiscent or opening loculicidally. Seeds usually arillate, with albumen. Embryo straight; radicle next the hilum. - Shrubs, trees or woody climbers, with alternate or opposite simple leaves. Flowers small, usually green.

A large Order, widely distributed over the warmer and temperate regions of the globe, with 2 genera in Polynesia, besides the following.

\section{PERROTTETIA, H. B. K.}

Flowers polygamo-dioecious. Calyx 5-parted, persistent, its lobes triangular, open or imbricate in the bud. Petals short triangular, valvate or imbricate. Stamens 5, inserted in the margin of the disk. Ovary ovoid, almost free from the disk, 2-celled, each cell with 2 erect anatropous ovules. Style short, bifid, with recurved lobes, stigmatose inside. Berry globose, with 2 or 4 seeds. Seeds subglobose, crustaceous, with a broad hilum. Albumen fatty. - Unarmed shrubs, with alternate petiolate serrate leaves, deciduous stipules and axillary panicles.

A genus of 4 species, natives of the Andes, of New Granada and Mexico, besides the following.

1. P. Sandwicensis, Gray, Bot. U. S. E. Exp. p. 291, pl.24. - A tall shrub or small tree, $8-16 \mathrm{ft}$. high, nearly glabrous. Stipules minute, eaducous. Leaves ovate or oblong, $3-5^{\prime} \times 1^{1 / 2}-2^{1 / 2^{\prime}}$, on petioles of $1 / 2-1 '$, shortly acuminate, dentate or serrulate with callous teeth, chartaceous. Panicles 2-4' long, with horizontal branches, the peduncle $1-1^{1 / 2^{\prime}}$, the pedicels about $1^{\prime \prime}$, bracteolate below the middle, puberulous. Calyx $1^{\prime \prime}$ or less, parted to the middle into ovate imbricate lobes. Petals scarcely longer, triangular, imbricate, greenish, ciliate at the margins. Stamens twice as long in the sterile, half as long in the fertile flowers, the anthers versatile, short ovoid, without apparent connective. Style short and thick, bifid in the fertile, truncate in the sterile flowers. Berry globose, $2^{1 / 2}-3^{\prime \prime}$, bright red. Seeds marked with minute transverse wavy lines, the dorsal rhaphe broad but not arillate. Embryo more than half the length of the scant fatty albumen, the thick terete radicle as long as the short and thick round cotyledons.

In the lower and middle woods of all islands, rather common. Nat, name: =Olomeas.

\section{ORDER XXII. RHAMNACEAE.}

Calyx 4-5-cleft, valvate, lined at the base with a disk. Petals as many, small unguiculate hood-shaped or rarely flat, inserted at the base of the lobes of the calyx and alternate with them, or rarely wanting. Stamens as many as petals and opposite to them. Ovary free or immersed in the disk, 2-4-celled, with a single erect ovule in each cell, the styles free 
or combined into one. Fruit free or adherent to the enlarged and persistent base of the calyx, indehiscent and entire or separating into 2 or more 1-seeded carpels or cocci. Albumen fleshy, usually thin, sometimes none. Radicle inferior; cotyledons flat. - Trees, shrubs or climbers, with simple, mostly alternate leaves and minute stipules. Flowers small, in clusters or panicles.

A considerable Order, spread over all parts of the globe; represented in Polynesia by the genera Ventilago, Smythea, Rhamnus and the following.

Fruit globose, partly covered by the adherent calyx:

Three-grooved at the apex, the calycine cup not extending beyond the base

Not grooved, the calycine cup extending to the middle; seed covered by a red filmy axil

Fruit triangular, entirely covered by the adherent calyx and crowned by its limb

\section{Colubrina.}

2. Alphitonia.

3. Gouania.

\section{COLUBRINA, L. C. Richard.}

Calyx 5-parted, with hemispherical tube and spreading triangular deciduous lobes. Petals 5, inserted below the disk, unguiculate and cucullate. Stamens 5, enclosed by the petals. Disk thick, annular or lobed. Ovary immersed in the disk, 3-celled, terminating in a trifid style with obtuse stigmas. Fruit a subglobose dry drupe, slightly 3 -lobed, its base invested by the adherent calyx-tube, 3-coccous, the cocci opening along the inner side. Seeds obovoid, trigonous. Albumen scanty; cotyledons orbicular, radicle short. - Shrubs or trees, with small deciduous stipules. Flowers clustered in axillary cymules.

About 10 species, mostly American, but our second species peculiar to the Hawaiian group.

Leaves alternate

Leaves opposite

1. C. Asiatica.

. . 2. C. oppositifolia.

1. Ahamn. in Ann. Sc. Nat. X, 368. - A large sarmentose shrub, quite glabrous. Leaves alternate, ovate or cordate, $2-3^{\prime} \times 1-1^{3} / 4^{\prime}$, on petioles of $4-6^{\prime \prime}$, acuminate, crenulate, penni-nerved, with 2 prominent basal nerves which converge toward the apex, membranous, glossy. Flowers greenish, in cymose fascicles which are shorter than the petioles. Pedicels naked, $2-3^{\prime \prime}$. Calyx $1^{\prime \prime}$. Petals as long, narrow ligulate, enfolding the short stamens. Fruit $3-4{ }^{\prime \prime}$ in diameter, 3-grooved, the calycine cup covering less than one third; epicarp and endocarp thin, separable. Seeds black, angular-convex, the foliaceous cotyledons as broad as the albumen. - Ceanothus Asiaticus, L. - C. capsularis, Forst.

Near the seacoast here and there on all islands. A native of the W. Indian islands, Tahiti. Hawation most islands of E. India and the Pacifie - Philipines, Samoa, Viti,

. C.

2. C. oppositifolia, Brongn. in herb. Gray. - Mann, Enum. no. 86. A small, sparingly branching tree, quite glabrous. Leaves opposite, ovate or oblong, $5-7^{\prime} \times 2-3^{\prime}$, on petioles of $1^{1 / 2}-2^{\prime}$, thin chartaceous, 
acuminate, entire, penni-nerved, with a gland at the base of each nerve on the lower face. Flowers 5-10 in an umbellate cyme on a common peduncle of about $6^{\prime \prime}$, the pedicels $3-6^{\prime \prime}$, with minute ovate bractlets at the base. Calyx cup-shaped, $1 \frac{1}{2} 2^{\prime}$, parted to the middle. Petals not exceeding the calyx and enclosing the short stamens. Anthers ovoid. Style very short, 3-lobed. Fruit subglobose, 3-grooved at the apex, 5 " in diameter, the calycine cup not exceeding the lower third; the epicarp woody and not separating from the endocarp, therefore the cocei separating tardily and imperfectly, the dissepiments thin and transparent in their lower halves. Seeds angular-convex. Cotyledons rather thick and fleshy, obovate-oblong, slightly curved, nearly as long and broad as the thin albumen; the radicle short papillaeform.

Hawaii! in the serub of S. Kona and Kau; Oahu, S. W. slope of Kaala! Remy's specimens probably came from Kauai. Nat name: "Kauwilas.

\section{ALPHITONIA, Reissek.}

Flowers as in Colubrina, the ovary 2-3-celled, terminating in a $2-3$-fid style with obtuse lobes. Drupe globose or ovoid, invested below by the cup-shaped calyx-tube, with 2 or 3 pyrenae, the epicarp thick corky, the pyrenae or cocei woody or crustaceous, opening inward by a longitudinal slit. Seeds broad-oblong, plano-convex, enclosed in a thin arillus which is open at the apex, the testa hard, shining. Trees, with alternate parallel-veined entire tomentose leaves and small deciduous stipules. Flowers small, in terminal and axillary cymes.

A small genus of 2 or 3 elosely allied species, spreading from the Hawaiian Islands through all the groups of Polynesia to tropical Australia and thence to Borneo and the Philipines.

1. A. ponderosa, sp: $n$. - A tall tree, often attaining $50-80 \mathrm{ft}$., the young branches tomentose. Stipules subulate, $3^{\prime \prime}$, soon caducons. Leaves ovate, ovate-oblong or lanceolate, $2-6^{\prime} \times{ }^{3 / 4}-2^{\prime}$, on petioles of $1 / 2-1^{\prime}$, generally acute, entire, coriaceous, with straight prominent veins and minute rectangular areoles, dark green and glabrous above, covered underneath with a short rust- or ash-colored tomentum, which however is often confined to the areoles only. Flowers in the axils of the youngest leaves, in short tomentose dichotomous eymes; the naked peduncles $3-5^{\prime \prime}$, the thick angular pedicels $1^{1 / 2}-3^{\prime \prime}$, shortly bracteolate at the base. Calyx tomentose, leathery, $3^{\prime \prime}$ in diameter, the lobes prominently ridged and expanded. Petals, half as long as the calyx-lobes, of delicate texture, spathulate and cucullate from a narrow flat base, enclosing the short stamens. Anthers short ovoid, emarginate at the base, their cells somewhat acute below but not pointed. Disk pentagonal. Style very short, 2-3-fid, surrounded by a few hairlets. Fruit globose, $7-9^{\text {" }}$ in diameter, prominently ringed at the middle by the border of the adnate calyx, almost indehiscent. Arillus a dark red separable film which envelops

Hillebrand, Flora of the Hawaiian Islands. 
the whole seed and opens by a transverse slit at the top. Cotyledons broad oblong; radicle papillaeform. - A. excelsa, Mann. Enum. no. 87. - Mrs. Sinclair, pl. 25.

On dry slopes of the leeward sides on all islands, but nowhere common except in Waimea, Ka u a i, where it attains a greater height than any other tree of that island (Knudsen); Oahu! Kaala; Molokai! Maunaloa; Lanai! Maui! Ulupalakua; Hawaii! Kau and $S$. Kona. Nat. name: "Kauwila". - The wood is remarkable for close grain, hardness and heavy weight, on which account the natives preferred it for making spears, mallets for beating kapa", and other tools. It turns black with age.

Our tree was referred to $A$. excelsa, Reiss., by Mann, together with the Tahitian $A$. zizyphoides and the Vitian A. frangutoides, Gray, but it differs in the larger fruit, which is invested by the calyx-tube up to its middle and beyond, while in the smaller fruit of the other species (size of a pea, Hk. \& Arn., 4-5" in diam., Gray) the calyx hardly extends beyond the base. For this reason the fruit of our species never splits up into cocci while on the tree, nor does the hard woody epicarp fall away from the seeds so as to leave them standing on the cupula, as is observed in the Australian and Tahitian species. The anther-cells also, although somewhat acute at the base, do not present the pointed prolongation exhibited in Gray's figures (Bot. U. S. E. E. pl. 22) of A. franguloides and $A$, zizyphoides. Some flowers have a short truncate style, indicating polygamy.

\section{GOUANIA, L.}

Calyx cohering with the ovary, 5-lobed. Disk epigynous, 5-angled or produced in 5 horns. Petals 5, inserted under the margin of the disk, hooded and enclosing the opposite minute stamens. Ovary 3-, rarely 2-celled. Style 3-2-fid, with minute stigmas. Fruit coriaceous, inferior, crowned by the persistent limb of the calyx, 3-(2-)winged, the calycine covering enclosing 3 or 2 woody indehiscent cocci which separate from the axis. Seeds plano-convex, obovate, with a horny and shining testa and scanty albumen. Cotyledons rounded, plane; radicle short. - Shrubs, often climbing and tendril-bearing, with alternate leaves and deciduous stipules. Flowers polygamous, small, in terminal and axillary spikes or racemes, or in axillary cymes.

A genus of 30 species, natives of tropical America, Asia, Afriea and Polynesia, absent from Australia.

Inflorescence cymose; leaves entire; no cirrhi:

Calyx deeply parted, with spreading lobes; capsule winged in its entire length

Calyx eampanulate, the limb produced beyond the ovary; eapsule winged only in its upper portion

Inflorescence glomerato-spicate; leaves notched; cirrhi present:

Spikes terminal on axillary shoots; leaves tomentose; cirrhi revolute

Spikes axillary; leaves glabrous; eirrhi involute

1. G, orbicularis.

2. G. Hillebrandi.

3. G. Bishopii.

4. G. vitifolia.

1. G. orbicularis, Walp. Rel. Meyen. p. 323 . - An erect shrub, 6-10 ft. high, with numerous stiff ascending branches, the young shoots silky with appressed hair. Leaves suborbicular or broadly ovate, $1^{1 / 2}-2^{\prime} \times 1-1^{1 / 2^{\prime}}$, on slender petioles of $1-1^{1 / 2} 2^{\prime}$, shortly pointed, quite entire, glabrous on both sides, chartaceous, penni-nerved. Stipules scarious, subulate, $1^{1 / 2}-2^{\prime \prime}$. Cymes axillary, puberulous or glabrate, racemoso-paniculate, $1^{1 / 2}-2^{\prime}$ in length, 5-7-, rarely $9-13-$, or by 
abortion of the lowest pair 3-flowered, the slender peduncle $12-18^{\prime \prime}$, the pedicels $2-3^{\prime \prime}$, bibracteolate and articulate at the base, the bractlets $1^{1 / 2} 2^{\prime \prime}$. Calyx pubescent, $2-3^{\prime \prime}$ in diameter, with spreading triangular lobes. Peatals shorter, thin. Anthers globose. Disk pentagonal in the fertile, small cup-shaped without style in the sterile flowers. Styles $2-3$, distinct, very short. Capsule $5-6 "$ "long, $2-3$-winged, the wings $2^{\prime \prime}$ broad, extending the whole length and projecting below the base of the fruit. Seed oblong, rather flat, with a brown shining testa. - Gray, Bot. U. S. E. E. p. 284. - G. integrifolia, Meyen (not Link).

Oahu! Waianae range (Lihue, Makaha).

2. G. Hillebrandi, sp. n. Oliver in liter. - A low decumbent shrub, the slender rambling branches silky with a rust- or ash-colored pubescence. Leaves ovate-oblong or lanceolate, $1^{1 / 2}-2^{1 / 2^{\prime}} \times^{3 / 4}-1^{\prime}$, on petioles of $1 / 2-1 '$, obtusely pointed or acute, entire, dark green, pubescent and pale below, thin chartaceous. Stipules $3-4^{\prime \prime}$. Cymes tomentose, $1-1^{1 / 2}{ }^{\prime}$ long, $3-5$-flowered, the slender naked peduncle $6-15^{\prime \prime}$, the pedicels $1-1^{1 / 2}{ }^{\prime \prime}$, bracteolate at the base. Calyx coriaceous, tomentose, $2^{\prime \prime}$, shortly 5 -lobed, the tube continued beyond the ovary and in the fertile flowers constricted below the throat. Disk plane and continuous without style in the sterile flowers. Style in the fertile flower short, with 3 obtuse stigmas. Capsule 4-5", tomentose, coriaceous, top-shaped, often 3 -horned, the wings broad and projecting above, contracting or ceasing toward the base. Seeds erect, oblong, flattish. Embryo central in scanty albumen, the cotyledons broad-oblong.

Ma ui! gulches of Kula and Lahaina.

$\beta$ var. - Leaves emarginate at the truncate apex, canescent on both sides with a gray tomentum, as is the whole inflorescence, including the ripe capsules. Wings of capsule extending to the base.

Maui! Kula (Lydg.).

3. G. Bishopii, sp. n. A deeumbent cirrhiferous shrub, ferrugineotomentose, with the inflorescence terminal on short axillary branches with one or two leaves and a stiff revolute tendril in their axils. Stipules less than $1 / 2 "$, broad and obtuse. Leaves ovate or slightly cordate, $2^{1 / 2} 3^{\prime} \times 1^{1 / 2}-1^{3} / 4^{\prime}$, on petioles of $4-5^{\prime \prime}$, acuminate, erenate with glandular teeth, thickly tomentose below, sparsely so on the upper face, thick chartaceous and strongly penni-nerved, the lowest nerve dividing pedately. Inflorescence tomentose, spicaeform, the flowers on sessile clusters along an axis of $2-3^{\prime}$. Calyx patent, $2^{1} / 2^{\prime \prime}$ in diam. Petals nearly as long as the calyx-lobes. Disk 5-lobed or rayed, the broad emarginate rays opposite the sepals. Capsule tomentose, $3^{\prime \prime}$ high and $4^{\prime \prime}$ wide, 3-winged, with wings continued to the base, finally separating 
into 3 cocci, each coccus suspended by two filaments of the 6-partite axis. Seeds plano-convex, brownish.

W. Maui! back of Lahaina, collected by the late Mr. E. Bishop. Leaf like that of Waltheria Americana.

4. G. vitifolia, Gray, Bot. U. S. E. Exp. p. 283. - A prostrate cirrhiferous shrub, the inflor axillary, the cirrhi from the axils of the uppermost leaves and involute. Stipules acute, 1", leaves broadly ovate and cordate, $3-5^{\prime} \times 2^{1 / 2}-3^{1 / 2}$, on petioles of $6-14^{\prime \prime}$, acuminate or obtuse, coarsely crenate or lobate with glandular tips, glabrous, membranous, the basal sinus broad and the lowest nerves pedate. Flowers glomerate in long axillary spikes of $2-4^{\prime}$, the rhachis, calyx and capsule rusty-tomentose. Mature capsule on a pedicel of $1^{\prime \prime}$, subglobose, $4-5^{\prime \prime}$ in diameter, 3 -winged in its entire length, with the wings slightly projecting above.

Oahu! Kaala range (Waianae and Makaleha).

\section{ORdER XXIII. SAPINDACEAE.}

Sepals 4 or 5, imbricate, free, or rarely united into a cup-shaped calyx. Petais as many or one fewer or none, free, hypogynous, imbricate, having often a scale on the inside inserted near the base. Stamens 5-10, or rarely up to 20 , often 2 less than twice the number of sepals, inserted within, upon, or rarely outside a hypogynous disk, which is sometimes reduced to 1 or more glands. Anthers 2-celled, opening lengthwise. Ovary free, 3-celled or rarely 2- or 4-celled. Ovules 1 or 2 or rarely more in each cell. Styles as many as ovary-cells, usually more or less united. Fruit either a dehiscent capsule, or indehiscent and succulent, or separating into winged nuts. Seeds usually arillate. Albumen none. Embryo curved or twisted or rarely straight, with thick cotyledons sometimes completely united into a fleshy mass. Radicle next the hilum. - Trees, shrubs, or climbers, or rarely herbs. Leaves generally alternate, rarely opposite, with or without stipules, often pinnate or otherwise compound. Flowers usually small, in terminal or axillary racemes or panicles.

A large Order, chiefly tropieal, In cultivation the Litshi, Nephelium Litshi.

Petals present:

Leaves disseeted; sepals and petals 4 ; fruit a bladdery capsule; seed arillate.

Leaves simple, entire; sepals and petals 5 ; fruit of $1-3$ coeci; seed caruneulate

Leaves abruptly pinnate; fruit of 1 or 2 cocci; seed arillate Petals wanting; fruit a winged capsule which breaks away from
its axis

1. Cardiospermum.

2. Sapindus.

3. Mahoe.

4. Dodonaea.

\section{CARDIOSPERMUM, L.}

Flowers polygamous. Sepals 4, imbricate, the two outer ones small. Petals 4 , in pairs, the two larger ones with a large scale, the two smaller ones with a crested scale. Disk reduced to 2 prominent glands opposite 
the lower petals. Stamens 8, oblique, unequal. Ovary excentrical, 3-celled, with 1 ovule in each cell ascending from the axis. Stigmas 3 , nearly sessile. Capsule membranous, vesicular, more or less 3-cornered, loculicidal. Seed in the center of each cell, globose, with a thick funis or small aril. - Herbs or undershrubs, mostly climbing. Leaves dissected. Flowers few, small, on long axillary peduncles, usually bearing a tendril under the panicle.

A small American genus, of which 2 species are also widely spread over the Old World within the tropies.

1. C. Halicacabum, L. - DC. Prod. I, 601. - A straggling or climbing annual or biennial, several feet in length, glabrous or slightly pubescent. Leaves usually twice ternate, with ovate or ovate-lanceolate segments, coarsely toothed or lobed; the upper leaves smaller, narrower and less divided. Peduncles $2-3^{\prime}$ long, bearing a double or treble short recurved tendril under the small panicle, which is often reduced to an umbel of few small white flowers. Capsule flat on the top, usually pubescent, about $6^{\prime \prime}$ in diameter. - Benth. Fl. Hongk. p. 46. - C. microcarpum, Kth.

On all islands, but not common, in open glades or on the outskirts of woods, trailing over shrubs or crawling among the herbage. A native probably of America, but now scattered over most tropical countries.

\section{SAPINDUS, L.}

Sepals 5, imbricate in 2 series. Petals 5 or rarely 4 , each with a scale at the base. Disk annular or rarely incomplete. Stamens $8(-10)$, free, generally hairy; anthers versatile. Ovary 3-2-lobed, rarely 4-lobed. Style terminal; stigma 2 -4-lobed. Ovule 1 in each cell, ascending from the base of the axis. Fruit of $3-1$ indehiscent roundish cocci, the epicarp coriaceous, the mesocarp fleshy, containing saponine, the endocarp chartaceous. Seeds globose; not arillate, with a crustaceous or coriaceous testa. Embryo curved, with thick cotyledons and a short radicle. Trees. Leaves alternate, without stipules, abruptly pinnate or, in our species only, simple. Flowers in terminal and axillary panicles.

A genus of 9 species, 4 of which belong to Malaysia, China and Japan, 3 to the warmer parts of America with 1 species extending to Easter Island, 1 peculiar to the Viti and 1 to the Hawaijan Islands. All contain saponine in the large eavities of the fruitflesh, a substance which, shaken with water, forms a frothy detergent lather, like soap, whence the name soaptrees.

1. S. Oahuensis, Hillebr. - Radlkofer, in Ber. d. K. Bayer. Akad. d. Wiss. 1878, p. 401 . - A tree, $20-30 \mathrm{ft}$. high, glabrous, with a whitish bark covered with lenticels, the wood pale. Leaves ovate, $4-8^{\prime} \times 2-4^{\prime} / 2^{\prime}$, on petioles of $1-3^{i}$, acuminate, rounded or truncate at the base, but slightly decurrent (inequilateral in the larger forms), quite entire, thick chartaceous, pale, glabrous. Panicles tomentose with a fulvous pubescence, either several in the axils of the uppermost leaves and then $2-4^{\prime}$ long, 
or single, terminal and $4-8^{\prime}$ long with the lowest bracts foliaceous, the branches alternate and patent, the pedicels $1^{\prime \prime}$, minutely bracteolate about the middle. Sepals subequal, orbicular, conchoid, $1^{1} / 2^{\prime \prime}$, coriaceous, with scarious margins, tomentose, slightly connate at the base. Petals 5, little longer, equal, hyaline, pubescent and ciliate. Stamens 8, inserted on the thick margin of a pentagonal glabrous disk, $1^{\prime \prime}$, the short subulate filaments villous. Ovary glabrous, 3 -2-lobed. Stigma subsessile, its lobes broad, rounded but coherent. Cocci either 2, connate in the lowest third or fourth and divaricate above, or oftener a single one with the rudiments of 1 or 2 abortive ones at the base, the single coccus obovoid, $15^{\prime \prime} \times 10^{\prime \prime}$. Pericarp leathery, shining; endocarp pergameneous, pale, villous in the immature state. Seed obovoid, $10^{\prime \prime} \times 6^{\prime \prime}$, with a black rugose osseous testa, erect, with a broad truncate, rather carunculate base, the hilum next the chalaza. Embryo curved, the thick fleshy (united?) cotyledons accumbent to the short tapering radicle and separated from it by a duplicature of the endopleura only. - Celastrinea? Wawra, in Flora, 1873, p. 141.

Oahu! valleys of Makaha and Makaleha of the Kaala range; very rare in the main range (Kalihi and Wailupe). Is conspicuous from a distance by its pale foliage. Nat, names: "Aúlu" and "Kaúlus.

$\beta$ var. - Leaves narrowing at the base and gradually running into a short petiole of $3-4^{\prime \prime}$, elliptico-oblong, often somewhat obtuse and mucronate.

Valley of Niu!

A species remarkable in the genus for the simple leaves, which never show any indication of division, and for the position of the stamens on the disk. The thickened base of the seed, entirely formed by the outer seed-coat, often presents itself as a caruncle, separated by 2 lateral notches from the body of the seed. It is obliquely traversed in the direction of the radicle by a narrow channel, the remnant of the micropyle. As the growth of the cocei is ehiefly confined to the outer wall the stigmatic scar is pushed to the bottom of the sinns when the fruit is didymous, and almost to its base when only 1 coceus matures. Here it remains visible as a small nipple just above the two knoblets which represent the aborted carpels. The fruit-flesh is full of saponine and forms a strong lather when beaten with water, even in small quantities.

\section{3. МАHOE, gen. nov.?}

In Molokai on the pali of Kalaupapa and in Oa hu on the S. W. slope of Mt.Kaala (left branch of Makaleha) grows a tree, 20-30 ft. high, known in Molokai by the name Mahoe", of which only an old inflorescence with fruit of the antecedent year has been collected. Its leaves are alternate, exstipulate, abruptly pinnate with $2-5$ pairs of opposite leaflets, all of equal size; the rhachis from $6-12$ long, petiolate in the lower third, the leaflets $8-12^{\prime} \times 3-5^{\prime}$, on petioles of $1 / 2-1^{\prime}$, oblong, acuminate, entire, rounded or contracted at the base, glabrous or slightly tomentose underneath, chartaceous, with straight, parallel, very prominent veins. Panieles terminal and axillary or lateral, $4-5^{\circ}$ long, branching from near the base; the pedicels $2^{\prime \prime}$. Fruit a globose indehiscent coccus, $15-22$ " in diam., with the rudiment of an abortive one along its side and the remnant of the style right above it. The dry, rather corky shell resembles that of a litshi and is covered with numerous areolate rugosities which, probably on account of age, are mostly cracked along their ridges. A dark circular patch on the inner side of the closely adhering endocarp, $6-8^{\prime \prime}$ in diameter, next to the fundus, marks the broad attachment of the single ascending seed, which lies loose in the cavity. The seed is covered at its 
summit by a crustaceous, brown and shining, shield-like testa with a sharp jagged margin, in form of a crescent with a short beak in the middle of the concavity. To the lower face of the shield adheres a thick, circular, sinuous and pitted, woody mass, from the center of which projects downward a short hollow cylinder. The absence of a testa in the lower and middle parts suggests the idea that the seed here was covered by a fleshy arillus, which filled the space between it and the shell and perhaps corroded the underlying coat by means of an acrid juice. The soft parts of the seed, apparently naked, are so shrivelled and wasted that it is impossible to arrive at a satisfactory interpretation; yet so much can be made out, that the upper lobed expansion, which adapts itself to the inequalities of the woody mass and surrounds the hollow pivot, represents the cotyledons of a large embryo, and a short and thick pointed radicle seems to be curved npon them. The tree, when fully known, will probably represent a new type which is likely to find a place near Nephelium, Euphoria and Pometia.

\section{DODONAEA, L.}

Flowers unisexual or polygamous. Sepals $2-5$, imbricate or valvate. Petals none. Disk obsolete in the male flowers, small in the female. Stamens 5-10, central, the filaments very short, the anthers linear-oblong, 4-angled. Ovary 2-6-celled, the angular style 2-6-cleft. Ovules 1 or 2 in each cell. Capsule septicidally $2-6$-valved, the valves winged at the back, generally breaking away from the placentiferous axis. Seeds exarillate. Embryo spirally convolute. - Trees or shrubs, often viscid. Leaves alternate, simple or abruptly pinnate. No stipules. Flowers inconspicuous, axillary or terminal, in racemes, corymbs or panicles.

About 50 species, mostly Australian, a few dispersed over the tropical regions of both Worlds.

Capsule broadly winged, with wings projecting above:

Capsule glabrous, flat, 2-winged, or, in the variety, 2-3-

$$
\text { winged } 1 . \text { D. viscosa. }
$$

Capsule (or at least the ovary) pubescent, 3-4-winged, turgid 2. D. eriocarpa. Capsule bladdery, with 4 narrow wings evanescent above . 3. D. stenoptera.

1. D. viscosa, L. - DC. Prod. I, 616. - A small tree, $12-25 \mathrm{ft}$. high, apparently dioecious. Branches angular, stiff, glabrous, glutinous at the ends. Leaves lanceolate, oblanceolate or obovate, $2^{1 / 2-4^{\prime}} \times 1 / 2-1^{1 / 4^{\prime}}$, including the petiole in which the cuneate base gradually merges, acuminate or obtuse, entire, thin chartaceous, with straight parallel nerves, viscid. Panicles terminal and axillary, $1-2$ long, the naked pedicels $1^{1 / 2}-2^{\prime \prime}$ in the male, $2-4^{\prime \prime}$ in the female flowers. Male $f l$. Sepals 4 (rarely 5), lanceolate, glabrous, about $1^{\prime \prime}$ long. Stamens $7-9$, as long or little longer. Ovary rudimentary. Fem. fl. Sepals 4. Stamens wanting. Ovary shortly stipitate, viscid, glabrous or faintly pubescent, 2- (very rarely $3-$ ) celled, each cell with 2 superposed ovules. Style several times as long as the ovary, $2^{1 / 2}-5^{\prime \prime}$, its two linear lobes glued together. Capsule brownish or pale, membranous, $6-9$ " high and $8-10^{\prime \prime}$ broad, flat, orbicular, faintly ridged along the middle on each face, 2-(rarely $3-$ ) winged, the wings uniformly $2-3$ " broad, leaving a deep sinus at the top and base. Seeds $2^{\prime \prime}$, ovate, flattened or plano-convex, with a brown crustaceous testa. - Griseb. Fl. W. Ind. p. 127. - Seem. Fl. Vit. p. 49. - 
Mann, Fl. Haw. Islds. p. 47. - Benth. F1. Austral. I, 475. - Hook. Fl. N. Zeal. p. 45. - Mrs. Sinclair, pl. 39?

One of the commonest trees, and often gregarions, at elevations of $1000-3000 \mathrm{ft}$. on all islands. Nat. name: salii" (Tahit. "Apiriv). It is valued for its hard-grained, dark wood. The species is common in tropieal America, New Zealand and Australia, and occurs on probably all the voleanic island groups of Polynesia, since it is known from the Society and Viti Islands and from New Caledonia. This wide dispersal may be accounted for by the glutinous capsules, which would ensily adhere to the plumage of birds.

$\beta$ var. spathulata. - Shrubby, 4-6 ft. high. Leaves stiff chartaceous, spathulate or obovate, $1-2^{\prime} \times 1 / 2-3 / 4^{\prime}$, shortly acuminate, or rounded and apiculate, often with a distinct petiole. Flowers dioecious. Capsule 2 - or 3 -winged, as above, either as large as in $\alpha$, or small, $3^{n} \times 4-5^{n}$. - D. spathulata, Smith. - Gray, Bot. U. S. E. E. p. 261.

Molokai! Kalae; Lanai! Hawaii! Waimea, Kilauea, on exposed elevations of 2000-4000 ft. Would seem to oceur also in Tahiti and New Zealand.

2. D. eriocarpa, Smith. - DC. Prod. I, 617. A tall, much branched shrub, 6-10 ft. in height, polygamous, with male, female and hermaphrodite flowers (the latter rare) on the same plant. Leaves narrow lanceolate or oblanceolate, $1-2^{1} / 2^{\prime} \times{ }^{1 / 4}-1^{1 / 2^{\prime}}$, acute, puberulous underneath when young. Panicle terminal, pubescent. Sepals 5, ovate, pubescent, $1-2^{\prime \prime}$. Stamens 10 round a ciliate torus in the male flowers. Ovary pubescent, even tomentose, shortly stipitate. Style either quite short, the stigmas indicated by 4 dots, or $2-3$ "long (in the fem. fl.). Capsule generally turgid, $4-8^{\prime \prime}$ high, $3-4$ winged, with wings $1^{1 / 2}-2^{1 / 2}$ " broad projecting above and below and often (but not always) pubescent along their margins. Seeds ovoid. - Gray, l. c. p. 260.

Ka uai! Waimea (leaves distinetly pubescent); Ma ui! Haleakala, $6000-8000 \mathrm{ft}$. (leaves mostly glabrate); Hawaii, Kau. The pubescence of the various parts is very inconstant, even in flowers of the same plant.

3. D. stenoptera, sp. $n$. - Shrubby, $2-4 \mathrm{ft}$. high, the angular branches glabrous, spreading, not much viscid. Leaves lanceolate, $2^{1 / 2}-3^{\prime} \times{ }^{1 / 3}-1^{1 / 2^{\prime}}$, bluntly acuminate, gradually tapering into the rather long and margined petiole, entire, chartaceous. Racemes or panicles terminal, few-flowered, $1 / 2-1$ ' long; the fruit-bearing pedicels $4^{\prime \prime}$. Sepals 4 , narrow, glabrous, $1^{\prime \prime}$. Capsule shortly stipitate, membranous, straw-colored, inflated, ovoid, 8 "long, $6-7 "$ broad, 4 -celled, the 4 wings very narrow (scarcely ${ }^{1} / 2^{\prime \prime}$ ) and evanescent toward the apex. Seeds 2 in each cell, ovoid, $1^{1 / 2}-2^{\prime \prime}$ long, black. Albumen none. Embryo spiral. - Only specimens with ripe fruit collected in the month of July.

Molokai! Kamalo, $1500-2000 \mathrm{ft}$. - A very distinet speeies, probably dioecious, as no vestiges of stamens are seen under the capsules.

D. Burmanniana, DC., has existed in Honolulu gardens $n$ number of years. 


\section{ORDER XXIV. ANACARDIACEAE.}

Flowers partially or wholly unisexual, or more rarely hermaphrodite. Sepals 5 , or rarely 3,4 , or 7 , more or less united and usually very small. Petals as many, inserted on the outside or margin of a perigynous or hypogynous disk, rarely wanting. Stamens as many or twice as many. Ovary superior, $1-5$-celled, with 1 or 2 ovules in each cell. Styles $3-5$, usually distinct. Fruit usually a drupe, 1-celled, with the single seed either ascending or pendulous. Albumen none. Radicle usually next the hilum; cotyledons thick and fleshy. - Trees or shrubs, sometimes climbers, usually with a caustic, resinous, gummy or milky juice. Leaves alternate, usually pinnate, sometimes simple, not dotted, without stipules. Flowers small, paniculate.

A large Order, distributed over the warmer and temperate regions of the globe.

Here belong the following enltivated trees: Mangifera Indica, the Mango, with 3 varieties, very common, Spondias dulcis, the Wi fruit from Tahiti, Anacardium occidentale, the Cashew nut, and the Pepper tree, Schinus molle, from S. America.

\section{RHUS, L.}

Sepals and petals $5(4-6)$, imbricate. Stamens $5(4-6)$ or 10 . Ovary 1-celled, with 2 or 3 short styles or stigmas. Ovule 1, suspended from an erect filiform funis. Drupe small, oblique, with very little juice, or nearly dry. Radicle short, curved against the edge of the flat cotyledons. Trees or shrubs. Leaves impari-pinnate, sometimes simple. Flowers polygamous or dioecious.

A considerable genus with nearly the geographical range of the Order, but most abundant in subtropical and temperate regions, chiefly in S Africa. Two more Polynesian species grow in the Viti and Society Islds. Several Sumachs are poisonous, even to the touch, others are used for tanning and dyeing, while some Japanese species furnish the varnish for the much prized laequer ware of that country. One of the latter, $R$. vernix or $R$. succedaneum, has been introduced into the Islands.

1. R. semialata, Murray. - DC. Prod. II, 6\%. - Var. Sandwicensis, Engler, in De Cand. Monogr. IV, 380. - A small tree, 12-20 ft. high, which sends up numerous shoots from the roots and thus forms dense clumps of often great extent. Branches ferruginous at the ends. Leaves impari-pinnate, with $2-6$ pairs of leaflets; the rhachis $4-12^{\prime}$ in length, terete, not margined, petiolate in the lower third or fourth; the leaflets ovate-oblong, $3-6^{\prime} \times 1^{1} / 4-3^{\prime}$, almost sessile, acuminate, crenate or serrate, the lateral ones unsymmetrical at the base, the terminal one cuneate, chartaceous, with prominent straight veins, dark-green above, tomentulose underneath. Panicle terminal, 6-12' long, rusty-tomentose, very dense, branching from the base; the pedicels less than $1 / 2^{\prime \prime}$. Flowers apparently dioecious, $1^{1 / 2} 2^{\prime \prime}$ in diameter. Calyx ${ }^{1 / 2} 2^{\prime \prime}$, deeply 5 -cleft, tomentose. Petals 5, 1" or more, obovate, reflexed, pale yellowish, glabrous or ciliate. Anthers 5, ovoid, obtuse, emarginate at the base, on very short filaments. 
Styles $2-3$, short, with capitate stigmas. Fruit $1^{1 / 2}-2^{\prime \prime}$, ovoid and somewhat flattened, tomentose. - Mann, Fl. Haw. Islds. p. 49, and Enum. no. 93. - R. Sandwicensis, Gray, Bot. U. S. E. E. p. 369.

Oceurs in isolated elusters on Oahu! Maui and $\mathrm{Hawaii}$ ! chiefly in the districts of Hilo and Kona. Nat. name: "Neneleaus. The species, generally with winged rhachis, extends from India to China and Japan.

\section{ORDER XXV. LEGUMINOSAE.}

Sepals combined into a single calyx, more or less divided into 5 or fewer teeth or lobes, rarely entirely distinct. Corolla of 5 or rarely fewer petals, perigynous or rarely hypogynous, very irregular in the first suborder, less so in the second, small and regular in the third. Stamens twice the number of petals, rarely fewer, or sometimes indefinite, inserted with the petals. Ovary single (consisting of one carpel), with 1, 2 or more ovules arranged along the inner or upper angle of the cavity. Style simple. Fruit a pod, usually flattish and opening round the margin into 2 valves, but sometimes indehiscent or variously shaped. Seeds with 2 large cotyledons, a short radicle, and (with few exceptions) without albumen. - Herbs, shrubs, trees or climbers. Leaves alternate, or in a few genera opposite, usually furnished with stipules, compound or simple (reduced to a single leaflet or to an expanded petiole), the leaflets or simple leaves entire or rarely toothed. "Flowers in axillary or terminal racemes or spikes, when terminal often becoming leaf-opposed by the growth of a lateral shoot, rarely solitary.

The largest natural Order next to Compositae, and widely distributed over the whole surface of the globe.

Suborder I. Papilionaceae, - Corolla very irregular; the upper petal (standard) outside in the bud.

Stamens all united, or the upper one alone free:

Leaves simple or of 2 or 3 leaflets:

Pod eontinuous, not articulate:

Leaflets digitate or solitary; pod inflated

Leaflets pinnately arranged, the two lateral ones inserted below the terminal one:

Pod 1-seeded, small, reniform, with the veins incurved.

Pod generally 1 or 2-seeded. Inflorescence nodose-racemose :

Upper stamen quite free, or only connate at the base:

Standard much longer than keel and wings; flowers red

Standard as long as the beaked keel, the wings much shorter; flowers red

Standard shorter than the nearly equal keel and wings; anthers dimorphous; flowers green or yellow

1. Crotalaria.

2. Medicago.

10. Erythrina.

11. Strongylodon.

Upper stamen free at the base, connate at the middle; flowers blue

Pod with more than 2 seeds (see also Mucuna):

Keel spirally twisted

Keel not twisted:

An erect undershrub. Standard with 2 callosities

12. Mucuna.

13. Dioclea.

15. Phaseolus.

18, Cajanus. 
Twining or trailing herbs or undershrubs:

Upper stamen connate at the middle; upper calyx-lobes very large, 3 lower ones very small

14. Canavalia.

Upper stamen quite free; upper calyx-lobes not larger than the lower:

Stigma oblique or lateral; pod nearly terete

Pod articulate Stigma terminal; pod compressed

16. Vigna.

17. Dolichos.

6. Desmodium.

Leaves impari-pinnate, with more than 3 leaflets:

Climbing. Leaflets stipellate; flowers axillary .

9. Clitoria.

Erect. Leaflets not stipellate:

Upper stamen free; anthers tipped with a point or gland; flowers in axillary racemes

Stamens monadelphous, at least in the middle; anthers obtuse; racemes terminal or leaf-opposed

Leaves abruptly pinnate:

Climbing:

Leaves ending in a terminal tendril; 10 stamens

3. Indigofera.

4. Tephrosia.

Leaves ending in a terminal mucro; 9 stamens

7. Vicia.

8. Abrus.

5. Sesbania.

Erect, shrubby

Stamens all free

19. Sophora.

Suborder II. Caesalpinieae. Corolla regular or nearly so, imbricate, the upper petal inside in the bud.

Leaves twice pinnate:

Pod winged along the upper suture, calyx very oblique

Pod not winged

Leaves once pinnate

21. Mezoneuron.

20. Caesalpinia.

22. Cassia.

Suborder III. Mimoseae. Corolla regular; petals small, valvate. Leaves twice pinnate; flowers in heads or spikes:

Stamens 10

24. Leucaena.

Stamens indefinite; leaves mostly replaced by dilated petioles

Stamens $4-6$; the valves or joints of valves breaking away from

the entire border or replum of the pod

23. Acacia.

25. Mimosa.

\section{SUBORDER I. PAPILIONACEAE.}

Calyx 5-toothed or cleft, or 4-toothed by the union of the 2 upper lobes, rarely splitting irregulary. Corolla very irregular, of 5 petals, the upper one or standard (vexillum) outside in the bud, the 2 lateral ones, wings (alae), intermediate, the 2 lowest more or less united along one edge into a single boat-shaped one called the keel (carina). Stamens usually 10 , either all united, or diadelphous (when one is usually free and the 9 others united), or all free.

\section{TRIBE I. GENISTEAE.}

Leaves simple or of 3 (rarely 5) digitate leaflets, all inserted at the end of the petiole. Racemes terminal or leaf-opposed. Stamens all united into a tube open on the upper side.

\section{CROTALARIA, L.}

Calyx 5-cleft. Standard broad. Wings free, transversely wrinkled above the claw. Keel with a straight or curved point or beak. Anthers alter- 
LEGUMINOSAE.

[Crotalaria.

nately ovoid and oblong. Style suddenly bent in above the ovary. Pod inflated. - Herbs or shrubs. Leaves simple and sessile or with 3 or 5 digitate leaflets at the end of the petiole. Pedicels solitary to each bract, with 2 bracteoles close under or even upon the calyx. Flowers yellow, or rarely bluish or purplish.

A large genus, chiefly tropical, with no speeies indigenous to Polynesia. The following, although well naturalized, are all of recent introduction.

Leaves simple:

Raceme with short bracts; leaves evenly tapering at both ends 1. C. Assamica.

Raceme with large ovate braets; leaves oblanceolate . . 2. C. sericea. Leaves of 3 leaflets

3. C. longirostrata.

$\dagger$ 1. C. Assamica, Benth. in Hook. Journ. Bot. II, 481. - An erect undershrub, 4-8 ft. high, with silky branchlets. Leaves lanceolate, tapering at both ends, glabrous above, sericeous underneath, $4-6^{\prime} \times 1^{\prime}$, on short petioles. Racemes many-flowered. Bracts lanceolate, $2^{\prime \prime}$. Calyxlobes $4-5^{\prime \prime}$, the lower 3 joined $2 / 3$ of their length. Flowers ${ }^{3} / 4^{\prime}$ long, yellow, with a line of silky hairs on the back of the standard. Pod glabrate. - Mann, Fl. Haw. Islds. p. 53, and Enum. no. 95.

Oahu! Pauoa, at the head of the valley. A native of Assam.

†2. C. sericea, Retz. - Wight \& Arn. Prod. Fl. Ind. Or. I, 168. Erect, 3-4 ft. high, glabrous. Leaves oblanceolate, blunt, mucronulate, tapering to a short petiole, glabrous above, silky-pubescent underneath, pellucid, dotted, $2-5^{\prime} \times 1-2^{1} / 2^{2}$. Stipules sessile, semisagittate. Bracts large, ovate. Calyx bilabiate, ${ }^{1} / 2^{\prime}$ long, half the length of the bright yellow corolla, the superior lobes ovate, the inferior ovate-lanceolate. Pod oblong, shortly stipitate, glabrous. - Mann, Enum. no. 96.

A native of India.

† 3. C. longirostrata, Hook. \& Arn. Bot. Beech. p. 285. - Suffruticose, $2-3 \mathrm{ft}$. high, the branches minutely pubescent. Leaves on long petioles, 3-foliate, the leaflets obovate or oblong, mucronulate, tapering to a cuneate base, the terminal one $1^{\prime}$ or more long, the lateral ones smaller. Stipules and bracts very small, $1^{\prime \prime}$, subulate, caducous. Pedicels $2-3^{\prime \prime}$ long, recurved in fruit. Flowers large, yellow. Keel with a long straight beak, 7 " long, exceeding the other petals. Calyx pubescent, the two upper lobes ovate-lanceolate, the others linear-lanceolate. Pod oblong, $6-9^{\prime}$ long, pubescent, on a short stipe. Ovules about 10. Seeds 4-6. - Mann, Enum. no. 97.

A roadside weed in Nuranu valley and on the Waikiki plains near Honolulu, escaped from the Agricultural Society's garden. A native of Mexico.

\section{TRIBE II. TRIFOLIEAE.}

Stems herbaceous, not twining. Leaves 3 -foliolate, without stipellae, the numerous veins of the leaflets extending to the edge and often projecting 
into minute teeth. Racemes usually axillary. Stamens diadelphous. Ovary with 2 or more ovules, rarely with a single ovule.

\section{MEDICAGO, I.}

Pod very much curved, usually spirally twisted, or sometimes 1-seeded and reniform, and then with much eurved veins.

A considerable genus, the species almost all indigenous to the Mediterranean region.

$\dagger$ 1. M. lupulina, L. - DC. Prod. II, 172. - Rhizome perennial, with several decumbent or ascending pubescent stems, $1-2 \mathrm{ft}$. long. Stipules entire. Leaves pubescent, with 3 obovate or obcordate, slightly toothed leaflets. Flowers very small, yellow, in short dense pedunculate axillary racemes. Pod very small, scarcely $1 \frac{1 / 2}{2}$ long, ovoid-reniform, rather thick, glabrous or pubescent, black when ripe, with a single seed. - Benth. Fl. Hongk. p. 75.

On grassy plains near Honolulu and elsewhere.

\section{TRIBE III. GALEGEAE.}

Herbs, not twining, or shrubs, trees or woody climbers. Leaves pinnate, often stipellate. Racemes axillary or terminal. Stamens monadelphous or diadelphous. Ovary with 2 or more ovules. Pod opening into 2 valves.

\section{INDIGOFERA, L.}

Calyx small, broadly and obliquely campanulate, with 5 teeth or lobes, the lowest the longest. Standard ovate or orbicular. Keel erect, with long claws and a small protuberance or spur on each side above the claw. Stamens diadelphous, the sheath slender and usually persistent after the fall of the petals. Anthers tipped with a small gland or point. Ovary sessile or nearly so, with several ovules. Pod usually slender, cylindrical or 4-angled, with transverse cellular partitions between the seeds, rarely flattened, or, when reduced to a single seed, nearly globular. - Herbs or shrubs, hoary or sprinkled with appressed hairs. Leaves usually impari-pinnate (sometimes reduced to 3 or 1 leaflets), with small stipules. Flowers in axillary racemes, purplish or red.

A large genus, widely spread over tropical Asia and America, but still more abundant in tropieal and southern Afriea, with a few Australian species.

$\dagger$ 1. I. Anil, L. - DC. Prod. II, 225. - An undershrub, $3-5 \mathrm{ft}$. high, hoary on the branches and underside of the leaves. Leaflets in $2-8$ pairs besides the terminal one, obovate or oblong, 6-12' long, all opposite. Flowers scarcely exceeding $2^{\prime \prime}$, in short, dense, almost sessile racemes, on very short recurved pedicels. Calyx campanulate, with short broad teeth. Pods about $1 / 2^{\prime}$ long, usually densely packed and much incurved, slightly tetragonous, with 6-10 seeds. - Benth. Fl. Hongk. p. 77. 
One of the most common weeds on all islands. It was introduced in 1836 from Java by a Dr. Serrière, who is said to have manufactured a good quality of indigo from it. The species, of American origin, is cultivated now in many countries in preference to other indigo yielding species. The $I$. tinctoria, at present chiefly planted in Bengal, is easily distinguished by the looser racemes with longer and more slender pods, which are always straight. This too has been introduced and may possibly still be found in the country.

\section{TEHPROSIA, Pers.}

Calyx 5-toothed. Standard broad, as long as or longer than the obtuse keel. Upper stamen free at the very base, but adhering to the sheath of the others in the middle. Style curved, glabrous, but sometimes with a tuft of hairs on the terminal stigma. Pod linear, compressed, 2-valved, without partitions between the seeds. - Herbs or rarely shrubs. Leaves impari-pinnate, with several pairs of opposite leaflets, rarely reduced to a single leaflet, their veins numerous, parallel and oblique. Racemes terminal, leaf-opposed, or in the upper axils, often leafy at the base. Flowers 2-6 together at each bract.

A widely spread tropical genus.

1. T. piscatoria, Pers. - DC. Prod. II, 252. - Stock perennial and often woody, with slender erect stems 1-2 ft. high, the younger shoots silky-pubescent. Leaflets in 4-6 pairs, linear-oblong, $9-12^{\prime \prime}$, on petioles of less than $1^{\prime \prime}$, obtuse or truncate and mucronulate, with tapering base and oblique excurrent veins, but entire. Stipules subulate, $3^{\prime \prime}$. Raceme terminal or leaf-opposed, 8-12' long, the white-purplish flowers in distant clusters of 3 or 2 , or single near the end, in the axils of short stipellate bracts. Pedicels $2-3^{\prime \prime}$. Calyx $2^{1} / 2^{\prime \prime}$, its teeth subulate, the 2 upper approximate. Petals clawed, of nearly equal length, 3 ". Standard round and expanded; wings obliquely obovate and slightly adherent to the keel. Ovary silky, sessile, linear, with 5-8 ovules. Stigma pencilled. Pod straight, glabrate, $2^{\prime}$ in length, the valves spirally twisted after opening. Seeds oblong, $2^{\prime \prime}$, flat and somewhat kidney-shaped, speckled, the punctiform hilum in the middle of the concave side. - T. purpurea, Pers. T. toxicaria, Gaucl. in Bot. Freyc. (not Pers.). - Galega piscatoria, Sol. - G. littoralis, Forst.

Oecurs on all islands, on rocky ground near the seacoast and further inland. Is used by the natives for stupefying fish, the plant possessing a narcotic property kindred to that of Digitalis, with a similar effect on the action of the heart. Nat. names: "Ahuhu" and "Auhola"; Tahitian, "Hola". The species is spread over a great part of tropical Asia and Australia, and probably is not wanting in any of the Polynesian island groups.

\section{SESBAnIA, Pers.}

Tube of calyx truncate or 5-toothed. Standard roundish, patent or reflexed. Wings falcate. Keel incurved, obtuse, with long claws. Stamens diadelphous, the free stamen geniculate at the base. Anthers uniform, or the alternate ones a little longer. Ovary stipitate, many-ovuled; style 
incurved, with a eapitate stigma. Pod linear, compressed, subterete, or with 4 angles or wings, tardily dehiscent, septate between the seeds. Seeds transversely oblong. - Herbs, shrubs, or soft-wooded and shortlived small trees. Leaves abruptly pinnate, with many pairs of entire leaflets and deciduous stipules. Flowers large, scarlet, white or yellow, in loose axillary racemes. Bracts setaceous, caducous.

A small genus, belonging to the tropies of both hemispheres.

Calyx 5-toothed; flowers scarlet

Calyx truncate or bilabiate; flowers twice as large, and white

S. tomentosa.

S. grandiflora.

1. S. tomentosa, Hook. \& Arn. in Bot. Beech. p. 286. - A much branching shrub, 6-12 ft. high, the branches silky-tomentose when young, glabrate with age. Leaves $4-7$ ' long, short-petioled, with $8-18$ pairs of leaflets, cuspidate at the end. Leaflets pale, oblong, $6-14^{\prime \prime} \times 3-4^{\prime \prime}$, on petioles not exceeding ${ }^{1} / 2^{\prime \prime}$, obtuse or retuse, mucronate, silky-pubescent below when young. Stipules linear, $2-3^{\prime \prime}$ long, caducous. Raceme pubescent, few-(2-5-)flowered, the peduncle $1^{1} / 2^{\prime}$, the pedicels $10^{\prime \prime}$ long, with ovate or lanceolate, long-pointed, caducous bracts of $11 / 2-2^{\prime \prime}$ at the base and above the middle. Calyx cup-shaped, about 4 "long, with 5 broad acute teeth. Petals scarlet, all about $15^{\prime \prime}$ long, the standard emarginate, reflexed, the wings and keel auriculate. Stamens as long as the keel. Ovary pubescent; stigma slender, bidentate. Pod linear, $6-8^{\prime}$ long, $2^{\prime \prime}$ broad, compressed, somewhat torulose, with thick and grooved sutures and a long beak, almost indehiscent. Seeds 16-24, dark, shining, oblong, compressed, $2^{\prime \prime}$, with a punetiform hilum in the middle of the ventral side. - Agati tomentosa, Nuttall, in herb. Hooker. Gray, Bot. U. S. E. E. p. 409, pl. 46. - Mrs. Sinclair, pl. 22.

Along the seashore, Oahu! Waianae; southern shore of Molokai! Lanai! Hawai, Puna; Nilhau. Nat. name: Ohai . A very ornamental shrub on account of its large red flowers, but difficult to raise, as it is badly infested by the woolly coccus. According to Nadéaud (Enum. Pl. Tah.) the species occurs also in Tahiti, where it is known by the almost identieal name "Ofai"; but if this writer adds that it is the Aeschynomene coccinea, Forst., it must be remarked that Forster's circumstantial description, as given in Guillemin's Zephyritis Taitensis, agrees better with Sesbania (Agati) coccinea, Poir., a variety of $S$. grandiflora, than with our plant. The habitat given in Beechey's Voyage, viz., Acapuleo, is owing to a mistake, according to Gray.

$\dagger$ 2. S. grandiflora, Poir. - A small tree, $15-20 \mathrm{ft}$. high, the ultimate branches puberulous. Leaves $7-9^{\prime}$ long, with $14-20$ pairs of leaflets; these $12-15^{\prime \prime}$ long, glabrous. Racemes as before. Calyx cup-shaped, 6-9" long and broad, truncate or somewhat bilabiate, with both lips nearly entire. Petals white, about $3{ }^{\prime}$ long. Ovary glabrous. Pod nearly terete, $12-18^{\prime}$ long, $2^{\prime \prime}$ wide, torulose, at length dehiscent. Seeds $30-50$. - Agati grandiflora, Desv.

of early introduction, but scarcely naturalized. - A native of India. The red variety, $S$, coccinea, Poir., does not occur. 


\section{TRIBE IV. HEDYSAREAE.}

Herbs, or very rarely shrubs or trees. Leaves various. Pods separating transversely into one-seeded articles, usually indehiscent, or sometimes reduced to a single one-seeded indehiscent article.

To this tribe belongs also the Ground-nut or Pea-nut, Arachis hypogaea, L., which is cultivated for the sake of its oily seeds, It has abrupt leaves with 2 pairs of leaflets, a filiform calyx-tube, and is remarkable for the long-stipitate single-jointed and indebiscent pod which matures under ground.

\section{DESMODIUM, DC.}

Calyx campanulate, with 4 acuminate teeth or lobes, the upper one 2-cleft, or rarely equally 5-cleft. Petals narrow, the standard obovate, the wings usually adhering laterally to the keel, which has often an appendage at the points of adhesion. Stamens either monadelphous, with the sheath open on the upper side, or the upper stamen more or less free. Ovary with 2 or more ovules. Style with a minute terminal stigma. Pod consisting of 2 or more flat joints, usually reticulate. - Herbs, shrubs or trees. Leaves with 3 or 1 leaflets. Flowers usually small, in terminal or leaf-opposed racemes or panicles, or rarely in axillary clusters.

A large genus, widely dispersed over the tropies of both hemispheres, with a few extratropical species.

Hairs uncinate; leaves ovate-lanceolate; petals twice as long as the calyx.

Hairs not hooked; leaves very small, obovate; petals enclosed in the calyx

1. D. uncinatum.

2. D. triflorum.

† 1. D. uncinatum, DC. Prod. $I I, 331$. -- A perennial herb, $1-3 \mathrm{ft}$. high, ereet or decumbent, in rich ground climbing, viz., supporting itself by means of the stiff hooked hairs with which stem and pods are thickly covered. Leaflets 3 , ovate-lanceolate, $1^{1 / 2}-3^{\prime} \times \times^{1 / 2}-1^{1 / 2}$, glabrous above and generally with white specks or streaks, pubescent along the nerves underneath; the rhachis $1^{1 /} / 2-2^{1} / 2^{\prime}$, the petioles $1^{1} / 2^{\prime \prime}$. Stipules and stipellae small, subulate. Racemes terminal and axillary, pubescent, 4-6' long, naked below. Flowers $4-5^{\prime \prime}$ in length, pale-purplish, often almost white, generally 2 in the axils of ovate-acute bracts which measure 4 " and drop soon. Pedicels 2-3". Calyx 2", its sharp teeth as long as the tube, the 2 upper approximate. Keel without appendage. Stamens diadelphous. Pod subsessile, $1-1^{1 / 2^{\prime}}$ long, $2^{\prime \prime}$ wide, mostly curved, strongly uncinate-pubescent, $5-10$-jointed, the upper suture slightly sinuate or almost straight, the lower notehed to the middle and beyond. Hedysarum uncinatum, Jacq. - D. Sandwicense, E. Meyer, in Linnaea, XXIV, 230, and Gray, Bot. U. S. E. E. p. 433. - D. trigonum, DC. Griseb. Fl. W. Ind. p. 187.

A native of tropieal America, where it extends from northern Mexico to Chili, including the W. Indian islands (common in Jamaica). - Was introduced in early times and is now disseminated over the whole group, being much valued as pasture for horses and cattle, and generally known as Spanish or Chili elover. 
†2. D. triflorum, DC. Prod. II, 334. - Stems slender, much branched, prostrate or creeping, often not above a few inches long, sometimes $1-2 \mathrm{ft}$., hairy. Leaflets 3 , broadly obovate or obcordate, $3-4^{\prime \prime}$ or rarely $6^{\prime \prime}$ long and broad, glabrous, or sprinkled with silky hairs. Stipules acuminate, persistent. Flowers pink, scarcely $2^{\prime \prime}$ long, enclosed within the calyx, on slender pedicels of $2-8^{\prime \prime}$ in length, usually 2 together opposite the leaves. Pod sessile, 4-7" long, slightly eurved, pubescent or glabrous, the upper suture eontinuous, the lower slightly indented, consisting of 3 to 6 nearly square joints which sometimes separate, but frequently remain attached and open along the lower edge. - Mann, Enum. 103, and Fl. Haw. Islds. p. 55. - Benth. Fl. Hongk. p. 83. Griseb. Fl. W. Ind. p. 186. - Wight, Icon. Pl. Ind. Or. tah. 291, 292, - Hedysarum triflorum, L. - Sagotia triflora, Walp.

On the Waikiki plains near Honolulu, and probably elsewhere, in spring. - A common weed in tropieal Asia and Africa, and naturalized in various parts of tropical America.

\section{TRIBE V. VICIEAE.}

Low or climbing herbs. Leaves abruptly pinnate, with the terminal leaflet transformed into a tendril, rarely impari-pinnate or simple. Stipules usually large. Flowers solitary or in racemes. Stamens diadelphous. Pod 2-valved. Ovules 2 to many. Cotyledons thick.

Here belong the common Pea and Lentil.

\section{VICIA, L.}

Calyx 5-cleft, often oblique, the 2 upper teeth shorter. Wings adherent to the keel at their middle. Vexillary stamen free or to some extent united with the rest. Style filiform, pubescent or barbed at the top, the hairs usually only at its exterior side. Pod compressed, continuous within. - Usually climbing herbs, rarely low and spreading. Leaves with a terminal tendril or point. Inflorescence axillary. Bracts caducous.

A considerable genus, widely distributed, mostly through the temperate regions.

1. V. Menziesii, Sprengel, Syst. Veget. III, 26\%. - A strong climber, nearly glabrous. Stems angular, minutely pubescent, very leafy. Stipules large foliaceous, pectinately dentate with long and subulate teeth, especially the lower ones, which are roundish or flabellate and ${ }^{1 / 2}-1^{\prime}$ in diameter; the upper semisagittate. Leaves $6-7^{\prime}$ long. Leaflets $8-12$, mostly alternate, the lowest near the stem, $1^{1 / 2}-3^{\prime} \times{ }^{3 / 4}-1^{\prime}$, ovate oblong, obtuse, mucronulate, very veiny. Tendrils compound. Peduncles shorter than- the leaves, 2-4' long, 6-8-flowered, the pedicels slender, approximate, $3-5^{\prime \prime}$ long. Flowers large, $1-1^{1} / 2^{\alpha}$, pale purple. Calyx $8^{\prime \prime}$, its teeth as long as the tube, subulate, the lower one the longest. Standard recurved, without a callus. Style minutely pubescent all round above the 
middle. Stigma terminal, minute. Pod unknown. - Gray, Bot. U. S. E. E. p. 420. - V. grandiflora, Smith, in Rees Cyclop. no. 7.

Hawail, at the upper edge of the forests on Mauna Kea and Mauna Loa, 7000-8000 ft. (Menzies, Macrae, Remy). Not known from elsewhere.

\section{ABRUS, L.}

Calyx subtruncate, with very short teeth, the upper 2 connate. Standard ovate, adhering at the base to the staminal tube. Keel-petals united from the base, curved and longer than the wings. Stamens 9, the column slit, but the vexillary stamen wanting. Ovary with several ovules and a short curved style, the stigma capitate. Pod partitioned internally by transverse dissepiments. - Twining herbs or shrubs. Leaves with a terminal mucro and several pairs of leaflets. Racemes terminal, the flowers in fascicles arising from thick nodes.

A small ganus, common to the New and old World.

†1. A. precatorius, L.; DC. Prod. II, 381. - Leaflets in 7-10 pairs, oblong, about 6 "long, blunt, sprinkled underneath with appressed hairlets. Racemes with 1 or 2 leaves or at least a leafless pair of stipules below the flowers, the flowering part $1^{\prime}$ or more in length, with crowded nodes. Flowers pink or pale purple, $5-6$ " long. Pod sessile, oblong, $1-1^{1 / 2}{ }^{\prime} \times$ $1 / 2^{\prime}$, subtruncate at both ends. Seeds globose, shining, scarlet, with a black spot at the base. - Benth. Fl. Hongk. p. 92. - Griseb. Fl. W. Ind.

Escaped from gardens, here and there. The pretty seeds are known as "praying beads». The species probably derives from Asia, but is now found in most tropical countries.

\section{Tribe VI. PHASEOLEAE.}

Stems usually herbaceous, or woody at the base only, twining or prostrate, rarely erect shrubs or trees. Leaves with 3 mostly stipellate leaflets (rarely 5-7), the two opposite ones inserted below the terminal one or rarely wanting. Inflorescence usually axillary. Stamens diadelphous, with the upper stamen free at the base, although sometimes united with the others in the middle. Pod 2-valved. Cotyledons thick.

\section{CLITORIA, L.}

Calyx bibracteolate at the base, campanulate-tubular, 5-cleft or 5-toothed. Standard large, emarginate; wings falcate, patent, longer than the incurved acute keel. Style dilated and bearded beneath at the end. Climbers or suberect undershrubs. Leaves with 1 or several pairs of opposite stipellate leaflets besides the odd terminal one. Flowers axillary, large, blue, purple or white.

About 25 species, belonging to the tropies of the Old and New World.

† 1. C. Ternatea, L. - DC. Prod. II, 233. - Stem frutescent, twining, puberulous. Leaves with $2-5$ pairs of ovate blunt leaflets and subulate 
stipellae. Peduncles 1-flowered. Bracteoles roundish, almost half as long as the calyx. Flowers resupinate, blue or white. Calyx-lobes lanceolate. Standard $2^{\prime}$ long. Pod linear, flat, subsessile, pubescent, its valves not cordate. Seeds compressed.

Escaped from gardens. - A native of East India, but a common garden plant in most tropical countries.

\section{ERYTHRINA, L.}

Calyx truncate or 5-toothed. Standard large, conduplicate, without basal appendages. Wings very short, sometimes wanting. Keel much shorter than the standard, its 2 petals free or partially connate. Vexillary stamen free, or connate with the sheath at the base, the others connate to the middle. Ovary stipitate, with several ovules. Style subulate, glabrous, with a small terminal stigma. Pod torulose, falcate, filled with cellular tissue, sometimes follicular or indehiscent. Seeds ovoid, with an oblong lateral hilum. - Trees or erect shrubs, often prickly. Stipules small. Leaves pinnately 3 -foliolate, with gland-like stipellae. Flowers either in axillary leafless, or in terminal racemes which are foliose at the base, in fascicles of 2 or more, generally scarlet. Bracts and bractlets small or wanting.

About 25 species, all belonging to the tropies.

1. E. monosperma, Gaud. Bot. Voy. Freyc. p. 486, tab. 114. - A tree, unarmed or sparsely aculeate with short conical prickles, $20-25 \mathrm{ft}$. high, with a short thick trunk and a broad, spreading crown, the stiff, gnarled, whitish branches fulvo-tomentose at their ends. Leaflets ovate or deltoid, broader than long, $2-2^{1} / 2^{\prime} \times 2^{1} / 2^{-}-3^{1 / 2^{\prime}}$, obtuse, entire, truncate or subcordate at the base, chartaceous, tomentulose underneath, the terminal one largest; the petiole $4-5^{\prime}$, considerably extending beyond the lateral leaflets; the articulate petiolules $2^{1} / 2^{\prime \prime}$. Stipules gland-like, one or two for the base of the petiole, one for each lateral and two for the terminal petiolule. Racemes in the axils of the ultimate leaves, fulvo-tomentose, stout, dense, nodose, with 2 or 1 flowers at a node, $6-8^{\prime}$ long; bracts triangular, $1^{\prime \prime}$ or less; pedicels $2-4^{\prime \prime}$. Calyx thickly tomentose, tubular, minutely 5-toothed, 8-12" long, soon splitting laterally. Standard $1^{1 / 2}-2^{\prime}$ long and nearly as broad when spread out, scarcely stipitate. Wings oblong, obtuse, $9^{\prime \prime}$. Keel $7-8^{\prime \prime}$, its two petals free. Stamens as long as the standard, the alternate ones shorter, that opposite the standard connate at the base. Anthers pointed, versatile. Ovary tomentose, stipitate, 3-5-ovuled, narrowing to a slender and straight style of about $1^{\prime}$ in length. Pod $1^{1 / 2}-3^{\prime}$ long, torulose, dehiscent, 1 - to several-seeded. Seeds red, about $1 / \mathrm{g}^{\prime}$ long, the broad hilum occupying the greater part of their ventral side. - Flowers pale red or orange, rarely yellow. Hook. \& Arn. Bot. Beech. p. 81. - Gray, Bot. U. S. E. E. p. 444. Mann, Fl. Haw. Islds. p. 57. - E. Tahitensis, Nadéaud, Enum. Pl. Tah. no. 499. Mrs. Sinclair, pl. 18. 
On dry rocky hills and plains of all islands, to a height of about $1000 \mathrm{ft}$., much more common formerly than now. Nat. name: "Wiliwili". The tree loses its leaves in late summer, and flowers in spring before the new leaves are out. Not reported from elsewhere, but there anc hardly be a doubt, that Nadéaud's Tahitian species is identical with the present one.

\section{STRONGYLODON, Vogel.}

Calyx-teeth short, broad, obtuse. Standard ovate-oblong, acute, recurved or even reflexed, with 2 callose crests on the inner side above the claw. Wings much shorter than the standard and adherent to the keel, which is as long as the standard, much curved, beaked, with its two petals connate. Vexillar stamen quite free; anthers uniform. Ovary stipitate, with 1 or few ovules. Style very long, filiform, beardless; stigma terminal, minute. Pod obliquely ovate-oblong, 2-valved, the valves convex and coriaceous. Seeds large and thick, suborbicular, suspended by a broad and flat funis and half surrounded by a linear, not strophiolate rhaphe. Cotyledons thick, consolidated. - Tall woody twiners. Leaves pinnately 3-foliolate, stipellate. Flowers showy, red, fascicled on long axillary nodose peduncles. Bracts minute; bracteoles at the base of the calyx.

A genus of 2 species, one growing in the Philipines, with perhaps a third one from the New Hebrides.

1. S. lucidum, Seem. Fl. Vit. p. 61. - A tall woody twiner with herbaceous branches, glabrous throughout. Leaflets membranous, roundish, ovate to oblong-ovate, $2^{1 / 2}-5^{\prime} \times 2-3^{\prime}$, on petiolules of $2-4^{\prime \prime}$, triplinerved, acuminate, glossy, the two lower ones uneven-sided, the linear stipellae half as long as the petiolules; the petiole $2^{1 / 2}-4^{\prime}$, with 2 small ovate or deltoid persistent stipules at its base. Racemes drooping, slender, $10-18^{\prime}$ long. Flowers bright scarlet, generally in fascicles of 3 on short or somewhat elongate nodes; the slender pedicels about 1 ' long, the bracts at their base short conical, wart-like, the bractlets at the base of the calyx ovate obtuse, $1^{\prime \prime}$ long and soon caducous. Calyx campanulate, $4^{\prime \prime}$, the 2 upper teeth connate. Standard reflexed on a short elaw, $15^{\prime \prime}$ long and $6^{\prime \prime}$ broad. Wings and keel on longer $(3$ ") claws, the former less than half the length of the standard, oblong, obtuse, the keel falciform acute. Ovary glabrous, with 2 ovules. Pod chartaceous, transversely rugose, obliquely ovate or subrhomboidal, complanate, with both sutures acute, $3^{1} / 2-4^{\prime}$ long and $2^{\prime}$ broad, on a stipes of ${ }^{1} / 2^{\prime}$. Seeds 1, rarely 2, with a black bony testa, $12^{\prime \prime}$ long and nearly as broad, slightly compressed, the semicireular rhaphe cristate at the insertion of the funis. - Mann, Fl. Haw. Islds. p. 57. - Glycine lucida, Forst. Rhynchosia lucida, DC. - S. ruber, Vogel, in Linnaea, X, 585. - A. Gray, Bot. U. S. F. E. p. 446, pl. 48. - Mucuna altissima, Hook. \& Arn. Bot. Beech. p. 81. - Mrs. Sinclair, pl. 5.

All islands, in dense woods, at elevations of $1000-3000 \mathrm{ft}$, festooning trees; most common in Hamakua and Hilo, Hawaii. Nat, names: "Kaiwi and Nukniwis (from iwis, the name of a red bird, and "nukns, bill). A climber of great beauty, worthy of-cultivation. The species oceurs also in Tahiti, the Viti Islands and Ceylon. 


\section{MUCUNA, Adans.}

Calyx campanulate, the 2 upper teeth wholly connate, the lowest one longest. Standard conduplicate, shorter than the other petals, with inflected auricles at the base. Keel as long as or longer than the wings, curved, and usually tipped with a cartilaginous beak. Upper stamen free; anthers alternately basifixed and versatile. Ovary sessile, villous, with few ovules. Style filiform, with a small terminal stigma. Pod thick, ovate-oblong or elongate, usually covered with stinging hairs, 2-valved, coriaceous, filled between the seeds. Seeds with a linear rhaphe. Twiners or tall climbers. Leaflets 3 , the stipellae subulate or sometimes wanting. Flowers large, rising in fascicles from gland-like nodes at the ends of long axillary peduncles. Bracts small or caducous.

A considerable genus, spread over the tropical regions of Asia, Africa and America. Flowers green; pod smooth, glabrate Flowers yellow and red; pod with transverse lamellae, hirsute

1. M. gigantea.

2. M. urens.

1. M. gigantea, $D C$. Prod. $I I, 405$. - A tall climber, glabrous, with terminal or leaf-opposed compound tendrils. Leaflets thin, ovate or rounded, $3-5^{1} / 2^{\prime} \times 2-3^{3} / 4^{\prime}$, on petiolules of $2-3^{\prime \prime}$, obtuse or shortly acuminate, the lateral ones very uneven-sided, their lower half bulging out strongly and provided with a basal nerve that almost equals the midrib; the petiole $1^{1 / 2} 2^{\prime}$. Stipellae short subulate, $1 / 2^{\prime \prime}$ long. Flowers greenish, 3 in a fascicle, on pedicels of $4-8^{\prime \prime}$ which are placed on short and thick spurs of $2-3^{\prime \prime}$ in length, crowded near the apex of a slender and nodding axillary peduncle which measures $3-6:$ Bracts short, wart-like; bracteoles below the calyx ovate, $4-6$ ", pubescent, caducous. Calyx subtruncate, $4^{\prime \prime}$, very short-toothed, strigose with appressed stiff hairs in the bud. Standard broadly obovate, 9-11", emarginate. Wings free, 15 ", auriculate, ciliate at the back. Keel angularly curved, biauriculate at the base. Filaments clavate toward the apex, the anthers barbed and jointed with them. Ovary oblong, hirsute with appressed hairs, 2-4-ovuled; style long ( $\left.1^{\prime}\right)$ and slender, ciliate, with peltate stigma. Pod oblong, flat, coriaceous, $2-3^{1 / 2^{\prime}} \times 1-1^{1 / 2}$, destitute of transverse lamellae and glabrate, the thick margins prominently costate and 2winged, 2- or 1-seeded, the papery endocarp soluble, silky-glossy and projecting between the seeds. Seeds orbicular or almost square, nearly $1^{\prime}$ in diameter, slightly flattened, uniformly brown or with black lines, the testa hard bony, the rhaphe extending over three fourths of the circumference. - Dotichos giganteus, Willd. - Carpopogon giganteum, Roxb. - Citta nigricans, Lour.

Hawaii! Puna and Kau; Molokai, Koolaupapa! Nat.name: Kaeës, - Has been found in the Society, Samoa, Tonga and Viti Islds, as well as in N. Australia and India.

2. M. urens, DC. Prod. II, p. 405. - A tall climber, the young shoots silky with fine stinging hairs. Leaflets ovate, $2^{1 / 2}-5^{\prime} \times 1^{1 / 2}-3^{\prime}$, the 
lateral ones oblique, acuminate, densely sericeous underneath. Peduncle flexuose, 10-15-flowered; flowers in fascicles; bracteoles ovate, obtuse, silky, ${ }^{3} / 4^{\prime}$ long. Flowers large, $2^{\prime}$ long, bright yellow, with some red, very showy. Calyx 1', silky, unequally 4-cleft, the lowest lobe as long as the tube. Standard reflexed, ovate-lanceolate, two thirds the length of the wings. Pod sessile, compressed, oblong, with numerous transverse lamellae, hirsute with fulvous stinging hair, usually 1-seeded. Seed as before. - Dolichos urens, L. - Mann, Enum. 108, and Fl. Haw. Islds. p. 59. - Griseb. Fl. W. Ind. p. 198.

Maui, woods above Makawao; Hawaii, Waimea. (Gaudichaud, Remy, M. \& B.) A native of tropieal America from the W. Indies to Brazil and Peru, well known as the Cow-itch plant.

\section{DIOCLEA, H. B. K.}

Lowest calyx-lobe the longest, the 2 upper ones connate. Standard orbicular or ovate, reflexed, appendiculate at the base with inflexed auricles. Wings obovate or oblong, free, longer than the keel, which is incurved, beaked or obtuse. Upper stamen free at the base, but united with the others at the middle. Ovary subsessile, 2- to many-ovuled. Style incurved, beardless, thickened above; stigma terminal, truncate. Pod coriaceous, oblong or semiorbicular, with the upper suture dilated or two-winged, dehiscent, filled between the seeds. Seeds compressed, with a linear rhaphe. - Tall woody twiners with pinnately 3 -foliolate stipellate leaves. Flowers blue or white, in fascicles on the racemose nodes of a thick axillary peduncle. Bracteoles at the base of the calyx, caducous.

About 16 species, chiefly natives of tropical America, two of which are also found in tropical Asia.

1. D. violacea, Mart. - Benth. Annal. d. Wien. Mus. II, 133. - Young shoots hispid with dark brown hair. Leaflets ovate or ovate-oblong, $4-5^{1 / 2^{\prime}} \times 3-3^{1} / 2^{\prime}$, on petiolules of $2^{1 / 2^{\prime \prime}}$, obtuse or apiculate, coriaceous, with strongly salient oblique veins, glossy above, but the veins underneath pubescent; the petiole $4-4^{1} / 2^{\prime}$. Stipellae filiform, about $3^{\prime \prime}$; stipules linear-lanceolate, $6-7^{\prime \prime}$. Peduncle stiff angular, 12-15' long, naked in the lower half or distantly bracteate, tomentose, its nodes short or somewhat elongate. Pedicels $1-2^{\prime \prime}$; bracts linear-lanceolate, 6-9", the lowest bifid; bracteoles ovate, $1^{1 / 2} 2^{\prime}$. Calyx campanulate, tomentose, $5-6 "$, the upper tooth broad and obtuse or emarginate, the lowest about the length of the tube and acute. Corolla deep blue or violet, $6-8^{\prime \prime}$. Keel beaked, obtuse, half as long as the wings. Anthers uniform. Pod $3-4^{\prime}$ long, $1^{1 / 2}-2^{\prime}$ broad, tricarinate at the ventral suture, flattened, glabrate when mature. Seeds mostly 2, nearly orbicular, compressed, $9-10^{\prime \prime}$ in diameter, with a bony testa, the linear rhaphe extending more 
than halfway round the circumference. - Gray, Bot. U. S. E. E. p. 439. Mann, Fl. Haw. Islds. p. 59. - Dolichos altissimus, Velloz.

Hawaii! Hilo and Puna, in Cocoa-palm groves; Kauai, in the deep gulches of the plains, climbing over trees. Nat. name: "Maunaloas. - Probably indigenous in Brazil, but found also in the Society and Viti Islands.

\section{CANAVALIA, Adans.}

Calyx tubular-campanulate, the 2 upper lobes united into a large entire or 2-lobed upper lip, the 3 lower teeth very small, free or united into one. Standard large and broad. Wings and keel free, curved or sometimes slightly twisted. Upper stamen free at the base, united with the others in the middle. Style filiform, or slightly thickened in the upper part, with a terminal stigma. Pod oblong or linear, usually large, flattened or rarely turgid, with a prominent wing or rib on each side of the upper suture. Seeds with a linear rhaphe. - Trailing or twining herbs. Leaflets 3 , with small subulate stipellae; the stipules usually very small. Peduncles axillary, bearing in the upper part a few $1-3$ flowered nodes. Flowers rather large, pink, purple or white. Bracteoles small, caducous.

A genus not numerous in species, but widely dispersed over tropical and subtropical Asia, Africa and America.

1. C. galeata, Gaud. Bot. Voy. Freyc. p. 486, adnot. - Stem woody at the base, slender, twining on trees, often to a great height, the young shoots pubescent, but soon glabrate. Leaflets ovate, $3-5^{4} \times 1^{1 / 2}-2^{1 / 2^{\prime}}$, on petiolules of $3^{\prime \prime}$, apiculate or acuminate, membranous, glabrous. Petiole $21 / 2-4^{1 / 2}$ long; the stipules at its base very short $\left(1 / 2^{\prime \prime}\right)$ and thick, auricular; the stipellae at the base of the terminal petiolule subulate, $1^{\prime \prime}$. Peduncle $4-8^{\prime}$ long, with 2 warts at the base and often a gland in front above it, puberulous, with 3 to 9 short or elongate nodes near the apex, each bearing from 3 to 1 flowers, but entirely naked below. Pedicels $1 / 2-2^{\prime \prime}$, with 2 small warts at the base, the calycine bracteoles ovate obtuse, $1^{\prime \prime}$. Calyx $10^{\prime \prime}$, its upper lip broad, helmet-shaped, recurved, 6 " high and $8-10^{\prime \prime}$ broad when expanded, emarginate, the 3 lower teeth free, narrow, acute, $2^{\prime \prime}$ long. Petals pink or purplish, twice as large as the calyx. Standard obovate, recurved, emarginate or bifid. Wings and keel curved, not twisted, obtuse, auricled above the claws, nearly as long as the standard, or the wings shorter. Anthers ovoid, versatile, all equal. Ovary pubescent; stigma glabrous, dilated. Pod coriaceous, shortly stipitate, linear-oblong, $4-6^{\prime} \times 1-1^{1} / 4^{\prime}$, straight, compressed, laterally apiculate. Seeds 4-8, oblong, 8-10", pale. - Gray, Bot. U. S. E. E. p. 441. - Mann, Fl. Haw. Islds. p. 60. - Vogel, in Limnaea, X, 584. Dolichos galeatus, Gaud. 1. e. p. 486, tab. 115. - Canavalia Gaudichaudii, Endl. in Flor. Ins. Austral. - Mrs. Sinclair, pl. 6.

On all islands, in forests up to $2000 \mathrm{ft}$. Nat. names: *Awikiwilki, and sPuakauhio in Kauai. Not yet found elsewhere. 
$\beta$ var. pubescens. - Leaves pubescent underneath. Lower calyx-lobes obtuse. C. pubescens, Hook. \& Arn. in Bot. Beech. p. 81.

Niibau; Hawail, Kau!

From Kaua i (Kn. 24) my collection holds specimens with much smaller flowers $\left(10-12^{\prime \prime}\right)$, and the upper calyx-lobe shorter in proportion to the tube. - It also contains a pod, evidently of this genus, but chartaceous and turgid, with more salient wings along the ventral suture than in the species deseribed. The seeds also differ in being rather small and black, although with the rhaphe linear and straight.

\section{PHASEOLUS, L.}

Calyx campanulate or nearly tubular, 5-toothed or 5-lobed, rarely 4toothed by the union of the 2 upper teeth. Standard orbicular, recurved. Keel produced into a long twisted beak. Upper stamen free. Style thickened and cartilaginous in the upper part, usually with a line of hairs under the stigma, which is more or less oblique or lateral. Pod linear and nearly cylindrical, or more or less flattened and falciform. Seeds several, thick, with a short linear hilum. - Herbs, either dwarf or prostrate, or more frequently twining. Leaflets 3 , rarely reduced to one, stipellate. Peduncles axillary, bearing in the upper part several 3-or 2 -flowered nodes. Bracteoles at the base of the calyx. Corollas white, yellowish, red or purple.

A large genus, widely dispersed over the tropieal regions of Asia, Africa and more especially America. "Several species through long eultivation have established races, the wild origin of which it is now difficult to trace. Here belong the common Kidney Bean, $P$. vulgaris, and the Lima Bean, $P$. lunatus.

Upper calyx-lobes broad and obtuse; pod compressed.

1. P. Truxillensis.

All ealyx-lobes acute; pod terete; herb not twining

2. $P$, semierectus.

1. P. Truxillensis, H. B. K. Nova Gen. Amer. 6, 451. - DC. Prod. II, 391. - A twining herb, glabrate or pubescent, the hairs of the stem reflexed, those of the leaves appressed silky. Leaflets ovate or lanceolate, $1-3^{\prime} \times{ }^{3} / 4-2^{\prime}$, obtuse or acuminate, the lateral ones oblique. Stipellae minute, oblong; stipules small, not decurrent. Peduncles elongate, fewflowered near the apex. Pedicels $1-5^{\prime \prime}$; bracteoles shorter than the calyx, coriaceous, deciduous. Flowers large, nearly 1', purple, pale rose or violet. Upper calyx-lobe short, broad and obtuse, the others longer, acute. Pod eompressed, straight or falcate, $2-5^{\prime} \times 3-4^{\prime \prime},-P$. Cumingii, Benth. - P. amoenus, Sol. - P. rostratus, Wall. Pl. As. Rar. I, p. 50, tab. 63 .

Oahu, Diamond Hill (U. S. E. E.); Hawaii (Remy); also found by Menzies, Nuttall and Macrae. - A native probably of S. America, but collected also in most Polynesian islands, on the E. coast of Anstralia and in other tropical countries.

†2. P. semierectus, L. - DC. Prod. II, 396. - Stem herbaceous, suberect, rarely twining at the end, silky or glabrate. Leaflets ovate, membranous, triplinerved, $1^{1 / 2^{t}} \times^{3} / 4^{\prime}$, on petiolules of $11^{1 / 2^{\prime \prime}}$, acuminate, silky underneath when young, but soon glabrate, the petiole $1^{1 / 2}-2^{\prime}$. Stipules lanceolate, $3-4^{\prime \prime}$, not produced at the base. Peduncle $12-18^{\prime}$ 
long, bearing toward the apex 4-8 distant 2-flowered nodes; pedicels less than $1^{\prime \prime}$ in length, recurved. Bracts and bracteoles linear-lanceolate, the former $2-3^{\prime \prime}$, the datter $1^{\prime \prime}$. Calyx tubular, $2^{\prime \prime}$, its 5 short teeth nearly equal, acute. Standard beaked, greenish-purple. Wings straight and free, $9^{\prime \prime}$ long, exceeding the other petals, dark purple in the upper portion, as is the keel, greenish below. Ovary silky. Pod linear, 3-4' long, scarcely $1^{1 / 2} 2^{\prime \prime}$ broad, septate between the seeds, almost terete when ripe, the thin valves twisted after opening. Seeds numerous, oblong or angular, 1-1//2", dark brown, mottled, with a short oblong hilum. Jacq. Icon. Rar, tab, 558. - Mann, Fl. Haw. Islds. p. 61. - Griseb. Fl. W. Ind. p. 197. - P. lathyroides, L.

In pastures near Honolulu and elsewhere. Of recent introduction. A native of tropical Ameriea.

\section{VIGNA, Savi.}

The two upper teeth of the calyx connate or distinct. Standard orbicular, generally with inflexed auricles at the base. Wings falcate, oblong, shorter than the standard. Keel curved, as long as the wings. Upper stamen free; anthers uniform. Ovary sessile, many-ovuled. Style filiform or thickened above, longitudinally bearded on one side; stigma oblique or lateral. Pod linear, straight or nearly so, mostly terete, 2valved, projecting between the seeds. Seeds oblong-angular or kidneyshaped, with a short lateral rhaphe. - Twining or prostrate herbs with pinnately 3-foliolate stipellate leaves. Flowers yellow or rarely purplish, in racemosely arranged fascicles at the end of axillary nodose peduncles. Bracts and bracteoles small, deciduous.

A genus of about 30 species growing in the tropies of both Worlds.

Leaves obovate, triplinerved; flowers $6-7^{\prime \prime}$ long; pods flattened, torulose, with thick vaives

1. V. lutea.

All or only the upper leaves linear or narrow-lanceolate, acute, of firm texture; flowers $11-12^{\prime \prime}$; pods rather terete and thin, the valves twisted after dehiscence

2. V. Sandwicensis. All leaves small ovate, thin; flowers and pods as in no. 2 ; seeds black

3. V. Oahuensis.

1. V. Iutea, Gray, Bot. U. S. E. Exp. p. 452. - A prostrate trailing perennial, several feet long, scarcely twining. Leaflets rather fleshy, pubescent when young, ovate or obovate or suborbicular, the lateral ones oblique, subrhomboidal, $2-2^{1 / 2^{\prime}} \times 1^{1 / 2}-2^{1} / 4^{\prime}$, triplinerved; the rhachis $\left(1^{1} / 2-2^{1 / 2^{\circ}}\right)$ and petioles pubescent, the latter $1-1^{1 / 2^{\prime \prime}}$, their stipellae half as long, the stipules acute, $1^{1 / 2}{ }^{\prime \prime}$, soon eaducous. Peduncles thick, $3-5^{\prime}$ long, scarcely nodose, the yellow flowers racemose in the upper fourth, single or in fascicles of 2 or 3 ; pedicels $1^{1 / 2}-2^{\prime \prime}$, at length reflexed, the ealycine bracteoles ovate, obtuse, less than $1^{\prime \prime}$. Calyx campanulate, $2^{\prime \prime}$, the 4 teeth $1 / 3$ the length of the tube, the upper one short, broad and obtuse, the 3 lower ones triangular, acute. Standard orbicular, $6 \rightarrow 7^{\prime \prime}$ 
shortly 2-crested, without appendages; the wings obovate, auriculate, $4^{1} / 2^{\prime \prime}$; the keel as high, curved at a right angle, broad-beaked. Anthers minute. Style curved and twisted. Ovary glabrows. Pods nodding, linearoblong, 2-3' $\times 3-4^{\prime \prime}$, compressed, but torulose, straight, the thick valves not twisted after opening. Seeds $4-9$, globose-oblong, dark brown, $3-4 "$, the rhaphe oblong, white. - Mann, Fl. Haw. Islds. p. 62. Dolichos luteus, Sw., and Hook. \& Arn. Bot. Beech. p. 81. - D. luteolus, Forst. - Scytalis anomala, Vogel, in Rel. Meyen. - Vigna anomala, Walp. Repert. I, 779.

On all islands at short distances from the shore, but not common. Nat. names: "Nanea" and Pulihilihi" - Is found also in the Society and Viti Islds, and many tropical countries of both Worlds.

2. V. Sandwicensis, Gray, l. c. p. 451, pl. 50. - Stem suffruticose, twining, retrorsely hispid. Leaflets linear or linear-lanceolate, $1^{1 / 2}-2^{\prime} \times$ $1-4^{\prime \prime}$, on petioles of $1 / 2 "$, somewhat acute or obtuse and mueronulate, of firm texture, hispid on both sides; the rhachis $1-1^{1} / 2^{2}$; the subulate stipellae $1 / 2^{\prime \prime}$. Peduncle $1 / 2-11^{1} / 2^{\prime}$, with $2-4$ pale yellow flowers on pedicels of $3-5 "$. Calycine bracteoles linear, $1^{\prime \prime}$. Calyx hispid, $2^{\prime \prime}$ long, deeply 4-toothed, the uppermost tooth broad and obtuse or emarginate, the others subulate. Standard obovate, entire, short-clawed, with 2 callosities in front. Wings appendiculate, oblong, shorter than the keel. Keel rather straight, gradually curved, as long as the standard. Ovary hairy; the style curved. Pod hispid with appressed hair or glabrate, linear, straight, $3^{\prime} \times 3^{\prime \prime}$, flattened, not torulose, the chartaceous valves twisted after opening. Seeds $8-10$, dark-brown, oblong-oval, with oblong rhaphe. Root tuberous and «edible» according to Pickering. Mann, 1. e. p. 62.

Hawaii, 6 miles above Kilarea; W. Maui; Kauai (U. S. E. E.).

$\beta$. The above given description applies to plants from higher elevations. I have specimens from Makawao, Maui, and Kau, Hawaii, collected at altitudes of 1500 to $3000 \mathrm{ft}$, which present notable differences. The upper leaves of the pubescent stems are narrow lanceolate to ovate acute, and penninerved, $1-2^{1} / 2^{\prime} \times 1 / 2-1^{\prime}$, while the lower ones are broadovate, acute or obtuse, or even obovate as in no. 1. Peduncle $4-6$ '. Flowers in fascicles of 2 and 3 , on twisted pedicels of $5-6^{\prime \prime}$. Calyx $3^{\prime \prime}$, the upper lobe bidentate, the lowest narrower than the lateral ones. Standard 10-12" in diameter; wings obovate; keel arched. Style curved, but not twisted. Seeds 8-15, very dark, almost blaek, oblong-angular, $3^{\prime \prime}$ long.

3. V. Oahuensis, Vogel, in Linnaea, X, p. 585. - A more slender twiner than the two preceding species, the stem hispid with patent or retrorse hairs. Leaflets subsessile, thin membranous, hispid, small, ovate, $3 / 4-1^{4} \times{ }^{1} / 2^{2}$, somewhat acute, the filiform rhachis $1 / 2-1^{1} / 2^{2}$, the stipellae minute. Peduncle filiform, hispid, short, $1 / 2-1^{1} / 2^{4}, 1-3$-flowerd, the pedicels $2^{1 / 2}-4^{\prime \prime}$, the bracteoles very minute. Calyx $11^{1 / 2^{\prime \prime}}$, the broad upper tooth obtuse or 
bidentate, the lowest narrowest and longest. Flowers large as in no. 2; the keel arched, longer than the wings. Ovary hairy. Style incurved and hirsute as in no, 2. Pod linear, narrow, only $2^{\prime \prime}$ wide by $2^{\prime}$ in length, rather terete, hispid, the thin valves twisted after opening. Seeds oblong-angular to kidney-shaped, almost black, shining, $2^{\prime \prime}$ in length, with a short hilum. - Gray, 1. e. p. 450. - Mann, 1. c. p. 62. - V. villosa, Hook. \& Arn. in Bot. Beech. p. 81.

- Oahu, Makaleha of the Kaala range! Kauai! (Kn.).

\section{DOLICHOS, L.}

Calyx campanulate, with short teeth, the 2 upper teeth united. Standard orbicular, auricled at the base, bicallose in front. Wings adherent to the keel, which is much incurved and often beaked, but not twisted. Upper stamen free; anthers uniform. Ovary many-ovuled. Style tbickened above, with a longitudinal line or a tuft of hairs below the terminal stigma. Pod falciform or straight, compressed, filled between the seeds, 2-valved, the sutures often thickened. Seeds compressed, with a short rhaphe. - Prostrate or twining herbs or undershrubs. Leaves pinnately trifoliolate, with small stipellae. Flowers either single or fascicled in the axils of leaves, or along the nodes of an axillary peduncle, purple, yellowish or white. Bracteoles striate, usually small and caducous.

A genus of the tropics of Africa, Asia and Australia, with a few species in S. Ameriea.

†1. D. Lablab, L. spec. 1019. - A stout twining perennial, glabrous. Leaflets broadly triangular-ovate, $2^{1 / 2}-4^{\prime}$ long and nearly as broad, the lateral ones rhomboidal, obtuse or acuminate, more or less truncate at the base. Flowers racemosely fascicled along a stout rhachis, white or purplish-red, $6-7^{\prime \prime}$ long, on short pedicels; the-bracteoles obovate, as long as the calyx, or nearly so. Lower calyx-lobes broad, acute, the upper one obtuse. Keel beaked. Pod falciform, 3-4' long and 1' or less broad, flat-convex, with an oblique or recurved point and somewhat muricate margins. Seeds 4 or less, 5-6" long, subcompressed, the thick white rhaphe two thirds the length of their diameter. - Mart. Fl. Bras. 24, tab. 51. - Griseb. Fl. W. Ind. p. 196. - Lablab vulgaris, Savi. - DC. Prod. II, 401 .

of early introduction, originally cultivated for its beans, but now widely dispersed over all islands. - A native of tropical Asia, but carried into most tropical countries.

\section{CAJANUS, DC:}

Calyx campanulate, 4-toothed or lobed, the upper lobe 2-toothed. Standard orbicular, with inflexed auricles at the base and 2 callosities inside above the claw. Wings and keel of nearly the same length, the latter straight, obtuse. Upper stamen free from the base. Ovary with several ovules. Style thickened above the middle; stigma terminal, oblique. 
Pod flattened, oblong, marked externally with oblique indented lines between the seeds, but hardly septate internally. Seeds subcompressed, with a lateral oblong rhaphe. - An ereet undershrub. Leaves pinnately 3 -foliolate, without stipellae. Flowers yellow, in axillary, not nodose racemes. Bracteoles none.

A single species.

†1. C. Indicus, Spreng. Syst. Veget. III, 248. - Stem 3--4 ft. high, covered with a short soft tomentum. Leaflets hroadly lanceolate or oblong, $1^{1 / s}$, -3'long, acute, dotted underneath with resinous specks, on petiolules of $6^{\prime \prime}$. Stipules lanceolate, caducous. Peduncles axillary, bearing at the summit a short raceme of mostly geminate flowers, either entirely yellow or the standard veined outside with purple. Bracts deciduous. Calyxlobes subulate, recurved. Pod $2-3^{\prime}$ long, with an incurved point, more or less hairy and glandular. Seeds $4-5$, mottled. - Benth. Fl. Hongk. p. 89. - C. bicolor, DC. - Cytisus Cajan, L.

of early introduction; near native dwellings. - Derives from Asia, but is generally cultivated for its seeds in tropieal countries; the dhal of India,

\section{TRIBE VII. SOPHOREAE.}

Trees or tall shrubs, rarely herbs or climbers. Leaves pinnate, with 5 or more leaflets, rarely reduced to 3 or 1 . Stamens all free, Pod continuous (not articulate), indehiscent or 2-valved.

\section{SOPHORA, L.}

Calyx campanulate, shortly 5-toothed. Standard rather broad. Keelpetals equal to or rather longer than the others, scarcely cohering. Stamens free. Ovary shortly stalked, with several ovules. Style glabrous, with a minute terminal stigma. Pod cylindrical or slightly compressed, sometimes 4-winged, fleshy or hard and woody, contracted between the seeds and usually indehiscent. Radiele curved. - Trees, shrubs, or very rarely herbs. Leaves pinnate, the leaflets usually opposite, with a terminal odd one. Stipellae setaceous or wanting. Racemes simple, terminal, or several forming a terminal panicle.

A genus not very numerous in species, but widely scattered over tropical and temperate Asia and tropical and subtropical America.

1. S. chrysophylla, Seem. Fl. Vit. p. 66. - A tree, $20-30 \mathrm{ft}$. high, the young shoots silky-pubescent. L.eaves $5-6^{\prime}$ long, with $6-10$ pairs of leaflets. Leaflets obovate-oblong, $10-18^{\prime \prime} \times 4-6$ ", obtuse, often retuse, with a cinereous or tawny pubescence underneath, or glabrate, on petioles not exceeding $1 / 4^{\prime 4}$. Stipellae wanting. Racemes terminal and lateral, $1 / 2-I^{\prime}$ long, tomentose, the pedicels $6-9^{\prime \prime}$, at length reeurved. Bracts triangular, $1^{1} / 2{ }^{2}$; bracteoles none. Calyx tomentose, $4-5 "$ high, cupshaped, the broad blunt teeth very short, the 2 upper ones divided by 
a deeper cleft. Petals pale yellow. Standard scarcely recurved, almost 1 ' long; the suberect wings and keel-petals nearly as long. Stamens as long, the anthers short ovoid. Ovary silky-pubescent. Style filiform, straight. Pod long-stipitate, straight, beaked, 4-6' long, about $4^{\prime \prime}$ wide, turgid, 4-winged, deeply constricted between the seeds, indehiscent. Seeds $4-8$, ovoid, light brown or yellow, $4^{\prime \prime}$ long, the punctiform hilum near the base. Radicle very short and curved; cotyledons plano-convex. Edwardsia chrysophylla, Salisb. in Linn. Transact. 9, p. 302, tab. 26; Ker. Bot. Reg. tab. 738; Gray, Bot. U. S. E. E. p. 459.

Hawaii! Maui! Kauai! Forms, together with Myoporum Sandwicense and Raillardia struthioloides, the highest belt of forest on the lee side of those islands up to $8000-10000 \mathrm{ft}$. It descends however as far as $2000 \mathrm{ft}$, and even iower, but then becomes shrubby. These lower forms are nearly glabrate and bear smaller flowers. Nat. name: "Mamani*. Its hard and durable wood is much valued for fence posts.

Cultivated species belonging to this tribe are: Sophora tomentosa, Virgilia aurea.

\section{SUBORDER II. CAESALPINIEAE.}

Petals all free, imbricate in aestivation, the upper one innermost and the two lower outside, either nearly equal, or unequal, and occasionally all wanting except the upper one. Stamens usually 10 and all free, but sometimes fewer, or monadelphous, or indefinite. Radicle usually straight. Leaves pinnate or bipinnate, rarely reduced to 2 or 1 leaflets.

of trees and shrubs belonging to this Suborder which are more or less general in eultivation and do not fall under the following genera, have to be mentioned: the Tamarind tree, Tamarindus Indica, which is found near most settlements, several species of Bauhinia, as B. acuminata, tomentosa, variegata, diphylla, corymbosa etc., Haematoxylon Campechianum (the Logwoed tree), Poinciana regia, Saraca Indica, Hymenaea Courbaril. Here also must be given a place to the anomalous Inocarpus edulis, Forst., or Tahitian Chestnut, the Ivi or Mapé.

\section{CAESALPINIA, L.}

Sepals 5, shortly united at the base, nearly equal, or the lower one larger and concave. Petals 5, nearly equal, or the upper one the smallest, the two lowest outer ones the largest. Stamens 10, free, all fertile, the filaments often hairy. Ovary with 2 or more ovules. Pod flattened, ovate, oblong, lancenlate or falcate, opening in 2 valves. Seeds ovoid, globose or flattened. - Trees or shrubs, often climbing and prickly. Leaves bipinnate. Flowers yellow or red, generally showy, racemose in the axils of the upper leaves, or paniculate and terminal.

About 38 species, dispersed over the tropienl regions of both Worlds.

1. C. Bonducella, Fleming, Asiat. Res. XI, 159. - A tall spreading shrub, not climbing, the branches glabrous and with numerous hooked prickles which are scattered indiscriminately, chiefly over the petioles, but also take the place of stipules and stipellae, geminate when in place of the former. Leaves abruptly bipinnate, the common petiole $1-1^{\mathrm{t} / 2} \mathrm{ft}$, the pinnae in $4-6$ pairs, each $4-6$ ' long. Leaflets in $6-8$ pairs, 
oblong, $18-20^{\prime \prime} \times 9-12^{\prime \prime}$, obtuse, not cordate at the base. Racemes supra-axillary, 4-8' long, fulvo-tomentose, bare of flowers only in the lowest fourth or sixth. Bracts lanceolate, $6^{\prime \prime}$, running out into a subulate recurved point. Pedicels $9^{\prime \prime}$, jointed above the middle. Calyx tomentose, 7", deeply 5-parted, its lobes oblong, the 2 lower ones connate higher up than the others. Petals yellow, not much longer, the uppermost one shorter, suborbicular, the others obovate. Ovary stipitate, covered with stiff hairs, 4-ovuled. Style erect, with truncate stigma. Filaments hairy. Pod on a long stalk, broadly ovate-oblong, $2-3^{\prime} \times$ $1^{1 / 2^{\prime}}$, coriaceous, covered with straight prickles. Seeds mostly 2 , large globose, $6-7^{\prime \prime}$, of stony hardness and lead-color. Hilum basal, punetiform. Guilandina Bonducella, L. - G.Bonduc, Hook. \& Arn., Gray, Mann. Mrs. Sinclair, pl. 31.

In gulches of the lower plains on all islands, less common than formerly. Nat. name: "Kakalaioa . - The species is widely spread over most tropieal eountries.

C. pulcherrima, the well known "Pride of Barbadoess, is oecasionally found escaped from gardens in the yellow-flowering variety as well as in the ordinary one with orangered petals. C. sepiaria is planted in hedges. Besides these there are in cultivation C. Sappan, which yields the well known dye, C. coriaria, rich in tannic acid, C. (Poinciana) Gillesii and C. (Coulteria) Mexicana.

\section{MEZONEURON, Desf.}

Calyx-tube short and very oblique, its lowest lobe the largest and concave, rarely all lobes connate into a tube. Pod compressed, rather thin and indehiscent, winged along the upper suture. Otherwise as in Caesalpinia.

About 10 species, natives of tropical Asia and Afriea, with one from Australia.

1. M. Kauaiense, Hillebr. - A tall shrub, about $12 \mathrm{ft}$. high, with loose spreading branches, unarmed, the young shoots covered with a hoary pubescence. Leaves abruptly bipinnate with $1-5$ pairs of pinnae, each pinna with $4-8$ pairs of leaflets, the common rhachis $3-5^{\prime}$, the pinnae $1^{1 / 2}-3^{\prime}$ long. Leaflets oblong, $1-1^{1} / 4^{\prime} \times{ }^{1 / 2^{\prime}}$, obtuse at both ends, retuse, membranous, on petiolules of $1^{\prime \prime}$. Stipules and stipellae none or small wart-like. Raceme terminal, hoary, $1-3^{\prime}$ long, densely floriferous from the base; the pedicels $1-2^{\prime}$, jointed above the middle. Bracts acute, ciliate, $2^{\prime \prime}$, caducous; bracteoles wanting. Calyx glabrous, pinkish, the short tube $2^{\prime \prime}$, the lowest lobe concave, $6-7^{\prime \prime}$; the others oblong, obtuse, 4-3". Petals pinkish-purple, not or scarcely stipitate, shorter than the calycine lobes, the uppermost one obcordate, folded, $3-4 "$ in diameter, of deeper color, the lateral ones suborbicular, the 2 lowest obovate, $5-6^{\prime \prime}$ in length. Stamens exserted, declinate, the filaments hairy, broad and flat below. Ovary glabrous, sessile, 3-5-ovuled. Style incurved; stigma small. Pod broad-oblong or obovate, $3-3^{1 / z^{\prime}} \times$ $1{ }^{1 / 4}-2^{\prime}$, with a dorsal wing of $3-4^{\prime \prime}$ in width running along its whole 
length and ending in an uncinate point, quite flat, thin, indehiscent, not projecting internally. Seeds $2-4$, transverse, pale, ovate, flat, $9-10^{\prime \prime}$ $\times 7-8^{\prime \prime}$, with a punctiform hilum at the base. - Caesalpinia Kanaiensis Mann, Enum. 120.

Kauai! Oahu! Waianae mountains and Wailupe; E. Maui, Ulupalakual and W. Mauil on dry fore hills. Nat, names: "Keas and *Kalamona"? The wood is hardgrained and dark.

\section{CASSIA, L.}

Sepals 5, somewhat unequal, scarcely connected at the base. Petals 5, usually unequal, spreading. Stamens usually 10, either all equal and fertile, or the upper ones smaller and sterile, with 2 or more of the lower fertile ones much larger. Anthers, when fertile, opening at the end only in pores or short slits. Ovary with several ovules. Pod cylindrical or flattened, usually long, but variously shaped. Seeds usually oblong and transverse, with a small quantity of albumen. Radicle short and straight. - Herbs, shrubs or trees. Leaves abruptly pinnate, the leaflets opposite. Flowers yellow, rarely pinkish.

A large genus, widely distributed over the warm regions of the World, but particularly numerous in South America.

All anthers fertile; a low spreading shrub Three anthers sterile; an erect undershrub

1. C. Gaudichaudii.

2. C. occidentalis.

1. C. Gaudichaudii, Hook. \& Arn. Bot. Beech. p. 81. - A low shrub, $3-4 \mathrm{ft}$. high, with spreading branches, the young shoots fulvo-tomentose. Leaves $3-4$ ' long, with $4-5$ pairs of leaflets, the rhachis pubescent, with a stipitate or clavate gland between the lowest pair; the leaflets $1-2^{1} / 2^{\text {t }}$ $\times 1 / 2-1$ ', elliptico-oblong, retuse, membranous, on petioles of $1^{\prime \prime}$. Stipules subulate, $5-6^{\prime \prime}$. Racemes axillary, slender, 2-3'long, naked in the lower half; the pedicels $9-12^{\prime \prime}$, pubescent, articulate a short distance below the calyx. Bracts lanceolate, $1^{1 / 2}$ ". Sepals pubescent, $4-5^{\prime \prime}$, obtuse, the 2 outer ones smaller. Petals pale yellow or greenish, scarcely longer than the sepals. Stamens 10, all fertile, the oblong anthers opening by short slits, enclosed, the short filaments glabrous. Ovary stipitate, hairy. Pod linear-oblong, 2t/2-41/2' long, 4-5" broad, quite flat, apiculate at the middle of the apex, impressed between the seeds, 2-valved with thin valves, septate internally. Seeds $8-10$, oblong, flat, black, transverse, and parallel with the valves. - Vogel, Synops. Cass. p. 26. Gray, Bot. U. S. E. E. p. 463.

Common on all islands, on low hills and in open woods, to the height of about $2000 \mathrm{ft}$. Nat.name: "Henhiuhi", Belongs to the Section Psilorhegma, Vogel. - Oceurs also in Tahiti, according to Nadéaud.

†2. C. occidentalis, L. - DC. Prod. II, 49\%. - An erect glabrous perennial, $2-3 \mathrm{ft}$. high, somewhat woody at the base. Leaflets in $4-6$ pairs, ovate-lanceolate or lanceolate, $1-3^{\prime}$ long, with an ovate gland near 
the base of the petiole. Raceme terminal, short and few-flowered, with oceasionally a few flowers on short pedicels in the upper axils. Flowers yellow. Two of the anthers large oblong, 4 or 5 others like them but smaller, the 3 uppermost small and sterile, Pod linear, slightly curved, $3-5^{\prime}$ long, about $3^{\prime \prime}$ broad, at first flat with the edges thickened, but becoming at length as thick as broad. Benth. Fl. Hongk. p. 98.

of early introduction, now common on all islands along roads and in pastures. Widely dispersed over all tropical regions.

The 3 following species are also occasionally found as escapes from gardens: C. glauca, C. laevigata, C. viminea. Besides these there are in cultivation: C. alata, C. auriculata, C. florida, C. mimosioides and other shrubby species. Of ornamental trees: C. grandis, C. Parahyba, C. Fistula, C. Javanica, C. marginata, C. nodosa.

\section{SUBORDER III. MIMOSEAE.}

Sepals 5 , rarely 4 or 3 , free or united. Petals as many, equal, valvate in the bud, free or united. Stamens as many, twice as many, or indefinite, free or united, usually hypogynous. Radicle of the embryo straight. Leaves twice pinnate, rarely simply pinnate. Flowers usually small, in dense globular heads or cylindrical spikes.

\section{ACACIA, WILLD.}

Sepals 5, 4 or 3 , free or united. Petals as many, free or united. Stamens indefinite, usually very numerous, free, or slightly connected at the base. Pod linear or oblong, flat or nearly cylindrical, opening in 2 valves or indehiscent. - Trees or shrubs. Leaves twice pinnate or apparently simple, the petiole dilating into a phyllodium and taking the place of the true leaf. Flowers usually white or yellow, in globular heads or cylindrical spikes, often polygamous.

A very large genus, one half Australian, the remainder dispersed over the warmer regions of the Globe. The Polynesian species, of which there are 3 besides the Hawailian (natives of the Samoa, Viti, N. Caledonia and N. Hebrides Islands), belong to the Australian type, with phyllodis instead of leaves.

Phyllodia instead of true leaves; pod flat:

Sepals and petals united; flower-heads in axillary racemes:

Pod broad and straight

Pod narrow and curved

Sepals and petals free; flower-heads in a terrainal pauicle Only true leaves present; pod cylindrical
1. A. Koa.
2. A. Koaia.
3. A. Kauaiensis.
4. A. Farnesiana.

1. A. Koa, Gray, Bot. U. S. E. Exp., p. 480. - A tall tree, often attaining a height of $50-60 \mathrm{ft}$., with far spreading branches. The adult tree bears only phyllodia, or rarely true leaves springing from adventitious buds near the base of the trunk. The true leaves of the young plant have a margined or winged pubescent rhachis of $6-7^{\prime}$ in length, with 5-7 pairs of pinnae and an oblong pitted gland halfway between the lowest pair and the base, each pinna bearing 18-24 pairs of subsessile, oblong, mucronate leaflets, about $3^{\prime \prime}$ long and over $1^{\prime \prime}$ broad. Phyllodia 
coriaceous, falcate, $5-7^{\prime} \times 1 / 6-1^{\prime}$, tapering below, acute, with $5-8$ prominent nerves, the gland persisting on the convex side of the short petiole. Flowers white, numerous in globose heads of about $4^{\prime \prime}$ in diameter, the heads on peduncles of $6^{\prime \prime}$ in length, $3-5$ of them racemosely arranged along an axillary rhachis of $3-6^{\prime}$, except in the upper axils, where single heads are often seen. Bracts minute, ovate. Calyx turbinate, with 5 very short obtuse teeth, the teeth only puberulous. Petals ${ }^{1 / 3}$ longer than the calyx, united to the height of the same. Stamens very numerous, shortly exserted. Ovary glabrous, the naked style several times longer, twisted in the bud, with truncate stigma. Pod straight, oblong, about $6^{\prime} \times 1^{\prime}$ when fully developed, obtuse at both ends, flat, thin, without thickened margins, 2-valved, continuous. Seeds about 12, dark brown. A. heterophylla, Hook. \& Arn, in Bot. Bech. p. 81 (not Willd.).

One of the most common forest trees on all islands, chiefly occupying the zone from 1500 to $4000 \mathrm{ft}$. above the sea, but also occurring lower down and higher up. Nat. name: "Koas, It is perhaps the most valuable tree of the islands, equally useftul for fuel and for purposes of construction; for eabinet-work there are few woods to excel it. Being eapable of receiving a high polish, under which its wavy lines appear to great advantage, it is much employed for veneers. Out of its trunks the natives in former times eut their great war-canoes. The bark is used for tanning.

$\beta$ var. Leaves shorter, $2-3^{\prime} \times 4-6^{\prime \prime}$, little curved, almost straight, obtuse, mucronate. Racemes shorter.

Lanai!

2. A. Koaia, sp. n. - Leaves as before. Axillary racemes with not more than 3 heads, generally reduced to a single one. Pod very narrow, not over $4^{\prime \prime}$ in width by $5-6^{\prime}$ in length, and somewhat curved. Seeds oblong, the long diameter $\left(3^{\prime \prime}\right)$ in the direction of the valves, flattened, with a funis of about the same length. Otherwise as in no. 1.

Molokai, Kalae! E. Maui, Kula? Nat. name: "Koaias, Has a harder wood than the Koa.

3. A. Kauaiensis, sp. n. - Phyllodia falciform as in no. 1, but somewhat obtuse, mucronate, with a pitted gland on the petiole. Inflorescence tomentose, terminal, paniculate, the panicle foliose below with smaller phyllodia which are uncinate at the apex, the paniculate raceme of the lowest axilla $3^{\prime}$ ' long and floriferous along its entire length with numerous, mostly single heads on tomentose peduncles of only $1-1^{t} / 2^{\prime \prime}$. Bracts minute. Sepals 5-6, free to near the base, spathulate, obtuse, glandular-pubescent. Petals free, oblanceolate, by one half longer than the sepals. Ovary puberulous.

Kauai! (Kn, 55).

†4. A. Farnesiana, Willd. - DC. Prod. II, 461. - A much branched shrub, quite glabrous or slightly pubescent on the petioles and peduncles. Leaves of 4 to 6 or rarely 8 pairs of pinnae. Leaflets $10-20$ pairs to a pinna, linear, about 2 "long. Stipules converted into slender straight thorns very variable in length, the plant otherwise unarmed. Peduncles 
usually 2 or 3 together in the older axils, each bearing a single globular head of sweet-scented yellow flowers. Pod thick, irregularly cylindrical or fusiform, indehiscent, filled with a pithy substance, in the midst of which lie the seeds. - Benth. Fl. Hongk. p. 101. - Vachellia Farnesiana, Wight \& Arn.

Of early introduction, but spread over all islands. Along the Pearl River inlet of $\mathrm{Oahu}$ it forms extensive thickets. Is supposed to be of American origin, but has become naturalized in many warm countries. The flor aroma of the Spaniards.

Of introduced species A. Arabica, A. Catechu, A. pennata and A. cornigera are most frequently met with. A. lophantha, A. dealbata, A, mollissima, A. longifolia only thrive in the higher regions of $\mathrm{E}$. Maui and $\mathrm{Hawail}$. The nearly allied genus Albizzia, distinguished by the long monadelphous stamens, is represented by $A$, Lebbek, A. stipulata and $A$, procera.

\section{LEUCAENA, Benth.}

Calyx 5-toothed. Petals 5, free. Stamens 10, free, all fertile. Anthers tipped with a gland. Pod broadly linear, flat, 2-valved. Seeds numerous, transverse. - Trees or shrubs. Leaves twice pinnate. Flowers in globular heads, usually hermaphrodite.

A few species, nearly all American, of which the following has migrated to many warm countries.

†1. L. glauca, Benth. in Journ. Bot. IV, 416. - A small unarmed tree. Leaves with $4-6$ pairs of pinnae. Leaflets in $10-20$ pairs on each pinna, oblong-linear, very oblique and slightly falcate, $4-6^{\text {" }}$ long, pale or glaucous underneath. Peduncles solitary or 2 or 3 together in the upper axils, $1-1^{1} / 2^{i}$ long, the upper ones forming a terminal raceme, each bearing a globular head of $6-8^{\prime \prime}$, or, with the stamens, nearly $1^{\prime}$ in diameter. Pod short-stalked, 4-6' long, 4-6 $6^{\prime \prime}$ broad. Benth. Fl. Hongk. p. 100. - Acacia glauca, Willd. - A. leucocephala, Link.

of early introduction; frequent.

\section{MIMOSA, L.}

Calyx dentate. Petals more or less connate. Stamens as many or twice as many as the petals ; anthers globose, without glands. Pod compressed, jointed or continuous, the valves breaking away from the entire border or replum. - Herbs, shrubs or trees with bipinnate leaves. Flowers in pedunculate heads, red or white.

A large genus, chiefly American.

† 1. M. pudica, L. - DC. Prod. II, 426. - A low trailing, rather herbaceous undershrub with infra-stipular and scattered prickles, hairy or glabrate. Leaves with 1 or 2 pairs of pinnae, each pinna with $15-25$ pairs of oblong-linear pointed ciliate leaflets, which are drawn back and folded up on being touched, together with the pinnae and the petiole. Flower-heads pinkish, ovoid. Stamens as many as the petals, 4 or 5 . 
Pod oblong, sinuate, 2-5-seeded, pointed, the border (replum) armed with spreading prickles. - Griseb. Fl. W. Ind. p. 219.

The well known sensitive plant, a native of tropical America, is firmly established in some parts of $\mathrm{Kauai}$ and in Kaneohe, $\mathrm{O}$ ahu.

Among the introduced trees of other genera belonging to this suborder an important place belongs to the Algaroba, Prosopis juliflora, DC. or $P_{+}$dulcis, Kunth, which on account of its quick and easy growth, even in the driest situations, has been freely planted in the low lands and commences to spread spontaneously. Its seeds are imbedded in a sweet pulp, as is also the case with the Pithecolobium dulce, Benth, which likewise promises to become generally spread. Pithecolobium Samang, the Samang or Monkeypod tree, enjoys great favor as a shade tree, as is also the case with Parkia Africana. Of lesser importance are: Adenanthera pavonina, Calliandra haematoma, Dichrostachys cinerea and others.

\section{ORdER XXVI. ROSACEAE.}

Sepals 5, rarely 4, united into a lobed calyx, either enclosing the ovary, or adhering to it, or quite free. Petals as many, inserted on the calyx at the base of its lobes, or rarely wanting. Stamens usually numerous, inserted with the petals, free. Ovary of 1,2 or more carpels usually distinct at the time of flowering, superior, free from the calyx, but sometimes combined even then into a single $2-5$-celled ovary which is always inferior or connate with the calyx. Ovules 1 or 2 or rarely more in each earpel. As the fruit enlarges the earpels either remain free or are variously combined with each other or with the calyx; when ripe they are indehiscent, or occasionally open on the inner edge. Seeds without albumen, Embryo with large cotyledons and a short radicle. Trees, shrubs or herbs with alternate, mostly toothed or divided leaves. Stipules seldom wanting. Flowers either solitary at the end of the years shoot, or in cymes or panicles, or more rarely in lateral branches or racemes.

A numerous Order, more at home in the temperate and cooler parts of the northern hemisphere than in the tropies or southern hemisphere.

Ovaries or carpels superior, free from the calyx:

Calyx open, without bracteoles

Calyx open, its lobes alternate with 5 bracteoles
Calyx-tube constricted at the throat, spinous; no petals; leaves

1. Rubus.

pinnate
Carpels inferior, united into a 5-celled ovary and adherent to the

2. Fragaria. calyx-tube, which is elosed over it

3. Acaena.

4. Osteomeles.

\section{RUBUS, L.}

Calyx free, deeply 5-lobed, persistent. Petals 5. Stamens numerous. Carpels numerous, with 2 pendent ovules in each, only one of which matures. Styles subterminal. Fruit a kind of granulated berry, formed by the union of the succulent carpels round the conical or shortly oblong dry receptacle. - Scrambling or suberect shrubs, sometimes herbaceous, usually prickly. Leaves pinnately or palmately divided into distinct segments or leaflets, or rarely simply lobed. Flowers axillary or in terminal leafy panicles. Stipules adnate to the petiole. 
A large genus, widely distributed over almost every part of the globe. Ineludes the Raspberries and Brambles.

Stem and branches aculeate:

Leaves without prickles, the leaflets not over 3 inches long:

Leaves coriaceous, tomentose, subacute, with bluntish lobes and teeth; caiyx-lobes subacute; achenes very hairy. Stem decumbent

Leaves membranous, tomentose, acute, with sharp lobes and teeth; calyx setose at the base, its lobes drawn out into a long point; achenes glabrate or nearly so. Stem erect

Leaves prickly on ribs and veins, large, the leaflets $7-8$ inch. long

1. R. Macraei.

2. R. Hawaiiensis.

3. R. sp. n.

2. $R$. Hawaiiensis. 3. var, inermis.

1. R. Macraei, Gray, Bot. U. S. E. Exp. p. 505, pl. 5\%. - Stems prostrate or rambling, both flowering and flowerless shoots tomentose and sparingly covered with patent setaceous prickles, toward the end with longer glandular hairs besides. Leaves on stout petioles of $1-1^{1} / 2^{\prime}$, pinnately 3 -foliolate, or those of the short flowering branches simple and 3-lobed; the leaflets coriaceous, gray-tomentose and net-veined underneath, broad ovate, the terminal one mostly subcordate, $2-3^{\prime} \times 1^{1 / 2}-3^{\prime}$, acuminate or somewhat obtuse, bluntly inciso-lobate and dentate, the petiole of the terminal one $3-9^{\prime \prime}$, those of the lateral ones $1 / 2-2^{\prime \prime}$. Stipules linear-lanceolate, $4-6 "$. Flowers numerous, subpaniculate, the upper 1 -flowered peduncles in the axils of reduced leaves, $1-2^{\prime}$ long, prickly and viscous-tomentose. Calyx tomentose, 5-parted nearly to the base, the sepals broadly ovate, 5-9", subacute, more or less serrate in the upper half. Petals as long as the sepals, obovate, often emarginate, pinkish. Achenes very fleshy, $1^{1 / 2}-2^{\prime \prime}$, densely covered with glandless hair, deeply net-pitted when dry, as long as their styles or longer. - The fruit often attains a diameter of nearly 2 inches, is of a deep red color, even dark at maturity, very juicy and, although slightly bitter, quite agreeable to the taste.

Maui, Haleakala! 4000 to $6000 \mathrm{ft}$; rather common above Makawao; Hawaii, Mauna Kea, plentiful in the neighborhood of Laieha. In the specimens from Haw aii collected by the Expl. Exp, the sepals are deeply serrate, even laciniate, while Mann's and my own from E. Maui present them almost entire. Nat, name: "Akalas. The species ean be recommended for enltivation.

2. R. Hawaiiensis, Gray, l. c. p. 504, pl. 56. - Stem erect, 5-8 ft. high and often $2^{\prime}$ thick at the base, sparingly branched, both flowering and flowerless branches slender, flexuose, covered with short compressed prickles and glandless tomentum. Leaves on slender petioles of $1-1^{1 / 4^{\prime \prime}}$, pinnately 3-foliolate, or those of the short flowering branches simply lobed, the leaflets orate or ovate-lanceolate, $2-3^{\prime} \times 1^{1} / 2-2^{\prime}$, acute, sharply inciso-lobate and dentate, cuneate or truncate at the base, membranous, sparsely pubescent above, densely tomentose underneath with a dark olivaceous pubescence; the lateral leaflets subsessile, the terminal one on a petiolule of $2-3^{\prime \prime}\left(4-8^{\prime \prime}\right.$ in the sterile branches). Stipules 
filiform. Flowers few. Peduncles 9-12" long, single, or two or more at the ends of short spurs in the axils of the 3 to 5 latest leaves, prickly or not. Calyx tomentose, setoso-aculeate at the base, $8-9^{\prime \prime}$ high, cleft to one half its length or more, the lobes ovate, entire, drawn out into a long acute point. Petals longer, glandular-ciliate, obovate, entire, pink. Stamens half as long. Achenes scantily pubescent, rather dry, shorter than the truncate styles. - Fruit ovoid, red, about $8^{\prime \prime}$ in diameter, dry and unpalatable. - Mrs. Sinclair, pl. 43 (stem 10-15 ft. high).

"On the bullock plains and in forests of Mauna Kea and Mauna Loa, Hawaii. (U. S. E. E.), Kona, (M. \& B.)? Maui, southern slope of Haleakalal near the path from Ulupalakua to the crater, where it grows at an elevation of $6000-7000 \mathrm{ft}$. in company with Geranium arboreum. According to Gray the species finds its nearest relative in $R$. spectabilis, Pursh, from the N. W. coast of America.

$\beta$ var.? inermis. - Stems prostrate, the branches unarmed, subherbaceous, faintly pubescent. Leaves as in $\alpha$, but the leaflets on longer stalks, and puberulous enly along the rib and nerves underneath, or almost glabrate. Calyx silky (not setose) at the base, otherwise as in $\alpha$. Achenes glabrous, or faintly pubescent with glandular hair. - Wawra, in Flora, 1873 , p. 80.

Maui! Molokai! Kauai! Hawaii, Waimea and Hilo (U. S. E. E.), at elevations of $2000-4000 \mathrm{ft}$. Ought perhaps to rank as species on acount of the different habit and want of spines, although in other respects it agrees fairly with $R$. Hawaiiensis.

3. R. sp. n. - From Mr. J. Lydgate I received a single leaf, collected on the Kula side of Haleatiala, which is of extraordinary size, more than $1 \mathrm{ft}$. in length, the 3 leaflets membranous, glabrous, pale green, ovate, $7-8^{\prime} \times 5-6^{\prime}$, acute, sharply inciso-lobate and dentate, even at the rounded or subcordate base, the petiolule of the terminal leaflet $20^{\prime \prime}$, those of the lateral ones $6 "$, all densely covered, as well as the petiole, midribs and veins, with patent and slender rufous prickles of $1-3^{\prime \prime}$ in length (a few even on the upper side), besides a scanty pubescence.

About the specific distinetness of the specimen there can hardly be a doubt, and it is to be expected that closer attention to the Hawaiian Raspberries will bring to light other additions to this polymorphous genus.

\section{FRAGARIA, Tourn.}

Calyx flat, deeply 5-cleft, with as many bractlets at the sinuses, thus appearing 10 -cleft, with lobes valvate. Petals 5, obovate, shortly clawed. Stamens many in one series on the margin of a calycine disk. Carpels many, collected in a head on a raised receptacle which in fruit becomes conical, pulpy and scarlet, bearing the minute dry achenes scattered over its surface. Styles lateral. Ovule solitary, ascending. - Stemless perennials with runners and with white cymose flowers on scapes. Leaves radical, with 3 obovate, wedge-shaped, serrate leaflets. Stipules cohering with the base of the petiole.

A few species, spread over the temperate and alpine regions of the northern hemisphere, as also the Andes of S. America. 
1. F. Chilensis, Ehrh. - DC. Prod. II, 571. - The whole plant, excepting the upper surface of the leaflets, villous with long silky hair, which is appressed on the underside of the leaves and on the calyx. Petioles stout, $4-8^{\prime}$ long. Leaflets thick, obovate, $1^{1 / 2}-2^{\prime} \times 1-1^{1 / 2^{\prime}}$, coarsely inciso-serrate (the terminal tooth the smallest), with cuneate base, the lateral petiolules $1^{\prime \prime}$, the terminal 2-4". Stipules lanceolate, $6-8^{\prime \prime}$, adnate in half their length. Scape half as long as the petioles, 1- to few-flowered, its leaflet above the middle, simple, 2-3-toothed and small, $3^{\prime \prime}$. Pedicels $1^{\prime}$ or more. Sepals and their bracteoles linear-lanceolate, of equal length, 5", ereet. Petals little longer, rounded. Fruit large. - Torr. \& Gray, Fl. N. Am. I. 448, - Bot. Calif. I, 177.

On the high mountains of $\mathrm{Hawaii}$ and $\mathrm{E}$. Maui at elevations of 4000 to $6000 \mathrm{ft}$. On the latter island the strawberry region forms a well defined zone or belt of a couple of miles in width around Haleakala, where the mountain is not covered with forest. Nat. name: "Ohelo papas. The fruit is in much favor with the inhabitants of those islands, there being abundance of it between the months May and September. It also forms the chief food of the wild Hawaiian goose, Bernicla Sandwicensis. - The species is found in the lowlands of Chili and on the island of Chiloe, as well as in the mountains of Mexico, in California, Oregon, and up to Alaska.

$F$. vesca and $F$. grandiflora are cultivated and thrive well, even in Nuuanu valley down to $300 \mathrm{ft}$. above the sea, yielding fruit during five months of summer.

\section{ACAENA, L.}

Calyx tube constricted at the throat, with $3-7$ valvate, generally deciduous lobes. Petals none." Stamens $1-10$, inserted in the throat of the calyx. Disk investing the tube and almost closing its throat with the annular orifice. Carpels $1-2$, sessile, free from the calycine tube. Styles short, subterminal, with peltate or dilated and fimbriate stigmas. Ovule solitary, pendulous. Achene dry, enclosed in the indurated tubercular or spiny calycine tube. - Decumbent or creeping perennials with erect, scapiform, flowering branches. Leaves alternate, impari-pinnate, the leaflets serrate or eut. Stipules adnate to the sheathing base of the petiole. Flowers small, in heads or spikes, bracteate.

A genus of about 30 species, natives of the temperate and cold regions of the southern hemisphere, one of them also occuring in California and one being peculiar to the mountains of Mexieo; the following one is peculiar to our flora.

1. A. exigua, Gray, Bot. U. S. E. Exp. p. 498. - A small perennial with a creeping and branching, short, thick caudex, which is covered with old stalks and bears at its ends a rosulate cluster of leaves. Leaves about $1^{\prime}$ long, including the petiole, which is broadly winged in its entire length with the adnate scarious stipules. Leaflets in $6-8$ pairs, oblong or rounded, about $1^{\prime \prime}$ in length, 3- or 4 -lobed or toothed (excepting the lowest pair, which is entire), coriaceous, glabrous, whitish underneath, and coneave. Flowering scape slender, $6-10^{\prime}$ high, sparsely beset with distant smaller leaves and bearing at the apex a short crowded spike of flowers not above $1 / 2^{\prime}$ in length. Bracts linear or oblong, $11 / 2^{\prime \prime}$. Calycine 
tube $3 / 4^{\prime \prime}$, spiny and setose, the 4 brownish lobes of the same length, and deciduous. Stamens 2, exserted, the anthers didymous, rounded. Achene solitary, ovoid, glabrous. Style short, with a thick capitate and fimbriate, scarcely exserted stigma.

Top of Mt. Eeka! Maui, and table land of the highest mountain of Kauai, in swampy ground, where the plant forms tufts or tussocks of alpine character.

\section{OSTEOMELES, Lindl.}

Calyx-tube adnate to the carpels, with 5 persistent lobes. Petals 5, oblong, patent. Stamens 10 to many, inserted in the throat of the calyx. Carpels 5, cohering with each other and with the calyx; styles as many, with thickened truncate stigmas. Ovule 1 in each carpel, erect. Drupe fleshy, its 5 pyrenae crustaceous, cohering, their apices often free from the calyx. Seed compressed, with membranous testa and plano-convex cotyledons. Trees or shrubs with alternate simple or impari-pinnate leaves. Stipules small. Flowers corymbose, bracteolate.

A genus of about 9 species; 7 of which belong to the S. American Andes and 1 to Japan,

1. 0. anthyllidifolia, Lindl. Transact. Linn. Soc. 13, p. 98, tab. 8. DC. Prod. II, 633. - A much branching stiff shrub, 3-6 ft. high, with a grayish tomentum. Leaves about $2^{\prime}$ long, impari-pinnate, with 10 or 11 pairs of leaflets and a deeply grooved, submarginate, pubescent rhachis. Leaflets sessile, oblong, $6-8^{\prime \prime} \times 1^{1 / 2}-2^{\prime \prime}$, obtuse, mucronate, entire, coriaceous with evanescent veins, shining above, appressedly pubescent underneath. Stipules linear or subulate, 2-3". Flowers in a subcorymbose panicle, the lower peduncles in the axils of true leaves, 1' long or more and generally 3 -flowered, the pedicels $1-6^{\prime \prime}$ long; the upper peduncles shorter, 2-1-flowered, supported by subulate bracts. Calyx subtended by 2 subulate bracteoles, tomentose, campanulate, $2^{\prime \prime}$ long, 5-fid, the lobes lanceolate, acute, at length reflexed. Petals white, 3 "long. Stamens $15-20$, reddish, shorter than the petals, the anthers small ovoid, versatile. Styles $2^{\prime \prime}$, woolly below, clavate, with terminal stigma, persistent, and exserted from the fruiting calyx. Fruit white, globose, the angular-convex woody pyrenae cohering to the top, surrounded by the fleshy tomentose calyx and crowned by its lobes. - Hook. \& Arn. in Bot. Beech. p. 82. - Gray, Bot. U. S. E. E. p. 507.

Common on all islands at elevation of $1000-3000 \mathrm{ft}$., but often descending to near the sea. Nat. name: *Uulei". The fruit is quite unpalatable.

To this Order belongs the Loquat, Eriobotrya Japonica, which is much eultivated for its pleasant fruit. Rhaphiolepis Indica is to be found in gardens, but there is no indigenous species of this genus on the group, as stated with a doubt in Hooker \& Bentham's Genera Plantarum. The Peach tree, Amygdalus Persica, thrives remarkably well in a few seedling varieties, and bears abundantly from the seashore up to $3000 \mathrm{ft}$, while its near congener, the Almond tree, never produces fruit. The Apple tree, again, does well up to the same height and higher, while trials with the Pear, Plum, Cherry and Apricot 
have always resulted in failure. The Peach tree is bound to a season, commencing to flower in January and bearing between April and June, while the Apple tree flowers twice a year, and often may be seen, even in gardens of Honolulu, with flowers and fruit at the same time. Both trees have a tendency to send up suckers or shoots from the roots and the lower part of the trunk, and thus to lose their arboreous character unless carefully pruned. - Rosa Damascena and $R$. multiflora are occasionally found in places of deserted settlements, and numerous varieties of other roses thrive to perfection, even in gardens of Honolulu.

\section{ORDER XXVII. SAXIFRAGACEAE.}

Sepals 4 or 5 , free, or united into a calyx, with the tube wholly or partially adherent and with 4 or 5 lobes or teeth. Petals either as many, perigynous, seldom epigynous or hypogynous, or rarely wanting. Stamens as many, or twice as many, or very rarely more, inserted with the petals, the anthers opening by introrse or lateral slits. Ovary single, either more or less inferior or adherent, or free with a broad base, 2-5-celled, the placentas at the introflexed edges of the carpels, or rarely 1-celled, with 2 or more parietal placentas. Styles as many as cells or placentas, or single, with an entire or lobed stigma. Fruit a capsule or berry. Seeds usually many; albumen copious, rarely wanting.

A considerable Order, ranging over nearly the whole World, the shrubby or arborescent genera chiefly tropical, the herbaceous from the temperate and colder regions chiefly of the northern hemisphere. - In cultivation Hydrangea Japonica.

\section{BROUSSAISIA, Gaud.}

Flowers polygamo-dioecious. Male fl. Calyx short, free, deeply divided into 5 triangular or ovate lanceolate lobes. Petals 5 , valvate, with inflected apex. Stamens 10, inserted with the petals at the base of the calyx, the filaments subulate, the anthers erect, ovoid or shortly oblong, opening laterally. Ovary almost free, imperfect, the stigma undeveloped. Fem. $\mathrm{fl}$. Calycine tube ovoid, adnate to the ovary, 5-toothed. Petals small, scale-like or lanceolate. Stamens none. Ovary semi-inferous, incompletely 5 -celled. Ovules numerous, in several rows along thick bipartite, retroflexed placentas, which do not coalesce into a central axis. Style short and thick. Stigma thick 5-lobed or sulcate. Berry globose, fleshy. Seeds horizontal, oblong, anatropous, with a striate testa. Embryo in the axis of fleshy albumen, and half its length, the cotyledons very short. - Small trees with opposite or whorled serrate leaves and no stipules. Flowers in terminal corymbs.

A Hawaiian genus, nearly related to the Malaysian genus Dichroa, Lour., (Adamia, Wall., Cyanitis, Reinw.).

Leaves opposite; petals bluish green; stigma on a distinct style 1. B. arguta. Leaves ternate; petals reddish; stigma sessile

2. B. pellucida.

1. B. arguta, Gaud. Bot. Voy. Freyc. p. 479, tab. 69. - DC. Prod. $I V, 17$. - A small tree with stout and soft branches, fleshy, and hirsute with coarse short hairs at their ends. Leaves opposite (very rarely ter- 
nate), obovate-oblong or lanceolate, $5-8^{4} \times 2-3^{4}$, acuminate, closely serrate or dentate with incurved callose teeth, gradually tapering to a thick fleshy petiole of $1 / 2-2^{\prime}$, which is sulcate above and dilated at the base, coriaceous, glabrous and dark-green above, paler underneath, with midrib and veins short-hirsute. Corymb $2-3^{\prime}$ in height and as much or more in width, the main hranches hirsute, subtended by foliaceous sessile bracts of $1 / 2-1^{\prime}$, the bractlets smaller and narrower, caducous; pedicels 2-3". Male $f l$. Petals greenish-blue, spreading, broad triangular, 3 " high, coriaceous, twice or three times the length of the narrow acute sepals. Stamens exserted. Fem. fl. Calyx ovoid, its narrow acute teeth or lobes $1^{\prime \prime}$, one half or one third the length of the tube; the petals scale-like, ${ }^{1 / 2} "$. Ovary adnate to about ${ }^{3 / 4}$ of its length. Berry bluish, globose, $4-5^{\prime \prime}$ in diameter, with a free conical apex, pointed with the distinct persistent style and crowned by the calycine teeth and petals. Seeds ${ }^{1 / 4} "$ - Gray, Bot. U. S. E. E. p. 683, pl. 87. - Gaud. Bot. Bon. tab. 9, f. 11, 12. - Hook. \& Arn. in Bot. Beech. p. 84. - Mrs. Sinclair, pl. 36 ?

From Kauai! to Maui! in forests at elevations of 1000 to $3000 \mathrm{ft}$.; not uncommon. In the specimens from Kauai the serratures of the leaves are straight. Nat. names: "Kanawaus, sPuahanuis.

2. B. pellucida, Gaud. Bot. Bon. tab. 9. -- Leaves whorled, ternate, narrower, not over $1^{3 / 4}$ in width. Corymb larger and denser. Male $\mathrm{fl}$. Calyx about $1^{\prime \prime}$. Petals $2^{\prime \prime}$, reddish. Fem. $f l$. Calycine lobes short dentiform, not longer than the petaloid scales. Ovary adnate only in the lower half. Berry smaller, the stigma sessile on the free conical apex. - Gray, 1. c. p. 685 .

Hawail in the woods of Kona and Puna.

\section{Order XXVIII. CRASSULACEAE.}

Sepals 3 or more, usually 5 , but sometimes up to 20 , free from the ovary, but occasionally united into a lobed calyx. Petals as many, sometimes united into a lobed corolla. Stamens as many or twice as many, inserted with the petals at the base of the calyx. Ovary superior, the carpels as many as the petals, distinct, usually with a small scale at the base of each, with several ovules in each. Style simple, distinct. Ripe carpels capsular. Seeds several, with a thin albumen and straight embryo. - Herbs or shrubs. Leaves succulent, alternate or rarely opposite. Stipules wanting. Flowers in terminal racemes, cymes or panicles.

The plants contained is this Order inhabit chiefly dry and rocky regions.

\section{BRYOPHYLLUM, Salisb.}

Sepals united into an inflated 4-lobed calyx. Petals united into a cylindrical 4-lobed corolla. Stamens 8, attached to the base of the corolla. Scales gland-like. Carpels 4. Styles filiform.

A single species. 
†1. B. calycinum, Salisb. - DC. Prod. III, 396. - A glabrous, erect, succulent perennial, $2-5 \mathrm{ft}$. high. Leaves opposite, flat, fleshy, ovate or ovate-oblong, $3-5^{\prime}$ long, deeply crenate, rarely lobed. Flowers green, tinged with reddish-yellow, nodding, in a loose terminal panicle, the inflated calyx $1-1^{1 / 2} 2^{\prime}$ long, the corolla longer. - Bot. Mag, tab. 1409. - Benth. Fl. Hongk. p. 127.

In lava-fields of Kau/Hawaii, along the Kona road. - The well known Air-plant, a native of tropical Africa, but spread over various parts of America and Asia. Of reeent introduction.

\section{ORdER XXIX. DROSERACEAE.}

Sepals or lobes of calyx 4 or 5, imbricate. Petals 5, hypogynous, rarely perigynous, imbricate, withering-persistent. Stamens 4-20, hypogynous or perigynous, the anthers opening on the outer side. Ovary free or nearly so, 1-5-celled, with mostly parietal or basilar placentas. Styles $1-5$, often bifid or multifid. Ovules numerous, anatropous. Capsule membranous, splitting loculicidally into $2-5$ valves. - Embryo straight, in the axis or at the base of albumen. - Bog-herbs with usually glandularhaired leaves which often are irritable and secrete a digestive principle kindred to pepsine. (See Ch. Darwin, On insectivorous plants, 1875.)

A small Order of 5 local genera and the following large and widely diffused one.

\section{DROSERA, L.}

Sepals usually 5 , shortly united at the base, persistent. Petals as many, hypogynous or perigynous, mostly convolute in the bud, withering-persistent. Stamens as many, inserted with the petals. Ovary 1-celled, with $3-5$ parietal placentas and several ovules to each. Styles as many as placentas, but sometimes divided to the base, so as to appear twice the number. Capsule opening in 3 to 5 valves bearing the placentas in their center. Seeds minute. - Herbs with a short perennial stock, sometimes lengthening out into leafy stems. Leaves either radical or alternate, more or less covered with long glandular hairs or bristles, rolled up in the bud. Peduncles radical or axillary, terminating in a simple or forked one-sided spike.

A considerable genus, found in nearly all parts of the world.

1. D. longifolia, L. - Roots-tock short. Leaves radical, spathulateoblong, obtuse, $2-3^{\prime}$ long, including the long erect and naked petiole into which the short narrow blade gradually tapers, the spreading glandular bristles of the latter as long as its width. Scapes radical, erect, twice as long as the leaves, circinnate before evolution, racemosely fewflowered near the end, naked, or rarely bearing a small leaflet above the middle; the short filiform caducous bracts irregular between the flowers, not at the base of the pedicels. Calyx campanulate, 2-3", parted $2 / 3$ 
its length into lanceolate lobes. Petals little longer, white. Capsule exceeding the calyx, 3-valved; the seeds linear or clavate, with a close testa. - Gray, Bot. U. S. E. E. p. 100.

Kauai! in the marshes of the high table-land of Waimea (U. S. E. E., and Kn.) and on Waialeale (Wawra); has not been found yet on Mt. Eeka, which has so many rare plants in common with those localities. - The species extends over the northern regions of Europe, Asia and America (from New Foundland to the N. W. coast). A flesh-eating plant; the leaves covered with the dead bodies of flies in every stage of decomposition, as reported by Mr. Knudsen.

\section{Order XXX. HALORAGACEAE.}

Flowers hermaphrodite or unisexual, often imperfect. Calyx-tube adnate to the ovary, the limb entire or with as many teeth or lobes as petals. Petals 2 or 4 , inserted around an epigynous disk or on the calyx-border, or wanting, valvate or imbricate. Stamens as many or sometimes fewer, inserted with the petals. Ovary inferior, 1- or more-celled, with 1 pendulous ovule in each cell. Styles as many as cells of the ovary. Fruit dry and indehiscent. Seeds with fleshy albumen. Embryo straight, with a superior radicle and small cotyledons. - Herbs, often aquatic, rarely woody at the base. Leaves opposite, alternate or sometimes whorled. Flowers small, axillary or in terminal racemes or panicles.

A small Order, widely dispersed over the globe.

\section{GUNNERA, L.}

Flowers hermaphrodite or monoecious. Calycine lobes 2 or 3, unequal or equal, in the male fl. often imperfect or wanting. Petals wanting or 2, cucullate. Stamens 1-2; filaments filiform; anthers oblong, basifixed, opening laterally. Ovary 1-celled. Styles 2, subulate, papillose all round. Drupe coriaceous or somewhat fleshy, with crustaceous putamen. Seed filling the cell, with a thin testa. Embryo small, at the apex of a copious fleshy albumen, pyriform or obcordate. - Perennial, often very large, smooth or hispid scapigerous herbs, with generally creeping rhizome. Leaves radical, stalked, ovate or cordate-orbicular, simple or lobed, thick fleshy. Flowers spicate along the branches of a panicle, small, greenish, bibracteolate; the male fl. on the upper branches.

A genus of 11 species, all terrestrial, and, with exception of 2 species, belonging to the southern hemisphere. (Andes of S. America, Juan Fernandez, N. Zealand, Tasmania, Java, 8. Africa, Abyssinia), being natives either of high and cold latitudes or of high mountains.

1. G. petaloidea, Gaud. Bot. Voy. Freye. p. 512. - Caudex erect, generally short, but in some places rising to a height of 3 to $4 \mathrm{ft}$,, being several inches thick and quite fleshy, with a crown of leaves near the apex. Leaves very large and thick, rugose, rounded-reniform, $2-3 \mathrm{ft}$. in width, on a thick, fleshy, muricate petiole of $1 \mathrm{ft}$. or more in length, 10-lobed, with the lobes rounded and dentate, covered with short hairlets above, 
pedately 5-nerved, the nerves dichotomous, all more or less hispid with short coarse hairs; the basal sinus broad and open. Stipules broad, fleshy, adnate to the base of the petiole. Panicle terminal, the grooved rhachis $2-3 \mathrm{ft}$. high, hirsute and scabrous, branching from near the base, the undivided branches $4-7^{\prime}$ long, at last patent, covered in their entire length with scattering or clustered sessile flowers. Bracts linear, scarious, $1-1^{1} / 2^{\prime}$. Flowers hermaphrodite. Calyx globular, adnate, with 2 lobes, one lobe anterior and one posterior, each $1 / 2-1^{\prime \prime}$ long, 3-toothed, with a raised line along the inner face. Petals 2, alternate with the calycine lobes and twice as long, cucullate, receiving the 2 short opposed stamens. Pollen grains 4-lobed. Styles opposite the stamens and nearly twice their length, subconnate at the base. Drupe ovoid, $1^{1 /} / 2-2^{n}$, yellow or reddish, crowned with the calycine lobes, the crustaceous putamen 3-or 4-angled. Embryo subcordate. - Gray, Bot. U. S. E. E. p. 629, pl. 78, 79.

Eastern and western slope of Mt. Kaala! Oa a ; pali of Pelekunu! Moloka i; above Lahaina! Maui; summit of Kohala range, Hawaii; Pohakupili, Kauai (Wawra); at altitudes of 2500 to $5000 \mathrm{ft}$. Nat, name: sApén. Probably the largest species of the genus.

$\beta$. Leaves nearly glabrous; bracts ovate or oblong, $3-4^{\prime \prime}$.

Kauai (U. S. E. E.).

\section{ORDER XXXI. MYRTACEAE.}

Calyx-tube adhering to the ovary and often projecting above it, the limb of 4 or 5 or rarely more lobes or teeth. Petals as many, inserted in the calyx at the top of the tube, imbricate in the bud. Stamens usually indefinite, sometimes twice as many or as many as the petals, curved inward in the bud, free, or variously connected. Anthers small, 2-celled. Ovary inferior, 2-5- or more-celled, rarely 1-celled by incompleteness or failure of the partitions. Ovules 2 or more in each cell, or rarely solitary, the placentas axile. Fruit dry or succulent, dehiscent or indehiscent. Seeds without albumen. Embryo straight or curved. Trees or shrubs. Leaves opposite or rarely alternate, entire, generally with a marginal nerve, almost always dotted. Flowers axillary or terminal.

A large Order, widely spread over Sonth America, tropieal and subtropical Africa and Asia, and especially Australia, with a few South-Afriean, North-American and one European species.

In cultivation: Myrtus communis, the common Myrtle, Punica Granatum, the Pomegranate, Barringtonia speciosa and several species of Eucalyptus, especially E. globulus. Fruit a capsule

Fruit a berry:

Calyx 4-lobed or toothed; 1 or 2 large seeds

Caiyx entire and closed in the bud, splitting irregularly as the flower opens; seeds many

1. Metrosideros.

2. Eugenia.

8. Psidium.

\section{Metrosideros, Banks.}

Calyx-tube adnate to the ovary near the base, the lobes slightly imbricate. Petals 5, patent. Stamens numerous, many times longer than 
the petals, in one or more rows, the filaments free and stiff. Ovary adnate or semi-adnate, enclosed in the calyx-tube, 3-celled. Style filiform; stigma minute, truncate. Ovules numerous in each cell, horizontal or ascending. Capsule more or less adnate, loculicidal in its upper portion. Seeds numerous, linear, fusiform or cuneate, with a thin testa. Embryo straight; cotyledons plane or folded, longer than the radicle. Trees or shrubs with opposite penni-nerved leaves and a marginal nerve. Flowers in compound terminal cymes, rarely axillary, with caducous bracts.

A genus of about 18 species, mostly belonging to the Pacific islands, only one each coming from tropical Australia, the Indian Archipelago and South Africa.

Leaves on short petioles of less than $6^{\prime \prime}$ :

Leaves faintly nerved; capsule almost free .

Leaves rugose and impressed above, the strong nerves ridged below; capsule adnate to near the apex

Leaves on long petioles of $1-2^{\prime}$

1. M. polymorpha.

2. M. rugosa.

3. M. macropus.

1. M. polymorpha, Gaud. Bot. Voy. Freyc. 482, tab. 108, 109. - A tree, 10-35 ft. in height, sometimes shrubby, with angular or terete branches, tomentose or glabrate. Bracts of leaf-buds short, scarlet, early deciduous, Leaves opposite, on short petioles, lanceolate, oblong, ovate, obovate or orbicular, at the base acute, rounded or cordate, glabrous or tomentose underneath, with faint nerves. Flowers in terminal cymose corymbs, pedicellate or subsessile, 3 on a branchlet or peduncle, red, rarely yellow. Bractlets $1^{1} / 2^{\prime \prime}$, caducous. Calyx turbinate, $1^{1 / 2}-2^{1 / 2^{\prime \prime}}$, glabrous or tomentose, with deltoid or rounded lobes. Petals $1^{1 / 2}-3^{\prime \prime}$, oblong or obovate. Capsule semi-adnate, at last almost free, 3-lobed, 3-valved, glabrous or tomentose. Seeds linear, fusiform.

The marginal vein generally commenees with the second pair of nerves. - One of the 3 divisions of the cymose corymb may become transformed into a foliose branch. If this be the case with the median branch, the two remaining ones become axillary, if with a lateral one, the middle one appears lateral. Again, the axis, of one or two of the divisions (often of both lateral ones) will sometimes continue as a foliose branch, thus giving the appearance of a bottie-brush to the flowering portion, as in Melaleuca.

M. lutea, Gray, Bot. U. S. E. E. p. 560, pl. 69. - Includes the extraHawaiian M. collina, Gray, 1, c. 558, pl. 68, M. villosa, Sm., M. spectabilis, Gaertn., M. diffusa, H. \& A., Leptospermum collinum, J. R. Forst., Melaleuca aestuosa, G. Forst.

The most generally prevailing tree on all Islands between 1500 and $6000 \mathrm{ft}$., usually gregarious. Nat, name: "Ohia lehuas, or simply "Lehna"; Vitian: "Vugas; Tahitian: "Puaratas. The wood is very hard, furnishes the best fuel, and is also used for building houses. Many of the old idols were made of it. - Occurs also on the Marquesas, Society, Samoa, Viti and Kermadee Islands.

Having already convinced myself from an examination in $\mathrm{hb}$. Gray that forms of $M$. collina from the Society and Viti groups were in no particular distinguishable from var. $\zeta$ of the Hawaiian $M$. polymorpha, I readily adopt the view of B. Seeman, who, after a review of the large material preserved in the British Museum, comes to the conclusion that all the Metrosideros of those groups belong to the Hawaiian polymorphous species. According to Seeman, all Hawaiian forms, except the extreme tomentose with round leaves, are represented in the Society Islands. The difference between subsessile 
and pedicellate flowers becomes effaced here and there by gradual transitions, and the flowers of all Hawaiian varieties oceasionally assume a yellow color, excepting that with narrow lanceolate leaves; but this form is said to do so in Tahiti.

Gaudichaud says (Bot. Freyc. p. 99): "Rien au monde n'est plus remarquable que le metrosideros polymorpha, à feuilles linéaires vers le sommet de la montagne, successivement linéaires-lancéolées, ovaies, obovales, elliptiques, arrondies, même cordiformes, à mesure qu'on en descend, et qui, de glabres et luisantes qu'elles étaient primitivement, devjennent pubescentes, velues et de plus en plus tomenteuses.» This statement is nowhere borne out by observation. The var. $\beta$, with round cordate leaves and woolly inflorescence, is found at heights of over $6000 \mathrm{ft}$. on Hawaii and Ma ui, and again of $1800 \mathrm{ft}$. in Nunanu, while the var. $\eta$, soliis lanceolatis et inflorescentia glabra , occurs lower down than any other. If Walpers (Repert. II, 165) says of Gaudichaud's 4 varieties, apparently quoting from that botanist: shas formas in una eademque arbore carptas vidi, , this certajnly cannot mean more than that sometimes the lower leaves of a branch are broader and more obtuse than the upper and, being older, have lost some of their wool. Two varieties may be found growing side by side, yet others are confined to certain regions, as $\gamma$, the acute form of $\zeta$, which covers large areas on $\mathrm{H} a \mathrm{wail}$, and $\eta$, which seems to be confined to $\mathrm{O} a \mathrm{hu}$ and $\mathrm{K}$ a uai. The different forms may be brought under the following heads:

a. Leaves rounded or oblong obtuse, cordate, $1 / 2-1^{1} / 4^{\prime}$ long, on very short petioles, often crowded and imbricate on the branches and gradually smaller, canescent or pruinose underneath, not very thick, the veins scarcely visible. Cymes elongate, with foliaceous bracts. Flowers small; the calyx $1-1^{1} / 2^{\prime \prime}$, white tomentose, excepting the tips of the lobes. Petals pubescent. Stamens $6^{\prime \prime}$. Capsule semisuperous, $2-2^{1} / 2^{\prime \prime}$.

Low shrubby, in high exposed localities. Oahu! Nuuanu; Hawa ii, Kohala range. Yellow $\mathrm{H}$. from Hawaii. The crowded small leaves on some branches probably grew during a very dry season.

$\beta$. Leaves thick coriaceous, suborbicular, $1-2^{\prime}$ in diameter, on petioles of $1^{\prime \prime}$, cordate at the base and often retuse at the apex, densely gray-or white-woolly underneath (on both sides while young). Cyme short corymbose, woolly, as are the calyx, petals and capsule. Bracteoles rounded, $1-1^{1} / 2^{\prime \prime}$. Peduncle $2-4^{\prime \prime}$; pedicels $1-1^{1 / 2^{\prime \prime}}$. Calyx large, $2-2^{1 / 2}$, with short rounded. lobes. Petals rounded. Stamens $6 "$. Capsule $3^{\prime \prime}$. - Small gnarled trees with angular branches.

Oahu, Nuranut 2000-3000 ft.; mountains of Hawaii! and E. Maui up to $8000 \mathrm{ft}$.; Kauai. - Gaud. 1. e. pl. 108, - Yellow fl. from the Kohala range.

$\gamma$. Leaves shaped as in $\beta$, but smaller, ${ }^{3} / 4-1^{\prime}$ in diameter, thick coriaceous, quite glabrous underneath. Cymes few-flowered, woolly-tomentose in all parts, as in $\beta$. Calyx $2-21 / 2^{\prime \prime}$. Stamens $10-12^{\prime \prime}$. - A low trailing shrub with stems only $3--6 \mathrm{ft}$. long.

Maui, in the bogs on the top of Eeka! $6500 \mathrm{ft}$.

o. Leaves shaped as in $\beta$, or oblong, but glabrate. Cyme with smaller calices, glabrate in all parts.

Hawai, Mauna Loa, and Maui, Hateakala! at elevations of $8000 \mathrm{ft}$. Gray, 1. c. $\gamma$. - Perhaps only glabrous forms of $\beta$ and $e$.

\&. Leaves coriaceous, obovato- or elliptico-oblong, shortly acuminate or obtuse, $1^{1 / 2}-2^{1 / 2^{\prime}} \times 1-1^{1 / 4^{\prime}}$, on petioles of $3-6^{\prime \prime}$, cinereo-tomentose on 
both faces, but the older leaves glabrate. Cyme tomentose, the peduncles $3-6^{\prime \prime}$, the pedicels $1-3^{\prime \prime}$. Calyx $2^{\prime \prime}$, tomentose. Petals oblong, tomentose or glabrate. Capsule pruinose. Stamens 10-12". - Good-sized trees with angular branches.

The predominating form in Kona, Puna and Hilo, Haw aill Leaves ovate to obovate, obtuse or rounded at top, contracted or rounded, even emarginate at the base. Lanai ! Maui, Molokai! Oahu! - Yellow fl. M. Lutea, Gray, 1. c. p. 560, pl. 69 A (not B) in forests of Hilo.

$\zeta$. Leaves thinner, ovate to ovate-oblong, acuminate or somewhat obtuse, glabrous on both sides (even in early age), $1-2^{\prime} \times^{3 / 4}-1^{1 / 4^{\prime}}$, on margined petioles of $3^{\prime \prime}$. Cymes large and open, with calices faintly tomentose or pruinose. Petals oblong. Stamens $6-9^{\mu}$. - Good-sized trees with terete branches.

Oahu! Kauai! (Mrs. Sinclair, pl. 2). Maui! (very small fl, from Wailuku and Kanapali.) Yellow fl. from Kula! Maui, and Konahuanui, Oahu (M. \& B.). Knudsen's no. 16, which has broad obtuse glabrous leaves, but a thick woolly tomentum on cyme and calices, as in $\beta$ and $\gamma$, forms a low prostrate shrub in the swamps of the high plateau of Ka uai!

$\eta$. Leaves narrow lanceolate or elliptico-oblong, acute at both ends and quite glabrous, shining, $1^{1 / 2}-2^{\prime} \times{ }^{1 / 2}-3 / 4^{\prime}$, on margined petioles of $1-3^{\prime \prime}$. Cymes large, quite glabrous, the peduncles $3^{\prime \prime}$, the pedicels $1-2^{\prime \prime}$; the oblong petals and stamens deep red, the latter $12^{\prime \prime}$ long. Capsules $1{ }^{1 / 2}$.

Handsome trees with terete branches and showy flower-cymes, called Lehua ahihis by the natives. In sheltered gulches on the lee-side of Oahul and Kauai.

2. M. rugosa, Gray, Bot. U.S. E. Exp.p. $561, p 7.69$ B (not A). - A small stunted tree or shrub with stiff angular branches. Leaves orbicular, contracting at the base, about $1^{\prime}$ in diam., thick coriaceous, rugose above and deeply impressed along the veins, which are remarkably strong and ridged underneath, the under surface thickly tomentose with a ferruginous wool; the petiole scarcely $1^{\prime \prime}$. Cymes small, solitary or in pairs at the summit of the branches, subtended by short triangular bud-scales, the peduncles and their divisions short and stout, thick tomentose. Bractlets as long as the calyx, soon deciduous. Flowers subsessile, as large as in no. 1. Calyx tomentose. Petals and stamens red, the former pubescent. Ovary deeply immersed in the tube of the calyx, its summit only free.

Oahu! dry hills back of Honolulu and Niu.

3. M. macropus, Hook. \& Arn. in Bot. Beech. p. 83. - A large tree, glabrous throughout, the branches rather terete. Leaves distant, ovate or ovate-oblong, $2^{1 / 2^{\prime}} \times 1^{1 / 2^{\prime}}$, on long petioles which measure $1-2^{\prime}$, obliquely acuminate, generally rounded at the base, but decurrent into the somewhat margined petiole, coriaceous, glabrous and shining. with distinct veins and marginal nerve. Cymes terminal, single or geminate, their axis or divisions often prolonged in a foliose branch, the base for a long time subtended, as are also the latest leaf-branches, by many scarious lanceolate bud-scales of $1 / 2-1$ ' in length. Cymes open, the 
pedicels 2-4". Bracts and bractlets ovate-lanceolate, 6-3". Flowers larger than in no. 1. Calyx glabrous, turbinate, $3^{\prime \prime}$, its ovate lobes half as long. Petals $2-3^{\prime \prime}$, red (or yellow), as are the long stamens. Capsule $4^{\prime \prime}$, scarcely projecting from the calyx-tube, free to the middle. Seeds fusiform. - Gray, 1. c. p. 564, pl. 70.

Oahu! Nuuanu to Palolo, yellow flower from Palolo; Molokai! leaves smaller and narrower; Ka uai! leaves contracting at the base.

\section{EUGENIA, L.}

Calyx-tube globose to elongate, 4-, rarely 5-toothed, or produced above the ovary with 4 or rarely 5 distinct imbricate lobes. Petals 4 , rarely 5 , distinct, or cohering in a cap and falling off together. Stamens numerous, with capillary filaments and small versatile anthers. Ovary 2-, rarely 3-celled, with several ovules in each cell. Style filiform; stigma small. Fruit a berry crowned by the teeth or truncate remains of the calyx. Seeds 1 or few. Embryo straight, with a short radicle, the cotyledons thick and usually consolidated into a single mass. - Trees or shrubs. Leaves opposite, penni-nerved. Flowers in trichotomous terminal and lateral or axillary cymes or corymbs, or single or few (on short spurs or buds) in the axils of leaves.

A large genus which comprises over 500 species, most copious in tropical and subtropical America and tropical Asia, with few species in Australia and Africa. Cultivated: E. (Jambosa) vulgaris, the Rose Apple, E. (Syzygium) Jambolana, E. uniflora, L. (E. Michelii, Lam.), fruit red and ribbed like a tomato, and another species of Eugenia with black fruit of the size of a large cherry, improperly called the Chinese Plum.

Flowers single in the axils of leaves

Flowers in simple or compound corymbose eymes; fruit less than $1 / 2^{\prime}$ in diam.

Flowers in paniculate cymes; fruit about 3 in diam.

3, E, rariflora.

2. E. Sandwicensis. 1. E. Malaccensis.

1. E. Malaccensis, $L$. - A glabrous tree, $25-50 \mathrm{ft}$. high. Leaves opposite, elliptico- or obovato-oblong, $6-7^{\prime} \times 2^{1 / 2}-3^{\prime}$, on petioles of ${ }^{1} / 2^{\prime}$, suddenly acuminate, dark green and shining, not dotted, the sinuate marginal nerve distant from the edge. Cymes axillary, usually cauline, short, about $2^{i}$ long, their lowest branches $4-6^{\prime \prime}$ long and 3 -flowered, the middle or terminal branch racemose. Pedicels short, gradually enlarging into the calyx. Calyx turbinate, produced beyond the ovary, with 4 rounded lobes. Petals obovate, red, $3 "$; the red stamens 9 "long. Fruit obovate, about $3^{\prime}$ in diameter, umbilicate at the top and crowned by the truncate scar of the calyx-lobes, deep crimson. Seed generally one. - Jambosa Malaccensis, DC. - J. domestica, Rumph. - J.purpurascens, DC. - Mrs. Sinclair, pl, 41.

$\beta$ var. - Flowers and fruit white (rare).

On all islands, in the lowest forest-zone up to about $18 n 0 \mathrm{ft}$.; always gregarious, forming a forest-belt on the north side of E. Maui. Nat. name: "Ohia ais, or simply "Ohia". - The tree occurs on all the larger island groups of Polynesia and in the Malaysian Arehipelago, being everywhere valued for its fine fruit. Tahitian name: "Ahias; Vitian: «Kawikas. 
2. E. (Syzygium) Sandwicensis, Gray, Bot. U.S. E. Exp.p. 519. - A tall tree, sometimes attaining a height of $40-60 \mathrm{ft}$., glabrous, the branches angular, sharply margined. Leaves obovate or obovate-oblong, $3-4^{1} / 2^{\prime} \times$ $1^{1 / 2}-2^{\prime}$, on petioles of about $6^{\prime \prime}$, obtuse, subcoriaceous, dark green, the marginal nerve subcontinuous. Cymes simple or compound, in the axils of the upper leaves, the common peduncle angular and elongate, $1-1^{1 / 2}$, the pedicels only about $1^{1 /} / 2^{\prime \prime}$, articulate and bibracteolate below the calyx; bractlets small triangular. Calyx turbinate, $1^{1 / 2}-2$ " long, 4-lobed, the small lobes $\left({ }^{1} / 2^{\prime \prime}\right)$ extending down to the disk, imbricate, early deciduous. Petals obovate, often emarginate, pinkish, about $1^{\prime \prime}$, generally discreet, but sometimes united and falling off together. Stamens 20-30, shorter than the petals. Style short. Ovary 2-celled, with 10 or more ovules in each cell. Berry turbinate or globose, flat at the top, $4-5^{\prime \prime}$ in diameter, red. Seeds 1 or 2 , with a pale thin testa, the thick cotyledons not consolidated.

\section{$\beta$ var, parvifolia. Leaves $1^{1 / 2}-2^{\prime} \times 1-1^{1 / 4^{\prime}}$.}

From Kauai to Maui! (probably also on Hawaii), at altitudes of $1000-3000 \mathrm{ft}$. Nat. name: "Ohia ha". The fruit is resinous-astringent, insipid.

3. E. rariflora, Benth. in Journ. Bot. II, 221. - A tall shrub with terete glabrous branches. Leaves broad, ovato- or elliptico-oblong, or rhomboidal and acuminate, or obovate and obtuse, even suborbicular, $1^{1 / 2}-3^{\prime} \times 1-1^{3 / 4^{\prime}}$, on short $\left(1^{1} / 2^{\prime \prime}\right)$ petioles, glabrous, pale green, shining above, chartaceous, with minute oil-dots. Flowers solitary in the axils, or 2 or more near the apex of short foliaceous axillary buds or spurs, on slender pedicels of $4-8^{\prime \prime}$, which are minutely bibracteolate below the calyx. Calycine tube puberulous, subglobose, $2^{\prime \prime}$, not produced, its 4 lobes obovate or oblong, of the same length and imbricate. Petals 4, obovate, $3-4^{\prime \prime}$, thin, patent. Stamens numerous, as long as the petals, all free. Style short, slightly curved. Ovary 2-celled, each cell with 8 amphitropous ovules. Berry dryish, globose, $4-6$ " in diameter, crowned with the calyx-lobes. Seeds 1 or 2, ascending, globose, with a thin membranous testa, filling the cell; the thick cotyledons not consolidated, the minute radicle slightly bent. - Gray, 1. c. p. 514, pl. 60. - Jossinia cotinifolia, Hook. \& Arn. in Bot. Beech. p. 62. - Fl. Vit. p. 78. - Our plant differs from that of the Southern islands in having thicker, more strongly veined, glabrous leaves and a smaller fruit.

Very rare. Oahul Wailupe; Maui, Wailukut; on the lower ridges.

$\beta$ var. parvifolia. Leaves narrow elliptical or almost lanceolate, about 1 ' long.

Northern slope of Kaala! O a hu (Lydgate).

This species, which hitherto was not known from the Hawaiian Islands, is said to be common on the Society, Samoa and Viti groups. In Tahiti it is ealled shitoas or :Totoes.

Hillebrand, Flora of the Hawaiian Islands. 


\section{PSIDIUM, L.}

Calyx-tube ovate and adnate at the base, the upper free portion quite entire and closed over the flower in the bud, coming off entire or splitting irregularly. Petals 4 or 5, free. Stamens numerous. Ovary 2or more-celled, with many ovules in each cell, inserted on bifid axile placentas. Fruit a berry. Seeds several, kidney- or horseshoe-shaped. Embryo curved, with a long radicle and short cotyledons. - Trees or shrubs with opposite leaves. Flowers solitary or few together on axillary peduncles.

An American genus, of which the following species has become naturalized in many tropical countries.

$\dagger$ 1. P. Guayava, L. - A small tree, pubescent on the young branches. Leaves on short petioles, ovate or oblong, usually acuminate, glabrous above, softly pubescent underneath, with the principal veins very prominent. Peduncles axillary, ${ }^{1} / 2-1^{\prime}$ long, $1-3$-flowered. Buds ovoid in the adnate part, the free part also ovoid, but much larger and more or less acuminate. Petals broad, fully $1 / 2^{\prime}$ in diameter. Fruit globular or pear-shaped. - Benth. Fl. Hongk. p. 120. - P. pomiferum and P. pyriferum, L.

The Guava is of early introduetion and has spread over many parts of the Islands, in some valleys forming close thickets, to the exclusion of every other shrub or tree. Its fruit is of the size and shape of a medium-sized apple, sweet aromatic to the taste. Another eultivated variety has a smaller, ovoid, more or less acid fruit, the pulp being yellowish or white. The variety with pear-shaped fruit is rather rare. A distinct species is $P$. Cattleyanum, the so ealled Chinese Guava.

To the Order Combretaceae belongs the Terminalia Catappa, L., generally called - Kamanis a tree much planted for the shade afforded by its horizontal branches and large leaves, less on account of the almond-like edible fruit.

\section{ORdER XXXII. LYTHRACEAE.}

Calyx-tube free, but usually enclosing the ovary, with as many or twice as many teeth as there are petals. Petals 4,5 or sometimes more, rarely deficient, inserted at the top of the calyx-tube, crumpled in the bud. Stamens as many or twice as many, or rarely indefinite, jnserted in the tube of the calyx, often lower down than the petals. Ovary 2-or morecelled, with several ovules in each cell. Style single. Fruit a capsule, often 1-celled by the drying up of the partitions. Seeds small, without albumen. - Trees, shrubs or herbs. Leaves mostly (at least the lower ones) opposite, entire, without stipules. Flowers axillary, or in terminal racemes, spikes or panicles.

A considerable Order, some of the herbaceous genera spread over the greater part of the globe, the larger woody-stemmed ones confined to the tropics of both Worlds.

Calyx straight; petals and cells of ovary equal

Calyx gibbous at the base; petals and ovarian cells unequal
1. Lythrum.

2. Cuphea. 


\section{LYTHRUM, L.}

Calyx-tube cylindrical, 8-12-ribbed, straight, with 4-6 small broadish and as many accessory pointed, erect, or patent teeth. Petals 4-6, obovate, scarcely unguiculate, occasionally none. Stamens $6-12$, inserted below the middle of the calyx-tube. Ovary sessile, oblong, 2-celled. Style filiform, with a capitate stigma. Ovules many, on thick axile placentas. Capsule enclosed, membranous, often spuriously 1-celled, septicidal or opening irregularly. Seeds many, plano-convex or angular. Cotyledons orbicular, biauriculate at the base, the radicle conical. - Herbs or undershrubs with quadrangularbranches and opposite entire leaves. Flowers axillary, solitary or in cymes.

A small genus, principally inhabiting the temperate regions of both Worlds.

1. L. maritimum, H. B. \& Kunth. - DC. Prod. III, 82. - A low prostrate perennial with often a woody base, $1-1^{1 / 2} \mathrm{ft}$. in length, glabrous, much branched. Leaves linear-oblong or lanceolate, $9-15^{\prime \prime}$ long, on very short petioles, acute, obtuse at the base. Flowers single, on short bibracteolate peduncles of $1-1^{1 / 2} 2^{\prime}$. Calyx-tube $3^{\prime \prime}$ long, with 12 ribs and 6 membranous deltoid teeth, the 6 accessory teeth more than twice as long as these and stiff subulate. Petals 6, purplish or pink, obovate, $1^{1 / 2} 2^{\prime \prime}$. Stamens 6 , enclosed or nearly so. Style exserted, with a thick globose stigma. Capsule about ${ }^{3} / 4$ the length of the calyx, 2-celled, the seeds numerous, minute, obconical, angular. Bracts subulate. - Hook. \& Arn. in Bot. Beech. p. 82. - Gray, Bot. U. S. E. E. p. 606.

On all islands, in open forests or on grass land, between 1500 and $3000 \mathrm{ft}$. of elevation. Is also a native of Peru, where it is said to grow near the sea.

\section{CUPHEA, P. Br.}

Calyx tubular, 12-ribbed, gibbous or spurred at the base, with 6 primary teeth, the accessory teeth as many and small or none. Petals generally 6, unguiculate, the 2 posterior larger. Stamens 11, short, unequal, inserted at different heights near the throat of the calyx. Ovary unequally 2-celled, with a basilar gland on the upper side, 2- to several-ovuled, the ovules raised on funicles ascending from an axile placenta. Style incurved; stigma capitate, 2-lobed. Capsule membranous, enclosed, spuriously 1-celled, with a free columnar placenta, splitting laterally. Seeds compressed. - Herbs or low shrubs with terete branches, generally viscous. Leaves mostly opposite or whorled, entire. Peduncles inter-petiolar, 1- to several-flowered.

A large genus of tropical and subtropical America.

†1. C. hyssopifolia, H. B. \& Kunth. - DC. Prod. III, 8\%. - Stem herbaceous, erect, about $1 \mathrm{ft}$. high, scabrous, and hispid with patent viscous hairs. Leaves opposite, ovato- or elliptico-oblong, $1-2^{\prime} \times{ }^{1 / 2}-3 / 4^{2}$, entire or faintly crenate, acuminate or obtuse, contracting at the base 
to a petiole of $2-3^{\prime \prime}$, scabrous. Flowers between the petioles, single at a node and alternate, or several alternately racemose on short foliaceous axillary shoots, the pedicels very short and acutely bibracteolate. Calyx ovoid or fusiform, hispid, 3 " long, gibbous at the base, faintly ribbed, the accessory teeth shorter than the small primary ones. Petals 1", purplish. Most of the filaments villous. Stigma minute. Capsule enclosed, very thin, 8-seeded. Cotyledons orbicular, emarginate, the short radicle tricuspid. - Grisebach, Fl. W. Ind. p. 270. - C. Balsamona, Ch. \& Schl. - Mann, Enum. no. 139.

Probably of early accidental introduction. Kauai! (Kn.); Oa hu! valley of Mannalua; E. Maui, Makawao. - Extends in America from Mexico to Montevideo, also to the Galapagos Islds.

Cultivated plants of this Order: Cuphea platycentra and other species, Lawsonia alba, Grislea tomentosa, Nesaea salicifolia, Lagerstroemia Indica (Crape-myrtle) in several varieties, $L$. reginae.

\section{ORdER XXXII. ONAGRACEAE.}

Calyx-tube adhering to the ovary, sometimes prolonged above it, the limb of 4,2 or rarely 5 lobes, valvate in the bud. Petals as many, inserted on the calyx below its lobes, contorted in the bud, or rarely wanting. Stamens as many or twice as many as the petals and inserted with them. Style simple, or divided at the top only into 2 or 4 stigmas. Ovary inferior, 2- or 4-celled, with several ovules in each cell. Fruit a capsule or berry. Seeds without albumen. Embryo straight. - Herbs or shrubs. Leaves alternate or opposite, undivided (unless growing under water), toothed, without stipules. Flowers solitary in the axils of the leaves or in terminal spikes or racemes.

A considerable Order, ranging over the whole world, but in greatest variety in North America. In cultivation: various species of Fuchsia (which do well only above $1500 \mathrm{ft}$.) and the water plant Trapa bicornis, the singular 2-horned fruit of which encloses an edible almond-like cotyledon.

\section{JUSSIAEA, L.}

Calyx-tube not produced above the ovary, the limb divided into 4 or rarely 5 segments. Petals as many as lobes of calyx. Stamens twice as many. Style often very short, with a 4- to 6-lobed stigma. Capsule 4or 5-celled, erowned by the calyx-segments and opening longitudinally between the ribs. Seeds numerous, small, without appendage. - Herbs with alternate leaves. Flowers axillary, solitary, yellow or rarely white.

A genus of several American species, with a few spread over Polynesia, Asia and Africa.

1. J. villosa, Lam. - Wight \& Arn. Prod. Fl. Ind. Or. I, 336. - An erect perennial, often $2-3 \mathrm{ft}$. high, and hard, almost woody at the base, glabrate in our form, but pubescent or hairy in other countries. Leaves oblong or lanceolate, $1^{1 / 2}-3^{\prime}$ long, narrowed to a short petiole. Flowers almost sessile. Calyx-tube about 6 "long when in flower, the 4 segments 
ovate-lanceolate, constricted at the base, $4-5^{\prime \prime}$ long. Petals 4 , rather longer than the calyx, obovate, emarginate, with hairy claws, yellow. Stamens hairy at the base. Capsule nearly cylindrical, $1-1^{1 / 2^{\prime}}$ long, 8ribbed. Seeds minute. - Benth. Fl. Hongk. 109. - Mann, Enum. no. 140. - J. octonervia, Lam. - Walp. in Rel. Meyen. p. 326. - J. octofila, DC. - Gray, Bot. U. S. E. E. p. 619. - J. angustifolia, Lam. - Hook. \& Arn. Bot. Beech. and Gaud. Bot. Freyc. - Grisebach, in Fl. W. Ind. p. 273, unites $J$. villosa and $J$. octonervia, Lam., and $J$. octofila, DC., with $J$. suffruticosa, L.

Very common over the whole group in old staro" patches and along water-courses. Undoubtedly present before the discovery. Nat. name: "Kamole". - The species is widely distributed over the warmer regions of America (from Arkansas to Brazil) and Asia.

\section{ORdER XXXIV. CUCURBITACEAE.}

Flowers usually unisexual. Calyx of fem. fl, superior (or adherent at the base and produced above the ovary), usually 5-toothed. Petals 5, or united into a 5-lobed corolla, apparently continuous with the calyx-tube, the calyx-teeth between the lobes or lower down. Stamens 3 or 5 , free or united, inserted in the base or mouth of the calyx, the anthers linear and curved or flexuose, one of them often 1-celled. Ovary inferior, usually 1-celled when young, with 3 parietal placentas which soon grow out so as to divide the ovary into 3 or 6 cells and which bear many horizontal ovules, or 1- to 3-celled, with 1 or few erect or pendulous ovules in each cell. Fruit pulpy, with a hard rind, or dry, indehiscent or bursting irregularly. Seeds compressed, without albumen. Embryo straight, with flat cotyledons, the radicle next the hilum. - Climbers, usually herbaceous, with lateral tendrils. Leaves alternate, palmately veined or lobed.

A large Order, dispersed over all but the colder regions of the globe, but most abundant in dry hot countries, especially in Afriea.

Filaments free; seeds many to each cell, horizontal:

Leaves undivided; petals distinct, white

Leaves lobed; corolla campanulate, yellow .

Filaments connate; seed single, pendulous

1. Lagenaria

2. Cucurbita.

3. Sicyos.

\section{LAGENARIA, Ser.}

Flowers mostly monoecious, solitary. Male fl. on long peduncles. Calyx campanulate, shortly 5-cleft or -toothed. Petals 5, free, obcordate or obovate. Stamens inserted in the calyx-tube, the filaments free; anthers enclosed, slightly cohering, their flexuose cells contiguous or discreet, the connective not produced. Female $f l$. on shorter peduncles. Calyx and corolla as before, but the tube of the former adnate. No rudiments of stamens. Ovary with 3 parietal placentas and many horizontal ovules. Style short, thick, the 3 stigmas 2-lobed. Fruit variously shaped, woody, indehiscent, many-seeded. Seeds compressed, margined. - A tall, pubescent, musk-scented climber. Leaves ovate or reniform-cordate or rounded, 
dentate, the petiole with 2 glands at the base. Tendrils bifid. Flowers large, white.

A genus of a single species.

1. L. vulgaris, Ser. in DC. Prod. III, 299. - Fruit elongate, often measuring $4 \mathrm{ft}$. and more. - Cucurbita Lagenaria, L.

The Bottle-gourd, which is eultivated or naturalized in most tropieal countries, was found in possession of the natives at the time of the discovery, just as was the case on most other Polynesian island-groups. The hard woody shell of the fruit served for containers in their households, while the largest gourds were converted into drums for use during their dances. The drastic pulp and seeds were a favorite medicine in the hands of the "Kahunas", although by no means free of danger. Nat, name: "Ipu". In Tahiti it is called shues, meaning a climber, which name applies in the Sandw. Islds. to Cocculus.

\section{CUCURBITA, L.}

Flowers monoecious, solitary. Male $f l$. Calyx campanulate, 5-lobed, the lobes often foliaceous. Corolla campanulate, deeply 5-fid with recurved lobes. Stamens 3 , inserted at the bottom of the calyx, the filaments free, the anthers linear, united into a head, one 1-celled, the others 2-celled, the cells flexuose. Fem. $f l$. Calyx and corolla as before. Stamens rudimentary. Ovary inferior, with 3 parietal placentas and many horizontal ovules. Style short; stigmas 3, two-lobed. Fruit fleshy, indehiscent, with a hard rind, very large. Seeds complanate, often margined. - Climbing or prostrate, often rooting, herbs with cordate and lobed leaves. Tendrils once or several times divided. Flowers large, yellow.

Contains 8 or 12 species, belonging to the warmer regions of both Worlds, several of them being Californian.

1. C. maxima, Duch. - DC. Prod. III, 316. - Leaves very rough; petioles hispid. Calyx-tube obovate, ending in a short neck. Fruit globose, somewhat depressed, very large, yellow, green or red. - $C$. Potiro, Pers.

The Calabash or large gourd, the original country of which is likewise unknown, was also met with at the Islands at the time of their discovery, but seems to have been unknown to the inhabitants of all other Polynesian islands before their contact with whites. The hard shell was then made, as it is now, into containers for "poin, water, ete. The fruit often attains several feet in diameter. Nat. name: *Ipu nui *

To this genus belong the Pumpkin, C. Pepo, the Squash-gourd, C. Melopepo, and the Vegetable marrow, C. ovifera, all in general eultivation. Of the nearly related genus Cucumis, the Cucumber, C. sativus, the Meion, C. Melo, in several varieties, and the Watermeion, C. Citrullus, are raised in abundance and grow to perfection. To the latter species has to be referred as a variety the much esteemed Pie-melon.

\section{SICYOS, L.}

Flowers monoecious. Male $f l$. racemose or paniculate. Calyx campanulate, with 5 small subulate teeth or none. Corolla deeply 5 -cleft, the triangular segments confluent with the calyx. Filaments connate; anthers $2-5$, united into a head or more or less free, the cells curved or flexuose. Fem. $f l$. on the same raceme as the male flowers, or clustered or solitary 
at the end of an axillary peduncle. Calyx produced beyond the ovary. No stamens. Corolla small. Ovary fusiform or ovoid, 1-celled, with 1 pendulous ovule. Style not exserted beyond the corolla, with 3 short, free or united, stigmatic lobes. Fruit dry and indehiscent, mostly ribbed, smooth, or covered with prickly bristles. - Climbing or prostrate herbs with angular stems. Leaves cordate, angular or lobed. Tendrils lateral, trifid. Flowers small.

About 20 species, belonging to America, Australia and the Hawaiian Islands.

In all Hawaiian species male and female inflorescences are distinct, but rise from the same axil. The fruit presents itself in my specimens under two forms, viz., a thiek fibrous pericarp is connate with the calyx-tube and closely surrounds a chartaceous endocarp - S. cucumerinus and $S$. hispidus - , or a small crustaceous endocarp is covered by a thin filmy epicarp, but is free from the calyx-tube, does not fill it $-S$. microcarpus and $S$. laciniatus. Of $S$. pachycarpus and $S$. macrophyllus I have not been enabled to examine ripe fruit, but from Prof. Gray's description of the first species it would appear that its fruit coincides in characters with that of the first series. - Nat. name of all species: "Anunu*.

Fruit hairy and plentiful:

Fruit sessile, tomentose, beset with soft papillae; anthers free, diverging; tendrils 4-5-cleft

Fruit shortly pedicellate, hispid and prickly or muricate when ripe; anthers connate.

Fruit smooth and glabrous; tendrils 2-3-cleft:

Fruit elongate, the ovary filling the tube of the calyx:

Female flowers many in a head, but only 4-8 maturing; fruit ovate-pyramidal, beaked, 5-7" long, and angular:

Leaves angular or shortly lobed, with broad shallow sinuses between the lobes; panicle of male flowers racemosely branching

Leaves more deeply lobed, with acute sinuses between the lobes; panicle of male flowers umbellately branching.

Female flowers few at the apex of the peduncle; fruit spindleshaped, without beak; leaves very variable, from entire to compoundly lobed

Fruit small ovoid or globose, bea ked; the ovary loose in the calycine tube and crustaceous; female flowers numerous, all maturing fruit:

Leaves eordate-angular .

1. S. Maximowiczii.

2. S. hispidus.

Leaves pedately 5-7-lobed:

Lobes of leaves serrate or laciniate, with an acute apex; stigmatic lobes connate

Lobes of leaves subentire, obtuse or rounded at the dilated apex; stigmatic lobes free and reflexed

4. S. pachycarpus.

5. S. macrophyllus.

3. S. cucumerinus.

6. S. mierocdrpus.

7. S. laciniatus.

8. S. Remyanus.

1. S. Maximowiczil, Cogniaux, in De Cand. Monogr. III, 895. - Stem stout, shortly villous. Leaves membranous, bright-green and shortly woolly, at last scabrous on the upper face, cinereous and densely woolly. tomentose, at last hirsute on the lower face, $3^{1 / 2-4^{\prime}} \times 4-5^{\prime}$, cordaterounded, obtusely 5-angled, acute and very shortly acuminate, wavy and finely toothed, with a subacute sinus; the stout petiole tomentose, $1^{1 / 2}$ to $2^{1 / 2} 2^{2}$. Tendrils $4-5$-cleft, very stout. Male $\mathrm{fl}$. in a racemose, rather simple paniele on a common peduncle of $1^{1 / 2}-3^{1 / 2^{4}}$, the pedicels $1-2^{1 / 2^{\prime \prime}}$. Calyx ashy-tomentose, campanulate, $1^{\prime \prime}$ broad, its teeth less than ${ }^{1 / 2}{ }^{n}$. 
Corolla tomentose, with patent triangular lobes of $1-1^{1 / 2} 2^{\prime \prime}$. Staminal column tomentose; anthers 5, free and diverging. Fem. fl. many $(12-20)$, sessile at the apex of a thick clavate peduncle of $9-14^{\prime \prime}$ in length. Fruit ovoid-compressed, obtusely angled, cinereous, $5 \times 3^{\prime \prime}$, beset with soft subulate papillae and long tomentum.

O a hu (Kastalsky, in herb. Acad. St. Petersb.).

2. S. hispidus, sp. n. - Stem herbaceous, hirsute throughout with spreading articulate glandular hairs. Leaves $4-7^{\prime}$ each way, cordateovate, angular or obtusely lobed with broad shallow sinuses, suddenly acuminate into a caudate point, dentate with patent subulate callous teeth, membranous, hispid with short scattering hairs above, scabro-puberulent underneath; the hairy petioles $2-3 \prime$. Male $f l$. in a racemose panicle with a common peduncle of $3-6^{4}$, pubescent, the perianth campanulate, $2-3^{\prime \prime}$ in diameter, 5-cleft to the middle, greenish-yellow. Anthers convolute. Fem. fl. many on short pedicels of $1^{\prime \prime}$, crowded at the apex of a peduncle of $6-8 "$, the hairy calyx-tube suddenly contracted to a short, filiform, deciduous neck bearing the campanulate perianth, which is 5 -cleft to the middle. Stigmatic lobes clavate, rather large. Fruit $7-12$, slightly compressed, without beak, not ribbed, $4-5^{\prime \prime}$ long and $2-3^{\prime \prime}$ broad, prickly and woolly, muricate when mature, the calycine covering connate with the thick, almost woody pericarp, which closely surrounds a white chartaceous endocarp or putamen. Cotyledons obtusely triangular, rather thick, with a conical radicle of $1 / 2$ their length.

E. Maui, Kula!

3. S. cucumerinus, Gray, Bot. U. S. E. Exp. p. 652, pl. 82. - Stem stout, glabrous. Leaves $4^{1} / 2-7^{\prime} \times 4-6^{\prime}$, very variable, but with the basal sinus always broad reniform, either entire, rounded or ovate, or hastate and 3-5-angled, or 3-5-lobed, or pedately 5-lobed, often to near the petiole, and then the lobes contracted at the base and sometimes again lobulate or dissected, but the middle lobe always longest, or, when not lobed, the leaf longer than broad, dentate with patent callous teeth, chartaceous, more or less punctate with white dots above, glabrous or scabrous underneath; the petiole $1-1^{1} / 2^{\prime}$. Male inflorescence full and large in racemose panicles, the common peduncle $1-3^{\prime}$ in length. Perianth yellow, $2-2^{1} / 2^{\prime \prime}$ high, 5-cleft, with minute calycine teeth. Anthers 5, slightly twisted. Fem. fl. 2 or 3 , sessile at the end of a filiform peduncle of $1 / 2$ to $2^{\prime}$ in length, puberulous; the calyx-tube fusiform and constricted below the perianth, or more rarely prolonged into a beak, the perianth $1^{1 / 4^{n}}$, funnel-shaped, 5-fid with distinct calycine teeth. Ripe fruit elongate, $10-20^{\prime \prime} \times 4-6 "$, mostly fusiform, obtusely 6-angled, flattened or grooved on one side, the thick fibrous pericarp connate with the calycine tube, the endocarp chartaceous, oblong, $5-6 "$. Testa membranous. Embryo 
with oblong thickish cotyledons and a short mamillaeform radicle. Cogniaux, 1. c.

Probably on all islands. The different leaf-forms oecur promiscuously, often three together on one and the same plant. Kauai, Waimea! leaves pedately lobed, whitedotted above, glabrous underneath; female fl. beaked. H aw a ii, Hito! pedately lobed, ovate and hastate leaves with round auricles, acute, glabrous; fem. fl, not beaked. Maui! Olualu, leaves pedately lobed, the lobes constricted at the base; Kanapali, leaves compoundly lobed, ovate- and hastate-angular, all on one branch, glabrous or scaberulous underneath; fem. fl. constricted below the limb, not beaked; Kula and Hamakua, leaves scabrous underneath, ovato- and hastato-angular and lobed, acute; fem. fl. not beaked. Molokai, Kamaloo! leaves obtuse, rounded, obtusely angled or lobed; panicle of male $\mathrm{fl}$, very large; fem. $\mathrm{fl}$, not beaked.

4. S. pachycarpus, Hook. \& Arn. in Bot. Beech. p. 83. - Stem puberulous or glabrate. Leaves membranous, cordate or reniform, with a broad basal sinus, $3-5^{\prime}$ long and as much or more in breadth, angular or obscurely $3-5$-lobed, the lobes subequal, broad triangular and short, faintly denticulate, glabrous above or sparsely covered with white papillae (the bases of hairlets), rather hispid underneath (or papilloso-scabrous); the petioles $1-2^{1} / 2^{\prime}$. Male $f$. Panicle racemosely branching, with a peduncle of $1-5^{\prime}$. Perianth as in no. 3. Anthers 3-5, united into a globose head, their cells curved. Fem. fl. numerous, sessile in a head on a peduncle of $2-10^{\prime \prime}$. Calyx glandular-pubescent, the tube ovoid, with a short beak which carries a small deeply cleft perianth only ${ }^{1 / 2}-1^{n}$ high. Ripe fruit 4 to 8 , ovoid-pyramidal, 5-9" long, including the pointed apex or beak, sharply trigonous, each face with a prominent midrib, smooth, pubescent or glabrate, the pericarp thick and hard, nearly crustaceous. Seed obovate, turgid, the testa rough, thick and coriaceous. Embryo amygdaloid, with rather thick cotyledons. - Gray, 1. c. p. 650, pl. 80. Cogn. 1. e.

Oahu, Diamond Hill (Lay \& Collie), Punahou! Waianae (U. S. E. E. and Wawra); Kauai! (Kn.). - The Ma u specimen referred here by Gray, and M. \& B.'s no. 444 from the same island, belong to no. 2. - As my specimens are without fruit, the description of it is copied from Gray, his "testa. probably corresponding to what I take to be the endocarp. It is somewhat doubtful, however, if Gray's S. pachycarpus is the same as that of Hooker \& Arnott, for the latter authors assign a height of only $1^{1 / 2}-2^{\prime \prime}$ to their fruit, which points to $S$, microcarpa.

5. S. macrophyllus, Gray, 7. c. p. 651, pl. 81. - Leaves on petioles of $3^{\prime}$, large, $7-10^{\prime}$ in diameter, membranous, glabrous above, softly puberulous underneath, cordate, with a deep narrow basal sinus, $3-5$-lobed, often deeply so and then with acute sinuses, the margins coarsely denticulate with callous teeth. Male $f l$. Panicle glandular-pubescent, with a long peduncle of $5-7^{\prime}$, umbellately dividing into 4 or 5 branches, the filiform pedicels often fascicled, $4-5 "$ long. Perianth greenish-white, large, $5^{\prime \prime}$ in diameter when expanded, the calyx teeth short subulate. Anthers slightly twisted. Fem. $f$. Ripe fruit few and shaped as in no. 3, clustered on a peduncle of $2^{\prime}$.

Hawaii in forests of Mauna Kea, toward their upper margin (U. S. E. E.). 
6. S. microcarpus, Mann, Enum. no. 146. - Stem weak and slender, glabrous. Leaves on petioles of $3 / 4-1^{i}$, thin membranous, papillose or smooth above, puberulous underneath, $1-2^{1} / 2{ }^{\prime}$ in diameter, cordate, with a deep rounded or angular sinus and obtusely 3 -5-angled, faintly dentate. Male fl. Panicle few-flowered, 2-3' long, racemosely or umbellately branching, the pedicels only $1^{\prime \prime}$. Perianth pale, $1^{1 / 2}-2^{\prime \prime}$ in diameter. Anthers 3, connate in a head. Fem. fl. numerous, 30-40, sessile, in a globose head of $3-5^{\prime \prime}$ in diam., on a peduncle of not more than $2-3^{\prime \prime}$; the calyx-tube globose, shortly beaked; the perianth or limb only $1-1^{1} / 2^{\prime \prime}$ in dian. and parted to the base. Stigmatic lobes short, clavate, often conglutinate, the style not exserted. Ripe fruit not over " 2 "long, globose, with a short beak, pubescent. Ovary loose in the calyx-tube, ovoid, scarcely $1^{\prime \prime}$ long, covered with a thin film, crustaceous, brownish, smooth and glossy. Embryo suborbicular. Cogn. 1. c.

Oahu! Makaleha, Waianae (Remy); Ka uai (Remy).

7. S. laciniatus, $s p . n$. - Stem scabrous. Leaves broadly reniform, or truncate at the base, $4-5^{\prime}$ in diameter, 5-9-lobed, the lobes acute, with acute sinuses between, and extending to one or two thirds the length of the leaf, irregularly toothed, serrate or laciniate, membranous, sparsely hispid with short hairs or only punctate with their white bases above, scabro-puberulous underneath, the petioles $1^{1} / 2-3^{\prime}$ long. Male $f l$. Branches of panicle umbellate on a common peduncle of $4-7$ ', the pedicels crowded near their ends, glandular-pubescent. Perianth $11 / 2-2$ " in diameter, 5-cleft to the middle. Anthers 3, connate in a globular head, slightly twisted. Fem. $f l$. numerous, sessile in a head at the apex of a peduncle of $1 / 2-1^{\prime}$; the calyx-tube ovoid and beaked, the minute limb or free perianth cleft down to the beak. Style filiform from a triangular base, exserted beyond the perianth, with a globose, entire, 3-sulcate stigma. Ripe fruit 20-30, obovate, 5" long, including the persistent beak, 3-6angled, puberulous; the coriaceous ovary loose, not filling the tube, ovoid, subcompressed, $1^{1 / 2}-2$ ". Seed suspended from a distinct funis, the testa membranous, the cotyledons broad oblong, complanate, with a short mamillaeform radicle.

E. Maui, Kula!

8. S. Remyanus, Cogniaux, in De Cand. Monogr. III, 89\%. - Stem almost filiform, much branching, glabrous and smooth. Leaves rather stiff, bright green and scabrous on the upper face, cinereous and shortly but densely villous-hirsute, at last scabrous on the lower, $1^{1 / 4}-2^{2} X$ $1^{1 / 2}-2^{1} / 2^{4}$, very deeply and palmately 5 -7-lobed, the lobes narrow-oblong, subentire, dilating and often lobulate near the obtuse or rounded apex, the sinus rounded; the slender petiole $3 / 4-1^{1 / 4} \cdot$ long. Tendrils 2-cleft. 
Male $\mathrm{fl}$. in simple or digitately branching racemes, the glabrous common peduncle $2^{3} / 4-3^{1} / 4^{t}$, the pedicels faintly pubeseent; $1 / 3-1^{1 / 2}{ }^{\mu}$. Calyx campanulate, glabrous. Corolla rotate, white, slightly villous and papillosoglandular, its lobes ovate-oblong, constricted at the base, $1-1^{1 / 2^{\prime \prime}}$ long. Anthers connate. $\mathrm{Fem}$. $\mathrm{fl}$. numerous $(30-40)$ in a globose head on a filiform peduncle of $1 / 2-1$. Style slightly exserted, curved, the 3 lobes of the stigma free and reflexed. Ripe fruit very small, $2^{1 / 4} \times 1^{1 / 2} 2^{\prime \prime}$, obovoid, obseurely angled, long-beaked, shortly and densely villous.

Oahu (Remy, no. 540, in herb. Mus, Paris.).

\section{ORdER XXXV. PAPAYACEAE.}

Flowers unisexual. Calyx inferior, minute, 5-toothed. Corolla of male flowers monopetalous, 5-lobed. Stamens 10, inserted in the corolla. Ovary free, 1-celled, with 5 many-ovuled parietal placentas. Stigma 5-lobed. Fruit succulent, indehiscent. Seeds enveloped in a loose mucous coat, with a brittle pitted testa. Embryo in the axis of albumen. - Milky trees with usually simple soft-wooded stems. Leaves alternate, palmatinerved or lobed. No stipules. Flowers in axillary racemes, or solitary.

The Order contains only 2 genera of tropical America.

\section{CARICA, L.}

Corolla of male flowers funnel-shaped, that of the female formed of distinct valvate petals. Stamens in two series, inserted on the throat of the corolla. Stigma sessile, 5-lobed, laciniate. - Flowers usually dioecious, but often intermixed with hermaphrodite ones.

A genus of about 20 speeies.

$\dagger$ 1. C. Papaya, L. -- Dioecious. Stem simple. Leaves glabrous, deeply 7-lobed, the lobes pinnatifid, pointed. Petioles very long. Male fl. in long axillary racemes or interrupted panicles. Fem. $f l$. single, or 2 or 3 together. Fruit obovate, large, yellow. - Papaya vulgaris, DC.

The Papaya, a native of Brazil, must have been introduced in very early times, as it is not only cultivated everywhere, but found in many waste places which had been settled upon in former times. The fruit is not much esteemed; the milky juice contains a digestive prineiple similar to pepsine and has the property of making tough meat tender; the seeds possess a vermifuge property.

of the nearly related Order Passiftoreae a number of species are in eultivation. The purple-fruited Water-lemon, Passiflora edulis, has already eseaped into the woods of East Maui. The Grenadilla, $P$. quadrangularis, and the yellow-fruited $P$. laurifolia are cultivated for their delicious fruit, $P$. incarnata, $P$. coerulea, $P$. minima, $P$. foetida and others on account of their flowers, also Disemma coccinea.

To the allied Order Turneraceat belong $T$. ulmifolia and $T$. trioniflora.

\section{ORdER XXXVI. FICOIDEAE.}

Sepals $4-5$, discreet or partly united, rarely adnate to the ovary, imbricate, persistent. Petals often wanting. Stamens mostly perigynous 
Styles free to the base, or connate. Capsule several-celled, with axillary or basal placentas, loculicidal or circumscissile. Otherwise as in Portulacaceae.

Includes the genus Mesembryanthemum, some species of which are cultivated.

\section{SESUVIUM, L.}

Calyx 5-parted, purplish inside, free, persistent. Petals wanting. Stamens $5-60$, inserted on the calyx. Styles discreet, 3-5. Capsule free, 3-5celled, circumscissile, many-seeded. - Succulent herbs with opposite leaves, without stipules. Flowers axillary, solitary or in cymes.

A small genus of littoral plants, spread over most tropical regions.

1. S. Portulacastrum, L. - DC. Prod. III, 453. - A prostrate or floating aquatic herb. Leaves fleshy spathulate or lanceolate, $1^{1 /} / 2^{\prime}$ long, tapering toward a sheathing base. Flowers solitary in the axils, on pedicels of $1-2^{\prime \prime}$. Calyx $4^{\prime \prime}$. Stamens numerous.

Common in and near wet ditches and ponds along the coast. Is found in most tropical countries.

\section{ORdER XXXVII. CACTACEAE.}

Sepals and petals numerous, imbricate in several rows, adherent to the 1-celled ovary. Stamens numerous, inserted on the inside of the tube or cup formed by the union of the sepals and petals. Style 1 , with 2 to many stigmatic rays. Fruit a succulent berry with numerous campylotropous seeds on several parietal placentas. Albumen little or none. Fleshy, mostly leafless plants of various shapes, globular or columnar and many-angled, or flattened and jointed, the abortive leaf-buds transformed into spinous tubercles. Flowers solitary.

\section{OPUNTIA, Tournef.}

Sepals and petals not united into a prolonged tube, spreading, regular, the inner petals roundish. Stigmatic rays $2-7$. Berry often prickly. Embryo with foliaceous cotyledons, curved round scanty albumen. Stems jointed, the joints mostly flattened, bearing tubercular cushions with bristles, down and often spines, supported by a caducous scale-like leaf or bract.

An American genus of many species.

†1. 0. Tuna, Mill. - Stem much branching, erect; the joints flat, ovate. Tubercles bearing bristles, down and 4 or 5 large spreading flavescent spines. Flowers lateral, orange. Stamens shorter than the corolla and nearly equalling the style. Berry obovate, truncate, as large as a small hen's egg, purplish, covered with minute uncinate bristles. Cactus Tuna, L. 
Of early introduetion from Mexico; very common on dry plains, as between Honolulu and Ewa. One of the cochineal-feeding species. The fruit is not unpleasant, but difficult to handle on account of its bristles, - Another species, without strong spines, probably 0 . tomentosa, also a cochineal-feeder, occurs here and there. Quite a number of other Cactaceae, species of Cereus, Echinocactus, Mamillaria, Phyllocactus and Pereskia are found in gardens, Cereus triangularis occasionally as an escape.

\section{ORDER XXXVIII. BEGONIACEAE.}

Flowers monoecious. Segments of perianth 2 to 8 , all colored, of which 2 or 3 are outer and 2 to 5 inner and often smaller, the latter occasionally wanting, or in Hillebrandia 5 sepals and 5 minute petals. Male fl. Stamens many on a convex torus, the filaments free or connate. Anthers continuous with the filaments, oblong, 2-celled, opening outward. No rudiment of ovary. Fem $\mathrm{fl}$. Stamens wanting, or in our genus replaced by minute staminodia. Ovary inferior, 1-celled, with 3 or 5 parietal placentas, but by prolongation of the placentiferous carpel-borders most frequently 3-celled. Ovules numerous, anatropous. Styles 3 to 5, free, or connate at the base, generally bifid. Capsule loculicidal, often winged. Seeds minute, with an areolate testa. Albumen generally wanting. Cotyledons very short; radicle terete. - Herbs or undershrubs, generally fleshy. Leaves alternate or rarely opposite, entire or divided and usually oblique, with stipules. Peduncles axillary, usually dichotomous.

About 350 species, in 3 genera, all but two belonging to the genus Begonia and distributed over the tropics of America, Asia and Africa.

\section{HILLEBRANDIA, Oliver.}

Male $f l$. Sepals 5, equal, ovate, acute. Petals 5, alternate with the sepals, minute, spathulate or cucullate. Stamens many, the filaments free, anthers erect, obtuse, the cells on the edges of a dilated connective. Fem. fl. Calyx-tube globose, adnate to the ovary, 5-lobed, the lobes like the male sepals. Petals as in the male flowers, and between them numerous minute filaments or stipitate globular bodies (staminodia). Ovary free at the apex, imperfectly 5-celled, with 5 bilamellate placentas projecting into the ovary. Styles 5, fleshy, persistent, opposite the calycine lobes, 2-forked, with the forks spirally stigmatose. Ovules numerous on the reflexed lamellae of the placentas. Capsule membranous, globose, not winged, opening at the apex by a broad hole between the styles. Seeds minute, ovoid, areolate. Albumen none. Embryo oblong, cotyledons short. - A succulent herb with alternate leaves and the habit of Begonia.

Only 1 species known, which is also the only representative of the Order in Polynesia.

1. H. Sandwicensis, Oliver, in Transact. Linn. Soc. XXV, 361, tab. 46. - Rhizome tuberous, the sparsely hairy or glabrate stems or branches 2-5 ft. high, dichotomous toward their ends. Leaves on long petioles 
of $2-5^{\prime}$, oblique, cordate, rounded in outline, $4-8^{\prime}$ in each diameter, irregularly 5-7-9-lobed, the lobes triangular, acute or obtuse, closely but irregularly serrulate, hispid all over with short papillose hairlets on the upper, along the veins only on the lower face. Stipules ovatecordate, $6^{\prime \prime}$. Peduncle from the axil of the uppermost leaf, $4-8^{\prime}$ long, forking into a cymose many-flowered corymb, bibracteate at each bifurcation, the bracts cordate to ovate, the lowest $4-6$ " long. Bracts, sepals, petals etc., bright pink- or rose-colored. Male and female flowers promiscuous, the latter generally median. Male $f l$. on shorter pedicels than the female. Sepals $3-4^{\prime \prime}$. Petals minute, spathulate, scarcely ${ }^{1 / 2}$ ". Stamens nearly as long as the sepals. Fem. fl. Pedicels $4-6^{\prime \prime}$, bibracteolate at or above the middle. Calycine lobes as long as the tube or longer, $3-4^{\prime \prime}$. Petals cucullate, ${ }^{1} / 2^{\prime \prime}$. Staminodia shorter. Capsule $4-6{ }^{\prime \prime}$ in diameter, free in the upper third or half, 1-celled at least in the upper portion. - Mrs. Sinclair, pl. 37.

Ka ua i! Hanalei and Waimea; Oahu! a single plant found in a gulch of the W. slope of Kaala; Molokai! pali of Pelekunu (3000 ft.); Maui! gulehes of Lahaina, Kanapali, Wailuku, Waiehu, Hamakua, generally in deep ravines or near waterfalls. Nat. names: *Puamakanuin (the big-eyed or showy flower), and "Akakasa "in Ka uai. The plant, when well developed, as on the pali of Pelekunu, is exceedingly showy and would attract attention if eultivated.

\section{ORDER XXXIX. UMBELLIFERAE.}

Calyx adnate to the ovary, generally with 5 small teeth. Petals 5, inserted round an epigynous disk, imbricate, very rarely valvate. Stamens 5 , alternate with the petals. Ovary inferior, 2-celled, with 1 pendulous ovule in each cell. Styles 2, with terminal stigmas. Fruit separating into 2 indehiscent dry carpels resembling seeds (called mericarps), usually leaving a filiform axis entire or split in two. Each carpel marked outside with 5 prominent ribs, and underneath their intervals (valleculae) or within the pericarp are often longitudinal oil-tubes (vittae). Embryo minute, in a hard albumen. - Herbs, rarely shrubs. Leaves alternate, often much divided, the petiole usually dilated at the base, but no real stipules. Flowers usually small, in terminal or lateral umbels, or sometimes reduced to heads, and often with one or more bracts forming an involucre at the base of the umbel.

A large Order, widely dispersed over the temperate regions of both hemispheres, particularly the northern, with few tropical species.

Umbels simple (several superposed); fruit laterally compressed.

Creeping or floating herbs

Umbels irregularly compound; flowers partly sessile in head-like umbellets; fruit ovoid, prickly

Umbels regularly compound:

Fruit dorsally compressed and margined, unarmed

Fruit terete, armed with barbed prickles:

Seed flat on the inner face

Seed coneave or furrowed

\section{Hydrocotyle.}

2. Sanicula.

3. Peucedanum.

4. Daucus.

5. Caucalis. 


\section{HYDROCOTYLE, L.}

Flowers in simple heads, umbels or whorls. Petals ovate, generally valvate in the bud. Fruit laterally compressed, orbicular, or broader than long; the carpels flat, placed edge to edge, with 1 or 2 prominent ribs on each side and without prominent calycine teeth. No oil-tubes. - Herbs, usually prostrate and creeping or aquatic. Leaves seldom divided, usually peltate or cordate.

About 70 species, spread over the whole globe, but chiefly the southern hemisphere. The genus has been placed among Araliaceae by some authors on account of the valvate aestivation of the petals.

1. H. verticillata, Thunberg, Diss. II. 415, tab. 3. - Stem slender, creeping, rooting at every joint. Leaves orbicular, $1-1^{1} / 2^{\prime}$ in diameter, crenate, 11-nerved, glabrous, peltate, on petioles of $3-4^{\prime}$. Peduncle about as long as the leaves, bearing 2 to 4 interrupted or superposed umbel-like whorls of flowers in its upper portion, each whorl with an involuere of $3-5$ short $\left({ }^{3} / 4^{\prime \prime}\right)$ ovate bracts, the pedicels $1^{1} / 2^{\prime \prime}$ long. Petals white, half the length of the ovary or more, acute, valrate. Fruit orbicular, with 1 (or 2 ) prominent ribs on each side of the carpels, $1-1^{1 / 2} 2^{\prime \prime}$ in diameter. - H. interrupta, Muehlenb. - Hook. \& Arn. in Bot. Beech. p. 84. - Gray, Bot. U. S. E. E. p. 692.

Common in ponds and along watereourses. A widely spread species, extending over North America and the W. Indies, Japan, Australia and the Cape of Good Hope.

H. Asiatica, $\mathrm{L}$, has also been noticed of late, distinguished by not peltate, reniform leaves and a single umbel or head with only 3 or 4 flowers.

\section{SANICULA, L.}

Flowers polygamo-monoecious. Calyx-teeth herbaceous, persistent. Petals slightly imbricate, their long points bent inwards and therefore apparently emarginate. Disk flat. Styles filiform. Fruit globular, the earpels not separating spontaneously, ribless, thickly covered with hooked prickles, each with 5 oil-tubes. Seed almost terete. - Perennial herbs with palmately lobed or dissected leaves, those from the root on long petioles. Umbels irregularly compound, the flowers capitate in the umbellets. Involuere and involucels few-leaved.

About 12 species, 9 of them North-Ameriean ( 7 Californian), 1 European, 1 belonging to the Azores and 1 to the Hawaiian Islands.

1. S. Sandwicensis, Gray, Bot. U. S. E. Exp. p. 705, pl. 88. - Root fusiform, perpendicular, $6-10^{\prime}$ long. Stem $10-18^{\prime}$ high. Leaves glabrous, rounded in outline, those from the base $2-4^{\prime}$ in diameter, palmately $3-5$ lobed or parted even to the petiole, the cuneate segments again deeply 3-5-cleft or dissected, the lobules or laciniae sharply serrate with aristate teeth. Petioles clasping, those of the basal leaves $6-12^{\prime}$, the uppermost stem- or branch-leaves sessile and passing into the two-leaved involucre. Umbels irregularly twice or thrice compound, the $3-5$ rays unequal, 
exceeding their involucres, those supporting the umbellets $6-12^{\prime \prime}$ long. Umbellets $2^{1} / 2^{\prime \prime}$ in diameter, exceeding the lanceolate entire divisions of the involucel, globose, many-flowered, often proliferous. Flowers yellow, the sterile ones shortly pedicellate and exterior, the fertile ones $(2-4$ only) sessile, their filiform styles exserted and recurved. Fruit ovoid, $2^{\prime \prime}$ long, bristling with stout hooked prickles.

Hawaii and East Maui! at altitudes of 6000-8000 ft. Comes near S. Menziesii, H. \& A, from California and Oregon.

$\beta$ var. Leaves much less deeply cut, and larger, those from the base $4-5^{\prime}$ in diameter, lobed only, the lobes not divided.

Summit of Mt. Eeka! M a ui.

\section{PEUCEDANUM, L.}

Flowers often polygamous. Calyx-teeth obsolete or small. Petals obovate or cuneate, with the apex inflected, apparently emarginate. Fruit oblong or orbicular, strongly compressed dorsally, the 3 dorsal ribs filiform or slightly prominent, the lateral ones of both carpels expanded and connate in a single thin and sharp wing which only splits at maturity. Oil-tubes generally 1 , but sometimes 2 to 4 in the intervals of the ribs. Seeds flat on the inner face. - Herbs, rarely shrubs or trees. Leaves once or several times pinnatisect or trisect. Umbels compound, terminal, with or without involucre, the involucels many-leaved.

A large genus distributed over the whole northern hemisphere, the Andes of tropical America and over tropical and southern Africa. No species were hitherto known from the Polynesian islands.

Oil-tubes several to each vallecula :

Ultimate divisions of leaves obliquely ovate

Ultimate divisions cuneate or truncate at the base

1. $P$. Sandwicense.

Oil-tubes single in each valiecula; divisions of leaf filiform

2. $P$. Kauaiense.

3. P. graveolens.

1. P. Sandwicense, sp. n. - A perennial with a tuberous rhizome. Stem glabrous, striate, hollow, $1-2 \mathrm{ft}$. high. Leaves glabrous and glaucous, the basal ones thrice pinnate or pinnatisect, with $2-4$ pairs of pinnae, $2 \mathrm{ft}$. long, with a clasping petiole of $1 \mathrm{ft}$., the lowest pinnae $10^{\prime}$ long, the ultimate lobes or pinnules obliquely ovate or ovate-lanceolate, $1^{1 / 2}-4^{\prime}$, serrulate; the upper stem-leaves simply pinnate or 3-lobed. Flowers yellow, polygamous, the fertile ones on a terminal peduncle of $4-6$. Involucral leaves many, linear-lanceolate, $3^{\prime \prime}$ long, soon caducous. Rays $20-25$, each $2-2^{1} / 2^{\prime}$ long. Involucel-leaves $1^{1} / 2^{\prime \prime}$. Raylets about 20 , each $3-4$ " long when with fruit. Petals equal, ovate, 1 ", acuminate, inflected. Calycine teeth ${ }^{1} / 3$ as long. Disk crenate. Styles short from a conical base, with truncate stigmas, moderately declinate, $1 / 2 "$. Fruit ovato-oblong, $4-5^{\prime \prime} \times 3-3^{1 / 2} 2^{\prime \prime}$, each wing ${ }^{1 / 3}$ the entire width, sharp and entire until dehiscence, the carpels almost flat, the 3 dorsal ribs filiform and equidistant, the intervals filled up to their level. Oil-tubes 
small, 2-3 under each vallecula and $4-8$ on the commissural face. Seed flat on the inner side, with 3 low ridges on the outer, closely surrounded by the endocarp. Carpophore splitting to the base, its divisions filiform. Sterile flowers mostly in smaller umbels which rise from short axillary shoots of the 2 or 3 uppermost leaves. Stamens longer than the petals. Styles short, erect.

Molokai! Koolaupapa and Waikolu. Nat. name: "Makou. The root is used by the natives as a medieine in some diseases of children.

$\beta$ var. Leaves thin, the lateral leaflets broader, almost orbicular, the terminal obovate, tricuspid.

Mani! ridges of Wailuku and Waiehu.

In placing this and the following species under Peucedanum I have been guided more by geographical than technical considerations. While the greater number of vittae, $2-4$ for each vallecule, points strongly toward Ferula, the oceurrence on our Islands of plants belonging to a genus which, under present limitation, is confined to Europe, northern Africa'and western Asia, would be a great anomaly. On the other hand, as some American species of Peucedanum, as $P$. foeniculaceum, Nutt., and $P$. dasyearpum, Torr. \& Gray, have $2-3$ vittae to a vallecule, and again Ferula asafoetida and $F$. communis are often found with a single one, our new species may help to efface completely the already indistinct boundary line beetween the two genera and to merge Ferula into Peucedanum. From the N. American Leptotaenia, Nutt., which Gray and Watson (Bot. Calif. I, 271) unite with Ferula, our plants differ in the thin and sharp wings of the fruit.

2. P. Kauaiense, sp. n. - Ultimate divisions of leaves larger, rhomboidal with a cuneate base, or deltoid with a truncate base, often broader than high, 4' broad above the base, sharply and deeply serrate. Involucral bracts linear, $6 "$; those of the involucel $3 "$. Rays and raylets $30-35$, the latter $4-6^{\prime \prime}$ long. Calycine teeth $1 / 3-1 / 2$ the length of the ovary. Styles twice as long as in the former species. Fruit $7^{\prime \prime} \times 3-3^{1 / 2} 2^{\prime \prime}$, the ribs partly buried under the suberous tissue which fills up the vallecules. Oil-tubes $3-4$ to each vallecule and about 12 on the commissural side.

Ka uai! mountains of Waimea (Knudsen).

†3. P. graveolens, Benth. \& Hook. Gen. Plant. I, 919. - An annual, 2-4 ft. high. Stem striate. Leaves 3 or 4 times pinnatisect, the ultimate segments linear or filiform. Petiole dilated, but not clasping; the sheath margined with a scarious wing and ending above in two auricles. Involucre and involucel wanting. Calyx-teeth obsolete. Petals strongly involute, yellow. Fruit elliptical, $2-3^{\prime \prime}$ long, with rather eonvex faces and the 3 dorsal ribs somewhat prominent, the wings less than ${ }^{1 / 4}$ of its width. Oil-tubes 1 in each vallecule. - Anethum graveolens, L.

The Dill, of Mediterranean origin, must have come to the Islands early in this century, for it has become a common weed in many parts, particularly on E. Ma ui.

\section{DAUCUS, Tourn.}

Calyx 5-toothed. Petals inflected, emarginate, often radiant (the outer ones longest). Disk flat. Fruit ovoid or oblong, the carpels scarcely Hillebrand, Flora of the Hawaiian Islands. 
compressed on the back, with 5 primary slender bristly ribs, 2 of them on the inner face, and besides with 4 equal, more or less winged, secondary ribs, each bearing a single row of larger barbed prickles; oil-tube 1 under each secondary rib. Seed flat on the inner face. - Biennial herbs with finely $2-3$-pinnate or pinnatisect leaves, foliaceous involucres and compound concave umbels.

About 30 species, chiefly natives of the old World, one of them the common Carrot, D. Carota.

1. D. pusillus, Michx. F7. Bor. Amer. I, 164. - Stem about $1 \mathrm{ft}$. high, retrorsely hispid. Leaves hispid, 3 or 4 times pinnatisect, the ultimate divisions linear-spathulate, acute. Involucre leaf-like, equalling the umbel. Rays $6-9^{\prime \prime}$; raylets $3^{\prime \prime}$. Bracts of involucel linear or forked, equalling the raylets. Petals creamcolored. Fruit $1^{1 / 2}-2^{\prime \prime}$ long, the barbed prickles equalling or exceeding the width of the fruit, the bristles of the primary ribs much shorter and in two rows. - Gray, Bot. U. S. E. E. p. 711. - Fl. Calif. I, 272.

On all islands at elevations of $2000-6000 \mathrm{ft}$., most common on Haleakala, but oceasionally descending much lower down, as to Diamond Hill near Honolulu. The plant belongs to the W. Coast of $\mathbf{N}$. America, from Nootka Sound to Mexico, extending thence to the Southern States, and has also been found in Patagonia; but it undoubtedly was at the Islands before the Discovery, for it chiefly grows in wild uninhabited mountain regions.

\section{- 5. CAUCALIS, L.}

Calyx 5-toothed. Petals obovate, inflected, the exterior ones radiating, bifid. Disk conical. Fruit ovate, somewhat compressed laterally, constricted at the commissure. Carpels almost terete, the 5 primary ribs filiform, shortly setose, the 2 lateral ones facing the commissure; the 4 secondary ribs prominent and beset with barbed prickles. Oil-tubes 1 under each secondary rib and 2 on the commissural face. Seed concave or channelled. - Annuals with multifid leaves. Involucre wanting or consisting of 1 or 2 bracts. Involuce] of $3-8$ lanceolate bractlets. Flowers white.

A small Mediterranean genus.

$\dagger$ 1. C. daucoides, $L$. - Stem 6-12' high, glabrous. Ultimate segments of leaves linear, acute. Umbels opposite the leaves, on a peduncle of $3^{\prime \prime}$, with 4-6 rays of $4^{\prime \prime}$ and as many raylets of $2^{\prime \prime}$ in length. Bracts of involucel linear, serrate, nearly as long as the raylets, Fruit ovoid, 1", with short ereet styles. Barbed prickles in one row, subulate, as long as the fruit is broad.

Ka u a I! in cultivated fields of Waimea (Kn.). A European weed of recent introduction.

\section{ORdER XL. ARALIACEAE.}

Calyx adnate to the ovary, either entirely so or showing a minute border round the summit, with as many teeth as petals. Petals usually 
5 or 4 , rarely more, valvate or rarely imbricate in the bud, inserted generally with a broad base round an epigynous annular disk. Stamens as many, alternating with the petals, or once or several times as many, the anthers affixed at the back, introrse, 2-celled, with cells dehiscing lengthwise. Ovary entirely or in part inferior, 5- or 2- to many-celled, with 1 pendulous anatropous ovule in each cell. Styles as many as cells, usually short and often united into one, or reduced to a small cone, stigmatose at the top or along the inner face. Fruit not readily separating into carpels, indehiscent and usually succulent. Embryo minute, next the hilum in a fleshy albumen. - Trees, shrubs or climbers, rarely herbs, with simple or compound, mostly alternate leaves. Flowers usually small, in heads or umbels or racemes, which are either solitary or arranged in compound umbels or panicles.

A considerable Order, chiefly tropieal, with a very few species extending into more temperate regions, represented in Polynesia by the genera Panax, Nothopanax, Heptapleurum, Seleeflera, Plerandra, Meryta, besides those following.

Leaves digitate, opposite; pedicels articulate .

1. Cheirodendron.

Leaves pinnate, alternate; pedicels not articulate with the calyx:

Leaflets entire; petals $5-8$ :

Leaflets 13-21; flowers racemoso-umbellate, arranged in a panicle; stamens as many as petals; cells of ovary as many or fewer; drupe ovoid, with conical vertex, and partly naked (superior) Leaflets 5-13; the entire drupe connate with the calyx (inferior): Inflor. umbellate; stamens as many as petals or twice or three times as many; cells of ovary as many as petals or fewer; drupe eylindrieal or ovoid, angular

2. Pterotropia.

Inflor, umbellate or racemoso-umbellate and paniculate; stamens 4 to 6 times as many as petals; cells of ovary more numerous than the petals; drupe globose, truncate, ribbed

Leaflets sinuato-crenate; petals $8-10$.

\section{Triplasandra.}

4. Tetraplasandra.

5. Reynoldsia.

\section{CHEIRODENDRON, Nuttall, Seem.}

Calyx-border short, 5-toothed. Petals 5, triangular, valvate. Stamens 5, shorter than the petals, with subulate filaments and ovoid anthers. Ovary 5-2-celled. Stigmas sessile on a conical elevation of the disk or apical on a thick and short style. Fruit globose, subtruncate, ribbed when dry, the exocarp somewhat fleshy. Pyrenae laterally compressed, coriaceous. Albumen even, not wrinkled, fleshy to horny. - Unarmed, glabrous trees with opposite digitate leaves, the leaflets generally toothed. Stipules none. Flowers umbellate on the ultimate divisions of a terminal or lateral panicle with opposite horizontal branches which are articulate at all nodes and below the calyx. Bracts minute, opposite, subconnate, forming a continuous involucel round the umbel and a $4-5$-toothed calyculus at the base of the calyx, their teeth soon deciduous.

A Hawailan genus, nearest related to Pseudopanax, Koch, which is represented in Chili, New-Zealand and the Samoa. Islands, differing from it in the opposite leaves and branches of panicle, the meiomerous ovary and probably also in the presence of a connate involucel and ealyculus. - Both species emit a strong carroty scent. 
Leaves longer than broad; stigmas mostly 3 . Leaves broader than long; stigmas mostly 5 .

1. C. Gaudichaudii.

2. C. platyphyllum.

1. C. Gaudichaudii, Seem. Journ. Bot. V, 236. - A tree, $30-50 \mathrm{ft}$. high. Leaflets 3 or 5 , the outer ones smaller, petioled, ovate, oblong or obovate, the margin generally thickened and appressedly toothed or serrulate, with a gland in the notch of the tooth or serrature, or nearly entire, chartaceous to coriaceous, quite glabrous, shining above. Panicle subpyramidal, shorter than the leaves, compact, with $4-5$ nodes to the rhachis. Flowers $2^{\prime \prime}$, greenish. Pedicels $1^{\prime \prime}$. Petals thick, ovate, spreading, $1-1^{1 / 2}{ }^{\prime \prime}$, soon caducous. Stamens nearly as long. Ovary generally 3-celled, or 2or 4-celled, rarely 5-celled. Stigmas short and thick, recurved, sessile or subsessile on a short stylopod. Drupe ovoid, 3 "long, 2-5-angled when dry. - Aralia trigyna, Gaud. in Bot. Freyc. p. 474, tab. 98. - Panax Gaudichaudii, Hook. \& Arn. in Bot. Beech. p. 84; DC. Prod. IV, 253. Hedera Gaudichaudii, Gray, in Bot. U. S. E. E. p. 719, pl. 90.

On all islands, not uncommon in forests between 2000 and $4000 \mathrm{ft}$. Called o Olápas and *Mahus (Molokai) by the natives, who know how to prepare a blue dye from the bark or leaves. The following forms are to be distinguished:

c. Leaflets as often 5 as 3 , ovate-oblong, $3-4^{1 / 2^{\prime}} \times 1^{1 / 2}-2^{\prime}$, somewhat obtuse, deeply crenate or appressedly serrate, on petioles of $9-12^{\prime \prime}$, the common petiole $2-2^{1}{ }^{1} 2^{\prime}$. Panicle short, $1^{1 / 2}-2^{1} / 2^{\prime}$ long, compact. Umbellets $9-12$-flowered. Styles generally 3 , rarely 2 or 4 . - Gand. l. e. tab. 98.

E. Maui! and Hawaii!

$\beta$. Leaflets generally 3 , rarely 5 , ovate or suborbicular, suddenly acuminate, even eaudate, remotely but sharply dentate or serrate with long incurved teeth, $3-3^{1} / 2^{\prime} \times 2-2^{1 / 2} 2^{\prime}$, on petioles of $1^{1 / 4}-1^{1 / 2^{\prime}}$, the common petioles very long, $3-4^{\prime}$. Panicles large, $3-4^{\prime}$ long; the umbellets $4-5$ flowered. Stigmas 3 or 2.

W. Maui! Molokai! Hawaii! Kohala range.

$\gamma$. Leaflets 3, rarely 5, generally obovate or rounded, even emarginate, remotely and faintly dentate, on petioles of $8-15^{\prime \prime}$; the common petiole $1^{1 / 2}-2^{1 / 2}$. Panicle drawn out, pedunculate, the umbellets $7-8$-flowered. Stigmas 3 or 2 .

Main range of $\mathrm{O}$ a hu!

b. Leaflets 3 , broadly ovate, $2^{1 / 2}-4^{1 / 2^{\prime}} \times 1^{3} / 4-3^{\prime}$, obtuse or shortly acuminate, entire, the common petiole $3-4^{1} / 2^{\prime}$. Panicle large and open, with $5-6$ flowers to an umbellet. Styles 3,4 or 5. - Panax ovatum, H. \& A. I. c.

Oahu! Mt. Kaala; Niihau (Lay \& Collie).

ะ. Leaflets subentire, smaller, membranous, the common petiole $2-2^{1 / 2}$. Styles 2-5.

Kaui! 
2. C. platyphyllum, Seem. l. c. - A smaller tree, quite glabrous. Leaflets 3 , ovate, broader than long, $2-2^{1} / 2^{\prime} \times 2^{1 / 2}-3^{1} / 2^{\prime}$, mucronate or suddenly and shortly acuminate, truncate at the base, entire or shortly dentate, with thickened margin, coriaceous and shining, on long spreading petioles of $1^{3 / 4}-2^{\prime}$, the common petioles $2^{1 / 2}-4^{\prime}$. Panicles single or 3 together, very open, $4-6^{\prime}$ long, pedunculate. Umbellets 5 or 6 -flowered, the pedicels 1-3". Flowers 3". Stigmas 5, rarely 4, incurved or truncate, triangular on a very short and thick stylopod. Drupe subglobose, $3-3^{1 / 2} / 2^{\prime \prime}$ in diameter, 5- or 4-angled when dry. - Panax platyphyllum, H. \& A. 1. c. - Hedera platyphylla, Gray, 1. c. p. 720, pl. 91.

On the two highest peaks of $\mathrm{Oahu}$, Konahuanui! and Kaala! $3000-4000 \mathrm{ft}$. above the sea.

\section{PTEROTROPIA, gen. nov.}

Flowers hermaphrodite. Calyx-border slightly prominent and repandly dentate. Petals 5-7-9, triangular, valvate, thick, uncinate at the apex, cohering or finally spreading. Stamens as many as petals and shorter, the ovoid introrse anthers inserted above the base on short complanate filaments. Disk convex. Ovary 5-2-celled, more or less free, or naked. Stigmas sessile on the top of the conical vertex, which is drawn out into a short stylopod when the stigmas number 4 or 5 . Drupe somewhat suceulent, globose or ovoid, with conical apex, round, not angular, ringed above or below the middle by the calycine border and naked above. Pyrenae with a thin endocarp, searcely separable, ovoid or slightly compressed, with a broad back and a prominent ridge on either side. Seeds with a ventral ridge or almost cylindrical, the albumen fleshy and even, the superior radicle fusiform, twice as thick and long as the minute cotyledons. - Trees with a glutinous sap. Leaves alternate, with clasping petioles without stipules, impari-pinnate with $13-21$ entire leaflets and generally furfuraceous with a scattering scaly or stellate pubescence, the hairlets single-celled. Inflorescence terminal and lateral, the flowers umbellate-racemose on the umbellate-racemose branches of a panicle with a short rhachis, not articulate at the nodes and continuous with the ealyx. Bracts minute, triangular subulate, early deciduous. - The petiole of the terminal leaflet articulate when more than three times the length of the lateral ones.

A genus of 3 Hawaiian species, in many respects like Heptapleurum, Gaertn., distin. guished by the pinnate leaves, the meiomerous ovary and the partly naked drupe. Two of the following species were described by $\mathrm{H}$. Mann and by him placed under the genus Heptapleurum, in which however, he adds, they would form a marked section, to which he gave the name here adopted for the new genus. This name is certainly preferable to the later one of Dipanax, applied by Seeman to our second species on no other ground than because its ovary is often 2-celled; an artificial principle which obliged him to separate from the same its near congener $P$. Kauaiensis, which he assigned to Miquel's genus Agalma. 
A repeated review of our Araliads has led me to regard the present and the two following genera as a continuous series, in which it is impossible to draw unimpeachable lines of division, and I should not have hesitated to unite them all in a single genus if I could have drawn up a definition sufficiently definite to distinguish it from other Araliaceous genera. The difficulty of accomplishing this will become apparent when we consider that we should have to crowd into one genus forms with simply umbellate and subracemose-paniculate inflorescences, - flowers with 5 to $9(-10)$ petals, in which the stamens equal the petals in number or present a two- to six-fold multiple - ovaries, with 2 to 13 cells, - drupes almost free from the calyx and such as are entirely inferior - drupes globose, ovoid and cylindrical, - such as are round, ribbed and angular, truncate at the apex and conical, - with stigmas sessile and raised on a short style. The last two characters which have been considered by some writers of sufficient importance for generic distinction, even now remain combined not only in one genus, but even in a single species, where an elongation of the ovarian apex to a style seems to go parallel with an increase in the number of stigmas. In fact, the only constant character, which runs through the whole series lies in the pinnate division of the leaves, and this, again, is one which in this Order has appeared irrelevant to some systematists. Even Reynoldsia, with isomerous petals, stamens and ovaries, but all in twice the typical number, may fairly be added as a collateral branch to our group. Leaves cordate at the base; drupe ringed about the middle or above $1 . P$. dipyrena.

Leaves rounded at the base:

Drupe ringed about the middle or below

Drupe ringed at the base

2. P. Kauaiensis.

3. P. gymnocarpa.

1. P. dipyrena, Hillebr. -- A small tree, $12-20 \mathrm{ft}$. high, sparingly branching, the young branches mealy, as is the entire inflorescence, including calyx and corolla, with small grayish scalelets which bear short and stiff 1-celled hairs. Leaves $1-2 \mathrm{ft}$. long, with $13-15$ leaflets, these ovate to ovate-oblong, $3-6^{\prime} \times 2^{1 / 2}-3^{\prime}$, on petioles of $3-6^{\prime \prime}$, acuminate cordate at the base, coriaceous, glabrous above, furfuraceous below. Panicle large and ample, its 5 primary branches $8-12^{\prime}$ long, mostly alternate on a common rhachis of $2-3^{\prime}$, the secondary branches $1-2^{\prime}$, mostly alternate, the flowers racemose and subumbellate on pedicels of $3-4^{\prime \prime}$. Bracts short triangular, $1^{\prime \prime}$. Calyx $1 / 2-3 / 4^{\prime \prime}$. Petals $6-7$, greenish, cohering, but free at last, $2-3^{\prime \prime}$ long, lanceolate from a broad emarginate base. Stamens accumbent on the ovary, which is free (superior) in its upper half. Drupe ovoid, 6 " long, ringed with the calyx-border at the middle or above. Stigmas 3 , or 2 or 4 , sessile and discreet on the conical disk or slightly raised. Pyrenae coriaceous, inseparable. - Heptapleurum dipyrenum, H. Mann, Enum. no. 155. - Dipanax Mannii, Seem. Journ. Bot. VI, 141.

Lanai! on the highest ridge; E. Ma ui! S. slope of Haleakala, $3000-4000 \mathrm{ft}$. (Lydg.); Hawail! Kawaihae iuka. - The Maui form has more elongate and furfuraceous leavies than the others.

2. P. Kauaiensis, Hillebr. - A tree $30-50 \mathrm{ft}$. high, the smooth trunk erect and sparingly dividing at the end into ascending branches, the young shoots and inflorescence tomentose with fawn-colored stellate scales as before. Leaves $1^{1 / 2-2} \mathrm{ft}$. Leaflets $13-21$, ovate-oblong, $4-8^{i} \times 1^{1 / 2}-$ $2^{1 / 2}$, on petioles of $3-4^{\prime \prime}$, acuminate, rounded at the base, chartaceous to coriaceous, sprinkled above but densely tomentose underneath. Panicle as before. Petals $6-7$, rarely 9 , tomentose, $2^{1 / 2}-3^{\prime \prime}$. Ovary generally 
4-celled, or 3-5-celled. Stigmas on a distinct stylopod of less than $1^{\prime \prime}$. Drupe ovoid, $5-6^{\prime \prime}$, ringed at or below the middle, the pyrenae chartaceous. - Heptapleurum Kauaiense, Mann. - Agalma Kauaiense, Seem.

Kauai! mountains of Waimea (Mann, Kn.).

$\beta$ var. Leaves thin, glabrous above, sprinkled underneath. Panicle very large, the common rhachis often $1 \mathrm{ft}$. in length. Flowers half the size of those of a. Stylopod shorter, disappears with the growth of the drupe, so that the stigmas appear sessile on the conical apex.

oahu! Kaala and w. end of the main range.

3. P. gymnocarpa, $s p \cdot n$. - A small tree, $12-15 \mathrm{ft}$. high, only the youngest shoots mealy, otherwise glabrous. Leaves $1 \mathrm{ft}$. long or more. Leaflets $15-17$, ovate-oblong, $3-4^{\prime} \times 1-1^{1 / 4^{\prime}}$, on petioles of $2-3^{\prime \prime}$, obtuse or obliquely acuminate, with rounded base, ehartaceous to coriaceous, glabrous underneath, shining above. Rhachis of paniele very short, $1-2^{\prime}$, with 3 to 5 umbellately radiating primary branches of $8-9^{\prime}$, the flowers about 12 in an umbel at the ends of racemose and umbellate secondary branches of $1-2^{\prime}$, on pedicels of $4-5^{\prime \prime}$. Calyx very short, with a loose undulating border. Petals 6 , rarely 7 , cohering at the apex, $2^{\prime \prime}$. Ovary 3-celled. Stigmas sessile. Drupe globose, $5 "$ in diameter, almost entirely free and naked, the adherent calyx forming a low disk at its base. Pyrenae thin papery, ovoid, beaked above and faintly notched below the beak. - Bracteal scars cover the upper portions of both primary and secondary rays.

Oahu! valley of Niu (Lydg.).

\section{TRIPLASANDRA, Seem.}

Petals 5-8. Stamens as many as petals or two or three times as many. Ovary 5-2-(6-)elled, quite inferior. Drupe not succulent, ovateelongate or cylindrical, angular or compressed, the $5-2(-6)$ reniform stigmas sessile on the conical vertex or raised on a short stylopod; the pyrenae compressed, with a prominent ridge on either side, the endocarp thin chartaceous. - Small glabrous trees or shrubs with alternate imparipinnate leaves and $5-13$ folioles, the terminal petiolule articulate when more than 3 times the length of the lateral ones. Flowers in a simple or compound umbel, the umbel in the bud involucrate by discreet, broad ovate, soon deciduous bracts. Otherwise as in Pterotropia.

\section{Stamens as many as petals}

Stamens two or three times as many:

Drupe ovoid, with conical vertex .

Drupe cylindrical, truneate:

Stamens 10-15; ovary 5-6-eelled

Stamens $12-18$; ovary 4 -3-celled

The var. $\alpha$ of no. 1 , and no. 2 , with broad exserted eonical vertex, form a fit transition from Pterotropia, while nos. 3 and 4 , with multiple stamens and an occasionally pleiomerous ovary, lead into Tetraplasandra.

1. T. meiandra.

2. T. Lydgatei.

3. T. Oahuensis.

4. T. Kahuensis
4. Talae.

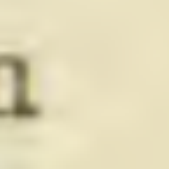


1. T. meiandra, Hillebr. - A small glabrous tree, branching from near the base. Leaves $1-1^{1 / 2} \mathrm{ft}$. long, the petiole dilated at the base and clasping. Leaflets $7-13$. Inflorescence umbellate but variable: either the pedicels at the ends of $3-5$ terminal peduncles (simply umbellate), or at the ends of rays which proceed from the ends of $3-5$ peduncles, and rarely the peduncles united at the base by a common rhachis (compoundly umbellate). Bracts broadly ovate, $2-4^{\prime \prime}$ long, some empty along the rays or peduncles, caducous long before the flowers expand. Calyx cylindrical, with a short repand-denticulate border. Petals $5-8$, triangularlanceolate. Stamens as many and shorter. Ovary 2-5-celled. Stigmas $2-5$, sessile on the conical vertex, or, when 4 or 5 , raised on a short stylopod. Drupe cylindrical, angular when dry.

Under this collective species I have united the following forms, which are all exceedingly rare, each corresponding to a single or a few individuals, found in closely circumscribed localities.

† Stigmas 2, rarely 3.

a. $7-13$ leaflets, $3-4^{\prime} \times 1^{1 / 1} 2^{\prime}$, ovate or oblong, somewhat acute, contracted below, coriaceous, the lateral ones on petioles of $1^{1 / 2} 2^{\prime}$. Inflorescence compoundly umbellate: $3-5$ peduncles of $7-10^{4}$ (occasionally emitting a lateral ray) umbellate at the apex with $12-14$ rays of $1-2^{\prime}$, each bearing an umbellet of $10-12$ pedicels of $3-4^{\prime \prime}$. Drupe narrow-elongate, compressed, 6 "long, the 2 stigmas sessile on the broad conical exserted vertex. - Heptapleurum Waimeae, Wawra, in Flora, 1873, p. 159.

Wawra's specific name is wrong; his specimens were collected during a joint excursion with the author upon the western ridge of Nuranu, Oahu.

$\beta$. 7-9 leaflets, $5-7^{\prime} \times 2-3^{\prime}$, ovate, bluntly acuminate, with broad or contracting base, chartaceous. Inflor. compound-umbellate, as in $\alpha$. Bracts 2". Petals and stamens 5. Stigmas 2, sometimes 3, sessile on the slightly raised vertex of an ovoid compressed or 3-angled drupe of $4^{\prime \prime}$ in height. In one specimen the 5 peduncles stand at the end of a common rhachis of $6-7$ '

Oahu, Makaleha!

$\gamma .11$ leaflets, $3-3^{1 / 2^{t}} \times 1^{1 / 4}-1^{1 / 2^{\prime}}$, oblong, obtuse at both ends, thick chartaceous, the lateral ones on petioles of $1^{1 / 2} 2^{\prime}$. Infl. compound-umbellate, the rays $2-3^{\prime}$, the $15-25$ pedicels $6^{\prime \prime}$. Petals and stamens $5-8$. Stigmas $2-3$, sessile.

Hawaii, Kawaihae iuka! Height $12-20 \mathrm{ft}$.

† 3 (4) stigmas.

j. $7-9$ leaflets, $3-4^{\prime} \times 2-3^{\prime}$, ovate and obtuse at both ends to suborbicular, coriaceous, the lateral ones on petioles of $4-9^{\prime \prime}$ and unsymmetrical at the base. Inflor. compound-umbellate, the $3-5$ peduncles $3-6^{\prime}$, the $8-10$ rays $1^{1 / 2}-2^{1} / 2^{\prime}$, the $8-12$ pedicels $4-6^{\prime \prime}$. Calyx $2^{1 / 2^{\prime \prime}}$, 
obconical, with distinct limb. Petals and stamens $5-7$, the former 2 " long. Stigmas $3-4$, sessile.

Oahu! Wailupe; Molokai! Maunahui; and the same form with smaller leaves on shorter petioles from $\mathrm{L}$ anai! Height $8-12 \mathrm{ft}$.

†ो 3-4-5 stigmas.

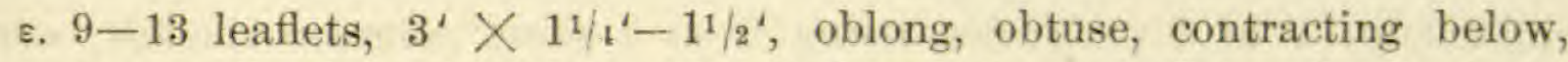
coriaceous, the lateral petioles $3^{\prime \prime}$. Infl. simply umbellate, the $3-5$ peduncles $6-7^{\prime}$, the $15-20$ pedicels $7-9^{\prime \prime}$. Drupe $4-5^{\prime \prime}$, with $3-5$, but mostly 4 stigmas on a conical disk contracted to a short stylopod.

Oahu, Niu!

†ों 4-5-6 stigmas.

५. As $\varepsilon$, but the leaflets larger, $4-6^{\prime}$ long. Infl. both simply and compoundly umbellate, the peduncles $4-7^{\prime}$, bearing at their apices an umbel of $15-20$ pedicels or of rays which are again umbellate, the pedicels of the mature fruit $10-12^{\prime \prime}$. Drupe ovoid truncate, $5 "$, with 5, 4 or 6 stigmas on a short stylopod.

Hawaii, woods of Hilo! (Lydg.).

2. T. Lydgatei, $s p . n$. - A small tree, quite glabrous. Leaves $8-12$ ' long. Leaflets $5-9$, on petioles of $4-8^{\prime \prime}$, oblong, $3-3^{1} / 2^{1} \times 1-1^{1} / 2^{4}$, obtuse and slightly emarginate, contracting at the base, thin chartaceous. Infl. compound-umbellate from a short common rhachis of ${ }^{1} / 2^{\prime}$, the 4 or 5 slender peduncles bearing umbels of about 12 slender pedicels of $8-9^{\prime \prime}$. Calyx broad obconical, $2^{1} / 2^{\prime \prime}$, with undulating border. Petals 5 , cohering at their apices, $3^{\prime \prime}$. Stamens 12 , about $1 / 3$ shorter, with straight or recurved anthers. Ovary 4-celled, inferior, the disk slightly raised, with sessile stigmas. Drupe ovoid-globose, $4-5^{\text {" }}$ in diameter, obtusely 4 -angled, the short conical apex finally elongated into a short stylopod.

Oahu, Wailupe! (Lydgate). In habit of plant and shape of fruit much like Pterotropia gymnocarpa, which grows in the neighboring valley of Niu.

3. T. Oahuensis, Seem. Journ. Bot. VI, 139. - A small tree. Leaves about $1 \mathrm{ft}$. long. Leaflets $7-13$, ovate or broad oblong, $2^{1 / 2} 2^{1}-3^{1 / 2} \times$ $1^{1}{ }^{14}-2^{\prime}$, on petioles of $1^{1 / 2}-3^{\prime \prime}$, obtuse, coriaceous, glabrous. Inflor. compound-umbellate: $3-5$ peduncles, $2-3$ ' long, either free or united on a short rhachis of less than $1 / 2^{4}$, each bearing an umbel of $16-20$ pedicels "of $6 "$ in length. Calyx cylindrical, $2-3^{\prime \prime}$. Petals 5-6, about $3^{\prime \prime}$ long. Stamens $10-15$, half as long as the petals, with recurved anthers. Ovary 5-6-celled. Drupe ovoid or short cylindrical, 3-4", inferior, 5 -6-ribbed or angled, truncate, the stigmas on a short stylopod. Gastonia

Oahuensis, Gray, Bot. U. S. E. E. p. 726 .

Oahu! on the slopes of Waiolani and Konahuanui.

$\beta$. The peduncles $5-6$. Leaves oblong, contracted at the base. Oahu, Niu! 
4. T. Kaalae, sp. n. - A small tree of $12-16 \mathrm{ft}$, glabrous, the ultimate branches slightly furfuraceous. Leaves about $1 \mathrm{ft}$. long, with widely clasping base. Leaflets $7-11$, ovate or ovate-oblong, $3-4^{\prime} \times 2-3^{\prime}$, on petioles of $6-12$, obtusely acuminate, rounded and unsymmetrical at the base, thick coriaceous, glabrous underneath, dark-green. Inflor. thrice umbellate: 3 to 5 peduncles rising from a short common rhachis, each $1^{1 / 2}-2^{1 / 2} 2^{\prime}$ long, with an umbel of about 12 rays of $1-1^{1} / 2^{\prime}$, these again umbellate with $10-12$ pedicels of $4-6^{\prime \prime}$. Calyx obconical, glabrous, $1^{\prime \prime}$. Petals 6, expanded at last, $3-4^{\prime \prime}$. Stamens three times that number or less, 18-12. Ovary 4-, rarely 3-celled. Stigmas sessile on the conical apex.

Oahu! on the top of Mt. Kaala, $4000 \mathrm{ft}$. Almost like $\delta$ of no. 1, excepting the multiple stamens.

\section{TETRAPLASANDRA, Gray.}

Flowers hermaphrodite. Calyx-border prominent, truncate or wavy. Petals 5-8, epigynous, with a broad base, valvate, coherent or expanded. Stamens shorter, 4 to 6 times as many, in 1 to 3 circles, inserted round a broad annular disk, with thick filaments and sagittate anthers. Ovary 7-13-celled, the stigmas subsessile or on a short style. Drupe inferior, not fleshy, globose or ovoid, with truncate vertex, ribbed when dry; the pyrenae compressed, beaked and notched at the apex, with 2 ridges on either side. Seeds flat, with a thin albumen. Embryo minute, the thick superior radicle smaller than the ovate cotyledons. - Unarmed glutinous trees with alternate impari-pinnate clasping leaves and entire leaflets. Stipules wanting. Inflorescence both paniculate, with racemoso-umbellate flowers, and umbellate. Pedicels not articulate with the calyx. Bracts small.

A genus of 2 or perhaps 3 species, the third growing on the Sunda Islands and in New Guinea. Stamens 3 to 4 times as many as petals; inflor. paniculate; leaves
tomentose underneath.

Stamens 6 to 8 times as many as petals; inflor, umbellate; leaves
glabrous

1. T. Hawaiiensis.

2. T. Waimeae.

1. T. Hawaiiensis, Gray, Bot. U. S. E. Exp. p. 728, pl. 94. - A tall and stout, much branching tree with a smooth and pale bark, 40 to $50 \mathrm{ft}$. high, the ultimate branches hirsute with a stellate and coarse fawn-colored tomentum. Leaves $1-1^{1} / 2 \mathrm{ft}$. long. Leaflets $5-9$, oblong, $4-7^{\prime} \times 1^{1 / 2}-2^{1} / 2^{\prime}$, on petioles of $2-4^{\prime \prime}$ (that of the terminal one not jointed when elongate), obtuse, somewhat contracted at the base, the lateral ones unsymmetrical, pale, coriaceous, densely tomentose underneath, the ribs hirsute. Panicles 1 with 3 nodes, or 3 with 2 nodes each, densely tomentose, often $1 \mathrm{ft}$. long and undivided in the lower half, the pedicels $3-4^{\prime \prime}$, umbello-racemose along umbellate and racemose tertiary 
or secondary branches. Calyx $1^{1} / 2^{\prime \prime}$, cup-shaped, tomentose. Petals $5-8$, tomentose, cohering at the apex, $3-4^{\prime \prime}$ long. Stamens $4^{\prime}$ times as many or less in one circle, recurved. Ovary 7-13-celled. Stigmas radiating at the apex of a short persistent stylopod of about $1^{\text {" }}$ in length which rises abruptly from the truncate vertex. Fruit globose, $3-5^{\prime \prime}$ in diameter, many-ribbed when dry, with $7-13$ flat and closely contiguous chartaceous pyrenae.

Hawaii! Puna; Maui! Kanapali; Molokai! Kalauwau; at elevations of 1000 to $3000 \mathrm{ft}$. In the Hawaii forms $7-8$ petals are generally combined with $28-32$ stamens and a 7 -10-celled drupe of $5^{\prime \prime}$ in diameter, while those from Ma ui and Molok ai have only 5-7 smaller petals with $17-19$ stamens and a $9-13$-celled drupe of $3^{\prime \prime}$ in diam. The tree is easily recognized from a distance by its pale foliage.

2. T. Waimeae, Warra, in Flora, 18\%3, p. 158. - A tall smooth-barked tree with an erect trunk of $30-40 \mathrm{ft}$., sparingly dividing near the summit into short ascending branches, glabrous. Leaves $1-1^{1 / 2} \mathrm{ft}$. long. Leaflets $5-13$, oblong or ovate-oblong, $4-6^{\prime} \times 1^{1 / 2}-2^{\prime}$, on petioles of $6-9^{\prime \prime}$, obtuse, with rounded, the lateral ones with unsymmetrical bases, chartaceous to coriaceous, glabrous. Inflorescence a terminal umbel of 10 to 12 rays, with or without a short common rhachis, each $4-6^{\prime}$ long and bearing at its apex an umbel of $15-20$ flowers on thick and long pedicels of $1-2^{\prime}$. Calyx $4-6^{\prime \prime}$ long, broad tubular, slightly constricted below the wavy denticulate border. Petals $7-8$, triangular-lanceolate, $6^{\prime \prime}$ long, reddish, coriaceous, glabrous, at last expanded. Stamens 6,7 or 8 times the number of the petals, $4-5$ "long, in two circles, sometimes fewer. Ovary 7 -8-celled, the stigmas on a short stylopod of ${ }^{1 / 2} 2^{\prime \prime}$. Drupe globose, $8-9^{\prime \prime}$ in diameter, somewhat fleshy, strongly ribbed when dry. Pyrenae compressed, separated by pulp, thick coriaceous, deeply notched at the upper inner angle, with a rather sharp back and 2 prominent ridges on each side.

Woods of Wrimea, Kauai! (Wawra and Knudsen). Wawra remarks that he has seen 2 ovules in a few cells.

\section{REYNOLDSIA, Gray.}

Calyx-border very short, wavy. Petals $8-10$, broadly inserted, valvate. Stamens as many as petals and shorter, the filaments inserted above the base of the linear incumbent anthers. Ovary 8-10-22-celled. Stigmas sessile on the conical apex or raised on a short stylopod, arranged in a circle. Drupe somewhat fleshy, globose. Pyrenae laterally compressed, papery or crustaceous, thickened at the back. Embryo minute, at the apex of an even fleshy albumen. - Unarmed glabrous trees with alternate impari-pinnate leaves, without stipules; the leaflets sinuate-crenate. Flowers polygamous, racemoso-umbellate on the alternate branches of a terminal panicle. Pedicels not jointed. Bracts minute linear. 
A genus of 3 Polynesian species, one each belonging to the Hawaiian, Society and Samoa Islands. It has been merged in the Indian genus Trevesia, which has palmate leaves, by the authors of the Genera Plantarum.

1. R. Sandwicensis, Gray, Bot. U. S. E. Exp. p. 724, pl. 92. - A low scrubby tree, $15-25 \mathrm{ft}$. high, with a thick trunk and spreading crown, glabrous, only the youngest shoots sprinkled with a stellate pubescence. Leaves about $1 \mathrm{ft}$. long, the slender petioles shortly toothed at the dilating base. Leaflets $7-11$, ovate to ovate-oblong, $2-4^{1 / 2^{\prime}} \times 2-3^{1 / 2^{\prime}}$, on petioles of $6-12^{\prime \prime}$, obtuse or acuminate, repando-crenate, rarely almost lobate, cordate or truncate at the base, stiff membranous, light-green, glossy. Inflor. of 3 terminal peduncles rising from a short common rhachis, each $6-9^{\prime}$ long and branching from the base upward, the branches horizontal, $1^{1 / 2}-2^{\prime}$ long and racemoso-umbellate in their upper halves, with pedicels of $3-4^{\prime \prime}$. Calyx obconical, truncate, $1-1^{1 / 2}{ }^{\prime \prime}$. Petals 8 10, linear-lanceolate, nearly $3^{\prime \prime}$ long, cohering. Anthers little shorter. Ovary 8-10-celled, wholly inferior. Drupe globose, $3-4$ " in diameter, ribbed, with flat vertex, the stigmas on a short cone or stylopod. Pyrenae crustaceous, with smooth sides.

On all islands here and there, on open exposed fore-hilis up to about $1500 \mathrm{ft}$. The tree has the shape and habit of the *Wiliwili or Erythrina monosperma, loses its leaves in winter and flowers in early summer before the reappearance of the leaves. Nat. name: "Ohe". In Tahiti the name Ofe applies to another Araliaceous tree, the Meryta lanceolata, Forst.

\section{ORdER XLI. RUBIACEAE.}

Calyx-tube adnate, the limb entire or with as many divisions as lobes of the corolla. Corolla inserted round an epigynous disk, regular, with 4 , 5 or more lobes, the lobes valvate, imbricate or convolute in the bud. Stamens as many as lobes of the corolla, alternate with them and inserted in the tube. Ovary inferior, 2- or more-celled, with 1 or more ovules in each cell, rarely 1-celled, with parietal placentae. Style simple, with a simple terminal stigma, or with as many stigmatic branches as cells to the ovary. Fruit varying. Seeds with a horny albumen, the embryo usually small, with flat cotyledons. - Trees, shrubs, herbs or rarely climbers. Leaves opposite, entire, with interpetiolar stipules which are either small and often extend inside the leaves, or resemble the leaves and form with them a regular whorl. Inflorescence various.

One of the largest Orders of flowering plants, mostly tropical, only some Anthospermeae and nearly all Galieae belonging to the temperate zones.

Ovules many in each cell:

Lobes of corolla valvate in the bud; ovary 2 , rarely $3-4$-celled:

Seeds minute, laterally attached; fruit a dry capsule opening at the apex

Seeds larger, peltately attached; fruit an indehiseent fleshy berry

Lobes of eorolla contorted in the bud; ovary 1-celled, with parietal placentae

1. Kadua.

2. Gouldia.

3. Gardenia. 
Ovules one in each cell:

Fruit a fleshy drupe; stipules entire, one on each side:

Flowers hermaphrodite or polygamous:

Ovule suspended from near the top of the cells:

Lobes of corolla imbrieate in the bud; ovary 2-10-celled 4, Bobea.

Lobes of corolla valvate; ovary 2-celled . . 5. Plectronia.

Ovule peltately attached to the middle of the septum 6. Coffea.

Ovule erect from near the base of the cell:

Ovary 4-celled; drupes united into a compound fleshy fruit 7. Morinda.

Ovary 2-celled; drupes not united

Stigmas united into a bifid style; anthers inserted in the throat or tube of the corolla:

Corolla small, rotate; trees

Corolla large, funnel-shaped; trees

Corolla tubular with short lobes; a climber

Stigmas free to the base; anthers rising from the base of the corolla; a creeping herb.

Flowers dioecious; stigma bifid to the base; anthers $4-11$.
ruit dry, splitting into $3-4$ indehiscent carpids or cocei; stipules

bristly; a low herb

8. Straussia.

9. Psychotria.

10. Paederia.

11. Neriera.

12. Coprosma.

Cultivated plants of this Order are: Cinchona succirubra, of which a small plantation was started at Ulupalakua, Ma ui, in 1868, various species of Ixora, Pavetta, Bouvardia, Mussaenda, Pentas carnea, Serissa foetida and others.

\section{KADUA, Cham. \& Schl, char. auct.}

Calyx-tube turbinate or hemispherical, round or angular, with 4 persistent teeth or lobes. Corolla coriaceous, salver-shaped, with a naked throat, its 4 lobes valvate in the bud, with the tips mostly inflected and the margins induplicate. Anthers 4, oblong or linear, included, subsessile near the throat of the corolla, rarely lower down, the short filaments affixed at their backs. Ovary 2-(rarely 3-4-)celled. Style filiform, generally hairy below, its $2(3-4)$ branches papillose on the inner side. Ovules hemitropous, numerous on thick round placentas which occupy the middle of the septum. Capsule loculicidal at the apex. Seeds numerous, triquetrous or angular-compressed, rarely margined, with mostly lateral attachment of the membranous testa. Embryo central in fleshy albumen, but shorter, clavate or cylindrical, the thick radicle as long and broad as the cotyledons, pointing sideways from the hilum, - Straggling or erect shrubs or lignescent herbs with terete or angular branches. Leaves penninerved, entire, with arcuately converging nerves. Stipules solitary on each side, mucronate, placed on and connate with the clasping bases of the petioles and coalescing inside the latter so as to form a complete ring. Flowers greenish-yellow or white, cymose, either 1 to 3 in the axils of lower leaves, or many clustered or paniculate in the axils of the upper reduced and sessile leaves, forming glomerate, thyrsoid, paniculate or corymbose inflorescences.

A peculiarly Hawaiian genus, nearly related to Oldenlandia and Hedyotis. The flowers are dimorphous, there having been observed in many species a considerable difference in length of corolla and in eharacters of style, often in one and the same plant, viz., 
in smaller flowers the stigmatic branches thickened and dilated, plano-convex, even spathuiate; in larger flowers the stigmatic branches linear, and the style less hairy. In flowers with very long corollas the style-branches are coadunate. A great number of ovaries fail to reach maturity in most species.

The loculicidal dehiscence remains confined to the vertex of the capsule until the calycine tube has withered away, which then leaves a network with 8 prominent longitudinal fibres. At this time the dehiscence takes place also in the line of the septa and extends nearly to the base. The minute seeds are generally angular, triquetrous or pyramidal, but in some species more or less compressed, as in $K$. acuminata, grandis, cordata and glaucifolia. In $K$. glomerata and centranthoides the albumen does not fill the flattened seeds, which thereby become margined or even winged, while, as was already pointed out by Gray, they are generally affixed edgewise. However, peltate insertion is occasionally seen in much flattened seeds.

In $K$. glomerata, centranthoides, parvula, formosa and probably also littoralis the corolline lobes are not inflected in the bud. - In 2-edged branches the ridges proceed from the prominent mucros and ribs of the stipules, in quadrangular branches from the ribs of the stipules and leaves; in terete branches generally 8 faint lines are observable, the additional ones being supplied by the lateral faseicles of the leaves.

Flowers 1 to 3 in the axils of lower leaves:

Leaves lanceolate; lobes of corolla $1 / 2$ the length of their tube; eapsule roundish

Leaves ovate-oblong; lobes of corolla nearly as long as their tube; capsule quadrangular

1. K. acuminata.

2. $K$. grandis.

Flowers clustered or paniculate in the axils of the upper reduced leaves :

Corolla green or greenish yellow:

Inflorescence thyrsoid, interrupted, the flowers clustered on short peduncles:

Lobes of corolla not inflected in the bud; seeds mostly margined or winged:

Floral leaves (subtending the flowering branehes) ovate; corolla puberulous

Floral leaves cordate; corolla glabrate

Lobes of corolla inflected in the bud; capsule with a conical vertex; seeds not margined

3. K. glomerata.

4. $K$. centranthoides.

12. K. Menziesiana.

Inflorescence an open pyramidal panicie with patent branches;

floral leaves sessile, cordate:

Ultimate bractlets broad foliose, longer than their pedieels

Ulimate bractlets linear or subulate:

Branches stout quadrangular

Branches terete or faintly lined:

Paniele large, 4-8' long, the longest internode much elongate:

Leaves sessile, ovato-cordate; calyx-lobes subulate .

Leaves all petiolate, the upper ones oblong; calyx-lobes ovate to lanceolate

7. K. Remyi.

8. $K$, Knudsenii.

Panicle small, 2-3' long, the longest internode scarcely exceeding the others:

Corolla large, 12 "

Corolla small, $2-3^{\prime \prime}$

Inflorescence short corymboid, with ascending branches; leaves glancous

6. $K$. cordata.

5. K. laxiflora.

Corolla white:

Inflor. corymbose, regular cymes on elongate ascending peduncles; leaves linear

Infl. thyrsoid, the fl. clustered in the axils of upper reduced leaves: Capsule cylindrical; tube of corolla $9-12$ ", salver-shaped; anthers sessile at the throat

9. K. Waimeae,

11. $K$. folioga.

10. K. glaucifolia.

15. K. Cookiana.

13. K, formosa. 
Capsule subglobose; tube of corolla less than $6^{\prime \prime}$, dilated above; anthers at the middle of the tube or lower:

Frutescent, the branches foliose to the top Subherbaceous, leafy only at the base

14. K. parvula.

16. $K$. littoralis

1. K. acuminata, Cham. \& Schl. in Linnaea, IV, p. 163. - An erect shrub, 3-6 ft. high, the slender solid branches horizontally divaricate, evenly foliose to the end and terete or faintly lineate. Leaves ovato- or elliptico-lanceolate, $2-4^{1 / 2^{\prime}} \times{ }^{3 / 4}-1^{1 /} 4^{\prime}$, on petioles of $1-12^{\prime \prime}$, acute, membranous to chartaceous, glabrous and often pale underneath. Stipules triangular or shortly mucronate. Flowers axillary, single, or 2 or 3 together, in the latter case supraaxillary (owing to the accretion of the common peduncle), on slender pedicels of $6-9 "$. Calyx-lobes $2-3^{\prime \prime}$, lanceolate or spathulate, with broad sinuses intervening, shorter than the tube of the corolla. Corolla greenish, glabrous, the tube $5^{\prime \prime}$, the spreading or reflexed lobes about half that length, with tips inflected and margins induplicate. Anthers linear, sessile below the throat and enclosed. Style almost as long as the tube, puberulous in the lower half, bifid to the middle with broad linear lobes, or the lobes dilated, plano-convex and shorter. Capsule obconical, 3-4" in diameter, 2-celled, thick and hard, but not fleshy, marked with 8 longitudinal lines, loculicidal at the flattish vertex, crowned by the increased $\left(3-6^{\prime \prime}\right)$ calycine lobes. Seeds small, compressed or angular, not margined. - Hook. \& Arn. in Bot. Beech. p. 85. - Gray, Proc. Amer. Acad. 4, p. 318. - Includes $K$. petiolata, a, Gray.

Probably on all islands, but ehiefly on Oahu! and Kauai; on Oahu in most valleys of both ranges. The leaves of both this and the following species emit, when bruised, a nauseous odor resembling that of excrements of mice.

$\beta$ var. - Leaves narrower, $1^{1 / 2}-4^{\prime} \times{ }^{1} / 4-1^{\prime}$, on petioles of $6-15^{\prime \prime}$, chartaceous, glabrate and pale underneath. Style glabrous, with linear lobes. Fruit in Kanapali specimens elongate pyriform.

Maui! Olualu and Kanapali.

2, K. grandis, Gray, Proc. Amer. Ac. IV, p. 318. - Erect, 8-12 ft. high, the stout branches herbaceous, hollow, bilineate at the ends. Leaves ovate-oblong, $3-7^{\prime} \times 1^{1 / 2}-3^{1 / 2^{4}}$, on petioles of $3-12^{\prime \prime}$, suddenly and pointedly acuminate, mostly thick chartaceous, often with strong nerves, dark underneath and puberulous along costa and nerves. Stipules annular, strongly cuspidate. Flowers axillary, 3 on a thick and short, often accrete peduncle, the middle pedicel longest, $6-14^{\prime \prime}$ when with fruit. Calycine lobes foliaceous, ovate to lanceolate, with narrow sinuses intervening, nearly as long as the tube of the corolla. Tube of the greenish corolla $4-6$ ", ampliate above, the reflexed lobes nearly of the same length, otherwise as in no. 1. Style as before. Capsule pyriform, 4-5" long, acutely quadrangular, the angles decurrent along the thickened pedicel. Seeds as in no. 1. - Includes $K$. petiolata, $\beta$, Gray. 
On all islands, but prevailing from Molokai to Hawail! Specimens from Koolaupapa! Molokai, have almost winged eapsules. In a form from Lanai! with large and strongly nerved leaves the styles with linear lobes were found almost glabrous, This was also the case in Wawra's $K$. petiolata from Wailuku, Maui, which combines large broad leaves and angular capsules with short corolla-lobes.

$\beta$ var. - Leaves small, $2^{1 / 2^{\prime}} \times 1^{\prime}$, ovato-lanceolate, dark, puberulous underneath, as are the calyx-lobes and the corolla. Capsule quadrangular. - K. Kaalae, Wawra, in Flora, 1874, p. 273.

Oahu, Waianae Mts. - My specimens from the same region agree as to leaves and capsule, but have the corolla glabrous and large, in one specimen foliaceous, lobes to the calyx.

3. K. glomerata, Hook. \& Arn. in Bot. Beech. p. 85. - A rambling glabrous shrub, 6-8 ft. long, with terete, bollow, subherbaceous branches which are distantly foliose and compressed toward their ends, the longest internode (below the first pair of flower-branches) 3-5'. Leaves oblonglanceolate, $3-5^{\prime} \times{ }^{3} / 4-1^{1} / 2^{\prime}$, shortly petiolate, acute or caudato-acuminate, rounded at the base or suddenly contracting into the short margined petiole, thick fleshy, glabrous underneath; the upper floral leaves ovate, shortly petiolate. Stipules triangular, scarcely sheathing. Inflorescence thyrsoid, the distant eymes glomerate from the axils of the upper 3 or 4 pairs of reduced leaves, on short puberulous peduncles, the lowest not exceeding $1 / 2-1^{1 / 2} 2^{\prime}$ when with fruit, the flowers clustered on pedicels of $1 / 2-1^{1} / 2^{\prime \prime}$. Bractlets small dentiform. Calycine lobes acute, as long as the tube or shorter. Corolla greenish-yellow, puberulous, its slender tube 6 ", the lobes $1^{1 / 2}-2^{\prime \prime}$, not inflected at the tips. Anthers linear, sessile at the throat. Style hairy below, $1 / 2$ the length of the tube, its 2 lobes very short subulate. Capsule obconical or subglobose, $1^{1 / 2}-2^{\prime \prime}$, slightly grooved on each side, flat at the top. Seeds compressed and margined (scarcely winged), round or angular. Gray, 1. c. p. 317. - Wawra, in Flora, 1874 , p. 260.

Kauai! Oahu! Waianae Mts.; Molokai! Mopulehu, Pelekunu; Lanai! and on Hawaii a form intermediate between this and the next species.

4. K. centranthoides, Hook. \& Arn. l. c. - Habit as in no. 3, only the branches more slender and the internodes longer. Leaves as in no. 3, but thinner; the floral leaves cordate or broad ovate, sessile. Inflorescence thyrsoid, but less compact, the clustered cymes on longer peduncles, the lowest $1^{1 / 2}-2^{\prime}$ long, with often secundiflorous branches, the lateral florets on pedicels of over $3^{\prime \prime}$ when with fruit. Bractlets subulate. Calycine lobes dentiform. Corolla nearly glabrous, with a tube of $4-5^{\prime \prime}$. Style glabrous below or faintly pubescent, deeply bifid with linear lobes. Capsule and seeds as in no. 3. - Gray, 1. c. p. 317 .

Hawail! Puna, Kohala; Maui! Molokai! Oahu. Seems to take the place of $K$. glomerata on Hawaii, while on the other islands mentioned both species occur, which cannot always be strictly separated. A really glabrous corolla and style were only observed in specimens from Puna, Haw aii, and Halawa, Molokai, while all others exhibit 
a trace of hairiness. In both species abortive ovaries are frequent and the length of the stigmatic lobes is variable.

5. K. laxiflora, Mann, Enum. no. 182. - A decumbent straggling shrub, $4-8 \mathrm{ft}$. long, the hollow branches stout, quadrangular, even 4-winged, glabrous, the longest internode $2-4^{\prime}$. Lower leaves shortly petiolate, oblong or lanceolate, $5-8^{\prime} \times 1^{1 / 2}-3^{\prime}$, acute, contracted below, membranous to chartaceous, pale and glabrous underneath; the upper and reduced floral leaves sessile, cordate, the latter from $1-^{-1 / 4^{\prime}}$. Stipules annular, with a long subulate point or mucro. Panicle ample and open, 8-12' long, with $5-7$ pairs of subascending branches, the lowest branches often again ramifying with foliaceous bracts; the flowers in open trichotomous or secund compound cymes; the lateral pedicels $2-3^{\prime \prime}$, with subulate bractlets of $1^{\prime \prime}$. Calyx-lobes linear, longer than their tube, often twice as long. Corolla greenish, glabrous, the tube $4-5^{\prime \prime}$, the short lobes inflected in the bud. Anthers sessile below the fauces. Style sparsely ciliate or glabrous, almost as long as the tube, the lobes $1 / 3$ of its length, complanate, coadunate. Capsule subglobose, $1^{1 / 2}-2^{\prime \prime}$ in diameter, occasionally 3 -celled, the vertex slightly raised. Seeds triquetrous or angular, small.

W. Maui! Wailuku and Waihee; Molokai! Kalauwau; Lanai! The majority of ovaries fail to reach maturity. Wawra's plant from the Waiance. Nts., Oahu, belongs to var. $\hat{\partial}$ of the following species. Nat. name: "Pilo"?

6. K. cordata, Cham. \& Schl., l. c. IV, 160. - A much branching and spreading glaucous shrub, 4-6 ft, long, the solid terete branches faintly lined, their longest internode $1^{1 / 2}-3^{\prime}$. Lower leaves shortly stalked, ovate or ovate-oblong $3-5^{t} \times 1^{1 / 2}-2^{1} / 2^{\prime}$, acuminate, chartaceous, minutely papillose underneath; the floral leaves sessile, broadly ovate-cordate, $2^{1} / 2-1 / 2^{\prime}$. Stipules annular, long-mucronate. Panicle pyramidal, $4-5^{\prime}$ long, with $4-5$ horizontal pairs of branches, the lowest $2-3^{\prime}$ long; the flowers in clusters at their ends, hidden between broadly cordate or ovate foliaceous bractlets which exceed the calycine lobes; the ultimate pedicels ${ }^{1 / 2-1} 1^{1 / 2} 2^{\prime \prime}$. Calycine lobes lanceolate or spathulate, 2 or 3 times the length of their tube and $1 / 2$ as long as the tube of the glaucous glabrous corolla; the latter ampliate, $6-7^{\prime \prime}$, the lobes $1 / 3$ as long, with tips inflected in the bud. Anthers below the throat. Style $2 / 3$, the length of the tube, hairy and thickened below, split to the middle into 2 linear or spathulate lobes. Capsule subglobose, $2^{1 / 2^{\prime \prime}}$ in diameter, lineate, with slightly convex vertex. Seeds angular, often compressed. - Hook. \& Arn. l. c. - Gray, 1. c. - Wiegmannia glauca, Meyen, Reise II, 139.

Oahu! on both mountain ranges; Kauai!

$\beta$ var. laxa. - Panicle large and open, 8-10' long, with 6 nodes, the lowest branches $3-6^{t}$ long, with 1 or 2 pairs of divaricate branchlets, each bearing compound open cymes with broad foliaceous bractlets, the Hillebrand, Flora of the Hawailan Islands. 
lateral pedicels $2-3^{\prime \prime}$, the median ${ }^{1 / 2}-1^{\prime \prime}$. Upper leaves broad cordate and sessile. $-K$. cordata, var. $\gamma$, Wawra, 1. c. 262 .

High plateau of Kauai! (Wawra, and Kn.)

iv var. secundiflora. - Panicle open, but short, with only 2 or 3 pairs of branches, which divide at their ends into 2 long secundiflorous forks. Bractlets as before. Calyx-lobes broad ovate. Capsule turbinate, with flat vertex, sometimes 3 -celled. Leaves as in $\alpha$, but variable in size and texture, sometimes thin and large, over $3^{\prime}$ broad, in other plants small and stiff chartaceous.

Oahu! Mt. Kaala (Makaleha); W. Maui!

o var. - Lower leaves obovate or lanceolate, rather distant, $6-10^{\prime} \times$ $2-4^{\prime}$, on petioles of $3^{\prime \prime}$. Floral leaves and bracts ovate-lanceolate to lanceolate, not cordate. Panicle quite open, with 3 or 4 pairs of branches, the lowest $2^{\prime}$ before forking into regular open trichotomous, rarely secund, cymes. Calyx-lobes lanceolate, $2-3 "$. Bracts ovate-lanceolate to lanceolate, shorter than their respective branchlets, the ultimate ones not exceeding the calyx. - var. $\beta$, Wawra, also his $\alpha$ from Kauai (panicula conferta).

Oahu! Niu, Waianae; Kauai, Pohakupili (Wawra).

7. K. Remyi, sp. n. - A low undershrub, $2--3 \mathrm{ft}$. high, with few branches; these very slender, herbaceous, long virgate, terete, with faint lines, distantly foliose even below. Leaves all sessile and ovato-cordate, acute, rarely the lowest rounded at the base and shortly stalked, $1-2^{\prime}$ $\times 1-1^{1} / 2^{\prime}$, stiff chartaceous, dark-green, pubescent underneath along the prominent nerves; the floral leaves broad cordate, ${ }^{3} / 4-^{1 / 4^{\prime}}$ long. Stipules mucronate, pubescent. Panicle pyramidal, open, $4-6^{\prime}$ long, with 3 or 4 pairs of patent branches, the lowest again divaricately branching with foliose bracts; the flowers in regular open trichotomous cymes with subulate bracts which are shorter than their pedicels. Calyx pubescent, the linear or subulate lobes scarcely longer than their tubes, $2-3^{\prime \prime}$ with the fruit. Corolla glaucous, often puberulous, with a tube of $5-6^{\prime \prime}$, the lobes $11 / 2^{\prime \prime}$, inflected in the bud. Style little shorter than the tube, woolly below, with spathulate branches. Capsule subglobose, $2^{\prime \prime}$ in diameter, with the conical vertex much exserted, almost semisuperous, generally 3 -celled and then loculicidal to near the base, besides also splitting septicidally. Seeds as in $K$. cordata.

On the highest ridge of Lanai! and in Hamakua, E. Maui! The specimens from the latter locality, collected by Mr. Lydgate, are very slender, the branches scarcely ${ }^{1 / 9}$ " thick, subscandent, with much smaller contracted panieles. One specimen with ovateoblong stem-leaves makes an approach to $K$. laxiflora.

8. K. Knudsenii, sp. n. - Branches slender, bilineate, the longest internode $2^{1} / 2^{2}$. Stipules triangular. Upper leaves $3^{4} \times 1^{3 / 4^{4}}$, on petioles of $2^{\prime \prime}$, broad oblong, shortly acuminate, rounded at the base, chartaceous, 
faintly puberulous underneath. Lowest floral leaf cordate, sessile, $1^{\prime}$, the uppermost very small, not over 1 "long. Panicle pyramidal, ample and open, $8^{\prime}$, long, with 6 nodes, the lowest branches again ramifying divaricately, with simple or compound cymes at their ends, the lateral flowers on pedicels of $1-1^{1} / 2^{\prime \prime}$; the ultimate bractlets linear-spathulate to dentiform, about ${ }^{1 / 2}$ "long. Calyx-lobes ovate or lanceolate, shorter than their tube. Corolla glabrous, its tube $3^{\prime \prime}$, the spreading lobes more than $1 / 2$ that length, with tips inflected in the bud. Anthers sagittate, sessile below the throat. Style $1 / 2$ as long as the tube, with linear lobes, hairy at the base.

Kauail Waimea (Kn. 87).

9. K. Waimeae, Wawra, in Flora, 1874, p. 264. - An arborescent shrub with a distinct trunk and drooping, sparingly foliose branches, these terete, with $6-8$ faint lines, their longest internode $1-1^{1} / 2^{\prime}$. Leaves glabrous, stiff chartaceous, equally green and shining on both faces, with sharply marked areoles; the lower oblong-lanceolate, shortly petiolate, $2-2^{1 / 2^{\prime}}$ long, the upper and floral leaves sessile, broadly cordate, sharply acuminate, gradually decreasing to a length of ${ }^{1} / 2^{1}$. Panicle glabrous, pyramidal, with rounded top, $2-3^{\prime}$ long, with $3-4$ pairs of branches, all regularly and openly cymose at their ends, the median flowers on pedicels of $4-1^{1} / 2^{\prime \prime}$, the ultimate bracts small subulate. Calyx-lobes subulate, $2-3^{\prime \prime}$ long on the fruit. Corolla greenish-yellow, pruinose, the tube $12^{\prime \prime}$ long, the lobes $3^{\prime \prime}$. Style ${ }^{1 / 3}$ the length of the tube, with short linear lobes, hairy up to the division. Capsule subglobose, $1^{1 / 2}-2^{\prime \prime}$ in diameter, with a convex vertex.

Ka uait woods of Halemanu (Wawra, and Kn. 31).

10. K. glaucifolia, Gray, l. c. p. 318. - A smail, erect, glabrous shrub, the short slender branches woody and densely foliose throughout, bilineate, with leafy shoots from most axillas. Leaves stiff chartaceous, dull, glaucous or hoary underneath; the lower manifestly stalked, ovate to ovate-lanceolate, $1^{1 / 2}-3^{\prime} \times 3 / 4-1^{1 / 2} / 2^{\prime}$, acute; the upper cordate and sessile. Stipules low annular, with a subulate mucro. Cyme-branches in 2 to 4 short, closely approximate pairs, ascending, forming a corymboid panicle not over $2^{\prime}$ long. Cymes pruinose, forking in a regular manner, the middle florets subsessile. Bractlets subulate, $1^{1 / 2^{n}}$. Calyx-lobes subulate, longer than their tube, $1^{\prime \prime}$. Corolla pale yellow, slender, its tube in some specimens $4^{\prime \prime}$, in others $7-9^{\prime \prime}$ long, the lobes $1^{i} / 2^{\prime \prime}$ and $3^{\prime \prime}$, with inflected tips. Style hairy, in the larger flowers $1 / 2$ the length of the tube, with short linear lobes, in the smaller flowers nearly the length of the tube, the long lobes spathulate and thickened. Capsule subglobose, $1^{1 / 2}-2^{\prime \prime}$ in diameter, 2 -celled, with a flat vertex. Seeds angular or compressed. - Wawra, 1. c. p. 263.

Kauai! woods of Halemanu. Leaves with a red border according to Wawra. 
11. K. foliosa, sp. n. - Decumbent, straggling, the subherbaceous branches slender, terete, faintly lined, nodose, purplish, evenly foliose with rameal shoots from each axilla, or sometimes the upper leaf-internode elongate to $2-4$ '. Leaves mostly reflexed, ovate to ovate-lanceolate, small, $1-2^{\prime} \times{ }^{1} / 2-{ }^{3} / 4^{\prime}$, all rameal ones distinctly stalked, dark-green, membranous, puberulous underneath; the floral leaves sessile, broadly cordate, 6-3'. Stipules triangular, pubescent. Panicle open, 2-4' in length, with 2 to 4 nodes, the lowest branches $1-2^{1} 2^{1}$, rather fewflowered. Cymes open, the ultimate bractlets linear, 1-2", shorter than their pedicels. Calycine lobes narrow lanceolate, $1^{\prime \prime}$, rather longer than their tube. Corolla glaucous and glabrous, its tube $2-3^{\prime \prime}$, the lobes inflected. Style as long as the tube, hairy below, with lobes dilated. Capsule $1^{1 / 2} /$ in diameter, 2 -celled, with subconvex vertex. Seeds triquetrous.

E. Maui! at heights of about $4000 \mathrm{ft}$.

$\beta$ var.? - Branches pale. Leaves not exceeding $6-9 "$ in length and $3-4 "$ in width. A short depauperate inflorescence, sometimes only a simple cyme at the end of nearly every axillary shoot. Calycine lobes lanceolate acute, $1^{1 / 2}-2^{\prime \prime}$, much longer than their tube.

Oahu! Waianae Mts. Perhaps a distinct species. Only a few fragments on hand.

12. K. Menziesiana, Cham. \& Schl., l. c. IV, 160. - Erect, $3-4 \mathrm{ft}$. high, dichotomously branching, the solid woody and terete branches ending in an elongate compressed herbaceous scape, the longest internode $3-4^{\prime}$. Leaves rather distant, elliptico-oblong, $2-3^{\prime} \times \times^{3 / 4}-1^{3} / 4^{\prime}$, the rameal ones on petioles of $2-5^{\prime \prime}$, obtuse or bluntly acuminate, coriaceous, puberulous underneath and marked with a distinct rete in which the primary nerves disappear; the floral leaves subsessile, ovato-lancelate. Stipules triangular. Inflorescence thyrsoid (as in $K$. glomerata), of $3-4$ nodes, the 2 uppermost approximate, the lowest branches 1 ' long, with clustered flowers, the median florets subsessile. Bractlets short dentiform. Calycine lobes shorter than the tube, deciduous. Corolla puberulous, as is the calyx, greenish, the tube $4-6^{\prime \prime}$, the narrow lobes $1 / 2$ as long and inflected in the bud. Anthers subsessile at the throat, partly exserted. Style nearly as long as the tube, hairy below, with the stigmatic lobes very short and clavate. Capsule obconical, with convex vertex, $2-3^{\prime \prime}$, rather woody. Seeds angular. - Gray, 1. c. p. 318. - K. Smithii, Hook. \& Arn. - Hedyotis conostyla, Gaud. Bot. Freyc. 147, tab. 94. H. coriacea, Smith. - Oldenlandia conostyla, DC. Prod. IV, 428. Leaves dull brown, when dry.

$\mathrm{Haw}$ ail in various regions (near the coast, U. S. E. E.). Nat. name : "Kioele" according to Gaudichaud.

$\beta$ var. - Branches short, woody and leafy to near the top, the longest internode $1^{\prime}$ or less. Leaves smaller, $1^{\prime} \times{ }^{1 / 2^{\prime}}$ or less, soon glabrate, 
but areolate and dark as in $\alpha$. Stipules mucronate. Inflor. short, of 2 or 3 nodes, the lowest cymes in the axils of rameal petiolate leaves, on ascending peduncles of $3 / 4^{\prime}$ or less. Calycine teeth very short. Tube of corolla $3-4^{\prime \prime}$, the limb globular in the bud. Anthers exserted. Style as long as the tube, even longer, hairy in the lower half, its branches short spathulate, acute, convex outside.

Oahu! on the ridge west of Nuranu and in the Waianae Mts. near Pearl River. This seems to have been Chamisso's plant.

13. K. formosa, $s p . n$. - An undershrub of $2-3 \mathrm{ft}$. in length, with the habit of $K$. glomerata, the branches herbaceous, hollow, compressed, distantly placed on a woody prostrate stem, closely foliose at the base, ending in a long $\left(6-12^{\prime}\right)$ naked or bifoliate scape. Leaves lanceolate or obovate-oblong, very acute, $4-5^{\prime} \times 1-2^{\prime}$, the upper ones sessile, the lower on broad petioles of about $1^{\prime \prime}$, chartaceous, the dark veins forming a conspicuous network underneath, with a sparse pubescence. Floral leaves broad ovate and sessile, the lowest ${ }^{1 / 2} / 1^{1}$. Stipules annular, mucronate. Flowers in a dense cluster which comprises the 2 or 3 approximate uppermost nedes, with generally 2 additional smaller clusters at the next lower distant node on short peduncles of 2-4". Bractlets dentiform. Calycine teeth short. Corolla snow white, salver-shaped, the slender tube $10-12^{\prime \prime}$, somewhat widening above, the lobes (occasionally 5) narrow lanceolate, 3-4", neither inflected in the bud nor induplicate. Anthers short, sessile below the throat. Style as long as the tube, quite naked, with 2 or 3 short ( 1 ") linear stigmatic lobes. Capsule cylindrical, $5-6$ " long, 2-, rarely 3 -celled, with exserted vertex, loculicidal at the apex, finally septicidal to the base. Seeds minute, angular.

W. Maui! on the rocky walls of deep gulches in Kanapali, Honokawai, Lahaina, Waihee. A very handsome plant when in flower.

14. K. parvula, Gray, 7. c. p. 317. - An erect glabrous shrub, 1-2 ft. high, the few short woody branches 2 -edged and densely foliose to the top. Leaves all sessile, or the lower ones shortly stalked, ovate, $1-1^{1 / 2}$ $X^{1 / 2}-{ }^{3 /} 4^{\prime}$, acute, coriaceous, with nerves indistinct, glabrous. Stipular mucro laterally compressed. Inflorescence few-flowered, very short and clustered, the often single terminal cyme subsessile, with median pedicels of $1 / 2-1 "$, or, when there are cymes from the next node, these on assurgent peduncles of scarcely $3^{\prime \prime}$. Bractlets lanceolate $1^{1 / 2}-1$ ". Calycine lobes ovate to obovate, longer than their tube, $1 \frac{1 / 2}{2}-3^{\prime \prime}$. Corolla white, with a pinkish tinge, funnel-shaped, the tube $3-4^{1 / 2} 2^{\prime \prime}$, the suberect lobes ovatelanceolate or obovate, almost as long as the tube, obtuse or subacute, not inflected and margins not induplicate. Anthers linear, affixed to the middle of the tube. Style $1 / 2$ as long as the tube, very woolly above the base, with clavate coadunate lobes. Capsule subglobose, $2^{\prime \prime}$ in diam., with conical vertex, 2-celled. Seeds angular. - Wawra, 1. c. 263.

$\mathrm{Oahu}$ ! mountains of Waianae, valley of Makaha. 
15. K. Cookiana, Cham. \& Schl., l.c.p. 158. - A small suberect glabrous undershrub, ${ }^{1 / 2}-1^{1 / 2} \mathrm{ft}$. high, branching from a woody base, the virgate reddish branches 2 -edged or 4 -angled, distantly and evenly foliose to the top, the upper leaves gradually smaller. Leaves linear-lanceolate, the lowest $2-6^{\prime} \times 1-6^{\prime \prime}$, acute at both ends, rather coriaceous, pale and smooth underneath, with indistinct nerves, gradually narrowing into the clasping petioles. Stipules triangular acute or annular with a subulate mucro. Inflor. terminal: in small plants a simple or ternate cyme with median pedicels of $1^{1 / 2}-3^{\prime \prime}$, the lateral ones of $3-6^{\prime \prime}$, or in larger plants also assurgent cymes from the axils of the one or two upper leaf-pairs; the cyme-branches sometimes secundiflorous. Bractlets linear to filiform. Calycine lobes subulate, longer than their tubes, $1^{1 / 2}-3^{\prime \prime}$. Corolla white, the tube $4-6^{\prime \prime}$, the lobes with inflected tips. Anthers_oblong, subsessile at the middle of the tube. Style included, hairy below, bifid to the middle with linear or spathulate lobes. Capsule subglobose, $1^{1 / 2}-2^{\prime \prime}$ in diameter, 2-, rarely 3-celled, the conical exserted vertex almost as high as the adnate portion. Seeds triquetrous or compressed-angular, not margined. - Gray, 1. c.

Probably on all Islands, collected in Kealakeakua, Hawaii; Halawa and Kalawau, Molokai! at the foot of the pali of Koolau, Oahu! Nat. name: "Awiwis or "Uiwis in Molokai. The subherbaceous habit and narrow leaves impart to the plant the appearance of a Kohautia.

$\beta$ var, elatior. - Leaves larger, $6-8^{\prime} \times 6-8^{\prime \prime}$. Corolla citron-colored, with a tube of $8^{\prime \prime}$, the lobes $2-3 "$, obtuse. Style $1 / 2$ as long as the tube, with linear lobes. - Mann, Enum. 186. - Wawra, 1. c. p. 263.

Kauai, Hanalei.

16. K. littoralis, sp. n. - Low, subherbaceous, erect, glabrous, 1/2 to $1 \mathrm{ft}$. high, single-stemmed or branching from the ground, the stem or branches quadrangular, densely foliose near the base, terminating in an elongate naked or two-leaved scape. Leaves broadly ovate or obovate, $2-4^{\prime} \times 1-2$ ', all sessile and clasping, shortly acuminate or apiculate, fleshy, smooth underneath, with only the lowest nerves prominent. Floral leaves ovate, the lowest 4 "long. Stipules annular, mucronate. Flowers in a terminal cluster which consists of $1-3$ pairs of closely approximate subsessile cymes, often with an additional pair of shortly pedunculate clusters with reduced leaves from the next lower distant node, the cymes trichotomous or secund, with thick angular pedicels of $1^{\prime \prime}$ or less, the secund branches lengthening with fruit to about $1^{\prime}$. Bractlets linear, $1^{1 / 2}$ ". Calyx-lobes as long as the tube, spathulate, persistent. Corolla white, short and broad. Anthers inserted near the base of the tube(?) Style $1 / 2$ the length of the tube(?) shortly $3-4$-fid with clavate or spathulate branches, thick and hairy at the base. Capsule $3-4$-celled, subglobose, $3^{\prime \prime}$ in diam., with rather flat vertex. Seeds small angular. - Aborted ovaries very scarce. 
On rocks near the seashore in Waikolu, Molokai! and Hanalei, Kauai! A single damaged corolla only was available for examination; the position of the anthers, shape of corollar lobes and relative length of style remain therefore donbtful.

\section{GOULDIA, Gray.}

Calyx obovoid, with 4 persistent teeth. Corolla salver-shaped, coriaceous, with a slender tube and naked throat, the 4 lobes thick, linearoblong, valvate in the bud. Stamens 4, inserted in the throat or tube of the corolla, the linear anthers affixed to short filaments at their backs, enclosed, or exserting the pointed connective only. Disk annular. Ovary 2-celled. Style slender, with 2 filiform branches. Ovules many, on thick placentas which are attached to the middle of the septum. Fruit a fleshy indehiscent drupaceous berry, globose, bisulcate, with flattened top and pergameneous endocarp. Seeds many, tesselate over the fleshy placentas, vertically compressed, suborbicular or angular, peltate, with a crustaceous black testa. Albumen dense. Embryo straight, with small cotyledons and elongate radicle. - Shrubs or small trees with obtusely quadrangular branches. Leaves with arched confluent nerves. Stipules solitary on each side, inter- and intra-petiolar, caducous. Flowers small, purplishgreen, in terminal or axillary cymose panicles, with dentiform bractlets.

A small Hawaiian genus.

The generie description has been modified here to suit the Hawaiian species only, as the position of G. Romanzoffiana, Gray, (Kadua, Ch. \& Schl, Petesia carnosa, H. \& A.), from the coral islands, is doubtful, and by reason of its vaginating stipules and pyriform fruit, which splits at the apex, probably nearer to Kadua than to Gouldia. The aestivation of the corolline lobes, in Bentham \& Hooker's Genera Plant. given as rstriete contortas, is in reality valvate in the manner that the 4 thick fleshy, almost trigonal, erect lobes touch each other with their sides or inner faces, while the acuminate tips are deflected outward, gaping in the bud. Dimorphism manifests itself also in this genus (excepting perhaps the fourth species), but only by difference in length of the corolline tube and enclosed or exserted styles, while the stigmatic branches nearly always appear linear. The stipular costa bifurcates in its descent from the apex some distance above the base, the forks uniting with the lateral fibro-vasal fascicles of the petiole. It is by the further descent of these combined fascicles that the angles of the branches are formed; eonsequently there are no 2-edged or 2-lined branches as in Kadua, but always 4 angles or lines, to which the median fascicle of the petioles sometimes adds 2 additional fainter lines.

The seeds are much larger than in Kadua, less numerous (8-22 to a placenta) and always peltately attached.

Four of the following species were comprehended as varieties under one polymorphous species by Gray, and to these varieties Wawra has since added 8 more. I am fully aware that as species they are not unimperachable, that exceptions exist to their definitions, that forms of transition connect most of them, but this is what occurs in the speeies of all leading Hawaiian genera. As defined here, they constitute natural groups, in which the great number of specialized forms fit tolerably well. An improvement must be expected from an increase rather than a decrease in the number of groups.

Berry small, not over $2^{\prime \prime}$ in diameter:

Panicles terminal, sometimes on axillary leaf-shoots:

Panicle short; leaves obovate, contracted below, pale, coriaceous; tube of corolla $2-4^{4}$

Panicle and upler internodes elongate; leaves variable, but mostly elongate and acute, with a truncate and emarginate or rounded base; corolla $4-6^{\prime \prime}$; style enclosed.

1. G. coriacea.

2. G. terminalis. 
Panicles terminal and axillary, very short; leaves short, subsessile, obtuse at both ends and pubescent, thick, glossy, with a marked rete; tube of corolla $2^{\prime \prime}$ with exserted, or $6^{\prime \prime}$ with enclosed style

Panicles mostly axillary and short; leaves thin, oblanceolate, pubescent underneath; tube of corolla pubescent, $2-3{ }^{\prime \prime}$; style exserted

Berry large, 4" in diameter; leaves coriaceous, ovate or obovate; panicles short

5. G. macrocarpa. Stylocoryne sambucina, Gr., a Rubiacea of similar habit,

1. G. coriacea. - A tall glabrous shrub, the woody branches faintly angular or lineate. Leaves obovate-oblong, $3-5^{\prime} \times 1-1^{3 / 4^{\prime}}$, shortly acuminate or obtuse, contracting at the base, but passing abruptly into a not margined petiole of $1-3^{\prime \prime}$, coriaceous, with faint nerves and without distinct rete, pale, glabrous. Stipules triangular obtuse to lanceolate, $3-6^{\prime \prime}$. Panicles terminal at the ends of the branches, more rarely on axillary leaf-shoots, round-topped, mostly nodding, 11/2-21/2' long, inclusive of peduncles of $3-9^{\prime \prime}$, the lowest branches patent, $3-6^{\prime \prime}$; the lowest bracts linear-spathulate, 2-6", occasionally foliaceous; bractlets dentiform. Calyx 1 " or less. Corolla glabrous, the tube either $2-3$ " with lobes of the same length, or $4^{\prime \prime}$ with lobes half as long, the latter thick leathery, almost triquetrous. Anthers subsessile near the throat, partly exserted in the longer flowers. Style as long as the tube, or shorter, bifid to ${ }^{1 / 4}$ or $1 / 2$ of its length. Berry bluish, globose, $2-2^{1 / 2}$ ", with two faint longitudinal furrows. Seeds about 13 on each placenta. - Petesia coriacea, Hook. \& Arn. - G. Sandwicensis, var. coriacea, Gray, Proc. Am. Acad. IV, 310. - G. Sandw. var. g, form $\alpha$, and probably also var. c, lanceolata, Wawra, in Flora, 1874, p. 295. - Kadua affinis, Ch. \& Schl.

Oahu! common on both mountain ranges; Ka uai! In plants from the Kaala range the leaves are much smaller and aeute at the base, with smaller panicles,

$\beta$ var. - Leaves larger, $4-7^{4} \times 1^{1} / 2-2^{1} / 2^{\prime}$, bright green, thin chartaceous, the large panicle open, mostly erect.

Oahu! Wailupe and Niu; Maui! Hamakua (leaves acute, on longer petioles of $\left.6-9^{\prime \prime}\right)$. - Var. g, form $\beta$. Wawra.

$\gamma$ var. - Leaves and panicles as in $\beta$, but the former pubescent underneath.

Hawait (or Niu, Oahu)?

$\delta$ var. - Leaves thin, pale and glabrous, but rounded at the slightly contracting base. Panicles subsessile, contracted, short, about $1^{\text {t high }}$ and broad. Berries pale blue.

W. Maui, Olualu!

\& var. - Leaves pale, subcoriaceous and large, $3^{1 / 2}-5^{\prime} \times 2^{3 / 4}-3^{1 / 2}$, on petioles of $12-18^{\prime \prime}$, broad obovate and obtuse to suborbicular, with conspicuous patent nerves. Panicle much elongate and open, about 5 ' in length and curved. 
Hawai, Waipio! - Other forms from Hamakua and Hilo, of the same island, with broad obovate-oblong leaves and gradually reduced, always recurved panicles, lead this extreme form back into $\alpha$, from which they only differ in the prominent veins and less contracted base.

2. G. terminalis. - A tall rambling, almost scarident shrub, the long virgate branches subherbaceous, glabrous, faintly angular or lined, with distant leaves, the internodes often $3-4^{\prime}$. Leaves oblanceolate, $3-4^{1} / 2^{\prime} X$ $1-2^{4}$, on petioles of $2-6^{\prime \prime}$, acute or acuminate at the apex, rounded or truncate or emarginate at the base, rarely ovate-oblong and subcordate, membranous, dull, glabrous, but papillose, with nerves indistinct. Stipules obtusely triangular, $2-3$ ". Panicles terminal, exserted beyond the leaves, pyramidal, open, 3-4' long, with 3-4 nodes; the lowest rays supported by reduced leaves, the bracts from spathulate to dentiform; the pedicels subequal, $2-3^{\prime \prime}$. Tube of corolla $4-6^{\prime \prime}$, very slender, dilating above; the lobes $1 / 2$ as long. Anthers enclosed. Style in smaller flowers as long as the tube, in the larger only $1 / 2$ its length. Berries $11 / 2-2^{\prime \prime}$ in diameter, bluish. Seeds 8-14 on a placenta. - Petesia terminalis, Hook. \& Arn. G. Sandwicensis, var. terminalis, Gray. - G. Sandw., var. f, terminatis, and probably also var, e, ovata, Wawra.

Leaves large ovate to ovate-oblong: Oahu, Waianae Mts. (Wawra); Molokai, Kalae! (subcordate), Maui, Wailuku (M. \& B. 416), Hawaii. Leaves obovate-oblong, with a truncate, often emarginate base: Molokai! Maui, Hamakua! (leaves small, 2-3' long).

$\beta$ var. - Leaves thin, lanceolate or oblong, acute at both ends.

Molokai! (leaves large, $3-5^{\prime}$, with an ample panicle $3-4^{\prime}$ long and as broad); Ka uai! (leaves and panicle smaller) $\mathrm{Kn} .75$, and perhaps Wawra's var. b from Kalihi, Oahu.

$\gamma$ var. - Leaves pale green, subcoriaceous, with evanescent nerves, broad oblong, obtuse or rounded at the apex, emarginate at the base, often suborbicular, $1^{1 / 2}-2^{\prime} \times 1^{1 / 4}-1^{1 / 2} 2^{\prime}$. Panicle smaller than before. Stipules coriaceous, long persistent. - One specimen exhibits an ovate acute leaf, another an obovate leaf with emarginate base, forms which occur in $\alpha$. Longest internodes 2-3'. - G. Sandwicensis, var. d, cordata, Wawra, 1. c. p. 277.

W. Marui!

3. G. hirtella. - An erect or arborescent shrub, the stiff woody branches quadrangular, with an ochraceous pubescence. Leaves subsessile or on very short petioles of $1-2^{\prime \prime}$, obovate to ovate or orbicular, small, $1-2^{1} / 2^{\prime} X$ $1-11 / 2^{\prime}$, obtuse or rounded at the apex, often emarginate or cordate at the base, stiff chartaceous, dark green, shining above, with a finely marked rete, more or less pubescent underneath along the strongly prominent nerves. Stipules broad triangular. Inflorescence terminal and axillary, the contracted paniculate or corymbose cymes short, not over 1' long, and numerous. Tube of purplish corolla $2^{\prime \prime}$ with exserted styles (or $6 "$ with a style $1 / 2$ as long, Wawra), the anthers inserted above the middle 
of the tube. Berry lead-colored, with 12 seeds to a placenta. - G. Sandwicensis, var. hirtella, Gray, in part. - var. hirtella, $\beta$, Wawra, 1. c. p. 295 ,

On the high plateau of Ka uai! Wawra and Kn. - Top of Mt. Kaala! Oahu (leaves oblong). - Rather glabrate forms with broad oblong leaves up to 3 ' in length have been collected by Mr. Knudsen on the Kauai platean, and quite the same form I found on Mt. Kaala. They come very near to Wawra's $\alpha$ of var. hirtella.

$\beta$ var. stipulacea, Wawra, is described as a densely branching shrub, $3 \mathrm{ft}$. in height, with similar small obovate leaves of $1^{\prime}$ in length or less, and long persistent broad and round stipules.

Kauai, plateau Waialeale (6000 ft.).

4. G. axillaris, Wawra, in Flora, 18\%4, p. 297. - A small tree with angular solid branches which are densely and evenly foliose throughout and coarsely pubescent with short brownish hair. Leaves on petioles of $2-6^{\prime \prime}$, elliptico- to obovato-oblong or lanceolate, $2^{1 / 2}-6^{\prime} \times 1-2^{1 / 4^{\prime}}$, more or less acuminate, contracted, rarely rounded at the base, bluishgreen when fresh, membranous to chartaceous, with faint nerves, papillose and coarsely but sparingly pubescent underneath. Stipules 3", caudatoacuminate. Panicles numerous, pubescent, short, 1-2' long, in the axils of mostly older leaves, but also terminal between two sterile branches, with slender peduncles of $2-6^{\prime \prime}$; the lowest bracts $3-6 "$, or foliaceous. Corolla puberulous, small, $2-2^{1} / 2^{\prime \prime}$, the lobes $1 / 2$ as long. Anthers subexserted. Style in all flowers exserted. Berry pale blue, $1^{1} / 2-2^{\prime \prime}$ in diam. Seeds $20-22$ on each placenta, - G. Sandwicensis, var. hirtella, Gray, in part. - The larger leaves glabrate.

W. Maui! the prevailing form; Molokai, Maunahui! (leaves thicker with prominent nerves); Haw a ii! (axillary panieles with redueed leaves on the peduncle; leaves lanceolate, $5-6^{\circ}$ long, on petioles of $\left.6-8\right)$.

$\beta$ var. - Panicles mostly terminal on short branches, those of the axils foliaceous at the lowest node. Leaves and panicles very pubescent, the former smaller than in $\alpha$, often rounded at the base, firmer and prominently nerved, the rete sometimes impressed above.

Woods of E. Maui! G. Sandwicensis, var, i, parvifolia, Wawra.

$\gamma$ var. - Panicles axillary. Branches stout, elongate, sharply angular. Leaves on short petioles of $1-2 "$, obovate-oblong, rounded at the base, $3-4^{\prime} \times 1^{1 / 2}-2^{\prime}$, thick chartaceous, with prominent nerves and impressed rete, shining above, the young ones papillose but glabrous.

Lanai!

5. G. macrocarpa, sp. n. - A small gnarled tree with angular solid branches, glabrous. Leaves ovate- or obovate-oblong, $2-4^{4} \times 1^{1 / 4}-2^{1} / 2^{\prime}$, on petioles of $3-6^{*}$, bluntly acuminate, rather pale, subcoriaceous, shining above, glabrous underneath, with distinct but faint nerves. Stipules triangular, caudato-acuminate. Panicles terminal, shorter than the upper leaves, $1^{1} / 2-2^{\prime}$, often nodding. Corolla purplish-green, glabrous, 
small, its tube $2-3$ ", dilating above. Anthers enclosed. Style exserted. Berry large, about $4^{\prime \prime}$ in diam., with a large disk. Seeds about 12 on a placenta, $1 / 2$ " in diam.

Ka uai! (Kn.) leaves ovate; Oahu, Mt. Kaala! leaves obovate. Color and texture of the leaves are much like those of $G$. coriacea. - Corresponds tolerably well with G. Sandwicensis, var. $\alpha$, Wawra, from Hanalei, $\mathrm{K}$ a uai, in which were found corollas with a tube of $3^{\prime \prime}$ and others with a tube of $6^{\prime \prime}$ in length.

\section{GARDENIA, L.}

Calyx-limb tubular and truncate, toothed or lobed, or divided to the base into $4-5$ or more lobes. Corolla-tube cylindrical, with 5 or more lobes contorted in the bud. Anthers subsessile, usually exserted. Style with 2 thick erect lobes, or nearly entire. Ovary 1-celled, incompletely divided by 2 to 5 parietal projecting placentas. Fruit succulent or dry, indehiscent, usually crowned by the calycine limb. Seeds numerous, immersed in the fleshy placentas in several rows. - Shrubs or trees. Stipules solitary on each side, often connate and sheathing. Flowers usually large and solitary, terminal or axillary, white or yellow.

A genus inhabiting the tropical regions of Africa, Asia and the Pacific Ocean, - New Caledonia, Viti, Society and Marquesas Islands.

Cultivated species: G. Tahitensis - Tiara, G. florida, G. Iucida, G. radicans.

Branches not glutinose; leaves ovate; calyx-lobes linear-oblong, erect

Branches glutinose; leaves obovate; calyx-1obes falciform, dilated, spreading and vertical

1. G. Brighamii.

2. G. Remyi.

1. G. Brighamii, Mann, Enum. no. 179. - An unarmed shrub, 6-12 ft. high, with strictly dichotomous densely foliose branches, scarcely glutinous at the ends. Leaves on short petioles of $2^{\prime \prime}$, ovate, $1^{1 / 2}-4^{\prime}$ $\times 1-2^{1 / 2} / 2^{\prime}$, shortly acuminate, chartaceous, with prominent straight nerves, shining above, papillose and in the young state puberulous underneath. Stipules triangular or truncate, connate inside the petioles into a complete sheath of $2-3$ " in height. Flowers single, terminal, subsessile. Calyx-tube quadrangular, shortly produced above the ovary, $5^{\prime \prime}$ long, 4-lobed, the linear-oblong lobes erect, 5-6". Corolla white, salver-shaped, 6 -lobed, the ampliate tube $7-9^{\prime \prime}$, the obovate lobes $6^{\prime \prime}$. Anthers subsessile, linear, 5 "long, their apices exserted. Style as long as the tube, the 2 clavate branches nearly half its length. Fruit globose, with 4 faint lines, about $1^{\prime}$ in diameter, coriaceous, indehiscent, tipped with the contracted limb of the calyx, 1-celled, with 4 (or 3 or 5) parietal placentas projecting about $2^{\prime \prime}$ from the pergameneous endocarp. Seeds many in a yellowish pulp, horizontal, flattened, obtusely 3- or more angled, about $2^{\prime \prime}$ in diameter, with a coriaceous black testa and fleshy albumen. Embryo near the hilum, about ${ }^{1} / 2^{\prime \prime}$ long, the flat cotyledons ovate or rounded, as long as the terete radicle.

Lanail Molokai! Maunaloa; Oahu! Nuuanu, Makaleha, on dry fore hills. Nat. 
name of both species: "Nanü. The pulp of the fruit was employed for dying "Kapa " yellow.

2. G. Remyi, Mann, Enum. no. 180. - A tree, $30-40 \mathrm{ft}$. high, the young shoots exuding a glutinous substance which covers the leaves as with a layer of varnish. Leaves obovate-oblong, $4-9^{\prime} \times 2-4^{\prime}$, on petioles of $2-4^{\prime \prime}$, shortly acuminate, contracted at the base, chartaceous, papillose underneath, prominently nerved. Stipules truncate and sheathing as before. Flowers terminal, single, sessile. Calyx-tube angular, $9^{\prime \prime}$ long, the lobes 4 to 5 , falciform, dilated toward the obtuse apex and net-veined, spreading with the plane vertical, $1^{1 / 2^{\prime}}$ long, equalling or exceeding the corolla. Corolla white, its ampliate tube 1 ', the $7-8$ obovate-oblong suberect lobes about $10^{\prime \prime}$ long, narrowed at the base and separated by broad sinuses. Anthers enclosed. Fruit $4-5$-angled, pyriform, $1 \frac{1 / 2-2}{}$ ' in both diameters, the permanent calyx-lobes surrounding a disk of $3-4^{\prime \prime}$ in diam.

Oahu! Nuиanu, Palolo, Halemanu; Kauai, Kealia, Hanalei, seattering and rare. Both species recommend themselves for cultivation on account of their large white and fragrant flowers.

\section{BOBEA, Gaud.}

Flowers polygamous. Limb of calyx persistent, truncate or 4-toothed or lobed. Corolla coriaceous, salver-shaped, with naked throat, its 4 lobes imbricate in the bud. Stamens 4, inserted below the throat on short filaments, the anthers affixed dorsally below the middle, linear, exserted with their tips. Disk annular or conical. Ovary 2-11-celled. Style enclosed or shortly exserted, thick, with 2-11 long filiform, introrsely stigmatose branches in the fertile and only 2 short ones in the sterile flowers. Ovules solitary, suspended from the apex of each cell with a thickened funis. Drupe globose, rather dry, 2-11-furrowed, consisting of 2-11 uni-seriate osseous pyrenae. Seed cylindrical, almost straight, the thickened and hardened funis closing the open apex of the putamen like a stopper; testa membranous. Albumen very scanty. Cotyledons minute and short, somewhat flattened, the superior radicle much larger and oblong. - Trees with terete branches. Stipules one on each side, early deciduous. Leaves minutely reticulate, jointed. Flowers in axillary cymes, the median sessile, generally 3 to 7 , rarely 1 . Bracteoles at the base of the calyx cup- or saucer-shaped, but minute. - See the valuable observations by A. Gray on this and allied genera in Proc. Amer. Acad. Scienc. IV, p. 36 et seq.

A Hawaiian Guettardaceous genus, distinguished from the nearly related MalayoPolynesian Timoniug by the aestivation of the corolla and the uni-, not pluri-seriate
pyrenae.

The subjoined species cannot fairly be separated generically. The differences in the Sir J. Hooker to dis the number of ovarian cells or pyrenae which prineipally induced Sir J. Hooker to distribute them in three genera. - Rhytidotus, obbea and the present 
one - occur exactly in the parallel genus Timonius, as circumscribed in the Genera. Plantarum, and to some extent in Guettarda and Antirrhoea. The genera Coprosma and (among Lobeliads) Cyanea and Clermontia offer still greater variability in the calyx. The flowers are certainly dimorphous in all species. The induplicate or crumpled condition of the corolla in the $4^{\text {th }}$ and $5^{\text {th }}$ species is owing to the greater development of the obovate lobes in the bud, and exists to a less degree also in the first species.

All are called "Ahakea" by the natives and in the forests can be recognized from a distance by their pale green foliage.

Limb of calyx cup-shaped, truncate; drupe with 3 to 11 pyrenae:

Leaves glabrous; peduncle erect

Leaves hairy underneath; peduncle drooping

Limb of calyx cup-shaped, toothed

Limb of calyx broadly 4-lobed; lobes of corolla crumpled:

Flowers in cymes; drupe with 2 pyrenae

Flowers single; drupes with 4 to 6 pyrenae.

1. B. elatior.

2. B. Mannii.

3. B. timonioides.

4. B. Sandwicensis.

5. B. Hookeri.

1. B. elatior, Gaud. Bot. Freyc. p. 473, tab. 93. - A glabrous tree, $20-30 \mathrm{ft}$. high. Leaves pale, obovate-oblong, $2-4^{\prime} \times 1-2^{\prime}$, on petioles of $3-12$ ", acuminate, chartaceous, glabrous. Stipules oblong-lanceolate, $4-6 "$, rather convolute in the bud. Flowers 3 to 7 in a cyme, with a common peduncle of $2-3^{\prime}$, the pedicels of the lateral flowers $6-9^{\prime \prime}$. Bracts and bractlets cup-shaped, low. Calyx $2-2^{1 / 2^{\prime \prime}}$, the cup-shaped truncate limb as long as the adnate portion. Corolla coriaceous, greenishpurple, glabrous, or the lobes in the bud faintly silky near the apex, the tube $2-4^{\prime \prime}$, plicate at the throat, the obovate or rounded lobes $1^{1 / 2}-2^{1 / 4^{\prime \prime}}$, two external and two internal. Anthers sessile at the middle of the tube. Style 3-11-cleft. Drupe rather fleshy, purplish, ovoid, 3", many-ribbed, crowned by the calycine limb, which surrounds a glabrous disk of $1^{\prime \prime}$ in diam. Pyrenae 3-11, thick-walled, complanate. - Gray, l. c. p. 36. Burneya Gaudichaudii, Ch. \& Schl. in Linnaea, IV, p. 189. - Timonius Gaudichaudii, DC. Prod. IV, 461.

Oahu! on both mountain ranges; Kauai? - The petioles as well as the calyces are very loosely jointed at their bases and therefore apt to fall off the dried specimens, as is also the ease to a less degree in the other species. Chamisso states, probably in error, that the 3 -flowered eymes bear fertile and the 7 -flowered ones sterile flowers.

$\beta$ var. brevipes. - Leaves ovate-oblong, $2-3^{\prime} \times{ }^{1 / 2}-1^{\prime}$, on petioles of $2-3^{\prime \prime}$, pubescent beneath on midrib and nerves. Stipules $3^{\prime \prime}$ long. Flowers solitary on peduncles of $3 "$. Drupe $3^{\prime \prime}$ in diam., with 4 pyrenae. - B. brevipes, Gray, 1. c.

Oahu (U. S. E. E.). - The Ahakess of Pauoa, Oa hu! with obovate leaves like those of $\alpha$, but slightly pubeseent along the median nerve, bear single flowers on a peduncle of $12-20^{\prime \prime}$, the drupes being large, $5-6^{\prime \prime}$ in diam.

2. B. Mannii, sp. n. - Leaves elliptico-oblong, $2-3^{\prime} \times 1-1^{1 / 2^{\prime}}$, on petioles of $2-2^{1} / 2^{4}$, the nerves, ribs and petioles hirsute with ashcolored hairlets. Peduncle (in bud) drooping, 3-4" in length, 3-flowered, the lateral flowers on pedicels of $2^{\prime \prime}$. Calyx cylindrical, $2^{\prime \prime}$, with truncate limb. Corolla 2 or 3 times as long, pubescent, as are also calyx and peduncle.

Kanai, Kealia and Waimea, 2000-3000 ft. (M. \& B. 621 in hb. Gray). 
3. B. timonioides, Hillebr. - A small tree with the ultimate branches slender and straggling, pubescent and ciliate on the deep cicatrices of the fallen stipules. Leaves pale, ovate to ovate-lanceolate, sometimes falcate, $3-5^{\prime} \times 1-2^{\prime}$, on petioles of $4-6^{\prime \prime}$, pointedly acuminate, chartaceous, glabrous or slightly puberulous on the nerves underneath. Stipules triangular, acute, pubescent, $1^{1 / 2}-2^{\prime \prime}$. Cymes many, tomentose, $3-7$-flowered, the common peduncle $4-6$ ", the lateral flowers on pedicels of $1-2^{\prime \prime}$. Bractlets minute, calyculate. Calyx and corolla densely tomentose, the former turbinate, $2^{\prime \prime}$, with the free limb cupshaped and 4-toothed. Tube of corolla $3-4^{\prime \prime}$, the obovate lobes $1 / 3$ shorter, the 2 interior ones involute in the bud. Anthers sessile above the middle of the tube, elongate, included or the tips exserted. Disk conical, hairy. Style thick, pubescent, about $1 / 2$ the length of the corolla, deeply bifid into 2 pointed branches. Ovary 2-celled, the single seed suspended from a short and broad funis. - No matured fruit on the specimens. - Obbea timonioides, Hook. f. Icon. plant, tab. 1070, and Gen. plant. II, 102. Chomelia? sp. Wawra, in Flora, 1874, p. 330.

Hawaii! S. Kona and Kawaihae iuka. Collected only by the author. - The short style with pointed branches, on which no stigmatic papiliae are visible, probably belongs to sterile flowers.

4. B. Sandwicensis, Hillebr. - A tall much branched shrub or small tree, the slender branches puberulous at their ends. Stipules triangular,

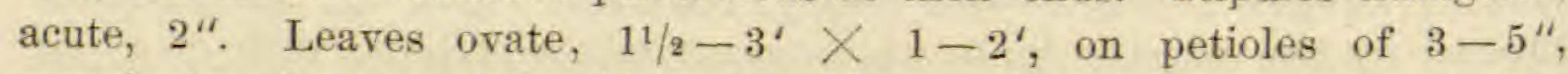
acuminate, ehartaceous, pale, tomentulose underneath when young, but quite glabrous and shining above when old. Flowers $3-7$ in a contracted cyme, the lateral ones sessile or on short pedicels of ${ }^{1} / 2-1^{\prime \prime}$, the common peduncle $5-6^{\prime \prime}$, tomentose, as are the minute clasping bractlets. Calyx silky-tomentose, the tube $2^{\prime \prime}$, somewhat produced beyond the ovary, with 4 broadly obovate, obtuse recurved lobes which with fruit attain a length of $4^{\prime \prime}$ and are imbricate in the bud. Corolla greenish-yellow, silkytomentose, its tube cylindrical, 3-5", with glabrous throat, the lobes $1 / 3-1 / 2$ as long, obovate, with crumpled margins, recurved. Style on a raised hairy disk, rather thick, bifid to the middle or further, tomentose, exserted or quite short, ${ }^{1 / 3}-1 / 4$ the length of the corollar tube. Drupe globose, $2^{1 / 2} 2^{\prime \prime}$ in diameter, pubescent when young, with a small disk, a thin sarcocarp enclosing 2 bony pyrenae. Cotyledons very minute, at the end of a straight oblong radicle. - Chomelia Sandwicensis, Gray, l. c. p. 38. - Guettardella Sandwicensis, Mann, Enum. no. 177.

W. Maui! Olualu; Molokai! Kalae; Lanail on dry open slopes.

The aestivation of the corolla is imbricate, but not always so as seen by Hooker, viz, one pair of lobes external and one internal. I have as often found one of the lobes belonging to a pair external and its mate internal, while the lobes of the decussating pair were external with one and internal with the other edge, an arrangement which probably occurs oceasionally also in the other species of the genus. Dimorphism is indicated by larger flowers with the style half the length of the tube and bifid to the 
base, and smaller ones with a style fully as long as the tube and bifid only to the middle. In the expanded corolla the apex of the inner lobes appears rather dorsal, as the inflected crumpled margins extend in front and somewhat above it.

5. B. Hookeri, Hillebr. - Branches and leaves glabrous. Flowers single, on peduncles of $3-4^{\prime \prime}$ in length. Drupe larger, $4^{\prime \prime}$ in diameter, purplish, with 4 to 6 pyrenae. Otherwise as in no. 4 . - Rhytidotus Sandwicensis, Hooker f. Icon, plant. tab. 1071.

Oahu! Wailupe and Makaleha, on exposed slopes.

\section{PLECTRONIA, L.}

Calyx-limb short, cupular, truncate, or 4-5-toothed. Tube of corolla short, the 4-5 lobes spreading, valvate. Stamens inserted near the throat, the ovate or oblong anthers affixed dorsally near the base. Style enclosed or exserted, with an entire ovoid or bifid stigma. Ovary 2-celled, with 1 pendulous anatropous ovule in each cell. Fruit a globular or didymous drupe or berry with crustaceous putamen or pyrenae. Seeds oblong, with thin testa. Embryo in fleshy albumen, elongate, terete, with generally short cotyledons and superior radicle. - Shrubs with terete branches. Stipules one on each side, triangular, connate inside the petioles. Flowers axillary, in clusters or corymbose cymes.

A considerable genus spread over tropical Africa, Asia, Australia and the Pacific Islands.

1. P. odorata, Benth. \& Hook. Gen. Pl. II, 110. - A tall glabrous unarmed shrub. Leaves elliptico-oblong, sometimes lozenge-shaped, 2--34 $\times 1-1^{1} / 2^{\prime}$, on petioles of $2^{\prime \prime}$, acuminate or somewhat obtuse, chartaceous, dark green, glossy above. Stipules mucronate. Flowers in cymose corymbs of $1-1^{1} / 2^{\prime}$ in length, the common peduncle $3-9^{\prime \prime}$, sometimes with a pair of minute bracts, the cymes irregular, bractless, somewhat circinnate, the median flowers on pedicels of $3-1^{\prime \prime}$. Calyx $1^{\prime \prime}$, dentate. Corolla white, 3 "long, 4-5-fid, pilose at the insertion of the stamens, the linearoblong lobes as long as the tube or longer. Stamens exserted, as long as the lobes. Style a little longer, glabrous, with a short ovoid stigma, or rather the 2 thick lobes coadunate. Fruit a fleshy drupe, obovoid, compressed, emarginate, grooved on each side, 4 " high and 5 "broad, 2-celled, with thick osseous putamen, the inner wall of each cell arcuately projecting into its cavity below the attachment of the pendulous seed. Seed incurved. Embryo in horny albumen, as long as the same, subarcuate, the foliaceous cotyledons as long as the radicle. - Coffea odorata, Forst. - Canthium odoratum, Seem, in=Fl. Vit. - C. lucidum, Hk, \& Arn. in Beech. Voy. p. 65. - Wawra, in Flora 1874, p. 298. - In Wawra's plants the style was bifid to the base.

All Islands, on dry open slopes of mean elevation, rather common in the southern parts of Hawaii and on E. Maui. Nat. name: "Walahee. The speeies has been collected on Tahiti, Gambier Island, the Vitis, and Tanna of the New Hebrides. The flowers are sweet- 
scented. The corolla is sometimes slit to near the base, in which ease the stamens appear with a very low attachment. Gray refers to this species the Myonima umbellata of Hk. \& Arn,, 1. c. p. 86, while Seeman believes he has identified it with Straussia Mariniana.

\section{COFFEA, L.}

Calyx-limb truncate, toothed or lobed, often glandular inside, persisting. Corolla salver- or funnel-shaped, with 5 or 4 lobes which are contorted in the bud. Anthers 5 or 4 , on short filaments or sessile in the throat of the corolla, affixed near the base, linear, at last recurved or twisted. Style glabrous, with 2 linear branches. Ovary 2-celled, with 1 amphitropous ovule in each cell peltately affixed to the middle of the septum. Fruit a fleshy berry with 2 pergameneous pyrenae which are convex on the back and longitudinally furrowed on the plane inner side. Testa thin, lining the sulcus of the albumen. Embryo curved, near the base and back of the horny albumen, the cotyledons cordate foliaceous, the inferior radicle terete. - Glabrous shrubs with terete branches. Stipules one on each side. Flowers in axillary clusters, white.

About 20 species, natives of tropical Asia, Africa and the Mascaren Islands.

† 1. C. Arabica, L. - DC. Prod. IV, 499. - A small tree. Leaves elliptico- or ovato-oblong, acuminate, glabrous, shining, chartaceous. Stipules triangular, mucronate, joining within the petioles, persistent. Flowers clustered on short pedicels. Corolla deeply 5-lobed, with a smooth throat. Anthers and style exserted. Berries ovoid, fleshy, red.

Well naturalized in the woods of Kona, Hawail, and elsewhere. Iis native country is Abyssinia with the adjoining parts of the Soudan.

The coffee tree was introduced in the year 1823 by a Frenchman, who established a small plantation in Manoa, Oa hu. Its cultivation soon spread over the whole group, and between the years 1840 to 1856 quite a number of plantations had sprung up, chiefly on the islands $\mathrm{Kauai}$ and $\mathrm{Haw}$ a ii, which promised excellent results, when the sudden a check to the cultivation of the tree. The punctures of this insect cause the exudation of a sweet gummy juice which forms a nidus for the spores of a black fungus, large patches of which soon cover the leaves and ail green parts, impede the respiration of the plant and exhaust it by the drain upon its sap. With the commencement of the winter rains the insect disappears from the plant, but colonies of it are then found underground, adhering to the roots, whence at the end of the rainy season they are earried to their breeding places, the axils of the leaves, by a small red ant. The fresh leaf and flower-buds are consequently the first parts to suffer from their attacks. Within a few years after the appearence of the disease most plantations were cut down to make room for sugar-eane, a blow from which this branch of agriculture has never recovered, although the disease seems to have abated of late years. The finest berry came from the rich lava soil of Kona, Hawaii, where the tree flourishes splendidly in the woody regions
up to an elevation of $3000-4000 \mathrm{ft}$.

\section{MORINDA, L.}

Flowers united at the base in a small head. Calyx-limb short, scarcely toothed. Corolla-tube eylindrical, or widening at the top, usually short, the lobes 5 or 4 , or rarely 3 , valvate in the bud. Anthers enclosed in 
the tube or rarely exserted. Ovary 2-4-celled, with 1 erect ovule in each cell. Style exserted, bifid or entire. Drupes or berries united into one fleshy fruit. Pyrenae or putamen cartilaginous. Seeds obovoid or reniform, with thin testa. Albumen fleshy. Embryo terete, with inferior radicle. - Shrubs or small trees or climbers. Stipules membranous, connate inside the petioles. Flowèr-heads on axillary or terminal, single or clustered peduncles.

A tropical genus, chiefly Asiatic and Oceanic, with a few African and 2 or 3 American species.

Leaves oblong; corolla 3 -toothed; fruit 1 inch in diam. Leaves ovate; corolla 5-lobed; fruit $3-4$ inch in diam.

1. M. trimera.

2. M. citrifolia.

1. M. trimera, sp. n. - A tree, $20 \mathrm{ft}$. high, with yellowish wood, the pale terete branches covered with numerous warts or lenticels. Leaves opposite, elliptico- or obovato-oblong, $4-6^{\prime} \times 1^{1 / 2}-2^{1} / 4^{\prime}$, on petioles of $1-1^{1} / 2^{\prime}$, equally acuminate at both ends; chartaceous to membranous, pubescent underneath, particularly along the nerves and in their axils, almost black when dry. Stipules $3^{\prime \prime}$, acuminate, connate into a deep sheath. Peduncles in the axils of old leaves and cauline, $1^{1 / 2}-2^{\prime}$ long, pluribracteate at the base - the bracts connate, apiculate or subulate - and often with a pair of leaflets at the middle. Flowers 8-12 in a glomerule, connate with their bases. Calyx $1-1^{1 / 2} 2^{\prime}$, free from the ovary, urceolate or cupular, truncate, with 3-toothlets. Corolla 4", coriaceous, puberulous, tubular-ventricose, shortly 3-toothed, the teeth or lobules induplicate-valvate or cucullate. Anthers 3, subsessile on the lower third of the corolla, oblong, included. Ovary small, globose-depressed, immersed in an annular disk at the bottom of the calyx. Style about the length of the calyx, bifid, with one branch shorter than the other. Drupe or berry of 4 distinct woody pyrenas, fleshy, adherent with and enclosed within the globose calyx, each pyrena with 1 erect seed, and the calices connate into a syncarpium which measures about $1^{\prime}$ in diameter.

Collected by Mr. Lydgate in the forests of Hamakua and Waikapu, Maui!

$\beta$ var. - Leaves thicker, chartaceous, shining, obovate-oblong, obtuse. Calyx truncate, with $5-6$ toothlets. Corolla oceasionally 4 -toothed, with 4 anthers. Flowers $10-15$ in a glomerule.

Mt. Puakea of the Waianae range, Oa hu! From a small specimen collected by Dr. Wawra, who has omitted to take notice of the species in his published report, unless he should have mistaken it for $M$. citrifolia.

†2. M. citrifolia, L. $-D C$. Prodr. IV, 446. - A small glabrous tree with angular branches. Leaves broadly ovate, $6-8^{\prime} \times 4-6^{\prime}$, on short petioles, somewhat obtuse, thick. Stipules broad and rounded, $4-6 "$, connate below into a loose sheath which encloses the peduncle. Flowerheads on short bractless peduncles placed opposite the leaves, their own

Hillebrand, Flora of the Hawaiian Islands. 
supporting leaves remaining undeveloped. Calycine limb short truncate. Corolla white, tubular to funnel-shaped, 3-4" long, 5-cleft, pilose at the insertion of the sessile anthers below the middle of the corolla. Style shortly bifid, as long as the tube. Syncarpium several inches in diameter, fleshy. - Mrs. Sinclair, pl. 40.

The "Noni", probably of aboriginal introduction, is only found in open low lands. The species has a wide range, ocenrs on most Pacific islands, and extends over Malaysia, Ceylon and S. India to the African Continent. It used to be eultivated as a dye-plant by most Polynesians, the root, according to Seeman, yielding a yellow and the bark a red color. The fruit is insipid, and very fetid when decaying. Noni is also the Tahitian name.

\section{STRAUSSIA, Gray.}

Flowers polygamous. Calyx turbinate, jointed with the pedicel, the limb short truncate or obscurely $4-6$-toothed, persistent. Corolla rotate, 4-6-cleft, valvate in the bud.. Anthers $4-6$, inserted in the throat of the corolla, on short filaments, basifixed, oblong, with thick connective, partly exserted in the sterile, enclosed and shorter in the fertile flowers. Disk convex. Ovary 2-celled, with 1 erect anatropous truncate ovule in each cell: Style short, with truncate and generally coadunate branches in the sterile, longer and subexserted, with complanate or spathulate lobes in the fertile flowers. Drupe with 2 plano-convex pergameneous pyrenae. Seeds erect on a broad scale-like funiculus, the flat ventral side furrowed by a deep sulcus, which runs out into two forks above and receives the rhaphe, and by which the firm testa enters a fissure of the horny albumen; the albumen slit, besides, by a semilunar fissure concentrical with the convex back into an outer and inner lamella. Embryo at the basis of the semilunar fissure, small, the inferior radicle as long as the broad cordate cótyledons. - Trees, with dichotomous terete branches. Stipules interpetiolar, broad, touching or overlapping each other inside the petioles, but not connate, soon deciduous. Leaves often with flat glands in the axils of the nerves underneath. Flowers small, white, sessile (or the lateral ones subsessile) in cymes which are placed in close whorls or umbels at the ends of verticillate rays of a terminal panicle. Bracts minute, eaducous.

A Hawailian genus, nearly related to Prychotria and Chasalia. - The median tlower of the cymes is mostly 5-6-Iobed, while the lateral ones are 4-lobed. The corolla in no species exceeds $2^{\prime \prime}$ without the lobes. The glands on the under side of the leaves are not constant in any species, largest and most frequent in $\mathrm{S}$. Havaiiensis, next in S. Mariniana; in the other species they are very small, often hidden by the pubescence, and of irregular occurrence. The inner border of the stipular scar is lined in all species with a fringe of short stiff hairlets. Nat. name: "Kopikos.

Drupe obovate or turbinate, with a flat disk:

Drupe small, not exceeding $3^{\prime \prime}$

Drupe larger, about $6^{\prime \prime}$ long:

3. S. Hawaiiensis.

Drupe tumid or apophysate at the base; corolla pubescent.

4. S. oncocarpa. 
Drupe not apophysate; corolla glabrous:

Pedunele long and mostly drooping, with $1-3$ nodes; corolla generally naked at the throat

Peduncle ereet, with $3-6$ nodes; corolla with hairy patches at the throat.

Drupe ellipsoidal, with a conical disk

1. S. Kaduana.

2. S. Mariniana.

5. S. leptocarpa.

1. S. Kaduana, Gray, in Proc. Am. Acad. IV, 43. - A small tree, $15-20 \mathrm{ft}$. high. Leaves obovate or obovate-oblong, $2-4^{\prime} \times 1^{1 / 4}-2^{\prime}$, on short petioles of $2-6^{\prime \prime}$, rounded or shortly acuminate, cuneate toward the base, chartaceous, with nerves little prominent, papilloso-puberulous or glabrate and pale underneath. Stipules short, $2-3$ ", broadly triangular. Panicle $2-5^{\prime}$ long, erect or nodding, puberulous or glabrate, with only 1 or 2 approximate whorls of rays toward the end of a long peduncle. Calyx ${ }^{1} / 2^{\prime \prime}$, with limb denticulate. Corolla about $2^{\prime \prime}$, naked at the throat, its $4-6$ lobes generally longer than the tube, often 2 or 3 times as long. Drupe obovoid or top-shaped, almost quadrangular, with a broad flat disk, $5-7^{\prime \prime}$ long and about $4 "$ broad near the top. - Wawra, in Flora, 1874, p. 321. - Coffea Kaduana, Ch. \& Schl. in Linnaea, IV, 33. - Hook. \& Arn. in Bot. Beech. p. 86. - DC. Prod. IV, 502. - C. Chamissonis, H. \& A. ibid, - Apionema obovatum and A. penduliflorum, Nutt. in herb. Kew.

Oahiu! Molokai! rather common.

B var. coriacea. - Leaves coriaceous, with strong nerves, pale, moderately contracting toward the base, almost sessile, $4-5^{\prime} \times 2-2^{1} / 2^{\prime}$. Stipules broad obovate or pentagonal, 3 ". Panicle erect, few-flowered, with 2 whorls of short rays at the end of a long peduncle. Lobes of corolla scarcely longer than the tube.

Oahu! Kalihi.

$\gamma$ var. Leaves and panicle as in $\alpha$, but puberulous, the latter always drooping. Lobes of corolla scarcely longer than the tube, and faintly hairy at their bases.

Oahu! Paroa and Makiki.

2. S. Mariniana, Gray, l. c. - A small glabrous tree. Leaves obovateoblong, acute at both ends or the apex bluntly aeuminate, $4--6^{4} \times 2-2^{1} / 2^{4}$, on petioles of $6-12^{\prime \prime}$, chartaceous, glabrate underneath, and dark green, with rather prominent reddish rib and nerves. Stipules obovate from a broad base, somewhat obtuse, $3-6^{n}$ long. Panicle glabrous, erect, about $4 "$ long, with $3-6$ whorls, each of $4-8$ rays, the free peduncle only half its length. Calyx truncate. Corolla with a pilose patch at the base of each lobe, the lobes scarcely longer than the tube. Drupe as before. - Coffea Mariniana, Ch \& Schl, l. c. - DC. 1. c. - Apionema sulcatum, Nutt.

Oahu! Maui! Kauai. - The species was named by Chamisso in honor of Mr. Marin, or, as the natives pronounce the name, Manini, an early settler from Mexieo, of whose interest in agriculture the poet and betanist makes honorable mention in his cCireumnavigation of the Worlds. Both to him and the late Capt. Adams the islands are indebted for the introduetion of many nseful plants and trees. 
3. S. Hawaiiensis, Gray, l. c. - A tree, 20-30 ft, high. Leaves thick chartaceous, with stout nerves, obovate, $4-7^{\prime} \times 2^{1} / 2-3^{i} / 2^{\prime}$, on petioles of $1-1^{1 / 2}$, generally rounded at the apex, with a very short point, cuneate toward the base, glabrous except on the flat glands in the axils of the nerves, which are unusually large and somewhat pubescent. Stipules triangular, obtuse, 3 ". Panicle as in no. 2, and glabrous, as are the flowers. Calyx-limb truncate. Corolla $1^{1 / 2}-2^{\prime \prime}$, the $4-5$ lobes as long as the tube or a little longer, each with a manifest patch of hairlets at the base. Drupe obovoid, small, $3^{n}$ or less.

Hawail Puna, Kona. - The bearded spots of the corolla were missing in one specimen from Kona. The leaf-glands are often seen in every axilla in the shape of isoseeles triangles; in other specimens they are more searce and smaller, often round, but always larger than in the other species. A specimen, probably from the Kohala range, has the large leaves rounded at the base and pubescent underneath along the nerves, which are almost destitute of glands; the panicle also is pubescent and inclined.

4. S. oncocarpa, sp. $n$. - A tall and stout tree, $40-50 \mathrm{ft}$. high. Leaves obovate or suborbicular, $2-3^{\prime} \times 1^{1 / 2}-2^{\prime}$, on petioles of $2-6^{\prime \prime}$, rounded at both ends, subcoriaceous, pubescent underneath, the costal glands hidden under the hairs. Stipules triangular, obtuse, $1^{1 / 2}-2^{\prime \prime}$. Panicle short, $1-2^{\prime}$ long, bearing only 1 whorl of short rays, rusty-pubescent, as are also calyx and corolla. Calyx distinctly dentate. Corolla naked at the throat, its tube $2^{\prime \prime}$, the lobes as long. Drupe obovoid, 4-ribbed, tumid (apophysate) at the base, $6 \times 4^{\prime \prime}$, with a small disk.

E. Maui! Ulupalakua.

$\beta$ var. - Leaves obovate-oblong and rounded, cuneate at the base, on petioles of $6-7^{\prime \prime}$, rather glabrate. Panicle very short, less than $1^{\prime}$, and contracted. Corolla naked at the throat, the $5-6$ lobes 2 to 3 times longer than the short tube. Drupe apophysate.

Ka uai! Waimea (Kn.).

5. S. leptocarpa, sp. n. - A tall shrub. Leaves obovate or ellipticooblong, $4-5^{\prime} \times 1-1^{3} / 4^{\prime}$, on petioles of $6--9^{\prime \prime}$, bluntly acuminate, contracted below, membranous to chartaceous, papilloso-pubescent or furfuraceous underneath. Stipules short, triangular, obtuse, $1^{1 / 2}{ }^{\prime}$. Panicle furfuraceo-pubescent, erect, short, with 2 to 3 whorls, the peduncle about 1. Calyx and corolla puberulous in the bud, the latter 6-lobed in the single flower examined), with faint hairs at the throat, the lobes scarcely longer than the tube. Stamens 6. Ovary semi-superior. Drupe slender ellipsoidal or fusiform, $6^{\prime \prime}$ long and only $2^{\prime \prime}$ broad at the middle, the conical apex or disk projecting beyond the calycine limb.

E. Maui! woods of Pumelei.

\section{PSYCHOTRIA, L.}

Calyx-limb short, 5-lobed, toothed or entire. Corolla funnel- or bell shaped, 5-, 4- or 6-lobed, the lobes valvate in the bud. Stamens as many 
as lobes, inserted in the throat, the anthers affixed near the base. Style 2-lobed. Ovary 2-celled, with 1 erect ovule in each cell. Fruit a drupe with 2 coriaceous pyrenae. Seeds flat on the inner face and usually furrowed or costate on the convex back. Embryo near the base of horny albumen and almost dorsal, small, with flat ovate or orbicular cotyledons and inferior radicle. - Shrubs or small trees. Stipules 1 or 2 on each side, sometimes united into a sheath within the petioles. Flowers in terminal cymose corymbs or panicles, rarely axillary.

A large genus, ranging over the tropical regions of both the New and old World. Leaves pale; flowers in a trichotomous corymbose cyme . 1. P. hexandra. Leaves dark; flowers in a panicle with verticillate rays . . 2. $P$. grandiftora.

1. P. hexandra, Mann, Enum. no. 170. - A small tree with glabrous, quadrangular, compressed branches, the ridges decurrent from the stipular and leaf-ribs. Leaves green when dry, obovate or obovate-oblong, $3-6^{4} \times$ $1-1^{3} / 4^{\prime}$, on petioles of $3-12^{\prime \prime}$, shortly and abruptly acuminate, euneate at the base, membranous, pale and glabrous underneath. Stipules one on each side, oblong, broad, $4-6^{\prime \prime}$ long, overlapping each other, whitish in the living plant, caducous, leaving a fringe of hairlets in the axils. Flowers in a terminal, erect, corymbose, trichotomous, glabrous cyme of about $4^{\prime}$ in height, the peduncle ${ }^{1 / 2}-1^{\prime}$, the pedicels of the median flowers $1^{\prime \prime}$, of the lateral $2-3^{\prime \prime}$. Bracteoles below the calyx ovate, acute, subconnate, $2-1^{\prime}$. Calyx $3^{\prime \prime}$, the urceolate limb twice as long as the tube, with 6 toothlets. Corolla waxy white, funnel-shaped, villous at the throat, 6-lobed, the tube $6^{\prime \prime}$, the linear-lanceolate lobes $3^{\prime \prime}$. Anthers subsessile at the throat, oblong, acute at both ends, little exserted. Style slightly exserted, the short lobes dilated, plano-convex. Drupe ovoid, 6", crowned with the calycine limb. Pyrenae with 3 ridges at the back. Wawra, in Flora, 1874 , p. 328.

Ka uail mountain forests of Waimea (Kn.).

$\beta$ var. hirta. - A dense shrub with short knobby branches. Leaves elliptical, $2-3^{1 / 2^{\prime}}$ long, the young ones densely pubescent underneath. Cymes contracted, few-flowered. Flowers large, pale lemon-colored. Wawra, l. c. Same locality.

2. P. grandiflora, Mann, Enum. no. 171. - A small glabrous tree. Leaves dark green and glossy when fresh, deep copper-colored when dry, obovate-oblong, $3-4^{1} / 2^{\prime} \times 1^{1 / 2}-2^{\prime}$, on petioles of $2-6^{\prime \prime}$, obtuse or shortly acuminate, papillose but glabrate underneath, subcoriaceous, with reflected margins. Stipules as before, $4^{\prime \prime}$. Inflorescence a terminal, puberulous, strongly deflected panicle with a long peduncle of $1-2^{\prime}$ and generally 2 nodes, the lower with a whorl of $4-6$ rays, each carrying a simple cyme, the median pedicel $1^{1 / 2}-2^{\prime \prime}$, the lateral $3-4^{\prime \prime}$. Bracts small dentiform, connate. Calyx as before. Corolla waxy white (copper-colored when dry), 
funnel-shaped, glabrous at the throat, 5-6-lobed, the tube 9-10" long, the lanceolate, greenish, finally reflected lobes $3^{\prime \prime}$. Anthers $1^{1 / 2} 2^{\prime \prime}$, oblongobtuse, on filaments of the same length, exserted. Style much exserted, $14-15^{\prime \prime}$ long, with bidentate or bifid stigma. Drupe as before, ovoid, 5 "long and 4 " broad, the two pyrenae with 3 dorsal ribs and protruding lateral angles, chartaceous. Seed plano-convex, emarginate at the apex - a bifureating longitudinal sulcus on the ventral face and a semilunar slit in the interior, at the base of which lies the small embryo - exactly as in Straussia. - Wawra, 1. c. p. 329

Kaua I! in the woods of Waimea. A highly ornamental tree (Kn.).

\section{PAEDERIA, L.}

Calyx-limb small, 5-4-toothed, persistent. Corolla tubular, broad, with 5-4 short lobes, which are valvate and folded in the bud. Anthers linear-oblong, subsessile, enclosed. Style with 2 linear twisted branches. Ovary 2-celled, with 1 erect anatropous ovule in each cell. Drupe rather dry, the thin fragile rind soon seceding from the pyrenae, which are orbicular or ovate and dorsally compressed. Seeds with fleshy albumen, the thin testa adhering to the endocarp. Embryo large, with cordate broad cotyledons and a short inferior radicle. - Stem twining, terete. Stipules one on each side. Cymes loosely dichotomous or trichotomous, axillary or in a terminal panicle.

A small genus, almost limited to tropical Asia.

†1. P. foetida, L. - DC. Prod. IV, 471. - A tall glabrous twiner, woody at the base. Leaves on petioles of $1-1^{1 / 2}$, ovate or lanceolate, $2-3^{\prime} \times 1-1^{1} / 2^{\prime}$, membranous. Stipules short triangular. Cymes axillary, compound, generally secund, $1^{1 / 2}-2^{1} / 2^{\prime}$ long, the common peduncle $1 / 2-1^{\prime}$, the median flowers sessile, the lateral on pedicels of $1-1^{1 / 2} 2^{\prime \prime}$. Bracts minute. As cymes grow from the axils of many, often 12, pairs of leaves which gradually beeome reduced to bracts, the inflorescence has the appearance of a long foliose panicle or thyrsus. Calyx less than 1", with 5 short teeth. Corolla $3-4^{\prime \prime}$, white or pale pink, mealy-tomentose outside, hirsute on the inside of the entire tube, the small spreading limb marked with a star-like pink spot. Anthers inserted below the middle of the tube, hidden between the hairs. Style as long as the tube, bifid to near the base into long filiform twisted branches. Berry globular or ovoid. - Benth. Fl. Hongk. p. 162. - The leaves are fetid when bruised.

Oahu! Kalihi, Nuuanu, Makaleha, aceidentally introduced. Appeared first about the year 1854, in Kalihi, whence the birds have spread the seeds. A common plant of southern Asia, extending over most islands and coasts from Mauritius and Ceylon to Japan. 


\section{NERTERA, Banks \& Sol.}

Calyx-tube ovoid, the limb truneate or obscurely 4-toothed, persistent. Corolla tubular or funnel-shaped, 4-5-lobed, with lobes valvate. Stamens $4-5$, inserted at the base of the corolla, exserted, the anthers basifixed, pendulous. Styles bifid to the base into filiform exserted branches. Ovary 2-celled, with 1 erect anatropous ovule in each cell. Drupe fleshy, containing 2 plano-convex coriaceous pyrenae. Seed-coat membranous. Embryo axile in fleshy albumen, the cotyledons foliaceous. - Small creeping herbs. Stipules one on each side, connate with the petioles. Flowers solitary, sessile, axillary or terminal, hermaphrodite or unisexual.

A small genus, widely diffused over the southern hemisphere, most species being natives of N. Zealand, one species extending over the Andes to Mexico and another to Java and the Philippines.

1. N. depressa, Banks. - DC. Prod. IV, 451. - Glabrous, the slender quadrangular stem creeping and rooting, freely branching, 1 to several ft. in length. Leaves fleshy, with neryes imperceptible, broadly oblong, trapezoid or suborbicular, 2-6" long, shortly acuminate or rounded, on a petiole of half their length or less. Stipules small triangular, connate inside the petioles, the connecting portion very low; the uppermost pair, which supports the flower, often deeply and broadly emarginate, forming 2 semilunar lobes. Flowers terminal, sessile. Calyx ${ }^{1} / 2^{\prime \prime}$, truncate. Corolla $1^{\prime \prime}$, thin, greenish yellow, urceolate or tubular, 4-fid to the middle or beyond. Stamens as long as the corolla or shorter, with short, ovoid, somewhat obtuse anthers. Style branches linear-complanate, exserted and divaricate, not hirsute, stigmatose inside along the upper half. Drupe fleshy, red, ovoid, $1^{1 / 2}-2^{\prime \prime}$ high, the 2 pyrenae suborbicular, chartaceous. Seeds dorsally compressed. Embryo small, at the base of fleshy albumen, the radicle longer than the cotyledons. - Mann, Enum. no. 166. Wawra, in Flora, 1874, p. 330. - Both Endlicher and De Candolle attribute a terminal flower to $N$. depressa, while in Benth. and Hooker's Genera Plant, all species are credited with axillary flowers.

On all islands, at altitudes of $2500-5000 \mathrm{ft}$., in woods, ereeping on the ground or on old trunks. The species extends, with slight modifications of form, from Tristan d'Acunha and the Falkland Islands and Fuegia over the Andes to Mexieo, also to Tahiti. Some authors even combine with it plants from Java, Borneo and Luzon, which have however cordate leaves and lanceolate stipules.

\section{COPROSMA, Forst.}

Flowers unisexual, dioecious in all Hawaiian species. Male fl. Calyx minute, eup-shaped, indistinctly toothed. Corolla 3 to 4 times as long, funnel- or bell-shaped, 4-9-lobed, with lobes erect, valvate in the bud. Stamens 4-11, inserted at the base of the corolla, the slender filaments exserted, the linear apiculate anthers affixed at their bases. Fem. fl. Calyx ovoid or urceolate, with a dentate, lobed or entire and produced limb. 
Corolla 4-9-parted, with valvate, mostly revolute lobes. Style divided to the base into 2 long exserted, divaricate, linear, pubescent branches. Ovary 2-celled, with 1 erect ovule in each cell. Fruit a fleshy drupe with 2 pergameneous plano-convex pyrenae; the seeds with a membranous testa. Embryo axile in horny albumen, with foliaceous cotyledons and an inferior radicle. - Shrubs or trees, with opposite, rarely verticillate leaves. Stipules connate with each other inside the petioles. Flowers greenish, inconspicuous, mostly axillary, single, or several variously disposed in imperfectly developed branch-like inflorescences, with a pair of stipellate connate bracts at the base of the calyx in single and lateral flowers.

About 37 species, principally natives of New Zealand and the Sandwich Islands, a few belonging to Australia, Borneo, Tahiti and the Vitis, one to Juan Fernandez. Native name for all species: "Pilo". None of our plants emit a fetid odor as do some of the New Zealand species. From the New Zealand and Australian species ours also differ in being strictly dioecious, the male flowers without style and the female without anthers, also in having the corolla more than 4-1obed, excepting the first species.

This most difficult and intricate genus exhibits in the axis of its inflorescence a steady transition from a leafy branch to a slender naked peduncle. In $C$. ernodeoides a single bractless flower sits at the end of a short leafy branch. In $C$. montana the leaves, reduced to spathulate or linear bracts, retaining their stipules, cover a short axillary spur which either bears a single sessile flower at its end or, besides, one or more lateral ones in the axils of the uppermost bracts. Next, this short spur lengthens to a slender peduncle with 2 or 3 pairs of often foliaceous bracts, besides a terminal one which supports a head of 3 sessile flowers, as in C. Menziesii. This changes to a cyme when the lateral flowers are stalked, or to a raceme when other flowers rise from all lower bracts, or to a fascicle when only the lowest pair sends forth elongate pedicels. All these modifications occur in $C$. stephanocarpa, where the lateral flowers are supported sometimes by short reduced, sometimes by foliaceous bracts. Agnin, the bracts with their flowers erowded toward the apex form terminal glomerules, as in C. longifolia, C. pubens, and often in C. rhynchocarpa. Further on we have a naked peduncle bearing at the end a regular cyme of 3 flowers, as in C. cymosa, and finally a single flower on a naked pedunele, as often happens in the last named species and in C. foliosa.

Leaves linear, 1-nerved; lobes of corolla 4, ereet in the fem. fl.; drupe black

Leaves penni-nerved; lobes of corolla $5-9$, revolute in the fem. fi. ; drupes yellow or red:

Leaves opposite:

Flowers sessile on short axillary spurs

Flowers raised on distinet peduncles:

Drupes beaked with the long tubular limb of the calyx, ovoid

Drupes crowned with the long discreet calycine lobes, small obovoid

Drupes shortly dentate, 3 sessile in a head, or single: Leaves coriaceous, with nerves impressed above, obovate;
drupes small ovoid

Leaves thin, acute at both ends; drupes large globose or obovoid

Drupes naked at the apex:

Drupes globose, single or in a cyme, with the lateral flowers pedicellate

Drupes ovoid or ellipsoidal; flowers numerous, crowded on short peduncles.

Leaves ternate, with long sheathing stipules: flowers many, erowded at the ends of long peduneles; drupes ellipsoidal.

1. C. ernodeoides.

2. C. montana.

7. C. rhynchocarpa.

6. C. stephanocarpa.

3. C. Menziesii.

4. C. foliosa.

5. c. cymosa.

8. C. pubens.

9. C. longifolia. 
1. C. ernodeoides, Gray, in Proc. Am. Acad. IV, 49. - A low prostrate shrub, not rising above $2 \mathrm{ft}$. from the ground, with long and stiff trailing branches which send up short densely foliose branchlets at every node, and with erect branches which fork copiously and are densely covered below the leaves with stipular rings, sparsely hispid in the youngest shoots, otherwise glabrous. Leaves appressed, sessile, linear-

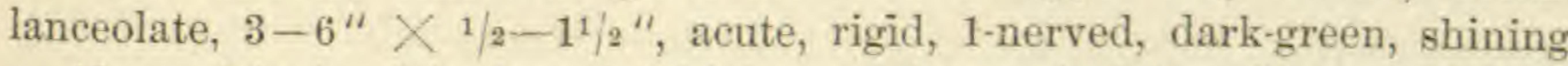
as if varnished. Stipules $1 / 2^{\prime \prime}$ high, annular, apiculate, eiliate. Male $\mathrm{fl}$. unknown. Fem. $f$. solitary and sessile at the end of a ramule, hidden between the leaves. Calyx tubular, 4-fid, $1^{1 / 2} 2^{\prime \prime}$ long, the acute teeth shorter than the tube. Corolla funnel-shaped, $2^{1 / 2}-3^{\prime \prime}$ long, shortly 4 -fid, with the lobes or teeth erect. Styles much exserted, 8-10", pubescent. Drupe ovoid, black, fleshy, 4-5", crowned by the short calycine teeth. - Wawra in Flora, 1874 , p. 325.

-High mountains of Hawaii, E. and W. Maui! from 5000 to $7000 \mathrm{ft}$., where it covers the ground in abundance on the bare lava. The wild mountain-geese (Bernicla Sandw.) feed upon the berries, which are ealled by the natives "Kukai neenees, droppings of geese.

2. C. montana, $s p . n$. - Prostrate, rising about $3-4 \mathrm{ft}$. from the ground, with much the habit of the preceding species, the stout decumbent branches quadrangular, the short divaricate or ascending branchlets densely foliose, covered with stipules below and more or less pubescent. Leaves obovate or spathulate, $9-12^{\prime \prime} \times 5-6^{\prime \prime}$, penni-nerved, bluntly acuminate or rounded, the base contracting into a margined petiole, thick coriaceous, shining, with nerves impressed on the upper face. Stipules coriaceous, broad triangular, $1-1^{1 / 2} 2^{\prime \prime}$ high, ciliate at the upper border. Flowers axillary, sessile on very short and thick axillary spurs, single and terminal when the spur is short, or several when it is longer, and thus sometimes giving the appearance of a cluster or fascicle. Fem. fl. Calyx $1^{\prime \prime}$, urceolate, its limb produced and denticulate, constricted at the base, as long as the tube. Corolla $2^{\prime \prime}$, deeply 5-6-parted, with lobes reflexed. Styles $3^{\prime \prime}$ long. Drupe yellow or reddish, ovoid, $3-4^{\prime \prime}$, tipped with the short calycine limb. - C. Menziesii, var. $\gamma$. Gray, 1. c. - Wawra, 1. c. p. 326, no. 1906 and probably also no. 2312.

Hawaii, Mauna Loa and Mauna Kea; Maui! Haleakala, 6000-9000 ft.

$\beta$ var. Leaves shorter, suborbicular. Stipules rounded, bordered with a fringe of short and coarse hairlets.

Mauil top of Eeka.

$\gamma$ var. Leaves elliptico- or obovately-oblong, somewhat acute, $5-6^{\prime \prime}$, including the distinct petiole. Stipules apiculate, pubescent. C. Menz. var. $\gamma$. Wawra, 1. c. no. 2171.

Ka uai! plateau of Lehua makanui (U. S. E. E. and Mr. Knudsen), Waialeale (Wawra).

3. C. Menziesii, Gray, l. c. p. 49, var. a and $\beta .-$ A large diffuse shrub, $4-8 \mathrm{ft}$., with angular, ascending, loosely foliose, puberulous branches. 
Leaves obovate- or elliptico-oblong, $1^{1 / 2}-2^{\prime} \times{ }^{1 / 2}-3^{3} / 4^{\prime}$, somewhat obtuse, or acute, the base contracting into a petiole of $3-5^{\prime \prime}$, thick chartaceous, glabrous, shining, the nerves impressed on the upper face. Stipules triangular or apiculate, $1^{\prime \prime}$, faintly pubescent at the upper horder. Peduncles $2-6 "$ long, either axillary and single, or on short axillary spurs and then sometimes 2 or 3 together, slender, puberulous, bearing 3 or 1 sessile flowers at their ends, those of the male flowers generally shorter. Bractlets linear or spathulate, $1-1^{1 / 2} 2^{\prime \prime}$. Calyx of male $f l$. scarcely $1 / 2^{\prime \prime}$, cupshaped, in the fem. $f l$. the limb much shorter than the tube, not constricted at the base. Male corolla $3^{\prime \prime}$, with 5-9 linear erect lobes; fem. corolla $1^{1 / 2} 2^{\prime \prime}$, deeply parted into revolute lobes. Styles $3^{\prime \prime}$. Drupe small ovoid, $3^{\prime \prime}$, minutely toothed at the top.

Hawaii! Kohala, Puna, Hilo (leaves acute, with often 2 or 3 peduncles in the axils). Gray, in uniting the present and preeeding species, did so under the impression that the former were high mountain forms of the present species, but against this view stands the faet that C. Menziesii has not been found in the lower regions of Ma ui or Kauai. The slender elongate pedunele also of $C$. Menz., although its bracts are sometimes foliaceous, is too much differentiated from the short and thiek spur of $C$. montana.

4. C. foliosa, Gray, 7. c. p. 48. - An open shrub, 3-5 ft, high, with slender terete glabrous branches. Leaves elliptico-lanceolate, $1-2^{1} / 2^{\prime} \mathrm{X}$ $1 / 3-3 / 4^{\prime}$, acute at both ends, the base running out into a margined petiole

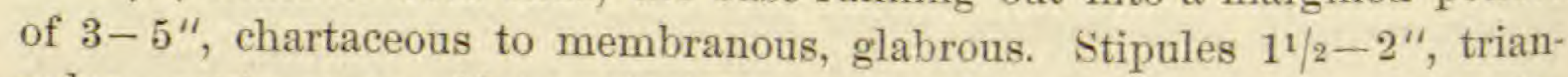
gular, acute or cuspidate, ciliolate. Peduncle $2-4^{\prime \prime}$, with $3(-5)$ sessile flowers at the end, or the lateral ones very shortly pedicellate. Bractlets $1^{\prime \prime}$. Male $f l$. Calyx $1 / 2^{\prime \prime}$, cup-shaped, repando-dentate. Corolla $4-5^{\prime \prime}$, cleft to the middle into $6-8$ lobes. Stamens $6-8$. Drupes generally single, ovoid or subglobose (obovate, Gray), 4-5", crowned by short calycine teeth, bright orange-colored.,- Wawra, 1. c. p. 317.-Euarthronia foliosa, Nutt. in herb. Hooker.

Oahu! on both ranges; Lanai! Molokai! Kalae and Maunahui - a form with small and narrow, almost rhomboidal acute leaves and generally single drupes from the axils of nearly every leaf of the short branchlets, the drupes smaller than in the other
forms, and ovoid.

Here must also be placed the imperfectly described $C$. Waimeae, Wawra, 1. c. p. 327, from Halemanu, Kauai; "drupis ternis in peduneulo axillari, plerumque geminato, petiolo sublongiore, subglobosis, cerasi fere magnitudine, calicis dentibus coronatisn.

5. C. cymosa, sp. $n$. - A straggling shrub, $6-8 \mathrm{ft}$. high, with horizontally divaricate branches pubescent at the ends. Leaves broad oblong, $2-3^{i} X$ $1-1^{1} j^{\prime}$, on petioles of $2-6^{\prime \prime}$, obtuse at both ends, chartaceons, glabrate, the under side rather pale. Stipules triangular, $11 / 2^{\prime \prime}$, pubescent at the apex. Flowers single on long peduncles of $6-9 "$, or cymosely ternate, the middle one sessile, the lateral ones on pedicels of $2-5^{\prime \prime}$; sometimes an additional pair of lateral pedicellate flowers lower down. Bractlets lanceolate, $1^{1 / 2} 2^{\prime \prime}$. Fem. $f l$. Calyx $1^{\prime \prime}$, with a short denticulate limb. Corolla $1^{\prime \prime}$, with 6 revolute lobes. Styles $6^{\prime \prime}$. Male fl. Calyx ${ }^{1 / 2}-1^{\prime \prime}$; 
corolla $3^{\prime \prime}$. Stamens 6 . Drupes bright orange, large, 4-5", globose or somewhat compressed, naked at the apex or very shortly dentate.

Haw aii! Hamakua and $S$. Kona; Oahu? Waianae range.

6. C. stephanocarpa, $s p$. $n$. - A low rambling shrub with slender pale branches pubescent at the ends. Leaves lanceolate or oblong, $1-2^{1 / 2^{4}} X$ ${ }^{1} / 3-2 / 3^{\prime}$, acute or acuminate, narrowing into margined petioles of $3-6^{\prime \prime}$, thin chartaceous, with rather straight nerves, papillose and sparsely hispid underneath. Stipules triangular, $2-2^{1 / 2} "$, ciliate, often hirsute with coarse brownish hair at the base and upper border. Flowers either single or ternate in a cluster or eymelet, or more numerous in racemes, the slender common peduncle measuring from $1^{1 / 2}$ to $7^{\prime \prime}$, the lateral flowers on pedicels of $1 / 2-2^{\prime \prime}$. Male $\mathrm{fl}$. Calyx truncate, $1-1^{1 / 3}{ }^{\prime \prime}$. Corolla 6-lobed, 2 to $2^{1 / 2}$. Fem. $f l$. Calyx $2^{\prime \prime}$, the deeply 6-parted limb constrieted at the base and longer than the globose tube. Styles $4^{\prime \prime}$. Drupes generally single, yellowish-red, small globose, only $2--2^{1} / 2^{\prime \prime}$ in diameter, or obovate, with impressed apex, and bisulcate, crowned by the spreading, lanceolate, discreet calyx-lobes, which measure $1^{1 / 2}-2^{\prime \prime}$ in length.

E. and W. Maui! at elevations of $3000-6000 \mathrm{ft}$. The forms from the higher regions have smaller leaves, hirsute stipules, and shorter, generally 1-3-flowered peduncles, while in the plants collected lower down the flowers are often arranged in racemes or fascicles, the leaves being larger and glabrate (M. \& B. 455).

B var. Kauaiensis. - Leaves obovate or suborbieular, 1-2' long. Peduncle $6-10^{\prime \prime}$, generally naked, with 3 sessile flowers at the apex, supported by spathular bracts of $1^{1 / 2}{ }^{\mu}$, or spuriously racemose, the lower pedicellate flowers in the axils of enlarged bracts. Calyx of the fem. $\mathrm{fl}$. urceolate, $1^{1 / 2}-2^{\prime \prime}$, the funnel-shaped limb longer than the globose tube and parted to the middle or deeper into $5-6$ lanceolate lobules. *Drupe small, obovate, very obtuse.» - C. pubens, var. Kauaiensis, Gray, 1. c. Wawra, 1. e. p. 323 .

Mountains of Waimea, Kauail My specimens are with flowers only; the character of the fruit is from Gray, who adds that it is naked at the apex; but the character of the flowers agrees so well with that of $\alpha$ that the absence of a crown in the fruit of his specimens must be attributed to an accidental cause.

7. C. rhynchocarpa, Gray, l. c. p. 48. - A tall arborescent shrub with spreading branches. Leaves elliptico- or obovately-oblong, $1^{1 / 2}-2^{1 / 2^{\prime}} X$ $3 / 4-1^{\prime}$, on petioles of $3-12^{\prime \prime}$, acuminate at both ends, chartaceous, papillose underneath or faintly puberulous. Stipules $2^{1 / 2}-3^{\prime \prime}$, connate into a loose funnel-shaped sheath, finally caducous, the free portions triangular, puberulous. Flowers 3 , rarely 5 or 6 , subsessile at the end of a peduncle of $2-3^{\prime \prime}$; the bracts $1-1^{1 / 2} "$. Male fl. sometimes racemose. Calyx minute, $1 / 3^{\prime \prime}$, truncate. Corolla $2^{\prime \prime}$ long, 6-8-lobed. Fem. fl. Calyx $3^{n}$, the limb twice as long as the adnate portion and equalling the corolla, constricted below, tubular or funnel-shaped, with $5-6$ small teeth. 
Styles rather short. Drupe yellowish red, globose or ovoid, 3-4", crowned with the long $\left(2-3^{i}\right)$ beak-like limb of the calyx. - Wawra, 1. c. p. 325 .

Hawaii! Kohala range and Mauna Kea.

8. C. pubens, Gray, 7. c. p. 49 (except. var. (3). - A tall straggling shrub with divaricate angular branches. Leaves lanceolate or obovateoblong, $2-5^{\prime} \times 1-1^{1} / 2^{\prime}$, on petioles of $4-9^{\prime \prime}$, acuminate, narrowing at the base, membranous or chartaceous, reticulate and papillose below, or, at higher elevations, pubescent with a short pale down, dull and dark when dry. Stipules $2-4^{\prime \prime}$, loosely sheathing on half their length, breaking away from the base at last, the free portion triangular, strigoso-pubescent, pectinately ciliate on the upper border. Flowers numerous, glomerate at the apex of short peduncles which measure not over $1-3^{\prime \prime}$. Male fl. Calyx $1^{\prime \prime}$. Corolla $3-4^{\prime \prime}$ long, 6-7-lobed. Fem. fl. Calyx $1-1^{1 / 2} 2^{\prime \prime}$, cylindrical, the very short limb dentate. Corolla $2^{\prime \prime}$ long. Styles $9-8^{\prime \prime}$. Drupes reddish, ovoid or ellipsoidal, 4-6" long, naked at the top, the pointed apex projecting beyond the calycine scar. - Wawra 1. c. p. 324 .

Haw ii! Waimea and elsewhere (drupes $6^{\prime \prime}$ long); Ma ui! Lanai! Molokai! (drupes ovoid, 4" long, 10-15 on a short pedumele, forming with the glomerule of the opposite side close clusters around the branches). Quite hairy forms are those of the U. S. E. E., from the Bullock plains, Hawaii, M. \& B.'s no. 561, from the top of Kaala, Oahu (the peduncles few-flowered), and Wawra's no. 2123, from the high plateau of Kauai, the two latter with small leaves.

9. C. longifolia, Gray, 7. c. p. 48. - A tall arborescent shrub with assurgent fistular branches, quite glabrous. Leaves ternate, elliptico-oblong or lanceolate, of even breadth in their greatest length, $2^{1 / 2}-4^{\prime} \times{ }^{1 / 2}-1^{\prime}$, on petioles of $6-9^{\prime \prime}$, acute at both ends, chartaceous, the brown veinlets distinctly reticulate underneath. Stipules rather thin, $3-6^{\prime \prime}$ long, connate into a deep and loose 3 -lobed sheath, which is early caducous by breaking from its base and by lateral splitting. Flowers 6-15, glomerate at the end of axillary peduncles of $3-5^{\prime \prime}$. Bracts $3^{\prime \prime}$, sometimes foliaceous. Male fl. Calyx $1^{\prime \prime}, 5-8$-toothed. Corolla $3-4^{\prime \prime}$, with $5-8$ lobes. Stamens long exserted, 6-8". Fem. $\mathrm{fl}$. Calyx urceolate, $2 "$, the lobes half as long as the adnate portion. Corolla $2^{\prime \prime}$, with revolute lobes. Styles $4-66^{\prime \prime}$. Drupes ellipsoidal, $3-4$ " long, reddish, tipped with the short calycine teeth. Wawra, 1. c. p. 324.

Oahu! both ranges; Hawaii! Kohala range; Kauai (Wawra). -. Neither Gray nor Wawra mention the ternate position of the leaves, which is constant in all my specimens, as also in M. \& B.'s no. 132. Dried specimens turn dark, almost black.

$\beta$ var. - Drupes small globose, bisulcate, $2-2^{1} / 2^{\prime \prime}$ in diameter, erowned by a tubular but deeply cleft calycine limb of $1^{t} / 2^{\prime \prime}$ in length. Leaves rather broad, $2^{1 / 2^{\prime}} \times 1^{\prime}$, but ternate.

Lanai! The very different shape of the fruit, similar to that of $C$. stephanocarpa, would justify a separation of this form from $C$. Iongtfolia, were not leaves and stipules too much like those of the latter. 


\section{RICHARDSONIA, Kunth.}

Calyx-limb 4-8-lobed, persistent. Corolla funnel-shaped, 3-5-cleft, with valvate lobes, Stamens $3-5$, inserted in the throat of the corolla, with slender filaments, the anthers linear-oblong, affixed near their bases, exserted. Style filiform, with 3-4 exserted linear or spathulate branches. Ovary 3-4-celled. Ovules 1 in each cell, affixed to the middle of the septum or lower. Fruit dry, papillose or prickly, $3-4$-coccous, the cocei breaking asunder after the circular rupture of the calyx below the limb, indehiscent, with 2 furrows on the inner side. Seed peltate. Embryo axile in horny albumen, with foliaceous cotyledons, the radicle terete, inferior. - Perennial, hispid herbs, with terete stems. Leaves opposite, subsessile. Stipules connate into a sheath with many bristles. Flowers small, collected in terminal heads, involucrate by the 2 uppermost leaf pairs.

A genus of 5 to 6 species, natives of tropical America.

†1. R. scabra, L. (sub Richardia). - DC. Prod. IV, 56\%. - A small decumbent herb with hirsute stems. Leaves subsessile, ovate to lanceolate, 1 to $1^{1} / 2^{4} \times{ }^{1} / 3^{1} / 2^{\prime}$, acuminate, rough at the margins and underneath along the nerves with short stiff hairlets. Stipular bristles 3 to 4 on a side, as long as their sheath. Heads many-flowered. Calyx in fruit $2^{1} / 2^{\prime \prime}$, stiff hairy, its limb as long as the tube, constricted at the base, with $5-6$ ovate lobes. Corolla twice as long as the ealyx-lobes, pubescent, white, 5-6-lobed. Fruit muricate, splitting into $3-4$ obovate flattish cocci or carpids. Embryo straight, almost as long as the albumen. St. Hilaire, Pl. Us. tab. 8. - Griseb. Fl. W. Ind. p. 351.

Kauai! on pasture lands between Koloa and Nawiliwili, and in Waimea. A native of $\mathrm{S}$. America and the W. Indies.

\section{ORDER XLII. COMPOSITAE.}

Flowers or florets collected together into a head surrounded by an involucre of several bracts, either in one row or imbricate in several rows, the whole having the appearance of a single flower. Receptacle on which the florets are inserted either naked or bearing chaffy scales or hairs or bristles (paleae) between the florets. In each floret the calyx is wanting or represented by a pappus or ring of hairs or scales on the top of the ovary. Florets either all hermaphrodite, with corolla ligular (heads ligulate), or tubular, and 5-, rarely 4-toothed (heads discoid); or those of the center or disk hermaphrodite or male and tubular, and those of the circumference female, either ligular (in Remya bilabiate), forming a ray (heads radiate), or tubular and filiform. In Xanthium and Franseria flower-heads monoecious, male and female flowers in distinct heads. Stamens 5, inserted in the tube of the corolla, the anthers linear and united into a sheath round the style (except in Xanthium and Franseria), often sagittate at the base, the basal lobes sometimes prolonged 
into fine tails (caudate anthers). Ovary inferior, with a single erect ovule. Style filiform, usually divided at the top into two short stigmatic branches. Fruit a small dry nut or achene, crowned by the pappus or naked. Albumen none. Embryo erect, with a short inferior radicle. - Herbs or shrubs, rarely trees, with alternate or opposite leaves, without stipules.

The most extensive Order among flowering plants, comprising about 10000 species, and spread over all parts of the globe.

Of the 81 species described in the following pages 61 are endemie, and of these 45 , or, if we include Lipochaeta, which has only one other representative in the Galopagos Islands, 56 are distributed between 9 endemic genera. Of these genera one, Tetramolopium, stands midway between the small Australian genus Vittadinia and the much larger American Erigeron; the other 8 are all of decidedly Ameriean affinities. Two of them, Lipochata and Campylotheca, so closely resemble American genera that some of their species have been referred to the latter by previous writers. Raillardia and with it Dubautia aiready recede a considerable distance from their next neighbor, the Raillardella, Gray, of the Sierra Nevada; but Argyroxiphium, Wilkesia, Hesperomannia and Remya, although belonging to tribes which only oceur on the American Continent, stand quite isolated, and probably belong to the oldest denizens of our islands - a supposition countenanced by the fact that each holds no more than 2 species. It is also worthy of remark that all the species of the 6 lnst named genera are woody, shrubby or arborescent, and restrieted to the higher regions. One Hesperomannia and two or three Raillardias are real trees.

Of the remaining s. endemic species one belongs to a small southern genus, Lagenophora, which has ramified from Australia northward by way of the Pacific islands and the Andes of America, and four others to two large genera, Senecio and Artemisia, which are distributed over the temperate regions of both Worlds.

of 6 non-endemic species which existed before the discovery 1, Adenostemma viscosum, is cosmopolitan in the tropics, 4, one Aster, two Erigeron and one Gnaphalium, are American, and only 1, Gnaphalium luteo-album, is of old World origin, but found in some very remote countries.

The species introduced since the discovery amount to 14 .

Flower-heads monoecious, male and female flowers in distinet heads :

Leaves entire or lobed

Leaves bi-tripinnatisect .

10. Xanthium.

Flower-heads not monoecions:

Style of all florets entire or shortly bidentate

Style of fertile flowers bifid:

11. Franseria.

Heads discoid and homogamous, all flowers tubular and hermaphrodite:

Bracts of involucure in one row, connate:

Stem undivided; pappus of stiff paleaceous seales

Stem branching; pappus of plumose bristles

Bracts of involuere in one row, free:

Leaves opposite or ternate

Leaves alternate

Bracts of involuere imbricate in more than one row:

Leaves alternate

Leaves opposite:

Pappus of $3-5$ short bristles, each tipped with a gland

Pappus of 5-10 chaffy bristles

Pappus of $2-5$ retrorsely barbed awns .

27. Hesperomannia.

Heads discoid, heterogamous:

Marginal flowers enlarged, female but sterile

Marginal flowers slender filiform, female, fertile:

Yappus of numerous capillary bristles:

Invol. bracts scarious, often colored; woolly herbs

Invol. bracts herbaceons, linear

Pappus wanting (compare also Tetramolop. conyzoides).

21. Wilkesia.

23. Raillardia.

22. Dubautia.

24. Senecio.

1. Vernonia.

2. Adenostemma.

3. Ageratum.

18. Bidens pilosa.

26. Centaurea.

9. Gnaphalium.

7. Erigeron.

25. Artemisia. 
Heads radiate, heterogamous

Receptacle paleaceous; leaves opposite:

Pappus wanting:

Inner bracts of involuere spinescent

Outer bracts of invol, ovate or oblong

Outer bracts of invol. linear, spreading, glandular

Pappus of $1-4$ short paleaceous awns; base of style bulbous

Pappus of $1-5$ retrorsely barbed or hispid awns or bristles: Achene beaked

Achene not beaked, straight, with $2-4$ barbed persistent awns

Achene not beaked, complanate, winged and straight, or wingless and curved or twisted, with 2 or 1 deciduous bristles which bear upright and retrorse ciliae, or naked; the style surrounded at the base by an ureeolate disk

Receptacle paleaceous; leaves alternate or spiral :

One palea to each floret; disk-achenes broadly winged

Paleas combined in an intra-radial ring; disk-achenes linear;

leaves linear, silvery

Receptacle naked; leaves alternate:

Ray-flowers bilabiate, not exserted; florets of disk and ray yellow; a spreading shrub

Ray-flowers ligulate, pink or pale purple:

Pappus none; disk yellow, ray pinkish; a scapigerous herb Pappus of numerous capillary bristles:

Ray-flowers in one row; disk yellow

Ray-flowers in several rows; disk purple

12. Acanthospermum.

13. Eclipta.

14. Siegesbeckia.

16. Lipochaeta.

19. Cosmos.

18. Bidens.

17. Campylotheca.

15. Verbesina.

20. Argyroxiphium.

4. Remya.

5. Lagenophora.

6. Aster.

8. Tetramolopium.

Heads homogamous, the florets all ligulate and hermaphrodite; leaves alternate:

Invol. bracts nearly equal, in a single row, with a few small outer ones

Invol. bracts unequal, imbricate in several rows

28. Crepis.

29. Sonchus.

\section{TRIBE I. VERNONIEAE.}

Heads discoid, the florets all tubular, hermaphrodite and fertile. Anthers sagittate but not caudate. Style-branches subulate. Leaves alternate.

\section{VERNONIA, Schreb.}

Florets all tubular and equal, 5-cleft. Involucre imbricate, not longer than the florets, the inner bracts the longest. Receptacle naked. Achenes mostly striate or angular, rarely cylindrical. Pappus of numerous capillary bristles, usually surrounded by an outer row of very short, often scaly bristles. - Herbs, shrubs or climbers, with alternate leaves. Flower-heads terminal or in the upper axils, in cymes or panicles or sometimes solitary.

A large genus, diffused over the tropics of all continents, excepting Australia.

†1. V. cinerea, Less. - DC. Prodr. V, 24. - An erect annual, 1 to $1^{1 / 2} \mathrm{ft}$. high, usually of an ash color, owing to a minute pubescence on stem, leaves and involucre. Lower leaves stalked, ovate, oblong or lanceolate, decurrent on the petiole, often irregularly toothed or sinuate, the upper few and narrow. Heads small, on slender pedicels, forming a terminal leafless cymose panicle. Invol. bracts acute. Corollas bluish. 
Achenes cylindrical, scarcely striate, hairy. Pappus white, the outer row very short and sometimes reduced to a few bristles. - Fl. Hongk.p. 169.

Around Honolulu and elsewhere, of late introduction. A common weed in China and India.

\section{TrIBE II. EUPATORIEAE.}

Heads discoid. Anthers almost entire at the base. Style-branches elongate, obtuse and usually thicker upwards. Leaves opposite, rarely alternate.

\section{ADENOSTEMMA, Forst.}

Heads campanulate or hemispherical. Invol. bracts imbricate in 2 rows, nearly equal, herbaceous, rarely connate into a many-toothed cup. Receptacle naked. Tube of corolla short, the limb campanulate, 5-toothed. Anthers truncate, the connective often ending in a small gland. Achenes obovoid, 5-ribbed, muricate or glandular. Pappus of $3-5$ short, stiff, spreading bristles, each tipped with a globular gland. - Viscous-hairy or glabrous perennials, with opposite, often triplinerved, almost entire leaves. Flowers small, whitish, in loose corymbose panicles.

A genus of few American species, of which the following is spread over many warm countries.

1. A. viscosum, Forst. - DC. Prod. V, 111. - Stem erect or ascending, rooting at the base, glandular-pubescent, $1--2 \mathrm{ft}$. high. Leaves triplinerved, ovate to deltoid and decurrent into the petiole, or rhomboidal, $3-6^{\prime} \times$ $1^{1 / 2}-3^{4}$, thin, coarsely toothed or serrate, on a margined petiole of $1 / 2$ 1', scabrous or papillose-hispid on both faces. Heads hemispherical, about $3^{\prime \prime}$ in diameter, in a loose-spreading di-trichotomous panicle with very small leaves under the branches. Pedicels $1 / 2^{\prime}$ or more. Invol. bracts oblong. Florets numerous, often hispid. Achenes more or less muricate. - Fl. Hongk. p. 171. - Lavenia glutinosa, Gaud. in Bot. Freyc. p. 471.

Common in the lower woods of all islands. Nat. name: sKamanamanas, An infusion of the leaves is used as a remedy in fevers by the natives. The species is widely spread over America, Polynesia, N. Australia, Asia and Africa.

\section{AGERATUM, L.}

Heads as before. Invol. bracts in 2 or 3 rows, linear, of about equal length. Receptacle flat, naked or bearing a few caducous paleas. Corolla regular, the tube scarcely distinct from the short 5-toothed limb. Anthers appendiculate at the top. Achenes 5-angled. Pappus of 5 or 10 (rarely $10-20$ ) chaffy scales or bristles, dilated and sometimes connate at the base. - Erect herbs or shrubs. Lower leaves opposite, the upper alternate. Heads small, with blue, purple or white florets, in dense corymbs or loose panicles.

A genus of about 16 American species. 
1. A. conyzoides, L. - DC. Prod. V, 108. - An erect branching annual, $1-2 \mathrm{ft}$. high, hirsute with spreading hair. Leaves ovate, $2^{1 / 2}-$ $3^{\prime} \times 2-2^{1 / 2^{\prime}}$, on hispid petioles of $1-1^{1 / 2^{\prime}}$, obtuse, crenate, truncate or cordate at the base, thin. Heads $2-3^{\prime \prime}$ in diameter, in dense terminal cymes. Invol. bracts striate, acute, in about 2 rows. Florets numerous, pale blue or white. Achenes black, smooth. Pappus of 5 lanceolate, aristate, chaffy scales, often serrate in the lower part, - Fl. Hongk, p. 171. - Hook. Exot. Fl. tab. 15.

Common in the lower regions of the whole group. Of Ameriean origin, but now diffused over most tropical countries.

\section{TRIBE III. ASTEROIDEAE.}

Heads either heterogamous and radiate, the ray-florets female, ligulate or bilabiate or filiform, the disk-florets hermaphrodite, tubular and 4-5toothed; or by defect of the ray homogamous, the florets all hermaphrodite and tubular. Receptacle generally naked. Anthers obtuse, almost entire at the base. Style-branches in the hermaphrodite florets flat or flattish, the stigmatic lines conspicuous and not confluent. Leaves alternate, rarely opposite.

\section{REMYA, Hillebr.}

Heads heterogamous, radiate, the ray-florets in one row, female and fertile, those of the disk hermaphrodite, but mostly sterile. Invol. bracts subcoriaceous, 1-nerved, appressed, imbricate in several rows, the outer ones gradually shorter. Receptacle flat or nearly so, naked. Florets resino-glandular, all of equal length, those of the ray bilabiate, the outer lip ovate or oblong, entire or bidentate, the inner one very short, entire; the disk-florets funnel-shaped, 4-5-lobed. Anthers obtuse at the base, apiculate. Style as long as the corolla, bifid, the branches flat-convex, prolonged beyond the stigmatic lines in a lanceolate appendage in the disk-florets, without appendage in the ray-florets. Achenes obconical, 3-4-angular, with 1 or 2 nerves on the broader faces, subtrunctte, those of the disk generally empty. Pappus of $3-8$ stiff, unequal, persistent bristles. - Canescent shrubs with alternate, serrate, penninerved leaves. Heads in terminal corymbs or panicles. Flowers yellow. - Benth. \& Hook. Genera Plant. II, 536.

A peculiar Hawailan genus, dedicated to Mr. Jules Remy by the author in recognition of his valuable researches in the flora of our archipelago and in grateful remembrance of friendly relations. - The corollas of the ray are distinctly bilabiate, but anthers and style differ so much from all the labiatiflorous genera grouped together in the Tribe Mutisieae that the authors of the Genera Plantarum have judged best to join our genus with the Tribe Asteroideae, in which, if the shape of the corolla be disregarded, it finds a proper place next to Grindelia among the Homochromeae.

Leaves serrate; heads ovold; invol. bracts obtuse; lobes of diskflorets revolute

Leaves dentate; heads globular; invol. bracts acute; lobes of diskflorets erect

1. R. Mauiensis.

Hillebrand, Flora of the Hawaiian Islands.

2. R. Kauaiensis. 
1. R. Mauiensis, sp. n. - A much branching shrub, about $3 \mathrm{ft}$. high, the canescent branches decumbent, and densely foliose near the ends. Leaves chartaceous, lanceolate, $3^{1 / 2}-5^{\prime} \times{ }^{1 / 2}-1^{1} / 2^{\prime}$, on petioles of ${ }^{1 / 2^{\prime}}$ or less, acute at both ends, coarsely serrate with sharp incurved serratures, canescent underneath with a thick grayish-white tomentum. Inffor. a densely flowered, soon bracteate panicle, $2-5$ ' long, the ultimate pedicels $1^{1 / 2}-2^{\prime \prime}$, the bractlets linear to subulate. Heads small ovoid, $2-2^{1 / 2} 2^{\prime \prime}$. Invol. bracts spathulate or obovate-oblong, somewhat obtuse, denticulate near the apex. Florets not much exceeding the involucre, those of the ray generally 14 , of the disk 8 . Corollas dark yellow, the outer lip of the rayflorets and the lobes of the disk-florets only ${ }^{1 / 3}$ the length of their tubes, always revolute. Achenes $3 / 4^{\prime}$, glabrous. Bristles of pappus shorter than the achene.

Maui! in gulches back of Lahaina and on a ridge of Wailuku valley.

2. R. Kauaiensis, sp. n. - An erect canescent shrub, with branches distantly foliose. Leaves ovate to elliptico-oblong, $1^{1 / 2}, 2^{\prime} \times{ }^{3} / 4-1^{\prime}$, on petioles of $1 / 4-1 / 2^{2}$, somewhat acuté, sharply denticulate with inflected cartilaginous teeth, tomentose underneath with a pale fawn-colored wool, which is less dense than in the preceding species. Panicle broad corymbose, rather open, the ultimate pedicels only $1 / 2$ ". Heads globular, less than $2^{\prime \prime}$ in diam. Invol. bracts curved, lanceolate, with black nerve, acute, ciliolate. Receptacle a little elevated and fimbrillate. Ray-florets 20 or more; diskflorets $30-40$. Corollas pale yellow, about $1 / 2$ as long as in the first species; those of the disk urceolate, with lobes as long as their tube, and erect. Achenes pubescent. Bristles of pappus soft, 2 of them longer than the achene, the others much shorter.

Kauai! Waimea, Collected by Mr. Knudsen.

\section{LAGENOPHORA, Cassin.}

Heads heterogamous, radiate, the ray-florets in one or several rows, female, fertile, the disk-florets hermaphrodite, often sterile. Invol. bracts in mostly 2 rows, imbricate, of almost equal length, with scarious margins. Receptacle convex, naked. Corollas of ray ligulate and spreading or almost tubular and short, those of the disk tubular, with ampliate limb, 5-toothed. Style-branches of disk-florets narrow complanate, with triangular or lanceolate appendage. Achenes compressed, with thick margins and nerveless faces, obovate-oblong, suddenly narrowed into a short beak. Pappus none. - Small herbs. Leaves radical or on short stems, entire or toothed. Heads single on a naked or sparsely foliose scape. Ray never yellow.

About 12 species, chiefly belonging to New Zealand and Australia, with one of their Amecies extending into tropical Asia, and one species severally peculiar to antarctic 
1. L. Mauiensis, Mann, Enum. no. 195. - A perennial herb with a thick creeping rhizome. Leaves radical or erowded on a short stem, coriaceous, sessile, spathulate, $2^{\prime} \times{ }^{1 / 3}-{ }^{1} / 2^{\prime}$, shortly acuminate, coarsely dentate or serrate toward the apex, triplinerved, sparsely covered with resinous glands above and a short evanescent pubescence, pale underneath. Scape 4-12', distantly foliose with 3-9 leaflets. Head large globose, $4-9^{\prime \prime}$. Invol. bracts in 3 rows, linear-oblong, acute, membranous, pubescent, equalling the disk. Ray·florets ligulate, entire, pointed, in 3-4 series, little longer than the yellow disk, pale red. Achenes glandular near the apex, hispid.

Maui! on the top of Eeka, in marshy ground.

\section{ASTER, L.}

Invol. bracts imbricate in several rows, of uneven length. Ray-florets generally in one row, radiating with expanded ligules. Hairs of pappus always in a single row. Otherwise as in Frigeron.

1. A. divaricatus, Torr. \& Gray, Fl. N. Amer. II, 163, var. Sandwicensis, Gray. - A much branching glabrous perennial, 2-3 ft. high. Leaves linear-lanceolate to linear, the lowest about $6^{\prime}$ long, including the long margined petiole, $3-6$ " broad above the middle, entire, thin, glabrous. Inflor. a large foliose corymboid panicle, the ultimate bracteiform leaflets subulate, the ultimate pedicels $4-5$ "long. Heads turbinate, $3-4$ " in diam. Invol, bracts linear, quite acute, with scarious margins, 3 " high, loosely patent in $2-3$ rows, the outer ones shorter. Ray-florets $20-28$, in at least 2 rows, mostly fertile, about $1 / 3$ longer than the disk-fl., the slender pale-purplish ligules expanded, entire and revolute. Disk-fl. about half as many, partly sterile, the corollae tubular, 4-toothed, with slightly ampliate limb, not projecting beyond the involucre, yellowish. Pappus soft, longer than the pubescent achenes, which are little compressed, with a prominent nerve on each face. - Walp. Repert. II, 573. - Mann, Enum. no. 196. - Tripolium divaricatum, Nuttall. Trans. Am. Phil. Soe. VII, 296. Aster subulatus, Less. in Linnaea, VI, 120 (non Michx.). - Tripol. subulatum, Nees, var. DC. Prod. V, 254. - Erigeron multiflorus, Hook. \& Arn. in Bot. Beech. p. 87.

Oahu; Kauai; Molokai! Halawa; W. Maui! Waihee; near taros-patches and running (not brackish) water. Not common; collected first by Chamisso. - The species to which Gray (Mspt. U. S . E. E.) refers our plant, is found in many of the warmer portions of the American Continent, both east and west. From the description it will be seen that its position is a rather ambiguous one between Aster and Erigeron, the imbrieate invol. pointing to the former genus, the several-ranked ray-fl. to the latter. According to the authors of the Genera Plantarum it is very similar to Erigeron fruticosus, DC., from the island Juan Fernandez. 


\section{ERIGERON, L.}

Flower-heads heterogamous. Ray-fl. female, fertile, ligulate in several series, very narrow, either longer than the involucre and erect or spreading, or shorter and filiform. Disk-fl. hermaphrodite, mostly fertile, numerous or few. Invol. bracts numerous, narrow, in one or two nearly equal rows. Receptacle flat, naked. Style-branches narrow, with lanceolate appendages. Achenes compressed. Pappus of copious capillary, nearly equal bristles, mostly in a single row. - Herbs with alternate or radical leaves. Heads usually small, corymbose or paniculate, rarely solitary and larger. - Ray-florets white or purple.

A large genus ranging over the greater part of the globe, but chiefly found in the temperate regions of the northern hemisphere.

Glabrate; pappus whitish, twice as long as the achene

Canescent, with broader leaves; pappus tawny, 4 times as long as the achene

1. E. Canadensis.

2. E. albidus.

1. E. Canadensis, L. - An erect annual with stiff wand-like branches, $2-4 \mathrm{ft}$. high, mostly glabrate or bristly-hairy. Leaves linear-lanceolate, entire, 2-3' long, those from the base cut-lobed. Heads small cylindrical, $2^{\prime \prime}$, numerous in leafy panicles. Invol, bracts linear-lanceolate, with scabrous margins, glabrate, in 2 rows. Ray-fl. numerous, scarcely exceeding the pappus, narrow filiform, minutely ligulate, white. Disk-fl. few, 4-7, tubular, $4-5$ toothed. Achenes short, $1 / 2^{\prime \prime}$, ciliolate. Pappus twice as long, expanded, whitish.

A common weed on all islands. Nat. name: Mliohes. Of American origin, but now naturalized in most parts of the globe, particularly in the temperate latitudes.

2. E. albidus, Gray, Bomplandia, IX, 36. - A perennial, stouter than the preceding, canescent with short and soft hairs. Leaves broader lanceolate, only the upper ones entire, the lower distantly serrate or laciniate. Heads larger, $2-3^{\prime \prime}$, in close panicles. Invol, as before, but pubescent. Ray-fl. pale, very numerous, filiform, scarcely ligulate, not exceeding the pappus. Disk-fl. broadly tubular, 5 -toothed, few. Achenes hairy, $1 / 4$ as long as the 1-serial erect tawny pappus. - Conyza albida, Willd. - Ineludes, aceording to Gray, C. erigeroides, DC., C. diversifolia, Weinm., C. chenopodioides, DC., C. floribunda, H. B. K., Erigeron solidaginoides, Schlecht.

Interspersed with the former species, gregarious in parts of Molokai and Maui. A native of tropical America, but now a common weed in many countries of the warmer zones.

\section{TETRAMOLOPIUM, Nees.}

Flower-heads obconical or hemispherical, heterogamous, radiate or subdiscoid. Invol. bracts linear, with scarious margins, imbricate in 3 rows, those of the outer row very short. Receptacle flat, naked. Ray-fl. numerous in several rows, female, fertile, ligulate, the ligules either longer than their tubes, explanate and white, or shorter, revolute and pale purplish. 
Disk-fl. always fewer, in some species very few, hermaphrodite, sterile in the distinctly radiate heads, fertile in the subdiscoid ones, their corollae purplish, slender, funnel-shaped or tubular, 5-fid. Anthers apiculate, obtuse at the base. Style-branches of the disk-florets short, flat-convex, with subulate apex. Achenes compressed, with stout marginal nerves and a weaker, rarely evanescent, median nerve on each face. Bristles of pappus capillary, scabrous, of even length, in one or two rows, about equalling the disk. - Low shrubby plants, resiniferous or viscous, dichotomously or verticillately branching from near the apex of the last season's growth, so as to include the old inflorescence in the fork or whorl. Leaves alternate, crowded along the youngest branches. Flower-heads single, several or many, on simple, rarely on dividing peduncles, which rise from the ends of the branches.

A Hawaiian genus bordering closely upon Erigeron and the Australian Vittadinia, but to be distinguished from the former by the 3-serial involucre, the subulate stylebranches and purple disk, from the latter by the 1-nerved faces of the achenia. Gray has joined our plants with Vittadinia, adopting however a subsection Tetramolopium for all the Hawaiian species except no. 3, which last, on acconnt of the nerveless achene, was placed in the subsection Eurybiopsis. In Bentham and Hooker's Genera Plant. the genus Tetramolopium has been restored with the species comprised under Gray's section of that name, while $T$. humile was, for the same reason as Gray's, together with Eurybiopsis, transferred to Vittadinia. But when we consider the great similarity of $T$. humile to $T$. tenerrimum, the faet that an unquestionabie variety of it exhibits faint nerves on both faces, and that, on the other hand, in $T$. Chamissonis and conyzoides the facial nerves are often so weak that they become visible only at the base, there would seem to be sufficient ground for maintaining the phylogenetic unity of all our species.

\section{Faces of achenes often nerveless}

Faces of achenes always with a median nerve:

A single flower-head at the end of each branch; ligules exserted:

Leaves stiff needle-shaped, acerose

3. T. humile.

Leaves linear or linear-spathulate, membranous

Several flower-heads in an inflorescence; ligules not or searcely exserted:

Disk-florets several :

Leaves, at least the lowest, tricuspid or sharply serrate or dentate

Leaves all entire:

Invol, bracts obtuse, dentato-ciliate

Invol. bracts aeute, entire

Disk-florets only 1 or 2

1. T. Remyi.

2. T. tenerrimum.

1. T. Remyi, Gray, Proc. Am. Ac. V, 119 (sub Vittadinia). - Erect, quite woody, ${ }^{1 / 2}-1^{1 / 2} \mathrm{ft}$. high. Leaves stiff needle-shaped, ${ }^{1 / 2}-1^{\prime}$, channelled, involute above, scabrous. Peduncles single at the ends of the branches, $1-4$ ' long, with several remote small filiform bracts - or in older plants the shorter and loosely foliose branch gradually passing into the peduncle. Heads $6-8^{\prime \prime}$ in diam. Invol. scales linear-acute, one third shorter than the disk. Receptacle slightly convex. Ray and disk quite distinet. Disk-fl. about 60 , purple, $1^{1 / 2} 2^{\prime \prime}$ long, funnel-shaped. Ray-fl. about 150 , white, in two series, exserted, $3-4^{\prime \prime}$ long, their ligules twice 
as long as the tubes, strap-shaped, revolute, 2-3-toothed. Achenes puberulous, obovate, $1^{\prime \prime}$, with a strong facial nerve (exceptionally 2 ) on each side, those of the disk all empty and terete. Bristles of pappus white, few, as long as the achene, shorter than the disk.

W. Maui! above Maalaea bay; Lanai!

2. T. tenerrimum, Nees, Aster. p. 203. -- Low decumbent, 6-9' high, only the ultimate branches foliose. Leaves patent, linear-spathulate, very acute, entire, 6-14" long, the expanded portion speedily contracting into a long filiform base, the uppermost erect, needle-shaped, channelled above as in $T$. Remyi, the lowest reflected, expanded and tridentate, even tricuspid as in T. Chamissonis, membranous and papillo-ciliate. Peduncles one or three to four from near the end of the branch, $1-2^{\prime}$ long, projecting beyond the leaves, slender, with a few filiform bracts, bearing a single large head of $3^{1 / 2}-5^{\prime \prime}$ in diam. Invol. scales linear, acute, more than $1 / 2$ the length of the head. Disk-fl. 12 to 16 , purplish, $1^{1 / 2}{ }^{\prime \prime}$ long, the campanulate limb as long as the tube. Ray-fl. 40 in one row, white, exserted, their ligules as long as the tubes or longer, subentire, expanded or revolute. Achenes $1^{\prime \prime}$, glabrate, obovate, flat, with thick margins and 1 -nerved faces, those of the disk all empty. Pappus as long as the achene, shorter than the disk, dirty white. - DC. Prod. V, 262. - Vittadinia tenerrima, Gray, 1. c. - Aster tenerrimus, Less. in Linnaea, VI, 120.

Oahu! Chamisso and Macrae. I met with it on the S. E. slope of Kaala in Makaha. The more perfect specimens gathered by myself have served for the deseription; older plants exhibit only linear, even acerose leaves.

3. T. humile, Hillebr. - Low decumbent, 4-8' high, quite villous with curly viscous hair, repeatedly dichotomous from a woody base into short and thick branches, both latest and older sets densely foliose. Leaves linear-spathulate, about $1 / 2$ ' long, acuminate, the base gradually attenuate, entire, quite hispid, thick, with a prominent rib. Peduncle single from the end of a branch, 1-2', thick and stiff, with 2 or 4 linear bractlets. Heads $6-10^{\prime \prime}$ in diam. Invol. scales lanceolate-linear, acute, scabrous or hispid, $1 / 3$ shorter than the disk. Disk-fl, 10 to 18 , pale purple, $3^{*}$ long, with slender tube, and funnel-shaped limb. Ray-fl. 20 to 24 , in one row, scarcely longer than the disk, their ligules not exceeding $1 / 3$ the length of the tube, and decreasing toward the circumference, 3-dentate. Achenes of disk and ray alike, those of the former all fertile, elongate from a narrow base, $1^{1 / 2}{ }^{\prime \prime}$, pubescent, with nerveless faces. Bristles of pappus twice as long as the achenes, numerous (36-40), apparently in more than one row, fulvous, equalling the disk or exceeding it. - Vittadinia humilis (Eurybiopsis), Gray, 1. c. p. 118, and Hook. \& Benth. Gen. Pl. II, 282.

Ma ui! Haleakala, 6000-9000 ft. 
$\beta$ var. - Plant more erect and less hairy. Heads often several from a branch and then smaller, on shorter peduncles and with fewer florets. Achenes faintly 1-nerved, particularly at the base of their faces.

Hawaii! Central Plateau, Mauna Loa, Mauna Kea.

4. T. Chamissonis, Gray, l. c. (sub Vittadinia). - Erect, 1-11/2 ft. high. Leaves hispidulous or glabrate, thin, spathulate, $8-12^{\prime \prime} \times 1-1^{1 /} / 2^{\prime \prime}$, running out into a slender base, generally with a prominent pair of teeth or serratures near the apex and then 3-nerved, 3-cuspid, or with one or more additional smaller teeth lower down, or subentire. Peduncles singleheaded, several, 7--8 from the top of a branch, 3-5" long, pubescent, forming a searcely exserted umbel or corymb. Heads $3^{\prime \prime}$ in diam. Invol. scales linear, acuminate, $1 / 2$ the height of the disk. Disk-fl. $6-12$, pale purplish. Ray-fl. 20 to 25 , shortly exserted, the ligules nearly as long as their tubes, white, generally revolute. Achenes 1", obovate, with faces strongly 1-nerved. Pappus white, equalling the disk, 1-serial. - Erigeron lepidotus, Less. in Linnaea, VI, 502. - E. pauciflorus, Hook. \& Arn. Bot. Beech. p. 87 and DC. Prod. V, 284.

Oahu! Nunanu, Waianae.

$\beta$ var. luxurians. - Larger, the leaves $1-2^{2} \times 3-4^{\prime \prime}$, laciniately tricuspid or serrate. Peduncles 8 to 14 , projecting beyond the leaves, sometimes several-headed. Heads smaller, the outermost ray-fl, decreasing in size. Achenes glabrate, flattish and often with nerveless faces.

Lanai! Oahu! Waianae.

$\gamma$ var. arbuscula. - Shrubby, $2-3 \mathrm{ft}$. high. Leaves stiffer and narrower, $1 / 2$ " broad, often almost filiform, covered with resinous dots. Heads fewer but larger, on shorter peduncles. Disk-fl, 6, purplish. - Gray, I. c. p. 120.

Maui, summit of Haleakala (U. S. E. E.).

5. T. consanguineum, Gray, 7. c. (Vittadinia). - «Shrubby, much branched, glabrate. Leaves linear-spathulate, attenuate at the base, ciliate, quite entire, seldom with one or more pairs of teeth. Peduncles several, short and slender, single- or several-headed, forming a kind of corymb. Heads small, $2^{\prime \prime}$ in diam. Invol. bracts broader than in no. 4, very obtuse, the scarious margins fringed with fine ciliate denticulations. Ray-fl, 25 to 30 , scarcely exceeding those of the disk, their ligules white, linear, as long as the tubes, protruding over the whitish simple uni-serial pappus.»

Hawaii, Waimea, and mountains of Kauai (U. S. E. E.).

6. T. arenarium, Gray, l. c. (Vittadinia). - Erect, about $2 \mathrm{ft}$. high, sparsely branching, the wand-like branches herbaceous, hispid and viscous, foliose also in the older portions. Leaves lanceolate, tapering into a plane base, $1-1^{1 / 2} \mathbf{2}^{t} \times{ }^{1 / 4}-1^{1} s^{\prime}$, shortly acuminate, mucronate, entire, 
membranous with obsolete veins, hispid. Flower-heads 5 to 10 , in terminal shortly projecting corymbs on often branching hispid peduncles of $1 / 2-1^{\prime}$, $3-4 "$ in diam. Invol. $2-3^{\prime \prime}$ high, pale, its scales broad lanceolate, thin. Disk-fl. 6 to 8 , all fertile, their corollae pale, $2^{\prime \prime}$, the limbs ampliate. Ray-fl. 30 to 35 , in several series, $2^{1} / 2^{\prime \prime}$ long, the ligules as long as their tubes. Achenes hispid, with faces strongly 1-nerved. Pappus of 20 to 26 bristles, silky-white, as long as the disk-flowers.

Maui! Kula; Hawaii! Waimea and Central Plateau.

$\beta$ var. dentata. - Leaves with 1 or 2 pairs of cuspidate teeth on each side, as in $T$. Chamissonis, but much shorter.

Maui! Hamakua.

7. T. conyzoides, Gray, 7. c. (Vittadinia). - Erect, 2-3 ft. high, much branched, hispid-villous, the ultimate branches herbaceous. Leaves oblanceolate, $1-3^{\prime} \times 2-4^{\prime \prime}$, acuminate, mucronate, entire, contracting into a distinct petiole, obscurely 3-nerved, hoary with a fine and soft pubescence. Corymb many-flowered ( $30-60$ heads), exserted beyond the leaves, the peduncles repeatedly branching. Heads small, $1^{1 / 2}$ " in diam. Invol. scales few, linear, almost equalling the disk. Disk-fl. only 1 or 2 , fertile. Ray-fl. 16-30, the outermost sterile, with very short, mostly erect ligules, which do not protrude beyond the pappus. Achenes hispid, flat, obovate, small, ${ }^{1} / 2 "$, the faces faintly 1 -nerved, the nerve often visible only at the base. Pappus white, rather open, equalling the disk.

Maui! on the isthmus and in Kula; Hawaii! Central Plateau; Lanai! (Mann). M. $\&$ B.'s no. 361 has larger and remotely dentate leaves. - The last two species have the habit of an Erigeron of the Coenotus group, and approach the same also in structure.

\section{TRIBE IV. INULOIDEAE.}

Heads heterogamous, discoid or radiate, or by defect of the ray homogamous. Anther-cells setiform or caudate at the base. Style-branches linear-obtuse, or the style of the sterile flowers often undivided. Leaves generally alternate.

\section{GNAPHALIUM, L.}

Heads heterogamous, but all flowers fertile. Involucral bracts imbricate, scarious and colored. Receptacle flat, without scales. Florets of the circumference numerous, female, filiform; those of the disk or center few, hermaphrodite, 5-toothed. Achenes oblong, nearly cylindrical, often papillose. Pappus of a single series of capillary bristles. - Herbs, more or less white-cottony or woolly. Leaves alternate, mostly soft, narrow, entire. Heads usually clustered, either in the upper axils or in terminal spikes or corymbs.

A large genus, distributed over the whole globe.

Heads in terminal clusters or corymbs; bristles of pappus free Heads in spikes; bristles of pappus united at the base 
1. G. luteo-album, L. - DC. Prod. VI, 230, - Stem simple, or branching from the base, ${ }^{1 / 2}-1^{1 / 2} \mathrm{ft}$. high, white with thick wool. Leaves woolly on both sides, somewhat clasping, the lower obovate obtuse, the upper spathulate or linear. Heads in dense leafless terminal clusters, several clusters at the end of a stem, glomerate on short or corymbose on longer peduncles. Invol, bracts stramineous, in several rows, the outer ovate, the inner lanceolate. Hermaphrodite flowers 8-10, brownish. Bristles of pappus free to the base. Achenes glabrous. - G. Sandwicensium, Gaud. Bot. Freyc. p. 464. - Lessing, in Linnaea, VI, 525.

All islands, in dry or rocky localities, particulary of the upper regions. Nat. name: "Enaenas. A common plant in many countries, diffused over nearly the whole of Europe and parts of Asia and Africa; occurs also in New Zealand.

2. G. purpureum, L. - DC. Prod. VI, 232. - An annual. Stem simple, or branching from the base, $1 / 2-1 \mathrm{ft}$. high, woolly. Leaves oblongspathulate, mostly obtuse, not decurrent, green or cobwebby above, white with elose wool underneath, the lowest $2-3^{\prime}$ long and somewhat petiolate. Heads about $1^{1 /} / 2^{\prime \prime}$ long, clustered in the axils of the upper leaves, the lower clusters distant, the upper forming a terminal leafy spike. Invol. bracts all linear-lanceolate (outer ones few), scarious but woolly, tawnywhite. Hermaphr. fl. 2 or 3 . Achenes terete. Bristles of pappus united at the base. - Gamochaeta Americana, Wedd. Chlor. And.

Oahu! near Diamond Hill; Hawail, and perhaps on other islands. A native of the American Continent, on which it extends, under a variety of names from the United States East and West to the southern extremity. Has migrated also to Hongkong and a few other places of the Old Worid.

\section{TRIBE V. HELIANTHOIDEAE.}

Heads heterogamous and radiate, the ray-florets female, ligulate or irregular, or by defect of the ray homogamous, the florets all hermaphrodite or male, tubular, 4-5-toothed. Receptacle paleaceous or ehaffy. Anthers obtuse at the base. Style-branches of fertile florets truncate or appendiculate, the style in sterile florets often entire. Pappus of few stiff awns or short scales or none. Leaves opposite or rarely alternate.

\section{XANTHIUM, Tourn.}

Heads homogamous and unisexual, monoecious. Male heads globose, many-flowered. Invol. bracts few, short, and narrow. Receptacle elevated, paleaceous. Corollas tubular, 5-toothed. Filaments united; anthers free, obtuse below, mucronate at the top. Style rudimentary, undivided. Female heads 2-flowered. Involucre united and closed, ovoid, covered with hooked prickles, 2-beaked, 2-celled. Corollas wanting. Style-branches exserted from the beaks. Achenes without pappus, enclosed within the hardened bur-like involucre, - Coarse scabrous annuals, armed or unarmed, with 
alternate lobed or toothed leaves. Heads in axillary clusters or short spikes or racemes, the upper heads male, the lower female.

About 4 widely dispersed species of uncertain, probably American origin.

$\dagger 1$. X. strumarium, L. var. echinatum. - Unarmed, 1-3 ft. high. Leaves deltoid, ovate or somewhat cordate, obtuse, on long petioles of $5-6$ ', tripli-nerved, 3 -lobed and coarsely dentate. Fruiting involucre oblong, nearly 1' in length, with straight hooked prickles and stout incurved beaks, both prickles and beaks viscous-hispid at their bases. - Gray, Manual Bot. p. 212. - X. echinatum, Murr. - X. macrocarpum, DC.

The Cocklebur, very common near Honolulu, carried over many parts of the islauds, where the burry fruits are troublesome to horses and cattle. Springs up after the first rains and dies off in summer. A widely spread weed.

\section{FRANSERIA, Cavan.}

Heads homogamous and unisexual, monoecious. Male heads manyflowered. Invol. bracts united into a 5-12-lobed herbaceous cup. Receptacle flat, naked or with filiform paleae. Corollas with very short, tube and eampanulate 5-toothed limb. Anthers almost distinet, obtuse at the base, apiculate or setose at the inflected top: Style undivided. Female heads 1-4-flowered, several united into a glomerule, interspersed with bracts. Involucre united, and closed over the achenes, 1-4-celled, 1-4-beaked at the top, and armed when mature with several rows of prickles or spines. Corolla none. Style deeply bipartite, the branches exserted. Achenes without pappus, enclosed in the indurate involucre or its cells. - Hairy herbs. Leaves alternate or the lowest opposite, cut-lobed or pinnately dissected. Heads small, inconspicuous, the male subsessile and nodding in terminal spikes or racemes, the female sessile in the axils of the uppermost leaves.

About 10 species, all from the W. coast of America.

† 1. F. tenuifolia, Gray, in Pl. Fendl. p. 80. - An erect annual, 1 to $2 \mathrm{ft}$. high, canescent. Leaves pubescent, hoary underneath, twice or thrice pinnatisect into linear segments with smaller lobes interposed, the terminal segment longest. Male heads 10-20 flowered, greenish-yellow. Invol. 5-7-toothed, hispidulous. Anthers 5-6, subsessile. Female involucres $1-2^{\prime \prime}$ long when mature. 1 -flowered in our specimens, with a $1-2$ toothed beak and $5-7$ uncinate spinelets (accrete bracts) at the base; many involucres crowded into glomerules which are surrounded by and interspersed with broad-ovate hispid bractlets. - Bot. Californ. I, 346.

Gregarious along roadsides in Ewa and Punahou, Oahu! Has a heavy scent like wormwood. A late importation from Mexico or Lower California; was first observed in 1854 . 


\section{ACANTHOSPERMUM, Schrank.}

Heads heterogamous, radiate. Invol. bracts herbaceous in one row. Receptacle small, conical, paleaceous, the outer paleas bearing hooked prickles and folding round the achenes. Ray-florets in one row, female, fertile, their ligules short, 3-toothed. Disk-florets hermaphrodite, sterile, with short tube and campanulate 5-fid limb. Anthers truncate below. Style of disk-florets undivided. Achenes compressed, without pappus, enclosed by the prickly paleas. - Diffuse branching annuals with opposite leaves, which are glandular beneath. Heads small, solitary and subsessile at the ends or in the forks of the branches. Flowers yellow.

Two species of tropical America.

†1. A. Brasilum, Schrank, Pl. Rar. Hort. Monac. II, 53. - Pubescent. Leaves ovate or obovate, toothed or almost entire, petiolate. Ray-florets 5. Outer paleas (enveloping the achene) furrowed, armed with soft hooked prickles, obtuse, not beaked at the top. - A. xanthioides and A. hirsutum, DC. Prod. V, 521 \& 522.

Kauai (U. S, E. E. and Wawra).

\section{ECLIPTA, L.}

Heads heterogamous, radiate. Invol. bracts in two rows, broad, almost leafy. Receptacle flattish, the outer paleas folding round the achenes, the inner very narrow or wanting. Ray-florets in two rows, female, shortly ligulate, the ligules entire or 2 -toothed. Disk-florets hermaphrodite, fertile, tubular, 4-5-toothed. Style-branches of disk-florets linearflattened, obtuse. Achenes of the ray triangular, of the disk flattened. Pappus none or reduced to a border of minute teeth. - Diffuse herbs with opposite leaves. Heads single or twin at the ends of the branches or in their forks.

A genus of 4 species, 3 Ameriean and 1 Australasian.

†1. E. alba, Hassk. - Miq. F7. Ned. Ind. II, 65. - "A branching annual, usually prostrate and creeping, sometimes ascending or erect, $1 \mathrm{ft}$. long or more, sprinkled with closely appressed short hairs. Leaves shortly stalked, from nearly ovate to oblong-lanceolate or almost linear, $1-2^{\prime}$ long, coarsely toothed to nearly entire. Peduncles very variable in length, the single flower-head about $3^{\prime \prime}$ in diameter. Ray-florets small, white.» - Benth. Fl. Hongk. p. 181. - Verbesina alba, L. - E. erecta and E. prostrata, L. and the whole section Eueclipta of DC. Prod. V, 490.

Along water courses near Honolutu; of recent introduetion, A common weed throughout the warmer regions of the globe. 


\section{SIEGESBECKIA, L.}

Heads heterogamous, radiate. Invol, bracts in about 2 rows, the outer linear-spathulate, spreading, glandular-hispid, the inner like the scales of the small receptacle, half enclosing the achenes, glandular-hispid on the back. Ray-florets in a single row, female, fertile, shortly ligulate or irregularly 2-or 3-lobed. Disk-florets hermaphrodite, tubular, 5-toothed, fertile, or the inner ones sterile. Style-branches of disk-florets short, somewhat flattened, obtuse. Pappus none. - Herbs with opposite leaves. Heads small, in loose leafy panicles.

Two species, of which the following is widely distributed over the warmer regions of the world, the other belonging to S. America.

†1. S. orientalis, $L$. - DC. Prod. V, 495. - A pubescent, branching, rather stiff annual, $1-2 \mathrm{ft}$. high. Leaves from broadly ovate-triangular to lanceolate, 2-4' long, on petioles of variable length, nsually dilated upward, but not at the base. Heads $3-6^{\prime \prime}$ broad, in a dichotomous leafy panicle. Outer invol. bracts often $4-5^{\prime \prime}$ long. Florets of the ray 5 , very short, of the disk about 10. Achenes turgid and usually curved. Benth. Fl. Hongk. p. 182.

In the neighborhood of Honolulu; a late arrival.

\section{VERBESINA, L.}

Heads heterogamous, radiate. Invol. bracts in about 2 rows. Rayflorets in one row, female, ligulate. Disk-florets hermaphrodite, fertile, with short tube and elongate 5-cleft limb. Paleae lanceolate, those of the disk folding round the achenes. Achenes of the disk flat, winged. Pappus of 2 setose bristles which either fall off or coalesce with a projection of the wing. - Chiefly herbs with opposite or alternate leaves. Heads irregularly corymbose, or the larger ones solitary at the ends of the branches; corollas yellow, rarely white.

A large genus, diffused over the warmer parts of the American Continent.

1. V. encelioides, Benth. \& Hook. in Gen. Pl. II, 380. - An erect canescent annual, $1-2 \mathrm{ft}$. high. Upper leaves alternate, broadly ovatetriangular to lanceolate, $2-3$ ' long, acute, sharply serrate, strigoso-pubescent on both faces, gray underneath. Petioles about $1^{\prime}$ long, winged and broadly auriculate at the base. Heads hemispherical, 8-9" broad. Invol. bracts herbaceous, canescent, linear-lanceolate, the outer ones as long as the disk or longer. Receptacle convex. Tubes of corollas hairy. Ligules twice as long as their tubes, cuneate-oblong, 3-lobed, bright yellow. Disk-achenes pubescent, with a median rib on each face, broadly winged, deeply emarginate at the top. Bristles of pappus caducous. Ray-achenes glabrous, not winged, smaller and apparently sterile. - Bot. Calif. I, 350. - Ximenesia encelioides, Cavan., DC. Prod. V, 627.

Maui! on the isthmus and in Kula. - A native of Mexico, Arizona and Texas. 


\section{LIPOCHAETA, De Cand.}

Flower-heads hemispherical, heterogamous, radiate. Involueral bracts herbaceous to coriaceous, 2 -seriate, $4-7$ in each row, of nearly equal height. Receptacle plano-convex, its paleae stiff, cuneate, folded round the achenes and longer than these, persistent. Ray-flowers female, fertile, 1 -seriate, the ligules patent, several times longer than their tubes, entire or 2-3-toothed. Disk-flowers hermaphrodite, the outer ones fertile, their corollae with a short narrow tube and a campanulate 5 -toothed limb. Anthers minutely sagittate. Style bulbous at the base, its branches linearobtuse, and in the disk-flowers with a conical appendage. Achenes obovate, those of the ray trigonous, of the disk compressed, with sharp, often winged or eroded angles, the obtuse apex surrounded by a coronula of hairs or stiff scalelets. Pappus of 3 or 2 , rarely 4 or 1 short awns or teeth (in one species wanting) around a narrow epigynous disk. Perennial herbs with woody base, mostly scabrous or canescent with stiff hairlets. Leaves opposite, entire, lobed or pedately cut, with the segments pinnatisect. Inflorescence a terminal simple or compound cyme with the median ray or peduncle little shorter than the lateral ones, often reduced to a single peduncle and flower-head. Corollas of disk and ray yellow.

A genus of 12 species, one of which belongs to the Galopagos Islands, nearly related to the American genus Zexmenia and to Wedelia. Characteristic is a pair of prominent nerves, which in the sessile leaves is about the third from the base and leaves the midrib at a more acute angle than the others, sending backward one or more strong rays. In the petiolate leaves that part of the blade which lies below this pair is suppressed, in consequence of which they appear triplinerved. In lobed leaves these nerves determine the direction of the sinuses or slits. - Nat. name of all species: "Nehe.

Leaves entire:

sessile, often clasping; cyme compound, foliose petiolate:

1. L. connata.

ovate:

rounded at the base, with petioles not margined, seabrous; cyme simple or compound

contracted at the base into a margined petiole, fleshy, smooth; inflor. a single flower-head

2. L. calycosa.

3. L. succulenta.

cordate or truncate at the base, the petiole not margined; cyme simple or compound

lanceolate, triplinerved; inflor. eymose

linear, single-nerved; inflor. a single head

4. L. subcordata.

5. L. lavarum.

6. L. integrifolia.

Leaves palmately lobed:

stiff and seabrous, large:

sessile, with elasping base, oblong or hastately lobed . . 7. L. hastata.

petiolate, ovate in outline, 3-5-lobed $\quad$ 8. L. lobata.

thin herbaceous, small:

sessile; ultimate segments euneate; cyme simple.

10. L. micrantha.

sessile; ultimate segments linear-filiform; infl. a single flowerhead.

11. L. tenvifolia.

petiolate; ultimate segments cuneate; cyme simple or compound

9. L. Remyi. 
1. L. connata, DC. Prod. V, $611 \& 619$. - Suffrutescent, $3-4 \mathrm{ft}$. high, much branching and spreading. Leaves thin, dark green, scabrous above, hispid on both faces, rhombeo-ovate, $5-8^{\prime} \times 2-3^{1} / 2^{\prime}$, quite acute, irregularly laciniate-serrate, moderately narrowing below into a broadly clasping, often auriculate base. Inflor, a compound corymbose cyme of 3 (to 5) terminal rays, 4-5' long, viscous-hispid, the lateral rays, and generally also the median, dividing again in an irregular subpaniculate manner. Outer bracts of involucre herbaceous, linear-or ovate-lanceolate, long acuminate, equalling or exceeding the disk. Disk $3-4$ ". Paleae obovate, shortly pointed. Ligules $10-12$, oblong or obovate-oblong, subentire, $8-10^{\prime \prime}$ long. Achenes pubescent at the top, with 2 or 3 short subulate teeth round a narrow disk, their margins narrowly winged when young, but thick suberose, warty, when old. - Verbesina connata, Gaud, in Bot. Freyc. p. 464. - L. australis, «, Gray.

Maui! isthmus, Wailuku; Kahoolawe.

$\beta$ var. decurrens. - Leaves contracting at the base and sessile, but not clasping, broad rhomboidal as before, or lanceolate, stiff and harsh with more prominent nerves, generally less deeply serrate, $3-6^{\prime} \times$ $1^{1 / 4}-2^{1} / 4^{\prime}$. The median ray of the inflor. generally undivided. Ligules strap-shaped, entire or shortly toothed, $4-5^{\mu}$. - L. australis, $\beta$, Gray. Microchaeta lanceolata, Nutt. - Mrs. Sinclair, pl, 21.

All islands, from the plains up to 2000 or $3000 \mathrm{ft}$.

$\gamma$ var. littoralis. - Leaves rather fleshy, chartaceous when dry, but not harsh, with inconspicuous veins, faintly hispidulous on both faces, rhomboidal or ovate, with contracted sessile base, but not clasping, obtusely erenate or shortly serrate. Outer invol. bracts ovate, shorter than the disk. Ligules obovate, $4-5 "$. Mature achenes warty, with thick runcinate angles and 2 or 3 short cartilaginous teeth or none, the top round the disk pubescent or glabrate.

Northern shores of Molokai! Kalawao; Maui (M. \& B. 375); Hawaii!

2. L. calycosa, Gray, Proc. Am. Ac. V, 130. - Suffrutescent, 2 ft. high. Leaves pale, scabrous, glabrate above, stiff pubescent underneath, ovate or lanceolate, with rounded base, $1^{1 / 2}-2^{1} / 2^{t} \times{ }^{1 / 2}-1^{1} / 4^{\prime}$, somewhat obtuse, obsoletely crenate-serrate, on petioles of $1-2^{\prime \prime}$, the lanceolate ones prominently tripli-nerved. Inflor. mostly a simple cyme, 1-2' long, with the shorter median ray aphyllous. Outer bracts of invol. coriaceous, longer than the disk, oblong or obovate, quite obtuse. Paleae stiff, carinate, broatly obtuse. Ligules $4-5^{\prime \prime}$ long, strap-shaped. Achenes with thick warty margins, the 2 or 3 unequal awns about half their length and connected by intermediate scalelets or hairs.

Oahu! dry rocky region between Diamond Hill and Koko Head. 
\& var. - Leaves ovate, acute, sharply serrate, darker green and thinner, not scabrous, petiolate. Inflor. and flower-heads as in $\beta$ of no. 1 , the involucral bracts herbaceous, narrow acute.

Ka ua I! (Kn, and M. \& B. 542), - Might as well pass for a petiolate variety of no. 1.

3. L. succulenta, DC. 7. c. - Hook. \& Arn. in Bot. Beech p. 8\%. "Herbaceous, fleshy, glabrous. Leaves glossy, ovate-oblong, obtuse, mucronulate, crenulato-serrate above the middle, the base attenuate into a short petiole. Inflor. a solitary peduncle. Outer invol, bracts orbicular. Achenes compressed or trigonal, with one angle sharp or produced into a denticulate wing and crowned by 2 or 3 short awns.»-Gray, I. c. - Verbesina succulenta, Hook. \& Arn.

Niihau and Kauai, near the shore. Collected only by Lay \& Collie and by Remy.

4. L. subcordata, Gray, l. c. p. 130. - Herbaceous, erect, 1-2 ft. high, loosely foliose, pubescent. Leaves ovato-cordate or deltoid, $1^{1 / 2}-2^{\prime} \times$ $1-1^{1 / 2}$, on immarginate petioles of ${ }^{1 / 2}-1^{\prime}$, acute, duplicato-serrate, triplinerved, membranous, with a short and soft grayish pubescence. Inflor. a compound cyme, the two lateral rays or branches elongate, foliose and once or twice dichotomous, the median often accrete to one of them. Heads small, the disk $2-3^{\prime \prime}$. Outer invol. bracts patent, ovate, bluntish,

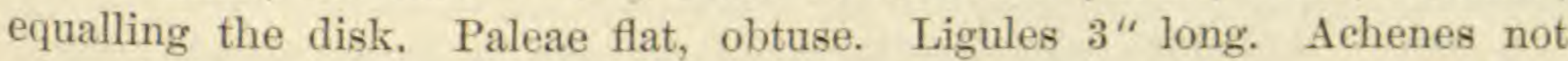
winged, but dentate or warty at the angles, with a paleaceous coronula at the apex; the awns slender, of nearly the length of the achene, rarely more than one, often wanting.

Hawaii! S. Kona, Kau, Puna. A very distinct species. Maui! back of Lahaina (leaves deltoid, flower-heads larger).

5. L. lavarum, DC. 7. c. - Suffrutescent, erect, 1-1'/2 ft. high, with stiff strigoso-canescent branches. Leaves elliptico-lanceolate, 1 to $3^{\prime} \times 3-6^{\prime \prime}$, including a petiole of $1-4^{\prime \prime}$, acute at both ends, serrulate, crenate or almost entire, canescent, thick, strongly tripli-nerved. Heads $3-4^{\prime \prime}$ in diam. Infl. a simple cyme with stiff peduncles of variable length, 1-3'. Outer invol. bracts stiff coriaceous, canescent, obtuse, shorter than the conical disk. Paleae hooded and keeled. Ligules 9 to 12, tridentate, $6-10$ " long. Achenes thick and short, broadly winged, the wings expanding upward in broad processes which, together with the paleaceous hair, form an outer coronula round the long and stout awns. - Gray, 1. c. - Verbesina lavarum, Gaud, in Bot. Freyc. p. 464.

Maui! Lariai! Hawaii, on dry rocky slopes of the leeward sides.

$\beta$ var - Leaves linear-lanceolate, $2-3$ " broad, somewhat obtuse, quite entire, thin membranous, with feeble nerves, green on the upper and only faintly pruinose on the lower face.

Maui, near Lahaina (E. Bishop). 
$\gamma$ var. - Leaves linear-oblong or spathulate, rather fleshy, coriaceous when dry, tripli-nerved, canescent, quite obtuse and entire. Peduncles 3, 2 or 1 , at the end of a branch. Achenes with interrupted wings, the top surrounded by a pectinate coronula of equal stiff triangular scalelets, the incurved puberulous awns or teeth of the pappus early deciduous, mostly wanting in the mature fruit of the radial flowers. - A low divaricately branching and spreading shrub, the leaves in my specimens only $1^{\text {' long. }}$ - L. Lahainae, Wawra, in Flora, 1873, p. 77.

Ma ui! Lahaina and Maalaea bay, on rooks near the sea.

6. L. integrifolia, Gray, l. c. p. 130. - Low prostrate, canescent, the branches not over $1 \mathrm{ft}$. long, with a woody base. Leaves linear to spathulate, 1/2-1' long, obtuse, entire, thick, veinless, silky-haired on both faces. Flower-heads solitary at the ends of short branches, $2-3$ "broad, on naked peduncles of $1-2^{\prime}$. Invol. bracts shorter than the disk, obtuse or rounded. Paleae stiff, keeled, obtuse. Ligules very short, $2-2^{1} / 2^{\prime \prime}$, tridentate. Achenes stout obconical, pilose at the apex, their angles lacerate or dentate; awns very short, obsolete. - Microchaeta integrifolia, Nutt. in Transact. Am. Phil. Soc. VII, 451. - Walp. Repert. II, 620.

In sandy soil near the seashore. Kauai; Oahu! Puloa, Kaena; Maui, Madaca, Waihee,

$\beta$ var. - Suberect, scarcely canescent, the leaves $2-3$ " broad, spathulate, faintly 3 -nerved.

Oahu! Kailua.

7. L. hastata, sp. n. - A weak straggling undershrub, scabrous but glabrate, the slender branches often twisting or leaning for support on other shrubs, bearing at their ends 1 or 3 slender single-headed peduncles of $3-5^{4}$. Leaves thin chartaceous, scabrous, oblong, $1-2^{4} \times 1 / 4-3 / 4^{4}$ obtuse, mucronate or emarginate, sessile and clasping, with a broad or contracted base, entire or finely dentieulate, most of them bluntly notched or lobed above the lower third. Heads $3-4^{\prime \prime}$ in diam. Invol. bracts puberulous, ovate or oblong, acuminate, equalling the disk. Paleae flat, mucronate. Ligules 4-5" long, 3-dentate. Achenes with lacerate angles and short chaffy apical hairlets, the awns dilated at the base but not connate, sharp pointed, about half the length of the achene.

Lanai! A form from W. Maui! is stouter, rather hispid, with coarser leaves of $2-3^{\prime}$ in length.

8. L. lobata, DC. l. c. - Suffrutescent, rather erect, about $2 \mathrm{ft}$. high, scabro-hispid. Leaves pale, chartaceous, scabro-hispid on both faces, ovate in outline, $1^{1 / 2}-3^{\prime} \times 1-2^{\prime}$, palmately $3-5$-lobed, the lobes acute and serrate or incised, the middle one longest, the base truncate but suddenly decurrent into a margined petiole of ${ }^{1 / 2}-1^{1} / 2^{i}$; nerves prominent. Inflor. a compound cyme as in no. 2. Heads about $3^{\prime \prime}$, on 
pedicels of $1 / 2-1$. Invol. bracts ovate-lanceolate, acute, as long as the disk. Ligules $4-6^{\prime \prime}$ long. Paleae cuneate, shortly acuminate. Achenes with narrow eroded wings running out into upward processes, the apex hispidchaffy, the awns short and broad, connate with their bases. - Verbesina lobata, Gaud. in Bot. Freyc. p. 464, and Hook. \& Arn. in Bot. Beech. p. 87. L. australis, var. $\gamma$, Gray, l. c. - Lipotriche australis, Less, in Linnaea, VI, 510. - Includes also Verbesina hastulata, H. \& A. 1. c.

Eastern end of $\mathrm{Oahu}$ ! and western end of Molokai! in dry rocky places.

$\beta$ var. heterophylla. - Leaves more deeply, almost to the base, $3-5$ parted, with linear lobes, the median much the longest, all dilating toward the end, irregularly incised and dentate. Peduncles generally 3 at the end of a branch. - L. heterophylla, Gray, l. e.

Molokai! Kamalo; Maui! (a large Ieaved form with long virgate branches).

9. L. Remyi, Gray, l. c. p. 131. - «Herbaceous, much branching, spreading, hirsute with grayish hair. Leaves ${ }^{1 / 2^{\prime}}$ long, petiolate, oblong, obtuse, often distantly toothed or almost lobed, the upper ones alternate. Flower-heads small, 2-3" long, subpaniculate, shortly pedunculate. Bracts of involucre oblong, obtuse. Ligules 5-7, short obovate. Rayachenes tuberculate along the angles or interruptedly winged, pubescent at the top, those of the disk empty. Pappus obsolete.s

Oahu (Remy). - Not seen by me, but to it I must refer, notwithstanding some discrepancy in the description, the following.

$\beta$ var, - Leaves thin membranous, pale, hispid, ovate or deltoid in outline, $9-15^{\prime} \times 6-12^{\prime}$, palmately cut into 3 to 5 sinuate or incised lobes which dilate toward their ends, the middle one longest, on wingless petioles of $6-10^{\prime \prime}$. Inflor. of 3 short hispid peduncles of $6^{\prime \prime}$ or less, but often the 2 lateral ones elongate into foliose floriferous branches. Heads small, $1^{1 / 2}-2$ "in diam. Invol. bracts few, lanceolate or spathulate, hispid, the outer ones patent. Paleae obovate, with recurved apex or mucro. Ligules few, obovate, short. Achenes wingless, slightly hairy at the apex, the pappus reduced to a single slender bristle or wanting altogether. A diffuse, dichotomously branching, scabro-hispid herb with slender branches.

Northern slope of Kaala, Oahu! As to division of leaves almost like var. heterophylla of the preceding species, but a much more delicate plant. M. \& B. 533 is from the same region.

'r var. ? - Leaves 2' long and broad, pedately 5-parted to the base, the segments cut again to the winged rhachis into narrow cuneate or oblong and bi- to tri-sected lobules.

A single flowerless specimen collected on a ridge of the main range of 0 a hu! quite herbaceous and almost glabrous, the slender branch virgate, $1^{1 / 4} \mathrm{ft}$. long without dividing, with_internodes of $3-4^{*}$.

UTill Hillebrand, Flora of the Hawaiian Islands. 
10. L. micrantha, Gray, l. e. «Herbaceous, much branching and diffuse, the branches shortly hispid and very slender. Leaves membranous, twice or thrice pinnato-partite, the small segments cuneate, often 2-3-lobed. Flower-heads 3 at the end of a branch, on short peduncles (subsessile Endl.), $2^{n}$ in diam. Outer bracts of involucre linear-spathulate, patent. Paleae acuminate. Ligules 2 or 3 , obovate, bidentate. Disk-flowers 6 to 8 . Style bulbous at the base. Achenes wingless, shortly pubescent at the top, their awns evanescent.» - Schizophyllum micranthum, Nutt. - Aphanopappus, Endlicher, in Gen. Plant. Suppl. II, 43. - Walp. Repert. II, 620.

$\mathrm{K}$ a uai, in shady woods of Koloa, Hanapepe, Waimea. - Collected by Nuttall, Remy and Mann \& Brigham. It is not stated whether the leaf is sessile or petiolate; in the latter case it would hardly differ from that of var. $\gamma$ of the preceding species.

11. L. tenuifolia, Gray, 1. c. - Herbaceous from a woody base, the long and slender branches decumbent, $1-2 \mathrm{ft}$. long, with few and distant ascending branchlets and long internodes, glabrate. Leaves sessile, $2-3$ r long, pedately cut to the very base into 3 or 5 segments, which are again deeply pinnatisect to the rhachis, the rhachides and lobules being alike linear-filiform, the latter quite acute, the whole appearing like a whorl of 6 or 10 pinnate leaves round the node. Peduncle single at the end of a branch or in the fork of two long floriferous branches, the head $3^{\prime \prime}$ broad. Invol. bracts lanceolate, exceeding the disk. Receptacle conical. Paleae scarious, bluntly acuminate. Ligules $8-10$, broad obovate, $3-4$ " long, 2-3-dentate. Style bulbous at the base, the branches with a conical termination. Achenes $1 / 2-1 "$, wingless, with an apical coronula of short paleaceous hairs. Pappus of 2 to 4 subulate awns which equal the young achene.

Oahu! Waianae range, Makaha.

\section{CAMPYLOTHECA, Cassin. char. auct.}

Heads heterogamous, radiate. Involucral bracts herbaceous in 2 rows, 5 to 8 in each, the outer narrow, free from the base and somewhat spreading, generally shorter than the inner ones, which are broad and appressed, similar to the paleae and equal to them in length. Receptacle flat, paleaceous, its paleae flat and thin, shorter than the mature achenes, deciduous. Ray-florets $3-8$, neutral, sterile, their ligules entire or $2-3$ toothed. Disk-florets hermaphrodite, fertile, the limb campanulate, 5-cleft, longer than the tube. Anthers bidentate at the base, appendiculate at the top. Style surrounded at the base by a tubular or urceolate nectary, its branches clavately dilated, with a short conical or (in one species) subulate appendage. Achenes black, linear, compressed, their faces parallel to the paleae, lineolate, the margins stiff ciliate and mostly winged (at least in the immature state), the apex not beaked, chaffyciliolate, and generally crowned with 2 slender erect- and retrorsely-ciliate 
deciduous awns or teeth. - Shrubs or suffruticose herbs, glabrous, with opposite simple or variously pinnatisect leaves, and yellow flowers. Heads single on a terminal peduncle or in cymes or corymbs. - The inner involucral bracts represent the paleae of the sterile ray-florets.

A Hawaiian genus intermediate between Bidens and Coreopsis.

The plants comprised under this genus form a compact group and cannot well be generically separated without doing violence to nature. Gray, relying on the supposed absence of retrorsely barbed or eiliate awns in some species, divided them between the genera Coreopsis and Bidens, but careful examination of the much larger material in my possession has revealed the presence of such awns in immature achenes of some of the species which were supposed to be destitute of them, and also in the mature achenes of manifest varieties of others of the same class. In such species the awnlets are very slender and fall off early, and their barblets, which however are always accompanied by erect cilioles, can only be seen under a magnifying power. Thus far barblets have been found wanting only in C. Menziesii, which is elosely connected with the barbed C. micrantha, and in C. cosmoides. The genus, as it presents itself now, stands evidently nearer to Bidens than to Coreopsis, and might be merged in the former if it were not for the winged achenes of so many species, which, if admitted in the character of Bidens, would efface the limits between that genus and Coreopsis. There are also never more than 2 awns, and the achenes are quite flat, while in all true Bidens they are more or less 4-gonal, at least with a rib on both faces, and bear 2 to 4 persistent awns. The genus Campylotheca, thus uniting the two most prominent characters of Bidens and Coreopsis - barbed awns and winged achenes - cannot be dispensed with unless both genera shall coalesce in one of indefinite limits, while by the twisting of the achenes, the limited number of awns, the presence of glands in the involucral scales of several species, and the tubular or urceolate nectary round the base of the style, distinctive characters of minor importance are furnished. This nectary, which seems to be present in all species, and remains visible for a long time as a pale and small cup at the apex of the achene, is replaced by a low shallow disk or annulus in those species of Bidens which I have had an opportunity to examine.

The plants, when bruised, emit a peculiar carroty odor, and several species are employed as sudorific remedies by the natives, who know them by the generic name -Kokolan.

Leaves undivided:

Inflorescence a single-headed peduncle

Inflorescence a $3-5$-headed cyme.

Inflorescence a many-flowered paniculate corymb

1. C. Molokaiensis.

4. C. dichotoma.

7. C. Hawaiiensis.

and var. $\beta$ of 9. C. macrocarpa.

Leaves cut into 3 to 7 leaflets:

Inflor. a single-headed peduncle

Leaflets 3 ; mature achenes awnless

Leaflets $3-5$; achenes with barbed awns .

Leaflets 5 ; flowers very large, $1^{1 / 2}-2^{*}$ in diam.

Leaflets $3-5$, bipinnatisect into short cuneate segments

Inflor, a many-flowered corymb

Leaflets $5-3$, petiolate.

Leaflets $5-3$, sessile:

Corymb not exserted beyond the leaves; heads large; achenes with distinctly barbed awns; leaflets spinuloso-serrate, ovate, with short cuneate base

8. C. Sandwicensis.

Corymb projecting beyond the leaves; heads small:

Leaflets undivided, narrow-lanceolate, rhomboidal, serrate only at the middle

Leaflets pinnatiseet into entire linear segments.

2. C. pulchella.

3. C. Remyi.

6. C. cosmoites.

5. C. Mauiensis.

9. C, macrocarpa.

Inflor, an elongate paniele

11. C. mierantha.

12. C. Menziesii.

10. C. grandiflora.

a. Adenolepis. Low, prostrate, with mostly dichotomous branches. Inflor. a single peduncle or a simple cyme. Invol. bracts often tipped with a terminal gland. 
1. C. Molokaiensis, sp. n. - Low, diffuse, woody only at the base, the branches crowded at the end of a short stem, 6-12' long, prostrate-erect, scarcely dividing, often rooting. Leaves ovate or deltoid, $1-1^{1} / 2^{1} X^{3} / 4-1^{\prime}$, on petioles of $3 / 4-1^{1} / 4^{\prime}$, acuminate, serrate, the broad base often subcordate, pale underneath. Flower-heads single on a terminal naked peduncle of $4-8^{\prime}$, with sometimes 1 or 2 equally long bracteate peduncles alongside of it. Disk $4-5^{\prime \prime}$ in diam. Invol. bracts 8 in a row, the outer ones longer than the inner, some or all of them tipped with a large gland. Ray-fl. 8, obovate, entire, 6" long. Disk-fl. 24. Style-branches short, little exserted, with conical appendage. Achenes linear, 5 " long, straight, wingless, ciliate at top and aristate with 2 sharp awns, which are retrorsely ciliate near the apex.

N. shore of Molokai! Waikolu.

2. C. pulchella, Hillebr. - «A slender annual (?), puberulous. Leaves petiolate ternatisect, or the upper sessile ones 3 -lobed. Heads small, $2^{\prime \prime}$ high, solitary. Ray-fl. about 4, the ligules elliptical, 2-dentate. Invol. hispid, as long as the disk, the external bracts (?) tipped with a large gland. Achenes hispid, wingless and awnless, attenuate above. - Adenolepis pulchella, Less. in Linnaea, VI, 510, tab. 6. - DC. Prod. V, 607.

Collected by Chamisso on Oahu. My herbarium contains two small specimens from Molokai which in many respects agree with Lessing's description; they do not however come from an annual plant, but from one which has the habit of no. 1. The coarsely serrate leaves with their petioles measure $1-2^{\prime}$, the terminal leaflet being larger than the narrow cuneate lateral ones. Peduncle 4'. Ext. invol. bracts 8, linear-lanceolate, somewhat obtuse, not all of them glandular at the apex. Disk as large as in no. 1. Ray-fl. short obovate, less than $3^{\prime \prime}$. Immature achenes winged as in no. 5, the wings extending to and fringing the two short and broad awns, which are smooth otherwise.

3. C. Remyi, sp. n. - Branch herbaceous, apparently prostrate and rooting, angular, $1-1^{1 / 2} \mathrm{ft}$. long. Leaves $3 / 4-1^{1} / 4^{\prime} \times 1 / 2-3 / 4^{\prime}$, on petioles of $7-9^{\prime \prime}$, pinnately cut into 3 to 5 decurrent, obovate or oblong, obtuse, crenate segments. Flower-head single on a terminal peduncle of $2^{\prime}$. Disk $4-5 "$ in diam. Achenes ciliate, with 2 stiff awns of about ${ }^{1 / 3}$ their own length, which are armed with pale retrorse barblets.

Hawaii, Hilo (Remy 287). Invol. glands were not noticed, or perhaps overlooked, on the single defective specimen in hb. Gray.

4. C. dichotoma, sp. n. - Low, prostrate, with woody base, glabrous, the short branches dichotomous, with the withered cymes of previous growths in their forks. Leaves simple, rather fleshy, ovate to obovate, $1-1^{1} / 2^{\prime}$, shortly acuminate, sharply and appressedly but not closely serrate or dentate, except at the rounded base, which suddenly contracts into a petiole of about $1 / 2^{2}$. Infl, a 3 - or 5 -headed cyme with a common peduncle of $1-1^{1} / 2^{\prime}$ and pedicels of $1 / 2-1^{\prime \prime}$, with linear bracts. Heads $3-4^{\prime \prime}$ in diam. Ext. invol. bracts $2^{\prime \prime}$ long, linear-spathulate, only few glandular in my. specimens. Ray-fl. obovate, $3^{\prime \prime}$. Achenes $4^{\prime \prime}$, linear, 
twisted, wingless, bi-aristate, the slender awnlets about $1 / 2$ ", retrorsely barbed at the apex.

Mani! collected above Maalaea or on Haleakala. Is identical with M. \& B.'s no, 450 , which derives from Waikapu of the same island.

5. C. Mauiensis, Hillebr- - Decumbent, woody at the base, pubescent, the branches ${ }^{1 / 2}-1^{1 / 2} \mathrm{ft}$. long, dichotomous, with withered peduncles in the older forks. Leaves on petioles of ${ }^{1 / 2}-1^{\prime}$, deltoid in outline, $1 / 2-1^{\prime} \times$ $1 / 2-3 / 4^{4}$, deeply cut into 3 or rarely 5 segments or leaflets, these oblong or somewhat cuneiform, obtuse or acute, coarsely incised, the lateral pair about $1 / 2^{\prime}$ long, the terminal one petiolate and usually $1^{\prime}$ long, sometimes all of them trifid or the terminal one more dissected into oblong linear lobes. Heads single on a terminal peduncle of $3-7^{4}$, or occasionally 2 or 3 . Outer invol. bracts $6-8$, spathulate, some or all tipped with a gland. Ray-fl. 8 , obscurely 3 -dentate, $4^{\prime \prime}$ long. Disk-fl. 10 , about $2^{1 / 2} 2^{\prime \prime}$ long. Achenes glabrous, straight or slightly curved, 3-4" long, winged, the wings running out into short cartilaginous teeth which unite with short awnlets and occasionally exhibit a minute horizontal barb. - Coreopsis Mauiensis, Gray, Proc. Am. Ac. V, 125.

Isthmus of Ma ui and mountain slopes above Maalaea.

$\beta$ var. - Leaves smaller, bipinnatisect with 2 or 3 pairs of primary segments, these deeply cut into oblong or cuneate lobules. Invol. bracts less commonly glandular. Achenes shorter, scarcely winged, plano-convex, with a strong facial ridge, awnless, but with a short coronula around the epigynous disk.

Lanail

b. Campylotheca. Tall erect undershrubs, with branches not dichotomous and invol. bracts mostly glandless.

6. C. cosmoides (Coreopsis), Gray, in Proc. Am. Ac. V, 126. - Erect, 5 to $8 \mathrm{ft}$. high and much spreading, the branches herbaceous, glabrous. Leaves on petioles of $1-2^{\prime}$, pinnately cut into 5 or 3 leaflets, or the uppermost entire. Terminal leaflet ovate-oblong, $1^{1 / 2}-3^{\prime} \times 3 / 4-1^{1 / 4^{\prime}}$, cuspidate, sharply serrate except at the cuneate base, the lateral ones sessile but not decurrent. Infl. a single peduncle, terminal or on short axillary spurs, $3^{\prime}$ long and bracteate, bearing a single nodding flowerhead. Head large hemispherical, $2^{\prime}$ in diam. with the rays, $1^{\prime}$ without. Extern. invol. bracts 8, foliaceous, oblong or lanceolate, acute or somewhat obtuse, ciliolate, exceeding the colored inner ones. Ray-fl. $8-14$, about $1^{1} / 2^{\prime}$ long, 2-3-dentate. Disk-fl, about 50. Anthers wholly exserted, $3^{\prime \prime}$ long. Styles projecting $3-5^{\prime \prime}$ beyond the anthers, their recurved branches suddenly thickening, hairy, and abruptly tipped with a long subulate appendage. Immature achenes linear, twisting, wingless, stiffly ciliate at the margins 
and round the epigynous disk, terminating in 2 short and stiff naked awns. - Mann. Enum. no. 211. - Mrs. Sinclair, pl. 19.

Ka uai! mountains of Waimea (U. S. E. E., Remy, Mann, Knudsen). Nat, name "Poolanui". I find a minute gland at the apex of the ext. invol. bracts in some flowerheads. With the large showy flower, foliaceous involucre and the long subulate appendages to the style-branches the species occupies a singular position in the genus.

7. C. Hawaiiensis, Hillebr. - «Herbaceous, $3 \mathrm{ft}$. or more high, much branching, glabrous. Leaves all simple, firm, prominently nerved, smooth, shining, ovate-oblong to lanceolate, $1^{1 / 2}-3^{1 / 2^{\prime}}$ long, serrate, cuneate or roundish at the base, on petioles of $1^{\text {t }}$ or less. Inflor. a paniculate corymb, the heads large, 3-4" high when in flower. Exter. invol. bracts linear, obtuse. Ray-fl. oblong, 5-9". Achenes linear, 6", glabrous, not winged, aristate with two slender, retrorsely barbed awns.» - Bidens Hawaiiensis, Gray, 1. c. p. 128.

Hawaii, Waimea, Kilauea (U. S. E. E.). We have specimens from E. M a ui which bear a few trisected and trifoliolate leaves besides the simple ones; achenes as above described, but the barbed awns very slender and soon caducous.

8. C. Sandwicensis, Hillebr. - An erect shrub, 3-4 ft. high, the upper branches herbaceous, glabrous. Leaves dark green, chartaceous, rather fleshy, quite glabrous, pinnatisectly 5 - or 3 -foliolate, on petioles of $1^{1 / 2}$ ". Leaflets sessile, ovate-lanceolate, with an unequally cuneate base, $1^{1 / 2}-2^{\prime} X$ $1 / 2-3 / 4^{\prime}$, long cuspidate, spinuloso-serrate. Inflor. a few-headed (5-9) corymb which does not protrude beyond the leaves, the ultimate pedicels $3-5^{\prime \prime}$. Heads large, the disk $4-5^{\prime \prime}$ high. Ray-fl. 5-8, oblong, 5-6". Disk-fl. 10-15. Achenes linear, 5-6"long, narrowly margined, dentatociliate, straight or lightly curved, aristate with 2 short subulate awns which are retrorsely barbed near the apex. - Bidens Sandwicensis, Less. in Linnaea VI, 508. - Gray, 1. c. p. 127 (pro parte). - B. angustifotia, Nutt. in Trans. Am. Phil. Soc. VII, 369. - Walp. Rep. II. 618.

Main range of Oahu! Nuranu, Manoa.

$\beta$ var: - Upper leaves 1 -foliolate or trisected, the leaves or segments more elongate, with serratures and cusps less deep. Flowers smaller and much more numerous, in a scarcely protruding corymb. Achenes not margined, the filiform awns indistinctly barbed and soon caducous.

Molokai!

9. C. macrocarpa (Coreopsis), Gray, 7. c. p. 126. - Shrubby, erect, 4-6 ft. high, quite glabrous. Leaves thick chartaceous, pinnately 5-3foliolate, the uppermost often simple, on petioles of $4-2^{\iota}$. Leaflets

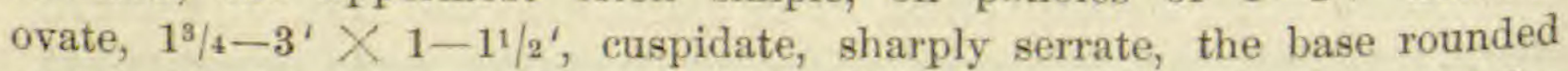
and in the lateral ones strongly excised in the upper half, on petiolules of $9-3^{\prime \prime}$. Inflor, a loose, open, much projecting corymb with linear bracts, the ultimate pedicels $1-1^{1} / 2^{\prime}$. Heads $4^{\prime \prime}$ high. External invol. bracts $5-7$, linear-lanceolate, 3 "long. Ray-florets 5-7, trifid, $7-8$ "long. Disk-florets 15-20. Style-branches shortly exserted. Achenes linear, 
$6-10^{\prime \prime}$, stiff ciliolate, particularly at the apex, narrowly winged or margined and erect, or almost wingless and slightly twisted, the wings running out below the naked apex into 2 short teeth, or rarely uniting with 1 or 2 short thick awnlets, which bear faint erect and retrorse barbs. - Bidens mutica, Nutt. 1. c. p. 368. - Walp. l. e.

Main range of $\mathrm{Oahu}$ ! rather common on the ridges of Nuиanu and neighboring valleys. Nuttall's name has precedence, but is inappropriate on account of the strongly barb-awned varieties.

$\beta$ var. ovatifolia. - Most leaves simple, only some of the lowest 3 -foliolate, with the lateral leaflets stalked, ovato-cordate and otherwise like those of $\alpha$, as is also the inflorescence and size of heads. Achenes $6^{\prime \prime}$, wingless, ciliate, often spirally twisted and mostly aristate with 2 retrorsely hispid slender awns. - Bidens Sandw. var. Gray.

Same locality as $\alpha$

$\gamma$ var. - Leaflets mostly 3, more rarely 5, smaller and thinner, pale underneath, coarsely serrate, ovate or ovate-lanceolate, but not cordate, the upper pair sessile, but those of the lower, when present, stalked. Inflorescence fuller and broader, corymbose, considerably exserted, with linear bracts. Heads as before. Achenes either as in $\beta$, with barbed awns, or awnless and with a setulose corona. - B. Sandwic. Gray (pro parte), and probably also B. gracilis, Nutt.

Oahu! Niu and Makaleha. A more herbaceous plant than the two first forms.

10. C. grandiflora, DC. Prod. V, 593. - Suffruticose, with elongate branches and long internodes, puberulous. Petioles $1-3$ '. Leaflets 3, ovate-oblong, $3-5^{+} \times 1^{1 / 4}-1^{3} / 4^{\prime}$, the lateral ones sessile or shortly stipitate, cuspidate, obtusely serrate, with the serratures mucronate rounded or contracting at the unequal base, flaccid, with faint nerves. Inflor. a projecting, loose and open, bracteate panicle, the ultimate pedicels $1-1^{1 / 2} 2^{\prime}$. Disk $4-5^{\prime \prime}$ in diam. ( $7^{\prime \prime}$ long according to DC.). Ray-florets 5-8. Achenes linear, 4-5", twisted, glabrous, thick-margined, awnless, or the younger ones with slender bristles. - Coreopsis Macraei, Gray.

Hawaii! in Kohala, Waimea and Hamakua. In my specimen the paniele is $10^{\circ}$ long, made up of 3 to 4 distant, long pedunculate, axillary pairs of eymes. The flowers are searcely larger than those of C. macrocarpa, and do not compare with C. cosmoides.

$\beta$ var. - Leaves on petioles of $3^{\prime}$, with 5 or 3 leaflets, the uppermost simple, the leaflets of the lowest pair, when present, shortly stipitate, ovate-oblong with cuneate base, or rhomboidal, $3-3^{1 / 2^{\prime}} \times 1^{1 / 1} \leqslant-1^{1 / 2^{2}}$, sharply serrate, shortly cuspidate. Panicle shorter than in $\alpha$, but the axillary cymes more compound and again paniculate. Ray-florets $5-8$, obovate oblong, $7-8^{\prime \prime}$. Disk-florets $15-20$. Achenes slender, twisted, ciliate, and armed with 2 long $\left(2^{\prime \prime}\right)$ filiform deciduous awns, which bear erect and retrorse teeth.

N. coast of Molokai! and probably also of Maui. 
11. C." micrantha, Cassin, - DC. Prod. V, 593. - Suffruticose, with reddish stem, 2-3 ft. high, resino-puberulous. Leaves on petioles of $1-1^{1 / 2^{\prime}}$, pinnatisect into 7,5 and 3 leaflets, the uppermost ones simple. Leaflets sessile, decurrent, or those of the third pair, when present, subpetiolate, narrow elliptico-lanceolate or rhomboidal, $1^{1 / 2}-3^{\prime} \times{ }^{1 / 4}-1 / 2^{\prime}$, acutely dentate or serrate about the middle, but entire at the long drawn out apex and the narrowly contracting base. Inflor. a dense and broad, many-flowered, foliolose corymb, the ultimate pedicels less than $1^{\prime \prime}$. Heads small, $2^{\prime \prime}$, the resino-pubescent invol. as high or less. Ray-fl. 3 to 5, obovate, $3^{\prime \prime}$ long. Disk-fl, $6-10$. Achenes linear, $4-6 "$, indistinctly or not at all margined, straight or twisted, setulose at the margins and apex, biaristate with retrorsely ciliate awns, or oftener awnless. Bidens micrantha, Gaud. in Bot. Freyc. V, p. 464, tab. 85. - Coreopsis micrantha, Gray, 1. c. - Campyloth. australis, Less. in Linnaea, VI, 509.

Hawaii! Central Plateau, Waimea. - To a plant of this species with mostly trisect and simple leaves will have to be referred the var. $\beta$ of Bidens Sandwicensis, Gray.

$\beta$ var. laciniata. - Leaves broader, more deeply serrate, even laciniate about the middle. Heads larger, 3-4". Ray-fl, 5-7.". Achenes generally with hooked awns.

Maui! Honuaula, Kula, Wailuku; Hawaii!

$\gamma$ var. - Leaflets mostly 3, their apex and base less drawn out, the serratures less deep. Heads very small, 1-2". Ray-fl. 2-3". Achenes mostly awnless, with a setulose corona.

Oahu! Kaala, and Waianae range. Some specimens have much larger flowers and might pass for $C$. Sandwicensis if it were not for their copious and projecting inflorescence.

12. C. Menziesii (Coreopsis), Gray, l. c. - Habit, size and infl. of C. micrantha. Leaves $3-4^{\prime}$ long, on petioles of $2^{\prime}$, bipinnatisect with 3,2 or 1 pairs of primary lateral segments, these entire and $2^{\prime \prime}$ broad or again more or less deeply eut into lobes or linear-lanceolate segments. Invol. $1^{1 / 2} 2^{\prime \prime}$. Ray-fl. 5, about $4^{\prime \prime}$ long. Disk-fl. 6-10. Achenes 4-6", linear, slightly margined, straight or twisted, quite glabrous and bidentate or awnless.

Molokai! Kalae.

$\beta$ var. - Leaves $2^{\prime}$ long. Primary segments eut to the rhachis; secondary segments 1 " broad, with often one or more prominent teeth.

E. Maui! Hawaii! Kohola, Waimea.

i var. - Secondary segments and rhachis filiform.

Hawail Central Plateau, where it covers large patches of ground with lively yellow.

\section{BIDENS, L.}

Heads radiate or sometimes discoid. Disk-florets tubular. Epigynous disk round the base of the style low annular. Achenes always straight, not margined, either compressed, short and broad, or 4-angled, elongate, 
with 2-4 stiff persisting retrorsely aculeate or barbed awns. Otherwise as in Campylotheca. - Annual or perennial herbs with opposite simple or pinnately dissected leaves. Flowers either large and single at the ends of branches and in forks, or numerous, corymboso-paniculate. Florets yellow, or rarely the ray white.

A large genus, spread over the temperate and warm regions of the whole world, but especially of America.

Leaves petiolate, hispid; achenes 4-angled

Leaves sessile, glabrous; achenes compressed

1. B. pilosa.

2. B. chrysanthemoides.

†1. B. pilosa, L. - DC. Prod. $V, 597$. - An erect, generally hispid annual, $1-1^{1 / 2} \mathrm{ft}$. high. Leaves thin, either all simple or, at least the upper ones, trisect to trifoliolate, the simple leaves ovate, $1-2^{\prime}$ long, acuminate, sharply serrate, on petioles of $1 / 2-1$. Flower-heads few in a foliose cyme or corymb, about $3^{\prime \prime}$ high, on pedicels of ${ }^{1} / 2-1^{1} / 4^{\prime}$, commonly discoid (viz, the ray-florets wanting), or with a few whitish ligules. Disk-florets 12-20. Style-branches scarcely thickened below the long subulate appendage. Achenes straight, 4-angled, 4-6" long, eiliate or glabrate, 2-4-awned, the awns ${ }^{1 / 4}-1 / 3$ the length of the achenes and strongly barbed. - B. leucantha, Willd. - B. hirsuta, Nutt. in Trans. Am. Phil. Soc. VII, 369. - Walp. Rep. II, 618. - B. peduncularis, Gaud.? Bentham, Fl. Hongk. p. 183.

On all islands, from the plains to altitudes of $4000 \mathrm{ft}$., a plague to cattle and sheep on account of the adherent achenes. Of American origin, but now a common weed in many warm countries.

†2. B. chrysanthemoides, Michx. - DC. Prod. V, 595. - A glabrous annual, the creeping or floating stem one to several feet long and rooting. Leaves lanceolate, $4-6^{\prime} \times{ }^{1 / 2}-1^{\prime}$, sessile, the upper ones clasping, acute, distantly serrate. Heads radiate, large, $3-4^{\prime \prime}$ high and $6-8^{\prime \prime}$ broad, terminal, one or few on peduncles of $1-2^{\prime}$. Outer invol. bracts herbaceous, lanceolate, as long as the inner ones, which are thin, broad and colored. Ray-florets 8-12, about 1'long, yellow. Disk-florets numerous. Style-branches clavate, with conical appendages. Achenes broad wedgeshaped, compressed, the margins retrorsely ciliate or aculeate, as are the 2,3 or 4 awns, of which the longest about equals the floret. - B. helianthoides, H. B. K.

Oahu! Kapalama and Waikiki iuka near Honolulu; Kauai (Remy); in *kalo-patches and slow running streams. Flowers in July and August. A native of N. America, East and West, where it extends from the northern U. 8. to Mexico.

\section{Cosmos, Cav.}

Heads radiate, the ray-florets generally red. Achenes narrow, almost 5 -angled or somewhat compressed, the apex attenuate in a beak with 2-5 persistent retrorsely aculeate awns. Otherwise as in Bidens. Herbs with opposite lobed or pinnatisect leaves.

About 10 species, belonging to tropical Ameriea. 
†1. C. caudatus, H. B. K. - DC. Prod. V, 606. - An erect annual, $1 \mathrm{ft}$. high, glabrous. Leaves pinnatisect, the segments obovate-oblong, dentate or more deeply cut. Ray-florets sterile, red, with trifid ligules. Disk-florets 10-20. Achenes $9 "$ long, scabrous-hispid at the angles, shortly beaked, 4-6-awned.

Hawaii! Kealakeakua and elsewhere; escaped from gardens, but well naturalized. A native of Mexico.

\section{ARGYROXIPHIUM, De Cand.}

Heads large, many-flowered, heterogamous, radiate, the ray-fl, in one row, female, those of the disk hermaphrodite, both fertile. Invol. broadly campanulate, its bracts in one row, equal, herbaceous, narrow, holding the ray-achenes in their cavities. Receptacle convex, with a circle or ring of partially concrete paleae within the circle of ray-florets, representing a second longer involuere, otherwise naked. Ray-fl, ligulate, the broad spreading ligules 3 -dentate. Disk-fl. tubular, the elongate limb little widening, 5-fid. Anthers obtuse at the base, appendiculate. Stylebranches of disk-fl. linear, complanate, widening at their ends and hispidulous, with conical appendages. Achenes linear, 5-angular. Pappus of 5 short and broad, unequal, acute paleae, or in the ray-fl. truncate, coroniform. - Robust plants with a short and thick simple stem, crowded with numerous spirally arranged, dagger-shaped, entire, thick, Iongitudinally nerved, silky-tomentose or hispid leaves. Flower-heads large, with yellow disk and rose-purple ray, arranged in a terminal centripetal raceme or panicle.

A Hawaiian genus of the Subtribe Madiea, the representatives of which are confined to the west coast of America and the Sandwich Islands, including also the following genus Wilkesia.

Leaves silvery; peduncles bracteate in the outer half; heads large, with darker ligules

1. A. Sandwicense.

Leaves greenish, narrower; peduncles bracteate at the end; heads smaller, with paler ligules.

2. A. virescens.

1. A. Sandwicense, DC. Prod. V, 668, and Mem. Comp. p. 27, tab. 8 . - Stem 2 or 3 inch. in diam,, with a thin woody zone and large pith, short, soon tapering into a long pyramidal foliose raceme (or paniele) 4 to $8 \mathrm{ft}$. high with numerous flower-heads. Leaves linear, $8-16^{\prime} \times 5-6^{\prime \prime}$, shortening toward the panicle, densely villous with silvery-silky appressed wool. Peduncles $4-6^{\prime}$ long, each supported by a leaf of equal length, glandular-pubescent, bearing 2 to 4 bracts along its upper half. Heads nodding, less than 1' in diam. Invol, bracts viscous-villous, green, Ianceolate, long and finely acuminate. Ray-fl. 12 to 16 , with cuneate bi- or trifid ligules of $5-6^{\prime \prime}$ in length. Receptacle about $1 / 2^{\prime}$ broad. Inner involucre of 24 paleae, viscous-pubescent outside, exceeding the outer involucre in length. Achenes glabrous, $5-6^{\prime \prime}$ long, the radial ones shorter and curved, enclosed and exceeded by their bracts. Pappus 
corneous, about $1^{\prime \prime}$ long, consisting of 5 to 6 broad and aeute but unequal paleae, which are concrete at their bases, that of the ray-achenes short truneate or reduced to one palea. - Hooker, Icon. Plant. tab. 75. Gray, Proc. Am. Ac. V, 136, and Msept. U. S. E. E. - Argyrophyton Douglasii, Hook. Comp. Bot. Mag. II, 163.

Hawaii; Mauna Kea, Mauna Loa, Hualalai; 7000 to $12000 \mathrm{ft}$. The *Ahinahina of the natives and silversword” of the foreigners. Flowers from July to Septemb. The lustrous silver-gray down which thiekly covers all leaves makes this plant an object of great beauty.

$\beta$ var. macrocephalum. - Heads larger, 1-1 $11^{\prime}$ in diam. Ray-fl. 20 to 30 , their ligules shorter. Appendages of style-branches longer than in $\alpha$. A. macrocephalum (as species), Gray, 1. c. p. 137, and II, 160. - Mann, Enum. no. 229.

Maui! Haleakala! On the outside rim and in the bottom of the crater. The tuft of silvery leaves from the short and thick stem is sometimes as much as four feet in diam," Gray describes the pappus of the disk-achenes as reduced to a narrow truncate coronula, as in the ray-achenes, but in my specimens all disk-achenes are crowned by a perfectly developed pappus, as in $\alpha$.

2. A. virescens, sp. $n$. - Somewhat smaller than the preceding species. Leaves hispid with short appressed hair, but green, the lower not exceeding $12^{\prime}$ in length by $1^{1 / 2}-3^{\prime \prime}$ in width, the upper ones shorter and broader. Inflorescence a simple foliose raceme, the viscous-pubescent peduncles $3-4^{\prime}$ long, bearing 2 to 3 short linear bracts quite near the apex, each peduncle supported by a narrow leaf which exceeds it in length. Heads $6-9 "$ in diam. Ray-fl. about 20 , pale, the ligules shorter, $3^{\prime \prime}$, and narrower, twice the length of their tubes. Achenes as before, those of the ray naked at the top, the paleae of the pappus in the disk-fl. narrower and sharper than in no. 1, the two outer ones much the longest, all soon deciduous.

Maui! northern slope of Haleakala, from 8000 to $9000 \mathrm{ft}$.

\section{WILKESIA, Gray.}

Flower-heads homogamous, discoid, all florets hermaphrodite and fertile. True invol. wanting, together with the ray-florets, the disk surrounded only by the inner eup-shaped involucre of Argyroxiplium, made up of the connate, linear, 1-seriate paleae of the receptacle, which is naked otherwise. Corollae tubular-campanulate, 5-fid. Style bulbous at the base, its branches with conical or subulate appendages. Achenia as in Argyroxiphium, the short pappus consisting of $6-12$ unequal, slender, acute paleae. - Arborescent plants with the habit of a Yucca, the straight, undivided, medullary stem bearing a crown of whorled, ensiform, entire, coriaceous, longitudinally nerved leaves and gradually continuing in a large thyrsoid, resino-viscous raceme or panicle. Flowers yellow.

A Hawaiian genus which may be considered as an Argyroxiphium with elongate stem and suppression of ray-florets together with their external involnere. 
Leaves and peduncles in whorls, the former connate at the base and fringed, the latter several-headed

Leaves free at the base, glabrous; the peduncles alternate, singleheaded

1. W. gymnoxiphium.

2. W. Grayana.

1. W. gymnoxiphium, Gray, Proc. Am. Ac. II, 160, and V, 136. Stem or trunk 8-14 ft. high, including the panicle of 2 to $3 \mathrm{ft}$. Leaves not crowded, in whorls of 10 or more, connate at their bases, linear-lanceolate, very acute, minutely many-lined, fringed with a close border of white silky ciliae, otherwise glabrate and shining, those of the stem about $1 \mathrm{ft}$. long and $4-6^{\prime \prime}$ broad, those of the panicle much shorter, only $2-1^{\prime}$ long and almost 1' broad; the whorls at distances of $1 / 2^{\prime}$ and less on the stem, of $2^{\prime}$ and more on the panicle. Peduncles covered with viscid hairlets, slender, $6^{\prime}$ or more long, each bearing at its end two or three nodding heads on pedicels of $1 / 2-1^{\prime}$ supported by linear bracts, otherwise naked. Heads globose, $6-8^{\prime \prime}$ high. Invol, resinous, $4-6^{\prime \prime}$, consisting of about 24 connate scales. Disk-fl. 120-200, the corollae $33^{1} / 2^{\prime \prime}$, pale yellow. Anthers exserted, pale. Style exserted, its long reflexed branches dilating above and ending in long subulate appendages. Achenes hispidulous, the pappus one third their length and consisting of $10-12$ subequal, very acute, corneous paleae. - Mann, Enum. no. 230.

Kauail dry leeward slope of the tabular summit above Waimea, at a height of 3000 to $5000 \mathrm{ft}$. - The leaves unite at their bases to the height of $1 / 2-2^{\prime \prime}$, forming cups, which on the stem not only cover the internodes but also overlap each other. The peduncles of the inflorescence stand in regular whorls, 10 to 6 in each,

2. W. Grayana, $s p . n$. - Stem about $3^{\prime}$ thick at the base, 5 to $8 \mathrm{ft}$. high when full grown, bearing a dense crown of verticillate ensiform entire acute leaves, which are either straight or slightly curved and free to the base, resino-puberulous and ciliate at the margins near the base when young, but glabrate with age, dark green, thick chartaceous, the lowest about $1 \mathrm{ft}$. long and $8-10^{\prime \prime}$ broad, with 9 to 13 distinct nerves. Peduncles single-headed, stiff angular, furfuraceous, 6' long, in the axils of more remote and irregularly alternate leaves, bearing 3 to 4 distant bracts along its course, the whole inflorescence forming a large foliaceous raceme of $1^{1 / 2}-2 \mathrm{ft}$. in length with a thick angular rhachis, the supporting leaves equalling the peduncles in length. Heads globose, $9-10^{\prime \prime}$ high, $1-1^{1 / 2} 2^{\prime}$ broad. Invol. $6^{\prime \prime}$, viscous-pubescent, made up of about 40 equal linear bracts rather loosely connate. Receptacle conical, with 200 to 300 florets. Corolla orange, $2^{1 / 2} 2^{\prime \prime}$. Anthers not exserted. Style-branches searcely projecting, with short conical appendages. Achenes glabrous, about $4^{\prime \prime}$ long, 5-angular, with an oblique pappus of 6 to 9 acute paleae, the two or three outer ones of which are Iongest, about $1 / 4$ the length of the achene. 
W. Maui! on the southern slope of Eeka at a height of 5000 to $6000 \mathrm{ft}$. - Dedicated to Prof. A Gray, the founder of the genus, to whose labors we are so much indebted for a proper knowledge of the Hawaiian flora and in especial of this interesting group of Compositae. - The leaves, free to the base, are so closely set that their verticillate position can only be ascertained in young plants. There are from 5 to 8 in a whorl, but at the transition into the flowering raceme the whorls are obliquely drawn out and become spirally connected, to pass finally into the irregular alternate arrangement of the raceme.

\section{TRIBE VI. SENECIONIDEAE.}

Heads heterogamous and radiate or discoid, or by defect of the ray discoid and homogamous. Involuere of one or two series of equal herbaceous bracts, or with a few smaller outer ones. Receptacle naked or with few paleas to the outer florets. Anthers obtuse or scarcely pointed at the base. Style-branches of fertile florets truncate and penicillate or ending in pubescent points. Pappus of numerous eapillary or plumose bristles. Leaves mostly alternate, rarely opposite. Flowers usually yellow.

\section{DUBAUTIA, Gaud.}

Flower-heads homogamous, discoid, all florets hermaphrodite and fertile. Invol. turbinate, with 5-10 equal bracts in one row, free (except in one species), narrow, herbaceous, curving round the outermost achenes. Receptacle naked or paleaceous, the paleae similar to the invol. bracts, and corresponding in number to the inner florets, none when the number of florets does not exceed that of the bracts. Corollae tubular, with a campanulate 5-fid limb, the lobes reflexed. Anthers purple, dentate at the base, shortly appendiculate. Style-branches revolute, subtruncate, or with short conical appendages. Achenes hispid, black, wedgeshaped, 4-5-ribbed, the faces often again prominently costulate. Pappus dirty brown, not longer than the achenes, consisting of about 20 flat subulate or lanceolate ciliate rays in a single row. - Shrubs or small trees, resinous, with opposite or ternate, lanceolate, sessile or subsessile, clasping, parallel-nerved leaves. Inflor. terminal, paniculate or corymbose. Corollae deep orange or purple.

A Hawaiian genus, closely allied to the following one. Its distinguishing characters consist in the free involucral bracts, the paleate receptacle and the broader rays of the pappus, which are only shortly ciliate, not plumose. Dubautia raillardioides has however a connate invol, while in Raillardia Menziesii and arborea the union of the loracts is very loose; in the few-flowered $D$. plantaginea and raillardioides the receptacle is mostly naked, while in the large heads of $R$. Menziesii several paleae are always found to be present; and again, the long-ciliate rays of the pappus in $D$. plantaginea approach closely in structure to those of a Raillardia.

Leaves opposite, lanceolate; inflorescence a panicle:

Leaves strongly nerved, sessile; heads with $7-8$ florets

Leaves faintly nerved and areolate, subpetiolate; heads with 15 florets

1. D. plantaginea.

2. D. laevigata. 
Leaves opposite, obovate; inflor. a corymb:

Leaves strigoso-hispid or papillose; corymb folioso-bracteate, heads subsessile

Leaves glabrous; corymb bracteate, heads on long pedicels

3. D. laxa.

4. D, Knudsenii.

5. D. paleata.

6. D. raillardioides.

Involucral bracts free, elasping

Involueral bracts flat, connate

1. D. plantaginea, Gaud. in Bot. Voy. Freyc. p. 468, tab. 84. - A shrub or small tree with spreading branches, 8-16 ft. high. Leaves opposite, lanceolate, $4-8^{\prime} \times{ }^{1 / 3}-1^{1} / 4^{4}$, acute, gradually contracting to both ends, clasping with the narrow base, entire, or remotely denticulate in the upper half, strongly 7-13-nerved, coriaceous, brownish when dry, glabrate. Panicle pubescent, pyramidal, $6-10^{\prime}$ long, projecting beyond the leaves, with horizontal branches, the lowest $2-3^{\prime}$ long; the ultimate pedicels $1-1^{1 / 2} 2^{\prime \prime}$, racemosely arranged. Heads $3-4^{\prime \prime}$, cylindrical, bearing 7 to 10 florets. Invol. bracts 7 or 8 , narrow lanceolate, $2^{\prime \prime}$, puberulous. Receptacle mostly naked. Corollae orange-colored, exserted, often curved, the long slender tube suddenly dilating into a campanulate limb with reflexed lobes. Style-branches revolute, with distinct conical appendages. Rays of pappus linear-subulate, with rather long upright ciliae. - Gray, Proc. Am. Ae. V, 134.

Oahu! on both mountain ranges at elevations of near $3000 \mathrm{ft}$., those from Kaala with narrow erowded leaves; Ma u i! Eeka, Wailuku, Ulupalakua, $3000-5000 \mathrm{ft}$.; Haw aii! Kohala, Holopalau, as low down as $800 \mathrm{ft}$. (the inflor. very full, its lowest branches paniculate and ascending from the axils of the upper leaves). - The leaves resemble entirely those of Plantago princeps. - The native name sNaenae applies to this and other species of the genus, as well as to the larger Raillardiae.

$\beta$ var. platyphylla. - Leaves broadest near the base, the shorter floral ones ovate and broadly clasping. Pubescence slightly viscous. Invol. bracts connate at the base,

Ma ui, N. slope of Haleakala, $4000 \mathrm{ft}$. (Lydg.). - A curious instance of mimicry, if such a term be admissible in plants, the leaves and habit being altogether as in Raillardia platyphylla, a denizen of the same region, but the inflor., heads and pappus as in the present species of Dubautia.

2. D. laevigata, Gray, in Proc. Am. Ac. V, 135. - Habit as before. Leaves oblong-lanceolate, $6-8^{\prime} \times{ }^{3} / 4-1^{\prime}$, narrowing below into a margined petiole, acute, sharply and appressedly dentate to near the base, chartaceous, glabrous and shining on both faces, light green underneath, the numerous nerves faint and connected by a distinct areolar network. Panicle pubescent, large and open, attaining a length of $15^{\prime}$, with the lowest branches often $11^{\prime}$ long, 3 to 4 times dividing, the heads in clusters of 3 to 5 . Invol. bracts 8, pubescent. Receptacle paleaceous. Florets 12-16, not exserted. Achenes subglabrate. Bristles of pappus with a broader rhachis than before.

Kauai! woods of Waimea, 2000-3000 ft. 
3. D. laxa, Hook. \& Arn. in Bot. Beech. p. 8\%. - A shrub, 5 to $10 \mathrm{ft}$. high. Leaves not crowded, opposite, oblong or oblanceolate, $3-4^{\prime}$ $3 / 4-1$, distantly dentate or serrulate, narrowing below into a short petiole, 5-9-nerved, coriaceous, glabrate above, shortly papilloso-hispid underneath, greenish when dry. Inflor. a folioso-bracteate hispid corymb which projects but little beyond the leaves, the heads subsessile, ternate, about $2^{1 / 2} 2^{\prime \prime}$ high. Invol. bracts $6-8$, hispid, dark purplish, $2^{\prime \prime}$ high. Florets 10 to 14 , not exserted; the corollae purplish, glandular, the short tube gradually widening into the 5-toothed limb. Style-branches short, almost truncate. Pappus reddish, the rhachis of its rays broader and the ciliae shorter than in no. 1. - Gray, 1. c.

Oahu ! on the highest ridges, less common than $D$. plantaginea; W. Maui!

$\beta$ var. hirsuta. - Branches hirsute with stiff brownish hair. Leaves broader, obovate, $3-4^{\prime} \times 1-1^{3} / 4^{\prime}$, shortly acuminate, crenate to serrulate, papilloso-hispid with appressed hair on both faces, dark brown when dry. Flower-heads $3^{\prime \prime}$ long, very numerous, in ample projecting hirsute corymbs, the ultimate pedicels $2^{\prime \prime}$ or less. Invol. nearly as long as the heads. Florets $16-22$, each folded by a pubescent bract, 7 or 9 of which constitute the involucre.

Lanai! W. Maui! Wailuku and above Lahaina (leaves 5' long); 0 a hu! Kaala, at elevations of 3000 to $5000 \mathrm{ft}$.

4. D. Knudsenii, sp. n. - Branches slender, glabrous. Leaves opposite, distant, obovate, $2^{1 / 2}-3^{\prime} \times{ }^{3} / 4-1^{\prime}$, sharply cuspidate and serrulate, the base contracting into a distinct petiole, inconspicuously 5 -nerved, perfectly glabrous and shining on both faces, sparingly hispid only on the petiole, thin chartaceous, pale underneath. Corymb bracteate, ample and open, projecting beyond the leaves, its branches very slender, puberulous. Flower-heads obconical, $3-3^{1} / 2 "$ long, single or ternate, the lateral ones on pedicels of $6-9^{\prime \prime}$, that of the median $1-1^{1 / 2} 2^{\prime \prime}$. Invol. $2^{\prime \prime}$ high, its bracts 7 to 9 , flat, glabrate, purplish, fimbriate, as are the paleae of the receptacle. Florets 13, short, not exserted, purplish, as is the pappus, which does not differ from that of no. 3 .

Kauai! Collected only by Knudsen on the mountains of Waimea or Halemanu.

5. D. paleata, Gray, l. c. p. 135. - Branches woody and hirsute, as is the inflorescence. Leaves ternate, sessile, broadly lanceolate, 2$3^{\prime} \times{ }^{1 / 2}-3 / 4^{\prime}$, acuminate, moderately narrowing below, remotely denticulate, with 9 to 11 prominent nerves, strigoso-hispid on both faces, coriaceous. Flower-heads large, globose, 4-6 in diam, not numerous, on short pedicels in groups of 5 to 8 at the ends of the short erect branches of a contracted folioso-bracteate corymb. Invol. bracts 5 to 6 , nearly as high as the heads, oblong, clasping. Receptacle conical, with 5 to 6 spiral turns and numerous concave paleae. Florets 25 to 30 . 
Corollae purplish, exserted, the limb little dilated, deeply 5 -cleft. Pappus chaffy, the broad lanceolate rays slit at the apex, very shortly ciliate and only half as long as the sparingly hispid, often curved achenes.

Kauai! Waimea. - Distinguished from all its congeners by the broad rays of the pappus, which are not at all plumose. Gray omits to mention that the leaves are ternate.

6. D. raillardioides, $s p . n$. - Branches glabrate, purplish, herbaceous, the annular cicatrices ciliate. Leaves ternate, sessile, lanceolate, $4-5^{\prime} \times$ $3 / 4-1$ ', sharply pointed and remotely denticulate, contracting toward the broad base, 7-9-nerved, glabrous, ehartaceous. Flower-heads obeonical, $5-6 "$ long, racemose on the ascending branches of a large, compound, scarcely projecting, foliose, viscoso-pubescent corymb, the ultimate pedicels $3-4$ ". Invol. 3 "long, glabrous, purple, its $6-8$ narrow lanceolate bracts connate into a cylindrical or obconical toothed cup. Receptacle flat, naked in the few-flowered heads, with 2 or 3 flat and small paleae when the florets are numerous. Florets 8-14. Corollae slightly exserted beyond the pappus, orange to purplish, funnel-shaped. Style-branches long, plano-convex, clavate, with a short conical point. Achenes linear, $3^{\prime \prime}$, sparingly hispid, 5-angular. Pappus of a dirty straw-color, its flat subulate rays connate with the broadish bases and very minutely ciliate.

Kanai! Waimea (Knudsen and Wawra). - A remarkable species which connects closely the present with the following genus. The plant has entirely the habit of $\mathrm{Du}$ bautia, the leaves not differing from those of $D$. plantaginea; the pappus also, although somewhat peculiar, bears the character of the genus, but as to the involuere it is altogether raillardioid. The invol: bracts remain connate, and at maturity the cup splits only on one or two sides. No indication as to habit accompanies Mr. Knudsen's two specimens, but as both of them are herbaceous, although thick, the plant is likely to be low suffruticose.

\section{RAILLARDIA, Gaud.}

Flower heads as in Dubautia. Invol. cylindrical or campanulate, its bracts in one row, flat and more or less connate. Receptacle small, convex or almost conical, naked. Tube of corolla slender, suddenly dilating at the insertion of the filaments, the limb campanulate, 5-fid. Anthers dentate at the base, appendiculate. Style-branches elongate, clavatocomplanate, with lanceolate or subulate appendages, recurved or spirally twisted. Achenes narrow, attenuate at the base, 4- to 5-angular. Pappus of a dirty brown, its rays $12-20$ in one row, as long as the achene or longer, setoso-plumose, with a stiff rhachis. - Shrubs or small trees, resinous, with ternate, alternate or opposite, sessile, entire leaves. Flowers in terminal racemes, panicles or corymbs, yellow.

A Hawaiian genus, which however has a close relative in the Califorvian Raillardella, Gray.

Leaves penni-nerved, areolate

1. R. latifolia.

Leaves 1-nerved, alternate

Leaves 1-nerved, ternate:

Branches naked above; flowers in a corymb

2. R. scabra.

Branches foliose throughout; flowers in a raceme or panicle

3. R. Laxiflora.

4. R. ciliolata. 
Leaves 3 -nerved, rarely 1 -or faintly 5 -nerved:

Leaves alternate

Leaves ternate, linear-lanceolate

Leaves ternate, ovate

Leaves 5-to 11-nerved:

Leaves opposite, with glandular pubescence

Leaves irregular, ternate, opposite or alternate, rather thin and distinctly nerved

Leaves ternate, thick, with indistinet nerves:

Leaves lanceolate acute, silky-pubescent

Leaves elliptico-oblong, obtuse :

Leaves glossy, stiff-eiliate; fl-heads in a foliose raceme

Leaves neither glossy nor ciliate, pubescence viseous, inflor. paniculate

5. R. Molokaiensis.

6. R. linearis.

7. R. Hillebrandi.

8. R. platyphylla.

9. R. montana.

12. $R$. struthioloides.

11. R. Menziesii.

10. $R$. arborea.

1. R. Iatifolia, Gray, Proc. Am. Ac. V, 132. - A rambling shrub, glabrous, with long virgate branches, the internodes from $3-5$ inches long. Leaves opposite, on short petioles, elliptico-oblong, $3-4^{\prime} \times 1-1^{1 / 2^{4}}$, acute, entire, thinly coriaceous, shining, penni-nerved from a median rib, and areolate. Inflor. a large and open, foliaceous, thyrsoid panicle with leaves soon reduced to bracts, puberulous, $1-2 \mathrm{ft}$. in length, its lowest branches $4-9^{\prime}$ long, dividing from the base; the ultimate bracts ovate. Flower-heads in clusters of $3-5$, on pedicels of about $2 "$, each with 4-5 florets. Invol. cylindrical, $3^{\prime \prime}$ high, of $4-5$ connate bracts, cinereopubescent, as are the pedicels. Corollae included in the pappus. Style far exserted, its branches reflexed and curled. Achenes hispidulous.

Kauai! mountains of Waimea and Halemanu. Innovations seem to rise from the end of the flowering branch.

2. R. scabra, DC. Prod. VI, 441. - Low decumbent, woody only at the base, the subherbaceous slender branches $1 / 2-1^{1 / 2} \mathrm{ft}$. long, purplish, hispidulous or glabrate, distantly foliose, almost naked toward the ends. Leaves alternate, sessile, with a broad base, spreading or the lower ones reflexed, linear-lanceolate, $6-12^{\prime \prime} \times 1^{1 / 2-3^{\prime \prime}}$, the single nerve impressed above, the rolled up margins with 1 or 2 pair of toothlets, coriaceous, strongly scabrous on both faces and often hispid on the lower, shining, as if varnished on the upper. Heads $4-5^{\prime \prime}$ high, not numerous, in long projecting open and bracteate paniculate corymbs, the ultimate pedicels 3-5" long, hispidulous. Invol. 3", purplish, of 5-6 linear-lanceolate soon separating bracts. Florets $4-7$, the corollae pale sulphur-colored or whitish, slightly exserted beyond the whitish soft pappus. Achenes pubescent, almost stipitate. - Gray, 1. c. var. scabra and hispidula.

Hawaii! near Kilauea. Nat, name: ‘Kupaua.

$\beta$ var. leiophylla. - Leaves linear, mostly plane, twice as long as in $\alpha$ and about $1^{\prime \prime}$ broad, chartaceous, scabrous only at the margins, the upper face smooth with little lustre, often dull when growing in lower regions. - Gray, l. c. p. 133.

E. and W. Maui! Wailuku, Hamakua; Lanai! Molokai! Maunahui - the inflor. stubpaniculate, hispid, leaves plane, with indieations of lateral nerves.

Hillebrand, Flora of the Hawailan Islands. 
3. R. laxiflora, DC. l. c. - Suffruticose, erect, $1^{1 / 2}-2 \mathrm{ft}$. high, the puberulous branches openly foliose up to the inflorescence. Leaves as in the first form of $R$. scabra, but plane and ternate, except the upper reduced ones, which are alternate. Panicle or corymb less ample than before, its slender branches spreading, little dividing, single-headed or racemose, with heads inclined, the pedicels $4-6^{\prime \prime}$. Invol. bracts 5-6, purplish. Florets $7-13$, of a deeper yellow than in no. 2. - Gray, 1. c.

Hawaii! Kilauea.

4. R. ciliolata, DC. . . c. - An erect shrub, 3-4 ft. high, with numerous stiff branches, hispidulous or pubescent, densely foliose up to the inflorescence. Leaves as in no: 3 , about $1^{\prime}$ long, all ternate, or the uppermost opposite, with scabro-ciliate, remotely denticulate margins and varnished, spreading or erect and in the sterile branches appressed. Inflor. a folioso-bracteate, erect or inclined raceme of $1^{1 / 2}-3^{\prime}$ in length, or paniculate with the lowest branches dividing; the heads obconical, $5^{\prime \prime}$, drooping on hispid pedicels of $4-9^{\prime \prime}$. Involucre $4^{\prime \prime}$, greenish or purple, pubescent, of $8-9$ connate bracts. Florets $7-14$, the corollae deep yellow, exserted. Achenes subglabrate. - Gray, 1. c.

Ha wail! at heights of 4000 to $6000 \mathrm{ft}$.; abundant on the Central Plateau and in Waimea.

It varies with the leaves flat and spreading, even reflexed (var. laxifolia, Gray), and leaves short imbricate, involute, almost acerose, channelled above, the racemes depauperate, sometimes only bearing a single head:

$\beta$ var. juniperoides, Gray.

$\gamma$ var. trinervia. - Leaves ovate-lanceolate, $1^{\prime} \times 4^{\prime \prime}$, indistinctly 3 -nerved at the base, scabrous. Infl. an erect panicle, $3^{\prime}$ long, with several branches dividing, and erect pedicels of $3^{\prime \prime}$. Invol. bracts $9-10$. Florets $15-17$. - R. Menziesii, pro parte Gray?

Same localities; a taller and stiffer shrub.

5. R. Molokaiensis, $s p . n$. - A spreading shrub, 2-4 ft. high, with pubescent or hispid stiff woody branches, loosely but evenly foliose up to the inflorescence. Leaves alternate, sessile, spreading, linear-lanceolate, $2-3^{\prime} \times 3-4^{\prime \prime}$, coriaceous, glabrous but dull, strongly 3 -nerved, with $3-4$ remote teeth on the scabrous margins. Inflor. an open foliose panicle, 4-8 high, with ascending branches, the lowest rather long and foliose, floriferous at their ends. Heads numerous, very narrow, $5-6$ " long, on pedicels of $2-3 "$. Involucre $3-4$ ", of $5-7$ loosely connate bracts, pubescent at the top. Florets 5-7. Corollae slender, not exserted beyond the pappus, deep yellow. Achenes hispid.

Molokai! Maunahui; Lanai! - In some of the Molo kai specimens the leaves have the lateral nerves only faintly developed, the paniele is also more open and corymboid, thus making an approach to the var. leiophylla of $R$. scabra. 
6. R. linearis, Gaud. Bot. Voy. Freyc. p. 469, tab. 83. - A diffuse, much branching shrub, 4-6 ft. high, with slénder branches covered by a pale pubescence, foliose throughout. Leaves ternate, spreading, subpetiolate, linear-lanceolate, $1-2^{1} / 2^{\prime} \times 2-3^{\prime \prime}$, acute at both ends, entire, plane, 3-(rarely 5-)nerved, chartaceous, quite smooth and glabrous. Inflor, a dense folioso-bracteate panicle of $1-2^{\prime}$ in height, the heads $4^{\prime \prime}$, subsessile in loose clusters of $3-7$ at the ends of the short branches. Involucre green, pubescent, cylindrical, $2^{1 / 2^{\prime \prime}}$, of $4-6$ connate bracts. Florets generally 4, but sometimes 5-8, exserted. - Gray, l. c. p. 133. - DC. Prod. VI, 440.

E. Maui! Ulupalakua; Lanai! leaves occasionally 5-nerved; Hawaii! Mauna Kea and Kilauea (U. S. E. E.); Oahu, Kaala (?) U. S. E. E. The receptacle of 6-8-flowered heads sometimes bears one or more small paleae.

7. R. Hillebrandi, Mann, Enum. no. 238. - Habit of the preceding species, the slender branches distantly foliose and pubescent. Leaves ternate, ovate or ovato-lanceolate, $6-9^{\prime \prime} \times 2-3^{\prime \prime}$, broadly sessile, acute, with entire scabrous margins, chartaceous, faintly 3-(rarely 1-)nerved, dull, not shining. Infl. a folioso-bracteate raceme or simple panicle, $2^{1 / 2}-4^{\prime}$ long, the pedicels about $6^{\prime \prime}$. Heads $4-5^{\prime \prime}$. Involucre green, pubescent, cylindrical, $3^{\prime \prime}$ high, of 6 connate bracts. Florets $5-12$, exserted.

Hawail! Hualalai and Waimea. - The centrifugal character of the inflorescence comes out strongly, the terminal flowers of the paniele having arrived at full maturity while those of the lowest branch are still in the first stage of budding.

8. R. platyphylla, Gray, 7. c. p. 134. - A straggling shrub, 5-10 ft. high, the branches stout, hirsute with long glandular hairs, foliose throughout. Leaves opposite, ovate-lanceolate, $2-3^{\prime} \times{ }^{1 / 2}-1^{\prime}$, sessile, with a broad base and from it gradually tapering to an acute point, entire, thick coriaceous, strongly 7-11-nerved, very scabrous on both faces and glandular-pubescent when young. Infl, a foliose panicle $3-6^{4}$ long, with rather few and large $\left(6-8^{\prime \prime}\right)$ heads single on pedicels of $3-6^{\prime \prime}$. Involucre campanulate, 5", viscous-hairy, of $9-11$ bracts. Florets 12-24, exserted. Achenes 5 -angular, glabrate.

E. Maui! in the Kaupo gap of the crater of Haleakala, $7000-8000$ ft. (U. S. E. E. and Lydg.).

$\beta$ var. - Pubescence scarcely viscous. Leaves lanceolate, $1-2^{\prime} \times$ 4-5", scabrous on both faces but scarcely hairy, 3-5-nerved. Invol. of $6-7$ bracts. Florets $8-10$.

Southern slope of Haleakala/ $4000-6000 \mathrm{ft}$.

9. R. montana, Mann, Enum. no. 243. - A tall shrub, 6-8 ft. high, with spreading branches, finely pubescent. Leaves not closely set, ternate, opposite and alternate, oblong, $1^{1 / 2}-2^{\prime} \times 4-5^{\prime \prime}$, somewhat acute, broadly sessile, with $3-4$ minute teeth on the scabrous margins or entire, stiff 
chartaceous, distinctly 5-3-nerved, with nerves impressed, green when dry, glabrate and smooth on both faces. Panicle $4-6^{\prime}$ long, foliosobracteate, pubescent. Heads $6 "$, racemosely arranged on peduncles of $3-6^{\prime \prime}$. Involucre obconical, 3-4", pubescent, of $8-12$ connate bracts. Receptacle naked. Florets 15-24. Corollae exserted. Achenes glabrate, 5 - ribbed.

Hawaii! Hualalai (M. \& B.) and lava-stream of 1856 on the Plateau (Hbd.). In some specimens the leaves are laterally curved, similar to the obtuse forms of Acacio Koa, one side convex, the other straight or concave.

10. R. arborea, Gray, 7. c. - «A small tree, $20 \mathrm{ft}$. high, with a trunk $1 \mathrm{ft}$. in diam., the young branches and inflorescence hirsute with glandular hair. Leaves close, ternate, rather spreading, sessile with a broad base, but not clasping, elliptico-oblong, $1^{1 / 2}-2^{\prime} \times 6-9^{\prime \prime}$, obtuse at both ends, entire, thick chartaceous, scabrous above, pubescent and viscous when young, 5-3-nerved. Panicle 3-4' long. Involucre $4^{1 / 2} 2^{\prime \prime}$, campanulate, of $12-14$ bracts. Receptacle conical, with a few small and thin paleae. Florets 22-45; corollae glandular. Achenes glabrate, 5-ribbed.»

Ha wai! Mauna Kea, $8000-10000 \mathrm{ft}$, in company with the Mamani* (U. S. E. E.). In the single specimen of my collection only the hair of the inflorescence is glandular

11. R. Menziesii, Gray, l. c. p. 133. - A shrub or small tree, 6-12 ft. high, with stiff and stout assurgent branches, densely foliose throughout, cinereous with a hispid, not glandular pubescence. Leaves ternate, appressed, sessile, ovato- or elliptico-oblong, $1-1^{1 /} / 2^{\prime} \times 5-9^{\prime \prime}$, shortly acuminate or somewhat obtuse, entire or faintly and remotely denticulate, coriaceous, with $3-5$ impressed nerves, glabrate and lucid when full grown, but even then retaining a fringe of stiff scabrous ciliae along the margins and a few on the upper face. Heads $\left(5^{\prime \prime}\right)$ few in a foliose raceme or simple panicle of $2-3^{\prime}$ in length, on pedicels of $2-4^{\prime \prime}$. Involuere obconical, $4^{\prime \prime}$, hispid, of $11-13$ loosely connate bracts. Receptacle convex, with $3-4$ linear paleae. Florets 17-25. Corollae funnel-shaped, not exserted. Stylebranches short. Achenes glabrate,

E. Maui! Haleakala, 8000 to $10000 \mathrm{ft}$.

12. R. struthioloides, Gray, l. c. p. 134. - «A shrub, or, at the elevation of $9500 \mathrm{ft}$., a tree, $20 \mathrm{ft}$. high, with the trunk 9 inches in diam., the branches overhanging, canescent with a silky, not glandular pubescence,» Leaves closely crowded, erect, imbricate, or at length spreading, lanceolate, $1^{1} / 4-2^{\prime} \times 4-7^{\prime \prime}$, acute, broadly sessile, entire, coriaceous, rather concave when young, with $3-5$ indistinct nerves, dull opaque, canescent with soft appressed hairs, scabrous on the margin, but not ciliate. Inflor. a raceme or panicle of $4-6^{\prime}$ in length with recurved pedicels. Heads $6^{\prime \prime}$. In volucre $4^{\prime \prime}$, pubescent, of $7-11$ bracts. Florets $12-22$, the corollae almost tubular, not exserted. 
Hawaii! Mauna Kea, up to an elevation of $11500 \mathrm{ft}$. - The last four are what may be called weak species; more material from various localities is needed to warrant a proper appreciation of their characters. Possibly 9 and 10 may have to be united in one species and 11 and 12 in another.

\section{SENECIO, L.}

Florets all fertile, either all tubular and hermaphrodite or the outer ones female and ligulate. Involucre of a single row of nearly equal bracts with mostly a few small ones round the base. Style-branches in the disk-florets truncate and penicillate, or very rarely with a short obtuse appendage. Achenes striate or angular. Pappus of numerous soft capillary bristles. - Herbs, or rarely shrubs, with alternate leaves. Heads terminal, solitary, corymbose or paniculate, the florets usually yellow, rarely purple.

The largest genus of Compositae, ranging over nearly the whole world.

1. S. Sandwicensis, Less. in Linnaea, VI, 526. - DC. Prod. VI, 375. - «An erect herb, probably several feet high, the simple stem bearing in its upper portion a few distant, small and clasping leaves. Lower leaves elliptico-oblong, obtuse, entire, penni-nerved, glabrous, fleshy, about $3^{\prime} \times 1^{\prime}$, contracting at the base into a margined petiole. Heads in a sparingly foliose or bracteate dichotomously dividing panicle, longer than their pedicels, $4-5^{\prime \prime}$ in diameter, discoid, homogamous. Involucre shorter than the florets, with a few small outer bractlets, its bracts numerous, several-nerved, pubescent at the apex, broadly scarious, and obtuse ones alternating with such as are narrow and acute. Florets about 20, all tubular, the little dilated limb longer than the tube, yellow. Pappus white, the scabrous bristles much shorter than the corolla. Achenes oblong, glabrous.» - The description from the Linnaea.

Oahu, only found by Chamisso.

2. S. capillaris, Gaud. Bot. Voy. Freye. p. 468. - stem erect, frutescent, branching. Leaves few, linear-capillary, glabrous. Peduncles terminal, foliose, single-headed.»

sSandwich Islands, 2000-2400 ft. Called *Pamakanin by the natives. - DC. 1. c. - Only collected by Gaudichaud.

\section{TRIBE VII. ANTHEMIDEAE.}

Heads heterogamous or rarely homogamous. Florets of circumference usually female, ligulate or tubular. Disk-florets tubular, hermaphrodite or rarely male, 4 - or 5 -toothed. Anthers obtuse at the base. Stylebranches as in Senecionideae. Pappus wanting or reduced to a small cup or ring or auricle. Involucre of dry or scarious scales appressed and imbricate in 2 or more rows. Receptacle mostly naked. Leaves alternate, generally much cut. 


\section{ARTEMISIA, L.}

Heads heterogamous, rarely homogamous, usually few-flowered. Invol. bracts imbricate, unequal, mostly scarious at the edges. Receptacle naked. Florets all tubular, those of the circumference female, fertile, 2-3-toothed, in one or two rows or sometimes wanting. Disk-florets hermaphrodite, 5 -toothed. Style-branches in the disk-florets truncate. Achenes obovoid, rounded at the top. Pappus none. - Erect herbs or shrubs. Leaves alternate, usually divided into narrow segments. Heads usually small, numerous, nodding.

A large genus, widely spread over the temperate and cold regions of the northern hemisphere, but scarcely penetrating into the tropies.

Involueral bracts linear, longer than the florets

Involucral bracts ovate, scarious, shorter than the florets
1. A. australis.

2. A. microcephala.

1. A. australis, Less. in Linnaea, VI, 522. - DC. Prod. VI, 106. - A spreading shrub, 2-3 ft, high. Leaves canescent underneath or on both sides, petiolate, those of the sterile branches $2-3^{\prime}$ long (including a long petiole), pinnatisect with $5-7$ oblong cuneate or linear obtuse segments which rarely are again lobed or cut, the upper leaves of flowering branches linear entire. Heads globose, $2^{1 / 2}{ }^{\prime \prime}$, not numerous, in leafy racemes or panicles of $2-3^{\prime}$ in length which do not project beyond the foliage, the peduncles densely crowded with reduced leaflets. Invol. bracts canescent, lanceolate or linear-spathulate, herbaceous, the inner ones longer than the florets. Receptacle conical, Florets 25-40, glandular. - Gray, 1. c. p. 137. - A. Eschscholtziana, Bess.

Oahu! only on the highest ridges; Molokai! Maui.

$\beta$ var. - Leaves bi-, tri-pinnatisect with acute segments, $3-4^{\prime}$ long. Heads smaller.

Kauai!

2. A. microcephala, Hillebr. - A spreading, canescent shrub, 3-5 ft. high. Leaves smaller, $1^{1 / 2}-2^{\prime}$, the lower pinnatisect with linear acute segments, but those of the flowering branches nearly all linear entire, canescent below. Heads small, about $1^{\prime \prime}$, numerous in open panicles which are exserted beyond the foliage, the peduncles with few short linear bractlets. Invol. bracts glandular, ovate, scarious, with a green base, the inner ones shorter than the florets, about ${ }^{1} / \mathrm{g}^{\prime \prime}$ only. Receptacle almost flat. Female florets 11-16, their corollae linear, bidentate, glandular, with style-branches exserted and reflexed. Hermaphrodite florets 9-12, broad tubular or urceolate, glandular, as are the achenes. - A. australis, var. mierocephala, Gray, in Mann's Enum. no. 245.

Hawail Central Plateau, 5000-6000 ft. 


\section{TRIBE VIII. CYNAROIDEAE.}

Heads homogamous, discoid, the florets all hermaphrodite, tubular and deeply cleft, or some of the outer ones enlarged but not ligulate. Anthercells tailed at the base. Style truncate, simple or with 2 short truncate branches, generally bulbous at the base of the branches. Pappus of numerous bristles. Invol. bracts imbricate in several rows, mostly spiny. Leaves alternate, mostly spiny.

\section{CENTAUREA, L.}

Involucral bracts imbricate in several rows, with scarious or spinescent appendages. Receptacle bristly. Florets of the circumference mostly enlarged, sterile, the others tubular, 5-fid, hermaphrodite and fertile. Achenes compressed, affixed by an oblique or lateral areole. Pappus of many rigid bristles of variable length, or wanting. - Herbs with alternate leaves and single or paniculate heads.

A large genus of the Old World.

1. C. Melitensis, L. - DC. Prod. VI, 593. - An erect annual, 1 to $2 \mathrm{ft}$. high, branching in the upper portion, rough-pubescent and, when young, with a little deciduous wool. Radical leaves pinnato-partite, attenuate into a petiole, those of the stem broadly linear, toothed, decurrent. Heads single on a branch, sessile, rather small. Involucre tomentose, coriaceous, the middle bracts running out into a trifid or pinnately divided spine. Marginal flowers 3-5-cleft, not enlarged. Bristles of pappus stiff, in several rows, those of the inner row short and convergent. Florets yellow.

Maui! around Wailuku and elsewhere, also o a u. A native of the Mediterranean countries which has found its way also to the Cape, to Chili and California. Another plant of this Orfer, the Safflower, Carthamus tinctorius, is oceasionally met with as a relic of former cultivation.

\section{TRIBE IX. MUTISIEAE.}

Heads homogamous or sometimes heterogamous, with the limb of the corollas bilabiate, at least in the outer florets, rarely all corollas equally but deeply divided. Anthers tailed or pointed at the base. Style-branches obtuse or truncate. Receptacle mostly naked. Leaves alternabe.

\section{HESPEROMANNIA, Gray.}

Heads homogamous, all florets hermaphrodite and equal. Involucre turbinate-campanulate, the bracts imbricate in many rows, dry, thin chartaceous to coriaceous, the inner bracts longest, linear-lanceolate, gradually decreasing to the outer ones, which are short ovate. Receptacle flat, naked. Corollae regular, slender, slightly ampliate above, deeply 5 -cleft into linear acute straight lobes. Stamens affixed to the base of the 
corolla, the anthers long linear, united until fertilization, exserted, caudate with filiform tails, the connective ending in a free lance-shaped appendage, the thin loculi evanescent after fertilization. Style filiform, long exserted, shortly bidentate with somewhat obtuse or truncate branches, or entire. Achenes linear-oblong, 5-angular, with several faces ribbed. Pappus of many pluri-seriate stiff and scabrous capillary bristles which are twice the length of the achene. - Trees or shrubs with very hard-grained wood. Leaves alternate, penni-nerved, entire. Heads large and few in terminal clusters or in the forks of the branches. Corollae brownish-yellow.

A Hawaiian genus, the only representative of the tribe Mutisieae in Polynesia. The large flower-heads with the long tawny pappus are much like those of Stifftia chrysantha. The linear lobes of the corolla are of equal length, and although two and three of them are occasionally parted by slightly deeper slits the corolla cannot be called bilabiate. In the outer florets the style is generally entire, yet their achenes are well formed.

Leaves oblong, narrowed at the base; heads $5-7$ in a cluster; achenes linear-oblong

Leaves ovate, with a rounded base; heads single or 2 or 3 together; achenes cuneate

1. H. arborescens.

1. H. arborescens, Gray, Proc. Am. Ac. VI, 554. - A small tree, $12-20 \mathrm{ft}$. high, the trunk 5-6 inches thick, with spreading branches. Leaves glabrous, dark on both faces, thin chartaceous, lanceolate or obovate-oblong, $5-6^{\prime} \times 1^{1} / 2-2^{\prime} / 2^{\prime}$, bluntly acuminate, erenato-dentate, almost entire, gradually contracting into a petiole of $1 / 2-1^{\prime}$. Heads $2-2^{1 / 2}$ high, 5-7 in a terminal cluster or cymose umbel on thick pedicels of about $1 / 2^{\prime}$. Involucre $1-1^{1} / 2^{\prime}$ high, quite glabrous, its bracts in $4-7$ rows. Corollae $12-15$ "long, divided to the middle. Anthers $4-5$ ". Achenes glabrous, $6-7 "$, linear-oblong, the tawny or reddish pappus twice that length. - Brigham, in Mem. Bost. Soc. Nat. Hist. I, 527, pl. 20 (the anther inexactly rendered).

Lanai! on the highest ridge. Mann met with only one tree, but the writer saw about eight four years later. As innovations mostly take rise from the uppermost axils, remnants of older inflorescences may be seen between two branches and also laterally.

$\beta$ var. Oahuensis. - A tree, 20-30 ft. high, the young branches pale with short ashy-gray tomentum. Leaves thin, gray-tomentose underneath, broadly ovato- or elliptico- or obovato-oblong, $5-8^{\prime} \times 2^{1 / 2}-4^{\prime}$, shortly acuminate, faintly denticulate, on petioles of $1 / 2-3^{2}$. Heads in clusters of 4-6. Invol. $1^{\prime}$ long, the lowest bracts tomentose. Corollae pale yellow, 9-10". Pappus ashy-gray, $10^{\prime \prime}$. Mature achenes not seen. H. arborescens, Wawra, in Flora, 1873, p. 76.

Oahu! Waianae range, Puakea (Wawra), Makaleka (Lydg.).

2. H. arbuscula, sp. $n$. - «A weak shrub with long and slender branches which extend over the ground or lean for support on neighboring shrubs, $\gg$ (Bishop.) Leaves ovate to ovate-oblong or suborbicular, $4-6^{\prime} \times 2^{1} / 2-3^{1} / 2^{\prime}$, sharply and closely dentate, rounded below, on petioles of $1-1^{1} / 2^{\prime}$, pale puberulous underneath, quite thin. Heads $2^{\prime}$ or less in 
height, single or 2 or 3 together at the end of a branch, on short pedicels. Involucre, corollas and pappus each $12^{\prime \prime}$ long. Achenes cuneiform, $4-5$ "long.

W. Maui! about $1200 \mathrm{ft}$. above Lahaina. Collected by the late Mr. E. Bishop.

\section{TrIBE X. CICHORIEAE.}

Heads homogamous, the florets all hermaphrodite and ligulate, the ligules 5-toothed. Style-branches filiform. Leaves alternate. Herbs, rarely trees, with milky juice.

\section{CREPIS, L.}

Involucre a single row of nearly equal bracts with a few small outer ones. Receptacle naked. Achenes oblong cylindrical or scarcely flattened, striate, tapering at the top, sometimes beaked. Pappus of copious soft white simple hairs.

A large genus, widely distributed over the temperate regions of the northern hemisphere, with a very few subtropical species.

† 1. C. Japonica, Benth. Fl. Hongk. p. 194. - An erect slender annual, $1 / 2-2 \mathrm{ft}$. high, glabrous. Leaves mostly radical, petiolate, varying from obovate nearly entire and $1-2^{\prime}$ long to lyrate or pinnatifid and $2-4^{\prime}$ long with a large terminal toothed lobe. Heads numerous in a short corymbose slender panicle, sometimes almost umbellate. Involucre about $2^{1} / 2^{\prime \prime}$, with 8 keeled bracts, holding $10-22$ small yellow florets. Achenes hispid, short. Pappus twice as long, soft white. - Prenanthes Japonica, L. - Youngia Japonica, DC. Prod. VII, 194.

Oahu! in woods here and there, Kailua, along the foot of the high pali. A common Indian weed which extends from Ceylon and Mauritius to China and Japan.

\section{SONCHUS, L.}

Involucre with imbricate bracts and usually becoming conical after flowering. Receptacle naked. Achenes flattened and striate, not beaked, with a white pappus of soft and fine simple hairs.

A considerable genus, ranging over the temperate regions of the northern hemisphere.

† 1. S. oleraceus, $L$. - An erect annual, 1-3 ft. high. Leaves thin, bordered with irregular pointed or prickly teeth, otherwise either undivided or pinnatifid with a broad heart-shaped or triangular terminal lobe; the upper leaves narrow and clasping the stem with short pointed auricles. Heads in a short corymbose panicle, sometimes almost umbellate. Florets pale yellow. Achenes transversely rugose.

A common weed, the spualeles of the natives, extending from the low plains to the summit of Haleakala. Indigenous probably in Europe and Asia, but now found over nearly the entire globe. S. asper, distinguished by rounded auricles and smooth achenes, is not unlikely to oceur also. 


\section{Order XLIII. LOBELIACEAE.}

Calyx-tube adnate to the ovary, the limb 5-lobed, but the lobes sometimes connate. Corolla gamopetalous, 5 -lobed, the lobes valvate, slightly 2 -lipped, the upper ones separated by deeper slits from the lower and from each other. Stamens 5, alternate with the lobes of the corolla, the filaments and anthers united into a tube, the anthers introrse, opening longitudinally, all, or the two lower ones only, bearded at the apex. Ovary either 1-celled with 2 parietal placentas, or more commonly 2-celled with everted placentas and numerous anatropous ovules. Style simple, 2 -lobed, with a ring or patches of hair below the lobes. Fruit a capsule or berry. Embryo straight in fleshy albumen. - Herbs, shrubs or small trees with milky juice. Leaves alternate, without stipules.

A considerable Order, spread over the tropical and subtropical regions of all continents.

Of this Order, the most interesting and characteristic of our flora, 58 species are known thus far, all endemic and distributed in 6 genera, 5 of which are also endemic. Of these 5, one, Brighamiu, stands near the Australian genus Isotoma, which has also sent an outrunner to the Society Islands; the other four, Clermontia, Rollandia, Delissea and Cyanea, are very peculiar and intimately connected with each other, so that it is not easy to determine where one ends and the other begins. They were all established by Gaudichaud, but very unsatisfactorily defined by irrelevant technical characters which separated in different genera closely related species and brought together quite heterogeneous ones. In the following new arrangement, which is based upon the study of a much larger material than was at the disposal of any previous writer and upon the knowledge of the mode of growth of the different species, it is claimed that they have been grouped according to their natural affinities, but not that every debatable ground between the several genera has been removed. The sixth genus, Lobelia, which is widely spread over the tropical and subtropical regions of the whole world, comprises among its 5 species two distinct types, of which one, represented by one species only, is closely connected with a plant of the Loo Choo and Bonin Islands.

All the species have a woody stem; by far the greater portion are tall shrubs or trees, many with a simple undivided trunk and palm-like habit.

In determining the range of a species in the fleshy-fruited genera it is necessary to attend to two peculiarities in their mode of growth and to frequent sources of error. In the first place, the axillary centripetal raceme continues to grow until the last flower is matured, and this growth proceeds at a very slow rate, perhaps occupies a couple of months in the many-flowered racemes, and the length of a fruit-bearing raceme may be several times that of one which only holds the first expanded flowers. In the second place, the same rule prevails to some extent in the calycine lobes. In many species these are larger with the fruit than with the flower; the increase seems to take place at the base of the sepals and to continue until the seeds mature. But, aside from this circumstance, there is no part of the plant more subject to variation than the calycine lobes. Their relative length, far from offering a useful character for limiting genera, cannot even be made available for determining varieties. Both in Clermontia and in Cyanea we meet with lobes which are short toothlike and with those which exceed their corollae, and connate lobes do not belong exclusively to the former, but occur also in a new species of the latter genus.

Corolla salver-shaped, with a straight entire tube; the fruit capsular 1. Brighamia.

Corolla tubular, curved, deeply slit at the back:

Fruit a capsule; flowers in terminal raeemes

Fruit a berry; inflorescence axillary :

Flowers 2 or 3 in simple cymes, the median pedicel equal to the lateral ones, or 5 to 13 in compound cymes or cymose umbels Flowers in strict racemes:

Staminal column in part adnate to the corolla, the latter deep red or reddish-purple, laterally compressed

2. Lobelia.

3. Clermontia.

4. Rollandia. 
Staminal column free from the corolla:

Seeds white, wrinkled, with a thin testa; corolla white or greenish, with a dorsal and often 2 lateral knobs; leaves fleshy, glabrous .

Seeds crustaceous, smooth and shining; corolla more or less purplish, without knobs; leaves not fleshy

5. Delissea.

6. Cyanea.

\section{BRIGHAMIA, Gray.}

Calyx-tube cylindrical, 10 -ribbed, with short lobes. Corolla salvershaped, with a long and straight entire tube, the lobes spreading, valvate in the bud with inflected tips and margins, nearly equal, but two of them separated by deeper slits. Staminal column adnate to the corolla below the middle, highest at the back; all anthers bearded at the apex. Ovary bilocular, with peltate placentas. Stigma shortly 2 -lobed, the rounded flat lobes faintly pubescent externally. Fruit a thin-skinned (fleshy?) capsule opening by 2 slits on each side. Seeds numerous, small ovoid, with a thin and smooth pale testa. Embryo shorter than the albumen. - A perennial plant with a thick fleshy simple stem, conically enlarging at the base and densely foliose at the apex. Leaves entire. Flowers white, on erect axillary racemes, with small deciduous bracts and straight pedicels.

A Hawaiian genus of a single species, nearest related to Isotoma, an Australasian genus, of which also a species occurs in the Society Islands.

1. B. insignis, Gray, in Mann, Emum. no. 283. - Stem 5-12 ft. high, several inches thick at the base, fleshy throughout and glabrous. Leaves $9-12^{\prime} \times 5-6^{\prime}$, obovate or ovate, with contracting base, subsessile, thick fleshy, glossy, subentire or sinuate-crenate. Peduncle $2-5^{\prime}$ long, naked below, bearing 5-15 flowers in its upper half on naked pedicels of ${ }^{1 / 2}-1^{\prime}$. Bracts small dentiform. Calyx-tube $6-7^{\prime \prime}$, its lobes triangular or lanceolate, $1^{1 / 2}-4^{\prime \prime}$. Tube of corolla $3-5^{\prime}$ long, the lobes $9-12^{\prime \prime}$, ovate acuminate, with contracting base, sometimes subbilabiate, the 2 upper ones on a common claw divided by deeper sinuses from the others. Staminal column glabrous, almost white. Capsule ovoid to cylindrical, $8-9^{\prime \prime}$ long, crowned with the calycine lobes. - Mann, in Mem. Bost. Soc. Nat. Hist. I, 531, pl. 23.

Molokai! on steep palis of the northern coast, from Koolaupapa to Halawa, in great numbers at the outlet of the latter valley; Niihau (Remy). The singular plant has been aptly compared to a big eabbage-head stuck on a naked pole. The flowers are sweetscented, with an odor like that of violets, whence the native name spaalas.

\section{LOBELIA, L.}

Calyx 5 -toothed or lobed. Corolla slit open on the upper side to near the base, 5 -lobed, the 2 upper lobes half the length of the corolla, forming an upper lip, the 3 lower united into a tridentate or trifid lower lip. Staminal tube free from the corolla, the $\dot{2}$ lower anthers or all bearded 
at the top with a tuft of short stiff hairs. Style shortly 2-lobed, with 2 patches or a ringlet of short hairs below the lobes. Capsule 2-celled, opening at the top into 2 loculicidal valves. Seeds numerous, small, with a thin smooth testa. - Mostly herbs, but all Hawaiian species shrubby. Peduncles 1-flowered, in the axils of leaves, or in terminal bracteate racemes or spikes.

A very large genus, spread over the tropical and temperate regions of the whole world. Corolla curved, with converging upper lobes, cream-colored; all anthers penicillate; seeds marginate

Corolla suberect, the upper lobes spreading; lower anthers only penicillate; seeds ovoid:

Stem ending in a single raceme; flowers bluish .

Stem branching near the end into several racemes:

1. L. Gaudichaudii.

Flowers pink or rose-colored; capsule globose, with a flat vertex Flowers bluish; capsule partly superior, with a conical vertex:

Leaves glabrate; eapsule ovoid

Leaves white tomentose underneath; capsule cylindrical .

2. L. yuecoides.

3. L. macrostachys.

4. L. neriifolia.

5. L. hypoleuca.

1. L. Gaudichaudii, DC. Prod. VII, 384. - Stem erect, 2-3' thick near the base, with a thin woody zone and a thick compact medulla, elosely covered with rhomboidal leaf-scars, loosely foliose near the top, 4-6 ft. high, generally simple and continuing directly into a pyramidal bracteate raceme of $1^{1 / 2}-2 \mathrm{ft}$, in length, rarely with 1 or 2 short suberect secondary racemes from the base of the terminal one. Leaves coriaceous, quite glabrous, sessile with a broad base, oblong-lanceolate, $6-9^{\prime} \times$ $1-1^{1} / 2^{\prime}$, shortly acuminate, narrowing little toward the base, the margin entire, revolute and lined with a conspicuous row of resinous glands, the oblique veins hidden. Bracts ovate-oblong, glandular-dentate, $1^{1 / 2}-3 / 4^{4}$. Pedicels suberect, $1--2^{\prime}$, puberulous, with 2 accrete bractlets at the base. Calyx greenish, glabrous, the obconical tube $5 \times 6^{\prime \prime}$, the broad foliaceous lobes twice as long, and imbricate in the bud, deciduous after flowering. Corolla large curved, $3-3^{1} / 2^{\prime}$ long, $1 / 2^{\prime}$ broad at the base and widening toward the apex, of thick texture, cream-colored, glabrous, deeply bilabiate, both lips eurving downward, the lower 3 -dentate or shortly 3 -fid. Staminal column glabrous. Anthers 7 "long, pale greenish with bluish edgings, all penicillate at the apex. Capsule hard, almost woody, obconical, $10 \times 7^{\prime \prime}$, with 10 ribs, free in its upper third, which is conical and opens late by loculicidal dehiscence. Seeds compressed, reniform or orbicular; margined, with little albumen, attached edgewise, $1^{\prime \prime}$ long, the testa thin and pale. - Gaud. Bot. Voy. Bon., tab. 45. - Gray, in Proc. Am. Ac. V, 150. - Wawra, in Flora, 1873, p. 58. - The seeds are, as described, in capsules already open at the vertex. With age the calycine covering withers away, leaving a fenestrate woody net-work which encloses the now freed pergameneous capsule.

Oahu! on Konahuanui and Waiglani; Maui! Eeka; Kauai! Pohalnuili and Waialeale (Wawra \& $\mathrm{Kn}$.); at elevations of 3000 to $6000 \mathrm{ft}$. On Eeka the plant is not scarce, 
growing in company with Wilkesia Grayana. It is resinous in all parts and has a very thick milksap. The racemes, bearing from 80 to 100 flowers, make a showy appearance. After the maturation of the fruit the stem dies off, as is also the case with the next following species, but probably becomes replaced by offshoots from near the base. The Harvard herbarium contains an undeseribed Lobelia from the Loo Choo Islands, collected by Mr. Ch. Wright, which resembles the present species greatly,

2. L. yuccoides, $s p . n$. - Trunk simple, erect, with a thin woody zone and compact medulla, $4-6 \mathrm{ft}$. high, $1-1^{1} /^{\prime}$ thick, closely covered with spires of rhomboidal leaf-scars and bearing a crown of leaves at the end, thence passing at once into a thick terminal raceme of $2-3 \mathrm{ft}$. in length which is closely covered with $200-400$ flowers. Leaves linear, $12-15^{\prime} \times$ $2-6 "$, acute at both ends, with revolute entire margins, whitish and puberulous underneath, chartaceous, with almost horizontal nerves. $\mathrm{Pe}$ dicels $4-6^{\prime \prime}$, with setiform bracts and bractlets. Calyx whitish, the obconical striate tube about $2 "$, the subulate lobes somewhat longer. Corolla puberulous, bluish, very slender, suberect, 18-20" long, the upper lip spreading, the lower deeply trifid. Filaments puberulous, a small patch of pubescence at the base of each anther; only the 2 lower anthers penicillate. Capsule ovoid or almost cylindrical, $5-6^{\prime \prime}$ high, semi-inferior, with a conical apex, loculicidal in the free portion and at last down to the base.

Oa hu ! ridge of Waianae, mountains above Lihue; Ka u a i! Waimea (Kn.); at elevations of $2000-3000 \mathrm{ft}$.

3. L. macrostachys, Hook. \& Arn. in Bot. Beech. p. 88. - A shrub, $5-6 \mathrm{ft}$. high, the erect woody stem $1-1^{1 /} / 2^{\prime}$ thick, dividing at the apex candelabra-like into 5-9 horizontal branches, each $1^{1 / 2}-3 \mathrm{ft}$. long and terminating in a many-flowered raceme, the leaves rather abruptly falling off to bracts. Leaves glabrous, membranous, lanceolate, $10-12^{\prime} \times{ }^{3} / 4-1^{\prime}$, acuminate, gradually narrowing into a margined petiole, faintly crenate in its upper portion, with a small gland under each crenature. Racemes about $1 \mathrm{ft}$. long, the pedicels horizontal, 9 "long, bibracteolate below the middle, the bracts as long as the pedicels. Calyx glabrous, its tube globose, about $3^{\prime \prime}$, the lobes lanceolate, of nearly the same length. Corolla glabrous, pale rose or pink, slender, about $2^{\prime}$ long and $3^{\prime \prime}$ wide, suberect before expansion, the 2 upper lobes spreading, the lower lip shortly trifid. Staminal column glabrous, excepting a small hairy patch at the base of each anther; only the 2 lower anthers penicillate. Stigmatic hairs in a ringlet. Capsule coriaceous, subglobose, $3-4^{\prime \prime} \times 5-6^{\prime \prime}$, with prominent lines and a broad depressed umbonate vertex, inferior throughout, indehiscent or opening by small pores at the vertex, with permanent calyx-lobes. Seeds minute, ovoid, not margined. - Gaud. Bot. Voy. Bon., tab. 46. - Gray, 1. c. - The seeds would seem to become free only after the maceration of the calycine tube, which then presents 
the same fenestrate appearance as in L. Gaudich. The plant is scarcely resinous, the marginal leaf-glands being much smaller than in no. 1. Milksap watery.

On high ridges at elevations of 2000 to $3000 \mathrm{ft}$. Oahu! on both ranges; Kauai, Pohakupili (Wawra); Molokai! Hawaii. This and the first speeies are plants of striking beanty and deserve to be cultivated.

4. L. neriifolia, Gray, in Proc. Am. Ac. V, 150. - Low prostrate, the woody trailing stem about $3^{\prime \prime}$ thick and studded below with knobby leaf-scars, distantly foliose above and ending in a long raceme, with generally one or more distant smaller ones in the axils of the upper leaves. Leaves chartaceous, linear-lanceolate, $8-10^{\prime} \times 4-7^{\prime \prime}$, acute at both ends, glandular-dentate or with revolute margins, subentire, generally pale underneath with a faint pubescence. Terminal raceme $6-10^{4}$ long, rather loose; bracts linear. Pedicels $4-6^{\prime \prime}$, bracteolate below the middle. Calyx-tube short obconical, 1--2", the subulate lobes about twice as long, persistent. Corolla lilac, slender, suberect, $9-10^{\prime \prime}$ long, its lips revolute. Filaments pubescent; anthers glabrous, only the lower ones shortly penicillate. Capsule ovoid, 3-4", semi-superior, the free conical portion loculicidal and septicidal. Seeds minute ovoid.

Maui! ridges of Wailuku and Waikapu, Haleakala, 2000-3000 ft.

$\beta$ var. - Leaves green underneath. Inflorescence paniculate, $5-6$ secondary racemes besides the terminal one,

Molokai! Maunahui, where it was found trailing among Lycopodium fastigiatum.

$\gamma$ var. - Leaves narrow linear, $2-4$ " wide, green underneath, membranous, crenulate. A single raceme, 5--6' long. Capsule $3^{\prime \prime}$, the free portion more than half its length.

Oahu! Niu, on a dry exposed slope. The stems, only $1 \mathrm{ft}$. long, exhibit the growth. of several seasons, the remnants of old racemes standing at the base of the latest growth.

5. L. hypoleuca, $s p . n$. - Erect, subherbaceous, the hollow stem $2-4 \mathrm{ft}$. long, with few distant leaves, branching above, the long branches bearing $1-4$ distant leaves and ending in a rather loose raceme of $6-10^{\prime}$ in length. Leaves broadly lanceolate, $12-18^{\prime} \times 1-3^{\prime}$, acute, gradually narrowing into a petiole of ${ }^{1} / 2-1^{\prime}$, sharply dentate or serrulate with callous teeth, soft chartaceous, white underneath with a thick layer of matted wool. Bracts linear or filiform, as long as the pedicels or longer, these $6^{\prime \prime}$, bibracteolate near the base. Calyx tomentose, white, with an elongate tube of $3^{\prime \prime}$, the lobes of about the same length, subulate from a broad base. Corolla bluish, puberulous, very slender, erect, 15-18" long, with revolute lobes. Filaments puberulous; anthers glabrous, bluish, only the lower ones penicillate. Capsule whitish, cylindrical, 8-9" long, the free conieal vertex less than $1 / 4$ of the length, with 10 warty ridges. 
The calycine covering being very thin the capsule is apt to split laterally even before the vertex. Seeds very minute, smooth, ovoid, light brown.

Oahu! Wailua and Hatemano; Molokai! pali of Pelekunu; Maui! gulehes of Lahaina and Wailuku; Hawai1! woods of Kohala.

\section{CLERMONTIA, Gaud.}

Calyx-lobes either as long as the corolla and then connate bilabiate, colored, caducous, or shorter than the corolla and free, persistent; the ovarian portion globose or turbinate. Corolla tubular, of even width throughout, arched or suberect, almost uni-labiate, the dorsal slit extending to the base, the lateral slits to the middle and the anterior ones falling little short of the latter. Staminal column free from the corolla, generally glabrous; only the 2 lower anthers penicillate. Stigma 2-lobed, hairy below the lobes. Fruit a globose berry with a broad epigynous disk, 2-celled, with thick everted fleshy placentas which fill the entire cells. Seeds numerous, crustaceous, ovoid, smooth. - Unarmed glabrous trees or shrubs with a thick tenacious milksap, branching horizontally from the base upward. Flowers few in simple or irregularly compound eymes.

A genus of Hawaiian plants, characterized by the cymose inflorescence ${ }^{*}$, the uni-labiate corolla, the full bushy spreading habitus, and the pale or glaucous foliage. Much more numerous in individuals than the other genera of this Order, it constitutes in many regions a leading feature of the vegetation. The trunk of the arborescent species, although measuring several inches in diameter, encloses a small medullary cavity. The thick milksap is used as bird-glue by the natives, who apply the common name aOha wai to all species.

Clermontiae genuinae. - Calycine lobes connate, as long as the corolla or little shorter. (In anthesi the upper lobe of the calycine tube becomes completely detached from the others, which only split to the middle, forming a bilabiate calyx; at maturity the entire tube falls with the corolla).

Peduncle generally 2-flowered; flowers eurved in the bud, over $1^{1 / 2}$ inch long:

Peduncle long filiform and pendulous.

1. C. grandiflora.

Peduncle short erect:

Calyx and corolla little curved when open, with spreading lobes: Leaves dull, pubescent underneath; bracts linear . Leaves glossy above, glabrous and glaucous underneath; bracts

dentiform
Calyx and corolla strongly arched when open; leaves pale and glabrous underneath

Pedunele cymosely 3-11-flowered :

Flowers more than $1^{1 / 2^{\prime}}$ in length, eurved when open

Flowers less than $1^{1 / 2}$ suberect even in the bud:

Leaves lanceolate, pale; bracts dentiform; color of ealyx and corolla with a tinge of red or purple.

Leaves broadly oblong, dark; bracts linear; color of ealyx and corolla blue

2. C. macrocarpa.

3. C. persicaefolia.

4. C. oblongifolia.

5. C. pallida.

6. C. multifiora.

7. C. parvifiora.

- Each of the three plates in the Botany of Freycinet's Voyage gives a wrong representation of the inflorescence. 
Clermontioideae. - Calycine lobes free, shorter than the corolla, persistent; peduncle 2-3-flowered.

Peduncle short, $1 / 2^{\prime}$ or less:

Calyx 5-toothed; corolla puberulous; upper anthers pubescent 9. C. Gaudichandii.

Calyx 5-lobed; corolla glabrous as well as the anthers . 8. C. arborescens.

Peduncles $1^{\prime}$ or more in length:

Peduncle 1' long; corolla blue; berry globose

10. C. coerulea.

Peduncle $2^{\prime}$ long; drooping, with resupinate pedicels; berry pyriform 11. C. pyrularia.

1. C. grandiflora, Gaud. Bot. Voy. Freyc. p. 459, tab. 73. - A small tree, $12-15 \mathrm{ft}$. high, glabrous. Leaves obovate to oblong, $3^{1 / 2}-5^{\prime} \times 1^{1 / 4}-1^{1 / 2} 2^{\prime}$, on petioles of $1 / 2-2^{\prime}$, shortly acuminate or cuspidate, bluntly serrulate or dentate, narrowing at the base, chartaceous, glabrous, dull. Peduncle filiform and pendulous, $1-4^{\prime}$, with a pair of empty bracts near the middle, 2 -flowered, the slender pedicels $1-2^{1 / 2}$, bracteolate near the middle, or sometimes 3 - or by dichotomy of the pedicels cymosely $4-5$-flowered. Calyx glabrous, rather thin, purplish or greenish, the ovarian portion low cup-shaped, $4 \times 5^{\prime \prime}$, the free portion tubular, strongly curved before expansion, much less so after, $2^{1 / 2}-3^{\prime}$ in length, $3-4^{\prime \prime}$ in width, the anterior lobes $1 / 3-1 / 2$ the length of the whole calyx. Corolla purplish, as long as the calyx or a little longer, its lobes spreading. Berry yellow, subglobose, with a broad depressed disk, $6-12^{\prime \prime} \times 4-8^{\prime \prime}$. - C. grandiflora, var. brevifolia, Gray, 1. c.

W. Maui! Lanai! Molokai! The infloreseence of this well marked species is quite incorrectly given in Gaudichaud's plate, but the leaves and flowers are true to nature, the latter by no means too large. Specimens from Gaudichaud's collection, distributed by the Musce du Jardin des Plantes, agree entirely with my plants. Old deflorate specimens, colleeted in Waihee, Maui (not Kauai), were described by Wawra as Delissea filigera.

2. C. macrocarpa, Gaud. Bot. Voy. Bon. tab. 49. - A tall shrub or small tree with the young shoots tomentose. Leaves obovate-oblong, $6-10^{4} \times 2-3^{\prime}$, shortly acuminate, closely denticulate with callous teeth, contracting into a petiole of $1-1^{1 / 2^{\prime}}$, membranous, dull, not shining above, puberulous beneath. Peduncle puberulous, longer than the pedicels, about $1^{\prime}$, two-flowered, with an empty pair of linear bracts $\left(2-3^{\prime \prime}\right)$ in its upper half; pedicels ${ }^{3} / 4^{\prime}$, bracteolatè at the middle. Calyx green, its ovarian portion globose, $5-6 "$ in diameter, the tubular portion equalling the corolla, 15-18" long and 4 " wide, suberect. Corolla yellowish-green. Staminal column pale green, the anthers rose-purplish. Berry globose, yellow, $10-15^{\prime \prime}$ in diameter, faintly 5 -ribbed. Seeds pale. - C. Kakeana, Meyen, in Presl, Lobel. (name only), and Walp. Rep. II, 708. - C. grandiflora, var. longifolia, Gray, 1. e. - C. macrophylla, Nutt.

Oahu! Molokai! Maui! at the lower edge of the woods up to $2500 \mathrm{ft}$. above the sea. The insipid fruit, which on E. Maui grows to the size of a crab-apple, is eaten by the natives. Meyen's name is older than Gaudichand's, but, as it was published withont description and the word Kake is the native rendering of the English name Jack, probably adopted by the traveller's guide, I forbear from reintroducing it. 
$\beta$ var. cymosa. - Peduncle cymosely 5-7-flowered. Bracteoles accrete to the pedicels and therefore apparently at the base of the calyx.

Oahu! slopes of Kaala.

$\gamma$ var. rosea. - Peduncle 2-flowered. Calyx and corolla pale rose. Only the youngest leaves puberulous.

Oahu! Halemanu.

ò var. Hawaiiensis. - Leaves chartaceous, glabrous. Peduncle 2-flowered, $1^{\prime}$ or more long, but shorter than the pedicels. Bracts linear, $6^{\prime \prime}$. Ovarian portion of calyx turbinate, $10-12$ "long when with flower.

Hawaii! from Hilo to Waiohinu.

3. C. persicaefolia, Gaud. Bot.'Voy. Freyc. tab. 72. - Size of C. macrocarpa, but the youngest branches glabrous and purplish. Leaves lanceolate or oblong, $4-5^{\prime} \times{ }^{3} / 4-1^{1} / 4^{\prime}$, acuminate or somewhat obtuse, coarsely crenate or serrulate, the base gradually contracting into a long petiole of $2-3^{\prime}$, subcoriaceous, glossy above as if varnished, glabrous and, when fresh, glaucous underneath. Peduncle 4-6" long, 2-flowered, with a pair of short $\left(1^{\prime \prime}\right)$ bracts lower down, shorter than the pedicels, these $6-12^{\prime \prime}$, bibracteolate near the base and in the young inflorescence, here often dividing again. Calyx and corolla suberect as in C. macrocarpa, but smaller and with a purplish or bluish tinge, the ovarian portion turbinate. - DC. Prod. VII, 342. - Probably Wawra's C. parviflora from Puakea, Oahu.

Oahu! Kaala range and western portion of the main range.

4. C. oblongifolia, Gaud. Bot. Voy. Freyc. p. 459, tab. 71 . - A tree, $15-25 \mathrm{ft}$. high, quite glabrous. Leaves oblong, $4-6^{4} \times 1^{1 / 2^{\prime}}$, obtuse or rounded, crenate or bluntly serrulate toward the apex, abruptly contracting into a long petiole of $2-4^{\prime}$, chartaceous, pale, even whitish, underneath. Peduncle $1 / 2-1$ 'long, 2 -, rarely 3 -flowered, with one or two pairs of empty dentiform $\left(1 / 2-1^{\prime \prime}\right)$ bractlets, the pedicels about as long as the peduncle and bibracteolate near the base. Calyx pale greenish, its free portion as long as the corolla, strongly arched, the apex returning to the level of the base, $2-3^{\prime}$ long, $4-6^{\prime \prime}$ wide. Berry globose, $8-9^{\prime \prime}$ in diameter, not furrowed. Seeds dark brown. - DC. Prod, 1. c.

Oahu! on the highest ridges of the main range, Manoa, Palolo, Niu, Waipio, ete. In adopting Gaudichaud's name for our plants I do not feel quite certain about their identity. In the plate the corolla appears like that of no. 3 , and possibly his plant was not specifically distinet from $C$. persicaefolia.

5. C. pallida, $s p . n$. - A tree, $15 \mathrm{ft}$. high, quite glabrous. Leaves crowded at the ends of the branches, pale, chartaceous, dull, not shining, elliptico-oblong, $4-5^{\prime} \times 1^{1} / 4-1^{9} / 4^{\prime}$, on long petioles of $2^{1 / 2}-4^{\prime}$, cuspidate, bluntly serrulate. Peduncles $3 / 4^{4}$, eymosely $3-7$-flowered, with a pair of empty bracts. Pedicels of the same length, bracteolate below the middle. Bracts $7^{u}$, linear-oblong; bractlets $5^{\prime \prime}$. Calyx green with a Hillebrand, Flora of the Hawaiian Islands. 
reddish tinge, the free tubular portion moderately arched, about $2^{\prime}$ long, a little shorter than the corolla.

Molokai! on the highest ridge, near the palis of Wailau and Pelekunu.

6. C. multiflora, sp. n. - A glabrous shrub, 6-12 ft. high. Leaves lanceolate-oblong, $4^{1} / 2-5^{\prime} \times 1-1^{1} / 4^{\prime}$, on long petioles of $2^{1 / 2}-3^{\prime}$, equally acute at both ends, crenulate, pale, chartaceous to membranous. Peduncle $1 / 2^{\prime}$ long, slender, umbellately many- (7-10-) flowered, with empty bracts only when fewer-flowered. Pedicels as long, bracteolate at the base; the bracts $1-1 / 2^{\prime \prime}$. Calyx of thin texture, glossy, pale green, the ovarian portion obconical, $4^{\prime \prime}$ long, the free tubular portion as long as the corolla, $12-16^{\prime \prime}$ long and $2^{1 / 2}$ " wide, suberect. Corolla purple at the top, as are the anthers.

Maui! gulches of Waihee and Lahaina; Oahu! Wailupe. Differs from no. 5 in the smaller suberect flowers and the umbellate inflorescence.

$\beta$ var. micrantha. - A shrub of only $3-5 \mathrm{ft}$. in height. Leaves $3-4^{\prime} \times 4-9^{\prime \prime}$, on petioles of $1-2^{\prime}$. Peduncle $3^{\prime \prime}$ long, $3-5$-flowered. Free portion of calyx $10-12^{\prime \prime}$, purplish-red, as is the corolla. Berry subglobose, $3^{\prime \prime}$ in diam., orange-colored, as are the seeds.

Maui! Waihee, in the bare gravel along the stream.

7. C. parviflora, Gaud. - Gray, in Proc. Am. Ac. V, 150. - A shrub, 6-10 ft. high. Leaves broadly oblong, $3-4^{\prime} \times 1^{1 / 4}-1^{1 / 2^{\prime}}$, on petioles of $3 / 4-1$, evenly but shortly acuminate at both ends, closely denticulate, thin chartaceous, faintly pubescent. Peduncle rather thick, $6-10^{\prime \prime}$ long, bearing $3-6$ flowers at the apex. Pedicels 6 "; bracts linear, $3-4$ ". Calyx suberect, the free portion $12^{\prime \prime}$ long and $3^{\prime \prime}$ wide, blue, as is the corolla, and equalling the same. Berry ovoid, $8^{\prime \prime}$ long.

Hawaii! on the Kohala range.

$\beta$ var. pleiantha. - Peduncle $6-10$-flowered, the bracts $2--1 "$. Free portion of the calyx $9^{\prime \prime}$ long and $1^{1 / 2} 2^{\prime \prime}$ wide, with spreading lobes.

Hawail in the woods of Hilo, - Here the median branch of the cyme often divides in place of the lateral ones and lengthens out, simulating a short raceme, but in the young inflorescence the lowest lateral branches generully bear 2 or 3 flowers.

8. C. arborescens, Hillebr. - A tree, 15-25 ft. high, with the habit of all true Clemontias. Leaves obovate to oblong, $6-8^{\prime} \times 2--2^{1} / 2^{\prime}$, on petioles of $1^{1 / 2}-3^{\prime}$, shortly acuminate or rounded, gradually narrowing at the base, crenate or serrulate, rather coriaceous, dark green and glossy above, with impressed veins. Peduncle fleshy, very short, $2-4^{\prime \prime}$, always 2 -flowered and without empty bracts, the pedicels much longer, $8-18^{\prime \prime}$. Bracts $2-4^{\prime \prime}$; bractlets at the base of the pedicels $2-1^{\prime \prime}$. Calyx green, with a campanulate adnate tube of $7-12^{n}$ in length and thick obtuse or deltoid lobes of very variable length, $2-12^{\prime \prime}$, which are separated by sinuses when small, contiguous and partly connate when large. Corolla 
thick coriaceous (or rather fleshy), 2-3' long and of an even width of $1 / 2$ ', strongly arcuate, the apex returning to the level of the base, greenishwhite, the lobes in the expanded flower longer than the tube, but converging. Anthers glabrous. Berry yellow, globose, $1-1^{1 / 2} 2^{\prime}$ in diameter, deeply furrowed, crowned by the calycine lobes. Seeds pale yellow, shining. - Cyanea arborescens, Mann, Enum. no. 275. - Delissea Waihiae, Wawra, in Flora, 1873, p. 8.

A rather common tree in the eastern division of Molokai! on Lanai! and W. Maui! at elevations of 2000 to $3000 \mathrm{ft}$. Wawra's plant eame from Waihee, Ma ui, where we eollected specimens with both extremes in the length of the ealycine lobes. Remarkable for the thick texture and large size of the corolla, which generally falls off before it expands, and resembles in shape that of Cyanea superba. The species is doubtfully distinet from the following, and offers a striking instance of the unreliability of the relative length of the calycine lobes for purposes of generic division in this Order.

9. C. Gaudichaudii, Hillebr. - Size and habit as before. Leaves elliptico-oblong to lanceolate, $4-6^{\prime} X^{3 / 4}-2^{\prime}$, on pedicels of $1-1^{1 / 2} 2^{\prime}$, equally acute at both ends, crenulate, glabrous, pale and dull, chartaceous. Peduncle short, $3-6^{\prime \prime}, 2$-flowered, the pedicels longer, 6-9". Bracts $2^{\prime \prime}$. Calyx broad campanulate, $4-5^{\prime \prime}$ high, with 5 short $\left(1^{\prime \prime}\right)$ acute teeth. Corolla arcuate, ahout $2^{\prime}$ long and $3-4^{\prime \prime}$ wide, greenish-purple. Anthers pale, glabrous. Berry globose, furrowed, less than $1^{\prime}$ in diam: - Delissea clermontioides, Gaud. Bot. Voy. Bon. tab. 47. - Mann, Enum. no. 255.

Kauai! Waimea, Pohakupili, Waialeale (Wawra, Kn.).

$\beta$ var. - Calyx and corolla as above. Upper anthers pubescent along the sutures and at the apex. Leaves broader oblong, glossy, as if varnished on the upper face, as in the preceding species.

E. Maui! Hamakua (Lydg.).

10. C. coerulea, $s p . n$. - Shrubby, about $12 \mathrm{ft}$. high, freely branching. Leaves oblong, $6-8^{\prime} \times 1^{1 / 2}-1^{3 / 4^{\prime}}$, on petioles of $1-1^{1 / 2^{\prime}}$, shortly acuminate, contracting at the base, almost entire, glabrous, membranous. Peduncle slender, $1-1^{1} / 2^{\prime}, 2-3$-flowered, with a pair of short $\left(1^{1 / 2} 2^{\prime \prime}\right)$ empty bracts above the middle; pedicels shorter, $3 / 4-1$, bracteolate at the middle. Calyx colored, the campanulate tube 7 "long and wide, the lobes of the limb thin membranous, broad deltoid, acute, from $2-9$ in length, without intervening sinuses when long. Corolla moderately curved, about $2^{\prime}$ long and $4-5^{\prime \prime}$ wide, bluish, of thin texture.

Hawail! woods of Koma.

11. C. pyrularia, $s p . n$. - Leaves lanceolate, $8-10^{\prime} \times 1^{1 / 2}-1^{3 /} / 4^{\prime}$, bluntly acuminate, denticulate, gradually running out into a short petiole of 1', puberulous underneath. Peduncle $2^{\prime}$ long or more, deflected, nodding, quite naked, 2-3-flowered at the apex, the pedicels resupinate, $4-6^{\prime \prime}$, with short bracteoles near the base. Calyx turbinate, 6 "long and broad, with short obtuse teeth, puberulous. Corolla moderately curved, 
$3-4^{\prime \prime}$ wide, puberulous. Berry large pear-shaped, $10-12^{\prime \prime} \times 6-8^{\prime \prime}$. Seeds dark brown, shining.

Hawaii! woods of Hamakua. The position of this species is somewhat doubtful, as no notes are preserved with the rather imperfect specimens collected many years ago.

\section{ROLLANDIA, Gaud.}

Calyx-tube adnate, ovoid-elongate, the limb 5-toothed or lobed, the lobes imbricate in the bud, persistent. Corolla tubular, falciform or sigmoid, laterally compressed, grooved at the back, gradually widening from the base and contracting toward the mouth (beaked in the bud), with lobes subequal and spreading, short, not exceeding one fourth of its length, the dorsal slit never extending to the base. Staminal column often pubescent, the 3 posterior filaments partly adnate to the corolla, the middle one highest. Stigma 2-lobed, the lobes thick ovoid, with a patch of hairs at their bases. Berry rather dry, 2-celled, obovoid. Seeds small ovoid, crustaceous, smooth and shining. - Woody plants with a simple erect trunk, foliose at the top. Leaves often dimorphous, those of the young plant more or less lobed, those of the adult one lanceolate-oblong, entire, or dentate with patent callous teeth. Flowers alternate in axillary racemes, purplish-red, the pedicels bibracteolate about the middle.

A genus confined to the island $\mathrm{Oahu}$.

The stem or trunk in all the species of this well defined genus is undivided, and it is a matter of surprise that Gaudichaud in the text of the Bot. Voy. Freyc. should have assigned the character "ramosas to both his species. Fleshy at the top, it encloses a compact medulla which with advancing age becomes chambered by thin diaphragms and at last disappears, leaving a hollow cavity surrounded by a woody zone of moderate thickness. The adherence of the posterior filaments to the corolla, although reduced to less than one third the latters length in $R$. calycina, exists in all species, and by it is determined the length of the dorsal slit, this being shortest where the former is most extensive, and vice versa. Another peculiarity in the shape of the corolla depends on this adhesion. The staminal column continuing to grow after the corolla has arrived at its fuli development, the adherent portion of the latter is drawn in at the back, so as to form a dorsal groove which at its upper end often terminates in a projection or gibbus, at least in those species with extensive adherence $-R$. longiftora and $R$. lanceolata -, so as to give the appearance of a piece having been cut out of the back. Probably the same cause will account for the double sigmoid curvature in the corolla of these two species. The color, of a deep blood red in $R$. longiflora, preserves a tinge of this, or rather of a purplish red, through all species, although it is toned down to an ashy paieness in some forms of $R$. lanceolata. All species flower in the early part of the year, from January to May.

With regard to the length of the raceme in this genus and in the two following ones, it may not be superfluous to observe that only one with fruit gives the true measure, for, as it is centripetal, the rhachis continues to increase until the last flower is developed. This circumstance will explain differences in the descriptions by different collectors, and also may necessitate some modifieations of the measures given below.

Leaves tomentose underneath:

Raceme pendulous, $5-10^{\prime}$ long

Raceme shorter and erect:

Leaves papilloso-hispid above; petioles and stem muricate 2. $R$. calycina.

Leaves glabrous above; petioles smooth :

Staminal column glabrate

Staminal column hairy .

6. R. Humboldtiana.

5. $R$. lanceolata. 
Leaves glabrate underneath:

Staminal column hairy .

Staminal column glabrous:

5. R. lanceolata.

Leaves broad obovate, whitish underneath; corolla pale reddish, with deeper stripes, falcate

Leaves slender lanceolate, green underneath; corolla of a deep blood red, sigmoid

1. $R$. grandifolia.

4. R. longiftora

1. R. grandifolia, Hillebr. - Subherbaceous, 2-4 ft. high, smooth. Leaves large obovate-oblong, $1-2^{1 / 2} \mathrm{ft}$. long, $5-8^{\prime}$ broad, shortly acuminate, sinuately crenate or entire, gradually running out into a thick fleshy margined petiole of less than $4^{\prime \prime}$, membranous, glabrous above, pale, almost white beneath, the widely sweeping nerves shortly puberulous or glabrate. Raceme short and thick, $1-1^{1}{ }^{\prime} 2^{\prime}$, many-flowered or bracteate from the base, the pedicels $6-12^{\prime \prime}$. Bracts broad oblong, obtuse, 9-4", bractlets below the middle of the pedicel and often accrete, $4-2^{\prime \prime}$. Calyx puberulous, obconical, the ovarian portion $4-6^{\prime \prime}$, the lobes as long or longer, broad oblong, obtuse, apiculate, strongly imbricate. Corolla falciform, $2^{1 /} / 2-3^{\prime}$ long, puberulous in the bud, pale purplish-red, with deeper stripes along the nerves. Staminal column adherent in the lower third or half, glabrous, pale, the anthers of a deeper color, the upper ones often hispid at the apex in the bud, but soon glabrate. Berry globose, 5 " in diam. - R. crispa, Mann, Enum. no. 253, and probably $R$. lanceolata, var. grandifolia, DC. Prod. VII, 344.

Main range of $\mathrm{O} a \mathrm{~h} u$ ! from Pauoa to Halemanu.

2. R. calycina, G. Don, Gen. Syst. III, 699. - Stem 4-6 ft. high, muricate, the young shoots and inflorescence covered with a dark brown tomentum. Leaves chartaceous, obovate-oblong, $9-14^{\prime} \times 3-5^{\prime}$, on petioles of $1-1^{1} / 2^{\prime}$, shortly and bluntly acuminate, suddenly contracted at the base, unevenly crenulate or dentate, the upper face dotted with short stiff hairs on conical papillas, the lower coarsely tomentose, particularly along the veins; the rib and petiole muricate. Raceme $1^{1 / 2}-2^{d}$ in flower, $3^{1} / 2^{\prime}$ when with fruit, several-flowered near the apex, distantly bracteate below, the bracts $4^{\prime \prime}$, the pedicels 6-9". Calyx tomentose, the obconical tube $6^{\prime \prime}$, the broad oblong truncate lobes $3-5^{\prime \prime}$. Corolla faleate from a rather broad base, $2^{1 / 2^{\prime}}$ long, faintly pubescent, dark purple, with blackish stripes. Staminal column adnate to less than $1 / 3$ its length, pubescent or glabrate, the anthers generally hairy along the base and furrows, the upper ones (in young flowers) tufted at the apex, but soon glabrate. Berry ovoid, 6". Seeds pale yellow. - Lobelia calycina, Cham. (according to the specimen in the Royal Herb. Berlin). - Detissea calycina, Presl, and Mann, Enum. no. 267. - Cyanea aspera, Gray, and Mann. Enum. no. 274. - R. crispa, Meyen, in Herb. Berlin.

Oahu! Mt. Kaala and Waiolani. 
3. R. racemosa, Hillebr. - Stem 5-6 ft. high, rough but not prickly. Leaves chartaceous, obovate-oblong, $10-14^{\prime} \times 3-4^{\prime}$, acuminate, gradually narrowing into a distinct smooth petiole of about $1^{\prime}$, eroso-denticulate, the upper face sparsely papillose when young, but glabrate with age, the lower densely covered when young with a dark brown tomentum which at last becomes confined to the renules, including pale areoles. Peduncle tomentose, 4-11' long when in fruit, distantly bracteate below, loosely racemose above; pedicels $6^{\prime \prime}$; bracts $4-6^{\prime \prime}$, bracteoles $1{ }^{1} 2^{\prime \prime}$. Calyx pubescent, the tube $3-4$ ", the lobes $2-3^{1} / 2^{\prime \prime}$, oblong, truncate. Corolla as in no. 2. Staminal column adnate only in the lower third or fourth, glabrous as well as the anthers, but the upper anthers tufted with a short pencil. Berry ovoid or obovoid, 8 "long. - Delissea racemosa, Mann, Enum. no. 266. - R. pedunculosa, Wawra, in Flora, 1873.

Oa hu! Kalihi and Konahuanui. - Is not unlikely to be the Lobelia ambigua, Cham. in Linnaea, VII, 222, Delissea ambigua, Pr., Rollandia ambigua, G. Don. The original specimen in the Herb. Berlin is much like it and bears a raceme of $5-6^{\prime}$ in length. Unfortunately it is without flower, but the description speaks of "nervi corollae hirti. From it, Chamisso thought, his L. pinnatifida (collected on the Waianae Mts., but which is not in the Berlin herb.) might not be specifically distinct, and such may well be the case if the specimen came from a juvenile plant, which, as in other species of this genus, is not unlikely to have lobed or pinnatifid leaves; for otherwise the deseription fits to the present plant, the character aramosas in DC. Prod. being an addition of the latter author. That Chamisso should not have made out the short adherence of the staminal column in the miserable specimens brought home by him is not to be wondered at.

4. R. longiflora, Wawra, in Flora, 1873, p. 95. - Stem smooth, 4-5 ft. high. Leaves lanceolate, $15-18^{\prime} \times 2^{1 / 2}-4^{\prime}$, acute, gradually narrowing into a short petiole of $1 / 4-1^{\prime}$, entire or denticulate, sinuate, particularly near the base, even faintly laciniate, glabrous on both sides, sbining, thin chartaceous. Raceme slender, $1-2^{\prime}$, bracteate from the base, $5-10$ flowered; pedicels $9^{\prime \prime}$; bracts $2^{\prime \prime}$; bractlets dentiform or wart-like. Calyx glabrous, cylindrical, $5-6$ ", its limb tubular, about $2^{\prime \prime}$ long and sinuately 5-toothed. Corolla dark red, sigmoid, $3-3^{1} / 2^{\prime}$, gradually widening from a slender base to a width of $4^{\prime \prime}$, with a deep dorsal groove. Staminal column adherent up to the middle of the corolla, dark red, glabrous, the upper anthers not tufted. Berry pyriform, $5^{\prime \prime}$. - The young plant is prickly or muricate and has the leaves unevenly lobed or laciniate. R. sanguinea, Hbd., in herb.

Oahu! western division of the main range, from Waipio to Halemanu, Kaala. Wawra's specimens came from the author's herbarium.

$\beta$ var. angustifolia. - Leaves linear-lanceolate, $6-12^{\prime} \times{ }^{3 / 4}-1^{\prime}$, nearly entire.

Oahu! enstern division of the main range, from Kalihi to Niu.

5. R. lanceolata, Gaud. Bot. Voy. Freyc. p. 458, tab. 74 (R. montana). - Trunk unarmed, about $6 \mathrm{ft}$. high. Leaves oblanceolate, $16-24^{\prime} \times$ 
$3-4^{1} / 2^{\prime}$, gradually acuminate at both ends, on distinet petioles of $1-3^{\prime}$, denticulate, often sinuate, chartaceous, the veins underneath with a short pubescence and always more prominent near the margin. Peduncle $4-5$ ' long when with fruit, distantly bracteate from the base, many-flowered $(8-16)$ in the upper portion; pedicels $9^{\prime \prime}$; bracts $4-2^{\prime \prime}$; bractlets minute, accrete. Calyx often colored, the elongate tube $5^{\prime \prime}$, the lobes $1 / 5-1 / 2$ of its length. Corolla pale reddish, with darker streaks, sigmoid, $2^{1} / 2-3$ ' long, very slender below, grooved at the back. Staminal column adherent to the middle or higher, reddish, hirsute with soft hairs, particularly at the base of the anthers; the upper anthers tufted or ciliate at the apex. Berry pyriform 8-9" long. Seeds smooth and shining, reddish (not reticulate). - The young plants are muricate and have short ovateoblong obtusely lobed leaves, sparsely covered with papillose hairs on the upper face, which in the adult plant sometimes reappear near the edges. - Mann, Enum. no. 252, - Delissea lanceolata, Gray. - R. Delessertiana, Gaud. Bot. Voy. Bon. tab. 75.

Oahu! Of this species my herbarium contains the following forms.

* Glabratae, - Leaves puberulous along the veins only. Calyx and corolla glabrous.

a. - Calyx-lobes ${ }^{1 / 2}-1^{\prime \prime}$, triangular or ovate acute. Corolla slender, pale greenish, with purple stripes, grooved and adherent to the stamens for $2 / 3$ of its length. Anthers hairy throughout, or at least along the sutures. Leaves lanceolate.

Moanalua, Halawa.

$\beta$. - Calyx-lobes $1-1^{1} / 2^{\prime \prime}$, oblong, obtuse, contiguous. Corolla pale purplish, with darker stripes. Anthers hairy. Leaves oblong.

Kalihi, Waipio.

\%. - Calyx-lobes $1-1^{1 / 2} 2^{\prime \prime}$, oblong or obovate, apiculate, overlapping. Corolla as in $\beta$, the lobes scabrous. Anthers scabrous, faintly pubescent. Leaves narrow-elongate, $2 \mathrm{ft}$. long and only $2^{1 / 2-3^{\prime}}$ broad, quite acute, gradually drawn out into a margined petiole of $2^{\prime}$.

Halemanu.

b. - Calyx-lobes $2-2^{1 / 2}{ }^{\prime \prime}$, oblong to obovate, obtuse or truncate. Corolla as in $\beta$. Anthers pubescent along the sutures. Leaves thick and broad $\left(5^{\prime}\right)$, the prominent scabrous veins forming a fenestrate network near the margin, which appears crisp and sinuous. $-R$. crispa, Gaud. R. scabra, Wawra,

Wailupe, Niu, Nuramu.

Tomentosae. - Calyx and corolla pubescent. Leaves tomentose underneath with an olivaceous tomentum. 
s. - Calyx-lobes as in $\beta$. Corolla ashy-pale, faint purple at the back, dark inside, pubescent along the lobes. Anthers almost glabrate, but the upper ones ciliate at the top. Leaves lanceolate.

Ewa, Wahiawa.

ל. - Calyx-lobes $2^{1} / 2^{\prime \prime}$, oblong, obtuse, contiguous or overlapping. Corolla rather broad at the base, hairy throughout, of the same color as in $\varepsilon$. Anthers pubescent at the base only and with a few ciliae at the apex of the upper ones. Leaves elongate, narrow $\left(1^{1} / 2-2^{1} / 2^{\prime}\right.$ broad) as in $\gamma$, with which it shares the same habitat.

Halemanu.

6. R. Humboldtiana, Gaud. Bot. Voy. Bon. tab. 76. - Trunk 10-15 ft. high. - Leaves broad obovate-oblong, $12-20^{\prime} \times 3-5^{\prime}$, narrowing into a petiole of $1-3^{\prime}$, more or less tomentose underneath with olivaceous

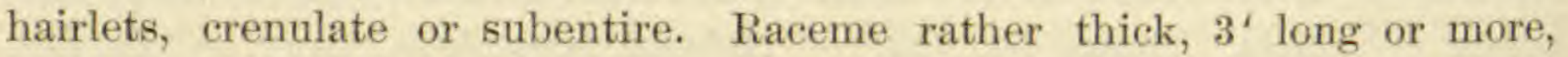
floriferous from the base, with pedicels of $6-8^{\prime \prime}$, the oblong bracts $3^{\prime \prime}$, the bractlets $11^{1} /{ }^{\prime \prime}$. Calyx pubescent, obconical, the oblong truncate lobes $2^{1} / 2^{\prime \prime}$, half the length of the tube, contiguous or imbricate. Corolla falciform from a rather broad base, $2-2^{1} / 2^{\prime}$, pale purple, with reddish streaks, pubescent at least on the lobes. Staminal column adnate up to the middle, glabrate, but the upper anthers ciliate at the apex. Berry obovoid, 5". Seeds smooth. - Mann, Enum. no. 254. - R. Kaalae, Wawra. - From, Gaudichaud's plate without text it cannot be made out whether the leaves were glabrous or tomentose. Mann's specimens seem to have been glabrate.

Oahu! slopes of Kaala, and Moanalua. Distinguished from the last species chiefly by the large size of its trunk, but we have to admit that in this respect our knowledge of several of the varieties of $R$. lanceolata is defective. The plants would seem to begin flowering at an early age, and the size of flowering individnals which fall under the eye of the collector may vary much in one and the same species.

\section{DELISSEA, Gaud.}

Calyx-tube turbinate or oblong, its lobes dentiform or subulate. Corolla more or less curved, tubular, widening from a narrow base, shortly bilabiate, the dorsal slit not extending beyond the middle, the termination of the dorsal and often also of the lateral slits indicated in the bud by a knob or gibbus. Staminal column free from the corolla, white, glabrous, only the 2 lower anthers tufted at the apex. Stigmatic lobes shortly pubescent outside. Berry ovoid, with narrow epigynous disk, 2-celled. Seeds dull white, the thin testa finely wrinkled in transverse wavy lines. - Unarmed, glabrous, often subherbaceous shrubs, the stems branching or simple, more or less fleshy. Leaves entire or laciniate, succulent when fresh, flaccid and transparent when dry, bright green, glossy. Flowers 
in axillary racemes with small deciduous bracts and naked pedicels, always white or greenish white.

This Hawaiian genus, thus restricted to only 3 of its former constituents, to which several new ones have been added, forms a natural group well defined by the white wrinkled seeds, the white corolla with 1 or 3 protuberances, and the suceulent leaves. The Delissea of Gaudichaud and later writers differed from Cyanea only in the comparative shortness of the calycine lobes, a character utterly unreliable in our Lobeliads. Most of its members have here been referred to Cyanea, and a few to Clermontia and Rollandia.

Macranthae. Flowers over $1^{1 / 2} 2^{\prime}$ long, eurved, white:

Leaves broadly cordate or ovate-oblong .

1. D. subcordata.

Leaves lanceolate or spathulate.

3. D. sinuata.

Leaves laciniately lobed

2. D. laciniata.

Micranthae. Flowers less than 1' long, subereet, greenish white:

Leaves ovate-oblong, on petioles of $1 / 2$ their length; corolla with 3 knobs; stem simple

Leaves short lanceolate or oblong, on petioles of less than $1 / 3$ their length; stem branching

Leaves elongate-oblong, on petioles of more than $1 / 2$ their length; corolla with a single dorsal knob

Leaves laciniate, on petioles of $1 / 4$ their length or less .

5. D. undulata.

4. D. rhytidosperma.

7. D. fallax.

6. D. parviflora.

1. D. subcordata, Gaud. Bot. Voy. Freyc. p. 45\%, tab. $7 \%$ - DC. Prod. VII, 342. - A branching shrub, 5-10 ft. high. Leaves ovate-oblong, $6-10^{\prime} \times 3-5^{4}$, on long petioles of $3-8^{\prime}$, acute, dentate or serrulate with sharp cartilaginous teeth, the base often truncate or subcordate and uneven sided, strongly ridged underneath with subhorizontal veins. Raceme fleshy, $3-4^{\prime}$, many-flowered $(12-24)$, naked in the lower fourth; pedicels 8-9"; bracts $1^{1 / 2} 2^{\prime \prime}$. Calyx shortly dentate. Corolla falciform, $2^{\prime}$ long, ampliate above, with a single dorsal knob above the middle, the short lobes connivent. Berry ovoid or oblong, 5-7", bluish. - Mann, Enum. no. 263. - D. undulata, Gray, pro parte.

Kauaj! Oahu! Wailupe, Manoa, Nuuanu, Wailua, Kaala.

$\beta$ var. obtusifolia. - Leaves $9-12^{\prime} \times 4-7^{\prime}$, broadly oblong, obtuse, even suborbicular. Calycine teeth longer, often almost equalling the tube; the dorsal knob of the corolla often wanting.

Oahu! Halemanu, Waipio.

2. D. laciniata, $s p . n$. - A branching shrub, Leaves oblong in outline, $5-6^{\prime} \times 2-3^{1} / 2^{\prime}$, on petioles of $3-5^{\prime}$, irregularly cut into patent acute lobes, the lowest lobes $1-1^{1 / 2^{\prime}}$ deep, with irregular serratures, somewhat decurrent along the petiole. Raceme $1^{1 / 2}-2^{\prime}$, slender, naked in the lower half, $6-10$-flowered, the pedicels $6^{\prime \prime}$; bracts short linear. Calyx obconical, its teeth sharp triangular or subulate, $I^{\prime \prime}$ or more. Corolla $1^{1 /} / 2^{\prime}$ long, falcate, white, a dorsal knob below the middle and generally 2 lateral ones a little higher, the lobes rather long, their slits extending to the knobs. Anthers faintly pubescent at the base. Berry bluish, obovoid, about 6" long.

Oahu! Wailupe. A variety from the same region has smaller leaves which are only irregulary serrate. 
3. D. sinuata, $s p . n$. - Stem simple, erect, $2-4 \mathrm{ft}$. high, subherbaceous. Leaves oblanceolate or spathulate, $10-11^{\prime} \times 2-3^{\prime}$, bluntly acuminate, gradually contracting into long petioles of $3-5^{\prime}$, the margin sinuate and denticulate with appressed teeth. Peduncle $1^{1 / 2}-2^{\prime}$, nearly naked, the numerous flowers crowded near the apex; pedicels 5"; bracts short linear. Calyx-tube cylindrical, $4-5^{\prime \prime}$ long, the sharp subulate teeth $1 / 4-1 / 3$ of its length. Corolla about $1^{1} / 2^{\prime}$, curved, white, the dorsal gibbus generally wanting, but at the middle when present. - Anthers faintly puberulous at the base.

Oahu! Makateha.

$\beta$ var. - Leaves oblong or oblanceolate, $6-7^{\prime} \times 2^{\prime}$, on petioles of $1-2^{\prime}$. Peduncle ${ }^{1 / 2^{\prime}}$ or less, fewer-flowered. Berry cylindrical, 5".

Lanai!

4. D. rhytidosperma, Mann, Enum. no. 261. - A branching shrub or (according to Mann) a small tree. Leaves oblong or lanceolate, $3-5^{\prime} \times$ $1-1^{1 / 2}$, on short petioles of $1-1^{1} / 2^{\prime}$, bluntly acuminate, contracted at the base, sinuate, dentate or serrulate. Peduncle $1-1^{1} / 2^{\prime}$, naked below, bearing in its upper half $7-12$ flowers on pedicels of $4-6^{\prime \prime}$. Bracts linear, 4-2". Calyx-tube obconical, $2^{1 / 2} 2^{\prime \prime}$, shortly dentate. Corolla small, 6-9", greenish-white, suberect, with a dorsal gibbus below the middle. Anthers naked or faintly ciliate at the base. Berry subglobose, $3-5 "$, ribbed. $-D$. Kealiae, Wawra.

Kauai! woods of Waimea, Kealia and elsewhere. The description of the flowers from a specimen of Knudsen's. Mann states the species to be arborescent, yet his specimens in herb. Cornell Univ, appear to have come from herbaceous or fleshy branches. $D$. Kealiae is said by Wawra to be a branching shrub, $4 \mathrm{ft}$, high, with leaves $6-8^{\prime}$ long, $2^{\prime}$ broad, on petioles of $2^{\prime}$, which in all other respects agrees with the above given description.

5. D. undulata, Gaud. Bot. Voy. Freyc. p. 457, tab. 78, - DC. Prod. VII, 342. - Stem simple and straight, $6-10 \mathrm{ft}$. high, densely foliose at the apex and closely covered with contiguous spirals of rhomboidal leaf-scars, fleshy throughout, with a compact medulla, conically enlarging at the base to the thickness of several inches. Leaves ovate- or subcordate-oblong, $4-5^{\prime} \times 1^{1 / 2}-2^{\prime}$, on petioles of $2-3^{\prime}$, sinuate, dentate or serrulate, the transparent veins exhibiting before the light a close and fine network. Peduncle short, ${ }^{1} / 2-1^{1} / 2^{\prime}$, the pedicels $2-3^{*}$. Calyx obconical, with short subulate teeth. Corolla greenish-white, suberect, $9-12^{\prime \prime}$ long, with a strong dorsal and two lateral conical knobs about the middle. Anthers glabrous. Berry globose, $3^{\prime \prime}$. Seeds white and wrinkled as in all the other species. - Mann, Enum. no. 264.

Niihau (Brigham); Kauai! (Remy); Maui! gulches of Lahaina, Oloalu and Waikapu, on exposed open cliffs. The specimens from Maui agree with those from Niihau, except that in the latter the raceme attains a length of $1^{1} / 2^{\circ}$, while in the former it is only $3 / 2^{\prime}$ 
long. Gaudichaud gives it as of equal length with the petiole. A specimen from Lahaina which seems to belong here has ovate-oblong leaves, contracting and slightly laciniate at the base, with a short peduncle of $1 / 2^{2}$.

6. D. parviflora, sp. $n$. - Branching (?), the stem or branches fleshy and distantly foliose. Leaves lanceolate or oblong in outline, $5-6^{\prime} \times{ }^{1 / 2}-1^{1 / 2} 2^{\prime}$, sharply cut into irregularly dentate or serrulate lobes of $1 / 4-1 / 2^{\prime}$ in depth, gradually tapering into a petiole of $1-1^{1 / 2}$, dull, not shining in the badly preserved specimens, but flaccid and pellucid. Peduncle 9-12", severalflowered in the upper half; pedicels $3^{\prime \prime}$; bracts dentiform. Calyx $2-2^{1 / 2}$ ", shortly toothed. Corolla suberect, $9^{\prime \prime}$, with a dorsal tubercle at the middle. Berry subglobose, 4". Anthers quite glabrous. Seeds white, wrinkled.

Hawaii! Kohala range, and woods of Mauna Kea (4500 ft.).

7. D. fallax, sp. $n$. - Stem simple (?), fleshy in the upper portion, distantly foliose. Leaves lanceolate or elongate-oblong, $8-9^{\prime} \times 2^{\prime}$, on long petioles of $4-5^{\prime}$, obtuse, sharply denticulate, suddenly contracting at the base, dull, but translucent. Peduncle with fruit $1^{1 / 2-2^{\prime}}$, naked in the lower half; pedicels $5^{\prime \prime}$; bracts subulate, $1^{1 / 2} 2^{\prime \prime}$. Calyx-tube $2-3^{1 / 2} 2^{\prime \prime}$, the teeth about $1^{1 / 2} 2^{\prime \prime}$. Corolla $9^{\prime \prime}$, suberect, with a dorsal gibbus at the middle. Anthers glabrous. Berry subglobose, $3-4$ ". Seeds white, wrinkled.

Hawaii! woods of Hamakua and Hilo, Leaves in shape like those of Cyanea obtusa.

\section{CYANEA, Gaud.}

Calyx-tube adnate, globose to cylindrical, the lobes of variable length, short tooth-like to several times the length of the tube, often foliaceous, valvate, rarely connate, persistent. Corolla tubular, more or less curved, 5-cleft, sub-bilabiate, the dorsal slit extending beyond the middle. Staminal column free from the corolla, the two lower anthers, or rarely all, tufted at the apex. Stigma 2-lobed, hairy at the back or base of the short fleshy lobes. Berry 2 -celled, with fleshy placentas. Seeds small ovoid, with a crustaceous smooth shining testa. - Milky shrubs or small trees with a simple erect or branching stem which includes a medullary cavity, armed or unarmed. Leaves entire or lobed or pinnate. Flowers in axillary racemes, always with a tinge at least of purplish-blue, the pedicels bibracteolate about the middle.

A large Hawaiian genus.

Calycine lobes shorter than their tube:

Leaves entire:

Corolla glabrous:

Corolia suberect, slender:

Corolla lilac-colored; staminal column glabrous:

Leaves membranous with a close and fine rete, linear-oblong $1 . C$. angustifolia.

Leaves coriaceous, with larger elongate areoles, obovateoblong

Corolla white; staminal column pubescent

5. C. eoriacea.

3. C. acuminata. 
Corolla curved, $2-3$ " wide:

Corolla pale lilae to purple:

Peduncle 6-12' long; calyx subglobose:

Leaves petiolate

Leaves sessile

10. C. comata.

Peduncle short, less than $2^{\prime}$; calyx cylindrical

21. C. arborea.

22. C. procera.

Corolla white; petiole prickly or muricate; leaves fleshy 28. C. platyphylla.

Corolla pubescent:

Corolla suberect, slender, lilac or purple; staminal column glabrous:

Leaves glabrous; calycine teeth very short

8. C. recta.

Leaves with gray tomentum; ealycine teeth ${ }^{1 / 2}$ as long as the tube, or shorter

4. C. obtusa.

Leaves with rusty tomentum; calyeine lobes nearly as long as the tube.

6. C. hirtella.

Corolla curved, larger, deep purple; staminal column hispid 23. C. tritomiantha $\beta$. Corolla hirsute; staminal column hispid:

Corolla dark purple, broad; calycine lobes obtuse

Corolla whitish, slender; calycine lobes acute

25. C. atra.

Corolla tomentose, large arcuate, cream-colored

Leaves sinuate or lobed; stem prickly:

Calycine lobes acute

Calycine lobes obtuse

Leaves pinnatisect or pinnate; stem prickly

27. C. Kunthiana.

19. C. superba, $\beta$.

28. C. platyphilla.

16. C. solanacea.

18. C. asplenifolia.

Calycine lobes as long as the tube or longer:

Leaves entire:

Corolla glabrous:

Calycine lobes 1-nerved, as long as the tube or little longer:

Leaves glabrous

Leaves hairy

Calycine lobes linear-subulate, twice as long as the tube.

Calycine lobes several-nerved, linear-oblong:

Leaves rounded at the base, on long petioles; corolla white 12. C. holophylla.

Leaves narrowing into short petioles; corolla purple . 24. C. macrostegia.

Corolla tomentose or hairy:

Peduncle elongate, 6 inches or more . . . . . 19. C. superba.

Peduncle short; calycine lobes connate. . . . . 15. C. solenocalyx.

Peduncle short; calycine lobes free:

Calycine lobes many-nerved; corolla purplish blue.

Calycine lobes 1-3-nerved, corolla whitish, scabrous

24. C. macrostegia.

Calyeine lobes 1-nerved, acute:

Corolla slender, suberect:

Corolla purple; staminal column glabrous

Corolla pale, whitish; staminal column hairy

2. C. Mannii.

9. C. pilosa.

20. C. leptostegia.

Corolla large, curved, dark purple:

Corolla pubescent: staminal column hispid

Corolla hirsute; staminal column glabrous .

Calycine lobes 1-nerved, obtuse; corolla dark hirsute

11. C. scabra.

7. C. fissa.

27. C. Kanthiana.

23. C. tritomantha.

26. C. Gibsonii.

25. C. atra.

Leaves lobed:

Corolla glabrous, or the lobes ohly muricate.

Corolla hairy:

Calyx muricate, the lobes thick, 1-nerved

Calyx smooth, the lobes thin, 1-3-nerved

13. C. lobata.

17. C. ferox.

11. C. scabra, $\beta$.

14. C. Grimesiana.

Leaves pinnatisect to pinnate.

"Delisseoideae. - Calycine lobes dentate, linear or subulate. Tube of corolla suberect and slender, not exceeding $1^{1} / 2^{\prime \prime}$ in width. Berry generally small globose. - Unarmed shrubs with erect sparingly branching stems, the branches ascending. Leaves entire. - Young plants generally with 
a simple stem; several species (nos. 1, 3, 10) seem only to branch when the apex has been broken.

1. C. angustifolia, Hillebr. - A shrub, 5-8 ft. high. Stem simple or sparingly branching, the branches suberect, densely foliose at the ends, glabrous. Leaves lanceolate or elongate-oblong, $5-10^{\prime} \times 1-2^{\prime}$, on long petioles of $3-4$ ', equally acuminate at both ends, appressedly serrulate, glabrous, membranous, the transparent veinlets minutely reticulate. $\mathrm{Pe}$ duncle $1-4$ ' long, slender, densely flowered near the apex, naked below; the pedicels filiform, ${ }^{3 / 4}-1^{\prime}$; bracts subulate, ${ }^{3 / 4}$ "; bractlets minute or wanting. Calyx turbinate, $2^{1} / 2^{\prime \prime}$, purplish, shortly toothed. Corolla slender, moderately curved, $1-1^{1} / 2^{\prime}$ long, $1-1^{1 / 2^{\prime \prime}}$ wide, the dorsal slit extending to near the base, pale violet. Anthers glabrous. Berry globose, 3-4", bluish. Seeds dark yellow. - Lobetia angustifotia, Cham. in Linnaea, VIII, 219. - Detissea angustifolia, Presl. - Mann, Enum. no. 260. D. acuminata, var. angustifolia, Gray. - D. Honolulensis, Wawra. - The medullary cavity of the woody stem is chambered by numerous thin papery diaphragms.

Oa hu! main range; common in Nuranu and adjoining valleys; - peduncles $1^{1 / 2}-2^{1 / 2^{2}}$, with flowers erowded at the apex. Moloka 1! Halawa; - peduncles $3-3^{1 / 2}$, the flowers disposed along the upper half, smaller, not exceeding 1 , the leaves faintly pubescent along the rib. Maui! Lahaina, Oloalu; - flowers small, $9-12$ ", on short peduneles of 1; leaves short and broad.

$\beta$. - Leaves rounded at the base, coarsely serrate with uncinate teeth. Lanai!

$\gamma$ var. racemosa. - Peduncle much elongate, 5-10', drooping, naked in the lower third or half, racemosely flowered above; leaves chartaceous, longer, $2^{1} / 2^{\prime}$ broad, crenate.

Oahu! Waipio, Halemanu, Kaala.

¿ var. tomentella. - Traces of pubescence on leaves, calyx and corolla. Leaves oblanceolate, $12^{4} \times 2^{3} 4^{\prime}$, on petioles of $3^{4}$. Peduncles thicker, $3^{i}$. Calycine teeth $1 / 4$ the length of the tube.

Oahu! Halemanu. Renders easy the transition to C. obtusa.

2. C. Mannii, Hillebr: - Habit and size of the preceding species. Leaves elongate-oblong with a rounded base, $6-8^{\prime} \times 1^{3 / 4}-2^{\prime}$, on petioles of $1^{1} / 2-2^{1} / 2^{4}$, glabrous or puberulous along the midrib below. Peduncle (with advanced buds) 2-3', naked in the lower half, puberulous; pedicels $4-6^{\mu}$, bracteolate below the middle; bracts linear, $3^{\prime \prime}$, but often foliaceous; bractlets $1-1^{1 / 2} 2^{\prime \prime}$. Calyx puberulous, the adnate tube $3^{u}$, the lanceolate, mostly 3-nerved, lobes as long or longer. Corolla almost straight, and probably of the same size as in no. 1, glabrous, purplish-blue. Staminal column glabrous. - Delissea Mannii, Brigham, in Mann. Enum. no. 270.

Molokai! Kalae. - The seeds are given by Brigham as -minutissime striato-reticulatas, but this is so much at variance with what is observed in all allied species that the correctness of the statement may fairly be donbted. Neither the herbarium of Harvard Univ. nor that of Mr. Mann at Cornell Univ. contain specimens. Those collected by myself 
are without fruit. The extraordinary development of the braets in some specimens is certainly abnormal, for a few of the pedicels rising from their axils bear several buds.

3. C. acuminata, Hillebr. - Stem simple and erect, or sparingly branched, $4-5 \mathrm{ft}$. high. Leaves broad oblong, $8-11^{\prime} \times 2^{1 / 2}-3^{4}$, on petioles of $1^{1 / 2}-2^{1 / 2^{\prime}}$, acuminate at both ends, entire or faintly denticulate, pale below and puberulous along rib and nerves, flaccid. Peduncle commonly not above $1^{1 /} / 2^{\prime}$ long when in fruit, but oecasionally longer, puberulous, rather thick, covered with close knobby scars from the base, but seldom bearing more than $6-10$ flowers near the apex; pedicels slender, $4-6^{\mu \prime}$; bracts linear, $4-6$ "; bractlets minute, deciduous. Calyx faintly pubescent, the tube $2^{1 / 2^{11}}$, the narrow sharp lobes ${ }^{1 / 3}-1 / 2$ its length. Corolla white, with a bluish tinge, glabrous, suberect, $16^{\prime \prime}$ in length and $1^{1 / 2}$ " in width. Filaments and anthers puberulous. Berry globose, yellow, $2-3^{\prime \prime}$. Seeds pale. - Lobelia acuminata, Cham. I. c. - Delissea acuminata, Gaud. Bot. Voy. Freyc. p. 457, tab. 76. -- DC. Prod. VII, p. 342. - Mann, Enum. no. 259. Oahu! Manoa, Nuиanu, Kalihi, Moanalua.

4. C. obtusa, Hillebr. - A much branching shrub, 8-14 ft. high, the stem of a compact wood with narrow cavity, the branches spreading, tomentose. Leaves elongate-oblong, $6-12^{\prime} \times 1^{1 / 2}-3^{1 / 2^{\prime}}$, on petioles of $1^{1 / 2}-4^{\prime}$, obtuse or shortly acuminate, contracting below, serrulate with patent teeth, membranous, the ribs and veins puberulous on both faces. Peduncle $2^{\prime}$, naked in the lower half or two thirds; pedicels $8-12^{\prime \prime}$, bracts $1^{\prime \prime}$. Calyx tomentose, bluish, the cylindrical tube $3^{\prime \prime}$, the acute triangular teeth $1 / 3-1 / 2$ of its length. Corolla tomentose, grayish-blue, suberect, 15-18" long. Staminal column glabrous. - Detissea obtusa, Gray, in Proc. Am. Ac. V, 148, - Mann, Enum. no. 257.

Ma u i! Honuaula, Hamakua, Waikapu, Lahaina; Ha waii, Mauna Kea, leaves tomentose underneath. M, \& B, s no. 466 , from Makawao, has small flowers of only 10 " in length.

5. C. coriacea, Hillebr. - A branching shrub, $12 \mathrm{ft}$. high, the leaves erowded at the ends of the branches. Leaves obovate-oblong, $9-14^{\prime} \mathrm{X}$ $2^{1 / 2}-3^{\prime}$, on petioles of $2^{1 / 2}-5^{\prime}$, shortly acuminate, moderately contracting at the base, crenate or denticulate, glabrous, subcoriaceous, the veins somewhat prominent below and less closely areolate than in the preceding species. Peduncle $3-4^{4}$, slender, naked in the lower half or two thirds; pedicels filiform, $9-12^{\prime \prime}$; bracts and bractlets evanescent. Calyx glabrous, the tube obovate, $2^{1 / 2}$ ", with minute teeth. Corolla, berry and seeds as in C. angustifolia. - Delissea coriacea, Gray, 1. c.p. 147. - Mann, Enum. no, 256.

Ka uai! Waimea, at elevations of about $2000 \mathrm{ft}$. - Gray's var, pinnatiloba, described from a single leaf of Remy's collection - the leaves with $5-7$ obtuse lobes on each side - , may belong to a young plant of this species.

$\beta$ var. spathulata. - Leaves narrow spathulate, $4-6^{\prime} \times 3 / 4-1^{\prime}$, on petioles of $1 / 2-1^{1} / 2^{\prime}$, coriaceous, slightly pubescent underneath along the prominent rib and veins. Calyx $2^{\prime \prime}$. Corolla $8^{\prime \prime}$.

Same region, at heights of $4000 \mathrm{ft}$. (Kn.). 
6. C. hirtella, Hillebr. - A tall branching shrub, 12-20 ft. high, the young shoots hirsute with short rusty hairs. Leaves chartaceous, obovateoblong, $9-11^{\prime} \times 2^{1} / 2-4^{\prime}$, on petioles of $2-3^{\prime}$, obtuse or shortly acuminate (more or less), often cuneately contracting at the base, sinuate-dentate or serrulate, the ribs and veins shortly pubescent underneath. Peduncle (in flower) 1-2', naked below, 10-12-flowered in the upper third or half, the pedicels about $6^{\prime \prime}$; bracts $\left(1^{\left.1 / 2^{\prime \prime}\right)}\right.$ and bractlets deciduous. Calyx rusty-tomentose, the tube cylindrical, $4-5$ "long, the narrow triangular or subulate lobes half as long or nearly as long. Corolla moderately curved, $20^{\prime \prime}$ long and $2^{\prime \prime}$ wide, slit beyond the middle at the back, purplish-blue, tomentose. Anthers glabrous. Berry pyriform. Seeds pale brown. - Delissea hirtella, Mann, Enum. no. 258.

Ka uai! Waimea and elsewhere (Kn.).

7. C. fissa, Hillebr. - A branching shrub, 10-12 ft. high. Leaves obovate-lanceolate, $16 \times 3^{1 / 2^{4}}$, including the petiole in which they gradually merge, acuminate, crenate, glabrous above, sparsely hairy underneath, particularly along the rib and veins. Peduncle covered with coarse glandular hairs, as are the calyx and corolla, 1-2' long, 8-12-flowered; pedicels $6^{\prime \prime}$, bracteolate; bracts $3-4^{\prime \prime}$. Calyx-tube $3-4^{\prime \prime}$, the acute narrow-lanceolate lobes as long or longer. Corolla pale purple, in shape and size like that of $C$. hirtella, the dorsal slit extending to the base. Anthers glabrous. - Delissea fissa, Mann, Enum. no. 271.

Kauai, Kealia and Hanalei (Mann). - Has the aspect of C. hirtella.

$\beta$ var. - Peduncle $2-3^{\prime}$; bracts $6^{\prime \prime}$. Calycine lobes $2-4$ times as long as their tube. Otherwise as above. - C. humilis, Wawra, in Flora, 1873, p. 47 , with a stem of only $1 \mathrm{ft}$. in length, was probably a young plant. The extent of the dorsal slit - to the middle in his specimen - has little value in this genus; in well developed flowers it generally extends to near the base.

Ka uai, Hanalei.

8. C. recta. (Delissea), Wavra, in Flora, 1873, p. 4\% - «Stem $2 \mathrm{ft}$. high, simple. Leaves broad lanceolate, $1 \mathrm{ft}$. long, bluntly acuminate, gradually narrowing into a petiole of $1^{\prime}$, entire, glabrous, rather fleshy. Peduncle twice as long as the petiole, scaly (covered with small rudimentary leaves), racemose; pedicels filiform, $6 "$, sparsely pubescent, as are calyx and corolla. Calyx globose, 5 -toothed. Corolla slender, straight, about 2 long, purple, with dorsal slit beyond the middle, the lobes obtuse. Anthers glabrous. Berry subglobose, larger than a pea. Seeds brown. smooth, shining.

Kanai! Kealia. Not seen by me; seems to border close upon var. $\delta$ of no 1.

9. C. pilosa, Gray, in Proc. Am. Ae. V, 149. - Low, shrubby. Leaves broadly obovate, $10-12^{\prime} \times 4-5^{\prime}$, acuminate or acute at both 
ends, eroso-erenate, flaccid, hirsute with short soft hairs on both faces. Peduncle $1-2^{\prime}$, densely hirsute, few-flowered; pedicels 4 ". Calyx glabrous, the elongate foliaceous lobes as long as their oblong tube. Corolla small, grayish-blue, glabrous. Berry small, subglobose, 4 " (in Macrae's specimen); seeds smooth, brown. - Delissea pilosa, Mann, Enum. no. 272.

Hawail at the lower margin of the forests on the windward side of Mauna Kea (U. S. E. E. and Macrae). Imperfectly known from two poor specimens, one of them quite young.

10. C. comata, sp. n. - An unarmed shrub, 5-8 ft. high, with few ascending, distantly foliose branches. Leaves obovate-oblong, $6-8^{\prime} \times$ $3-3^{1 /} / 2^{\prime}$, on petioles of $1-1^{1} / 2^{\prime}$, obtuse or shortly pointed, somewhat contracted at the base, closely and sharply dentate, puberulous underneath, chartaceous, the veins minutely areolate. Peduneles much longer than the leaves, often exceeding $12^{\prime}$, slender and drooping, naked, bearing from $6-12$ resupinate flowers toward the end, the pedicels $8-10^{\prime \prime}$, curved upward, with minute bractlets above the middle; bracts $1^{1 / 2} 2^{\prime \prime}$. Calyx glabrous, broader than high, $3 \times 4^{\prime \prime}$, the short triangular teeth about ${ }^{1 / 3}$ the length of the tube. Corolla strongly arched, $2^{\prime}$ long, $2-2^{1 / 2}$ " wide, with the dorsal slit very deep, glabrous, grayish or pale lilac. Anthers glabrous, much exserted, $2^{1 / 2}-3^{\prime \prime}$ long. Berry subglobose, truncate, $4 \times 7^{\prime \prime}$, broadest at the base. Seeds complanate, smooth and shining.

Ma ui! southern slope of Haleakala, $3000-4000 \mathrm{ft}$. In shape of calyx and corolla very different from all the other species which constitute this group.

* Cyaneae genuinae. - Calycine lobes as long as the tube or longer. - Branching shrubs or small trees, generally muricate or aculeate with thick and pale conical spines, the branches ascending. Leaves sinuate, lobed or pinnate.

$†$ Calycine lobes broad foliaceous, contiguous or connate. Corolla ampliate, curved, thin, with spreading lobes. Upper anthers tufted or ciliate at the apex (except no. 15).

11. C. scabra, sp. n. - A small shrub, $4 \mathrm{ft}$. high, the erect branches prickly toward the ends. Leaves broad, obovato- or elliptico-oblong, $10-14^{\prime} \times 3^{1} / 2-5^{\prime}$, on petioles of $2^{1} / 2-4^{\prime}$, shortly acuminate at both ends or obtuse at the base, the undulating margin denticulate, ribs and veins faintly hispid underneath and sparsely covered, as well as the petiole, with short conical spines or tubercles, membranous. Peduncle $2-3$, hispid and muricate, many-flowered from the base; pedicels slender, $6-8^{\prime \prime}$; bracts linear-oblong, $4^{\prime \prime}$, occasionally foliaceous. Calyx sparsely hispid, the tube obconical, $2^{1 / 2}-3^{\prime \prime}$, the lobes of the same length or a little longer, obtuse, $1-3$-nerved. Corolla eurved, $2^{\prime}$ long, $2^{1 / 2^{\prime \prime}}$ wide, with the dorsal slit less than half its length, hispid, the lobes muricate, whitish, with 
lilac streaks. Stamens glabrous, the upper anthers recurved and scantily ciliate at the apex.

W. Maui! Kaanapali, 1500-2000 ft.

$\beta^{\prime}$ var. - Leares drawn out at the base into a shorter petiole, sinuatelobate with numerous triangular somewhat obtuse ascending lobes about ${ }_{1 / 2}^{1 / 2}$ deep. Corolla sparsely hispid, sometimes glabrate, but muricate on the lobes. Peduncle $1-1^{1 / 2^{\prime}}$. Berry ovoid, 5-6".

W. Maui! Lahaina, Wailua, Waiehu.

12. C. holophylla, $s p . n$. - An unarmed shrub, $4 \mathrm{ft}$. high. Leaves ovate- or obovate-oblong, $10-14^{\prime} \times 3-5^{\prime}$, on petioles of $4^{\prime}$, shortly acuminate, rounded or subcordate at the base, sinuate or entire, glabrous, flaccid. Raceme $3 / 4-11^{1 / 4}$; pedicels ${ }^{3 / 2}$ '. Calyx-lobes nearly twice as long as the tube, $6-7^{\prime \prime}$. Corolla quite glabrous and smooth, otherwise as in C. scabra. Upper anthers ciliate at the apex.

W. Maui! Waiehu.

$\beta$ var. - Leaves obovate, larger, narrowing at the base.

W. Maui!

13. C. lobata, Mann, Enum. no. 276. - A branching shrub, 4-7 ft. high, sparsely muricate or aculeate, or unarmed. Leavies obovate- or ellipticooblong, $18-22^{\prime} \times 6-7^{\prime}$, irregularly cut into broad triangular lobes, acuminate, narrowing at the base, glabrous, membranous, on petioles of $4-7$, these and the midrib generally with some scattering conical spines. Peduncle $2^{1} / 2-3^{\prime}$, bracteate from the base, many-flowered, the pedicels $1-1^{1} / 2^{\prime}$, the bracts linear, $4-6^{\prime \prime}$, often foliaceous. Calyx-tube obconical, $6^{\prime \prime}$, its lobes 9-12", foliaceous, 5-9-nerved, net-veined and denticulate, oblong, obtuse, mucronate. Corolla $2-2^{1} / 2^{\prime}$ long, $3^{1 / 2^{\prime \prime}}$ wide, glabrous and smooth, white below, purplish above. Stamens glabrous; anthers purplish, the upper ones ciliate at the apex. Berry yellow, globose. Seeds yellowish.

W. Maui! gulehes of Kaanapali, Honokahau, Wailuku and elsewhere.

$\beta$ var. - Stem quite prickly. Leaves $12^{\prime} \times 6^{\prime}$, more deeply lobed. Tube of calyx 3 ", its lobes 5-6". Lobes of corolla muricate.

E. Mani! Hamakua (Lydg.).

The three preceding species are closely related and their distinetive characters seem to be subject to variability, but the following long known species is not more than a further evolution of the same type.

14. C. Grimesiana, Gaud. Bot. Voy. Freye. p. 45\%, tab. 75. - A stout branching shrub, 6-10 ft. high, aculeate, the stem hollow. Leaves broadly oblong in outline, $12-18^{\prime} \times 8-12^{\prime}$, on muricate or prickly petioles of $3-8^{\prime}$, pinnate below, pinnatisect toward the apex, the pinnae 9-12 on each side, broadly sessile, often separated by small lobules, lanceolate, entire or sinuate, $6-15^{\prime \prime}$ broad, the lowest diminishing to mere

Hillebrand, Flora of the Hawailan Islands. 
auricles, membranous, glabrous. Raceme $2-3$ ' long, bracteate from near the base, $6-10$-flowered in the upper half; pedicels $1-1^{1} / 2^{\prime}$; bracts lanceolate, $6^{\prime \prime}$. Calyx glabrous, the tube obconical, $6-8^{\prime \prime}$ long, the lobes broad foliaceous, crisp and brittle, $10-18^{\prime \prime} \times 4-6^{\prime \prime}$, many-nerved and net-veined, acute. Corolla falciform, nearly $3^{\prime}$ long and $1 / 2^{\prime}$ wide, light purple or lilac, with deeper stripes, glabrous, but the lobes sometimes warty. Staminal column glabrous, of the same color, the upper anthers tufted at the apex with long and stiff hairs. Berry large obconical $1-1^{1 / 2}$ ' long, orange, crowned with the calycine lobes. - DC. Prod. VII, 344. Gray, l. c. p. 148. - Mann, Enum. no. 277. - Occasionally a pinnatisect leaf occurs on young plants. Gray's var. citrullifolia probably represents a young plant of no. 16 or 17 .

Oahu! on both ranges, those from Kaala with lobules between the pinnae.

ß. - Pinnae larger and broader, laciniate, decurrent along the rhachis. Calyx-tube cylindrical, the lobes twice as long, $12-18^{\prime \prime}$. Corolla almost white.

w. Maui! Oloalu.

\%.- Pinnae sinuately notched, contracted at the base. Calyx-tube short cylindrical, $4^{\prime \prime}$, the lobes $6-8^{\prime \prime}$.

E. Maui! Hamakua (Lydg.).

15. C. solenocalyx, sp. $n$. - A stout and tall shrub, 6-12 ft. high, the stem hollow, the thick and stiff branches muricate below, aculeate above with pale yellow conical spines. Leaves dimorphous, those of the young plant broadly ovate or cordate, shortly lobed, prickly on both faces; those of the adult plant obovate-oblong, $15-24^{\prime} \times 5-9^{\prime}$, on fleshy muricate petioles of $5-10^{\prime}$, shortly acuminate or obtuse at either end, sinuate or entire, thin chartaceons, coarsely hispidulous underneath, the rib muricate. Raceme fleshy, $1^{1} / 2-2$, bracteate from near the base, the pedicels $6-12^{\prime \prime}$, the bracts linear-lanceolate, $9-18^{\prime \prime}$; the bractlets $4-6^{\prime \prime}$. Calyx scabrous and hirsute or hispid, but almost glabrate with age, the adnate portion $6 "$, the broad foliaceous several-nerved lobes 10-12" long and connate entirely or in part in a broad cylindrical or funnel-shaped sheath. Corolla semierect but ampliate, $15-20^{\prime \prime}$ long, $4-5$ " wide, slit beyond the middle, scabro-hispid, dark purple. Staminal column glabrous; anthers purple, the upper ones beardless. Berry ovoid, 8 ". Seeds pale yellow.

Molokail in deep gulches of Kalae, Mopulehu and elsewhere. Called "Puakala by the natives. The flowers generally rot inside the long calyx-tube; well developed corollas
are therefore of rare occurrence.

$\beta$ var. schizocalyx. - With hesitation I refer to this species a form collected by Mr. Lydgate in Hamakua, E. Maui at an elevation of $3000-4000 \mathrm{ft}$. Leaves as above. The short peduncle $\left(1^{\prime}\right)$ and calyx 
densely muricate, but the lobes of the latter ( $12^{\prime \prime}$ long) free to the base, Bracts lanceolate, $15-18^{\prime \prime}$; bractlets $6^{\prime \prime}$. Flowers wanting.

† Calycine lobes narrow, 1-nerved. Corolla suberect, slender. Upper anthers not tufted.

16. C. solanacea, $s p \cdot n$. - A stout freely branching shrub, $6-8 \mathrm{ft}$. high, the stiff ascending branches aculeate with slender straw-colored thorns. Leaves of young plants deeply cut into sharp sinuate segments, the stem, petioles, ribs and nerves bristling on both faces with thorns, which resemble those of Solanum aculeatissimum. Leaves of adult plants obovate-oblong, $10-13^{\prime} \times 3-5^{\prime}$, on petioles of $1-1^{1 / 2}$, shortly acuminate, contracting at the base, sinuate or lobed, the blunt lobes seldom exceeding $1 / 2^{\prime}$ in depth, hispidulous underneath, unarmed, thick chartaceous, with prominent veins. Peduncle fleshy, $1-2^{\prime}$, bracteate from the base, but bearing flowers only near the apex; pedicels $4-6^{\prime \prime}$; bracts $1-2^{\prime \prime}$. Calyx green, glabrous, the tube obconical, $4^{\prime \prime}$, the lobes oblong, truncate, 2-4", thick fleshy, 1-nerved, apiculate, with intervening sinuses. Corolla white, with a lilac tinge, semierect, slender, $2^{\prime}$ long, $2^{\prime \prime}$ broad, sparsely hispid or glabrous, with lobes warty, the dorsal slit deep. Staminal column pubescent; the upper anthers beardless. Stigmatic hairs in a ring; style lilac. Berry obovoid, 8 "long, orange-colored. Seeds reddish, smooth.

Moloka i! Kalae, Mopulehu and elsewhere, 1000 to $2000 \mathrm{ft}$. Called *Popolos on account of the resemblance of the leaf to forms of Solanum incompletum.

$\beta$ var. quercifolia. - Leaves larger, $11-20^{\prime} \times 3^{1} / 2-6^{\prime}$, thicker, scabrous on the upper, hispid on the lower face, with prominent nerves, the lobes deeper and rounded, cut to the rhachis at the narrow base. Calyx glabrous, the lobes $2 "$. Corolla as above, but glabrous; the staminal column and anthers pubescent. Berry $8^{\prime \prime}$.

E. Maui! Ulupalakua and Hamakua, at elevations of $3000-4000 \mathrm{ft}$. Attains the size of a small tree, $15 \mathrm{ft}$. high.

17. C. ferox, sp. n. - Size and habit of the preceding species, the branches bristling with thorns. Leaves of young plants bipinnatisect, to the rhachis in the lower portion, and covered with spines; those of the adult plant oblanceolate in outline, $10-12^{\prime} \times 3-4^{\prime}$, deeply cut into patent oblong sinuate segments of $1-2$ in depth which shorten to auricles at the base, on petioles of $1^{1} / 2-2^{\prime}$, papilloso-hispid on the upper, scabrohispid on the lower face, thick chartaceous, with prominent nerves, not aculeate. Peduncle (with buds) 1' long, floriferous at the end. Calyx muricato-hispid, the lobes 1-nerved, oblong, obtuse, apiculate, longer than the tube, $6^{\prime \prime}$. Corolla coarsely hairy.

Molokai! heights of Kamalo.

$\beta$ var. - Leaves thinner, pinnatisect to near the rib. Berry glabrate and smooth, ovoid, $7^{\prime \prime}$ long, the linear-oblong lobes $7-9^{\prime \prime}$. Pinnae or 
segments of the leaves in young plants separated by small lobules or auricles.

E. Maui! Ulupalakua, Makawao, Hamakua. Nat. name: «Hahanui`.

18. C. asplenifolia, Hillebr. - A branching shrub, 4-6 ft. high, sparsely aculeate. Leaves obovate-oblong in outline, $12-16^{\prime} \times 4-10^{\prime}$, on prickly petioles of $3-4^{\prime}$, deeply cut into connected segments, or pinnatisect to the rhachis with or without intervening lobules, or pinnate, the segments contracted at the base, almost stipitate, gradually or suddenly decreasing in size toward the base, all bluntly acuminate, entire or sinuate, membranous, glabrate, sparsely muricate on ribs and nerves. Peduncle 2 ' long, slender, naked or distantly bracteate below, $10-15$-flowered near the apex; pedicels 4-6"; bracts setaceous, $11^{1 / 2} "$, but sometimes foliaceous. Calyx glabrous, the tube obconical, $2-3^{\prime \prime}$, its lobes as long or shorter, linear-lanceolate, acute. Corolla semierect, $1^{1} / 2^{\prime}$ or more in length, $1^{1 / 2}-2^{\prime \prime}$ wide, pale lilac, glabrous or sparingly hispid, the lobes muricate. Staminal column glabrous; upper anthers naked, - Delissea asplenifolia, Mann, Enum. no. 273.

W. Maui! Kaanapali (leaves pinnatisect), Waihee and Waiehu (leaves pinnate). The stem has a compact wood with a small cavity. The least divided leaves resemble those of var. $\beta$ of $C$. ferox, the pinnate ones those of $C$. Grimesiana.

* Palmaeformes. Stem or trunk undivided, straight, unarmed, foliose at the apex. Leaves entire. Calycine lobes of variable length. Upper anthers beardless.

19. C. superba, Gray, l. e. p. 149. - Trunk smooth, 12-16 ft. high and $3-5^{\prime}$ thick at the base, with a thin woody zone, the large medullary cavity septate by closely set chartaceous diaphragms. Leaves obovateoblong, $2-3 \mathrm{ft}$. long, $6-8^{\prime}$ broad, obtuse or rounded, but shortly acuminate, narrowing at the base, on distinct petioles of $2-3$, crenate but almost entire below, coriaceous, glabrate. Peduncle (with ripe fruit) $12-14^{\prime}$ long, tomentose, drooping, with the numerous subsessile berries crowded in a cluster near the apex, for the rest distantly bracteate, the bracts tomentose, broad-oblong or lanceolate, obtuse, 12-20" long, besides 2 bracteoles of $6^{\prime \prime}$ in length at the base of each flower. Calyx velvetytomentose, the tube obconical, $5-7 "$, the oblong coriaceous lobes 5-8" long. Corolla arcuate, tubular, with short connivent lobes and a long dorsal slit, $2^{1} / 2^{\prime}$ long, coriaceous, tomentose, whitish or cream-colored. Staminal column glabrous. Berry obconical, $8-10^{\prime \prime}$ long, $6-8^{\prime \prime}$ wide, yellow or orange, ribbed, crowned by the ealycine lobes, which are separated by conspicuous sinuses. Seeds rather large, $1^{\prime \prime}$, dark brown, smooth and shining. - Mann, Enum. no. 280. - Lobelia superba, Cham. in Linnaea VIII, 223-225. - Macrochitus superbus, Presl. - Endlicher, Gen. Pl. p. 513. Oahu! gulches of Makaleha on Mt. Kaala. My specimens are with ripe fruit to which
a single corolla remained adhering. 
$\beta$ var. - Leaves with a brownish tomentum underneath. Gulches on the eastern slope of Mrt. Kaala!

$\gamma$ var. reginae. - Leaves chartaceous, tomentulose underneath when young, but glabrate with age, $20-30^{\prime} \times 4-7^{\prime}$, commonly acuminate but sometimes rounded, the base gradually narrowing into a petiole of $2-3$ '. Peduncle about $8^{\prime}$ long, drooping, naked below, distantly bracteate above, bearing near the apex $5-10$ flowers on short resupinate pedicels of 3 "; bracts $6-18^{\prime \prime}$; bractlets $2-3^{\prime \prime}$. Calyx velvety-tomentose, bluish, as are also the upper bracts, the tube $8^{\prime \prime}$, the oblong obtuse lobes $3-5^{\prime \prime}$, separated by intervals. Corolla coriaceous, velvety-tomentose, cream-colored, with purplish nerves (not «rosea»), arcuate, the apex returning to the level of the base, $2^{1 / 2}-3^{\prime}$ in length and of even width $\left(4^{1 / 2^{\prime \prime}}\right)$ throughout, the lobes short connivent, the dorsal slit extending to the middle. Staminal column glabrous; anthers white, with purplish stripes, the upper ones beardless. Stigmatic hairs in 2 patches. Berry obconical, ribbed, $8-10^{\prime \prime}$ 5-6". - Flowers in April. - Delissea reginae, Wawra, in Flora, 1873.

A truly superb and royal plant. Oahu! Niu and Wailupe, at 1500-2000 ft. elevation, not Kaala, as ineorrectly stated by Wawra, who seems to have forgotten that his specimens were obtained from the author. (Collected by my son and Mr. Lydgate).

20. C. leptostegia, Gray, l. c. p. 149. - Trunk smooth, $30-40 \mathrm{ft}$. high, densely covered in its upper portion with rhomboidal leaf-scars. Leaves sessile, narrow lanceolate, $20-24^{\prime} \times 2-2^{1} / 2^{\prime}$, denticulate or subentire, glabrous, shining, chartaceous. Peduncle (with flower) $1-1^{1 / 2} 2^{4}$, slender, naked below, many-flowered at the apex, $12-20$ flowers in a crowded cluster, on pedicels of $4^{\prime \prime}$; bracts linear, $12^{\prime \prime}$; bractlets $6^{\prime \prime}$. Calyx glabrous, the tube cylindrical, somewhat produced beyond the ovary, $7^{\prime \prime}$, the linear erect lobes 18-24" long and less than $1 / 2^{\prime \prime}$ broad. Corolla dark purple, glabrous, semierect and slender, $2^{\prime}$ long and $2^{\prime \prime}$ wide, thin, with a long dorsal slit. Anthers glabrous. Berry ovoid, $8 \times 4^{n}$, crowned by the calycine lobes. - Mann, Enum. no. 278.

Ka uai! Waimea, upper edge of the forest near the tabular summit.

21. C. arborea, Hillebr. - Trunk 12-24 ft. high, smooth. Leaves sessile, oblanceolate, $16-26^{4} \times 2^{1 / 2}-4^{1 / 2^{4}}$, shortly acuminate or rounded and apiculate, gradually narrowing toward the base, faintly dentate, but almost entire and wavy toward the base, glabrous, or with some pubescence along the rib, glossy, chartaceous to coriaceous. Peduncle slender but stiff, $6-12^{\prime}$ long, almost naked below, closely many-flowered in the upper fourth, the pedicels short, $1^{1 / 2}-^{\prime \prime} 4^{\prime \prime}$ bracts $1-2^{\prime \prime}$; bractlets ${ }^{1 / 2^{\prime \prime}}$. Calyx subglobose, glabrous, shortly toothed, small, the tube $3^{\prime \prime}$. Corolla slender, moderately curved or suberect, $2^{\prime}$ long, $2^{\prime \prime}$ wide, glabrous, grayish blue, rather thin, with a deep dorsal slit and connivent lobes. Staminal column glabrous. Berry globose, faintly ribbed, $5-6^{\prime \prime}$ in diam. - Delissea arborea, Mann, Enum. no. 262, where however the length of the peduncle 
is incorrectly given as «brevis and pauciflorus». - D. coriacea, var. $\beta$, Gray, 1. c. p. 148.

E. Mani! Ulupalakua, 3000-4000 ft. One specimen exhibits a monstrous infloreseence, similar to that which occurs in C. Mannii, viz., the empty bracts foliaceous and the flowering part of the raceme branching. Kula! leaves narrowing into a short petiole.

$\beta$ var. - Leaves broader $\left(4-6^{\prime}\right)$, glabrous, subsessile. Peduncles $8-12^{\prime}$ long, drooping, distantly bracteate, bearing near the end $15-20$ subsessile flowers. Corolla dark purple, moderately curved; otherwise as above.

Hawaii, woods of Hilo (Lydg. in lit.).

$\gamma$ var. pycnocarpa. - Leaves smaller, membranous, running out into a distinct petiole of $1^{1} / 2^{\prime}$, pubescent underneath. Peduncle slender, naked, $3-4$ ' long bearing at its end a cluster of sessile subglobose truncate berries $6^{\prime \prime}$ in diam, the acute triangular calyx-lobes $2 "$.

Haw aii! Kohala range.

22. C. procera, sp. n. - Trunk and leaves as in no. 21, the leaves broader, $4-6^{\prime}$, closely denticulate, pubescent underneath. Peduncle short, thick and fleshy, $1-1^{1 / 2^{\prime}}$ long, with many $(10-20)$ flowers near the apex, the pedicels $3-5^{\prime \prime}$, bracteolate at the base; bracts $5 "$, bracteoles $2^{\prime \prime}$. Calycine tube glabrous, cylindrical, $5-7 "$ in length, with triangular lobes of $1^{1} / 2-2^{\prime \prime}$. Corolla (undeveloped) glabrous, over $3^{\prime \prime}$ broad, bluish below, greenish-yellow above, thick fleshy.

Molokail Kamalo, $2000 \mathrm{ft}$. Nearly related to the preceding species. In both the trunk has a thick woody zone which includes a narrow cavity septate by numerous papery
diaphragms.

23. C. tritomantha, Gray, l. c. p. 149. - Trunk 6-10 ft. high, rough tuberculate. Leaves broadly lanceolate or obovate, $15-28^{\prime} \times 5-8^{\prime}$, on muricate petioles of $5-8^{\prime}$, acuminate, sinuate-dentate, suddenly contracting at the base, thick chartaceous, pubescent underneath along the prominent nerves. Peduncle $1-2^{1} / 2^{i}$, thick fleshy, closely bracteate from the base, with $5-7$ flowers near the apex on pedicels of $9-12^{\prime \prime}$ which are bibracteolate about the middle; bracts linear-oblong, $9-15^{\prime \prime}$. Calyx scabropubescent, the tube obconical or cylindrieal, $7-8^{\prime \prime}$, the lobes linear, 1-nerved, acute, herbaceous, as long as the tube or longer, $6-12^{\prime \prime}$. Corolla pubescent, falciform, $2^{1 / 2}-3^{\prime}$ long, $2-2^{1} / 2^{\prime \prime}$ wide, cinereous, blue inside, with deep dorsal and lateral slits (but the anterior lip not entire). Filaments slightly pubescent.

Ha wail! windward side of Mauna Kea, 3000 ft. (U. S. E. E.), Hilo (Lydg.), Kohala range (Hbd.). The racemes are sometimes barren and develop only large foliaceous bracts,
in which case they grow to a length of often one foot and are apt to branch as in $C$.
arborea. Nat. name. arborea. Nat. name: Aku. According to Lydgate the leaves are cooked and eaten by

$\beta$ var: - Leaves smaller, $12-14^{\prime} \times 3^{\prime}$, thicker, with a crisp margin. Bracts lanceolate, short, $2-3^{\prime \prime}$; bracteoles ovate subulate $1-1^{1 / 2}$ ". Calyx- 
tube $4^{\prime \prime}$ long, the narrow lanceolate acute lobes as long or shorter, $3-4 "$. Corolla faintly pubescent, with muricate lobes. Filaments glabrous, the anthers pubescent along the sutures.

Haw aiil Kona (Lydg.).

24. C. macrostegia, $s p . n$. - Trunk $6-12 \mathrm{ft}$. high, rather rough but unarmed. Leaves large as in C. tritomantha, but the base gradually narrowing into a short petiole of $1-2^{\prime}$, pubescent underneath, when young, and papillose above, membranous. Peduncle $1-1^{1 / 2} 2^{\prime}$, thick fleshy, racemose from the base, the pedicels $4-8^{\prime \prime}$; bracts broad oblong, $18-24^{\prime \prime}$; bractlets $6 "$. Calyx smooth and glabrate, its tube obconical, 6 "long, the oblong lobes several times as long, $15-24^{\prime \prime}$ long and $2-3$ " broad, erect, obtuse or emarginate, herbaceous, many - nerved. Corolla suberect, 24-30" long and $4^{\prime \prime}$ wide, at first pubescent along the linear lobes, but soon glabrate, fleshy, dark purplish-blue, deeply slit at the back, the lateral slits extending to the middle and the anterior ones nearly as far. Staminal column glabrous, purple. Berry large ovoid, $10 \times 8^{\prime \prime}$, yellow, erowned by the long lobes. Seeds shining.

W. Maui! Kaanapali, Honokahau, Waihee, in deep wooded ravines. The flowers are hidden between the long crowded bracts and calycine lobes, which always retain a large quantity of water and organie debris, in consequence of which the fleshy corollas are apt to perish by rot and intact ones are rare.

$\beta$ var. - Calycine lobes 9-12". Corolla pubescent. Adult leaves pubescent underneath.

E. and W. Maui!

25. C. atra, sp. n. - Trunk 4-6 ft. high, tubereulate in the upper portion. Leaves lanceolate, $16-20^{\prime} \times 3-4^{\prime}$, gradually tapering into a thick muricate petiole of $2-2^{1} / 2^{\prime}$, crenulate, coriaceous, with prominent nerves, papillose above, the lower face covered with an olivaceous soft tomentum. Peduncle very short and thick, 4-6-flowered; the pedicels $6^{\prime \prime}$; bracts only $2-3^{\prime \prime}$; bractlets $1^{1 / 2} 2^{\prime \prime}$. Calyx dark, hirsute, the cylindrical tube $6^{i}$, the thick oblong and obtuse or emarginate lobes 1 -nerved, of

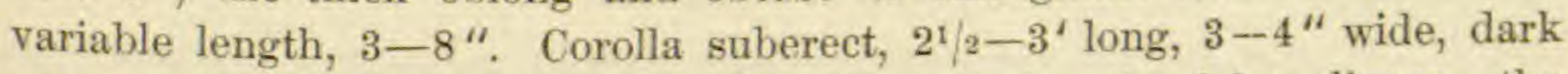
purple, almost black, hirsute with coarse hair, the lobes linear, the posterior ones as long as the tube. Staminal column dark purple, the filaments and anthers hispid. Berry ovoid, $8^{\prime \prime}$. Seeds pale yellow.

W, Maui! back of Lahaina, Wailuku (3000-4000 ft.).

26. C. Gibsonii, sp. $n$. - Trunk $3-5 \mathrm{ft}$. high, smooth. Leaves broad elliptico- or obovato-oblong, acute, generally rounded at the base, wavy, crenate or denticulate, membranous, pubescent but green underneath, $12-16^{\prime} \times 4-6^{\prime}$, on petioles of $3-5^{\prime}$. Peduncle dark purple, thick fleshy, $1-1^{1 / 2^{\prime}}$, many-flowered, the pedicels $8-10^{\prime \prime}$, bracteolate above the base, the bracts narrow linear, 6-9". Calyx dark purple, pubescent, the ob- 
conical tube $6 "$, the lobes $8-10^{\prime \prime}$, oblong, somewhat acute, thin, herbaceous, 1-nerved. Corolla hirsute as in the preceding species, dark purple. Staminal column glabrous.

Lanai! on the highest ridge.

27. C. Kunthiana? - Stem $3-5 \mathrm{ft}$. high, unarmed, rather hairy at the top. Leaves elliptico- to obovato-oblong, $7-9^{\prime} \times 3^{\prime}$, on petioles of $1^{1} / 2-3^{\prime}$, shortly acuminate at both ends, wavy, subentire, pale, almost white underneath, both faces shortly pubescent with scattering pale hairlets. Peduncle about $1^{\prime}$, pubescent, as is the whole inflorescence, bracteate from the base, the pedicels $3^{\prime \prime}$, bracts linear, $6^{\prime \prime}$. Calyx-tube $2-3 "$, the linearlanceolate lobes 2-4". Corolla (bud) white, with pale violet streaks, hairy, suberect, less than $1^{\prime}$ long and $1^{1 / 2} 2^{\prime \prime}$ wide. Filaments and anthers hispid, particularly at the base of the latter. - Delissea Kunthiana, Gaud. Bot. Voy. Bon. tab. 77 (without description).

W. Ma ui! back of Lahaina, $4000-5000 \mathrm{ft}$. (on the ridge overlooking Wailuku). Collected by the late Mr. E. Bishop. The identity of our plant with D. Kunthiana is rather doubtful. The corolla, even when developed, will not attain the size given in Gaudichaud's plate, and the calycine lobes are longer in proportion to the tube. The characteristic pallor of the leaves also, which reminds of $C$. acuminata, is not expressed in the figure.

28. C. platyphylla, Hillebr. - Stem slender, $3-5 \mathrm{ft}$. high, covered in its upper portion with short and sharp paie spines. Leaves obovateoblong, $12-20^{\prime} \times 5-8^{\prime}$, on prickly or muricate petioles of $3-4^{\prime}$, obtuse or rounded at the apex, contracted at the base but not decurrent, wavy or sinuate, denticulate, glabrous, rather fleshy. Peduncle muricate, $1-2^{\prime}$ long, naked or distantly bracteate below, many-flowered at the apex, the pedicels $6-8^{\prime \prime}$; bracts $2-4^{\prime \prime}$, often foliaceous. Calyx glabrous, the tube cylindrical, $3-4^{\prime \prime}$, the lobes sharp dentiform or subulate, $1^{1 / 2}-2^{\prime \prime}$. Corolla white, thin, glabrous, falciform, $2^{\prime}$ long, $3^{\prime \prime}$ wide. Staminal column pale, glabrous. Berry obovoid, 4". Seeds crustaceous, reddish, smooth. Detissea platyphylla, Gray, 1. c. p. 148. - Mann, Enum. no. 265.

Hawail lower woods of Hilo and Puna. In several respects like a Delissea, but the corolla is not knobby, nor are the seeds of that genus,

\section{Order XliV. GOODENIACEAE.}

Calyx-tube adnate to the ovary, the limb 5-toothed or entire. Corolla irregular, slit open on the upper side, 5-lobed, the lobes valvate and generally induplicate in the bud. Stamens 5, alternate with the lobes of the corolla and inserted at its base; anthers opening in longitudinal slits, free or rarely united. Ovary usually 2-celled, with 1 or more erect ovules in each cell. Style simple, the stigma surrounded by a cup-shaped or 2-lipped usually ciliate indusium. Fruit either a capsule opening into 2 valves, or an indehiscent drupe or nut. Seeds usually with a flesby 
albumen, the embryo straight, with the radicle next the hilum. - Herbs or shrubs, the juice not milky. Leaves usually alternate, without stipules.

A small Order of ehiefly Australian species, only the following genus having a wider range.

\section{SCAEVOLA, L.}

Corolia slit to the base on the upper side, its lobes margined and induplicate, subequal, the 2 upper spreading or all conniving. Anthers free, erect from an entire narrow base, continuous with the filaments, the 2 narrow cells parallel before a broad connective. Indusium cupshaped, surrounding a truncate or 2-lobed stigma. Ovary 2-, rarely 4-celled, with 1 erect ovule in each cell. Fruit a drupe with a fleshy or suberose mesocarp and a ligneous or crustaceous endocarp. Embryo as long as the albumen, with terete or foliaceous cotyledons. - Herbs or shrubs with generally (in all Hawaiian species) alternate entire or toothed leaves. Flowers axillary, generally bibracteolate at the base of the calyx and articulate with the pedicels, single or cymose with the median flower sessile, white, purplish or yellow, the corolla always hairy inside. Style incurved below the indusium in all our species.

About 60 species, natives principally of Australia and the Hawaiian Islands, only one other Polynesian mountain species known from New Caledonia, a few littoral species spread through Polynesia, the coasts of tropical Asia, Africa, and of some islands of the W. Indies, - Nat. name: :Naupakas.

Corolla straight, with spreading lobes; anthers enclosed in the

tube, truncate at the top; style as long as the corolla; calyx

bibracteolate at the base:

Corolla pale blue, with gray tomentum; cymes very short; leaves gray-tomentose underneath, entire or shortly many-toothed; drupe 2-or 4-celled

7. S. mollis.

Corolla white, with purplish streaks; leaves glabrous, at least with age; drupe 2-celled:

Leaves obovate, rounded or emarginate:

Cymes 5-9-flowered; limb of calyx 5-toothed. . 1. S. Lobelia.

Cymes 1-3-flowered; limb of calyx entire. . . 2. S. coriacea.

Leaves acute or acuminate:

Leaves spathulate, entire or with a few teeth; cyme 1-3flowered, very short .

Leaves obovate-oblong, toothed or serrate in the upper half: Cymes short, crowded; leaves pubescent when young .

Cymes as long as the leaf, many-flowered; leaves glabrous:

Drupe ovoid or ellipsoidal

Drupe elongate, cylindrical colling
Corolla curved, with lobes scarcely spreading, yellow; stamens as long as the corolla, style exserted beyond, the anthers deltoid at the top; calyx without bracts at the base .

3. S. Gaudichaudii.

6. S. procera.

4. S. Chamissoniana.

5. S. cylindrocarpa.

8. S. glabra.

1. S. Lobelia, L. - De Vriese, in Kruidk. Arch. II, 20. - An erect shrub, 4-6 ft. high, extensively branching from the base, the succulent branches, leaves and inflorescence generally silky-pubescent, rarely glabrate, but always with a tuft of long silky hairs in the axils. Leaves fleshy, bright green, obovate, $3-5^{\prime} \times 1^{1 / 2}-2^{\prime}$, rounded, even emarginate at the 
top, entire, narrowed into a short broad petiole, the nerves hidden. Cyme compound, shorter than the leaf, 1-3' long, 5-9-flowered, the peduncle $4-9^{\prime \prime}$, the lateral pedicels $3-4^{\prime \prime}$, bracts $2-1^{\prime \prime}$. Calyx tomentose, $3^{\prime \prime}$, the lanceolate lobes nearly as long as the tube. Corolla $6-8^{\prime \prime}$, white, with purple streaks, tomentose, the lobes somewhat shorter than the tube, spreading, obovate, pointed, the broad wings confluent at the apex. Style and indusium hispid, the former truncate, as long as the corolla, the latter densely ciliate at the rim. Drupe 2-celled, obovoid, 5-6"long, pubescent, white, 5- or 10-ribbed, the thickened mesocarp suberose, the putamen crustaceous. - Benth. Fl. Hongk, p. 198. - S. Koenigii, Vahl. - S. sericea, Forst. - S. plumierioides, Nutt. - Mrs. Sinclair, pl. 32 .

Along the seashore here and there on all islands. Specimens from Kailua, Oahu! and Kohala, Hawaii! have nearly glabrous leaves, while in those from Kolaupapa, Molokai! the cyme is of unusual length. The species is widely diffused over Polynesia and the shores of tropieal Asia and adjoining islands (Hance, in Walp. Ann. I, 1054, sub S. latevaga).

2. S. coriacea, Nutt. in Trans. Am. Phit. Soc. VIII, 253. - A low prostrate or trailing shrub, with remote and short ascending branches which are foliose at their ends and tufted in the axils with a little short matted wool. Leaves obovate or spathulate, $1-1^{1 / 2^{\prime}} \times{ }^{1 / 2}-3 / 4^{4}$, broadly rounded or shortly apiculate, entire, contracting into a short and broad petiole, coriaceous, with veins hidden, puberulous or glabrate, pale. Cymes $1-2$ - or rarely 3 -flowered, with the median flower sessile, the peduncle $6-9 "$, the lateral pedicels $3-4^{\prime \prime}$, bracts $1-1 / 2 "$. Calyx cylindrical, $2^{\prime \prime}$ glabrate, the short limb truncate or sinuate. Corolla whitish, glabrous outside, hairy inside, $6-8^{\prime \prime}$, the lobes half as long as the tube, narrowly margined. Stamens $1 / 2$ the length of the tube. Style hispid throughout, as long as the corolla, the indusium shortly ciliate. Drupe ovoid, glabrous, 3". - Gray in Proc. Am. Ac. V, 151. - Walp. Ann. II, 1055 .

Ka uai! Maui! Kalepolepo; Oahu! cape Kaena, on lava near the seashore; Niihau (Remy).

3. S. Gaudichaudii, Hook \& Arn, in Bot. Beech. p. 89. - A low divaricately branching shrub, $2-3 \mathrm{ft}$. high, the young branehes glabrous or puberulous, the axils with faint, soon evanescent patches of hair. Leaves narrow spathulate, $1^{1 / 2}-3^{\prime}$ long including a petiole of $1 / 2-1^{\prime}$, and $2-8^{\prime \prime}$ broad, obtuse or shortly acuminate, quite entire or faintly dentate with 1-3 distant callous toothlets on each side, rather fleshy, with inconspicuous veins, glabrous. Peduncle filiform, puberulous, 1 -flowered, shorter than the petiole, $2-3^{\prime \prime}$; bracts filiform, $3-4^{\prime \prime}$. Calyx glabrate or puberulous, $2^{n}$ long, truncate or shortly and broadly 5 -toothed. Corolla purplish-white, glabrous, the slender erect tube $5-6^{\prime \prime}$, the spreading lobes linear-lanceolate with a subulate point, $3-4^{\prime \prime}$ long, scarcely margined. 
Stamens almost as long as the tube. Style pubescent throughout, as is the pectinately ciliate indusium. Drupe ellipsoidal, $3^{1 / 2} "$, glabrous. DC. Prod. VII, 507. - Gray, 1. c. - S. montana, Gaud. Bot. Voy. Freyc. (non Labill.). - S. Menziesiana, var. glabra, Cham. in Linnaea, VIII, 227. - Temminckia Gaudichaudii, De Vriese. - Walp. Ann. II, 1057.

In the scrub of the forehills on Kauai! Oahu! eastern end; Molokai! Kalae; W. Maui! Halona, leaves entire, very narrow and often subfoliate; Hawail! Puna and Hilo. Not frequent, but generally gregarious where it occurs.

$\beta$ var. - Young leaves and inflorescence puberulous, the former rather oblong, $6-8$ " broad and often denticulate, the latter mostly 3 -flowered, short as before. Calyx-limb and corolla puberulous, the lobes of the latter distinctly and abruptly winged. - S. coriacea, var. $\gamma$, Gray.

Molokai! Gregarious on the high land ( $800 \mathrm{ft}$.) between Honouliwai and Halawa.

$\gamma$ var. - Young shoots pubescent. Leaves small obovate, $1 \times 1 / 2$, on petioles of $1 / 2^{2}$, mucronate, sharply dentate with $2-4$ callous toothlets on each side. Peduncle $4-5^{\prime \prime}$ long, 1 -flowered, with 2 linear hispid bracts of $5^{\prime \prime}$. Corolla as in $\alpha$, but faintly pubescent and yellow.

Kauai! (Kn.).

4. S. Chamissoniana, Gaud. Bot. Voy. Freyc. p. 461, tab. 82. - A shrub, 4-6 ft. high, the glabrous branches tufted in the axils. Leaves obovate or lanceolate, $2-4^{\prime} \times{ }^{3 / 4}-1^{1 / 2} 2^{\prime}$, on petioles of $1 / 4-1 / 2^{\prime}$, acute, with a cuneate base, callous-dentate in the upper half, chartaceous, quite glabrous. Cyme as long as the leaf or longer, 7-15-flowered, often secund, the common peduncle $1^{1 / 2}-2^{1} / 2^{\prime}$, the lateral pedicels $3-4^{\prime \prime}$, the linear bracts $3-1^{\prime \prime}$. Calyx ovoid, $2^{\prime \prime}$, the limb shortly 5-toothed, glabrous, but the teeth sometimes ciliate. Corolla white, with purple streaks, glabrous outside, puberulous inside, the erect tube $7-9^{\prime \prime}$, the lanceolate lobes $4-6 "$, broadly winged, with truneate margins and a short protruding tip. Stamens almost as long as the tube. Style pubescent below only, the glabrous indusium faintly eiliate. Drupe ellipsoidal, $4-5^{\prime \prime}$, pale blue or white, glabrous. - DC. 1. c. p. 506. - Gray, 1. c. p. 152 . - S. ciliata, Don. - S. Tigustrifolia. Nutt. - Temminclia chamissoniana, De Vriese.

$\mathrm{O}$ ahu! the common form on the main range; Kauai! leaves broad, with projecting teeth and cymes exceeding their leaves; E. Ma ui!

$\beta$ var. - Young branches and inflor. puberulous. Leaves larger, $4-5^{\prime} \times 1^{1 / 2}-2^{\prime}$, faintly crenato-dentate, thinner, and papillose underneath. Cymes 5-7-flowered, shorter than their leaves. Calyx and corolla pubescent, the latter silky-haired inside. - S. Menziesii, Cham. - S. pubescens, Nutt.

Oa bu: Kaala range.

ir var. - Leaves narrower, oblanceolate and shortly acuminate, faintly dentate or subentire, thin, glabrous, on longer petioles. Cyme shorter 
than the leaf, as in $\beta$, generally 3 -flowered, the common peduncle $10-16^{\prime \prime}$, the lowest bracts very long, $6-12^{\prime \prime}$. Corolla glabrous, as in $\alpha$.

W. Maui! the leaves like $S$. Gaudichaudii in shape, but much larger.

ò var. bracteosa. - Leaves large, subcoriaceous, obovate, almost sessile, sharply dentate to serrulate with $10-12$ teeth on a side, puberulous underneath. Cymes long as in $\alpha$, repeatedly dichotomous, but its bracts ovate-lanceolate, the lowest $6-8$ "long and $2^{\prime \prime}$ broad, Calyx and corolla pubescent, the latter large, with a tube of $12^{\prime \prime}$ and lobes of $6^{\prime \prime}$ in length. - S. Dielliana, Gaud. in herb. Gray.

Hawaii! from Kohala to Hilo; Molokai! Kamalo. The same form, with as large flowers and as long but narrow bracts, and glabrous in leaves and corolla, prevails in the southern parts of Hawaii and oecurs aiso on Maui! and Molokai!

5. S. cylindrocarpa, $s p . n$. - A glabrous shrub, 8-10 ft. high, shortly tufted in the axils. Leaves rather fleshy, glabrous, obovate or obovateoblong, $3-6^{\prime} \times 1^{1} / 4-2^{\prime}$, shortly petiolate, acuminate, denticulate. Cyme shorter than its leaf, glabrous, generally 3-, but sometimes 1- or 5-flowered, the peduncle $1-1^{1} / 2^{\prime}$, the lateral pedicels ${ }^{1} / 2^{\prime}$, the linear bracts $7-4^{\prime \prime}$. Calyx elongate, with teeth of $1-1^{1} / 2^{\prime \prime}$. Corolla white, with purplish streaks, glabrate, slightly pubescent inside, its tube $12^{\prime \prime}$, the $3-5$-lined lobes 5 " long and broadly winged to the very apex. Style pubescent near the base only, the rim of the indusium apparently not ciliate. Drupe cylindrical, $7-8^{\prime \prime}$ long, slightly $8-10$-ribbed, the persistent calyx constricted at the base. Stamens as long as the tube.

Lanai! on the high ridge.

6. S. procera, $s p . n$. - A tall shrub or small tree, often attaining a height of $15 \mathrm{ft}$., the young branches and inflorescence cinereous with a soft pubescence, shortly tufted in the axils. Leaves chartaceous to membranous, with distinct veins, pale pubescent underneath and hispidulous above, but glabrate with age, obovate-oblong, euspidate, $3-4^{\prime} \times$ $1-1^{1} / 2^{\prime}$, contracting into a petiole of $1 / 2^{\prime}$ or less, sharply dentate to serrulate in the upper half with $4-10$ rather distant callous teeth. Cyme several times shorter than its leaf, 3-9-flowered, with divaricate branches, the stiff peduncle $2-6^{\prime \prime}$, the lateral pedicels $2-6^{\prime \prime}$, the linear-lanceolate bracts $2-1^{\prime \prime}$. Calyx $2 "$, puberulous, at least on the short bluntish teeth. Corolla tomentose, white, with purplish stripes, the tube erect, 5-7", the spreading lanceolate lobes $4-6 "$, winged with excurrent margins. Style pubescent near the base only, the indusium shortly eiliate. Drupe ovoid, $3^{\prime \prime}$, with a thick crustaceous endocarp, at length glabrate, 2-celled.

The common form on Molokai! but also occuring on W. Maui! and Kauai! The cyme, which does not exceed 4-6" in the plants from Kauai and Maui and $6-9^{\prime \prime}$ in those from Kalae, Molokai, attains a length of $15^{\circ}$, with $7-12$ flowers, in the tall leaves and color of flom the palis of Wailau and Pelekunu, Molokai. As to shape of hairiness it approaches $S$, mollich like $S$. Chamissoniana, but in the inflorescence and hairiness it approaches $S$, mollis. It is Remy's no. 311. 
7. S. mollis, Hook. \& Arn. 7. c. p. 89. - A much branching shrub, $4-6 \mathrm{ft}$. high, the young branches and inflorescence gray-tomentose, the axils shortly tufted. Leaves chartaceous to coriaceous, with distinct nerves, dark green and shortly pubescent above, gray-tomentose underneath, elliptico-oblong, $3^{1 / 2}-5^{4} \times 1-1^{1 /} / 2^{4}$, on petioles of $6-9^{\prime \prime}$, equally acuminate at both ends, shortly denticulate with numerous callous teeth, often almost entire. Cymes shorter than the petioles, divaricate, 3-5-flowered, the peduncle $3^{\prime \prime}$, the lateral pedicels $1^{\prime \prime}$, the subulate recurved bracts $5-2^{\prime \prime}$. Calyx $2 "$, tomentose, with a short truncate or obtusely 5 -toothed limb. Corolla pale violet, gray-tomentose, with a slender erect tube of $6-8^{\prime \prime}$, the narrow lanceolate 3-nerved lobes $4-7^{\prime \prime}$, broadly and abruptly winged. Stamens nearly as long as the tube. Style pubescent below only, the rim of the indusium faintly ciliate. Drupe 2- or 4-celled, ellipsoidal, 4" long, with suberose mesocarp, 8-ribbed, bluish, tomentose. DC. 1. c. - Gray, 1. c. - Temminckia mollis, De Vriese. - Walp. Ann. II, 1058.

Oahu! on both ranges.

8. S. glabra, Hook. \& Am. l. c. - A stout glabrous shrub or small tree, $8-16 \mathrm{ft}$. high, with short and thick branches, the leaves erowded at their ends, the short axillary hairs united into scales. Leaves coriaceous, with inconspicuous veins, glabrous on both sides, bright green, obovate, sometimes suborbicular, $2-4^{\prime} \times 1-2^{\prime}$, on petioles of ${ }^{1 / 2}-1^{\prime}$, shortly acuminate, suddenly contracting at the base, remotely callous-dentate, often nearly entire. Peduncle 1 -flowered, $1 / 2-1$ ' long, entire, or rarely articulate near the base, with 2 very minute obtuse bractlets; no bractlets below the calyx. Calyx 4-5", glabrous, the linear-lanceolate lobes nearly or quite as long as the obconical tube. Corolla deep yellow, coriaceous, glabrous, faintly pubescent inside, tubular, curved, $1-1^{1 / 2^{\prime}}$ long and $4^{\prime \prime}$ wide at the mouth, the suberect lobes about $1 / 3$ its length and moderately winged with excurrent margins. Stamens as long as the entire corolla. Style exserted beyond the lobes, complanate, quite glabrous, the indusium ciliate. Drupe 2-seeded, black, globose or ovoid, 6", fleshy, but faintly 10-ribbed when dry, the raised vertex surrounded by the calycine lobes. - Gaud. Bot. Voy. Bon., tab. 48, - Gray, 1. c. and DC. 1. c. p. 507. Camphusia glabra, De Vriese, Gooden. p. 15, tab. 1. - Mrs. Sinclair, pl, 33.

Oahu! eastern part of the main range; Kauai! W. Maui! A disk-like expansion of the articulation takes the place of the calycine bracts. Nat. name: =Ohenaupaka=.

\section{Order XLV. VACCINIACEAE.}

Calyx adnate, its limb 5-(4-6-)lobed. Corolla superior, gamopetalous, with 5 ( 4 or 6$)$ lobes which are imbricate in the bud. Stamens twice as many as lobes of the corolla, or rarely of the same number, epigynous 
or adherent to the base of the corolla. Anthers affixed dorsally near the base, 2-celled, opening at the top in pores or short oblique slits, and generally with awn-like appendages at the back. Style 1. Ovary 3-10celled. Fruit a berry. Seeds small, anatropous. Embryo minute, in fleshy albumen, - Shrubby plants with alternate simple leaves without stłpules.

\section{VACCINIUM, L.}

Calyx 4-5-toothed or lobed, the lobes persistent. Corolla ovoid, campanulate or shortly tubular, the limb 4-5-cleft or toothed. Stamens 8-10. Anthers often 2 -awned on the back, their cells separate and prolonged into a tube which opens by a pore at the apex. Berry 4-5-celled, with several small compressed seeds in each cell. - Shrubs with angular branches and alternate toothed leaves. Flowers clustered or single in the axils, or in axillary or terminal racemes, white or reddish.

A large genus, widely distributed over mountainous and boggy regions, ehiefly of the northern hemisphere, but occurring also in the southern, as well as in tropical mountains.

In the Hawaiian, as in some other species, the innovations, which rise from near the ends of the branches, begin with one or more soft and thin scales which either suddenly or gradually pass into true leaves. From the axils of these scales and simuitaneously with them grow the first flowers, all or nearly all when the scales are numerous, and then the young shoot often presents the appearance of a short raceme, while at a later period, when the further developed axis has produced true leaves and the scales have fallen off, the flowers stand unsupported at the base of the branch.

Leaves loose and large, of thin texture; calycine lobes generally longer than the tube; anther-cells obtuse or shortly pointed at the base

Leaves erowded and small, coriaceous, reticulate; lobes of calyx not longer than the tube; anther-cells obtuse at the base

1. V. penduliflorum.

1. V. penduliflorum, Gaud. in Bot. Voy. Freyc. p. 454, tab. 68. - A sparingly branched shrub, $3-6 \mathrm{ft}$. high, generally growing on the trunks of old trees, glabrous throughout, with angular branches, loosely foliose. Leaves chartaceous, obovate-oblong, $1^{1 / 2}-2^{\prime} \times^{3 / 1}-1^{\prime}$, on short petioles of $1^{\prime \prime}$, shortly acuminate, densely and acutely dentate to the base, the teeth often spinulose. Flowers single, one or few from the axils of scales, but most from the axils of true leaves, on spreading or nodding bractless pedicels of $6-12^{\prime \prime}$. Calyx about $4^{\prime \prime}$, its 5 lobes broadly lanceolate, acute, as long as the tube or longer. Corolla $4-5^{\prime \prime}$, twice the length of the calyeine lobes, broad urceolate, shortly 5-toothed, red. Stamens 10, more than half the length of the corolla, the filaments as long as the anthers, these obtuse or faintly pointed at the base, shortly 2 -awned, running out in parallel tubes of the same length as the cells. Style slightly exserted. Berry globose, $4-5^{\prime \prime}$ in diameter, 5-celled, dark red, insipid. Seeds numerous, fusiform or elongate triquetrous, with reddish testa. - DC. Prod. VII, 575. - Gray, in Proc. Am. Ac. V, 323, incl. the var. berberifolium. - Metagonia penduliflora, Nutt. - V. reticulatum, $\beta$, Wawra, in Flora, 1873 , p. 60. 
In forests of $1000-4000 \mathrm{ft}$. of elevation, chiefly of $\mathrm{Oahu}$ ! The base of the anthers is not always pointed or cuspidate, as Gray was led to believe, but on the contrary oftener obtuse. Misled by this fallacious character, Gray united with $V$. reticulatum the variety $\gamma$.

$\beta$ var. gemmaceum. - Tall, $6-12 \mathrm{ft}$. in height. Leaves broadly oblong

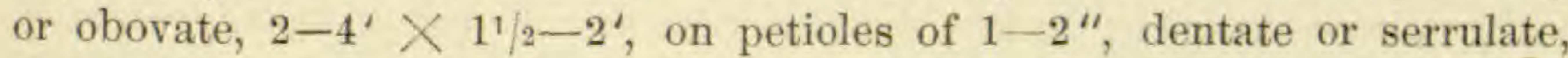
chartaceous to membranous, the young leaves puberulous along the miditb and quite flaccid. Flowers generally all from the axils of bud-scales at the base of a branch, on nodding pedicels of $1-1^{1 / 2}$. Calycine lobes broadly lanceolate or ovate, half the length of the corolla or more. Stamens almost as long as the corolla; the anthers obtuse at the base or shortly pointed, with awns almost obsolete. - V. Meyenianum, Klotzseh, in Linnaea, XXIV, 59. - V. reticulatum, var. $\alpha$, Wawra.

In dense forests at heights of 3000 to $4000 \mathrm{ft}$. It is only this varjety which produces the tall arborescent plants spoken of by the naturalists of the U. S. E. E. It oceurs chiefly on Kauai!, but I have collected it also on most of the other islands.

r var. calycinum. - Low terrestrial, $1-3 \mathrm{ft}$. high. Leaves thin chartaceous, oblong or lanceolate, little smaller than in a, shortly dentate. Calycine lobes narrow lanceolate, acute. Otherwise as in $\alpha_{.}-V$. calycinum, Sm. and probably also $V$. dentatum, Sm.

On grassy slopes or open glades in forests of low elevation. In specimeus from W. Ma ui! we find the anthers shortly pointed at the base, but quite obtuse in exactly similar ones from Molokai!

ò var. - Habit and leaves of $\gamma$, but the calyx-lobes broad and rather ovately obtuse, shorter than their tube, almost as in V. reticulatum.

Hawaii! woods of Hilo and Hamakua.

2. V. reticulatum, Smith, in Rees, Cyclop. no. 30. - Don, Gen. Syst. III, $85 \%$ - A low erect shrub, 1-2 ft. high, the stiff crowded branches angular and densely foliose, puberulous when young. Leaves coriaceous, closely areolate, with nerves prominent on both faces, puberulous when young, on very short petioles of $1 / 4-1 / 2^{\prime \prime}$, oblong to obovate to suborbicular, ${ }^{3} / 4-1^{\prime} \times{ }^{1 / 2}-3 / 4^{\prime}$, obtuse, often rounded and mucronate, minutely and not closely callous-toothed, particularly toward the apex, often almost entire. Flowers solitary, mostly in the axils of true leaves, on puberulous erect or patent bractless pedicels of $4-8^{\prime \prime}$. Calyx soon glabrate, $2^{\prime}$, the ovate somewhat obtuse lobes shorter than the tube or as long. Corolla tubular urceolate, $3^{1} / 2-4^{\prime \prime}, 3-4$ times longer than the calycine lobes, shortly 5 -toothed, with teeth erect; reddish or greenish. Stamens half the length of the corolla, the anthers much longer than the filaments, quite obtuse at the protruding base, shortly 2-awned at the back, their divergent tubes exceeding the cells in length. Style as long as the corolla. Berry globose, $4-5^{\prime \prime}$, pale rose or yellow, covered with a waxy bloom. - Gray, 1. c. Wawra, 1. c. as to var. $\delta$ and $\zeta$. - V. cereum, Ch. \& Schl, in Linnaea, I, 527. (non Forst.) - Hook, Je. PI, tab. 87. - V. Macraeanum, Klotzseh, 1. c. 
High mountains of $\mathrm{Haw}$ a ii! and $\mathrm{E}$. Ma ui! from about 4000 up to $8000 \mathrm{ft}$, where it grows gregariously, often covering large tracts of open ground. Leaves generally oblong on the Maui plants and obovate on those from Hawaii. From the higher regions of both islands, as from the erater of Haleakala, comes a plant with spinulose leaves. M. \& B.'s no. 430 from the Central plateau of Hawail, with such leaves, has a corolla lobed to about $1 / a$ of its length. Apparently the same form, but with numerous sharp toothlets, was collected on the bare mountain ridge near the pali of Kalihi, Oahu!

The shining fleshy berry, the "Ohelo", famous in native song and as a propitiatory offering to the fire-goddess Pele, is the prineipal food of the wild mountain goose. Although astringent it is not unpleasant to the taste, and makes a good preserve. The species is nearly related to the Tahitian V. cereum, Forst.

$\beta$ var. lanceolatum, Gray. - Low decumbent, quite glabrous. Leaves linear-lanceolate, coriaceous, serrate. Calyx-lobes as above.

Swamps of Lehua makanui, Kau a i. - "Has the habit of V. penduliflorum", Wawra, 1. c.

\section{ORdER XLVI. EPACRIDACEAE.}

Calyx 5-, rarely 4-parted, permanent, supported by two or more bracts of the same shape and texture as its lobes. Corolla inferior, gamopetalous, the limb 5-, rarely 4-cleft. Stamens as many as lobes of the corolla and alternate with them; filaments free or adnate; anthers simple, spuriously 2-celled, but opening by a single line along their entire length. Ovary sessile, usually girt by 5 distinct or combined scales, several-celled. Seeds solitary or indefinite. Style 1; stigma entire. Fruit a drupe, berry or capsule. Seeds albuminous, with a slender straight embryo. - Shrubs or small trees with generally alternate entire leaves, confined to Australasia and Polynesia.

\section{CYATHODES, R. Br.}

Calyx deeply 5-cleft. Corolla tubular, with 5 patent or recurved lobes which are valvate in the bud. Stamens 5, adnate below the throat, enclosed or the anthers only exserted, the latter affixed at the back. Disk cup-shaped, 5-toothed. Ovary 5-10-celled, with one pendulous ovule in each cell. Fruit a fleshy drupe with a crustaceous 5-10-celled putamen. - Leaves striately veined. Flowers axillary, solitary, small, the short peduncles imbricate with bracts of the same shape and texture as the calyx lobes.

A small genus spread over Australia, New Zealand, the Society and Sandwich Islands. Leaves glabrous, with most nerves forking; tall shrubs or trees. 1. C. Tameiameiae. Leaves eiliate at the margins, the nerves all simple or only the outer pair dividing; Iow, often trailing shrubs .

2. C. imbricata.

1. C. Tameiameiae, Cham. in Linnaea, I, 539. - DC. Prod. VII, 741. - A much branching shrub, 4-6 ft. high, but in the upper regions often a small tree of $10-15 \mathrm{ft}$. with stiff erect branches. Leaves stiff coriaceous, erecto-patent, linear or oblong, $4-6^{\prime \prime} \times 1-2^{n}$, on broadish petioles of less than ${ }^{1 / 2} 2^{n}$, acute or somewhat obtuse, shortly mucronate, 
cuneate or somewhat obtuse at the base, naked, smooth above, waxy-white or glaucous underneath and striate with 9-13 longitudinal nerves which fork or branch more or less, particularly in the obovate leaves. Peduncle with flower shorter than the leaf. Bracts (5-9) and sepals obtuse, coriaceous. Corolla whitish, $1^{1 / 2}{ }^{\prime \prime}$, the tube included in the calyx, the acute lobes ${ }^{1 / 2}$ the length of the tube, with 5 lines of hairlets running down the tube. Anthers oblong obtuse, subexserted, about as long as their filaments; pollen 4-lobed. Disk small. Ovary 5-8-celled. Style as long as the ovary, thick, tapering. Drupe globose, $2-3^{\prime \prime}$ in diameter, red or white, rather dry. Seeds ovoid, with thin testa. Embryo axile, ${ }^{2} / 3$ the length of the mealy albumen, the radicle scarcely distinguishable from the taper cotyledons. - Gray, in Proc. Am. Ac. V, 325.

On all islands from $1800 \mathrm{ft}$, up to the limit of vegetation. Leaves obovate-oblong, thinly margined, white underneath, or green when growing under shade (O a h u !). Leaves linear, white or glaucous underneath (C. Banksii, Gaud.), the common form of Maui! Molokai! and Kauai! the first leaflets however always shorter and broader. The -Maieli or "Puakeawe of the natives, one of the most characteristic plants of the Islands, particularly of the higher mountain regions of Maui and Hawaii. The species exists also in Tahiti and Eimeo of the Society group.

$\beta$ var. Macraeana. - Leaves spreading, even deflexed, ovate or short ovate-oblong, $2-3^{\prime \prime} \times 1-2^{\prime \prime}$, obtuse, scarcely mucronate, white underneath, with faint nerves. Lobes of corolla naked, or ciliate only near the sinus. - var. Brownii, Gray. - C. Macraeana, DC.

Hawail! Kilauea.

2. C. imbricata, Stschegleew, in Mosc. Bull. XXXII, 10. - «Low upright or diffused. Leaves erect or appressed, ovate or lanceolate, $3-5^{\prime \prime} \times$ $1-1^{1} / 2^{\prime \prime}$, acuminate in a sharp cusp or awn, pectinately ciliate along the sharp margin, at least in its upper half, pale or glaucous underneath, prominently striate with 5-9 simple nerves, only the outer pair occasionally branching. Flowers twice as large as in the preceding species. Bracts and sepals ovate, obtuse or the latter somewhat acute, finely ciliate. Corolla $3^{\prime \prime}$, its tube included, the lobes densely bearded "inside. Ovary 6-celled. Style 2 or 3 times the length of the ovary. Drupe as before. - C. Douglasii, Gray, 1. c. - Descr. from Gray.

Higher regions of Mauna Loa, Mauna Kea and Haleakela (U. S. E. E. and Wawra).

$\beta$ var. struthioloides, Gray. - Stem slender, trailing on the ground, densely covered with prominent leaf scars, and with few assurgent branches. Leaves ovate, $2-3^{\prime \prime} \times 1-1^{1 / 2} 2^{\prime}$, closely imbricate, ciliate along the nerves as well as the margins, ending in a long yellowish awn. Peduncle with flower longer than the leaf, reflexed. Sepals acute. Corolla $1^{1 / 2}-2^{\prime \prime}$. Disk large, 5-lobed.

Swamps of Lehua makanui and summit of Waialeale, Kauai! (U. S. E. E., Kn., and Wawra). Top of Eeka, Maui! (Hbd.).

Hillebrand, Flora of the Hawaiian Islands. 


\section{Order XLVII. EBENACEAE.}

Flowers regular, usually dioecious. Calyx free, $3-5$-lobed, or rarely with 6 or 7 lobes. Corolla-lobes as many, imbricate in the bud. Stamens inserted at the base of the corolla or on the torus within it, numerous, usually about 15 in the male flowers, much fewer and sterile in the female; anthers erect, linear or oblong. Ovary free, 3- or more-celled, with 1 or 2 pendulous ovules in each cell. Styles as many or half as many as cells, distinct or more or less united, simple or 2-cleft, with small terminal stigmas. Fruit a fleshy or dry berry, usually indehiscent. Seeds albuminous; embryo axile, with a superior radicle and foliaceous cotyledons. - Trees or shrubs. Leaves alternate, entire, without stipules. Flowers axillary, the female often solitary, the male usually clustered or in small eymes.

A small tropical and subtropical Order.

\section{MABA, Forst.}

Flowers dioecious. Calyx cup-shaped, 3 -fid, permanent. Corolla campanulate, 3 -fid, the lobes convolute in the bud. Male $\mathrm{fl}$. Stamens 3-18, distinct or rarely connate, the anthers opening laterally. Ovary rudimentary. Fem. fl. Stamens none or imperfect and fewer than in the male fl. Ovary 3 -celled with 2 ovules or 6-celled with 1 ovule in each cell. Styles or style-branches 3. Fruit indehiscent, dry or fleshy, 6-1-seeded, the albumen sometimes ruminate. - Hard-wooded trees or shrubs. Flowers solitary or clustered on axillary nodes, small, subsessile.

About 60 species, natives of the tropies of both Worlds.

Leaves smooth on both faces; calyx hairy, with obtuse lobes . 1. M. Sandwicensis Leaves wrinkled on the upper face; calyx glabrous, with aeute lobes 2. M. Hillebrandii.

1. M. Sandwicensis, A. DC. Prod. VIII, 242. - A tree, 20-40 ft. high. Leaves distichous, distant, coriaceous, with hidden veins, pale elliptico- or ovato-oblong, $1^{1 / 2}-2^{\prime} \times{ }^{1 / 2}-1^{\prime}$, on petioles of $2-3^{\prime \prime}$, shortly acuminate, entire, glabrous, but silky-haired when young. Flowers single, rarely the male in clusters of $2-5$, the very short peduncle covered with about 6 small ovate-obtuse deciduous bracts. Calyx coriaceous, silky with stiff appressed hair, cupular, 2-2 $2^{1} 2^{\prime \prime}$, shortly $3-4$-fid with broad obtuse lobes. Corolla coriaceous, urceolate, $2^{1 / 2}-3^{\prime \prime}$, densely hairy in the upper half, 3-toothed with blunt connivent teeth or lobules which are sinistrorsely convolute in the bud. Male $f l$. Stamens free, 12-18, around the hirsute rudiment of an ovary, $1 / 3$ the length of the corolla, glabrous; the anthers short oblong, with a broad connective, as long as the filaments. Fem. $f l$. without stamens; the ovary hairy, with a very short 3 -rayed style. Fruit dry, ovoid, with chartaceous pericarp, about 
9 " high, pubescent when young, 3-celled, with 1 seed in each cell, but generally 1 -seeded when mature. Seeds oblong, with thin testa and smooth albumen. Cotyledons half the length of the radicle, complanate, oblong, obtuse. - Gray, in. Proc. Am. Ac. V, 327.

Oahu! Molokai! Lanai! Maui! Hawaii! Hilo. Nat. name: eLamas. The seeds are eaten by the natives.

B var. - Leaves ovate or ovate-oblong, broadiy rounded at the base, even emarginate, acute or somewhat obtuse, sometimes approximately orbicular, generally with some pubescence underneath, much larger than in $\alpha$.

Hawail! Kona and Kau, leaves $2-3^{\prime} \times 1-2^{\prime}$ on petioles of $3-4^{\prime \prime}$; Ka uai! Waimea, leaves $4-5^{\prime} \times 2-2^{1 / 2}$ : on petioles of $4-6^{\prime \prime}$.

2. M. Hillebrandii, Seem. in Fl. Vit. p. 151. - A tree of the same size as before. Leaves oblong, $3-5^{\prime} \times 2^{1 / 2}-2^{\prime}$, on petioles of $2^{\prime \prime}$, obtuse, moderately contracted or rounded, sometimes emarginate at the base, entire, glabrous, dark-green, coriaceous, smooth on the lower face, but deeply rugose on the upper by a close and fine net of areoles. Bracts and calyx glabrate, the latter $3^{\prime \prime}$, coriaceous, trifid almost to the middle with broad triangular acute lobes. Corolla $3^{1 / 2} 2^{\prime \prime}$, hairy, shortly 3-toothed. Stamens 9, short, glabrous, with pointed anthers. Fruit obovoid, pubescent at the apex only, $9-12^{\prime \prime}$ long.

Seattering on Oahu! particularly in the hills of Kahuku and Waialua, also in Makaleha and Niu.

\section{ORdER XLVIII. SAPOTACEAE.}

Calyx free, of $4-8$, usually 5 divisions or teeth. Corolla regular, divided into as many or rarely twice as many lobes. Stamens adnate, either equal in number to the lobes of the corolla and opposite to them, or twice as many, besides which there are often staminodia - sterile stamens alternating with the fertile ones, or petaloid scales alternating with the lobes of the corolla. Ovary superior, 2- or more-celled, with 1 ascending or pendulous ovule in each cell. Style simple, entire or slightly lobed. Fruit a berry or drupe, usually indehiscent. Seeds either with a fleshy albumen and foliaceous cotyledons, or without albumen and with fleshy cotyledons. - Trees or shrubs with milky juice. Leaves alternate, entire, usually coriaceous and without stipules. Flowers axillary, solitary or elustered.

An Order widely distributed over both Worlds within the tropies or not spreading far beyond them. To it belongs the Sapotilla Plum, Achras Sapota, L., and a Mexican Bumelia, both cultivated in gardens.

Corolla 5-Iobed, with staminodia within the sinuses of its lobes:

fruit large globose, with $5-2$ secds

Corolla 8-10-lobed, without staminodia; fruit olive-shaped, with generally 1 seed

1. Sideroxylon.

2. Chrysophyllum. 


\section{SIDEROXYLON, L.}

Calyx 5-6-parted, the lobes imbricate. Corolla tubular-campanulate, $5-6$-lobed, the lobes imbricate in the bud. Staminodia 5-6, either placed in the sinus of the corolla or more commonly in one row with the stamens. Stamens 5-6, opposite the lobes of the corolla, often retrorsely inflected in the bud, the anthers extrorse. Ovary 5- (4-2-)celled, with mostly a short style. Fruit a berry. Seeds $5-1$, with a shining hard testa and an oblique-basilar or linear lateral hilum or rhaphe, albuminous. Cotyledons broad foliaceous, radicle very short. - Milky trees with coriaceous parallel-veined leaves. Flowers in axillary clusters.

About 60 species, distributed between the tropics of both Worlds, a few species only occuring outside the tropics.

Pedicels 6-9"; lobes of calyx and corolla obtuse or rounded; filaments inserted at the bottom of the corolla

Pedicels $2-3^{\prime \prime}$; lobes of calyx and corolla somewhat acute; filaments inserted at the middle of the corolla

1. S. Sandwicensé.

1. S. Sandwicense. - Benth. \& Hook. Gen. Pl. II, 655. - A tall tree, $20-50 \mathrm{ft}$. high, conspicuous in forests by its reddish foliage, the young shoots and inflorescence covered with a rufous tomentum. Leaves coriaceous, obovate-oblong, $3-6^{4} \times 1^{1 / 2}-3^{\prime}$, on petioles of $1-1^{1} / 2^{\prime}$, equally rounded at both ends or contracted at the base, quite entire, glabrous on both faces, shining, the main veins prominent, straight and close, including elongate areoles and connected by a continuous intramarginal nerve. Flowers in elusters of $2-4$, on naked pedicels of $6-9^{\prime \prime}$. Calyx tomentose, coriaceous, 5-parted to near the base, 3", the broad lobes obtuse or rounded ( 2 ext., 3 int.). Corolla reddish, as long as the calyx, tubular, 5-parted to the middle, the lobes obtuse, erect (1 ext., 1 int.). Staminodia linear-lanceolate, shorter than the lobes but veined like them, with a faint not decurrent nerve, inserted before the sinus. Stamens 5 , enclosed, inserted near the base of the corolla, hairy below; the anthers erect, ovate, scarcely sagittate, bluntish, their cells confluent at the apex and opening laterally. Ovary hirsute with stiff hairs, 5-celled, with 1 ascending ovule in each cell. Style short conical, grooved at the apex. Berry globose, depressed, $1^{\prime}$ in diameter, rather dry, 5-1-seeded, drupaceous, each seed enclosed in a thin chartaceous pyrena, 9" long, elongatecompressed when many, rather ventricose when single or few, the crustaceous testa fawn-colored and shining, the elongate scar of the rhaphe oceupying nearly the whole ventral angle. Cotyledons nearly as long and broad as the albumen, the minute radicle inferior. - Sapota Sandwicensis, Gray, in Proc. Am. Ac. V, 328.

Kauai! Oahu! Molokai! W. Maui! Rare on Oahu, but frequent on Molokai and W. Maul. The =Aulu or saulus of the natives, who use the thick milk-sap as bird-glue. The fruit, of the size of a crab-apple, is dry and insipid, but rarely met with, 
perhaps on account of dimorphism in the flower, the stigma having been found peaked, tapering in all flowers examined.

$\beta$ var. auratum. - Leaves densely ferruginous underneath, even when old, as are also calyx and corolla. Flowers generally single.

Dry fore-hills of Molokai! and Lanai!

2. S. spathulatum, $s p \cdot n$. - A emall stiff-branched tree or shrub, $8-12 \mathrm{ft}$. high. Leaves spathulate or elliptico-oblong, $1^{1} / 2-2^{\prime} \times{ }^{3 / 4}-1^{\prime}$, bluntly acuminate, contracting into a margined petiole of $6-9^{\prime \prime}$, rustytomentose underneath, thick coriaceous, with the veins little prominent. Flowers single or in clusters of $2-3$, on short pedicels of $1-2^{\prime \prime}$. Calyx and corolla rusty-tomentose, $2^{\prime \prime}$ high, their lobes somewhat acute. Stamens inserted at the middie of the corolla, at the base of the lobes, the short filaments slightly reflected, not hairy below, the anthers apiculate. Staminodia or corollar appendages broad, half the width of the lobes. Ovary hairy, with short style. Fruit not seen. - Sapota Sandwicensis, var. $\beta$, Gray.

Lanai! in the scrub of the open plateau on the leeward side; Hawail?

$\beta$ var. densiflorum. - Leaves larger, 3'long, generally glabrous when old. Flowers in clusters of $4-6$ in the axils of the upper closely set leaves, on pedicels of $2^{\prime \prime}$, completely covering the end of the branch.

Dry leeward slope of Mt. Kaala, Oahu!

\section{CHRYSOPHYLLUM, L.}

Calyx and corolla 5- $(6-7$-) parted, imbricate. Stamens as many as lobes of the corolla and opposite to them, in a single row, the anthers opening outside or laterally. Staminodia none. Ovary hairy, 5- (6-10-) celled, each cell with 1 ovule affixed to the middle or base of the axis. Berry fleshy or coriaceous. Seeds several or single, with a shining or opaque testa and an elongate lateral hilum. Cotyledons thin foliaceous in copious albumen or thicker in scanty albumen. - Milky trees with thick penni-nerved leaves without stipules; the small flowers in axillary fascicles or on prominent nodes.

A genus of 60 species, chiefly of tropical America, a few inhabiting Africa and still fewer tropical Asia, with the following single species from Polynesia. - The species which I refer here disagrees with the character of the genus, as condensed from Benth. and Hook. Genera Plant., in various not unimportant details, which however may not appear irreconcilable on a revision of the genus. The calyx is often 4-merous, the lobes of the typieal corolla are double the number of the sepals, the testa of the seed is thick osseous and has an oblique basal hilum.

1. C. Polynesicum, sp. n. - A small tree, $10-15 \mathrm{ft}$. high, with rugose cinereous stiff branches, the young leaves and inflorescence rusty-tomentose. Leaves scattering, oblong or obovate, $2-4^{\prime} \times 1-2^{\prime}$, on petioles $1 / 2-1^{\prime}$, entire, rounded or emarginate at the apex, thick coriaceous, with in- 
conspicuous veins, glabrate with age. Flowers on axillary gemmules of late and on prominent nodes of older leafless growths, $3-6$ in a cluster, on pedicels of $2-3^{\prime \prime}$ which are shortly bracteate at the base. Calyx persistent, coriaceous, deeply 4-5-parted, the lobes broadly ovate, obtuse, with scarious margins, 2 ext. and 2 or 3 int. Corolla a little longer than the calyx, $2-2^{1} / 2^{\prime \prime}$, urceolate, at length rotately expanded, pale reddish, deeply divided to near the base into twice as many lobes as the calyx, the lobes ovate-oblong, obtuse, imbricate-convolute in the bud, one or two often smaller, the larger ones semi-auriculate. Staminodia none. Stamens inserted at the base of the corolla, as many as lobes, slightly exserted; the filaments complanate subulate, contiguous with their dilated bases, extrorsely inflected or geniculate near the apex in the bud; the anthers much shorter, sagittate, with cells confluent at the apex and opening outside. Ovary hairy, 4- (5-)celled. Style angular, obliquely truncate or recurved, as long as the filaments. Fruit a rather dry and black olive-shaped berry (?) with a thin papery endocarp (?), about $7^{\prime \prime}$ long, 1 -, rarely 2 -seeded, the single seed ovoid, with a thick bony and shining pale brown testa, ascending from the base, the hilum obliquely basal, leaving a broad and roundish deep scar. Embryo axile, the cotyledons oblong obtuse, foliaceous, as long and broad as the albumen, the radicle very short, inferior.

On dry fore-hills of Lanai! rather common; Molokai! Kalae and Maunaloa; Oahn! Wailupe, Makaleha (leaves large oblong, pedicels of fruit 5-6"). Nat. name: - Keahi . Flowers and fruit are abundant in nearly every axil, the former on the youngest shoots and both flowers and fruit on the older leafless portions. In many corollae one or two of the inner lobes are reduced in size and may at first view be mistaken for staminodia, particularly as their respective stamens are often imperfect and even wanting when the lobes are very small. The fruit has little flesh and a thin endocarp composed of longitudinal fibres. In its dried state $4-5$ faint ridges or lines become manifest on one side, which correspond to slight grooves in the testa, and these are determined in their position by 3-4 minute canals which appear on a cross section in the ventral side of the bere generally thicker osseous testa. The canals contain a white mealy substance, and probably are the remnants of aborted ovules which have become consolidated with the testa of the maturing seed, in the manner of Argania; yet in the single instance of a 2-seeded fruit both seeds were free from each other, not separated by any dissepiment. Here also it deserves to be noted that the hilum of the twin seeds is more elongate, partly lateral. As my specimens only hold mature fruit and quite young flowers, besides buds, I have not been able to follow up the early relations between ovary and ovules.

\section{ORdER XLIX. MYRSINACEAE.}

Flowers hermaphrodite or polygamo-dioecious. Calyx and corolla divided into 4-7 lobes. Stamens as many as lobes of the corolla and opposite to them, adnate to the base of the tube, the filaments very short, the anthers 2-celled, erect, introrse. Ovary generally free, 1-celled, with a free central placenta, Style simple. Fruit an indehiscent berry or drupe. Ovules campylotropous. Embryo transverse in fleshy albumen, the radicle 
longer than the cotyledons. - Trees or shrubs with alternate simple or toothed leaves without stipules. Flowers small, generally in axillary. clusters or racemes.

A large Order, widely distributed over the tropical and subtropical regions of both Worlds, nearly allied to Primulaceae, and representing that order within the troples.

Flowers in axillary clusters; filaments free . . . . 1. Myrsine.

Flowers in racemes; filaments adnate

\section{MYRSINE, L.}

Calyx persistent, 4-6-lobed. Corolla deeply 4-6-parted, the lobes generally imbricate in the bud. Anthers longer than the short filaments, lanceolate, opening lengthwise. Ovary free. Style short, with a capitate or fringed stigma. Ovules many or few, peltately affixed to the swollen apex of the placenta. Drupe small globose, with crustaceous putamen, the single seed impressed at the base and partly covered by the remnants of the placenta. Embryo elongate, cylindrical, often curved. - Shrubs or trees. Leaves entire, rarely toothed. Flowers mostly polygamous, small, on short pedicels in dense axillary clusters, bracteate at the base.

A considerable genus, spread over the tropical and subtropical regions of the whole World and found in most island groups of the Pacific.

The corolla in the Hawaiian species is deeply divided to the base, so that its lobes soon separate from each other like free petals and fall off early; but they are certainly imbricate in the bud, quincuncial, viz., 1 external and 1 internal, the others so slightly overlapping that they appear almost valvate. Of the 4 ovules which the ovary holds one only attains maturity. The trees are conspicuons in spring and early summer by the roseate hue of the new leaves; their wood is bright yellow. The sexual differences in the style and stamens of fertile and sterile flowers have not been fairly made out; for that reason, and also on account of the smallness of the flowers, it does not appear safe yet to take leading specific characters from those organs.

Leaves thick opaque, euneate at the base:

Leaves large, 2 or more; drupes reddish

Leaves small, 1 or less; drupes black.

1. M. Lessertiana.

4. M. Sandwicensis.

Leaves thinner, semitransparent, with an obtuse base and distinct petiole :

Leaves tomentose, dotted, with a distinet marginal nerve, emarginate at the base; drupes globose ovoid; corolla puberulous

Leaves glabrous, not dotted, without marginal nerve; drupes globose, depressed; corolla glabrous

2. M. Kauaiensis.

3. M. Lanaiensis.

1. M. Lessertiana, A. DC. Prod. VIII, 96. - A tree, 20-50 ft. high, with a rough tuberculate bark. Leaves crowded at the ends of the branches, thick coriaceous, opaque, the veins little prominent and connected by a continuous straight marginal nerve, glabrous on both faces, lanceolate or elliptico-oblong, acute at both ends, quite entire, gradually merging in a short petiole, $3-6^{4} \times{ }^{3} / 4-2^{1} / 2^{\prime}$. Flowers in the axils of the oldest leaves and on projecting spurs of the bare branches, in fascicles of $3-7$, the pedicels $3-5^{\prime \prime}$, supported at the base by short bracts. Calyx deeply 5-7-parted, the lobes somewhat acute (slightly ciliate at the apex DC.). Corolla $1^{1 / 2}-2^{n}$, twice the length of the calyx, yellowish, with 
reddish dots, thin, deeply divided into $5-7$ lanceolate lobes or petals. Stamens litte shorter than the petals, the broad ovate anthers emarginate at the base. Ovary with $3-4$ ovules. Stigma on a short style, capitate, on the fruit 5-laciniate or fimbriate. Drupe dry, globose but pointed, $2-3^{\prime \prime}$, reddish, with a chartaceous pyrena and a single round seed. Gray, in Proc. Am. Ac. V, 331. - M. Gaudichaudii, forma acuminata, Wawra, in Flora, 1874, p. 523. - (Specim. Gaud. ex itinere Bonite.)

Oahul from 2000 to $3500 \mathrm{ft}$., common on Konaliuanui; Maui, Kula. Wawra's $M$. Lessertiana from Halemanu, Kauai, may belong here. - The natives call this and the 2 following species eKoolean; from the bark they extracted a red dye.

$\beta$ var. - Leaves obovate, obtuse, rounded or shortly acuminate, almost sessile, $3-8^{1} \times 1-2^{1} / 2^{\prime}$. Fascicles of $4-10$ flowers; the pedicels short, $3-2^{\prime \prime}$, rarely $1^{\prime \prime}$ only. Lobes of calyx somewhat acute, or obtuse. Gray, 1. c. - M. Gaudichaudii, DC. 1. c. (specim. ex itinere Freycinet).

The common form on Maui! and Hawaii! seattering on Oahu!. In Wawra's $M$. Gaudichaudii from Waiolani, $\mathrm{O}$ ahu, the fascicles held 20-30 probably sterile flowers on petioles of $4-5^{\prime \prime}$. Calyx and corolla were sparingly ciliate, the latter 3 times the length of the former, the anthers pointed with a ciliate beak, while the ovary bore a subsessile membranous peltate stigma.

2. M. Kauaiensis, $s p \cdot n$. - A small tree, about $12 \mathrm{ft}$. high, with slender branches, the flowers rameal, below the leaves. Leaves pubescent underneath when young, glabrate but papillose when old, chartaceous, with numerous transparent minute dots, elliptico- or obovato-oblong, somewhat obtuse or shortly acuminate, entire, or faintly and remotely crenulate near the end, rounded, even emarginate at the base, $2-3^{1} / 2^{2} \times{ }^{3} / 4-1^{1} / 2^{1}$, on petioles of $2^{\prime \prime}$, the veins little prominent, minutely areolate, with a sinuous marginal nerve. Flowers on salient bracteate gemmules, in fascicles of $5-7$, the linear scarious bracts $1-1^{1 / 4} 4^{\prime \prime}$, the pedicels $2-3^{\prime \prime}$. Calyx puberulous, with $5-6$ somewhat obtuse lobes. Corolla puberulous, $1^{1 / 2^{\prime \prime}}$, scarcely twice as long as the calyx, whitish, dotted, the lanceolate lobes free to the base. Stamens as long as the corolla, their anthers sagittate-acute. Stigma sessile, broad obconical, truncate and radiate, excavated at the top. Ovary 4 -ovulate. Drupe globose ovoid, $2^{n}$.

Kauai! Waimea (Kn, 191).

$\beta$ var. hirsuta. - Young branches and inflorescence covered with a thick brown tomentum. Leaves larger, $4-5^{1} \times 2-2^{1} / 2^{4}$, thick chartaceous, with tomentose rib, prominent veins and a straight marginal nerve, rounded or obtuse at the base, on distinct petioles of $4-5^{4}$. Flowers numerous on pedicels of $5^{\prime \prime}$. Calyx and corolla tomentose. Drupes $3^{\prime \prime}$ in diam. - M. Gaudichaudii, var. hirsuta, Wawra.

In Wawra's plants the clusters held up to 50 flowers, and the stigma is described as cylindrical, excavated.

High plateau of Kauai! (Wawra, and Kn. 124). 
3. M. Lanaiensis, $s p . n$. - Shrubby, $8-12 \mathrm{ft}$. high, glabrous throughout, the bark of the rather stiff branches densely covered with lenticels. Leaves elliptico- or obovato-oblong, $3-3^{1} / 2^{\prime} \times 1^{1 / 4}-1^{3 / 4^{\prime}}$, equally but moderately acuminate at both ends, on distinct petioles of 3 ", pale, dull, membranous to chartaceous, not dotted, with large areoles and without marginal nerve, the veins uniting by irregular sinuous anastomoses. Flowers rameal and in the axils of leaves, on salient bracteolate gemmules, $5-8$ to each, on pedicels of $2-3 "$. Calyx 4-6-parted, the obtuse lobes dotted. Corolla $2^{\prime \prime}$, three times the length of the calyx, yellowish-brown, dotted and striate, parted to the base into lanceolate acute lobes or petals. Stamens about half the length of the corolla, the anthers sagittate. Stigma capitate on a very short style. Drupe globose, depressed, $2^{1 / 2}-3^{\prime \prime}$, reddish, with chartaceous putamen, 1-seeded with the rudiments of 2 or 3 ovules. Embryo arcuately curved in horny albumen.

Lanai! in the scrub of the fore-hills.

4. M. Sandwicensis, A. DC. 7 . c. - A much branching shrub, $4-8 \mathrm{ft}$. ligh, the young branches and the inflorescence puberulous. Leaves scattering, obovate or spathulate, $7-12^{\prime \prime} \times 3-5^{\prime \prime}$, rounded or emarginate, quite entire, the cuneate base passing into a margined petiole of $1-2^{\prime \prime}$, coriaceous, with hidden veins, quite opaque, rugose underneath, glabrous. Flowers all in axils of leaves, $3-7$ in a cluster, on not protruding gemmae, the pedicels $2-3^{\prime \prime}$. Calyx pubescent, $4-5$ parted, with ovate lobes. Corolla pubescent, 4-parted to near the base, scarcely twice as long as the calyx, $1^{1 / 2} / 2$ ", yellowish, with red streaks, the lobes ovato-lanceolate. Stamens $1 / 2$ as long as the corolla. Stigma subsessile, obconical, fimbriate or radiate. Drupe black, globose or ovoid, $1^{1 / 2}-2^{\prime \prime}$; one half of the single seed covered with remnants of the placenta. Albumen horny. - Gray, l. c. - Wawra, l. c.

In forests of mean elevation, on all islands.

$\beta$ var. denticulata. - Low, $2 \mathrm{ft}$. high. Leaves oblong-lanceolate, only $2^{\prime \prime}$ broad, acute, sharply denticulate toward the apex. - Wawra, l. c.

Platean of Waialeale, Kauai.

\section{EMBELIA, Burm.}

Calyx free, deeply 4-5-lobed. Petals $4-5$, distinct, or cohering at the base, spreading, imbricate in the bud. Stamens as many, inserted at the base of the petals, not longer than these, with accrete filaments and short anthers which open lengthwise. Ovary superior, with $1-4$ ovules on a globose placenta. Style short; stigma capitate or slightly lobed. Fruit a globose drupe with a single seed which is attached and partly excavated at the base. Embryo transverse, curved in smooth or wrinkled 
albumen. - Shrubs or woody climbers. Flowers small, in simple or branched racemes, either axillary or forming a terminal panicle.

About 55 species, belonging to tropical Africa, Asia and Australia, New Caledonia and the Hawaiian Islands.

1. E. pacifica, $s p . n$. - A straggling shrub, oceasionally twining, the wide-spreading divaricate branches tuberculate with lenticels. Leaves membranous, closely and minutely papillose on both faces, rarely pubescent, obovate or elliptico-oblong, $2-3^{1} / 2^{\prime} \times 1-2^{\prime}$, on distinct petioles of $2-5$ ", rounded or bluntly acuminate, quite entire. Flowers in axillary racemes of $1^{1 / 2}-3^{\prime}$, on pedicels of $3-4^{\prime \prime}$ which are bracteolate at the base. Calyx persistent, deeply $4-5$-parted into ovate lobes. Petals $4-5$, discreet, 2 or 3 times the length of the calyx, about $2^{\prime \prime}$, greenish, densely papillose or puberulous like the ealyx, spreading. Stamens $1 / 2$ the length of the petals, the short filaments entirely adnate; the ovoid anthers affixed at the base. Ovary ovoid, the central placenta stipitate, 3-ovulate. Stigma capitate on a short style. Drupe globose, depressed, 4-5" transversely, dryish, with a chartaceous putamen. Seed solitary, peltately affixed, with a loose and thin testa. Albumen smooth, horny. Embryo straight, transverse across the entire breadth of the albumen, cylindrical, the radicle much longer than the short cotyledons.

Lanai! not unfrequent; Maui! Kaanapali, and slopes back of Lahaina, Ulupalakua; Oahu! Wailupe. - M. \& B. no. 448. - Hawaii, Laupahoehoe.

Jacquinia aurantiaca, Ait. is eredited to the Sandw. Islands in DC. Prod. VIII, 150, but most probably erroneously. It was supposed to have been collected by Menzies in 1796. The genus Jacquinia is entirely confined to America and easily to be distinguished from Myrsine and Embelia by the monopetalous corolla, which is furnished at the sinuses with sterile staminodial appendages, in the manner of Sapota, the fruit being a berry with several small angular seeds.

Cultivated plants of this Order are several species of Ardisia.

\section{ORder L. PRIMULACEAE.}

Calyx usually of 5, sometimes of 4,6 or 7 divisions or teeth, free, rarely adherent to the ovary. Corolla regular, more or less divided into as many lobes or teeth as divisions of the calyx, or rarely wanting. Stamens as many as lobes of the corolla, inserted in the tube opposite the lobes; the anthers introrse, opening lengthwise. Ovary 1-celled, with 1 or more ovules attached to a free central placenta. Style simple, with a capitate stigma, Fruit a capsule. Seeds albuminous, with a straight axile embryo. - Herbs or rarely shrubs. Leaves simple, entire or toothed, without stipules. Flowers axillary or terminal.

A widely spread Order, inhabiting chiefly the northern hemisphere and high mountains.

\section{LYSIMACHIA, L.}

Calyx deeply 5-6-9-cleft, free. Corolla rotate or campanulate, deeply 5-9-lobed, the lobes convolute. Stamens with short filaments and ob- 
long obtuse anthers. Ovules mostly numerous, hemitropous on a globose central placenta. Capsule opening from the top into $5-10$ valves. Seeds small orbicular-angular, with a thin testa and a transverse embryo. Herbs, rarely shrubs, with opposite, whorled or alternate entire leaves. Flowers usually yellow or pink, rarely purple or blue, solitary and axillary, or collected into terminal racemes, umbels or corymbs.

A considerable genus, with a wide range in the northern hemisphere and a few species only in Southern Africa, America and Australia.

Flowers large, purplish, axillary, single:

Leaves petiolate; corolla reddish-purple:

Flowers in the axils of foll-sized leaves:

Leaves pale, lanceolate, on short petioles, generally glabrous 1. L. Hillebrandi.

Leaves pale, linear, 1-nerved

Leaves dark, elliptico-oblong, on long petioles, brown-tomen-

tose underneath
Flowers in the axils of reduced leaves; leaves ovate or orbienlar

4. L. Remyi.

2. L. Lydgatei.

3. L. rotundifolia.

Leaves broadly sessile; corolla bluish-purple

Flowers small, yellowish, in terminal racemes

5. $L$, daphnoides.

6. L. spathulata.

1. L. Hillebrandi, Hook. f. - Gray, in Proc. Am. Ac. V, 328. - A handsome shrub, 3-4 ft. high, diffusely branching, the branches slightly ferrugino-tomentose at their ends. Leaves mostly alternate, glabrous, pale, coriaceous, the little prominent veins and alveoles united in an intromarginal nerve, lanceolate, $1-1^{3} / 4^{\prime} \times 2-6^{\prime \prime}$, acute at both ends, on petioles of $2^{\prime \prime}$. Flowers solitary in the axils of full-sized leaves, $4-6$ to a branch, on erect or nodding naked pedicels of about 1'. Calyx green, glabrous, about $1 / 2$ the length of the corolla, equalling the capsule, parted to near the base into $5-7$ ovate acute lobes which are contorted in the bud. Corolla urceolate to campanulate, $6-7$ "long, reddish-purple, with darker veins, the tube very short, $1-1^{1 / 2} 2^{\prime \prime}$, with $5-7$ broad obovate lobes. Stamens ${ }^{1 / 2}$ the length of the corolla or little more, the filaments dilated at the base and subconnate, the anthers erect basifixed. Style nearly as long as the corolla. Capsule ovoid, smooth, crustaceous, breaking from the style at the top into $5-7$ valves. Seeds numerous, black, peltately affixed to a thick placenta, the ventral side angular-conical, the dorsal side flat. - Wawra, in Flora, 1874, p. 521 (in part).

$\mathrm{O}$ ahu! on bare mountain ridges of Kalihi and Manoa. Nat, name: :Puahekili,

$\beta$ var. subherbacea. - Prostrate, $1^{1 / 2}-2 \mathrm{ft}$. high, with elongate branches, glabrate. Leaves distant, all alternate, longer acuminate, $2-3^{\prime} \times 4-6^{\prime \prime}$. Pedicels $11^{1 / 2}-3$. Lobes of calyx and corolla $5-6$. Capsules $4^{\prime \prime}$ long, chartaceous.

Gulch of Halawa, Molokai! among pebbles alongside the stream.

ivar, - Tall, erect, $5-8 \mathrm{ft}$. high, the elongate branches and peduncles ferruginous. Leaves distant, alternate, opposite and ternate, obovateoblong, $2^{1 / 2}-3^{\prime} \times 1^{\prime}$, suddenly acuminate from a broad apex, obtuse 
or subtruncate at the base, the lower ones on petioles of $1^{\prime \prime}$, slightly pubescent. Flowers as in $\alpha$. Capsule 5 "long and almost woody.

Molokai! pali of Pelekunu, and smaller forms, quite glabrate, with subsessile leaves from Maunahui; E. Ma ui! Haleakala; at heights of 3000 to $4000 \mathrm{ft}$.

$\delta$ var. venosa. - "A diffusely branching shrub, $3 \mathrm{ft}$. high, glabrous, with virgate fistular branches. Leaves patent, thin chartaceous, of variable size, the largest $4 \times 2$, oblong or obovate-oblong, drawn out into a long and very acute point, narrowing into a short petiole or sessile, bright green, glossy, pale underneath, with prominent nerves and alveoles. Pedicels $1^{1} / 2^{\prime}$. Lobes of calyx lanceolate, $6^{\mu}$. Corolla roseate-purplish, $12^{\prime \prime}$. Capsule small. - A plant of striking beauty for its bright green foliage and large showy flowers.» - Wawra, 1. c. p. 523.

On the top of Waialeale, Kauai! (6000 ft.).

2. L. Lydgatei, $s p . n$. - A spreading shrub, $3-4 \mathrm{ft}$. high, the decumbent branches angular or fluted, covered with a ferruginous tomentum. Leaves alternate, on long petioles of $6-8 "$, coriaceous, pubescent and dark-green on the upper, brown-tomentose on the lower surface, ellipticooblong, $1^{1 / 2}-2^{\prime} \times 3 / 4-1^{\prime}$, cuspidato-acuminate, suddenly contracting at the base. Pedicels short, $1 / 2-1$ '. Capsule thick woody, glossy inside, 6-valved. Flowers not collected.

Maui! on slopes and in gulches back of Lahaina.

3. L. rotundifolia, sp. $n$. - Erect, 5-7 ft. high, the young branches and inflorescence slightly rufous. Leaves alternate or suboppositê, broadly ovate or suborbicular, cuspidato-acuminate, entire, subcoriaceous, with marginal nerve, dark-green, glabrous on both faces, $1^{1 / 2^{\prime}} \times 1-1^{1 / 4^{\prime}}$, on petioles of $2-3^{\prime \prime}$. Flowers $5-7$, in a terminal raceme or in the axils of the uppermost reduced bracteaeform leaves, on pedicels of $3 / 4-\mathrm{i}^{\prime}$. Calyx $1 / 2$ the length of the corolla, glabrate, parted to the base into $7-9$ ovate-acute lobes. Corolla reddish-purple as in no. 1, cup-shaped, $5-6^{4}$ high, deeply divided into $7-9$ obovate lobes. Stamens nearly equalling the corolla.

Oahu! Nuranu. The inflorescence is not a genuine raceme, for the innovation of the branch starts from the terminal or uppermost axillary bud, as in $L$. daphnoides, yet the supporting leaves are smaller than the rameal ones.

4. L. Remyi, Hillebr. - Low prostrate, 1-2 ft. high, glabrate. Leaves crowded, alternate, binate or ternate, pale, linear, $1-1^{1 / 2} 2^{\prime} \times 1 / 2-1^{\prime \prime}$, acute at both ends, subsessile, costate, the veins hidden. Flowers solitary in the axils of the uppermost full-sized leaves, on erect pedicels of about 1 ', corymbosely spreading at the ends of the branches. Calyx and corolla divided into $6-7$ lobes, those of the former glabrate, acute. Corolla $4-6^{\mu}$ long, otherwise as in no. 1. Capsule crustaceous, small, globose-ovoid, 
peaked, $2-2^{1} / 2^{\prime \prime}$. Seeds small triquetrous, $-L$. Hillebrandi, var. angustifolia, Gray, 1. c. p. 329.

Ma ui! Haleakala, Waihee, Waiehu; Molokai! Halawa, Waikolu. Collected also by Remy.

5. L. daphnoides, Hillebr. - Stem 1--3 ft, high, erect, undivided, naked below and rough with permanent leaf-scars, densely foliose near the end and tomentose with rufous wool, as are the peduncles. Leaves thick chartaceous, dark-green, erect, alternate or almost binate or ternate, spathulate to obovate-oblong, $1^{1 / 2}-3^{\prime} \times 1 / 2-1^{1} / 4^{\prime}$, shortly acuminate, sessile with a broadish base, papilloso-pubescent underneath or glabrate. Pedicels $1-2^{\prime}$, nodding, thickened at the end when with fruit. Calyx glandularpubescent, half the length of the corolla or more, parted to the base into 6-7 narrow lanceolate sepals. Corolla large, 9-10", divided into as many obovate lobes as the calyx, dark bluish purple when dry (with a white border when fresh). Capsule 5", lignescent. - L. Hillebrandi, var. daphnoides, Gray, and Wawra, I. c. - Mrs. Sinclair, pl. 27. -Flowers sweet-scented.

Kauai! in thel bogs of the high platean above Waimea, which derives its name from the native name of the plant, "Lehua makanoev. (Kn.). Mrs. Sinclair has the native name solokolo kuahiwi. (mountain-creeper).

6. L. spathulata. - Benth. \& Hook. Gen. Pl. II, 635. - A perennial herb with a lignescent base, the erect stem not exceeding a couple of inches, thickly foliose at the top and sending off a number of elongate horizontal simple or sparingly divided branches which are loosely foliose and end in flowering racemes. Leaves alternate, fleshy, glabrous or papillose undemeath, spathulate, $1^{1} / 2-2^{\prime} \times{ }^{1 / 4}-1 / 2^{\prime}$, inclusive of the rather long petiole into which the base gradually runs out, shortly acuminate, entire, the upper rameal leaves gradually reduced to bracts. Raceme $2-3$ ' long when in fruit. Flowers single in the axils of the bracts, the lowest on angular pedicels of $1-2^{\prime \prime}\left(3-6^{\prime \prime}\right.$ when with fruit). Sepals free to near the base, imbricate, ovate to lanceolate, acute and strongly keeled, half the length of the corolla, punctate. Corolla thin, greenish-yellow, $3-3^{1 / 2}$ ", parted two thirds of its length into 5 obovate-oblong lobes. Stamens free from each other, inserted at the base of the lobes, enclosed, the anthers affixed at the back, introrse. Style as long as the stamens, with punctiform stigma. Capsule crustaceous, ovoid, $3^{\prime \prime}$, opening with 5 short teeth. Seeds numerous, small, angular-convex. - Lubinia spathulata, Vent. DC. in Prod. VIII, 60. - Lysimachia lineariloba, Hook. \& Arn. in Bot. Beech. p. 268. - DC. in Prod. VIII, 61. - Gray, 1. c. - L. lubinioides, Sieb. \& Zuccar.

Near the senshore; Hito, Hawaii (U. S. E. E.); Maui and Nilha u (Remy); Waikolu, Molokai! (Hbd.). - The plant has been collected also on the Marianne, Loo Choo and Bonin Islands, and in Japan (but not in Bourbon as is erroneously stated in the Prodromus).- - 
We have referred our plant according to the weighty opinion of the authors of the Genera Plant. It has to be remarked, however, that to Lubinia are attributed a salver-shaped corolla, with stamens adnate to the middle of the tube, and axillary flowers, to Lysimachia lineariloba linear obtuse corolla-lobes. Keeled sepals are not mentioned in the description of either of those speeies.

\section{ORdER LI. PLUMBAGINACEAE.}

Calyx tubular, plaited, often enlarged and scarious or petal-like at the top, persistent. Corolla gamopetalous with a narrow angular tube, or of 5 free petals with long narrow claws. Stamens 5, opposite the petals or lobes of the corolla, epipetalous or hypogynous. Ovary superior, of 5 valvate carpels, 1-celled, with 1 suspended ovule. Styles 5, distinct, or united at the base. Fruit an indehiscent utricle or irregularly opening capsule. Seed albuminous. Embryo axile, straight; radicle superior. Small shrubs or herbaceous plants with alternate simple leaves. No stipules. Flowers in terminal heads, spikes or panicles.

A small Order extending over the greater part of the world.

\section{Plumbago, Tourn.}

Calyx tubular, 5-ribbed, 5-toothed, herbaceous, covered with stipitate glands. Corolla monopetalous, salver-shaped, the tube longer than the calyx, the limb 5-lobed with lobes convolute in the bud. Stamens hypogynous, rising from a lobed disk. Style with 5 filiform branches. Utricle membranous, torn at the base. - Shrubs or perennial herbs. Flowers in long terminal spikes, tri-bracteate.

A small genus, distributed over the Mediterranean countries, South Africa, Asia and America. In cultivation: $P$. Capensis, $P$, coccinea, $P$. coerulea.

1. P. Zeylanica, L. - Boissier, in DC. Prod. XII, 692. - A low straggling shrub with grooved branches. Leaves thin, glabrate, ovate or oblong, $1-2^{\prime} \times 1^{\prime}$, shortly acuminate, broadly rounded at the base, on short $\left(2-4^{\prime \prime}\right)$ clasping and auriculate petioles. Spikes $3-4^{\prime}$, loosely flowered, glandular-viscid. Bracts ovate-acuminate, $1 / 3$ as long as the calyx, the lowest one largest. Calyx $4-5 "$, with several rows of stipitate glands along the strong ribs. Corolla pale blue, the tube twice as long as the calyx, the lobes ovate, shortly acuminate. Utricle elongate, attenuate at both ends, 5 -grooved at the top.

Common in the lower plains and lava fields. Nat. name: slieon. - The acrid juice of the plant is considered poisonous, and used to be employed like that of Sisyrhynchium acre for black tattooing. - The species extends from the W. coast of tropical Africa through India and Australia into Polynesia.

\section{ORDER LII. GENTIANACEAE.}

Sepals 4 or 5 , rarely more, usually united into a lobed or toothed calyx. Corolla usually regular, with as many lobes as sepals, contorted in the 
bud. Stamens as many as corolla-lobes and alternate with them, or rarely fewer, inserted in the tube. Ovary 1-celled, but with 2 parietal placentas often projecting into the cavity so as to partially divide it into 2 or 4 cells. Ovules numerous. Style single, entire or shortly 2-lobed. Fruit a capsule opening septicidally into 2 valves, or an indehiscent berry. Seeds small. Embryo cylindrical in fleshy albumen. - Herbs or shrubs, usually glabrous and bitter. Leaves opposite, entire, often 3- or more-nerved at the base, without stipules. Flowers usually in cymes.

An Order chiefly abundant in the temperate or mountainous regions of the northern hemisphere, with a few tropical or southern species.

\section{ERYTHRAEA, Pers.}

Calyx tubular, 5-4-parted into narrow keeled lobes. Corolla funnel-or salver-shaped, with a slender tube and a 5-4-parted limb which in withering twists round the pod. Anthers erect, exserted, twisting spirally. Style slender; stigma bilamellate. Capsule 2-valved, 1- or incompletely 2-celled, with 2 spongy placentas. - Erect herbs with angular stems and often connate leaves. Flowers in terminal dichotomous cymes.

A small genus, spread over the temperate regions chiefly of the northern hemisphere.

1. E. sabaeoides, Gray, in Proc. Am. Ac. VI, 41. - A glabrous erect annual, about $6^{\prime}$ high. Leaves sessile, ovate to obovate, $5-7^{\prime \prime} \times 3 \div 5^{\prime \prime}$, obtuse or shortly acuminate. Flowers on very short pedicels, in terminal cymes, the median flowers sessile, the lateral branches elongate. Calyx $4-5^{\prime \prime}$, its divisions unequal, erect, two or three of them keeled. Corolla pale pink, funnel-shaped, constricted at the throat, 4-5-lobed, its tube about as long as the calyx, the oblanceolate lobes half as long. Stigmatic lobes thick triangular or semiorbicular, cohering at first. Capsule eylindrical or fusiform, as long as the calyx, the valve-margins moderately projecting within. Seeds minute, black, scrobiculate, - Schenkia sabaeoides, Griseb. in Bonplandia, I, 226.

On grassy plains near the coast; Oa hu! Honolulu, Puloa, Kahuku; Moloka i! Wrikolu; isthmus of Maui. Nat. name: "Awiwis. Resembles closely the Mediterranean E. spicata, which has also found its way to the United States.

\section{ORdER LIII. LOGANIACEAE.}

Calyx 5- or 4-lobed or -toothed, or the sepals free. Corolla regular, the limb with 5 or 4 or rarely more lobes, valvate, contorted or otherwise imbricate in the bud. Stamens as many as lobes of the corolla, alternate with them, inserted in the tube. Ovary free, 2- or 3-, rarely 5-celled, or incompletely divided, the dissepiments not reaching to the center. Style single, with an entire or lobed stigma. Ovules one or more in each cell. Fruit a berry or septicidal eapsule. Seeds albuminous. 
Embryo straight or oblique, with leafy cotyledons. - Trees, shrubs, climbers or rarely herbs. Leaves opposite, usually connected by interpetiolar stipules or raised lines.

A small Order, in many respects allied to Rubiaceae, but distinguished by the free ovary. It is chiefly tropical, ranging over both the Old and New World.

\section{LABORDEA, Gaud.}

Calyx persistent, 5-lobed, or rarely the lobes all free, quincuncially imbricate in the bud, unequal, the outer ones generally broader than the inner. Corolla subcoriaceous, yellow or greenish, with a cylindrical tube, the narrow lobes pointed, erect or spreading, sinistrorsely contorted in the bud, slightly overlapping. Anthers 5, subsessile near the throat, partly exserted, linear-oblong, acute, affixed at the back near the base, 2-celled. Ovary ovoid, incompletely 2-3-celled; ovules numerous, anatropous or nearly amphitropous, on thick apparently axile placentas. Style as long as the tube of the corolla, the stigma elongato-clavate, pubescent, 2-3-lamellate with lobes connate, complanate or trigonous. Fruit capsular, with a thick exocarp, septicidal from the apex downward, the woody or pergameneous concentrically striate valves, with part of the inturned dissepiments, breaking away from the at last free and pulpy placentas. Seeds small ovoid $\left(1-1^{1 / 2} 2^{\prime \prime}\right)$, smooth, imbedded in an orange-colored or greenish pulp. Embryo straight cylindrical, nearly as long as the fleshy albumen, the radicle little longer than the cotyledons and nearly as broad. - Small trees or shrubs. Leaves entire, obliquely penni-nerved. Stipules sheathing. Inflorescence a terminal eyme, simple or compound corymbiform or paniculate, sometimes reduced to a single flower, with a pair of foliose bracts at the base of the peduncle and small linear bractlets about the middle of the pedicels.

A Hawailian genus nearly related to the Polynesian and Malaysian genus Geniostoma. The dehiscence of the capsule does not take place until after marcescence of the thick leathery exocarp.

Labordeae verae. Innovations from the uppermost axils below the inflorescence, therefore the branches dichotomous, enclosing between them the old fruit. Branches angular, the leaves crowded near their ends. Stipules intra-petiolar, connate only with the bases of the petioles, loosely sheathing, generally emarginate midway between the petioles. Cyme shortened corymbiform, sessile or nearly so, often reduced to a single flower. Calyx divided to the base into lobes or sepals, these unequal, the outer ones often foliaceous. Corolla yellow, the apices of its longacuminate lobes patent in the bud. Capsule 2- or 3-valved, the valves woody. 
Calyx at least as long as the broad tube of the orange-colored corolla, its outermost lobe at least 3-nerved:

Flowers single, rarely three:*)

Entire corolla enclosed within the foliaceous calyx-lobes or sepals; capsule crested

1. L. lophocarpa.

Calyx-lobes lanceolate, only equalling the tube of the corolla

4. L. glabra.

Flowers several or many :

Flowers $3-7$, subumbellate, the outermost calycine lobe generally ovate or ovate-lanceolate, foliaceous; leaves pale underneath

2. I. fagraeoidea.

Flowers many in a large compound cyme; outer calycine lobe lanceolate; leaves not pale underneath

Calyx shorter than the slender tube of the pale yellow corolla, its

lobes linear or subulate:

Calyx-Iobes $1 / 2$ the length of the tube of the corolla; pubescence rufous

Calyx-lobes $1 / 3$ the length of the tube; pubescence gray

Flowers unknown, leaves small, ${ }^{1 / 2}-1^{\prime}$ long, on petioles of $4-6^{\prime \prime}$.

3. L. Grayana.

Geniostomoideae. - Innovations not confined to the uppermost axils. Branches terete, pale, with leaves distant. Stipules low annular, rather inter-petiolar, not forming a rising auricle inside the petiole. Cyme pedunculate, simple or paniculate. Calyx small, 5-fid with equal narrow lobes. Corolla slender salver-shaped, greenish, its lobes closed to the apex in the bud. Capsule nearly always 2-valved, the valves pergameneous.

Leaves cordate at the base; cyme 3-flowered

Leaves contracted at the base; cyme paniculate
9. L. triflora.

8. L. tinifolia.

1. L. lophocarpa, $s p$. n. - A much branching shrub, glabrous, the younger branches fleshy, slender, and sharply ridged or angular. Stipular sheath large, emarginate laterally. Leaves elliptico-or obovato-oblong, $2-4^{1} / 4^{\prime} \times 1-1^{3} / 4^{\prime}$, shortly acuminate, suddenly narrowing into a petiole of $2-6 "$, thin chartaceous, dark underneath when dry, and glabrous or distantly hispidulous. Inflor. a single terminal flower on a puberulous pedicel of $2-5^{\prime \prime}$; bractlets lanceolate or spathulate, $6{ }^{\prime \prime}$. Calyx as long as the corolla with its lobes, $7-10^{\prime \prime}$, divided to the base into 5 or 4 free broad foliaceous sepals, the outer ones rounded, nearly as broad as high and shortly acuminate, 9-11-nerved, the inner less than half as broad as high. Corolla deep yellow, enclosed in the calyx, glabrous outside, puberulous inside, the broad tube $5-6$ "long, the lobes (often 6 or 7) $3-4$ ". Style $2^{\prime \prime}$, shorter than the broad clavate stigma. Capsule $6-7^{\prime \prime}$ high, 2-3-valved, the valves broadly winged at the back above, with the wings rounded and generally not confluent at the apex, almost globose when 3-valved, complanate when 2-valved.

Molokai! the prevailing form on that island, all my numerous specimens from Kalae, Wailau, Mopulehu exhibiting a remarkable uniformity; also Lanai! with smaller leaves. The wing-like crests of the capsule are chiefly formed by the coriaceous exocarp, the woody mesocarp being hardly more keeled than in the next species.

*) It often happens that of several flowers only one arrives at maturity; therefore it is not safe to infer from the presence of a single eapsule the character of the inflorescence.

Hillebrand, Flora of the Hawaiian Islands. 
$\beta$ var. pluriflora. - Inflor. of $1-3$ often nodding flowers on pedicels of $4-6^{\prime \prime}$, the bractlets linear or spathulate. Sepals more acuminate, the outer ones broadly ovate.

Molokai! Halawa.

$\beta$ var. phyllocalyx. - Flower solitary, nearly sessile. Sepals large foliaceous, oblong and penni-nerved, stipitate at the base, the outermost $16 \times 8^{\prime \prime}$.

Oahu, western ridge of Nuuanu. Possibly Wawra's L. Waiolani on the improbable assumption that the foliaceous sepals had been mistaken for a rosette of leaves". Stipules broad auricular, distinct as in the next species.

2. L. fagraeoidea, Gaud. in Bot. Voy. Freyc. p. 450, tab. 60. - A tall shrub or small tree, generally glabrous, but sometimes the young shoots and inflorescence coarsely pubescent. Stipules large auricular, disconnected or, if connected, deeply emarginate laterally. Leaves obovate-oblong, $3^{1 / 2}-4^{1 / 2} \times 1^{1} / 4-1^{3} / 4^{i}$, shortly acuminate, cuneately narrowing into a very short petiole or subsessile, coriaceous, pale underneath and glabrous or distantly puberulous. Cyme contracted, erect, umbellately $3-5^{-}$, rarely 7 -flowered, the pedicels 2-4", the bractlets linear, 3". Calyx $7-8^{\prime \prime}$, parted to near the base into lanceolate lobes of very unequal width, the outer ones generally foliaceous, the 2 inner always narrow-lanceolate. Corolla deep orange, pubescent outside, hispidulous within, about 1 'long, the broad tube as long as the calyx or shorter, the spreading lobes nearly as long as the tube. Capsule short ovoid, 5-6"long, generally 3-valved, the valves moderately carinate at the back, the keels confluent at the apex. - DC. Prod. IX, 21. - L. sessilis, Gray, in Proc. Am. Ac. IV, 323. - L. pallida, Mann, Enum. no. 384, at least as regards the plant from Oahu. - L. Waiolani, Wawra, in Flora, 1872, p. 516.

Oahu! in both mountain ranges; Kauai. The great variability in the width of the ealycine lobes, together with a probable inexaetness in Gaudichand's figure, has given rise to considerable confusion regarding this species. Specimens which I collected in Nuuanu agree tolerably well with Gaudiehaud's figure, the original for which also came from $\mathrm{Oahu}$ and probably from the same locality. In them the outermost calycine lobe does not measure more than $2^{\prime \prime}$ in width, while the innermost is scarcely ${ }^{1 / 2} 2^{\prime \prime}$ broad. In the bud the division extends only to the middle, but in the developed flower to near the base, which eircumstance may explain the inexactness of Gaudichaud's figure, where the ealyx is parted only to the midale. Specimens from Mt. Kaala, on the other hand, have the outermost calyx-lobe $4-5$ " broad and 5-nerved, while those from Wailupe are intermediate between the two extremes. M. \& B.'s no. 611 from Kealia, Kauai, the type of Mann's $L$, pallida, agrees in the main with my forms from Nuranu, but the calyx is shorter, as well as the corolla, and the leaves are on petioles of $3-4^{\prime \prime}$. In fruiting speeimens often a single capsule only is found to have matured; from such specimens the character of $L$. sessilis and $L$. Waiolani would seem to have been drawn.

$\beta$ var. pumila. - Low, sparingly branched, $1 \mathrm{ft}$. high. Leaves crowded at the ends of the branches, $1-1^{1} / 2^{\prime}$ long.

Kauai, top of Waialeale, $6000 \mathrm{ft}$, - L. pallida, forma alpina, Wawra, 1. c. p. 516.

3. L. Grayana, Hillebr. - A small tree with stiff angular branches, glabrous or pubescent. Stipules large, connected in a cup-shaped emar- 
ginate ring. Leaves ovato-, elliptico- or obovato-oblong, shortly acuminate, suddenly contracted at the base or even rounded, $3-4^{1 / 2^{\prime}} \times 1^{1 / 4}-2^{\prime}$, on petioles of $3-6^{\prime \prime}$, subcoriaceous, glabrous above, sparingly pubescent underneath with short stiff hairlets, but often almost glabrate and dark brown on both faces when dry. Cyme many- (6-22-) flowered corymbiform, $1^{1} / 2-3^{\prime}$ wide, with a very short peduncle and divergent, in part reflected branches, the ultimate pedicels slender, $2-6^{\prime \prime}$. Bractlets filiform, $3-6^{\prime \prime}$. Calyx $5-6^{\prime \prime}$ (as long as the tube of the corolla or a little shorter), parted to the base into 5 lanceolate to linear lobes, the outer one being generally 3-nerved, rarely 1- or 5-nerved. Corolla orange-colored, glabrous, puberulous within, the tube moderately $\left(2^{1 / 2} 2^{\prime \prime}\right)$ wide and $6^{\prime \prime}$ long, the lobes (generally 6) $3-4^{\prime \prime}$. Capsule conico-elongate, $9-12^{\prime \prime}$ long and $6 "$ broad at the base, pointed, generally 2 , rarely 3 -valved, the valves moderately carinate in the upper half with the keels confluent at the apex. - L. fagraeoidea, Gray, 1. c. and Mann.

Haw a ii! woods of Hilo and Puna (U. S. E. E. and Lydg.), leaves glabrate underneath, ryme pubescent, 6-9-flowered; Ma ui! Haleakala, capsules very large, exceeding $13^{\prime \prime}$ in length, Eeka, 3000-5000 ft. above Lahaina and in Kaanapali, leaves pubescent underneath, cymes many-flowered, eapsule $12^{\prime \prime}$; Lanai! cyme few-flowered, capsule 8"; Molokai! heights of Pelekunu, leaves thick coriaceous, strongly veined and pubescent, even hirsute along the rib and veins underneath; also a single specimen, but with a doubtful label, from the eastern end of Oahu! M. \& B.'s no, 434 in herb. Cornell Univ. is from W. Maui, and quite agrees with my specimens from that island, but Mann's description of $L$. $f a$ graeoidea, for which that specimen served as basis, by no means agrees with it, but would seem to be influenced by an attempt to reconeile the character of the specimen with Gaudichand's figure. This and the preceding species are the skamakahalas, the flowers of which were so much prized for leis or wreaths, but tabooed to common people, reserved only for bigh chiefs.

4. L. glabra, $s p . n$. - Stipules connected in an entire or emarginate ring. Leaves oblanceolate, $4-4^{1 / 2^{4}} \times 1^{1 / 2}-1^{3 / 4^{4}}$, on petioles of $2-3^{n}$, suddenly and long acuminate, cuneate at the base, membranous, glabrous underneath and dark when dry. Flower solitary on a peduncle of $2-4^{\prime \prime}$ which carries 2 linear-lanceolate bracts $\left(3^{\prime \prime}\right)$ above the base. Calycine lobes glabrous, linear-lanceolate, subequal, as long as the tube of the corolla. Corolla glabrous outside, puberulous within, with a broad tube of $4-5^{\prime \prime}$ in length and $21 / 2^{\prime \prime}$ in width, the reflected lobes of the same length. Capsule 3-valved, short globose, $6^{\prime \prime}$ high, the valves not carinate.

Maui! Waikee and Wailuku.

5. L. membranacea, Mann, Enum. no. 386. - A shrub about $6 \mathrm{ft}$. high, the extreme branches thick herbaceous, acutely angular, pubescent with short dark brown hair. Stipules connected in an entire ring. Leaves broad oblong, $4-7^{\prime} \times 2^{1 / 2}-4^{\prime}$, on petioles of $4-7^{\prime \prime}$, shortly acuminate, contracting at the base, membranous, pale underneath and dotted with dark rufous papillose hairlets. Cyme many-(12-20-) flowered, subsessile, contracted, with diverging branches, not exceeding $2^{\prime}$ in the transverse 
diameter, viscous-pubescent or even hirsute; pedicels $1-2^{\prime \prime}$; bractlets $1-1^{1} / 2 "$. Calyx rufo-pubescent, $3^{\prime \prime}$ (half the length of the corolla-tube or less), divided to near the base into subequal linear or subulate lobes. Corolla glabrous outside and within, pale stramineous, the slender tube $6-7^{\prime \prime}$, dilating above, the erect or spreading lobes half as long. Capsule 2 -valved, conico-elongate, about $12^{\prime \prime}$ in height, the pergameneous valves not ridged at the back.

Oahu! Wailupe, Palolo, Paroa, Wahiawa.

6. L. hirtella, Mann, Enum. no. 385. - A tall shrub or small tree, the slender branches sharply angular, pubescent. Stipules low annular. Leaves obovate or oblanceolate, $2^{1 / 2}-4^{\prime} \times 1-1^{1 / 2^{\prime}}$, on petioles of $2-3^{\prime \prime}$, suddenly acuminate, cuneate at the base, chartaceous, pale and pubescent underneath with grayish hair. Cyme 3-9-flowered, open and loose, with rather long and slender, generally reflected, branches, the pedicels 3 ". Calyx $1 / 3-1 / 2$ the length of the corolla-tube, pubescent, with linearlanceolate finely acuminate or subulate lobes. Corolla pale yellow, glabrous outside and inside, the very slender tube $5-8^{\prime \prime}$ long, the lobes about half as long. Style filiform. Capsule 2-valved, ovoid-elongate, about $12^{\prime \prime}$ long and 4 " wide, the valves rounded, not carinate.

Lanai! rather common; Molokai! pali of Pelekunu and Maunahui, leaves larger, on petioles of $3-6^{\prime \prime}$, eyme $12-20$-flowered; W. Maui!

$\beta$ var. microphylla. - Leaves and flowers smaller, the former $1-1^{1 / 2^{\prime}} X$ $1 / 2-3 / 4^{*} ;$ tube of corolla $3-4^{\prime \prime}$.

W. Maui! Kaanapali.

$\gamma$ var. microcalyx. - Leaves large, $4-5^{\prime} \times 1^{1 / 2}-2^{\prime}$, oblanceolate and quite pale underneath, as in $L$. fagraeoidea. Calyx scarcely $1 / 3$ the length of the corolla-tube, its lobes ovately dilated at the base, but with a long acumination. Corolla slender as before.

Haw aii! woods of Hilo (Lydg.).

The species has some relation to $L$. membranacea as well as to $L$. Grayana. In Lanai, where both it and the latter species oceur together, it is often difficult to assign a flowering specimen to one or the other on account of the variable length of the calycine lobes. On the other hand the small calyx, the slender pale corolla and the open inflorescence make a partial approach toward $L$. tinifolia, but the final link to complete the connection between the two divisions of the genus remains to be diseovered.

7. L. Waialealae, Wawra, in Flora, 1872, p. 516. - "A much branching shrub, $6 \mathrm{ft}$. high. Leaves ovate, ${ }^{1 / 2}-1$ ' long, shortly acuminate, acute at the base, on petioles of $4-6 "$, membranous, glabrous, sparingly pubescent underneath. Fruit solitary, axillary (?) and spuriously (?) terminal, on a peduncle of $3^{\prime \prime}$, ovoid, 2-valved, the valves echinate or smooth, oblong or cordate. Pulp greenish (aeruginea). ,

Kauai, slope of Waialeale (Wawra).

8. L. tinifolia, Gray, in Proc. Am. Ac. IV, 322, - A small tree, glabrous, with slender and pale terete branches. Leaves elliptico-or obovato- 
oblong, $2-4^{\prime} \times{ }^{3 / 4}-1^{1 / 2}$, on petioles of $2-6^{\prime \prime}$, acuminate at both ends, chartaceous, glabrous. Flowers many in a paniculate cyme of $1^{1 / 2}-4^{\prime}$ in length, with a peduncle of $1 / 2-1^{\prime}$, the primary branches opposite and rather distant, the ultimate pedicels $3-9 "$, subequal. Bractlets subulate. Calyx $11^{1 / 2}$, divided beyond the middle into 5 triangular acute lobes. Corolla greenish, very slender, salver-shaped, the tube $3-4^{\prime \prime}$, glabrous, but pubescent within, the lobes about $1 / 3$ as long. Capsule globose or short ovoid, somewhat obtuse, $4-5^{\prime \prime}$ high, slightly sulcate, 2 -valved or very rarely 3 -valved, the valves rounded at the back. - A single capsule in my numerous specimens is 3 -valved.

Oahu! Maui!

$\beta$ var. - Leaves smaller, $1^{1 / 2}{ }_{2}-2^{\prime} \times{ }^{1 / 2}-3 / 4^{\prime}$. Cyme few-flowered. Capsule obovoid, $3-4^{\prime \prime}$.

Molokai! Kalaupapa.

r var. - Capsules ovoid, acute, 6" long.

Kauai! Maui! Kaanapali; Lanai! leaves small obtuse, almost rounded at the base; Hawaii!

9. L. triflora, sp. n. - Habit as in no. 8. Leaves ovate- or obovateoblong, $3-3^{1} / 2^{2} \times 1-1^{1} / s^{\prime}$, subsessile or on short petioles of scarcely $1^{\prime \prime}$, acuminate, cordate or emarginate at the rounded or truncate base, thin chartaceous, glabrous. Cyme 3 -flowered, with a slender, often reflected peduncle of $1 \frac{1}{1 / 2}-2^{\prime}$, the pedicels all equal, $6-12^{\prime \prime}$, minutely bracteolate about the middle, rarely $4-5$-flowered by division of the median branch. Calyx and corolla as before, the tube of the latter $5-6^{\prime \prime}$. Capsule conicoelongate, pointed, $7-10^{\prime \prime}$ high, 2 -valved.

Molokai! Mopulehu.

\section{ORDER LIV. APOCYNACEAE.}

Sepals 5 or rarely 4 , free, or united at the base, imbricate in the bud. Corolla with 5 or rarely 4 lobes contorted in the bud and usually oblique. Stamens as many as lobes of the corolla, alternate with them, inserted in the tube and generally included; the anthers opening inward, free, or cohering with the stigma. Ovary either 2-celled, or rarely 1-celled with 2 parietal placentas, or more frequently the 2 carpels are distinct, but united at the top by a single style which is usually thickened or expanded into a ring under the stigma. Ovules usually several in each cell or carpel. Fruit a berry, drupe, or more frequently consisting of 2 follicles opening inward. Seeds laterally affixed or pendulous, rarely erect, usually with albumen. - Trees, shrubs, woody climbers, or herbs, the sap mostly milky. Leaves opposite or whorled, rarely alternate, entire, without stipules, but frequently having glands between the leaves or in 
their axils, as also within the calyx at its base. Flowers usually in axillary or terminal cymes or panicles.

A large Order, chiefly tropical. To it belong the following cultivated plants: Nerium Oleander, L., Plumieria acutifolia, Poir., Tabernaemontana coronaria, R. Br., Thevetia neriifolia, Juss., Allamanda cathartica, L., Strophanthus dichotomus, DC., Rhynchospermum jasminoides, Lindl., Beaumontia grandiflora, Wall., Cerbera Odollam, Gaertn,, Alstonia scholaris, $\mathrm{R}$. Br., and some others.

Fruit of 2 distinct follicles opening by a ventral suture, manyseeded; an herb

Fruit drupaceous; shrubs or trees:

Two carpels or drupes partly united in a didymous fruit; numerous stipitate glands in the axils of leaves

1. Vinca.

Both drupes free to the base, or one only developed:

Leaves whorled or opposite:

Cymes axillary, 3-5-flowered; no axillary glands, drupes stipitate

Cymes terminal at first, corymbose, many-flowered; axillary glands variable, drupes not stipitate

Leaves alternate or scattering; a single cup-shaped gland in the axils

\section{Rauwolfia,}

5. Alyxia.

3. Ochrosia.

4. Vallesia.

\section{VINCA, L.}

Calyx without glands inside, but the sepals sometimes glandular-ciliate on the edge. Corolla salver-shaped, 5-lobed, its tube slender, the lobes ovate or oblong, sinistrorse*, without scales at the throat. Anthers enclosed, not appendiculate. Disk of 2 oblong glands alternating with the carpels. Ovary of 2 distinct carpels united by a single style, with several ovules in each carpel. Stigma conical or cylindrical, with a tuft of hairs at the top. Fruit of 2 cylindrical erect or spreading follicles. Seeds oblong-cylindrical, truncate on both sides, laterally affixed. - Erect or creeping herbs or undershrubs with opposite leaves. Flowers axillary, solitary or two together.

A small genus belonging to the temperate and tropical regions of the old World, excepting the following species.

†1. V. rosea, L. - DC. Prod.VIII, 382. - An erect, slightly pubescent perennial, $1-2 \mathrm{ft}$. high, branching only at the base. Leaves obovate or oblong, obtuse, $1-\dot{2}^{\prime}$ long, narrowed into a very short petiole. Flowers pink, rarely white, 2 together, almost sessile. Sepals short, subulate, pubescent. Corolla-tube about $y^{\prime \prime}$ long, with a narrow callous throat, the lobes broad, oblique, not much shorter than the tube. - Bot. Mag. tab. 248. - Benth. Fl. Hongk. p. 220. - Catharanthus rosea, G. Don. Lochnera rosea, Reichenb.

A native of tropical America, now fairly naturalized in various parts of H a wai and Maui, as it is in many other countries.

*) The terms dextrorse and sinistrorse, as applied here and in the following descriptions, designate the direction in which the lobes of the contorted eorolla overlap each other
on a front view. 


\section{RAUWOLFIA, L.}

Calyx 5-cleft, without glands. Corolla salver-shaped, without scales, 5 -lobed, the lobes sinistrorse in the bud. Stamens inserted below the throat, the anthers not appendiculate. Ovaries 2, distinct or partly connate, surrounded by an urceolate disk. Ovules 2, rarely more in each carpel, collateral on a ventral placenta. Stigma clavate, with a thick or membranous ring at the base, emarginate. Drupes distinct, or more frequently in part connate in a didymous emarginate or 2 -cleft fruit, each pyrena with 1 seed. Embryo within fleshy albumen, with foliaceous cotyledons and a straight or recurved superior radicle. - Shrubs or trees with opposite or whorled leaves. Flowers in compound often umbellate cymes, at first terminal.

A genus of about 40 species, chiefly inhabitants of tropical America, a few African and Malaysian, and 2 species in New Caledonia.

1. R. Sandwicensis, A. DC. Prod. VIII, 339. - A small milky tree, $10-20 \mathrm{ft}$. high, with short and stiff glabrous whitish branches which are striate and densely studded with leaf-scars. Leaves 4 in a whorl, elliptico-oblong, $3-6^{\prime} \times 1^{1 / 4}-2^{\prime}$, acuminate at both ends, pale, thin chartaceous, the faint parallel veins confluent inside the margin, the petioles $1-1^{1 / 2} "$, with $5-12$ stipitate or linear glands in each axilla. Flowers crowded into 4 umbellately compound cymes which are scarcely longer than the petioles, at first terminal, but soon axillary through innovations from the apex; the common peduncle angular, $1-1^{1 / 2} 2^{\prime}$, the pedicels $1^{\prime \prime}$ or less, the acute bracts $2-1$ ", including some stipitate glands. Calyx $2^{1 / 2} 2^{\prime \prime}$, parted to near the base into 5 oblong and somewhat obtuse lobes of unequal width. Tube of the yellowish corolla $4^{\prime \prime}$, scantily hairy inside, dilated below the constrieted throat, the obovate oblique lobes $1^{1 /} / 2^{\prime \prime}$. Anthers subsessile, sagittate, shortly exserted. Disk small, annular or 5lobed. Ovules 4 in each carpel. Style filiform, as Iong as the tube, the clavate stigma subtended by a narrow hairy ring. Drupe didymous, compressed, obcordate or deeply emarginate at the top, $4-6^{\prime \prime}$ in height and more in width, rather fleshy, black; the pyrenas thick woody. Albumen scanty, not ruminate, the terete radicle superior and shorter than the flat ovate cotyledons, - Wawra, in Flora, 1874, p. 367. Cerbera parviflora, Hook. \& Arn. (not Forster). - Ochrosia Sandwicensis, A. DC. Prod. VIII, 357 (not Gray). - The stalked glands sometimes appear on the borders of the bracts as well as in their axils, and, when imperfectly developed, assume the appearance of "spinous processes or teeth", as noticed by the authors of Beechey's Botany and by De Candolle.

In the open woods of the Iower regions, probably on all islands; in 0 ahu on the west side of Nunanu! in Wailupe and Kaala! Nat. name: "Haos. 


\section{OCHROSIA, Juss.}

Calyx 5-parted, the lobes glandless. Corolla salver-shaped, 5-lobed, the tube scaleless at the constricted throat, the lobes dextrorse. Stamens 5, inserted at the middle of the tube, included, the lanceolate anthers longer than the filaments, not appendiculate. Disk wanting. Carpels of ovary distinct, cohering at the apex. Stigma oblong, indistinctly bifid. Ovules $2-6$ in a carpel, in 2 rows on each side of the protruding ventral placenta. Drupes 2 (or 1 by abortion), free to the base, diverging, rather dry, with woody endocarp, dorsally compressed, furrowed on the ventral side. Seeds 2, large and compressed, with thin testa, separated by the thin placenta. Albumen fleshy and scanty or wanting. Embryo straight, with plane cotyledons and a superior radicle. - Milky shrubs or small trees with verticillate or opposite leaves. Flowers in cymes from the axils of the uppermost leaves, finally rameal through terminal innovations.

A genus of about 12 species, extending from the Mascarene Islands, through Malaysia and tropical Australia into Polynesia, only one other species spread over many islands south of the equator (Tahiti, Viti, New Caledonia and others).

1. 0. Sandwicensis, Gray, in Proc. Am. Ac. V, 333. - A much branching glabrous shrub, $6-12 \mathrm{ft}$. high. Leaves 3 or 4 in a whorl, elongate-oblong, $4-6^{4} \times 1^{1 / 2}-2^{\prime}$, on petioles of ${ }^{1 / 2}-1^{\prime}$, shortly acuminate, chartaceous, shining above, the close and faint nerves perpendicular to the rib and parallel, including rectangular areoles, and united by a distinct intramarginal nerve. Cymes compound, 2-3' long, divaricately branching, the angular peduncle ${ }^{1 / 2}-1^{1 / 2} 2^{i}$, the lateral pedicels $1-1 / 2$, the median flowers subsessile; the bracteoles short ovate to dentiform. Calyx $1 \frac{1}{2}-2^{\prime \prime}$, with acute lanceolate teeth. Corolla yellowish, the tube $3-5^{\prime \prime}$, hairy inside, dilated below the throat, the lobes linear-oblong, of the same length. Stamens inserted above the middle, with short hairy filaments and elongate acute included anthers. Stigma included, clavate, separable into 2 truncate lobules. Disk of 2 glands. Drupes dry, yellow, ellipsoid or ovoid-elongate, $2^{\prime}$ long, $8^{\prime \prime}$ broad and nearly as thick, pointed, with a thin layer of suberose mesocarp on the ventral side, the endocarp woody and very thick, particularly on the sides and near the base $\left(3^{\prime \prime}\right)$, smooth and shining within; the narrow cavity completely partitioned into two halves by the thin foliaceous bilamellate placenta. Seeds 1 on each side of the placenta and peltately attached to it, conformate to the cavity, ellipticooblong, quite flat on the placentar side, foliaceous at the margins and slightly convex on the outer face. Testa thin chartaceous. Albumen hard fleshy, not ruminate. Embryo axile, shorter than the albumen, the narrow lanceolate cotyledons about $1 / 3$ of its width, the superior radicle as long as the cotyledons. - Wawra, in Flora, 1874, p. 366. - The axils sometimes hold one or several small, mamillaeform, sessile or shortly stipitate glands. 
The "Hoolei, of the natives, scattering but rare in the open woods of the lower and middle regions on all islands; rather frequent above Makawao, Maui.

$\beta$ var. - Leaves opposite, $7-9^{\prime} \times 2^{1 / 2}-3^{\prime}$, on petioles of $1-1^{1 / 2^{\prime}}$, coriaceous, with prominent nerves. Cymes densely-flowered.

Oahu! Nuuanu. Probably, the same form as Wawra's 1866, b, from Hanalei, Kauai, which bore a drupe of the same size as that of $\alpha$, but obovate and rounded at the top.

\section{VALlESIA, Ruiz \& Pavon.}

Calyx 5-cleft, glandless. Corolla salver-shaped, without scales at the constricted throat, the 5 lobes shorter than the tube, sinistrorse. Anthers enclosed, not appendiculate, longer than their filaments. Disk none or obscure. Carpels distinct, cohering at the apex. Ovules 2 or 4 in each earpel, amphitropous, superposed in pairs on the ventral suture. Style filiform, enclosed, with a thickened cylindrical stigma. Drupes 2, discreet (one often abortive), diverging, oblong, often incurved, with a dry coriaceous exocarp and a cartilagineous or thin woody endocarp, the ventral suture protruding within. Seed single, conformate to the cavity, with a thin testa, furrowed on the ventral side for the reception of the sutural dissepiment or placenta. Albumen ruminate, fleshy or corneous. Embryo axile, with oblong plano-convex cotyledons and a long inferior radicle. Shrubs or trees. Leaves alternate, petiolate, with axillary glands. Flowers in terminal but by prolongation of the axis often lateral cymes.

A small genus of 2 American species, one of them extending from Chile and Buenos Ayres to Mexico and Florida, to which has to be added the following.

1. V. macrocarpa, sp. $n$. - A small gnarly tree, $15-25 \mathrm{ft}$. high, with short and thick pale diverging branches and a very tenacious milksap. Leaves obovate or obovate-oblong, $3-9^{\prime} \times 1^{1 / 2}-4^{\prime}$, on petioles of ${ }^{1 / 2-2^{\prime}}$, rounded at the apex, coriaceous, with revolute margins, pale, glabrous and glossy, the veins prominent, perpendicular to the midrib, strictly parallel and connected by an intramarginal nerve. A single large scale-like concave or eup-shaped gland in each axil. Cymes contracted, 6-12-flowered, about $1 / 2^{\prime}$ in diameter, terminal and sessile on short leafy spurs or branches, the thick angular pedicels very short, with squamaceous bractlets. Calyx coriaceous, $1^{\prime \prime}$, with short obtuse lobes. Corolla pale yellow, the cylindrical tube $3-4^{\prime \prime}$, with a few hairlets inside, constricted at the throat, the obtuse suberect lobes $1-1^{1 / 2} 2^{\prime \prime}$. Stamens inserted below the throat, with very short filaments, the anthers acute, emarginate at the base. Style nearly the length of the tube, the short cylindrical stigma emarginate. Carpels cohering at the apex only, each with 2 ovules attached to the middle of the ventral suture. Drupes dry, obovoid, $2^{\prime}$ long and $1^{\prime}$ broad, compressed in the ventro-dorsal axis, narrowed, almost stipitate at the base, horizontally diverging. Pyrenae thin and soft-woody, 
with 2 sharp lateral angles and 2 sharp crests in the upper portion of the ventral face, the ventral suture or placenta within protruding into the deep furrow of the albumen. Seed ellipsoidal, $18^{\prime \prime}$ long, 8 "broad and 6 " deep, pointed at both ends, but sharper at the base, the large horny albumen deeply wrinkled by transverse sinuous folds which are invested with the thin membranous testa. Embryo axile, straight, nearly as long as the albumen, the linear-oblong fleshy cotyledons about as long as the inferior radicle and scarcely broader.

Nuramu and Makaleha on Oahu! It is the plant of my early collection referred to by Mann and Wawra under Ochrosia Sandwicensis. Called "Kaulu" by the natives, as is Sideroxylon Sandw., to which the tree and leaves bear a resemblance.

5. ALYXIA, R. Br.

Calyx without glands, 5- or 4-cleft. Corolla salver-shaped, its tube cylindrical or slightly contracted at the throat, without scales, the 5 or 4 lobes sinistrorse. Anthers subsessile. Disk none. Ovary of 2 distinct carpels united by a single style with a capitate or oblong stigma. Ovules $4-6$ in each carpel, in two series. Fruit generally a single ovoid or oblong drupe, often lomentaceous, viz., consisting of 2 or more 1 -seeded joints placed end to end, sometimes both carpels maturing in the same flower and then both distinct. Seeds single in each carpel or joint, ovoid or oblong, furrowed on the ventral side by the intruding placenta. Albumen corneous, ruminate-lobed, the folds lined with the thin testa. Embryo axile, straight or curved, the cotyledons oblong, obtuse, foliaceous, the radicle superior (inferior according to De Candolle). - Evergreen shrubs or small trees, often with twining branches. Leaves opposite or whorled. Flowers axillary or terminal, disposed in umbellate or spicate cymes.

A genus of about 30 species extending from Madagascar and Ceylon through Australasia to Polynesia. Five species are known from the islands of the S. Pacific.

1. A. olivaeformis, Gaud. in Bot. Voy. Freyc. p. 451. - A straggling or somewhat twining glabrous shrub. Leaves opposite and ternate, elliptico-oblong, $1^{1 / 2}-2^{1} / 4^{\prime} \times{ }^{1 / 2}-3 / 4^{\prime}$, acuminate at both ends, on petioles of $11 / 2-2^{\prime \prime}$, coriaceous, glossy, with evanescent veins, the margins generally revolute over the distinct intramarginal nerve. Peduncles axillary, $4^{\prime \prime}$ long, 3 , rarely 4 -flowered, all flowers on pedicels of $1^{1 / 2}-2^{\prime \prime}$; two very minute acute bracts at the head of the peduncle. Calyx small, $1 / 2-1^{\prime \prime}$, acutely 4-, rarely 5-parted. Corolla yellowish, the tube $2-2^{1 / 2}$ ", slightly widening below the contracted throat, puberulous within along the adnate filaments, the 4 , rarely 5 ovate lobes ${ }^{1 / 3}$ the length of the tube. Anthers small, acute, enclosed. Style enclosed, the stigma at first conical and slightly hairy at the top, but capitate afterwards. Ovules 2 in each carpel, super- 
posed. Drupes often twin in a single flower and stipitate, fleshy, black, elliptico-oblong, sometimes curved, $7-10^{\prime \prime}$ long, acuminate at both ends, not rarely lomentaceous; the chartaceous endocarp lined by 6 prominent furrows. Embryo cylindrical, $2 / 3$ the length of the horny albumen, the radicle little longer than the fleshy cotyledons, superior (inferior and slightly curved according to Wawra). - DC. Prod. VIII, 347. - Gray, in Mscpt. U. S. E. E. - Wawra, in Flora 1874 p. 365, - The direction of the radicle probably depends upon the position of the seed which becomes developed, for it is to be supposed that the upper ovule curves upward and the lower downward.

All islands, in the woods of the lower and middle regions.

$\beta$ var. ovata. - Leaves mostly opposite, rarely ternate, broadly ovate or rhomboidal and mostly obtuse, $1^{1 / 4}-2^{\prime} \times{ }^{3 / 4}-1^{1 / 4^{\prime}}$. Drupes ovoid or obovoid, about 6 " long. - A. sulcata, Hook. \& Arn. in Bot. Beech. p. 90.

Oahu! on both ranges.

r var. lanceolata. - Leaves ovate-lanceolate, acute, often emarginate at the base, binate, ternate or quaternate, $1^{1 / 2-1^{3} / 4^{\prime}} \times 6-8^{\prime \prime}$. Peduncles umbellately $3-5$-flowered. Lobes of corolla $1 / 2$ the length of the short tube. Drupes oblong, 6-7", obtuse at both ends.

Woods of Kaanapali, W. Maui!

¿ var. myrtillifolia, Gray. - Leaves in whorls of 3 and 4, small oblong or obovate, $4-9^{\prime \prime} \times 2-4^{\prime \prime}$, obtuse at both ends or contracted at the base, sometimes orbicular. Peduncle umbellately 4-5-flowered. Calyx and corolla mostly 5-lobed. Drupe short ovoid, $4-6 "$.

Lanai! E. and W. Maui!

The longitudinal furrows of the putamen, which correspond to as many ridges on its inner side, are determined by the main folds of the deeply plicate albumen and connected by numerous weaker transverse bars or lines which indicate the horizontal infoldings of the same. On longitudinal and transverse sections the folds appear as straight continuous, not wayy lines. - The fragrant and glossy branches of the -Maile are in great favor with the natives for decorating their houses and "lanais on festive occasions. The same name =Maire, is applied in Tahiti to Alyxia stellata.

\section{ORDER LV. ASCLEPIADACEAE.}

Character mostly of Apocynaceae, but the filaments connate and the pollen-grains of each cell cohering in wax-like masses - pollinaria which, having a glandular appendage, are connected with the pentagonous stigma by 5 projections of the latter. Fruit of 2 follicles. Seeds several, usually terminating in a tuft of silky hairs, with thin albumen. - Mostly herbs or twiners, often milky. Leaves generally opposite. Flowers in axillary or lateral cymes, racemes or umbels.

A large Order, chiefly tropical, to which belong Hoya carnosa, Stephanotis floribunda, Calotropis gigantea, Cryptostegia grandiflora, and several species of Stapelia, all eultivated in gardens. 


\section{ASCLEPIAS, L.}

Corolla rotate, 5-lobed, the lobes valvate in the bud, at first spreading, then reflexed. A corona of 5 scales attached to the top of the staminal column, the scales hood-shaped, each with a horizontal horn-shaped process projecting from the base toward the stigma and curved over it. Pollen-masses pendulous, affixed in pairs by their attenuate ends (one half of each pair furnished by a polinarium of contiguous anthers). Stigma flat. Seeds tufted. - Herbs with opposite or whorled, rarely alternate leaves. Umbels terminal and interpetiolar.

A genus of many species, all, excepting two which are African, from the American continent and chiefly from its northern half.

†1. A. curassavica, L. - DC. Prod. VIII, 566. - An erect perennial, $2-3 \mathrm{ft}$. high. Leaves opposite, lanceolate, acute, $3-4^{\prime}$ long, narrowed into a short petiole, glabrous. Umbels many-flowered on peduncles of $2^{\prime}$, the pedicels $6-8^{\prime \prime}$. Calyx $1-2^{\prime \prime}$. Corolla ${ }^{1 / 2} 2^{\prime}$ in diameter, orange-red, with acute lobes. Staminal corona light yellow, the hood-shaped scales ovate, shorter than the inner curved horns. Follicles smooth, 2-3' long, acuminate and narrowed to a stalk at the base. - Griseb. Fl. W. Ind. p. 419. - Benth. Fl. Hongk. p. 225.

A common way-side weed, generally ealled Wild Ipecac, of early introduction. A native of Mexico and the W. Indies, but now spread over many other tropical regions.

\section{ORdER LVI. HYDROPHYLLACEAE.}

Calyx 5-cleft, persistent. Corolla 5-lobed, the lobes imbricate in the bud. Stamens inserted in the tube and alternate with the lobes of the corolla; anthers versatile, opening inside. Ovary superior, 1-celled with 2 parietal placentas, or more or less completely 2 -celled, the placentas protruding and bipartite, sometimes meeting at the axis. Ovules 2 to many on each placenta. Style bifid, often to the base, with truncate or capitate stigmas. Fruit a 2 -valved capsule. Seeds generally tuberculate or rugose. Embryo small, axile in copious albumen. - Herbaceous or suffrutescent plants with alternate simple leaves, without stipules, generally hispid or viscous. Flowers generally on one-sided scorpioid branches of a dichotomous cyme, or single, terminal and lateral.

A small Order of mostly American plants.

\section{NAMA, L.}

Corolla funnel-shaped. Stamens included, unequal, the anthers ovate, with broad dehiscence. Styles 2 , distinct to the base, with capitate stigmas. Capsule 2 -valved, loculicidal, at length also septifragal, the valves breaking away from the dissepiments; the placentas bipartite, at first meeting at the axis, at length free. - Low herbs, dichotomously 
branching, glandular-hispid. Flowers irregularly cymose, or solitary and axillary.

About 15 species, all but the following from the Andes, chiefly of Mexico and California.

1. N. Sandwicensis, Gray, in Proc. Am. Ac. V, 338. - A low, divaricately branching annual, not exceeding $4^{\prime}$ in height, densely hispid with short gray hairs. Leaves subsessile, spathulate, $3-6$ "long, obtuse, entire, rather thick. Flowers single or more generally two on a short bractless peduncle of $11 / 2-3^{\prime \prime}$, which, terminal at first, soon becomes lateral and forks close to its base. Calyx parted to the base into linear-spathulate lobes, $1^{1 / 2}-2^{\prime \prime}$, twice as long with fruit. Corolla purplish, $2-3^{\prime \prime}$, its lobes as long as the tube. Capsule $3^{\prime \prime}$, ovoid-elongate. Seeds minute, scrobiculate.

On grassy plains and slopes: Ma ui! Kula and Wailuku; Oa hu! Kahuku and Waikiki; Kauai.

\section{Order LVII. OLEACEAE.}

Calyx usually small, 4- or 5-(rarely 6-8-) lobed or toothed. Corolla 4- or 5-(6-8-) lobed, with a long or short tube, or sometimes divided to the base into 4 or 2 petals, or entirely wanting. Stamens 2, adhering to the base of the corolla on opposite sides of the ovary, or rarely 4 alternating with the lobes of the corolla, or hypogynous in apetalous flowers. Ovary 2-celled, with 2 ascending or pendulous ovules in each cell. Fruit suceulent or capsular, entire or 2-lobed, often reduced to a single cell and seed. Albumen present or wanting. Embryo straight. Trees or shrubs, rarely herbs. Leaves opposite or rarely alternate, entire or pinnate. Flowers in axillary or terminal racemes or panicles, sometimes reduced to dense clusters.

A small Order, dispersed over the warmer regions of the globe. To it belong the Jessamines, of which Jasminum Sambac, Ait., and $J$. revolutum, Sims, are common in gardens, less so $J$. Azoricum. Of the following genus Olea fragrans and 0 . paniculata, R. Br., are in cultivation, also 0 . Europaea, which however seldom bears fruit.

\section{OLEA, L.}

Calyx 4-toothed or truncate. Corolla 4-lobed, with a short tube, or rarely none, the lobes usually imbricate. Stamens 2, rarely 4. Ovary 2-celled, with 2 pendulous ovules in each cell. Style short, entire. Fruit a drupe. Seed usually 1 , with a fleshy albumen. Trees or shrubs, often polygamous. Leaves opposite, entire. Flowers small, in axillary, rarely terminal, panicles, racemes or clusters.

A genus spread over the Mediterranean countries, tropical Asia, S. Africa, the Mascarene Islands, Australia and N. Zealand, with one species from N. America and the following one from our islands, which differs from all others in the 4-staminate flowers.

1. 0. Sandwicensis, Gray, in Proc. Am. Ac. V, 331. - A tall handsome tree, $30-50 \mathrm{ft}$. high, quite glabrous. Leaves pale, coriaceous, 
elliptico-oblong or lanceolate, $3^{1 / 2}-6^{i} \times 1-2^{\prime}$, on petioles of $6^{\prime \prime}$, acute. Flowers hermaphrodite, in axillary racemes of $1-2^{\prime}$ in length, on pedicels of $2-3^{\prime \prime}$, the short lanceolate bractlets soon deciduous. Calyx ${ }^{1} / 2^{\prime \prime}$, obtusely 4 -toothed. Corolla $2^{\prime \prime}$, pale yellow, with brownish streaks, rotate, parted to near the base into 4 rather obtusely ovate lobes which are imbricate in the bud. Anthers always 4, alternate with the lobes of the corolla and nearly of their length, sessile on the short tube, oblong, obtuse, dehiseing laterally. Ovary conical, elongate; stigma subsessile, 2-lobed. Drupe ovoid, peaked, 6-8" long, rather dry, bluish when mature, with an osseous putamen and a single seed. Embryo straight in the axis of horny albumen and $1 / 2$ its length, the obtuse foliaceons cotyledons turice as long as the superior radicle. - Wawra, in Flora, 1874, p. 548.

Seattering in the lower and middle woods of all islands; a prevailing tree in S. Kona, Hawaii! Nat, name: "Pua" or =Ulupua".

$\beta$ var. - Leaves ovate-oblong, sometimes ovate and somewhat obtuse, with broad-margined petiole and the lowest nerves pedate, the youngest leaves puberulous underneath along the costa. Racemes often branching from the base and their bracts foliaceous. Drupes large, 8-11" long, obtuse.

Kauai! Waimea (Kn., and M. \& B. in herb, Cornell Univ. without number).

\section{Order LVIII. SOLANACEAE.}

Flowers regular or nearly so. Calyx usually with 5 or 4 teeth or segments. Corolla with 5 or rarely 4 teeth or lobes, valvate and folded or rarely imbricate in the bud. Stamens as many as lobes of the corolla and alternate with them. Ovary superior, 2-celled or rarely incompletely 4-celled, with several ovules in each cell. Style simple, with an entire or lobed stigma. Fruit an indehiscent berry or a capsule, with several seeds. Albumen copious, fleshy. Embryo usually curved or spiral, surrounding the albumen, less frequently straight and central. - Herbs, shrubs or soft-wooded trees. Leaves alternate, without stipules.

A large Order, principally inhabiting the warmer regions of the globe.

Fruit a berry :

Calyx not inflated, though often enlarged after flowering:

Limb of corolla valyate-plaited in the bud; anthers longer than their filaments:

Corolla rotate, 5-lobed; anthers connivent

Corolla salver-shaped, 4-lobed; anthers sessile at the throat

Lobes of the funnel-shaped corolla imbricate in the bud; anthers shorter than their filaments

Calyx inflated after flowering; corolla campanulate:

Calyx shortly 5-lobed

Calyx of 5 broad cordate sepals.

1. Solanum.

2. Nothocestrum.

Fruit a capsule:

3. Lycium.

Capsule prickly, spuriously 4-celled

Capsule smooth, 2-celled

4. Physalis.

5. Nicandra.

To these might be added the genera Lycopersicum, represented by the Tomato, L. es-
culentum, Mill., and Capsicum, culentum, Mill., and Capsicum, the Red Pepper, with C. frutescens, L., C. baccatum, L., 
and one or two other species which, being of universal cultivation, are often found on refuse heaps or along roadsides. Ornamental shrubs belonging to this Order and not mentioned below are: Cestrum aurantiacum, Lindl., C. diurnum, L., C. nocturnum, L., Habrothamnus elegans and $H$. cyaneus, Brunfelsia Americana, Sw., and B. Hopeana, Benth.

\section{SOLANUM, L.}

Corolla rotate or slightly cup-shaped, the limb 5-angled or 5-lobed, folded in the bud. Anthers on very short filaments, oblong or linear, erect and connivent in a cone round the style, opening at the top by 1 or 2 pores, without any prominent connectivum between the cells. Ovary 2 -celled, with placentas attached to the dissepiment, and manyovuled. Style simple; stigma obtuse. Berry 2-celled. Seeds compressed, reniform or roundish. Embryo spiral, peripherical. - Herbs, shrubs or low trees. Leaves entire or irregularly toothed, lobed or divided, alternate, often in pairs, without stipules. Flowers in dichotomous or unilateral racemose or umbellate cymes, at first terminal but lateral at last, often disposed in a corymbose panicle.

A very large genus with the geographical range of the Order.

Anthers attenuate toward the apex:

The whole plant prickly with slender pale spines

Plant without spines:

Leaves cordate or orbicular, with ferruginous tomentum

Leaves ovate, white underneath; cyme-branches divaricate; eorolla 5 -fid to the middle; berry black

Leaves oblong, ferruginous underneath; cyme-branches erect; corolla parted to near the base.

1. S. aculeatissimum.

2. S. Nelsoni.

3. S. Sandwicense.

4. S. Kauaiense.

Anthers not attenuate at the apex:

Inflorescence cymose; corolla plaited; berry orange; plant generally prickly with short red spines

Inflorescence racemose; corolla deeply parted, not plaited.

Inflorescence umbellate, many-flowered

Flowers 2 on a common peduncle

5. S. ineompletum.

6. S. puberulum.

7. S, nodiflorum.

8. S, pseudocapsicum.

Here also the Potato, S. tuberosum, L, must be mentioned, which has maintained itself in some patehes on the slopes of Haleakala and the mountains of $\mathrm{Haw}$ aif, where it was cultivated years ago. The Egg-Plant, S. Melongena, L., in several varieties, is a common garden vegetable.

$\dagger$ 1. S. aculeatissimum, Jacq. - DC. Prod. XIII, 244. - Suffruticose, erect, 1-3 ft. high, hispid, the stem, leaves and calyx armed with long slender $\left(2-7^{\prime \prime}\right)$ stramineous thorns. Leaves ovate-oblong in outline, $3-7^{\prime} \times 1^{1 / 2}-6^{\prime}$, on petioles of ${ }^{1 / 2}-3^{\prime}$, deeply cut into 2 or 3 subacute lobes on each side besides a broad terminal one, rounded at the base, membranous, hispid on both faces with long simple spreading hairs, besides being speckled with a short stellate evanescent pubescence. Cymes short, $1 / 2-1^{\prime}$, few-(1-5-)flowered, with a common peduncle of about $1^{\prime \prime}$ only, the pedicels $4-6$ ". Calyx less than ${ }^{1 / 2}$ the length of the corolla, 5-fid into triangular lobes. Corolla 5 "long, whitish, hispid, parted to near the base into narrow lanceolate lobes. Anthers elongate, $3^{\prime \prime}$, slender, with 2 round apical pores, inserted near the base of the corolla with 
very short filaments. Style as long as the corolla, straight, with a 2-grooved stigma. Ovary glabrous. Berry globose, $1^{\prime}$ in diam., bright scarlet, with a tough rind. Seeds large discoid, winged. - Griseb. Fl. W. Ind. p, 442. - S. xanthocarpum, Seem. in Fl. Vit. (not Schrad).

Here and there in the lower regions of all jslands. The scarlet berries, strung into wreaths or leis, are worn as neck-ornaments by the native women. The name *Popolo* applies also to other species of the genus and recurs for such with dialectical modifications in Tahiti (*Oporo"), Viti (*Boro") and New Zealand. A native of Mexico and Brazil, but occurring also in S. Africa and Java.

2. S. Nelsoni, Dunal, in DC. Prod. XIII, 123. - A low shrub, unarmed, the sarmentose branches covered with a brownish-yellow stellate tomentum, as is the inflorescence. Leaves cordate-ovate to suborbicular, $1^{1 / 2}-2^{\prime} X$ $1-1^{3 / i^{\prime}}$, on petioles of $5-9^{\prime \prime}$, obtuse, quite entire, thick, clothed on both faces with a dense tomentum, paler below; the second leaf, when present, much smaller. Cymes few-flowered, longer than the leaves, the peduncle about 1:. Calyx tomentose, 5 -fid into ovate obtuse or narrow lobes. Corolla tomentose, 3 times longer than the calyx, 6 " in diameter, strongly plaited. Anthers twice as long as their filaments, short, attenuate at the apex, not incurved, opening by apical pores. Ovary hairy. Berry $4-5^{\prime \prime}$ in diam. - Gray, in Proc. Am. Ac. VI, 42. - S. rotundifolium, Nutt.

Hawaii (Nelson); isthmus of Maui (U. S. E. E.); Oahu! (Remy); Kauai (Nuttall).

$\beta$ var. thomasiaefolium. - Leaves sinuately lobed with $5-7$ lobes. Berry globose, as large as pea. - Seem. in Fl. Vit. p. 174. - S. vestitum, Nutt. in herb. Brit. Mus.

Kauai (Nuttall).

3. S. Sandwicense, Hook. \& Arn. in Bot. Beech. p. 92. - Shrubby, erect, unarmed, $4-6 \mathrm{ft}$. high, the branches canescent with a short cinereous or pale ochraceous tomentum, as are also the underside of the leaves and the entire inflorescence. Leaves single or geminate and subequal, ovate, $2-6^{\prime} \times 1-4^{\prime}$, on petioles of $1-2^{\prime}$, bluntly acuminate, subentire, sinuate or angular-sinuate, rounded at the base, sometimes subcordate, rarely somewhat contracted, often oblique with the blade deeper decurrent on one side, chartaceous, the upper face sprinkled with an evanescent stellate pubescence. Cymes $2-3^{i}$ long, corymbiform with divaricate, at last reflected, branches, the common peduncle ${ }^{1 / 2}-1^{\prime}$, the pedicels $6-8^{\prime \prime}$ when with fruit. Calyx $1-1^{1} / 2$ ", , its lobes triangular acute. Corolla puberulous outside, bluish-white, $5-6^{\prime \prime}$ in diameter, 5 -fid to the middle, plaited. Anthers almost sessile, scarcely $1 / 2$ the length of the corolla, short ovoid or oblong, curved, attenuate at the apex, with 2 apical pores. Style short, villous, as is also the young ovary. Berry globose, black, $4-6^{\prime \prime}$ in diameter. - DC. Prod. 1. c. p. 269. - Gray, 1. c. p. 43. - S. Woahense, Dunal, in DC. Prod. 1. c. p. 268.

In forests of Oahu! and Kauai! not uncommon. Fruiting eymes often appear racemose, since many flowers drop without being fecundated. 
$\beta$ var. - Leaves smaller, shortly 3-4-lobed on either side, the lobes broad and somewhat obtuse.

W. Maui!

My first collection from $\mathrm{Hawaii}$ holds, without label, a very large-leaved specimen with flower-buds too young to serve for examination, which possibly may belong here; but the ochraceous pubescence is Ionger and patent, not appressed, and the leaves resemble altogether those of $S$. repandum, Forst. This latter species Prof. Gray, 1. e., calls the "Feejee Tomato*, but Seeman in Fl. Vit. omits to mention that it is cultivated, and leaves us to infer that the "Feejee Tomato" is his $S$. anthropophagorum $=S$. viride, Sol. Be this as it may, I am not aware that the plant in question ever was cultivated on our group, and it would not seem unlikely that a species which is spread over the Viti, Society, Gambier and Marquesas Islands shonld occur on our islands also. The leaves are ovate, $8-9^{\prime} \times 3^{1 / 2}-5^{\prime}$, sinuately and acutely lobed, inequilateral at the base. Cymes short, many-flowered, stellately pubescent.

4. S. Kauaiense, Hillebr. - Erect, shrubby, unarmed, the branches, leaves and entire inflorescence thickly covered with a ferruginous woolly stellate tomentum. Leaves ovato- or elliptico-oblong, $4^{1 / 2}-7^{\prime} \times 2-3^{1} / 2^{\prime}$, on petioles of $1-2^{\prime}$, very acute, sinuate, moderately contracted at the base, subcoriaceous, with strong veins, thickly tomentose on the lower, sparsely so on the upper face. Infl. a corymbose cyme, $4-5^{\prime}$ long with a peduncle of $1^{1 / 2}-2^{\prime}$, its branches all erect, not divaricate. Calyx $1^{1 / 2}-2^{1 / 2^{\prime \prime}}$, deeply parted into linear or subulate lobes. Corolla rotate, $10^{\prime \prime}$ in diameter, villous inside and outside, parted to near the base into oblong not plaited lobes. Anthers subsessile, straight, short, attenuate, with apical pores. Ovary and style villous. - S. Sandwicense, var. (?) Kauaiense, Gray, I. c. p. 43.

Kauai! Waimea, in forests (U. S. E. E. and Kn.).

5. S. incompletum, Dunal, in DC. Prod. XIII, 311. - A decumbent straggling shrub, not rising above 2 or $3 \mathrm{ft}$. from the ground, the branches and inflorescence ochraceo-tomentose and sparingly armed, as are the leaves on both faces, with shining red short and broad compressed thorns. Leaves geminate, both nearly of equal size, ovato- or elliptico-oblong, $2^{1 / 2}-3^{\prime} \times 1-1^{3} / 2^{4}$, on petioles of ${ }^{1 / 2}-1^{\prime}$, sinuate or sinuate-lobed (3-5 lobes on each side), somewhat acute, slightly contracted at the base, stellate-pubescent on the upper face when young, ochraceo-tomentose or subglabrate on the lower, chartaceous. Cymes dichotomous and divaricate, on peduncles of $2-6^{\prime \prime}$. Calyx $1-2^{u}$, tomentose, with triangular or lanceolate teeth. Corolla purplish-white, $4-5^{\prime \prime}$ in diameter, tomentose, divided to the middle or less, and plaited. Filaments shorter than the anthers, these $1-1^{1 / 2} 2^{\prime \prime}$, broad, obtuse and straight, opening by 2 transverse apical pores or chinks. Berry about $6^{\prime \prime}$ in diameter, orange. Seeds not margined, 2 " in diam. - Gray, 1. c.

Haw aii! (Remy, Nelson and U. S. E. E.), Kawaihae iuka (Hbd.).

$\beta$ var. Mauiense. - Leaves larger, broad ovate, $4-7^{\prime} \times 2^{1 / 2}-3^{1} / 2^{\prime}$, on petioles of $1-1^{1} / 2^{4}$, sinuate-lobed, with uneven sided sometimes subcordate base, of thicker texture, with prominent nerves, tomentose underneath. 
Cymes large corymbose, compound, measuring $4-6^{\prime}$ each way, the peduncle $2^{\prime}$, the fruit bearing pedicels thickened at the end and recurved, $1^{\prime}$ long. Corolla hairy inside and outside, $5-6 "$ in diameter, the short filaments hairy at the base.

E. and W. Ma ui! Ulupalakua.

There is great variability as to prickliness; while some specimens fairly bristle with spines it requires eareful search to discover them in others, and such may be confounded with S. Sandwicense.

$\gamma$ var. glabratum. - Leaves glabrate on both faces, only the young ones sparingly furfuraceous underneath, elliptico-, rarely ovato-oblong, $2^{1} / 2-6^{\prime} \times$ $1^{1 / 4}-2^{1 / 2}$, sinuate or almost entire. Calyx glabrous. Corolla hispid externally. Berries large, $6-8^{\prime \prime}$, on thickened recurved pedicels.

Two forms from Lanai! both with large nnd many-flowered cymes, but one prickly all over, the other quite unarmed; E. Maui! Hamakua (Lydg.), a few scattering spines on the stem only, the eymes little developed and few-flowered.

6. S. puberulum, Nutall. - Seem. in Journ. Bot. I, 20\%. - "Shrubby, the younger branches furfuraceo-tomentose, at Jength glabrate. Leaves geminate, one much smaller than its mate, ovate-oblong, $3-4^{\prime} \times 2^{\prime}$, acuminate, quite entire, or sinuate-lobate with acute lobes, oblique at the base, furfuraceo-puberulous on both faces, ochraceo-tomentose when young. Flowers in simple racemes. Calyx glabrous, with lobes subulate, $1 / 3-^{1 / 4}$ as long as the tomentose deeply 5 -parted corolla. Berry globose, 9 " in diam., on pedicels of 1 . - S. puberulum and S. pulverulentum, Nutt. in herb. Brit. Mus.»

In forests of Oahu (Nutt.); Sandw. Islds. (Menz, in herb. Brit. Mus.). No account being given of the anthers or of the color of the berries, it does not appear to which of the two leading species it approaches. I have collected specimens in the forests of Mauna Kea, near Parker's ranch, which in most respects agree with the above description, but the cymes, although short and few-flowered, are not racemose, nor are the ealyxlobes subulate, although narrow and acute. Corolla $8-9^{\prime \prime}$ in diameter, deeply 5 parted withont folds. Anthers short, straight and obtuse, as in S. incompletum. Berry large, reddish. The branches are unarmed, thick woody, and, if recollection serves aright, for the label is lost, they came from a small tree.

7. S. nodiflorum, Jacq. - DC. Prod. XIII, 46. - A glabrous annual or biennial, $1-2 \mathrm{ft}$. high. Leaves flaccid, ovate, $2-4^{\prime} \times 1-2^{\prime}$, with a few sinuate teeth or lobules in the lower half, or nearly entire, the rounded or contracted base shortly decurrent into a margined petiole of $1 / 2-1$ '. Flowers $4-8$, subumbellate on peduncles of $9-12^{\prime \prime}$, the puberulous pedicels $4-6^{\prime \prime}$. Calyx $1^{\prime \prime}$, with deltoid lobes. Corolla $2-3^{\prime \prime}$, whitish, eleft to the middle. Stamens little shorter than the corolla, the anthers longer than their glabrous filaments, straight, oblong, broad at the top, with apical transverse chinks which finally extend down the sides. Style as long as the anthers, pubescent, incurved above. Berry black, $3-4^{\prime \prime}$ in diameter, pulpy. Seeds small obovate. $-S$. oleraceum, Dun., with many other species of the Morella section. - The peduncles rise from the upper half of an internode, often from under the next upper leaf pair. 
Rather common in clearings of the woods and along their outskirts; the "Olohua, and "Popolon of the natives, who eat the berries. The species is common in most tropical countries and eultivated in some as a potherb.

†8. S. pseudocapsicum, L. - DC. Prod. XIII, 152. - Suffruticose, erect, 1-2 ft. high, glabrous. Leaves narrow lanceolate, entire, acuminate at both ends, $1^{1 / 2}-2^{\prime}$ long including the short petiole, $1 / 4-1 / 2^{\prime}$ broad. Flowers extraaxillary, generally 2 on a peduncle of $1^{\prime \prime}$ or less, the pedicels $4-5$ " when in fruit, and thickened at the ends. Calyx 3 ", its lobes linear. Corolla 4 ", whitish, divided beyond the middle into ovate lobes. Anthers on very short filaments, about $1 / 2$ the length of the corolla, not attenuate, opening by transverse pores or chinks at the broad apex. Style longer than the anthers. Berry globose, $4^{\prime \prime}$ in diameter, reddish.

Molokai! Mopulehu and Kamalo; Mani! Kula; Hawaii, Hilo. A native probably of Southern Brazil and Buenos Ayres, but spread into various countries by eultivation.

\section{NOTHOCESTRUM, Gray.}

Calyx ovoid or tubular, unevenly 4 -toothed or the teeth almost bilabiate, persistent, splitting laterally at maturity. Corolla silky, salver-shaped, 4-lobed, the lobes ovate, valvate and folded in the bud. Anthers 4, sessile below the throat, linear acute, the cells opening inward and lengthwise. Ovary 2-celled; ovules many, attached to axile placentas. Style short, with a 2 -lobed stigma. Fruit a berry. Seeds suspended from a funicle, reniform, complanate, the testa chartaceous and pitted. Embryo peripherical, curved around a fleshy albumen, the thick clavate radicle longer than the eylindrical cotyledons. - Soft-wooded trees with a sweetish gummy sap. Leaves alternate, often approximate in pairs, entire. Flowers solitary or elustered on prominent spurs, obliquely axillary or interaxillary, viz., between the axils of a leaf-pair. Corolla greenish - yellow.

A small Hawaiian genus, nearest related to the $\mathrm{S}$. American genus Acnistus, Schott. Nat. name of all species: sAieas.

Flowers single, rareiy 2 or 3 ; ealyx and berry elongate: tube of corolla included

Flowers several, clustered on short axillary spurs; berry globose:

1. N. longifolium.

Leaves narrow oblong, acuminate at both ends; tube of corolla little longer than the campanulate calyx, which closes over the fruit

Leaves ovate or ovate-oblong; tube of corolla twice the length of the ureeolate calyx, which remains open with fruit .

\section{N. breviflorum.}

Leaves ovate-cordate; flowers as in $N$. latifolium, but often single

3. $N$, Latifolium.

4. N. subcordatum.

The species differ in characters of small value, nor are these very stable; their geographical areas also are rather diffise. No. 1 seems to run jnto no. 2 , but this latter is a tree of considerable size, while the former has only been observed by me as a tall branching shrub. Of no. 4 the material is very scanty, and it may prove to be only a good variety of no. 3 . 
1. N. longifolium, Gray, in Proc. Am. Ac. VI, 48. - A shrub or small tree with rather slender branches, quite glabrous. Leaves thin membranous, lanceolate or elliptico-oblong, acuminate at both ends, $4-7$ ' $X$ $1^{1 / 2}-2^{1 / 2}$, on petioles of $3-4^{u}$. Flowers axillary, single, rarely 2 or 3 together, drooping on pedicels of $4-9^{\prime \prime}$. Calyx tubular, 4-6" with flower, 7-10" with fruit, glabrous, sharply or obtusely and always unevenly 4 -toothed. Corolla pale yellow, with the tube not longer than the calyx, the reflexed lobes silky in the bud but soon glabrate, more than $1 / 2$ the length of the tube, obovate, with broad and erisp margins. Anthers $2^{\prime \prime}$, partly exserted. Stigma clavate, included. Berry elongate or fusiform, $6-10^{\prime \prime}$ long, orange-colored, rather fleshy, included in the calyx or exserted beyond.

Oahul Pauoa, Makaleha (flowers 2-3 together); Molokai! Kalae (leaves small, flowers single); Maui! Makawao, Ulupalakua, Lahaina (flowers 2 or 3, sometimes on short spurs).

$\beta$ var. brevifolium. - Leaves short, $2-4^{\prime} \times 1-1^{\prime} 2^{\prime}$, acuminate or obtuse at both ends.

Kauai!

2. N. breviflorum, Gray, l. c. p. 49. - A tree, 20-30 ft. high, with white bark, greenish wood and short scraggy branches. Leaves oblong, $2^{1 / 2}-4^{1 / 2}$ $\times 1^{1 / 4}-2^{1 / 4^{\prime}}$, on petioles of $1-2^{1 / 4^{\prime}}$, acute or obtuse at both ends, thin chartaceous, faintly tomentose underneath when young. Flowers many, clustered on short axillary spurs, the pedicels $2-4^{\prime \prime}$. Calyx tomentose, $4-5^{\prime \prime}$, campanulate with flower, globose with fruit and closed over it, dentate, almost bilabiate. Corolla greenish-yellow, silky at first, with the tube enclosed or only little exserted, 5-6" long, the lobes ${ }^{1 / 2}$ as long and narrowly margined. Berry globose, $3-4^{\prime \prime}$ in diam.

H a waii! Kawaihae iuka, Kilauea (leaves narrow aeute), Waimea (leaves broad obtuse, the flowers often few to two only).

$\beta$ var. longipes. - Leaves as above, acute at both ends. Pedicels erowded at the base of short branches, supported by scaly bracts, slender and long, $1-2^{\prime}$, drooping. Calyx ovoid, $3-4^{\prime \prime}$ with fruit, shortly 4 -toothed or- 2 -lipped.

Communicated by Mr. Lydgate without indication of habitat. The singular inflorescence may be owing only to an accidental rameal development of the spur, but the pedicels are much longer than in any other form of the genus.

3. N. latifolium, Gray, l. c. p. 48. - A small tree with rigid branches. Leaves broad ovate- or obovate-oblong, $2-5^{\prime} \times 1^{1 / 2}-2^{1^{1} / 2^{\prime}}$, on petioles of $3 / 4-2 ;$, obtuse, often rounded, ochraceo-tomentose underneath when young, puberulous at a later age, mostly of thick texture. Flowers clustered on short spurs, the pedicels $3-4^{\prime \prime}$. Calyx urceolate, 2-4", truncate, at length globose, tomentose or glabrate, open with fruit. Corolla greenish yellow, silky, the tube twice as long as the calyx, the lobes less than 
${ }^{1 / 2}$ its length. Anthers protruding. Style as long as the tube. Berry globose, $2-3^{\prime \prime}$ in diameter, dryish, pale yellow.

On dry forehills. Oahu! Waianae range; Ka uai! Waimea, leaves emarginate at the base, coriaceous, with ochraceous tomentum; calyx and corolla tomentose, the latter coriaceous, with narrow lobes; Molokai! Kalae, leaves ovate acute; Lanai! leaves obtuse, short, sometimes suborbicular.

$\beta$ var. - Leaves broadly ovate, the larger ones $8 \times 5^{\prime}$, with sinuate margins, sometimes subcordate, rather thin, pubescent along ribs and nerves; the calyx and corolla as above.

E. Maui! Ulupalukua and Hamakua.

4. N. subcordatum, Mann, Enum. no. 330. - A tree, 20-30 ft. high. Leaves ovate or cordate, $3-5^{\prime} \times 2-4^{\prime}$, on petioles of $1^{1 / 4}-1^{3 / 4^{\prime}}$, bluntly acuminate, thick coriaceous, glabrous. Flowers clustered, but often only a single one developed, on pedicels of $2-2^{1 /} / 2^{\prime \prime}$. Calyx $2-4^{\prime \prime}$, glabrous, campanulate with flower, globose with fruit but not closed over it. Corolla exserted, silky, yellow, its tube $4-5^{\prime \prime}$, the limb half as long and 4-5-lobed.

Oahu! ravines of Kaala and Wailupe.

\section{LYCIUM, L.}

Calyx 5- or 4-toothed or lobed, persistent but scarcely enlarged after flowering. Corolla tubular or funnel-shaped, with a small spreading or eampanulate 5-or 4-lobed limb, the lobes imbricate in the bud. Stamens inserted on the middle of the tube or lower; the anthers shorter than the filaments, opening lengthwise. Disk annular or cupular. Ovary 2-celled, the cells many-ovuled. Style filiform, with a shortly bilamellate stigma. Fruit a berry. Seeds reniform, compressed, with a pitted crustaceous testa. Embryo curved round fleshy albumen. - Shrubs, often thorny. Leaves usually small, entire, often fasciculate on short spurs. Flowers pedicellate, solitary or clustered in the axils of leaves or at the old nodes.

A geuus of $60-70$ species, chiefly of extratropical America and S. Africa, with a few species dispersed over the warmer regions of the old World.

1. L. Sandwicense, Gray, in Proc. Am. Ac. VI, 44. - An erect shrub, $2-3 \mathrm{ft}$. high, with stiff branches, glabrous. Leaves mostly fascieulate, fleshy, spathulate, about $1^{\prime}$ long and $3^{\prime \prime}$ broad near the rounded apex, thence narrowing gradually to the slender base, not distinctly stalked, veinless, with faint midrib. Pedicels single, $4-6^{\prime \prime}$. Calyx $1^{1 / 2}-2^{\prime \prime}$, eleft into 4 triangular lobes. Corolla glabrous, whitish or pink, its tube not exceeding the calyx, the 4 lobes longer, about $3^{\prime \prime}$, ovate, spreading, reticulate-veiny. Filaments naked. Berry globose, $4-5^{\prime \prime}$ in diameter, red. - Mrs. Sinclair, pl. 24.

Nibau; Oahu! along the seacoast, Honolulu, Kapalama, Dinmond, Hill, Wailupe, Kailua, Kahuku; probably also on other islands. Nat. names: Aeae and Ohelo kai. The berry is edible but not very palatable. 


\section{PHYSALIS, L.}

Calyx 5 -toothed or lobed, permanent, inflated after flowering. Corolla broadly campanulate or nearly rotate, 5 -angled, folded in the bud. Stamens 5 , included, inserted near the base of the corolla; anthers erect, opening lengthwise. Ovary 2-celled. Stigma'shortly bilamellate. Berry globular, enclosed in the bladdery calyx. Embryo curved round albumen. Herbs. Leaves often in pairs. Flowers solitary on axillary or lateral pedicels, often in forks of the stem.

About 30 species, chiefly American, with a few species dispersed over parts of the old World.

1. P. Peruviana, L. - DC. Prod. XIII, 440. - A perennial spreading herb, villous-pubescent with simple hairs. Leaves ovate or cordate, sharply pointed, sinuately toothed or almost entire, $2-3^{\prime} \times 1^{3 / 4}-2^{\prime}$, on petioles of $1 / 2-1^{4}$. Pedicel $4-6^{\prime \prime}$. Calyx pubescent, campanulate, 5 -fid with acute lobes, $4^{\prime \prime}$ long when with flower, $1^{1 / 2}-2^{\prime}$ long when with fruit, inflated and obtusely keeled. Corolla campanulate, $6-8^{\prime \prime}$, yellowish, with 5 large purple blotches within. Anthers purple. Berry yellow, 5-6" in diameter, enclosed in the bladdery calyx. - Bot. Mag. tab. 1068. P. pubescens, R. Br. (not Cliff.). - P. edulis, Sims. - Griseb. Fl. W. Ind. p. 435.

Common on open mountain slopes and in elearings of woods, particularly on Maui and $\mathrm{H}$ a wa $\mathrm{i} i$ between 1500 and $4000 \mathrm{ft}$. Nat. name: Poha. The edible berry is of pleasant flavor and makes an excellent jelly. - A native of Brazil, but naturalized in many warm countries; commonIy known as eCape Gooseberry».

\section{NICANDRA, Gaertn.}

Calyx of 5 distinct broadly cordate sepals which become much enlarged and inflated in fruit. Corolla campanulate with 5 broad short lobes, folded in the bud. Stamens 5, subexserted; anthers short, opening lengthwise. Stigma oblong, 3-5-lobed. Ovary 3-5-celled, with axile placentas. Fruit a berry, enclosed in the enlarged ealyx. Seeds many, reniform, compressed, dotted. Embryo curved round albumen.

A single species.

†1. N. physaloides, Gaertn. - DC. Prod. XIII, 434. - An erect glabrous annual or biennial, $1-3 \mathrm{ft}$. high. Leaves ovate, $5-6^{t} \times 2^{1} / 2-3^{\prime}$, acuminate, irregularly sinuate or coarsely toothed or lobed, the suddenly cuneate base decurrent into a petiole of $1 / 2-1$. Flowers solitary on pedicels of $3-9^{\prime \prime}$ in the upper axils, forming a terminal leafy raceme. Sepals at first herbaceous and $6-9^{\prime \prime}$ long, but with fruit $15-18^{\prime \prime}$ long, stramineous, much veined and closely connivent, forming a vesicular calyx with very prominent angles. Corolla pale blue, about 1 ' long. Berry globose. - Benth. Fl. Hongk. p. 244.

Oahu! on the plains between Ewa and Waialua, also in Kapalama and Moanaluat. A native of S. America. 


\section{DATURA, L.}

Calyx tubular, breaking away transversely near the base after flowering. Corolla funnel-shaped, with a long tube and a broad 5-angled or 5-toothed limb, folded in the bud and twisted. Ovary 2 -celled, each cell incompletely divided into two. Style filiform, with an oblong bilamellate stigma. Fruit an ovoid or globular prickly capsule, opening into 4 short valves. Embryo curved. - Tall coarse herbs, shrubs or small soft-wooded trees. Leaves alternate, often in pairs. Flowers solitary, terminal or lateral, usually very large.

A small genus, common to both Worlds.

† 1. D. Stramonium, L. - DC. Prod. XIII, 540. - A glabrous annual, 2-4 ft, high. Leaves large ovate, sinuately dentate. Calyx 5-toothed, half as long as the white corolla, which is $2-3^{\prime}$ long with the limb pointedly 5 -toothed, spreading and gradually passing into the cylindrical tube. Upper prickles of the capsule much shorter than the lower.

A tronblesome weed near Honolulu; and spread over various parts of the Islands. Nat. name: "Kikania". A plant of uncertain origin, but naturalized in many warm and temperate regions of both Worlds. The leaves and seeds are narcotic. The fFloripondio: D. (Brugmansia) arborea, L., an inmate of most gardens, is occasionally met with in the outskirts of the lower woods, but as the plant rarely produces seed its presence in those places is probably due to the agency of man.

\section{NICOTIANA, L.}

Calyx tubular, 5-toothed or lobed, persistent. Corolla funnel-or salvershaped, plaited in the bud and twisted. Stamens included. Stigma capitate, 2-lobed. Capsule 2 -celled, septicidal, the valves bifid. Embryo slightly curved. - Tall herbs or shrubs, usually viscous. Leaves almost entire. Flowers in terminal panicles or racemes.

A large genus of American origin.

†1. N. glauca, Grah. - DC. Prod. XIII, 562. - A tall shrub, 8-12 ft. high, quite glabrous. Leaves ovate-cordate, $5 \times 3^{\prime}$, on petioles of $3^{\prime}$, acute, entire, of glaucous hue. Flowers in terminal panicles with subulate bracts. Calyx faintly angular, 5-toothed. Corolla yellow, softly pubescent, 3 times longer than the calyx, its tube incurved, inflated at the throat and contracted at the mouth, the limb very short.

Of late introduction, but fairly naturalized. A native of the La Plata countries.

N. Tabacum, L., the common Tobacco, is cultivated by the natives, but, although occasionally a plant escapes from the enclosures, it cannot be considered as naturalized. It thrives admitably and yields a weed of fine flavor but too strongly narcotic to be available for cigars by the ordinary methods of euring the leaf.

\section{ORDER LIX. CONVOLVULACEAE.}

Sepals 5, persistent, distinct and imbricate or very rarely united into a 5 -toothed calyx. Corolla usually campanulate or funnel-shaped, or rarely with a cylindrical tube or rotate, the limb entire and 5 -folded, 5 -angled 
or lobed, generally convolute or twisted in the bud. Stamens 5, alternate with the lobes or angles of the corolla and inserted in the tube, often of unequal length. Ovary usually free, entire, 2-4-celled, with 2 or 1 erect ovules in each cell, rarely divided into 2 or 4 distinct uni-ovulate carpels, or 1 -celled with $2-4$ ovules. Style single, entire or bifid, or two distinct styles. Fruit either a capsule, opening into 2 or 4 valves, leaving the dissepiments attached to the axis, or opening transversely, or succulent and indehiscent. Seeds with a small quantity of mucilaginous albumen, or without any. Cotyledons folded or crumpled, rarely straight, or undivided and minute. - Herbs, often twining or parasitical, or rarely shrubs, woody climbers or even trees. Leaves alternate, without stipules. Inflorescence various, usually axillary and more or less cymose.

A large Order widely spread over the globe, but most abundant in warm countries. Corolla plaited or induplicate in the bud (Convolvuleae):

Corolla contorted or twisted :

Style 1, with 2 globose stigmas:

Fruit 4-celled, indehiscent

Fruit a 2-celled eapsule opening into valves

Style 1 , with 2 clavate-oblong compressed stigmas

Corolla not twisted in the bud; styles 2 , connate at the base, with globose stigmas

Corolla lobed, the lobes imbricate in the bud; styles 2

Cotyledons straight, twice plaited; a low prostrate herb (Cresseae)

Embryo undivided, eurved or spiral; a leafless parasitie twiner (Cuscuteae)

1. Argyreia

2. Ipomoea.

3. Jacquemontia.

4. Breweria.

5. Cressa.

6. Cuscuta.

\section{ARGYREIA, Lour.}

Sepals 5. Corolla large, funnel-shaped, plaited-angular or 5-lobed. Stamens included, with oblong anthers. Style 1 , filiform, with 1 globose 2-lobed or with 2 globose stigmas. Ovary 4-celled, 4-ovuled, seated on an annular disk. Capsule indehiscent, coriaceous or fleshy, surrounded by the enlarged calyx, often 1 -seeded. - Frutescent climbers with showy purple or white flowers.

An Indian genus of 24 species, one of African origin.

$\dagger$ †. A. tiliaefolia, Wight, in Calcutta Journ. Nat. Hist. VIII, 179. - Icon. Pl. Ind. Or. tab. 1358. - A stout woody climber, the young shoots canescent. Leaves cordate or reniform, $2^{1 / 2-3^{\prime}}$ in length and as much or more in breadth, shortly acuminate or obtuse, with rounded auricles, glabrate with age. Peduncles stout, $1-3^{\prime}$, subumbellately $3-4$-flowered, the pedicels $1 / 2-1^{\prime}$. Sepals coriaceous, silky - pubescent, $5-10^{\prime \prime}$, the outer ones larger, broad orbicular, with scarious margins. Corolla pale purple, $2^{1} 2^{\prime}$ long. Style enclosed. Capsule large, coriaceous. Seeds rounded, tomentose. Convolvulus tiliaefolius, Desr, - Rivea tiliaefolia, Choisy, in DC. Prod. IX, 325. - Ipomoea Turpethum, Mann, Enum. no. 376. - Mrs. Sinclair, pl. 14. Here and there on most islands. Molokai! Mopulehu; W. Maui! Kaanapali; Hawaii!
Hilo; Oahu! (M. \& B. 42); Kauai! (Mrs. Sinclair). Nat. name: "Pilikai *. Probably
an escape from egrly an escape from early cultivation. The species is common in India and has spread to various other countries. In eultivation : $A$. speciosa, Sw., and $A$. argentea, Chois. 


\section{IPOMOEA, L.}

Sepals 5. Corolla campanulate, or tubular with a spreading limb, entire or angular or shortly, seldom deeply, lobed. Ovary 2-(or 3-)celled with 2 ovules in each cell, or 4 -celled by the addition of a spurious partition between the ovules. Style filiform. Stigma capitate, entire or with 2 short round lobes. Fruit a dry capsule with valves seceding from the dissepiments. - Twining, prostrate, creeping, or rarely low and erect herbs, occasionally woody at the base, or very rarely shrubby. Leaves entire or lobed. Flowers often large and showy, solitary, or more frequently in small cymes, generally in the axils of leaves, rarely paniculate.

A very large genus, dispersed over all warm climates, with a few species extending into N. America and extratropical Africa and Australia.

In cultivation: I. purpurea, I. Nil, I. Quamoclit, I. coccinea, I. umbellata and others.

Terrestrial creepers, rooting at the joints

Leaves rounded at the base and emarginate at the apex:

Leaves obovate or orbicular

Leaves ovate- or linear-oblong

1. I. pes-caprae.

Leaves cordate at the base:

Leaves entire; flowers white

Leaves sinuate, angular or dissected

2. I. acetosaefolia.

Twiners :

Leaves entire, cordate

Corolla long tubular, with a spreading limb, white

3. I. reptans.

4. I. Batatas.

Corolla tubular-eampanulate:

Glabrous; uppermost leaves hastate; corolla small, pinkish; stigma 2-lobed

5. I. bona-nox.

Pubescent; all leaves broadly ovate-cordate; corolla large, blue; stigma almost entire

9. I. Forsteri.

Leaves palmately eut:

Palmatifid, the lobes linear-oblong, not narrowed at the base

Palmatisect, the lobes ovate-lanceolate, contracted below or stipitate:

Hispid; flowers white

Glabrous; flowers purplish to pink

10. I. in sularis.

8. I. dissecta.

6. I. pentaphylla.

7. I. tubereulata.

1. I. pes-caprae, $S w$. - DC. Prod. $I X, 349 .-$ A glabrous perennial with prostrate creeping stems. Leaves ovate, obovate or suborbicular, $2-3^{\prime}$ in diameter, on petioles of the same length or longer, broadly emarginate or obtusely 2 -lobed at the top, rather thick, with nearly parallel oblique veins, the lowest converging at the base of the leaf, which sometimes bears one or two glands. Peduncles $1-2^{\prime}$ long, 1 - or fewflowered, the pedicels ${ }^{1 / 2}-1$ '. Sepals obtuse, broadly ovate, $3-4^{\prime \prime}$, the inner ones rather longer. Corolla dusky-pink, $1^{1 / 2}-2^{\prime}$, obscurely lobed, campanulate, gradually tapering to the base. Ovary partially 4-celled at first. Stigma 2-lobed. Capsule 2-celled, ovoid, ${ }^{1} / 2 \%$. Seeds pubescent. - Benth. Fl. Hongk. p. 238. - Griseb. Fl. W. Ind. p. 470. - Convolvulus pes-caprae, L. - I, maritima, R. Br. - Mrs. Sinclair, pl. 16.

On all sandy beaches. 'Nat. name: PPohuehues. - A common sea-coast plant in nearly all tropical countries. 
2. I. acetosaefolia, Roem. \& Sch. - A glabrous creeper, Leaves ovateor linear-oblong, obtuse or emarginate, entire or sinuate, cordate or rounded at the base. Peduncles about as long as the petioles, 1 -flowered. Sepals $4-5^{\prime \prime}$, ovate-oblong, obtuse, mucronate, the two outer ones a little shorter. Corolla white, $2^{\prime}$ long, gradually tapering to the base. Ovary 4-celled at the summit, 2 celled below. Stigma 2-lobed. - Griseb. Fl. W. Ind. p. 471. - Convolvulus acetosaefolius, Vahl. - Batatas acetosaefolia, Chois. in DC. Prod. IX, 338. - Conv. repens, Sw. - Mrs. Sinclair, pl. 28.

Niih a u (Remy). Nat. name: sHunakai - A native of the W. India Islands, Guiana and Brazil, where it grows on sandy sea-shores.

$†$ †. I. reptans, Poir. - DC. Prod. IX, 349. - Creeping and rooting on swampy ground or floating on still waters, herbaceous, glabrous. Leaves thin, ovate-cordate or oblong, often sagitatte, $2^{1 / 2}-4^{\prime} \times 1^{1 / 2}-3^{\prime}$, on petioles of $2-3^{1 / 2^{1}}$, acuminate with a subulate point, entire, the auricles rounded or rather acute or somewhat angular. Peduncles $2-3^{\prime \prime}$ cymosely $3-5$-flowered, the pedicels ${ }^{1 / 4}-3 / 4^{\prime}$. Sepals $3-4^{\prime}$, ovate, obtuse. Corolla white, campanulate, with rather narrow tube, $1-1^{1 / 4^{\prime}}$ long, the broad spreading limb nearly entire. Ovary 2-celled. Stigma 2-lobed. Convolvulus reptans, $\mathrm{L}$.

Oahu! in old taro ponds round Honolulu, Pauoa. The plant, which oceurs in tropical Africa and Asia and is cultivated in China and parts of India as a potherb, probably came over with the Chinese.

4. I. Batatas, Lam. - A glabrous creeper with a tuberous root. Leaves very variable, cordate, repand-entire, angular or more or less deeply 5 -lobed, $2-6^{\prime}$ long. Peduncles as long as the petioles or longer, cymosely 3- to several-flowered. Sepals ovate or oblong, mucronate, $5-6^{\prime \prime}$, the outer ones shorter. Corolla campanulate, about $2^{4}$, pale purple or red, sometimes whitish. Capsule 2 - or imperfectly 4 -celled. Seeds glabrous, excepting a few puberulous lines. - Convolvulus Batatas, L. - Batatas edulis, Chois. in DC. Prod. -- Mrs. Sinclair, pl. 15.

The Sweet Potato, of aboriginal eultivation, was, next to the taro, the principal article of food to the natives at the time of the discovery. They enumerate about 20 varieties which differ as much in shape, color and quality of the tuber as in shape of the leaves. The vernacular name "Ualav corresponds well with the Tahitian "Umaras and the New Zealand "Kumara*, and it is interesting to note that $B$. Seeman has met with the same verbal root "Cumar" for this esculent among the Quichuas of Ecuador. While the plant used to be considered formerly as of Asiatic origin, Grisebach supposes it to be a eultivated variety of the American $I$. fastigiata, Sw. The Malayan name "Ubis is certainly not an original one, but transferred from the yam, the name for which has retained the same root in the Polynesian *Ufis and "Uhi.

5. I. bona-nox, L. - A glabrous twiner, often of great size, the stems sometimes retrorsely muricate. Leaves on petioles of $4-64$, cordate, $4-6$. in length and little less in width, long acuminate, with rounded auricles. Peduncles $3-7^{\prime}$ long, 3 - or cymosely several-flowered, the pedicels $1 / 2-1^{\prime}$ long. Bracts lanceolate, $1^{\prime}$. Sepals chartaceous, unequal, the two interior ones ovate-oblong, obtuse, the three exterior $9^{\prime \prime}$ long, ovate-lanceolate, 
running out into long filiform points. Corolla white, salver-shaped, the long slender tube measuring $3-4^{\prime}$ in length, the spreading limb $3-4^{\prime}$ in diameter. Stamens and style exserted. Anthers linear, at length twisted. Ovary 2-celled. Stigma 2-lobed. Seeds glabrous. - Benth. Fl. Hongk. p. 238. - Calonyction speciosum, var. vulgare, Chois. in DC. Prod. IX, 345.

Interspersed with $I$. insularis, but much less frequent. The large showy flowers are fragrant and open only late in the afternoon, to fade the next moruing. The species is widely spread through the tropical regions of both Worlds, but probably originated in India,

6. I. pentaphylla, Jacq. Icon. Rar. tab. 319 (not. Cavan.). - A herbaceous annual, twining, the stems, leaves and inflorescence hirsute with stiff spreading tawny hairs which are at least 2 "in length. Leaves on long petioles of $3-7$ ', membranous, hairy on both faces, suborbicular in outline, $4-5^{\prime}$ in diameter, palmately cut to the base into 5 obovate or elliptical acuminate segments which are contracted, often stipitate at the base. Peduncles shorter than the petioles, $1^{1 / 2}-5^{\prime}$, bearing $3-7$ flowers in regular dichotomous cymes, the ultimate pedicels $7-8^{\prime \prime}$, the linear bracts $3^{\prime \prime}$. Sepals chartaceous to scarious, ovate-lanceolate, $6-8^{\prime \prime}$, the three exterior longest and somewhat acute. Corolla twice as long as the calyx, white, tubular-campanulate. Anthers included, at length recurved. Ovary spuriously 4-celled. Stigma 2-lobed. Seeds glabrous. - Convolvulus pentaphyllus, L. - Batatas pentaphylla, Choisy, in DC. Prod. IX, 339. Griseb. in Fl. W. Ind.

In grassy plains and on fallow fields of the lower and midale regions. Occurs in most tropical countries of the New aud old World.

7. I. tuberculata, Roem. \& Sch. - DC. Prod. IX, 386, var. trichosperma. - A stout glabrous twiner with a tuberous root. Leaves on petioles of $1-2^{i}$, thin, ovate or orbicular in outline, with a diam. of $2-3^{i}$, palmately cut to the base into 5 lanceolate or ovate-lanceolate, at both ends acuminate, entire lobes, the two lowest being generally again bifid. Flowers 3,5 or 7 in a subumbellate cyme, on a common peduncle of $3 / 4-1 \frac{1}{2}$, the pedicels ${ }^{3} 4^{\prime}$, with minute bractlets at their bases. Sepals $3-4^{u}$, chartaceous to scarious, ovate-lanceolate, acute when with flower, much broader with fruit. Corolla purplish red, campanulate, 2', the limb angular-lobed. Ovary 2-celled. Capsule smooth. Seeds globose, 3", obtusely angular, silky with fulvous hair, this being longest on the angles. - Conv, tuberculatus and C. Cairicus, Hook. \& Arn. in Bot. Beech. - I. palmata, Mann, Enum. no. 378. - In the typical form of the species the seeds are naked. The African I. palmata has hairy seeds but serrulate leaves. - Mrs. Sinclair, pl. 13.

Common on all islands in low and dry rocky regions, - Nat. names: "Koaliv and Koali ais. - The tuberous roots are said to have been eaten formerly by the natives in times of scareity; the stems were used as cordage. The species extends over tropical Asia and parts of $\mathrm{S}$. America. The supposed stipular organs are the first leaflets of an axillary bud which deflect outward and generally remain undeveloped. They are not present with all leaves, and are wanting in the youngest near the end of a branch. 
$\beta$ var. lineariloba. - Leaves small, $1-1^{1 /} / 2^{\prime}$ in diam., with $7-9$ linear lobes, those of the one or two outer pairs deeply bifid.

South coast of Molokai!

8. I. dissecta, Willd. \& R. Br. - DC. Prod. IX, 363. - Leaves on petioles of only $1 / 2^{\prime}$ in length, subcoriaceous, shortly and softly pubescent on both faces, $13 / 4-2^{\prime}$ long and about as broad, deeply eut, but not to the base, into 3 (the 2 outer bifid) or 5 linear-oblong lobes which are $3-4^{\prime \prime}$ broad and bluntly acuminate, not contracted below, the 2 outer ones being provided with an acute tooth near the base. Peduncle stiff, $1-1^{1} / 4^{\prime}$, bearing 3 flowers on pedicels of $7-9^{\prime \prime}$, the outer ones minutely bracteolate at the base and middle. Sepals $6-7$ ", linear-oblong, bluntish, nearly equal, perhaps the two inner ones a little longer. Corolla (in bud) apparently purple.

W. Maui! above Maalaea bay, communicated by Mr. Lydgate. It is with some hesitation that I refer this very distinet plant to the above named species. From the small fragment which came without accompanying notes it is impossible to judge whether the plant is a twiner or creeper; nor bave I learnt whether it grew by the sea or on the hills. $I$ : dissecta, Willd. ( $I$. diversifolia, $\mathrm{R}$. Br.) is a native of $\mathrm{E}$. India and Australia,

9. I. Forsteri, Gray, Bot. U. S. E. Exp. (ined.). - Subherbaceous, the stems slender, twining, glabrous. Leaves gradually decreasing in size toward the apex, membranous, brownish when dry, on petioles of $2-1 / 2^{\prime}$ the lowest ovate-cordate, $3-3^{1} / 2^{\prime} \times 1{ }^{1 / 2}-2^{\prime}$, pointedly acuminate, with broad sinus and rounded auricles, the upper ones ovate-oblong to lanceolate-sagittate, falling off to $1^{\prime}$ in length and $4^{\prime \prime}$ in width, with narrow sinus and somewhat acute approximate auricles, often mucronate at the apex and sometimes at the everted tips of the auricles also. Peduncle $1^{1 / 2}-3^{\prime}$, bearing a cymose umbel of $3-7$ flowers on pedicels of $1 / 2$. Sepals $3-4^{\prime \prime}$, nearly equal, chartaceous, scarious when with fruit ovate, mucronate to aristate. Corolla $1-1^{1} / 4^{\prime}$, dusky-red, tubular-funnel-shaped, the limb little spreading and slightly lobed. Style $1 / 2$ the length of the corolla or little more, with a biglobose stigma. Stamens shorter, of equal height, the flat filaments as well as the oblong sagittate anthers coarsely pubescent. Seeds black and glabrous. - I. carnea, Forst. (non Jacq.). I. obscura, Guillem, in Zephyr. Taitens. - I. sepiaria, Seem. in Bonpl. 1861, p. 258. - I sidaefolia, Wawra, in Flora, 1874, p. 363.

Hawaii! Hilo (U. S. E. E. and Lydg.).

$\beta$ var. pauciflora. - Peduncle very short, $2-3^{n}$, bearing generally 1 , sometimes 2 or 3 flowers, on pedicels of $6-9^{\prime \prime}$, the bractlets minute, linear.

On the borders of taro ponds in Haula, Oahu! Halawa, Molokai! and W. Maui! The slender plant twines round the stems of rushes and low shrubs and does not seem to be creeping in the proper sense; otherwise it is much like I. littoralis, Bl., from Java and Ceylon. Occurs also in the Society, Viti and Tonga Islands, probably not distinct from I. denticulata, Choisy, which inhabits the same and other Polynesian islands and varies like our plant spedunculis raro multifloris et aurieulis integris. Our var. $\beta$ answers well to the typical description of that species in the Prodromus. 
10. I. insularis, Steud. Nomencl. - A stout twiner with woody base, the young branches hispid with soft retrorse hairs. Leaves cordate, with broad rounded sinus and auricles, $3-4^{1} / 2^{\prime}$ long and nearly as broad, acuminate, silky-pubescent on both faces when young, the petioles 2-4' long. Peduncles exceeding the petioles, 2- to several-flowered, the pedicels $2-6^{\prime \prime}$, the linear-lanceolate bracts of the same length or more. Sepals herbaceous, lanceolate, long acuminate, ${ }^{1} / 2-3 / 4^{1}$, pubescent. Corolla tubular-campanulate, $2-3^{\prime}$ long, azure blue, reddish when dry, ciliate at the bottom of the tube, as are also the bases of style and stamens. Stamens $1 / 2$ as long as the corolla. Style as long as the stamens, the stigna entire, globose. Capsule globose, about the size of a small cherry, the two seeds dark brown, glabrous. - Pharbitis insularis, Choisy, in DC. Prod. IX, 341. - Convolv. purpureus, Hook. \& Arn. in Bot. Beech. - Mann, Enum. no. 374. - Wawra, 1. c. 1874, p. 363. - Remy's No. 414 has the leaves lobed and rather obtuse. - Mrs. Sinclair, pl, 12.

Very common in the lower woods, where it wraps small trees and shrubs in dense entangled masses. Corolla oecasionally roseate. Nat. names: "Koalin and "Koali awahia" The species oceurs also in the Tonga and Viti Islds., the Ladrones, in Tanna, Norfolk Isld., and on the east coast of Australia. The root is a powerful cathartie, much used in native medicine, but not without danger, as it irritates the kidneys; is also employed externally in bruises and fractures of bones.

\section{JACQUEMONTIA, Chois.}

Sepals 5. Corolla campanulate, angular or broadly 5-lobed. Stamens included. Style filiform, with 2 flattened ovate or oblong stigmatic lobes. Ovary 2-celled, 4-ovuled. Fruit a capsule opening into 4 or rarely 8 valves. - Twining or prostrate herbs, sometimes woody at the base. Leaves entire, very rarely lobed. Flowers rather small, in axillary pedunculate cymes, rarely paniculate.

A tropical genus, chiefly American, distinguished from Convolvulus by the thicker and complanate stigmatic lobes. Our plant is in this respect intermediate between the two.

1. J. Sandwicensis, Gray, in Proc. Am. Ac. V, 336. - Stems prostrate, $1-2 \mathrm{ft}$. long, glabrous or pubescent, scarcely woody at the base. Leaves rather thick, obovate or broadly cuneate, $3 / 4-\left.1^{1 / 2}\right|^{4} \times{ }^{1 / 2}-1^{4}$, on petioles of $3-6^{\prime \prime}$, emarginate at the apex, entire, generally glabrate. Peduncles slender, about 1 ' long, umbellately or cymosely $3-7$-, often only 2 - or 1 -flowered, the pedicels $6-9^{\prime \prime}$, the bractlets linear and small or lanceolate and larger. Sepals herbaceous, $3-5^{\prime \prime}$, the three outer ones broadly ovate obtuse, the two inner ones little shorter, but much narrower and acuminate. Corolla campanulate, 5-6", angularly lobed, glabrous, pale blue. Stamens shorter than the style, dilated and puberulous at the base, the anthers sagittate, versatile. Stigmatic lobes thick clavate-oblong, slightly complanate. Capsule globose, $2^{\prime \prime}$. Seeds glabrous or slightly puberulous. - 
Wawra, in Flora, 1874, p. 364. - Conv. ovalifolius, Hook. \& Arn. in Bot. Beech. - Ipomoea ovalifolia, var. $\beta \& \gamma$, Choisy, in DC. Prod. as to the Sandw. Isld. plants.

Common on the plains and rocky slopes of the lower regions. In the neighborhood of the sea the leaves are apt to become fleshy. Dr. Pickering reported the root to be tuberous and edible, while in Andrew's dictionary it is stated to be cathartic. Nat. name: *Pauohiiakas.

$\beta$ var, tomentosa. - The whole plant, including the inflorescence, clothed with a thick and soft fulvous tomentum. Leaves thick fleshy. Peduncles Jonger than the leaves. Calyx and corolla larger than in $\alpha$.

Southern shore of Molokai!

\section{BREWERIA, R. Br.}

Sepals 5. Corolla tubular-campanulate, the limb entire or nearly so, plaited but not contorted in the bud, Stamens included, with slender filaments and ovoid or oblong anthers. Ovary $2-$ celled, each cell with 2 ovules. Style 1, deeply bifid, or 2 styles, filiform with small capitate stigmas. Capsule opening into 4 valves or indehiscent. - Diffuse or prostrate herbs or undershrubs, sometimes climbing, with entire leaves. Flowers white, yellow or red, axillary or in a leafy thyrsus.

A genus of about 20 species spread over the warmer parts ot all continents. - Benth. $\&$ Hook. Gen. Pl. II, 876. - The authors of the Genera Plant. keep separate the genus Bonamia, Thouars, founded on a single species from Madagasear, on the ground that the latter has a fleshy aril to the seed and exserted stamens affixed to the middle of the tube, which again is deeply 5 -fid. Gray has united both genera under the older name Bonamia. The mucilaginous layer, which covers the entire seed in our species, does not seem to be of the nature of an arillus.

1. B. Menziesii, Benth. \& Hook. Gen. Plant. II, 876. - Woody, with far spreading straggling branches, twining at the ends, tomentose with fulvous hair, as are the underside of the leaves and the inflorescence. Leaves broad-oblong, $2-3^{\prime} \times 1-2^{\prime}$, on petioles of $1 / 2-1^{\prime}$, obtuse, mucronate, often emarginate, entire, rounded at the base, soft coriaceous. Flowers single (rarely two) on peduncles of $6-9{ }^{\prime \prime}$, which are articulate above their bases, the linear bractlets $2^{\prime \prime}$. Sepals coriaceous, silkytomentose, $4-5^{\prime \prime}$ long, ovate, obtuse, the inner ones a little shorter. Corolla broad funnel-shaped, $8-10^{\prime \prime}$, very shortly cut into 5 broad truncate apiculate lobes, of thick texture, yellowish-brown to greenish, silky externally, except in the infoldings, glabrous inside. Stamens inserted near the base, more than half the length of the corolla, the filaments naked, not dilated, the short oblong acute anthers dorsally affixed. Styles as long as the corolla, separate to near the base. Capsule ovoid, $8^{\prime \prime}$, peaked, thick chartaceous, indehiscent, the dissepiment wanting in the middle. Seeds mostly 2, elongate, angular-convex, the chartaceous deep red testa uniformly and completely covered with a mueilaginous episperm which appears black when dry. Embryo surrounded by some mucilaginous 
albumen, the broad ovate-cordate cotyledons corrugate-plicate, rounded at the apex, the terete radicle geniculately inflexed, inferior. - Bonamia Menziesii, Gray, in Proc. Am. Ac. V, 336. - Mann, Enum. no. 380. - The black episperm will on first sight of the dry seed be taken for the testa, but on soaking in hot water it becomes soft and can be easily rubbed off with the finger, when the crimson testa appears to view. In Gray's description the episperm is called crimson by mistake.

Oahu! on the western slope of Kaala and in Wailupe; Molokai! Kalae; Lanai! W. Maui (Remy); very rare. Mann reports his plant from Kaala as a tall climber $20 \div 30 \mathrm{ft}$. in length; my plants appeared more like stragglers.

\section{CRESSA, L.}

Sepals 5. Corolla funnel-shaped, 5-lobed, the lobes imbricate in the bud. Stamens exserted. Ovary 2 -celled, 4-ovuled. Styles 2, with capitate stigmas. Capsule often 1-celled, with a single seed. Cotyledons linear, twice plaited.

A genus of a single species.

1. C. Cretica, L. - DC. Prod. IX, 440. - A stemless perennial, the prostrate spreading branches about $6^{\prime}$ long, canescent with short hairlets. Leaves sessile, ovate or elliptical, $2-4^{\prime \prime}$ long, somewhat acute, canescent. Flowers single and subsessile in the axils of the upper leaves. Calyx $1^{1 / 2} / 22^{\prime \prime}$, pubescent, the sepals ovate-lanceolate. Corolla white, its tube included in the calyx, little longer than the spreading oblong lobes. Stamens inserted at the middle of the tube. Top of ovary and styles hairy. Seeds glabrous, shining, with a crustaceous testa.

Oahu! Pearl River bay, east of the inlet; Molokai (Remy). Widely diffused through the warmer regions of both Worlds. In our plant the flowers are not spicate.

\section{CUSCUTA, L.}

Sepals 5, rarely 4, distinct or partly connate. Corolla campanulate, ovoid or globular, with a short 5-, rarely 4 -lobed limb, the lobes imbricate in the bud, the throat naked or with a scale at the base of each lobe, alternating with the subsessile or shortly exserted obtuse anthers. Ovary 2 -celled, 4-ovuled. Styles 2, distinct or more or less united. Stigmas acute, clavate or capitate. Fruit usually a dry capsule, opening transversely. Embryo without cotyledons, spiral or curved round a fleshy albumen. - Leafless parasites, without chlorophyll, with threadlike twining stems, bearing sessile or cymose clusters of small white or pink flowers.

About 80 species, dispersed over every part of the globe except the extreme north and south.

1. C. Sandwichiana, Chois. Cuscut. p. 184, tab. 5. - DC. Prod. IX, 458. - Flowers in a compound open cyme on a peduncle of $3-4^{\prime \prime}$, the pedicels 1 "long, with a scaly bract at their bases. Calyx scarious, shining, campanulate, $1^{1 /} 2^{\prime \prime}$, deeply 5 -cleft with ovate rather acute lobes, sometimes 
dotted with glands as well as the corolla. Corolla $2^{\prime \prime}$, ochraceous, urceolate, 5-cleft to the middle, the somewhat acute lobes inflected at the tip, erect or reflexed, but at last appressed to the capsule. Anthers ovoid, subsessile below the sinus. No scales. Styles distinct, unequal, exserted; the stigmas capitate. Capsule globose, nearly 2 " in diameter, indehiscent, but with a small intrastylar aperture, surrounded below by the withered corolla. Seeds nearly $1^{\prime \prime}$ in diameter, reticulate or warty, angular-convex or depressedly globose, not beaked, with a small circular umbilicus and a short linear hilum. - Engelmann, in Trans. St. Louis Ac. Sc. I, 453.

The plants collected by myself grew on Ipomoea pes-caprae and on 1 . tuberculata, along the seashore of Waialua, Oahu! and on Kauai. Nat. name: "Pololos.

\section{ORDER LX. BORAGINACEAE.}

Calyx persistent, with 5 or rarely 4 divisions. Corolla regular or nearly so, 5 -lobed, usually imbricate in the bud. Stamens 5, alternating with the lobes of the corolla and inserted in the tube. Ovary 4-celled and often deeply 4 -lobed (consisting of two 2 -celled carpels), with 1 ovule in each cell. Style inserted between the lobes of the ovary, or terminal where the ovary is entire, simple, entire or once or twice bifid. Fruit either a 4 -seeded drupe or berry, or consisting of 4 distinct small 1-seeded nuts having the appearance of naked seeds. Albumen none or very thin. Embryo usually straight, with flat or rarely folded cotyledons. - Herbs, shrubs or trees, often rough with stiff hairs. Leaves alternate, entire or toothed, without stipules. Flowers usually in one-sided simple or bifid spikes or racemes, or on the one-sided branches of a dichotomous cyme which are rolled back (circinnate) before the flowers expand.

A widely spread Order, the arborescent or shrubby genera chiefly tropical, the herbaceous ones more common in the temperate regions, especially of the northern hemisphere. Ovary entire; style terminal, twice bifid; fruit a drupe; a tree. Ovary entire; style terminal, entire, with annular stigma below the apex; fruit separating more or less completely into $2-4$ dry

nutlets; suffrutescent herbs

1. Cordia.

vary 4 -lobed style between the lobes, entire, with eapitate stigma; fruit of 4 distinct seed-like nutlets; a tender annual

\section{Heliotropium.}

3. Bothriospermum.

\section{CORDIA, Plum.}

Calyx tubular, often closed in the bud, 4-8-toothed. Corolla funnelor salver-shaped. Style twice bifid, terminal; ovary entire. Fruit a 4 -celled drupe, but by abortion often 3-1-celled, each cell with 1 suberect seed. Cotyledons thick, folded lengthwise. Albumen none. Trees or shrubs. Flowers often polygamous, in expanded or contracted cymes.

A large genus, diffused through the tropical regions of both Worlds. 
1. C. subcordata, Lam. - DC. Prod. IX, 477. - A tree, 30-50 ft. high. Leaves ovate or subcordate, $5-6^{\prime} \times 3^{1 / 2-4^{\prime}}$, on petioles of $1-1^{1} / 2^{\prime}$, acuminate, entire or wavy, glabrous excepting slight tomentose patches or streaks in the axils of the principal veins. Flowers in short terminal and lateral corymbiform or subpaniculate cymes with one-sided branches, subsessile. Calyx 5-6", coriaceous, irregularly and obtusely 3-5-toothed. Corolla large campanulate, orange-colored, its tube twice the length of the calyx, the broadly expanded limb 5-7-lobed, the lobes rounded, imbricate-contorted, one lobe external. Style as long as the tube. Drupe ovoid, $1-1^{1} / 2^{\prime}$, enclosed within the calyx. - Cham. \& Schl, in Linnaea, IV, 474. - Seem. Fl. Vit. p. 168, tab. 34. - C. Sebestena, Forst. (not Linné), and Hook. \& Arn, in Bot. Beech. - Mrs. Sinclair, pl. 7.

Along the seashore here and there; formerly much planted by the natives round their houses, but now almost exterminated by the ravages of a small moth. The tree, although bearing an original native name "Kons (Tahitian :Tou*), which oceurs in old smeles* or songs, can hardly be considered indigenous. It ranges all the way from the Hawaiian Islands to Madagasear and Zanzibar, and would seem to have accompanied the MalayoMaori race in their migrations, a reason for which may be found in the large shade afforded by its broad crown, particularly valuable in a littoral tree. The wood, rather soft but durable, is much prized for cabinet work, cups and dishes, exhibiting wavy ribbons of light and dark brown when polished.

\section{HELIOTROPIUM, Linn.}

Calyx 5-cleft, rarely 5-toothed. Corolla-tube cylindrical, the limb spreading, 5-lobed. Anthers included in the tube. Style short, sometimes scarcely any, with an annular stigma below the capitate or conical apex. Ovary entire, 4- or rarely 5-6-celled. Fruit dry, separable into 4, 5 or 6 nutlets, or the nutlets united in pairs. No albumen. Cotyledons planoconvex. - Herbs or undershrubs, usually hairy. Leaves entire, rarely toothed. Flowers usually small in one-sided circinnate spikes or dichotomous eymes.

A considerable genus, chiefly tropical and subtropical, extending over both Worlds. In cultivation: $\boldsymbol{H}$. Peruvianum and the nearly allied Tournefortia heliotropioides, Hk, and T. argentea, $\mathrm{L}$.

Leaves glabrous; spikes elongate

Leaves silky-white; spikes short

1. H. Curassavicum.

2. $H$. anomalum.

1. H. Curassavicum, L. - DC. Prod. $I X, 538$. - Herbaceous or suffruticose, prostrate, $1-2 \mathrm{ft}$. long, glabrous. Leaves fleshy, glaucous, spathulate or linear-lanceolate, $1-2^{\prime} \times 2-4^{\prime \prime}$, somewhat obtuse, entire, gradually contracting into a short petiole, with veins evanescent. Spikes terminal and lateral, simple or bifid, $2-4^{\prime}$ long, bractless. Calyx parted to the base into linear lobes, $1^{\prime \prime}$. Corolla $2^{\prime \prime}$, white, its short lobes plaited and imbricate in the bud. Anthers subsessile near the base of the tube, linearlanceolate, inflected in the bud. Style very short, depressed at the truncate apex, with an expanded stigmatic ring. Fruit seceding into

Hillebrand, Flora of the Hawaiian Islands. 
4 angular-convex nuts which are foveolate near the base of the inner angle.

Common in low marshes near the sea. The species has a wide range, extending on the American continent from Oregon to Chile on the west, and from Mexico to Patagonia on the east, being found also in Moroceo and at the Cape of Good Hope.

2. H. anomalum, Hook, \& Arn. in Bot. Beech. p. 66. - A decumbent perennial, much branched, $4-6^{\prime}$ high, the branches densely foliose and canescent with soft silky appressed hair. Leaves thick, but not fleshy, linear-lanceolate or spathulate, $9-12^{\prime \prime} \times 1-1^{1} / 2^{\prime \prime}$, entire, gradually attenuate from above the middle. Spikes short, $4-6^{\prime \prime}$, on a long $\left(1^{1 / 2}-2^{\prime}\right)$ terminal once or twice forking peduncle, forming a sort of glomerule. Calyx $1^{1} / 2-2^{\prime \prime}$, stiff coriaceous, deeply parted into 5 unequal linear lobes, one or two being generally broader than the others. Corolla funnelshaped, 3-5", twice the length of the calyx, silky, pale blue, the limb $1 / 3$ the length of the slightly curved tube, 5 -6-lobed, with lobes folded in the bud, one a little longer than the others and spreading. Anthers $5-6$, linear-lanceolate, subsessile below the middle of the tube, conniving and cohering at first with their pointed and penicillate apices. Style short, annulate below the conical and penicillate apex. Nutlets 4, rarely 5 or 6, all free and strigoso-pubescent. - Gray, in Proc. Am. Ac. V, 339. - Pentacarya heliotropioides, DC. Prod. IX, 559. - Lithospermum incanum, Forst.

In dry sandy soil near the coasts, as in Puloa, Kailua and Waimea, Oahu! also in Koloa, Kauai, and on $\mathrm{H}$ awail. The flowers are quite fragrant. The species grows also on several coral-islands of the Pacifie, as Whitsunday, Savage, George and Palmerston, and in the Society group.

\section{BOTHRIOSPERMUM, Fisch. \& Meyer.}

Calyx deeply 5 -cleft. Corolla-tube cylindrical, the limb spreading with imbricate lobes, the mouth of the tube closed by obtuse scales. Anthers included. Ovary 4-lobed. Style very short, rising from the centre of the lobes, with a capitate stigma. Fruit of 4 distinct nuts erect and attached by the base, convex and warted on the back, marked with a margined cavity on the inner side. Cotyledons flat. - Hispid herbs with shortly pedicellate extra-axillary flowers disposed in a foliose terminal raceme, and white or bluish corollas.

A small genus of a few Indian and Chinese species.

† 1. B. tenellum, F. \& M. - DC. Prod. X, 116. - A slender diffuse much branched annual or biennial, usually $6-8$, long, more or less clothed with appressed or spreading hairs. Leaves ovate or oblong, shortly stalked, blunt, entire, $1 / 2-1$ 'long, the upper floral leaves smaller. Flowers very small, white or pale blue, on short recurved pedicels. Corolla searcely above $1^{\prime \prime}$ long. Fruiting calyx $1^{1 / 2}-2^{\prime \prime}$ long. - Benth. Fl. Hongk. p. 235.

Along eultivated fields in Pauoa, Oahu 1 A native of China and India; a recent arrival. 


\section{ORdER LXI. SCROPHULARIACEAE.}

Flowers irregular or seldom nearly regular. Sepals 5, either free or more frequently united into a lobed or toothed calyx, persistent. Corolla usually bilabiate, but sometimes nearly regular, with 4,5 , or rarely more lobes, imbricate in the bud. Stamens usually 2 or 4 , in pairs, inserted in the tube and alternating with the lower lobes of the corolla; the fifth stamen, between the two upper lobes, usually deficient or rudimentary. Ovary 2-celled, with several ovules in each cell. Style simple, with a 2 -lobed or rarely entire stigma. Fruit a 2 -celled capsule or rarely an indehiscent berry. Seeds albuminous. Embryo straight or rarely curved. - Herbs, or rarely shrubs or small trees. Leaves usually opposite or whorled in the lower part of the plant, alternate higher up, but sometimes all opposite or all alternate, without stipules. Flowers in terminal racemes or cymes, or more rarely axillary.

A large Order, widely dispersed over every part of the globe.

Calyx of 5 free sepals.

Calyx 5-lobed to about the middle

1. Herpestis.

2. Masus.

\section{HERPESTIS, Gaertn. fil.}

Sepals 5, distinct, the lowest one much the broadest. Corolla with a spreading, more or less bilabiate limb, the upper lip emarginate or 2-lobed, the lower 3 -lobed, or sometimes all 5 lobes nearly equal. Stamens 4 , in pairs, the anthers all with 2 perfect contiguous cells. Style dilated at the top, concave or slightly 2 -lobed. Capsule opening into two valves which are sometimes cleft so as to appear 4-valved, leaving a free central column. - Herbs, sometimes aquatic. Leaves opposite. Flowers axillary or in terminal racemes, without or rarely with bracteoles under the calyx.

A considerable tropical and subtropical genus, chiefly American, with a few speeies natives of the old world.

1. H. Monnieria, H. B. \& K. - Benth. in DC. Prod. X, 400. - A low creeping glabrous annual. Leaves obovate or oblong, generally $3 / 4-2^{\prime}$ long, thick fleshy, entire, rounded, euneate at the base, on very short petioles, without prominent veins, or obscurely 1 -3-nerved, Flowers generally solitary in the axils, white or pale blue, rather small, on pedicels usually longer than the leaves, with 2 small bracteoles under the calyx. Outer sepal ovate. - Bot. Mag. tab. 2557. - Benth. Fl. Hongk. p. 249.

Common in marshes near the sea. Oahu, Waikiki; Maui, Lahaina, and elsewhere. One of the commonest marsh plants throughout the tropieal regions of both Worlds, in America extending north as far as Maryland.

\section{MAZUS, Lour.}

Calyx broadly campanulate, 5 -lobed. Corolla with the upper lip erect, ovate, shortly 2 -lobed, the lower one longer, spreading, 3 -lobed, with 
2 slight protuberances at the base. Stamens 4. Cells of the anthers contiguous, divaricate. Style with 2 ovate stigmatic lobes. Capsule globular or compressed, opening loculicidally into 2 entire valves. - Low herbs. Lower leaves opposite, the upper ones alternate. Flowers in terminal one-sided racemes.

A small genus, limited to tropieal eastern Asia and Australia.

$\dagger$ 1. M. rugosus, Lour. - Benth. in DC. Prod. X, 375. - A low glabrous or slightly hairy annual, rarely continued through another year by means of ereeping runners. Leaves mostly radical, or nearly so, obovate or cuneate-oblong, 1-2' long, coarsely toothed, narrowed into a broad petiole. Branches short, spreading, ending in a leafless raceme of 2 or 3 inches or more. Flowers blue, with a white or yellow palate, on short peduncles. Calyx about $3^{\prime \prime}$, with foliaceous ovate or lanceolate lobes, enlarged after flowering. Corolla scarcely twice as Iong. Capsule shorter than the calyx. - Sweet, Br. Fl. Gard. tab. 36. - Benth. Fl. Hongk. p, 247.

Along water-courses near Honolulu. A common weed of eastern Asia, of late years aceidentally introduced from China.

Scoparia dulcis, L, is said in Seeman's Fl. Vit. to have been found by Macrae in 1824 - probably near Hilo or Honolulu -, but no other collector has since seen it.

\section{Order LXII. GESNERIACEAE.}

Flowers usually irregular. Calyx with 5 teeth, lobes or distinct sepals. Corolla tubular, the limb bilabiate or of 5 spreading lobes imbricate in the bud. Stamens 2 or 4 , inserted in the tube in pairs, sometimes with the addition of a fifth barren one. Anthers 2- or 1-celled. Ovary superior or more or less inferior, 1-celled, with 2 parietal entire or lobed placentas protruding into the cavity but not united in the axis. Ovules numerous. Style simple, with an entire or lobed stigma. Fruit a berry or capsule. Seeds small, numerous, with or without albumen. Embryo straight. Herbs or shrubs or climbers. Leaves opposite or whorled.

A considerable Order, chiefly tropical.

\section{CYRTANDRA, Forst.}

Calyx 5-toothed or cleft. Corolla tubular or funnel-shaped, either straight and almost regular, or curved with a 5 -lobed often bilabiate limb, the upper lip emarginate and the lower 3-lobed. Fertile stamens 2, anterior, affixed to the middle of the tube or its throat, with short twisted filaments, enclosed; the short anthers cohering with their apices, 2-celled, extrorse. Ovary superior, surrounded by a cup-shaped disk, the style enclosed in all our species, the stigma obtuse emarginate or 2-lobed. Berry ovoid or oblong. Placentas 2 -lobed, with lobes revolute. Seeds numerous and small, without albumen, often pitted. - Shrubs or herbs with opposite or whorled leaves. Flowers axillary, bracteate, solitary or 
in open or contracted cymes. Corollas and berries white in all Hawaiian species.

A large genus, spread over Malaysia and Polynesia from Sumatra to the Hawaiian group, remarkable for its proneness to variation. The Hawailan species are all shrubby, with a soft wood. A thin cup-shaped disk is present in all; the minute seeds are smooth and the stigma is bilamellate. The style presents a peeuliarity which deserves to be noted, viz., an articulation which begins to form long before the fruit is ripe. It indicates the place where the style will break off, and is often marked by a ring of small epidermoidal scalelets. Generally this takes place at its junetion with the ovary, but sometimes higher up, not however observing such regularity as to make it available for a specific character. Quite a number of new species have been found to possess verticillate leaves, the whorls being constant in some, while in others they occur in the upper portion of a branch only. The polymorphism of the Hawailan Cyrtandras is extraordinary: no single form extends over the whole group, and not many are common to more than one island. The variations affect nearly every part of the plant, and branch out and intercross each other in manifold ways to such an extent that it is next to impossible to define exact limits of species. Even the grouping of the numerous forms into more eomprehensive sections is surrounded with difficulties, and I have not been able to devise a systematic division which would not be vitiated by exceptions. The following classification, therefore, does not lay claim to more than an approximative rendering of the true relations of the different species, and it is to be hoped that further explorations, particularly on the two extreme islands Kauai and Hawaii, will bring to our knowledge new forms which may throw more light on the complieated chain of transmutation which prevails in this genus.

\section{Calyx persistent with fruit.}

Crotonocalyces, villosae. - Calyx cleft to the middle or less into broad lobes or teeth. Leaves broad, generally rounded or cordate at the base, villous.

Calyx globose or urceolate, with short obtuse teeth or lobes; tomentum thick, yellow; flowers single

1. C. Kealiae.

Culyx large crateriform to eampanulate, with mostly ovate lobes; flowers several, subumbellate; tomentum pale cinereous or ochraceous. Group of C. cordifolia.

Corolla straight, with equal lobes:

Leaves cordate.

Leaves peltate

Leaves rounded or contracted at the base

Leaves oblique, the base uneven-sided

1. C. Keatiae.

Corolla slightly eurved, with nnequal lobes:

Leaves eordate

Leaves rounded or decurrent at the base

2. C. cordifolia.

5. C. Wawrae.

3. C. Pickeringii.

4. C. begoniaefolia.

6. C. paritiifolia.

7. C. platyphylla.

Schizocalyces, fulvae. - Calyx large, split to near the base into ovate or lanceolate lobes. Flowers few, $1-3$, rarely more in a corymbose cyme. Leaves mostly lanceolate. Tomentum fulvous or deep ferruginous. Group of C. Lessoniana.

Corolla erect, with large unequal lobes:

Calyx crateriform, 5-fid with foliaceous lobes; leaves whorled

Calyx parted to the base into lanceolate lobes:

Leaves opposite or ternate, broad lanceolate; flowers 3 or 2

Leaves in whorls of $4-6$ :

Gradually narrowing into the petiole; flowers many

Truneate at the base; flowers $1-3$

Corolla erect, constrieted at the throat, with small subequal lobes; calyx parted to the base into ovate or lanceolate lobes; leaves opposite

8. C. maerocalyx.

11. C. Iysiosepala.

12. C. Grayana.

9. C. procera.

13. C. Lessoniana. 
Corolla curved, ampliate at the throat:

Leaves quaternate; calyx deeply parted into lanceolate lobes 10 . C. biserrata.

Leaves opposite:

Calyx cleft to the base into broad stipitate lobes

Calyx eleft to the middle

15. C. Kauaiensis.

14. C. Hillebrandi

Microcalyces, cinereae. - Calyx small, 5-fid to the middle into narrow lobes. Corolla erect, with small lobes. Flowers many in open cymes. Leaves broad obovate or elliptical. Tomentum, when present, short cinereous or pale ochraceous.

Corolla small, $6^{\prime \prime}$ or less

Corolla larger, $8-10^{\prime \prime}$ :

Inflor. birsute; calyx $1 / 2$ the length of the corolla or more

Inflor, pale ferruginous; calyx $1 / 3$ the length of the corolla

17. C. Garnotiana.

18. C. laxiflora.

16. C. trifiora.

Chaetocalyces, virides. - Calyx deeply split into linear or subulate lobes. Flowers mostly subumbellate. Leaves thin and glabrous or hispid. Group of C. Menziesii.

Corolla straight, with small lohes

Calyx and corolla pruinose, not hairy:

Flowers many on a short peduncle; corolla small

19. C. Maeraei.

Flowers few, generally 3 on a long peduncle; corolla large 20. C. gracilis.

Calyx and corolla hirsute or pubescent:

Flowers 1 or few on a long peduncle

21. C. Waiolanii.

Flowers many on a short peduncle:

Leaves large, rounded, decurrent into a winged petiole

Leaves small elliptical, not decurrent

Corolla curved, ampliate at the throat with large spreading lebes, rather small

22. C. Kalihii.

23. C. Menziesii.

24. C. Lydgatei.

II. Calyx deciduous from the fruit.

Cylindrocalyces, glabrae vel atro-fuscae. - Calyx campanulate, cylindrical or fusiform, 5 -toothed or shortly 5 -cleft into unequal lobes, splitting laterally at last. Corolla large, curved, bilabiate. Flowers single or few, subumbellate. Leaves straight-veined, mostly glabrous. Hairs, when present, dark brown or blackish and sometimes thickly matted. Group of C. paludosa.

Leaves opposite:

Calyx and leaves glabrate:

Peduncle long, 1-2-flowered; bracts large foliaceons

Peduncles short, several-flowered; bracts linear-lanceolate

Calyx and leaves villous with dark hairs

Leaves whorled:

Flowers solitary on a filiform long pedicel; calyx and corolla glabrous

Flowers $1-5$ on short pedicels; ealyx and corolla hairy

25. C. grandiflora.

27. C. paludosa.

29. C. venobarba.

26. C. filipęs

28. C. latebrosa.

1. C. Kealiae, Wawra, in Flora, 1872, p. 565. - Shrubhy, 6 ft. high, the young branches and inflorescence tomentose with bright golden hair. Leaves opposite or the upper ones ternate, ovate, subcordate, or ellipticooblong and acuminate at both ends, $4-6^{\prime} \times 2^{1 / 2}-3^{1 / 2^{4}}$, on petioles of $2-3$ ', denticulate, chartaceous, hirsute above, densely tomentose underneath. Flowers solitary on short stalks, the peduncle and pedicel $1-4^{\prime \prime}$ each; bracts narrow lanceolate, $2-3 "$. Calyx $6-9 "$, densely villous in- 
side and outside, coriaceons, ovoid or almost globose, with 5 short teeth or oblong obtuse lobes of about $1 / 4$ of its length. Corolla straight, $10-12^{\prime \prime}$, the tube broad, not ampliate above, with short ovate nearly equal lobes, villous outside and often inside. Ovary glabrate; style pubescent. Berry short ovoid, 6" long, invested by the closed calyx which at last splits laterally.

Kauai! Kealia (Wawra), Waimea (Kn.). The interior of the corolla, which Wawra found filled with a thick tomentum, is glabrous in Knudsen's specimens.

2. C. cordifolia, Gaud. Bot. Voy. Freye. p. 446, tab. 56. - A shrub, 5 -8 ft. high, freely branching from the base, the young shoots villous with pale ochraceous hair, as is the inflorescence. Leaves opposite, ovate or suborbicular, with a cordate base, shortly acuminate, sharply dentate or serrate, membranous, hispid on the upper, villous on the lower face, $5-9^{\prime} \times 4-8^{\prime}$, on petioles of $2-6^{\prime}$. Peduncles $1-2^{\prime}$, subumbellately several-flowered, the flowers $(4-10)$ on pedicels of $7-12^{\prime \prime}$. Bracts foliaceous, broad oblanceolate, $1 / 2-1^{\prime}$, sometimes petiolate. Calyx membranous,

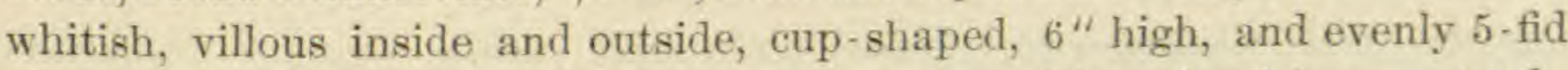
to the middle or beyond into broadly ovate or triangular lobes, rotately expanded when in fruit with an aperture of $8-12^{\prime \prime}$. Corolla villous, broad tubular, straight, $7-10 "$ long and $4-5$ " broad, not ampliate above, the short lobes rounded, nearly equal, one emarginate. Ovary and style villous, the latter very short, articulate below the stigma. Berry broad ovoid. - DC. Prod. IX, 284. - Gray, in Proc. Am. Ac. V, 350. - Hook. \& Arn. in Bot. Beech. p. 91.

Oahu! common on the main range; E. Maui! The sinus at the base of the leaf, although generally narrow and deep, is sometimes closed below the insertion of the petiole.

3. C. Pickeringii, Gray, in. Proc. Am. Ac. V, 350. - Size and habit as in no. 2. Leaves suborbicular or ovato- or broad elliptico-oblong, $5-7^{\prime} \times 3-4^{\prime}$, on petioles of $2-3$ ', shortly acuminate, dentate, sometimes contracting at the base, even shortly decurrent, membranous, papillosehispid above, gray-tomentose or pale-glabrate underneatb. Peduncle $9^{\prime \prime}$ long, 2- or subcymosely 5-6-flowered, the pedicels $7-9^{\prime \prime}$. Bracts lanceolate, $4-5^{\prime \prime}$. Calyx and corolla as in no. 2, but the lobes of the former though open, not expanded in fruit. Ovary villous or glabrate. Style $2-3^{\mu}$, villous. - C. Honolulensis, Wawra, in Flora, 1872, p. 567.

Oahu! main range, with the preceding species. Oblong-decurrent and suborbieular leaves oecur on the same plant. It is less villons than C. cordifolia, and the tomentum is shorter; sometimes even the leaves and calyeine lobes are nearly glabrate. Gray had only a single fragmentary specimen with narrow leaves at his disposal, which accounts for the apparent discrepancy in the description.

$\beta$ var, erassifolia. - Leaves thick coriaceous, with strong ribs and veins, broad ovate to orbicular, rather fulvo-tomentose or villous underneath. Flowers few, 1, 2 or 3 , their pedicels longer, $12^{\prime \prime}$.

High ridge of Niu, Onhu! 
4. C. begoniaefolia, $s p . n$. - Size and habit as in no. 2 , the young branches and inflorescence villous with a bright shining pale-fulvous tomentum. Leaves opposite, broadly ovate, $7-8^{\prime} \times 3^{1 / 2}-4^{\prime}$, inequilateral, oblique, cuspidate, sharply dentate with broad patent teeth, rounded at the base, with one side much more deeply attached than the other to a petiole of about 3 ', thick chartaceous, hirsute above, tomentose underneath, with ribs and veins villous. Peduncle fleshy, 12" long, bearing 3 or more flowers on pedicels of $10^{\prime \prime}$; bracts foliaceous, ovatelanceolate, 12 "long. Calyx villous, thin, funnel-shaped, $10^{\prime \prime}$ long, divided to the middle or less into erect lanceolate acute lobes. Corolla as long as the calyx, villous or pubescent, straight.

E, Maui! woods of Ulupalakua.

5. C. Wawrae, Hillebr. - A shrub, $12 \mathrm{ft}$. high, freely branching, the young shoots and inflorescence hirsute with pale ochraceous hairs. Leaves opposite, broad ovate or suborbicular, $8-9^{\prime} \times 5-6^{\prime}$, peltately affixed 1 or $2^{\prime}$ above the base to petioles of $3-4^{\prime}$, moderately acuminate, dentate, uneven sided, chartaceous, shortly pubescent above, slightly tomentose underneath. Peduncle $10^{\prime \prime}$, bearing $3-5$ flowers on flexuose pedicels of twice its length; bracts broad ovate, 10". Calyx tomentose outside and inside, urceolate to campanulate, 1' long, the lobes ovato-lanceolate, ${ }^{1} / 2$ the length of the tube. Ovary glabrate. Berry subglobose, enclosed in the calyx. - C. peltata, Wawra, 1. c. p. 565, the name anticipated for a Sumatra species by Jack.

Kauai, waterfall of Hanalei. Plants collected by Mr. Knudsen in Waimea! of the same island have shorter peduncles of $4-6^{\prime \prime}$ with $7-12$ flowers in a cymose umbel. The broad glabrate corolla is slightly curved and projects somewhat beyond the ealyx. The calyx is divided $1 / 4-1 / 3$ of its length and encloses the fruit within its tube.

6. C. paritiifolia, $s p . n$. - Habit of no. 2, the branches tomentose. Leaves opposite, ovate or suborbicular, $3^{1 / 2}-6^{\prime} \times 2^{1 / 2}-5^{4}$, on petioles of $2-3^{1} / 2^{2}$, cordate, obtuse or shortly acuminate, denticulate or almost entire, chartaceous, papillose-pubescent on the upper, ochraceo-tomentose or glabrate on the lower face. Hlowers 3-10, umbellate or cymosecorymbose, on a peduncle of $2 / 3-2^{\prime}$, the pedicels $4-9^{\prime \prime}$; bracts narrowlanceolate, $4-9^{\prime \prime}$. Calyx $4-8^{\prime \prime}$, tomentose or villous, divided to the middle or less into ovate or lanceolate lobes. Corolla exserted, arcuate, glabrate or slightly pubescent, $8^{\prime \prime}$ long and $2^{\prime \prime}$ broad, with lobes subbilabiate, the lower lip $2-3^{\prime \prime}$. Ovary glabrate. Style $3-4^{\prime \prime}$, articulate near the base. Fruit ovoid-elongate, $7-8^{\prime \prime}$, closely surrounded by the calyx-tube.

W. Maui! gulch of Oloalu; E. Maui! Hamakua. Distinguished from $C$. cordifolia chiefly by the glabrate slender and curved corolla and the enclosed fruit.

7. C. platyphylla, Gray, l. c. p. 350. - A shrub, 8-10 ft. high, the young shoots and inflorescence hirsute with dark ferruginous hairs. Leaves opposite, thin chartaceous, suborbicular, ovate or oblong, $5-9^{\prime} \times$ 
$3-6^{\prime}$, on hirsute petioles of $2-3^{\prime}$, obtuse or shortly acuminate, sharply dentate with patent teeth, rounded or sometimes subcordate, but oftener contracting at the base, hairy or papillose above, velvety-tomentose or subglabrate underneath. Flowers subumbellate, $5-9$ on a peduncle of about 1', the pedicels of nearly the same length, some of them again divided and bracteolate; the bracts foliaceous, lanceolate, $12-8^{\prime \prime}$ long. Calyx hirsute, $6-8^{\prime \prime}$, eleft to the middle or deeper into lanceolate acute lobes. Corolla $8-12^{\prime \prime}$, pubescent, slightly curved and subbilabiate. Ovary glabrous. Style puberulous, articulate near the ovary. Berry ovoid or subglobose, surrounded by the calyx.

Hawaii! woods of Hilo and Puna; from Kilauea a very dark and shaggy form with thick oblong leaves.

$\beta$ var. - Peduncle and pedicels only $4-6 "$ long. Calyx and corolla much shorter, the former less deeply lobed, the latter curved and exserted. Fruit short ovoid, enclosed in the calycine tube. Leaves thick, with strong and straight nerves, as in C. paludosa.

Woods of Hilo?

8. C. macrocalyx, $s p . n$. - Arborescent, $12-15 \mathrm{ft}$. high, the branches moderately hirsute. Leaves in whorls of 4 , elliptico-oblong, acuminate at both ends, serrulate, $4-5^{\prime} \times 1^{1 / 2}-1^{3} 4^{\prime}$, on petioles of $1 / 2-3 / 4^{\prime}$, thick chartaceous, with prominent veins, sparingly hairy above, with a faint ferruginous tomentum underneath. Peduncles $4-8^{\prime \prime}$, bearing 1 or 2 flowers on pedicels of $6-7 "$; the bracts large foliaceous, ovate, $6-12^{\prime \prime} \times 4-6 "$. Calyx of thick texture, pubescent, large erateriform, $9-12^{\prime \prime}$ long, divided to the middle into large foliaceous ovate obtuse lobes of $4-5^{\prime \prime}$ in width. Corolla a little exserted, slightly curved, pubescent.

Molokai! high ridge of Wailau and Pelekunu. Remarkable for the large calyx, which exceeds in size that of $C$. cordifolia.

9. C. procera, sp. $n$. - Arborescent, $12-18 \mathrm{ft}$. high, the fleshy branches hirsute with dark ferruginous hair. Leaves in whorls of 6 , linear-oblong or lanceolate, $5-6^{1} \times^{3 / 4}-1^{\prime}$, on petioles of ${ }^{1} / t^{\prime}$, acute, sharply and finely serrulate, truncate at the narrow base, coriaceous, dark green and glabrous above, thickly tomentose underneath. Flowers 1, 2 or 3 in each axil on a short peduncle of $1-4^{\prime \prime}$, the pedicels $8-12^{\prime \prime}$; bracts 3 ", linearlanceolate. Calyx thickly tomentose or hirsute, $6-9^{\prime \prime}$, split to near the base into $5-6$ linear-lanceolate lobes. Corolla $8-9^{4}$, villous, slightly curved, the large spreading lobes, somewhat acute, about $2^{1 / 2} / 2^{\prime \prime}$ long. Ovary glabrous.

Molokai! pali of Pelekunu, at a height of $3000 \mathrm{ft}$.

10. C. biserrata, sp. n. - A shrub, 5-6 ft. high, the branches and inflorescence hirsute with spreading rust-colored hairs. Leaves quaternate, membranous, green on both faces, papilloso-hispid on both faces, ellipticooblong, $4-5^{\prime} \times 1^{1 / 2 \cdots 2^{\prime}}$, on petioles of $1-2^{\prime}$, cuspidate, acuminate at 
the base, deeply and unevenly serrate, almost laciniate. Peduncles 4-6" long, 2 -flowered, the pedicels $6-8^{\prime \prime}$, the lanceolate bracts $3^{\prime \prime}$. Calyx thin hairy, $4-5^{\prime \prime}$, parted deeply into 5 lanceolate acute lobes. Corolla $7-8^{\prime \prime}$, villous, exserted, the slender tube slightly curved and ampliate at the throat, the large spreading lobes bilabiate. Ovary glabrous, the style 3 " long and broadly lobed. Berry ovoid, 9".

Molokai!

11. C. lysiosepala. - A shrub, 5-8 ft, high. Jeaves opposite or rarely the upper ones ternate, elliptico-oblong, $4-7^{\prime} \times 1^{1 / 2}-2^{\prime}$, on petioles of $1-2^{\prime}$, acuminate at both ends, serrulate, glabrate above, softly ferrugino-tomentose or almost glabrate underneath, membranous. Bracts, calyx and corolla white when fresh, almost glabrous. Flowers always 3 on a slender peduncle of $6-18^{\prime \prime}$, the pedicels $9-15^{\prime \prime}$; bracts lanceolate, $6-7^{\prime \prime}$. Calyx $6-12^{\prime \prime}$, parted to the base into 5 or rarely 6 broad lanceolate lobes which contract at the base and mostly turn back in fruit. Corolla pubescent or glabrate, straight, $9-10^{\prime \prime}$ long, the large spreading lobes about $1 / 2$ the length of the tube. Ovary glabrous; style articulate at the base. Berry ovoid, 6-9". - C.triflora, var. $\beta$ lysiosepala, Gray. C. triflora, Wawra, 1. c.

Hawail! E. and W. Maui! The true affinity of the species is with C. Lessoniana rather than with C. triflora.

$\beta$ var. - Calycine lobes subulate as in C. Menziesii, but the flowers ternate as in $a$, or single. Leaves opposite, often $3^{\prime}$ broad.

E. and W. Maui!

\% var pilosa. - Hairy-tomentose. Calycine lobes subulate as in $\beta$, but hirsute, and the corolla villous. Leaves chartaceous, opposite, papillosohispid above, hairy along rib and veins underneath.

W. Maui! Kaanapali; E. Maui! Hamakua and Ulupalakua; Hawaii! Hilo. - In some forms much like $C$. Waiolanii, but the calycine lobes shorter than the corolla and the latter with large lobes as in C. lysiosepala, the leaves smaller and with rusty tomentum. A thick-leaved form from Halcakala! Maui.

5 var. - Leaves all ternate. Peduncles 3- or 2-flowered. Calycine lobes narrow lanceolate, not contracted at the base.

Molokai! Halawa and Mopulehu.

12. C. Grayana, $s p . n$. - A shrub, 8-10 ft, high. Leaves in whorls of 6 , narrow-spathulate, $10-12$ long, including the long petiole in which they gradually merge, and $1^{1 / 4^{\prime}}$ broad near the apex, shortly acuminate, almost entire, thick chartaceous, papillose above, thickly tomentose underneath with appressed bright yellow hair. Flowers $8-12$ in an irregular corymbose cyme, the common peduncle $6-12^{\prime \prime}$, the pedicels $9^{\prime \prime}$, the broadly lanceolate bracts $6-7^{\prime \prime}$. Calyx $6-7^{\prime \prime}$, tomentose, parted to near the base into 5 oblong obtuse lobes. Corolla hairy, otherwise as in $C$. lysiosepala. Berry as before.

Maui! Eeka, 5000-6000 ft. Named after Prof. A Gray. 
$\beta$ var. latifolia. - Leaves quaternate, obovate-oblong, $10-12^{\prime} \times 3-4^{\prime}$. Flowers less numerous. Calycine lobes linear. Berry almost globose.

W. and E. Maui!

13. C. Lessoniana, Gaud. l. c. p. 44\%, tab. 54 . - An erect shrub, $5-8 \mathrm{ft}$. high, the branches and inflorescence fulvo-tomentose. Leaves opposite, elliptico-oblong, $4-5^{\prime} \times 1^{1} / 2-2^{1} / 2^{\prime}$, on petioles of ${ }^{1} / 3-1^{\prime}$, equally acuminate at both ends, denticulate or almost entire, thin chartaceous, glabrate or sparsely pubescent above, silky with soft tomentum underneath. Flowers solitary and mostly drooping, rarely 2 on a peduncle of $6-9^{\prime \prime}$, the pedicel $8-12^{\prime \prime}$, the 2 bracts linear lanceolate, $3-4$ ". Calyx white, thin, 6-9" long, tomentose or glabrate, parted to the base into broadly ovate acuminate lobes which are angular-valvate in the bud and quite open, even reflected with fruit. Corolla as long as the calyx or little longer, $9-10^{\prime \prime}$, straight-tubular or urceolate, ampliate above, contracted at the throat, with short obtuse lobes, silky-villous. Ovary glabrous; style articulate below the deeply lobed stigma. Berry ovoid, not longer than the calyx. - Hook. \& Arn. I. c. - Gray, 1. e. p. 531. - Wawra, 1. c.

Oahu! rather common on the main range.

$\beta$ var. - Calycine lobes lanceolate; peduncle and pedicels shorter.

Oahu! Waianae range.

$\gamma$ var. angustifolia. - Leaves narrow-lanceolate, $6-8^{+} \times 3 / 4-1$, the tomentum confined to rib and veins. Calycine lobes ovate to lanceolate.

Eastern portion of the main range of oahu! Wailupe.

$\delta$ var. pachyphylla. - Leaves thick coriaceous, with strong veins and dense tomentum, broad oblong or obovate. Peduncle generally 2-flowered, with broad oblong bracts. Calyx 5-12", parted not quite to the base into 5-6 narrow-lanceolate or linear lobes. Corolla generally exceeding the calyx, $9-12^{\prime \prime}$.

Oahu! Waianae range and high ridge of Niu. Looks a good deal like var. $\beta$ of C. Pickeringi $i$, and may possibly be connected with it, notwithstanding the great difference in the ealyx. In one of my specimens the thick flesby lobes of the same are almost trigonal, with a median ridge on the inner side.

14. C. Hillebrandi, Otiver, in lit. - Leaves opposite, coriaceous, with stout ribs and veins, elliptico- or ovato-oblong, $3-4^{1 / 2^{\prime}} \times 1^{1 / 2}-2^{\prime}$, on petioles of 1', acute, denticulate, pubescent above, faintly ferruginous or glabrate underneath. Flowers $3-5$, cymosely umbellate on a peduncle of $6-12^{\prime \prime}$, the pedicels as long or longer, the bracts ovate-lanceolate, 5-7". Calyx glabrate, thin, $6-9 "$, cleft to the middle or more, deeper on one side, into broad lanceolate long acuminate lobes. Corolla little exserted, 9-11", pubescent, somewhat curved, with ampliate throat and spreading lobes. Ovary glabrous. Berry ovoid-elongate, $9^{\prime \prime}$, enclosed in 
the calyx. - Different from the plant referred to by Mann under C. Lessoniana.

Oahu! from Nuuanu to Palolo.

15. C. Kauaiensis, Wavra, l. c. p. 566. - «Leaves and tomentum as in C. Lessoniana. Flowers solitary on thick recurved peduncles which are of the same length as the petioles $\left(1^{\prime}\right)$ and carry near the base two minute filiform bracts. Calyx 1' long, of 5 foliaceous green and patent lanceolate or ovate-lanceolate sepals which contract at the base into a short tomentose stipes. Corolla slightly exserted, somewhat pubescent, curved and gradually ampliate, the lobes $1 / 3$ as long as the tube, spreading, ovate, acute. Ovary glabrous. Berry oblong, $6^{\prime \prime}, »$

Kauai, woods of Halemanu. Not seen by me.

16. C. triflora, Gaud. l. c. p. 447, tab. 52. - Branches and inflor. glabrate or faintly ferrugino-pubescent. Leaves opposite, thick chartaceous, elliptico-oblong or lanceolate, $3-6^{\prime} \times 1^{1 / 4}-3^{\prime}$, on petioles of $1-2^{\prime}$, evenly acuminate at both ends, denticulate, glabrate above, faintly tomentose underneath or glabrate and pale, excepting the prominent ribs and veins. Flowers $3-12$, either in regular developed or contracted subumbellate cymes, the common peduncle $1-2^{1} / 2^{\prime}$, the pedicels $1 / 2^{\prime}$ or less; bracts linear-lanceolate $3-1^{\prime \prime}$. Calyx glabrous, $1 / 3$ or $1 / 2$ the length of the corolla, parted to the middle or deeper into narrow lanceolate lobes. Corolla $6-9^{\prime \prime}$, straight tubular, contracted below the short nearly equal lobes, villous. Ovary glabrous; style articulate below the stigma. Berry slender ovoid, $6-8$ " long. - DC. 1. c. p. 284 . - Gray, 1. c. p. 351.

Scattering over the whole island of $\mathrm{Oahu}$, but connected by intermediate forms with the next species. Very inappropriately named.

$\beta$ var. grandifolia. - Leaves large ovate to suborbicular, $7-8^{i} \times 4-5^{4}$. Cymes 4--5' long, with 20-30 flowers.

Oahu! Waialua and Waipio.

if var. ambigua. - Calyx $1 / 2-2 / 3$ the length of the corolla, cylindrical, shortly and unevenly divided to less than the middle into lanceolate acute lobes or teeth, peaked in the bud and splitting laterally (as in C. paludosa). Corolla, leaves, ete. as in $\alpha$.

Oahu!

17. C. Garnotiana, Gaud. l. c. p. 447, tab. 53. - A shrub, 6-12 ft. high, the spreading branches and inflor. canescent with short velvety tomentum. Leaves opposite, thin chartaceous, faintly puberulous above, gray-tomentose or glabrate and pale underneath, suborbicular, ovate or elliptico-oblong, $5-7^{\prime} \times 2-4^{\prime}$, on petioles of $1-3^{\prime}$, shortly acuminate, denticulate or serrulate, rounded or contracting at the base. Flowers numerous, $5-20$, in a compound corymbose cyme of $2-4^{\prime}$ in length, the common peduncle 
$1-2^{\prime}$, the pedicels $3-6^{\prime \prime}$; bracts ovate-lanceolate, $3-1^{\prime \prime}$. Calyx graytomentose, $2^{1 / 2}-4^{\prime \prime}$, divided to the middle into 5 triangular or lanceolate lobes. Corolla small, $4-6^{n}$, straight tubular, widening below, with nearly equal lobes, tomentose. Ovary and style pubescent. Berry ovoid, $7-8^{\prime \prime}$ long. - Hook. \& Arn. 1. c. - Gray, 1. c. p. 352. - DC. l. c.

Oahu! Waiance range and western half of the main range. To be distinguished from the preceding species chiefly by the small corolla and gray tomentum.

18. C. laxiflora, Mann, Enum. no. 31\%. - Leaves shaped as in C. Garnotiana, thin membranous, green on both faces, shortly hairy above, pale pubescent underneath. Flowers many in a compound cyme or subumbellate on long pedicels of $6^{\prime \prime}$ or more, the common peduncle $1-3^{1 / 2}$, hirsuto-tomentose as well as calyx and corolla. Calyx $4-6^{\prime \prime}$, divided to near the base into lanceolate lobes, reflected when with fruit. Corolla $6-10^{\prime \prime}$, straight, tubular, with short round lobes. Berry ovoid, 6" long, pubescent or glabrate.

Oahu! with the last species.

19. C. Macraei, Gray, 7. c. p. 352. - A tall spreading shrub, 8-10 ft. high, the branches subherbaceous, angular, and canescent with a hoary or pruinose (waxy) efflorescence, as is also the cyme. Leaves opposite, large, broad ovate, $5-8^{\prime} \times 3-6^{\prime}$, on petioles of $2-4^{\prime}$, acuminate, dentate, rounded at the base, but not unfrequently decurrent into the petiole for a short distance, thin membranous, glabrate above; canescent underneath with a faint pubescence. Flowers very numerous, 10-20, in a short contracted umbellate cyme, on a common peduncle of $2-4$ ", the pedicels longer, 4-6". Bracts small, subulate. Calyx pruinose, parted to near the base into narrow lanceolate or subulate lobes, about $1 / 3$ the length of the corolla. Corolla $4-6^{\prime \prime}$, pruinose, broad tubular and straight, widening at the throat, with small lobes, of thin texture. Ovary pruinose, soon glabrate. Style articulate below the middle. Berry $4-5^{\prime \prime}$.

Oahu! eastern division of the main range, Niu, Wailupe. The majority of the flowers are sterile.

20. C. gracilis, $s p . n$. - Habit of the preceding species, the angular branches more slender and faintly pruinose, soon glabrate, as is the cyme. Leaves opposite, membranous, green on both faces, but paler underneath and faintly puberulous along the veins, quite glabrous above, ovato- or elliptico-oblong, $4-6^{\prime} \times 2-3^{\prime}$, on petioles of $1^{1 / 2}-3^{\prime}$, eaudato-acuminate, serrulate, suddenly contracting and shortly decurrent. Flowers generally 3 , but occasionally fewer or more $(5-7)$, on a common peduncle of ${ }^{1 / 2}-1$, the slender pedicels much longer, $1^{1 / 2}-2^{\prime}$, thickening above. Bracts linear-lanceolate, $6-3^{\prime \prime}$. Calyx glabrate, generally longer than the corolla, $8-15 "$, split to the base into linear lobes. Corolla pruinose in the bud, slightly puberulous, straight, about $12^{\prime \prime}$, ampliate at the throat. Ovary 
glabrous; style articulate below the middle. Berry slender ellipsoidal, $12^{\prime \prime} \times 3-4 "$,

Oahu! in the farthest recesses of Konahuanui, Manoa, Palolo.

$\beta$ var. subumbellata. - Flowers 5-8, subumbellate. Peduncle 6"; pedicels $9^{\prime \prime}$. Calycine lobes only about half the length of the corolla, which measures $8-9^{\prime \prime}$. Leaves broader, approaching to C. Macraei. Other forms with somewhat hairy calyx and corolla and smaller leaves point to a relation with the following species.

21. C. Waiolanii, Wawra, 7. c. p. 566 . - A small tree, $12-20 \mathrm{ft}$. high, the slender branches and inflor. hirsute with pale rust-colored spreading hairs. Leaves generally ternate, sometimes opposite, thin herbaceous, papilloso-hirsute above, sparingly pubescent underneath, but hirsute on ribs and veins, oblanceolate, $4-9^{\prime}$ long including a petiole of $1-2^{1} / 2^{\prime}$ into which the blade gradually contracts, and $1-1^{3 / 4^{4}}$ broad, long acuminate, dentate with patent teeth. Flowers generally 1 , but sometimes 2 or 3 on a common peduncle of $6-10^{\prime \prime}$, the pedicels $6-8^{\prime \prime}$, the narrow lanceolate or linear bracts $4-6^{\prime \prime}$. Calyx hirsute with spreading hairs, $6-10^{\prime \prime}$ long, split to the base into 5 linear lobes which are recurved at the apex when with fruit. Corolla hirsute, straight, included or exserted, about $10^{\prime \prime}$ long, not ampliate at the throat, the short lobes nearly equal. Ovary glabrous; style hairy, articulate at the base, deeply bilamellate. Berry large ovoid, 12 " high. - C. hirsuta, Hbd. in herb. - C. Hillebrandi, Vatke, in Linnaea, 1874.

Oahu! gulch of Konahuanui, Kalihi, Moanalua, Kaala.

$\beta$ var. capitata. - Leaves thick chartaceous, with prominent veins. Flowers 5-7, with very short pedicels, almost clustered at the end of the peduncle. Calyx $6^{\prime \prime}$, corolla $8^{\prime \prime}$.

Konahuanui gulch.

22. C. Kalihii, Wawra, l. c. p. 564. - A shrub, 6-10 ft. high, with few almost horizontal branches, hirsute with coarse ferruginous hairs, as is the inflorescence. Leaves opposite, membranous, papilloso-hirsute above, coarsely pubescent underneath on ribs and veins, large suborbicular, obovate or oblong, $8-14^{\prime} \times 5-8^{\prime}$, cuspidato-acuminate, coarsely dentate, the mostly rounded bases suddenly contracting and decurrent into broadly winged petioles of $2-4^{\prime}$ which are clasping at the base or united by thick prominent ridges. Flowers $3-10$, crowded in a short compound cyme or umbel, on a peduncle of $4-6 "$, the pedicels of about the same length, the bracts narrow lanceolate or linear, $7-4^{\prime \prime}$. Calyx tomentose or hirsute, 5-8"long, parted deeply into narrow lanceolate or linear lobes. Corolla straight, hairy, as long as the calyx or longer, $8-10^{\prime \prime}$, the lobes about $2 "$. Filaments not twisted. Ovary glabrous; style puberulous, with elongate lamellae, - C. tristis, Hbd. in herb. 
Oahu! in deep gloomy ravines of both ranges, Manoa, Nuuanu, Kalihi, Niu, Makaleha, all valleys the more open portions of which are inhabited by $C$. Pickeringii and C. Waiolanii. The usual variability extends over hairiness, shape of leaves, inflorescence, and division of calyx. As to the latter, the species connects manifestly with $C$. Pickeringii on one side and Waiolanii on the other, toward both of which also the leaves verge in their extreme forms. The winged petioles will however serve to distinguish them from those of the former.

23. C. Menziesii, Hook. \& Arn. in Bot. Beech. p. 91. - Young branches and inflor, almost glabrate. Leaves quaternate to opposite, elliptico-oblong, $5-7^{\prime} \times 1^{3 / 4}-2^{1 / 2^{\prime}}$, on petioles of $1^{1 / 2}-2^{1 / 2^{\prime}}$, acuminate at both ends, sharply serrulate, almost glabrate excepting the ferruginous ribs and veins, membranous. Peduncle stout, $3-6^{\prime \prime}$, subumbellately $3-7$-flowered, the pedicels $6-12^{\prime \prime}$ long, the bracts linear or subulate, $3-4^{\prime \prime}$. Calyx $4-6 "$ ", split to the base into 5 linear or subulate lobes. Corolla straight, pubescent, 6". Ovary glabrous. Berry ovoid. - Gray, 1. c. - Mann, Enum. no. 319.

Hawaii! woods of Kona. My specimens exhibit both opposite, ternate and quaternate leaves, while in those collected by Menzies, Gaudichaud and Mann they were quaternate.

24. C. Lydgatei, $s p . n$. - Habit of no. 21, the branches villous with pale ochreous hair, transversely ridged between the bases of the petioles. Leaves opposite, thin flaccid, green on both sides, sparingly hispid above, underneath puberulous along rib and nerves, broadly ovate or suborbicular, $5-7^{\prime} \times 3-4^{\prime}$, suddenly and shortly acuminate, coarsely serrate and dentate, the base rounded or suddenly contracting and uneven-sided, the petiole not margined, $2-3^{\prime}$ long. Flowers $6-7$, subumbellate on a short peduncle of $3-4^{\prime \prime}$, the pedicels $4-5^{\prime \prime}$, the narrow lanceolate bracts $3^{\prime \prime}$. Calyx hirsute, small cylindrical, split to the base into $5-6$ linear or spathulate lobes. Corolla hirsute, shortly exserted, $6-7^{\prime \prime}$, the tube narrow and curved, ampliate at the throat and subbilabiate with large spreading lobes. Ovary glabrous, with broadly lamellate style. Berry broad ovoid.

Molokai! in deep ravines of Kalae and Mopulehu; W. Maui! Honokawai; a nearly glabrate form from Hamakua, E. Mauil One of the small-flowered kinds, at once distinguished from its next neighbors C. Macraei, Menziesii and Kalihii by the manifestly curved corolla with large lobes, besides from the first named by its hairiness and the larger, more deeply lobed calyx, and from the last by the not margined petioles and the smaller corolla.

25. C. grandiflora, Gaud. l. c. p. 44\%, tab, 55. - Sparingly branched, 8-12 ft. high, almost glabrous. Leaves opposite, membranous, glabrate above, pale underneath, with only the rib and veins faintly ferruginous, elliptico- or ovato-oblong, $4-6^{\prime} \times 2-3^{\prime}$, on petioles of $1-2^{\prime}$, shortly acuminate, entire, the base suddenly contracting into the partly margined petiole. Peduncle $1-2^{\prime}$, bearing 2 or 3 flowers on pedicels of $1 / 2-1^{\prime}$. Bracts broad foliaceous, petiolate, ovate-lanceolate, ${ }^{1 / 2}-2^{\prime} \times{ }^{1} / 4-1^{\prime}$. Calyx herbaceous, glabrate, large campanulate, 9-12" long, 5-toothed or lobed to less than the middle in unequal broad triangular acute lobes. Corolla 
glabrous, exserted, large, $15-16^{\prime \prime}$, the broad tube curved and ampliate at the throat, the large spreading limb bilabiate. Ovary glabrous; style articulate at the base, broadly lobed. - DC. I. c. - Hook. \& Arn. 1. e. - Gray, l. c. p. 351. - Mann, Enum. no. 312. - C. Endlicheriana, Nees - C. Ruckiana, Meyen.

Oahul on both ranges, not uncommon in Nuranu.

26. C. filipes, $s p, n$. - Habit of no. 25, glabrous. Leaves 3 or 4 in a whorl, flaccid, pale underneath and glabrate, oblanceolate, $4-6^{\circ} \times$ $1-1^{1 / 2^{\prime}}$, on petioles of $4-6^{\prime \prime}$, acuminate at both ends, remotely dentate or serrulate. Flower solitary on a short peduncle of $1 / 2-3$ ", the slender pedicel many times longer, 9-18". Bracts filiform, 2-3", soon caducous. Calyx herbaceous, glabrous, cylindrical or campanulate, $6-12^{\prime \prime}$, bilabiately 5 -fid to less than the middle into sharply pointed lanceolate lobes, deciduous from the fruit. Corolla glabrous, as long as the calyx or longer, 10-14", shaped as in C. grandiflora. Ovary glabrous. Berry slender fusiform, 9". W, Maui! gulches of Honokawai and Kannapali.

27. C. paludosa, Gaud. l. c. p. 447. - A low shrub, 4-6 ft. high, with rather fleshy glabrate branches. Leaves opposite, thick chartaceous, with prominent straight veins, pale and glabrous underneath, dark green above, lanceolate, $5-8^{\prime} \times 1^{1 / 2}-2^{\prime}$, cuspidato-acuminate, coarsely serrate, gradually narrowing into a petiole of $1-2^{\prime}$. Peduncles short, $1-2^{\prime \prime}$, umbellately $2-5$-flowered, the pedicels $4-6 "$, the bracts linear or subulate, $2-3^{\prime \prime}$, soon deciduous. Calyx 6-12"long, thin, glabrous, cylindrico-campanulate, peaked in the bud, unevenly 5 -fid to the middle or less into lanceolate long acuminate lobes or teeth, splitting laterally, and caducous when with fruit. Corolla generally exserted, glabrous, curved, 10-15"long, the broad tube ampliate at the throat with large bilabiate spreading lobes. Ovary glabrous, the style $6 "$, articulate at the base, deeply lamellate. Berry ovoid-oblong, $8-10^{\prime \prime}$, obtuse at both ends. - Hook. \& Arn. 1. e. - Gray, 1. c. - DC. 1. c. - Wawra, 1. c.

Common on Oahu! woods of Hilo and near Kilauea, Haw a ii!

$\beta$ var. brevicalyx. - Peduncle very short or almost wanting, often only 1 -flowered, the filiform pedicels $9-18^{\prime \prime}$. Calyx only ${ }^{1 / 3}$ the length of the corolla, $3-4^{\prime \prime}$, cyathiform with broad acuminate lobes or teeth. Berry slender fusiform, $10-12^{\prime \prime}$ long.

Oa hu! Kaula range. The long slender pedicels and elongate berries almost as in no, 26 . ; var. alnifolia. - Young shoots and inflor. hirsute with dark ferruginous hairs. Leaves broadly ovate, $4-5^{\prime} \times 2^{1} / 2-3^{\prime}$, somewhat obtuse, rounded at the base, the strong ribs and veins pubescent. Peduncle and pedicels $6-7 "$ each. Calyx and corolla faintly pubescent.

Oahu!

a var. microcarpa. - Leaves broad oblong, $6^{\prime} \times 3^{\prime}$, coarsely and bluntly serrate, glabrous, thin chartaceous, dark underneath. Peduncles very short, 
$1-2^{*}$, bearing $5-8$ flowers on pedicels of $6-12^{\prime \prime}$. Berry small ovoid, obtuse, $6^{\prime \prime}$ or less. - Wawra, 1. e., and including probably his var. confertiflora and herbacea.

Kauait Kealia and Waimea $\left(\mathrm{Kn}_{*}\right)$. Conspicuous for the closely crowded inflor. in nearly every axilla of standing and fallen leaves; stem sparingly branching or simple.

$\varepsilon$ var. subherbacea. - Glabrate. Leaves broadly ovate, rounded at the base, sinuato-dentate. Peduncles $6-12^{\prime \prime}$, the pedicels as long or longer. Calyx 6". - Wawra, 1. c.

Plateau of Waialeale, Kauai.

$\zeta$ var. integrifolia. - Leaves elongate, with entire margins, $7-9^{\prime} \mathrm{X}$ $2-2^{1} / 2^{\prime}$, on partly marginate petioles of $2-2^{1} / 2^{\prime}$, glabrate, but ferruginous underneath along the veins. Inflor. and fruit as in $\alpha$.

Hawaii! Kohala; Ka uai! Waimea (Kn.). Here also belong Wawra's var. longifolia and arborescens from Hanalei, Kauai.

28. C. latebrosa, sp. n. - Stem straight, undivided, 6-12 ft. high, with a thick glutinous sap, the young shoots and inflor. dark ferruginous with a thick squamaceous tomentum. Leaves verticillate, $3-5$ in a whorl, narrow oblanceolate, $6-12$ ' long, including a rather long margined petiole into which they gradually contract, and $1-2^{\prime}$ broad, acute, entire or shortly dentate, chartaceous, prominently penninerved, brownish underneath with a short and soft tomenturn, or glabrate. Peduncle very short, $1-4^{\prime \prime}$, bearing $1-5$ mostly drooping flowers on pedicels scarcely longer than the peduncle. Bracts linear-lanceolate, $7-5^{\prime \prime}$ long. Calyx deciduous, fleshy, shaggy outside and inside with dark squamaceous tomentum, $10-14^{\prime \prime}$ long, fusiform in the bud and generally also later, with a lateral slit through which the corolla protrudes, the peaked top remaining entire or splitting into 5 short teeth, but occasionally divided to the middle into 5 linear lobes. Corolla slightly exserted and villous when the calyx is lobed, but included and almost glabrate when the same is fusiform, curved with large spreading limb, bilabiate, the upper lip deeply emarginate, the lower 3 -lobed, $4-5^{\prime \prime}$ long. Style twice as long as the glabrous ovary, with rounded lobes. Berry olive-shaped, $13^{\prime \prime}$ long. - C. paludosa, var. $\gamma$, degenerans, Wawra, 1. c. p. 558 .

In deep and dark ravines of Kalihi and Manoa, Oahnl Mopulehu, Molokai! - The singular form of the calyx, attributed by Wawra to a morbid degeneration, is simply the normal bud-state in the present group, which here remains permanent probably for want of elasticity, owing to its thick unyielding substance and to the exclusion of direct sunlight. By the narrow slit at the apex water with organic matter is apt to find an entrance, perhaps also insects, which soon canse decay of the hairy lining and with it of the corolla, so that flowers or fruit are seldom seen in this form; but when the flower developes it forces itself through the lateral slit indicated. The fruit remains a long time surrounded by the closed ealyx, which however at last breaks away from its base, as is the case in C. paludosa. The forms with closed calyx oceur at the bottom of the onen calyces are found on the more exposed slopes. It has to be remarked also that in the former the peduncles are very short and generally bear only one flower, while the longer inflor. with several flowers is only found with the second form. The plants from Molokai perfectly agree with those from Oahu, only that the leaves are rather glabrate.

Hillebrand, Flora of the Hawaiian Islands. 
$\beta$ var. subglabra. - Leaves quaternate or ternate, membranous, almost glabrate underneath, and pale, obovate-oblong, $10-13^{\prime} \times 2^{1 / 2}-4^{1} / 2^{\prime}$, shortly acuminate, subentire or dentate, gradually contracting toward the base and sessile or running out into a broadly winged petiole. Calyx membranous, sparingly clothed with dark brown hairs or nearly glabrate, seldom fusiform, but commonly split to the middle or less into broad lanceolate long acuminate lobes. Corolla as long as the calyx, more or less hairy or glabrate.

Molokai! Kalae; Maui! Waiehu; Hawail! valley of Holopalau in Kohala. - In the measure as the leaves recede from the type by becoming broader and longer petiolate, the inflorescence lengthens out. Thus an extreme form from Waiehu presents 5 flowers in an elongate compound cyme on a peduncle of $1^{\prime}$, with pedicels of nearly equal length.

29. C. oenobarba, Mann, Enum. no. 313. - « Low decumbent, 1-2 ft. high, fleshy, the stem and petioles shaggy with stiff dark brown reflected

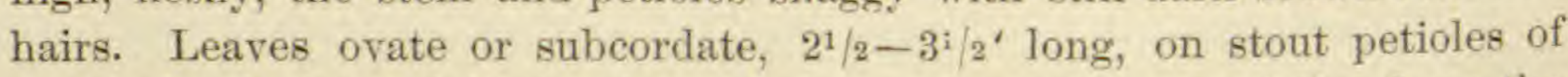
$1-2^{\imath}$, denticulate, glabrate above, hairy underneath, especially along the rib and veins. Peduncles $1-2$-flowered, as long as the petioles. Calyx shaggy, oblong, 5 -fid, the lobes ovate-lanceolate, sharp acuminate, foliaceous. Corolla slightly exserted, fully 1 ' long, quite glabrous, ampliate at the throat, with a large spreading limb.» (Descr. from Mann.) Wawra, 1. e., var. $\beta$ (leaves glabrate).

Kauai, Wahiawa falls and Waioli, foot of Waialeale.

$\beta$ var. petiolaris. - «Leaves elliptical or oblong, 4' long, on petioles of the same length or longer, acute at both ends, distantly denticulate, sparingly hairy on the upper face, glabrate underneath, excepting the rib and veins, which are villous as well as the peduncles and calyces. Peduncle $1 / 2^{\prime}$ long, many-flowered, the pedicels very short. Calyx $6-8^{\prime \prime}$, with lobes as long as the tube. Corolla $1^{1 / 2}-2^{4}$ long, the exserted portion much ampliate. - Wawra, 1. c. p. 562.

Waterfall of Hanalei, Ka uai.

$\gamma$ var. obovata. - «Leaves obovate. Flowers subsessile. Calyx closed, splitting laterally, 4-toothed. Corolla as long as the calyx.»-Wawra, 1. c.

With the preceding. The entire species is unknown to me; var $\gamma$ would appear to belong to the preceding species.

\section{ORdER LXIII. MYOPORACEAE.}

Character of Verbenaceae, but the lobes of corolla and stamens sometimes 5 or more. Ovary 2-4-(or in some Myoporum 5-10-) celled, each cell with 1 pendulous ovule, or in the 2 -celled ovary sometimes with 2 . Style terminal, with entire or emarginate stigma. Fruit drupaceous. Embryo taper in the axis of scanty albumen, the radicle superior. - Shrubs or trees. Leaves without stipules, mostly alternate. Flowers in axillary clusters, the pedicels without braets. 
A small Order of 5 genera, peculiar to the southern hemisphere, only 3 or 4 species occurring north of the equator.

\section{MYOPORUM, Banks \& Sol.}

Calyx 5-parted. Corolla bell-or funnel-shaped, 5-(rarely 6-7-)lobed, with lobes subequal or one lobe little larger. Stamens generally 4-5 (the fifth rudimentary) or rarely $6-7$, adnate to the tube and scarcely longer than it; anthers reniform. Ovary 2-10-celled. Stigma obtuse. Drupe globose, with 2-10 pendulous seeds. - Shrubs or small trees, with alternate, rarely opposite, entire or toothed leaves. Flowers fasciculate, axillary.

Natives chiefly of Australia and adjacent islands, with a few or one species each in New Zealand, the Mascarenes, China, Japan, the Bonin and Hawaiian Islands.

1. M. Sandwicense, Gray, in Proc. Am. Ac. VI, 52. - A tree of $20-30 \mathrm{ft}$. height in the higher, shrubby in the lower regions, glabrous throughout. Leaves crowded toward the ends of the branches, alternate, elliptico-lanceolate or oblong, $3-6^{1} \times{ }^{1 / 2}-1^{1} / 4^{\prime}$, including the short petiole, acute at both ends, quite entire, chartaceous, often somewhat fleshy, the veins then scarcely visible. Flowers in clusters of $5-8$ on pedicels of $3-5^{\prime \prime}$. Calyx $1-1^{1} / 2^{\prime \prime}$, parted to the base into ovate-lanceolate acute lobes. Corolla white, with purplish dots, campanulate, 3-4" long, cleft to the middle into 5, 6 or rarely 7 obovate lobes. Stamens as many as lobes, shorter, all antheriferous and alike, or two of them a little exceeding the others. Anthers pendulous, their cells free except at the apex. Style short, incurved near the apex, with truncate stigma. Drupe dry, globose, $3^{\prime \prime}$ in diameter, 5-10-celled, ribbed when dry. Embryo cylindrical, the cotyledons as long as the radicle. - Mann, Enum. no. 364. - Polycoelium Sandwicense, A. DC. in Prod. XI, 706. - M. tenuifolium, Hook. \& Arn. in Bot. Beech. p. 93 (not Forst.). Anther-cells in the younger flowers parallel, with pointed bases, in the older ones short divaricate, with obtuse bases.

Inhabits the high mountains of the group. On Mauna Kea it forms, together with Edwardsia chrysophylla and Raillardia struthioloides, the upper limit of the tree zone at an elevation about $10000 \mathrm{ft}$. on the leeside, attaining there its greatest height, but on $\mathrm{Haw}$ aii as well as on Maui it extends downwards to near the sea, gradually dwarfing to a low decumbent shrub. In $\mathrm{Moloka}$, where the mountains do not exceed $3000 \mathrm{ft}$., it seems to be wanting, and in $\mathrm{O} a \mathrm{hu}$ it is found only on $M t$. Kaala; but on the highlands of Kauai again it is not uncommon. The wood of the Naeos or "Naieos, most so that of the roots, becomes fragrant on drying, with an odor resembling that of sandalwood, whence its English name -Bastard Sandalwood". After the exhaustion of the true sandalwood it used to be exported to China for some time as a substitute.

\section{Order LXIV. VERBENACEAE.}

Flowers irregular or rarely regular. Calyx persistent, truncate, toothed or lobed. Corolla with 4,5 or rarely more lobes, imbricate in the bud, nearly equal or more or less bilabiate. Stamens usually 4 in pairs, in- 
serted in the tube of the corolla and alternating with its lower lobes. Ovary not lobed, usually 2 - or 4 -celled, with 1 ovule in each cell. Style terminal, entire or with 2 stigmatic lobes. Fruit dry or succulent, separating into 2 or 4 cocei, or indehiscent. Seed without any or with a small quantity of albumen. Embryo straight, with thick cotyledons. - Herbs, shrubs, trees or climbers. Leaves usually opposite or whorled, without stipules. Inflorescence various.

A large cosmopolitan Order, chiefiy tropical. Cultivated species: Tectonia grandis, the Teak tree, Duranta Plumieri, Jacq., Gmelina Asiatica, L., Lippia citriodora, H. B. \& K., Petrea volubilis, Jacq., and one or two species of Callicarpa.

Inflorescence indeterminate, centripetal, in racemes, spikes or heads; ovules

erect :

Fruit dry, separating into small nuts or cocei :

Fertile stamens 4:

Fruit of 4 nutlets

Fruit of 2 nutlets

Fertile stamens 2; flowers lodged in furrows of the rhachis

Fruit a fleshy drupe.

1. Verbena.

2. Priva.

3. Stachytarpheta.

4. Lantana.

Inflorescence determinate, centrifugal, in panicles, cymes or heads;

fruit drupaceous; ovules pendulous or laterally attached:

Lower lobe of the corolla much longer than the others

5. Vitex.

Lobes of the corolla nearly equal.

6. Clerodendron.

\section{VERBENA, L.}

Calyx 5-toothed, 1 tooth usually shorter than the others. Corolla with a distinct tube and a rather unequal 5 -lobed limb. Stamens 4 , all fertile, included. Style 2-lobed, with 1 stigma abortive. Ovary 4 -celled; ovules erect. Fruit dry, enclosed in the calyx, separating into 4 nutlets. - Herbs, rarely shrubs, with small flowers in terminal spikes.

A large American genus, with two speeies spread over the warmer regions of the old World.

†1. V. Bonariensis, L. - DC. Prod. XI, 541. - An erect perennial, several feet high, the stem tetragonous, scabrous and hispid, distantly foliose, naked above. Leaves opposite, about 3 'long, broadly lanceolate, distantly inciso-serrate from the middle, shortly stipitate or auricled and slightly clasping at the base, scabrous on both faces. Panicle cymose, elongate, the spikelike branches densely flowered, naked at the base. Flowers sessile, mostly single, the acute bractlets as long as the pubescent calyx. Calyx tubular, $1^{\prime \prime}$, with sharp teeth. Corolla $2^{\prime \prime}$, with slender tube and short limb, lilac.

The well known "Oïs, a troublesome weed of early introduction which has taken root in many parts of the Islands, most so on the highlands of Waimea, $\mathrm{Ha}$ wail, where large extents of pasture land have been ruined by it and where it grows to the height of $6 \mathrm{ft}$. and more. - A native of the La Plata region and southern Brazil, but which has become established also in southeru Africa, Mauritius and the Canary Islands,

If I remember rightly, $V$. officinalis, L., also occurs as a weed near Honolulu, but no specimen has been preserved. It is a smaller plant with pinnatifid leaves. 


\section{PRIVA, Adans.}

Calyx 5-toothed. Corolla salver-shaped, obliquely 5-lobed, the limb short and spreading. Stamens 4 in pairs, included. Stigma lateral or anterior. Ovary 4-celled. Fruit of 2 nutlets, each 2 -celled, or 1-celled by abortion. - Flowers distant, on short pedicels in terminal spike-like racemes.

Nine species, natives of America, Africa and India.

†1. P. aspera, H. B. \& K. - DC. Prod. XI, 534. - A perennial herb, pubescent with retrorse hooked hairs. Leaves ovate-acuminate, crenatedentate, suddenly contracting into a short petiole, scabro-hispid on the upper, gray-pubescent on the lower face. Pedicels shorter than the linear bracts. Calyx $11^{1} / 2^{\prime \prime}$, scabro-pubescent. Corolla pubescent, the tube a little exserted and ampliate at the throat. Fruit globose, surrounded by the calyx, the nutlets 1 -celled and 1-seeded, separating at maturity, convex and wrinkled or tuberculate at the back, the commissural area deeply excavated.

A Mexican weed, widely spread in the western division of $\mathrm{O}$ a hu.

\section{STACHYTARPHETA, Vahl.}

Calyx tubular, 5-ribbed, irregularly 5-toothed. Corolla 5-lobed, the tube often incurved. Stamens included, only 2 fertile, with anther-cells diverging. Stigma capitate. Ovary 2 -celled, with 1 erect ovule in each cell. Fruit of 2 linear nutlets. - Herbs or shrubs. Flowers spicate, sunk in pits or furrows of the thick rhachis.

About 40 species, chiefly American.

†1. S. dichotoma, Vahl. - DC. Prod. XI, 561. - An erect herb, 2-4 ft. high, pubescent, with angular branches. Leaves ovate, 2-4' long, acuminate, crenate-serrate, suddenly contracting to a short petiole, hispidpubescent on both faces. Spikes long and slender. Bracts subulate, gibbous at the base, about as long as the calyx. Calyx tubular, 2-3 long, shortly 4-toothed. Corolla deep blue, the curved tube scarcely longer than the calyx. Fruiting calyx semi-immersed in the rhachis.

A troublesome weed from tropical America, widely spread in the distriets of Hilo and Kona, $\mathrm{Haw}$ ail! also called : Oi" by the natives. In gardens: S. mutabilis, V.

\section{LANTANA, L.}

Calyx small and thin, truncate or sinuately toothed. Corolla-tube slender, the limb spreading, 4- or 5-lobed, nearly regular or slightly bilabiate. Stamens 4, included. Ovary 2-celled, each cell with 1 erect ovule. Fruit a fleshy drupe, the kernel 2 -celled or dividing into 2 nuts. - Shrubs, rarely herbs. Flowers in pedunculate axillary heads, rarely lengthening into spikes.

A considerable genus, chiefly from tropical and subtropical America. 
†1. L. Camara, L. - DC. Prod. XI, 598, - A spreading shrub with long weak branches, often armed with short recurved prickles and more or less hairy. Leaves petiolate, ovate or slightly cordate, crenate, $2-3$ ' long, wrinkled, and very rough with short stiff hairs. Peduncles stiff, as long as the leaves or longer. Flowers yellow or orange, turning to a deep red, the heads not lengthening into spikes. Bracts linear-lanceolate, shorter than the corolla. Corolla-tube $3-4$ "long, the lobes of the limb short and broad. Putamen of fleshy drupe wrinkled and excavated on both sides of the base, at length splitting into two nuts.

A native of the subtropical regions of $\mathrm{S}$. America; introduced in 185s, but now well naturalized, as it is in many other countries, chiefly by the agency of birds which feed on the aromatic berries. It varies greatly as to color of flowers; some are nearly white. - L. trifoliata, L., a smaller unarmed shrub with pinkish flowers, has existed in gardens about the same length of time without spreading.

\section{VITEX, L.}

Calyx 5-toothed or lobed. Corolla-tube short, the limb spreading, 5 -lobed, the lower lobe larger and longer than the others. Stamens 4 in pairs, exserted. Ovary 4-celled, ovules pendulous. Style acutely 2-lobed. Fruit a 4 -celled drupe. - Trees or shrubs. Leaves usually digitate, but simple in the Hawaiian species. Flowers in cymes, sometimes axillary, but usually in terminal panicles.

A considerable tropical or subtropical genus, chiefly Asiatic or African, with a few Ameriean and Australian species, one extending into southern Europe.

1. V. trifolia, L. - DC. Prod. XI, 683, var. unifotiata. A low decumbent shrub or frutescent herb, the branches, underside of leaves and inflorescence mealy-white. Leaves simple, obovate or rounded, $1-1^{1 / 2}{ }^{2}$ long, on petioles of $2^{\prime \prime}$, entire, nearly glabrous above. Flowers few in nearly sessile opposite cymes, forming short and simple terminal panicles. Calyx $2^{\prime \prime}$, very shortly toothed, the corolla blue, $6^{\prime \prime}$, with the tube ampliate at the throat, both mealy-white outside. Drupe globose. - V. ovata, Thbg. - Hook. \& Arn. in Bot. Beech. tab. 47. - Benth. Fl. Hongk. p. 273. - Mrs. Sinclair pl. 26.

On the sandy seashore of all isIands, here and there, Waialua and Kailua, Oahu! always gregarious. The flowers are fragrant. Nat. name: :Polinalina. The species is widely spread over the Polynesian islands and the seashores of $\mathrm{N}$. Australia and eastern tropical Asia, but generally in the form with 3 leaflets, which does not oceur on the Hawajian Islands.

\section{CLERODENDRON, L.}

Calyx campanulate or inflated, 5 -toothed or lobed. Corolla-tube slender, much longer than the calyx, except when the latter is inflated; the limb spreading, nearly equally 5 -lobed. Stamens 4 , usually much exserted. Ovary 4-celled; ovules pendulous or laterally attached. Style with 2 acute stigmatic lobes. Fruit a drupe, the kernel usually large, separating into 2 two-celled or 4 one-celled nuts. - Shrubs, trees or rarely herbs. 
Flowers loosely cymose or capitate, in terminal panicles or thyrsi, or rarely axillary.

A considerable tropical genus, chiefly Asiatic, with a few African and American species.

†1. C. fragrans, Vent. - DC. Prod. XI, 666, var. pleniflora. - Suffruticose, not exceeding $2 \mathrm{ft}$. in height, propagating by underground runners. Leaves broadly ovate or subcordate, shortly acuminate, repandodentate, hispid above, pubescent underneath, on rather long petioles with scattering glands. Flowers in a contracted and subsessile terminal cyme. Calyx 5-cleft, little exceeded by the corolla tube, its lobes acute. Corolla white with a roseate blush, filled or double, its lobes obovate-obtuse.

Along roadsides (Nuuanu) and near abandoned habitations, as on the hill back of Punahou where it covers several acres of ground to the exclusion of everything else. Flowers fragrant. Of early introduction; a native probably of China, but naturalized in Brazil and some W. Indian islands. Other cultivated species of this genus: C. fallax, Lindl., C. inerme, R. Br, C. Siphonanthus, R. Br.

\section{ORDER LXV. LABIATAE.}

Flowers irregular or rarely almost regular. Calyx persistent, usually 5 -toothed. Corolla with a distinct tube and 4 or 5 lobes, usually forming 2 lips, rarely almost equal. Stamens 2 or 4 in pairs, inserted in the tube of the corolla and alternate with its lower lobes. Ovary 4-lobed, with 1 erect ovule in each lobe. Style single, rising from the centre, with 2 short stigmatic lobes at the top. Fruit enclosed in the calyx, separating into 4 small seed-like nuts.. No albumen. - Herbs or rarely shrubs, frequently aromatic. Leaves opposite or whorled. Flowers in opposite cymes or rarely solitary, either forming axillary clusters, those of opposed axils being called verticillasters, false whorls or whorls, or in terminal spikes or racemes or spike-like panicles or thyrsi, or in loose panicles.

A large Order, distributed over every part of the globe.

Stamens 2, the filaments branched, one branch with a perfect cell, the other with an imperfeet one.

Stamens 4 , bending downwards

Stamens 4 , ereet or spreading:

Style or style-branches clavate; lower lip of corolla longer than the upper or as long:

Style bifid; ealyx open in fruit; nucules fleshy

3. Salvia.

1. Plectranthus.

Style bifid; ealyx open in fruit; nucules fleshy
Style emarginate or entire; calyx closed in fruit; nucules dry 5 . Phyllostegia.
Style-branches subulate:

Lower iip of corolla shorter than the upper; nucules fleshy .

Lower lip of corolla not shorter than the upper:

Corolla dilated at the throat, diffusely pubescent inside the tube.

Corolla not dilated, the tube with a distinct annulus near the base

\section{PLECTRANTHUS, L'Herit.}

Calyx campanulate when with flower, 5-toothed, much longer when with fruit, declinate or erect, with the teeth equal or bilabiate or the 
upper one ovate. Corolla exserted, gibbous or spurred at the base, curved or straight, exannulate, the upper lip 3-or 4-cleft, the lower elongate, entire, concave. Stamens 4, declinate, free, the lower pair longer than the upper. Anthers ovate-reniform, with the cells generally confluent. Style shortly bifid with subulate lobes. Nuts dry. - Herbs or shrubs, with simple or branched terminal racemes, the inflorescence either contracted in dense verticillasters or cymosely developed.

A large genus, natives of tropical and subtropical Africa, Madagascar, Asia and Australasia with Polynesia, one species also oceurring in Brazil.

1. P. parviflorus, Willd. - DC. Prod. XII, 6\% - Herbaceous, erect, $1 / 2-1^{1 / 2} \mathrm{ft}$. high, hispid-tomentose. Leaves rather fleshy, on petioles of ${ }^{1 / 2}-1^{\prime}$, ovate, $1-1^{1 / 2} / 2^{\prime} \times{ }^{3 / 4}-1^{1 /} / 2^{\prime}$, shortly acuminate, coarsely dentatocrenate or incised, truncate at the base, hispid-tomentose on both faces. Racemes terminal, $3-8^{\prime}$ long, simple or with a pair of branches from the uppermost leaf-axils. Bracts minute, soon caducous. Flowers in whorls of $10-16$ on pedicels of $1^{1 / 2}-2^{1 / 2^{\prime \prime}}$. Calyx hispid, $1-2^{1 / 2^{\prime \prime}}$, declinate, incurved, strongly nerved, bilabiate, the upper lobe flat-ovate, the 4 lower ones longer, subulate, assurgent. Corolla blue, less than 3 ", slightly gibbous above the base, the lowest lobe largest and concave. Stamens received within the lowest lobe. Nuts $1 / 2^{\mu}$, ovate-complanate, shining. - P. australis, Hook. \& Arn, in Bot. Beech. p. 92.

Rather common on exposed slopes of all islands. The species is a native also of the tropical and subtropical regions of eastern Australia.

\section{SPHACELE, Benth.}

Calyx campanulate, irregularly 10 -nerved and net-veined, naked within, deeply 5 -toothed, the teeth nearly equal or somewhat bilabiate, generally subulate. Tube of corolla hairy inside or with a hairy ring, the limb short, scarcely bilabiate, 4 -lobed, the lobes erecto-patent, broadly rounded, the uppermost emarginate or bifid, the lateral ones entire, the lowest larger, emarginate or entire. Stamens 4, distant, nearly straight, the lower pair longer than the upper. Anthers 2-celled, with linear diverging cells. Style bifid at the apex, the lobes subulate or complanate-acute. Nucules glabrous, smooth. - Shrubs or herbs with rugose canescent leaves, the floral leaves generally bract-like. Flowers in terminal racemes or panicles.

An Andine genus of about 20 speeies, extending from Chili to California.

1. S. hastata, Gray, in Proc. Am. Ac. V, 341. - Herbaceous, erect, $3-5 \mathrm{ft}$. high, canescent, viscous-tomentose. Leaves hastate, $6-9^{\prime} \times 2^{2}-4^{\prime}$, the lowest on petioles of $2^{\prime \prime}$, the upper ones nearly sessile, acute, closely crenate, thick chartaceous, tomentose underneath, less so above, minutely rugose. Lowest floral leaves $3-2^{\prime}$ long, subsessile, the upper ones gradually smaller. Flowers $6-15$, in compound cymes with lanceolate bract- 
lets, the median pedicels $2-4^{\prime \prime}$, the whole inflorescence forming an open thyrsoid panicle. Calyx $3-8^{\prime \prime}$, the subulate lobes as long as the tube and slightly bilabiate, closed at maturity. Corolla about 1 ', slightly curved, dilated at the throat, with the large upper lobe emarginate, purplish-red, somewhat pubescent, the entire tube puberulous within, most so near the base, but without proper annulus. Stamens from the middle of the tube, much exserted, as well as the style. Nuts surrounded by a glandular disk, short obovoid, 1", contracted above the base.

E. Maui! where the gregarious plant forms an interrupted belt round Haleakala at an elevation of $2000-3000 \mathrm{ft}$. above the sea; most plentiful at Ulupalakua. It emits a heavy odor. The flowers are much subject to the attacks of a dipterous insect, and ripe seeds are seldom found. Nat. name. "Pakaha". Not found elsewhere.

\section{SALVIA, L.}

Calyx bilabiate, the upper lip entire or minutely 3 -toothed, the lower 2 -cleft. Corolla with the upper lip erect, concave or arched, the lower spreading, 3-lobed, with the middle lobe often notched or divided. Stamens 2 ; anthers with a long slender connective transverse to the filaments, one half or branch of it ascending under the upper lip and carrying a perfect cell, the other half deflected forward and carrying a small empty or rudimentary one. Style bifid, the branches subulate or dilated.

A very large genus of herbaceous or shrubby plants, spread over the temperate and warmer regions of the globe. - Besides the following species $S$. coccinea (with scarlet flowers) is occasionally met with as an escape from gardens.

$\dagger$ 1. S. occidentalis, Swartz. - DC. Prod. XII, 296. - A diffuse weed, $1 \mathrm{ft}$. or more long, glabrous or pubescent. Leaves petiolate, broadly ovate, $1-1^{1} / 2^{\prime}$ long, acute, serrate, rounded or euneate at the base. Floral leaves bract-like, not longer than the pedicels, ovate-lanceolate. Flowers minute, $2-6$ in a whorl, the whorls distant, forming racemes of $4-6^{\prime}$ in length. Calyx scarcely $2^{\prime \prime}$, glandular-villous, the upper lip obtusely 3 -toothed. Corolla blue, glabrous, the tube as long as the calyx, the upper lip short, oblong, emarginate, the lower spreading. Style glabrous, its lobes complanate, dilated. - Griseb. Fl. W. Ind. p. 490.

Oahu! Kapalama near Honolulu, and Moanalua on the slope of the salt-lake crater Alia pakai; also on Kauai! A common weed in tropical America, also collected on the Galapagos Islds. and on Tahiti.

\section{STACHYS, L.}

Calyx tubular or campanulate, 10-5-nerved, equally 5 -toothed, or the upper teeth united into an upper lip. Corolla not dilated at the throat, with a hairy ring inside, the upper lip erect or spreading, often arched, entire or nearly so, the lower usually longer and spreading, 3-lobed, with the middle lobe larger and nearly entire. Stamens 4 , ascending under the upper lip, the 2 lower longest, deflected and spreading after flowering; anthers 2 -celled. Style bifid with subulate lobes. - Herbs or undershrubs, 
diffused over all temperate regions. Whorls 2- or many-flowered, approximate in terminal racemes or spikes.

†1. S. arvensis, L. - DC. Prod. XII, 47\%. - An annual, about $6^{4}$ high, the decumbent stems hairy. Leaves petiolate, ovate, $1 / 2-1$ ' long, obtuse, crenate, cordate, hispid on both faces. Floral leaves gradually decreasing, the uppermost bract-like, shorter than the calyx. Whorls 4-6-flowered, distant. Calyx $3^{\prime \prime}$, often declinate and slightly incurved, deeply and sharply 5-toothed. Corolla reddish, pubescent, short, with the tube included and the short lips nearly equal.

A weed, not uncommon in gardens and cultivated fields. A native of Europe and Asia, but now spread over many countries temperate and tropical.

\section{HAPLOSTACHYS, gen. nov.}

Calyx cylindrical, 5-toothed, closed at maturity. Tube of corolla nearly straight, scarcely widening at the throat, exannulate; the upper lip entire, the lower 3 -lobed, the lobes of both lips rounded with an undulating crisp margin, all of nearly equal size. Stamens as in Phyllostegia. Style included, subentire, clavately dilating and flattened near the apex, emarginate with 2 equal stigmatiferous cushions on the top, more or less hairy. Nucules dry, triquetro-convex, obconical, closely packed, pubescent at the top, retained within the closed calyx. - Erect herbs, sparingly branching near the base, densely tomentose, with coriaceous rugose leaves. Flowers subsessile in a simple terminal spike, the verticillasters 2-flowered. Corollas purplish-white or cream-colored, - Phyllostegia, sect. Haplostachya, Gray, in Proc. Am. Ac. V, 342.

A calyx closed at maturity, nearly equal and crisp lobes of the corolla, and dry cohering nucules may be considered sufficient grounds for separating the following species as a genus from the otherwise nearly related Phyllostegia, from all known species of which they are also distinguished at first sight by their habit.

Leaves truncate or cordate:

Calycine teeth acute

Calycine teeth obtuse

Leaves linear

1. H. Grayana.

2. H. truncata.

3. H. rosmarinifolia.

1. H. Grayana, Hillebr. - Erect, 1-2 ft. high, the branches or stems angular, hoary-tomentose. Leaves rather fleshy, rugose, cordate-oblong or lanceolate, $3-4^{\prime} \times 1-2^{\prime}$, on petioles of $1-2^{\prime}$, bluntly acuminate, coarsely crenate, the basal lobes rounded, both faces covered with a thick velvety tomentum. Flowers in a terminal spike of often $12^{\prime}$ in length, single and subsessile in the axils of lanceolate to linear bracts of $6-2^{\prime \prime}$ in length, patent at first, secund and deflected when with fruit, the lowest pairs distant. Calyx coriaceous, tomentose, $3-5$ "long, the narrow acute teeth $1 / 4-1 / 3$ the length of the tube, with a deeper slit between the two lowest. Corolla pubescent, white, with purplish tinge, the tube about $8^{\prime \prime}$. Filaments pubescent. Style puberulous or glabrate. Nueules large, closely 
packed, runcinate or suberose at the back and sides, pilose at the apex. - Phyllost. haplostachya, Gray, in Proc. Am. Ac. V, 345.

E. Maui! Kula and Honuaula; Hawaii (Remy.) Nat, name: "Honohonos. - While the fleshy fruit of Phyllostegia and Stenogyme appears black when dry and wrinkled, the nucules of the present genus are light brown and do not swell on soaking.

$\beta$ var. leptostachya. - Leaves smaller and narrower, $1^{1} / 2-2^{\prime} \times X^{1 / 2}-9 / 4^{4}$, less deeply cordate at the base, almost truncate; their upper face and the calyx less tomentose. Lowest whorls very distant.

Kauai, on barren ridges (U. S. E. E.).

2. H. truncata, Hillebr: - «Upper leaves lanceolate, $1-2^{\prime} \times{ }^{1 / 3}-{ }^{1 / 2^{\prime}}$, crenulate, truncate or subcordate at the base, velvety-puberulous above, white-tomentose beneath. Spike elongate, the lowest flowers $1^{\prime}$ apart, single, on short pedicels of $1-1^{1 / 2} 2^{\prime \prime}$. Calyx cylindrical, glandular-pubescent, repando-truncate, the broad teeth very short and obtuse. Corolla $1^{\prime}$ or more. Achenes slightly glandular at the top. $*$ Deser. according to Gray. - Phyllostegia truncata, Gray, 1. c.

E. Maui! (Remy.)

3. H. rosmarinifolia, sp. $n$, - Erect, $1-2 \mathrm{ft}$. high, gray-tomentose, the stems obtusely angular, nearly terete, rather woody at the base. Leaves linear, $4-5^{\prime} \times 1^{1 / 2}-2^{1 / 2^{\prime \prime}}$, sessile, acuminate at both ends, entire or finely crenulate, with revolute margins, densely tomentose on both faces, of thick texture. Spike or raceme $6-8^{\prime}$ long, the bracts $4-2^{\prime \prime}$. Pairs of flowers closely set, excepting the lowest, the pedicels $1 / 2-1^{\prime \prime}$. Calyx $3-4^{\prime \prime}$, villous-tomentose, acutely dentate as in no. 1. Corolla creamcolored, tomentose, the tube $1^{\prime}$, the upper lip $2^{\prime \prime}$, the lower $3^{\prime \prime}$. Filaments hairy. Style hairy, particularly near the almost entire stigma. Nucules pubescent, concavo-convex, smooth, dry.

Molokai! heights above Kamolo; Maui! sandhills of Wailukit.

\section{PHYLlostegia, Benth.}

Calyx obconical or ovoid, 10-nerved, equally 5-toothed or lobed, ampliate and open at maturity. Corolla exserted, slightly curved, exannulate, the tube scarcely dilating at the throat, bilabiate, the upper lip entire, flattish or concave, the lower much longer, spreading, trifid with lobes ovate and the middle one largest and entire. Stamens 4, parallel, ascending under the upper lip, not exserted, both pairs of the same length or the outer a little longer, the filaments adnate to near the throat and generally pubescent. Anthers 2 -celled, the cells divergent. Style included, shortly bifid, its lobes clavate and diverging or curved, stigmatose at the truncate ends, one lobe often rudimentary. Nucules fleshy, glabrous, obliquely affixed and connate at the base, spreading and exserted at maturity. - Much branching undershrubs. Leaves petiolate, generally 
membranous. Flowers in terminal or axillary racemes or panicles, the verticillasters of 6 or more flowers. Corollas white, with pinkish or purplish tinge.

A Hawaiian genus, one species also reported from Tahiti.

Inflorescence a terminal raceme or panicle:

Leaves entire, toothed or serrate:

Pedicels on a common peduncle

Pedicels not pedunculate:

Raceme branched, paniculate:

Pubescence of the raceme glandular; pedicels 6 in a whorl, much longer than their calices

Pubescence not glandular; pedicels $10-20$ in a whorl, shorter than their ealices

9. P. parviflora.

aceme not branching, or in $P$. mollizand racemosa apparently so, viz., the branches from the axils of large leaves:

Calyx prominently nerved, with acute narrow lanceolate or subulate teeth:

Leaves ovate-oblong, truncate at the base; calyx pubescent Leaves lanceolate, narrowing at the base; calyx glabrous

Calyx faintly nerved, with shorter or broader teeth:

Leaves rounded or slightly contracted at the base:

Hirsute; calycine Jobes foliaceous

8. P. glabra.

Pubescent or glabrous; calycine lobes shorter:

Pedicels as long as the calyx; verticillasters mostly in bracteate racemes:

Corolla large, the tube $10-12^{\prime \prime}$; whorls 6 -flowered Corolla smaller; whorls 8-10-flowered

Pedicels longer than the calyx; whorls $8-20$-flowered in the axils of gradually reduced leaves:

Calyx truncate or obseurely sinuate-dentate

Calyx distinctly toothed or lobed; pedicels $2-3$

times the length of the ealyx.

Leaves cordate at the base, gray tomentose:

Floral bracts sessile with a broad base, broader than high Bracts stipitate, narrow:

Calycine teeth acute; plant subherbaceous?

Leaves lobed

Cal, teeth obtuse; a straggling or climbing undershrub

Flowers in axillary racemes or panicles:

1 flower to each bractlet, on long pedicels; plant hirsute or hispid

2 to 3 flowers to each bractlet, on short pedicels; plant pubescent

10. P. hirsuta.

6. P. stachyoides.

7. P. Hillebrandi.

1. P. vestita.

2. P. grandiflora.

3. P. elavata.

4. P. brevidens.

5. P. ambigua.

12. P. Waimeae.

11. P. mollis.

13. $P$. racemosa.

14. P. hispida.

15. P. floribunda.

16. P. Knudsenit.

1. P. vestita, Benth. in DC. Prod. XII, 553, and Bot. Reg. XV, no. 1292. - Suberect, several ft. high, the stout angular branches hirsute with coarse spreading hair, as are the leaves and inflorescence. Leaves ovate, $4-6^{4} \times 2-2^{1 / 1} 2^{\prime}$, on petioles of $1-1^{1 / 2^{\prime}}$, acute, rounded at the base, serrate. Whorls 10-20-flowered, all or most in the axils of ordinary large leaves and distant, or oftener the upper whorls approximate in short racemes with reduced bract-like leaves, sometimes all in a raceme. Pedicels 5-6" ; bractlets subulate. Calyx hirsute, 6-9", the lobes broad foliaceous, even dentate, as long as the tube, somewhat acute. Corolla white or cream-colored, hairy, short, the tube scarcely exserted beyond the calyx, the upper lip helm-shaped. Filaments hairy. Branches of style truncate, 
one without stigma. - P. dentata, Benth. ibid - the forms with reduced floral leaves. - Gray, in Proc. Am. Ac. V, 342.

Hawaii! in the districts of Hilo and Puna. The calycine lobes continue to grow until maturity, as they do in the other species, and the tube splits laterally.

2. P. grandiflora, Benth. l. c. - Suberect as before, the branches pubescent with appressed short silky hair, as is the inflorescence. Leaves ovate, $3-4^{\prime} \times 1^{1 / 2}-2^{\prime}$, on petioles of $1-1^{1 / 2^{\prime}}$, shortly acuminate, often somewhat contracted at the base, crenate, sparingly hispid or glabrate above, softly pubescent underneath, rather thick. Whorls of 6 flowers, all in a crowded terminal raceme of $4-6^{\prime}$, or the one or two lowest in the axils of unreduced leaves. Pedicels $3^{\prime \prime}$; bracts subulate, very short. Calyx $3-4^{\prime \prime}$, pubescent, the broad and somewhat obtuse lobes reflected at maturity, $1 / s-1 / 2$ the length of the tube, which becomes eampanulate and ampliate with fruit. Corolla white, with purplish tint, tomentose, large, the tube far exserted, $10-12^{\prime \prime}$ in length, eurved, the upper lip emarginate, the lower broadly lobed and $7-9$ "long. Filaments puberulous. Stigmatic branches very short, only one clavate and stigmatiferous, the other short acuminate. - Prasium grandiflorum, Gaud. Bot. Freyc. p. 453, tab. 65, Hook. \& Arn. in Bot. Beech. p. 93. - Gray, l. c.

Oahu! rather common; Molokai! Maui! Nat. name: "Kapana*.

$\beta$ var. hirsutula. - Hirsute in all parts with soft scarcely spreading hair, but rather glabrate with age. Raceme loose, foliose below. Calyx larger, 4-5", its lobes shorter in proportion and not reflected. Pedicels $4-6 "$. Corolla large as in $\alpha$, but the tube rathèr shorter.

W. Maui! in forests.

3. P. clavata, Benth. l. c. p. 554. -- Habit as before, the branches retrorsely pubescent, villous at the nodes. Leaves broadly ovate, $3-4^{\prime} \times$ $2-2^{1} / 2^{1}$, on petioles of $1-2^{4}$, acuminate, rounded at the base or truncate or subcordate, crenato-serrate, more or less pubescent underneath, strigosohispid above, thin. Whorls of $12-10$ flowers below ( $8-6$ above), the lowest one or two in the axils of ordinary leaves, the others in a close raceme of $4-6^{\prime}$ in length. Pedicels $2-3^{\prime \prime}$, pubescent, bracts minute. Calyx $2-3^{\prime \prime}$, strigose, ampliate and open at maturity, the short and broad bluntish lobes ${ }^{1 / 3}$ the length of the tube. Corolla strigoso-pubescent, its tube $4-6$ ", the upper lip entire. Filaments puberulous. Stigmatic branches both clavate and stigmatiferous, but one larger. - Gray, 1. c. p. 344 .

Hawail! woods of Hilo and near Kilauea. Has the aspect of $P$. grandiflora, but much smaller flowers. Varies greatly as to pubescence.

4. P. brevidens, Gray, in Proc. Am. Ac. V, 343. - Habit as before, the slender branches loosely foliose and nearly glabrate. Leaves ovate, $3-4^{\prime} \times 11^{1 / 2}-2^{\prime}$, on petioles of $1^{\prime}$, cuspidate, dentato-serrate, rounded 
at the base, glabrous. Whorls of $14-20$ flowers, all in the axils of reduced narrow spathulate (but not bract-like) reflected leaves, quite distant, the lowest with internodes of $2-4^{\prime}$, forming a long and open raceme of $6-12^{\prime}$ or more. Pedicels slender, $4-6^{\prime \prime}$. Calyx $2-3^{\prime \prime}$, glabrous, topshaped, with truncate or sinuate or obtusely dentate limb. Corolla glabrous, white, small, the tube $4-6^{\prime \prime}$, the lower lip of nearly the same length and its middle lobe of nearly the same width as the broad lateral ones. - In the many-flowered lower whorls the pedicels are often found united into one or two short peduncles near the base.

Hawail! woods of Hilo and Hamakua.

5. P. ambigua, sp. n. - Habit as before, pubescent. Leaves ovate or oblong, $4-5^{\prime} \times 1^{3} / 4-2^{\prime}$, on petioles of ${ }^{1 / 2}-2^{\prime}$, cuspidate, serrate, rounded or contracted at the base, rather pale underneath and pubescent along rib and veins. Whorls of $8-24$ flowers, the floral leaves large-sized below, but toward the apex gradually smaller. Pedicels $5-7^{\prime \prime}$, pubescent. Calyx $3-4^{\prime \prime}$, pubescent, funnel-shaped, with rather acute teeth of about $1 / 2$ the length of the tube. Corolla pubescent or glabrate, the tube about $6^{\prime \prime}$, the large lower lip nearly as long. - P. brevidens, var.? ambigua, Gray, 1. c.

W, and E. Maui! Kula.

$\beta$ var. longipes. - Leaves puberulous underneath or glabrate. Whorls quite glabrous, distant in the axils of gradually diminishing leaves, $10-12$ flowered, the pedicels in the lower whorls $3-4$ times the length of the calyx, 10-15"; the calyx obconical, shortly and obtusely $3-4$-toothed or subbilabiate. Tube of corolla $10-12^{\prime \prime}$, glabrous, the lower lip $6-8^{\prime \prime}$ long and broadly lobed, the upper quite short. Filaments glabrous.

Collected by Lydgate, probably on Mauil

6. P. stachyoides, Gray, T. c. p. 344. - Suberect, the branches and inflorescence softly pubescent or glabrate. Leaves thin, ovate-lanceolate, $3-4^{\prime} \times 1-1^{1} / 2^{\prime}$, on petioles of ${ }^{1} / 2-1^{\prime}$, cuspidate, crenato-serrate, rounded, truncate or subcordate at the base, pubescent or glabrate underneath. Verticils of $10-14$ flowers in the axils of bracteiform leaflets, forming a continuous raceme of about $6{ }^{\prime}$. Pedicels very short, $1-2^{\prime \prime}$. Calyx glandular-pubescent, soon glabrate, $3-4^{\prime \prime}$, its teeth subulate, $2 / 3$ the length of the tube. Corolla pubescent, soon glabrate, small, its tube not exceeding $6 \%$. Outer stamens a trifle longer than the inner. Style-branches nearly equal, truncate.

Hawaii! Waimea and S. Kona.

7. P. Hillebrandi, Mann, in Mem. Bost. Soc. Nat. Hist. I, 536. Spreading, $3-5 \mathrm{ft}$. long, divaricately branching, the slender virgate branches distantly foliose and glabrous. Leaves glabrous, lanceolate, $3-5^{\prime} \times{ }^{1 / 2}-1^{1} / 4^{\prime}$, on petioles of ${ }^{1 / 2}-1^{\prime}$, long-acuminate, dentate or ser- 
rulate. Whorls generally of 10 or the upper of 8-6 flowers, distant, all in the axils of gradually diminishing leaves, forming a loose foliose raceme of $6-10^{\prime}$ in length. Pedicels $3-4^{\prime \prime}$. Calyx funnel-shaped, glabrous, prominently nerved, $2-3^{\prime \prime}$, ampliate and splitting at maturity, the lobes lanceolate, finely acuminate, as long as the tube or longer. Corolla glabrous, small, the tube $3-4^{\prime \prime}$, the two lips nearly equal. Stigmatic branches both truncate.

Maui! woods of Kula and Ulupalakua.

8. P. glabra, Benth. in Bot. Reg. XV, no. 1292, and Linnaea, VI, r9. Suffruticose, erect, much branched, $3-6 \mathrm{ft}$. high, glabrous. Leaves ovate, $3^{1} / 2-6^{\prime} \times 2-3^{\prime}$, on petioles of $1-1^{1 / 2^{\prime}}$, cuspidate, sharply serrulate, glossy, quite glabrous, rather pale underneath. Floral leaves all bracteiform, ovate, petiolate, about 6 " in length, of nearly even size through the whole raceme, which measures $6-18^{\prime}$ when with fruit. Flowers 3 in each axil, raised on a common peduncle of $3-4^{\prime \prime}$, the slender pedicels as long or longer, with short setaceous bractlets at the base. Calyx $3-4^{\prime \prime}$, glabrous, the triangular acute lobes $1 / 3-1 / 2$ the length of the tube. Corolla large, pure white, the tube $8-10^{\prime \prime}$, the lower lip $6^{\prime \prime}$ or more. Stamens equal, puberulous. Stigmatic branches both clavate, of equal length. - Gray, 1. c. - Hook. \& Arn. 1. c. p. 92. $\rightarrow$ P. Chamissonis, Benth. in DC. Prod. 1. c. p. 553. - Prasium glabrum, Gaud. in Bot. Freyc. p. 452, tab. 64.

$\mathrm{Oahu}$ ! in forests from $2000 \mathrm{ft}$. upward. A very ornamental plant, as most branches run out into flowering racemes with large white flowers.

$\beta$ var: - Flowers much smaller, with a tube of $4-6^{\prime \prime} .-P$. Macraei, Benth. in DC. Prod. 1. c. p. 554 .

W. and E. Maui! Pumelei; Lanai! perhaps also Oahu. The later flowers of the first form do not come up in size to the early ones, but in the variety $\beta$ small flowers seem to be the rule. Bentham's character of $P$. glabra refers to the variety, while Gaudichaud's has in view the large-flowered form.

9. P. parviflora, Benth. in DC. Prod. XII, 554, and Linnaea, VI, 79. Erect, $2-4 \mathrm{ft}$. high, gray-tomentose. Leaves ovate, $4-7^{\prime} \times 2^{\mathrm{t} / 2}-5^{4}$, on petioles of $1^{1 / 2}-3^{1} / 2^{i}$, shortly acuminate, coarsely crenate, rounded or subcordate at the base, hispid on the upper face, densely tomentose underneath, the ribs and veins rather villous. Inflorescence a branching raceme or panicle, $6-18^{\prime}$ long, the rhachides, pedicels and calices viscous with spreading glandular hairs, the floral leaves or bracts quite small, $4-2$ "long, ovate-lanceolate. Whorls of 6 flowers; pedicels $4-5 "$. Calyx small, $1^{1} / 2^{\prime \prime}$, eup-shaped at maturity, with short acute teeth. Corolla puberulous, white, with purplish tinge, the tube $4-6^{n}$, the spreading lower lip scarcely less. Style-branches nearly equal, both clavate. Gray, l. c. p. 344 , var. «, Gaudichaudi. - Hook. \& Arn. 1. c. p. 93. P. leptostachya, Benth. in Bot. Reg. - P. Honolulensis, Wawra (a depauperate form with verticils 4-2-flowered). - Prasium parviflorum, Gaud. Bot. Freyc. p. 453 , tab. 65 . 
Oahu! rather common; W. Maui! The depauperate form occurs on the lower outskirts of the forests.

$\beta$ var. glabriuscula, Gray. - Leaves smaller, faintly tomentose underneath. Inflor. paniculate, glandular-pubescent. Whorls 10 -flowered, the pedicels longer than in $\alpha, 5-6^{\prime \prime}$. - Gray, 1. c. - P. macrophylla, Benth?

Hawaii! in woods of Hamakua, Laupahoehoe (Lydg.).

10. P. hirsuta, Benth. in DC. Prod. l. c. p. 555. - Erect, suffruticose, $3-4 \mathrm{ft}$. high, densely hirsute in all parts with spreading gray hairs. Leaves ovate, $4-8^{\prime} \times 2^{1 / 2}-5^{\prime}$, on petioles of $1^{1 / 2}-3^{\prime}$, shortly acuminate, coarsely crenate, rounded or cordate at the base, rather thick, hairy above, tomentoso-villous underneath. Inflor. paniculate as in $P$. parviflora, the panicle $6-10^{\prime}$ long, villous, but the hair longer and not glandular. Whorls of $10-18$ flowers; pedicels very short, ${ }^{1 / 2}-1^{1 / 2}{ }^{\prime \prime}$. Calyx $1-1^{1 / 2} 2^{\prime \prime}$, shortly dentate. Corolla white, with a pink tinge, hairy, small, the tube $3-6^{\mu}$ long, the lips subequal. Stigmatic branches both truncate.

Oahu! Kaala, Nuиanu, Manoa, Palolo.

11. P. mollis, Benth. l. c. p. 554. - Suberect, 1-3 ft. high, the herbaceous branches loosely foliose and more or less tomentose with short and soft grayish pubescence. Leaves flaccid, ovate, $2-5^{\prime} \times 1-2^{1 / 2}$, on petioles of $1-1^{1} / 2^{\prime}$, cuspidate, crenato-serrate, commonly cordate, shortly pubescent underneath, at least along rib and veins. Inflorescence a loose terminal raceme with often one or two pairs of shorter racemes from the axils of the uppermost leaves, the former often $1 \mathrm{ft}$. long, the floral leaves or bracts lanceolate, $2-3^{\prime \prime}$ long. Whorls of $6-8$ flowers; pedicels very short, ${ }^{1 / 2}-2^{\prime \prime}$. Calyx puberulous or glabrate, $1^{1 / 2}-2^{1} / 2^{\prime \prime}$, acutely dentate. Corolla puberulous, pinkish-white, the short tube only $2-5$ " long: Stigmatic branches both truncate. - P. parviflora, var. $\gamma$, mollis, Gray, 1. c. - P. Haleakalae, Wawra.

Oahu! Waianae range; Molokai! Kalae (flowers subsessile); Maui!

The species stands intermediate between $P$. parviftora and $P$. racemosa. From the former the short pedicels and absence of glands in the pubescence suffieiently distinguish it, although a few glandular hairs can be made out in some of the large plants from the Waianae mountains; but from $P$. racemosa it is not so easy to separate some forms with unusually small leaves and flowers from Haleakala, in which also the character taken from the calyeine teeth fails to be reliable on account of the smallness of the calyx. The pubeseence is quite variable: plants from Honuaula, Ma ui, might almost be called villous, while others from Makawao of the same island are nearly glabrate. In the plants from $\mathrm{Oahu}$ the whorls are uniformly 6 -flowered, but those from E. Maui earry 8 in a whorl, and these are nearly sessile; on the other hand a depauperate specimen from Makawao exhibits a few whorls with only 4 and even 2 flowers. The smallest corcllas are seen in the mountain forms from $\mathrm{E}$. Mauj, the largest in those from $\mathrm{O}$ ahu.

12. P. Waimeae, Wawra, in Flora, 1872, p. 531. - Suffruticose, rather climbing, tomentoso-pubescent with patent or retrorse hairlets. Leaves ovate-cordate, $2-3^{1} / 2^{\prime} \times 1^{1} / 4-2^{\prime}$, on petioles of $1-1^{1} / 2^{\prime}$, cuspidate, finely crenate, thick, rather fleshy, hispid above, tomentose underneath. Inflores- 
cence as in $P$. mollis, but the reduced floral leaves or bracts broadly deltoid or ovate, broader than high, sessile, and contiguous with their margins so as to surround the whorl in the shape of a cup $4^{\prime \prime}$ high. Whorls rather elose, each of 6 nearly sessile flowers. Calyx $2-3^{\prime \prime}$, pubescent, the acute teeth about $1 / 3$ of its length. Corolla pubescent, pale pinkish, the tube about $4^{\prime \prime}$, the lower lip scarcely shorter. Style-branches subequal and both truncate.

Kauai! woods of Waimea (Wawra, also M. \& B. no. 555, and Kn.). A specimen of M. \& B. from Kaala, Oahu! without number, seems also to belong here. The flowers are sweet-scented aecording to Wawra, as is also the case with $P$. parviflora and $P$. mollis, if my memory serves me right.

13. P. racemosa, Benth. l. c. - Suffruticose, diffusely branching and scandent in the manner of the small-leaved Stenogynes, tomentosepubescent or somewhat villous. Leaves small, ovate-lanceolate, $3 / 4-1^{1 / 2}$ $X^{1 / 3}-3 / 4^{\prime}$, on petioles of $1 / 3-1 / 2^{\prime}$, somewhat obtuse, coarsely crenate, cordate, pubescent on the upper, softly tomentose on the lower face. Inflorescence spuriously paniculate. Whorls of $6-12$ flowers, their supporting leaves gradually decreasing, the uppermost small bracteiform, petiolate, thus forming short racemes of $3-4^{\prime}$. Pedicels very short, $1 / 2-1 "$. Calyx 1-2", obtusely dentate. Corolla purplish-white, pubescent, very small, the tube scarcely $3^{\prime \prime}$, the upper lip nearly as long as the lower. Style-branches both clavate and truncate. - Gray, l. c. Stenogyne parviflora, Mann, Enum. no. 357, also Wawra.

Hawaii! Maui! Molokai! from $2500 \mathrm{ft}$. upward. The plants from Molokai have, as a rule, 6 flowers in a whorl, like those from Haleakala. Nat, name: "Kiponaponas.

14. P. hispida, $s p . n$. - Diffuse, much branching, rough-hispid in all parts with long spreading, occasionally glandular hairs. Leaves flaccid, hispid on both faces, ovate-lanceolate in outline, $1-2^{\prime} \times{ }^{1 / 2}-1^{\prime}$, on petioles of $1 / 2-1^{\prime}$, cordate, somewhat obtuse, lobed, the bluntish lobes again notched. Whorls of 6 flowers in the axils of gradually diminishing leaves - the uppermost bracteiform - thus constituting short leafy racemes of $2-6^{\prime}$ in length. Pedicels very short, $1 / 2-1^{\prime \prime}$. Calyx $1^{1 / 2^{\prime \prime}}$, with acute teeth, open cup-shaped when mature.

Molokai! heights of Mopulehu.

$\beta$ var, - Whorls of 8 flowers, the pedicels $2-2^{1 / 2}$ "long. Calycine lobes ${ }^{1} / 2$ the length of the tube. Corolla-tube $2-3 "$.

Maui! Haleakala, 4000-5000 ft. (Lydg).

15. P. floribunda, Benth. l. c. p. 555 . - Suffruticose, erect, $2-3 \mathrm{ft}$. high, hispid or hirsute with spreading hairs. Leaves ovate or ovate-oblong, $4-6^{\prime} \times 1^{1 / 2}-2^{1 / 1} 2^{\prime}$, on petioles of $1^{1 / 2}-2^{1 / 2} 2^{\prime}$, acuminate, crenate, rounded or contracted at the base, flaccid, equally hirsute on both faces. Inflorescence in axillary simple or branching racemes of $1^{1 / 2}-5^{\prime}$ in length, hirsute

Hillebrand, Flora of the Hawaiian Islands. 
in all parts, the flowers opposite, a single one each in the axils of small linear bracts of $1^{1 / 2^{\prime \prime}}$. Pedicels $4-5^{\prime \prime}$. Calyx herbaceous, 5-fid to the middle into linear acute lobes, open at maturity. Corolla $4-5$ ", with long nether lip, pubescent, pink or purple. Filaments hairy. Both stylebranches clavate and truncate. Achenes fleshy, oblong-triquetrous. - Gray, 1. c. p. 345 .

Hawail woods of Hilo and Puna, and probably also of Kona (Nelson). The racemes are found in the axils of the lower older leaves, and often do not start before the leaf has fallen.

16. P. Knudsenii, $s p . n$. - Erect, apparently herbaceous, pubescent. Leaves quite flaccid, faintly pubescent on both faces, ovate, $4^{1 / 2}-6^{i} \times$ $2-3^{1} / 2^{\prime}$, on petioles of $1^{1 / 2}-2^{1} / 2^{4}$, acuminate, crenate, subcordate. Racemes axillary, erect, $1^{1 / 2}-2^{1 / 2^{\prime}}$ long, with small spathulate bracts of $1-1^{1} / 2^{\prime \prime}$, the flowers 2 or 1 in the axils of each bract; pedicels $1^{1} / 2^{\prime \prime}$. Calyx puberulous, $1 \frac{1}{2}{ }^{\prime \prime}$, with broad and short somewhat acute teeth, open at maturity. Corolla pubescent, 3-4". Style-branches both truncate. Achenes fleshy, short-triquetrous.

Kauai! woods of Waimea (Kn.).

$\beta$ var. - Hispid or hirsute in all parts, including raceme and calyx. Flowers 2 or 3 in the axils of ovate-lanceolate bracts of $3^{\prime \prime}$. Pedicels $2-2^{1 / 2} 2^{\prime \prime}$. Calyx $2^{1} / 2^{\prime \prime}$, with acute teeth of nearly the length of the tube. Corolla pubescent, with a tube of $4^{\prime \prime}$.

Kauai, Hanalei (M. \& B, 556 in herb. Cornell Univ.).

\section{STENOGYNE, Benth.}

Calyx turbinate, campanulate or tubular, 10-nerved, the tube splitting at maturity, the limb unequally dentate or lobed, or obliquely bilabiate with the upper lip entire or shortly 3 -toothed and the lower bifid. Corolla ampliate at the throat, more or less curved, with a hairy ring (complete or interrupted) inside the tube near its base, bilabiate, the upper lip longer than the lower, entire or rarely bifid, the lower trifid with nearly equal lobes. Stamens exserted and spreading in two pairs, those of the inner pair longest; the filaments generally hairy; the anthers 2-celled, with the cells shortly divaricate. Style exserted, the short stigmatic lobes of nearly even length and subulate, often only one stigmatiferous at the apex. Nucules fleshy, connate at the base. - Suffruticose, prostrate, ascending or climbing plants, divaricately branching, with rather scabrous leaves, the pubescence, when present, mostly spreading or retrorse. Verticillasters generally 6 - or 2 -flowered, rarely 8 -, 10 -, or 4 -flowered, always in the axils of full-sized or little reduced leaves. Bractlets setaceous. Corollas purplish-red or greenish-yellow.

No species known outside of the Hawaiian Islands. The two above described forms of the calyx are, with few exceptions, met with in individuals of the same species promis- 
cuously. The hairy annulus inside the tube of the corolla is never wanting, although sometimes faintly developed and often broken up into patches. Considerable variety takes place in this respect in otherwise nearly allied forms, even in individuals of the same species. As the branches generally grow by axial innovation their flowering portion is mostly continued by sterile leaves.

Leaves large, 1 inch or more:

Leaves sessile:

Leaves acute, mostly rugose; pedicels $3-9^{\prime \prime}$

Leavès obtuse, the lowest petiolate; pedicels very short

8. S. sessilis.

9. S. cordata.

Leaves petiolate:

Verticillasters or whoris generally 2 -flowered

Leaves linear-lanceolate

3. S. angustifolia.

Leaves ovate-lanceolate, acute

5. S. Kaalae.

Leaves ovate-obtuse or suborbicular, cordate; corolla pale 12.S. viridis.

Whorls generally $6-$, but also $4-, 8$, , or 10 -flowered:

Calyx elongate, eylindrieal, shortly dentate

1. S. calaminthoides.

Calyx obconical, turbinate or campanulate:

Calycine lobes linear or subulate, as long as the tube or longer:

Corolla reddish, its upper lip bifid

Corolla pale, its upper lip entire

6. S. bifida.

Calyeine lobes not linear, shorter than the tube:

Corolla purple or red; leaves ovate, acute, serrate:

Calycine teeth short obtuse; leaves often incised

Calycine lobes lanceolate acute:

Lower lip of corolla short, with acute teeth

Lower lip of corolla more than $1 / 2$ the length of the upper, with obtuse lobes

Corolla pale, silky with appressed white hair; leaves crenate :

Leaves cordate; plant hirsute or hispid.

13. S. cinerea.

7. S. serophularioides.

2. S. rugosa.

4. S, purpurea.

Leaves truncate; plant pubescent or retrorsely hispid

Leaves small, 9 lines or less:

Leaves lobed; plant creeping

Leaves crenate; shrubs diffusely branching and scandent:

Whorls 2-flowered; leaves $2-4^{\prime \prime}$;

Glabrous or pubescent .

Muricato-hispid

Whorls 6-, 4-, or 2-flowered; leaves 4-8"

10. S. maerantha.

11. S. rotundifolia.

17. S. serpenis.

* Sarmentosae. - Suberect or prostrate, sarmentose. Corolla red, with produced lower lip. Stamens and style scarcely longer than the upper lip.

†Leaves petiolate.

1. S. calaminthoides, Gray, in Proc. Am. Ac. V, 347. - Suffruticose, the stems decumbent, reddish, angular, sparingly branching, retrorsely pubescent at the angles or glabrate. Leaves ovate or rounded, $1-2^{1} / 2^{\prime} X$ $3 / 4-2^{1} / 2^{t}$, on petioles of $4-6^{\prime \prime}$, obtuse, crenato-serrate or dentate, truncate or subcordate at the base, rather thin, puberulous or glabrate. Whorls of 6 or 8 flowers (or 4 or $2 \mathrm{fl}$. in the upper whorls); pedicels $2-4^{\prime \prime}$, or $6-7^{\prime \prime}$ with fruit. Calyx glabrous, tubular, $4-6^{\prime \prime}$, obscurely nerved, with 5 broad and short somewhat obtuse teeth. Corolla dark purplish-red, $1-1^{1} / 2^{\prime} l o n g$, curved, gradually dilating upwards, pubescent above and along the back, with a hairy ring inside near the base, the lips of nearly equal length. Filaments pubescent. Stigmatic branches short, ${ }^{1 / 2}$ " or less, broad, acuminate.

Hawail! Waimea, Hamakua, Kitanea. 
$\beta$ var. Kamehamehae. - A larger and far spreading plant. Leaves chartaceous, mostly ovate or oblong, but sometimes broad suborbicular as in $\alpha$. Calyx glabrous, tubular, $6-10^{\prime \prime}$ long, with the short and somewhat obtuse teeth often bilabiate, but not always so, laterally splitting at maturity. Corolla of a rich and deep purple or crimson, $2-3^{\prime}$ long and $1 / 2-3 / 4$ wide at the throat, the lips sometimes of nearly equal length, sometimes the upper longer than the lower, the three lobes of the latter broadly ovate or triangular, obtuse and nearly equal. Nucules elongate, triquetroconvex, 3-4". - S. Kamehamehae, Wawra, in Flora, 1872, p. 532.

Molokai! in swampy ground on the mountains above Kamalo, also near the pali of Kalaupapa; Maui! on Mt. Eeka and the northern slope of Haleakala. The remarkably large and richly colored corolla would, on first sight, appear to belong to a distinct species better worthy of the name macrantha than the one so named; but aside from this it is difficult to find a difference, and even the increase in size of the corolla is so gradual that a dividing line would be purely arbitrary, corollas of $18^{\prime \prime}$ in length being found in $\alpha$; while the forms of $\beta$ which derive from Eeka exhibit some that fall short of $2^{\prime}$. The usual variability also manifests itself in the relative length of the lips. In nearly all from W. Ma ui and in many from Molok a i the upper lip is searcely longer than the lower one, while in others from Molokai the upper lip measures 8" against $4^{\prime \prime}$ of the lower. On the whole it would appear that in proportion to the size of the corolla increases the disparity of the lips. Silky pubescence is never absent from the upper portion and the back of the corolla, at least in the bud, but in the plants from Eeka it extends Jower down and is permanent. The bearded annulus is never wanting, but occasionally broken up into patches. S. Kamehamehae is a large form from the forests of the northern slope of Haleakala, in which the leaves measure $3-4^{\prime}$ in length and the calyx $10^{\prime \prime}$,

2. S. rugosa, Benth. in DC. Prod. XII, 556, and Bot. Reg. XV, no. 1292. - Suffruticose, erect and trailing, the branches obtusely angular, pubescent or glabrate, but ciliate at the nodes, the erect branches densely foliose, the trailing ones with narrower leaves. Leaves coriaceous to chartaceous, ovate to ovate-lanceolate, $2-3^{1} / 2^{4} \times{ }^{3} / 4-1^{1} / 2^{\prime}$, on petioles of 4-9", acute, sharply serrate, often rugose above and glossy, with impressed veins, generally puberulous underneath along the prominent veins or glabrate. Wharls $6-10$-flowered; pedicels $1^{1 / 2}-2^{1} / 2^{\prime \prime}$, those of the lower whorls often joining in a very short peduncle; bractlets short linear. Calyx glabrous, 4-6", distinctly nerved, subbilabiate, the lower lobes narrow lanceolate, acute, about as long as the tube. Corolla reddish or brick-colored, pubescent, 6-9", slightly curved, the upper lip $3^{\prime \prime}$, the lower about $1 / 2$ as long, with short triangular obtuse lobes. Annulus broad. Filaments puberulous. Nucules short. - Gray, 1. c. p. 348.

Hawaii! not uncommon from $2000 \mathrm{ft}$. upward to $8000 \mathrm{ft}$. Nat, name: "Maohíhi。.

$\beta$ var. - Pubescent or tomentose in all parts, including the upper face of the leaves, which are seldom rugose.

Upper regions of the same island.

$\gamma$ var.? - Subherbaceous (?), villous or tomentose in all parts, the long trailing branch with internodes of $3-6$ inches. Leaves small and rather 
thin, ovate, $1^{\prime}$ long or less. Corolla villous, $6^{\prime \prime}$ long, the tube included in the calyx.

Central plateau. A single defeetive speeimen preserved.

3. S. angustifolia, Gray, l.c. p. 348. - Prostrate, trailing, the slender sarmentose stems divaricately branching, glabrous. Leaves linear-lanceolate, $2-3^{\prime} \times 1 / 4-1 / 2^{\prime}$, on petioles of $4-6^{\prime \prime}$, acute, appressedly denticulate, contracted at the base, chartaceous, quite glabrous. Whorls 2-flowered; pedicels and linear bracts $4-5^{\prime \prime}$. Calyx as in S. rugosa, $6-8^{\prime \prime}$ long. Corolla reddish-brown, puberulous and minutely glandular or glabrate, $10-12^{\prime \prime}$ long, suberect, the upper lip $4-5^{\prime \prime}$, nearly twice as long as the lower, the lobes narrow lanceolate, acute. Filaments nearly glabrous. Annulus broad.

Hawaii! Hamakua, Hilo, Puna, Kau, not uncommon.

$\beta$ var. - Leaves shorter, $1-2^{\prime}$ long. Whorls 2 or 4 -flowered; pedicels $1^{1 / 2}-2^{\prime \prime}$. Calyx $4-5^{\prime \prime}$. Corolla hispid.

Mani! Kula and Honuaula.

$\gamma$ var, - Leaves broader, often spathulate or narrow -obovate, $1^{1 / 2}-2^{\prime} X$ $1 / 2-3 / 4^{\prime}$, shortly acuminate. Whorls 2 -flowered. Corolla pubescent, the lower lip only little shorter than the upper. Pedicels bracteolate some distance above the base.

Molokai! Kalaupapa.

4. S. purpurea, Mann, Enum. no. 354. - Suffruticose, prostrate, divaricately branching. Leaves membranous, ovate-lanceolate, $2-4^{\prime} \times 3 / 4-1^{3} / 4^{\prime}$, on petioles of $4-6^{\prime \prime}$, long-acuminate, minutely and sharply dentate or serrulate, pubescent underneath or almost glabrate. Whorls 6-flowered, the pedicels $2-4^{\prime \prime}$, the bracts short filiform. Calyx $4-6^{\prime \prime}$, glabrate, subbilabiate, the finely acuminate lobes about $1 / 3$ the length of the tube, the lower two broader. Corolla pubescent or hispid, purplish-red, 10-14" long, the upper lip $4-5^{\prime \prime}$, entire, the lower more than half that length with oblong obtuse lobes. Annulus interrupted. Filaments faintly pubescent. Nucules subglobose.

Kauai! woods of Waimea. Much like thin-leaved forms of S. rugosa, but the corolla approaching that of $S$. calaminthoides.

$\beta$ var. brevipedunculata, Wawra. - Leaves contracted at the base. Whorls $2-6$-flowered. Upper lip of corolla emarginate.

Same locality.

r var. Kealiae, Wawra. - Subherbaceous, prostrate, glabrous. Leaves subcoriaceous, glossy above, pale underneath, elliptico-lanceolate, almost entire, serrulate only near the apex. Calyx and corolla as in $\alpha$, but the former puberulous inside with appressed hairlets and the tube of the corolla not longer than the calyx. - S. Kealiae, Wawra, 1. c. p. 556.

Forests of Kealia, Ka uai. 
5. S. Kaalae, Wawra, in Flora, 1872, p. 556. - Habit of S. purpurea. Leaves ovate-lanceolate, $2-4^{\prime} \times 3 / 4-1^{1 / 2}$, on petioles of $6-12^{\prime \prime}$, acute, closely crenato-dentate, rounded or cordate at the base, membranous to chartaceous, glabrate. Whorls generally of 2, sometimes 4, rarely 6 flowers; the pedicels $2-3^{\prime \prime}$, when single often bracteate above the base, when several often joined in a short common peduncle. Calyx glabrous, $5-7^{\prime \prime}$, the narrow subulate lobes as long as the tube or longer. Corolla 9", faintly pubescent, purplish-red, the upper lip 4", entire or slightly emarginate, the lower about half as long. Annulus broken up into patches. Filaments glabrous. Nueules angular-convex, elongate, $3-4 "$.

Oahu! Waianae range. To be distinguished from the preceding species by the fewerflowered whorls, longer calycine lobes and elongate achenes.

6. S. bifida, sp. n. - Subherbaceous, prostrate, $2-3 \mathrm{ft}$. long, divaricately branching, the branches acutely angular, glabrous. Leaves ovate or ovatelanceolate, $2-3^{\prime} \times 1-1^{1} / 2^{\prime}$, on petioles of $6-12^{\prime \prime}$, cuspidate, sharply serrate, membranous, glabrous. Whorls generally of 6 , but often of 4 , 8 or 10 flowers, the pedicels $1-2^{\prime \prime}$. Calyx glabrous, distinctly nerved, $3-6^{\prime \prime}$ long, the linear or subulate lobes longer than the tube. Corolla short, 7-9", reddish, puberulous or glabrate, the upper lip $3-4^{\prime \prime}$, acutely bifid, the lower about half as long, with the middle lobe acute. Annulus complete. Filaments glabrous. Stigmatic lobes subulate. Nucules angularconvex, short, $2^{a}$.

Molokai! Kalae, Maunahui, Mopulehu. The only species with a bifid upper lip to the corolla. Nos. 2 to 6 form a elosely related group.

7. S. scrophularioides, Benth. $7 l$. cc. - Subherbaceous, rising or decumbent, the long virgate branches almost terete and glabrous. Leaves flaccid, ovate, $1-1^{1} / 2^{4} \times{ }^{3} / 4-1^{\prime}$, on petioles of $4-6^{\prime \prime}$, acute, rather sharply crenatoserrate, or the lower ones cut-lobed, truncate at the base, glabrous. Whorls of 6 flowers, distant, in the axils of full-sized leaves, the pedicels $3-6^{\prime \prime}$. Calyx $3^{\prime \prime}$, obconical, globose when with fruit, glabrous, with indistinct nerves, shortly and obtusely 5-toothed. Corolla $6-9^{\prime \prime}$, reddish, puberulous, the lower lip more than half the length of the upper. Filaments nearly glabrous. Annulus complete. Nucules short, flattened at the top. - Gray, 1. c. p. 347. - A sterile branch of my collection has the lower leaves palmately cut to near the base into $3-5$ segments.

Hawail! Hilo, Puna, Kau. Nat. name: "Mohihis.

$\beta$ var? - Leaves larger and of thicker texture. Whorls many-flowered. Calyx longer than in $\alpha$; corolla twice as long and glabrate. Stamens long exserted. - S. Nelsoni, Benth. in DC. Prod. 1. c.

Collected by Nelson on Hawaii; unknown to me, but referred by Gray to the present species.

†† Leaves sessile. 
8. S. sessilis, Benth. in DC. Prod. XII, 555. - «Ascending, the branches glabrous or hairy at the nodes. Leaves sessile, coriaceous, rugose, glabrous, cordate, obtuse or rounded, crenate. Whorls few and one-sided, approximate at the ends of the branches in the axils of smaller but not bracteiform leaves. Bractlets minute. Calyx 6 ", subsessile, glabrous, irregularly 5 -toothed or bilabiate, the teeth broad and rounded. Corolla twice as long as the ealyx, broad, incurved, villous.» Descr. according to Benth.

Collected by Menzies, probably on the S. W. slope of Mauna Loa, Haw a ii (herb. Banks \& Hook.).

$\beta$ var. - Subherbaceous, decumbent, $2-3 \mathrm{ft}$. long, the branches acutely angular, glabrous, hispid at the nodes. Leaves sessile, subcoriaceous, rugose, the nerves impressed above, strongly salient underneath, ovatecordate, $2-2^{1 / 2^{\prime}} \times 1^{1 / 2}-1^{3} / 4^{\prime}$, crenate, acute. Whorls of 4 or 6 flowers in the axils of the upper smaller leaves; pedicels $2-3^{\prime \prime}$. Calyx $6-8^{\prime \prime}$, glabrous, green, prominently nerved, bilabiate, the teeth or lobes acuminate, of variable length. Corolla reddish, hispid, twice as long as the calyx, the lips of nearly equal length.

Lanai! on the highest ridge.

$\gamma$ var. - Habit as in $\beta$. Stems virgate, hairy at the nodes only. Leaves ovate-lanceolate, $1^{1 / 2}-2^{1 / 2^{\prime}} \times{ }^{3} / 4-1^{1 / 2} / 2^{\prime}$, sessile, acute, undulating at the margins and broadly crenate-denticulate, cordate at the base, glabrous, chartaceous, not rugose, with the nerves little salient below, gradually decreasing in size without shortening distance. Whorls 2, but not rarely 4- or even 6-flowered, the filiform pedicels 4-9". Calyx campanulate, $6-7^{\prime \prime}$, bilabiate to the middle, the upper lip subentire or shortly 3-dentate, the acute lobes of the lower lip somewhat longer. Corolla purplishred, $12-14^{\prime \prime}$, curved, hispidulous at the lobes only, the two lips of nearly equal length with obtuse lobes. Annulus broken into 4 tufts. Filaments pubescent.

Ma ui! ridges above Waiehu and Wailuku, also Makawao (M. \& B. 406); and perhaps Mauna Loa, Hawail!

9. S. cordata, Benth. 7. c. - Habit as in no. 8, the slender branches pubescent at the angles and nodes. Leaves small, ovate-cordate, rather obtuse, $14^{\prime \prime} \times 10^{\prime \prime}$, or suborbicular, crenate, chartaceous, pale, glabrate or nearly so, the lower ones on short petioles of about $1^{\prime \prime}$, the upper sessile. Whorls $2-6$-flowered, the pedicels $1-1^{1 /} / 2^{\prime \prime}$. Calyx $5-6^{\prime \prime}$, subbilabiate, the teeth or lobes acute or somewhat obtuse, triangular or lanceolate. Corolla purplish-red, pubescent, $8-10^{\prime \prime}$, the lips of nearly even length $\left(2^{\prime \prime}\right)$ and the lobes obtuse. Annulus interrupted or complete. Filaments puberulous, as long as the upper lip. Achenes triquetrous, $2^{1 / 2-3^{4} .}-$ Gray, l. c.

Ma ui! top of Eeka, trailing; Hawaii, Waimea (Nelson and U. S. E. E.). The annulus, which Gray found missing, is certainly present, although often broken up, in my speeimens from Eeka. The stems are mostly virgate and, when dividing, the branches start at acute angles. 
** Scandentes, - Diffusely and divaricately branching, generally elimbing. Leaves generally rounded and crenate, occasionally lobed. Corolla pale. Stamens and style long exserted.

$\dagger$ Macrophyllae. - Leaves more than $1^{1} / 2^{\prime}$ in the long diameter. Corolla pale purplish or, when hairy, pale yellowish.

† Lower lip produced.

10. S. macrantha, Benth, in DC. Prod. XII, 555, and Bot. Reg. XV, no. 1292. - «Very hirsute. Leaves petiolate, ovate-cordate. Verticillasters axillary, distant. Pedicels as long as the calices. Corolla long exserted, $1^{1 / 2}$ ', eurved, much ampliate at the throat, the upper lip scarcely longer than the lower. Hairiness, leaves and calyx as in Phyllostegia vestita.»

Hawaii, Mauna Kea. The above short description of Bentham's was drawn from a single defective specimen of Macrae in herb. Lindl. It has been supplemented by Gray from no, 381 of Remy's collection, with which specimens sent to me by Mr. Lydgate agree, only that these bear still shorter corollas. Leaves membranous, coarsely serrate, $1^{1 / 2}-2^{1} / 2^{1}$ long, on petioles of $1 / 2-1$. Whorls 6 -flowered, the pedicels and calices quite hispid, the latter $4-5$ " long, with broad deltoid acute lobes of nearly half their length. Corolla scarcelly $12^{\prime \prime}$ long ( $9^{\prime \prime}$ in Lydgate's plants) silky-hairy, pale yellowish, the lower lip decidedly shorter than the upper. Annulus reduced to 4 minute tufts (not wanting). Filaments pubescent. - To this species I must also refer the following, collected by myself long ago in the same region.

$\beta$ var. latifolia. - Whole plant hispid, but scarcely hirsute, the branches elongate, curving. Leaves larger, $2-3^{\prime} \times 11^{1 / 2}-2^{\prime}$, on petioles of $1^{\prime}$, cuspidate, coarsely serrate, deeply cordate, hispid on both faces. Whorls 6 -flowered, with pedicels of $5-7^{\prime \prime}$. Calyx as above, the broad lobes rather shorter than the tube and subbilabiate. Corolla silky, pale, $6-10^{\prime \prime}$ long, the lower lip nearly as long as the upper, with obtuse lobes. Filaments ciliate, longer than the upper lip. Annulus complete. - S. scrophularioides, var. $\gamma$, Mann, Enum. no. 353.

11. S. rotundifolia, Gray, l. c. p. $34 \%$. - A large diffusely branching shrub, far spreading and generally forming a dense matting over neighboring shrubs. Branches obtusely angular, pubescent or hispid with spreading or retrorse hairlets. Leaves scabrous, rugose with age, ovate, $2-2^{1} / 2^{\prime} \times 1^{1 /} / 4-1^{3} / 4^{\prime}$ on petioles of $4-9^{\prime \prime}$, acute, crenato-dentate or serrate, rounded or truncate at the base, rarely subcordate, softly pubescent underneath. Whorls 6 -flowered; pedicels 3 ". Calyx softly pubescent, urceolate or campanulate, $3^{\prime \prime}$ long, subbilabiate, with the lips about as long as the tube or irregularly lobed. Corolla curved and broad, $15-18^{\prime \prime}$, densely villous with a whitish wool, the lips pale purple, the upper lip $4-5^{\prime \prime}$, the lower $3-3^{1} / 2^{\prime \prime}$ with broad deltoid obtuse lobes, glabrous inside, but the annulus complete. Filaments villous, exserted beyond the upper lip. Nucules large, fleshy, with crustaceous putamen, $3^{\prime \prime}$, cohering at the base, globose, waxy white when fresh. - S. Haliakalae, Wawra, 1. c. p. 554. - S. macrantha, M. \& B. 402. 
Maui! in forests of Haleakala between 3000 and $5000 \mathrm{ft}$., both on the southern and northern slope. Nat. name: ‘Puaainakan.

$\beta$ var. glabrata. - Leaves almost glabrate, as well as the calyx, the latter rather acutely dentate. Corolla slightly pubescent, pale purplish, with complete annulus.

W. slope of Haleakala, in the woods of Kula (Lydg.).

$\gamma$ var. montana. - A dwarfed mountain-form with a woody base and stiff rising branches retrorsely hispid at the somewhat acute angles. Leaves $1^{\prime}$ or more long, somewhat obtuse, sprinkled with scattering hairs, stiff scabrous. Calyx pubescent or glabrate, the obtuse lobes as long as the tube or shorter. Corolla about $10^{\prime \prime}$ long, otherwise as in $a$, but the annulus evanescent. Nucules as above. - S. rotundifolia, Gray, 1. c.

In the crater and on the upper slopes of Haleakala. There can hardly be a doubt that these three forms belong to one species, to which Gray's oldest specifie name must be given, although it referred ouly to a dwarfed form.

it Lower lip short 3-dentate.

12. S. viridis, sp. $n$. - Shrubby, far spreading or perhaps scandent, the' slender terete stems curved and divaricately branching, nearly glabrous. Leaves membranous, bright green, glabrous and glossy, broadly ovate-cordate or truncate, but not unfrequently suborbicular or oblong, $1^{1 / 2^{\prime}} \times{ }^{3} / 4-1^{1} / 4^{\prime}$, on petioles of $6-9^{\prime \prime}$, obtuse or acuminate, deeply crenate. Whorls 2 -flowered; pedicels $1-2^{\prime \prime}$. Calyx glabrous or puberulous, 5-6", prominently nerved, its lobes linear-lanceolate, as long as the tube or longer. Corolla narrow, suberect, 9-10", hispidulous, pale purple (or greenish), the lower lip very short 3 -toothed. Filaments puberulous, long exserted. Annulus complete.

In forests of Kaanapali, W. Maui!

13. S. cinerea, sp. n. - Subherbaceous (?), tomentose. Leaves ovate, $1^{1 / 2}-2^{1 / 2^{\prime}} \times 1-1^{1} / 2^{\prime}$, on petioles of $1^{\prime}$, acuminate, crenato-serrate, cordate or truncate at the base, gray-tomentose on both faces. Whorls of 6-2 flowers, the pedicels $1^{\prime \prime}$ or less. Calyx tomentose, $3-4^{\prime \prime}$, parted to the middle or more into linear acute lobes. Corolla pale, pubescent, suberect, $7-9^{\prime \prime}$ long, the lower lip very short, of 3 broad acute teeth. Filaments pubescent, exserted beyond the upper lip. Annulus complete.

E. Ma ui! Kula; only a few fragments collected by Lydgate, which have the appearance of Phyllostegia mollis.

† Microphyllae. - Leaves $3 / 4^{4}$ or less. Corolla greenish-yellow, suberect, with the lower lip truncate or very shortly toothed. Densely entangled climbers.

14. S. microphylla, Benth. in DC. Prod. XII, 556, and Lab. p. 655.Diffusely branching and climbing, glabrous except at the nodes and angles of the youngest branchlets. Leaves small oblong, narrowing at 
the base, about $3^{\prime \prime}$ long, on petioles of $1^{1 / 2} 2^{\prime}$, acute or somewhat obtuse, serrate or crenate, membranous, glabrous. Whorls 2 -flowered, the pedicels $1-2^{\prime \prime}$, subtended by setaceous bracts. Calyx $3^{\prime \prime}$, campanulate, unequally and obtusely 5-toothed. Corolla suberect, 7-8", greenish-yellow, minutely pubescent or glabrate, the upper lip 3-4", much exceeding the short and broadly 3 -toothed lower lip. Annulus complete. Filaments and style long-exserted. - Gray, 1. c. p. 348.

Hawaii! in forests of Mauna Kea.

$\beta$ var. diffusa. - More or less pubescent. Leaves of thicker texture, smaller, $1^{1 / 2}-2^{1 / 2} 2^{\prime \prime}$, obtusely ovate or suborbicular, truncate at the base, crenate. - S. diffusa, Gray, 1. c.

Higher and open regions of Hawaii.

15. S. crenata, Gray, 1. c. p. 348. - Habit of the preceding species, the stem with sharp angles muricately hispid with retrorse stiff hairlets and closely foliose. Leaves small, ovate-oblong, 2-4" , somewhat obtuse, crenate, tapering to a short petiole of $1^{\prime \prime}$ or less, hispid, rather firm. Whorls 2 -flowered; pedicels $1^{\prime \prime}$ or less. Calyx $3^{\prime \prime}$, strongly nerved, hispid, the lobes acute and as long as the tube. Corolla as is no. 14, but rather slender and hispid. Filaments long-exserted, pubescent. Annulus broken.

Maui! forests of Haleakala, northern and eastern slopes.

16. S. vagans, $s p . n$. - Habit as in the preceding species; the branches softly pubescent. Leaves ovate, $4-8^{\prime \prime} \times 3-5^{\prime \prime}$, on petioles of $1^{1 / 2}-2^{\prime \prime}$, obtuse, crenulate, rounded at the base, membranous, puberulous or glabrate. Whorls 6- or 4-, rarely 2 -flowered, the pedicels $1^{1 / 2}-3^{\prime \prime}$. Calyx $2-2^{1 / 2^{\prime \prime}}$, with acute teeth half the length of the tube or less. Corolla subfalcate, 10-11", greenish-yellow (?), pubescent, the upper lip $3^{\prime \prime}$, the lower almost truncate with short acute lobules. Annulus interrupted. Nucules short, $1^{1 / 2} 2^{\prime \prime}$.

Maui! southern and western slopes of Haleakala, in forests.

17. S. (?) serpens, sp. $n$. - Slender herbaceous, creeping on the ground and rooting, the branches hispid. Leaves flaccid and hispid, orbicular in outline, $6-7^{\prime \prime}$ in each diameter, on petioles of $3-4^{\prime \prime}$, deeply crenate or lobed, cordate or truncate at the base.

Not very rare in the higher forests of Oahu! (leaves truncate), and Kaanapali, Maui! (leaves cordate), but no flowers seen and therefore the genus uncertain.

\section{Order LXVI. PLANTAGINACEAE.}

Sepals 4, imbricate. Corolla small, scarious, with an ovate or cylindrical tube and 4 spreading lobes, imbricate in the bud. Stamens 4, inserted in the tube and alternate with the lobes of the corolla, usually very long; anthers versatile, 2-celled, opening lengthwise. Ovary free, 2- or 1 -celled, with $1-8$ ovules in each cell. Style terminal, simple. Capsule opening 
transversely or indehiscent. Seeds peltately affixed to the septum or to a basilar placenta, amphitropous; albumen fleshy; embryo parallel to the hilum, with a short inferior radicle, the cotyledons scarcely broader. Herbs with radical tufted or spreading leaves, rarely branched and leafy shrubs. Flower-stalks leafless, bearing a simple spike or head or a single terminal flower.

A small Order of 3 genera, widely spread over the globe, but most abundant in the temperate regions of the old World.

\section{Plantago, L.}

Ovary 2- or spuriously 3-4-celled. Capsule opening transversely. Seeds mucilaginous, $1-8$ in each cell; affixed to the septum. - Leaves crowded in stemless, alternate in caulescent or branching plants, the flower-stalks axillary.

Geographical range of the Order, of which this genus contains all but two species.

Herbaceous, stemless; $4-8$ ovules in each cell of the ovary

3. P. major.

Lignescent; $2-3$ ovules in each cell:

Caulescent, with woody stem; flowers patent; leaves and sepals acute, the leaves much narrowed at the base or petiolate with

the inner nerves confluent.

1. $P$. princeps.

Acaulous, with a woody rhizome; flowers subereet; leaves and sepals obtuse, the leaves mostly broad at the base, with nerves discreet. Plants of high altitudes

2. P. pachyphylla.

1. P. princeps, Cham. \& Schl. in Linnaea, I, 167.-DC. Prod. XIII, Sect. I, Pp. $\% 00$ and $\% 04$. - Stem woody, 2-6 ft. high, erect, simple, rarely branching, covered with annular leaf-scars and foliose near the top, glabrous excepting a faint caducous tomentum in the axils of the leaves. Leaves coriaceous, glabrous, linear-lanceolate to elliptico-oblong, $4-9^{\prime} X^{1} / 3-1^{2} / 3^{\prime}$, acute, entire, 7-11-nerved, the nerves running down to the moderately contracting and broadly sessile base, the inner ones uniting at the contracted portion. Scapes several, about $1 \mathrm{ft}$. long, naked in the Iower third, glabrous, the flowers not close, sessile and patent. Bracts as long as and similar to the sepals. Sepals broad ovate, acuminate, with a broad black median streak and scarious margins, $1^{1} / 2^{\prime \prime}$. Corolla scarious, its tube as long as the calyx, the lobes $1 / 2$ as long, ovate-acute, 1 -nerved, at last reflexed. Stamens rising from the base of the tube, long-exserted, the short anthers broadly sagittate, almost cordate, pointed at the apex and at the base of the cells. Ovary 2 -celled, with 2 ovules in each cell. Style long-exserted, pulescent in its entire length, bidentate. Capsule ovoid-elongate, twice the length of the calyx, circumscissile above the base, with entire dissepiment and 2-4 plano-convex oblong black seeds. - Gray, in Proc. Am. Ac. VI, 54, - var. elata, Wawra, in Flora, 1874, p. 563. - P. Queleniana, Gaud. Bot. Freyc. p. 445, tab. 50. - Hook. \& Arn. in Bot. Beech. p. 93.

Oahu! Kauai! Molokai! at altitudes of 2000-4000 ft. Nat. name: sAles. - Placed next to P. Fernandeziana, Bert, from Juan Fernandez, by Decaisne. 
$\beta$ var. laxifolia, Gray. - Stem ${ }^{1 / 2}-2 \mathrm{ft}$. high, fistulous, with deciduous wool in the axils of the young leaves. Leaves rather distant, membranous, glabrate on both faces, broad lanceolate, $7-8^{\prime} \times 1-2^{1} / 2^{\prime}$, narrowing into a margined petiole of $1-2^{\prime}$. Scapes $1-1^{1 / 2} \mathrm{ft}$, with a few hairs at the base of the flowers or glabrate.

Hawaii! Kohala and Hamakua, on low plains and near the seashore; Maui! ravines back of Lahaina; Ka uai? leaves puberulous (Wawra).

rvar. longibracteata, Mann, Enum. no. 305. - Subherbaceous, with a short fistular prostrate and rooting stem, sparingly foliose, with a ferruginous matted wool between the leaves. Leaves on slender not margined petioles of $2-2^{1} / 2^{\prime}$, narrow lanceolate or elliptical, $4-8^{\prime} \times{ }^{3} / 4-1^{1} / 4^{\prime}$, acute at both ends, 7 -nerved, the nerves underneath covered with a coarse ochraceous matted wool, otherwise glabrous. Scapes slender, flexuose, loosely flowered in the upper half, with some wool between the flowers. Bracts of the lower flowers as long as the calyx or longer, sometimes 2 or 3 times as long, very acute, as are the sepals and lobes of the corolla. - var. aquatitis, Wawra, 1. c.

Waterfalls of Hanalei and Hanapepe, Kauai. Beyond the reach of the falls the stem turns upright and the plant approaches the habit of laxifolia (Wawra).

o var. hirtella, Gray. - Stem erect, about $2 \mathrm{ft}$. long, fistular, with permanent wool in the axils. Leaves rather flaccid, elliptico-oblong, $4-6^{\prime} \times 1^{1} / 4-1^{1} / 2^{\prime}$, narrowing into petioles of $1-2^{\prime}$, with $7-9$ nerves, beset with crisp hairlets on both faces, particularly on the nerves underneath. Scapes stramineous, flexuose, $1-1^{1 / 2} \mathrm{ft}$., hispid below and between the rather distant flowers. Bracts and sepals ciliate, the latter exceeding the former.

Kauai! Waimea, 2000-3000 ft.; Oahu! Makaleha.

8. var. denticulata. - Stem 2-3 ft., solid, with permanent scaly wool in the axils. Leaves obovate-oblong, $6-10^{\prime} \times 1^{1 / 2}-2^{3} / 4^{\prime}$, not distinctly petiolate, glandular-denticulate, papillose or papilloso-hispid on both faces, with 9-11 nerves. Scapes often $2 \mathrm{ft}$. long, always hispid, loosely flowered in the upper half. Capsules not longer than the calyx.

Molokai! pali of Pelekunu, leaves large, with the nerves densely hairy underneath; pali of Waikotu, leaves smaller, with glabrous nerves.

2. P. pachyphylla, Gray, in Proc. Am. Ac. VI, 54. - Stemless, with a short creeping or suberect thick caudex emitting rootlets along its whole length, clothed with the vestiges of old leaves and with a dense coating of long and soft fawn-colored wool. Leaves crowded, with wool in the axils and underneath, thick coriaceous, obovate-oblong, sessile with a short contracted base, $5-7^{\prime} \times 1^{1 / 2}-2^{\prime}$, obtuse, entire, $7-11$-nerved, the nerves broad and impressed above, prominent beneath, discreet to the base. Scape generally single, stiff, compressed, $10-16^{\prime}$ long, flocculose, 
densely flowered in the upper half, the flowers suberect, imbedded in a dense wool. Bracts and sepals ovate, obtuse, $2^{\prime \prime}$, thick cartilaginous, conchoid, keeled with a broad and dark middle band, pubescent. Corolla little longer than the calyx with lobes half the length of the tube, acute, reflexed at last. Anthers pendulous, apiculate, the bases of the cells blunt. Style as before. Ovary 2 -celled, each cell with $2-3$ ovules. Capsule not exceeding the calyx, somewhat obtuse, with 3 black seeds. Wawra, l. c. p. 567.

Ma ui! Haleakala, 6000-8000 ft. Resembles $P$. Aucklandica, Hook, f., from the Auckland Islands.

$\beta$ var. Hawaiiensis, Gray. - Caudex less woolly. Leaves narrower, $4-6^{\prime} \times 1 / 2-1^{\prime}$, obtuse, very thick, 3-9-nerved, with nerves hidden, stibsessile, or distinctly stalked on often rather long petioles, shortly and evenly puberulous on both faces. Seape and rhachis faintly floceulose, sometimes almost glabrate, the spike rather lax. Bracts and sepals dark. Capsule slightly exserted, with $4-6$ seeds.

High mountains of Hawaii! from Kilanea up to $8000 \mathrm{ft}$. on Mauna Loa. A similar form with a very thick caudex and still shorter broadly sessile and denticulate leaves, the scape and rhachis almost glabrous, grows on Eeka, Ma ui!

rvar. Kauaiensis, Gray. - A small plant with a very short caudex, woolly between the leaves. Leaves coriaceous, rugose on the upper face, narrow lanceolate, $1^{1 / 2}-2^{\prime} \times 2-6^{\prime \prime}$, acute or somewhat obtuse, narrowing below, but without manifest petiole, with $5-3-1$ nerves which are prominent on the lower but not conspicuous on the upper face. Scapes several, slender, glabrous, $3-6^{\prime}$ long, with only few $(8-5)$ distant flowers and few hairs at their bases. Bracts gibbous at the base, half as long as the calyx, the lobes of the latter quite obtuse to subacute. Lobes of corolla ovate, acute. Capsule not exceeding the calyx, circumscissile at the middle, often 1-seeded, the seed ovate, pale brown, not viscous. Wawra, 1. c.

Ka uai, high plateaus of Lehua makanui (U, S. E. E.) and Waialeale (Wawra). AWawra's var, pusilla, from Waialeale, is a still smaller plant with leaves 1 or less in length and strigose-hairy on the upper face, the setaceous seapes bearing only $3-2$ flowers, the short corolla-lobes quite obtuse, the capsule with 4 seeds.

ò var. rotundifolia, Wawra. - «Leaves coriaceous, broadly obovate, almost orbicular, suddenly narrowed at the base, with 5 impressed nerves, $2-3^{\prime}$ in length, densely covered with coarse ochraceous wool underneath. Peduncles $1-2$, silky-tomentose, longer than the dense spikes. Lobes of calyx and corolla very obtuse. Capsule circumscissile at the middle, not exceeding the calyx. Seeds 2, broad ovate, brownish, not gelatinous, »

Top of Waialeale, Kauai, imbedded in tufts of moss, on the trunks of old trees. Wawra, 1. e. p. 567, - Only one specimen found.

P. Brongniartii, Barn., DC. Prod. 1. c. p. 736 , imperfectly described from a single lost specimen of Gaudichaud's collection - leaves obtuse, lobes of corolla very acute - may possibly be the $\beta$ of the present species. 
†3. P. major, L. - DC. Prod. XIII, 694. - A perennial herb. Leaves radical, broadly ovate or ovate-oblong, entire or toothed, glabrous or $\mathrm{pu}$ bescent, 5-9-nerved, on rather long petioles. Peduncles usually longer than the leaves, bearing a long slender spike of small sessile flowers. Bracts similar to the sepals. Sepals about $1^{\prime \prime}$, green, with a scarious edge, somewhat obtuse, the anterior ones keeled. Corolla brownish. Capsule 2-celled, with $4-8$ seeds in each cell.

Along roadsides and on pastures. The well known Plantain, a native of Europe and Asia, which has followed the white man to nearly every part of the globe. On the high pasture-lands of $\mathrm{Haw}$ a i i the leaves attain large proportions, with petioles of $6-8^{*}$, while the spikes reach $1^{1 / 2}-2 \mathrm{ft}$.

\section{ORdER LXVII. NYCTAGINACEAE.}

Flowers apetalous, supported by distinct or connate bracts. Calyx generally colored, funnel-shaped or tubular, with a short limb, the tube persistent, at last indurated and enclosing the fruit, the limb plaited in the bud, deciduous. Stamens definite, hypogynous; anthers 2-celled, the cells rounded. Ovary 1 -celled, with a single erect ovule. Style simple. Embryo spiral or straight. Albumen mealy. - Herbs, shrubs or trees, with tumid nodes. Leaves entire, mostly opposite, but the pair unequal.

Natives of the warmer parts of the world.

Erect herbs; involucre large eup-shaped; stamens 5

Prostrate herbs; involucre of many small bracts; stamens 2-4. 2, Boerhaavia.

Trees; involucre of $1-3$ deciduous bracts; stamens $6-20$. . 3. Pisonia.

In cultivation: Bougainvillea spectabilis, Willd.

\section{MIRABILIS, L.}

Flowers hermaphrodite, each surrounded by a cup-shaped 5-cleft involucre. Calyx or perigone tubular, with spreading limb. Stamens 5, connate at the base, about as long as the tube. Style a little exserted, with globose stigma. Embryo curved round mealy albumen, with foliaceous cotyledons and inferior radicle. - Herbs. Flowers solitary in the axils, crowded near the apex.

Five or six species, natives of Mexico.

$\dagger$ 1. M. Jalapa, L. - DC. Prod. XIII, Sect. II, p. 42\%. - An erect glabrous perennial, 1-2 ft. high. Leaves ovate or subcordate, 2-4' long, on petioles of $1 / 2-1$ ', acute. Flowers $3-6$, on short pedicels, purple, red, yellow or white. Calyx about 1', exceeding the involucre.

The well known *Four o'clocks flower, along roadsides here and there, an escape from gardens.

\section{BOERHAAVIA, L.}

Flowers hermaphrodite, supported by deciduous bractlets. Perigone colored, tubular, constricted about the middle, the nearly entire 5-plaited 
limb soon deciduous. Stamens 1-4, connate below, slightly exserted. Style as long as stamens; stigma obtuse. Achene free inside the close and hardened angular tube of the perigone. Cotyledons folded round mealy albumen, the radicle external and inferior. - Herbs, sometimes with a woody base. Leaves opposite. Flowers glomerate on simple axillary peduncles or on their umbellate or paniculate rays.

About 25 species, spread over most tropical countries.

Leaves acute, gradually decreasing; inflorescence paniculate; stamens 2 .

Leaves obtuse; peduncles axillary; stamens $2-4$

1. B. diffusa.

2. B. tetrandra.

1. B. diffusa, L. - DC. Prod. XIII, Sect. II, p. 452. - A glabrous perennial, prostrate, branching from the base, $1-2 \mathrm{ft}$. long. Leaves ovate or ovate-lanceolate, acute, ${ }^{1 / 2}-1^{1 / 2^{\prime}} \times 3-8^{\prime \prime}$, on petioles of $2-5^{\prime \prime}$, the uppermost ones small linear-lanceolate. Inflorescence umbellate-paniculate, a slender peduncle of $1-3^{\prime}$ in length bearing an umbel of $4-5$ unequal rays, $4-8^{\prime \prime}$ long, each of which carries a glomerule of 4-6 sessile flowers, supported by small ovate bractlets. Perigone pinkish, $11 / 2^{\prime \prime}$, glandular-pubescent, the tube as long as the limb or longer, obtusely angular. Stamens 2. Stigma flat-capitate. Nutlet viscid, clavate, $1^{1 / 2}{ }^{\prime \prime}$ long. - B. hirsuta, Hook. \& Arn. in Bot. Beech. p. 93.

Common on the lower plains and slopes. Like other species of this genus, the plant possesses some drastic property in the root and forms part of the native materia medica. It has a wide geographical range, from the Mascarene to the Hawaiian Islands.

2. B. tetrandra, Forst. Prod. no. 5. - DC. l. c. p. 456. - A stouter plant than the preceding one, $2-4 \mathrm{ft}$. long. Leaves of thick texture, broadly ovate or oblong, obtuse, even suborbicular, $1-1^{1 / 2^{\prime}} \times{ }^{3} / 4-1^{\prime}$, sometimes subcordate at the base and emarginate at the apex. Peduncles in the axils of full-sized leaves, stiff, $1^{1 / 2}-4^{\prime}$, subumbellate, with $3-6$ rays of $1-6^{\prime \prime}$ in length, each bearing a cluster of stipitate flowers, rarely a peduncle carrying a single cluster. Perigone $1 \frac{1}{2}{ }^{\prime \prime}$, with the limb longer than the tube, glandular. Stamens $2-3(-4$ ?). Style exserted; stigma flat-capitate. Nutlet sharply angular, viscid. - Hook. \& Arn. 1. c. Guillem. Zephyr. Taitens. p. 38.

Hawaii! on lava fields of Kona, near Kealakeaku; collected also by the naturalists of Beechey's Expedition, probably on Niihau. Forster gives the number of stamens as $2-5$. The species occurs also on the Society, Gambier, and Radack Islands.

\section{PISONIA, Plum.}

Flowers polygamous. Bractlets $1-3$, minute, deciduous. Calyx or perigone funnel-shaped, entire, 5-toothed or lobed. Stamens 6-20, unequal, connate at the base, exserted in the male flowers, rudimentary in the female; anthers short ovoid, their cells almost discreet. Style often lateral, the stigma capitate or divided into few or many fringes. Fruit ovoid-elongate or cylindrical, surrounded by the coriaceous angular smooth 
or muricate perigone. Embryo straight; radicle inferior; cotyledons clasping the albumen. - Soft-wooded trees or shrubs with opposite or scattering leaves. Flowers inconspicuous, glomerate or loosely fascicled, the clusters arranged in terminal or axillary cymose corymbs or panicles.

A genus of about 30 species, spread over the tropical regions of the whole world, but chiefly Ameriean.

Limb of perigone lobed; stigma fimbriate (Vieillardia, Brongn.):

Leaves mostly cuneate; flowers pedicellate; stamens 8-12, scarcely exserted; stigmatic fimbriae radiating from the apex; fruiting perigone smooth

1. P. umbellifera.

Leaves broad at the base; flowers sessile; stamens $17-20$, long exserted; stigmatic fimbriae along the clavate extremity of the style; fruiting perigone rough

Limb of perigone entire; stigma orbicular or peltate; stamens $8(-12)$

2. P. Sandwicensis.

3. P. inermis.

In the Hawaiian species the characters, taken from the perigone, stamens and stigma, seem to be pretty constant and, on the whole, to run parailel with those less reliable ones which concern the leaves and inflorescence. In referring nos, 1 and $3 I$ have followed B. Seeman, who was in a position to examine the large material in the herbariums of the British Museum and of Kew. To that author also belongs the responsibility for the synonyms adduced.

The fruiting perigone of all three species exudes a very viscid glue which the native woodmen make use of for catching birds. It will stick fast to paper in the herbarium for years, and this property may account for the wide distribution of some species by the agency of birds. The native name "Papala" occurs again in the Maori "Parapara" of New Zealand.

1. P. umbellifera, Seem. in Bonplandia, X, 154. - Fl. Vit. p. 195. A low tree, 15-20 ft. high, with spreading branches, glabrous. Leaves broadly obovate, contracted at the base, obtuse or shortly acuminate, but sometimes broad at the base and suborbicular, 5-11' $\times 3-5^{\prime}$, on petioles of ${ }^{1} / 2^{\prime}$, fleshy, the upper ones crowded in a kind of whorl, the lower subopposite. Inflorescence terminal, subumbellate: one or several peduncles rising from the apex of a branch, each 2-6' long, dividing at or near the apex into a loose umbel or contracted panicle of $4-8$ rays, $1-2^{\prime}$ long, which again bear loose umbellets of $3-6$ flowers; the ultimate pedicels $1^{1 / 2}-3^{\prime \prime}$. Perigone greenish, smooth, with the limb 5-fid; that of the male $\mathrm{fl}$. campanulate, $2-3^{\prime \prime}$, of the female tubular, $3-4^{\prime \prime}$ long. Stamens 8 , rarely 9-12, as long as the perigone in the male, half as long in the female flowers. Style in the fertile fl. as long as the perigone, with the stigma radiating at the apex into a parachute of long fringes, shorter and with an abortive stigma in the sterile $\mathrm{fl}$. Fruiting perigone linear-elongate, $2^{1} / 2-3^{\prime}$ in length and $2-2^{1} / 2^{\prime \prime}$ in thickness, on pedicels of $3-9^{\prime \prime}$, obtusely 5 -ribbed, generally thickest at the base, straight or curved, closed at the apex and truncate (the lobes at last caducous), viscid, but smooth. Utricle $1 / 2-2 / 3$ the length of the perigone. Embryo $10-12^{\prime \prime}$ long, the inferior radicle $2^{1} / 2^{\prime \prime}$, the cotyledons foliaceous, $4^{\prime \prime}$ broad, cordate-ovate, induplicate round a scant mucilaginous albumen, the outer one broader and longer than the inner. - Nadéaud, Enum. Pl. Tah. p. 46. - Ceodes umbellifera, 
Forst. (from the island of Tanna, N. Hebrides). - With it Seeman joins as synonyms P. excelsa, Bl., P. macrocarpa, Presl, P. Forsteriana, Endl., P. Sinclairii, Hook. f., P. Mooreana, F. Mueller, which would give to the species a wide geographical range, including most of the high Polynesian islands, the Society, Viti, and N. Hebrides groups, together with N. Zealand and Norfolk Island, tropical Australia, Timor, Java and the Philipine Islds. In none of the descriptions, however, do I find mention made of a fimbriate stigma.

Kauai! Oahu! Maui! in forests of the lower and midale regions; probably also in Hilo, Hawaii.

2. P. Sandwicensis, sp. $n$. - Young leaves and inflorescence ferruginous. Leaves scattering, thick coriaceous, $5-8^{+} \times 2^{1 / 2}-3^{1 / 2^{\prime}}$, on petioles of $1-2^{\prime}$, ovate-oblong, obtuse or rounded at the apex, the base rounded, even subcordate, sometimes uneven-sided, rarely contracted, the ribs and veins prominent. Peduncles in the axils of the uppermost leaves, $1-3^{\prime}$ long, umbellately dividing into $3-5$ short rays of $2-4^{\prime \prime}$, which bear contracted heads of sessile flowers at their ends, the whole forming a globose inflorescence of $1-2^{\prime}$ in diameter. Perigone $2^{1 / 2}-3^{\prime \prime}$, deeply parted into $5-6$ somewhat obtuse lobes. Stamens $18(17-20)$, long-exserted, nearly twice the length of the perigone, shorter in the fem. fl. Style as long as the perigone or longer, fringed along its clavate upper portion. Fruiting perigone (probably not mature) $15^{\prime \prime}$ long, ovoid-elongate, crowned with the lobes of the limb, faintly muricate along its entire length.

Lanai! Maui! Molokai! Kauai! The tendeney to polygamy seems to be slight, most of the flowers having the style as long as the stamens. Remy's no. 217 and M. \& B's. no. 347, both from Lanai, seem to belong here.

3. P. inermis, Forst. Prod. p. 75, no. 397. - Seem. Fl. Vit. p. 195. - Var. leiocarpa, Hillebr. - A glabrous tree of small size. Leaves distant and mostly opposite, elliptico- or obovato-oblong, $4-8^{\prime} \times 1^{1 / 2}-3^{1 / 2^{\prime}}$, on petioles of $1 / 2-1^{1} / 2^{\prime}$, bluntly acuminate, contracted at the base, thin, almost membranous. Flowers mostly hermaphrodite, in a loose open panicle of $6-8^{4}$ in length, the opposite or verticillate peduncles supported by reduced leaves, the scattering rays and pedicels not divaricate but ascending, the pedicels $2-4$ ", increasing to $12^{\prime \prime}$ when with fruit. Perigone pale pinkish, $2-3^{\prime \prime}$, tubular-funnel-shaped, the spreading limb entire, plaited with 5 or 10 erenatures. Stamens generally 8 , but sometimes $9-12$, scarcely exserted. Style of the same length, the stigma oblique, capitatedepressed or somewhat peltate, not fringed. Fruiting perigone fusiform, $11 / 2^{\prime}$ long, 5-ribbed, faintly muricate at the neck of the persistent limb. - P. procera, Bertero, in Guillem. Zephyr. Taitens. - P. Brunoniana, Endl.? - P. grandis, R. Br.?

Onopen fore-hills of Kohala, Hawaii! Hamakua, E. Maui! Kalae, Molokai! Specimens from Moloka $\mathrm{i}$ are hermaphrodite, those from $\mathrm{Hawai}$ and Mani exhibit a slight difference between fertile and sterile flowers, the former being more elongate, but 
both kinds occur in the same inflorescence. The stigma in Forster's plant from Tahiti, "bilobum, laciniis albidis laceris", does not agree with ours, nor does the fruit, which is thickly murieate and only :-4" long both in Forster's plant, in specimens from the Gambier Islands in herb. Gray, and in the figure of $P$. grandis in Lindley's Veget. Kingdom. Delessert's figure of $P$. procera, in which the expanded stigma is simply toothed, makes a nearer approach. P. Brunoniana from Norfolk Island is said to be dioecious. Assuming the synonyms to be correct, the species would extend over the Society, Gambier, Viti, and Tonga groups, Norfolk and Prata Islands, Australia and Ceyion, probably confined to coast regions.

\section{OrdER LXVIII. AMARANTACEAE.}

Perianth or calyx scarious, deeply 5-3-parted, the sepals imbricate, not enlarging with fruit. Stamens hypogynous, opposite the sepals, often alternating with sterile staminodes. Ovary I-celled. Ovules erect from the base or from free basal funicles, amphitropous, usually single, in one tribe several. Fruit generally a utricle which opens transversely or irregularly. Seeds lenticular, compressed. Embryo excentrical round a mealy albumen. - Mostly herbs, but sometimes shrubs or trees, with opposite or alternate entire leaves, without stipules. Flowers supported by 3 , rarely by 2 bracts, in sessile clusters or in spikes.

A considerable Order, chiefly tropical and American.

Style simple, with a capitate stigma:

Flowers glabrous; sepals and stamens 5 ; staminodes present .
Flowers villous or hispid; sepals and stamens 4 ; staminodes none

tyle deeply divided into 2 stigmatic branches; stamens 5 , connate at the base; staminodes present:

-Flowers woolly, in simple spikes; a shrub

Flowers glabrous, in paniculate spikes; trees

1. Achyranthes.

2. Nototrichium.

Style divided into 3 stigmatic branches; stamens 3; utricle indehiscent 5. Euxolus.

In general enitivation and oecasional eseapes from gardens: Amarantus paniculatus, A. melanchoticus, Celosia eristata, the Cockscomb, and Gomphrena globosa.

\section{ACHYRANTHES, L.}

Flowers hermaphrodite, 3-bracteate. Perianth of 5 unequal segments, hardened after flowering. Stamens 5, united into a cup at the base, with as many small scales or staminodes between them. Anthers ovoid, 2-celled. Ovule solitary. Style simple, with a capitate stigma. Fruit an indehiscent utricle. Seed-coat subcrustaceous. Embryo coiled round albumen. Herbs with opposite leaves. Flowers green or scarions, patent or reflexed, in terminal spikes or heads. Bracts very acute, the lowest persistent on the rhachis, the lateral ones longer and generally spinescent, approximate on the inner side of the flower.

About 16 species, natives of the tropienl and subtropical regions of Africa, Asia, Australia and Polynesia.

Spikes $6^{\prime}$ long or more:

Leaves silky; awn of lateral bracts as long as the blade.

Leaves pubescent or glabrate; awn of lateral bracts several times longer than the blade.

Spikes short, $1^{\prime}$ or less

1. A. splendens. greenish-silvery flowers, which are reflexed at last, and subulate bracteoles. 
1. A. splendens, Mart. - DC. Prod. XIII, Sect. II, p. 316. - Suffruticose, $2-3 \mathrm{ft}$. high, divaricately branching, canescent with an appressed silky tomentum. Leaves rather thick and faintly curved, obovate or oblanceolate, with the petioles $2-4^{\prime} X^{3} / 4-1^{1} / 4^{\prime}$, shortly acuminate or mucronate, cuneate at the base, greenish but silky above, silvery or pale fulvous underneath. Flowers stramineous, slender, ovoid-elongate, $4-5^{\prime \prime}$, glabrous, horizontally patent and close on the thick, angular, villous, foveolate rhachis of a terminal spike, which is $6-12^{\prime}$ long when full grown and naked at the base for $1 / 2-1^{\prime}$ only. Lateral bracts about half the length of the flower, broadly-ovate, the single nerve excurrent in a stiff awn of about the same length as its blade. Sepals narrow lanceolate, acute, the outer ones 3-nerved. Stamens connate in a deep cup, half as long as the perianth or more. Staminodes little shorter, broad oblong, laciniate or fimbriate at the apex. Utricle ovate-oblong, $1^{1 / 2}-2^{\prime \prime}$, truncate and thickened at the apex.

Maui! common in Kula, back of Lahaina, on ridges of Wailuku; Lanai! sometimes the leaves silvery on both faces.

$\beta$ var: rotundata. - Leaves obovate, broadly rounded, silvery on both faces. Flowers $3-4$ ".

Oa hu! Waianae and Cape Kaena, near the sea.

ivar. reflexa. - Leaves as in $\beta$. Rhachis of spike thick, densely woolly. Flowers ovoid, 3 ", angular, completely reflexed at an early period, hard, almost cartilaginous. Lateral bracts ovate, oblique and callous at the base, $1 / 2-2 / 3$ the length of the flower, the very stiff median nerve not prolonged into an awn. Onter sepals 5 -nerved. Staminodes as before.

Molokai! pali of Kalaupapa. The speeies approaches closely to the Australo-Polynesian A. canescens, R. Br. (A. velutine, H. \& A.).

2. A. bidentata, Bl. - DC. Prod. l. c. p. 312 - Habit as before. Leaves elliptico-oblong, $2-2^{1} / 2^{\prime} \times{ }^{3} / 4^{\prime}$, acuminate at both ends, pubescent or glabrate, dull green on both faces. A single terminal spike, $6^{\prime}$ long, with a slender pubescent rhachis, naked below for $1-1^{1 / 2} 2^{\prime}$, loosely flowered, the flowers horizontally patent, slender, $3-3^{1 / 2^{\prime}}$ long, shining. Lowest bract lanceolate, $1^{1 / 2} 2^{\prime}$; lateral bracts nearly as long as the flower, a long and stiff deflected awn rising from a very short $\left(1 / 2^{\prime \prime}\right)$ truncate or bidentate blade. Sepals linear-lanceolate, faintly nerved. Stamens and staminodes as before. - The description from Remy's specimen. - Gray, in mss. U. S, E. E. - Mann, Enum. no. 420.

Lanai (Remy 209). - The species has been found also in Java and Nepaul.

3. A. mutica, Gray, in Bot. U.S.E.Exp. (ined.). - Mann, Enum. no. 418.Shrubby, much branched. Leaves obovate, spathulate, or almóst lanceolate, $1^{1 / 2}-2^{2} \times{ }^{1 / 2-3 / 4^{\prime}}$, obtuse, attenuate at the base, on petioles of ${ }^{1 / 2^{11}}$, glabrate and green on both faces, membranous, brown when dry. Spikes 
small ovoid, about ${ }^{3} / 4^{4}$ long, subsessile, terminal and in the axils of the two uppermost leaves; the rhachis villous. Flowers glabrous, patent, $2^{\prime \prime}$ long, coriaceous. Lateral bracts broadly ovate, mucronulate, ${ }^{1} / 2$ or $1 / 3$ as long as the flowers. Sepals 5, lanceolate-acute, 3-nerved at the base. Stamens $5,2 / 3$ the length of the sepals, connate below in a cup and alternating with broad staminodes of their own length which are truncate and deeply torn into $3-4$ laciniae. Style as long as the sepals; stigma small.

Kauai (Remy 208). - The Oahu specimen referred here by Gray is Nototrichium humile, to which the present species bears a great resemblance. Gray observes that this species, which seems to combine Moquin's second and third sections of Achyranthes, is a pentamerous congener of Brown's $A$. arborescen from Norfolk Island. See remarks under the following genus.

\section{NOTOTRICHIUM, gen. nov.}

Flowers hermaphrodite, tribracteate, small, conical, hispid-villous or pubescent. Perianth or calyx deeply 4 -parted, the sepals equal, not awned, an outer pair enclosing the inner one. Stamens 4, slightly connected at the base; anthers 2 -celled, affixed near the apex, the cells divergent at the base. Staminodes none. Ovary 1-celled, 1-ovulate. Ovule erect, anatropous; style slender; stigma capitate. Fruit an oblong or obovoid thin utricle which breaks transversely at a late period, enclosed in the perianth. Seed lenticular, with a thin testa (strophiolate?); the embryo spiral round mealy albumen; the cotyledons broader and longer than the superior radicle. - Shrubs or trees, with dichotomous branches. Leaves opposite, penni-nerved. Flowers sessile, suberect, in terminal and axillary spikes with a woolly or pubescent rhachis; the bracts short, not awned, the lowest persistent. - Ptilotus, sect. Nototrichium, Gray, in Bot. U. S. E. E. ined.

Gray, in nniting the first species of this genus with the Australian Ptilotus, R. Br., in which again he includes the East Indian genus Psilotrichium, B1., seems to have overlooked the quaternary type of the perianth and stamens, which I find constant in the numerous flowers submitted to examination. In addition Ptilotus has alternate leaves and crustaceous seeds, and probably there exists a difference also in the anthers, which Moquin describes as ovate or elliptical. Excepting the agreement in position of leaves, the same differences hold good also with regard to Psilotrichium. Both genera comprise only herbaceous or at most suffruticose species, while those of Nototrichium are decidedly shrubby or even arboreous; and as trees or shrubs are of rare oceurrence in this Order, it may be proper to point out the elose relationship which exists between our genus Nototrichium and the second section (Achyropsis) of Achyranthes, viz., A. arborescens from Norfolk Island, which also has a quadrimerons flower. Small staminodes in the latter and short awns to its bracts, with an iudehiscent utricle, constitute all the difference. Spikes stout, hispid-rillous:

Leaves ovate to obovate, silvery- or fulvo-tomentose underneath; stamens and style about as long as the perianth Leaves ovate; green on both faces and glabrate; stamens and
style half the length of the perianth

Spikes slender, puberulous; leaves glabrous, brownish when dry;
style and stigma very short

1. N. Sandwicense.

2. N. viride.

3. N. humile. 
1. N. Sandwicense, Hillebr. - Arborescent in the upper, shrubby in the lower regions, the young branches angular, canescent with silky tomentum. Leaves ovate or lanceolate, $1^{1 / 2}-2^{1} / 2^{\prime} \times 3^{3 / 4}-1^{1} / 2^{\prime}$, on petioles of $6-9^{\prime \prime}$, acute, moderately contracted at the base, silky on both faces, the lower face silvery-tomentose. Spikes generally 3 or 5 at the end of a branch, thick ovoid to cylindrical, $1 / 2-1^{\prime}$ long, on peduncles of $3-6^{\prime \prime}$, the rhachis densely villous. Flowers crowded, ovoid, $1-1^{1 / 2^{\prime \prime}}$ long, villous with spreading hairs, mostly so at the base. Bracts $1 / 2$ as long or more, ovate, thin conchoidal, acute. Sepals ovate or lanceolate, $3-5$-nerved, somewhat acute, not mucronate, hispid at the back, not at the scarious margins. Stamens nearly as long as the perianth, the filaments subulate from a broader base. Ovary oblong, truncate. Style as long as the perianth, with punctiform stigma. - Ptilotus Sandwicensis, Gray, 1. c., and Mann, Enum. no. 417. - Psilotrichium Sandwicense, Seem. Fl. Vit. p. 198. Benth. \& Hook. Gen. P1. III, 32. - Wawra, in Flora, 1875, p. 186.

Hawaii! Kawaihae iuka; Maui! Kula, Honuaula; Molokai! Kalae; Oahu! Waianae. - Nat. name: "Kului"

$\beta$ var. Kauaiense, Gray. - Low shrubby, the branches almost herbaceous. Leaves obovate, very obtuse or rounded, contracting into a margined petiole, fulvo-tomentose underneath. Spikes ovoid-elongate, on peduncles of $1-1^{1 / 2}$.

Kauai (U. S. E. E.).

$\gamma$ var. longe-spicatum. - Leaves larger and broader, ovate or rhomboidal, greenish underneath. Spikes elongate-cylindrical, $1 \frac{1}{2}-2$ ' long, on peduncles of $1 / 2-1^{1}$.

W. Maui! Molokai! Kalaupapa.

2. N. viride, sp. $n$. - Leaves broad ovate, glabrous and green on both faces. Spikes terminal, ternate and axillary, short-ovoid, densely villous with white hair. Sepals $1^{1} / 2^{\prime \prime}$, villous at the middle, greenish and somewhat open. Stamens and style half the length of the perianth.

Ka ua i, Hanapepe (M. \& B. 590, in herb: Cornell Univ.).

3. N. humile, sp. $n$. - A low decumbent shrub, the young branches slender, herbaceous, nodose, puberulent. Leaves ovate or oblong, $1^{1 / 2}-2^{\text {}}$ $\times{ }^{3} / 4-1^{1 /} / 4^{\prime}$, on petioles of $3-4^{\prime \prime}$, obtuse, glabrate on both faces, sparingly silky when young, brownish when dry. Spikes terminal, single or ternate, and axillary, slender, $1^{1 / 2}-2^{\prime}$ long and only $2^{\prime \prime}$ thick when full grown, on peduncles of $3-5^{\prime \prime}$, the rhachis pubescent. Flowers erowded, short conical, $3 / 4 "$, stiff coriaceous, appressedly pubescent. Lateral bracts conchoid, $1 / 4-1 / 3$ the length of the flower, cordate-ovate, with scarious margins, keeled at the thick base. Sepals broadly ovate, obtuse, tightly clasping over the fruit. Stamens and style very short. Ovary globose. Seed strophiolate. Embryo spiral.

Oahu! Cape Kaena, near the coast. 


\section{AERVA, Forsk.}

Flowers hermaphrodite, tribracteate. Sepals 5, erect, woolly. Stamens 5, connate at the base. Staminodes triangular or subulate. Anthers 2-celled. Ovary 1-ovulate. Style short, divided into 2 stigmatic branches. Fruit an indehiscent utricle, enclosed by the perianth. Seed-coat crustaceous. - Herbs or undershrubs, generally white-tomentose. Leaves alternate, rarely opposite. Flowers minute, in terminal and axillary spikes.

Tropies of the Old World, about 20 species.

1. A. sericea, Moq. in DC. Prod. XIII, Sect. II, p. 304. - «Shrubby, pale puberulous or whitish. Leaves opposite, ovate or rhomboidal, $1-2^{\prime} X$ $6-9^{\prime \prime}$, including a petiole of $2-4^{\prime \prime}$, the uppermost lanceolate-acute, silkytomentose, green above, white underneath, thin, with prominent nerves. Spikes solitary or twin, ovate, $3-4^{\prime \prime} l$ long and $2^{\prime \prime}$ broad, obtuse, villous, on peduncles of $3-12 "$. Flowers $3 / 4 "$, reddish-white, not shining. Bracts exceeding the flowers, unequa], keeled, villous, the lower ovate, acuminate, mucronate, the lateral ones concave, long acuminate. Sepals 1-nerved, acute, the two outer ovate, villous, the three inner ones narrower. Anthers ovate-oblong. »

Collected ouly by Gaudichand in the Voyage of the Bonite (no. 45).

\section{CHARPENTIERA, Gaud.}

Flowers hermaphrodite, tribracteate. Sepals 5, erect, glabrous, coriaceous. Stamens 5, united at the base into a short cup, alternating with short and rounded entire staminodes. Anthers 2 -celled, oblong, sagittate. Ovary 1-ovulate. Style very short or none; stigmatic branches 2, short and thick, subulate, diverging, papillose on the inner side. Fruit an ovoid indehiscent utricle, enelosed by the perianth. Seed vertical, lenticular, notched, exarillate, with a black shining crustaceous testa. Embryo hemicyclical. - Trees with alternate entire penni-nerved leaves. Flowers minute, distantly sessile in axillary paniculately arranged loose filiform spikes, all bracts persisting on the rhachis.

A Hawailan genus, nearly related to the American Chamissoa. Leaves broad at the base; sepals somewhat acute; stamens as long as the sepals

Leaves contracted at the base; sepals obtuse; stamens half as long as sepals

1. C. ovata.

1. C. ovata, Gaud. Bot. Voy. Freyc. p. 444, tab. 48. - A soft-wooded tree, $15-20 \mathrm{ft}$. high, with spreading branches, glabrous. Leaves ovate, $4-6^{4} \times 3-4^{\prime}$, on petioles of $2-3^{1} / 2^{\prime}{ }_{2}$ somewhat acute, rounded or truncate at the base, but slightly decurrent into the petiole, fleshy when fresh, with thin margins, glabrous, dark, the veins straight parallel. Panicles compound, $10-12^{\prime}$ long, on peduncles of about $4^{\prime}$. Flowers $1^{\prime \prime}$, thin paleaceous, rather pale. Bracts $1 / 3-1 / 2$ the length of the flower, ovate. Sepals 
broadly ovate, conchoidal, somewhat acute, 3-nerved. Stamens of the same length. Stigmas exserted at last. Utricle 1", ovoid, quite enclosed. - Moquin, in DC. Prod. XIII, Sect. II, p. 322. - Hook. \& Arn. in Bot. Beech. p. 94.

Kauai; Oahu! on the main range; Maui. In appearance much like Pisonia um. bellifera, with which it shares the same name, "Papaln.

2. C. obovata, Gaud. 1.c.tab. 4\% - Leaves obovate-oblong, varying much in size, $2-7^{\prime} \times 1-4^{\prime}$, shortly apiculate, rounded or emarginate, coriaceous, with thickened and partly reflexed margins, the petioles $1-3^{\prime}$. Flowers brownish, $1-1^{1} / 2^{\prime \prime}$. Bracts $1 / 3-1 / 4$ as long, ovate or orbicular. Sepals somewhat obtuse. Stamens about $1 / 2$ the length of the sepals. Utricle 1- $11 / 2^{4}$, enclosed or partly exserted. - DC. Prod. 1. e. - Wawra, in Flora, 1875 , p. 188.

Oahu! leaves large, obtuse; Hawaii! Kau, leaves smaller, apiculate, occasionally suborbicular.

$\beta$ var. elliptica. - Leaves elliptical or lanceolate, $2-6^{\prime} \times 1-2^{\prime}$, obtuse or acuminate. Sepals rather acutely lanceolate. Stamens ${ }^{1} / 2$ their length. Kauai! Ma ui! (Mrs, Sinclair, pl, 44).

\section{EUXOLUS, Raf.}

Flowers usually monoecious, tribracteate. Sepals and stamens 3 , rarely 5 , the latter free. Staminodes none. Anthers 2-celled. Ovary 1-ovulate. Style short, divided to the base into 3 stigmatic lobes. Fruit an indehiscent utricle. Seed vertical, crustaceous. Embryo coiled round albumen. Annual herbs with alternate leaves. Flowers sessile in clusters, these all or only the upper ones arranged in spikes or panicles.

About a dozen species, widely distributed, distinguished from Amarantus only by the indehiscent fruit.

† 1. E. lineatus, Moq. in DC. Prod. XIII, Sect. II, p. 276:- Erect, 1-2 ft. high, glabrous, with striate stems. Leaves lanceolate to linear, $2-4^{\prime} X$ $3-9 "$, including a petiole of $10-18^{\prime \prime}$ in which they gradually merge, obtuse, mucronulate, glabrous, with prominent nerves; the lower leaves obovate-oblong. Flowers almost dioecious, green, less than $1^{\prime \prime}$, in the lower part of the braneh in axillary clusters of 5 or 6 , in the upper part crowded in paniculate spikes of $x / 3-1$ ' in length with a pubescent rhachis. Bracts unequal, about $1 / 2$ the length of the calyx. Sepals of male fl. lanceolate-acute, of the female $\mathrm{fl}$. spathulate-obtuse, both mucronulate. Utricle obovoid, puckered or rugose, dark green, rather thin. Seed lentieular, black, shining. - Amarantus lineatus, R. Br.

Near cultivated fields in Kola and Honuaula, Maui! Hawail and Kauai. An early immigrant from Australia.

E. viridis, Moq., a smaller plant with ovate or rbomboidal leaves and a long terminal spike, was a common weed in gardens and probably has become naturulized since. The Amarantus Blitum, enumerated by Wawra and collected in canefields of Maui, is likely to be the same plant. 


\section{ORdER LXIX. PHYTOLACCACEAE.}

Perianth cut down to the base into 4-5 rounded segments, greenish or colored. Stamens 4 or 5 and alternate with the segments of the perianth, or indefinite. Several carpels (a single one in Rivina) either connate at the base or discreet, indehiscent in fruit, each with a single erect ovule. Styles distinct, usually introrse, or none. Embryo excentrical; albumen mealy or wanting. - Herbs with alternate entire leaves, without stipules, mostly with drastic properties. Flowers small, racemose.

A cosmopolitan Order of about 70 species.

\section{PHYTOLACCA, L.}

Segments of perianth 5, often colored. Stamens 5-30. Ovary of $5-12$ carpels united in a ring, with as many short introrsely stigmatiferous styles, in fruit forming a depressed globose 5-12-celled berry. Embryo curved in a ring round the albumen. - Tall perennials with terminal and lateral racemes.

A small genus, distributed over the warmer regions of the world, but chiefly of America.

1. P. brachystachys, Moq. in DC. Prod. XIII, Sect. II, p. 31. - An erect undershrub, $3-5 \mathrm{ft}$. high. Leaves ovate, $4-6^{\prime} \times 2-3^{\prime}$, on petioles of $3 / 4-1 '$, acuminate, contracting at the base, membranous, glabrous. Racemes $2-6^{\prime}$, the rhachis angular, naked at the base for $1 / 2-1$ inch; pedicels $2-3^{\prime \prime}$, filiform, with a linear bract at the base and 1 or 2 smaller ones about the middle. Sepals $1^{1 / 2}-2^{\prime \prime}$, obtuse, pink or purplish. Stamens 5-10. Carpels 5-7, not beaked in fruit. Berry dark purple, umbilicate, $2^{\prime \prime}$ in diameter, 5-7-ribbed. - P. Abyssinica, Hook. \& Arn. in Bot. Beech. p. 94. - P. Bogotensis, Mann, Enum. no. 396. - The Andine species has $7-13$ stamens and $7-9$ earpels, with a small perianth which is white as in $P$. decandra.

Common in the lower forests, the Poke of the Americans. Nat. name: "Popolo".

A species of Rivina, probably $R$. laevis, L., has of late years appeared as a weed in gardens and may become naturalized.

\section{ORDER LXX. POLYGONACEAE.}

Perianth of 6,5 or fewer segments, regular and equal, or the inner ones enlarged. Stamens variable in number, usually 9,8 or 6 , alternate with the segments when of the same number. Ovary free, with a single erect ovule. Styles or stigmas 2, 3 or rarely more. Fruit a small seedlike nut, usually with as many angles as styles, enclosed in or scarcely protruding from the persistent perianth. Embryo straight or curved. Albumen mealy. - Herbs or rarely shrubs. Leaves alternate, usually entire. Stipules usually thin and scarious, rarely herbaceous, forming a sheath or ring (ochrea) round the stem within the petiole. Flowers small, 
herbaceous or sometimes colored, clustered in the axils of the leaves, or in spikes or racemes, forming terminal panieles.

A considerable Order, dispersed over every part of the globe.

Fruiting perianth of 6 segments, the 3 inner ones enlarged Frniting perianth of 5 nearly equal segments .

1. Rumex.

2. Polygonum.

In general cultivation is the beautiful Mexican creeper Antigonon leptopus, Hk. \& Arn.

\section{RUMEX, L.}

Flowers hermaphrodite or diclinous. Perianth-segments 6 , the 3 inner ones of the fertile flowers (valves) enlarged and elosing over the triangular nut. Stamens 6. Styles 3, very short, with fringed stigmas. Émbryo slightly curved, lying along one side of the albumen, slender. - Coarse herbs or rarely shrubs. Flowers numerous, small, herbaceous, but often turning red, usually pedicellate in whorl-like clusters, axillary or in terminal simple or paniculate racemes.

A large genus with nearly the range of the Order, but more confined to the temperate regions,

Leaves ovate-oblong, glabrous; male flowers $1^{\prime \prime}$ long; valves of fem.

fl. deep red at last

Lower leaves elongate, with cordate base, pubescent; male 11. 2" long;

valves of fem. fl, white at last

1. R. giganteus.

1. R. giganteus, Ait. - Meisn. in DC. Prod. XIV, 53. - Woody at the base, in open grounds decumbent and only a few feet long, but in forests, when supported by trees, rising to a height of $20-40 \mathrm{ft}$. Stemleaves ovate or oblong, $5-9^{\prime} \times 1^{1 / 2}-2^{1 / 2^{\prime}}$, on petioles of $1-2^{\prime}$, acute, rounded or truncate at the base, thin, glabrous. Panicles in the axils of the upper leaves, 8-12' long, constituting a large compound inflorescence 1 to several feet long, foliose only in its lower portion with reduced lanceolate leaves contracted at the base. Pedicels fascicled in the axils of small deciduous ochreas, filiform, $4^{\prime \prime}$. Flowers polygamous, but one sex much prevailing in a plant. Male $f l$. Perianth $1^{\prime \prime}$, its divisions oblong or obovate, the outer as long as the inner ones or a little shorter. Anthers subsessile. Ovary small, with eapitate stigmas. Fem. fl. Perianth $1^{1} / 2^{\prime \prime}$, its outer divisions linear-lanceolate, reflexed and half as long as the inner ones. Stigmas penicillate on a short style. Fruiting valves without callus, cordate, suborbicular, $2^{1} / 2^{\prime \prime}$, acuminate, prominently reticulate, eroso-dentate or serrulate, turning red at last, even crimson. Achenes smooth, triangular, with plane faces, about as high as broad. Embryo straight cylindrical, the cotyledons little longer and broader than the thick radicle. - Mann, Enum. no. 397. - Wawra, in Flora, 1875, p. 188. - Lowest leaves not collected.

Hawaii! Maui! Molokai! Kauai? Attains its full development in forests at elevations of $2000-4000 \mathrm{ft}$., but is also met with lower down. Nat name: Pawales in Hawaii, "Uhauhako" in Molokai. - Meisner's description seems to have been partly taken from $\mathrm{Oahu}$ specimens which have to be referred to the following species. 
2. R. albescens, sp. n. - Low decumbent. Leaves elongate, the lowest $10-16^{\prime} \times 3^{1 / 2}-5^{\prime}$, on petioles of $4-6^{\prime}$, cordate at the base with rounded ears and eroso-denticulate, the upper ones truncate, and only those of the inflorescence contracted at the base, gradually acuminate, gray-pubescent underneath and along the midrib on the npper face also. Panicle shorter, 6-10'long, naked, the capillary pedicels mostly reflexed. Flowers polygamous, both sexes in equal proportion. Male fl. as before, but larger, $2^{\prime \prime}$. Fem. $f l$. small as in no. 1, the short outer divisions green, erect, the inner ones in fruit $4-6$ times as large, pale whitish, ovato-cordate, acuminate, without callus, reticulate, eroso-dentate. Achenes with acute protruding angles and receding faces, almost 3 -winged.

Oahu! N. and W. slope of Mt. Kaala; Kauai? (Kn. 161). - The plant seen by the botanists of the U. S. E. E., as mentioned by Mann, no. 398, sub R. longifolius? The lowest leaves are exactly like those of Scolopendrium vulgare.

\section{POLYGONUM, L.}

Perianth of 5 , rarely fewer segments, all equal or the 2 or 3 outer ones enlarged. Stamens 8 or sometimes fewer. Styles 2 or 3 , sometimes united at the base; the stigmas entire. Nut flattened or triangular, enclosed in the persistent perianth. Embryo curved halfway round the albumen, the radicle and usually the cotyledons slender. - Herbs. Flowers small, green or red, clustered in the axils of leaves or of small bracts, and then collected into terminal spikes, heads or panicles.

A large genus with the range of the Order.

1. P. glabrum, Willd. - DC. Prod. XIV, 114. - Erect, $1-3 \mathrm{ft}$. high, glabrous, the sheathing stipules half the length of the internode or longer, horizontally truncate, without hairs or bristles. Leaves lanceolate, $6-9^{4} \mathrm{X}$ $1^{1 / 2}-2^{1 / 2}$, acute at both ends, on petioles of about ${ }^{1} / 2^{\prime}$ which rise from above the base of the sheath. Spikes slender but nearly continuous, $2-4$ ' long including the naked peduncle, arranged in a terminal panicle of $6-10^{4}$ in length. Bracts turbinate, obliquely truncate, enclosing clusters of $2-5$ flowers. Pedicels exserted, articulate with the flower. Perianth pinkish-green, small, not dotted. Stamens $6(7-8)$, included. Style deeply bifid. Achene biconvex, black, shining. - Benth. Fl. Hongk. p. 288. - Griseb. Fl. W. Ind. p. 161. - Seem. Fl. Vit. p. 201.

Common along streams and watercourses. Nat, name: Kamolen, identical with the Tahitian name for $P$. imberbe. - The species is widely spread over India, China, the Viti Islds. and tropical America.

\section{Order LXXI. CHENOPODIACEAE.}

Perianth small; segments 5 or in some flowers fewer, herbaceous, imbricate in the bud. Stamens 5, opposite the segments. Ovary free, with a single erect ovule. Styles 2 or 3 , either free, or united at the base. 
Fruit consisting of a single seed in a very thin or sometimes succulent pericarp, and enclosed in the persistent calyx, which is sometimes enlarged or altered in form. Seed usually orbicular and flattened. Embryo coiled round a mealy albumen, or spirally twisted with scarcely any albumen. - Herbs or rarely shrubs, often suceulent. Leaves alternate or rarely opposite, sometimes none. Stipules wanting. Flowers in sessile clusters, either in axillary or terminal spikes or panicles, and often unisexual. Bracts inconspicuous, or in a few genera 2 lateral ones to each flower, adhering to the perianth and then often described as an outer two-lobed calyx.

A large cosmopolitan Order, most abundant in maritime or saline stations.

Stems erect or procumbent; bracteoles inconspicuous; embryo coiled round mealy aibumen

Stems twining; bracteoles adhering to and enclosing the calyx; embryo spiral, without albumen

\section{Chenopodium.}

2. Basella.

\section{CHENOPODIUM, L.}

Perianth of generally 5 equal concave segments which enclose the ripe fruit without appendages or alteration, except a slight enlargement or thickening. Stamens generally 5, inserted at the base of the perianth. Ovary globose, depressed. Styles 2 or 3, often connected at the base. Seed crustaceous, usually horizontal. Embryo curved or coiled round a mealy albumen. - Herbs, rarely shrubs, glabrous, mealy or glandularpubescent. Leaves alternate. Flowers minute, bractless, glomerate in paniculate spikes.

About 60 species, distributed over the whole world.

Leaves mealy:

Leaves deltoid; seeds obtusely edged, dull .

Leaves ovate to lanceolate; seeds sharp-edged, shining

Leaves bright green :

Leaves rhomboidal, irregularly toothed or laciniate .

Leaves larger, subcordate with few acute lobes.

Leaves glandular-pubescent, aromatic

1. C. Sandwicheum

2. C. album.

3. C. murale.

4. C. hybridum.

5. C. ambrosioides.

1. C. Sandwicheum, Moq. in DC. Prod. XIII, Sect. II, p. 6\%. - Shrubby erect, the young branches striate; the whole plant generally whitish with a mealy pubescence, but sometimes nearly glaucous. Leaves rather fleshy, rhomboidal or almost triangular, somewhat 3-lobed and sinuate-dentate with the apex and angles obtuse, the base truncate or euneate, 8-20" long and nearly as broad below, on petioles of $6-10^{\prime \prime}$. Flowers glomerate along the patent branches of a terminal, almost leafless panicle of $6-8^{\prime}$ in length, quite mealy. Perianth ${ }^{1} / 2^{\prime \prime}$, with rather acutely ovate lobes which are closed over the fruit and not keeled. Pistil exserted. Utricle glandular, depressed. Seed obtusely margined, rugose, not shining. - Wawra, in Flora, 1875, p. 189. - Mann, Enum. no. 411. 
On all islands, but most common on the high plains of Haw aii. While near the coast it is low decumbent, only a few feet high, I have seen it arborescent, with a woody trunk, and $12-15 \mathrm{ft}$. high, in the upper woods of Maunakea. Nat. name: "Aweoweon. The leaves are used as a potherb.

2. C. album, L. var. candicans Moq. in DC. Prod. 7. c. p. 71. - Herbaceous, erect, with striate branches, $1-3 \mathrm{ft}$. high. Leaves petiolate, $2-3$ ' rhomboid-ovate to oblong-lanceolate, or the upper linear-lanceolate, acute, sparingly sinuate-dentate, quite mealy, pale glaucous on the upper, white on the lower face. Clusters of flowers in short axillary spikes, dense or interrupted, the upper ones forming a panicle leafy at the base. Lobes of perianth keeled, closed over the fruit. Seed sharp-edged, shining. Atriplex Oahuensis, Meyen, Reise, II, p. 127.

Oahu! Molokai! and elsewhere, along the seashore. The species, a common weed in Europe, is spread over many temperate and tropical regions.

†3. C. murale, L. - DC. Prod. l. c. p. 69. - Ascending, 1-11/2 ft. high. Leaves rhomboid-ovate, $1-3^{\prime}$ long, acute, coarsely and sharply cut into unequal teeth or lobes, thin, bright green. Spikes diverging and somewhat corymbose, not paniculate. Lobes of perianth scarcely keeled. Seed sharpedged, rugose, opaque.

Oahu; E. Maui! Kula and Ulupalakua. A common weed in Europe.

†4. C. hybridum, L. - DC. Prod. l. c. p. 68. - Herbaceous, erect, $2-4 \mathrm{ft}$. high. Leaves thin, glabrous and bright green, the upper ones deltoid, the lower ovate-cordate in outline, $3-5$-nerved, 3-6' long, sinuately $2-3$-lobed on each side, both the lobes and the long taper point very acute; the petioles $1-3^{\prime}$. Spikes diffuse, loosely paniculate, leafless. Lobes of perianth obtuse, smooth, keeled, imperfectly elosed over the fruit. Seed sharp-edged, closely adhering to the thin and pitted pericarp.

Oahu! (Lay \& Collie). A eommon European weed; the leaves heary-scented like Datura Stramonium.

†5. C. ambrosioides, L. - DC. Prod. l. c. p. 72 . - Ereet, $2-3 \mathrm{ft}$. high, viseid-glandular, emitting an aromatic scent. Leaves shortly petioled, lanceolate or oblong, sinuately toothed or nearly entire, the upper ones tapering at both ends, the lowest $4-6^{\prime}$ long. Spikes leafy, or rather the clusters in the axils of reduced leaves. Perianth closely appressed, not keeled, its divisions obtuse, often only 3 or 2 . Seed obtusely margined, sometimes vertical, shining. Embryo incompletely annular.

E. Maui! Molokai! Hawaii. - Probably of Mexican origin, but now earried into many warm and temperate regions.

\section{BASELLA, L.}

Bracteoles adhering to the perianth and united into a 2 -lobed external calyx. Perianth ovoid, shortly 5-lobed, almost closed. Stamens at the base of the perianth, connate below. Style short, with 3 oblong introrse 
stigmatic lobes. Fruit enclosed in the globular, succulent perianth and bracts, its pericarp cartilaginous. Seed vertical. Embryo spiral, with little or no albumen. - Stems twining. Leaves alternate, flat but succulent. Flowers in simple or branched spikes.

A small tropical Asiatic genus.

† 1. B. rubra, L. - DC. Prod. XIII, Sect. II, p. 222. - An herbaceous twiner of considerable length, glabrous. Leaves petiolate, broadly ovate, about $2^{\prime}$ long. Spikes axillary, pedunculate, simple, $2-3$ ' long. Flowers about $1^{\prime \prime}$, pale red, at first closely set, but becoming distant as the spike lengthens. Berries (or fruiting perianths) dark purple, very juicy, about $3^{\prime \prime}$ in diam. - Benth. Fl. Hongk. p. 283.

Of early introduetion and now naturalized in a few places. Nat. name: "Inikas (ink).

\section{ORDER LXXII. BATIDEAE.}

Character of the single genus.

\section{BATIS, L.}

Flowers dioecious, amentaceous, naked. Male fl. Stamens 4, alternating with as many membranous scales (petals, Torrey), enclosed in a bifid delicate involucre (calyx, Torrey) and inserted on the base of an orbicular bract. Fem. fl. Semi-immersed in the fleshy axis, without involucre, supported by a single bract. Ovary 4-celled, crowned by a 2 -lobed stigma; a single erect anatropous ovule in each cell. Fruit fleshy, consisting of the united ovaries and the rhachis. Endocarp coriaceous. Seedcoat membranous. Embryo nearly straight, without albumen. - Suffruticose marsh-plants with opposite fleshy leaves. Catkins oblong-cylindrical, axillary and terminal. - Torrey, in Smithsonian Contributions, 1853, VI, pl. 11.

A genus of probably a single species.

†1. B. maritima, L. - A, DC. Prod. XVII, 35. - A low diffuse undershrub with the young branches erect, $2-3 \mathrm{ft}$. long. Leaves fleshy, oblong-linear, about 1' long, flat above, convex underneath. Stipules none. Catkins considerably shorter than their leaves. Stamens exserted; anthercells discreet, subglobose, yellowish. Fem, catkins shorter than the male, quadrangular, made up of about 12 pistils in 4 rows, in fruit nearly 1 . long, often bicornute at the top, the horns being formed by the two uppermost sterile ovaries. - Mann, Enum. no. 415. - Wawra, in Flora, 1875 , p. 189. - Jacq. Amer. Pict. tab. 246. - Griseb. Fl. W. Ind. p. 61.

The plant was first discovered by the writer in 1859 in the saltmarshes of Prison Island, near Honolulu, and has since extended to Fisherman's point and to Quarantine Island, where it grows with Lycium Sandwicense, a plant much like it in appearance. The species is a native of the W. Indies (Florida, Bahamas, Jamaica, Venezuela), but has also been found on the west coast of Mexico and in Lower California. 


\section{ORDER LXXIII. LAURACEAE.}

Perianth herbaceous, with 6 or rarely fewer divisions, imbricate in the bud, in 2 series, or rarely wanting. Stamens usually as many or twice as many, opposite the perianth-segments, either all fertile or the 3 innermost reduced to staminodes, or abortive. Anthers adnate, 2-4-celled, the cells opening by persistent valves turned upward. Ovary free, 1-celled, with 1 or rarely 2 pendulous ovules. Style simple, with an entire, usually disk-shaped, or a shortly $2+-3$-lobed stigma. Fruit a 1-seeded berry or drupe, the persistent perianth or part of it often enlarged under or round it. Seed without albumen. Cotyledons large. - Trees or shrubs, with alternate entire leaves, or, in one genus, leafless twiners. Stipules none. Flowers usually small, in panieles, umbels or lateral clusters.

A large, ehiefly tropieal Order, to which belong the Avoeado or Alligator Pear, Persea gratissima, the Cinnamom and Camphor trees, Cinnnmomum Zeylanicum and C. camphora, cnltivated in gardens.

A tree

A twining leafless parasite

1. Cryptocarya.

2. Cassytha.

\section{CRYPTOCARYA, R. Br.}

Flowers hermaphrodite. Perianth 6-lobed, funnel-shaped, the tube persistent and enlarging, with narrowed neck, the lobes deciduous. Fertile stamens 9 , inserted in the throat with short flat filaments, the 3 inner ones with a sessile gland on each side; the anthers ovoid-oblong, 2-celled, not surpassed by the connective, the 3 inner extrorse. Staminodes 3 , stipitate. Style short, with subeapitate stigma. Ovary immersed in the tube of the perianth. Fruit dry, free but entirely enclosed within the fleshy or dry periantheal tube. - Trees with alternate penninerved leaves and short axillary panicles.

About 40 speries, scattered over the tropies of all continents.

1. C. Mannii, Hillebr. - A small tree with angular branches, the young leaves and inflorescence silky with a brownish tomentum. Leaves alternate, thick coriaceous, glabrate, oblong, $3-4^{\prime} \times 1^{1 / 4}-1^{3} / 4^{\prime}$, obtuse, narrowing at the base, the broad and flat midrib running out into a flat margined petiole of $4-8^{\prime \prime}$, the main veins at acute, not scrobiculate, angles, the veinlets at right angles to the latter and forming a close rectangular network. Panicles or racemes axillary, $1 / 2-3 / 4^{\prime}$ long, few-flowered, the pedunele thick angular, about $4^{\prime \prime}$, the pedicels very short, articulate at the base, 1", with linear bracts of the same length. Flowers hermaphrodite. Perianth sericeons outside and within, coriaceous, funnel-shaped, $2-2^{1} / 2^{\prime \prime}$, the angular narrow tube shorter than the lobes. Lobes 6 in two series, the inner ones larger, rounded. Stamens 9 , of nearly equal length, the 6 outer ones inserted at the base of the lobes and shorter than these, their anthers longer than the broad hairy filaments, oblong, 
obtuse at both ends, 2-celled, with valvular dehiscence, the cells in front of a broad connective which extends beyond them; the 3 inner anthers extrorse (?), ovoid, apiculate, alternating with broad triangular staminodia. Ovary free, ovoid; style short obtuse. Ovule 1, pendulous. Drupe ovoidglobose, black, dryish, about $8^{\prime \prime}$ high, 12-ribbed; the thin putamen elosely adherent to the perianth. Seed with thin testa, the large amygdaloid cotyledons plano-convex, the radicle quite small, superior. - Oreodaphne? Mann, Enum. no. 403.

In woods of Waimea, Ka uai! about $2000 \mathrm{ft}$. above the sea (M. \& B. 584, Kn. 72). Mann's specimens had only quite young buds. From Mr. Knudsen I received a few with buds somewhat more advanced, in which I was able to make ont the character of the outer anthers, but the inner stamens were qnite imperfect, so that the position of their anthers and the absence of glands has to be verified yet with aid of better material. The drupe has no trace of a cupula at the base, as is the case in Oreodaphne; but whether it is naked or covered by the perigone is not so certain. The latter state I have inferred from the presence at the top of a narrow disk or umbo, in which may be seen a few small free bodies, the probable remnants of anthers; but, if really present, the perigone is closely connate with the drupe, a condition not quite in agreement with Cryptocarya. The generic position of the tree, therefore, still remains under some doubt.

\section{CASSYTHA, L.}

Flowers hermaphrodite. Perianth ovoid or tubular, with 3 inner equal lobes and 3 outer minute ones. Fertile stamens 9 , the 3 inner with 2 glands at the base. Anthers 2-celled, those of the inner stamens turned outwards. Staminodes 3, small. Ovary free; style short; stigma depressed. Fruit enclosed in the succulent tube of the perianth. -Parasitical twiners with the habit of Cuscuta, the leaves reduced to minute scales. Flowers sessile in axillary spikes, each supported by 3 bracts.

A small genus, distributed over the tropical regions of the New and old World.

1. C. filiformis, I. - Meisn. in DC. Prod. XV, Sect. I, p. 255. - Stems filiform or wiry, glabrous or slightly pubescent when young, twining round and attaching themselves to other plants by means of small protuberances or suckers. Flowers small, distant, in spikes of $1-2$. Perianth about $1^{1} / 2^{\prime \prime}$, the inner lobes obovate, longer than the tube, the outer ones equal and similar to the small rounded bracts. Filaments of the 3 outer stamens petal-like, of the 6 others filiform. Fruit about $3^{\prime \prime}$ in diameter, crowned by the connivent perianth-lobes. - Benth. Fl. Hongk. p. 294.

Seattered over the entire group, but frequent only on the island of Kauai. The species extends from tropjeal Africa and Asia into Australia and Polynesia.

\section{Order LXXIV. THYMELAEACEAE.}

Flowers usually hermaphrodite. Perianth tubular or campanulate, 4-5-lobed, the lobes imbricate in the bud, with the addition in many genera of 1 or 2 small scales alternating with the lobes at their base. Stamens as many or twice as many as lobes, or rarely 2 only, and, if of 
the same number as the lobes, opposite to them. Anthers opening longitudinally. Ovary free, 1 - or rarely ' 2 -celled, with 1 or rarely 2 or 3 pendulous ovules. Fruit an indehiscent nut or berry, or very rarely a 2-valved capsule. Seed without or rarely with albumen. Embryo straight, with a superior radicle. - Shrubs or trees with a stringy bark, or rarely herbs. Leaves alternate or opposite, always simple and entire. Flowers in terminal or axillary clusters, heads, umbels, racemes or spikes.

A large Order, distributed over most parts of the globe.

\section{WIKSTROEMIA, Endl.}

Perianth colored, tubular, with a spreading 4 -lobed limb, the 2 lateral lobes enclosed in the bud by the anterior-posterior. No scales at the throat. Anthers 8, sessile in 2 alternate rows, the upper near the top of the tube opposite the lobes. Hypogynous scales 4 or 2. Ovary with 1 pendulous ovule. Style short or wanting; stigma capitate. Fruit a drupe-like berry, covered by the long persistent perianth, which at length breaks away, either from the base or by splitting laterally. Seed without albumen. Embryo see under no. 5. - Shrubs or trees, dichotomously branching. Leaves opposite, rarely scattering, articulate. Flowers in terminal or axillary clusters which often lengthen into racemes or spikes.

A small tropical Austral-Asiatic and Polynesian genus. - In the Hawaian species the inflorescence is almost always terminal, sometimes by budding from one or both uppermost leaf-axils lateral or between the forks. The leaves are opposite, strictly so in the more densely foliose forms, but sometimes scattering in elongate branches of the larger and sparingly dividing species. The inner pair of perianth-lobes is smaller than the outer, most so in the small flowers, in which the lobes are of greater length in proportion to the tube. Like many other plants of this Order the Hawaiian Akeas contain an acridnareotic prineiple, and are employed by the natives, in common with Awa and Ahuhu, for nareotizing fish. Their strong and flexible bast-fibres serve for many useful purposes and are of the best which the Islands prodnce. A Japanese species furnishes the material for the finest paper made in that country.

Leaves large, $1^{1 / 2}$ inch and more in length:

Spikes slender, glabrate; leaves pale:

Leaves ovate, small; spikes short, suberect . . . . 1. W. foetide.

Leaves elliptico-oblong, large; spikes short or long, deflected 2. W. elongata.

Spikes thick tomentose, pitted-areolate, densely-flowered; leaves dark-green :

Leaves velvety-tomentose underneath

Leaves glabrate, ovate-oblong; spikes long, oflen forking

Leaves obovate; spikes very short, rednced to a fascicle

4. W. villosa.

3. W. Sandwicensis.

5. W. bicomuta.

Leaves small, 1/2-11/2 inch in length (see also $W$. foetida):

Leaves ovate or obovate, obtuse; flowers in short spikes

Leaves oblong, lanceolate or spathulate; flowers elustered

6. W. uva ursi.

7. W. phillyreaefolia.

As appears from the foregoing disposition, I have seen no better way of distributing the elosely related forms of this genus than by characters taken from the leaves and inflorescence, although (or perhaps because) the material in my herbarium was large. Wawra, indeed, in a rather elaborate aceount of the Hawaiian species believes he has found striking specific differences in the pistil. To $W$. foetida he attributes a pistil eylindrical, glabrous, but strigoso-pubescent at the apex, with a short style and very small stigma; to $W$. elongata a pistil ovoid, quite glabrous and tapering into a long style with thick globose stigma; to $W$. phillyreuefolia a pistil cylindrical, glabrous and ending in 
2 horns which hold between them the short style with a small stigma. From my description of $W$. phillyreaefolia, however, and the remarks appended it will be seen that the flowers of that species are dimorphous, and that there is only too good reason to suspect that dimorphism exists in other species, perhaps in all. Thus the characters taken from the relative length of the style and the size of the stigma loose their specific importance. The bicornute apex of the ovary, again, which Wawra observed in specimens of W. phillyreaefolia, deriving from my herbarium, I have entirely failed to find in other specimens of the same set; but I met with it in all the flowers of a new species nearly allied to $W$. Sandwicensis. I am therefore inclined to believe that this state of the pistil, far from being constant and specific, is rather accidental, probably will be found in more species yet, and may not oceur again in other specimens of $W$. bicornuta, which I have taken occasion to name from it.

1. W. foetida, var. Oahuensis, Gray, in Seem. Journ. Bot. III, 302. A small shrub, 2-4 ft. high, glabrous, excepting some pubescence in the uppermost axils. Leaves ovate or ovate-lanceolate, $1-2^{\prime} \times \times^{1 / 2}-1^{\prime}$, on petioles of $1-2^{\prime \prime}$, acute at the apex, rounded or slightly contracted at the base, glabrous, pale underneath, thin chartaceous. Flowers $6-12$, on pedicels of ${ }^{1} / 2^{\prime \prime}$, clustered at the head of a terminal peduncle of $3-5^{\prime \prime}$, the cluster at most elongating into a spikelet of 2 " in length with a nearly glabrate slender rhachis. Perianth pale- or greenish-yellow, tubular, puberulous, $3^{1 / 2}$ "long, including the spreading lobes, which are somewhat obtuse and $1 / 2$ the length of the tube, - at last breaking away from the base. Lower stamens at the middle of the tube. Hypogynous scales 4-5, linear, connate at the base, as long as the ovary, which is glabrous except at the strigose-pubescent apex. Style very short, with capitate stigma. Drupe ovoid, 3-4", reddish-yellow. - Daphne foetida, Forst. - D. indica, Hook. \& Arn. in Bot. Beech. tab. 15. - Wikstroemia Forsteri, Decaisne. W. Indica, C. A. Meyer; Meisn, in DC. Prod. XIV, 543.

In valleys and along the lower skirts of the woods, on all islands. - Nat, name: akia. or sAkeas, the root of which recurs in the Vitian name Matis. In Tahitian it is called sOvan.

The species, according to Gray, occurs also in the Society, Samoa and Viti Islands, but not in India, as was erroneously supposed.

2. W. elongata, Gray, l. c. p. 303. - A sparingly branching shrub, 4-6 ft. high, glabrous, excepting some tufts in the upper axils. Leaves opposite or seattering, thin chartaceous, indistinctly veined, glabrous but often pitted, pale underneath, brownish when dry, lanceolate or elliptico-oblong, $2-4^{1} / 2^{\prime} \times{ }^{1 / 2}-1^{1} / 2^{\prime}$, on petioles of $2-3^{\prime \prime}$, acute at both ends. Flowers on pedicels of $1^{\prime \prime}$, numerous in close heads on a short peduncle of $1-2^{\prime \prime}$, the deflorate rhachis glabrous and scarcely lengthened when with fruit. Perianth silky, $4^{\prime \prime}$, the lobes $1 / 3$ the length of the tube, which splits laterally. Ovary sericeous at the top, with a short style and thick stigma. Scales narrow lanceolate, shorter than the ovary. Drupe elongate, $5-6^{\prime \prime}$, pointed at both ends. - Wawra, in Flora, 1875, p. 184.

In the lower woods of Kauai, Lanai! Maui! (the spikes elongating to about $3^{*}$ ).

Hillebrand, Flora of the Hawaiian Islands. 
$\beta$ var. recurva. - Leaves as before, but smooth and glossy. Spikes on peduncles of $3-10^{\prime \prime}$, much lengthening with growth and strongly recurved, the slender almost filiform and glabrous rhachis often attaining a length of $2^{1 / 2}$ inches, covered with persistent pedicels, but the flowers confined to the apex. Perianth glauco-pruinose, slender, 6 "long, the lobes $1 / 3$ the length of the tube. Lower stamens at the middle of the tube.

Oahu! woods of Kahuku and Halemano.

$\gamma$ var. - Here seems also to belong W. Hanalei, Wawra, l. e. p. 185. - Erect, dichotomous, sparingly branching. Leaves membranous, oblonglanceolate, sharply acuminate, narrowing at the base, glabrous, over $6^{4}$ long and $2^{1 / 2}-3^{\prime}$ broad. Spikes between the forks of the branches, very short, glabrous, on peduncles of nearly $1^{\prime}$ in length and recurved in fruit. Pedicels very short. Berries ovoid, larger than a pea, numerous in a globose cluster. Seeds obovoid.

Kauai, Hanalei (Wawra).

3. W. Sandwicensis, Meisn. in DC. Prod. XIV, 545. - A glabrous shrub, 6-8 ft. high. Leaves dark-green, glabrous, often pitted, chartaceous and faintly nerved, ovate or ovate-oblong, $2-4^{4} \times 1-1^{3} / 4^{4}$, on petioles of $3-4^{\prime \prime}$, acute or somewhat obtuse, rounded at the base, sometimes subcordate. Adult spikes $2-15^{\prime \prime}$ long, on peduncles of $1-3$ ", suberect, densely flowered near the apex, the rhachis thick squarrose and tomentose, sometimes dichotomously forking. Perianth on a short pedicel of $1 / 2^{\prime \prime}$, silky-tomentose, $2^{1 / 2}-3^{\prime \prime}$ long, the lobes somewhat obtuse, $1 / 3-1 / 2$ the length of the tube. Scales 4, linear, free, as long as the ovary. Drupe ovoid, $4-5^{\prime \prime}$. - W. foetida, var. glauca, Wawra? - Gray, 1. c.

Hawaii! Hilo and Konq; Maui! Oahu!

$\beta$ var. furcata. - Leaves large, somewhat obtuse, subcordate. Spike $2-3$ in length, repeatedly forking (3-5 times). Perianth $4-5^{\prime \prime}$. Apex of ovary silky-pubescent, as well as the short style and thick stigma. Scales setaceous.

Kauai! Waimea (Kn.).

4. W. villosa, $s p . n$. - A tall shrub with the young branches velvetytomentose, almost villous, as is also the inflorescence. Leaves dark-green, thick chartaceous, with prominent nerves, thinly pubescent on the upper face, gray-tomentose underneath, almost villous along the rib and nerves, elliptico-oblong, $3-4^{\prime} \times 1^{1 / 2}-2^{\prime}$, on petioles of $3-5^{\prime \prime}$, equally acuminate at both ends. Spike thick squarrose, deflected, $1^{\prime}$ ' or more long when full grown, on a peduncle of $1-2^{\prime \prime}$, densely flowering along its entire length, often forking. Perianth on a pedicel of $1 / 2-1$ ", subcoriaceous, villous, $4-5^{\prime \prime}$, with the lobes $1 / 3$ the length of the tube, which is fusiform and splits laterally at an early period. Lower stamens in the upper third of the tube. Scales much shorter than the ovary, lanceolate, connate 
below. Style $1 / 2$ as long as the ovary, which reaches the middle of the tube and is hairy at the apex. Drupe obovoid, $5-6 "$.

W. Ma ui! on ridges near Wailuku.

5. W. bicornuta, sp. $n$. - A tall shrub or small tree with short and stiff branches, the youngest fusco-tomentose, tufted in the uppermost axils. Leaves dark-green, thick chartaceous, faintly pubescent underneath along the prominent nerves, obovate- or ovate-oblong, obtuse at either end, $2^{1 / 2}-3^{1} / 2^{\prime} \times 1^{1 / 2}-2^{1} / 4^{\prime}$, on petioles of $4-6^{\prime \prime}$. Flowers clustered at the end of a short $(1-2 ")$ and thick peduncle, the subglabrate and rather thin rhachis not lengthening perceptibly; the pedicels $1-1^{1 / 2}$ ". Perianth $5-6^{\prime \prime}$, with lobes $1 / 3$ the length of the tube, faintly pubescent, finally breaking away from the base. Lower stamens in the upper third of the tube. Scales 2 or 3 , oblong, as long as the ovary, 1 or 2 of them bifid. Ovary pubescent above, clavate, generally bifid at the apex, each division bearing a subsessile capitate stigma, but one generally rudimentary. Drupe ovoid, 6", orange-colored, with a smooth chartaceous putamen. Seed pendulous from a short funis, with a thin integument, exalbuminous, the superior radicle short and terete, the thick cotyledons plano-convex, amygdaloid.

Highest ridge of Lan ai! - The singular appearance of the ovary probably indicates a tendency to, or an ataval remnant of a 2-celled state, as it exists in the Suborder Aquilarieae of the present Order. It is however far from uniform; sometimes only one of the two horns bears a full-sized stigma, at others the second division, being much more slender, rises from lower down, and in one instance there seemed to be a third one. Not having examined fresh flowers, I am unable to state whether the ovary in its earliest stages is really partitioned. The fruit exhibits an undivided apex with a lateral scar in place of the second pistil.

6. W. uva ursi, Gray, l. c. p. 304 . - Low, scraggy, 2-4 ft. high, ferrugino tomentose, tufted in the upper axils. Leaves crowded, broad obovate or ovate or suborbicular, $1 / 2-1^{1} / 2^{\prime} \times 1 / 3-1^{\prime}$, on petioles of $1^{\prime \prime}$, obtuse, even retuse, glabrous, coriaceous, brownish when dry, with obscure veins. Flowers in a subsessile terminal cluster, at last lengthening into a short spike of $3-5$ " with a moderately thick tomentose rhachis. Perianth $3-4$ ", more or less puberulous, the obtuse lobes nearly $1 / 2$ the length of the tube. Lower stamens at the middle of the tube. Scales (two 2 -cleft according to Gray) linear, much shorter than the ovary, which is almost glabrous and sometimes presents one or more knobby prominences at the apex. Style short; stigma globose. Drupe globose, about $3^{\prime \prime}$ in diam.

On dry forehills of the leeward sides: Kauai, Koloa (Remy, M. \& B.); Oahu, near Honolutu (U. S. E. E.); Molokai! Kalae and Halawa.

$\beta$ var. buxifolia. - Leaves as before. Lobes of perianth somewhat acute, the two inner much smaller than the outer ones. Style long, with small stigma. Ovary knobby at the apex, as before. - W. buxifolia, Gray, 1. c.

Hawail, Puna, near the coast (U. S. E. E.). 
7. W. phillyreaefolia, Gray, l. c. - A low densely branching shrub, 2-4 ft. high, glabrous throughout. Leaves crowded, small, oblong-lanceolate or spathulate, ${ }^{3} /_{4}-1^{\prime} \times 3-5^{\prime \prime}$, bluntly acuminate, gradually narrowing at the base to a short petiole, coriaceous, glabrous, pale brownish when dry. Flowers dimorphous, glabrous, bright yellow, clustered on short terminal peduncles of $1^{1 / 2}-2^{\prime \prime}$ which often appear lateral at a later period, the rhachis not lengthening, glabrate. Sterile perianth $5-6^{\prime \prime}$, slender; the anthers oblong, with the lower circle at the middle; ovary rudimentary, the rather long style without stigma. Fertile perianth $3^{1 / 2}-4^{\prime \prime}$, turgid; the lobes $1 / 2$ the length of the tube, the outer ones much the largest. Anthers small ovoid. Ovary glabrous, ovoid, with short style and large globose stigma. Scales linear, much shorter than the ovary. Drupe globose, $2-3^{\prime \prime}$ in diameter, bright yellow, the perianth breaking away from the base.

Hawaii! Central plateau and the adjoining high mountains from $4000-7000 \mathrm{ft}$. Only the var, $\beta$ of Gray belongs here, the form $\alpha$, "fol. viridibus majoribus ovato-oblongis", being a small-leaved form of $W$. Sandwicensis. The dimorphism, well established in this species, is likely to prevail also in others, notably in $W$. elongata and $W$. uva ursi, and to be associated with a difference in the inflorescence; however this may be, only the specimens with contracted spikes exhibit fruit.

\section{ORDER LXXV. SANTALACEAE.}

Tube of perigone wholly or in part adnate, the limb 3-5-lobed, valvate in the bud. Stamens as many as lobes and opposite to them, inserted at their bases or within the free part of the tube. Anthers 2-celled, opening lengthwise. Ovary wholly or in part adnate, 1-celled, with $3-5$ ovules suspended from the apex of a free central placenta. Fruit an indehiscent nut or berry, with a single seed which is destitute of a proper seed-coat. Albumen fleshy. Embryo straight, with a superior radicle. - Herbs, shrubs or trees, with entire leaves, without stipules. Flowers usually small, greenish or dusky-red or yellow.

An Order spread over the temperate regions of the whole world and the tropies of Australasia and Polynesia.

Leaves all perfect, explanate. Drupe connate with the perigonial tube.

Leaves mostly rudimentary, dentiform or linear. Drupe connate at the base only

1. Santalum.

2. Exocarpus.

\section{SANTALUM, L.}

Tube of perigone at first free, but finally connate with the ovary, the limb 4-, rarely 5-lobed, each lobe with a tuft of hairs at its base. Disk investing the tube and running out into lobules which alternate with the lobes of the perigone. Stamens 4 (5), inserted at the base of the lobes. Ovules 2, pendulous, anatropous. Style simple; stigma 2-4-cleft. Drupe 1-seeded, marked at the apex with the scars of the fallen lobes. Embryo 
at the apex of the albumen, - Trees or shrubs, with opposite, rarely alternate leaves. Flowers in terminal and axillary cymes.

The Sandaltrees, about 16 species, inhabit Polynesia with New Zealand and Juan Fernandez, Australia and tropical Asia.

The Sandalwood has played an important part in the early history of the Hawaiian kingdom, as it was the first article of export which attracted commerce to the islands and furnished a revenue to the rising government. In consequence the trees soon became so searce that it was deemed expedient to lay a tabu on the few remaining ones. Since then a good many have sprung up again in various localities, but nowhere in sufficient numbers to warrant a revival of the trade, which fortunately has also become less luerative.

The following speeies are weakly defined, and all furnish an equally fragrant wood, called "laan ala", while the name of the tree is Iliahis, of which the root recurs in the Tahitian Eai and probably also in the Vitian "Yasi*. The maori name in N. Zealand, - Mairi ", is evidently a transfer from the likewise fragrant Alyxia, which has no representative in that island. Our trees are probably parasites, as is the Indiun $S$. album; at least all attempts to cultivate them in my garden have resulted in failure.

\section{Inflorescence axillary and terminal:}

Disk-lobes short rounded; drupes smooth .

Disk-lobes narrow ligulate, as long as the filaments; drupe larger

1. S. Freycinetianum.

\section{and rough}

The cymose panicles crowded into a terminal bracteate eorymb

2. S. pyrularium.

3. S. Haleakalae.

1. S. Freycinetianum, Gaud. Bot. Voy. Freyc. p. 442, tab. 45. - A tree, 15-25 ft. high. Leaves opposite, ovato-, elliptico-, or obovato-oblong, $2^{1 / 2}-3^{\prime} \times 1^{1 / 4}-1^{1 / 2^{\prime}}$, on short petioles of $1-2^{\prime \prime}$, somewhat obtuse at both ends, chartaceous, glabrate or slightly ochraceous underneath. Cymes paniculate, $1^{1 / 2}-2^{\prime}$ long, terminal and in the axils of the uppermost leaves, the flowers almost sessile in elusters of 3-9. Bracts short deciduous. Perigone dull-red, campanulate, $3^{\prime \prime}$, the rather acutely ovate lobes as long as the tube or longer. Disk-lobes short and broad, almost emarginate. Tufts of hair scanty and short. Anthers longer than the filaments, included. Style little shorter than the perigone, shortly $3-4$-cleft, the lobes capitellate. Drupe ovoid, 5" long, with a glaucous bloom when young and a truncate apex; the putamen smooth. - DC. Prod. XIV, 682. - Gray, in Proc. Am. Ac. IV, 326.

In forests of Hawail Maui! Lanai! Molokai!

$\beta$ var. latifolium, Gray, l. c. - Leaves coriaceons, pale glancous underneath, tomentulose when young, and broader, $3^{\prime \prime} \times 2^{\prime}$, generally rounded at the top and contracting at the base. Panicles numerous in the upper axils and terminal. Perigone larger, $4^{1 / 2} 2^{\mu}$. S. paniculatum, Hook, \& Arn. in Bot. Beech. p. 94.

Hawaii! on Hualalai and from Kilatea upwards on Mauna Loa; a mountain form, about $12 \mathrm{ft}$. high. Similar forms with mostly axillary inflorescence oceur in the lower scrub of Maui, on Kaboolawe (Remy), and above Halawa, Molokait

$\gamma$ var. cuneatum. -- Leaves thick as before, but smaller, suborbicular, with cuneate base. Perigone small, 3 " and less, pale.

In the scrub of Lanail 
o var. ellipticum. - Size of $\alpha$, the branches rather slender. Leaves thin chartaceous, ovato- or elliptico-oblong, $2^{1 / 2}-3^{\prime} \times{ }^{3} / 4-1^{1} / 4^{\prime}$, on petioles of 6-9", acuminate, glabrous. Panicles in the axils of the upper leaves, but generally the axis of the branch prolonged beyond, rather loose, the flowers on distinet pedicels of $1^{\prime \prime}$. Perigone $4--5^{\prime \prime}$, its lobes somewhat acute, as long as the tube or longer, with long tufts of hair. - Gray, 1. c. - S. ellipticum, Gaud. 1. c. and DC. Prod. 1. c. - Mrs. Sinclair, pl, 34.

The common form on $\mathrm{Oah} \mathrm{u}$ ! where it seems to be confined to the forests of the western division; Ka uai.

\& var. littorale. - A low and stiff shrub, not exceeding $4 \mathrm{ft}$. in height. Leaves small elliptico-oblong, acute or somewhat obtuse, coriaceous, dull and pale. Flowers axillary and terminal, very small, $1 \frac{1 / 2}{2} 2^{\prime \prime}$, distinctly pedicellate, brick-red, the short perigonial tube and young fruit glaucous. Drupe globose, $3-3^{1} / 2^{\prime \prime}$.

Oahu! Cape Kaena and Kailua, near the seashore.

2. S. pyrularium, Gray, l. c. - A tree. Leaves as in var. $\delta$ of no. 1 , but rather glaucous underneath. Panieles axillary, loose, the flowers on pedicels of $1^{1 / 2} 2^{\prime \prime}$. Perigone dull-red, rather cylindrical, 5-6", the lobes as long as the tube or shorter. Anthers as long as their filaments, the cells diverging at base and apex. Hair-tufts long. Disk-lobes narrow ligulate, as long as the filaments. Style nearly as long as the perigone, 3 -cleft. Drupe large obovoid, $8-12^{\prime \prime}$ long, with a conical apex, the putamen rough, runcinate.

Forests of Kauai!

3. S. Haleakalae, Hillebr. - A dense shrub, 6-10 ft. high, with stiff erect branches. Leaves coriaceous, ovate- or obovate-oblong, $1^{1 / 2}-2^{\prime} X$ $1-1^{1 / 4^{\prime}}$, on petioles of $2-3^{\prime \prime}$, bluntly acuminate or obtuse. Panicles crowded near the end of each branch, their supporting leaves soon reduced to bracts, so as to constitute a terminal corymb of $1^{1 / 2}-2^{1 / 2^{\prime}}$ in length and as broad. Flowers subsessile, deep-red, the perigone $4-5^{\prime \prime}$, with the lobes as long as the tube or longer. Disk-lobes lanceolate, longer than the filaments. Anthers on short filaments, their cells diverging at base and apex. Style subexserted, 3 -cleft. Drupe ovoid, 6-8" long, truncate at the apex, the putamen smooth. - S. pyrularium, var. $\beta$. Gray, in mss. U. S. E. E.

Ma u i Haleakala, 8000-10000 ft.

\section{EXOCARPUS, Labill.}

Flowers hermaphrodite or polygamous. Perigone 5-4-parted. Stamens $5-4$, inserted at the base of the lobes, the filaments short ligulate, the anther-cells often again 2 -celled. Ovary superior or partly adnate, fleshy. Stigma almost sessile, capitate-lobate, Placentation unknown. Fruit a 
coriaceous ovoid nut supported by the partly adnate, thickened and fleshy tube of the perigone. Embryo minute, at the apex of fleshy albumen, the radicle much longer than the small connate cotyledons. - Shrubs or small trees, with jointed branches, the ultimate ones sometimes flattened in the manner of phyllodia. Leaves alternate, either all minute dentiform or some large foliaceous, palmately nerved, entire. Flowers minute, subsessile in axillary spikes, the bracts caducous.

About 20 species, natives of Australia, New Guinea, the Moluccas, Philipines, Norfolk Island, New Zealand and the Hawaiian Islands.

Leaves dentiform, rarely with a few small flat ones; spikes elongate, $3-6^{\prime \prime}$ long

1. E. Gaudichaudii.

Leaves of two kinds, some large expanded; spikes short elavate, about 2 "long .

2. E. brachystachys.

1. E. Gaudichaudii, A. DC. in Prod. XIV, 690. - A much branching shrub with stiff striate short branches, the ultimate ones triquetrous. Leaves minute, tooth or scale-like, triquetrous, $1 / 4-1 / 2^{11}$ long, rarely interspersed with a few flat oblanceolate ones which are 1-3-nerved and measure only $3-6^{\prime \prime}$. Spikelets $3-8^{\prime \prime}$ long, rather distantly $5-9$-flowered, with some empty dentiform bracts below. Perigone reddish, about $1 / 2^{\prime \prime}$, the short tube adnate to the ovary, the limb about twice as long and 5-, rarely 4-parted, persistent. Stamens 5 (4), shorter than the lobes, the anthers 2-celled, as long as the filaments, and the cells again biloculate. Nut ovoid, $3^{\prime \prime}$, the base immersed in the enlarged fleshy and reddish tube of the perigone, which shows distinctly the unaltered now dentiform lobes. - Gray, in mss. U. S. E. E., var, a. - E. cupressiformis, Hook. \& Arn. in Bot. Beech. p. 95. (not Brown).

High mountains of Hawai1! Hualatai and Mauna Loa; Lanai! Molokai!

2. E. brachystachys, Hillebr. - Arborescent with elongate eminently striate branches, the ultimate branchlets flat.. Leaves distant, of two kinds, the smaller ones ${ }^{1} / 2-2^{\mu}$, dentiform, subulate to flat-linear, the larger ovate or elliptical, $1^{1} / 2-2^{\prime}$ long, subsessile, 5-9-nerved. Spikelets only $2^{\prime \prime}$ long, closely $3-5$-flowered at the apex. Perigone greenish, very small. Anthers almost sessile. Nut obovoid, $6^{\prime \prime}$, the fleshy perigone at its base Jarge and truneate. - E. Gaudichaudii, var. foliosa, Gray, l. c. - Wawra, in Flora, 1875.

On mountain ridges of Oahu! and Molokai! between 2000 and $4000 \mathrm{ft}$. Nat. name: "Heau. - Expanded leaves occur chiefly on sterile branches, sometimes to the exclusion of the smaller ones.

\section{ORDER LXXVI. LORANTHACEAE.}

Calyx-tube adnate, the limb of $2-5$ valvate lobes, coherent at the base. Petals none. Stamens as many as calycine lobes, opposite to and usually inserted on them, 1-2-celled. Ovary inferior, 1-celled, with 1 
(2 or 3) erect orthotropous ovules, usually not perceptible till the flower is past. Style or stigma simple. Fruit a berry with a glutinous endocarp. Seed with copious fleshy albumen, enclosing a straight axile embryo with a superior radicle. - Shrubs, usually much branched, parasitical on trees. Leaves opposite or rarely alternate, thick leathery, or wanting. Bracts under each flower, usually connate in a little cup which often has the appearance of an external ealyx.

A chiefly tropical Order of both Worlds, with a few genera; represented in Polynesia by Loranthus and Viscum.

\section{VISCUM, L.}

Flowers unisexual, monoecious or dioecious. Calyx-lobes $3-5$, very short. Male $\mathrm{fl}$. Anthers sessile on the inside of the calyx-lobes and opening inward with several pores. Fem. $f$. Calyx entirely adnate or with a minute annular border. Ovules 1(-3). Stigma sessile. Seed solitary, erect. - Branches dichotomous. Leaves opposite or none. Flowers at the nodes, very small, green or yellowish.

A genus of few species, confined to the old World.

1. V. articulatum, Burm. - DC. Prod. IV, 284. - A much branched parasite, forming tufts of $1-2 \mathrm{ft}$, in diameter. Branches leafless, flattened, rarely terete, often branching at every node, articulate, the joints thick and somewhat fleshy, 3-12" long and $1-10^{\prime \prime}$ broad, mostly broader at the top than at the base. Flowers monoecious, minute, sessile, clustered at the nodes, the female scarcely ${ }^{1} / 2^{\prime \prime}$ long, nearly globular and half buried in the cup-shaped entire bract; the male still smaller, usually with 3 sepals and anthers. - Benth. Fl. Hongk. p. 141. - V. monitiforme, Bl. - Wawra, in Flora, 1873, p. 139.

Not uncommon on a variety of trees. The species is widely spread oter Polynesia and southern Asia.

c. - Joints all flat, broader at the top, 1 -ribbed, $3-1^{1 / 2} "$ in width, the lowest often $6^{\prime \prime}$ wide and $2-3$-ribbed. Flowers many on cushion-like receptacles.

The most common form; grows on the "Koas, "Lehue", "Kukui and other trees.

$\beta$. - Joints $8-10^{\prime \prime}$ broad, quite flat, with 3 prominent ribs, scarcely contracted at the joints. Berries quite prominent.

On Antidesma platyphyllum, Ka uai! Oahu!

\%. - Joints $1-2^{\prime \prime}$ broad, with a single longitudinal streak, the lowest terete. Flowers few. - V. monitiforme, Bl.?

On Elacocarpus bifidus. Kauail (Kn.),

oे var. salicornioides. - Joints all terete, $1^{\prime \prime}$ in diameter, not narrowing above, the 2 clusters of flowers approximate, almost whorled. - Perhaps a distinct species.

On Maba Sandwicensis. Moloka i! Halawa. 


\section{Order LXXVII. EUPHORBIACEAE.}

Flowers unisexual, either without a perianth in one or both sexes, or more frequently with a simple calyx-like perianth, or sometimes also with 4 or 5 petals alternating with the calyx-lobes. Stamens various. Ovary consisting of 3 , sometimes of 2 , or more than 3 united 1 -celled or rarely 2-celled carpels, each with 1 or 2 pendulous ovules. Styles as many as carpels, free or more or less united, entire or divided, the stigmatic surface usually lining the inner face. Fruit either capsular, separating into as many elastically 2-valved cocci as carpels, leaving a persistent axis, or succulent and indehiscent, the endocarp consisting of as many indehiscent nuts or cocci as carpels. Seed laterally attached at or above the middle, with or without an arillus. Embryo straight, with flat cotyledons and a superior radicle, in a fleshy albumen, or very rarely the cotyledons fleshy, and little or no albumen. - Trees, shrubs or herbs, often abounding in acrid milky juice. Leaves alternate or opposite, rarely divided or compound, usually with stipules. Inflorescence very varied. Flowers usually small.

A very large Order, most abundant in the tropies, gradually diminishing in numbers in more temperate regions, and very few ascending into alpine or cold elimates.

Tribe I. Euphorbieae. Involucre calyx-like, ineluding several male flowers (single stamens on staminophores) and 1 central female flower (a pistil on a gynophore), without any perianth, forming a flower-head which resembles a single flower

\section{Euphorbia.}

Tribe II. Crotoneae. Male and female flowers within separate bracts in the same spike, or in different spikes or plants, mostly with a perianth. Ovary-cells 1-ovulate:

Perianth ealyx-like; petals none:

Filaments simple

Filaments branched

Calyx and corolla present:

Calyx 2-3-cleft, valvate; stamens 15 or more + + . 4. Aleurites.

Calyx 5-cleft, imbricate; stamens $8-10 . \quad$. . 5. Jatropha.

Tribe III. Phyllanthece. Male and female flowers separate. Ovarycells 2-ovulate:

Flowers in axillary clusters; ovary 3-celled . . . . . 6 Phyllanthus.

Flowers in axillary spikes, racemes or panicles; ovary 1-celled 7 . Antidesma.

To this Order belong also the following eultivated plants besides those mentioned under their respective genera below : Manihot utilissima, Pohl, the Tapioea plant, Stillingia sebifera, Michx, the, Japanese Wax-tree, Siphonia elastica, Pers, one of the American Indiarubber trees. - Codiaeum Moluccaneum, Desne., in several varieties is a favorite garden shrub on account of its variegated leaves. Hura crepitans, L., the West Indian Sandbox tree, is also met with in a few places, and perhaps Acalypha Indica, L., an Indian weed, ought to be mentioned, which had appeared as a weed in gardens and may possibly have become naturalized.

\section{EUPHORBIA, L.}

Flower-heads resembling a single flower. Involucre calyx-like, cupshaped, with 4 or 5 minute lobes alternating with as many horizontal glands, which are sometimes expanded into petal-like appendages. Within are $10-25$ male flowers, consisting each of a single staminophore, which 
is articulate with a short filament bearing a 2 -celled anther, and a single female flower in the centre, reduced to a stipitate 3 -celled ovary protruding from the involucre, with 1 pendulous ovule in each cell. Style 3-cleft, the branches (or distinct styles) entire or 2-lobed. Capsule separating into 3 two-valved cocci. - Herbs or shrubs, abounding in milky juice. Stem-leaves alternate without stipules, the flowering branches umbellate, dichotomous, with usually opposite leaves; or all the leaves opposite and often stipellate, with the flowers in axillary cymes; or succulent leafless shrubs,

A very large genus, dispersed over nearly the whole world.

\section{Stipules present:}

Stipules of each side connate in one triangular interpetiolar one; leaves all opposite and distichons; inflorescence axillary; invol. glands entire, those of no. 7 often appendiculate; seed without caruncle; shrubs or trees:

Leaves large, $2-6^{\prime}$ long, the veins nearly at right angles to the rib : Cyme open developed; seeds smooth; veins effaced

1. E. clusiaefolia.

2. E. Remyi. Leaves smaller, $2^{\prime}$ or less; veins oblique to the rib: Leaves linear, oblong or spathulate: Inflorescence a developed open cyme.

3. E. celastroides.

Flower-heads subsessile, single or rarely 2 or 3 together 4 . E. lorifolia.

Leaves obovate, entire

Leaves ovate, crenate or rarely entire

Leaves orbicular, cordate, sessile

5. E. multiformis.

6. E. Hookeri.

7. E. cordata.

Stipules not connate; leaves opposite; flowers axillary

Stipules none; lower leaves scattering; inflorescence terminal. Seed earunculate

8. E. pilulifera.

9. E. Peplus.

\section{A. Anisophyllum.}

1. E. clusiaefolia, Hook. \& Arn. in Bot. Beech. p. 95. - An erect shrub, $3-6 \mathrm{ft}$. high, with thick stiff branches, quite glabrous. Leaves opposite, obovate- or elliptico-oblong, $2^{1 / 2}-4^{\prime} \times 1-1^{1} / 2^{\prime}$, on petioles of $1^{\prime \prime}$, obtuse, even rounded, and often retuse, entire, with revolute margins, moderately contracted at the base and often uneven-sided, subcoriaceous, opaque, with the evanescent veins nearly at right angles, quite smooth. Interpetiolar stipule obtusely triangular, $1^{1 / 2} / 2^{\prime \prime}$ high or less. Cymes axillary, ${ }^{1}{ }_{2}-2$ ' long, once or repeatedly di- or trichotomous, rarely bearing only a single head, the pedicels stiff, $4-6^{\prime \prime}$ in length. Invol. campanulate,

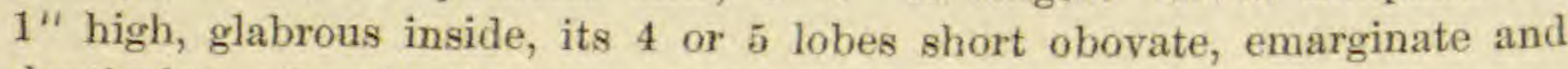
denticulate, the glands transversely oblong, not appendiculate. Stamens numerous, each supported by a cuneate bractlet which is split into linear lobes and fimbriate. Capsule smooth, long-stalked, nodding, 3 "long, the cocci slightly sulcate on each side of the obtuse keel. Seeds smooth. Boissier, in DC. Prod. XV, Sect. II, p. 11, and Ic. Euphorb. tab. 1. Wawra, in Flora, 1875 , p. 145. - Anisophyllum nodosum, Kl. \& Garcke.

Main range of $\mathrm{Oahu}$ ! not uncommon. 
$\beta$ var. grandifolia. - Leaves $6-7^{\prime} \times 1-1^{1} / 2^{\prime}$, very uneven-sided at the base, thin chartaceous, the veins underneath scarcely visible.

Oahu! Makaleha in the Kaala range.

2. E. Remyi, Gray, in Mann's Enum. no. 438. - A glabrous shrub, taller than in no, 1, inclining to be simple-stemmed, arborescent. Leaves opposite, elliptico- or obovato-oblong, 3-6 $31-3^{\prime}$, on petioles of $6^{\prime \prime}$, somewhat obtuse or shortly acuminate, entire, moderately contracted at the base, even- or uneven-sided, thin chartaceous, the veins distinct on both faces, nearly perpendicular, Lateral stipules triangular, $1^{1 / 2}-4^{\prime \prime}$. Flowers numerous in contracted cymes which do not exceed $6^{\prime \prime}$ in length, often densely glomerate, the pedicels $2^{\prime \prime}$. Bracts $2^{\prime \prime}$. Invol. campanulate, glabrous outside, pubescent inside opposite the transversely oblong glands and along the 5 prominent ridges leading to them, its lobes minute, lanceolate-obtuse. Bractlets less deeply slit than in no. 1, the outer ones almost entire. Style-branches short, almost free, thickened at the apex. Capsules on long stalks, nodding, smooth, trigonous, $2-3^{\prime \prime}$, the angles obtuse. Seeds scrobiculate-rugose. - Wawra, l. c. p. 146.

Ka uai! Hanalei (Mann), Waimea (Wawra, Kn.); Oa hu (Remy). Mr. Knudsen collected two forms, one with smaller somewhat obtuse leaves which are subtruncate and unevensided at the base, with low $\left(1-1^{1 / 2^{\prime \prime}}\right)$ triangular stipules, the other with large and broad leaves, shortly acuminate, contracted at the base, the stipules $4^{\prime \prime}$ high.

3. E. celastroides, Boiss. in DC. Prod. XV, Sect. II, p. 11. - A shrub or small tree (?), the stiff branches nodose with short internodes, glabrous. Leaves rather glaucous, opposite, spathulate or obovate-oblong, $1-2^{1} / 2^{\prime} X$ $4-6^{\prime \prime}$, on petioles of $1-1^{1 / 2} 2^{\prime \prime}$, obtuse or rounded, entire, moderately narrowing toward the base, which is uneven-sided, truncate or subcordate, subcoriacenus, with the veins very oblique and little conspicuous. Stipules broadly triangular, $1^{1 / 2} 2^{\prime \prime}$. Cymes axillary, open as in E. clusiaefolia, with $1-5$ heads, the pedicels $3-6^{\prime \prime}$, the bracts scarious, broad, rounded, $1^{\prime \prime}$. Invol. $1-1^{1 / 2} / 2^{\prime \prime}$, its $4-5$ lobes narrow lanceolate, fimbriate, the glands suborbicular, pubescent on the inner side and along the nerves leading to them. Staminophores exserted; bractlets deeply slit. Styles very short, deeply bifid with capitate stigmas. Capsules erect on short stalks, less than $1^{1 /} 2^{\prime \prime}$, smooth, with rounded cocci. Seeds rugososcrobiculate. - E. multiformis, var. celastroides, Gray, in Mann's Enum. no. 439.

Kauai! (Remy and Kn.); Niihau (Remy); Oahu! Niu (Hbd.).

4. E. lorifolia, Hillebr. - A small tree, 10-20 ft. bigh in the upper regions, the trunk $6-8^{\prime}$ thick, shrubby in the lower regions, the stiff branches nodose with short internodes and puberulous. Leaves opposite, linear or oblong, $1-2^{\prime} \times 2-5^{\prime \prime}$, on petioles of $1^{\prime \prime}$, obtuse or truncate, often retuse at the apex, entire, slightly contracted and subtruncate at the 
uneven base, chartaceous, with distinct oblique dark veins. Stipules very low. Flower-heads terminal and axillary, generally single, subsessile on pedicels of less than ${ }^{1 / 2} /{ }^{\prime}$, supported by several short roundish bracts, rarely $2-4$ in a dense cluster. Invol. less than $1^{1 / 2} 2^{\prime}$, pubescent outside, glabrous within, with 4 suborbicular glands; the lobes obovate or quadrate, with ragged margins. Staminophores exserted; bracteoles 3--4-fid. Styles free to the base, very shortly bifid with clavate branches. Capsule erect on a short stalk, $1^{1 / 2}$ ", puberulous, obtuse at the angles. Seeds rugososcrobiculate. - E. multiformis, var. lorifolia, Gray, in Mann's Enum. no. 439 ; also the forma angustifolia of $E$. multiformis in DC. Prod. I. c, from Hawaii.

Hawail Mani! Lanai! Molokai! A tree at elevations of $2000-4000 \mathrm{ft}$; the form with narrow linear lenves from E. Maui. Perhaps the true E. multiformis (without description) of Gaudichaud, who during his first visit collected also on $\mathrm{H}$ a w a ii and Ma ui. The native name -Koko or -Akokos (blood), which is given to all Euphorbias on account of the milksap, applies principally to the present species. The same name recurs in Tahiti for the Euphorbias of that island. The tree is much used as firewood.

5. E. multiformis, Hook. \& Arn. l. c. (an Gaud?). - A glabrous shrub, $2-5 \mathrm{ft}$. high, with slender nodose branches, the internodes rather long. Leaves opposite, obovate or obovate-oblong, $9-18^{\prime \prime} \times 4-9^{\prime \prime}$, on petioles of $1^{\prime \prime}$, obtuse, rounded or retuse, entire, moderately narrowing at the base, thin chartaceous, pale underneath and papillose, the conspicuous veins oblique and purplish. Stipules very low, $1 / 2$ ", rounded. Flower-heads single, terminal and axillary, on pedicels of about $1^{\prime \prime}$. Invol. less than $1^{\prime \prime}$, glabrous, with 4 , rarely with 5 glands which are broader than high and pubescent on the inner side, the lobes broad triangular or ovate, fimbriate. Staminophores not exserted; bractlets short, finely slit and fimbriate. Styles very short, connate at the base, with rather slender branchlets. Capsule nodding on a long stalk, less than $1^{1} / 2^{\prime \prime}$, glabrous, the cocci slightly keeled. Seeds ovoid-tetragonous, transversely rugose and scrobiculate. - Boiss. in DC. Prod. 1. c. and Ic. Euphorb. tab. 2. - Gray, var. $\alpha$ and $\gamma$, in Mann's Enum. - Wawra, 1. c., var. tenuior.

Oahu! in the lower and middie regions, not uncommon.

\$ var: tomentella, Gray. - Young branches, leaves and involucres tomentulose. Plant low prostrate, with thick diverging branches, Leaves smaller, $6-12^{\prime \prime}$ long. -

Oahu! along the seashore in Kailua and elsewhere; M a ui.

6. E. Hookeri, Steud. Nomenct. I, 612. - A glabrous shrub, 3-5 ft. high, with slender subherbaceous elongate branches, the nodes scarcely thickened. Leaves opposite, ovate, $1^{1 / 2}-2^{\prime} \times{ }^{3} / 4-1^{\prime}$, on petioles of $1^{1 / 2^{\prime \prime}}$, somewhat acute, repando-crenate or crenato-serrulate, rounded at the base, sometimes subcordate, membranous, pale, polished underneath, with veins 
little conspicuous. Stipules triangular, low, ${ }^{1} / 2{ }^{\prime \prime}$. Flower-heads terminal and axillary, single on pedicels of $1 / 2-1 "$, or several in simple or compound cymes, the cyme-branches multi-bracteate with minute pairs of bractlets but bearing only $1-3$ flower-heads at their ends. Bractlets minute, rounded, searious. Invol. ${ }^{1 / 2}-1^{\prime \prime}$, glabrous, with 4 roundish glands which are puberulous inside; the lobes small triangular, entire. Staminophores not exserted; bractlets 2-3-fid. Capsule exserted, nodding, $1^{1 / 2}{ }^{\prime \prime}$, glabrous, the cocci slightly keeled. Styles free to the base, with short clavate branches. Seeds transversely rugose, - Boiss. in DC. Prod. 1. c. p. 12 . E. myrtifolia, Hook. \& Arn. (non L.).

Oahu! in forests. The cymes often attain a length of $1-2^{\prime}$ and sometimes, by alternate prevalence of a branch in successive divisions, produce a true cicinnus or eyma unipara.

$\beta$ var. integrifolia. - Leaves ovate, entire, sometimes contracted at the base. Flower heads mostly single, the invol, more pubescent inside of the glands and the lobes fimbriate. Styles connate at the base. Forms a transition to the larger-leaved forms of $E$. multiformis.

W. Maui! Lanai!

7. E. cordata, Meyen, Reise II, 150. - A low prostrate undershrub, 1-2 ft. high, with rather thick nodose and tortuous tomentose branches, the internodes short. Leaves opposite, subsessile, orbicular, $5-8^{\text {" }}$ in diameter, entire, cordate, fleshy, with inconspicuous nerves, glabrous, or slightly puberulous near the base only. Stipules quite low and obtuse, fringed. Flower-heads terminal and axillary, subsessile, single, rarely 2 or 3 together. Invol. campanulate, $1^{\prime \prime}$ or less, glabrous outside, pubescent at the throat within, with 4 small roundish substipitate glands which are sometimes (but by no means always) bordered with a narrow membranous appendage; the lobes triangular, fringed. Staminophores exserted; bractlets slit to the middle or deeper. Capsule $1^{\text {" }}$ or more, exserted, inclined, puberulous when young, the cocei slightly keeled. Styles free, suberect, with short thickened branches. Seeds oblong, 4-angled, white, scrobiculate. - Klotzsch, in Act. Nat. Cur. XIX, 412. - Boiss. in DC. Prod. 1. e. p. 13, and Ie. Euphorb. tab. 4.

Oahu! Diamond Hill, Kailua, Waimanalo, near the sea; Hawaii (Menzies).

† 8. E. pilulifera, L. - DC. Prod. l. c. $p$. 21. - A decumbent sparingly branched annual, $6-8^{\prime}$ long, more or less hirsute with fulvous hair. Leaves opposite, ovate-rhomboidal or ovate-lanceolate, $1-1^{1 / 2} \times 2^{4} \times 8^{\prime \prime}$, on petioles of $1^{\prime \prime}$, acute, serrulate, oblique and cuneate or truncate at the base. Stipules not connate, small linear. Flower-heads minute and numerous, crowded into lead-like axillary cymes on short peduncles. Invol, about ${ }^{1} / 2^{*}$, puberulous, glabrous within, with 4 small entire glands which are generally without appendages; lobes triangular, fimbriate. Capsule $3 / 4 "$, declinate, puberulous, the cocci keeled. Styles very short, 
bifid. Seeds reddish, ovoid, obtusely angled, transversely wrinkled. E. hirta, Hook. \& Arn. 1. c. - For other synonyms see DC. Prod. I. c,

A common weed in gardens and cultivated fields, probably of early introduction. The species is widely dispersed over most tropical regions.

Another allied and widely spread weed, E. thymifolia, $L$, diffuse, smaller and more slender, the opposite leaves only $2-4^{\prime \prime}$ long, has also appeared of late in gardens of Homolulu, with Chinese plants.

\section{B. Tithymalus.}

†9. E. Peplus, L. - DC. Prod. I. c. p. 141. - A glabrous erect annual, $1 / 2-1 \mathrm{ft}$. high, the stem dividing umbellately into 3 branches, each of which bifureates again. Leaves thin, $6-9^{\prime \prime}$ long, obovate, obtuse or retuse, entire, the lowest scattering and petiolate, the upper ones opposite, subsessile. Stipules none. Flower-heads in terminal, open, leafy cymes. Invol. small, with 4 or 5 semilunar 2 -horned glands, the lobes ovate, fimbriate. Capsule smooth, inclined. Seeds white, carunculate, hexagonal, the 2 inner faces with a depressed furrow, the 4 outer ones each with 2 or 4 pits. - E. helioscopia, Mann, Enum. no. 443.

H a waii! in the upper woods of Kona and on the Central Plateau. A common European weed which has found its way into N. America and various other countries.

Other intruders are $E$. heterophylla, L., which I collected many years ago in the upper parts of Nuиanu, Oahu, but have not met with since, and E. geniculata, Ortega, which showed itself in gardens of Honolulu before my departure. Both are glabrous annuals with dichotomous flowering branches, the lowest leaves alternate and the stipules gland-like. Invol. with a single stipitate gland and 5-7 fimbriate lobes. Seeds tubereulate, in $E$. heterophylla some of the tubercles running out into dilated crests. They are of the A meriean Section Poinsettia, to which belongs also the cultivated E. pulcherrima, Willd., conspicuous for the large scarlet or white floral leaves.

\section{ClaOXYLON, A. Juss.}

Flowers dioecious or rarely monoecious, in spikes or racemes. Perianth calyx-like, without petals. Male $f l$. Calyx of 3 or 4 segments, valvate in the bud. Stamens indefinite, central upon an elevated receptacle. Anther-cells distinct, connected only at the base, erect. No rudiment of ovary. Fem. fl. Calyx 3- (rarely 2-) lobed, with glands alternating with its lobes. Ovary 3 - or 2 -celled, with 1 ovule in each cell. Styles free to the base, entire, reflexed, plumose inside. Capsule not muricate, divided into 2 -valved cocci. - Trees or shrubs. Leaves alternate, undivided, stipulate. Spikes or racemes axillary; loose.

A considerable genus, spread over the tropical regions of the old World and Australia from the W. coast of Africa through Madagascar and Indo-Malaysia into Polynesia to the Hawaiian Islds.

1. C. Sandwicense, Mueller Argov. in Linnaea, XXXIV, 165, and in DC. Prod. XV, Sect. II, p. 780. - A small soft-wooded tree or shrub, 10---12 ft. high, with pale spreading branches, the youngest shoots tomentose but soon glabrate, Leaves obovate-oblong, $4-7^{\prime} \times 2-3$ ', on petioles of $1-2^{\prime}$, shortly acuminate or obtuse, crenato-serrate with callous uncinate teeth, 
contracted at the base, stiff membranous, lurid-green, scabro-papillose but glabrate. Stipules lanceolate, $2^{\prime \prime}$, caducous. Flowers monoecious, clustered in distant fascieles of $2-4$ and minutely bracteate along a simple rhachis of ${ }^{1 / 2}-2^{1} / 2^{\prime}$ in length; the terminal flower of the extreme or sometimes of several fascicles being female, sometimes only one or few female flowers (without male) at and near the end of a much shorter rhachis. Pedicels $2-6^{\prime \prime}$, those of the male flowers longest. Male $f$. Calyx $3^{\prime \prime}$, parted to the base into 3 (rarely 2 or 4 ) triangular lobes, tomentulose or glabrate. No disk or glands. Stamens numerous (about 200), with filaments very short and anther-cells ovate, dehiscing externally. Fem. $f$. Calyx $1-1^{1 / 2}{ }^{\prime \prime}$, silky, the ovate sepals overlapping at the base. Glands 3 , oblong, nearly equalling the sepals. Ovary tomentose or silky. Styles short, spreading. Capsule reddish, 3-coccous, $2^{1 / 2}$ " high and $3^{\prime \prime}$ broad, deeply furrowed, obtuse at the angles. Seeds globose, rugoso-scrobiculate. Embryo axile, the orbicular cotyledons nearly as broad as the fleshy albumen and twice as long as the radicle.

On all islands from $\mathrm{Hawaii}$ to $\mathrm{O}$ a hu! but rare on the latter island; rather common in parts of Maui! and Lanai!

$\beta$ var. tomentosa. - Leaves obovate, rounded at the top, cuneate at the base, tomentose underneath. Infl. sometimes paniculate, $2-3^{\prime}$ long. - Wawra, in Flora, 1875.

Ka uai! (Kn. and Wawra).

\section{RICINUS, L.}

Flowers moneecious in terminal raceme-like panicles, the upper ones female, the lower male. Calyx $3-5$-cleft, the lobes valvate. Petals and glands wanting. Male $f l$. Stamens very numerous; anthers crowded on branching filaments, the cells distinct, globose. Fem. fl. Ovary 3 -celled, with 1 ovule in each cell. Styles deeply 2 -cleft and plumose. Capsule mostly echinate, dividing into 2-valved cocei. Seeds carunculate. - A tall herb or shrub. Leaves alternate, peltate, palmately divided.

A single species.

†1. R. communis, L. - DC. Prod. XV, Sect. II, p. 101\%. - A glaucous and glabrous erect plant, 6-16 ft. high. Leaves large, with mostly 7 broadly lanceolate serrate lobes. Racemes or panicles $3-6^{\prime}$ long. Male sepals $4^{\prime \prime}$. Capsule $6-12^{\prime \prime}$.

The Castor-oil plant, of early introduction, is quite common in waste places. A native of western Asia or eastern Africa.

\section{ALEURITES, Forst.}

Flowers monoecious. Calyx tubular, irregularly 2-3-cleft, the lobes valvate. Petals 5, convolute in the bud, alternate with 5 glands or scales which in the male flowers are connected into an urceolate disk. Male fl. 
Stamens numerous on a conical receptacle, without rudiment of oyary, the anthers erect, adnate. Fem. $f$. Ovary wrapt in a villous coat which finally breaks at the top, $2-5$-celled, with 1 ovule in each cell. Styles $2-5$, deeply bifid into acute branches. Fruit fleshy-capsular, 1-seeded and indehiscent or splitting at the top into $2-4$ cocci. Seeds large subglobose, with a bony testa and a copious fatty albumen. Cotyledons broad orbicular, the radicle very short. - Trees. Leaves alternate on long petioles, biglandular at the base, entire or lobed, palmately 5-7-nerved at the base, penni-nerved above. Flowers in terminal eymose corymbs, the female few on thicker pedicels, terminating the lower branches. Down stellate.

A genus of 3 species, natives of Malaysia, Polynesia, the Philipines and Japan.

1. A. Moluccana, Willd. - DC. Prod. XV, Sect. II, p. 723. - A tall softwooded tree, $40-60 \mathrm{ft}$. high, with far-spreading branches, which are pale-tomentose at their ends. Leaves $6-8^{\prime}$ long, of variable shape, ovate or rhombeo-lanceolate, undivided or 3-5-7-lobed with triangular acuminate lobes, rounded, often cordate at the base, entire-margined or repando-dentate, pale, with the rib and nerves underneath tomentose. Corymb $4-6^{4}$ long, with subulate bracts, the pedicels longer than the calyx. Male calyx $1^{1} / 2^{\prime \prime}$, ovoid in the bud; female calyx $3^{\prime \prime}$. Petals white, somewhat longer than the calyx, oblanceolate in the male fl. and bearded at the base, linear-oblong in the fem. $\mathrm{fl}$. Stamens about 18, the filaments hispid, the anthers erect introrse. Ovary hairy, 2-celled. Fruit fleshy-coriaceous, globose, about $2^{\prime}$ in diam., with 4 shallow furrows. Seeds 1 or 2, rugose-gibbous. - Jatropha Moluccana, L. - A. triloba, Forst.

Common on all islands, being the most prevailing tree in the woods of the lower zone, recognizable from afar by the pale hue of its foliage. It is widely spread over tropical Polynesia and a great part of Malaysia and the Philipine Islands, and all branches of the Polynesian race call it by the same name, sKukui» or *Tutuis. The nuts, strung together on stieks, served the natives for eandles to light their houses, whence the English name Candle-nut tree. The gum, "pilalis, which it exudes, seems also to have been in use. Of the acrid juice contained in the fleshy covering of the fruit they prepared a black dye which likewise served to tattoo their skins. The expressed oil of the nuts, besides being useful for burning in lamps, makes a good paint-oil, but is rather slow to dry.

\section{JATROPHA, L.}

Flowers monoecious, in terminal cymose panicles. Calyx 5-cleft, imbricate in the bud. Petals 5, free or united, convolute in the bud, or none. Disk of 5 free or united glands. Male $\mathrm{fl}$. Stamens 8 or 10 , shortly united at the base, the 3 or 5 inner ones longest. Fem. fl. Ovary 3-celled, with 1 ovule in each cell. Styles 2 -lobed. Capsule dividing into 2-valved cocci. Seeds carunculate, - Trees, shrubs or herbs, with alternate entire or palmately lobed leaves.

A considerable genus of tropical America, with a few species African or generally naturalized in tropieal Africa and Asia. 
†1. J. Curcas, L. - DC. Prod. XV, Sect. II, p. 1080. - A shrub or small tree, glabrous, with a milky juice. Leaves on long stalks, broadly cordate or peltate, $3-5^{\prime}$ long and broad, angular or obtusely lobed. Cyme shorter than the leaves, with numerous small yellow flowers. Calyx deeply 5-lobed. Petals united at the base. Stamens 10, the 5 inner united into a column. Capsule ovoid, about 1' long. - Benth. in Fl. Hongk. p. 309.

Occasionally found near settlements. A native of America, but naturalized in many parts of India. The oil of the seeds is very drastic, causing violent purging and vomiting; the eating of a few nuts will produce symptoms of poisoning.

\section{PHYLLANTHUS, L.}

Flowers monoecious or rarely dioecious, in axillary clusters or solitary. Segments of perianth or calyx $6(-9)$, or rarely 5 or 4 in the male flowers, imbricate in the bud, in one or two rows. Disk extrastaminal, prominent and entire, or lobed, or consisting of small distinct glands, or wanting. Male $f l$. Stamens 3, rarely 2-15, united into a central column or free. Fem. fl. Ovary 3-, rarely 2-15-celled, with 2 ovules in each cell. Styles free, or united at the base, more or less 2 -lobed. Capsule separating into 2 -valved cocei or loculicidally dehiscent. - Herbs, shrubs or trees. Leaves alternate, entire, usually small and distichous, giving the smaller branches the appearance of pinnate leaves, in some American species entirely wanting. Stipules small, usually persistent. Flowers small.

A very large genus, copiously diffused over the tropical and subtropical regions of both Worlds.

Flowers dioeeions; stamens free

Flowers monoeeious; stamens united

1. P. Sandwicensis.

2. P. Niruri.

1. P. Sandwicensis, Mueller Argov. in DC. Prod. XV, Sect. II, p, 389. A low, glabrous, often prostrate shrub, $1-3 \mathrm{ft}$. high, with the leaf-bearing branches compressed, two-edged, margined or winged. Leaves distichous, the lowest ones generally smaller, ovate or lanceolate, of very variable size, ${ }^{1 / 2}-3^{1} / 2^{4} \times 3-15^{\prime \prime}$, on petioles of $1^{\prime \prime}$ or less, acute, slightly contracted or rounded at the base. Stipules small, $1 / 2-1^{\prime \prime}$, cordate. Flowers dioecious. Male $f l$. numerous on axillary cushions, their pedicels $1-2 "$. Calyx reddish, rotate, $1^{1 / 2}-2^{\prime \prime}$ in diameter, deeply parted into 6 lanceolate lobes. Disk of 6 free quadrangular glands. Stamens 3, free. Fem. $f$. few or solitary on pedicels of $2-5^{\prime \prime}$, the calyx $2-3^{\prime \prime}$ in diameter, with 6 linear-oblong lobes. Disk annular crenate. Capsule globose depressed, $1^{1} / 2^{\prime \prime}$ in diam. Styles free, spreading, deeply bifid, the branches somewhat acute. Seeds trigonal, smooth at the convex back. - P. distichus, Hook. \& Arn. in Bot. Beech. p. 95. (non L.).

On all islands. In dry loealities the leaves are much crowded and small. Nat. name: -Pamakani - - The stipules are minute and low, glandlike, sometimes cordate and apiculate, sometimes horseshoe-shaped, often with one shank longer, resembling an athyroid indusium.

Hillebrand, Flora of the Hawaiian Islands. 
$\beta$ var. - Leares broadly oblong or suborbicular, $6-15^{\prime \prime} \times 4-8^{\prime \prime}$, obtuse or rounded at both ends, often emarginate at the base. - Var. $\beta$, $\gamma, \delta$, Muell. 1. c.

Oahu! Kauai!

†2. P. Niruri, L. - DC. Prod. 7. c. p. 406: - A glabrous annual, monoecious, about $1 \mathrm{ft}$. high, erect or decumbent, the branches angular in the upper portion. Leaves distichous, oblong or laneeolate, $4-5^{\prime \prime} \times 1-1^{1 /} / 2^{\prime \prime}$, on petioles of less than $1 / 2 "$, somewhat acute or somewhat obtuse. Stipules linear-lanceolate, ${ }^{1} / 2^{\prime \prime}$. Male $f l$. at the base and the end of a branch, $2-4$ in a cluster on very short pedicels. Calyx $1^{\prime \prime}$ in diameter, parted into 6 obovate unequal segments, whitish, with a green costule. Disk of 6 distinct glands. Stamens 3, united. Fem. $f$. at the middle or the base of a branch. Disk annular. Capsule globose, depressed, smooth, 1". Styles very short, slightly bifid. Seeds minutely striate at the back lengthwise. $\beta$, genuinus, Muell. 1. c.

A garden weed of late introduction, probably from China. It is found in many parts of tropical Asia, Africa and America.

\section{ANTIDESMA, L.}

Flowers dioecious, the male in catkins, the female in racemes or spikes. Male $f l$. Calyx of $3-8$ segments or lobes, imbricate in the bud. Petals wanting or rarely rudimentary. Stamens as many as calycine lobes and opposite to them, the anthers 2 -celled, with the cells pendulous at last and diverging. Disk annular or glandular. Ovary rudimentary. Fem. fl. Calyx as before. Petals wanting. Ovary 1 -celled, with 2 pendulous ovules, surrounded by an annular disk. Style short, 3-partite, its branches diverging, slightly bifid. Fruit a drupe with a bony putamen, flattened and oblique. Seed generally solitary, albuminous; cotyledons broadly ovate, flat; radiele terete. - Trees or shrubs, with alternate, entire, bistipulate leaves.

Natives of the tropieal regions of the Old World, chiefly of Malaysia, and extending into Polynesia; about 66 species.

Leaves ovate or obovate, glabrous

1. A. plafyphyllum.

Leaves cordate or retuse at the base, with a patch of hairs in the angle between rib and veins

2. A. pulvinatum.

1. A. platyphyllum, Mann, Enum. no. 444. - A tree, 20-30 ft. high. Leaves ovate or obovate, $3-5^{4} \times 2-3^{\prime}$, on petioles of $1^{1 / 2}-3^{\prime \prime}$, shortly acuminate, glabrous, shining above but punctato-papillose, subcoriaceous, the oblique veins connected inside the margin by prominent arches. Stipules linear-lanceolate, $3 "$, caducous. Male $f l$. sessile along the simple branches of a paniculate rhachis of $1^{1 / 2}-3^{\prime}$ in length, two or several panicles arising from an undeveloped axillary bud. Bracts conchoid, as long as the calyx or longer. Calyx less than $1^{\prime \prime}$, puberulous, urceolate, 
with 5-4 roundish lobes. Between calyx and stamens, outside the latter and alternating with both, are 5 small stipitate obovate glands or scales, connected at the bases - rudimentary petals. Stamens 5 (or 4), long exserted. Disk inconspicuous, with 5 small glands opposite the petaloid bodies. Ovary rudimentary, glabrous, with peltate stigma. Fem. fl. pedicellate along the branches of a solitary, axile, paniculate rhachis of $2-4^{\prime}$ in length, the pedicels $1 / 2-2^{\prime \prime}$. Bracts linear, scarcely $1^{\prime \prime}$. Calyx less than $1^{\prime \prime}$, pubescent, tubular-urceolate, 5-8-cleft into oblong obtuse lobes. Disk small annular. Ovary glabrous; style terminal. Drupe reddish, little fleshy, $4-5^{\prime \prime}$ high, compressed, suboblique, the osseous putamen irregularly ridged. Cotyledons suborbicular, as broad as the seanty albumen, 2 or 3 times as long as the radicle. - Youngest leaves speckled with a peltato-stellate pubescence.

Hawaii! Mani! Molokai! Oahu! Nat. name: "Haa.

$\beta$ var. - Leaves obtuse, broadest at the base and subcordate, shining on both faces.

Kauai! (Kn.).

In 4-staminate flowers one filament often bears 4 anther-cells.

2. A. pulvinatum, sp. n. - Young branches and inflorescence ochraceotomentose. Leaves ovate, $3^{1 / 2}-6^{\prime} \times 2-3^{1 / 2} 2^{\prime}$, on petioles of $6-9^{\prime \prime}$, shortly acuminate, generally retuse or cordate at the base, thin chartaceous, pale underneath and always with a villous patch in the angles of rib and veins, sometimes the veins tomentose throughout. Panicles short, branching only near the base, those with male flowers from projecting axillary spurs. Ovary tomentose. Drupe smaller, 2-3". Female calyx tomentose, 5-6-cleft. Style-branches very short, subentire.

Hawaii! S. Kona; E. Maui! Hamakua; Oahu! Waianae.

\section{ORder LXXVIII. URTICACEAE.}

Flowers unisexual or rarely polygamous, usually in cymes or heads. Perigone calyx-like, of $1-5$ divisions. Stamens as many as perigone segments and opposite to them, rarely reduced to fewer. Anthers 2-celled, opening lengthwise. Ovary free or adherent, 1 -celled with 1 ovule, rarely 2 -celled with 2 ovules of which one only comes to perfection. Style usually short or none, with 1 or 2 long or short stigmas. Fruit a 1-seeded indehiscent drupe or winged samara or small seed-like nut. Albumen fleshy or none. Radicle superior. - Trees, shrubs, herbs or climbers, furnished with stipules. Foliage and inflorescence very various. A scabrous surface and a milky juice or acrid or stinging secretions are very common.

A large Order, distributed over the whole world, but most abundant within the tropies, remarkable for the large number of fibre-plants it contains. 
Subiorder I. Celtideae. - Flowers monoeceo-polygamous. Stamens erect in the bud or slightly curved and elastic. Styles or stigmas 2. Seed suspended. Sap watery. - Flowers in cymes

1. Sponia.

Suborder II. Moreae. - Flowers monoecious or dioecious. Stamens inflexed in the bad, usually elastic. Ovule pendulous, campylotropous. Style simple, or divided into 2 filiform stigmas. Leaves conduplicate in the bud. Stipules lateral, not clasping. Sap milky.

Female flowers in spikes:

Fruit naked but fleshy, supported by the unchanged dry perigone

Fruit eovered by the fleshy perigone

2. Pseudomorus.

Female flowers on a globose receptacle.

3. Morus.

4. Broussonetia.

Stborder III. Artocarpeae. - Flowers unisexual. Stamens ereet in the bud. Style or stigma simple, unilateral, or rarely with a second shorter branch. Leaves convolute in the bud. Stipules axillary, clasping. Sap milky.

Female flowers on a globose receptacle.

5. Artocarpus.

Suborder IV. Urticeae. - Flowers unisexual. Stamens inflexed in the bud, elastic Style or stigma simple, usually penicillate. Ovule erect, atropous Sap watery (except perhaps in Neraudia).

Leaves opposite:

Female perigone membranous when mature:

Flowers in simple axillary clusters:

Female perigone 4-toothed; an erect stinging herb

Female perigone 3-parted, one segment larger; a small prostrate herb

Small heads of flowers spicate along the mostly simple branches of a long rhachis

Female perigone fleshy when mature; flowers in axillary clusters Leaves alternate:

Flowers in cymes:

Cymules scorpioid, paniculate, forming short branches on a long rhachis; achene naked.

Cymes divaricately dichotomous, corymbose; achene covered by the fleshy perigone

Flowers in axillary elusters:

Female flowers on a globose receptacle, the perigone dry with fruit .

Female flowers without receptacle, the perigone fleshy with fruit

Flowers on globose receptacles, these arranged in simple or compound, generally unilateral cymes

6. Hesperoenide.

9. Pilea.

10. Boehmeria.

12. Cypholophus.

\section{Fleurya.}

8. Urera.

11. Pipturus.

14. Neraudia.

13. Touchardia.

\section{SPONIA, Lam.}

Flowers polygamous, monoecious. Perigone free, persistent, of 5 segments, those of the male flowers subvalvate near the base, with induplicate margins, of the female flowers imbrieate. Stamens inserted under a pilose disk, erect in the bud, the anthers introrse. Ovary 1-, rarely 2-celled, with 1 pendulous ovule in each cell and 2 short plumose permanent styles. Drupe ovoid or globose, naked, with a single seed. Albumen scanty. Embryo curved, with thick falcate cotyledons. - Trees or shrubs, with tripli-nerved alternate leaves and free lateral stipules. Flowers in axillary cymes, articulate with the pedicels.

About 27 species, spread over the tropical regions of the whole world. 
1. S. Amboinensis, Decaisne, in Brongn. Voy. de la Coq. p. 212, tab.47. DC. Prod. XVII, 198. - A small tree, 20-30 ft. high, the young branches softly gray-pubescent. Leaves distichous, ovate-oblong, $4-6^{\prime} \times 1^{1 / 2}-2^{\prime}$, on petioles of $4 "$, long acuminate, closely serrulate, cordate and often oblique at the base, tripli-nerved, with the lateral nerves extending beyond the middle, chartaceous, very rough and papillose on the upper face, silky-tomentose underneath when young, but sparingly pubescent when old. Stipules lanceolate-acute, $21^{1 / 2}$ ". Cymes compound, divaricately branching, short, about 4 " long and 6-9" broad, on a short peduncle of $1^{\prime \prime}$, carrying male, female and hermaphrodite flowers. Male $\mathrm{fl}$. Perigone $1^{1} / 2^{n}$, pubescent, 5-parted to the base, the lobes conchoid, somewhat obtuse, imbricate, with the scarious margins induplicate. Stamens as long as the lobes, erect, with subulate filaments and obtuse anthers. Ovary obovate, hairy, without style. Fem. fl. Perigone ${ }^{3 / 4}$ " high, 5 -fid to the middle with lobes imbricate. Ovary 2-celled, with 1 ovule in each cell. Drupe ovoid, $2^{\prime \prime}$, puberulous, little fleshy, black with crustaceous putamen. Cotyledons oblong, folded, at a right angle with the short radicle. - Wight, Ic. Pl. Ind. Or. tab. 1990. - Celtis Amboinensis, Willd. - Trema Amboinensis, Blume. - S. velutina, Planch. in Ann. Se. Nat. Ser. 3, X, 327. S. argentea, Benth.

Oahu! woods of Manoa and of the northern slope of Kaala; Molokai! Mopulehu. The tree, which was not hitherto known to grow on the Hawaiian Islands, is widely spread through southern India, Malaysia, China and tropical Australia, and has also been found on the Viti group and on Uvea, or Wallis Island. S. Tahitensis, Nad., from Tahiti, does not seem to differ.

\section{PSEUDOMORUS, Bureau.}

Monoecious (and dioecious?), the flowers in unisexual spikes. Male fl. Perigone 4-parted, the segments ovate, imbricate, at last patent. Stamens 4, the filaments inflected in the bud, elastic, the anthers introrse, subglobose. Pistil rudimentary. Fem. fl. Perigone 4-parted or lobed, the segments imbricate in the bud. Ovary free, 1-celled, with 1 pendulous campylotropous ovule. Stigmas 2, elongate-filiform, papillose on the inner face, long persistent. Drupe naked, fleshy, supported at the base by the unchanged perigone, the endocarp almost woody. Seed subglobose, with a thin testa. Albumen almost none. Embryo globosocompressed, with plano-convex cotyledons, the short inflected radicle ineumbent on the upper one. - Lactescent trees with alternate leaves and short deciduous lateral stipules. Flowers in spikes with peltate bractlets.

A genus of a single variable species which has been found in Australia, Norfolk Island, New Caledonia and the Hawaiian Islands.

1. P. Brunoniana, Bureau, in DC. Prod. XVII, 249. - A small tree or shrub, about $12 \mathrm{ft}$. high. Stipules triangular to lanceolate, quite acute, $1^{1 / 2}-2^{\prime \prime}$. Leaves distichous, ovate-oblong or lanceolate, $2^{1 / 2}-5^{\prime} \times 1-2^{\prime}$, 
on petioles of $3-4^{\prime \prime}$, acute, sinuato-dentate with patent teeth, more or less rounded or truncate, even emarginate at the base, thin, pale, scabrous above, glabrous on both faces, penni-nerved with $10-12$ almost horizontal pairs, which anastomose inside the margin by prominent sinuous arches. Flowers monoecious. Male spikes in the upper axils, slender, 3-4' long, on peduncles of $1-2^{\prime \prime}$. Perigone $1^{\prime \prime}$, pubescent, pale bluish, 4-, rarely 3-parted, umbilicate in the bud, the lobes ovate-acute. Stamens 4, rarely 3 , twice as long as the perigone, the inflected filaments not transversely rugose, the anther-cells reniform, cohering at the apex. Pistil obcordate, naked. Fem. spikes shortened, often ovoid, at most 6 "long by $4^{\prime \prime}$ broad, with few drupes when mature, generally carrying 4 , often only a single one. Perigone $1^{\prime \prime}$, pubescent, membranous, free, deeply parted into 4 ovate-obtuse segments. Ovary ovoid, peaked, as long as or shorter than the 2 divaricate conico-elongate stigmas. Fruit a black fleshy drupe, subglobose, $3-4 "$, 2 -horned with the conical style-bases. Pyrena trigonous. Embryo uncinate, the very scanty albumen only filling the interstice between cotyledons and radicle. - Morus Brunoniana, Endl. Atakta Bot. tab. 32. - M. pendulina, Bauer, Ill. Pl. Norf., tab. 186, ined. - Endl. Prod. Fl. Norf. - Mann, Enum. no. 436.

O a hu! Wailupe, Waianae range (eastern end and Makaleha); H aw a ii ! Kawaihae iuka, Kau (Remy); E. Maui! (Lydg.); Kauai! (Remy and Kn.). The specimens from the Waianae range are all monoecious, as described above, those from the other localities bear only spikes of one sex. It deserves to be noted that the male spikes in the upper axils are still in bud while the fruit below is fully matured.

\section{MORUS, L.}

Fruit enclosed by the fleshy and adherent perigone, the mesoearp pulpy and the endocarp fibrous. Seed-coat hard. Embryo surrounded by albumen. Otherwise as in Pseudomorus.

A few species, natives of Asia and America.

†1. M. nigra, L. - DC. Prod. XVII, 238. - A small tree. Leaves on short petioles, ovate-oblong, rounded or subcordate at the base, unevenly serrate, sinuately incised on young plants, scabrous on the upper face, pubescent on the lower. Flower-spikes tomentose, those of the male flowers elongate, of the female short elliptical. Filaments transversely rugose. Stigmas subulate, papillose or pubescent all round. The fleshy fruits confluent with each other and with the rhachis in a black succulent synearpium.

The Black Mulberry, "Kilikas of the natives, originally cultivated for the raising of silk-worms, has become naturalized in various parts of the Islands, particularly in Kula, Maui, and on Kauai.

\section{BROUSSONETIA, Vent.}

Dioecious. Male fl. in bracteate spikes. Perigone 4-parted, the segments ovate, acuminate, valvate in the bud, at last patent. Stamens 4, with 
elastic complanate filaments, the anthers subglobose, introrse. Fem. $\mathrm{fl}$. on a globose receptacle, intermixed with clavate bracteoles. Perigone urceolate, 3-4-toothed. Ovary on a clavate gynophore, 1-celled, with a single filiform and puberulous excentrical stigma and 1 pendulous or parietal ovule. Achene raised by the elongate gynophore, exserted from the perigone, fleshy at the base and on the stigmatiferous margin, the endocarp crustaceous. Seed-coat thin. Embryo within seanty albumen, uncinate, the cotyledons oblong. - Lactescent trees with alternate leaves and lateral caducous stipules.

A genus of 4 species, natives of Japan and the Philipine Istands.

1. B. papyrifera, Vent. - DC. Prod. XVII, 224. - A small tree. Leaves ovate, entire or 3 -lobed, $5-7^{4} \times 3-4^{1 / 2}$, on petioles of $1-1^{1 / 2} 2^{4}$, acuminate, dentate, subcordate, often oblique, chartaceous, scabrous and hispidulous on the upper face, tomentose beneath, tripli-nerved at the base, the lateral nerves scarcely reaching the middle of the blade, penni-nerved above. Flowers tomentose. Male spikes $1-2^{\prime}$ long on peduncles of $3-5^{\prime \prime}$. Female glomerules axillary, globose or elongate, about $1^{\prime}$ in diameter, on peduncles of $6 "$, the bracteoles conical and hispid at the ends, the fleshy achenes with their gynophores orange-red. - Endlicher, Gen, Pl. no. 1858. Morus papyrifera, L. - Papyrius, Lam. - Seem. Fl. Vit. p. 246.

The well known Paper-mulberry, "Wanke" of the natives, which furnished the fibre for their paper cloth or "kapan, formerly cultivated, as it was by all the Polynesians of the Maoli race and by the Vitians. At present it is found in isolated clumps along the lower wood-zone, mostly in Kona, $\mathrm{Hawaii}$, and in various parts of $\mathrm{Maui}$. It generally branches from the base, and does not form trunks or grow to large trees as in its probable native country Japan. The native name reappears in the Tahitian and New Zealand "Autis. The Vitian name, "Malo", is preserved by the Hawaiians in the word for the principal fabrie made of its fibres, the loin-girdle. According to Seeman the tree has not been found wild anywhere, and its cultivation is unknown in any part of India.

\section{ARTOCARPUS, L.}

Flowers monoecious, those of either sex on distinct receptacles, bractless or with peltate bracteoles. Male $\mathrm{fl}$. Perigone 2-4-parted, the lobes imbricate in the bud. Stamen 1, central, exserted. Fem. fl. Perigone tubular, entire. Ovary 1-(rarely 2 - or 3 -) celled, with 1 pendulous ovule in each cell. Style lateral, simple and linear (or 2-3-fid), protruded from the narrow aperture of the perigone. Fruit compound, consisting of the enlarged and fleshy consolidated perigones, each enclosing a minute nut. Albumen none. Embryo uncinate, the thick cotyledons incumbent on the short radicle. - Trees or shrubs, with milky juice. Leaves alternate, with deciduous axillary stipules. Flower-heads or eatkins axillary.

A small genus, dispersed over tropical Asia and Polynesia.

1. A. incisa, L. f. Suppl. p. 61. - A tree, 40-60 ft. high. Leaves coriaceous, scabrous, appressedly pubescent, 1 foot and more in length, 
oblong in outline, pinnatifid with acute or somewhat obtuse lobes. Stipules 2 , free, very large, rolled round the bud and imbricate, soon caducous. Male $f l$. on thick oblong, fem $f l$. on large globose receptacles, both at first covered by 2 large spathaceous bracts, the latter terminal. Male perigone of 2 divisions. Style simple or 2-3-fid. -- G. Forster, Pl. Escul. p. 23. - Trécul, Ann. Sc. Nat. Ser. 3. VIII, 109, tab. 4.

The Breadfruit tree, called =Ulu by the natives, has accompanied the Polynesians in all climates which allow the tree to live. At the Sandwich Isiands, however, which form the northern boundary of its area, it never played so important a part in the household of the natives as it does with those of Tahiti and other southern groups. Its fruiting season is short, from June to August, and the art of preserving the fruit was not understood. While in the Viti Islands some twenty or more varieties are enumerated, there is only a single one on the Hawaiian group, which, as it never matures seed, has to be propagated by suckers. It cannot therefore be considered as fairly naturalized, although one meets with large numbers of it in Kona and Hilo on $\mathrm{Hawaii}$, and elsewhere, generally marking the place of abandoned cultivation. The ancient Tahitiun name "Uru" corresponds with the Hawaiian, but the Vitian "Uto is of different origin.

Of late years a seed bearing variety of the breadfruit with less deeply divided leaves has been introduced from the Caroline Isiands. The Jack fruit, A. integrifolia, has likewise been added to the stock of cultivated fruit trees.

To this Suborder belongs also the genus Ficus, which is so largely represented in all tropieal eountries, but entirely wanting in our flora. The common fig, F. Carica, has been long in cultivation in two or three varieties. It thrives and fruits well, but is subject to the destructive attacks of a wood beetle - a Saperda. F. elastica, the Indiarubber tree, of S. Asia, F. religiosa, the Peepul tree, F. Indica, the Banyan-fig, F. retusa and $F$. Wightiana, have also been introduced.

On the island of Molokai a tradition is preserved of a poisonous tree which grew somewhere about the middle of the island, not far from the southern shore, but has been long extinct. It had a sacred eharaeter, but was resorted to by skahunas and men in power, when they wanted to get rid of obnoxions persons. As it is said to have bled when cut, it may have belonged to this Suborder, which in the Antiaris toxicaria includes one of the most formidable poison trees.

\section{HESPEROCNIDE, Torr. \& Gray.}

Flowers monoecious, in axillary clusters, with both sexes intermixed. Male $f$. Perigone 4-parted, depressed in the bud. Stamens 4, with reniform anthers. Fem. fl. Perigone tubular or urceolate, minutely 2or 4 -toothed, with 2 teeth larger. Ovary straight, with 1 ereet ovule, the stigma sessile, globose-penicillate, persistent. Achene ovate, compressed, closed in by the membranous perigone. Albumen scarce. Cotyledons suborbicular, emarginate at both ends, about as long as the conical radicle. - Annual herbs with hooked stinging hairs, opposite incised leaves, free lateral stipules, and bractless flowers which are articulate with their pedicels.

A genus of 2 species, the second one Californian. It differs from Urtica in the tubular perigone of the female flower.

1. H. Sandwicensis, Weddell, in DC. Prod. XVI, Sect. I. p. 68. - Erect, 1-2 ft. high, much branching, hispid all over with stiff, spreading, mostly barbed hairs, besides a short pubescence in the younger parts. Leaves ovate, small, $5-9^{\prime \prime} \times 3-6^{\prime \prime}$, on petioles of $4-6^{\prime \prime}$, coarsely and obtasely 
serrate or incised, quite thin, sparingly and shortly pubescent on both faces. Stipules small oblong. Clusters of flowers sessile, those of both sides confluent and together not exceeding $2^{1 / 2} "$ in diam. Fem. fl. subsessile, less than $1^{\prime \prime}$ when full grown, hispid. Male $f l$. very few, smaller, less hispid. Achene pale and smooth. - Urtica Sandwicensis, Wedd. Monogr. Urt.

Haw aii! on the high plains between Mauna Kea and Mauna Loa, at an elevation of $5000-6000 \mathrm{ft}$. The plant makes altogether the impression of being an introduced weed, it growing gregariously in the rich soil formed by the wash from the mountains, in places where the wild cattle congregate. The difference between it and the Californian species amounts to little, and I am inclined to think that it came with Vancouver's cattle from the American coast.

\section{FLEURYA, Gaud.}

Flowers monoecious or dioecious. Male $\mathrm{fl}$. Perigone 4-5-parted, umbilicate in the bud. Stamens 4-5. Fem. fl. Perigone 4-parted or lobed, the inner segments generally larger. Ovary at length oblique, with $1 \mathrm{ob}$ lique ascending ovule. Stigma ovate or elongate, at length recurved. Achene oblique, compressed, generally margined and tuberculate, breaking away from the pedicel together with the perigone. Embryo as in Hesperocnide. - Annual herbs, mostly stinging, with alternate serrate leaves and bifid axillary stipules. Flowers bractless, single, or clustered in dichotomous, unilateral, axillary cymes or cymose panicles.

A small genus, spread over the tropics of both Worlds.

1. F. interrupta, Gaud. - DC. Prod. XVI, Sect. I, p. 74. - Erect, $1 \mathrm{ft}$. high, with few branches, sparingly hispid. Leaves ovate, $2-4^{\prime} \times 1-3^{\prime}$, on petioles of $1-4^{\prime}$, acute, coarsely serrate, often subcordate or truncate at the base, thin, pale underneath, with few hairlets. Stipules bifid beyond the middle, the lobes setaceous. Flowers in distant androgynous glomerules along a naked, filiform, simple or shortly branching rhachis of $5-10^{4}$ in length, the glomerules often evolute in scorpioid cymes. Male $f l$. few, subsessile, with white or pinkish 4-parted perigone, soon caducous. Fem. fl. with 4-toothed perigone, the lateral teeth finally larger, the upper one keeled. Stigma $1 / 2$ the length of the achene, hooked at the apex, with 2 rudimentary appendages at its base. Achene 1", pale, ovate, much compressed, thick-margined, tuberculate on the depressed faces. - Mann, Enum. no. 425 .

Colleeted by Maerae. I only know of it as a not common garden weed. - The species extends from Ceylon and $\mathrm{S}$. India through Malaysia into Polynesia to Tahiti. Although it bears a bad reputation elsewhere for stinging, the plant growing at the Islands seems to be harmless.

\section{URERA, Gaud.}

Flowers dioecious, rarely monoecious. Male perigone colored, of $4-5$ divisions, umbilicate in the bud. Stamens $4-5$, inflected in the bud, with reniform obtuse anthers. Ovary rudimentary. Fem. perigone 4-lobed or 
toothed, the inner teeth largest, one of the outer defective. Ovary straight or oblique, with 1 erect ovule. Stigma subsessile, globose-penicillate, persistent. Achene enclosed in the fleshy and colored perigone. Albumen very scanty. Cotyledons rounded, emarginate, much longer than the radicle. - Trees or shrubs, sometimes climbing, with alternate leaves and axillary bicarinate stipules. Flowers articulate with the pedicels, single, or glomerate in axillary cymes.

About 20 species, chiefly tropical, natives of America, Africa, Mauritius, Timor and the Hawailian group.

Leaves oblong or ovate; cymes corymbose Leaves cordate-suborbicular; eymes panieulate

1. U. Sandwioensis.

2. U. Kaalae.

1. U. Sandwicensis, Wedd. in DC. Prod. XVI, Sect. I, p. 92. - A tall shrub or small tree, $8-16 \mathrm{ft}$. high, freely branching, not stinging. Leaves oblong, $6-8^{\prime} \times 2-3^{\prime}$, on petioles of $1-1^{1} / 2^{\prime}$, acuminate, moderately elliptico-contracting but obtuse at the base, wavy-crenulate in the upper, entire in the lower portion, chartaceous, glabrous, pale underneath, shortly tripli-nerved at the base, otherwise penni-nerved with 12-15 strong nerves on either side, all parallel, straight and nearly excurrent, but the lowest shorter than the others, the anastomoses in rectangular areoles. Stipules lanceolate, $1^{1 / 2^{\prime}}$, soon caducous. Flowers dioecious. Cymes in the lower axils, often rising from the naked branch, regularly and repeatedly dichotomous with divaricate branches, corymbiform, $1^{1 / 2}-3^{\prime}$ in diam., with a peduncle of ${ }^{1 / 2}-1^{4}$, those of the female flowers shorter. Male perigones $8-12$ in a glomerule, subsessile, each $1^{1 /} 2^{\prime \prime}$ in diameter, pale reddish, with 5-4 ovate glabrous segments. Anthers pale, large, horseshoe-shaped, their cells cohering at the apex. Fem. perigones mostly ternate, surrounded by a deciduous cup of bractlets, shortly pedicellate, urceolate, 3-4-toothed, at length somewhat fleshy and reddish yellow, less than 1". Achene suboblique, with reddish stigma, ovate, compressed, tuberculate on both faces, entirely enclosed by the perigone, - Villebrunea crenulata, Gand. Bot. Bon. tab. 92.

Hawaii! Waipio.

$\beta$ var. - Leaves elliptico - to ovato-oblong, $6-8^{\prime} \times 3-4^{\prime}$, crenatoserrulate, not tripli-nerved at the base, but the lowest pair much the shortest, the rib and nerves underneath pubescent. - Var. mollis, Wedd. l. c.

Hawail! Mauna Kea (Macrae), woods of Hilo (Hbd.).

$\gamma$ var. - Leaves broadly ovate, with rounded base, $4-7^{\prime} \times 2-5^{\prime}$, on petioles of $1^{1} / 2-2^{1} / 2^{\prime}$, only penni-nerved with $8-12$ nerves on either side, the lowest pair as long as the next and prominently semipinnate, sbortly but acutely pointed, crenato-serrate, excepting the entire base, glabrous and smooth underneath, excepting a tuft of soft hairlets in the axils of the lower nerves, - Var. glabra, Wedd. - Var. glabella, Wawra. - Procris glabra, Hook. \& Arn.

Oahu! Molokail Kalae; Lanai! 
o var. - Leaves as in $\gamma$, but gray-pubescent underneath. - U. glabra, var. mollis, Wawra.

Maui! Ulupalakua, cymes subpaniculate, trichotomous, with a leading branch; Ka u i, Hanalei (Wawra), cymes dichotomous, the achenes exceeding the perigone.

Hooker \& Arnott's specific name is much older than Weddell's, but as the former is not quite appropriate and the latter has passed into De Candolle's Prodromus, I have not deemed advisable to disturb it. Nat. name : "Opuhes. The plant yields a most valuable fibre, equally esteemed and used for the same purposes as that of Touchardia latifolia.

2. U. Kaalae, Wawra, in Flora, 1874, p. 542. - A small tree, $18 \mathrm{ft}$. high. Leaves cordate, palmately 3-5-nerved, about 3 ' in each diameter, on petioles of the same length or more, abruptly acuminate, coarsely serrate, with the serratures broad and shortly apiculate, the basilar sinus deep and narrow, with the rounded lobes overlapping, membranous, sparingly dotted with reddish resinous specks, gray-pubescent underneath along the nerves. Stipules small triangular, bicarinate, bidentate, ciliate, persistent. Panicles or trichotomous cymes in the axils of the upper leaves, as long as the leaves or longer, glabrous, the slender peduncle as long as the petiole, the branches rather straight and bracteolate. Fem. perigones shortly pedicellate, single or ternate, $3-4$-toothed.

Oahu, on Mt. Puakea of the Kaala range (Wawra). Leaves like those of Tilia grandiftora. Wawra finds a close resemblance of this species to $U$. Punu, Wedd., from Brazil, also with $U$. Jacquinii, Wedd, a variety of $U$. Caracasana, Griseb.

\section{PILEA, Lindl.}

Flowers unisexual, glomerate. Male perigone 4-, rarely 2- or 3-parted, soon caducous. Stamens 4 , or 2 or 3. Fem. perigone deeply 3-parted, with one segment usually larger gibbous or hood-shaped. Stamens rudimentary, scale-like. Ovary straight, with 1 suberect ovule and a sessile shortly penieillate stigma. Achene suboblique, compressed, naked or nearly so. Seed without albumen, the ovate cotyledons longer than the radicle, - Erect or prostrate, often rooting herbs with opposite leaves. Stipules axillary, entire. Glomerules of flowers simple or arranged in dichotomous or trichotomous eymes.

A large genus of 160 species, spread over the tropical and subtropical regions of the whole world.

1. P. peploides, Hook. \& Arn. in Bot. Beech. p. 96. - DC. Prod. XVI, Sect. $I, p .109 .-$ A low prostrate herb, branching from the base, the branches $2-4^{\prime}$ long, floriferous in most axils. Leaves of each pair equal, small, ovate-rhomboidal, $3-4^{\prime \prime}$ in each diameter, obtuse, minutely crenate or almost entire, more or less cuneate at the base, tripli-nerved, the lateral nerves reaching the middle of the blade, membranous, dark-papillate beneath, on petioles of $2-3^{\prime \prime}$. Stipules very small. Cymes androgynous, densely glomerate, apparently sessile, the flowers minute on very short pedicels. Male perigones few, their lobes shortly mucronate. Fem. 
perigones numerous, the middle segment narrow oblong, curved, $2-3$ times as long as the lateral ones, little shorter than the minute ovate achene. - Dubrueilia peploides, Gaud. Bot. Freyc. p. 495. - P. pygmaea, Miq.

Rather eommon in the lower regions of all islands, on wet rocks. The upper surface of the leaves exhibits numerous linear eystoliths when dry. The species is reported also from the Galapagos Islands, from Java and Burmah.

$\beta$ var. major. - A larger plant. Leaves suborbicular, with cuneate base, $7-8^{\prime \prime}$ in diameter, crenato-dentate in the upper portion, on petioles of $6-12 \%$. Glomerules of flowers on a short leafy peduncle. - Wedd, in DC. Prod. 1. c. - Wawra, in Flora, 1874, p. 545.

Same habitat.

\section{BOEHMERIA, Jacq.}

Flowers monoecious or dioecious. Male perigone usually of 4 segments, valvate in the bud, with as many stamens. Fem. perigone tubular, 2- or 4-toothed. Ovary 1 -celled, with 1 erect ovule. Stigma linear, hairy on one side, continuous with the ovary and persistent. Achene enclosed in the thin and dry perigone and sometimes adherent to it, thin crustaceous. Seed albuminous; cotyledons elliptical. - Shrubs or small trees. Leaves alternate or opposite, tripli-nerved, usually dentate. Stipules generally axillary and free, or connate at the base. Flowers glomerate, the clusters solitary or in interrupted spikes or panicles.

A large genus, dispersed over the tropical regions of the whole world, with a few extratropical Asiatic and N. American species.

1. B. stipularis, Wedd. in DC. Prod. XVI, Sect. I, p. 209. - A shrub, $3-5 \mathrm{ft}$. high, with stout angular hispid branches. Leaves opposite, both equal, ovate, $6-7^{\prime} \times 4-5^{\prime}$, on petioles of $1-3^{\prime}$, shortly acuminate, coarsely serrate, emarginate or subcordate at the base, of thick texture, rugose, bullate and sparingly hispid on the upper face, tripli-nerved, the lateral nerves extending to the upper fourth of the blade, all nerves and the rectangular areoles strongly ridged or fenestrate underneath and coarsely pubescent. Stipules interpetiolar, broad lanceolate, $2-2^{1} / 2^{\prime} l o n g$, bicarinate, entire, strigoso-pubescent, soon caducous. Flowers monoecious with androgynous clusters, but one sex much prevailing; the clusters $1-2^{\prime \prime}$ in diam., all discreet and spicate along the mostly simple and patent branches of a pubescent axillary rhachis which measures from $4-8$ inches. Bracts soon caducous, small lanceolate, $1^{1 / 2}-1^{\prime \prime}$. Male perigone 4 -parted to the base into ovate-acute lobes, $1^{\prime \prime}$ high, peaked in the bud. Filaments puberulous; anthers short-oblong. Fem. perigone ${ }^{3 / 4} 4,4$-toothed, at length adherent to the ovoid subcompressed achene. Stigma long exserted, curved. - Wedd. Monogr. Urt. p. 376. - Urtica grandis, Hook. \& Arn. in Bot. Beech. p. 95. - Male flowers prevail at the extremities of the panicle, female 
along the lower parts of the branches; in particular the larger glomerules in the axils of the rhachis are always female.

Oa hu! Mt. Kaala.

$\beta$ var. - Leaves contracting at the base, not emarginate, narrower; otherwise as before. - Wawra, in Flora, 1874, p. 543.

Maui! Wailuku, Waihee.

$\gamma$ var. - Leaves ovate-oblong, contracting but obtuse at the base, unequal in some pairs, thin, almost membranous, glabrous, neither rugose nor strongly nerved. My specimens seem to be dioecious, the male panicles without axillary glomerules, but the leaves show gradations into $\beta$.

Molokait Maui! Kauai.

The species is said to occur also on the islands of Madagascar, Bourbon and Mauritius and only differs in the connate stipules from B. platyphylla, Don, a speeies which comprises in its range all countries from Tahiti westward to tropical Africa, including also Chima and Japan. The stipules are however not intraaxillary, as stated in the Prodromus, not made up by the coalescence of the two belonging to each leaf, but by coalescence of the corresponding ones of the opposite leaves, with only their margins inside the petioles. As our plant disagrees also in some other respects with Weddell's description, it is probable that two distinct speeies lie concealed in the present one, and that thus the difficulty of explaining the occurence of one species in only two limited areas which are removed from each other by half the circumference of the globe will find an easy solution. - The plant was used, like most Urticaceae, for the manufacture of kapa", although not to the same extent as the "Wauke* and "Mamake.

In cultivation: B. tenacissima, Roxb., or B. nivea, Hook. \& Arn., the Ramee plant.

\section{PIPTURUS, Wedd.}

Flowers dioecious, rarely monoecious. Male perigone 4-5-lobed, with 4-5 stamens and the tomentose rudiment of a pistil. Fem. perigone ventricose, 4-5-toothed, adnate to the ovary. Stigma filiform, pubescent on one side, articulate and caducous. Ovule 1, ereet. Achene nucumentaceous, closely invested by the perigone. Seed with little albumen, the cotyledons elliptical or ovate. - Shrubs or small trees, with alternate tripli-nerved leaves. Stipules axillary, bifid. Flowers bracteolate, glomerate, the clusters axillary, simple and sessile, or interruptedly spicate on an elongate rhachis, the female on globose, at last fleshy receptacles.

A genus of 8 species, natives of Polynesia, Malaysia, tropical Anstralia and the Mascarene Islands.

1. P. albidus, Gray, in Mann's Enum. no. 430. - DC. Prod. XVI, Sect. I, p. 23517 . - A shrub, 5-8 ft. high, the young branches gray-tomentose. Leaves ovate, $3-4^{i} \times 1-2^{1 / 4^{i}}$, on petioles of ${ }^{1 / 2}-1^{1 /} / 2^{\prime}$, quite acute, crenato-serrate, rounded or slightly contracting at the base, chartaceous, sparingly hispid or glabrate above, shortly white-tomentose underneath on the areoles between the darker veins, tripli-nerved, the lateral nerves extending to the upper fourth of the blade. Stipules about $2^{\prime \prime}$, triangularlanceolate, bifid to the middle into subulate lobes. Flowers all sessile in axillary clnsters of $3-4^{\prime \prime}$ in diam. which nearly clasp the stem, white 
tomentose or rather hispid, either dioecious, or monoecious and then the female heads occuping the upper portion of a branch, the male the lower, but not rarely both sexes in one glomerule. Bractlets minute. Male perigone reddish, acutely 4 -fid to the middle or less. Stamens little exserted. Fem. perigones on a thick, at last fleshy receptacle, minutely 2-4-toothed, the commonly uncinate stigma longer than the perigone. Fruit about $1 / 2 "$. - Includes var. Gaudichaudii, Wedd. - Wawra, in Flora, 1874, p. 547. - Boehmeria albida, Hook. \& Arn. - P. Tahitensis, Wedd, in Monogr. Urt. (not in Prod.).

On all islands, at the outskirts or in clearings of the lower forests. Very variable as to eanescence of leaves - generally only the areoles white, but sometimes the nerves and veins also, rarely areoles and veins of a pale green. The "Mamake" of the natives, one of the two principal "kapa" plants. Not known from elsewhere.

$\beta$ var. - Leaves almost coriaceous, with strongly salient nerves and veins, all white tomentose like the areoles, bullose and rugose on the upper face, coarsely crenate, narrowing at the base. - Probably var. Meyeniana, Wedd.

Oahu?

\section{CYPHOLOPHUS, Wedd.}

Flowers monoecious or dioecious. Male perigone 4-parted, the segments mucronate below the apex. Fem. perigone free, ventricose, unequally 2-4-toothed. Stigma filiform, much eurved, continuous with the ovary, hairy or plumose on the convex side. Achene closely surrounded by the fleshy perigone, but not adherent to it. - Shrubs or trees, with opposite leaves and free axillary-lateral stipules., Flowers in axillary glomerules, with scarious bracts.

A genns of 9 Malaysian and Polynesian species.

1. C. macrocephalus, Wedd. in DC. Prod. XVI, Sect. I, p. 23510. - Leaves uneven-sided, ovate-oblong, sharply serrulate, membranous, scarcely rugose, hispidulous on the upper, softly pubescent on the lower face, one of a pair generally smaller than its mate and subcordate, with a shorter petiole. Glomerules unisexual and androgynous, densely flowered, those of both sides confluent. Male perigones pedicellate. Mature fruit obovate and the pericarp of the achene thickened at the apex. - Var, mollis, Wedd. 1. c. - Boehmeria mollis, Wedd, in Ann. Sc. Nat. Ser. 4 I, 198. - B. Moluccana, Bl.

Credited to the Sandwich Islands, besides the Moluecas, by Weddell, 1. c., without reference to a collector. I know nothing about it, nor is it mentioned in Mann's Enumeration. In appearance it is much like Pipturus albidus.

\section{TOUCHARDIA, Gaud.}

Flowers dioecious, on globose receptacles. Male perigone 5-parted, the segments imbricate in the depressed bud. Stamens 5 . Fem. perigone 
subcampanulate, 4-lobed or toothed. Ovary straight, almost as long as the perigone. Ovule oblique, ascending. Stigma spathulate, with one face and the margins papillose-ciliate. Achene ovate, smooth, compressed, invested by the rather fleshy adherent perigone. Albumen very scanty, Cotyledons ovate, subcordate, conduplicate, twice as long as the thick radicle. - A shrub with large alternate tripli-nerved leaves. Stipules axillary, large, entire. Flowers pedicellate, bracteolate, the globose glomerules at the ends of simple, forked or dichotomously branching, axillary peduncles.

A Hawaiian genus of a single species.

1. T. latifolia, Gaud. Bot. Voy. Bon.tab. 94. - DC. Prod. XVI, Sect. I, p. 23513 . - A shrub, 4-8 ft. high, with a viscid juice, sparingly dividing into stout branches, the youngest hispid but soon glabrate. Leaves on petioles of $3-9^{\prime}$, ovate, $9-16^{\prime} \times 5-9^{\prime}$, acute or acuminate, obtusely crenate, rounded at the base, chartaceous, dark green on both faces and glabrous, excepting a few hairlets on the nerves, tripli-nerved, the lateral nerves not reaching the middle of the margin, penni-nerved higher up, with rectangular areoles. Stipules 2', acute. Glomerules of flowers generally arranged in repeatedly forking cymes, with one branch suppressed and the middle glomerule sessile; the male cymes longer $\left(3-5^{\prime}\right)$ and broader $\left(5-6^{i}\right)$ than the female, which are also more crowded. Male glomerules $6-8^{\prime \prime}$ in diameter. Perigone $1^{1 / 2}-2^{\prime \prime}$, the lanceolate segments hooded and obtuse or tuberculate below the apex. Stamens shortly exserted, anthers large, white. Rudiment of pistil glabrous. Fem. glomerules $4-5$ ". Perigone $1^{\prime \prime}$, orange-colored when mature. Style as long as the achene. - Wedd. Monogr. Urt. p. 142, tab. 3. - Wawra, in Flora, 1874, p. 547.

In deep ravines on all islands, but by no means common. It is the "Olona of the natives, which yields a fibre highly prized for tenacity and durability, and is ehiefly employed for making fishing nets. See also under Urera. - Wawra says of the inflorescence: "eapitula mascula femineis superpositas, and ceapitula feminea in axillis foliorum inferiorum paniculata, erocean; yet, if such occasionally is the ease, the species, as a rule, is dioecious. The cymes at least seem always to be unisexual.

\section{NERAUDIA, Gaud.}

Flowers dioecious, clustered in the axils, without raised receptacle. Male perigone 4-parted, the segments ovate, acute, thickish, valvate in the peaked bud. Stamens 4, exserted. Rudiment of pistil conical, woolly. Fem. perigone ventricose, contracted and beaked at the mouth, 4-toothed. Ovary ovoid, free. Ovule 1, erect. Stigma filiform, articulate with the ovary and deciduous, pubescent in its entire length. Achene ovoid, crustaceous, expanded at the base into a broad orbicular lobate disk, loosely enveloped by the globose fleshy perigone. Albumen almost none. Cotyledons orbicular, cordate, plano-convex, twice as long as the short 
conical radicle. - Shrubs with a milky (?) sap. Leaves alternate, entire, triplinerved. Stipules short axillary.

A Hawaiian genus. The peculiar disk-like expansion of the lower half of the achene, at first little conspicuous, inereases with maturity, so that at length the conical apex, which remains nearly stationary, appears as if it were immersed in it. The presence of a white milksap rests upon Gaudichaud's statement. I do not remember to have observed it.

1. N. melastomaefolia, Gaud. Bot. Voy. Freye, p. 500, tab. 11\%. DC. Prod. XVI, Sect. I, p. 235 16. - A low shrub, 3-5 ft. high, branching from the base, the spreading, rather nodose branches pubescent with appressed silky hair. Leaves ovate or elliptico-oblong, $3-6^{\prime} \times 1-2^{1} / 2^{\prime}$, on petioles of $1 / 2-2^{\prime \prime}$, short or long acuminate, entire, thin, chartaceous, tripli-nerved, the lateral nerves extending to the upper fourth of the blade, penni-nerved beyond, glabrous above, appressedly gray-pubescent underneath, at least along the nerves, or glabrate. Flowers sessile, apparently bractless, pubescent, $3-10$ in a cluster, Male perigone $2^{\prime \prime}$. Fem. perigone $1-1^{1} / 2^{\prime \prime}$, globose and $2-3^{\prime \prime}$ in diameter when mature, fleshy and red. Stigma 4 times the length of the achene. - Wedd. Monogr. Urt. p. 437. - Wawra, in Flora, 1874, p. 546. - Includes $N$. ovata, Gaud. and N. glabra, Meyen. - Boehmeria melastomaefolia, Hook. \& Arn. - B. glabra, Steudel.

On all islands, on dry slopes of the lower regions.

$\beta$ var, sericea. - Leaves silvery underneath with appressed silky hair, otherwise as before. - N. sericea, Gaud. 1. c. and Bot. Bon. tab. 133.

Oahu! Waianae Mts.

$\gamma$ var. parvifolia. - Leaves close and small; about $1^{\prime}$ long, on petioles of $1-2^{\prime \prime}$, acute at both ends, pubescent along the nerves, otherwise glabrous. Clusters few- to 2 -flowered.

Oahu, Waianae Mts. (Wawra, 1. e.).

' var. Kauaiensis. - Leaves large ovate-rhomboidal, $5-6^{\prime} \times 2^{1 / 2}-3^{\prime}$, on petioles of $11^{1} / 2^{4}$, suddenly acuminate, slightly contracting, but rounded and even retuse at the base, shortly puberulous and green underneath. Flowers numerous in a cluster, pubescent.

Ka uai! (Kn.).

Nat. name of the species: "Oloas or :Maoloa .

2. N. Kahoolawensis, $s p . n$. - Leaves broad obovate, $1^{1 / 2^{\prime}} \times 1^{\prime}$, on petioles of $1 / 2^{\prime}$, rounded and shortly apiculate at the apex, chartaceous, gray-tomentose but not silky underneath, the hairlets short, not appressed. Fem. flowers very few, mostly single in the axils, tomentose.

Found on the small island Kahoolawe by Mr. Lydgate; a single imperfect scrap only collected, but sufficient to establish the genus. A most interesting find, it being the only speciality from that small island, the vegetation of which, however, like that of Nihau, is very little known. 


\section{Order LXXIX. PIPERACEAE.}

Flowers hermaphrodite or unisexual, in closely packed spikes, or rarely in racemes, each with a subtending bract. Perianth none. Stamens 2-10. Ovary 1 -celled, with 1 erect atropous ovule. Stigmas $1-6$, sessile or on a short style. Fruit a 1-seeded berry. Embryo minute, enclosed within the embryo-sac, at the top of a fleshy albumen. - Herbs, shrubs or climbers, sometimes succulent, often articulate at the nodes. Leaves alternate, opposite or in whorls, entire, with or without stipules.

A considerable Order, almost entirely tropical, ranging over the New and old World.

Flowers dioecious; spikes opposite the leaves; anthers 4-valved. . 1. Piper.

Flowers hermaphrodite; spikes axillary and terminal; anthers 2-valved 2. Peperomia.

\section{PIPER, L.}

Flowers polygamous or dioecious. Bracts free. Stamens 2 or 3 , rarely 4 ; the anthers articulate, 4-valved, opening laterally. Ovary with 3 or 4, rarely 5 stigmas. - Shrubs, undershrubs or woody climbers, the stems with scattering vascular fibres inside of a fibro-vascular annulus. Leaves mostly alternate and the spikes opposite the leaves.

A large genus dispersed over all tropieal regions. In cultivation: the Siri or Betel Pepper $P$, Betle, L.

1. P. methysticum, Forst. - Cas. DC. in Prod. XVI, Sect. I, p. $35 \tilde{4}$. Dioecious. Stems erect, $2-3 \mathrm{ft}$. high, glabrous, fleshy, with a thick softwooded rhizome. Stipules free, soon caducous, linear-lanceolate, $1^{1 /} 2^{\prime}$ long. Leaves alternate on petioles of about $1^{\prime}$, broadly cordate-ovate, with a deep sinus at the base, shortly acuminate, about $6^{\prime}$ long and more in breadth, membranous, green on both faces and glabrous, except on the puberulous nerves, prominently 11-13-nerved, the 3 middle nerves joining at the apex. Male spikes single, $2-2^{1 / 2}$ long including a peduncle of $4-6^{\prime \prime}$, densely flowered. Bracts peltate, imbricate at first. Stamens 2; anthers subglobose, shorter than the filaments. Fem. spikes? - Hook. \& Arn. in Bot. Beech. p. 96. - Deless. Ic. p. 53, tab. 89. Macropiper latifolium, Miq.

The Awa plant, from which the Polynesians extract their well knowu intoxicating beverage. I have never seen it in a truly wild state, but it is extensively cultivated in clearings of the forests, particularly on $\mathrm{Hawaii}$. The natives distinguish 4 or 5 varieties, principally by the color of the stem, green, mahagony or purple. The species occurs also on the Marquesas, Society, Tonga, Viti and Wallis Islands.

\section{PEPEROMIA, Ruiz. \& Pav.}

Flowers hermaphrodite. Bracts free, orbicular, peltate. Stamens 2, lateral to the ovary. Anthers not articulate, 2-valved, opening ontward. Ovary sessile; stigma simple, penicillate or minute. Pericarp thin. Herbs with alternate, opposite or whorled leaves, the spikes in all our 
species terminal and axillary. No stipules. Stem with a single fibrovasal annulus.

A large genus of 370 species spread over the tropies of the whole world.

All Hawaiian Peperomias have a sessile stigma, which in the fuily formed fruit is always apieal. In the young ovary it is either apical also or oblique subanterior; the difference seems to depend on the depth and length of the foveole in which the ovary is imbedded. In deep foveoles, which, as a rule, are also short, the apex of the growing ovary is by pressure from behind and above foreed forward, so as to appear oblique for a period, but to become straight again as soon as the berry has emerged, as has been pointed out by Wawra. In shallow and long foreoles the stigma is apical from beginning to end, and, as these occur in slender spikes, while deep and short foveoles are characteristic of thick spikes, apical and oblique stigmas in the ovary simply become convertible terms for slender and thick spikes.

The stigma would seem to be broad and expanded in all species, but, as it is apt to be torn by the drying paper in consequence of its adhesiveness, the character seldom comes out properly in the dried plant. Oil-glands, as indicated by pellueid dots, seem to be present in all species, but visible on superficial examiuation only in those with thinner and areolate leaves.

As to position of leaves, alternate leaves generally hold their ground, but as to distinetion of species according to binate (opposite) or verticillate leaves, the case is very different. I do not know any Hawaiian speeies with uniformly or even prevailingly opposite leaves, while there are several in which the young plant has them so and the adult one in the lower cauline nodes or in much elongate branches; but on the upper nodes of the adult plant the leaves stand in whorls of $3-8$. It is true that the whorls are not generally genuine vertieils - as in P. reflexa -, but are caused by periodical arrest of growth, whereby the internodes are excessively shortened; but this circumstance increases the strength of the objection against a systematic division on this ground.

Several of the following species are of very doubtful validity, but as I have not been able to inspect all the originals in the various herbaria, I have deemed best to enumerate them, as they have been admitted into the $16^{\text {th }}$ Volume of De Candolle's Prodromus, with such remarks as are suggested by the contents of my own herbarium, adding thereto two others described by Wawra since the appearance of that Volume and three new ones collected by myself. Native name of all species: "Alaalawainui".

Leaves alternate:

Leaves obtuse rhomboidal, thin, pubescent

Leaves obtuse rhomboidal, thick, glabrous

Leaves elliptico-lanceolate, acute

1. P. purpurascens.

2. P. pallida.

Leaves opposite

Leaves not dotted

Leaves dark-dotted on both faces

3. P. Oahuensis.

Leaves in whorls, at least the upper cauline ones:

Leaves large, $1^{1 / 2^{*}}$ or more in length:

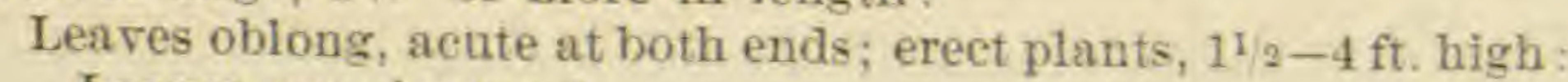

Leaves penni-nerved

Leaves pedately 5-nerved:

Leaves glabrous and mostly thin; spikes filiform, projecting beyond the leaves

Leaves pubescent and whitish underneath, subcoriaceous; spikes not projecting

Leaves linear-lanceolate, 1-nerved

Leaves obovate or ovate-obtuse, 5 -7-nerved; plant less than $1 \mathrm{ft}$. high

Leaves less than $1^{1 / 2^{\prime}}$ in length:

Leaves orbicular, obovate or spathulate, rounded at the apex:

Leaves thick fleshy, about $1^{\prime}$ in length or more:

Spikes several, axillary and terminal

Spike single, terminal, very long

4, $P$, insularum.

5. P. Fernandeziana.

\section{P. Macraeana.}

8. P. membranaeea.

9. P. hypoleuca.

7. P. Hesperomannii.

11. P. latifolia.

12. P. pachyphylla.

13. P. Sandwicensis. 
Leaves thin, less than $1^{\prime}$ in length:

Leaves ovate-obtuse or orbicular, purplish underneath $17 . P$. parvula.

Leaves spathulate or obovate-cuneate.

Leaves, at least the upper ones, more or less acuminate:

Leaves 1- or faintly 3-nerved; stem sulcate:

Leaves lanceolate, flat and thin

Leaves ovate-obtuse, thick fleshy

14. P. Mauiensis.

Leaves 3-nerved; stem terete:

Plant ereet, branching near the top with erect branches leaves pale underneath, oblong

Plant erect, horizontally branching from the base; leaves Janceolate

Plant weak decumbent, branching from the base upward; leaves ovate or obovate

Leaves 5-nerved, thin reticulate; spikes numerous and long, filiform

15. P. ligustrina.

16. $P$ reflexa.

9. P. hypoleuca. var. mont. Eeka.

19. P. pleistostachya.

18. P. Cookiana.

10. P. leptostachya.

1. P. purpurascens, Nutt. - DC. Prod. XVI, Sect. I, p. 41\%. - Branches pubescent. Cauline leaves alternate, on long $\left(1^{1 / 4^{4}}\right)$ pubescent petioles, rather obtusely rhomboidal or obovate, $18-20$ "long and half as broad, glabrous above, pubescent underneath, membranous, rather pellucid, $3-5$-nerved, the central nerve extending to the apex, the lateral ones nearly as high, all slender and with the veins reticulate. Spikes terminal, filiform, densely flowered, 3 times as long as the leaves. Ovary immersed, with a minute oblique stigma. Berry ovoid, acute. (Descr. from the Prod.)

Sandw. Islds. (Nuttall in herb. Brit. Mus.). - Probably Wawra's P. latifolia, var. alternifolia, from Hanalei, Kauai, belongs here: "folia ovata et orbicularia, infima minuta et longitudine latiora, manifeste nervosa, 5-nervia, nervis ramulosis, tenere membranacea. Amenta in caulis apice plerumque gemina. Ovarium late obovatum, in apice plano stigmatiferum". - Nuttall's plants were mainly collected on Kauai.

2. P. pallida, A. Dietr. - DC. Prod. 7. c. p. 418. - Stem erect, glabrous. Leaves alternate, on glabrous petioles of $3^{\prime \prime}$, elliptico- or obovatorhomboidal, $2^{1} / 2^{\prime} \times 10^{\prime \prime}$, somewhat obtuse, subcoriaceous, glabrous on both faces, 3-5-nerved, the 3 middle nerves extending to the apex, the external ones smaller. Spikes axillary, single, filiform, densely flowered, about $1^{1 / 2}{ }^{\prime}$ long, on glabrous peduncles of $6-7^{\prime \prime}$. Stigma minute, oblique. Berry ovoid, half immersed. (Deser. from the Prod.) - Miq. Syst. Pip. p. 103. - Hook. \& Arn. in Bot. Beech. p. 96. - Piper pallidum, Forst. and Willd.

Oahu (Lay and Collie). - Occurs also in Tahiti and the Viti Islands. - Doubtful as to the Sandw. Islands.

3. P. Oahuensis, Cas. DC. in Prod. l. c. p. 422. - Branchlets glabrous. Leaves alternate, on glabrous petioles of $4^{\prime \prime}$, oblong-elliptical, $12^{\prime \prime} \times 4^{\prime \prime}$, acute, glabrous, subopaque, reticulate, 3-nerved (?). Spikes axillary, on peduncles of $4^{\prime \prime}$, filiform, densely flowered. (Descr. from the Prod.) P. pallida, Dietr.?

$\mathrm{O}$ a h u (Beechey in herb. Kew), - I have plants from Halemano, Oahu! and from the leper settlement of Kalawao, Molokai! which correspond with the above. Several slender stems from a fibrous root, erect and decumbent, glabrous, $4-6$ long. Leaves 
alternate, lanceolate, $1-2^{1} /^{\prime} \times 3-5^{\prime}$, acute at both ends, on petioles of $3-4^{\prime \prime}$, quite glabrous, membranous, with minute pellucid dots, pale underneath, reticulate, 3-nerved, the weak lateral nerves seldom excurrent to the apex. Spikes axillary, single or twin, slender, not exceeding the leaves, on petioles of $3-6^{\prime \prime}$, glabrous, loosely flowered. Stigmas apical and suboblique. Berries globose, obovoid, emersed. - On trees.

4. P. insularum, Miq. - DC. Prod. l. c. p. 444: - Stems pubescent, rooting below, tumid at the nodes. Leaves all opposite, on petioles of $3-5^{\prime \prime}$, ovate, acute at the apex, rounded or attenuate at the base, $7^{\prime \prime} \times 4^{\prime \prime}$, rigid, subopaque, the younger ones pubescent particularly along the nerves underneath, not reticulate, 3 -nerved, the central nerve running to the apex, the lateral ones only to the middle. Spikes axillary and terminal, on peduncles of $2-3^{\prime \prime}$, filiform, densely flowered, somewhat hairy. Ovary projecting. Stigma minute, apical and subanterior.

Oahu (Diell, no. 53 in herb. Kew).

$\beta$ var. glabrata. - Leaves larger, $14^{\prime \prime} \times 6^{\prime \prime}$, on petioles of $2-4^{\prime \prime}$, glabrous. Spikes thicker. (Deser. from the Prod.) - Diell, in herb. Kew.

My herbarium contains mixed with $P$, pachyphylla from $\mathrm{O}$ ahu three specimens only 3-4 high, most leaves of which correspond with the above description while the lowest ones are obovate to orbicular as in true $P$. pachyphylla. I had taken them for young plants of that species, the leaves being hairy, rigid, opaque, with impressed nerves and not areolate. From the pali of Wailau, Molokai, again, there is a specimen with broadly ovate and shortly acuminate leaves, 6-12"long, exactly as in $P$. insularum. Here the leaves stand opposite, except at the apex where they are ternate. These grew together with $P$. Cookiana, are somewhat less hairy and fleshy than ordinary small-leaved forms of $P$. pachyphylla, but otherwise not very different. Perhaps they mark a transition from $P$. pachyphylla to $P$. Cookiana.

5. P. Fernandeziana, Miq. - DC. Prod. l. c. p. 445. - Stems erect, slightly branching, pubescent, hirsute at the nodes. Leaves opposite, rarely ternate, on pubescent petioles of $3-9^{\prime \prime}$, about $10-12^{\prime \prime}$ long, the upper ones ovate-oblong, somewhat acute, the lower suborbicular, truncateretuse, all glabrous, ciliate toward the apex, dark-dotted on both faces, membranous to subcoriaceous, not reticulate, 3 -nerved, the median nerve leading to the apex, the lateral ones disappearing above the middle. Spikes axillary, opposite or ternate, $16-20^{\prime \prime}$ long, on peduncles of $6 "$, loosely flowered. Ovary impressed, obtuse, with minute stigma. (Deser. from the Prod.) - Miq. in Hook. Lond. Journ. Bot. V, 4, p. 423. - Wight, Ic. Pl. Ind. Or, tab. 1923.

Oahu (Nutt. in herb. Brit. Mus.). - A species of Juan Fernandez, Chile and the Andes of Peru.

6. P. Macraeana, Cas. DC. in Seem. Journ. Bot. 1866, p. 145. - DC. Prod. l. c. p. 457 . - Branches glabrous, or puberulous with ochraceous hairlets. Leaves ternate, elliptico-oblong, $2^{1 / 2}-3^{1 / 2^{\prime}} \times 1^{1 / 4}-2^{1 / 4^{\prime}}$, on glabrous petioles of $1^{1 /} 2^{\prime}$, acute at both ends, glabrous above, puberulous underneath along the nerves, stiff membranous, subpellucid, penni-nerved, the median nerve extending to the apex, prominent underneath and sending 
off on each side in the lower third $2-4$ ascending weaker nerves, the uppermost of which almost reach the apex. Spikes filiform, equalling the leaves in length, on glabrous peduncles of $5^{\prime \prime}$, densely flowered. Ovary impressed, obovate, with oblique stigma. (Descr. from the Prod.)

Hawaii! (Macrae, in herb. Brit. Mus.); W. Maui! Molokai! Maunahui, Pelekunu in forests. - My specimens from Hawaii were collected in the Kohala range and in the woods of Hilo.

The species is probably the largest of all known Peperomias, the fleshy brown stems, which equal a mau's thumb in thickness, often exceeding $4 \mathrm{ft}$. in height. Leaves opposite or in whorls of $3-5$, dull green below (not pale), and mostly long acuminate, up to $4^{\prime}$ in length, sometimes thin and subpeilucid, oftener chartaceous and subopaque, but always areolate and with several smaller nerves issuing from the median, nerve in its upper third, besides the larger ones from the lower. Spikes in the axils of the one or two uppermost whorls, not projecting beyond the leaves, $2-3^{1} / 2^{\circ}$ in length, rather thick and glabrous, densely flowered. Stigma sessile, broad, oblique. - In a fragmentary specimen collected by Mr. Lydgate near Hilo, probably on open and dry ground, the leaves are subeoriaceous and much smaller, $2^{\prime}$ in length. 'Spikes numerous in the three upper whorls, only half the length of the leaves.

$\beta$ var. picta. - Leaves opposite (in young plants often alternate) and ternate, ovato- or elliptico-oblong, acute or acuminate, $1^{1 / 2}-2^{\prime}$ long, chartaceous, opaque, purplish underneath excepting the nerves, and papillo-puberulous throughout.

Maui! Waihee and Waiehu.

\% var. nervosa. - Stems shorter, $1^{1 / 2}-2 \mathrm{ft}$. high, quite glabrous. Leaves $3-5$ in a whorl, elliptico-lanceolate, $2-3^{\prime} \times 6-10^{\prime \prime}$, acute at both ends, on petioles of $4-8^{\prime \prime}$, thick chartaceous, glabrous on both faces, opaque, purplish underneath excepting the course of the nerves, penni-nerved in the manner of P. Macraeana, but all the nerves prominent underneath and impressed above, the inner pair joining the margin near the apex.

Kanai! Waimea (Kn. 107). - Along with this Mr. Knudsen sends a form with very narrow leaves, 3-nerved from the base, not colored underneath.

7. P. Hesperomannii, Wawra, in Flora, 1875, p. 226. - Stem solitary, $1 \mathrm{ft}$. high, erect from a decumbent base, simple or once forking, slender, quite glabrous. Leaves opposite below, quaternate above, linear or linearlanceolate, $2-2^{1} / 2^{\prime} \times 2-3^{\prime \prime}$, gradually narrowing to petioles of $2-3^{\prime \prime}$, bluntly acuminate, membranous, glabrous except at the ciliate apex, deep green and glossy above, pale underneath, densely dotted with small pellucid glands, 1-nerved, sometimes with 2 faint lateral nerves besides. Spikes terminal, solitary or twin, $3^{\prime}$ long on peduncles of $3-4^{\prime \prime}$, loosely flowered, the flowers in spirals separated by broad bands of naked rhachis and approximating near the apex. Bracts peltate, glandular, with a broad diaphanous margin. Filaments twice the length of the anthers. Ovary appressed to the rhachis, with apical or suboblique stigma.

Kauai, Mt. Waialeale, $6000 \mathrm{ft}$. Not unlike P. myrtillus, Miq., or P. Swartziana (Wawra). - Probably is connected with var. $\gamma$ of the preceding species. 
8. P. membranacea, Hook. \& Arn. in Bot. Beech. p. 96. - DC. Prod. l. c. $p .459$. - Stems ereet, glabrous, $1^{1 / 2}-2 \mathrm{ft}$. high, dichotomously branching near the summit. Leaves often opposite below, in whorls of $3-5$, above, elliptico-, ovato-, or obovato-oblong, acute or acuminate, $1^{1 / 2}-3^{\prime} \times 1-1^{1 / 2^{\prime}}$, on petioles of ${ }^{1} / 4-1^{1}$, membranous with 5 conspicuous basal or subbasal nerves, the median extending to the apex, the two next converging close to it, the two external running out near the middle, more or less reticulate and dotted with pellucid glands, dark green, glossy above, glabrous underneath. Spikes in terminal and axillary whorls, slender filiform, projecting beyond the leaves, $2-4^{\prime}$ long including a peduncle of $6-9^{\prime \prime}$, rather loosely flowered. Stigma on a short oblique beak. Berry short ovoid, almost free. - Wawra, l. c.

Oahu! in dense woods. - In narrow and more elongate leaves the inner pair of lateral nerves often leaves the median at some distance above the base, thus approaching $P$. Macraeana. Short- and broad-leaved forms, with the terminal whorls fuller and the spikes longer, tend toward $P$. leptostachya. - The species is reported also from the Marianne Islands.

$\beta$ var. Gaudichaudii. - Leaves thicker and rather pale, but quite glabrous. - P. Gaudich. Miq. Syst. Pip. p. 137. - DC. Prod. 1. c. p. 460. - Wawra, 1. c.

Oahu! on both ranges.

9. P. hypoleuca, Miq. - DC. Prod. l. c. p. 459. - Stems 1-2 ft. high, erect, branching near the top; the young branches, petioles, larger nerves and peduncles shortly hairy. Leaves thick, opaque, pale, almost whitish underneath and papillo-puberulous, their position, shape and size as in P. membranacea, the lower ones generally smaller and obovate, obtuse. Spikes thick fleshy, densely flowered, not projecting beyond the leaves, about $2^{\prime}$ long including a peduncle of $3-6 "$ ".

Oahu! Kaala range.

$\beta$ var. montis Eeka. - A much smaller plant, many-stemmed from the root, the erect stems $6-10^{4}$ long, thickly tomentose with coarse dark-brown hairlets. Leaves $3-8$ in a whorl, broad elliptical, ovate or obovate, obtuse, even rounded, or somewhat acute, $4-12^{\prime \prime} \times 3-8^{\prime \prime}$, on petioles of $2-4$ ", thick, opaque, dark green and glabrate above, pale rust-colored and pubescent underneath, conspicuously 3 -nerved, the lateral nerves extending to the middle and the median mostly penni-nerved besides. Spikes terminal in whorls of $3-7$, short and thick, $1-1^{1} / 4^{\prime}$ long, pubescent, densely flowered. Stigma broad, sessile, papillose, oblique in the ovary, apical in the berry.

W. Mauil Eeka. - Has the appearance of P. hirsuta, Miq., from Brazil, but is less hairy and has shorter spikes.

; var. Kauaiensis, - Leaves $1-2^{\prime}$ long, oblanceolate or oblong, bluntly acuminate, opaque, pale underneath but almost glabrate, at most only 
faintly puberulous. Spikes exceeding the leaves, $3-3^{1 / 2} 2^{\prime}$ long and rather slender.

Ka uai! Waimea (Kn.). - Intermediate between the present species and $P$. membranacea.

10. P. leptostachya, Hook. \& Arn. in Bot. Beech. p. 96. - DC. Prod. l. c. p. 448. - Stems weak and slender, suberect or decumbent, $1-2 \mathrm{ft}$. long, hirsute with gray spreading hairlets, horizontally branching from the base upward, the branches in whorls and the lowest often exceeding $1 \mathrm{ft}$. in length with internodes of $1^{1 / 2}-4^{\prime}$. Leaves mostly ternate, often opposite below, in whorls of 4 or 5 or more above, on hairy petioles of $3-9^{\prime \prime}$, elliptico-oblong or obovate, acuminate, $1-1^{1 / 2^{\prime}} \times{ }^{1 / 2}-1^{\prime}$, the uppermost and the lowest cauline (these obovate-obtuse) much smaller, thin but opaque, scarcely areolate, with minute pellucid glands, 3-5-nerved, the lateral nerves running out above the middle, hairy on both faces or glabrate above. Spikes very numerous in terminal and axillary whorls of every branch, $4-7$ to a whorl, but often $7-12$ in the terminal one, slender filiform, $2-5^{\prime}$ long including a puberulous peduncle of ${ }^{1 / 2}-1^{\prime}$, distantly flowered. Bracts orbicular, very small. Berry small ovoidglobose, scarcely immersed. Stigma minute, oblique at first, but short apical at last. - Miq. Syst. Pip. p. 138. - Hook. Lond. Journ. Bot. V, 4, p. 423 .

H awaii! Kohala range; E. \& W. Maui! between 3000 and $4000 \mathrm{ft}$. above the sea; Oahu (Lay. \& Collie). - The plant grows in dense clumps or leans for support against otber shrubs. Is found also in Tahiti, Nukahiva, and N. E. Australia from Sydney to Brisbane.

$\beta$ var. nodosa. - Stems suberect, $6-10^{\prime}$ high, contracted with tumid closely approximate nodes. Leaves mostly opposite, ovate or oblong and somewhat obtuse, $6-9^{\prime \prime} \times 4^{4}$, on puberulous petioles of $1^{\prime \prime}$, faintly 3 -nerved, pubescent on both faces or glabrate above. Spikes numerous as before and filiform, but shorter, $2-2^{1 / 2}$.

In the dry scrub of the eastern end of Oahu! and the western end of Moloka i! Kalae. The leaves break readily at the articulation of the petiole with the stem, and so does the stem at the nodes. - Resembles P. galioides, Kth., a species spread over the greater part of tropical America. - Wawra's $P$. insularum probably belongs here.

11. P. latifolia, Miq. - DC. Prod. 7. c. p. 448. - Stem fleshy, $10^{\prime}$ high, decumbent and rooting at the base, the younger stems with reddish hairlets. Leaves opposite or ternate, on pubescent petioles of $7-8^{\prime \prime}$, ovate-elliptical or obovate-rounded, acute at the base, $16-20^{\prime \prime} \times 12-16^{\prime \prime}$, glabrous above, puhescent underneath, dotted, 5- or obsoletely 7 -nerved and reticulate, the median nerve reaching the apex, the first lateral pair extending to beyond the middle, the second to the middle, the external ones losing themselves in the margin. Spikes axillary and terminal, twice as long as the leaves, filiform, densely flowered, on hairy or glabrate peduncles which exceed the petioles. Stigma minute, apical. Berry 
ovoid-globose, partly immersed. (Descr. from the Prod.) - Miq. Ill. Pip. p. 20, tab. 15. - Wawra, in Flora, 1875, p. 191. - P. subcrenata, Klotzsch, in herb. Berlin.

Oahu (Meyen, in herb. Berlin). - Is hardly more than a larger and often thinnerleaved form of P. pachyphylln, with which it shares the same habitat. My collection contains specimens from $\mathrm{Oahu}$ ! and from the pali of Wailau, Molokai! Stems several, $6-8^{\prime}$ high, divaricately branching near the top, puberulous when young. Leaves binate to quaternate, obovate or suborbieular with rounded apex, or broad rhomboidal, or rarely ovate-oblong with narrowing apex, $1^{1 / 2}-3^{\prime} \times 1-1^{3 / 4^{\prime}}$, on petioles of $1^{1 / 2}-1^{\prime}$, sometimes as thick as in $P$. pachyphylla, with the nerves impressed below, but generally thinner, glabrate above, puberulous and pale underneath. Spikes of variable thickness, but not filiform, mostly terminal and projecting beyond the leaves, $2-4$ ' long, including a pubescent peduncle of $1 / 2-1$. Foveoles shallow. Stigma suboblique at first, apical in the berry. Wawra's description agrees quite well. His specimens eame from Hanalei, Kauai. P. marginata, Miq., from the island of Bourbon (in hb. Berlin) only differs in the dark dots on leaves and spikes.

12. P. pachyphylla, Miq. - DC. Prod. 7. c. p. 460. - Stem smooth, $8^{\prime}$ high, rooting at the base, dichotomously branching, the younger branches pubescent. Leaves opposite and quaternate, on petioles of $4-7^{\prime \prime}$, obovate or obovate-orbicular, $1^{1} / 2^{*} \times 1^{\prime}$, hairy above, puberulous underneath or glabrate with age, fleshy, opaque, generally 3 -, sometimes 5 -nerved, the median nerve reaching to the apex, the lateral ones nearly as far, the external ones to the middle. Spikes axillary on peduncles of $5-7^{\prime \prime}$, filiform, densely flowered, glabrous, 1' long. Stigma oblique. Berry immersed with the base, ovate-acute. (Descr. from the Prod.) Oily dots, when perceptible, few and large.

Oahu! (Cham. in hb. Berlin, Lay \& Collie, Seem. in hb. Brit. Mus, and hb. DC.), The species is common on the mountains back of Honolulu and on Molokai! Stems several, subereet, $4-8^{\prime}$ high, branching divaricately in verticels near the top. Leaves variable in shape, from broad-obovate with euneate hase to orbicular, to rhomboidal and ovate-obtuse, $6-12^{4} \times 6-9^{*}$. What principally distinguishes them is the thick fleshiness without areoles and the pale, levigated, generally convex underside with the basal nerves only visible, but these deeply impressed underneath and prominent above in the dried plant, both lateral pairs shorter than in any other species. According to elevation and moisture of locality it varies in hairiuess, being sometimes met with quite glabrous in low and dry localities. Spikes terminal and axillary, $1-2^{*}$ long, pubescent, rather thick and dense, - Should the preceding species be united with the present one, the name pachyphylla ought to be retained as being most characteristic.

$\beta$ var. picta. - Leaves obovate or rhomboidal, $10-15^{\prime \prime} \times 8-10^{\prime \prime}$, purplish underneath except along the nerves. P. verticillata, Hook. \& Arn.?

Oahu! Makiki and Pauoa.

$\gamma$ var, insularum. - Coarsely hirsute with reddish hair. Leaves not exceeding $1^{\prime}$, crbicular or obovate, or ovate with a short acumination, less fleshy than before, with the basal nerves moderately impressed. Lower leaves mostly opposite, in young plants even alternate.

High ridge above Manoa and Palolo, Oahu!

13. P. Sandwicensis, Miq. - DC. Prod. l. c. p. 460. - Fleshy, 4' high, branching from the base, the branches simple or sparingly divided, 
appressedly hairy. Leaves opposite and ternate, obovate-spathulate, $10-12^{\prime \prime} \times 8^{\prime \prime}$, on hairy petioles of $5^{\prime \prime}$, shortly hairy on both faces, membranous, subopaque, pellucid-punctate, reticulate, 3-nerved, the median nerve reaching to the apex, the lateral ones falling short but continued to it by a weak marginal nerve. Spikes axillary (?) and terminal, $3-4$ times as long as the leaves, including a peduncle of about $10^{\prime \prime}$, filiform, rather densely flowered. Ovary semi-immersed, with minute oblique stigma. Berry impressed, ovoid-globose. (Descr. from the Prod.) - Miq. Ill. Pip. p. 19, tab. 14. - Wawra, 1. c.

Oahu (Meyen in herb. Berlin). - A good species, characterized by the spathulate or euneate-obovate leaves in conjunction with the unusually long spikes. These in all my specimens, which were collected on Molokai and W. Maui, are single and terminal at the ends of the stem and branches, as is the case also in Meyen's plant in herb. Berlin. The Molok a plants have terete stems, $4-6^{\prime}$ long, with horizontally spreading branehes and ternate to quinate leaves, the lower ones obovate-cuneate, rounded at top or obcordate, $9-18^{\prime \prime} \times 5-9^{\prime \prime}$, on petioles of $4-6^{\prime \prime}$, the upper ones spathulate or obovate-oblong and shortly and biuntly aemminate, thiek, opaque, not reticulate, pale and levigated underneath, impressedly 3 -nerved, the lateral nerves scarcely exceeding the middle. Spike $3-5 \cdot$ long, including a pubescent peduncle of $1 / 3$ to $1 / 2$ its length, not filiform, often clarately swelling toward the apex, densely flowered.

$\beta$ var. - Upper leaves rhomboidal or shortly obovate, purplish-red underneath as in var. $\beta$ of $P$. pachyphylla, those of the long branches generally opposite. Spike single.

Maui! Kaanapali.

14. P. Mauiensis, Wavra, 7. c.p. 141. - Stems several, slender, 6-8 long, erect, striate, glabrous, simple or sparingly dividing above into ascending branches. Leaves $3-6$ in a whorl, narrow spathulate or cuneate, $6-10^{\prime \prime}$ $\times 2-3^{\prime \prime}$, on petioles of $2-3^{\prime \prime}$, rounded at top, glabrous, 1-nerved, thin, reticulate, not perceptibly dotted, dark green above, pale olivaceous underneath (violaceous with white streaks according to Wawra). Spikes terminal, $2-2^{1} / 2^{\prime}$ long, on slender peduncles of $1^{1} / 2^{\prime}$, distantly flowered. Bracts orbicular, with hyaline margins. Stigma subobliqué, papillose.

Ma ui! Wailuku, Hamakua. Some of my Ma ui specimens exhibit 2 faint lateral nerves. Only one bears a single and slender terminal spike of about $4^{\prime}$ in length, like $P$. Sandwicensis. Others, collected on Molokai! have shorter and proportionally broader leaves, with $1-3$ terminal spikes which measure $1-3^{\prime}$ in length. - The/species does not seem to differ much from the American P. quadrifolia, Kth.

$\beta$ var. parvifolia. - Leaves elliptico-oblong, obtusely acuminate, $4-6$ " long, 1-nerved.

Ma ui! Kaanapali.

15. P. ligustrina, sp. n. - Stems several, erect, 6-9" long, slender, angular, nodose below with short internodes, and only a few short branches near the end. Leaves opposite below, ternate above, narrow-lanceolateacute, $8-10^{\prime \prime} \times 2-3^{\prime \prime}, 1$-nerved or with 2 short evanescent lateral nerves, quite glabrous, dark-green, rather pale underneath, thin but opaque, 
without pellucid dots. Spikes terminal or on short axillary shoots, $1-3$ in the uppermost whorl, slender, $1-1^{1 / 2^{\prime}}$ long, with a peduncle or $3-4^{\prime \prime}$. Ovary pointed but not beaked; stigma apical.

W. Ma ui! Waihee, and forms with shorter and proportionally broader, somewhat obtuse, 1-nerved leaves from Kaanapali, about $2000 \mathrm{ft}$. above the sea. - This, and not P. Hesperonannii, is the nameless no. 463 of Mann's Enumeration (Remy 184).

16. P. reflexa, A. Dietr. - DC. Prod. l. c. p. 451, - Stems several from a fibrous root, $4-6^{\prime}$ long, decumbent and rooting below, angular-sulcate, glabrous, or sometimes puberulous at the nodes. Leaves in close whorls of $3-4$, broadly ovate-obtuse, or rhomboidal, or suborbicular, $4-8^{\prime \prime} \times$ $4-6^{\prime \prime}$, on short pubescent petioles which do not exceed $1^{\prime \prime}$ in length, pale, glabrous and glossy above, puberulous or punctulate underneath, thick fleshy, with the lower face convex, indistinctly 3 -nerved, wrinkled in the dried state, with pellucid dots. Spike solitary, terminal, $1^{1 / 2}-2^{1 / 2} 2^{\prime}$ long, including a puberulous peduncle of $6-9^{\prime \prime}$, thick, densely pubescent and very closely flowered, with deep foveoles. Stigma apical, suboblique. Berry ovoid-elongate, shortly beaked, immersed at the base. - Piper reflexum, L. f. - Piper tetraphyllum, Forst. - Peperomia tetraphylla, Hook, \& Arn. - Wawra, 1. c.

On all islands, growing on rocks and trees. - Is found on many islands of the Pacific, in the East Indies, from tropical Africa to the Cape, and in America from Jamaica to Brazil. The species is pretty uniform throughout our group, but the following forms deserve to be mentioned as local varieties.

$\beta$ var. Honolulensis, Wawra. - Quite glabrous, the stems as thick as a goose-quill and $1 \mathrm{ft}$. long. Leaves oblong or ovate-oblong obtuse, over $1^{\prime}$ long, on glabrous petioles of $1^{1 / 2}-2^{\prime \prime}$. Spikes hirsute along the ridges of the foveoles.

Dry gulches above Honolutu (Wawra).

ir var. elongata. - Quite glabrous. Stems very slender, 5-8' long, decumbent and rooting freely, with long internodes of $1^{1 / 2}-2^{\prime}$. Leaves occasionally opposite below, rhomboidal or ovate-obtuse, $3-4$ "long, thin membranous when dry, 3-nerved, the lateral nerves converging and joining the median near the apex. Spikes faintly pubescent.

On trees; Mopulehu, Molokai!

The shape of the leaves varies in the same plant; they may be orbicular with emarginate apex below, while the upper ones are ovate with obtuse apex.

17. P. parvula, $s p . n$. - Stems decumbent, rooting, the ascending portion slender, $2-5^{\prime \prime}$ long, densely hirsute with fawn-colored hair. Leaves opposite to quaternate, orbicular or ovate-obtuse, $3^{1 / 2}-5^{\prime \prime} \times 3-5^{\prime \prime}$, on hairy petioles of ${ }^{1} / 4-1^{1} / 2^{\prime \prime}$, subchartaceous when diry, hispid above, pubescent underneath and purplish-red except along the nerves, opaque, obscurely 3 -nerved, the lateral nerves ceasing about the middle, dotted with a few pellucid glands. Spikes terminal, 3 in a whorl, $16^{\prime \prime}$ long 
including the pubescent peduncles of $1 / 4$ their length, puberulous, distantly flowered, with shallow elongate foveoles. Berries very small, subglobose, with apical stigma.

Only two specimens without label, mixed with $P$. reflexa, probably collected on the high ridge of Waiolani to the left of the pali of Nuuanu, O a hu. A small creeping plant, in appearance like $P$. Deppeana, Schl, from tropical America.

18. P. Cookiana, Cas. DC. in Prod. 7. c. p. 450. - Stem herbaceous, pubescent, $1 / 2$ " thiek, rooting below. Leaves ternate to quaternate, suborbicular, the upper ones elliptico-lanceolate, 8 "long, on pubescent petioles of $3-5^{\prime \prime}$, membrano-coriaceous, opaque, pubescent underneath, 3-nerved. Spikes axillary (?), with hairy peduncles. Bracts orbicular, peltate. Ovary subimmersed; stigma apical, fleshy-papillose. (Descr. from the Prod.)

Sandw. Islds. (Gaud. in herb. De Cand.). - I have suites of plants from Eeka above Lahaina and Kaanapali, Maui! and from the pali of Wailau, Molokai! which agree with most of the above characters. As Gaudichaud collected above Lahaina, his plants probably derive from there. Mine were found growing between moss on the trunks of old trees.

Stems decumbent, rooting below, $4^{\prime}-7^{\prime}$ long, slender, coarsely pubescent, horizontally branching from the base upward as in P. leptostachya, the branches opposite below, ternate above. Leaves opposite to quaternate, elliptical or ovate, obtuse or bluntly acuminate or obovate and rounded, the lower ones suborbicular, $4-12^{\prime \prime} \times 3-7 "$, on petioles of $2-4^{\prime \prime}$, hispid or glabrate above, pubescent and pale underneath, thin, reticulate and dotted, or more or less opaque, with an excurrent median and 2 indistinct short lateral nerves. Spikes several in terminal whorls at the end of each branch or of short axillary shoots, slender filiform, $1-3^{\prime}$ long including a hispid peduncle of $3-6^{\prime \prime}$, glabrous, loosely flowered. Berry small ovoid, with sessile apical stigma.

It is a much smaller plant than $P$. leptostachya and coarser in texture, but like it in habit and profusion of spikes, which are however mueh shorter. Yet Mani specimens with larger and thinner ovate leaves exhibit also longer spikes, thus making a real approach toward that species. Some Molok ai plants have thick and rather acutely ovate leaves, all opposite and about 12 "long, answering to the description of $P$, insularum. On the other hand, in plants from the same island obovate leaves with rounded apex lengthen out into a cuneate base and pass into the form of $P$. Mauiensis, to which also the less divided stem begins to accommodate itself: Stem-leaves are generally much larger and more pointed than those of the branches.

19. P. pleistostachya, sp. $n$. - Erect, much stouter than the preceding species, $6-10^{\prime}$ high, the stem fleshy, $2-3^{\prime \prime}$ thick near the base and densely hirsute throughout, horizontally branching from the base upward, the branches again dividing at nearly every node. Leaves opposite below, ternate and quaternate above, ovate-oblong to lanceolate, acuminate, $9-15^{\prime \prime} \times 4-7^{\prime \prime}$, on pubescent petioles of $3-4^{\prime \prime}$, hispid above, pubescent underneath, thick, opaque, without pellucid dots, dark-colored when dry, 
3-nerved, the lateral nerves faint and short. Spikes very numerous, crowded in terminal whorls on the stem and every branch, and axillary, slender, $1-2$ long including a pubescent peduncle of $1 / 4-1 / 3$ their length, glabrous. Stigma apical, sessile, papillose.

Molokai! pali of Pelekunu. - Terrestrial; remarkable for the great number of short spikes.

\section{Class II. MONOCOTYLEDONOUS OR ENDOGENOUS PLANTS.}

Stem not divisible into pith, wood and bark, but, when perennial, consisting of bundles of vascular fibres irregularly imbedded in cellular tissue, with a firmly adherent rind outside. Embryo with 1 undivided cotyledon, the young stem being developed from a sheath-like cavity on one side.

Besides being distinguished by the above characters Monocotyledons may be generally known by the simple, entire, alternate or radical leaves with simple parallel veins, the base usually encircling or sheathing the stem or the base of the next leaf; and the parts of the flower are most frequently in threes, the calyx and corolla, when present, being generally similar in appearance, forming a perianth of six parts. In several families, however, the perianth is wholly wanting, or the parts are reduced in number when irregular, or in the Najadaceae are in twos or fours. The leaves are exceptionaJly pinnately or netted-veined, in Scitaminaceae, in most Aroidaceae, in Dioscoridaceae and in Smilax. The stem is woody in the Palms, Pandanaceae, some Liliaceae, and Bamboos.

* Ovary inferior; perianth of 6 segments in 2 series.

† Flowers irregular.

LXXX. ORCHIDACEAx. Anthers 1 or rarely 2, sessile on a column bearing the stigma.

LXXXI. Scitaminacfae. Stamens normally 6 , but $1-5$ barren and changed into staminodes or petals; leaf-veins usually pinnate.

\section{+† Flowers regular.}

LXXXII. Iridacear. Perianth corolla-like; stamens 3; ovary 3-celled, with several ovules in each cell.

LXXXIII. TACCACEAE. Perianth subherbaceous; stamens 6 , included, the anthers hooded; ovary 1-celled, with parietal placentas and many ovules.

LXXXIV. Drosconeaceat. Flowers unisexual; perianth small; anthers 6 or 3 ; ovary 3-celled, with 2 ovules in each cell. Twiners.

** Ovary superior, synearpous, 8-celled; perianth of 6 segments in 2 series.

$\dagger$ Perianth, or at least its inner series, corolla-like.

LXXXV. LrLiceae. Perianth regular, wholly corolla-like; cells of ovary 2- to manyovulate.

LXXXVI. CommelinaceaE. Perianth rather irregular, its outer series calyx-like; stamens 6 , or by abortion less; cells of ovary 1-ovulate.

$$
\text { † Perianth small, calyx-like, stiff or herbaceous. }
$$

LXXXVII. Flageldartaceaf. Fruit a drupe, 3-celled, with 1 seed in each cell; leaves longitudinally plaited, sheathing; stem woody, bamboo-like. 
LXXXVIII. JUNCACEAE. Fruit a 1- or incompletely 3-celled capsule with 3 seeds. A grass-like herb.

LXXXIX. Palmaceae. Fruit drupaceous or baccate, 1-seeded; leaves palmate or pinnate; flowers on a branching spadix, usually spathaceous. Mostly single-stemmed trees.

"* Ovaries superior, naked, or rarely with a few scales instead of a perigone; the flowers generally unisexual, disposed on spathaceous spadices.

XC. Pandanaceae. Flowers dioecious, in heads or branched spikes; anthers stipitate; leaves elongate, prickly at the keel and edges; stem woody.

XCI. AraCEAE. Flowers monoecious, on a simple spadix; anthers sessile; leaves sheathing at the base, often net-veined; stem fleshy or tuberous.

**s Ovaries superior, solitary or apocarpous, with or without perianth, not disposed on spadices nor in glumaceous spikes.

XCII. Alismaceate. Perianth of 6 segments, the 3 inner petaloid; carpels $3-6$ or more. Aquatic herbs.

XCIII. NAJADACEAE. Perjanth wanting or of 4 scale-like herbaceons divisions; carpels 1,2 or 4 . Aquatic herbs.

"*s* Flowers in spikes or heads, sessile within imbricate dry bracts or glumes; perianth rudimentary or wanting; ovary 1-celled, with a single ovule.

XCIV. CYPERaceae. Each flower in the axil of 1 glume without palea; anthers basifixed; fruit a nut, the pericarp free from the seed; leaf-sheaths entire; stem trigonous, solid.

XCV. Graminaceae, Flowers with a second bract (palea) opposite the glume; anthers versatile; fruit a caryopsis, the pericarp generally adherent to the seed; leafsheaths split open opposite the blade; stem terete, usually hollow.

\section{ORDER LXXX. ORCHIDACEAE.}

Perianth superior, irregular, of 6 usually petal-like segments; the 3 outer ones, called sepals, and 2 of the inner ones, called petals, usually similar; the third one, called labellum or lip, differing from the others in shape, direction or insertion. Opposite to the labellum, in the axis of the flower, is the column, consisting of 1 or rarely 2 stamens combined with the style; the 2 -celled anther or anthers being variously situated on the style itself, and each cell of the anthers sometimes spuriously divided into 2 or 4 smaller cells. Pollen usually cohering in 1, 2 or 4 pairs of oblong or globular pollen-masses, tapering at one end into a point, and in many genera attached in pairs to a stalk or caudicle, or all cohering by their points or eaudicles to a gland detaching itself from the rostellum. Ovary inferior, with 3 parietal placentas. Stigma usually forming a hollow disk on the column, often with an erect projection in front of the anthers called the rostellum. Capsule 3 -valved. Seeds innumerable, minute, resembling fine saw-dust. Embryo a solid, apparently homogeneous mass. - Herbs, always perennial, either by means of a continuous stem or rhizome, or by annually renewed tubers, terrestrial or epiphytes; in the latter case the aërial tubers (or thickened stems) are called pseudo-bulbs. Leaves entire, parallel-veined, usually sheathing at the base. Flowers usually in racemes or spikes, sometimes solitary or paniculate, with a bract under each flower. 
A large Order, distributed over all parts of the globe, but most abundant within the tropics. The scanty representation of this Order in the Hawaiian group has been much commented upon.

Anther terminal, lid-like, not adnate, deciduous. Pollen-masses waxy, without caudicles or stigmatic glands. Malaxideae. - Epiphytical, with pseudo-bulbs

1. Liparis

Anthers dorsal, free at last, but persistent. Pollen-masses granular, cohering by caudieles to a stigmatie gland. Neottieae. - Terrestrial, with fibrous roots and foliose stems

Anther terminal, adnate to the face of the column. Pollen-masses many-lobed, granular or waxy, cohering by numerous elastic caudicles and terminating in naked glands. Ophrydeae. - Terrestrial, with annually renewing tuberous rhizome; stems foliose

2. Anoectochilus.

3. Habenaria

\section{LIPARIS, L. C. Rich.}

Sepals and petals free, spreading, all alike or the petals narrower. Lip erect or ascending, shortly united with the column at the base, entire. Column elongate, incurved, winged at the top, continuous with the ovary. Anther terminal, lid-like. Pollen-masses waxy, without caudicles, in two pairs, attached by their summits, but spreading laterally into the two anther-cells. - Terrestrial or epiphytic herbs. Stem often thickened at the base into pseudo-bulbs. Leaves few. Flowers small, greenish-yellow or white, in a terminal raceme.

A large genus, widely dispersed through the tropical and temperate regions of both hemispheres.

1. L. Hawaiiensis, Mann, Enum. no. 488, - Epiphytical. Pseudo-bulbs small ovoid. Leaves 2, besides a few leaf-like scales, thin membranous, rather fleshy when fresh, ovate or oblong, $3-10^{\prime} \times 1-3^{1 / 2^{\prime}}$, somewhat obtuse, contraeted below and almost petiolate, the parallel nerves numerous and rising from the whole length of the midrib. Scape angular, $5-18^{\prime}$, naked below, bearing $3-9$ thin delicate greenish-whitish flowers in its upper half or third. Pedicels twisted, $3^{\prime \prime}$; bracts ovate, about half as long. Sepals ascending, linear or narrow lanceolate, $4-5^{4}$. Petals little shorter, filiform, spreading. Lip as long as the sepals, thin membranous, ascending below and channelled or folded, but without tubercles, ending in a flat oblong or obovate entire blade. Column erect, incurved, slender, half as long as the sepals. Capsule 5-8", obovate-oblong, costate.

On trees or mossy ground in the lower and middle forests of all islands. Intermediate between $L$. Loeselit and $L$. liliifolia according to Mann.

\section{ANOECTOCHILUS, Blume.}

Sepals spreading, broadly ovate, connate at the base, the upper one united with the petals into a kind of 3 -pointed helmet, the lateral ones oblique. Lip continuous with the column, deflected, saccate at the base or shortly spurred, prolonged into a narrow channelled unguis or claw which is dilated and two-lobed at the apex. Column short, curved above 
and emarginate, callous on each side below the projecting rostellum and generally bilamellate below the stigma. Anther terminal, free, incumbent on the apex of the column, persistent, bilocular; the pollen-masses 2-lobed, consisting of rather large easily separable granules, prolonged into short caudicles which are attached to a common stigmatic gland. Terrestrial herbs with prostrate leafy stems. Leaves membranous, with nerves rising from near the base, often variously colored. Flowers in terminal spikes.

A weakly defined genus, extending from India and Malaysia into Polynesia.

1. A. Sandwicensis, Lindl. Gen. \& Spee. Orchid. p. 500. - Stem terete, fleshy, purplish, decumbent and rooting, leafy throughout, 6-12' long. Leaves 4 or 5 , on petioles of $1 / 2-1^{\prime}$ which dilate at the base into a loose saccate sheath, ovate or oblong, $1^{1 / 2}-3^{1 / 2} 2^{\prime} \times 3^{3 / 4}-2^{\prime}$, acuminate, with one pair of primary nerves which reunite with the distinct midrib a short distance below the apex, besides a number of weaker nerves which join the primary ones, of a glossy and velvety dark-green and iridescent when fresh. Spike terminal, many-flowered, with a few empty bracts near the base, the ovate-lanceolate bracts (leaf-sheaths) as long as the sessile ovary. Perigone $4^{\prime \prime}$, its upper lobe or helmet 3-dentate or entire, the lateral sepals oblique, ovate-oblong. Lip $5-6^{\prime \prime}$, saccate at the base, the narrow unguis entire or denticulate, the broad terminal expansion deeply 2-lobed. Color yellow, with or without a few pinkish spots. Column short, with 2 large globose callosities in front. Anther erect at last. Capsule $6^{\prime \prime}$ long, 3-ribbed.

$\beta$ var. - The unguis of the lip serrulate or fimbriate. - A. Jauberti, Gaud. Bot. Bon. tab. 100.

In the lower forests of all islands, but rather rare; $\beta$ in woods of Hilo, Hawaii! and elsewhere. The variety is of doubtful value. I have found flowers with both forms in one elump of plants, and entire and slightly toothed claws are sometimes met with in one and the same spike. Benth. \& Hook. in Gen. Pl. III, pp. 598 and 600, even go so far as to divide both forms between different genera, assigning our $\alpha$ to Vrydagzenia $\mathrm{Bl}$, and $\beta$ to Odontochilus, Bl., two genera elosely allied to Anoectochilus, and inhabiting, like this, the Malayan islands. Vrydagzenia differs from Anoectochilus in a short, not elawed, labellum and 2 warts descending from the column into the short spur, neither of which characters I find apply to our plants, althongh the length of the unguis is somewhat variable. In Odontochilus the lateral sepals are connate in a short chin below the base of the labellum, which is simply gibbous, not spurred, bnt unguiculate as in Anoectochilus. Excepting the coalescence of the lateral sepals below the labellum our plants agree with Odontochilus, and might rank under this genus if Anoectochilus be restricted to forms with calcarate labellum; but perhaps it will be better to unite both these genera into a single one.

\section{HABENARIA, Willd.}

Sepals and petals nearly alike, or the petals narrower and sometimes bifid, all converging over the column in the shape of a helmet, or the lower sepals spreading. Lip spreading, entire or 3 -lobed, spurred at the 
base. Column short, with a short beak or rostellum erect under the anther. Anther terminal but adnate on the face of the column, the cells parallel or diverging and sometimes free at the tips. Pollen-masses 2, granular, the caudicles terminating in naked glands distant from each other and not immersed in cells of the 2-lobed stigma. - Terrestrial. Rhizome tuberous, but annually renewed by the formation of a fresh tuber when the previous one decays. Stems also annually renewed, erect, leafy at the base or throughout; the leaves passing into sheathing scales. Flowers bracteate in a terminal spike.

A very large genus, dispersed over the greater part of the world.

1. H. holochila, $s p . n$. - Erect, $1-2^{1 / 2} \mathrm{ft}$. high. Tuber slender, fusiform or cylindrical, with many fleshy rootlets near its apex. Stem leafy throughout, fistulous. Leaves 5-10, membranous, ovato- or ellipticooblong, $4-6^{\prime} \times 1^{1 / 2} / 2-2^{\prime}$, acuminate, sessile, sheathing at the base, with $3-5$ primary and 6-14 secondary nerves. Flowers dull greenish, inconspicuous, arranged in a long many-flowered spike, shorter than their supporting bracts, which are lanceolate and leaf-like below, gradually decreasing in size toward the apex of the spike. Sepals coriaceous, subequal, broadly ovate, 2 "long, all connivent. Petals as long as the sepals, connivent, suddenly tapering from a broad uneven-sided base to a slender linear truncate or emarginate recurved apex. Lip thick, linear, entire, truncate, ridged in the middle, curved-ascending, nearly as long as the sepals and provided with a thick clavate spur longer than itself and only little shorter than the ovary. Anther-cells nearly parallel. Capsule $6-8^{\prime \prime}$. Seeds oblong, margined.

In boggy ground of the heights above Kamalo, Molokai! on Eeka, Maui! near the mountain house, and on the plateau of Waimea, Kauai! (Kn.).

\section{ORdER LXXXI. SCITAMINACEAE.}

Flowers usually hermaphrodite and irregular, rarely unisexual. Perianth superior, in 2 series, both petal-like, or the outer herbaceous or stiff, each 3 -toothed, 3 -lobed, or of 3 segments. Stamens usually 3 or 6 ; but in most genera only one bears an anther, the others are without anthers or barren and petal-like, and then called staminodes or inner corolla; one of these, usually larger and opposite the fertile stamen, is the labellum. Anthers 2- or 1-celled. Ovary inferior, 3-celled, with 1 or more ovules in each cell, or rarely 1 -celled. Style single, with an entire or lobed stigma. Fruit a berry or capsule. Seeds arillate, with copious albumen (perisperm). Embryo central. - Herbs, usually with a perennial rhizome. stem usually short, or formed of convolute leaf-sheaths and then attaining a considerable height. Leaves entire, with long-sheathing petioles, the limb often very large, with numerous parallel veins diverging from the 
midrib. Flowers often very showy, in racemes or panicles, on a radical or terminal scape or peduncle.

A considerable tropical Order, common to the old and New World.

Fertile stamens 5; stem tall

1. Musa.

Fertile stamen 1; anther 2-celled; stem short; spike strobilaceous:

Lateral staminodes very small or wanting; connective of anthers prolonged beyond the cells; leaves narrow

Lateral staminodes petaloid; anther with 2 spurs; leaves broad; tupper bracts spreading

Fertile stamen 1, petaloid; anther 1-celled

\section{Zingiber.}

3. Curcuma.

4. Canna.

of eultivated plants belonging to this Order and not mentioned below, two, Alpinia nutans, Rosc, and Hedychium coronarium, Koen, are very common and occasionally found as escapes. Confined to gardens are: Elettaria speciosa, B1., E. coccinea, Bl., Costus speciosus, Sm., Alpinia Galanga, Sw., Hellenia scabra, Maranta dichotoma and a few others.

\section{MUSA, L.}

Calyx striate, tubular, 3-5-toothed, splitting laterally. Corolla shorter and included, truncate or dentate. Stamens 5, perfect, with sometimes a rudimentary sixth one, included in the corolla, the filaments thick filiform, the anthers linear erect, 2-celled, the cells contiguous. Ovary 3 -celled, with many ovules in each cell. Style filiform, central, the stigma concave, 6-toothed. Fruit fleshy, indehiscent, elongate. seeds angular, the thick and hard testa impressed in the albumen at both ends. - Tall, often tree-like herbs, the convolute sheaths of their large leaves forming a stem of considerable height. Scape terminal, ending in a long raceme; several flowers in the axils of the large colored bracts, subsessile, generally unisexual, the male at the top, the female at the base of the raceme.

About 20 species, natives of the tropies of the 0ld World.

1. M. sapientum, L. Sp. Pl. - Raceme or spadix drooping. Bracts or spathes of the upper (male) flowers caducous, the lower ones green on the inside. Segments of corolla unequal. Fruit oblong, subtrigonal, slightly curved, seedless, 3-6' long.

The Banana, "Maia of the natives, besides being generally cultivated, is found apparently wild in the recesses of most mountain-gorges; but as the natives formerly used to earry on eultivation in such spots it possibly owes its presence there to aboriginal plantations, as may be the case with the -Kalon and "Apés. The natives, who seem to have possessed the plant from times immemorial, distinguish 6 varieties, of which one with a reddish sap, very tenacious fibre and a thick copper-colored fruit said to produce seed oceasionally, is likely to be indigenous. It is however rare, and I have not had the good fortune to find it with flowers. The most common of these varieties is the kind which in Spanish America is called "Guineo"; in S. Hawaii it is sometimes found with variegated white-striped leaves. Since the year 1855 the Chinese Banana, M. Cavendishii, Paxt., which was then introdueed from Tahiti, has almost erowded out the native kinds from the cultivated fields, both on account of the extraordinary yield of its fruit and because it holds its own against the high winds which are so destructive to the superficially rooted natives. This latter advantage is also shared by the much taller $(12-16$ ft.) so called Brazil Banana, which was received about the same time by way of Tahiti and seems to be identical with the "Pisang radjah of Java. Although a moderate bearer

Hillebrand, Flora of the Hawaiian Islands. 
the fine flavor of its subacid fruit gives it just preeminence over all others. From Tahiti has also come the "Fei", which grows in a few of the higher ravines of $\mathrm{Oahu}$.

An accession of greater importance is the $M$. Mindanansis, Rumph, or M. textilis, Nees, the "Koffo" of Mindanao and Celebes, the "Abacá" of Luzon, which yields the much valued Manila hemp. It was brought over in 1866 , but has already been distributed over the entire group. It attains a height of $18-20 \mathrm{ft}$. and multiplies freely by suckers. By the presence of developed black seeds in the unpalatable fruit it is easily recognized.

Other Musaceae in cultivation are: Ravenala Madagascariensis, Adans, Strelitzia Reginae and S. augusta and Heliconia psittacorum, L.

\section{ZINGIBER, L.}

Calyx thin membranous, tubular, shortly 3 -lobed. Tube of corolla cylindrical, with narrow lobes, the posterior lobe concave, erect or incurved, the lateral ones patent. Lateral staminodes wanting or adnate as lateral lobes to the labellum, the labellum or its middle lobe entire or 2-cleft, sometimes crisp. Anther 1, on a short filament, erect oblong, its cells discreet, the connective not spurred, prolonged beyond the anther in a curved appendage or beak. Ovary 3-celled. Ovules many from axile placentas. Style filiform, wrapt in by the filament; the small globose stigma produced beyond the anther. Capsule oblong, irregularly breaking. - Rhizome horizontal, tuberous. Spike radical, or terminating a foliose stem, or lateral, strobilaceous (like a fir-cone); $1-3$ flowers inside of each of the densely imbricate bracts, each single flower surrounded by a spathaceous bracteole.

About 20 speeies, extending from the Mascarene Islands through India and Malaysia into Polynesia.

1. Z. Zerumbet, Roscoe, in Trans. Linn. Soc. VIII, 348. - Stem $1-2 \mathrm{ft}$. Leaves distichous, lanceolate, $7-8^{\prime}$ long, acuminate, glabrous, shortly stipitate on a long sheath which runs out into two ears. Scape radical, about $1 \mathrm{ft}$. in length, carrying along its entire length about 6 oblong closely sheathing bracts, each $2^{\prime}$ long. Spike ovoid, 2-3'long, its bracts broadly rounded. Flowers enclosed. Middle lobe of labellum emarginate, yellow.

A most common plant, often covering the ground entirely in the more open forests of the lower zone. The natives make no use of it. The species extends over all the voleanic islands of Polynesia into India. Nat. name: Awapuhi". Tahitian name: Reamoeruru. according to Nadéaud, the name opuhi or "Awapuhi applying to Amomum Cevuga, Lam., on that island. Vitian name: "Beta".

In cultivation: $Z$. officinale, $\mathrm{L}$.

\section{CURCUMA, L.}

Calyx tubular, 3 -toothed. Tube of corolla dilated above, 3-lobed, its lobes petaloid, subequal or the posterior one longer. Labellum large, spreading, entire or 2 -lobed; the 2 lateral staminodes connate at the base with the narrow petaloid filament, simulating a 3 -lobed filament with the middle lobe antheriferous. Anther 1 , its cells contiguous, the 
broad connective 2 -spurred at the base. Ovary 3 -celled, the cells with many ovules. Style filiform, the stigma produced beyond the anther, erect or inflected. Capsule loculicidal. - Rhizome thick with tuberous fibres. Stem erect. Leaves often broad. Flowers in an elongate strobilaceous spike, 2 to many inside of each bract, these large concave, imbricate, the uppermost empty and often colored; the single flowers surrounded by a spathaceous bracteole.

About 30 species, extending from India into tropical Africa, Australia and Polynesia.

1. C. longa, L. Sp. Pl. - Tuber oblong, palmate, deep yellow inside. Stem very short. Leaves few, membranous, elliptico-oblong, $8-12^{\prime} \mathrm{X}$ $3-4^{\prime}$, acuminate, on sheathing petioles of nearly their own length. Spike terminal. Bracts spathulate. - Amomum Curcuma, Jacq.

The Turmeric, "Oléna of the natives, is not nearly as common as the "Awapuhis, yet occurs seattering in open glades over the whole group. The natives extracted its dye for coloring kapa yellow, whence the name, lena" meaning yellow. The species has the same range as the preceding one. Tahitian name: "Rean; Vitian: "Cago".

\section{CANNA, L.}

Sepals 3 , imbricate. Petals 3 , connate at the base with the staminodial whorl or androecium, narrow, subequal, recurved. Androecium petaloid, shortly tubular at the base, its lobes cuneate-oblong, the 3 outer subequal and imbricate, or 2 of them connate, or all wanting; the 2 inner lobes narrower, one of them antheriferous, the other naked. Anther linear, 1-celled, the cell lateral on the petaloid filament. Ovary 3-celled, the cells with many ovules. Style linear, flat, connate below with the staminodial whorl, free above; stigma apical, often decurrent on one side. Capsule warty, opening by the wear of the fibrous pericarp. Seeds globose, crustaceous. - Stems erect, foliaceous. Flowers in a terminal simple or branching raceme, one in each bract; the bracts remote, about as long as the ovary.

A genus of about 30 species, all American.

1. C. Indica, L. - Stems $3-4 \mathrm{ft}$. high. Leaves ovate- to oblonglanceolate, acuminate, $6-8^{\prime}$ long. Flowers red, but generally variegated or speckled. Sepals scarious, ovate-obtuse, $3-4^{\prime \prime}$ long. Petals lanceolate, erect, with recurved tips, $1^{\prime}$ long or more, scarlet. Staminodes 3, longer, spathulate, more deeply colored. Filament shorter. Seeds black.

Spread over the whole group; probably introduced soon often the discovery. Nat. name: Aliipoes. It occurs with red, speckled and yellow flowers. Spread over most parts of tropical America and Asia. Occasional eseapes from cultivation are: $C$. Warszewiczii, Dietr., with purple bracts and calyces and crimson flowers, and C. glauca, L., leaves glaticous, flowers pale yellow.

The Order Bromeliaceae - flowers regular; external perianth calyx-like; stamens 6 ; ovary inferior or semiinferior, 3-celled, with numerous ovules; leaves mostly stiff and spinose; bracts generally large and colored - is represented by the Pine-apple, Ananassa sativa, Lindl., which runs wild in many places. Besides this several species of Bilbergia and Aechmea fulgens are not uneommon in gardens. 
To the Order Amaryllidaceae, which may be characterized as Liliaceae with an inferior ovary, belong two plants which are almost naturalized, viz., the Century plant, Agave Americana, L. - leaves glaucous, very thick and spinose - and Fourcroya gigantea, Vent., a similar but taller plant with green and mostly spineless leaves. Besides these there are generally cultivated and occasionally found as escapes: Hippeastrum in several species, Zephyranthes in 3 species, Crinum Asiaticum, also C. australe, C. giganteum and others, Pancratium maritimum and other species; less common Polianthes tuberosa, Sprekelia formosissima, etc.

\section{ORDER LXXXII. IRIDACEAE.}

Flowers hermaphrodite, regular or irregular. Perianth superior, with 6 petal-like segments. Stamens 3, inserted at the base of the outer segments. Anthers erect, opening outward. Ovary inferior, 3-celled, with several ovules in each cell. Style single, with 3 stigmas sometimes dilated and petal-like or fringed. Capsule 3-valved, loculicidal. Seeds albuminous, with a small embryo, the radicle next the hilum. - Herbs with usually a tuberous, creeping or bulbous rhizome. Leaves usually radical or equitant, that is, alternately sheathing on opposite sides of the stem, and vertically, not horizontally flattened. Flowers usually terminal, solitary or in spikes, racemes or panicles.

A large Order, belonging chiefly to the temperate regions of the northern hemisphere and southern Afriea, with a few tropical and Australian species. In cultivation: various species of Gladiolus, Pardanthus Chinensis, Ferraria tigridia, Watsonia sp. and a few others.

\section{SISYRINCHIUM, L.}

Segments of perianth nearly equal, free, or connate in a tube below. Filaments more or less connate; anthers emarginate at the base. Style mostly short, its branches filiform, involute, stigmatiferous at the apex, alternate with the stamens. Capsule thin, obovate-clavate. Seeds many, subglobose or angular, with a hard coriaceous testa and obsolete rhaphe. Embryo little shorter than the cartilaginous albumen. - Low herbs with a very short rhizome and fibrous roots. Stem compressed and 2 -edged. Leaves radical or nearly so, narrow grass-like, linear-terete or ensiform. Flowers small, fugacious, umbellate, or clustered with one or more spathaceous bracts.

About 50 species, all, except the present one, natives of temperate and tropical America.

1. S. acre, Mann, Enum. no. 479:-Glabrous, 6-15' high. Leaves radical, linear-ensiform, equitant, straight, 8-10-nerved, channelled in the lower two thirds. Scape simple, longer than the leaves, naked, compressed, almost winged. Umbel 5-8-flowered, the pedicels slender, $3 / 4-1^{\prime}$, each supported by a lanceolate hyaline bract of less than half its own length, the two outermost bracts green and spathe-like, ahout as long as the pedicels. Perianth deeply 6-parted, 4-5" long, yellow, very fugacious, the lobes ovate, obtuse, 5-7-nerved. Stamens $1 / 2$ or ${ }^{2 / 3}$ the 
length of the perianth, the short filaments connate halfway. Ovules many in each cell, biseriate, horizontal. Capsule obovate, $4-5$ "long, opening from the top downward. Seeds globose, with a dark crustaceous testa. Embryo small, nearly axile. - Wawra, in Flora, 1875, p. 246.

High mountains of Hawaii, and Haleakala, Maui! from $3500 \mathrm{ft}$. upward to about $7000 \mathrm{ft}$. The natives use the acrid juice to give a blue stain to their tattoo-marks.

\section{ORdER LXXXIII. TACCACEAE.}

Contains only two genera, the one not represented here differing from Tacca in a capsular fruit.

\section{TACCA, Forst.}

Flowers hermaphrodite. Perianth corolla-like or herbaceous, the tube connate with the ovary, the limb superior, parted into 6 biseriate connivent or patent lobes. Stamens 6, inserted on the tube or the base of the lobes, included; the filaments broad, hooded above and 2 -nerved; the anthers introrse, 2 -celled, the cells parallel, adnate to the inside of the hood. Ovary adherent, 1-celled, with 3 parietal placentas. Ovules numerous, horizontal, anatropous. Style short and thick, trigonous; stigma orbicular or peltate, divided into 3 bifid or emarginate rays. Berry many-seeded. Seeds angular, with a coriaceous striate testa. Embryo minute, at the base of a corneous albumen. - Herbs with a tuberous or creeping root-stock. Leaves radical, on long petioles, entire or palmatisect or bipinnatifid, with anastomosing veins. Flowers umbellate at the end of a long scape, involucrate by several large herbaceous or colored bracts, the inner bractlets filiform, longer than the umbel and pendulous. Perianth dirty-brown or green, black when dry.

A genus of 9 species, 3 of which are American, the others inhabitants of the tropics of the old Worla.

1. T. pinnatifida, Forst. - Kunth, Enum. Pl. V, 458. - Tuber large, roundish. Leaves on striate petioles of $1-3 \mathrm{ft}$., membranous, pedately tripartite to the base, the two external segments again deeply bipartite, the five lobes irregularly pinnatisect into lanceolate acute segments; the whole blade $6-10^{\prime} \times 10-20^{\prime}$. Scape $3 \mathrm{ft}$. long, grooved, fistulous. Involucral leaves $6-12$, ovate, somewhat obtuse, contracted at the base, $1^{1 / 2}-2^{4}$. Flowers numerous on pedicels of about $1^{\prime}$, the linear bractlets $4--5^{\prime}$. Perianth greenish, bell-shaped, $5^{\prime \prime}$, parted beyond the middle into 6 lanceolate-acute lobes. Stamens about half the length of the lobes, the anther-cells discreet, their apices free at last. Berry triquetrous. - Seem. Journ. Bot. III, 261, and Fl, Vit. p. 102, - T. littorea, Rumph. - T. ocernica, Nutt. 
The Arrowroot-plant, "Pias, is found wild in the open woods of the lower regions and on grassy plains, principally on the island of $\mathrm{Kauai}$. The leaves appear in early spring and wither by the end of summer. Formerly its cultivation was carried on to some extent, but now it seems to be entirely neglected. The species extends from the Hawaiian Islands through Polynesia, Malaysia with the Philipine Islands to Madagasear and eastern Africa. Tahitian name: "Pia"; Vitian: "Yabia".

\section{ORdER LXXXIV. DIOSCOREACEAE.}

Flowers regular, unisexual, usually dioecious. Perianth of 6 lobes or divisions in 2 series. Stamens 6 or 3 , inserted on the perianth and shorter than its lobes, free, or connate in a short column. Anthers 2 -celled. Ovary inferior, 3 -celled, with 2 pendulous anatropous ovules in each cell. Stigmas 3 , entire or 2 -cleft, on a single or on distinct styles, or sessile. Fruit a berry or 3-angled capsule. Seeds albuminous, with a minute axile embryo. - Herbs, sometimes woody at the base, usually twining, with a tuberous rhizome. Leaves petiolate, with digitate or parallel nerves and reticulate veins, sometimes compound. Flowers small, in axillary, simple or paniculate spikes or racemes.

An Order of few genera, dispersed over the warmer parts of the globe.

\section{DIOSCOREA, L.}

Flowers dioecious. Male $f l$. Perianth herbaceous, urceolate, campanulate or deeply 6 -cleft. Fertile stamens 6 , free or connate, or 3 with as many staminodes or without any. Anthers subglobose, the cells contiguous or discreet. Fem. fl. Ovary trigonous. Styles 3, very short, with entire or bifid reflexed stigmas. Capsule membranous, 3-angled or 3-lobed, opening loculicidally at the angles. Seeds compressed and mostly winged. - Twining stems with tuberous rhizomes. Leaves alternate or sometimes opposite, generally cordate or hastate, entire or palmatifid.

A large tropical and subtropieal genus, 150 species, common to the Old and New World. Leaves entire; fertile stamens 6

Leaves palmately lobed; fertile stamens 3

1. D. sativa.

2. D. pentaphylla.

1. D. sativa, L. Sp. Pl.p. 1463 (not Kunth). - Benth. Fl. Hongk. p. 368. - Stem glabrous, slightly angular, often bearing green globular bulbs or tubers in the axils of the leaves. Leaves scattering or subopposite; the petioles $2-3^{1} / 2^{\prime}$, twisted at the thickened base and thereby supporting the plant; the blade thin chartaceous, ovate-cordate with broad sinus, shortly acuminate, entire, 7-11-nerved, with nerves converging toward the apex, 5-7' long and $4-6^{\prime}$ broad. Male spikes slender, sessile, $2-4^{\prime}$ long, either in fascicles or arranged in long panicles, the flowers solitary and distant, each with 2 unequal ovate bractlets. Perianth-segments narrow, almost valvate, those of the inner series linear. Anthers 6, almost sessile round a rudimentary ovary, oblong, bifid at both ends, introrse, affixed above the base. Female spikes pedunculate, simple, often 
$1 \mathrm{ft}$, or more long, $3-5$ in axillary fascicles. Flowers bibracteate, slender, about $2^{\prime \prime}$, the limb half the length of the adnate portion. Staminodes 6. Styles recurved, emarginate. Capsule oblong, $9^{\prime \prime}$ long, the lobes scarcely $3^{\prime \prime}$ in width. Seeds winged at the lower end only. $-D$. bulbifera, Wight (not Linné). - Helmia bulbifera, Kunth, Enum. Pl. V, 435. - Mrs. Sinclair, pl. 29.

The Yam, common in the forests of the lower zone, was cultivated for the supply of ships before the introduction of the Potato, particularly on Kauai and Niihau. The species ranges westward over all the regions lying between the Hawaiian Islands and Africa, and its native name Hoi follows it to sumatra. The axillary bulbs are called *alaalas,

2. D. pentaphylla, L. - Kunth, Enum. Pl. V, 396. - Stems angular, prickly, puberulous. Leaves scattering, membranous with pellueid lines, pubescent, palmately $3-5$-lobed, the lobes or segments lanceolate, cuspidate, stipitate at the narrow base, $4-5^{\prime}$ long; the petioles $4^{\prime}$. Male racemes solitary or twin, simple or paniculate with branches solitary or ternate of about $1^{\prime}$ in length, the rhachis and pedicels pubescent. Pedicels $1 / 2$ ", bibracteolate: Segments of perianth equal, ovate-lanceolate, somewhat acute, conniving. Only 3 stamens fertile, the others abortive, scalelike. Seeds winged. - Wight, Ic. Pl. Ind. Or. tab. 814.

This yam, ealled "Piian, is less common than the preceding one; it has a small tuber and was, I believe, never cultivated. Its range is nearly that of the preceding species.

A third speejes has been seen by me in the neighborhood of Honolulu, but I regret not to find a specimen in my collection.

\section{ORDER LXXXV. LILIACEAE.}

Flowers usually regular, hermaphrodite or unisexual. Perianth inferior, petal-like, with usually 6 divisions or lobes. Stamens 6 (rarely 3 or $12-18)$, inserted at the base of the segments or in the tube. Ovary free, 3 -celled, with axile placentas (rarely the partitions incomplete and the placentas parietal), with several ovules or one only in each cell. Style single, with an entire or 3 -lobed stigma, or rarely 3 sessile stigmas. Fruit a berry or capsule. Embryo immersed in fleshy albumen. Perennial plants with a creeping bulbous or clustered root-stock and radical leaves and peduncles, or with annual, biennial or perennial, often woody, leafy stems.

In eultivation : Asparagus officinalis, Aspidistra Japonica, Hemerocallis fulva, Phormium tenax (New Zealand Flax), Aloe (several sp.), Yucca gloriosa, Agapanthus umbellatus, Allium Gepa and o

Woody elimbers; the leaves broad, with anastomosing nerves and with 2 cirrhi; flowers in umbels; segments of perianth distinet; ovules solitary or twin in each cell; style wanting or very short Stem erect, woody; leaves not areolate; flowers in a terminal panicle;

1. Smilax. perianth campanulate or funnel-shaped; style filiform:

Stem simple; leaves broad ovate; perianth deeply divided; ovules many in each cell

\section{Cordytine.}


Trunk dividing; leaves linear; perianth funnel-shaped; 1 ascending ovule in each cell

Stemless; leaves keeled, squamaceo-villous; flowers racemose in a terminal panicle; perianth rotate; style short and thick; ovules several

Herbaceous; leaves distichous, glabrous; flowers cymose in a terminal panicle; segments of perianth distinct; filaments short and thick; style filiform; ovules several

3. Dracaena.

4. Astelia.

5. Dianella.

\section{SMILAX, L.}

Dioecious. Segments of perianth 6, distinct, spreading or incurved, all equal or the 3 outer ones larger. Male $\mathrm{fl}$. Stamens generally 6 , but in the Hawaiian species $12-18$, inserted at the base of the segments, free; the anthers basifixed, dehiscing internally. Fem. $f$. Stamens 6 , rudimentary. Ovary 3 -celled, with 1 or 2 pendulous orthotropous ovules in each cell. Stigmas 3, sessile, distinct or shortly united, recurved. Fruit a globular berry. Embryo minute, remote from the hilum. - Climbers, mostly woody. Leaves alternate, distichous, with digitate nerves and reticulate veins, usually coriaceous and shining; the petioles bearing 2 simple tendrils and often winged below them (adnate stipules). Flowers small, greenish-white, in sessile or pedunculate axillary umbels, often forming terminal panicles with bract-like leaves.

One hundred and eighty seven species, dispersed over the tropical and temperate regions of the whole world. - Our species belong to the small subgenus or section Pleiosmilax, Seem., which is confined to the Hawaiian, Viti and N. Caledonia Islands, and differs in the presence of more than 6 stamens in the male flowers.

Unarmed; leaves ovate-cordate or orbicular

More or less prickly; leaves ovate-oblong

1. S. Sandwicensis.

2. S. melastomaefolia.

1. S. Sandwicensis, Kunth, Enum. Pl. V, 253. - A tall climber with tuberous rhizome and a woody, unarmed, terete, striate stem. Leaves broadly ovate, $3-5^{\prime} \times 2-4^{1} / 2^{\prime}$, abruptly acuminate or cuspidate, entire, cordate with narrow sinus, coriaceous, 5-7-nerved, glossy, dark green, with minute pellucid dots and lines in the dark areoles. Petioles $6^{4}$, twisted, bicirrhose between middle and base and slightly margined below the cirrhi. Umbels in both sexes $1-3$ from an axillary bud or spur, each supported by an ovate bract of $2-4^{\prime \prime}$ in length. Peduncles compressed, $9-12^{\prime \prime}$, bearing $12-20$ pedicels on a globose receptacle, each $3-6$ " long, articulate at the base and supported by a small bracteole. Perianth $4-6^{\prime \prime}$, white, its segments linear-lanceolate, equal, spreading in the male, revolute in the female $\mathrm{fl}$. Stamens $12-18$, rarely less or more $(8-20)$, free, as Iong as the perianth or longer; anthers linear, erect, ${ }^{1}{ }^{3}$ the length of the flattened filaments, curved or twisted at last. No trace of ovary in the male fl. Fem. $f l$. Ovary trigonous, surrounded by 6 sterile stamens. Ovules 2 (or 1 ) in each cell, pendulous. Stigmas distinct, $1^{1 / 2}{ }^{\prime \prime}$, thick, revolute. Berry globose, 3-4", green or bluish, 3-seeded. Seeds 
3-facial with back convex, the hilum large, the testa pale and thin. Embryo small, at the lower end of a large corneous albumen, opposite the hilum. - Wawra, in Flora, 1875, p. 297. - A. De Cand. in Monogr. I, 205. - S. pseudochina, Hook. \& Arn. in Bot. Beech. - S. anceps in Kunth, Enum. Pl. as to the H. I. plant. - S. Hawaiiensis, Seem. Fl. Vit. p. 309. - Pleiosmilax Sandwicensis, Seem., in Journ. Bot. VI, 193, The character of biovulate cells rests upon an old herbarium note which probably had reference to an examination of a fresh ovary; in the dried and shrivelled ovary I have not been able to verify it. - Mrs. Sinclair, pl. 4.

From Kauai to Maui! The "Uhi" and "Ulehihi" ("Pioi" in Kauai) of the natives, who eat the tuberous rhizome in times of searcity. I feel tolerably well satisfied that there exists no properly hexandrous Smilax on the group. Kunth had seen no male fl of $S$. Sandwicensis or of what he thought to be $S$. anceps, nor has Seeman observed any of his supposititous S. Hawaizensis, the description of which agrees entirely with the present species and which could hardly be excluder from it, even if some plants should be found with no more than 6 stamens in a species where their number is known to range between 8 and 20. - The floriferous axillary bud sometimes grows out to a regular foliaceous braneh. In such case an umbel or two of berries may be seen at the base of the branch, each supported by a small ovate bract. If it has not come to the development of leares, then 2 or 3 umbels appear as in a racemose inflorescence.

$\beta$ var. crassifolia. - Petioles $1-1^{1} / 2^{\prime}$, thick, channelled, often finely muricate. Leaves ovate, obtuse, broad, but scarcely cordate, 7 -ribbed, $5-6^{\prime} \times 4-5^{\prime}$, very thick. Umbels generally solitary, 20-25-flowered, the peduncle $1-1^{1} / 2^{\prime}$, the pedicels $6-9^{\prime \prime}$. Perianth large, 6". Stamens 15, not exserted; anthers less than ${ }^{1 / 4}$ the length of the filaments. Berry blue, 5-6" in diam.

Hawail woods of Hilo and of the Kohala range.

2. S. melastomaefolia, Sm., in Rees' Cyclop. V, 33. - "Stem and petioles densely aculeate with short conical prickles. Leaves ovate-oblong, 3-4' $\times 1^{1} / 2-2^{\prime}$, acuminate, 5-7-nerved, the nerves prickly underneath. Male umbels racemose, the smooth rhachis bracteate with ovate acuminate bracts. Stamens 12 , as long as the perianth, the oblong anthers $1 / 5$ the length of the filiform filaments. Fem. umbels solitary, the peduncles aculeate, $15-20$ flowered. Sterile stamens 6. Stigmas linear, erect, $1 / 2$ the length of the ovary. Berries 3-seeded. - A. De Cand., 1. c. - Pleiosmilax Menziesii, Seem., 1. e. p. 194, tab. 81.

Collected by Menzies, probably on Haw aii (spec. in hb. Brit. Mus.).

$\beta$ var. subinermis. - From Mr. Lydgate I have two leaf-specimens, said to come from one plant, collected on the slope of Haleakala Ma ui. The larger one has the slender stem and petioles finely muricate, the leaves oblong, $3^{1 / 2}-4^{\prime} \times 1^{1 / 2^{2}}$, shortly apiculate, eordate at the base, 5-nerved. In the other, which probably comes from the apex of a branch, the stem and petioles are smooth and the leaves narrow lanceolate, $3^{\prime} \times{ }^{2 / 4^{\prime}}$, with a eontracting entire base, 3-nerved. Perhaps the same as Wawra's no. $1815 \mathrm{~b}$, which comes from the same region. There is some ground for suspecting that prickles beiong to the younger state of the plant and disappear with age. 


\section{CORDYLINE, Commers.}

Perianth colored, cylindrical or campanulate, divided into six 3-5-nerved lobes. Stamens 6, inserted at the throat; filaments subulate; anthers versatile, introrse, bifid at the base. Ovary 3 -celled; ovules numerous. Style filiform; stigma 3 -lobed or nearly entire. Berry globose, often fewseeded. Seeds obovoid, compressed, often curved; testa black, shining. Embryo axile, curved. - Trees or shrubs, with generally a simple trunk which emits shoots from the base. Leaves crowded at the top, elongatelanceolate, closely striate. Flowers spicate or racemose on the alternate branches of a terminal panicle, bibracteate, the perianth jointed with the short pedicel.

About 10 species, belonging to India, the Malay archipelago, Australia, N. Zealand, the Pacific islands; one species indigenous to Brazil.

In cultivation : C. Jacquinii, Kth., with rust-colored leaves, and C. Sieberi, Kth.? with purple and scarlet leaves.

1. C. terminalis, Kunth, Enum. Pl. V, 25. - Shrubby, 6-12 ft. high, with a large tuberous saccharine root. Stem simple or sparingly branched, erect, marked with spires of leaf-scars. Leaves broad lanceolate, $1-2 \mathrm{ft}$. long, $3^{1 / 2}-4^{\prime}$ broad at the middle, contracting to a petiole of $2-3^{\prime}$, with many longitudinal nerves diverging from a short rib. Panicle $1 \mathrm{ft}$. long or more, the branches $5-6^{\prime}$, supported by foliaceous bracts. Flowers sessile, tribracteate, the outer bract ovate, $1^{1 / 2}-2^{\prime \prime}$, the two lateral ones half that size. Perianth $4^{\prime \prime}$, split to the middle into 6 equal lobes which are reflexed at last, 3 -nerved, white, the outer ones with a purplish tinge. Stamens and style as long as the perianth, the anthers yellow. Berry 2-3" in diameter, yellowish. - C. Eschscholziana, Mart. - C. Ti, Schott. - Dracaena terminalis, Reichard. - Calodracon terminalis, Planch. Stigma simple punctiform in my specimens (sterile fl.?).

Very common on all islands at the lower edge of the woods. The *Tis or "Kis of the natives, who understood how to ferment a kind of beer from the root and at a later period learned to distil from it a strong rum. The leaves, "lai or "laui", served them as wrappers for food, or for plates; they are also excellent fodder for horses and cattle. The species ranges from the Hawaiian Islands through all Polynesia to the Malayan arehipelago and China. Tahitian name: "Tir.

\section{DRACAENA, Vandell.}

Flowers as in Cordyline, but the lobes, of the perianth 1 -nerved. Cells of ovary each with 1 ascending ovule. Stigma entire or scarcely divided. Berry 1-3-seeded. Seeds globose, with a thick, often pulpose testa. Embryo small, at the base of horny albumen next the hilum. - Trees or shrubs, with a simple or dichotomonsly dividing trunk. Leaves crowded at the tops, linear or lanceolate, closely striate. Inflorescence a terminal foliaceous panicle, sometimes reduced to a simple raceme, spike or head, the pedicels articulate with the perianth. 
A bout 35 species, natives of India and tropical Africa with adjacent islands, the following being the only one known from Polynesia.

1. D. aurea, Mann, Enum. no. 489. - A glabrous tree, 20-25 ft. high, with soft whitish wood, emitting roots above ground, freely branching, the branches suberect and densely ridged by transverse leaf-scars. Leaves sessile, linear-ensiform with entire margins, about $2 \mathrm{ft}$. long and $6-8^{\text {" }}$ broad at the base and middle, gradually drawn out into a spinescent point, coriaceous, densely striate without midrib. Flowers racemose on a terminal recurved panicle of about $2 \mathrm{ft}$. in length, with a woody rhachis and foliaceous bracts, single or 2 or 3 together on slender pedicels of $6-8^{\prime \prime}$, which are jointed some distance below the perianth and bear 2 linear flaccid bracts of less than half their length. Perianth tubular, $2^{\prime}$ long and $3^{\prime \prime}$ wide, suberect, divided to one third into linear-lanceolate erect lobes, pale- or golden-yellow, persistent. Stamens inserted at the base of the lobes and of the same length as these, the filaments flat subulate, the versatile anthers sagittate. Style shortly exserted, stigma entire, trigonal. Berry globose, trisulcate, $6-8^{\prime \prime}$ in diameter, yellow, with a chartaceous endocarp. Seed generally single, globose. Embryo minute, axile, near the base of horny albumen. - Wawra, in Flora, 1875, p. 244.

Not uncommon on all islands, at altitudes of $1000-2500 \mathrm{ft}$., as in Nuranu, Oahu, near the palis. The "Halapepe of the natives, who used to earve their idols out of the soft wood.

\section{ASTELIA, Banks \& Sol.}

Flowers polygamo-dioecious. Perianth withering-persistent, the 6 segments connate at the base in a small tube, spreading. Stamens 6 , inserted at the base of the segments, abortive in the female fl. Ovary 3-celled, with axile placentas, or the dissepiments incomplete and the placentas parietal or apical, abortive in the male fl. Ovules many. Style none or very short; stigmas 3 , obtuse. Berry subglobose, trisulcate. Seeds ovoid or angular, with a black crustaceous testa. - Herbs of the habit of Tillandsia. Root fibrous. Stem short or wanting. Radical leaves imbricate, ensiform, carinate, generally squanaceo-villous on both faces, or underneath only, and woolly at the base. Flowers generally silky, racemose on the branches of a dense terminal panicle, rarely few only in the axils of the upper leaves. Pedicels not jointed, with a single bract at the base.

About 9 species, spread over the Hawaiian, Society, and Viti Islands, N. Zealand, Tasmania, Australia, the Falkland Islands and Tierra del Fuego

Leaves 3-nerved, villous, expanded, long; perianth silky; seeds 4-6

in each cell

Leaves 1-nerved, glabrous, folded, short; perianth glabrous; seeds

$2-3$ in each cell

1. A, veratroides.

1. A. veratroides, Gaud. in Bot. Voy. Freyc. p. 420, tab. 31. - Caudex short, sometimes creeping. Leaves linear-lanceolate, gradually running out into an acute point, $1^{1 / 2}-4 \mathrm{ft}$. long, $1 / 2-3^{\prime}$ broad, clasping at the 
base, coriaceous, with 3 primary nerves - the median channelled above, the two lateral ones prominent on both faces - and with numerous parallel smaller nerves, squamaceo-villous and silvery on both faces when young, but with age often glabrate on the upper face or on both. Panicle densely villous throughout, shorter than the leaves, its stout peduncle or scape leafless, $6-18^{\prime}$ long, the $3-8$ alternate branches $3-6^{\prime}$ long, either all simple and floriferous to the base, or the lower ones compound; each supported by a foliaceous ovate-lanceolate bract, the lowest bract being longer than its branch. Pedicels sometimes several from a common base, $1-3^{\prime \prime}$, bearing at the base a linear bractlet of twice their length. Perianth $3^{\prime \prime}$, greenish, membranous, the segments biseriate in the bud and valvate, the outer ones ovate-lanceolate, villous outside, the inner narrower and glabrate or villous only along the middle, all spreading or recurved. Stamens shorter than the perianth, with slender filaments and short oblong, obtuse, versatile, laterally dehiscent anthers. Ovary ovoid, often slightly villous, 3 -celled, each cell with $4-6$ oblong ovules which are suspended by broad and short funes from an almost apical placenta. Style persistent, short and thick, entire; stigmatic dots trigonal or roundish. Berry globose-depressed, 2 " in diameter, 6 -ribbed, yellow. Seeds tapering at both ends, with small hilum, either flat-convex, or trigonal with one side convex. Embryo clavate, axile, nearly half the length of the fleshy albumen. - Steudel, Synops. Pl. Glum. II. 312. - Wawra, in Flora, 1875, p. 242. - Mann, Enum. no. 492 and 493.

Common on all islands, on exposed ridges or slopes from $2000-6000 \mathrm{ft}$. above the sea, growing on old trunks or on the ground. Nat. name: : Painiuw. - The forms with more or less glabrate leaves - A. Menziesiana, Sm. - are chiefly found at lower elevations; in such from Hamakua, Maui! the perianth too is nearly glabrous. Plants again from the top of Eeka are silvery-woolly all over, and in these the prostrate caudex lengthens and throws out roots. - A. montana, Seem., from the Viti Islds, does not seem to differ essentially.

2. A. Waialealae, Wavra, in Flora, 1875, p. 243. - Dioecious. Caudex very short. Radical leaves much dilated and villous at the base, linearlanceolate, scarcely over $6^{\prime}$ long, reclinate, folded throughout, glabrous, rugose and shining above, polished underneath, 1-nerved. Panicle hirsute, with a very short peduncle, the lowest bract ovate-lanceolate, $1^{1 / 2^{\prime}}$ long, the upper ones much shorter or wanting. Pedicels $1^{\prime \prime}$. Segments of perianth linear-lanceolate, glabrate. Ovules $2-3$ in each cell. Stigmatie dots concave. Seeds obovoid, larger than in the preceding species. Embryo nearly as long as the albumen. - Deser. from Wawra.

Kauai, summit of Waialeale and plateau of Halemanu.

\section{DIANELLA, Lam:}

Segments of perianth 6 , distinct, equal, spreading, 3-7-nerved. Stamens 6 , hypogynous, or the 3 inner inserted at the base of segments; the 
filaments short, thick fleshy, at least near the apex; the anthers basifixed, opening by a terminal pore, but the pore often continued in an introrse slit. Ovary 3-celled, with several anatropous ovules in each cell. Style filiform; stigma entire. Fruit a berry. Seeds solitary or few in each cell, with a black crustaceous testa. Embryo linear, straight or curved, little shorter than the albumen. - Herbs with a short branching rhizome and fibrous roots, the stem leafy, at least at the base. Leaves distichous and equitant, linear-lanceolate, parallel-nerved. Flowers usually blue, loosely cymose and pendulous in a terminal panicle, the pedicels jointed below the flower. Bracts small or wanting.

A genus of 8-10 species, extending from the Masearene over the Malay Islands and Australia to N. Zealand and through the Pacifie.

1. D. odorata, Bl. - Kunth, Enum. Pl. V, 51. - Stem short. Leaves stiff, $1^{1 / 2}-3 \mathrm{ft}$. long, $1 / 2-1^{\prime}$ broad at the base, quite entire, closely nerved, with a keeled unarmed midrib. Panicle as long as the leaves or longer, its peduncle leafy, the foliaceous bracts quickly falling off in size, the branches ascending, twice divided and drooping at the ends, the flowers secund (on one side). Pedicels $3-6^{\prime \prime}$; bractlets dentiform. Perianth pale lilac, campanulate, $3-4$ " long, deeply parted into subequal oblong 5-nerved segments. Berry bluish, obovoid, $4-5^{\prime \prime}$. Seeds $2-3$ in each cell, ovoid, compressed and margined, about $2^{\prime \prime}$. - D. Sandwicensis, Hook. \& Arn. in Bot. Beech. p. 97. - Mrs. Sinclair, pl. 20.

Common on the lower hills. Flowers somewhat sweet-scented. Nat. name: "Uki". The speeies, as distinguished by the entire unarmed leaves, is reported also from Tahiti, s. China and Khasia; but $D$. ensifolia, Redouté, which ranges over the greater part of India and Malaysia to the Mascarene Islands, differs only in minutely serrate leaves with a scabrous keel. In S. China and Khasia both forms occur together with gradual transitions. See Benth. Fl. Hongk. p. 312, and Hook. \& Arn. Bot. Beech. p. 218.

\section{ORDER LXXXVI. COMMELINACEAE.}

Flowers hermaphrodite or rarely polygamous, usually slightly irregular. Perianth of 3 outer, thin, but calyx-like segments, rarely united at the base, and 3 inner, very delicate, petal-like segments or lobes, imbricate in the bud. Stamens 6 , or fewer by abortion; anthers basifixed, 2 -celled, or some deformed or barren. Ovary free, 3-celled or rarely 2-celled, with 1, 2 or more orthotropous ovules in each cell. Style simple; stigma entire or 3-lobed. Fruit a capsule or rarely indehiscent. Seeds peltate or angular, the testa usually wrinkled, a short or linear hilum on the inner side. Embryo small, partly sunk in a foveole at the apex or outer side of the fleshy albumen, covered by a scalelet - embryostega. - Herbs, often creeping at the base. Leaves parallel-nerved, with sheathing petioles. Flowers blue, purple or white, in panicles, clusters or umbels, either terminal or issuing from the leaf-sheaths. 
A chiefly tropical Order, common to both Worlds Flowers irregular; fertile stamens 3 .

1. Commelina. Flowers regular; fertile stamens 6

2. Tradescantia.

\section{COMMELINA, L.}

Perianth irregular, 2 sepals larger than the third, and 1 petal differently shaped or more sessile than the 2 others. Stamens 6 , or rarely fewer, of which 3 are fertile, one of them larger than the others; 3 barren, with deformed anthers. Stigma entire. Ovary with 2 biovulate and 1 uniovulate cells. Capsule oftener 2-valved, one cell remaining undeveloped. Embryo horizontal. - Peduncles terminal and lateral from the split leaf-sheath opposite the blade, bifid, bearing a conduplicate or hoodshaped hract at the division, the branches cymose, one of them weaker and with fewer male or sterile flowers.

A genus of 88 species, with the range of the Order.

1. C. nudiflora, L. Sp. Pl. p. 61. - C. B. Clarke, in De Cand. Monogr. III, 144. - Creeping, glabrous. Leaves shortly petiolate from a loose ciliate sheath, oblong-lanceolate, $1-3^{\prime} \times{ }^{1 / 2}-3^{3} 4^{\prime}$, with $9-13$ nerves, scabrous on the margins and above, smooth below. Peduncles about $1^{\prime}$ long; the bract cordate, acuminate, folded; the two branches $3-4$-flowered, one remaining enclosed, the other exserted, puberulous, about as long as the peduncle; the fasciculate flowers polygamous. Petals blue, the lateral ones on claws, the third subsessile, rounded, very small. Seeds scrobiculate. - C. Pacifica, Vahl. - Seem. in F]. Vit. p. 313. - C. Virginica, Forst. - C. Cayennensis, Rich. - C. agraria, Kth.

Common in moist localities of the lower regions. Is spread over the warmer zones of the whole world.

\section{TRADESCANTIA, L.}

Perianth regular. Sepals herbaceous, free, concave. Petals shortly clawed, persistent. Stamens 6, all fertile. Ovary sessile, 3-celled, each cell with 2 superposed ovules. Style elongate, with an entire obtuse or peltate stigma. Capsule 3 -celled, loculicidal. Seeds angular. - Leaves entire, on undivided sheaths. Flowers in simple or branched, mostly subumbellate cymes, the umbels sessile and involucrate by foliaceous bracts, or pedunculate with small bractlets.

Twenty six species, all American.

†1. T. geniculata, Jacq. - C. B. Clarke, in De Cand. Monogr. III, 300, - Stem 1-2 ft. long, nodose, rooting below, scarcely dividing. Leaves distant, sessile on short loose sheaths, oblong-lanceolate, $3^{1 / 2}-4^{1 / 2^{4}} \times$ $1-1^{1} / 2^{\prime}$, acuminate, rounded or contracting at the base, glabrous above, lanuginous below and more so at the mouth of the sheath. Peduncles in the axils of the upper gradually decreasing leaves, $1-2^{\prime}$ long, once 
or repeatedly forking, the flowers $6-9$ in an umbel on filiform pedicels of about $6^{\prime \prime}$, the whole forming a thyrsus with short linear-lanceolate bractlets. Sepals greenish, ovate-acute, glabrous, $1-1^{1 / 2}{ }^{\prime \prime}$. Petals hyaline, white, about the same length. Stamens shorter, the filaments bearded, the anther-cells subglobose, yellow, occupying the margins of a broad transverse connective. Stigma obtuse. Capsule $1^{1 / 2}{ }^{\prime \prime}$. Seeds 1 or 2 in each cell, peltate. - Griseb. FI. W. Ind. p. 523. - T. floribunda, Kth. - T. effusa, Mart. Fl. Bras. p. 15, tab. 34 .

Only found in the small ravine at the head of Pauoa, Oahu! where Mr. Marin or "Manini", an early settler from Mexico, used to raise trees and plants from seeds received from his native country. The species ranges in America from Mexico and the W. Indies to Brazil.

\section{Order LXXXVII. FLAGELLARIACEAE.}

Flowers regular, hermaphrodite or dioecious. Perianth scarious, persistent, of 6 nearly free imbricate segments in two series, the inner ones of the same length as the outer or shorter. Stamens 6, opposite the segments, hypogynous, free; anthers erect, introrse. Ovary superior, 3-celled, each cell with a single ovule which is suspended from near the apex by a short funis. Stigmas 3, filiform, diverging, papillose inside along their entire length, discreet or shortly connate below. Fruit baccate or drupaceous. Albumen (perisperm) farinaceous. Embryo lenticular, imbedded in a depression of the albumen, next the hilum. - Reed-like or climbing, sometimes woody plants with long-sheathing parallel-nerved leaves. Flowers numerous in a terminal panicle, the bracteoles minute or wanting. - See Brongniart \& Gris, Fragm. Fl. N. Cal. p. 7.

An Order of only 3 genera, confined to Malaysia and Polynesia.

\section{JOINVILLEA, Gaud.}

Flowers hermaphrodite. Segments of perianth stiff, acute. Stigmas discreet, very short. Drupe globose, scarcely fleshy, with bony pyrenae, $1-3$-seeded. Seeds ovoid, with appressed testa. Embryo subdiscoid, with a nipple-like projection toward the micropyle. - Bamboo-like plants with fistulous nodose stems, leafy in their whole length. Leaf-sheaths convolute, with a projecting 2 -eared ligule; the blade plicate along the nerves, acute, without cirrhi. Flowers small, sessile along the branches of a large panicle, single or clustered.

A genus of 1 or perhaps 2 species in New Caledonia, the New Hebrides and Viti Islds., besides the following.

1. J. adscendens, Gaud. Bot.Voy. Bon.tab. 39 and 40. - Stems $15-20 \mathrm{ft}$. high (15-40, Wawra), over one inch thick at the base, undivided, the internodes $6-12^{\prime}$. Leaves alternate, with a smooth sheath of $6-8^{\prime}$ in length, the blade lanceolate, $2-3 \mathrm{ft}$. long, $3-5^{+}$broad about the middle, 
contracting at the base, many-nerved, with 20-25 plaits which converge toward the base into a short striate rib, the nerves scabrous on both faces with minute spinules. Panicle pyramidal, $3-4$ times compound, $8-14^{\prime}$ long and as broad or broader at the base, its peduncle enveloped in the uppermost leaf-sheath, the flexuose branches horizontally spreading or deflected, shortly puberulous. Flowers singly sessile, supported by a tooth-like bractlet. Perianth $1^{1} / 2^{\prime \prime}, 6$-parted to the base, the outer segments ovate, obtuse, conchoid, with a short reflected mucro below the apex, thin glumaceous with a cartilaginous base, the inner of equal length, but narrower and thinner. Stamens subexserted, with slender filaments and sagittate anthers. Stigmas longer than the ovary, exserted. Drupe globose, $2-3$ " in diameter, yellow, rather dry, with a loose fragile shining epicarp; the pyrenae consolidated. Seeds globose, apiculate, with a dark subcoriaceous wrinkled testa. - Wawra, in Flora, 1875, p. 248. J. Gaudichaudiana, Brongn. \& Gr. Fragm. Fl. N. Cal. p. 8. - Leaves as in Panicum plicatum.

In the lower and middle forests of all islands, but rare. Ka uai, Hanatei to Kealia (Wawra and Remy); Oahu! Palolo to Niu; Molokai! Wailau to Halawa; Maui; Haw aii! near Hilo (Remy and Lydg.). Nat. name: Ohem. Brongniart and Gris made 2 Hawaiian species, the above given description applying to their $J$. Gaudichaudiana, to which they assign the windward islands from $\mathrm{Ha}$ w a i to $\mathrm{O}$ a $\mathrm{h} \mathrm{u}$, their $J$, adscendens being confined to $\mathrm{Kauai}$. This latter is said to differ in the outer segments being muticous, without reflected mucro, and besides in "perispermii granulis amylaceis simplicibus, angulosis, cellulas dense replentibus (non granulis compositis). Against this separation speaks Wawra's description, who attributes to his Kauai specimens mucronate outer segments, while the character of the starch granules finds its explanation in difference of maturity.

\section{ORDER LXXXVIII. JUNCACEAE.}

Perianth regular, dry and calyx-like, of 6 free segments. Stamens 6 or rarely 3 only, inserted at their bases. Ovary 3 -celled with 1 or more anatropous ovules in each cell, or 1 -celled with 3 or more ovules. Styles usually 3, stigmatose on the inner side. Capsule 3-valved. Seeds albuminous, with a very small embryo next the hilum, the dull testa covered by a thin hyaline integument which often forms a tail-like appendage. - Herbs, usually stiff, with nodose stems and narrow, sometimes cylindrical and stem-like leaves. Flowers small, glumaceous, in terminal or apparently lateral clusters or panicles.

A small Order, abundantiy spread over the temperate regions of both hemispheres, with few species within the tropies.

\section{LUZULA, DC.}

Stamens 6 , shorter than the perianth, the elongate anthers introrse. Ovary 1 -celled, with 3 erect ovules. Style 3 -fid. Capsule 3 -valved, loculicidal. Seeds 3 or fewer, the testa minutely reticulate or striate, sometimes appendiculate. - Tufted herbs with triquetrous stems and flat, usually soft-hairy leaves. Flowers small, in fascicles or discreet, 
the fascicles or single flowers arranged in an irregular umbel or panicle, sometimes contracted into a head or spike; the single flowers in the axil of a searious bract with 1 or 2 bracteoles besides.

About 26 species with the range of the Order, but chiefly belonging to the northern hemisphere.

1. L. campestris, DC. - Kunth, Enum. Pl. III, 307.-Grass-like, 6-18' high. Leaves radical and cauline, linear, flat, ciliate at least near the base, or glabrate. Flowers irregularly cymose, contracted into close spikelike clusters, the clusters in umbels on peduncles of various lengths $\left(1 / 3-1^{1} / 2^{\prime}\right)$, the majority terminal, a few lateral. Perianth dark brown, supported by $2-4$ hyaline and ciliate bracts, its segments very acute, 1 -nerved, $2^{\prime \prime}$ long, exceeding the obtuse capsule. Anthers linear, on very short filaments. Style shorter than the sepals, half as long as the linear stigmas. Capsule incompletely septate. Seeds with a conical appendage at the base.

High mountains of $\mathrm{Hawail}$, Maui! and $\mathrm{Kauai}$, from $3000 \mathrm{ft}$. upward. In the plants from the higher elevations the leaves and bracts are almost woolly at the base, the clusters of flowers compaet and mostly subsessile or on short peduncles.

$\beta$ var. glabrata. - Leaves and bracts glabrous. Inflorescence more open, the clusters of flowers again umbellately expanding. Perianth pale.

Molokai!

The species is spread over the temperate and cold regions of the entire northern hemisphere and many parts of the southern, as the Society Islds., New Zealand, Tasmania and the Cape of Good Hope.

\section{ORDER LXXXIX. PALMACEAE.}

Perianth dry and calyx-like, of 6 lobes or segments in 2 distinct series, contorted or valvate in the bud. Stamens 6 , or rarely more, or 3 only. Anthers versatile, 2 -celled. Pistil usually of 3 carpels, free, or united into a 3 -celled ovary. Ovules solitary, or rarely 2 in each cell, erect. Stigmas 3 , usually sessile, undivided. Fruit either a 3 -celled or 1-celled drupe or berry, or of 3 distinct drupes or berries. Seed erect, or laterally attached. Embryo small, in a cavity near the outside of a hard albumen. - Stems woody, usually simple and often attaining a great height. Leaves large, usually at the summit of the stem, folded in the bud and pinnately or palmately divided. Flowers usually sessile, in simple or paniculate spikes (the whole inflorescence called a spadix), enclosed when young in large sheathing bracts ealled spathes, and usually with 3 small bracts or bracteoles under each flower.

A large tropical Order with a very few extratropical species in the warmer parts of the northern and southern temperate zones.

The number of eultivated palms is very large, the most prevailing ones being the Royal Palm, Oreodoxa regia, and the Date Palm, Phoenix dactylifera.

Leaves fan-shaped, palmatisect.

Leaves pinnate

Pritchardia.

Hillebrand, Flora of the Hawaiian Islands. 


\section{PRITCHARDIA, Seem. \& Wendl.}

Flowers hermaphrodite, singly sessile, coriaceous. Outer perianth tubularcampanulate, 3 -toothed, the inner 3 -parted and with a very short tube which is connate with the staminal cup, the segments ovate-lanceolate, valvate, deciduous from the tube. Stamens 6, equal, connate below in a tube or cup, the anthers linear-oblong. Ovary trigonous or three-lobed, 3-celled, with 1 erect ovule in each cell. Style single, tri-sulcate, attenuate, with 3 minute stigmas. Drupe dryish, with a single nut or coccus, the pericarp thin fibrous, the endocarp crustaceous. Albumen smooth, slightly impressed on the ventral side by the rhaphe and chalaza, the embryo located at its back above the base. - Trunks straight, unarmed. Leaves terminal, fan-shaped, palmatisect, with unarmed petioles. Spadix a thrice branching panicle on a long axillary peduncle, enclosed at first in several thick coriaceous cylindrical spathes.

A Polynesian genus of 3 known species, one of which inhabits the Viti, Samoa and Tonga Islands, perhaps also the Marquesas, unless the palm growing there should prove to be a distinct fourth species. Vid. Seem. F1. Vit. p. 274.

Leaves woolly-matted underneath; fruit small, ovoid Leaves glabrous underneath; fruit larger, globose

1. P. Gaudichaudii.

2. P. Martii.

1. P. Gaudichaudii, H. Wendl. in Bompl. X, 199. - Trunk about $20 \mathrm{ft}$. high and $1 \mathrm{ft}$. in diameter. Leaves on petioles of $2-3 \mathrm{ft}$, orbicular, measuring $3-4 \mathrm{ft}$. in length and somewhat less in width, covered underneath, particularly near the base, with a pale-brown matted wool, slit for the space of about $1 \mathrm{ft}$. into about 60 segments, a fibrous thread of about $6^{\prime}$ in length projecting from each sinus, the segments again slit at the top into 2 linear-acute lobes; the petioles ragged at the base, concaveconvex, with sharp edges, ending in front of the leaf with a short semicircular plate, but prolonged at the back into a suddenly contracting arrowshaped rhachis of about $6^{\prime}$. Spadix $1^{1 / 2}-2 \mathrm{ft}$. long, enveloped before expansion by 5 lanceolate-oblong spathes of nearly $1 \mathrm{ft}$. in length, which are furfuraceous externally. Flowers sessile along nearly the entire length of the tortuous, more or less tomentose branches of the panicle; the bractlets short filiform. Calyx $1^{1 / 2}-2^{\prime \prime}$, glabrous. Petals coriaceous, lanceolate, $3-4^{\prime \prime}$, inserted above the base of the staminal cup. Filaments $2-3$ ", their free portions at length reflexed. Style as long as the petals, somewhat acute. Drupe ovoid, $9^{n}$, yellowish-red, the somewhat fleshy mesocarp traversed by longitudinal fibres. - Livistonia(?) Gaudichaudii, Mart. Palm. p. 242.

This palm, the sLoulu lelos of the natives, has been found in its wild state on rocky eliffs of the northern coast of Molokai! and on the Kohala ridge of $\mathrm{Haw}$ aii! Single trees $\mathrm{I}$ have seen also in the woods of $\mathrm{E}$. Ma ui and Lanai, but under circumstances whieh made it probable that they had been planted by the hand of man. It is not unfrequently met with cultivated near native dwellings, and between Kailua and Kealakeakua, Hawaii, there are two small groves of it. There seem to be two marked varieties of this species, for the trees from Molokai and those generally eultivated have the spadices only faintly tomeutose, while a fragment of an inflorescence, collected by 
Mr. Lydgate on the Kohala ridge, Hawaii, has the rhachis and its branches quite woolly. Possibly the latter specimen, which comes without leaf or notes attached, may represent a distinet species.

It is this same palm which covers part of Bird Island, a small volcanic rock 400 miles N. E. of Kauai. A tree, raised from seed brought thence in 1858 by the late Dr. Rooke, stands in the Palace yard in Honolulu.

The natives distinguish varieties with yellow and red fruit. They eat the kernel of the fruit before it is ripe, and of the leaves they make fans and hats; hence the trees are often found mutilated, with only one or two leaves at the top of the bare trunk.

The Hawaiian name foulu does not seem to be known on the other island groups where the genus is represented; but the Hawailan name for the nut or kernel, "Hawane", or its inversion "Wahane", recurs at the Marquesas Islands as the name of the tree. The Tongan and Vitian names "Bius and "Viu " point to "Niu", the name of the cocoanut palm or palms in general.

2. P. Martii, $H$. Wendl. $l$. $c$. - Trunk shorter, generally not exceeding $5-6 \mathrm{ft}$, , but as thick as in no. 1. Leaves on longer petioles, glaucous below and glabrous, not woolly, but in the younger state sparsely covered underneath with thin appressed and soon deciduous sealelets; segments about 40 , less deep than in no. 1 , the intermediate threads shorter or wanting and the lobes of the bifid segments truncate. Spadix $3 \mathrm{ft}$. long, with 5 glaucous spathes. Calyx densely striate, the streaks converging toward the teeth. Drupe greenish, globose, $15-20^{\prime \prime}$ in diameter, with a dense fibrous layer under the exocarp. Embryo almost axile. - Livistonia (?) Martii, Gaud. Bot. Voy. Bon. tab. 58, 59. - Mart. Palm. p. 242.

The LLulu hiwa exists in elumps on almost inaccessible palis in various parts of Oahu! as Kalihi, Nuuanu, Palolo, Niu, also in Kalaupapa and Waikolu, Molokai, and on a small rocky islet opposite Waikolu, probably also on Kauai between Waimea and Hanalei. In Nuuanu, where until a recent time two clumps could be seen from the upper part of the valley, one was completely exterminated when the natives found that the trees were saleable to amateurs of gardening in Honolulu; the other owes its preservation to the absolute inaccessibility of the cliff on which it stands. A note accompanying the fragment of an inflorescence collected by Mr. Lydgate in Niu, Oahu, gives the height of the tree as $12 \mathrm{ft}$. and that of the peduncle as $10 \mathrm{ft}$. ! Both this and the former species have been introduced into the botanieal gardens of Europe.

\section{Cocos, L.}

Flowers monoecious, both sexes in the same spadix, which is enclosed before expansion in a single woody fusiform spathe, sessile, bracteate, the male in the upper, the female in the lower portion. Male $f l$. Sepals and petals valvate, the former lanceolate, the latter oblique-oblong. Stamens 6, inserted on the torus; anthers linear-sagittate, erect. Fem. fl. much larger than the male, increasing after flowering. Sepals and petals coriaceous, broad ovate, imbricate, the latter enclosed by the former. Ovary 1 -celled ( 2 cells rudimentary). Style short, with 3 subulate stigmas. Drupe ovoid, rather trigonous, 1-seeded, woody, with a thick layer of fibres under the exocarp, the bony putamen with 3 holes near the base. Albumen hollow. Embryo near one of the basilar holes. - Unarmed palms with mostly tall trunks. Leaves terminal, pinnate, the petioles 
expanding at the base into a broad sheathing network of tough fibres. Spadices in the axils of the lower leaves, simply branched.-

About 30 species, probably all of American origin.

- 1. C. nucifera, L. Fl. Zey7. - Trunk 60-100 ft. high, annulate, thickened at the base. Leaves spreading, their segments narrow linearlanceolate, acuminate. Fem. $f l$. subglobose. Drupes large ovoid, subtrigonal.

The Cocoanut Palm reaches on our group the northern boundary of its range in the Pacific; yet, although it does not yield such abundant harvests of fruit as in more equatorial latitudes, it still thrives very well, as can be seen in the vigorous groves of Lahaina and southern $\mathrm{H}$ a waii. For a number of years, however, its leaves have been subject to the attacks of a moth which deposits its eggs in the folds of the leaf-segments. Before the caterpillars have entered the pupa stage the young leaves are literally reduced to shreds, which gives to the trees a sad appearance and creates in the occasional visitor the impression that they live under unsuitable elimatic conditions. Formerly there existed only one variety with very large fruit, but since then several new ones have been introduced. The nat. name "Niu" extends through all Polynesian island groups, those of the Maoli as well as of the Papuan races, and under slight modifications, adapted to the peculiar idioms, it maintains itself alongside with some other appellations through the Malayan and Tagalo arehipelagoes, even to Madagasear (vide Miquel, Fl. Ind. Bat. III, 66,67 , where the names current in the various groups are given). The original home of this widely diffused tree is unknown. Martius, whose speculation has met with most. favor, places it on the western border of the isthmus of Panama. (Cf. also Seem. Fl. Vit. pp. $276-277$.)

\section{ORDER XC. PANDANACEAE,}

Flowers dioecious, without perianth or bracts, densely packed in simple or branching spikes or heads (spadices), enclosed by persistent or deciduous spathes. Male $f l$. Stamens numerous, the filaments often connate; anthers 2-celled, basifixed, dehiscing lengthwise. Fem. fl. Ovaries distinct, or several connate in phalanges, 1-celled, with 1 laterally inserted ovule, or with many ovules on parietal placentas. Stigmas sessile or stalked, distinct. Fruits drupaceous, many aggregated in a head or spike. Endocarp bony. Seeds oblong; testa membranous; embryo small, at the base of a fleshy albumen. - Trees or shrubs, usually with a branching stem, supported by strong adventitious roots. Leaves simple, narrow elongate, firm, spiny, imbricate in three spiral rows.

Two genera, spread over the tropics of the old World.

No staminodes in the female flowers; a single ovule in each carpel;

an erect tree

Staminodes present; ovules numerous; a woody elimber

1. Pandanus.

3. Freycinetia.

\section{PANDANUS, L.}

Male fl. Spadix compound, thyrsoid, borne at the end of a branch, the lateral spikes each in the axil of a leafy, often colored spathe, which is generally longer than the spike. Stamens numerous, usually connate in bundles. No rudiment of an ovary. Fem. $f l$. Spadix usually simple, 
borne at the end of a branch, surrounded by many spathes. Staminodes none. Ovaries free, or several connate in phalanges, with 1 laterally inserted ovule in each. - Arborescent or fruticose, rarely stemless plants.

About 50 species, chiefly inhabiting the East African islands, the Malaysian arehipelago and Oceania; a single one in the W. Indies.

1. P. odoratissimus, L. fil. - Kunth, Enum. Pl. III, 94. - A small tree, $10-20 \mathrm{ft}$. high, the short whitish trunk soon branching in a dichotomous manner, emitting numerous aerial roots above the base and some from the branches. Leaves crowded at the ends of the branches, linear, $3-5 \mathrm{ft}$. long, about $3^{\prime}$ broad at the base, prickly at the margins and the keeled midrib, coriaceous. Spadix of male $\mathrm{fl}$. pendulous, 5-6 long, its bracts white, large ovate-lanceolate, concave. Stamens (10-15) connate in fascicles; anthers linear, mucronate. Spadix of fem. $f l$. solitary, surrounded by 3 sets of white imbricate leaf-like bracts, erect, globose, of the size of a childs head when mature and orange-colored. Drupes or phalanges $50-80$, turbinate, angular, $1^{1 / 2}-2^{\prime}$ long and $1-1^{1 / 4^{\prime}}$ broad at the end, each composed of 5-10 carpels (one in the centre), the flat top divided by shallow grooves into as many spaces as there are carpels, the sessile stigmas at first oblique but finally apical, reniform. Endocarp surrounded by copious fibres. $-P$. verus, Rumph. (Kurz, in Seem. Journ. Bot. V, 125). - P. fascicularis, Lam. - Solms-Laubach, in Linnaea, XLII, 37. - Arthrodactylis spinosa, Forst.

Common in dry plains of the lower regions, but extending up to elevations of $2000 \mathrm{ft}$. Nat. name "Lauala or "Lauhala", or simply "Hala", so called from the sweet scent of the male flowers. Coarse mats are made of the leaves. The species extends all the way from the Hawaiian to the Seychelle Islands and Arabia. - To this speeies have to be referred also the fruits figured in the Atlas Bot. Voy. Bon, by Gaudichaud, tab. 22, figs. 9, 14, 16, under the names $P$. Chamissonis, P. Menziesii, P. Douglasii.

\section{FREYCINETIA, Gaud.}

Male $f l$ on a simple spadix. Stamens numerous round a rudimentary germ, the filaments short conical or flexuose. Fem. $f l$. Spadix simple. Ovaries numerous, surrounded by short abortive stamens or staminodes, each ovary of 2 or several carpids aggregated in a truncate phalange. Ovules many in two rows on 3 or more linear parietal placentas. Stigmas sessile, distinct or more or less confluent. Fruit fleshy, but often woody near the apex, 2-to several-celled, or by absorption of the dividing walls 1 -celled. Seeds imbedded in pulp, oblong or spindle-shaped, with a fleshy lateral rhaphe. - Climbing shrubs of the habit of Pandanus.

About 30 species, extending from Ceylon through Malaysia and Oceania to the Hawailan Islands, with one species each in Australia, Norfolk Island and New Zealand.

1. F. Arnotti, Gaud. Bot. Voy. Bon. tab. 36 \& 3\%. - Solms-Laubach, in Linnaea, XLII, 95. - A tall woody climber, the stem about 
$1^{\prime}$ in diameter, ringed, and emitting many aerial roots. Leaves stiff coriaceous, crowded near the ends of the branches, linear-lanceolate, $1^{1 / 2}-2^{1 / 2} \mathrm{ft}$. long and $1^{1 / 2} 2^{4}$ broad at the clasping base, tapering gradually to an acute point, spinuloso-serrate along the margins and the keeled midrib. Male $f l$. on $2-4$ terminal cylindrical spadices, each $5-6^{\prime} \times 4-6^{\prime \prime}$, naked in the lower third, the whole surrounded by a rosette of rose-colored leaf-bracts which are ovate-lanceolate, $10-15^{\prime}$ long and $2^{1} / 2^{\prime}$ broad below, the inner bracts oblong-obtuse, ${ }^{3 / 4}-1^{\prime}$ long. Filaments $2^{\prime \prime}$, orange; anthers $1^{\prime \prime}$, clavate-oblong, obtuse at both ends, the broad connective continuous with the filament. Fem. $f l$. Spadices and spathes as in the male flowers. Phalanges surrounded by $2-4$ short staminodes, composed of $5-10$ carpels, but generally 1 -celled at last, dotted at the smooth polished and truncate top with 5-10 reniform or subannular cartilaginous stigmas arranged in a circle or ellipse. Exocarp pulpy, orange-colored. - F. arborea, Gaud. Bot. Freyc. p. 341, tab. 41. - Mann, Enum. no. 469. - Solms-Laubach, 1. c. p. 100 . - F. scandens, Hook. \& Arn. in Bot. Beech. (not Gaud.). Mrs. Sinclair, pl. 3.

Common in the lower woods, climbing on trees or trailing over the ground in absence of trees, often forming impenetrable thickets. The older name $F$. arborea has to be abandoned as inappropriate and misleading. There is only one species on the Islands, unless, what is most improbable, the trailing plant should represent a second species. There is no arboreous form. Near the pali of Nuuanu, where in all probability Gaudichaud first saw the plant, as I did myself, it was found climbing on Dracaena aurea, the leaves of which tree resemble somewhat those of the present species. This circumstance probably misled that author in the belief that the flowering spadices, intermingled with the foliage, belonged to the tree. Count Solms-Laubach in the Monograph quoted has admitted, not without hesitation, both species of Gaudichand on the faith of the difference in the stigmatiferous apex of the phalanges, as represented in the respective plates of that author's two works: a roundish or angular apex with $4-6$ stigmas in F. Arnotti, an elongate apex with 6-9 stigmas in $F$. arborea. But the difference has no specific value, for my fruiting specimens show both kinds in one inflorescence: phalanges with few stigmas have a roundish apex, those with many have an elongate one. Nat. name: "Ieie, which also recurs in Tahiti for $F$. demisga, $\mathrm{R}, \mathrm{Br}$.

\section{Order XCI. ARACEAE.}

Flowers monoecious or rarely dioecious or hermaphrodite, on a simple spike or spadix which is supported by a convolute or rarely flat, colored or leaf-like bract or spathe. Stamens and ovaries either in different parts of the spadix without perianth or bracts, or 6 or fewer stamens round each ovary with or without a small scale or perianth-segment under each stamen. Anthers usually 2 -celled and opening upward, sessile or on short filaments, distinct or connate by their connectives. Ovaries 1- to several-celled, with 1 or more ovules in each cell. Stigma sessile or on a simple style. Fruit a berry. Seeds in a pulpy testa, with or without albumen. - Herbs, usually with a watery, often caustic milksap, stemless, with a tuberous rhizome, or caulescent, sometimes fruticose, 
with aerial roots, the stem creeping or erect. Leaves entire or divided, the veins usually pinnate or reticulate as in Dicotyledons, rarely parallel as in most Monocotyledons. Spadix often bearing barren organs (abortive stamens or ovaries) above or below the stamens, or ending in a thickened barren portion called the appendix.

A large Order, ehiefly tropical, but dispersed also over several more temperate regions. - In cultivation: Richardia Africana, Kth., Caladium bicolor, Vent, in several varieties, Monstera deliciosa, Liebm., and a few others.

Appendix smooth

Appendix marked with reticulate furrows

Colocasia. Alocasia.

\section{COLOCASIA, Schott.}

Spathe convolute, tubular below, the blade finally breaking away. Spadix enclosed in the spathe, interruptedly androgynous, with ovaries at the base, stamens higher up and barren organs in the interval, the appendix oblong or conoidal, smooth. Perianth wanting. Stamens $3-6$, united into short truncate or peltate bodies with the anthers laterally adnate. Ovaries 1 -celled; stigma capitate, subsessile. Ovules numerous, hemitropous or nearly orthotropous, affixed in 2 rows to $3-5$ parietal placentas. - Herbs with a tuberous root-like or caulescent stock. Leaves usually large and glaucous, cordate and sometimes peltate. Tube of spathe persistent, $1 / 2-1 / 5$ the length of the blade.

A genus of 5 species, natives of tropical Asia, but one of them widely spread by cultivation.

1. C. antiquorum, var. esculenta, Schott, in Synops. Aroid. p. 41. - A perennial herb, $1-1^{1 / 2} \mathrm{ft}$. high, with a tuberous stock. Leaves ovatecordate and peltate, the obtuse basal lobes or auricles being shortly connate below the insertion of the petiole, about $1 \mathrm{ft}$. in length, smooth velvety above. Spadices several from one axil, shorter than the petioles; their spathes yellow, ovate-lanceolate and straight. Appendix acuminate, smooth, about half as long as the staminate portion. Staminal bodies stipitate. Style of ovaries very short. - Arum Colocasia, L. - A. esculentum, L. \& Forst. - Colocasia esculenta, Schott, Melet. - Caladium esculentum, Vent. - Engler, in De Cand. Monogr. II, 491.

In general cultivation and along mountain-streams of the lower regions. The "Kalo" or -Tares still affords, as it did of old, the principal staple of food to the natives of the Hawaiian Islands, as is the case, though to a less degree, with the other branches of the Polynesian race, who all call it by one common name. The Hawaiians distinguish a considerable number of varieties according to the quality of the tuber and the color of the leaf-stalk. It is propagated by the tops of the corms, which readily strike root, either under water, or in the higher rain-favored regions in clearings of wood-land; but in the latter case the plant-tops need to be mulched at first. The tuber matures in about 15 months. All parts of the plant contain an acrid principle, particularly in the coarser varieties, which is destroyed by cooking. The tuber is eaten boiled or baked, or as -poi - the baked root pounded, mixed with water and exposed to fermentation for a short time. The baked and pounded tuber, sun- or kiln-dried and pressed, will keep for many months and is sold as pai ai. The leaf-stalks, too, form an excellent vegetable, not unlike asparagus in taste. 
The species is of Indian origin, but its cultivation has extended both eastward and westward to Egypt, several Mediterranean countries, Madeira, the Canaries and the West Indies. Nowhere else, however, does the tuber grow to that perfection which it attains at the Hawailan Islands.

\section{ALOCASIA, Sehott.}

Ovaries 1-celled (or sometimes 3-4-celled at the apex). Ovules few, orthotropous, attached by short funes to a basilar placenta. Appendix conoidal, marked with reticulate furrows. Otherwise as in Colocasia.

About 20 species, natives of tropical Asia and the Malayan archipelago.

1. A, macrorrhiza, Schott, in Oestr. Bot. Wochenbl. 1854, p. 409, and Gen. Aroid. tab. 40. - A caulescent herb, the stout stem 2-4 ft. high, sending up shoots from the base. Leaves terminal on long petioles, sagittate. ovate, with the broadly ovate obtuse basal lobes or auricles distinct to the petiole, $2-3 \mathrm{ft}$. in length, the stout nerves prominent above and below. Spadices pedunculate, one or two from an axil, as long as or shorter than the spathes, which are 6-8' long or more, of a pale greenish yellow, convolute at the base, with an oblong obtuse or shortly pointed incurved blade. Flowers densely packed, the ovaries occupying about $1^{\prime}$

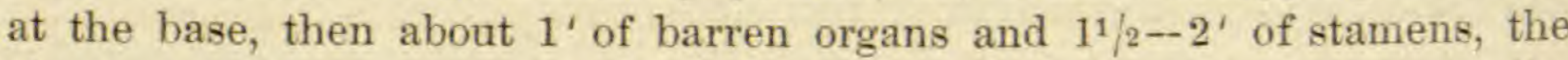
obtuse reticulate appendix about $2^{\prime}$ or more. Staminal bodies sessile. Berries reddish. - Engler, in De Cand. Monogr. p. 502. - Colocasia macrorrhiza, Schott, Melet. - Arum maximum macrorrhizum, Herm. Arum macrorrhizum, Forst. in part. - Arum mucronatum, Lam. - Colocasia odora, Brongn.

The "Apii or" Apé of the natives, who eat the coarse farinaceous stem in times of scarcity only. Its cultivation is not carried on methodieally and is restricted to small patches of dry land in mountain-recesses or elearings in the lower zone of forests. The flowers emit a strong sickish odor. A native of India, but eultivated and naturalized in many Polynesian islands, as in the Viti and society groups, in the latter of which it is also called "Apés. Vitian names: Via" and "Dranu", v. Seem. in Fl, Vit. p. 286.

\section{ORDER XCII. ALISMACEAE.}

Perianth of 6 segments, either all similar, or the three outer ones small and sepal-like, the three inner large and petal-like. Stamens 6, 9 or indefinite. Ovary of 3,6 or many earpels, either distinct from the first or separable when in ripe fruit, each with 1, 2 or many ovules. Embryo horseshoe-shaped, consolidated into a homogeneous mass, the radical extremity often thick. No albumen. - Marsh- or water-plants with radical leaves and leafless flower-stems, or rarely with leafy stems. Flowers whorled in terminal racemes or spikes, rarely in spurious umbels or single. 


\section{SAGITTARIA, L.}

Flowers unisexual. Perianth of 3 outer herbaceous segments and 3 larger inner ones petal-like and very delicate. Stamens numerous. Carpels numerous in a dense globular head, each with a basilar erect ovule. Leaves long-stalked, usually cordate or hastate. Flowers in a raceme or narrow panicle, the lower ones female or hermaphrodite, the upper male.

A genus of 15 species, dispersed over the northern hemisphere and extending into South America.

†1. S. sagittifolia, L. - Kunth, Enum. Pl. III, 156. - Micheli, in De Cand. Monogr. III, 66. - Rhizome thick tuberous, stoloniferous. Leaves on long petioles of $1-2 \mathrm{ft}$., sagittate, the basal lobes $4-5$ ' long, diverging, acute. Scape exceeding the leaves. Flowers monoecious, in whorls of 3 , at long intervals, the lower female on shorter $\left(1^{\prime}\right)$, the upper male on longer $\left(1^{1 / 2^{\prime}}\right)$ pedicels. Bracts 3 at the base of each whorl, ovate to lanceolate, 3-4". Sepals reflexed. Petals white, 3-4". Stamens indefinite; the anthers linear, basifixed, as long as the glabrous filaments. Carpels very numerous, complanate, glandular, winged when mature Style short, erect or curved.

In "taro"-ponds of Kapalama near Honolulu! a late arrival. The species ranges over the whole of Europe, middle and southern Asia to Java, and in America extends from Canada to southern Mexico. The Chinese cultivate the plant for the sake of the tuber.

\section{Order XCIII. NAIADACEAE.}

Flowers usually proceeding from a small sheathing bract. Perianth wanting or of 4 small scale-like segments. Stamens 1,2 or 4 . Ovary either of 2 or 4 distinct carpels, each with a single ovule and a separate stigma, or single, with 1 ovule and $2-4$ stigmas. Fruit of 1,2 or 4 seedlike nuts, each with 1 seed, without albumen. - Aquatic floating or submerged herbs. Leaves either sheathing at the base or accompanied by sheathing stipules, alternate or rarely opposite. Flowers axillary, inconspicuous, solitary or in spikes.

An Order not numerous in species, but abundantly diffused over all parts of the world, in shallow seas as well as in fresh water.

Flowers unisexual, axillary, mostly single; male fl. of a single anther; fem. fl. of 1 carpel .

1. Naias.

Flowers hermaphrodite,-spicate:

Perianth wanting; stamens 2 ; ovary of 4 earpels, long stipitate when mature

Perianth of 4 segments; stamens and carpels 4 , the latter sessile when mature

\section{Ruppia.}

3. Potamogeton.

\section{NAIAS, L.}

Flowers unisexual. Male $f l$. with a double perianth, the outer (spathe?) tubular, entire or 2-4-cleft, the inner hyaline, adnate to the anther. Stamen 1, the sessile anther 1-4-celled. Fem. $f l$. a single ovary, naked 
or closely invested by a hyaline perianth, sessile in the sheathing base of the leaf, with $2-4$ subulate stigmas or style-branches and 1 basilar anatropous ovule. Fruit a small seed-like nut. Embryo straight. Submerged fresh-water plants with thread-like creeping rhizome. Leaves opposite, ternate or alternate, often crowded in clusters, linear, sheathing at the base, nerveless, usually serrulate. Flowers solitary or glomerate.

Ten species, widely dispersed over the temperate and tropical regions.

1. N. major, All. var. angustifolia, A. Braun, in Seem. Journ. Bot. II, 275. Stem almost smooth. Leaves narrow-linear, with 5-10 short patent teeth on each margin, the sheath generally toothless. Flowers dioecious, solitary. Staminal perianth or spathe bicuspidate. Stigmas 3. Nut 2-3", ovoid, crustaceous, rugose or reticulate. $-N$. marina, $\alpha$, L. - N. fluviatilis, Lam, in part. - Kunth, Enum. Pl. III, 112.

Collected by Chamisso on Oahu. The speeies oecurs in lakes and ponds over the greater part of the northern hemisphere.

\section{RUPPIA, L.}

Flowers hermaphrodite, naked, $2-6$ sessile on a slender spadix which is at first enclosed in the sheathing spathe-like base of a leaf. Anthers 2, sessile, each with 2 large and distinct reniform cells dehiscing outwards. Carpels 4, small, sessile, free, with a single campylotropous ovule suspended in each. Stigma sessile, depressed. Fruit of little ovoid beaked drupes, each raised on a slender stalk which appears after flowering; the spadix itself also then raised on an elongate thread-like peduncle. Embryo ovoid, with a short pointed plumule from the upper end, by the side of the short cotyledon. - Submersed salt-water plants with long and threadlike forking stems. Leaves opposite and alternate, slender, almost capillary, with a sheathing stipuliform base. Flowers rising to the surface at the time of expansion.

One or several species of the temperate and subtropical regions.

1. R. maritima, L. - Kunth, Enum. Pl. III, 123. - Leaves linear-capillary. Spadix generally 4 -flowered, erect or deflexed. Fruiting peduncle capillary, $1 / 2-1$ ' long. Nut oblique.

In shallow waters along the coast, found by Chamisso and the naturalists of Capt. Beechey's Expedition, also by the writer on the southern shore of Molokai. The species extends over the coasts of Europe, western Asia and N. America.

\section{POTAMOGETON, L.}

Flowers hermaphrodite, spicate, bractless. Perianth herbaceous, of 4 rounded and elawed segments valvate in the bud. Stamens 4, opposite the segments, the anthers nearly sessile, 2-celled, the cells discreet, opening laterally. Carpels 4 (rarely 1 ), each with 1 ascending campylotropous ovule; stigmas sessile, peltate, or introrse on a short style. Nutlets 
drupe-like, more or less compressed. Seeds curved or cochleate, the thick radicular end of the embryo pointing downward. - Fresh-water weeds with jointed rooting stems and 2-ranked pellucid leaves which are alternate or rarely opposite, the upper ones sometimes dilated, of a firmer texture, and floating. Stipules inside the leaf, free, or adnate to the base of the leaf. Spikes sheathed by the stipules in the bud, raised on a peduncle to the surface of the water when in flower.

About 50 species, spread over the cold and temperate regions of the whole world, with a few species extending into the tropics.

Leaves brond oblong

Leaves narrow linear

1. P. fuitans.

2. P. pauciflorus.

1. P. fluitans, Roth, Tent. Fl. Germ, I, 72. - Stem terete. Floating leaves elliptico- or lanceolate-oblong, somewhat obtuse, tapering at the base, chartaceous, with a prominent rib and $5-7$ obseure parallel nerves on each side, $2-3^{1 / 2^{4}} \times 7-14^{\prime \prime}$, on petioles of $1^{1 / 2}-3^{1 / 2^{4}}$, which are convex above. Submersed leaves alternate, lanceolate or linear, thin pellucid. Stipules connate, free from the petiole, lanceolate-acute, less than 1'. Peduncles $1^{1} / 2-2^{1} / 2^{\prime}$, terete, thicker than the stem, the spike $6-9^{\prime \prime}$, cylindrical. Nutlets laterally compressed, with somewhat acute margins. - P. Owaihiensis, Cham. in Linnaea, II, 228. - P. natans, var. angustatus, Kunth, Enum. Pl. III, 128.

In taron-ponds and watercourses of Nuuanu! and elsewhere. The species is widely spread over Europe, Asia, Africa, and N. America with the W. Indies.

2. P. pauciflorus, Pursh, Fl. I, 121. - Kunth, Enum. Pl. III, 136. - Stem slender, thread-like, flattish, forking from the base. Leaves all alike and submersed, alternate, sessile, narrow-linear, grass-like, 3- or 1-nerved, $1-3^{\prime}$ long and $1 / 3-1^{\prime \prime}$ broad. Stipules connate, free from the leaf, clasping the stem, $3-5^{\prime \prime}$ long. Peduncles $3-5^{\prime \prime}$, compressed, thiekened above, reversed after flowering. Spikes very short, subglobose, $1 / 3-3 / 4^{\prime \prime}$ in diameter, 4-6-flowered. Nutlets semilunar, compressed, distinctly crested with 1 or 3 keels on the broad convex back, the short style oblique, almost facial. Seed curved. - Cham. in Linnaea, II, 176, tab. 4, fig. 7 .

Near Honolulu! in ponds and "taros-patches. A North Ameriean species.

H. Mann enumerates also P. Gaudichaudii, Cham., which is referred to $P$. lucens, L., by Kunth, 1. c. p. 132, but a reference to his quotation (Linnaen, II, 199) shows that Gaudichaud's plant was collected on the island of Guam or Guajan of the Ladrones.

\section{Order XCIV. CYPERACEAE.}

Flowers hermaphrodite or unisexual, in spikelets consisting of several scale-like bracts called glumes, distichous or imbricate all round, with one flower in the axil of each, or the lower ones empty. Perianth either wanting or replaced by bristles or scales. Stamens usually 3, but sometimes more $(4-6)$ or fewer. Ovary 1 -celled, with a single erect anatropous ovule, in fruit forming an achenium. Style 3 -cleft when the achene is 
3-angular, or 2-cleft when the achene is flattened or lenticular. Embryo minute, at the base of a farinaceous albumen. - Grass-like or rush-like herbs with mostly trigonal solid stems and closed leaf sheaths. Spikelets solitary, or several in a cluster, spike, umbel or panicle. Inflorescence and its branches almost always subtended by bracts which are usually leaf-like under the principal rays or branches, glume-like (reduced to the sheath) under the spikelets. When the inflorescence is umbellate it is very irregularly so, one or more spikelet-clusters or partial umbels being always sessile, while the others are supported on peduncles or rays of very unequal length.

A large Order abundantly distributed over the whole globe, but more especially preferring moist situations or the edges of waters.

Flowers, at least the fertile ones, hermaphrodite:

Glumes distichous, 2-ranked (Cypereae):

Spikelets several-flowered, or, if 1-flowered, the spikes or rays more or less umbellate

Spikelets 1-flowered or with a second male flower, crowded in a sessile head

1. Cyperus.

2. Kyllingia.

Glumes imbricate all round:

Spikelets several-flowered (Scirpeae):

No hypogynous bristles or scales

A perianth of hypogynous bristles:

Base of the style bulbous, persistent on the achene; stem leafless; spikelet solitary .

Base of the style not thickened; spikelets generally numerous in elusters or psendo-umbels

A perianth of 2 lateral fold edand keeled scales (Hypolytreae) Spikelets 1- or few-flowered, with several empty glumes below

(Rhynchosporeae):

No hypogynous bristles:

Base of the style thickened, at last extending as a fleshy cap on the achene or entirely surrounding it; inflorescence a thyrsus of dense corymbs

Base of the style enlarged, persistent as a horny pyramidal beak on the achene; inflorescence paniculate:

Ovary sessile, not winged.

Ovary stipitate, winged

Base of the style not enlarged; achenes ovoid or fusiform, shining black, red or yellow; sometimes $1-3$ perianthscales present; inflorescence spicate-paniculate

A perianth of 6 hypogynous bristles:

Bristles discreet, deciduous; erect herbs with mostly compound panicles; achene beaked

Bristles coherent, persistent after the glumes have fallen; low dichotomous herbs with single spikelets at the ends of leafy branches; achenes not beaked

Flowers all unisexual, the sexes in distinct spikelets, the pistillate spikelets 1-flowered, mixed in clusters with the male; aghene globose, white, seated on a disk (Sclerieae)

Flowers all unisexual, both sexes in separate or in androgynous spikes, the male $\mathrm{H}$. generally occupying the upper, rarely the lower portion of the spike; achene enclosed in a bidentate utricle (Cariceae):

A barbed awn in the utricle besides the achene

Only the achene in the utriele

3. Fimbristylis.

4. Eleocharis.

5. Scirpus.

6. Hypolytrum.
8. Cladium.

9. Baumea.

10. Vincentia.

11. Gahnia.

7. Rhynchospora.

12. Oreobolus.

13. Scleria.

14. Uncinia.

15. Carex. 


\section{CYPERUS, L.}

Spikelets many- to few-flowered, laterally compressed, rarely terete, in clusters or spikes, rarely solitary, the clusters or spikes sessile or on the sheathed rays of a simple or compound involucrate umbel. Glumes distichous (2-ranked), their decurrent bases often forming margins or wings to the joints of the axis next below, the one or two lowest empty. Flowers hermaphrodite, without hypogynous scales or bristles. Stamens 3 or fewer. Style not bulbous at the base, 3- or 2-cleft, deciduous. Achene triangular or biconvex, often pointed with the base of the style. - Stems simple, triangular, leafy at the base and with one or more leaves at the summit which form the involucre.

A large tropical and subtropical genus, represented by a few species in the more temperate regions.

The number of the involucral leaves really corresponds to that of the rays of the umbel, but they are of very unequal length, and those pertaining to short sessile spikes are quite minute. Each ray is, besides, provided with a sheath or ochrea, which is most manifest and closed in the long ones, but open and bracteiform in those which are less developed. Involucral leaf and ochrea are opposite to each other and repeat themselves not only in the radioles or branches of the ray, but also in the spikelet, the former as involucellar leaf or bract and as lowest glume (which is always more pointed than the others), the ochrea as closed sheath in longer radioles or branches, or as inner soon deciduous bract in shorter ones, and as second empty glume (or vorblatt) in the spikelet. The latter is always shorter than the upper fertile glumes, more obtuse, and generally clasping at the base.

In the lowest spikelets both. are present, but in the upper ones the outer or lowest empty glume generally disappears; not rarely, however, one or more of the other glumes are found sterile. In many species (Mariscus) the rhachis is articulate above the two empty glumes, and these remain on the ray after the lapse of the spikelet; in others, again, with a continuous rhachis (C. polystachyus, C. trachysanthus), they are the first to fall.

In the following descriptions the number of involucral leaves given refers to those only which are conspicuous on first sight. In the number of glumes the two lowest empty ones are always included.

Style bifid:

Nuts dorsally compressed; spikelets in a dense eluster (Juncellus)

Nuts laterally compressed; spikelets in a fascicle or nmbel (Pycreus)

1. C. laevigatus.

2. O. polystuehyus. Style : - fid:

Fertile glumes 4 or more (Eucyperus):

Spikelets more or less compressed:

Spikelets reddish, linear, spicate on the rays of a simple umbel

Spikelets pale brown or rust-colored :

Spikelets erowded in dense heads at the apex of the rays or of umbellate raylets, each with $12-30$ scabrous glumes

Spikelets spicate on the rays of a simple or the alternate branches of a compound umbel, each with $6-12$ smooth glumes:

Umbel short, eompact, with rays less than $3^{\prime \prime}$ :

Spikelets ovate, compressed, acute; rays of umbel mostly branching

Spikelets obovate, rather turgid, obtuse; rays mostly simple, or their branches very short

Umbel large, open, twice or thrice compound; spikelets ovate-oblong, turgid

3. C. rotundus.

7. C. trachysanthus.

4. C. pennatus.

5. C. Hillebrandi.

6. C. caricifolius. 
Spikelets greenish; umbels large, open, with longest rays 6-9' and branching in their upper third or fourth only (subumbellate when young):

Ochreae foliolate; branches or raylets many, alternate; glumes thin, acute, mucronate below the apex

Ochreae truncate or bidentate; branches few, 1 or 2 pairs, elosely set; spikelets at last resupinate

Glumes thin, obtuse, not mucronate; spikelets 3 " long, densely set

Glumes thick coriaceous, acute, mucronate at the apex; spikelets $6-8$ " long

Spikelets linear terete; umbel large compound:

Radioles umbellate; spikeiets pale brownish, with 8-16 glumes; rhachis articulate (Diclidium)

Radioles alternate, brachiate; spikelets reddish, with $5-7$ glumes; rhachis continuous?

Fertile glumes 4 or less; spikelets crowded, articulate above the two lowest empty glumes (Mariscus):

Spikes deep brown or reddish; spikelets compressed:

Spikes ovoid, or short-and thick-eylindrical

Umbel simple, short, compact, the longest rays not exceeding $1^{1 / 2} 2^{2}$, most spikes sessile; spikelets $1-2$-flowered;

Glumes, at least the lower ones, scabrous at the keel Glumes smooth at the keel

Umbel compound, the ovoid spikes closely set at the ends of rays, the longest rays $4-5^{+} ;$fertile glumes $3-4$.

Spikes elongate, cylindrical, in a compact but compound umbel; fertile glumes $1-3$, obtuse

Spikes green, elongate; spikelets terete, subulate .

10. C. strigosus.

11. C. decipiens.

12. C. hypochtorus.

8. C. auriculatus.

9. C. Prescottianus.

15. C. phleoides,

16. C. Hawaiiensis.

13. C. Kunthianus.

14. C. Mauiensis.

17. C. umbellatus.

1. C. laevigatus, L. - Steudel, Synops. Pl. Glum. II, 12. - Rhizome creeping. Stems $1-2 \mathrm{ft}$. long, terete below, trigonous above, leafless or with only one very short linear leaf, besides a leafless sheath. Spikelets $2-30$, mostly sessile, densely crowded in a terminal cluster, each $4-6^{4}$ long, 15-30-flowered, oblong, moderately compressed, the lowest often curved. Involucral leares 2, the upper one stiff, erect, appearing like a continuation of the stem and much exceeding the cluster in length. Glumes pale, stiff, ovate, conchoid, obtuse, shortly mucronate, not keeled, but with a prominent median nerve. Rhachis compressed parallel to the glumes, foveolate. Stamens 3, enclosed. Style bifid, exserted. Nut compressed parallel to the rhachis, plano-convex, ovate or rounded, apiculate, smooth, about ${ }^{1 / 3}$ shorter than its glume. - Boeckeler, in Linnaea, XXXV, 486. - C. mucronatus, Rottb, var. ж. - Kunth, Enum. Pl. II, 17. - Hook. \& Arn. in Bot. Beech. p. 99. - Mann, Enum. no. 500.

In and near sweet or brackish water, plentiful near Honolulu (Aliipukai). - A common plant in many tropical countries of the New and Old World, extending also to the Cape of Good Hope and the Mediterranean region. - Nat name: "Ehuawa. The fine and highly prized Niihau mats are made of this plant.

2. C. polystachyus, Rotth. - Kunth, Enum. Pl. II, 13. - Stems tufted from a short horizontal rhizome, slender, trigonous, glabrous, $8-30$ ' long, leafy at and above the base. Leaves generally shorter than the stem, rarely as long, hardly $2^{\prime \prime}$ broad, flat, distantly scabrous on the 
margins. Umbel 3-8-rayed, either contracted, appearing like a fascicle of $1 / 2-3 / 4^{\prime}$ in length, or more frequently some or most ravs lengthened out (to $2^{\prime}$ or more), each with $10--20$ spikelets, which are arranged in a racemose or subcorymbose manner toward their ends, erect in the contracted, horizontally patent in the long-rayed umbels. Involucral leaves $3-6$, the 2,3 , or more largest ones much exceeding the umbel in length. Spikelets linear-lanceolate, 4-9"long, sharply compressed, 12-24-flowered. Glumes pale-brown, with lighter colored edges, ovate-elliptical, about $1^{\text {" }}$ long, thickened at the greenish keel and shortly mucronate, indistinctly several-nerved, about twice as long as the narrow, and at the base thinly wing-margined foveoles. Stamens 2. Style deeply bifid, exserted. Nut pale-brown, oblique-oblong, laterally compressed, about $1 / 2$ the length of its glume. - Steudel, 1. c. p. 8. - Bcklr. 1. c. p. 478. - C. paniculatus, Rottb. (the form with long rays). - C. brunneus, Hook. \& Arn. in Bot. Beech. (not Sw.), and probably also C. caespitosus of the same authors, 1. c. $\beta$ var. pallidus. - Whole plant pale; the stem thick and short, $8-12^{\prime}$ long; leaves stiff, about $1 / 2$ the length of the stem; umbel contracted; involucral leaves short.

Very common on open grassy slopes; the variety on dry lava-fields of E. Ma ui and H awaii! - Found all round the world in tropical and subtropical countries.

†3. C. rotundus, L. - Kunth, l. c. p. 58. - Rhizome creeping and bearing small nut-like tubers. Stems ${ }^{1 / 2}-1^{1 / 2} \mathrm{ft}$. long, slender, acutely trigonous. Leaves considerably shorter, flaccid, flat, about $2^{\prime \prime}$ broad, acute, somewhat scabrous near the apex. Umbel simple, of $4-6$ slender rays, the longest $1-1^{1 / 2}$, each bearing in its upper third or fourth $4-9$ ascending spikelets. Invol. leaves 3 or 4 , not exceeding the umbel. Spikelets sessile, linear, moderately compressed, nearly 1 'long, 12-35-flowered, with 1 or 2 empty glumes at the base. Glumes ovate, not mucronate, $1^{1 / 2}$ " long, closely imbricate, dark brown or reddish except at the greenish 3-nerved keel. Foveoles of rhachis broadly margined with hyaline wings. Stamens 3. Style 3-fid, long-exserted. Nut obovate, trigonous, dotted, shorter than its glume. - Steudel, 1. c. p. 32. - Beklr., in Linnaea, XXXVI, 283.

A most troublesome weed in gardens, where it was first observed about the year 1850 . - It is widely diffused over the tropical and subtropical regions of the world. In America it extends as far north as Virginia. The tubers of the rhizome have a pungent taste somewhat resembling that of Valerian.

4. C. pennatus, Lam. - Kunth, 7. c. p. 80, but not of Boeckeler. Rhizome strong, creeping. Stem rather stout, obtusely trigonous, $1-3 \mathrm{ft}$. high. Leaves longer, stiff, flat, $3-6^{\mu}$ broad, very scabrous along the margins and on the entire under face. Umbel compact, rather globose, elosely many-rayed, the rays $2^{1 / 2}-3^{1} / 2^{\prime} l o n g$, stiff, spreading, even deflected downward, branching from the middle or from below the middle 
upward, the branches horizontal and close, rather loosely spicate along their entire length. Involucral leaves $6-9$, very long, the longest $1-2 \mathrm{ft}$., scabrous also along the keel. Spikelets brownish-stramineous, horizontally patent, with a small bracteole of less than ${ }^{1 / 2}{ }^{\prime \prime}$, ovate-lanceolate, $3-5^{\prime \prime}$ long, compressed but at last turgid, acute. Glumes 7-11, subcoriaceous, broadly ovate, keeled above, somewhat acute, sometimes mucronate, $1^{1 / 2^{\prime \prime}}$ long, 9-11-nerved, pale,-with reddish dots or lines. Rhachis flexuose, with broad hyaline wings to the lower halves of the foveoles. Stamens 3. Style deeply 3 -fid. Nut acutely trigonous, dark brown, one third the length of its glume. - The scabrosities on the lower face of the leaves occupy the short transverse veinlets. - Benth. in Fl. Austral. VII, 284, also in Fl. Hongk. - Seeman, in Fl. Vit. - Baker, in Fl. Maur. C. canescens, Vahl; Bcklr. in Linnaea, XXXVI, 340. - Pycreus Owahuensis, Nees. - Mariscus albescens, Gaud, in Bot. Voy. Freyc. p. 415.

In the lower regions; sometimes gregarious. Oahu (Meyen); Molokai! Waikolu, near the sea; Ma ui (Wawra). - Also found by Remy and M. \& B. - The species extends from the Masearene Islds. and India through Malaysia, Australia, S. China to the Philipines and most of the Pacific islands. - Viti, Ebon (Gulick), Tahiti, Marianas.

5. C. Hillebrandi, Boeckel. in schedul. herb. reg. Berolin. - Rhizome short and thick. Stem swollen at the base, rather slender, acutely trigonal, $2 / 3-3 \mathrm{ft}$. high, foliaceous in the lower third or fourth. Leaves mostly shorter than the stem, $2-4$ " broad, slightly scabrous. Umbel compact, rather globose, $1-3^{\prime}$ in diameter, either simple, with $6-8$ rays which are spicate along nearly their entire length, or compound, the larger rays sending out a few short horizontal branches from below the middle which are spicate in the same manner. Longest involucral leaves $6-10^{4}$. Spikelets horizontally patent, each supported by a subulate bractlet of $1 / 2$ its length or more, short ovoid and subcompressed, rather turgid and somewhat obtuse, fulvous-brownish, $1^{1 / 2}-3^{\prime \prime}$ long. Glumes mostly 8 , closely imbricate, rather thin, broadly obovate, rounded at the top and very shortly mucronate, convex with a thick rib, but not keeled, finely channelled or striate, but very indistinctly many- (9-) nerved. Foveoles of rhachis narrowwinged. Stamens 3. Style 3 -fid. Nut pale brown, obtusely trigonal, with one angle less prominent, sometimes almost plano-convex, with the convex face ridged. - C. caricifolius, var. Hbd. (not Hook. \& Arn.) in herb. Berolin.

Southern slope of Haleakala, Maui! on old lava fields, at an elevation of $3000-5000$ ft. - Boeckeler places the species next to his C. Graeffei (Flora, 1875, p. 84) from Upolu of the Samoa Islands.

6. C. caricifolius, Hook. \& Arn. in Bot. Beech. p. 99. - «Stem trigonal, $1^{1 / 7}-2 \mathrm{ft}$. long. Leaves carinate, scabrous on edges and keel. Invol. leaves 5-6. Rays of umbel racemosely branching in their upper halves with several alternate branches, of which the lower are the longest and 
the upper ones gradually shorter; these again (particularly the lower ones) dividing into alternate branchlets which are closely spicate or racemose with patent ovate-oblong turgid spikelets. Glumes roundish, concave, obtuse, nervose, whitish. - Has many points in common with C. Monti. The leaves resemble those of some of the larger species of Carex.»

Oahu or Niihau (Lay and Collie).

7. C. trachysanthus, Hook. \& Arn. in Bot. Beech. p. 99. - Stem 1-2 ft. high, obtusely trigonal, grooved on the faces, smooth or seaberulous below the umbel. Leaves pale, glossy, about as long as the stem, 1-2" broad, long acuminate, thick-keeled, generally folded, distantly but sharply aculeolate along the margins and keel. Umbel simple or compound, with $4-5$ projecting rays besides the sessile clusters, the longest ray $2-3^{\prime}$, each bearing at its very apex a cluster of $12-25$ spikelets or an umbellet of about 3 radioles which terminate with clusters of spikelets. Two or three involucral leaves much longer than their rays, those of the involucel short filiform and few. Spikelets broad oblong, much compressed, 4-6" long, $2-2^{1} / 2$ " broad, 10-16-flowered. Glumes gaping, quite discreet in fruit, 2 "long, broad ovate, carinate-navicular, hooded below the sharppointed recurved apex, subcoriaceous, grayish-fawn, faintly many-(9-11-) nerved without prominent rib, the keel distinctly serrulate below the apex. Rhachis slender, very narrowly margined, the shallow foveoles only $1 / 3$ the length of the glumes. Stamens 3. Style deeply 3-cleft. Nut 1", half as long as its glume, obovoid or pyriform, trigonal, apiculate, black, with a film of grayish (waxy) exudation. -- Bcklr. in Linnaea, XXXV, 548. - Mariscus glutinosus, Schrad. in herb. Berolin. - C. viscosus, Mann. Enum. no. 504?

Oahu! on lava rocks of the eastern end near Cape Mokapur. Collected first by Chamisso. All my specimens answer to the description given above, but Hook. \& Arn. had before them also a variety with larger compound umbels, the spikelets about 30 -flowered and the stem free from all asperities. In shape and color the spikelets are much like those of $C$. pennatus. The leaves are described as glutinous by Boeckeler, but in my specimens they appear simply glossy.

8. C. auriculatus, Nees. - Kunth, l. c. p. 83. - Stem 2-3 ft. high, stout, acutely trigonal, spongy below. Leaves longer, flat, $5-9$ " broad, scabrous on nerves and margins. Umbel compound, about 12-rayed, the rays suberect, compressed, with long truncate or shortly ligulate ochreae, about 8 rays exserted, $3-8^{\prime}$ long and again umbellate at their tops with 8 secondary rays, which are sheathed with closed ochreoles, spicate in their upper halves and the longer ones again branching at the middle. Involucral leaves two to three times the length of the umbel, those of the involucel a little longer or shorter than their umbellets. Spikelets with a subulate bracteole of about $1^{\prime \prime}$, horizontal, linear-terete, acute, rather flexuose, $5-12^{\prime \prime}$ long, with glumes gaping, pale nut-brown. Glumes $8-20$, 
obovate-oblong, convolute, over $1^{1 / 2} 2^{\prime \prime}$, obtuse, rounded, even truncate, or somewhat acute, subnucronate, subcoriaceous, 5-7-nerved, pale brown, with short lines of deeper color. Stamens 3, brownish. Style 3-fid, exserted. Rhachis articulate, moniliform, the single joints obovate, dotted with rustcolored spots, separately deciduous with the nuts, which are tightly clasped by the broad subcoriaceous wings extending along the entire side of the joint. Nuts black, oblong, apiculate, about as long as the joints and half as long as their glumes, rather plane-convex, the convex face next to the rhachis and the outer face strongly ridged. - Steudel, 1. c. p. 44. - Bcklr. in Linnaea, XXXVI, 408. - C. multiceps, Hook. \& Arn. in Bot. Beech. p. 100.

In swampy places. Hamakua and Hilo, Hawaii! Maui! Oahu! Native name: “Kilioopun. - Is nearly related to the Ameriean C. lomentaceus, Nees (C. pennatus, Bcklr.), which has also been found in the Philipines, Java and Timor.

$\beta$ var. - Leaves shorter than the stem; glumes with green lines along the median nerve; wings of the joints narrowing above. $-C$. Wawraeanus, Reichardt, in Ber. der k. Akad, d. Wissensch, in Wien, LXXV, 553.

Oahu, Kaala Mts., in a dry locality (Wawra no. 2255).

9. C. Prescottianus, Hook. \& Arn. l. c. p. 100. - Stem 3-4 ft. high, acutely trigonal, scabrous in the upper portion. Leaves as long, or shorter, $6-8^{\prime \prime}$ broad below, very scabrous on both faces. Umbel 8-12-rayed, the rays suberect, scarcely compressed, 4-6 long, with ochreae shortly ligulate, alternately branching in the upper half or third;

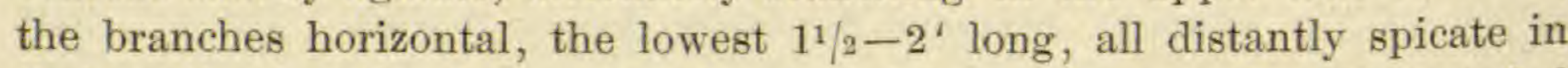
their entire length. Only 3 or 4 involucral leaves longer than their umbel (two to four times as long). Bracteal leaves of raylets filiform, pale and much shorter than the same, 9-4"; opposite to them a much shorter bract, clasping at the base and open (ochreola). Spikelets horizontal, with a linear bractlet of $1^{1} / 2^{\prime \prime}$, deep reddish-brown, linear-terete, rather flexuose, very acute, $4-5^{\prime \prime}$ long; the rhachis slender, with shallow foveoles and narrow hyaline wings along their entire lengths. Glumes 5-7, chartaceous, rather distant, closely appressed, with gaping ends, oblong, about $2^{1 / 2}$, convolute, keeled only near the apex, with 8 reddish nerves and a broad greenish rib, shortly mucronate at or near the subtruncate or emarginate apex. Stamens 3, with linear reddish anthers. Style trifid.

$\mathrm{O}$ ahu! It is with some hesitation that I refer this plant to the imperfectly deseribed species of Hooker \& Arnott, * as these authors make no mention of the deep red color of the spikelets and give them as compressed. In shape they are similar to those of the preceding species, but they hold fewer glumes. The two specimens collected are with early flowers, and it remains doubtful therefore whether the rhachis, when mature, is continuous or breaks up into joints; the wings however are narrower than in the preceding species.

* "Spiculis linearibus elongatis compressis horizontalibus alternis spicatis, spieís corymbo-racemosis, squamis hiantibus obtusiusculis nervosis, involucri universalis polyphylli foliolis tribus umbella duplo longioribus, partialibus umbellula brevioribus, culmo acute triquetro. 
10. C. strigosus, $L$. - Kunth, l. c. II, 87 . - Stem $3 \mathrm{ft}$. or more high, stout, acutely angular, scabrous in the upper portion. Leaves as long or longer, $5-6^{\prime \prime}$ broad, very scabrous on both faces near the end. Umbel compound, about 12 -rayed, the rays suberect, slender, $4-7^{\prime}$ long, their ochreae running out into a short subulate leaflet, horizontally branching in the upper third or fourth, the lowest $3-4$ branches longest, ochreolate and approximate in a kind of whorl, sometimes again dividing in their upper portions, all ultimate branches closely spicate in their entire length and supported by linear scabrous bracts of their own length or less. Involucral leaves many, most of them exceeding the umbel several times. Spikelets patent, each with a short subulate scabrous bracteole, linear-lanceolate, $3^{1 / 2}-5^{\prime \prime}$ long, compressed, with gaping glumes, greenish. Glumes $6-8$, thin, oblanceolate, acute, $2-2^{1} / 2^{\prime \prime}$ long, carinate, faintly $7-9$-nerved, pale or sometimes rufous at the margins, with the keel darker-green and ending below the apex in a short and stiff erect mucro. Rhachis slender and narrow, continuous, the thin white margin extending along the whole length of the furrow. Stamens 3, included. Style deeply 3 -fid, exserted. Achene(?) (half as long as its glume, obtusely trigonal, with rough dots, in the American plant). - Hook. \& Arn. l. c. p. 99. - Bcklr. in Linnaea, XXXVI, 346. - C. odoratus, Sol.

Molokai! on high palis; Oahu (Lay \& Collie). Only flowering plants collected.

$\beta$ var. - Spikelets greenish-brown, with a subulate, almost smooth bractlet of more than their own length. Glumes 4--6, obtuse, the subapical mucro deflected or uncinate.

Molokai! Kalae.

The species is common in N. America and has been collected in Brazil; occurs also in the Marquesas, Society, Viti and N. Hebrides groups of islands. Our plants are much larger than those from the American continent. In the young plants the raylets appear umbellate with an involucel. The ligule of the ochreae is sometimes bifid (2-bristled) as in the North Ameriean plants (Gray, Man. Bot. p. 492),

11. C. decipiens, $s p . n$. - Stem over $2 \mathrm{ft}$. high, sharply trigonal. Leaves as long or longer, over 6 " broad below, rather thin, rough on both faces. Umbel 9-12-rayed, the rays suberect, slender, $6-9^{\prime}$ long, with truncate orbidentate ochreae, bearing near their ends 2 pairs of closely set horizontal or resupinate branches of unequal length, the lowest measuring about $1^{\prime}$ and ochreolate with an open sheath, besides the terminal one of about $1^{1} / 2^{\prime}$, all densely spicate in their whole length, the spikes quite obtuse. Most involucral leaves much longer than the umbel, those of the involucel filiform, as long as their branches. Spikelets with linear bracteoles of about $1^{\prime \prime}$, horizontal or resupinate, ovato-lanceolate, slightly compressed, 3 "long, pale green. Glumes 7-9, membranous, broadly ovate or obovate, obtuse, not mucronate, faintly many-nerved, pale fawn colored, with a broad greenish keel, 2 "long or twice the length of their foveoles. Rhachis slender, its foveoles shallow, with narrow hyaline margins. Stamens 3 , style trifid, both pale and long exserted. Achene (immature) sharply triangular. 
Only one specimen, collected on Maui or Molokai! Stands near C. strigosus, yet is sufficiently distinguished by the fewer subumbellate, densely spicate and resupinate, quite obtuse branches, the inappendiculate ochreae and the obtuse muticous glumes. The branches have the bottle-brush appearance of many Mariscus.

12. C. hypochlorus, $s p . n$. - Stem $2-3 \mathrm{ft}$. high, sharply trigonal, smooth. Leaves as long or longer, 6 " or more broad, strongly nerved or channelled, very scabrous on edges and under side. Umbel compound, large, 8-10-rayed, open, the spreading rays 3-6/ long, with obliquely truncate ochreae, naked below, the larger ones emitting at nearly the same height 2-4 short horizontal ochreolate, finally resupinate branches (the lowest $1-1^{1 / 2^{\prime}}$ long), besides the longer terminal one, all spicate in their entire length. Largest involucral leaves several times the length of the umbel. Leaves of involucel linear or filiform, equalling the lateral branches. Spikelets horizontal or resupinate, supported by a persistent lanceolate or subulate bracteole of $3-1^{\prime \prime}$ in length, linear-lanceolate, 6-8" long, compressed, acute, green. Glumes 6-8, stiff coriaceous, ovato-lanceolate, $3^{\prime \prime}$ long, acute, shortly mucronate at the apex, carinate, 13-19-nerved, with nerves stout and prominent, the thick 5-nerved keel green, the sides whitish. Rhachis articulate above the empty glumes, pale green, with thick whitish wings extending the whole length of the deep foveola. Stamens 3, with yellow anthers. Style 3-fid. Achene ovoid or oblong, laterally compressed, apiculate, dark brown, smooth and shining, almost buried in the narrow and deep foveola, less than half the length of the glume.

Label lost. Suffieiently distinct from C. strigosus in the larger and resupinate, rather distant spikelets, the corirceous and strongly nerved glumes, which are mucronate at the apex, and the inappendiculate ochreae. A specimen in the herbarium of Cornell University, collected by M. \& B. in Waimea, Kauai (without number), bears the same kind of spikelets, only a little shorter, $4-5$ " long, in a short and contracted umbel of $11^{1} 2^{+}$in diameter. The plant is much less robust, $2 \mathrm{ft}$. high, with leaves only $3^{\prime \prime}$ broad.

13. C. (Mariscus) Kunthianus, Gaud. in Bot. Voy. Freyc. p. 415. Stem 2-4 ft. long, rather slender, acutely trigonal or somewhat compressed, smooth. Leaves mostly shorter, $4-6^{\prime \prime}$ broad below, scabrous on edges and both faces. Umbel open and large, compound, many-rayed, the rays compressed, with long bidentate ochreae, of very unequal length, and spreading, some reaching $4-5^{\prime}$ and others only $1^{\prime}$ in length, sending out near the apex a short contracted raceme or cluster of short branches, the lowest horizontal and not exceeding $1^{\prime}$, most of them more or less naked at the base and densely spicate beyond, forming thick subglobose, ovoid or short and obtuse, eylindrical spikes, none longer than $8-9^{\prime \prime}$. Four or five involucral leaves longer than the umbel. Bracteal leaves of branches filiform and shorter than these. Spikelets suberect, the lowest at length patent, with a filiform deciduous bractlet, lanceolate, $3-4^{\prime \prime}$ long, compressed with gaping glumes, reddish-brown, 2-4-flowered. Glumes 
5-7 (the upper empty one obtuse, eostate or ecostate, and the terminal one tabescent), rather thin and pale, lanceolate, somewhat acute or slightly mucronate below the apex, $2-2^{1} / 2$ "long, faintly 8 -nerved, besides the stiff and smooth reddish keel. Stamens 3, slightly exserted, style 3 -fid, longexserted, both anthers and stigmas reddish. Foveoles of the slender rhachis shallow, with narrow hyaline margins. Achene elongate, trigonal, apiculate, reddish-brown, half the length of the glume. - Kunth, 1. c. p. 126. - Steudel, 1. c. p. 65. - Mann, Enum. no. 509.

Valley of Waihee, Maui! - The reddish color of the spikes is more owing to the exserted anthers and stigmas than to the glumes, which are of a paler yellowish brown.

14. C. Mauiensis, sp. $n$. - Stem acutely trigonal, $1-1^{1 / 2} \mathrm{ft}$. high. Leaves stiff, not much exceeding the stem, 4 " broad below, scabrous on edges and keel near the apex. Umbel compound but short and compact, $2^{1} / 2-3^{\prime}$ high, with 12 or more crowded, shortly ochreate rays, all or most of them again umbellate, viz, bearing one or two pairs of short approximate branches which do not exceed $1^{\prime}$ in length, besides the longer terminal one, all branches densely spicate in their entire length, forming obtuse cylinders of $4^{\prime \prime}$ in thickness, the spikelets subascending in the upper portion. Involucral leaves many, most of them much exceeding the umbel; leaves of involucel as long as their branches or shorter. Spikelets with a filiform bractlet of $1^{1 / 2}-2^{\prime \prime}$, ovato-lanceolate, but slightly compressed, rather turgid, $2^{1} / 2-3^{\prime \prime}$ long, of a dirty straw or rust color, $2-3$-flowered. Glumes $4-5$, the upper empty one short roundish and ecostate, the terminal one tabescent, the fertile ones chartaceous, smooth, obovate, subcompressed and hooded, obtuse, 2 "long, shortly mucronate below the apex, 8-10-nerved, besides the darker broad and stiff 3 -nerved keel. Foveoles of rhachis shallow, broad, ${ }^{1} / 2-1 / 3$ the length of their glumes, with hyaline wings. Stamens 3. Style 3-fid. Achene elongate, trigonal.

Maui! Haiku.

$\beta$ var. - Umbel simple, less compact and shorter, either all its rays undivided or only the one or two longest, with 2 very short branchlets below the long terminal spike, which is about $1^{\prime}$ long and only $2^{\prime \prime}$ thick. Spikelets 2 ". Glumes $3-4$, only 1 or 2 fertile.

Maui!

The species would seem to eome nearest to Mariscus flavus, H. B. \& $\mathbf{K}$., from $\mathrm{S}$. America, which also extends to some Polynesian island groups.

15. C. (Mariscus) phleoides, Nees. - Steudel, 7. c. p. 62. - Stem $1 / 2-11 / 2 \mathrm{ft}$. long, rather stout and swollen at the base, acutely triangular. Leaves coriaceous, exceeding the stem, 3-4" broad below, sharply serrulate on edges and keel toward the apex. Umbel simple, short and compact, with $7-11$ unequal rays, the longest $1-1^{1} / 2^{\prime}$ and naked in the lower half, rarely with a pair of very short branchlets, the shorter ones spicate to the base, the densely crowded spikelets forming ovoid or short obtuse 
cylindrical spikes of $4-5^{\prime \prime}$ in thickness. Involucral leaves numerous, all much longer than the umbel, the longest 7 times its length. Spikelets dark brown, suberect or adpressed, ovato-lanceolate, $2^{\prime \prime}$, compressed, 1-flowered. Glumes 4 , including the glume-like bractlet, thin chartaceous, the two lowest smaller acute and serrulate at the sharp keel, the fertile one $1^{1 /} 2^{\prime \prime}$, ovate or obovate, somewhat acute, navicular, pale, faintly 11-nerved, with the stiff brown keel slightly dentate or smooth, the upper one tabescent. Rhachis narrowly margined. Stamens 3 ; style trifid, both long-exserted and brownish. Achene elongate, $2 / 3$ the length of its glume, trigonal, long apiculate, dark brown. - Seem. Fl. Vit. p. 319.

Hawaii! Mauna Loa (Macrae), Kohala; Molokai! Waikolu; on dry grassy slopes. Occurs also on the Viti Islands. Mariscus macrophyllus, Brongn., from Bolabola, only differs in the smooth keel of its glumes.

16. C. (Mariscus) Hawaiiensis, Mann, Enum. no. 511. - «Stem trigonal, smooth. Leaves linear, scabrous at the margins, equalling the stem. Involucral leaves $6-8$, two of them elongate. Spikes several, ovate, subsessile or shortly pedunculate, closely crowded. Lower glumes very small, the middle ones 3 times as long, 9-nerved, smooth, the inner (uppermost) ones shorter, 1-nerved.

Mountains of Hawaii, Maui and Kauai. Smaller than C. phleoides, and the spikes shorter (M. \& B, 246). Collected also by Wawra (v. Reichardt ut supra). - The number of glumes can hardly be inferred from the short description, but it probably corresponds with that of the preceding species.

17. C. (Mariscus) umbellatus, Vahl. - Kunth, l. c. p. 118. - Stem rather slender, $1-2 \mathrm{ft}$. high, acutely trigonal, compressed above. Leaves thin, pale, as long as the stem or shorter, $2-3^{\prime \prime}$ broad below, scabrous on margins and keel near the apex. Umbel simple, with about 8 rather spreading rays, the longest $2^{\prime}$, naked below but densely spicate in the upper half or third, their ochreae very short, bicuspid. Most involucral leaves several times longer than the umbel. Spikelets $2-3^{\prime \prime}$, horizontal when mature (each with a short subulate bractlet of less than $1^{\prime \prime}$ ), green, slender linear, acute, scarcely compressed, $1-3$-flowered. Glumes $4-5$, the uppermost often sterile, the fertile ones elongate, obtuse, $1^{1 / 2}-2^{\prime \prime}$ long, not mucronate, thin and pale, several-(5-)nerved, with a thick and green 3 -nerved rib. Rhachis slender and very narrow-margined. Stamens 3, short. Style 3-cleft. Nut oblong, trigonal, brownish, not much shorter than the glume. - Benth. Fl. Hongk. and Fl. Austral. - Steudel, l. c. p. 60. - C. eylindrostachys, Beklr.

A single specimen in my collection, without label. The species has not before been reported from this group, but it is widely spread over the tropical regions of the Old World and has been found in Tahiti and on the W. coast of N. America.

\section{KYLLINGIA, Rottb.}

Spikelets 1 -flowered or with a second minute sterile floret above, small and closely imbricate in globular or oblong heads or short spikes; the 
bracteoles under each spikelet very small or altogether wanting in the interior of the heads or spikes. Glumes 3-4, distichous, the lowest one or two smaller and empty, the two upper nearly equal, compressed, carinate, enclosing both the fertile hermaphrodite flower and the rudimentary one with its minute glume. No hypogynous bristles or scales. Stamens 3 or fewer. Style bifid, not thickened at the base. Nut laterally compressed, enveloped within and deciduous with the two larger glumes. Spikes $3-5$, sessile, crowded in a dense, usually solitary, globose or spike-like head, which is supported by $2-4$ long leafy bracts. Stems leafy at the base, rarely leafless. Leaves grass-like.

A small genus, chiefly tropical, but extending also into N. Amcriea and S. Afriea.

1. K. monocephala, Rottb. - Kunth, Enum. Pl. II, 129. - Stems from a long creeping rhizome, weak, compressed, 4-12' high. Leaves thin and flat, shorter than the stem, about $1^{\prime \prime}$ broad, scaberulous above on edges and keel. Spikelets 1 -flowered, numerous and dense in a single globose head of about 3 " in diameter, with an involucre of 3 very long leafy bracts. Glumes 3, thin; the lowest very small, transparent, obtuse and empty; the next also empty but much larger, compressed, carinate, 5-7-nerved, the thickened keel green, sharply serrulate and running out into a stiff point; the third flowering one similar but longer. Stamens 2 or 3 . Nut obovate, pale, about $1 / 2$ the length of its glume. - Bcklr. in Linnaea, XXXV, 403.

Very common on moist pastures from the sea up to $3000 \mathrm{ft}$. Nat. name: -Kaluhas. In sandy soil near the seashore it often does not reach more than $1-2^{\prime}$ in height. This is the $K$, pumila, $\beta$, in Kth, , 1. c. p. 132, from the Sandw. Islds. (in herb. Lucae). - The species is widely diffused over the tropical regions of the whole world.

\section{FIMBRISTYLIS, Vahl.}

Spikelets many- to several-flowered, terete, the glumes imbricate all round, only 1 or 2 of the lowest empty. Flowers hermaphrodite, without hypogynous bristles or scales. Stamens 3 or fewer. Style 2- or 3-cleft, thickened at the base and articulate below the bulb, which is generally deciduous from the apex of the lenticular or triangular achene. - Mostly low herbs with stems leafy at the base. Spikelets in simple or compound cymes, rarely single, oftener in contracted clusters or in irregular compound umbels. globe.

A large genus of $200-300$ species, widely distributed over the warmer regions of the

Style bifid, hairy; achene lenticular; spikelets acute:

Spikelets $3-5$, single in a simple cyme or cymose umbel

1. F. Hawaiiensis.

Spikelets numerous, in fascieles on the rays of a compound umbel 2. F. polymorpha.

Style trifid, naked; achene trigonal, spikelets obtuse:

Spikelets obovoid, clustered, in an open or contracted cymose umbel

Spikelets ovoid, crowded in a single terminal head

3. F. cymosa.

4. F. pycnocephala. 
1. F. Hawaiiensis, sp. $n$. - Stems densely tufted from a short and thick rhizome with black wiry rootlets, $6-9^{\prime}$ high, very slender, slightly compressed. Leaves few, straight and erect, filiform or wiry, plano-convex, not broader than the stems and about half their length, almost smooth, green, not glaucous. Spikelets ovoid-lanceolate, acute, $3-3^{1} / 2^{\prime \prime}$ long, either 3 in a simple cyme, the middle one sessile, the lateral ones on pedicels of about $4^{\prime \prime}$, or 4-5 in an irregular umbel with one only sessile. Largest involucral leaf about as long as the cyme or umbel, the others shorter. Bractlets glume-like. Glumes ovate, $1^{1} / 2^{\prime \prime}$, convex, carinate near the apex, 1 -nerved, mucronate, subchartaceous, pale or greenish at the base and middle, dark brown or blackish at the sides above, as is also the nerve near the apex. Stamens 3, enclosed. Style flat, bifid, fimbriate, slightly swollen at the base, deciduous with the bulb. Achene very shortly stalked, obovate, biconvex, brown, apparently smooth but under the lens exhibiting longitudinal and transverse lines, without however being pitted.

High plateau of Hawaii! Nearly allied to F. schoenoides, Vahl, yet sufficiently distingnished by the greater number of spikelets, which are neither obtuse nor pale, and by the single-nerved glume.

2. F. polymorpha, Boeckeler, in Linnaea, XXXVII, 14. - Stems tufted, $3 / 4-1 \frac{1 / 2}{\mathrm{ft}}$. long, angular, compressed above. Leaves numerous, about half as long, glaucous, thin and flat, grass-like, $1^{1 / 1} 2^{\prime \prime}$ broad, not carinate, shortly acuminate, glabrous, serrulate on the margins, mostly curved. Spikelets ovoid-oblong, acute, $3^{1 / 2}-4^{\prime \prime}$ long, brown, numerous, sessile and shortly stalked in fascicles at the ends of the very unequal rays of a cymose umbel; the 2 or 3 longest rays projecting to the length of $1^{1 / 2}-2^{1} / 2^{\prime}$, the shortest forming subsessile clusters. Involucral leaves slightly exceeding their corresponding rays. Bracteoles of spikelets filiform. Glumes $1 \frac{1}{1} 2^{\prime \prime}$, broadly ovate, obtuse, almost rounded, convex-carinate mucronulate, with 5-7 nerves close to the keel, scarious and shining, pale but brownish at the sides, apex and along the nerves. Stamen 1 . Style thick and short, bifid with revolute branches, fimbriate, deciduous with its bulb. Achene subsessile, lenticular, obovate, pale, cancellate with longitudinal and transverse streaks, less than $1 / 2^{\prime \prime}$.

Under this species Boeckeler unites over forty synonyms, six of them by Vahl, the most noteworthy being: F. diphylla, Vahl, F. laxa, Vahl, F. communis, Kth., F. annua, R. \& S.

Oahu! Molokai! Maui! Kaanapali. - Not reported before from this group. The species is widely diffused over the tropies of both hemispheres and in a depauperate form (F. annua) extends to the Mediterranean regions of Europe.

$\beta$ var. longifolia. - Stem 6'. Leaves twice as long or more, straight, rather flaccid. Involucral leaves $3-4$ times as long as their respective rays. Glumes navicular, pale hyaline, with two brown patches near the apex, the lateral nerves very faint. Style as before. Stamens 1 or 2 .

A single flowering specimen from the northern slope of Kaala, Oahu! 
3. F. cymosa, R. Br.-Kunth, Enum. Pl. II, 244. - Stems tufted, 1-11/2 ft. long, angular-compressed. Leaves many, ${ }^{1 / 2}$ or ${ }^{1 / 3}$ as long, linear, less than $1^{\prime \prime}$ broad, pale, straight and stiff, thick at the middle, keeled and channelled in the lower half, suddenly acuminate or truncate, scabrous near the apex. Spikelets $1^{1 / 2}-2^{\prime \prime}$, obovoid when young, ovoid-obtuse when older, with gaping glumes, pale brown, sessile in close clusters or heads of $3-5$ in the forks and at the ends of the cymose spreading rays of a decompound open umbel; the longest rays measuring $2-3$ '. Involucral leaves stiff subulate, less than half the length of their rays. Bracts of spikelets subulate, triquetrous. Glumes $1^{\prime \prime}$, ovate, obtuse or rounded, not mucronate, with a prominent and stiff keel, pale yellowish, excepting a brown band on each side of the keel which is made up of $5-7$ closely approximate nerves. Stamens 3. Style shortly exserted, trifid, naked, deciduous with its bulb. Achene very small, ${ }^{1} / 3^{\prime \prime}$, scarcely stalked, obovoid, trigonal, smooth, pale. - Hook. \& Arn. in Bot. Beech. p. 98. - Benth. Fl. Austral. VII, 318.

The spikelets are not found longer than given above, for, although the rhacheole elongates at maturity to 3 and $4^{\prime \prime}$, the remaining glumes then occupy only its upper half. The inflorescence in the flowering stage recalls that of Juncus obtusiflorus, Ehrh.

$\beta$ var. umbellato-capitata. - Smaller and more rigid. Stems $6-12^{\prime}$. Leaves one third as long or less, often curved. Umbel much contracted, the longest rays not exceeding $6-9^{\prime \prime}$, their cymose divisions contracted into dense fascicles or heads. Involucral leaves and bracts quite short and stiff. Glumes stiffer and darker than in $\alpha$, stronger keeled and compressed, with often a subapical mucro. - F. umbellato-capitata of Mann, Enum. no. 518, but probably not of Steudel.

Hawaii! Maui! Oahn! Niihau (Lay and Collie); the var. $\beta$ in higher and exposed localities and more frequent than the first form. - The speeies has been found also in Australia, Timor and Tutuila.

4. F. pycnocephala, $s p . n$. - Stems tufted, stiff, angular-compressed, $3-8^{\prime}$ high. Leaves about half as long, crowded at the base, spreading, pale glaucous, rather stiff, curved or straight, flat, not carinate, about $1^{1 / 2} 2^{\prime \prime}$ broad below, channelled or not, shortly acuminate or truncate. Spikelets numerous, 20-40, ovoid-obtuse, $2^{1 / 2}-3^{1 / 2} 2^{\prime \prime}$ long, all sessile and crowded in a globose head of $1 / 2-3 / 4^{\prime}$ in diameter; rarely a single short ray projecting with a smaller head. Involucral bracts $1-3$, only one as long as the head or a little longer. Glumes ovate, somewhat obtuse, $1-1^{1 / 2} 2^{\prime \prime}$, navicular-carinate, with the keel denticulate in the lower ones, not mucronate, pale brown along the rigid and faintly 5-7-nerved middle, with a broad hyaline border round sides and apex. Stamens 3. Style trifid, naked, deciduous with its bulb. Achene obovoid, trigonal or plano-convex, with the convex face ridged, dark brown when mature and smooth, scarcely $1 / 3$ " high, sessile. 
Near the seashore in Kau, Haw a ii! Waikolu, Molok ai! E. Ma ui! Koko Head, Oa hu (M. \& B.). A species nearly related to the preceding one, in appearance much like contracted forms of $F$. glomerata, Nees, from Brazil, which however has a bifid style, a lenticular achene, and very obtuse glumes with a smooth and green keel.

\section{ELEOCHARIS, R. Br.}

Spikelet single, terminating the naked stem, many- to several-flowered, the glumes imbricate all round, only 1 or 2 of the lowest empty. Flowers hermaphrodite. Perianth of $3-8$ (commonly 6 ) bristles, usually rough or barbed downwards, rarely obsolete. Stamens 3. Style 2-3-cleft, its bulbous base persistent as a tubercle which is jointed with the apex of the lenticular or obtusely triangular achenium. - Leafless herbs, chiefly perennial, with stems sheathed at the base, from matted or creeping root-stocks. Spikelet without involucre.

A considerable genus ( 80 species) spread over every part of the giobe, mostly aquatic or bog herbs.

Tufted; spikelet obtuse; style mostly trifid Creeping; spikelet acute; style bifid

1. E. obtusa.

2. E. palustris.

1. E. obtusa, Schultes. - Kunth, Enum. Pl. II, 152. - Var. enotata. Stems tufted, compressed, 5-15' high. Spikelet ovoid or short-oblong, obtuse, $2-4^{\prime \prime}$ high, dull brown, bractless. Glumes numerous, all nearly equal, ovate or oblong, obtuse or rounded, hyaline, 1-nerved, convex, not carinate. Bristles $6-8$, longer than the achene, retrorsely seabrous. Style trifid, rarely bifid. Achene obovoid or turgid, biconvex with the outer face ridged, pale-brown, shining, capped with the darker-colored short and broad conical base of the style. - Scirpus obtusus, Willd. - Gray, Man. Bot. p. 496. - Hook. \& Arn. in Bot. Beech. p. 98.

Common in "taro"-ponds and stagnant water. - A common plant also in the eastern United States. - The glumes in our variety do not exhibit the reddish-brown zone under the apex which distinguishes the American plant. The stem also is deeidedly flat. Nat. names: "Pipiwai" and "Kohekohes.

2. E. palustris, R. Br. - Kunth, l. c. p. 14\% - Root-stock creeping. Stems somewhat compressed. Spikelet oblong-lanceolate, acute. Glumes numerous (the lowest clasping half the circumference of the spikelet), ovate-oblong, rather acute, 1-nerved, somewhat carinate, reddish-brown, with the evanescent keel green and a white hyaline apex and margin. Style bifid. Achene obovate, turgid-biconvex, yellowish-brown, shining, crowned with the subcordate complanate pale base of the style. Bristles generally 4 . - Scirpus palustris, L.

Oa hu, according to Kunth, but doubtful. - A very common species in Europe, northern Asia and Ameriea; also found at the Cape of Good Hope and the Falkland Islds.

\section{SCIRPUS, L.}

Spikelets many- to several-flowered, terete, single, or mostly clustered, and subtended by one or more involucral leaves, often appearing lateral 
from the extension of an involucral leaf like a continuation of the stem. Glumes regularly imbricate all round in several ranks. Flowers hermaphrodite. Perianth of $3-6$ bristles. Stamens mostly 3. Style 2-3-cleft, not bulbous at the base, wholly deciduous, or leaving a persistent jointless base as a tip to the lenticular or triangular achenium. - Mostly perennials with stems leafy, or the leaves all radical or reduced to a sheath at the base of the stem.

A large genus of bog and water plants distributed over every part of the globe. Stem leafless

1. S. lacustris. Stem leafy

2. S. maritimus.

1. S. lacustris, L. - Kunth, Enum. Pl. II, 164. - Rhizome creeping. Stem large, $3-6 \mathrm{ft}$. high, terete, gradually tapering upward, naked, its single sheath bearing a small linear awl-shaped leaf or not. Spikelets numerous, ovoid-oblong, acuminate, $4-5$ "long, rust-brown, single and clustered on the unequal complanate rays of a compound umbel, the clusters often emitting one or two raylets; the umbel turned to one side by the stiff and erect subulate short upper invol. leaf, the other involucral leaves much smaller and thinner. Glumes ovate, $1^{1 /} 2^{\prime \prime}$, carinate-convex, mucronate, the lower ones mostly fringed, hyaline with brown dots. Stamens 3 . Style 3 -fid, rarely 2 -fid. Bristles 6 , longer than the achene, retrorsely spinulose. Achene obovate, mucronate, brownish, biconvex, with the outer face mostly obtusely ridged. - S. validus, Vahl, a form with bifid style.

Mann referred this plant to S, riparius, Presl., from the W. coast of N, and S. America, which however has a triquetrous stem and only 2 or 3 bristles. - Bcklr. in Linnaea, XXXVI, 712 .

Common in standing waters - Kapalama near Honolulu! Nat. name: "Akaakai". The species is widely spread over Europe, northern Asia and America, also Australia and N. Zealand.

2. S. maritimus, L. - Kunth, l. c. p. 167. - Var. digynus. - Root-stock creeping. Stem triquetrous, leafy, $2-4 \mathrm{ft}$. high. Leaves flat, linear, exceeding the stem, $2-6$ " broad below, almost smooth. Spikelets ovoidoblong, $6-10^{\prime \prime}$, light brown, 5-10 in a terminal fascicle with generally one or more elongate $1-3$-spiculate rays projecting from it. Two, three or four involucral leaves much longer than the fascicle or umbel. Glumes thin hyaline, ovate-lanceolate, convex-carinate, $4^{\prime \prime}$ long, shortly and acutely bifid, mucronate or aristate. Bristles 6 , retrorsely aculeate, shorter than the mature achene. Stamens 3. Style bifid (sometimes trifid?). Achene obovate, complanate, about $1^{1 / 2} 2^{\prime}$, pale, smooth and shining, sometimes the outer face faintly ridged at the middle. - Beklr. 1. c. p. 722 .

Very common in brackish and sweet water. - Range of the first species, but extending also in tropical regions and into S. America and S. Africa.

\section{HYPOLYTRUM, Rich.}

Spikelets many-flowered, ovoid or cylindrical, the glumes imbricate all round, persisting, some of the lower small and empty. Inside and contrary 
to them, parallel to the axis, 2 compressed and keeled perigonial scales. Flowers hermaphrodite. Stamens 3 or fewer. Style 2- or 3-cleft, not swollen below, deciduous. Achene slightly compressed or obtusely trigonous. - Herbs, usually coarse. Spikelets brown (resembling those of Scirpus), pedicellate in corymbose panicles, as in Rhynchospora.

A small genus, tropical and subtropical, common to the New and Old World.

1. H. dissitiflorum, Steudel, in Synops. Pl. Glum. II, 132. - «Stem 2-3 ft. high, triquetrous, scabrous in the upper half, foliaceous. Leaves broadlinear, with 3 prominent nerves and many smaller ones, very scabrous along the margins toward the apex, $1 / 2,-2 \mathrm{ft}$. long or more, $6-9^{\prime \prime}$ broad, Inflorescence of $3-4$ axillary panicles, their rhachides triquetrous and very scabrous, elongate, forking toward the apex in two or three divisions, each bearing at its apex 1-3 ovate-oblong spikelets. Glumes 1-nerved, obtuse or shortly mucronate below the apex, pale rust-colored, glabrous. Perigonial scales free, with ciliate keel. Stamens 2. The lower flowers female, the upper hermaphrodite. - Nearly related to H. latifolium, Rich.»

Hawaiian Islands (Menzies) according to Seeman in Fl. Vit. p. 317. - Collected also by d'Urville in Ualan or Kusaie (Strong's Island).

\section{RHYNCHOSPORA, Vahl.}

Spikelets ovoid, terete, 1- or 2-(rarely 3-) flowered, the lower of the loosely imbricate glumes empty, the uppermost usually with imperfect flowers. Hypogynous bristles 6, or sometimes more. Stamens 3 or fewer. Style 2-cleft. Achene lenticular or globular, beaked with the persistent dilated base of the style. - Stems usually leafy. Spikelets usually clustered, rich brown or rust-colored, in terminal or axillary heads or corymbs, sometimes forming large leafy panicles.

About 150 species, dispersed over the warmer regions of the whole world.

Leaves narrow, at most 1 "broad; achene brown, with paler beak:

A single contracted terminal corymb

A terminal and one or several axillary corymbs:

Leaves flattish or channelled; achene obovate, transversely waved $1 . R$. Iaxa. Leaves $5-10^{*}$ broad; achene obovate-oblong, longitudinally lined 2. R. lavarnm.

1. R. laxa, R. Br. - Kunth, Enum. Pl. II, 298. - Stems tufted, 1-2 ft. high, slender, obtusely triquetrous, distantly foliose. Leaves half as long or more, stiff erect, narrow linear, $1^{\prime \prime}$ broad, carinate, channelled, sometimes folded, scaberulous on edges and keel. Spikelets ovoid, pointed, $2-3^{\prime \prime}$ long, chestnut-brown, shortly pedicellate in eymose fascicles on the rays of axillary and terminal pedunculate corymbs $(12-30$ in each corymb); the few rays $2-6^{\prime \prime}$ long; the erect or appressed peduncles ${ }^{1 / 2}-2^{\prime}$, partly enclosed in the leaf-sheaths. Bracts and bracteoles filiform or subulate, not exceeding their rays or spikelets. Glumes $7-8$, of a 
uniform yellowish brown, 1-nerved; the 2 or 3 lowest empty, ovate, mucronate; the 2 or 3 middle ones fertile, lanceolate, acute; the 1 or 2 uppermost tabescent. Stamens 3. Style bifid. Achene obovate, lenticular, with rather acute angles, brown, faintly waved transversely, $1^{\prime \prime}$ high; the paler puberulous and compressed conical beak as long or shorter. Perigonial bristles 5-7, exceeding the beak of the achene, scabrous. There are generally 2 , rarely 3 axillary and 1 terminal corymbs.

All islands, but not common, on grassy or open slopes of more than 2000 or $3000 \mathrm{ft}$. elevation. - Native names: "Kuolohia" and "Puukoas. - The species ranges widely over Australia, S. Asia and Africa, and hardly differs from the American $R$. glauca, Vahl.

2. R. lavarum, Gaud. Bot. Voy. Freyc. p. 415. - A smaller plant, $9-15^{\prime}$ high, with thinner stems. Leaves filiform, not rigid, shorter than the stem, scarcely scabrous. Spikelets rather slender, pointed, $2-2^{1 / 2} 2^{\prime \prime}$ long, chestnut-brown, much less numerous than in the first species, 6-16 in the terminal and $3-7$ in the lower or often single axillary corymb. Glumes $7-8$, all lanceolate, 1 -nerved and mucronate; the 2 lowest empty and smaller, the 4 or 5 next higher fertile, the uppermost tabescent. Stamens 1, 2 or 3 . Perigonial bristles as before. Achene (according to Kunth) obovate-elliptical, lenticular-compressed, with obsolete longitudinal streaks, brown, shining; its beak shorter, conical, compressed, pale, continuous. - Kunth, 1. c. p. 298. - Hook. \& Arn. in Bot. Beech. p. 98. Bcklr. in Linnaea, XXXVII, 584.

On the high mountains of E. Maui and. Hawaii! My specimens are with flowers only; in them the fertile glumes, which Gaudichaud describes as obtuse, are all as above given.

3. R. spicaeformis, sp. n. - A smaller plant than no. 2, the stems $3-6^{2}$ high. Leaves stiff wiry or linear-convolute, equalling or exceeding the stem, smooth. Spikelets dark ferruginous, slender, 3-4" long, only few $(4-9)$ in a short terminal spike-like fascicle, sometimes with a 1-3-spiculate short axillary peduncle besides. One or two bracts longer than the fascicle. Glumes $6-7$, subcoriaceous, very dark, all mucronate, even aristate; the 2 or 3 lowest empty, truncate or emarginate, the 2 middle ones fertile, faintly striate on both sides of the strong median nerve, the 2 or 3 uppermost tabescent. Stamens 3. Bristles $6-8$, scabrous, much longer than the achene; the latter dark brown, obovate, elongate, with a strong beak, but not mature in my specimens.

Maui! in the swamp on the summit of Mt. Eeka. - The three preceding species form a close group; but of very different habit is the following.

4. R. thyrsoidea, Nees \& Meyen. - Kunth, l. e. p. 294. - Stems tufted, $2-3 \mathrm{ft}$. high, triquetrous, foliose. Leaves flat, as long or longer, gradually drawn out to a filiform point, $6-10^{4}$ broad, pale green or glaucous, chartaceous, very rough along the margins and keel. Spikelets dark brown, slender, very acute at first, 4 "long, single or clustered along 
the spreading, almost horizontal branches of axillary and terminal suberect panicles; the whole forming an elongate leafy thyrsus; the panicles numerous, $6-10$, and (inclusive of the long but partly ensheathed scabrous peduncles) $2-5^{\prime}$ long and $1^{1 / 2}-2^{\prime}$ broad. Glumes of a rich brown, $7-9$, appressed, 1-nerved, all long-mucronate from a rather obtuse apex; the lowest 3 or 4 empty, ovate, small, the 2-4 next following fertile, lanceolate, 3 "long, faintly. striate on each side of the greenish median nerve; the uppermost tabescent. Stamens 3. Style long exserted. Bristles 6, as long as the glume, their spinelets turned upward. Achene suborbicular, $1^{\prime \prime}$, complanate with thickish margins, pale straw-colored, minutely cancellate, the conical beak darker, narrow-pointed and nearly twice as long. Beklr., in Linnaea, XXXVII, 641. - R. sclerioides, Hook. \& Arn. l. c. p. 99.

In forests of the lower and middle zones on all islands. Not reported from elsewhere. According to Seeman, F1. Vit. p. 317, Sehoenus arundinaceus, Sol., in Forster, Prod. no. 491, from New Caledonia, is a Rhynchospora closely allied to our species.

\section{CLADIUM, P. Browne.}

Spikelets terete, ovoid or oblong, 1- to 2 -flowered, but the second floret mostly male. Glumes imbricate all round, the several empty ones gradually smaller toward the base of the spikelet. Hypogynous bristles or scales wanting. Stamens 3 or 2. Style 3- or 2-cleft, deciduous. Achene ovoid or globular, osseous, capped by the fleshy or spongy expansion of the base of the style. - Stems leafy. Leaves flat, not equitant. Spikelets glomerate in axillary and terminal compound umbel-like corymbs.

A small genus spread over all continents.

1. C. leptostachyum, Nees \& Meyen, in Linnaea, IX, 301, and in Rel. Meyen. p. 115 - Rhizome creeping and covered with short ovate scales. Stems 5-10 ft. high, terete, fistular, nodose, the upper internodes al ernately channelled on opposite sides. Leaves erect, flat, long acuminate, equalling the stem and $2-4^{\prime \prime}$ broad below, the keel and margins closely serrulate with ascending spinelets. Spikelets $2^{\prime \prime}$, slender ovoid-oblong and acute when in flower, subglobose when in fruit, chestnut-brown, clustered in heads of $3-6$ on the numerous subumbellate raylets of corymbose panicles, each panicle $2-4^{\prime}$ long without the closely ensheathed compressed peduncle and nearly as broad at the top; the whole inflorescence thyrsoid with $6-8$ panicles. Bracts linear or subulate from a broad base, shorter than their rays and raylets. Glumes 6 or 7 , ovate, obtuse, concave, 1 -nerved, thin, pale yellowish-brown, the uppermost with a hermaphrodite flower, the next with a staminate one, the lowest very small and round. Stamens 2. Style deeply 3 -cleft, with 1,2 or all the long convolute branches generally again bifid. Achene ovoid, pointed, about $1^{\prime \prime}$, brown, capped by a thick fleshy expansion of the style-base, 
which as a thinner pellicle extends nearly to the base. - Steudel, Synops. Pl. Glum. II, 152. - Mann, Enum. no. 521. - C. Mariscus, Kunth, Enum. Pl. II, 303. - Beklr., in Linnaea, XXXVIII, 232.

In swampy places on all islands, but by no means frequent. Oahu! Palolo; Molokai! Kamalo, near the sea; W. Maui! Oloalu; Hawaii! Apparently distinct from the widely spread $C$. Mariscus, $\mathrm{R}$. Br., in the scaly rhizome and the mostly divided style-branches. In the young plant the fleshy style-base appears as a distinct fungosity on the top of the oblong ovary.

\section{BAUMEA, Gaud.}

Spikelets ovoid, subcompressed, $1-3$-flowered, but 1 or 2 florets only fertile. Glumes few, subdistichous, carinate with scabrous keel. Hypogynous bristles or scales wanting. Stamens 3, exserted. Style 3-cleft, with thickened puberulous base. Achene osseous, trigonous, beaked with the persistent conical hairy base of the style. - Stems usually compressed, 2 -edged, foliaceous throughout. Leaves, at least the basal ones, distichous, equitant, sword-shaped. Spikelets in clusters, enclosed by sheathing bracts, on the tortuous compressed branches of panicles; the lower branches and branchlets of these partly enclosed in the sheaths of floral leaves and bracts.

A genus of about 20 species, chiefly Australasian, but extending to the Mascarene Islands and Madagascar on one side and to Japan and the Pacifie islands (Marianas, Hawaiian, New Zealand) on the other. The Australian species approach so closely to Cladium that Bentham has thought best to unite the two genera, together with Vincentia, in one genus. Having regard only to our species, it appears to me that Baumea and Vincentia might well be joined, but that Cladium ought to stand apart.

1. B. Meyenii, Kunth, Enum. Pl. II, 314. - Stems 2-3 ft. high, compressed, 2-edged, nodose, scabrous at the sharp angles. Leaves as long or longer, $3-6^{\prime \prime}$ broad, straight, acute, closely imbricate and clasping, with a narrow, apparently lateral slit at the base, without manifest rib or keel, roughish on the outer margin near the apex, corresponding to the keel, otherwise smooth, pale green to glaucous. Inflorescence a narrow and open, partly foliaceous panicle of $10-16^{\prime}$ in length, with lowest divisions $6-10^{\prime \prime}$ long; its rhachis compressed and scabrous, flexuose in a zigzag manner, with one division to each curve and the internodes alternately channelled on opposite sides. Bracteoles short ovate and clasping. Spikelets 1-2-flowered, ovate, compressed or plano-convex, 3 ", fawn-colored, in distant and sessile clusters of $3-5$. Glumes 4 or 5 , stiff, boat-shaped, $2^{\prime \prime}$ long, not mucronate, 1-nerved, with scabrous keel, pale yellowishbrown, with darker dots, the 2 or 3 lowest empty and smaller, the uppermost one tabescent. Ovary pubescent, substipitate, elongate trigonal, not margined. Style deeply 3-cleft, pubescent at the dilated base. Achene obovoid, trigonal or subglobose, over $1^{\prime \prime}$, reddish, shining, crustaceous, with a slender conical pale beak of its own length or more. - Bcklr, in 
Linnaea, XXXVIII, 240. - B. glomerata, Nees (non Gaud.), in Linnaea, IX, 298. - Trachyrhynchium iridifolium, Nees, in herb. Meyen.

In the woods of the middle region on all islands.

\section{VINCENTIA, Gaud.}

As in Baumea, but the spikelets 2-6-flowered, the ovary and achene stipitate, triquetrous, winged, the wings decurrent along the stalk.

A genus of 6 species, spread over Madagascar, the Mascarene Islands, New Zealand, the Hawaiian Islands, Chili and Brazil.

1. V. angustifolia, Gaud. in Bot. Voy. Freyc. p. 417. - A stout plant, the compressed stem 3-4 ft. high, smooth at the somewhat obtuse angles. Leaves as in Baumea Meyenii, but smooth and broader $\left(1 / 2-1^{\prime}\right)$. Inflor. as before, but the alternate curvatures of the smooth plano-convex rhachis less pronounced and the supporting leaves of the lower divisions reduced to long-sheathing short-bladed bracts; the divisions or panicles fuller and broader, densely many-branched; the whole forming a large interrupted thyrsus. Spikelets 5-9 in a cluster, dark ferruginous, almost black, as are the shorter bracteoles, plano-convex, $3^{1 / 2}-4^{\prime \prime}$ long, $3-5$-flowered. Glumes ordinarily 7 , subdistichous, the lowest 1 or 2 empty, the uppermost one tabescent, the fertile ones $3^{\prime \prime}$, coriaceous, ovate, rather obtuse, convexcarinate with smooth keel, blackish, but under transmitted light deep red and several-nerved. Stamens reddish, exserted. Ovary long-stipitate, triquetrous, the membranous angles decurrent in the 3 -winged stipes. Style long exserted, 3-cleft one third of its length, the base slightly thickened and puberulous. Achenes (according to Boeckeler) ellipticooblong, yellow, with a 3 -winged stipes, the slender conico-trigonal beak as long, rust-brown. - Hook. \& Arn. in Bot. Beech. p. 98. - Kunth, Enum. Pl. II, 314. - Bcklr., in Linnaea, XXXVIII, 249.

Woods of the middle zone on all islands. Bears a great resemblance to the last species, but can easily be distinguished by the dark-colored, fuller and broader panicle.

\section{GAHNIA, Forst.}

Spikelets 1 -flowered, or with a second male flower below the fertile one. Glumes imbricate all round, convolute or elasping at the base, the outer ones empty but the uppermost of these longer and stiffer than all others. Perigonial scales present in some species. Stamens $6-3$, the filaments very long and persistent. Style trifid, the subulate branches sometimes again bifid. Achene or nut bony, ovoid or fusiform, tipped with the acicular base of the style, its cavity often transversely ridged. - Tall, rigid, rush-like perennials with foliose stems and long-acuminate harsh involute leaves. Spikelets densely clustered in compound spikes, which are arranged in a narrow terminal leafy panicle. 
A genus of 20-30 species, spread over Australia, eastern tropical Asia, and Polynesia - N. Zealand, N. Caledonia, Viti, Aneiteum, Tahiti, Hawaiian Islds. - The perigonial scales, although not mentioned by previous writers, are quite manifest in nos. 2 and 4 and in a Javanese species, reduced to a single one in no. 1, and probably have been overiooked in others. Their shape, however, does not seem to be constant in the same species. All our species bear a single hermaphrodite flower.

Glumes glabrous; style 8-cleft:

Achene black; spikelets light brown

Achene pale yellow or straw-colored; spikelets dark brown

Achene red; spikelets almost black:

Achene obovate-elongate, trigonal; panicle long fusiform

Achene ovoid; panicle short, compact

Glumes pubescent; style 4-cleft

1. G. Gaudichaudii.

2. G. Beecheyi.

3. G. Mannii.

4. G. globosa.

5. G. leptostachya.

1. G. Gaudichaudii, Steud. Synops. Pl. Glum. II, 164. - Tufted on a short rhizome, the stiff stems $9-18^{\prime}$, obtusely trigonal, smooth, nodose, with $3-6$ rather distant leaves; the other leaves crowded at the base, multifarious, stiff, erect, as long as the stem or longer, $1-2^{n}$ broad, generally convolute and drawn out into a long filiform point, scabrous. Spikelets ovoid-elongate, very acute, 4" long, deep brown, 1-flowered, in clusters of 2-5 along the smooth rhachis or short branches of axillary appressed spikes or spike-like panicles, the lowest of which measure $1-2^{\prime}$; the whole inflorescence forming a leafy and narrow oblong stiff panicle of $2-8^{\prime}$ in length. Bracts and bractlets long-aristate or filiform, exceeding their fascicles and spikelets. Glumes $6-7$, the lowest half the length of the spikelet, thin, lanceolate, aristate, the upper empty one $3^{1 / 2}$, ovate, very acute, conchoid, 1-nerved, with many faint lines, coriaceous, brown, with darker dots; the fertile one enclosing a narrow lanceolate scale of less than $1 / 2$ its own length. Stamens 3, long-exserted; the anthers yellow, linear, very acute. Style brown, long-exserted; deeply trifid with simple branches. Achene shining black, thick bony, ovoid, with 3 longitudinal furrows, $1^{1} / 2^{\prime \prime}$ long, not ridged inside, suspended within the convolute filaments after detachment. - Mann, Enum. no. 524. - Beklr., in Linnaea, XXXVIII, 352. -- Lampocarya Gaudichaudii, Brongn. in Voy. de la Cog. p. 166. - Kunth, Enum. Pl. II, 333. - Morelotia gahniaeformis, Gaud, in Bot. Freye. p. 416, tab. 28. - Cladium quadrangulare, Nees, in Linn. IX, 301.

Hawaii! Maui! Lanait on the high mountains from $3000 \mathrm{ft}$. upward. Nearly related to $G$. affinis, Brongn., from N. Zealand.

2. G. Beecheyi, Mann, Enum. no. 525. - Stem 2-3 ft. high, terete, smooth, nodose. Leaves much longer, convolute, $3-5^{\prime \prime}$ broad below, drawn out into a very long filiform point, scabrous along the nerves. Spikelets 1-flowered, $4-5$ "long, narrow lanceolate, rather compressed when in flower, of a dirty rust-color, in rather loose clusters of $3-6$ along the compressed angular branches of closely appressed axillary panicles which measure from $2-4^{\prime}$; the whole inflor. forming a narrow virgate foliose panicle (interrupted below) of $1-1^{1 / 2} \mathrm{ft}$. in length. Bracts

Hillebrand, Flora of the Hawaiian Islands. 
shorter than their branches or spikelets, lanceolate, long-aristate, clasping at the base. Glumes $4-6$, subcoriaceous, the lowest about ${ }^{2 / 3}$ the length of the spikelet, ovate, long-acuminate, inequilaterally carinate with scabrous keel; the 2 or 3 next upper ones longest, conchoid, 1-nerved (or toward the apex 3-5-nerved), many-lined, pale at the base, ferruginous above; the flowering one enclosing 1 or 2 small unequal obovate apiculate scales. Stamens $3-5$, the anthers with a conical point. Style deeply trifid, pubescent below, its branches undivided. Achene coriaceous, rather suberose, obovate-elongate, obtusely trigonal, $2-2^{1 / 2} 2^{4}$, apiculate, pale yellow or straw-colored, solid in its upper portion, with 2 transverse circular ridges in the cavity. - G. mucronata, Bcklr., in Linnaea, XXXVIII, 342.

At lower elevations, from 1000 to $3000 \mathrm{ft}$. My specimens are from $\mathrm{H}$ a w a ii and $\mathrm{O}$ a hu? Stands nearest to the Tahitian G. schoenoides, Forst., and to G. Rawacensis, Kunth.

3. G. Mannii, sp. n. - Stem, leaves and panicle as in no. 2, but the latter shorter, $8-10^{\prime}$ long and $2-3^{\prime}$ wide at the middle, narrowing toward apex and base. Spikelets with their bracts almost black, otherwise as in no. 2. Glumes $7-8$, otherwise as before. Achene slender, obovateelongate, obtusely trigonal or compressed, tipped with the acicular base of the style, osseous, of a dark brick-red and glossy as in the next species, $2^{1 / 2}-3^{\prime \prime}$ long, the cavity without transverse ridges. Stamens 3 . Achenes retained by the elongate filaments.

Lanai! Only one specimen collected, the spikelets of which are partly worm-eaten, so that it is impossible to ascertain exactly the character of the inner glumes and the presence or absence of perigonial scales. There is no impression from them at the base of the achene. Except for the larger size and different color of the achene (which is pale yellowish-brown in the Java plant) this species agrees remarkably well with a specimen of $G$. Javanica, Z. \& M., collected by myself in that island and in which I have been able to confirm the presence of 2 obtuse perigonial seales.

4. G. globosa, Mann, Enum. no. 526. - Stem 1-11/2 ft. high, terete, smooth. Leaves two or three times as long, $4-5^{\prime \prime}$ broad below, scarcely convolute, aculeolate along margins and nerves, dark brown or black at the base. Inflorescence contracted in a dense foliose paniele, $3-4^{\prime}$ long and about $1^{\prime}$ broad. Spikelets $4^{1 / 2}-5^{\prime \prime}$, with acute bractlets of the same length, ovoid, acute, subcompressed when in flower, almost black, 1-flowered. Glumes 8-11, subcoriaceous, all of nearly equal size, multifarious, the lowest 5 or 6 ovate, long-acuminate, carinate, 3-nerved (5-7-nerved toward the apex), pale at the base, dark ferruginous above, the 3 or 4 upper ones a little shorter, conchoid, obtuse, even rounded. Perigonial scales 2 or 3 of about $1 / 3$ the length of the achene, pale, entire or acutely emarginate, connate at the base. Stamens 5 or 6 , inserted inside the scales, with long convolute dark brown filaments. Style trifid. Achene $3^{\mu}$, ovoid, apiculate with the persistent style, thick osseous, of a dark brickred, glossy, solid in its upper portion, the pyriform cavity only exhibiting faint transverse ridges which do not leave their impress on the seed. - 
G. congesta, Bcklr. 1. c. p. 353. - Morelotia gahniaeformis, Hook. \& Arn. (not Gaud.) according to Mann.

With the preceding; Oahu; Lanai! already collected by Chamisso. - The base of the achene exhibits the impress of the short perigonial scales.

Until examining the present species, I was inclined to consider the 2 seales of $G$. Beecheyi enclosed by the flowering glume and the single one in $G$. Gaudichaudii as tabescent glumes; but with $G$. globosa such an interpretation is altogether inadmissible, for the 3 counate scales exhibit a regular perigone, to the base of which the stamens are affixed. This view is further supported in $G$. Gaudichaudii by the circumstance that the single scale is interposed between the ovary and the fertile glume, closely pressed against its median nerve. Forster's description of $G$. schotnoides in Guillemin's Zephyritis Taitensis attributes to this species a "corolla bivalvis, valvis ovatis acutis, exteriore majore", nearly as is the case in G. Beecheyi.

5. G. leptostachya, Boeckeler, in Linnaea, XXXVIII, 354. - Stem stout. Leaves stiff, very long, narrowing to a long-pointed aculeolate apex; the upper stem-leaves $3-4^{\prime \prime}$ broad below. Panicle straight and narrow, $1 / 2-1 \mathrm{ft}$. long, foliaceous, compact, made up of 8-12 spikes; these solitary, straight, alternate, with short peduncles, their bases enclosed in the sheaths of very long bracts, at first compressed, sublanceolate, $1-1^{1 / 2} 2^{\prime}$ long, with spikelets crowded in fascicles, the upper ones close, the lower more distant. Lower bracts $2 \mathrm{ft}$. long, their sheaths broad and stiff. Primary rhachis stout, slightly flexuose, channelled on the inner (?) side. Bracts of fascicles scale-like, bristle-pointed, very rough near the apex, straw-colored, with a brown margin. Spikelets twin, entirely enclosed by two equal sharply keeled bracteoles, in their young state slender, terete, $4^{\prime \prime}$ long. Glumes 5 or 6 , closely crowded, stiff-chartaceous, pale, almost equal; the upper ones gradually smaller, convex, not keeled; oblong attenuate, somewhat obtuse, not mucronate, pubescent. Style exserted, 4-cleft. - A single specimen with spikelets not yet developed in herb. Berolin. - Lampocarya leptostachya, Schrad. in sched.

"Sandwich Islds. (Chamisso)." - Has much in common with G. Beecheyi." The mature achene is needed to settle the validity of the species.

\section{OREOBOLUS, R. Br.}

Spikelet compressed, 1-flowered, single at the end of a simple foliose scape or of its fork-branches. Glumes $3-5$, subdistichous, the outer or middle empty ones largest. Perigone cartilaginous, deeply 6-parted, persistent. Stamens 3. Style 3-parted, deciduous. Achene crustaceous, ovoid, smooth, not beaked. - Small tufted plants with stiff densely imbricate leaves, their sheaths soon opening.

A genus of 3 or 4 species, natives of Van Diemensland, the Australian Aips, New Zealand with Auckland Islands, Chili, the Falkland and Hawailan Islands.

1. O. furcatus, Mann, Enum. no. 52\%. - A small intricately tufted plant, $3-4$ ' high, repeatedly dichotomous from a short and thick ascending rhizome, the branches densely foliose. Leaves multifarious, closely im. 
bricate, elasping with open 5-7-nerved sheaths, their blades about $1^{\prime \prime}$ broad and $8^{\prime \prime}$ long, stiff subulate, but channelled or flattish, 1-5-nerved, with nerves prominent on the back only, acute, finely serrulate. Stems or scapes hidden among the leaves, slightly exserted at last, simple or dichotomous, foliose, stiff, trigonal, with 6 furrows, the scape or each branchlet terminating with a single compressed spikelet which is obovate or cuneate and pale rust-colored. Glumes 4 or 5, subdistichous, early deciduous, stiff, lanceolate, 1-nerved, compressed, serrulate, $5-2^{1} / 2^{\prime \prime}$ long, the outer ones largest. Perigone cartilaginous, dark brown, deeply 6 -parted, the acute teeth serrulate, less than $1^{\prime \prime}$. Style long-exserted, 3 -cleft beyond the middle. Achene less than $1^{\prime \prime}$, obovate, truncate, reddish brown, shining, sessile. - The perigone remains on the scape after the leaves and glumes have fallen.

Summit of Eeka, Manil and high plateau of Kauai (M. \& B.), where it forms dense mats and globose tussocks on the swampy ground. Distinguished from 0 . obtusangulus Gaud., (Chili and Falkland Islds.) not so much by the several-spiked scape and serrulate leaves (as was pointed out by Mann) as by the greater number of glumes. In the lowest glume sometimes a vaginal portion can be distinguished from the lamina. Thus, with few subfoliaceous glumes and a regular 6-partite perigone, the present genus represents in a manner the first stage of the Cyperaceous Order, connecting it with that of the Restiacede.

\section{SCLERIA, Berg.}

Flowers monoecious, in unisexual or androgynous spikelets, with several empty glumes below the flowering ones; the glumes imbricate all round. Male spikelets several-flowered; stamens 3, rarely fewer. Female spikelets 1-flowered; style 3-cleft. Androgynous spikelets with the lowest flower female, the others male. Nut bony or crustaceous, subglobose, not beaked, seated on a thick entire or 3-lobed disk (perigone?). - Grass-like herbs with leafy stems. Ligule or projection of the leaf-sheath opposite the blade often very conspicuous. Spikelets clustered, the clusters simple in the axils or in axillary and terminal cymes or panicles.

A large genus (100 species), scattered over the warmer regions of both hemispheres, extending also into the temperate zone of $\mathrm{N}$. America.

1. S. testacea, Nees. - Kunth, Enum. PI. II, 341. - Stem 1-1 1/2 ft. high, sharply triquetrous with retrorsely scabrous angles. Leaves of about the same length, 4" broad, flat, acute, chartaceous, strongly 3 -nerved, with scabrous margins; the sheath 3 -winged with an ovate-oblong obtuse ligule. Spikelets unisexual, elliptico-ovoid, $1 \frac{1}{2} 2-2^{\prime \prime}$, pale fawn-colored, clustered in axillary and terminal panicles of $3-4^{t}$ in length; the terminal panicle branched, the one or two axillary nes more simple, spike-like, the clusters of $2-4$ spikelets each and rather distant, 1 or 2 spikelets in each being female. Bracts shorter than their clusters or spikelets. Mate spikelets 4 -flowered, ovoid, $1-1^{1 / 2}$ "long, with 8 distichous glumes of which 4 are empty, the lowest shortest, the middle ones $1 \frac{1}{2} ?^{\prime \prime}$, ovate, 
conchoid, almost orbicular, apiculate, pale fawn-colored, with many darker lines, nerveless or 1-nerved only near the apex. Stamens 3 . Female spikelets $1^{1} / 2^{\prime \prime}$, obovoid-obtuse; glumes 4 , only one fertile; style short, trifid, with a bulbous deciduous base. Achene subglobose, $1^{1 / 2} 2^{\prime \prime}$, thin crustaceous, of porcelain whiteness and gloss. Disk eup-shaped, corky, obsoletely lobed, not fringed, adherent to glume and achene. - Steudel, Synops. Pl. Glum. II, 168. - Bcklr., in Linnaea, XXXVIII, 518.

Haw ail! Hilo and Kilauea; Maui! Eeka.

\section{UNCINIA, Pers.}

A single terminal androgynous spike, male above, female below. Glumes imbricate all round, 1 -flowered. No hypogynous bristles or seales. Stamens 3 , the filaments and anthers short. Pistil accompanied on its outer side by a hooked awn (the rudimentary axis of the spikelet), both enclosed in a second inner glume the margins of which are connate, thus forming a bicarinate utricle. Style $3-$, rarely 2 -cleft, short. Achene triquetrous or plano-convex, enclosed in the utricle with the persistent awn. - Stem simple, triquetrous. Leaves grass-like. - The genus differs from the androgynous Carices only in the presence of the exserted and hooked axis in the female florets or spikelets.

About 25 species, chiefly inhabiting the colder and mountainous regions of the southern hemisphere, a few only extending along the Andes into N. America.

1. U. Lindleyana, Kunth, Enum. Pl. II, 526. - Stems from a short creeping rhizome, $3 / 4-2 \mathrm{ft}$. long, slender, triquetrous, smooth, foliose in the lower half. Leaves exceeding the stem, sometimes much longer, $1^{1 / 2}-2^{\prime \prime}$ broad, flat, long-acuminate, scabrous on margins and back. Spike simple, linearoblong, 3-6', rather densely flowered, supported at the base by a filiform leaf of greater length, the narrow male portion only about $1 / 2^{1}$ long, the female portion enlarging upward. Glumes of female portion oblong, $2^{1 / 2}-3^{\prime \prime}$, acute or obtuse, carinate-convex, thin, greenish stramineous, faintly several-nerved, glabrous; those of the male portion smaller. Utricle stipitate, greenish, as long as the glume, thin, ovoid, plano-convex, drawn out into a long bidentate neck, smooth; the uncinate awn twice as long. Achene pale, ovate-oblong, plano-convex, with a longitudinal line on the back. Style trifid, the stigmatic branches exserted and reflexed. - Referred by J. Hooker to U. austratis,. Pers., in the Flora of New Zealand, also by Boeckeler, in Linn. XLI, 342; in this species, however, the awn is shorter than the utricle and, besides, Persoon's short description leaves in doubt which of the two New Zealand species he had before him.

High mountains of Hawaii (Kilauea)! W. Maui! Lanai! Molokai!

\section{CAREX, L.}

Flowers unisexual, the male and female in distinct spikes or in different parts of androgynous spikes. Glumes imbricate all round. Stamens in 
the male flowers 3 or fewer, without scales or bristles. Ovary in the female enclosed (as in Uncinia) in a bottle-shaped or inflated utricle or perigyne, contracted at the top, with a small oblique or bidentate opening through which protrudes the 2- or 3-cleft style. Achene lenticular or trigonal, enclosed in the persistent utricle. - Leaves grass-like, mostly radical or on the lower part of the stem. Spikes either solitary or few, one terminal, the others mostly distant and stalked, or forming a terminal compound spike or panicle.

A vast genus (500-600 species), widely spread over the cold and temperate regions of the whole world and the mountainous parts of the tropics.

In some species, as in our C. Oahuensis, the utricle contains a small bristle, not hooked and never so long as in Uncinia, but which nevertheless must be interpreted as the rudimentary axis of a spikelet, just as in that genus. This circumstance imparts to each female flower the character of a spikelet analogous to that of the other Cyperaceae, the utricle being in reality the fl. glume folded with connate margins. As in the staminate flowers nothing of the kind exists, the whole male inflorescence may be considered as a spikelet. For the sake of brevity, however, the term spike has been applied in the following to both inflorescences.

Spikes all unisexual; style trifid

1. C. montis Eeka.

Terminal spike male, the lateral ones androgynous, staminate above :

Style trifid; glumes awned, pale

Style bifid; glumes acuminate, dark

2. C. Oahuensis.

3. C. Sandwicensis.

Spikes all androgynous, staminate above, arranged in an elongate narrow panicle

Spikes all androgynous, pistillate above, short and crowded in a dense head

4. C. brunnea.

5. C. propinqua.

of C. nuptialis, Boott, sched. in herb. Gray (Remy 142), Mann, Enum. no. 582, I know nothing.

1. C. montis Eeka, sp. n. - Stems $1-2 \mathrm{ft}$. long, obtusely trigonal, compressed above, smooth, foliose in the lower third and carrying one or two smaller leaves in support of the lowest spikes. Leaves as long as the stem or longer, on long and broad very thin sheaths which are open above, $1-2$ " broad below, thick coriaceous, convolute or deeply channelled, subulate near the apex, almost smooth. Spikes unisexual, the terminal one male, the 2 or 3 lateral ones female, the lowest $1 / 2-2^{1} / 2^{4}$ below the terminal one. Male spike slender, ${ }^{1 / 2}-1$ 'long, its glumes narrow oblong or lanceolate, $2^{1} / 2-3^{\prime \prime}$, acute, stramineous, with hyaline margins, $1-3$-nerved. Female spikes sessile, short cylindrical or fusiform, $1 / 2-3 / 4^{\prime}$ long, $2^{1 / 2-3^{\prime \prime}}$ broad. Glumes appressed, ovate, not mucronate, $2^{\prime \prime}$, green, chartaceous, rather boat-shaped, with a stiff smooth keel and 2 lateral nerves. Utricle as long as the glume, thin, smooth, complanate, elliptico-oblong, not beaked, shortly apiculate and truncate. Achene half the length of the utricle, obovate, plano-convex, ribbed on the outside or almost trigonal. Style strictly terminal, erect or geniculate at the base, twice as long as the achene, trifid.

Top of Eeka, Mauil 
2. C. Oahuensis (Wahuensis), C. A. Meyer, in Mem. Acad. St. Petersb. I, 218, tab. 10. - Stems tufted, $1 / 2-2 \mathrm{ft}$. high, obtusely trigonal, slightly scabrous in the upper portion, or smooth, foliose at the base besides having the closely sheathing long bracteal leaves of the spikes. Basal leaves from short open darker sheaths, as long as the stem or longer and $2-4^{\prime \prime}$ broad below, flat, long pointed, stiff chartaceous, subcarinate, scabrous along keel and margins. Spikes male and androgynous. Male spike single, terminal, supported by a setaceous bract, ferruginous, slender fusiform, $1-3^{4}$ long and $2^{\prime \prime}$ broad, on a peduncle of $1 / 2-1^{1 / 2} 2^{4}$. Androgynous spikes $3-5$, at variable distances, the lowest sometimes only 1 ', at others $9-11^{\prime}$ from the terminal one; the uppermost ones often branching or fascicled, all suberect on scabrous peduncles of ${ }^{1 / 2}-4^{\prime}$ which are partly enclosed in their leaf-sheaths; the lower pistillate portion olivaceous, eylindrical, 1-2 long and $6^{\prime \prime}$ broad (including the awns of the glumes); the upper staminate portion ${ }^{1 / 2}-1 / 4$ of that length and $2^{\prime \prime}$ broad. Male $f$. Glumes obovate-oblong, $2^{1 / 2}-3^{\prime \prime}$, obtuse or truncate, even emarginate, 1 -nerved, with a serrulate awn of $1 . / 2$ their length or more, greenish, with a brown streak on each side. Stamens 3 ; anthers short. Fem. fl. Glumes broadly ovate, $2^{\prime \prime}$, flattish, thin, pale, 1 -nerved, with a long awn equalling or exceeding them in length. Utricle $2^{1 / 2}$, bidendate or bicuspidate scabrous beak, subcoriaceous, many-lined, includes a short awn besides the ovary. Achene obovate, trigonal, ridged at the angles, encircled by a transverse furrow about the middle, dark brown or blackish. Style geniculate at the base, trifid. - Boott, Ill. Gen. Car. III, 111, tab. 351-354. - Kunth, Enum. Pl. II, 515. - Beklr., in Linnaea, XLI, 278 .

Mountains of $\mathrm{Oahu!} \mathrm{Maui!} \mathrm{Hawaii!} \mathrm{Kauai!} \mathrm{from} 3000 \mathrm{ft}$. upward. - Has been found also in Corea by Wilford. - The circular groove of the achene, although not adverted to by Mever or by Boeckeler, is constant in all my specimens. The plants from the higher regions of $\mathrm{Maui}$ and $\mathrm{H}$ a waii generally do not exceed one ft., and their androgynous spikes, all simple, are approximate to the apex, excepting sometimes a long. pedunculate one near the middle or base of the stem. In the much taller O a hu specimens the upper androgynous spikes often freely branch, sometimes within the sheath, so as to appear fasciculate. The awns of the lowest glumes are always the longest.

3. C. Sandwicensis, Boeckeler, in Flora, 1875, p. 265. - Stems stout, $1^{1 / 2}-4 \mathrm{ft}$. high, sharply triquetrous, smooth, or slightly scabrous in the upper portion, foliose at the base, besides having $3-5$ almost sheathless shorter floral leaves. Leaves as long as the stem or longer, flat, $4-6^{\text {" }}$ broad below, slightly scabrous along the margins, subcoriaceous, carinate. Spikes male and androgynous. Male spikes terminal, generally single but sometimes 2 or $3,1^{1 / 2}-4^{\prime}$ long, $2^{\prime \prime}$ thick, sessile. Androgynous spikes $5-8$, generally crowded near the apex, but sometimes more distant, the lowest not rarely $5-6$ ' remote from it, shortly pedunculate, cylindrical, $4-8^{\prime}$ long, often drooping; the female portion chocolate-brown and $3-4^{\prime \prime}$ 
thick, the staminate portion terminal, $1 / 3-1^{1 / 2^{\prime}}$ in length. Male $f$. Glumes appressed, narrow lanceolate, rather acute, 3 ", pale and 3 -nerved along the middle, dark brown at the sides. Fem $\mathrm{fl}$. Glumes in 8 spiral rows, horizontally patent when mature, darker than the male glumes and ovate, cuspidate with a filiform serrate point, $2-3$ "; the lowest often more remote, narrower and longer, $3-5 "$. Utricle short ovoid, biconvex with two marginal ridges, $1^{1} / 2^{\prime \prime}$ including the short bidentate beak, pale or dark brown, shining. Achene obovate, complanate, smooth, dark brown. Style terminal, bifid. - C. Prescottiana, Mann, Enum. no. 533.

Molokait pali of Pelekunu; Maui! Haleakala; Central plateau of Hawaii! W. Maui! (spikes rather slender and pale). Boeckeler's description was taken from a defective specimen (Remy 148) which had lost its male spike. The species agrees in every respect with C. Prescottiana from Nepaul, with this exception, that in the latter the lateral spikes are said to be female. In young specimens of our plant their male termination is often very short, and in old ones it is apt to drop. In a Molokai specimen an upper androgynous spike branches at the apex, another near the base of the female portion.

4. C. brunnea, Thunb. - Boeckeler; in Linnaea, XXXIX, 145. - Stems $1-2^{1} / 2 \mathrm{ft}$. high, very slender, almost filiform, acutely triquetrous, smooth or slightly scabrous, foliose in the lower third or half. Leaves longer or shorter than the stem, linear, $1-1^{1 / 2} / 2$ broad, flat, those of the stem elosely sheathing at the base; very scabrous on edges, keel and upper face near the long-acuminate apex. Spikes slender, $1 / 2-1^{\prime}$ long, all androgynous (rarely the terminal one male), staminate in the upper portion, stiff erect in a narrow simple panicle of $3-9$ nodes and $5-12$ " in length. Lowest and uppermost branches of the panicle with a single spike, the middle nodes with a fascicle of $2-5$ long and wiry single-spiked peduncles or with a single branch, bearing as many short-stalked greenish linear spikes of $4-9^{\prime \prime}$ in length; the lowest bracteal leaf flat and longer, the other setiform and gradually shorter than their branches. Staminate portion as long as the pistillate or longer. Glumes ovate, acute, $1^{1 / 2}$ ", 1 -nerved, pale rufous. Stamens 3 ; anthers linear-oblong, obtuse. Pistillate portion. Glumes few $(5-9)$, rather distant, appressed, broader than those of the male flowers and with a green keel, mucronate or not, ciliate near the apex. Utricles longer than their glumes, stipitate, elliptico-ovoid, plano-convex, many-lined, gradually drawn out into a long bidentate neck, thin, green, puberulous on the margins. Achene obovate-oblong, compressed, with ridged margins, smooth, pale. Style terminal, slightly swollen at the base, bifid, with reddish branches. - Schkuhr, Car. II, 16, tab. 10. C. Commersoniana, Kunth, 1. c. p. 391. - Mann, Enum. no. 529. - C. Meyenii, Nees. - Steudel, Synops. Pl. Glum. II, 195. -- Mann, Enum. no. 530. - C. Remyi (Remy 141), Beklr., in Flora, 1875, p. 264.

Oahu! Niu, Wailupe, and Waiande Mts.; Lanai! on the highest ridge. 
$\beta$ var. - Plant densely tufted, shorter but stronger. Leaves only half the length of the stem. Spikes oblong-lanceolate, greenish-rufous, their staminate portion, excepting the terminal spike, much shorter than the pistillate portion, which carries 9-14 florets; the glumes and utricles glabrate, the latter quite flat.

Kaua 1, Waimea (M. \& B. no, 391) in herb. Cornell Univ.

The species is known from Mauritius and Bourbon, Ceylon, Australia (C. gracilis, $\mathrm{R}$. Br.) and Japan.

5. C. propinqua, Nees. - Kunth, Enum. Pl. II, 396. - Stems ${ }^{1 / 2}-1 \mathrm{ft}$. high, trigonal, compressed below, slightly scabrous above, foliose at the base only. Leaves about half the length of the stem, $1^{1 / 2}$ " broad, flat, slightly scabrous at the acute or filiform point, carinate. Spikes androgynous, staminate at the base (the terminal one entirely pistillate?), sessile, very short, about $3 "$, thick ovoid, $8-10$ crowded at the end of the stem in a close head or cluster which is $6-8^{\prime \prime}$ long, $5-6^{\prime \prime}$ broad, and supported by a lanceolate or subulate bract of scarcely $1^{\prime}$; besides 1 or 2 shorter and broader ones. Glumes $11^{1 / 2}$ ", ovate, acute, 1 -nerved, the staminate ones pointed or mucronate, pale olivaceous throughout, the pistillate ones pale along the keel and hyaline margins, otherwise olivaceous, with several faint lines. Utricle $13 / 4^{\prime \prime}$, thin, pale olivaceous, ovate, drawn out into an acute bicuspid neck, plano-convex, the sharp margins fimbriolate or denticulate. Achene smaller than the utricle, biconvex, abruptly apiculate, pale brown. Style terminal, shortly bifid with erect branches. - C. festiva, Dewey. - Steudel, 1. c. p. 198. - Mann, Enum. no. 534. - Beklr. in Linnaea, XXXIX, 73.

Oahu! Hawaii! Central Plateau; collected also by Mann and Remy, Nearly akin to C. leporina, L. - W. coast of Ameriea from the straits of Magellan to Alaska, Kamtchatka, Greenland, Norway,

\section{Order XCV, GRAMINACEAE.}

Flowers hermaphrodite or unisexual, in spikelets. Each spikelet consists of 3 or more (very rarely 2 or 1 ) chaff-like concave glumes (or bracts) arranged alternately on opposite sides of the spikelet, their concave face toward the axis. Two (sometimes 1 or 3 ) lowest glumes empty and often differently shaped from the others; the succeeding or flovering glumes (lower paleae of most authors) each enclosing a smaller scale or palea (upper palea of most authors, which represents the primary leaf - vorblattof the flower) placed either between the glume and the axis of the spikelet, with its back to the axis, or nearly opposite the glume at the end of the axis. Within the palea, or apparently between the flowering glume and the palea, is the real flower consisting of 2 (rarejy 3) lodicules or minute scales besides the stamens and pistil. The flowering glume and palea are, however, generally included in the term flower. Stamens usually 3, 
occasionally reduced to 2 or 1 , or in some genera 6 ; anthers versatile, 2-celled. Ovary 1-celled, with 1 suspended ovule. Style 2-or 3-lobed, or more frequently divided to the base into 2 or 3 more or less feathery styles. Fruit seed-like, called a grain or caryopsis, free or adhering to the persistent palea, or enclosed in the hardened palea and flowering glume. Pericarp very thin, adhering to the seed, or rarely loose or opening into 2 valyes. Embryo small, at the base of a mealy albumen. Herbaceous or lignescent plants with stems usually hollow, except at the nodes. Leaves alternate, entire, elongate, parallel-veined, sheathing the stem at their bases, but the sheaths split open on the side opposite the blade and furnished at the base of the blade with a scarious or hairy appendage called the ligula. Spikelets arranged in terminal spikes racemes or panicles.

The Grasses constitute one of the largest Orders, abundantly diffused over every part of the globe.

The following dichotomous key has been drawn np with reference to Hawailan species only.

Spikelets diclinous, the sexes in distinct inflorescences

14. Zea.

Spikelets hermaphrodite, or, if diclinous, the sexes in the same inflorescence:

Stamens 6 ; palea 3-nerved

Stamens 6; palea 2-nerved; spikelet several-flowered; pericarp thin and adherent; arborescent

Stamens 6 ; palea wanting; spikelet 1 -flowered; pericarp crustaceous, loose; arborescent

Stamens 3, rarely less; palea 2-nerved:

Spikelet with 1 fertile floret, but sometimes a second male or rudimentary floret below or above it:

Spikelets enclosed in a multifid aculeate involucre .

spikelets immersed in the excavations of a broad Hattened rhachis

15. Oryza.

35. Bambusa.

36. Schizostachyum.

Spikelets free, subsessile along one side of the rays of a simple, often digitate panicle, or of a simple spike: Fertile glume and palea enelosing the grain, as stiff as or harder than the sterile outer glumes:

Glumes concave; fertile floret terminal

Empty outer glumes 2

Empty outer glumes 3, but the uppermost of them supplied with a palea:

Lowest glume awnless

Both Jower glumes awned, the awn of the first longer

Glumes keeled; an imperfect floret above the fertile one, or the axis prolonged:

Axis prolonged into a bristle at the back of the palea Axis bearing one or more rudimentary glumes above the floret

Fertile glume thin and transparent, generally small and with a twisted and bent awn; spikelets in pairs, one sessile, one pedicellate:

Both spikelets with a hermaphrodite and a male floret and awned

6. Cenchrus.

7. Stenotaphrum.

1. Paspalum.

2. Panicum, no. 1.

2. Panicum, nos. 2\&3.

3. Oplismenus.

25. Cynodon.

26. Culoris.

10. Spodiopogon. 
Sessile spikelet hermaphrodite and awned, with lowest glume biplicate, the pedicellate one male and awnless or rudimentary

Sessile spikelet female and awned, with lowest glume convolute; the pedicellate one larger, male, flat and awnless

Spikelets free in a eompound panicle:

Spikelets in pairs, one sessile, the other pedicellate; the terminal ones ternate:

Spikelets surrounded by long silky hair

Spikelets naked at the base.

Spikelets all terminal and ternate, the middle one sessile, the lateral ones pedicellate

Spikelets all single and pedicellate:

Empty outer glumes 3:

Fertile glume awnless, hardened; spikelet dorsally compressed

Fertile glume with a twisted awn; spikelet terete

Empty outer glumes 2; spikelets terete or laterally compressed:

Grain enclosed in the hardened awned glume and its palea, which do not exceed the pointed or awned outer glumes.

Grain free:

Flowering glume a wnless, as are the outer empty ones, but longer.

Flowering glume generally with a dorsal awn, shorter than the outer awnless ones:

Axis of spikelet glabrous Axis of spikelet hairy .

Flowering glume with a subterminal awn, shorter than the outer awned glumes.

Spikelet with two perfect flowers:

Spikelet awnless; grain enclosed:

Panicle spike-like; pedicels with an awn-like bristle

Panicle onen, pedicels naked .

Flowering glume with a twisted or bent dorsal awn:

Flowering glume truncate, 4 -fid or 4-dentate.

Flowering glume bifid or bidentate:

Flowering glume keeled

Flowering glume rounded

Spikelet with more than two perfect florets:

Spikelets sessile and distichous in a single terminal spike

Spikelets subsessile on one side of the subdigitate rays of a simple panicle.

Spikelets pedicellate in a panicle:

Axis of spikelet hairy

Axis of spikelet glabrous:

Spikelet ventricose, triangular; flowering glumes rounded at the top

Spikelet compressed, ovate or lanceolate or linearoblong:

Grain free from the palea when mature; flowering glumes keeled:

Flowering glumes 3-nerved; paleas persistent on the often continuous axis of the spikelet

Flowering glumes 5-nerved, the nerves often hairy; axis of spikelet articulate . .

Grain adnate to the palea when mature; flowering glumes convex on the back:
9. Andropogon.

8. Heteropogon.

13. Saccharum

12. Sorghum.

11. Chrysopogon.

2. Panicum, nos, 4-1t.

17. Arundinella.

16. Garnotia.

19. Sporobolus.

18. Agrostis.

21. Deyeuxia.

20. Polypogon.

4. Setaria (Dissockondrus),

5. Isachne.

22. Deschampsia.

23. Trisetum.

24. Avena.

28. Lolium.

27. Eleusine.

34. Arundo.

33. Briza.

30. Eragrostis.

29. Poa. 
Flowering glumes 3-5-nerved, pointed or awned from the entire tip; styles terminal

Flowering glumes 5-9-nerved, awned from 31. Festuca. below the entire or bifid tip; stigmas on the sides or face of an obtuse pubescent ovary

\section{Bromus.}

Deducting 18 species, introduced and naturalized or cultivated at large since the arrival of the white man on the Islands, there remain 56 indigenous species, of which 33 , or 59 per cent., are peculiar to the Islands, distributed among 11 genera. Of these genera Panicum figures with 10 peculiar species, Eragrostis with 7 , Deschampsia and Agrostis with 3, Isachne, Deyeuxia and Poa with 2, Garnotia, Spodiopogon, Trisetum and Dissochondrus with 1 each, the latter the only genus or at least well marked subgenus which is peculiar to the flora.

Of the remaining $2 s$ indigenous species 4 are found also in other islands of the Pacific Ocean ( 1 of these in Luzon); 1 in Australia only; 5 extend over Polynesia to Malaysia, N. Australia and India ( 1 of them even into Africa); 7 are spread over both hemispheres, east and west; and 2 are in common with the American Continent only.

Of these last one, Chloris radiata, although found wild in two remote regions, was confined to the neighborhood of eattle-ranches and may possibly have to be classed with the recently introduced species, and the determination of the other, Eragrostis Mexicana. is still doubtful. It certainly forms a link in the series of true Hawaiian species. Thus is appears that in aetual species our flora has much less in common with the American than with the Asiatic Continent; but, on the other hand, the peculiar species of the two genera most largely represented, Panicum and Eragrostis, find their nearest relations in the genus on the American Continent, so that the Grasses help to support the conclusion arrived at from a study of the Compositae, viz., that in the earliest period of vegetable life on the Hawajian Islands a closer connection existed with the western continent, while at a later period hardly any American species have reached the Islands.

\section{TRIBE I. PANICACEAE.}

Spikelets with one fertile terminal floret, with or without a male or imperfect floret, rarely a perfect one below it. Pedicels articulate below the glumes, except in Isachne.

\section{Subtribe I. PANICEAE.}

Flowering glume and palea hardened, cartilaginous or leathery after flowering, and enclosing the grain. Outer empty glumes usually unequal and smaller, thin herbaceous or membranous.

\section{PASPALUM, L.}

Spikelets one-flowered, plano-convex, not awned, imbricate in 2 or 4 rows on one side of the flattened axis of slender spikes which form the branches of a simple panicle or rarely are solitary. Sterile glumes 2 , equal, membranous. Flowering glume coriaceous, concave, mostly orbicular or ovate, with its margins clasping the flat palea, which is of equal consistence and 2-nerved along the margins. Stamens 3. Ovary glabrous. Styles long, stigmatose in their upper halves. Grain enclosed.

A large genus, chiefly belonging to the American Continent, comparatively few species inhabiting the tropical regions of the old World.

Spikes 3 to 6 , alternate

Spikes 2, conjugate at the top of the stem

1. P. orbiculare.

2. P. conjugatum.

1. P. orbiculare, Forst. Prod. no. 7. - Steudel, Synops. Pl. Glum. I, 26. An erect coarse grass, $1^{1 / 2}-2^{1 / 2} \mathrm{ft}$. high, tufted, the compressed stem glabroth, leafy to the top. Leaves flat, chartaceous, $1-1^{1 / 2} \mathrm{ft}$. long, $2-3^{\prime \prime}$ broad, 
glabrous, rough along the margins, their sheaths plicate and keeled; the ligules ovate-rounded. Spikes $3-6$, distant, alternate, $1^{1 /} 2^{\prime}$ long, subsessile, with a few long hairs at the base, forming a simple panicle of $3-5^{\prime}$ in length. Spikelets suborbicular or broadly ovate-obtuse, $1-1^{1 / 4^{\prime \prime}}$, single, rarely in pairs, subsessile in two close rows on the outer side of the flattened broadly ribbed axis (which is $1^{\prime \prime}$ broad) and projecting over the same. Outer empty glumes equal, suborbicular, of the same length and breadth as the floret, very thin, 3 -nerved, the lateral nerves marginal. Fertile glume and palea cartilaginous, smooth, pale brownish; the latter biauriculate above the base. - P. scrobiculatum, \&, Kunth, Enum. Pl. I, 53.

very common in swampy ground or heavy elay soil. A coarse grass distasteful to horses and cattle, used by natives for thatching their houses. - It extends over Polynesia, Australia, Malaysia and S. China. P. scrobiculatum, L., which is common also in Iudia and Africa, differs in having 5-9-nerved sterile glumes, and shallow pits along the margins of the fertile one.

†2. P. conjugatum, Berg. - Kunth, Enum. Pl. I, 51. - A large and coarse decumbent grass, $2-4 \mathrm{ft}$. high, the stem branching, geniculate below, naked above, compressed, glabrous. Leaves $7-9^{\prime} \times 5-7^{\prime \prime}$, thin chartaceous, very acute, scabrous at the margins, ciliolate at the base, otherwise glabrous, as is the sharply compressed sheath. Ligule ciliate. Spikes 2, sessile and conjugate at the top of the stem, each $3-5^{\prime}$ long, very slender, the rhachis about $1 / 2$ " broad. Spikelets subsessile, small, $3 / 4^{\prime \prime}$ in length, broadly ovate or ovate-oblong apiculate, loosely imbricate in 2 rows. Empty glumes equal, thin, hyaline, with only 2 stiff and green marginal nerves; the lower convex one (next to the rhachis) ciliate at the margins, the upper plane one glabrate. Palea not auriculate. - Steudel, l. c. p. 21. - Griseb. Fl. W. Ind. p. 541. - Trin. Ieon. tab. 102.

The well known Hilo grass, which first appeared about 1840 in the district of Hilo and soon spread there to such an extent as to crowd out nearly every other kind of grass, thereby injuring greatly the pasturage; for not even donkeys or mules would touch it at first. - The species is a native of tropical America, where it extends from Louisiana to Brazil, but is found now also in tropical Africa, the Galapagos Islands, Australia and India.

\section{PANICUM, L.}

Spikelets usually small, with one fertile flower, awnless or rarely awned, either along one side of the simple branches of a panicle, or in a loose branching or close and spike-like panicle. Glumes 4, rarely the lowest one suppressed, the sterile ones thin membranous, the two outer ones awnless, the third sometimes awned, empty or with a thin, often minute palea and often a male floret in its axil; the innermost or fertile glume of a firmer texture, glabrous and faintly 3-nerved, the palea like its: glume, but smaller and 2-nerved. Stamens 3. Styles elongate terminal, the pencil-shaped stigmas with simple denticulate hairs. Grain grooveless, enclosed in its hardened glume and palea. 
A vast genus, chiefly tropical or $\mathbf{N}$. American, with a few species spreading into Europe and temperate Asia.

Panicle simple, with sessile, one-sided, spike-like branches:

Spike-like branches digitate or crowded near the summit of the

stem, the uppermost not shorter than the lowest:

Rhachis of spike flattened; lowest glume searcely ${ }^{1 / 4}$ the length of the spikelet

Rhachis of spike filiform, nearly terete; spikelets much smaller; lowest glume little shorter than the spikelet

1. P. pruriens.

2. P. filiforme.

Spike-like branches arranged in a pyramidal panicle, decreasing in size toward the top:

Spikelets not awned; lowest branches simple and distant

Spikelets awned in the third glume; lowest branches compound

3. $P$, colonum

4. P. crus-galli.

Panicle compound, with slender branches; spikelets awnless, each on a distinct pedicel:

Two outer glumes subequal, or the lower longer:

Spikeleţs naked:

Stem upright straight, simple or once divided .

Stem prostrate, branching, geniculate at each node in a zigzag manner

Spikelets hairy :

Leaves glabrous, convolute; panicle contracted

5. P. nephelophilum.

6. P. cynodon.

7. P. Beecheyi.

The entire plant hairy; leaves plane, panicle open:

Spikelets somewhat obtuse, very small, the second glume rather the longer

Spikelets acute, the first glume longer" :

Hairs gray or siivery; spikelet small, third glume glabrous : Plant small, pubescent and ciliate

Plant large, densely hairy or woolly

Hairs pale yellow or fawn-colored; spikelet larger, third glume hairy

8. P. affine.

9. P. pellitum.

10. $P$. cinereum.

11. P. torridum.

Two outer glumes unequal, the lower much the shorter, glabrous; stigmatic brushes short conical or globose:

Stem (at least in the upper portion) straight and undivided,

$1 \mathrm{ft}$. or more high

12. P. monticola.

Stem short and copiously forking, the erect branches crowded

in tussocks and densely foliaceous; leaves short:

Leaves lanceolate-acute, glabrous .

Leaves ovate or ovate-lanceolate, obtuse, pectinately ciliate at the margins

13. P. imbricatum.

14. P. isqehnoides.

Of these species only the four first oceur also in other parts of the world, the remaining ten must for the present be considered peculiar to our flora. - Besides them, the following species, accidentally introduced with living plants from abroad, had become established in gardens before my departure, and are likely to have escaped to the open country by this time:

P. prostratum, Lam. (Sect. Brachiaria). - A low prostrate branching glabrots grass with lanceolate leaves. Panicle of $4-8$ short and distant spike-like branches. Spikelets subsessile, often supported by a single long cilia. From India.

P. plicatum, Lam. (Sect. Ptychophyllum, A. Braun), - A tall grass, $3-5 \mathrm{ft}$. high, nearly glabrous. Leaves broad lanceolate, contracted at the base and deeply plaited. Spikelets subsessile on short branchlets of the rays of a long open paniele, the uppermost and lowest on each branchlet generally supported by a single long awn-like bristle. From China.

P. maximum, Jacq. (Seet. Virgaria). - Tall like the preceding onc, but the leaves less broad and not plaited. Spikelets all pedicellate and without bristies, in an open compound panicle. From India. - In all three the lowest glume is less than one third the length of the spikelet. 


\section{Digitaria:}

1. P. pruriens, Trin. Ieon. VIII, tab. 92. - Diss. II, 7\%. - A tufted grass, the stems $1-3 \mathrm{ft}$. high, decumbent-ascending, geniculate below, once dividing or simple, with the last internode very long. Leaves flat, linear-lanceolate, very acute, $4-10^{\prime} \times 5-6^{\prime \prime}$, membranous, spinulososcabrous at the white and wavy margins, pubeşcent with soft hairs on both faces but with longer ciliae at their bases, the carinate sheaths shorter than the internodes and densely pilose with patent or deflected hairs. Ligule short-ovate. Spike-like racemes $6-21$, crowded at and near the apex of the stem, erect, generally simple, of uneven length, the lowest 5-7', one-sided with a flattened scabrous rhachis of about ${ }^{1 / 2}{ }^{\prime \prime}$ in width. Spikelets in pairs, one sessile, one pedicellate, slender lanceolate, flat-convex, $1^{1 / 2}-1^{3 / 4}$ " in length. Lowest glume wanting, the second (in this species the first) very small, ${ }^{1 / 4}$ the length of the spikelet or less, the third (second) as long as the spikelet, empty, without palea, thin, lanceolateacute, clasping, with ciliate margins, 5 -nerved but the two lateral nerves on each side closely approximate, even confluent; the fertile glume little shorter than the last, stiff chartaceous, pale, lanceolate-acute, faintly 3 -nerved; its palea of the same size. Stigmas protruding at the apex of the floret. - Kunth, Enum. Pl. I, 83. - Steudel, Synops. Pl. Glum. I, 38. - Digitaria pruriens, Büne. - Miquel, Fl. Ind. Bat. III, 436. - Digitaria consanguinea, Gaud. in Bot. Freye. p. 410 (not Pan. consanguineum, Kunth). - Paspalum consanguin. Kunth, 1. c. p. 46. - Digitaria ciliaris, Hook. \& Arn. in Bot. Beech. p. 100. - Panicum sanguinale, Seem. in Fl. Vit. p. 325 as to the Hawaiian plant. - The numerous rays of the panicle occupy from $1-3$ inches at the end of the stem, by far the greater number forming a thick fascicle at the base of the panicle, only few rising from the top and intermediate space.

A common grass of the lower and middle regions of all islands, furnishing excellent fodder for cattle and horses. Nat. name: Kukai puaas. - Occurs also on the Marquesas, Society and Viti Islands, on the Moluecas, Java and Sumatra. - The species differs from D. ciliaris, Pers., in the suppression of the first glume, in the great reduction of the second, and the confluence of the lateral nerves in the third - a character constant in our species but not adverted to by Trinius, whose description and figure were taken from a plant from Nukahiwa.

2. P. filiforme, L. - Steud. Synops. Pl. Glum. I, 41. - Stems very slender, $1-2 \mathrm{ft}$. high, erect, the last internode very long. Leaves very narrow, less than $1^{\prime \prime}$ broad, the lower sheaths hairy. Ligule short, obtuse. Spikes $2-8$, suberect, alternate, approximate, their rhachis filiform, nearly terete, $1-3$. long. Spikelets in pairs, both shortly pedicellate (but the pedicels of

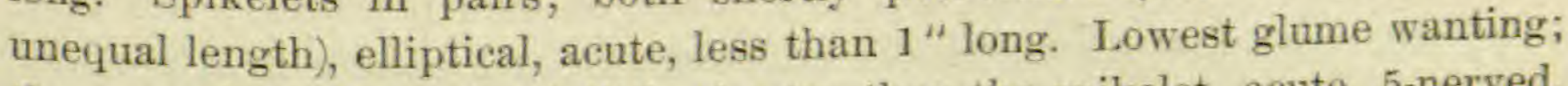
the second (here the first) little shorter than the spikelet, acute, 5-nerved, faintly pubescent along the margins; third (here second) glume as long as the spikelet, without palea, 7 -nerved, with pubescent margins. Fertile glume of the same length, stiff ehartaceous, lanceolate. - Trin. Icon. tab. 148. 
- Gray, Man. Bot. p. 577. - Digitaria filiformis, Muehl. - Griseb. Fl. W. Ind. p. 543. - Paspalum filiforme, Fluegge. - Kunth, l. c. p. 46.

Collected by the U. S. E. Exp, "in a valley behind Honolulu, Oahus (herb. Gray). The species is American, extending along the eastern coast from Massachusetts to Brazil.

\section{* Echinochloa.}

3. P. colonum, L. - Steud. l. c. p. 46. - Erect, 1-2 ft. high, the stem compressed, once or twice dividing, distantly foliose. Leaves flat, acute, $8-5^{\prime}$ long, glabrous, with rough margins, the sheaths shorter than their internodes; ligule wanting. Spikes $8-12$, almost sessile, single, undivided and erect, ${ }^{1 / 2}-1^{\prime}$ long, forming a simple narrow one-sided panicle of $3-4^{\prime}$ in length. Spikelets $1^{1} / 2^{\prime \prime}$, pale, plano-convex, acuminate, subsessile in fascicles of 2 or rarely 3 , with a few $(2-4)$ long ciliae at their bases, crowded in mostly 4 rows on the outer side of the scaberulose rhachis. Sterile glumes stiff-hairy along the nerves, ovate-acuminate, the lowest ${ }^{1} / 3$ the length of the spikelet, the second and third 5 -nerved, of equal size and as long as or a little longer than the fertile floret, the third glume pointed and supplied with a narrow hyaline palea of nearly equal length. Fertile glume and palea coriaceous, shining. - Optismenus colonus, Kunth, l. c. p. 142.

$\beta$ var. - A somewhat larger plant with a panicle of $5-6^{\prime}$, its longer branches or spikes more numerous, sometimes in fascicles and slightly compound, the lowest $1-2$ ' long. Third glume submucronate and even shortly awned in the spikelet which terminates the branch. Spikelets pale. - This form may with as much right be referred to the next species, of which it would constitute an awnless variety.

A grass growing in wet places, along the borders of streams and taron-ponds; the var. $\beta$ much more common than $\alpha$. It is found in most tropical and some subtropical countries. A nearly allied species, P. frumentaceum, Roxb., is cultivated for its grain in India.

4. P. crus.galli, var. longiseta, Trin. - Icon. tab. 162. - Steudel, l. c. p. $4 \%$ - A coarser and taller grass than the one preceding, $2-3 \mathrm{ft}$. high, the stem terete and dividing below, compressed or angular above. Leaves as in no. 2. Panicle about $6^{\prime}$, pyramidal with numerous $(12-24)$ rather patent branches, the lowest $1-2^{\prime}$ long, often 2 or more in a cluster and not rarely sending out branchlets; the rhachis hispid with numerous bristles. Spikelets in fascicles of 2 or rarely 3 , purplishgreen, spindle-shaped, the lateral ones plano-convex, $1^{1 / 2}$ "long. Sterile glumes stiff-hairy along the nerves, the lowest $1 / 3$ the length of the spikelet, 1-nerved, pointed; the second as long as the spikelet, 5-nerved (the outermost nerves marginal), mucronate or shortly awned; the third 5-nerved, with the lateral nerves approximate and ending in a purplish stiff scabrous awn of about $1^{\prime}$ in length, supplied with a hyaline palea of its own length. Fertile glumes as before. - Oplismenus crus-galli, Kunth, 1. c. p. 143 . $-P$. ech inatum, Willd, $-P$. erus-pavonis, Nees. 
In similar localities as the preceding species. This long-awned form occurs also in tropical America and the Caspian regions of Asia; the typical form with shorter awns is diffused over most tropical and subtropical countries.

\section{**: Eupanicum.}

5. P. nephelophilum, Gaud. Bot. Voy. Freyc. p. 411. - Kunth, Enum. Pl. I, 86. - A tall tufted grass, 3-4 ft. high, the stem erect, simple, pubescent below the exposed nodes, bearing from 5-9 leaves, the uppermost at the base of the panicle and partly enveloping it. Leaves plane, glaucous, chartaceous, linear-lanceolate, $6-12^{\prime}$ long and $6-9^{\prime \prime}$ broad, pubescent at the mostly open sheaths and the bases of the blades with soft spreading whitish hairlets, spinuloso-scabrous and mostly ciliate at the margins. Ligule short-ciliate. Panicle large, open, $8-14^{\prime} \times 3^{1} / 2-10^{\prime}$, its rays filiform, either single or $2-5$ (in large forms even 7 or 8 ) in the lower nodes with a length of $3-8^{\prime}$, patent but the lowest suberect, straight, angular, scaberulous, ciliate at their bases, dividing from the middle upward with branchlets patent. Spikelets on pedicels of their own length or less, slender ovoid or acute ellipsoidal, $1-1^{1} / 4^{\prime \prime}$ long, purplish or greenish, quite glabrous. Two lowest glumes ovate-lanceolate, subequal, the first rather longer and equalling the spikelet, strongly 5-nerved; the second 7 -nerved; the third little shorter than the second, 7-9-nerved, with a short ( $1 / 3$ of its length) entire and obtuse hyaline palea. Fertile glume $1 / 3-1 / 4$ shorter than the third, oblong and somewhat acute, coriaceous, nerveless, white. Stamens 3, purplish. Stigmatic branches cylindrical, half the length of the styles, protruding at the middle of the floret.

Kauai! Halemanu; leaves ciliate at the month of the sheath, otherwise glabrous. Oahu! top of Kaala; leaves ciliate at the margins, at least near the base; the sheaths pubescent, not rough, but the nerves connected by transverse veinlets. Haw ail! leaves eiliate on margins and both faces, the sheaths pubescent but not rough. Highest ridge of Lanai! panicle exserted; blades of leaves glabrous, the sheaths pilose with hairs seated on rough tubercles of the transverse veinlets, - Nat. name: sKonakonas. - From our Kaala specimens P. Hawaiiense, Reichardt, 1. c. sub no. 6, only differs in the presence of a few hairlets on the median nerve of the first glume and of a few toothlets at the apex of the second. It came from Mt. Puakea of the Kaala range (not Lihue, which is the name of the ranch at the foot of it). - Here also must be referred $P$. capillare, quoted in the Botany of Beechey's Voyage. The American species bears a great resemblance to ours, but differs in the short first glume (1/2 the length of the spikelet) and the want of a palea to the third. No true $P$. capillare, L., from the Hawaiian Islands eonld be found by Prof. Oliver in the Kew herbarium, which holds the collection of Beechey's Expedition; and the quotation of $P$. capillare among Wawra's plants is most probably owing to a similar mistake, for from the same locality where Whara picked the plants in question - Halemanu, Ka ua i - Mr. Knudsen has sent me specimens of genuine $P$. nephelophilum. M. \& B's. 300 also comes from there.

$\beta$ var. tenuifotium. - A smaller plant, about $1^{1 / 2} \mathrm{ft}$. high, the slender stems geniculate at the base, glabrous at the nodes. Leaves narrow, $3-1^{\prime \prime}$ broad, acute, glabrous throughout, as is the shorter and narrower panicle. Three sterile glumes of nearly equal length. - P. tenuifolium, Hook. \& Arn, in Bot. Beech. p. 101, a form with convolute leaves. 
Molokai! pali of Makonalua; Maui! Haleakala; Oahu (Lay \& Collie). In specimens from E. Maui a slight pubescence becomes visible on the nodes of the stems and on the leaf-sheaths,

rvar. xerophitum. - Stem $1-2 \mathrm{ft}$. high, simple or once dividing. Spreading hairs with a tubercular base cover the nodes of the stem and the sheaths and blades of the flat or convolute leaves. Panicle narrow, wand-like; its rays hairy throughout, the lowest $3-6^{\prime}$ long. Spikelets $1^{\prime \prime}$, glabrous. Lowest glume $3-$, the second 5-, the third 5-7-nerved. $-P$. nephelophilum, Hook. \& Arn. 1. c. - The ciliate ligule coalesces with the adjoining hairs and is therefore easily overlooked. The hairs are apt to drop early.

On dry exposed ridges of Oahu! Lanai! and Maui! Maalaea.

$\delta$ var. rhyacophilum. - Spreading hairs with tuberculhr bases on stem, leaves and sheaths, those of the Ieaves rather viscid. Leaves narrow and convolute, almost subulate, only $1 / 2$ " broad, rather stiff and erect. Panicle quite narrow and lean; spikelets as before, $1^{1 / 2}{ }^{\prime \prime}$; the first glume 3 the third 7 -nerved, with a palea of $1 / 3$ its length. Whole plant about $1 \mathrm{ft}$. high.

Hawaii! on lavafields of Laieha, $6000 \mathrm{ft}$. above the sea (Lydgate), Hualalai (M. \& B. $327)$. - Very different from $\alpha$ in appearance. Indeed every one of these varieties would be taken for a distinct species by any one not in possession of a comprehensive material.

6. P. cynodon, Reichardt, in Ber. d. k. Akad. d. Wissensch. in Wien, $L X X V$, 724. - A low prostrate grass, $4-9^{\prime}$ in length, the slender stems puberulous and branching 3 or 4 times, geniculate at nearly every node in a zigzag manner, leafy throughout, the last leaf at the base of the panicle. Leaves divaricate, linear, plane or convolute, puberulous, $1^{1 / 2}-2^{\prime}$ long, the blades only little longer than the sheaths and these exceeding their internodes. Ligule of a few long and soft whitish ciliae. Panicle small, $1-2^{\prime}$ long, narrow, the branches closely appressed, single or two together, each with only few spikelets, the lowest about $1 / 2^{\prime}$ long; rhachis and rays softly pubescent. Spikelets on short pedicels, greenish. ovoid, about $1 "$, glabrous. Sterile glumes broadly and somewhat obtusely ovate, of equal size, with prominent nerves; the first 3-, the second and third 5-7-nerved, the latter with a small hyaline palea of scarcely $1 / \mathrm{s}$ its own length. Fertile glume $1 / 3-1 / 2$ shorter than the others, chartaceous, white, rather acute. Styles as in no. 5 .

Ka ua i! Waimea (Wawra). The habit of the plant - prostrate, with divaricate leaves recalls that of Cynodon dactylon; but in the genus it finds a close neighbor in the Mauritian $P$. parvifolium, Lam., var. serpens, Kth. (P. umbellatum, Trin.). Reichardt states the lowest glume to be only half the length of the two following, but in a specimen which $I$ have from Wawra himself the 3 sterile glumes are all of equal size. The species has lain many years in the Kew herbarium, labelled $P$. eryptanthum, Nuttall. Gen. Munro also found it in either Wilkes's or Mann \& Brigham's collection.

7. P. Beecheyi, Hook. \& Arn. in Bot. Beech. p. 100. - «Stem decumbent, branching, glabrous silky at the nodes. Leaves convolute, glabrous in 
blade and sheath. Ligule short-ciliate. Panicle contracted. Sterile glumes subequal, strongly nerved, hairy, the uppermost with a very minute and rounded palea.»

Niihau (Lay and Collie); Kauai! (M. \& B.). - A specimen collected in Hanapepe by Mr. Mann is suberect and tufted, the slender stems $10-12^{\circ}$ high, slightly deflected at the rather tumid nodes, which are sparingly ciliate with long hairlets and leafy to the top. Leaves considerably overreaching the panicle, glabrous, linear, convolute, $6-10^{\text {}}$ long. Paniele $3-4^{\prime}$, contracted, the filiform rhachis and appressed rays quite glabrous. Spikelets on pedicels of nearly, their own length slender ovoid, $1-1^{1 / 4}$ ", pointed, the two outer glumes ciliate with long spreading grayish hairlets. Sterile glumes ovate-lanceolate, subequal, the lowest (longest) 5-nerved, the second and third 7-nerved, the latter with a very minute palea. Fertile glume $1 / 3$ shorter than the third glume. Styles as in no. 4. - Found also by Wawra near the sea in Kealia, Kauai, and near Waihee, Maui.

8. P. affine, Hook. \& Arn. in Bot. Beech. p. 100. - A densely tufted suberect grass, about $6^{\prime}$ high, the whole plant, stem, leaves and panicle pubescent with soft spreading grayish ciliae, as in $P$. pellitum. Stem leafy throughout, the leaves flaccid, $1-1^{1 / 2}{ }^{\prime \prime}$ broad. Ligule replaced by ciliae. Panicle $1-2^{\prime}$ long, not exserted, narrow, at last spreading; the rays single or two or three together. Pedicels about as long as the spikelets, these very small, ${ }^{3} / 4$ " or less, ovoid, rather obtuse. The two outer sterile glumes long-ciliate; the first and third perhaps a little shorter than the second; the first 3 -nerved, the second 5-, the third faintly 5-7-nerved; thin, glabrous and supplied with a narrow oblong and very obtuse hyaline palea of $1 / 3$ its own length. Fertile floret pale yellow, as long as the third glume. - The description from a small fragment of the original specimen kindly sent by Prof. Oliver and from M. and B.'s no. 283 in herb. Cornell Univ.

Oahu (Lay and Collie); Kauai (M. \& B.).

9. P. pellitum, Trin. Diss. II, 198. - Icon. XX, tab. 23\%. - Erect, tufted, ${ }_{1 / 2}-1 \mathrm{ft}$. high, the whole plant, stem, leaves, panicle and spikelets pubescent with soft spreading grayish hairlets. Leaves flaccid, plane, $3^{1 / 2}-5^{4}$ long and $1^{1 / 2}-2^{1} / 2^{\prime \prime}$ broad, the uppermost one at the base of the panicle. Ligule short, transverse, ciliate. Panicle short and rather open, $1^{1 / 2}-4^{\prime}$ $\times 3-12^{\prime \prime}$, its suberect rays single or 2 or 3 together, the lowest $1 / 2-2^{1} / 2^{\prime}$, scarcely dividing, bearing spikelets from near the base upward. Spikelets on pedicels shorter than their own length, slender ovoid and pointed, $1-1^{1} / 4^{\prime \prime}$ long. Sterile glumes subequal, ovate-lanceolate, very acute; the lowest (longest) 3-, the second and third 5-nerved, the latter glabrous, supplied with a small hyaline palea of $1 / 3$ its length. Fertile flower $1 / 3$ shorter than the last sterile glume. Styles as in no. 5. - Kunth, l. c. p. 133. - Steudel, 1. c. p. 78, - P. montanum, Gaud. Bot. Freyc. p. 411 (not Roxb.). - P. nubigenum, Kunth, 1. c. p. 98. - Neurachne montana, Gaud. Général. p. 94 , tab. 26. - P. gossypinum, Hook. \& Arn, in Bot. Beech. p. 100 (not Rich.).

Oahu (Chamisso, Lay \& Collie), Waianae Mts. (M. \& B. no. 272); Ma ui! plentiful on the bare slopes above Maalaea bay and elsewhere. 
10. P. cinereum, sp. n. - A stout grass, about $3 \mathrm{ft}$. high, lanuginous in all parts with long soft silky grayish hairs. Leaves $12^{\prime}$ long and $7-9^{\prime \prime}$ broad, thick chartaceous, silky throughout with appressed hair, the sheath ending in the blade with a broad beak-like truncate projection of about $6^{\prime \prime}$ in length, the ligule forming a thick woolly border to it. Panicle large and dense, pyramidal, $10-12^{\prime} \times 4-6^{\prime}$, its numerous branches in whorls or fascicles and dividing from near the base, the lowest 5-7'long; rhachis and rays hirsute with spreading hairs. Spikelets as in $P$. pellitum, the third glume glabrous, the two outer glumes hirsute with spreading hairs. Stamens short and purple. Styles fimbriate near the apex only.

Maui! Haleakala (Prof. Alexander), - Technically distinct from P. pellitum only in the peculiar shape of the ligule and the great development of the plant in all parts, but very different indeed in aspect. The large showy panicle resembles that of a Saccharum or Imperata, and its branches cohere so firmly that they can not be separated without tearing some spikelets.

11. P. torridum, Gaud. Bot. Voy. Freyc. p. 411. - Erect, tufted, clothed in all parts with soft silky pale yellowish or fawn-colored bairs. Stems 1-2 ft. high, simple or once dividing, bearded at the nodes and pubescent below, the uppermost leaf below the base of the panicle and not overreaching it. Leaves chartaceous, plane, erect, $6-12^{\prime} \times 4-5^{\prime \prime}$, the sheaths shorter than their internodes and hairy with spreading ciliae, the blades with shorter pubescence. Ligule ciliate. Panicle dense, pyramidal, $3-6^{\prime} \times 1-2^{\prime}$, the rays suberect, close, in fascicles of $3-5$, dividing from near the base, the lowest $2-2^{1} / 2^{\prime}$ long, all densely hairy. Spikelets on pedicels shorter than their own length, ovoid-acute, $1^{1 / 2}-2^{\prime \prime}$, elothed with spreading ciliae longer than the width of the spikelets. Glumes unequal; the lowest longest, lanceolate-acute, with $3-5$ brownish nerves; the second $1 / 3$ shorter, ovate, 5-7-nerved; the third hairy on margins and nerves like the outer ones, almost equal to the second, faintly $3-5$-nerved, with a minute obtuse hyaline palea. Fertile floret short, less than half the length of the first glume, yellowish. Styles as in no. 5 .

W. Maui! Molokai! Oahu! - Nat, name: "Kakonakona".

12. P. monticola, $s p . n$. - Stems erect from a prostrate rooting base and stoloniferous, $8-10^{\prime}$ high, undivided, glabrous, bearing 5-6 leaves, the uppermost one a short distance below the panicle. Leaves stiff chartaceous, the blade plane, linear-lanceolate, very acute, glabrate, $1^{1 / 2}-3^{\prime} \times 2-3^{\prime \prime}$, the sheaths softly pubescent; ligule ciliate. Panicle rather open, $2-3^{\prime}$ long, its rays single or in twos or threes, suberect, the lowest $1^{1} / 2^{\prime}$; rhachis and ravs stiff angular, puberulous. Spikelets on filiform pedicels of more than their own length, ovoid-oblong, somewhat obtuse, biconvex, $1^{1} / 2^{\prime \prime}$, purplish-green, glabrous. Sterile glumes ovate, unequal, the lowest $1 / 4-1 / 2$ the length of the second, which is $1^{1 / 2}{ }^{\prime \prime}$ long and 7-9-nerved; third glume like the second, but pale and supplied with a 
small ( $1 / 4$ its length) and narrow acute palea. Fertile flower $1 / 3$ shorter than the upper glumes, its own glume faintly 3-nerved. Stamens 3, anthers purplish. Style long, not swollen at the base, its stigmatic brushes globose or short conical, protruding near the apex of the floret.

In the swamps on the summit of Mt. Eeka, Maui. This grass is a near relative of P. repens, L. \& Trin., with which it also shares the swampy habitat. The latter is, however, confined to the neighborhood of the seacoast, while our plant inhabits the top of a high mountain. The most valuable distinctive character is to be drawn from the perfectly sterile and abortive neutral floret, which is supplied only with a small hyaline palea, while this in P. repens is fully formed, of the same size as its glume, and generally bears 3 stamens. Furthermore, the short outer glume is pointed here, not rounded or truncate as in $P$. repens, and the plant is much smaller, particularly its panicle, the rays of which are neither so distant nor so widely spreading as in the congener at maturity, while the rather obtuse and biconvex spikelets are raised on longer pedicels, thereby entitling the species to a place in the section Miliaria rather than in Virgaria.

13. P. imbricatum, $s \dot{p} . n$. - A densely tufted small grass of alpine character, with a short and creeping, much branching or forking stem, the crowded erect branches $2-3$ ' high, dividing freely, rooting and mostly sterile, densely foliaceous, the internodes $1 / 2-1^{\text {" }}$ in length. Leaves lanceolate, $5-7^{\prime \prime} \times 1^{1 / 2^{\prime \prime}}$, imbricate at the base, divaricate, often deflected to one side, strongly many-nerved, subcostate near the base, stiff chartaceous, glabrous; the short and open sheath eiliolate. Ligule short-ciliolate. Panicle or raceme short, only $5-7$ "long and somewhat exserted beyond the uppermost leaves, bearing $3-8$ spikelets, the rhachis spreading-pubescent at the lower nodes, as are the lowest rays or pedicels. Spikelets mostly single on erect or appressed angular rays or pedicels of more than their own length, and scarcely thickened above, ovoid-obtuse, $1^{1 /} 4^{\prime \prime}$, purplish, glabrous. Lowest glume less than ${ }^{1 / 2}$ the length of the next, rather obtusely ${ }^{*}$ ovate, 3 -nerved, the 2 lateral nerves very short; second and third glumes of equal size, ovate-obtuse, the former 7 -, the latter 5 -nerved and clasping the fertile floret, with a palea of $1 / 3$ its size. Fertile flower nearly equalling the upper glumes, white, chartaceous, its glume faintly 5-nerved. Stamens 2; anthers yellow. Ovary and styles as in the next species.

Swampy summit of Mt. Eeka, Mr a ui. - However different in habit and appearance, in structure it approaches the preceding species, and from Gen. Munro I learn that Mann's no. 435 is intermediate between the two. - The nearest approach in habit to our plant I find in $P$. nodiftorum, Lam., an autumnal state of $P$. dichotomum, L., and in $P$. thermate, Bolander, from California, but both are much less compact and stiff.

14. P. isachnoides, Munro, in Seem. Journ. Bot. 1869, p. 178 (name only). A low densely tufted grass of the habit of the preceding species, the much dividing branches stiff, erect, $2-2^{1} / 2^{\prime}$ long, elosely foliaceous, the internodes ${ }^{1} / 2-3 / 4^{\prime \prime}$. Leaves distichous, appressed, imbricate, ovate to ovate-lanceolate, rather obtuse, $3-4^{\prime \prime} \times 2-2^{1} 1_{2}$ ", closely and prominently many-nerved, with short scabrous anastomoses between the nerves, ribless, rigid, conchoid or plicate, glabrous above and below, but the margins lined in a pectinate manner with long and stiff ciliae which rise from prominent shining and 
roundish tubereles; the sheath short and open. Ligule short-ciliate. Raceme short, not protruding beyond the upper leaves, glabrous, seldom bearing more than 4 spikelets on subterete stiff appressed pedicels of nearly twice their own length. Spikelets ovoid-obtuse, $1^{1 / 4^{\prime \prime}}$, glabrous. Lowest glume ${ }^{1 / 3}$ the length of the spikelet, ovate, $1-3$-nerved, sometimes indistinctly tricuspid; second and third glumes equal, ovate-obtuse, prominently $5-7$-nerved and bicallose at their bases, the latter with a hyaline palea of about half its size. Fertile floret of nearly the same length, white, chartaceous, its glume obovate and faintly 5-nerved. Lodicules 2, short, truncate. Anthers 3, purplish. Ovary elongate ventricose, constricted below the clavate bases of the long styles, which end in short globose. stigmatic brushes and protrude near the apex of the floret. $-P$. conchoideum, Hbd. in herb.

In the same locality as the two last species, where it forms dense swards or tussocks on the boggy plateau, and, together with them and Oreobolus furcatus, Acaena exigua, Lagenophora Mauiensis, Viola Mauiensis, Lobelia Gaudiehandii, Wilkesia gymnoxiphia, Plantago pachyphylla, Schizaea robusta, Selaginella deflexa, etc., constitutes the peculiar vegetation of that unique spot.

\section{OPLISMENUS, Beauv.}

Spikelets with one fertile floret, in irregular fascicles on one side of the alternate spike-like branches of a simple panicle; the 3 herbaceous empty glumes unequal, gradually larger from the lowest one, either all awned, or the one or two upper ones only mucronate or pointed, the lowest with the longest awn, the third supplied with a palea. Fertile floret as in Panicum. - Weak decumbent grasses with broad leaves.

A tropieal and subtropical genus, only one species extending to the southern part of Europe and a few to S. Africa and Australia.

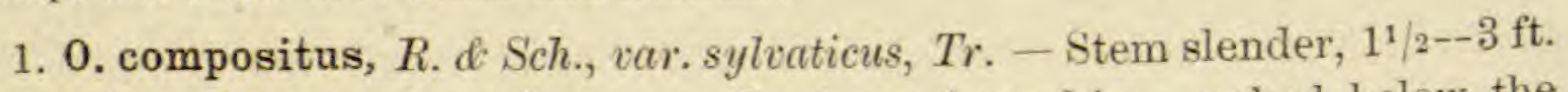
long, decumbent and rooting near the base, branching, naked below the panicle, puberulous at and below the nodes. Leaves thin, dark-green, occasionally variegated, broad-lanceolate, $4-5^{\prime} \times 5-7^{\prime \prime}$, very acute, rounded at the base, antrorsely scabrous at the margins, glabrous, with sheaths pubescent and shorter than their internodes. Ligule long-ciliate. Panicle $4-7$ ' long, bearing at long intervals $3-7$ spike-like branches of $1^{1 / 2}-^{-1 / 2^{\prime}}$ in length. Spikelets in fascicles of 2 or 3 , articulate on short pedicels which are setulose at their bases, $1^{3 / 4^{\prime \prime}}$ long, ovoid, purplish. Sterile glumes herbaceous, puberulous; the lowest $1 / 3$ shorter than the spikelet, 3-5-nerved, with the strong median nerve running into a smooth awn of two or three times its own length; second glume ${ }^{1 / 4}$ shorter than the spikelet, 5-7-nerved, with an awn of less than its own length. Third glume obovate, exceeding the fertile floret, 7-9-nerved, mucronate, glabrous, supplied with a short and narrow herbaceous palea. Fertile 
floret oblong-pointed, chartaceous. Anthers and stigmas purplish, the latter elongate, long-exserted from the apex of the floret. - O. Oahuensis, Nees. - Panicum compositum, L. - Trin. Icon. tab. 188. - Orthopogon compositus, R. Br. - Hook. \& Arn. in Beech. p. 101.

Common in the outskirts and open glades of forests. Nat, name :Honohono". - The species is found in most tropical and subtropical regions, especially of the old World.

\section{SETARIA, Beauv.}

Spikelets as in Panicum proper and awnless, but the short pedicels either lateral on a long bristly axis, or terminal and armed below with one or several long bristles. Panicle contracted, cylindrical, spike-like.

\section{Subgends DISSOCHONDRUS, Hillebr.}

Fertile florets 2, both hermaphrodite, with hardened glumes and paleae, raised on a distinct callus. Leaves stipitate on a biauriculate sheath.

Bears a relation to Setaria similar to that of Isachne to the Miliaria section of Panicum; but in Isachne the pedicels are continuous with the spikelet. Stipitate and biauriculate leaves do not oceur in any species of Setaria proper.

Geographieal range of Panicum, the subgenus limited to our species. - A quite recent intruder is $S$. verticillata, a small annual with interrupted spike and retrorsely barbed bristles.

1. S. biflora, sp. $n$. - Erect, branching, $1^{1 / 2}-3 \mathrm{ft}$. high, the stem compressed, geniculate below, puberulous at the nodes, foliaceous throughout. Leaves dark-green, flat, chartaceous, linear-lanceolate, $12^{\prime} \times 6-8^{\prime \prime}$, gradually acuminate, contracted at the base into a stipes, $11-13$-nerved and prominently ribbed, glabrous, rough at the margins and the upper end of the rib; the sheaths much longer than their internodes, glabrous, compressed, carinate, open, drawn out into two narrow lanceolate aurieles of $1 / 2-1^{\prime}$ in length. Ligule short ovate, scarious. Panicle cylindrical, spike-like, $6-9^{\prime}$ long, $2^{1 / 2}$ " thick, its short flexuose branches crowded and closely appressed; the spikelets single, articulate on very short pedicels, which are tumid above and armed about the middle with a single stiff flexuose antrorsely scabrous bristle of $3-4$ times the length of the spikelet, rarely with $2-4$ bristles. Rhachis and rays scabrous, puberulous. Spikelets 1", ovoid-pointed, glabrous. Empty glumes two, thin, greenish, ovate, the lowest $1 / 3-1 / 4$ shorter than the next and faintly nerved, the second 7-9-nerved. Fertile florets twin, hermaphrodite and equal, sessile on a short callus, $1 / 4-1 / 3$ shorter than the second empty glume, both coriaceous, white, smooth, plano-convex, contiguous with their flat faces, as in Isachne, their glumes coneave, oblong, rather obtuse, the paleas as long, clasping the ovary and stamens. Lodicules cuneate. Stamens 3, with pale sagittate anthers. Ovary glabrous. Styles tumid below, penicillate in the upper third.

Lanaì! 


\section{ISACHNE, R. Br.}

Spikelets small, obtuse, continuous with the pedicel, articulate above the sterile glumes, 2 -flowered, both florets hermaphrodite, rarely the upper female or the lower male. Empty glumes 2, membranous, nearly equal. Both flowering glumes with their paleas coriaceous, equal, plano-convex, contiguous with their flat faces, awnless. Grain enclosed. Inflorescence an open, mostly pyramidal panicle with slender branches.

About 20 species, dispersed over the tropics of both Worlds. - Of late introduction and spreading from gardens is $I$. myosotis, Nees, from China, a handsome creeping lawn. grass with small ovate-lanceolate leaves and few-flowered panicles, the outer glumes pubescent.

Florets glabrous; leaves broad, with a callous margin Florets pubescent; leaves narrow, their margins not callous

1. I. distichophylla.

2. I. pallens.

1. I. distichophylla, Munro, in Seem. Journ. Bot. 1869, p. 178 (name only). - A tall handsome grass, 4-6 ft. high, the stiff erect stem simple or divided, foliaceous to the top (with 6-12 leaves), but the panicle longexserted at last. Leaves stiff, glaucous, broadly lanceolate, 6-12' long, ${ }^{1 / 2}-1$ ' broad, very acute, suddenly rounded at the base, serrulate with appressed spinose teeth on the wavy callous margins, glabrous, excepting the upper part of the sheath, which is beset with darkish ciliae along the margins. Ligule ciliate. Panicle open, stiff, erect, $4-8^{\prime} \times 3-4^{\prime}$; the wiry rays remote and generally single, at last horizontal, dividing in the upper half or two thirds; the pedicels not longer than the spikelets; rhachis and rays rather terete, glabrous. Spikelets $1^{\prime \prime}$, obovoid, glabrous, with both florets fertile, the upper female, the lower hermaphrodite. Empty glumes equal, broadly ovate, almost orbicular, indistinctly 7-11-nerved. Fertile florets plano-convex, obtuse, as long as the empty glumes, thick coriaceous, quite glabrous, brownish when mature; their glumes nerveless. Stamens 3. Styles of fem. floret' with longer brushes than those of the hermaphrodite floret; the brushes purple, protruding below the apex. Lodicules truncate or rounded, - The leaves are distichous only in the lower portion of the flowering stem.

In the forests of all islands! at altitudes of $2000-3000 \mathrm{ft}$, but not common. Nat. name: "Ohen. - Near I. firmula, Munro.

B var. - Outer glumes pubescent; otherwise as before. W. Maui!

2. I. pallens, $s p \cdot n$. - More slender than the preceding species, about $2 \mathrm{ft}$. long, the stems geniculate below and-rooting, foliaceous as before. Leaves pale, linear-lanceolate, 6 ' long, $2-3$ " broad, glabrous, not callous at the margins, which are scaberulous only near the base; the sheaths shortly pubescent at the mouth. Ligule ciliate. Panicle as before, but the rays more slender, filiform, and the pedicels longer than their spike- 
lets. Spikelets as before, but less broad at the top, and both florets ciliate and white. Empty glumes slightly exceeding the florets, rather acutely ovate, the lower one indistinctly 5-, the upper 7 -nerved. Stamens and stigmas pale brown or yellowish. Lodicules truncate.

Woods of the eastern division of Oahu! - Much like $I$. albens, Trin.

\section{CENCHRUS, Beauv.}

Spikelets 1-flowered, or with a second neuter or male floret below the fertile one, single or few together in a stiff multifid involucre, the inner lobes of which are longest, flattened below and connate in a cup at the base; the spikelets deciduous with the involucres; these arranged in simple terminal spikes. Sterile glumes 3, unequal, membranous. Fertile glume and palea chartaceous, the former enveloping the latter. Lodicules none. Stamens 3. Styles terminal, connate below, their elongate linear stigmas protruding at the apex of the floret. - Upright grasses with flat leaves.

A genus of 12 species, distributed over the warmer regions of both the New and old World.

Involucres stipitate, including only 1 spikelet

1. C. calyculatus.

Involueres subsessile, including 3-6 spikelets

2. C. echinatus.

1. C. calyculatus, Cavan. Icon. V, tab. 463. - Var. uniflorus. - Perennial, erect, $1-2 \mathrm{ft}$. high, the stem stiff, lignescent at the base, branching repeatedly. Leaves plane, chartaceous, linear, 6-10' long, 4-7" broad, rough on margins and nerves but glabrous throughout; the sheaths compressed and sharply keeled. Ligule of short ciliae. Spike or raceme somewhat exserted, $3-5^{\prime}$ long, its rhachis stiff, flexuose, puberulous. Involucres shortly stipitate, patent, even reflexed, lignescent, puberulous, fusiform, $5-6^{\prime \prime}$ long, consisting of $6-8$ subulate connivent inner lobes, which are ciliate below and connate at the base, and of numerous shorter erect and spreading outer bristles. Spikelet $4^{\prime \prime}$ long, single in each involucre, slender, very acute, glabrous. Sterile glumes very thin, ovatelanceolate; the lowest $1 / 4-1 / 3$ the length of the spikelet and 1 -nerved, the second nearly as long as the spikelet and 5-7-nerved, the third 5-7-nerved, with a palea of the same length which is 4-nerved, folded along the lateral nerves and includes the stamens. Fertile glume as long as the last, thin chartaceous, very acute, 5-7-nerved, convolute round the palea, which is 3 -nerved and plaited along the lateral nerves. Stigmas long linear. - Pennisetum calyculatum, Spr. - Hook. \& Arn. in Bot. Beech. pp. 72 \& 101. - C.anomoplexis, Labill. - Seem. in Fl.Vit. p. 324. - C.Taitensis, Steud. - C. agrimonioides, Trin. Diss. II, 72 (our form). - C. fusiformis, Nees.

On dry exposed ridges between 1000 and $3000 \mathrm{ft}$. above the sea, probably on all islands, but chiefly on old lava fields of $\mathrm{E}$. Maui and $\mathrm{Hawaii}$. Nat, name: =Kamanomanos. Occurs also on the Society and Friendly Islands, on Pitcairn Isld., the Samoa and Viti groups and N. Caledonia, but generally has there $2-4$ spikelets to an involucre. - The peculiar nervation of the paleas is quite anomalous, but I am unable to say if it exists also in the forms from the other Pacifie islands. 
†2. C. echinatus, L. - Kunth, Enum. Pl. I, 166. - Annual, 1-2 ft. high, the stem geniculate below, leafy to the top. Leaves plane, $3-4^{\prime \prime}$ broad, scabrous on the margins, pubescent on blade and sheath; ligule ciliate. Spike $3-4^{\prime}$ long. Involucres crowded, subsessile, cup-shaped, $3^{\prime \prime}$ long, irregularly split to near the base into $8-10$ acute, mostly hispid lobes armed outside with spines which decrease downward to bristles and hairlets. Spikelets $3-6$ in each involucre, ovoid, 3 " long, glabrous. Lowest glume ${ }^{1 / 3}$, second ${ }^{2 / 3}$ the length of the spikelet, $3-5$-nerved; third glume as long as the fertile floret, $5-7$-nerved, with often a palea of equal length and then staminate. Fertile glume chartaceous, 5-nerved; its palea 2 -nerved. - Griseb. Fl. W. Ind. p. 556.

Our form belongs to the var, $\alpha$ of Grisebach. The spikelets contained in an involucre are not all-equally perfect, only one or two exhibiting a lowest glume, while the palea and stamens of the third glume are found only in the larger ones.

The species, which first appeared in the neighborhood of Honolulu in 1867 , is common in tropical America, Asia and Africa.

\section{STENOTAPHRUM, Trin.}

Spikelets awnless, 2 -flowered, with the lower or anterior floret male, in short spikes imbedded in excavations of a thickened, flat or cylindrical, articulate or continuous rhachis. Glumes 4 or 3, the lowest (anterior) very minute or wanting, the second thinner than the subcoriaceous flowering ones, the paleae of the latter fully developed and enfolding with thinner margins the inner organs. Lodicules 2, anterior, truncate. Stamens 3. Ovary pointed; the 2 long styles distinct below and narrowly penicillate in the upper half, protruding from the apex of the floret. - Long ereeping stoloniferous grasses with distichous flat leaves.

A genus of 4 or 5 species, diffused over the tropies of both Worlds.

1. S. Americanum, Schrank, in Hort. Monac, tab. 98. - Kunth, Enum. Pl. I, 138. - A low ereeping, much branching grass, glabrous throughout, the ascending branches $6-18^{\prime}$ long, with $4-8$ pairs of leaves. Leaves subopposite and equitant (except in the uppermost nodes of the fertile branches), pale glaucous, thick chartaceous, the blades about $3^{\text {" wide and }}$ 4-1' long (the uppermost shorter than their sheaths), plane or plicate, smooth at the edges, obtuse or obliquely truncate, suddenly contracted, almost stipitate at the base and diverging at a right angle from their sheaths, which are open to the base and compressed with a sharp keel. Ligule short-ciliate. Spike-like panicle terminal, sometimes with 1 or 2 smaller axillary ones, the rhachis complanate, $2-3^{\prime}$ long and $2-2^{1 / 2^{\prime \prime}}$ broad, excavated on one face for the reception of the short branchlets, and transversely constricted, at last articulate between them. Rays or branchlets alternate in two rows, $2^{1} / 2-3^{1 / 2}$ "long, thick angular, each with 2 (rarely 3 ) spikelets, one sessile near the base, the other near the 
apex of the rhacheole. Spikelets sub-quadrangular, somewhat obtuse, $1^{1 / 2}-2^{4}$ long, the anterior male floret of the same size as and parallel with the hermaphrodite one. Lowest glume minute seale-like or wanting, the second as long as the spikelet, rather thin, deep navicular 7 -nerved; flowering glumes subcoriaceous, that of the male fl. $3-5$-nerved and bicarinate, of the fertile one 5-7-nerved and rounded; their thinner 2-nerved paleae of the same length. Anthers yellow, linear. - Rottboellia dimidiata, Thbg. - R. stolonifera, Poir. - S. glabrum, Trin. in part.

All islands. Forms broad patches on open slopes up to $2000 \mathrm{ft}$. above the sea; is well liked by cattle. The original "Manienie (creeping grass) of the natives. - Oceurs in the tropics of all continents.

At the base and apex of the rhachis, and in narrow rhachides thronghout, the upper spikelet is rudimentary or wanting. Toward maturity the rays with their spikelets rise from their beds. The apparent opposition of the leaves is owing to a regular alternation of length in the internodes, a long internode mensuring from $1-4$ inches being succeeded by a short one of not more than 1 or 2 lines. As the short internodes are concealed by their leaf-sheaths, which extend at least to the middle of the next longer one, this circumstance becomes apparent only on the removal of the leaves. Not seldom a third node, or rather a dark-colored constrietion, without a leaf, is discovered close above the short internode, and here the stem is apt to break. In well developed stems a branch issues from every sheath.

\section{SUBtribe II. SACCHAREAE.}

Flowering glume thin and transparent, with a twisted awn, small, seldom entirely wanting; empty glumes usually of a firmer texture.

\section{Heteropogon, Pers.}

Spikelets monoecious, 1 -flowered, in pairs, in a simple one-sided spike, the rhachis articulate, at least toward the top. Female spikelets cylindrical, sessile, turned to one side of the spike; the outer glume hardened and convolute, the second keeled, the third very thin and transparent, the flowering glume reduced to a long stiff twisted awn; palea small or wanting. Styles distinct, with long and thick cylindrical stigmas. Grain enclosed in the outer glumes. Male spikelets lanceolate, herbaceous, awnless, imbricate on the other side of the spike, on short pedicels. At the base of the spike the spikelets are often all male or neuter.

A genus of several species, chiefly tropical, both of the old and New World.

1. H. contortus, Roem. \& Sch. Syst. II, 836. - Stems tufted, erect, branching, compressed, glabrous, $1^{1 / 2}-2 \mathrm{ft}$. high. Leaves pale, linear, flat, $4-10^{4} \times 2^{\prime \prime}$, glabrous, rough above and on the margins, the sheath keeled. Ligule short-ciliate. Spike single, exserted beyond the leaves, 1-2' long without the awns, the slender rhachis continuous and glabrous in the lower third or half which is exclusively male or barren, articulate and hairy, with brushes of brown hairlets above. Male or barren spikelets compressed, elongate, stramineous, $4^{\prime \prime}$, imbricate in 2 rows along the back of the spike, their glumes of nearly equal length, the lowest coriaceous, 
lanceolate, many-nerved, biplicate along prominent submarginal scabrociliate nerves which are crest-keeled in the upper half; the second transparent 3-nerved; the third and fourth hyaline 3 - and 1 -nerved, both ciliate at the margins, Female spikelets almost concealed by the male, slender cylindrical, $3-4^{\prime \prime}$; the outer glume dark brown, coriaceous, pubescent, indistinctly 9 -nerved, narrow convolute, truncate; the second glume stiff 5 -nerved; the third small, hyaline; the fertile one reduced to a stout twisted and geniculate brown awn of $2-3^{1} / 2^{4}$, pilose at the base and scabrous above. No palea. - Andropogon contortus, L. - Heteropogon hirsutus, Pers. - H. glaber, Hook. \& Arn. - The many-branched form with a spike at the end of each branch is $H$. polystachyus of authors.

Common on all islands, the sPili of the natives, very troublesome on account of its awns, which get entangled in the wool of sheep. - Widely distributed over tropical Asia, Africa, Australia, the Polynesian islands and parts of America.

\section{ANDROPOGON, L.}

Spikelets 1 -flowered in pairs, one sessile and hermaphrodite, the other pedicellate and male or neuter, in a simple spike or along the spike-like branches of a simple or compound panicle, the rhachis generally articulate, and at the terminal joint a pedicellate spikelet on each side of the sessile one. Iowest glume of sessile spikelet stiff, with two of the lateral nerves most prominent; second keeled; third very thin and transparent; flowering glume small and transparent, with a long twisted awn; palea very small and thin or wanting. Pedicellate spikelet smaller, reduced to a single glume. Styles etc., as in Heteropogon.

A large genus, extending through all tropical and many temperate regions of both hemispheres. - To it belongs the Lemon-grass, A. schoenanthus, L., of the gardens.

1. A. annulatus, Forst. - Kunth, Enum. Pl. I, 498. - A small grass, about $1 \mathrm{ft}$. high, the slender stem geniculate below, its nodes bearded with spreading silvery hairs. Leaves pale glaucous, flat, linear, $3-4^{\prime} \times$ $1-1^{1} / 2^{\prime \prime}$, roughish above and on the edges, hispidulous at the base, otherwise glabrous, the sheath closed. Ligule short truncate, entire or minutely ciliate. Spikes 3 , of which 2 are placed at the end of the stem, all on slender pedicels of $2^{\prime \prime}$, their filiform rhachis $2^{\prime}$, hairy, most so at the nodes. Sessile spikelets $1^{3 / 4} 4^{\prime \prime}$, oblong-oborate, compressed, long-ciliate; the lowest glume of the length of the spikelet, chartaceous, obtuse, truncate or 3-dentate, pitted at the base, 9 -nerved, with the inner nerves mostly confluent, plicate along the much stouter and ciliate outer nerves; second glume transparent, with 3 converging nerves, and plicate along the lateral ones; third glume shorter, truncate, hyaline. Fertile glume reduced to a capillary pale-yellowish twisted awn about $3 / 4^{\prime}$ long and geniculate at the middle. Lodicules cuneate and broadly emarginate. Stamens yellow. Styles discreet at the base. Pedicellate spikelet like the sessile one, but 
neuter, and without awn or flowering glume. - The spikelets are not exactly one-sided, but stand in 4 rows round the rhachis, of which only the one or two lowest internodes are without fertile spikelets, - Lepeocercis annulatus, Munro.

Lanai or Molokai! Ours differs from the African plant only in the shorter ligule. The species occurs in tropical Africa, Arabia, India, Timor and N. Australia.

\section{SPODIOPOGON, Trin,}

Spikelets in pairs, one pedicellate, one sessile, in simple, branched or paniculate spikes, both 2 -flowered, the upper floret hermaphrodite or female, the lower male. Rhachis angular and articulate, at least at the top. Outer glumes stiff, the lowest convex or flat, the second keeled. Flowering glumes and paleae very thin and transparent, the glume of the fertile floret with a twisted awn.

A small genus of the same geographical range as Andropogon.

stems ciliate at the nodes; second glume awned from an entire apex 1. S. Byronis.

Stems glabrous; second glume awned between the teeth of a bieuspid apex 2. S. aureus.

1. S. Byronis, Trin., Nova Act. Petropol. 1832, p.301. - Steudel, Synops. Pl. Glum. I, 398. - Tufted. Stems erect, 1-2 ft., sparingly branched, with 3-5 ciliate nodes, the uppermost leaf very short subulate and at some distance below the spike. Leaves plane linear, the lowest $6^{\prime} \times 2^{1 / 2} 2^{\prime \prime}$, acute, contracted at the base, glabrous, the sheath compressed. Ligule entire, that of the lowest leaf $2^{\prime \prime}$ long. Spikes digitate, 2 in all my specimens $(3-4$ according to Trinius), erect, stout, subsessile, fulvous, shining, $2-3^{\prime}$ long, the thick triquetrous rhachis hirsute with dark yellow hairs, readily breaking up into obconical joints each $1^{1 / 2} 2^{\prime \prime}$ long and hollowed out above into a glenoid cavity. Spikelets $2-2^{1} / 2^{\prime \prime}$, ovoid-pointed, subcompressed, hirsute, both the sessile and pedicellate one 2 -flowered, the upper floret in either hermaphrodite, the lower male or neuter. Sessite spikelet: lowest glume coriaceous, lanceolate, flattish, plicate along the margins, 9 -nerved and mostly bifid, the two extreme nerves on either side uniting in a short stiff mucro or seta, but sometimes all nerves coalescing in a single mucro; second glume of the same length, coriaceous, conchoid or keeled, 5-nerved, all nerves uniting in a stiff awn of the length of the glume or longer; third glume nearly one half shorter, lanceolate-acute, $3-5$-nerved, transparent, with a bicarinate palea of its own length; fertile glume as long as the third, hyaline, entire or bifid, 5-nerved, the stout middle nerve prolonged in a stiff brown awn of $8-10^{\prime \prime}$ in length which is contorted below the knee and scaberulous above; the 2 -nerved palea of the same length. Pedicellate spikelet nearly like the sessile one, but the first glume entire, with a single mucro of ${ }^{1 / 3}$ its own length, that of the second a little longer; awn of the fertile glume only 3-4". - Andropogon Byronis, Steud. 1. c.

Rather rare, on the highlands of $\mathrm{H}$ a wail! and E. Maui, also Molokai! Not known from elsewhere, unless the following species should prove not to be specifically distinet. 
2. S. aureus, Hook. \& Arn. in Bot. Beech. p. 273. - "Stems tufted, ascending, glabrous at the nodes. Leaves lanceolate, acuminate, subconvolute, glabrous, or sparingly ciliate at the margins near the base. Spikes 2 , at the end of the stem. Spikelets rather similar; the articles of the rhachis triquetrous, yellow-ciliate, with callous angles. Lower glume convex to the middle and smooth, plane above and nervose, pubescent toward the margins; that of the sessile spikelet acutely bicuspid, that of the pedicellate one subulate or with a single (sublateral) cusp far below the apex? Upper (second) glume bicuspidate and awned between the teeth. Awn of the upper hermaphrodite floret 4 times as long as the spikelet. Ischaemum murinum, Forst. Prod. no. 384, and Kunth, Enum. Pl. Suppl. Vol. I, p. 419 .

Admitted here as a Hawaiian Island plant on the authority of Gen. Munro, as is also the synonym. - It was collected by Lay and Collie on Loo Choo. Forster's plant came from the island Tanna. If the synonymy is correct Forster's specific name has precedence.

\section{CHRYSOPOGON, Trin.}

Spikelets narrow lanceolate, 3 together, terminating the branches of an erect panicle, the central one sessile and hermaphrodite, the two lateral ones pedicellate and male. Glumes and flowers of Andropogon, from the paniculate species of which this genus differs in all the spikes being reduced to the terminal joint.

A genus dispersed over tropical and subtropical Asia, Africa and Australia, with one species extending into southern Europe.

1. C. aciculatus, Trin. Fundam. p. 88. -- Stems ereeping and rooting at the base, then erect and stiff, about $1 \mathrm{ft}$. high, simple or branched, with $5-6$ nodes in the lower half. Leaves erowded below, $6-3^{\prime} \times 3-2^{\prime \prime}$, the upper ones short with long sheaths, plane, ciliolate at the margins of the sheaths, otherwise glabrous. Ligule very short. Panicle stiff, narrow, $2-3^{\prime}$ long, the erect rays about ${ }^{2} / 3^{4}$, pubescent, with a tuft of longer hairs below the spikelets. Spikelets purplish, slender, acute, glabrous, the lateral ones $2^{1} / 2-3^{\prime \prime}$ long, on pedicels ${ }^{2 / 3}$ the length of the sessile spikelet, which measures about 2". Sessile spikelet: two outer glumes chartaceous, of nearly equal length, the lower lanceolate, shortly bifid, indistinctly nerved, biplicate along the prominent lateral nerves and spinuloso-serrate along the keels, the second with one distinct nerve and a short mucro or awnlet, the keel spinuloso-serrate; third and fourth glumes shorter, hyaline, the former acute lanceolate, 3 -nerved, the latter running out into a spinulose awn $2-3$ " beyond the spikelet. No paleae. Stigmas protruding at the middle of the spikelet. Pedicellate spikelets: lowest glume entire, second shortly mucronate, third and fourth hyaline, both awnless, the former ciliate at the margins. - Benth. Fl. Hongk. p. 424. - Andropogon acieularis, Retz. Kunth, Enum. P1. I, 505. - Rhaphis trivialis, Lour. - Trin. Icon. I, tab. 8 and 9. 
A common grass which covers dry open plains and slopes, considered good pasture for cattle, but undesirable for sheep on account of the adherent spikelets and awns. Nat. name: "Piipii. - It in spread over other island groups of the Pacific, Tahiti, Viti, also Australia, Inđia and China.

\section{SORGHUM, Pers.}

Spikelets on the continuous ramifications of a compound panicle, the lateral ones in pairs, the terminal ones ternate, one sessile, one or two pedicellate, the sessile one hermaphrodite, with cartilaginous polished and generally colored outer glumes, the pedicellate ones male or neuter, with thinner outer glumes, often reduced to mere pedicels. Flowering glume of the sessile spikelet with a geniculate awn, or awnless; otherwise as in Andropogon.

Distribution of Andropogon.

Outer glumes pale; panicle compact

Outer glumes dark; panicle loose

1. $S$. vulgare.

2. S. saccharatum.

$\dagger$ 1. S. vulgare, Pers. Enchirid. I, 101. - Stem erect, $4-5 \mathrm{ft}$., puberulous at the nodes. Leaves plane, over $1 \mathrm{ft}$. long and ${ }^{1 / 2}-1^{\prime}$ broad, glabrous, with rough margins, pubescent at the base. Ligule short ovate. Panicle contracted and crowded, $4-8^{\prime} \times 1-2^{\prime}$, with suberect stiff rough and pubescent verticillate rays. Sessile spikelet broad ovoid, compressed, somewhat obtuse, about $2^{\prime \prime}$, its outer glumes pubescent at the top (in our variety), pale yellow when mature, the first faintly $7-9$-nerved, the second $3-5$ nerved; third and fourth glumes hyaline, the latter frequently awnless in the lateral spikelets. - Andropogon auct. - Holcus Sorghum, L.

The well known Sorghum or Guinea-Corn, cultivated for chieken feed and occasionally found escaped from eultivation. In Italy the grain is considered injurious to fowis, an opinion not borne out by the experience of poultry raisers on this group. The BroomCorn is a variety of this species with a more open panicle.

$\dagger 2$. S. saccharatum, Pers. - Panicle larger, open, its rays longer and more remote from each other, naked in their lower portions, patent and nodding at last. Spikelets more pointed; their glumes dark brown or blackish when mature. - Andropogon auct. - Holcus saccharatus, L.

The Sugar-Sorghum, mainly raised as fodder for cattle and horses. Former attempts at manufacturing syrup from the juice have been abandoned. Like the first species, it is a native of India and tropical Africa and of comparatively recent introduction into the Hawaijan Islands.

\section{SACCHARUM, I.}

Spikelets 1-flowered, awnless, surrounded by long silky hairs, in pairs, both fertile and sessile or one pedicellate, along the jointed rays of a large panicle. Two outer glumes largest, keeled, thin but rather stiff; third glume hyaline, without palea. Flowering glume and palea very small, thin and transparent.

A small genus of tropical Asia and Africa. 
1. S. officinarum, L. - Stems erect, stout and solid, 6-12 ft. high. Leaves $1^{\prime}$ broad or more, very rough at the edges. Panicle compound spreading, $1-3 \mathrm{ft}$. long, of a gray silvery color from the long hairs surrounding the spikelets. Spikelets much shorter than the hairs, all sessile or one of each pair shortly pediceilate; the outer glumes pointed, about 2 " long.

The Sugar-Cane was found at the discovery of the Islands in possession of the natives, with whom it goes by the same name as with all Polynesian tribes of the Maoli race "Ko", "Tos in Tahiti and adjoining groups, "Netto" in Aneitum. The varieties now eultivated are in great part the original native ones, to which have been added the Chinese "Ko pake", probably identical with the W. Indian Creole, and the "Tahitian* cane; another white cane which is extensively raised on low lands - "Kenikeni or Lahaina cane - is of doubtful origin. Planters distinguish about a dozen native varieties, of which the "Uala", "Kokea", "Olianas, "Lahi" have a pale yellow or greenish rind, the "Honuaula", "Papaa "Palanis are purpie, and the "Ainakea", "Manuleles, "Akilolo", -Laukono" and others belong to the variegated or ribbon canes. According to locality preference is given to one or another: the more tender, white and greenish eanes flourish best in low protected grounds, while the hardier variegated and purple varieties are more adapted to higher and exposed uplands. Intermediate between the two latter kinds stands the "Puaole or flowerless cane, which for its vigorous growth, richness of juice and adaptation to various heights used to be and probably continues in much favor, particularly as it tassels late and therefore allows a great latitude of season for cutting. The upper limit of profitable cultivation is about $2800 \mathrm{ft}$. on the leeward and $1800 \mathrm{ft}$. on the windward sides. In the lowlands the plant requires $12-15$ months to arrive at maturity, in the higher regions $18-24$ months.

\section{SubTribe III. MAYDEAE.}

Spikelets unisexual, the staminate ones in terminal panicles or spikes, or solitary, rarely surrounding the pistillate ones; the latter in axillary spikes or solitary.

Here belongs also Coix Zacryma or "Job's tears", remarkable for the hard bony involucre of the seed.

\section{ZEA, L.}

Monoecious. Male spikelets in pairs, in a terminal panicle, 2 -flowered. Glumes 4 , the 2 outer empty ones largest, subequal, membranous, acute, concave, awnless; third and fourth glume hyaline, each with a palea and 3 stamens. Female spikelets sessile in many rows over an axillary, thick cylindrical, corky rhachis or spadix, which is enveloped by several large bract-like sheaths. Glumes fleshy-membranous, concave, the outer ones broad, ciliate, the lowest emarginate or bifid; the third and fourth each with a palea, but the former sterile. Style simple, very long, shortly bifid. Grain subglobose, hard, surrounded by the dried glumes and paleae.

A single species of American origin.

$\dagger$ 1. Z. Mays, L. - Stem erect, hairy, 3-4 ft. high. Leaves broad lanceolate, drooping. Ligule short. Bract-like sheaths numerous. Male spikelets pedicellate.

Probably introduced by Vancouver or shortly after his visit. 
SUbTribe IV. ORYZEAE.

Spikelets hermaphrodite, rarely unisexual, in panicles or rarely in simple spikes; the rhachis of the inflorescence not articulate. Empty glumes 2, membranous, the lower often very small or wanting. Flowering glume chartaceous or coriaceous. Palea $1-3$-nerved. Stamens mostly 6.

\section{ORYZA, L.}

Spikelets 1 -flowered, flat, articulate, on short pedicels along the flexuose branches of a terminal panicle. Glumes 3, the 2 outer empty ones small lanceolate, the flowering one complicate and keeled. Palea 3-nerved. Stamens 6. Styles short, distinct. Grain enclosed in the hardened glume and palea, but free from them.

A genus of very few species, from the warmer regions of the old and New World.

† 1. 0. sativa, L. - Kunth, Enum. Pl. I, \%. - Stems creeping or floating at the base, ascending to several feet. Leaves long and very scabrous; the ligule scarious. Panicle narrow, erect, $6-12^{\prime}$ long. Spikelets ovateoblong, $3-4^{\prime \prime}$. Empty glumes scarcely ${ }^{1 / 2}{ }^{\prime \prime}$, and awnless. Flowering glume prominently 5 -nerved, with ciliate keel, mostly awned, closely embracing the equally long and 3 -nerved palea.

The cultivation of the Rice plant dates from the year 1856; it is chiefly carried on on the north side of $\mathrm{Oahu}$ and on Kauai.

\section{Subtribe V. TRISTEGINEAE.}

Spikelets nearly as in Paniceae, but the flowering glume with a twisted terminal awn.

\section{GARNOTIA, Brongn.}

Spikelets articulate with the pedicels, in pairs on the branches of a terminal panicle, 1 -flowered. Glumes 3, the 2 outer empty, awned or simply pointed. Flowering glume chartaceous, usually with a terminal awn twisted at the base and bent back at the middle, but sometimes straight or reduced to a minute point. Palea awnless, usually with 2 auricles at the base. Grain enclosed in the slightly stiffened glume and palea.

A small genus which extends over India, S. China, Japan, and parts of Polynesia - Tahiti.

1. G. Sandwicensis, sp. n. - Tufted. Stems simple, 1-2 ft. long, generally decumbent in their lower halves and curved, with geniculate pubescent nodes. Leaves mostly secund, turned toward the convex side when the stem is curved, the uppermost one near the panicle, pale glaucous, chartaceous, linear, $4-7^{\prime} \times 2-3^{\prime \prime}$, flat or convolute, rough near the apex, glabrous, excepting a ring of short hairs round the base; the sheaths sometimes pubescent and longer than their internodes. Ligule ciliate. Panicle narrow wand-like, 6--10' long, its rays distant, appressed, angular and scabrous, one to three at the lowest nodes, $2^{\prime}$ long or less,

Hillebrand, Flora of the Hawaiian Islands. 
all branching from the base. Spikelets twin, one subsessile, the other on a pedicel of its own length or less, surrounded by short hairs at the base, $1^{1 / 2}-2^{\prime \prime}$ long, slender acute, compressed from the back. Glumes all awned and equal, the two outer narrow lanceolate-acute, subchartaceous, 3 -nerved, serrulate along the nerves; the lower entire, with a straight awn of once or twice its length, the second bidentate, with a shorter geniculate awn. Flowering glume chartaceous, whitish, convex, ovate, with a median and 2 faint marginal nerves, the entire apex ending in a long awn of $3-6^{\prime \prime}$, twisted and bent before evolution but straight at last. Palea as long as its glume, lanceolate. Lodicules as long as the ovary, broad cuneate-emarginate, fimbriate at the angles. Anthers linear, emarginate at both ends, on short filaments. Ovary ovoid peaked. Styles approximate, elongate with short plumose stigmas. - G. patula, Munro, in Seem. Journ. Bot. 1869 , p. 178.

$\beta$. - Outer glumes with shorter awns, that of the second reduced to a mucro. Leaves subdistichous.

Molokait on grassy slopes of the northern shore (Waikolu), the var. $\beta$ from Hawaii! This latter form approaches G. patula, Munro, from S. China and Pegu, bnt differs in the awn of the lowest glume being longer than that of the second, and in the bidentate apex of the latter. The configuration of the lodicules is variable; in one instance they were seen obovate and irregularly fringed in the upper half, in another they seemed to consist entirely of two bundles of fringes.

\section{ARUNDINELLA, Raddi.}

Spikelets articulate with the pedicels, in pairs on the branches of a terminal panicle, 1 -flowered or with a second male flower below the fertile one. Glumes 4, acute, the second longest, the third similar but often with a palea and 3 stamens, the fourth hermaphrodite, smaller, thin, with a terminal awn which is twisted at the base and bent back at or below the middle. Palea smaller, awnless. Grain enclosed in the slightly stiffened glume and palea.

A tropical and subtropical genus, chiefly Asiatic, with a few African and S. American species.

1. A, agrostioides, Trin. Icon. tab. 265. - Steud. Synops. Pl. Glum. I, 116. - «Tufted, the stems about $1 \mathrm{ft}$, high, geniculate below, simple. Leaves spreading, linear, about 1 " broad, plane, but folded at the base, the lowest $6-7$ ' long, rough at the margins, glabrous as are the sheaths. Ligule very short, eiliate. Panicle pale, glabrous, $3-6^{\prime}$ long, with ascending rays, $3-5$ to a node, and branching from the base. Spikelets $1^{\prime \prime}$, ovatelanceolate, terete. Two lowest glumes herbaceous, sparsely ciliate at the back, ending in Iong subulate points, the first ${ }^{1 / 3} / 3$ shorter than the second and 3 -nerved, the second 5 -nerved; third glume also herbaceous, a little longer than the first, oblong, truncate, 3 -nerved, with a palea $1 / 3$ shorter. 
Fourth or flowering glume on a short-haired callus, shorter and narrower than the third, pale, chartaceous, scabrous, indistinctly 5-nerved, ending in a long awn of more than 3 times its length which is bent back at the middle, twisted and brownish below the bend, straight and pale above; its palea of the same length and enveloped by it, obtuse, with 2 distant nervess. »

"Oah u and Luzon." Probably collected by Chamisso, who visited the Philipines after leaving the Hawaiian Islands. As the species has not been met with by any other collector the authenticity of the Hawaiian habitat is not free from suspicion.

\section{TRIBE II. POACEAE.}

Spikelets with one or more perfect flowers, the male or rudimentary floret, if any, above the perfect ones, or the axis ending in a minute point. Pedicels continuous with the spikelets, the axis of the spikelet articulate above the empty glumes.

\section{SUBTRIBE VI. AGROSTIDEAE.}

Spikelets 1-flowered, usually pedicellate and small. Sterile glumes 2. Flowering glume thin, awnless, or with a simple awn. Grain free.

\section{AGROSTIS, L.}

Spikelets in panicles, 1 -flowered, the floret naked at the base or shortly pilose, without prolongation of the axis. Two empty glumes subequal, or the lower longer, generally much exceeding the floret, keeled, awnless. Flowering glume raised on a short callus, generally awned at the back, its palea bicarinate, sometimes minute or wanting. Stamens 1-3. Ovary glabrous. Styles short, their plumose stigmas protruding near the base of the floret. Grain oblong, slightly furrowed.

A large genus, spread over the temperate and cold regions of the whole world and the mountains of the tropies.

Flowering glume awned :

Awn short and straight; outer glumes puberulous

Awn longer and bent back; outer glumes glabrous Flowering glume awnless

1. A. Sandwicensis.

2. A, fallax.

3. A. Kauaiensis.

1. A. Sandwicensis, sp. $n$. - Tufted. Stems stiff and straight, $2 \mathrm{ft}$. high, undivided, terete, glabrous. Leaves erect, linear, glabrous, rough on both faces and margins, crowded below and plane, distant above, less than $2^{\prime \prime}$ broad and $6-2^{\prime}$ long, the uppermost at some distance from the panicle and its blade much shorter than the loose sheath. Ligule ovatelanceolate. Panicle very narrow, almost linear, $6-8^{\prime}$ long, the rays in distant fascicles, very unequal, closely appressed, dividing from near the base into short branchlets, the lowest $1^{1 / 2}-1^{3} / 4^{\prime}$ long; both rays and rhachis very scabrous. Spikelets on short pedicels, linear-lanceolate, $2^{1} / 2^{\prime \prime}$, compressed, pale, the sessile floret scarcely ${ }^{1 / 2}$ the length of the glumes, naked, or surrounded at the base by a few minute hairlets. Outer glumes herbaceous, linear-lanceolate, acute, 1 -nerved, puberulous, serrulate at the sharp 
keel, the lower one little longer than the upper. Flowering glume thin, glabrous, 4-nerved above, truncate or faintly denticulate, awned below the middle, the awn only $1 / 4$ longer than the glume and straight. Palea wanting. Ovary obovoid, the short styles rising from the angles and plumose from the base. Lodicules ovate-acuminate.

E. Mauit Oahu! The flowering glume exhibits under the microscope annular dots, an indication probably of a pubescent floret in some forms, which character would bring our species near A. Chamissonis, Trin., from Easter Island, A. elatior, Steud., from N. Zealand, and other species of the Southern Pacific.

2. A. fallax, sp. $n$. - Tufted, about $1 \mathrm{ft}$. high, the stems simple, erect, terete, glabrous, the uppermost leaf at the base of the panicle. Leaves linear, glabrous, rough at the margins, $3^{1} / 2-2^{\prime}$ long, the lowest convolute, the upper ones plane and considerably longer than their loose sheaths. Ligule ovate-lanceolate. Panicle narrow, $3^{\prime}$ or more long, the rays ternate in the lowest nodes, about 1' long, appressed, branching from above the middle. Spikelets on scabrous pedicels of their own length or longer, purplish, compressed, 2 "long, the floret naked at the base. Outer glumes herbaceous, glabrous, ovate-lanceolate, acute, 1-nerved, with the keel scaberulous above, the lower glume longer than the upper. Flowering glume nearly $1 / 3$ shorter than the latter, thin, concave, obtuse, entire, 4-nerved, awned from the base of the back, the awn twice as long as the glume and geniculate. Palea minute, shorter than the ovary. Lodicules 2, slightly emarginate. Ovary and styles as before.

Plateau of Mt. Eeka, Maui! In appearance much like Deyeuxia Hillebrandi from the same locality.

3. A. Kauaiensis, sp. n. - Stem weak, compressed, geniculate below, $1^{1 / 2}-2 \mathrm{ft}$. long, naked above, its uppermost internode very long $\left(8-9^{4}\right)$ Leaves rather firm, plane, glabrous, roughish on the margins, the blade of the uppermost $7-8^{\prime}$ long and $3^{\prime \prime}$ broad, its sheath $4-5^{\prime}$ long; ligule ovate-lanceolate, $2^{\prime \prime}$. Panicle $4-5^{\prime}$ long, oblong and contracted to pyramidal and quite open, with rhachis and rays smooth in their lower portions, the rays of the lower nodes very unequal in fascicles or whorls of $3-5$, horizontally patent at last, the longest measuring $2^{\prime}$ and dividing from near the middle, the shorter ones from the base, into short patent branchlets; the pedicels shorter than their spikelets and faintly scabrous. Spikelets ${ }^{3} / 4-1 "$, rather pale, glabrous, awnless. Empty glumes of equal length, broadest at the middle, rather obtuse, 1-nerved, faintly scabrous at the greenish keel. Floret half the length of the outer glumes, thin scarious, its glume obovate-truncate, 2-4-toothed at the apex, faintly $3-5$-nerved, the middle nerve not running into a tooth. Palea as long as its glume, truncate, bidentate, broadest and bulging at the middle. Anthers pale yellow. 
Kanai! Waimea (Kn., and M. \& B, no. 273). - Distinguished from A. stolonifera, L., which it most resembles, chiefly by the palea, which in length and breadth equals its glume, but also by the smaller size of the spikelet, the obtuse elliptical outer glumes and the more broadly truncate flowering glume, not to mention the elongate last internode and the great length of its leaf.

\section{SPOROBOLUS, R. Br.}

Spikelets in open or contracted, often spike-like panicles, 1-flowered, awnless, the axis not prolonged beyond the floret. Empty glumes 2, keeled, unequal, the lower shorter and the upper nerer longer than the sessile floret, 1-nerved or nerveless. Flowering glume of the same texture, 1 -nerved; its palea nearly as long, 2-nerved but both nerves closely approximate. Stigmas subsessile, protruding near the base of the floret. Grain short, free, separating from the thin pericarp.

A considerable genus of the tropical and subtropical regions of both Worlds.

1. S. Virginicus, Kunth, Rev. Gram. I, 6\%, - Enum. Pl. I, 210. - Stems procumbent, freely branching, terete, stiff, the branches ascending, $10-15^{\prime}$ long, foliose to the top with 5-20 subopposite pairs of leaves. Leaves pale, distichous, divaricate, stiff, convolute, with a filiform point, $5-2^{\prime}$ long, sparingly ciliate at the mouth of the sheath, otherwise glabrous and smooth, the sheaths exceeding their internodes. Ligule short, truncate. Panicle spike-like, $3-3^{1 / 2}$ long, narrowing at both ends, the closely appressed rays generally single and branching from the base upward, smooth. Spikelets on pedicels of their own length, $1^{1 / 2}$ ", slender ovoid, somewhat acute, glabrous. Outer glumes thin, rather obtusely ovate, 1 -nerved, keeled in the upper third, the lower nearly $1 / 3$ shorter than the upper which about equals the floret. Flowering glume rather acutely ovate, 1-nerved, the palea similar, folded, not bicarinate, its 2 nerves closely contiguous. Ovary short, pointed with short contiguous styles. Agrostis Virginica, L. - Vilfa Virginica, Beauv. - Trin, Icon. tab. 48.

Along the seashore in Kaneohe and Kailua, Oa hu! Kalepolepo and Lahaina, Ma u : A native of tropical and subtropical America, found also in S. Africa and Australia.

3. var. phleoides. - Spike-like panicle shorter and thicker, only $1^{1 / 2}$ long, and compact. Spikelets shorter, $1^{\prime \prime}$; compressed. Nerves of the palea not quite contiguous.

$\mathrm{Oah}$ u 1 Kaneohe.

\section{POLYPOGON, Desf.}

Spikelets in a dense spike-like or slightly spreading panicle, 1-flowered without prolongation of the axis, the floret naked at the base. Empty glumes 2, nearly equal, narrow, keeled, ending in a straight awn. Flowering glume shorter, thin-membranous, generally truncate-denticulate and awned below the apex. Palea bicarinate. Ovary glabrons. Stigmas subterminal, short, almost sessile. Grain oblong or linear, free.

A small genus, widely distributed over the globe. 
1. P. littoralis, Sm.-- Kunth, Enum. Pl. I, 233, - Tufted, the simple stems $9-15^{\prime}$, deeumbent below, with $6-10$ geniculate nodes, glabrous, terete, the uppermost leaf a short distance below the panicle. Leaves plane, 2-4' long, glabrous, roughish with antrorse teeth. Ligule ovatelanceolate. Panicle dense eylindrical or spike-like, 2-3'long, the lowest nodes with 4 or 5 rays, each $1 / 2-3 / 4^{4}$ long, appressed or somewhat patent,

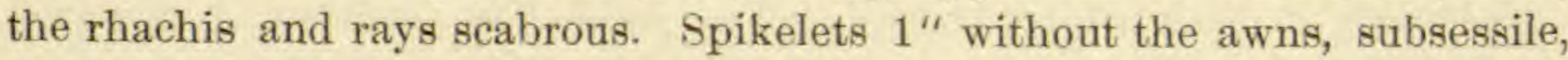
slender, pale. Empty glumes equal, puberulous, 1-nerved, the keels serrulate, with terminal awns of about their own length. Flowering glume half as long as the outer glumes, obovate, with rounded or truncate 4 -toothed apex, faintly nerved, its awn of the same length. Palea narrow lanceolate, hyaline. Lodicules falcate, fleshy. Stigmas sûbsessile below the apex of the ovary. - Agrostis littoralis, With.

Probably collected in Kapalama/ near Honolulu. - Oecurs near the seacoast in various parts of Europe, Asia and America.

\section{DEYEUXIA, Beauv.}

Character of Agrostis, but the flowering glume and palea surrounded by long hairs at the base and the axis prolonged in a plumose pedicelliform appendage at the back of the palea. - This genus is by many authors united with Calamagrostis, Adans., and placed in the Subtribe Arundinaceae.

Geographical range of Agrostis.

Spikelets small, less than $1^{1 / 2} 2^{\prime \prime}$; flowering glume pubescent . Spikelets larger, $2^{1 / 2 "}$; flowering glume glabrous:

Axial hairs shorter than the floret; awn from near the middle of the flowering glume

Axial hairs longer than the floret; awn from near the apex of the glume

1. D. Forsteri.

1. D. Forsteri, Kunth, Rev. Gram. I, 7\%. - Enum. Pl. I, 244. - Benth. Fl. Austral. VII, 5\%9. - Tufted, pale. Stems weak, decumbent below and geniculate, undivided, $1-1^{1 / 2} \mathrm{ft}$. long, terete, glabrous. Leaves flaccid, flat and narrow, $12-6^{\prime}$ long, $1^{1 / 2}-1 / 2^{\prime \prime}$ broad, glabrous, retrorsely scaberulous on blade and sheath. Ligule lanceolate, $3^{\prime \prime}$. Panicle partly ensheathed by the uppermost leaf, $6-12^{\prime}$ long, loose and spreading, its capillary rays in distant whorls, 4 or 5 in the lowest, these $5-8^{\prime}$ in length, dividing once or twice into whorls of $4-2$ branches, all floriferous only near their ends, scaberulous. Spikelets very pale, $1^{1 / 4}-1^{1 / 2^{\prime}}$, compressed. Empty glumes subequal, narrow-lanceolate, acute, 1-nerved, with scabrous keel, glabrous, nearly twice as long as the floret. Flowering glume clasping the palea, thin, obovate-obtuse, ciliate at the base and hairy all over, faintly 2-4-nerved, with a geniculate awn of twice or thrice its own length rising from the middle of the back. Palea as long as the glume. Axial prolongation short plumose. Anthers short ovoid. Styles very 
short, terminal, - Lachnagrostis Forsteri, Trin. - Avena filiformis, Forst. Prod. no. 46. - Agrostis filif. Spreng. - A. Forsteri, R. \& L. - Steud. Synops. Pl. Glum. I, 172. - A. aemula, R. Br. - A. retrofracta, Willd.

Molokai! Lanai! Maui! - Oecurs also on Easter Island, New Zealand, and in Australia.

2. D. Hillebrandi, Munro, in liter. - Tufted. Stems $12-15^{\prime}$, stiff, erect, terete, with 9-10 nodes, the lower leaves distichous and only the uppermost one near the panicle shorter than its sheath. Leaves coriaceous, convolute, erect, 7-3' long, $2^{\prime \prime}$ broad when expanded, glabrous, smooth throughout, with a subulate point. Ligule short ovoid or truncate. Panicle $4-5^{\prime}$ long, the rays suberect, quite smooth, $3-5$ in the lowest node, the longest $2^{1} / 2^{4}$. Spikelets on pedicels of their own length or more, $2^{1} / 2^{\prime \prime}$, glabrous, 1 -flowered, the sessile floret pubescent at the base, with a shorthaired axial prolongation. Outer glumes subequal, strongly 1-nerved, mucronate, with almost smooth keels. Flowering glume little shorter, 5-nerved at the base, navicular, keeled, acute, entire, at last splitting into 4 setiform teeth, the long and stout dorsal awn rising from its middle, $5-6^{\prime \prime}$ long and strongly declinate. Palea little shorter, sharply bifid, smooth. Stamens short, with oblong anthers. Stigmas terminal, subsessile, thinly plumose. Lodicules ovate.

Top of Mt. Eeka, Maui! - Near D. montana, Beuth., from Australia.

3. D. expansa, Munro, in Seem. Journ. Bot. 1869, p. 178 (name only). - Rays of panicle $3-4^{\prime}$ long, branching from the base, scabrous. Spikelets mostly sessile, $2-2^{1 / 2}$ "long, 1 -flowered, with a scarcely perceptible prolongation of the axis. Empty glumes subequal, lanceolate-acute, 1-nerved, carinate, the keel scabrous. Floret less than $2^{\prime \prime}$, surrounded at the base with many stiff hairs which exceed it in length, otherwise glabrous; its glume ovate, with an entire (?) apex, awned below the apex, the awn straight and about as long as the glume; the palea as long as its glume, narrow lanceolate, entire. Seed linear-oblong.

- North bank of the crater of Haleakala (U. S. E. Exp.). Very near D. elata, Munro (Calamagrostis scabrescens, Griseb.)., A few rays with old spikelets (only one with the floret) kindly furnished by Mr. S. Watson from the Gray herbarium at Cambridge, Mass, enable me to give the above partial description.

\section{Subtribe VII. AVENACEAE.}

Spikelets pedicellate, 2- or few flowered. Two empty glumes large, almost enclosing the florets; the flowering glumes often with a bent or twisted awn. Stigmas subsessile, protruding near the base of the floret.

\section{DESCHAMPSIA, Beauv.}

Spikelets in open panicles, continuous with their pedicels, 2 -flowered, the axis articulate, hairy, and prolonged beyond the second floret; both florets hermaphrodite and shorter than the outer glumes, the upper pe- 
dicellate. Glumes scarious, the 2 empty ones subequal, carinate, acute, the flowering glumes truncate, 4 -toothed, with a dorsal and mostly bent awn. Grain fusiform, not furrowed, enclosed in the glume and palea.

About 20 species, spread over the temperate regions of both hemispheres.

Leaves flaccid, plane or plaited, divaricate

Leaves stiff, convolute, erect:

Leaves 6 inches long or more

Leaves $1-2$ inches long.
1. D. pallens.

2. D, australis.

3. D. nubigena.

1. D. pallens, $s p \cdot n$. - Tufted, pale when dry. Stem $2-3 \mathrm{ft}$. long with $3-5$ geniculate nodes, the uppermost internode longer than all others together. Leaves narrow linear, $6-2^{\prime}$ long, flat or plaited, thin, glabrous, smooth, declinate and articulate with the back of a loose sheath, the lateral nerves of which pass directly into a thin lanceolate ligule, the uppermost blade much shorter than its sheath. Panicle loose, $6-10^{\prime}$ long, with $4-6$ nodes, the slender rays verticillate, $8-12$ in the lowest nodes, patent, undivided in the lower third, quite smooth. Spikelets on pedicels of their own length or longer, pale, shining, $2^{1 / 2-3}$ "long, 2 -flowered, the hairy axis produced beyond the second floret. Outer glumes glabrous, equal, scarcely exceeding the upper floret, lanceolate-acute, scabrous along the upper part of the keel, the lower 1-, the upper 1-3-nerved, with the lateral nerves approximate to the median and evanescent above. Flowering glumes thin, hyaline, rather convex, indistinctly 4-nerved, the truncate apex sharply and deeply 4 -cleft, their awns nearly basal, twisted below, bent at the middle and twice the length of the glume. Palea bifid, serrulate on both keels. Stigmas subapical, sessile.

Molokai! Lanai! Maui!

$\beta$ var. - Much smaller, densely tufted with many sterile shoots. Leaves narrow thread-like. Panjele narrow. Spikelets smaller, $2-2^{1 / 2} 2^{\prime}$. Upper floret projecting beyond the outer glumes.

\section{Maui! Makawao.}

Distinguished from D. caespitosa, Beauv., which it approaches closely, by the larger size of the spikelets, the deeper division of the flowering glumes, and by the long geniculate awn. In this latter eharacter and in the size of the spikelet it is almost like Aira flexuosa, with which the var. $\beta$ has also the thread-like leaves in common, but the deeply incised and truneate apex of the flowering glume separates it from this species. It occurs in the woods of the higher mountains and is certainly indigenous, being closely connected with the two following species. In a specimen of $\alpha$, collected by Mr. Lydgate, the axis of the spikelet is not prolonged beyond the second floret.

2. D. australis, Nees, in Steudel's Synops. Pl. Glum. I, 220 (not Aira australis, Raoul). - Tufted with many sterile shoots which attain more than half the height of the flowering stem. Stems $1-2 \mathrm{ft}$. high, stiff, erect, with $3-5$ nodes, the uppermost internode much the longest. Leaves articulate as before, but convolute, thick and stiff, glabrous, 9-6' long and $1^{\prime \prime}$ broad, smooth on back and edges but rough on the upper face, the upper blades much shorter than their compressed loose sheaths. Ligule lanceolate, 
$4-5^{\prime \prime}$. Panicle $6-12^{\prime}$, rather narrow, with $5-8$ rays on the lower nodes, the rays and pedicels scabrous. Spikelets as in no. 1, but the flowering glume shortly 4-toothed and its basal awn straight, scarcely longer than the same, not protruding beyond the outer glumes. Ovary obovoid, Stigmas subapical.

Mountains of Hawaii, Maui! and Molokai!

P. - Smaller. Panicles shorter, with only $3-5$ rays on the lower nodes. Awn of flowering glume twice the length of the same and often geniculate as in no. 1 .

Molokai! E. \& W. Maui! Spikelets purplish and shining, Haleakala.

From Mr. Lydgate I have a curious monstrosity, a panicle only without leaves. In it the lowest two nodes have the rays quite short, with spikelets clustered, as in Trisetum glomeratum; but the upper rays have mostly grown out into long and slender leafy branches with small panicles at their ends. In many spikelets, too, the axis is lengthened far beyond the upper floret, and bears at its end another abortive spikelet with or without a leaf-like glume below it. Of those spikelets which have not undergone any proliferation some exhibit the regular characters of Deschampsia australis, $\beta$, but in others I find the flowering glume longer and deeply bidentute, a long and straight awn proceeding from below the notch, as in Trisctum. The leaves in the upper branches are evidently metamorphosed glumes; some of them enclose a rudimentary scale with a long and fine awnlet. Possibly the monstrosity is owing to a cross between $D$. australis and $T$. glomeraium, but the smooth shining rhachis and spikelets and the stiff subulate glabrous leaflets are charaeters of the former species.

3. D. nubigena, sp. $n$. - Densely tufted, the stiff sterile shoots only one fourth the length of the stems. Stem 9-12', with only 3 distant leaves, the uppermost blade many times shorter than its sheath. Lowest leaves $1^{1} / 2^{\prime}$ long, stiff coriaceous, subulate, glabrous, smooth also on the upper face, the blade erect but articulate with the close sheath. Ligule $1^{1 /} / 2^{\prime \prime}$ long. Panicle $3-4^{\prime}$ long, with 2 or 3 suberect filiform smooth rays on the lowest node. Spikelets on pedicels of their own length, purplish, otherwise as in no. 1, the awn long and geniculate, but the glumes quite smooth at the keels, and the prolongation of the hairy axis not reaching to the top of the upper floret. Anthers purplish.

Top of Mt. Eeka, Ma ui! A grass of alpine character, perbaps only a variety of the preceding species, but very unlike in appearance.

\section{TRISETUM, Pers.}

Spikelets in contracted spike-like panicles, 2-4-flowered, the axis articulate, hairy and produced between the flowering glumes. Outer empty glumes 2, scarious, keeled, acute. Flowering glumes more hyaline, compressed, keeled, bearing a bent or flexuose awn below the sharply bifid apex. Palea bifid, bicarinate. Stamens 3. Ovary glabrous. Stigmas terminal, subsessile or on short styles. Grain not furrowed, enclosed in the glume and palea but free from them.

A considerable genus, spread over the temperate and cooler regions of both hemispheres. 
1. T. glomeratum, Trin. - Steudel, Synops. P7. Glum. I, 229.-A stiff grass, the erect stout stems $1-3 \mathrm{ft}$. high, pubescent, sparingly foliaceous. Leaves plane, with convolute apex, 10-6' long, 2-4" broad, erect, chartaceous, tomentose all over with retrorse silky hairlets, scabrous near the apex. Ligule ovate, entire. Panicle considerably exserted, spike-like, 6-7'long, repeatedly interrupted, the tomentose appressed rays in dense fascicles, 4 or 5 on the lower nodes and $1-1^{1 / 2^{\prime}}$ long. Spikelets in subsessile clusters of 4 or 5, stramineous, compressed, $3^{\prime \prime}$ long, 3-or 2-flowered, the ciliate axis prolonged beyond the last floret. Empty glumes subequal, as high as the upper floret, elliptico-lanceolate, acute, puberulous, serrulate or scabrous along keel and nerves, the lower one somewhat shorter and I-nerved, the upper 3-5-nerved. Flowering glumes glabrous, lanceolate, 5-3-nerved, sharply bidentate at the apex, emitting from the upper third of the scabrous keel a generally reclinate awn of less than their own length; the upper floret often awnless. Paleae shorter, bidentate, plaited along the middle, both keels serrulate. Lodicules sharply bifid. Anthers yellow, linear. Stigmas naked below. - Koeleria, Pers., in Benth. \& Hook. Gen. Pl. III, 1184. - K. vestita, Nees, in Steud. 1. c. p. 294.

Mountains of Hawaii! and Maui! between 3000 and $5000 \mathrm{ft}$.

$\beta$ var. - Taller and more slender, less tomentose, almost glabrate. Rays of panicle more distant and patent. Spikelets not glomerate but racemose along the raylets, $2-2^{1} / 2$ "long, generally 2 -, rarely 1 -flowered; the flowering glume sometimes with an entire apex and the awn often quite short, even wanting. Empty glumes puberulous, even ciliate. Koeleria glomerata, Kunth, Rev. Gram. II, tab, 219. - Enum. Pl, I, 526, and Suppl. Vol. I, p. 318.

At high elevations on $\mathrm{Oahu}$ ! - But for the transitions the latter form must pass for a genuine Koeleria.

\section{AVENA, L.}

Spikelets in a loose panicle, 2- or few-flowered, the rbachis articulate above the 2 outex glumes, hairy under the flowering glumes; the uppermost floret often male or abortive. Glumes scarious, the 2 outer empty ones lanceolate-acute, the flowering ones smaller, rounded at the back, shortly 2-cleft, with a long dorsal twisted awn. Styles distinct. Grain hairy at the top, grooved, adhering to the palea.

Temperate and cooler regions of the world.

†1. A. sativa, $L$. - Rays of panicle 8-4 in the lower whorls, drooping at last. Spikelets large, mostly 2 -flowered, the rhachis hairy only at the base of the lower floret. Empty glumes 7 -nerved. Flowering glumes glabrous, the lower one with a long geniculate awn.

The common Oats, not unfrequently found as an escape from cultivation. Crops used to be raised in various parts of $\mathrm{Oahu}, \mathrm{Maui}$ and $\mathrm{Haw}$ aii. 


\section{Subtribe VIII. CHLORIDEAE.}

Spikelets sessile on one side of spikes which are either solitary or digitate or scattered on a common rhachis, laterally compressed, 1- to several-flowered, with one or more of the upper florets imperfect, articulate above the persistent empty glumes.

\section{CYNODON, Pers.}

Spikelets 1 -flowered, awnless, singly sessile in 2 rows on one side of slender spikes which are digitate at the end of the stem. Outer empty glumes 2, subequal, keeled, thin. Flowering glume broader, keeled. Palea narrow, bicarinate, with a small bristle at its base. Styles distinct, terminal, with elongate stigmas. Grain free, not furrowed.

A genus of 4 species, the following one dispersed over the warmer regions of the whole world, the 3 remaining ones Australian.

†1. C. dactylon, Pers. - Kunth, Enum. Pl. I, 259. - Stems creeping and rooting, dividing freely, the ascending flowering branches $6-12^{4}$ long, weak, compressed, naked in the upper portion. Leaves linear, flat, 4-1 long, glabrous, the ligule consisting of long ciliae. Spikes $3-5$ at the end of the stem, each $1-1^{1 / 2^{\prime}}$ long, their rhachis narrower than the spikelets. Spikelets ovate, $1-1^{1} / 4^{\prime \prime}$. Empty glumes subequal, the lower one shorter, narrow lanceolate, 1-nerved, glabrous. Flowering glume longer and much broader, obtusely boat-shaped, rather chartaceous, with 1 median and 2 marginal nerves, the keel often eiliate with softish hairs.

- Panicum dactylon, L.

Introduced about the year 1835 (as I was informed by the late Dr. Judd) and called "Manienie, by the natives, like Stenotaphrum, on account of its creeping habit. It has now spread over all the islands and is considered the most valuable pasture-grass of the lower regions, in favorable situations forming dense mats which crowd out every other plant. Does not thrive well at higher elevations than $800 \mathrm{ft}$. above the sea. It is useful also in binding down the loose sand near the sea, for the roots penetrate to a depth of one and more feet.

\section{CHLORIS, Swartz.}

Spikelets with 1 fertile floret and 1 or more empty or rudimentary glumes above it, singly sessile in 2 rows on one side of simple spikes either solitary or several digitate at the end of the stem. Glumes thin, keeled; the 2 outer empty ones pointed, or the second shortly awned; the flowering one 3-nerved, mostly ciliate on keel and margins, produced into a fine straight awn; the upper empty ones often awnless and usually with their ends on a level with that of the flowering one. Styles distinct. Grain free, elongate, trigonal, with a thin, often loose pericarp.

A large tropical genus, common to the old and New World.

1. C. radiata, Sw. - Kunth, Enum. Pl. I, 265. - Tufted. Stems erect, 1-2 $\mathrm{ft}$. high, compressed, glabrous, branching below, the uppermost leaf a short distance from the panicle. Leaves subopposite and distichous 
below, pale glaucous, plane, $5-8^{i}$ long, $2-3^{\prime \prime}$ broad, somewhat obtuse, mucronate, sparingly ciliate with long hairs on the upper face but glabrous with age, rough below and on the margins, jointed with the sharply keeled sheath. Ligule short ciliate. Spikes $12-25$ in a loose fascicle or contracted raceme, pale silvery, slender, $2-4^{\prime}$ long, with a filiform rhachis. Spikelets imbricate in 2 rows, shortly pedicellate, with a ring of hairlets at the base, linear, $1^{1 /} / 2^{\prime \prime}$ long, with 1 hermaphrodite floret and 1 minute awned glume on a long pedicel beyond. Outer glumes stiff, linear, pointed, 1-nerved, with scabrous keel, the lower $1 / 2$ the length of the floret, the second equalling it. Flowering glume thin chartaceous, lanceolate-obtuse, with 1 median and 2 marginal nerves, the margins (not the keel) ciliolate near the apex, the scabrous awn of more than twice the length of the glume rising from below the apex. Palea narrow, bidentate, setulose along the keels. Griseb. Fl. W. Ind. p. 539. - Agrostis radiata, L.

Tufa hills of Maunalua (Koko Head), Oahu! Kapapala, Hawaii! The species is a native of tropical America from Cuba to Brazil, and occurs also in S. Africa from the Cape to Natal.

\section{ELEUSINE, Gaertn.}

Spikelets several-flowered, flat, awnless, imbricate in 2 rows along one side of the digitate or scattered branches of a simple panicle. Glumes spreading, keeled and complicate, thin but rigid, the 2 outer empty ones usually shorter, unequal. Flowering glumes obtuse, the terminal one empty or rudimentary. Palea folded back lengthwise. Styles short, distinct. Grain transversely wrinkled, enclosed in a loose pericarp.

A small, widely spread tropical genus.

1. E. Indica, Gaertn. - Kunth, Enum. Pl. I, 272. - A coarse tufted grass, the stiff erect stems branching, $1^{1 / 2}-3 \mathrm{ft}$. high, compressed, naked above, glabrous. Leaves distichous below, glabrous, flat, $8-10^{\prime}$ long and $3-4^{\prime \prime}$ broad, divaricate, jointed with the sheaths, which are keeled and ciliate at the mouths. Ligule short truncate, ciliate. Spikes $5-7$, digitate, with usually a solitary one an inch or two lower down, each 3-4' long and rather stout, with a smooth triquetrous rhachis. Spikelets imbricate, ovate, obtuse, about 3 "long, 4-8-flowered. Glumes thick, all boat-shaped and somewhat obtuse, with scabrous keels; the lower empty one $1 / 3$ the length of the spikelet, 1 -nerved, the second $1 / 2$ the length of the spikelet and 3 -nerved, the greenish nerves closely approximate. Flowering glumes broad and apparently 1-nerved, the lateral nerves coalescing with the median. Paleae ${ }^{1 / 3}$ shorter than their glumes. Filaments long; anthers yellowish. Pericarp persistent.

Very common near eultivated grounds in the lower regions. Spread over most tropical countries, including the southern Pacific islands. 


\section{SUbTribe IX. HORDEINEAE.}

Spikelets 1- to several-flowered, with the terminal flower often tabescent, sessile in alternate notches or on opposite sides of the rhachis of a simple spike. Glumes entire, unawned or with a straight terminal awn; one or both empty ones often wanting. Stigmas sessile, projecting from the base of the floret.

\section{LOLIUM, L.}

Spikelets in a simple spike, distichous, placed edgewise to the continuous rhachis, many-flowered. Outer empty glumes subequal, the lower one (next to the rhachis) mostly wanting in the lateral spikelets. Flowering glumes concave, sometimes awned below the apex. Ovary glabrous. Grain adherent to the palea.

A small genus of the temperate regions of the northern hemisphere

†1. L. temulentum, L. - Kunth, Enum. Pl. I, 437. - An annual grass without sterile shoots, the stems erect, $2-3 \mathrm{ft}$. high, naked and rough above. Leaves glabrous, rough near the ends, the uppermost falling short of the spike, which is $6-8^{\prime}$ in length. Spikelets compressed, 5-9-flowered. Empty glumes equal, as long as the spikelet, $5-6^{\prime \prime}$, stiff lanceolate, manynerved. Flowering glumes coriaceous, 5-nerved, $3^{\prime \prime}$ long, with a subapical awn of the same length. Palea of the same length and breadth.

In abandoned wheatfields of Kula and Makawao, Maui! A native of Europe, and spread with the cereals over many parts of the world.

To this subtribe belongs also the Wheat, Triticum vulgare, Vill., which used to be cultivated on the highlands of E. Maui! and Hawaii, until the increase of the cereal in California made the home production unprofitable. The grain abounded in gluten to such an extent that it required the addition of foreign flower to make light bread.

\section{Subtribe X. FESTUCACEAE.}

Spikelets 2- to many-flowered, with often a terminal rudimentary floret. Sterile glumes usually shorter than the next flowering one. Flowering glumes awnless or tipped at the apex with a straight awn or bristle. Stigmas protruding from the sides of the flower. Stamens $1-3$.

\section{POA, L.}

Spikelets in panicles, compressed, several-flowered, awnless, the florets deciduous with the jointed axis. Outer glumes mostly shorter than their next florets, the lower smaller. Flowering glumes herbaceous, with a scarious margin, keeled, 5-, rarely 7 -nerved, the nerves commonly clothed, at least near the base, with soft hairs or crisp cobwebby wool. Stamens 3. Ovary glabrous. Styles 2. Lodicules 2, bifid or entire. Grain free.

A large genus, spread over the cold and temperate zones of the whole world, in the tropies receding to mountain regions.

A weak decumbent annual with a loose open panicle; flowering glumes obtuse.

Erect, with a straight panicle:

Panicle long and Ioose; outer glumes scabrous

Panicle short, compact; outer glumes smooth

1. P. annua.

2. P. longe-radiata.

3. P. Mannit. 
†1. P. annua, L. - Kunth, Enum. Pl. I, 349. - A decumbent annual, glabrous, the weak stems compressed, $8-12^{\prime}$ long. Leaves flat, linear, $4-2^{\prime}$ long. Ligule ovate, entire. Panicle exserted, spreading, $2-3$ ' long, generally one-sided, the lowest node with 1 or 2 at last reflexed glabrous rays. Spikelets on short pedicels, greenish, ovate, $2-2^{1} / 2^{\prime \prime}$ long, $3-5$-flowered. Outer glumes persistent, unequal, lanceolate, the shorter lower one 1 -, the upper 3 -nerved and about $1^{1 / 2} 2^{\prime \prime}$ in length. Flowering glumes obtuse, diaphanous above, 5-nerved, pubescent along the keel and nerves, as are also the bidentate paleae.

Along watereourses and in the upland pastures of all islands, particularly of E. Maui and Hawaii! - A common weed of Europe, but now spread over all continents and zones.

2. P. longe-radiata, $s p . n$. - Erect, perennial, the stems $2^{1 / 2}-3 \mathrm{ft}$. high and foliose to the top. Leaves linear, $12-6^{4} \times 3-1^{1} / 2^{\prime \prime}$, flat, chartaceous, pale, the uppermost one exceeding the panicle, glabrous, with roughish margins and keel, the sheaths longer than their internodes. Ligule none. Panicle 5-8' long, open, the suberect filiform rays dividing only in the upper third, each branch bearing from 5-1 spikelets on pedicels of their own length or longer; the lowest nodes with $3-5$ rays, the longest of which measure 5-6'. Rhachis and rays smooth; axils naked. Spikelets quite flat, oblong, acute, $4^{\prime \prime}$, pale green, distantly $4-7$-flowered, with a straight pubescent axis. Outer glumes linear-lanceolate, acute, denticulate near the apex, the lower one rather shorter, 1-nerved with 2 faint lateral nerves at the base only, the upper one 3 -nerved to the apex, about $2^{\prime \prime}$ long, both $1 / 3$ shorter than their next florets. Flowering glumes lanceolateacute, 5-nerved, the intermediate nerves weakest, the sharp keel and margins closely fimbriate, at least near the base, with short hairlets, as are also the keels of the bidentate paleae.

Ka uai! Waimea (Kn., and M. \& B. 368); Maui? guleh of Waihee.

3. P. Mannii, Munro, in Seem. Journ. Bot. 1869, p. 178 (name only). - An erect tufted grass, $1^{1 / 2}-2 \mathrm{ft}$. high, quite smooth and glabrous, the stems weak, compressed, leafy to near the end. Leaves very narrow, $1 / 2-1$ " broad, the sheaths shorter than their internodes. Ligule very short or wanting. Panicle slightly exserted, short and lean, $1-2^{\prime}$ long, with few nodes, each node with $1-3$ short rays which bear $1-4$ spikelets. Pedicels shorter than their spikelets. Spikelets flat, stramineous, oblong, $3^{\prime \prime}$ in length, about 6 -flowered with patent and distant glumes. Empty glumes keeled, narrow-lanceolate, acute, 1-nerved, or the second with 2 weak lateral nerves not beyond the middle, about ${ }^{1 / 3}$ shorter than their next florets. Flowering glumes ovate-lanceolate, acute, with 3 strong and 2 intermediate weaker nerves, the median nerve only running to the apex, all nerves cobwebby with erisp hair near the base. Paleae nearly as Jong as their glumes, bidentate, cobwebby along the keels. Stamens 3. - The 
description from a specimen in herb. Cornell University, kindly lent by Prof. Prentiss.

Kauai, Waimea (M. \& B. 274).

\section{ERAGROSTIS, Beauv.}

Spikelets in open or contracted, often spike-like panicles, compressed, awnless, 3- to many-flowered, their axis usually glabrous and articulate under the flowering glumes, but often tardily so and sometimes inarticulate. Outer empty glumes shorter than the lowest florets, rarely equalling them, generally 1 -nerved and deciduous, as are the mostly 3 -nerved keeled and naked flowering glumes. Paleae shorter than their glumes, bicarinate, often curved, back, persistent after the glumes and grains have fallen. Styles with elongate stigmas, naked below. Grain free, not furrowed. Ligule of leaves ciliar.

A large genus nearly related to $P o a$ and taking the latters place in the tropical and subtropical regions of the whole globe, a few species extending to the warmer parts of the temperate zones.

Spikelets elongate, compressed, the axis continuous:

Spikelets without furrows, the glumes rather overlapping each other at the base, gaping at last; perennials:

Flowering glumes acute:

Panicle open, continuous;

Plants tall, $1^{1 / 2}-4 \mathrm{ft}$. high :

Empty glumes shorter than the contiguous florets; rhachis of panicle smooth

Empty glumes with filiform points equailing or exceeding the contiguous florets; rhachis of panicle scabrous

Plants smaller, $1 \mathrm{ft}$, high or less:

Empty glumes shorter than the next floret

Empty glumes with filiform points equalling the next florets; paniele narrow wand-like; leaves filiform

Panicle contracted and interrupted; spikelets dark green, subsessile

1. E. grandis.

2. E. variabilis.

6. E. Mexicana.

7. E. monticola.

3. E. thyrsoidea.

Panicle spike-like and continuous, at least in its upper portion; spikelets sessile, pale:

Nerves of flowering glumes evanescent before the apex; spikelets 5-9-flowered; panicle fusiform, loose below, spike-like above

Nerves of flowering glumes uniting at the apex; spikelets 9-19-flowered; panicle dense spike-like .

Flowering glumes obtuse or truncate, with obtuse keel, their nerves evanescing before the apex; spikelets narrow in a large and open panicle

Spikelets broad and flat, with a longitudinal furrow on each face between the two rows of glumes; annuals:

Spikelets obtuse .

Spikelets acute

Spikelets long and narrow, almost terete, the glumes closely appressed; plant small, $6-12^{\prime}$ high .

\section{E. Hawaíiensis.}

5. E. phleoides.

\section{E. atropioides.}

9. E. poacoides.

9 b. E. unioloides.

Thert, about $1^{\prime \prime}$ long, the axis breaking up into artieles; annual 11. E. plumosa.

Nos. $1-8$ are truly indigenous, the first 7 form a continuous serjes of which it is not easy to circumseribe the different species by invariable characters. Great as the difference appears between two picked individuals of contiguous species, there appear in a provoking 
manner intermediate forms which refuse to fit into the painfully elaborated frame, and efface the imaginary frontierline. Such is ehiefly the case with nos. $2-5$, and although no one would think of uniting the extremes the difficulty in drawing the dividing line is great, and I have found no better means to overcome it than to establish two intermediate species mainly upon the form of the inflorescence, supported by such secondary characters as the material in my collection warrants, without feeling sure that new forms may not arise yet which will break down their specific value. No. 8 has characters so much at variance with the others that one would be tempted to refer it to a different genus were it not that its var, $\gamma$ eonneets it with no. 2. No. 6 . is of value in as much as it clears up the relationship of the whole series, although its real identity with an American species is not fully established.

1. E. grandis, $s p: n$. - A tall grass, $3-4 \mathrm{ft}$. high, the erect terete

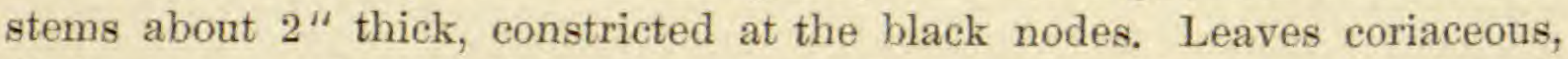
dark-green, paler on the upper face, flat, 15-20' long, 4-6" broad, gradually drawn out to a long scabrous point, bearded at the mouth of the close vagina, ofherwise glabrous. Panicle exserted at last, spreading, pyramidal-ablong, narrowing below, $12-15^{\prime} \times 4-5^{\prime}$, the slender rays erect-patent, dividing from near the base, mostly in irregular fascicles of $4-5$, the longest measuring $3^{1 / 2}-6$. Main rhachis smooth, bearded in the axils with long soft ciliae; rays roughish near their ends only. Spikelets subracemose on pedicels of much less than their own length, dark-green, lanceolate-oblong, flat, $2^{1} / 2-3^{1} / 2^{\prime \prime} l o n g, 10-13$-flowered, with glabrous axis. Outer glumes very acute from a broad base, 1-nerved, denticulate at the keels, slightly unequal, each ${ }^{1 /} / \mathrm{s}$ less in height than its next floret. Flowering glumes ovate-lanceolate, acute, 3-nerved, the nerves uniting at the apex, denticulate at the keels, as are also the bidentate or truncate paleae. Grain oblong, laterally compressed.

High mountains of Molokai! E. and W. Maui!

$\beta$ var. oligantha. A larger plant, with leaves $3 \mathrm{ft}$. long and $8^{\prime \prime}$ broad. Panicle often $20^{\prime}$ long, with nodding rays of $4-6^{\prime}$. Spikelets $1^{1 / 2}-2^{\prime \prime}$ long, 4-5-flowered.

Molokai! pali of Waikolu, and (doubtfully) top of Mt. Kaala, Oah u ! - The number of florets in the spikelet seems to be constant. Owing to the smallness of the spikelets the panicles appear more open than in the first form. (M. \& B. no. 279, 0.)

$\gamma$ var. polyantha. - Like $\alpha$, but the panicle much smaller, with $2-3$ rays on the lowest node, and the axils (in our single, rather old specimen) quite naked. Spikelets $3-9$ "long, $10-30$-flowered. Keels of outer glumes apparently smooth, but the teeth closely appressed. Lateral nerves of flowering glumes, evanescent above. Paleae subspathulate, obtuse. Leaves smooth throughout, the uppermost $2 \mathrm{ft}$. Iong.

Perhaps speeifically distinet. - Molokai!

2. E. variabilis, Gaud. Bot. Voy. Freyc. p. 408. - Tufted, the erect stems undivided, $1-3 \mathrm{ft}$. high, glabrous, with pale nodes, the uppermost leaves much surpassing the panicle. Leaves rather pale, suberect, chartaceous to coriaceous, convolute or those of the stem often plane, $1^{1 / 2}-2^{1 / 2} \mathrm{ft}$. 
long, $3-6^{\prime \prime}$ broad, drawn out into a long scabrous point, bearded at the mouth of the sheath, otherwise glabrous. Panicle open or slightly contracted, oblong, $6-10^{\prime} \times 1^{1} / 2-2^{1 / 2^{\prime}}$, the stiff patent or suberect rays in whorls of $5-2$, dividing from the base upward, $1^{1 / 2}-2^{1 / 2^{\prime}}$ long, very scabrous throughout, as is the sharply angular rhachis, with short teeth visible to the naked eye; axils ciliate. Spikelets on short pedicels of about $1 / 2^{\prime \prime}$, dark-green, oblong, about $1^{\prime \prime}$ broad and $2^{1 / 2}-5^{\prime \prime}$ in length, 14-18-flowered. Outer glumes sharply serrulate on the keel, the lower 1-nerved and rather longer than its mate, $2^{\prime \prime}$, drawn out into a filiform point and generally equalling or exceeding the lowest floret; the upper one often 3 -nerved. Flowering glumes ovate-lanceolate, acute, 3-nerved, all nerves uniting at the apex, the keel almost smooth. Paleae a little shorter, oblanceolate, entire, serrulate at the keels. - Hook. \& Arn. in Bot. Beech. p. 101. - Kunth, Enum. Pl. I, 338. - E. Wahowensis, Trin. in Act. Petropol. 1831, p. 412. - Steud. Synops. Pl. Glum. I, 279.

The prevailing form on the mountains of $\mathrm{Oahu}$ ! Distinguished from all other species by the extraordinary roughness of its rhachis and rays. The filiform points are apt to drop off the outer glumes, which then appear shorter than their next florets; in young spikelets they are seldom missing, - Nat. names: "Emoloas and "Kalamalo".

$\beta$ var. ciliata. - A smaller plant, about $1 \mathrm{ft}$. high or more. Leaves all convolute. Panicle narrow but continuous, ${ }^{1 / 2}-1^{\prime}$ wide, the seabrous rays $1-1^{1 / 2}$ long, all axils (even those of the secondary divisions) ciliate. Spikelets only 3-6-flowered. -- E. equitans, Trin. 1. e.

$\mathrm{Oahu}$ ! The leaves are equitant in the lower portion of the stem, where they are much crowded, just as in the form $\alpha$, but they are not strictly distichous, as is readily seen in the upper portion.

$\gamma$ var. - Panicle contracted and continuous, $7^{\prime}$ long, 8-9"' broad. Spikelets 12-14-flowered, Leaves flat.

Kauai (M. \& B. 251).

3. E. thyrsoidea, $s p . n$. - Stems about $3 \mathrm{ft}$. high. Leaves equalling the panicle or shorter, convolute, $2-3^{\prime \prime}$ broad when unrolled, gradually narrowing to a scabrous filiform point. Panicle $8-12^{\prime}$ long, contracted, ${ }^{1 / 2} / 1^{1} / 2^{4}$ wide, interrupted, the dense fascieles shorter than their internodes, appressed, $1 / 2-1^{1} / 2^{\prime}$ long; the rhachis smooth in the lower portion, the rays scabrous and ciliate in the secondary axils. Spikelets rather pale, oblong, compressed, 3 "long, 5-7-flowered. Glumes chartaceous, the empty ones narrow-acute, $1 / 4$ shorter than their next florets, scabrous on the keel, the lower 1-, the upper often 3-nerved. Flowering glumes ovateacute, the lower ones with roughish keels, their lateral nerves connivent, but evanescent below the apex. Paleae $1 / 4$ shorter, oblanceolate-obtuse, fimbriate, - Lower leaves often declinate.

Oahu! Maui!

Hillebrand, Flora of the Hawaiian Istands. 
4. E. Hawaiiensis, sp. $n$. - Stem stout, $2-3 \mathrm{ft}$. high, Leaves stiff coriaceous, pale, convolute, long acuminate, with scabrous points, otherwise glabrous, $16-20^{\prime}$ long, $6-8^{\prime \prime}$ broad below, shortly and sparingly ciliate at the mouth of the sheath. Ligule evanescent. Panicle scarcely exserted, narrow pyramidal or fusiform, drawn out into a long and dense whip-like point, $16^{\prime}$ long, $2^{\prime}$ wide at the middle, the lowest fascicles short and distant, those of the middle third 2' long and erecto-patent, the upper ones quickly shortening and close, appressed, forming a spike-like termination, the rays dividing into short appressed branchlets from the base upward, quite scabrous, sparingly ciliate near the base but not in the axils; rhachis smooth below. Spikelets pale, on short pedicels of $2-3^{\prime \prime}$, with 5-9 florets. Outer glumes scarious, $1 / 3$ shorter than their next florets, serrulate along the keels, both 1-nerved; the upper one ovate, caudato-acuminate; the lower quite narrow. Flowering glumes ovate, very acute, 3-nerved, the Jateral nerves evanescent, all serrulate on the upper part of the keel. Paleae subequal, shortly fimbriate.

Hawaii! Kohala.

5. E. phleoides, sp. n. - A stiff pale grass, the stout stems $1-2 \mathrm{ft}$. high, rising from a thick creeping woody rhizome. Leaves thick coriaceous, convolute, short pointed, smooth and shining, except a minute pubescence at the base, closely crowded and equitant to the middle of the stem and declinate, all shorter than the panicle, the uppermost one some distance below it, the lowest $12-15^{\prime}$ long and $4-6^{\prime \prime}$ broad at the base when unfolded. Ligule very short, ciliar. Panicle contracted, spikelike, $4-8^{\prime} \times{ }^{1} / 2-1^{\prime}$, the spike continuous throughout or interrupted toward the base; rhachis glabrous below, the rays scaberulous near their ends; axils naked. Spikelets sessile, straw-colored, ovate-oblong, planoconvex, 9-19-flowered. Glumes stiff chartaceous, the empty ones shorter than the lowest florets, broadly ovate-apiculate, rather smooth, both 1 -nerved. Flowering glumes conchoid, mucronate, denticulate near the apex, strongly 3 -nerved, with nerves uniting at the apex. Paleae subequal, serrulate at the keels.

On old lava fields of Mt. Haleakala, Ma ui! between 3000 and $5000 \mathrm{ft}$. above the sea.

6. E. Mexicana, Link. - Kunth, Enum. PI. I, 331. - A small tufted grass, the slender simple stems 8-16' long, suberect, distantly foliose with about 5 leaves, the uppermost leaf at the base of the panicle, the sterile tufts half as long as the stem or less. Leaves herbaceous but stiff, convolute, or those of the stem plane, $5-8^{\prime} \times 1-2^{\prime \prime}$, smooth, bearded at the mouth of the sheaths, which are shorter than their internodes. Panicle oblong, $4-6^{\prime} \times{ }^{1 / 2}-1^{\prime}$, open, mostly continuous, its filiform rays scattering, erecto-patent, few-(8-1-)spiked, $1-1 / 2^{\prime}$ long, the middle and upper ones dividing from the middle, the lower ones from near the base. 
Rhachis and rays roughish, faintly ciliate in the axils. Spikelets on pedicels of their own length or more, purplish-green, $2-2^{1 / 2}$ "long and ${ }^{3} / 4$ " broad, 3-7-flowered, ovate-lanceolate, flat, the zigzag axis deciduous above the empty glumes, which are thin, ovate-lanceolate, very acute, both 1-nerved or the upper with 2 faint lateral nerves, minutely denticulate and a little shorter than their next florets. Flowering glumes thin, broadly ovate-lanceolate, 3-nerved, with smooth keels. Paleae little shorter, serrulate, persistent. Anthers purplish. Styles approximate at the pointed apex of an elongate ovary. - Poa Mexicana, Lagasca. E. coerulescens, Hbd. in herb.

Lanai! on the highest ridge. Collected also by the U. S. E. Exped. - The species to which I refer our plant on the authority of Gen. Munro occurs in Mexico, Venezuela and Cuba. The short description, however, in Kunth's Enum. attributes to it a branching stem.

7. E. monticola, Hillebr. - Small, densely tufted, the slender and simple erect stems nearly twice as long as the numerous sterile tufts, $8-18^{\prime}$ high, bearing $3-4$ leaves in their lower parts only, the uppermost leaf falling much short of the panicle. Leaves filiform, thin, convolute, erect, $3-5^{\prime}$ long, glabrous, but bearded at the mouth of the close sheaths. Panicle linear, interrupted, $4-6^{\prime} \times 1-2^{\prime \prime}$, the closely appressed rays $1 / 4-1$ ' long, smooth, dividing from the base upward; only the lowest axillae sparingly ciliate. Spikelets on short pedicels, greenish, linearlanceolate, about $3^{\prime \prime}$ long and $1 / 2$ " or less broad, $6-10$-flowered, with a continuous zigzag axis. Glumes thin membranous, the empty ones nearly equal, as long as their next florets or longer, both 1-nerved, drawn out into a long filiform point and faintly denticulate; the flowering glumes ovate-acute, 1 - or faintly 3 -nerved with nerves uniting above, and smooth at the keels. Paleae as long as their glumes, olulanceolate, nearly smooth, persistent on the axis. Styles distant at the base. Anthers short oblong, emarginate at both ends. Grain dark red. - Poa monticola, Gaud. in Bot. Freyc. p. 408.

E. Maui! Lanai! Nat. name: "Kalamalo" according to Gaudichaud.

8. E. atropioides, $s p \cdot n$. - Stem $1^{1 / 2}-2 \mathrm{ft}$. high, rather weak, prostrate below and shortly stoloniferous, bearing $10-15$ leaves, the uppermost leaf much shorter than the panicle and at some distance from it. Leaves articulate with their sheaths, divaricate at right angles, chartaceous, plane or convolute, finely acuminate, the lowest about $8^{\prime}$ long and $1^{1 / 2}-2^{\prime \prime}$ broad, smooth throughout, bearded with silky hairs at the mouths of the sheaths. Ligule shortly ciliar, soon evanescent. Panicle open and interrupted, fusiform in outline, $10-15^{\prime}$ long and $1^{1 / 2}-3^{\prime}$ wide at the middle, the longest rays erect-patent, $3-5^{\prime}$ long, in fascicles of $3-5$, branching at the base with short appressed branchlets, subracemose toward the apex; rhachis smooth and the rays nearly so; axils ciliate. Spikelets on short pedicels, single or in clusters, linear-oblong, rather turgid, pale-green, 
about 4 " long and $1 / 2-3 / 4 "$ broad, 7-14-flowered. Glumes thin membranous, the empty ones as long as their next florets or the lower one a little shorter, both ovate-lanceolate, 1 -nerved, and nearly smooth at the keels. Flowering glumes broad ovate-obtuse or almost obovate, with hyaline margins and rounded or truncate, even denticulate apex, smooth at the rather obtuse keel, 3-nerved (or obsoletely 5-nerved), the nerves not connivent above but evanescent or running into the truncate apex. Paleae as long as their glumes, obtuse or truncate, nearly glabrous. Styles distant.

East Maui ? (label lost), probably growing in wet places.

$\beta$ var. - Panicle linear, wand-like, the rays closely appressed and quite smooth. Spikelets $3-7$-flowered, very slender, almost terete, acute. Glumes smooth, the empty ones exceeding the lower florets, the flowering ones obtuse but not rounded, the lateral nerves evanescent.

Hawaii or Maui!

$\gamma$ var. - Panicle as in $\alpha$, but its rhachis and rays scabrous and ciliate in their upper parts. Spikelets oblong, compressed, $1^{\prime \prime}$ broad, 10-14-flowered. Empty glumes quite scabrous and acute, equalling the contiguous florets, the lower narrow, the upper sometimes with a lateral nerve. Flowering glumes ovate-acute, with hyaline margins and apex, the weak lateral nerves evanescent before the apex, the keel scabrous. Leaves as above.

\section{Oahu!}

The two first forms with their narrow, rather turgid spikelets and the subconvex, indistinctly keeled, thin-margined flowering glumes, their nerves evanescent before the apex, are much like Glyceria or Atropis. They have however a continuous rhachis, and, though in old specimens this is generally devoid of paleae, the flowering glumes fall off before their paleae. The glumes are as a rule 3-nerved, and a ciliar ligule is foreign both to Glyceria and Atropis. Var. $\gamma$, which is an evident Eragrostis, cannot well be separated from the two first forms, and leads the transition to $E$. variabilis.

† 9. E. poaeoides, Beauv. - Steudel, Synops. Pl. Glum. I, 263. - Annual, tufted. Stems $6-12^{\prime}$, ascending from a geniculate base. Leaves shorter, flat and flaccid, acute, glabrous, but ciliate at the mouth of the sheath. Panicle open, 2-4' long, the branches patent, mostly single, only the lower ones with a few short branchlets near the base. Spikelets $2-4$ "long, $1^{1 / 2}$ " broad, oblong, rather obtuse, compressed, with a longitudinal furrow on each face, glabrous, $7-17$-flowered. Empty glumes narrow-acute, nearly as long as the flowering glumes; these ovate, rather obtusely mucronate, thin, with 3 prominent green nerves. Paleae shorter than their glumes, with very short ciliae along the keels. - Poa Eragrostis, L.

A plant, spread through the warmer zones of both hemispheres, which has made its appearance of late years together with the Indian and Chinese species $E$. unioloides, Nees (Poa unioloides, Retz). This latter is a similar but larger plant, 12-18' high, with a panicle of $4-6^{\prime}$ in length, and bears quite pale and acute spikelets, each with $14-20$ flowers.

†10. E. falcata, Gaud. in Bot. Voy. Freyc. p. 408, tab. 25. - A slender tufted glabrous grass, varying from a few inches to about $1 \mathrm{ft}$. in height. 
Leaves narrow, convolute, erect, scaberulous. Panicle 2-4' long, narrow, usually secund, slightly compound, its rays single and only the lowest dividing near the base. Spikelets sessile or nearly so, crowded or clustered along the short branches, very narrow, often curved, 4-12" long and about $1 / 2^{\prime \prime}$ broad, with $12-50$ or even more flowers, the rhachis scarcely

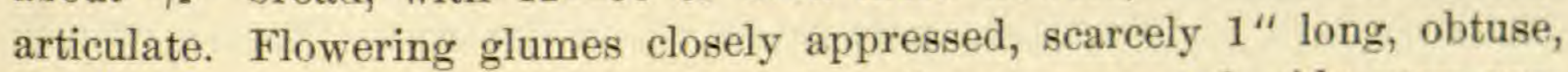
hyaline at the end, the keel and a lateral nerve on each side very prominent. Paleae rather shorter, curved, ciliate, persistent. Styles slender. Grain ovoid, flattened. - Benth. in Fl. Austral. VII, 649. - Poa falcata, Gaud. - E. nana, Munro.

Oahu (M. \& B. no. 44). - Probably a late arrival from Australia, where it is spread through all Colonies except Tasmania.

†11. E. plumosa, Link. - Steud. l. c. p. 266. - Annual, tufted. Stems slender decumbent at the base, ${ }^{1 / 2}-1 \mathrm{ft}$. long. Leaves flat, $1-1^{1 / 2}$ " broad, $3-4^{\prime}$ long, finely pointed, long-ciliate at and below the mouth of the sheath. Panicle long-exserted, ovate-oblong, open, $3-6^{\prime}$ long, the rhachis long-ciliate at the nodes, otherwise smooth, as are the filiform rays which divide into long branches from above the base. Spikelets on pedicels of more than their own length, greenish, short ovate, $1^{\prime \prime}$ or less, 4-6-flowered; the rhachis articulate (as in Poa). Glumes quite thin, the empty ones 1-nerved, acute, smooth, shorter than the contiguous florets; the fertile ones ovate-obtuse, with 2 marginal nerves besides the keel. Paleae fringed with long ciliae. Grain minute ovoid, reddish-olivaceous, shining. - Benth. Fl. Hongk. p. 431. - Poa plumosa, Retz.

The present species, a common grass in tropical Asia, is quoted by Trinius as a native also of the Hawaiian Islands. I only know it as of late aecidental introduction with living plants from China.

\section{FESTUCA, L.}

Spikelets in panicles or racemes, 3 - to many-flowered, the axis articulate. Outer empty glumes 2, unequal, mostly keeled. Flowering glumes chartaceous or nearly coriaceous, convex, not earinate unless near the apex, $3-5$-nerved, acute, mucronate or often ending in an awn. Paleae bicarinate. Lodicules emarginate or bifid. Stamens 3, or rarely 2 or 1 . Ovary mostly glabrous. Styles terminal, short, with feathery stigmas. Grain linear-oblong, adherent to the palea.

A large genus of the cold and temperate regions of the whole world.

Flowering glume with a long awn; a weak annual

Flowering glume not awned:

Flowering glume 3-nerved, ciliate along the nerves

Flowering glume 3 -nerved, the nerves not ciliate

2. F. myurus.

1. F. Sandwicensis.

3. F. drymeia.

1. F. Sandwicensis, Reichardt, in Ber. d. k. Akad. d. Wissensch. in Wien, LXXV, 726. - \&erennial. Stems straight, glabrous, about 
$3 \mathrm{ft}$. high, with brown nodes, the internodes $2-3^{\prime}$ long. Leaves very narrow, $1-1^{1 / 2} \mathrm{ft}$. long and $2-2^{1 / 2^{\prime \prime}}$ broad, plane, glabrous, bright green, rough along the nerves underneath. Ligule very short, $1 / 2^{\prime \prime}$. Panicle $6-8^{\prime}$ long, straight, open; $5-8$ filiform rays to a node which are $2-3^{\prime}$ long and divide near their ends; the rhachis and rays pubernlous. Spikelets lax, $4-5^{\prime \prime} \times 2-2^{1 /} /^{\prime \prime}$, pale-green, 5-9-flowered. Empty glumes lanceolate-acute, 3 -nerved, shorter than the contiguous florets, the first $1^{\prime \prime}$, the second $1^{1} / 2^{\prime \prime}$ long. Flowering glumes linear-lanceolate, $2^{\prime \prime}$ long, 3 -nerved, ciliate along the nerves, acute, not awned, hyaline at the apex. Paleae a little shorter. Lodicules 2-lobed. Anthers 3, linear, yellow, on short filaments. Styles short, with densely plumose stigmas. 》

Kauai, Halemanu (Wawra). - Reichardt places it next to $F$. insularis, Steud., from Chili, and to $F$. nervosa, Hook. This latter species, however, figures in the Botany of California, II, 313, as a synonym of Poa stenantha, Trin. - But for the 3-nerved flowering glumes, of which it is not stated whether they are convex or keeled, the description fits well to my Poa longe-radiata.

†2. F. myurus, L. - Kunth, Enum. Pl. I, 396. - A small tufted annual without sterile shoots, the slender stems $10-15^{\prime}$ long, geniculate and densely foliose at the base, the uppermost leaf at the base of the panicle. Leaves filiform, glabrous, $3-4^{\prime}$ long, the sheath with 2 auricles at the mouth; the ligule very short. Panicle linear, one-sided, erect or nodding, $3-5$ ' long, the angular and scabrous rays generally single or with a shorter second one, appressed, the lowest $1^{1 / 1} 2^{\prime}$ long, bearing $3-6$-spikelets on short and thick pedicels. Spikelets lanceolate, $3-4$ "long without the awns, compressed, distantly 4-5-flowered. Empty glumes thin, linearlanceolate, acute, the lower very small dentiform, the upper about $1^{1 / 4}$ "long, 1 -nerved. Flowering glumes terete, involving the palea, scabro-pubescent, about 2 "long, faintly 5 -nerved, gradually drawn out into a serrate awn of twice their own length. Paleae puberulous, linear-lanceolate, serrulate along the keels. Stamen 1. Stigmas subsessile at the angles of the truncate glabrous ovary. - $F$. bromoides, var. monandra, Parl.

E. Maui! Makawao, A native of southern Europe, also found in California.

†3. F. drzmeia, Mert. \& Koch, Flora Deutschlands, I, 6\%0. - A stout grass, the stems $2-4 \mathrm{ft}$. high, with the uppermost leaf at the base of
the panicle and exceeding it. Leaves flat, over $1 \mathrm{ft}$. long, $3-4^{\prime \prime}$ broad, scabrous. Ligule broad, rounded. Panicle pyramidal, open, about $1 \mathrm{ft}$. long, the patent scabrous rays in distant fascicles, $2-3$ only at the lowest nodes, $6-7$ ' long, dividing beyond the middle, the branches with few spikelets on long pedicels. Spikelets $6^{\prime \prime}$, elliptico-oblong, 5-6-flowered, with a scabrous rhachis. Empty glumes linear-lanceolate, acute, smooth, shorter than the next florets, the lower $2-2^{1 / 2}$ " and 1-nerved, the upper $3-31 / 2$ " and 3-nerved. Flowering glumes coriaceous, 4 "long, convex, acute, 
mucronate, 5-nerved, scabrous, dotted. Stamens 3. Ovary obovate, pubescent at the top. Stigmas almost sessile. - F. sylvatica, Host, not. Vill.

Without label; probably collected in Ulupalakua, Maui, where a number of foreign grasses have been introduced and become acelimated. The species is a native of southeastern Europe. My specimens, cut above ground, are destitute of the scaly stolons, and have longer and more scabrous spikelets than is usual in the species.

\section{BROMUS, L.}

Spikelets erect or drooping in panicles, 3-to many-flowered, the axis articulate between the flowering glumes. Outer empty glumes unequal, acute, keeled. Flowering glumes convex on the back, 5-9-nerved, awned or bristle-pointed from below the shortly bifid tip. Paleae bicarinate, pectinately ciliate. Lodicules entire. Stamens 3. Ovary obovate, hairy at the top. Stigmas nearly sessile below the apex, on the anterior face of the ovary. Grain linear, adhering to the palea.

A large genus of the temperate regions chiefly of the northern hemisphere. Lower empty glume 1-3-nerved; awn straight, longer than its glume $1 . \quad B$. tectorum. Lower empty glume 5 -nerved; awn bent back, equalling its glume $2 . \quad B$, squarrosus.

$\dagger$ 1. B. tectorum, L. - Kunth, Enum. Pl. I, 419. - Annual, the stems erect, foliose to the top, pubescent above, as is also the rhachis of the panicle. Leaves flat, $4-5^{\prime}$ long, pubescent. Ligule ovate. Panicle open, one-sided, about 6' long, the slender rays in fascicles of 2 to 5 at the lowest node, puberulous, $1-1^{1 / 2} 2^{\prime}$ long, bearing 1 or 2 drooping spikelets. Spikelets compressed, linear-lanceolate, cuneate at last, $1-1^{1 / 2^{\prime}}$ long without the awns, 5-7-flowered, the florets spreading at maturity. Empty glumes linear-lanceolate, very acute, with scarious margins, the lower 1-3-nerved, drawn out into a filiform point, the upper longer, about equalling its next floret, 5-nerved. Flowering glumes over 1'long, scabropubescent, lanceolate, acutely bifid, 7 -nerved, the 3 middle nerves continuing in a straight serrate awn $1^{1 / 2}$ times as long as the glume.

In abandoned wheatfields of Makawao and Kula, Maui! A common grass of Europe and northern Asia which has spread with wheat cultivation over many parts of the world.

†2. B. squarrosus, L. - Kunth, l. c. p. 414. - Var. villosus. Annual, the slender stems about $1 \mathrm{ft}$. high, glabrous. Leaves narrow linear, 4-5' long, softly pubescent, the hairlets retrorse on the sheaths. Panicle erect, drooping at maturity, $3-5^{\prime}$ long, simply racemose, the short scaberulous rays single at the nodes and each bearing a single spikelet. Spikelets pubescent, ovate-lanceolate, acute, $1-1^{1 / 4^{\prime}}$ long without the awns, sharply compressed, $7-10$-flowered, the florets closely imbri-

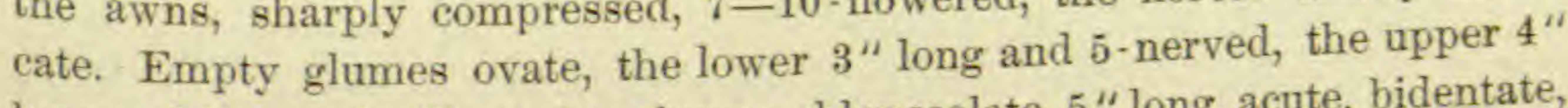
long and 7 -nerved. Flowering glumes oblanceolate, $5^{\prime \prime}$ long, acute, bidentate, 9 nerved, awned above the middle of the back; the slender awn about 
as long as its glume, rising from the median nerve only and soon bent back. Palea shorter than the glume, fimbriate.

Maui! Ulupalakua. Perhaps not truly naturalized yet. A native of the Mediterranean region. - Near the same locality I have also picked a few specimens of $B$. unioloides, Willd., an American species, with the lower empty glume 5-7-nerved, the awn subterminal very short; but as the grass was known to have appeared only a short time before it cannot be considered as naturalized.

\section{BRIZA, L.}

Spikelets mostly pendulous on the capillary branches of a diffuse panicle, many-flowered, ovate or cordate, flattish-tumid, the florets closely imbricate. Empty glumes subequal, rounded at the back; the flowering ones roundish, entire, flattened parallel with the empty glumes, ventricose on the back, stiff membranous, scarious-margined when dry, many-nerved. Paleae much smaller, ovate, flat. Lodicules ovate-lanceolate. Stamens 3. Ovary glabrous. Styles short, with plumose stigmas. Grain flattened, adherent to the palea.

A small genus, scattered over the temperate regions of both hemispheres.

$\dagger$ 1. B. minor, L. - Kunth. Enum. Pl. I, 372. - An erect annual, about $1 \mathrm{ft}$. high, the slender stems naked above. Leaves glabrous, thin, linear, $5-9^{\prime}$ long. Ligule long-lanceolate, scarious. Panicle open, about 5 ' long, the filiform scaberulous rays single or twin at the lower nodes, dividing from the middle. Spikelets on long pedicels, triangular, glabrous, about $2^{\prime \prime}$ high and as broad, 5-9-flowered. Empty glumes longer than the next florets, 3-nerved, boat-shaped, with rounded back.

In the woods and high pastures of $N$. Kona, Hawaii! A native of the Mediterranean countries, but now spread to the Cape, Brazil, Peru and Australia.

\section{ARUND0, L.}

Spikelets in large panicles, 2 -to several-flowered, with long silky hairs on the axis and flowering glumes. Glumes thin, keeled, distant, the 2 outer empty ones as long as the spikelet, the flowering ones bifid and shortly awned, the terminal one small, empty or rudimentary. Paleae small. Stamens 3. - Tall reeds.

A small genus, widely distributed over the warmer regions of the world.

†1. A. Donax, L. - Kunth. Enum. Pl. I, 246. - Stems 8-16 ft. high, woody below. Leaves stiff lanceolate, long-acuminate, $1-2 \mathrm{ft}$. long or more, scabrous at the margins. Ligule short hairy. Panicle oblong, 1-2 ft. long, dense, the rays scabrous. Spikelets purplish or yellow, $2-4$-flowered. Outer empty glumes about equal, lanceolate, 3-nerved, scabrous. Flowering glumes lanceolate, covered from the base to the middle with silky hairs, bifid, the middle nerve drawn out between the teeth into a short awn. Paleae a little shorter than their glumes. - Donax arundinaceus, Beauv.

Of late introduction. A native of the Mediterranean regions. 
Subtribe XI. BAMBUSEAE.

Spikelets 1-to many-flowered, with sometimes one or more rudimentary florets above the fertile ones. Outer empty glumes 2 or more, gradually increasing in size from the lowest one. Paleae generally large and bicarinate. Lodicules generally 3, rather large. Stamens 3, 6 or more. Styles 2 or 3 , mostly united at the base - Tall grasses, with woody stems and plane stipitate leaves.

\section{BAMBUSA, Schreb.}

Spikelets loosely clustered along the branches of a panicle, 1- to manyflowered, the uppermost floret often staminate only and the lowest sterile. Glumes stiff, awnless, sometimes mucronate, faintly many-nerved, the 3 or 4 lowest empty, the flowering ones longer. Paleae as long as their glumes, the 2 sharp keels prominent and ciliate. Lodicules 3 . Stamens 6 , free. Ovary hairy at the top. Style elongate, simple or with 2 or 3 stigmatic branches. Caryopsis oblong, free, the thin pericarp adherent. - Panicle very compound.

About 24 species of tropical Asia.

1. B. vulgaris, Schrad.\& Wendl. - Steudel, Synops. Pl. Glum. I, 329. Unarmed, 20-40 ft. high, the branches scaly below, striate. Leaves stipitate, oblong-lanceolate, $6-12^{i}$ long and $1 / 2-2^{i}$ broad, acute, rounded at the base, scabrous, ciliate at the mouth of the abruptly terminating sheath Spikelets $6-10^{\prime \prime}$ long, stramineous, 6-8-flowered, with 3 or 4 fertile florets, the upper ones tabescent; the glumes of the fertile florets ovatelanceolate, with subulate points, $15-19$-nerved, abruptly passing into the shorter sterile ones. Style long, pubescent, simple or 2-3 cleft. Anthers linear, purplish.

On all islands, but not frequent, both cultivated and apparently wild in low valleys (Kalihi, Oahu) or at the foot of palis. Nat. name: Ohe", as of Joinvillea and Isachne. The species, which is of Indian origin but has found its way into many other tropical countries of Asia, Africa and America, probably came from China in the early part of this century; at least such was the opinion of the late Capt. John Adams, whose residence in the country dated from the first decade and who during his long life-time took a lively interest in the introduction and domestication of useful plants and trees. While with the people of other countries the use of the bamboo has such a wide range in the building and fitting out of houses, in the manufacture of tools and articles of trade, the Hawailans use it almost solely in making fishing poles and outriggers of canoes.

\section{SCHIZOSTACHYUM, Nees.}

Spikelets loosely clustered along the rhachis and branches of a panicle, 1 -flowered, the axis scarcely articulate and continued beyond the floret in a bristle which often bears a reduced glume. Glumes 6-10, the lower ones empty and gradually increasing in size and becoming convolute, keel- and awn-less, many-nerved. Palea of the hermaphrodite flower wanting or similar to the glume. Lodicules 2 or 3, narrow. Stamens 6, free. Style elongate, 2-3-cleft. Caryopsis subglobose, enclosed in the persis- 
tent glume, free, the crustaceous pericarp loose round the seed. - Panicle little branching, rather simple. Spikelets slender.

About 8 species, belonging to the Malayan Archipelago, S. China and the Paciffe islands.

1. S. glaucifolium, Munro, in Transact. Linn. Soc. XXVI, 137. «Stems about $9 \mathrm{ft}$. high, emitting a few short branches at the nodes, the upper internodes $2-4^{\prime \prime}$ long. Leaves firm, glaucous, ovate- to linear-lanceolate, $10-20^{\prime}$ long and $1^{1 / 2-2^{\prime}}$ broad, long-acuminate, the unevensided base contracting into a petiole of $2-3 "$, their sheaths minutely striate, glabrous, shortly ciliate at the mouth. Ligule short, lacerate. Flowering branches short, in fascicles on lateral swellings of the nodes, the spikelets in distant clusters, narrow-cylindrical, pale.» - Seem. Fl. Vit. p. 323. - Bambusa glaucifolia, Rupr. - Steudel, Synops. Pl. Glum. I, 331.

Said to have been collected on the Hawaiian Islands by Wilkes's Expedition (Munro, Seeman). It probably is the smaller, cultivated bamboo, which attains a height of 9-15 ft. and grows much less dense than $B$. vulgaris, but has never been seen in flower. The oldest plants grew in Mr. Bailey's garden in Wailuku, Ma ui, and were, I believe, brought from Tahiti. - The species, originally reported from Nukahiwa of the Marquesas Islands, grows also on the Society, Samoa and Viti groups.

Besides these two species three others have been introduced from China and India of late years. 


\section{Series II. CRYPTOGAMOUS OR ACO- TYLEDONOUS PLANTS.}

Plants bearing no real flowers, the reproduction carried on by means of minute granules called spores.

\section{ClaSS I. VASCULAR CRYPTOGAMS.}

Plants with distinct stem and leaves and mostly also roots, the cellular tissue supplied with closed fibro-vascular ducts, which after the first year do not increase in thickness. Spores in capsules or sporangia, which grow on unchanged or changed leaves, rarely in their axils, and develop prothallia, small and delicate primordial plants with minute female and male organs - archegonia and antheridia - , the latter with antherozoids which fertilize the ovulum of the archegonium, out of which now grows the spore-bearing plant called fern, clubmoss and so forth.

\section{ORDER XCVI. FILICES.}

Spores of one kind. Sporangia at the back or margin of the leaves or fronds, originating from epidermoidal cells. Leaves circinnate in the bud (rolled up spirally). Prothallium green, expanded, developing above ground, carrying both archegonia and raised antheridia.

\section{SUBORDER I. MARATTIEAE.}

Sporangia thick-walled, of several layers of cells, sessile, without an annulus, opening laterally by a vertical slit or by a pore at the apex, loosely collected into oblong naked sori or firmly joined together as loculaments in concrete masses, synangia. Leaves with stipular appendages at the base. The sporangia originate from a group of epidermoidal cells. Gen. 1.

SUBORDER II. FILICES GENUINAE, OR FERNS PROPER.

Sporangia (spore-cases or capsules) of a single layer of cells, opening by means of a more or less complete elastic ring or annulus, which con- 
sists of a series of cells with thickened and darker walls. Leaves without stipular appendages. The sporangia originate from a single epidermoidal cell.

Sporangia pedicellate or sessile, scattered, or more generally collected into clusters or lines called sori, and these either naked or covered until maturity by an involucre or indusium. Fertile leaves similar to the sterile leaves or changed, smaller or contracted. Main stem usually perennial, either an erect or prostrate simple caudex, or reduced to a creeping rhizome. Leaves spiral on the erect, distichous on the creeping stem; the stalk - called a stipes - and often the rhachis carrying scales or hairs, which are most numerous at the base of the stipes and the end of the stem.

Tribe 1. SCHIZAEEAE. - Sporangia ovoid, crowned at the apex by a complete operculiform ring, opening vertically, sessile, not collected into sori. Gen. 2.

Tribe 2. GLEICHENIEAE. - Sporangia with a complete transverse ring, opening vertically, sessile. Sori of few sporangia on the back of the frond, naked. Frond rigid, dichotomous, generally with a bud between the fork branches. Gen. 3.

Tribe 3. CYATHEAE. - Sporangia with a complete ob 1que ring, opening transversely. Caudex erect, generally arborescent. Gen. 4.

TrIBE 4. POLYPODIEAE. Sporangia with an incomplete vertical ring, opening transversely, pedicellate. Gen. 5-22.

TRIBE 5. HYMENOPHYLLEAE. Sporangia orbicular, depressed, with a complete transverse or oblique ring, opening vertically, sessile on the free exserted prolongation of a vein (columella), forming a marginal sorus which is included within a tubular, urceolate or bilabiate involucre, the involucre supported by two lateral branchlets of the columella. - Delicate ferns, often moss-like, the frond generally consisting of a single layer of cells without stomata. Gen. 23-24.

The distribution of the veins or nerves in the frond is manifold, but always uniform in a species and often in a genus. According as they run free from each other in their course or unite, according to the presence or absence of a midrib, the angle at which they leave the latter, and the combinations of anastomosis when they unite, a number of divisions have been established by pteridologists which cannot be expounded here but will be referred to under the respective species.

The general character or habitus of a frond is in a great measure determined by the order in which the secondary nerves, segments or pinnules leave the primary segment or pinna of a frond. A pinna is called anadromous when the first nerve, segment or pinnule leaves it on the upper side, is turned to the apex of the frond and stands nearer to the rhachis than the first nerve, segmeut or pinnule of the under side; catadromus when the first nerve, segment or pinnule leaves it on the lower side, is turned toward the base; and homodromous when the first nerves, segments or pinnules of both sides stand opposite to each other.

In the anadromous pinna the succeding nerves, segments or pinnules maintain the same relative order as the first or basal ones, so that the fourth, fifth, \&c., of the upper side always stand nearer to the rhachis than the corresponding ones of the under side. In the cata- 
dromous pinna, however, this is often not the case, but at a certain point of its length the order becomes inverted by gradual approximation of the nerves or segments of the upper side. In homodromous pinnae this latter modification becomes the rule.

A frond is called polystichoid when all its divisions, primary, secondary pinnae or segments are anadromous; phegopteroid when the one or few lowest pinnae or primary segments are anadromous and all upper ones catadromous, but the secondary, \&c., pinnae, segments or nerves are again anadromous with regard to the pinnae or segments of the first order; and cyatheoid when the secondary pinnae, segments or nerves are catadromous as well as the primary ones, with exception of the one or few lowest primary ones and sometimes also of a few of the uppermost, which may be anadromous.

Polystichoid fronds have generally auriculate pinnae. Opposite pinnae occur only in phegopteroid and still more in cyatheoid fronds. In cyatheoid fronds the rhachides are often winged and emit in the wing the first veinlet from the fibro-vascular fascicle which is destined for the next upper segment.

When the upper pinnae of a phegopteroid frond are catadromous at their bases but become anadromous before the middle the frond is often ealled subphegopteroid.

Sporangia cemented together in oblong submarginal sori 1. Marattia. Sporangia free:

Sporangia arranged in spikes at the apex of a linear frond Sporangia investing the bare end of a vein beyond the margin of the frond:

Involucre bilabiate; receptacle enclosed

Involucre urceolate or tubular; the filiform receptacle exserted

2. Schizaea.

Sporangia covering the whole under face of the frond

Sporangia collected into globose or elongate sori :

Sori naked:

Sori globose:

Sporangia few, sessile; frond dichotomous, with a bud between the fork branches

Sporangia many, pedicellate; frond not dichotomous :

Stipes articulate with the rhizome . . .

Stipes continuous with the rhizome.

Sori linear:

Sori on veins diverging from the midrib

Sori in a marginal groove

24. Hymenophyllum.

23. Trichomanes.

5. Aerostichum.

Sori with an involucre or indusium:

Sori dorsal, on the back of the frond:

Sori globose:

Involucre peltate or cordate, inserted on the apex of the receptacle; stipes continuous with the rhizome

Involuere cordate; stipes articulate with the rhizome; frond leaves of indefinite growth .

Involuere hood-shaped, attached with a broad base under the sorus, laterally to the receptacle.

3. Gleichenia.

8. Polypodium.

9. Phegopteris.

6. Gymnogramme.

7. Vittaria.

10. Aspidium.

11. Nephrolepis.

12. Cystopteris.

Sori linear or oblong:

Sori oblique to the rib; the involuere opening upward and inward

Sori parallel to the rib; the involucre opening toward the rib:

Sori continuous, in a single line

Sori interrupted, in one or two lines

Sori submarginal or marginal; the involucre opening

outward :

Sori elongate

Sori globose:

Sori submarginal; involuere cup-shaped, adnate with the sides

Sori submarginal, free at the sides

15. Asplenium.

13. Sadleria.

14. Doodya.

16. Lindsaya.

18. Microlepia.

17. Odontoloma. 
Sori marginal; involucre apparently 2 -valved, horny Sori extramarginal on a bare nerve or tooth; the involucre renfform, very delicate

Sori marginal, with an involuere formed by the margin of the frond, opening inward:

Sorion an uninterrupted marginal nerve or receptacle; the involucre continuous

Sori on an interrupted marginal nerve or receptacle; the involucres interrupted

Sori aloug the extremities of the veins (not on an intramarginal anastomosis), at last confluent, covered by the narrow nerveless border of the frond

Sori along the extremities of the excurrent veins; the involuere formed by the soriferous lobe itself, the sori occupying the inner side of the involucre
4. Cibotium.

15. Asplenium deparioides.

(Deparia).

20. Schizostege.

\section{Pellaea.}

\section{Adiantum}

Of 134 species of Ferns and Ophioglosseae in the Hawailan flora 75, or nearly 56 per cent., are indigenous. Of the remainder 6 are found also in Polynesia only, 1 in the Philipines, 1 in Polynesia and Australia, 11 extend through Polynesia to Malaysia and tropical Asia, 7 to Madagasear, and 6 as far as the African Continent. Cosmopolitan, viz., scattered over both the New and Old World, are 16 . The remaining 11 are scattering waifs, 3 of American origin (Aspl. fragile and $A$. arboreum, Pellaea ternifol.), 3 others oceur in America and Africa (Aspl. monanthemum, Polyp. serrulatum and P. lanceolatum), 1 in America, Africa and Asia (Aspl. lunulatum), 1 each in Africa (Hymenoph. obtus.) and Asia ,(Aspl, normale), 1 (Aspl, varians) common to both these continents, and 1 (Aspl. adiant. nigr.) common to the entire Old World.

Although a statistical analysis of the Cryptogams of a flora cannot claim the importance which attaches to one of the higher classes of plants, yet two points come out in strong relief : first, the large proportion of indigenous species, and, second, the great number of ferns scattered over the long track which leads from the Hawailan Islands through Polynesia and Malaysia to the east coast of tropical Africa. This last number would still increase if the limits which I have deemed fit to adopt for a number of species were enlarged. But it cannot be inferred from this fact that all the species in question have travelled eastward to find the terminus of their long migration on this group, unless the principle be established that the formative energy of a species or genus (to use a metaphor) be greatest at the circumference or farthest extremity of its area.

\section{MARATtia, J. Sm.}

Synangia oblong, adnate to the veins or shortly stalked, each with two rows of loculaments which open on their inner faces by vertical slits. Large ferns, with a tuberous caudex and two fleshy auricles at the bases of the articulate leaf stalks; the frond large, twice or thrice pinnate.

About 8 species, which extend through the tropics of the whole world and a little beyond in the southern hemisphere.

1. M. Douglasii, Baker, in Synops. Fïl. p. 441 . - Stipes 3-5 ft. long, thick, smooth, naked, rising from between large fleshy auricles which cover the caudex on all sides. Frond dark-green, glossy, rather fleshy when fresh, naked, deltoid or ovate-oblong, $3-8 \mathrm{ft}$. in length, tripinnate, at least at the base. Pinnae oblong-lanceolate, the lowest $1 / 2--2 \mathrm{ft}$., on stalks of ${ }^{1 / 2}-2^{1} / 2^{\prime}$, the rhachis narrowly margined in its upper portion. Secondary pinnae linear, $3-6^{\prime}$ long, with broadly compressed and winged rhachis. Ultimate pinnules substipitate, ovate or oblong, ${ }^{1 / 2}-1^{\prime} \times 3-4^{\prime \prime}$, obtuse or acuminate, bluntly serrate, the base cuneate or subtruncate. 
Veins simple or forked. Synangia near the margin, sessile on an oblong receptacle, not surrounded by hairs, $1 / 2-3 / 4^{\prime \prime}$ long, one to each serrature, with 4-6 loculaments in each row. - Stibasia Douglasii, Presl. - De Vriese, Monogr. Mar. tab. 3, fig. 24. - Gymnotheca Douglasii, T. Moore. - M. alata, Hook. \& Arn. Bot. Beech. and Brack. Fil. U. S. E. E. Distinguished from $M$. alata only by its larger size and the want of scales on the under side.

Rather eommon in forests of medium elevation; the "Pala" of the natives. The thick fleshy auricles abound in starch and mucilage and furnish to the islanders not only a palatable food when baked in hot ashes, but also a useful remedy against bronchial and intestinal catarrhs. Slices of the same soaked in cold water soon part with their mucilage and form a pleasant diet drink. - Occurs also on the Viti Islands.

\section{SCHIZAEA, J. Sm.}

Sporangia sessile in two to four rows, covering one side of close distichous or digitate spike-like fertile segments at the apex of the frond, which is either linear or dichotomously divided. Spores tetraedro-globose.

A small but widely diffused genus.

1. S. robusta, Baker, in Synops. Fil. p. 429. - Caudex short, erect, scantily covered with stiff dark-brown hair. Stipes loosely tufted, dark chestnut, passing gradually into the frond, which is green, flat, linear, rigid and rush-like, $4-10^{\prime}$ long and less than $1 / 2$ " broad, with a broad midrib and two narrow thick edges; the fertile apical portion ${ }^{1} / 4-1 / 2^{4}$ in length, being formed of 4-10 pairs of closely set contracted spike-like pinnae or segments, which are suberect, stout, brownish, generally all turned to one side, the lowest $1-3$ " long. Sporangia in 2 rows, $6-10$ in each. - S. australis, Brack. Fil. U. S. E. E. p. 302. - Mann, Enum. no. 649.

Rare, at altitudes of more than $3000 \mathrm{ft}$. Oahu! Konahuanui, on trees; Maui! top of Eeka, in swamps; Ka uai, Waialeale (Wawra). Perhaps only a tropical form of S. australis, Gaud,, which is known from the Falkiand and Auckland Islands. Nat. name: “Oalii makaliis.

\section{GLEICHENIA, J. Sm.}

Sori subglobose, of $2-6$, rarely more sporangia, superficial or sunk, seated on the apex or back of a vein. Spores ovoid, with a single dorsal line. - A bud between the fork branches. Pinnae pinnatifid, with the segments small and concave suborbicular, or pectinate with elongate segments. Veins free.

Trailing ferns, tropical, or subtropical only in the southern hemisphere.-Our species belong to the subgenus Mertensia, which has superficial sori and elongate segments.

Frondose portion bipinnate

Frondose portion pinnatifia:

All or most branches of the frond leaf-bearing

Only the last pair of branches leaf-bearing, the lower branches with a single pinnule at the base

1. G. longissima.

2. G. Hawaiiensis.

All three species have far creeping and branching rhizomes and form densely matted iungles, especially the last. Nat. names: "Uluhis, "Unuhi', Enuhen. 
1. G. longissima, Blume, Fil. Javan. p.250. - Stipes (once or repeatedly?) forking, the last branches bearing a pair of bipinnate pinnae, the thick bud between them densely, and the plano-convex rhachides sparingly covered with stiff, black, ovate, pubescent scales 1 "long and cordate; the tender tips of the pinnae tomentose with a pale-brown cobwebby wool. Pinnae subcoriaceous, glaucous underneath, oblong, 2-4 ft., broadest about the middle. Pinnules $40-50$ on a side, linear, $6-9^{\prime} \times{ }^{1 / 2}-2^{4}$, subsessile or shortly stipitate, with an even-sided truncate base, acuminate, deeply pinnatifid, to the rhachis near the base. Segments linear, $1-1^{1} / 2^{4}$. broad, obtuse, the lowest pair longest and often reflexed over the rhachisi Veins distinct, almost vertical, simple, or forking near the base. Sor, dorsal on the anterior branch or at the fork, often one to each vein, each of 4 or 3 capsules. - Synops. Fil. p. 12. - G. glauca, Hook. Sp. Fil. I, 4. - Mertensia glauca, Brack. - M. pinnata, Kze. - G. excelsa, J. Sm.

ß. - Lowest segments again pectinate. - Mertensia glabra, Brack.

$\gamma$. Mr. Baldwin has sent a specimen in which the stipes, $10^{\prime} \mathrm{long}$ and broken at the end (without terminal bud), exhibits 3 pairs of opposite frondose branches or pinnae which are much shorter than in $\alpha$, only $15^{\prime}$ long, the longest pinnules $4^{\prime} \times \times^{1 / 2}$ '. The stipes has sharp edges, and a very shallow sulcus on the flat ventral side.

At elevations of $2000-4000 \mathrm{ft}$. here and there on all islands. The species is spread over Japan, China, the Malay peninsula and Islands and the Viti Archipelago (Graeffe). In the Synopsis Fil. the Himalayan G. gigantea, Wall, and the W. Indian G. Bancroftii, Hk., are also referred to it; on the other hand Carruthers, in the Flora Vit. p. 372, considers our fern to be distinet from the Chinese and Malayan plant, relying chiefly on the absence of scales and tomentum in the latter, and retains for it Kunze's specific name $G$. pinnata.

2. G. Hawaiiensis (Owhyhensis), Hook. Sp. Fil. I, 9. - Stipes rough, compressed, and margined with two lines of small scales, the frondose portion 3 or 4 times dichotomous at rather acute angles and in all divisions pectinately pinnatifid down to the rhachis. A bud in each fork, covered with small $\left(1^{1 / 2}-2^{\prime \prime}\right)$ falcate, acute, dark, ciliate scales. Last divisions of the frond linear-lanceolate, $6-12^{\prime}$ long, their segments linear, rather acute, subcoriaceous, dark-green, ${ }^{1} / 2-1^{1} / 2^{\prime}$, their under side, and more so the rhachis, chaffy with laciniate ferruginous scalelets. Veins vertical, with 2 or 3 branches. Sori on a raised punctiform receptacle, copious and close, with $3-6$ capsules in each, but often the capsules irregularly scattered. Annulus indistinct. Spores compressed. - Synops. Fil. p. 14. - Mertensia Hawaiiensis, Brack. - In two of my specimens the bud of the first dichotomy has developed into a naked rhachis of 6 and 12 inches, which bears at its end an intermediate forking frond.

At elevations of 3000-6000 ft., but rare: Hawaii! Mauna Kea; Ma ui! Eeka; M o1okai! Pelekunu; Oahu! Kaala and Konahuanui; Kauai! Halemanu. Peeuliar to the Hawaiian Islands, but near G. fagellaria, Spreng., which extends from southern Polynesia through Malaysia to Madagascar. 
3. G. dichotoma, Hook. l. c. p. 12. - Stip. slender, terete, not sulcate, often $10-15 \mathrm{ft}$. long, flexuose below, repeatedly forking in the upper portion at open angles, the ultimate pair of branches frondose, pinnatifid to near the base, and a smaller pair of similar lateral pinnules besides at the base of each bare fork. Buds small, covered with a brownish wool. Frondose branches or pinnae rigid, chartaceous, glaucous underneath, glabrous, elliptico-oblong, $6-9^{\prime} \times 2^{1 / 2}-4^{\prime}$, broadest about the middle; segments at right angles, linear, $1^{1 / 2}-3^{\prime \prime}$ broad, entire, obtuse or emarginate, the inner or upper ones shortening toward the base, the lowest one on the outer side deflexed and generally larger, crenate or pinnatifid. Lateral pinnules of varying sizes, the lower ones often equal to the frondose branches, the upper reduced, crenate, even subentire. Veins with 3-5 parallel branches (nerv. Neuropter.). Sori of $10-12$ capsules, seated on the middle of the anterior veinlet. - Synops. Fil. p. 15. - Polypodium dichotomum, Thunb. and Forster. - Mertensia dichotoma, Willd. Gaud. Brack. - G. Hermanni, R. Br. - Bot. Beech. p. 103. Whenever the lateral pinnules are large and deeply divided the lowest outer segments of the frondose pinna are so too, only in a less degree, suggesting the idea that the former are in reality only the lowest segments of an otherwise aborted frond or pinna.

Common on all islands from $600 \mathrm{ft}$. above the sea (Hilo district) to $3000 \mathrm{ft}$. It often covers extensive areas. - The species occurs in most tropical countries of both hemispheres and in many islands of the Pacific.

B. var. emarginata. - A stouter plant, the stipes muricate at the base and scantily villous. Frond thick eoriaceous, tomentose underneath with a fulvous wool of branching hairlets. Last branches $9-12^{\prime} \times 3-4^{\prime}$. Segments emarginate or bifid, the outer basal one pectinate or pinnatifid. Veins prominent above, exceptionally uniting to form a costal areole. All buds enclosed between two small but frondose, ovate, crenate leaflets. - Mertensia emarginata, Brack. Fil. U. S, E. E. p. 297, pl. 42.

The prineipal bud often continues the main axis and forks again at the next node. Oahu! Kaala; Hawaii! Hamakua. Most fronds fertile, while $\alpha$ is rarely found so. The two bracteal leaflets are present with all the buds in my specimens and just as invariably absent in all $m y$ specimens of $\alpha$ from the Hawaiian islands. However, they ean be made ont in the common form from the Viti Islands, Australia, Ceylou and Natal. The figure of G. gigantea, Wall, in Sp. Fil. tab, 3, shows bracts of much larger size.

\section{CIвотIUM, Kaulf.}

Sori globose, at the apex of a vein, marginal, enclosed in a prominent, coriaceous, deeply 2-valved involucre, the outer box-shaped valve proceeding from the margin of the segment, but being of different texture. Sporangia pedicellate. Annulus slightly oblique, in our species consisting of about 30 well developed and 8-10 indistinct articulations. Spores tetraedrous. - Arborescent ferns, with twice pinnate fronds of cyatheoid

Hillebrand, Flora of the Hawaiian Islands. 
habit, the apex pinnatifid. Fibro-vasal ducts arranged in shape of an omega at the base of the stipes. - Pinonia, Gaud.

A small genus, ranging over Mexico and Central Ameriea, the Hawaiian and Philipine Islands, Sumatra, S. China and India. It is distinguished from the true Dicksoniae (Balantium of Kaulfuss and Mettenius) by the changed cartilaginous texture of the outer valve, which is in reality formed, as in that genus, by the lobule of the leaf, the margins of which are inflected and unite below with the base of the flat internal valve or true indusium, this latter fitting npon the former like the lid of a box. The base of the leaf-stalks is densely covered with a soft and glossy yellowish wool, which is used for stuffing mattrasses and pillows and under the name of pulu forms a regular article of export to California. The wool of $C$. Barometz from tropical Asia and of Dicksonia Culcita from the Atlantic islands serves for similar purposes and has also found a limited employment in surgery for staunching bleeding from ulcers or wounds. The hairs consist of a single series of flat thin-walled cells which break readily at the joints, the cells being shortest in C. Chamissoi and longest in C. Menziesii.

The frond is eyatheoid, with the lowest pair of pinnae, rarely the two lowest pairs anadromous, all other pinnae, pinnules and segments or nerves catadromous.

Stipes tuberculate and shaggy with black hair in its upper portion;

frond thick coriaceous; sinuses between the segments broad

1. C. Menziesii.

Stipes smooth and mostly naked in its upper portion; frond charta-

ceous; sinuses acute:

Frond dull glaucous or greenish underneath and pubescent; pinnules stipitate; segments oblong

2. C. Chamissoi.

Frond bright glaucous underneath and naked; pinnules sessile; segments falcate

3. C. glaucum.

1. C. Menziesii, Hook. Sp. Fil. I, 84, tab. 29, C. - Arborescent. Stipes green, stout, with a ventral and two lateral furrows, tuberculate and shaggy at the base with a straightish and long brownish-yellow glossy pulu, which changes higher up into stiff long blackish hair, and as such often covers the entire stipes. Frond with stipes $6-12 \mathrm{ft}$. long and $3-5 \mathrm{ft}$. broad, pyramidal-oblong, coriaceous, naked underneath or sometimes with minute furfuraceous dots; the rhachis asperous with scattering tubercles. Pinnae with a stipes of $1-2^{\prime}$, oblong, $1^{1} / 2-2^{1 / 2} \mathrm{ft}$. long, bearing $18-24$ pairs of free pinnules besides the pinnatifid apex; most pinnules shortly stipitate, linear-lanceolate, $5-10^{4} \times 1-1^{1 / 2}$, acute, cut halfway or more, often to the rhachis at the base, into oblong rounded entire segments, which are separated by broad sinuses. Veinlets very prominent, simple or forked. Sori $8-14$ on a lobe, also fringing the sinus. Invol. corneous, large, ${ }^{3} / 4-1^{1} / 4 "$ in width, the outer valve fornicate and large, the inner flat and narrower. - Hook. \& Baker, Synops. Fil. p. 49. - C. Chamissoi and C. Menziesii, Brack. Fil. U. S. E. E. p. 280. - C. pruinatum, Metten. \& Kuhn, in Linnaea, XXXVI, 150.

All islands! at heights of $2000-4000 \mathrm{ft}$. Nat, names: "Hapu Hii* and *Heii". Ordinarily the trunk is not found higher than $4-8 \mathrm{ft}$., but in the Kohala range of $\mathrm{Haw}$ ail the writer measured one of $24 \mathrm{ft}$. in height and nearly $3 \mathrm{ft}$. in diameter, to which the plumage would add $10-12 \mathrm{ft}$. more. On $\mathrm{Haw}$ aii this tree, intermixed with the two following species, formed extensive thickets in former times which have been nearly cleared away by the pulu gatherers, who ruthlessly sacrifice the whole tree in order to get easily at the wool. Fortunately the felled trunk reproduces itself in the damp atmosphere by numerous lateral shoots, but full-grown trees are now rarely met with. 
The species is variable, like all Hawaiian ferns. Its only constant character consists in the straight and dark hair whieh rises from sharp tubercles often in the entire length of the stipes, rarely the tubercles, not the hair, extending to the lower portion of the main rhachis. The glaucous color of the lower surface (C. pruinatum) is often very conspicuous, particularly in the sterile frond, but sometimes nearly absent; moreover, it would seem to fade away in herbarium specimens. As a rule the lower surface is quite glabrous, but some deeply divided forms exhibit minute dots or papillas of very short hairlets or scales. In a variety from the high plateau of $\mathrm{Kauai}$ the division of the pinnules extends only to one third or one half of a side, even at the base which is equally truncate in both halves, with opposite nerves, while in other forms the division goes almost to the rhachis, with the one or two first pairs of segments free from each other. Still, even in these deeply divided forms the sinuses are broad and mostly fringed with sori. - The young frond is ovate or deltoid on a long stipes, simply pinnate with only 3 or 4 pairs of free pinnae, which are cut to the midale into broad and rounded, faintiy dentate lobes.

2. C. Chamissoi, Kaulf. Enum. Fil. p. 230, tab. 1, fig.14. - Trunk less high than in the preceding species. Stipes $4-8 \mathrm{ft}$. long, brownish, smooth, clothed at the base with a pale fawn-colored lustreless matted or cobwebby pulu, furfuraceous or naked above. Frond $4-8 \mathrm{ft}$. long, chartaceous, the under face green or dull glaucous and generally covered with a pale cobwebby pubescence. Lowest pinnae $1^{1 / 2}-2^{1 / 2} \mathrm{ft}$. long, with $24-28$ pairs of pinnules; these shortly stipitate, linear-lanceolate, $5-6^{\prime} \times 8-10^{\prime \prime}$, acute, the lower ones cut to near the rhachis into oblong, straightish, rather obtuse segments with narrow sinuses, the basal segments entire and not deflected. Veinlets little prominent. Sori $8-14$ to a segment, the involucre small, about $1{ }_{2} "$ wide, chartaceous. - Hook. Sp. Fil. I, 83. - Synops. Fil. p. 50. - Pinonia splendens, Gaud. Ann. Sc. Nat., Dec. 1824, and Bot. Voy. Freyc. p. 370, tab. 21.

All islands! In Hawaii trunks have been seen of 16 or more feet in height. The young stems of this, and probably also of the other species, are farinaceous and used to be eaten by the natives in times of scarcity. Baked in ashes they are by no means unpalatable. Nat. name of nos. 2 and 3: "Hapu".

The pubescence of the frond is occasionally abseut in the upper pinnae and pinnules. This must account for the difference in Kaulfuss's description, where the frond is stated to be glabrous. His figure otherwise agrees well with our specimens. A young plant, about $1 \mathrm{ft}$. high, is bipinnate, with the pinnules deeply serrate. One of my young plants has quite pale flaxen hair, not as curly as usual.

$\beta$ var. - Pulu as in $\alpha$. Frond smaller, thin chartaceous, dull glaucous underneath, the primary and secondary rhachides covered with short flakes of wool. Pinnae $12-15^{\prime}$ long; the pinnules $3-5^{\prime} \times 5-8^{\prime \prime}$, sessile, the lowest segments free, entire, that of the under half overlapping the rhachis, as in C. glaucum. Veinlets mostly simple. Invol, very small and thin.

On high lands of Kauai! (Kn.) and doubtfully also of Hawaii! (Lydg.).

3. C. glaucum, Hook. \& Arn. in Bot. Beech. p. 108. - Sp. Fil. I, 82, tab. 29, A. - Trunk and stipites as in no. 2, but the pulu at the base of the latter glossy, golden-yellow, moderately curled, the upper portion of the stipes naked or slightly furfuraceous. Frond $6-8 \mathrm{ft}$. long, subcoriaceous to chartaceous, bright-glaucous underneath and naked, as are 
the rhachides. Lowest pinnae $2-2^{1 / 2} \mathrm{ft}$. long, with $24-36$ pairs of pinnules, on short stalks of ${ }^{1 / 2}-1^{\prime}$. Pinnules sessile, $6-7^{4} \times 6-10^{\prime \prime}$, linearlanceolate, cut to the rhachis into narrow falcate, rather pointed, subentire segments with narrow acute sinuses between; the lowest pair of segments often auriculate or pectinate and overlapping the rhachis; the sterile ones erenate or dentate. Veins and sori as in no. 2, the involucres as small or a little larger. - Hook. \& Baker, Synops. Fil. p. 49. - Brack. 1. c. Dicksonia glauca, J. Sm.

On most islands! but rather rare. The pulu as to gloss and curl is intermediate between that of nos. 1 and 2 ; in a young, still circinnate frond its hairs appear connate, glued together so as to present narrow membranes. The frond is not always bright glaucous underneath, and forms occur which are intermediate between this and the preceding species.

\section{ACROSTICHUM, L.}

Sporangia naked, spread over the whole under surface of the frond or upper pinnae, excepting the rib and margin, or sometimes over both surfaces. - A large genus, almost entirely tropical, including groups with a wide range of venation and cutting. Stipes articulate above the base in all our species. Fertile fronds generally different in size or shape from the sterile ones.

Veins all free (Elaphoglossum, Schott):

Frond scaly over both faces

Frond naked, thin chartaceous, shining

Frond naked, coriaceous, dull:

Fertile fronds shorter than the barren ones; scales of rhizome brown .

Fertile fronds like the barren ones; scales of rhizome black along the middle, ciliate

Veins united by an intramarginal vein (Aconiopteris, Presl) $\quad 5$. A. gorgoneum.

Veins anastomosing in several series of meshes (Chrysodium, Fée) 6. A. reticulatum.

The spores are muricate or verrucose in all our species, ovoid-reniform to semiglobose, apparently with one short dorsal line which forks at one or both ends. Sporangium with $10-14$ cells to the ring, excepting no. 1 in which it has $17-20$.

1. A. micradenium, Fée, Acrost. p. 43, tab. 8. - Rhizome slender, long creeping, its few scales small, dark brown, shining, linear or subulate, sparingly glandular. Stip. at distances of $1 / 2-1^{1} / 2^{\prime}$, slender, $3-6^{\prime}$ long, stramineous or light brown, naked or slightly furfuraceous at the base and often glutinous. Barren fronds thin chartaceous, elliptico-oblong, $3-7^{\prime} \times$ ${ }^{8} / 4-1^{1} / 4^{4}$, caudato-acuminate, contracting at the base, naked, shining; the veins distinct, subhorizontal, close and parallel, mostly once forking, free. Fertile fronds on longer stipites, smaller, less acuminate at both ends, ${ }^{3 / 4}-2^{1} / 2^{\dagger} \times{ }^{1 / 4}-1 / 2^{\prime}$. Fibro-vasal fascicles 2 , closely approximate. - Hook. Sp. Fil. V, 216. - Synops. Fil. p. 400. - A. pellucidum, Gaud, Bot. Bon. tab. 79 ? - Elaphoglossum nitidum, Brack. Fil. U. S. E. E. p. 70. pl. 9.

On rocks or trees, from $1000-3000 \mathrm{ft}$. and upward. All islands. - Nat. names of all species: *Ekaha* and "Hoea Maui* (Maui's paddle). 
2. A. conforme, Sw. Syn. Fil. p. 10, tab. 1. - Rhizome woody, of the size of a crow's quill, wide creeping, its few scales lanceolate, about 2 " long, brown, darker along the middle, subentire or fringed with a few laciniate teeth and globose glands. Stip. $2-4^{\prime \prime}$ distant, rigid, $3-6^{\prime}$ long, stramineous, with blackish base, paleaceous below with scattering deciduous scales. Barren fronds coriaceous, pale, naked, oblong or narrow-lanceolate, $4-8^{\prime} \times 1 / 2-{ }^{3} / 4^{\prime}$, acute or somewhat obtuse, gradually or suddenly narrowing below, with thickened or revolute margins, the rib furrowed. Veins obscure, effaced in old fronds, close, parallel, simple or once or twice forked, free. Fertile fronds on longer stalks $\left(7-8^{\prime}\right)$ and usually shorter, $3-4^{\prime} \times{ }^{1} / 2-3 / 4^{\prime}$, suddenly or gradually narrowing below. Three fibro-vasal fascicles. - Occasionally two branchlets of the same vein unite near the margin. In some fertile fronds the sporangia only cover the upper half. - Hook. Sp. Fil. V, 198. - Synops. Fil. 401. - A. aemulum, Kaulf. Elaphoglossum aemulum, Brack.

Rather rare. Oahu! Kaala; Molokai! W. \& E. Maui! Kauai! from 3000-6000 ft. - The species has a wide range over tropical Africa, India, Malaysia, tropical America and Australia, the Viti and Samoa Islds.

3. A. Wawrae, Luerssen, Flora, 1875, p. 420. - Scales ciliate and the blade of the fertile frond equal to that of the barren ones, lanceolate, narrowing at both ends and larger, often $10^{\prime}$ long and $3 / 4^{\prime}$ broad; otherwise as $A$. conforme.

Kauai, Waiawa, at an altitude of $4000 \mathrm{ft}$. (Wawra 2125).

4. A. squamosum, Sw. l. c. p. 10. - Rhizome short and thick, woody, creeping, studded with the bases of fallen petioles, its few scales, like those of the stipes below the joint, lanceolate, running out into a long acuminate black and opaque point. Stip. crowded at the end of the rhizome, 2-8' long, brownish, densely clothed, as are both faces of the frond, with patent ovate-lanceolate scales which are $2-3^{\prime \prime}$ long, pale brown, diaphanous, fringed with long eiliae and bearing one or more subsessile glands at or near the subtruneate apex, those of the frond with sinuous cells. Barren fronds dark green, thick, flaccid, lanceolate, broadest in the upper third, subfalcate, $6-14^{\prime} \times{ }^{3 / 4}-1^{1 / 2^{\prime}}$, acuminate or somewhat obtuse, gradually narrowing at the base, their scales largest along rib and margins, those of the upper face often paler. Veins hidden, simple or once forked, subhorizontal, close, free. Fertile fronds smaller and narrower, with a rounded or cuneate base, $3-5^{\prime} \times{ }^{1 / 2}-{ }^{3} / 4^{\prime}$, generally but not always on longer stalks, the upper face covered thronghout with short scales, the lower one along rib and margin. Four or five fib. vas. fasc. - Hook. Sp. Fil. V, 239. - Synops. Fil. p. 411. - Elaphoglossum splendens, Brack. A. splendens, Bory, in Bot. Beech. p. 103, and Bot. Freyc. p. 303.

On exposed ridges, all islands. - Oceurs also in tropieal America, Tahiti, the Malay Archipelago, India, tropical Africa, Madeira and the Azores. - In large fronds from shady 
situations the scales, particularly of the upper face, are smaller, almost reduced to the ciliae which appear stellate, and quite sparse, except at the rib and margin. Specimens from high elevations exhibit black scales on the stipes like the plants from Madeira.

5. A. gorgoneum, Kaulf. Enum. Fil. p.63. - Rhizome short creeping, woody, $1 / 4-1 / 2^{\prime}$ thick, densely clothed at the end with long $\left(1 / 2-1^{\prime}\right)$ and stiff linear-lanceolate entire dark-brown scales. Stip. closely set near the end of the rhizome, stiff, $1-2^{\prime}$ long, stramineous, paleaceous below the joint. Barren fronds obovate-lanceolate, $9-26^{\prime} \times 2-3^{\prime}$, shortly acuminate, gradually narrowing below into the winged stipes, chartaceous, with attenuate margin, glabrous. Veins rather distinct, nearly vertical, parallel, simple or once or twice forking, the branchlets rarely anastomosing lower down, but all united at the apex by a straight intramarginal nerve. Fertile fronds smaller and narrower, $6-12^{\prime} \times{ }^{3 / 4}-1^{1 / 2^{\prime}}$, on much longer margined stalks of $6-14^{\prime}$. Five fib. vas. fascicles, - Hook. Sp. Fil. V, 254. - Synops. Fil. p. 416. - Brack. 1. c. p. 74. - Olfersia gorgonea, Presl. - Aconiopteris obtusa, Fée. - In the young plant the more distant veins anastomose by broad intramarginal arches.

On the roots of trees and rotten trunks; all islands. Is also a native of Tahiti.

$\beta$ var. - Frond smaller, 4-10' long, coriaceous, obtuse. Most veins ending free with tumid apices; only few distinetly anastomosing.

Ka uai! Halemanu (Kn.).

6. A. reticulatum, Kaulf. l. c. p. 64. - Caudex prostrate, 4-6' long and $1 / 3-1 / 2^{\prime}$ thick, densely clothed with ferruginous lanceolate fimbriate or laciniate scales of about 1 ' in length. Stip. confined to the apex, dark brown, paleaceous at the articulate base. Barren fronds pale, coriaceous, glabrous, elliptico-oblong, $8-16^{\prime} \times 1-2^{\prime}$, obtuse, euneate at the base, on stalks of $2-64$. Veins (nerv. Doodyae) obscure, anastomosing irregularly in 3 or 4 sets of narrow elongate areolae without appendages, their ends mostly free and tumid. Fertile fronds smaller, $6-10 \times 3 / 4-1^{1 / 4^{\prime}}$, on longer stalks of $5-10^{\prime}$. Three or five fib. vas. fasc. - Hook. Sp. Fil. V, 267. - Synops. Fil. p. 421. - Brack. 1. c. p. 81. - Elaphoglossum reticulatum, Gaud. Bot. Bon. tab. 79. - Hymenodium reticulatum, Presl, Epimel. p. 176. - A. crassifolium, Gaud. Bot. Freye. p. 303. - Hymenodium crassifol. Fée, Aerost. p. 94 , tab. 53.

All islands; rather common, on trunks and rocks. Is not known from elsewhere.

\section{GYMNOGRAMME, Desv.}

Sporangia occupying the veins over the under surface of the frond in linear or linear-oblong, simple or forked sori. No receptacle or involucre. - Ferns of varied forms and habits, with simple, forked or anastomosing veins; chiefly tropical.

1. G. Javanica, Bl. Fil. Javan. p. 95, tab. 41. - Rhizome creeping. Stip. 1-3 ft. long, naked, glossy, stramineous. Frond phegopteroid, $1-3 \mathrm{ft}$. 
long, ovate-lanceolate, chartaceous, olive-green, shortly pubescent underneath with white hairlets which consist of a single row of $3-7$ cells, pinnate with a terminal pinna, or bipinnate. Pinnae $3-7$ on a side, mostly opposite, stipitate, ovate-oblong to lanceolate, $6-9^{\prime} \times 1^{1 / 2}-2^{\prime}$, shortly acuminate, often caudate, finely serrate with adpressed cartilaginous teeth, obtuse, even rounded at the base, the lower 1, 2 or 3 pinnae often again pinnatifid or pinnate with $1-3$ pairs of pinnules. Veins close and parallel, subhorizontal, generally twice forking, all ending at the bases of the teeth with a clavate apex, in rare instances 2 branchlets anastomosing. Sori linear, on all veins and their branches, but stopping a space short of the edge. Annulus with 13 joints. Spores tetraedrous. - One large horeshoe-shaped fib. vas. fasciele in the stipes. - Nervatio inter Taeniopt. et Neuropt. - Hook. Sp. Fil. V, 145. - Synops. Fil. p. 381. - Metten. Fil. Hort. Lips. p. 40. - Coniogramme Javanica, Fée. - G. pilosa, Brack. Fil. U. S. E. E. p. 22, pl. 4.

Hawaii! Maui! Kauai! at altitudes of $3000-5000 \mathrm{ft}$. - Nat. name: "Loulus. - Is found also in the Viti group, Japan, Malaysia, India and tropical Afriea.

\section{VITTARIA, Sm.}

Sori linear, continuous, on a marginal or intramarginal vein or receptacle which connects the pinnate veins, either lying in a 2 -lipped groove at the very margin of the frond, or near the margin and parallel with it on the under side, and then more superficial. Grasslike ferns, with simple, linear, distinctly or scarcely costate fronds. Tropical.

1. V. elongata, Sw. Syn. Fil. p. 199. - Rhizome thick and short, creeping, its scales dark, linear-subulate from a suborbicular base, $1^{1 / 2}{ }^{\prime \prime}$ long, falcate, finely areolate in transparent meshes with black thickened walls, the flexuous margin dentate with patent teeth. Fronds closely set, thick chartaceous, opaque, linear or falcate, $12-20^{\prime} \times 2-4^{\prime \prime}$, acuminate, entire, gradually contracting below into the short margined stipes. Midrib distinct throughout or evanescent above. Veins obscure, very oblique, at distances of $1 / 2-1 "$, simple, straight and parallel. Sori sunk in a deep marginal groove with two nearly equal lips, opening outwards. Sporangia with 16-18 joints, intermixed with numerous clavate or lageniform paraphyses. Spores oblong-reniform, pale. Fib. vas. fasc. 2. - Synops. Fil. p. 395. V. rigida, Kaulf. Enum. Fil. p. 193. - Hook. Sp. Fil. V, 184. - V. zosteraefolia, Bory. - Hook. ibid. p. 183. - V. plantaginea, Bory. - Gaud. Bot. Freye. p. 382. - Compare also Luerssen, Fil. Graeff. pp. 77-95.

Common on trees and rocks. - Nat. name: cOheohes. - This ineludes V. zosteraefolia Bory, a form in which the nether lip of the groove is shorter and the sorus comes in sight when the frond is viewed from below. Hooker, 1 . e., quotes it from $\mathrm{Hawai}$ (Menzies) and I have it from Halemanu, Kauai (Knudsen 74). V. lineata, Sw, differs from it only in the thicker and somewhat broader margin, which consists of the whole thickness of the frond, so as to constitute an intramarginal groove. - The species is widely spread over Polynesia, Australia, India and tropical Afriea. 


\section{POLYPODIUM, L.}

Sori dorsal, usually round, or more or less oblong. Invol. none. Veins free and mostly ending with a clavate apex, or anastomosing. Sori terminal or median. Stipes articulate with the rhizome.

A large genus, spread over all zones.

Frond simple:

Frond lanceolate, entire, with 2 regular rows of sori:

Frond naked

Frond covered with peltate scales

Frond hispid, the sori close to the midrib .

Frond sparsely hispid, the sori near the edge

Frond linear, remotely denticulate, with one or few scattering sori

Frond palmately $3-5$-lobed

Frond serrate or deeply notched:

Frond spathulate, obtuse, the sori confined to the almost entire upper portion

Frond lanceolate, serrate at the middle, with one sorus to each serrature

Frond pinnatifid:

Frond elliptical, with a caudate point; several sori irregularly scattered over the lanceolate segments

Frond linear, the deltoid or short lanceolate lobes with two regular rows of sori

Frond broad ovate-oblong

Frond bipinnatifid :

Frond large; segments lanceolate, with several sori

Frond small; segments obovate, a single sorus to each

Frond bipiunate; one sorus to each pinnule:

Frond dark, narrowing below; pinnules linear-spathulate, obtuse

Frond pale, not narrowing below, the pinnules lanceolate or spathulate, acute, mostly again divided
12. $P$, lineare.

13. P. lanceolatum.

3. P. Hookeri.

4. P. Samoense.

1. P. pseudo-grammitis.

14. P. spectrum.

2. P. serrulatum.

5, P. Haalilioanum.

6. P. sarmentosum.

7. P. Adenophorus.

11. P. pellucidum.

11. P. pellucidum, $\delta$.

8. P. hymenophylloides.

9. P. tamariscinum.

10. $P$, Hillebrandii.

\section{A. Eupolypodium. - Veins free.}

a. - Spores tetraedro-globose, with 3 converging dorsal lines. Annulus with 10-14 joints. One central fibro-vasal fascicle. Nos. 1-10.

1. P. pseudo-grammitis, Gaud. Bot. Voy. Freye. p. 345. - Rhizome creeping, slender filiform, sparsely fibrillose with narrow lanceolate dark scalelets, Stip. at distances of $2-4^{\prime \prime}$, blackish at the base, naked, ${ }^{1 / 4}-1^{1 / 2^{\prime}}$ long. Frond subcoriaceous, pale, glabrous, linear, $2-5^{\prime} \times 1-3^{\prime \prime}$, gradually emerging from the stipes, obtuse or truncate, sometimes bifid, entire or obscurely sinuato-dentate, rarely laciniate, with a distinct costa. Veins hidden, mostly simple, straight, very oblique, running into the margin. Sori few, 1-16 upon the whole frond, dorsal or subapical on the veins, irregularly scattered, rather large and sometimes oblong, filling the space between rib and edge and even protruding beyond the latter. - Bot. Beech. p. 113, tab. 21. - Brack. Fil. D. S. E. E. p. 3. - Sp. Fil. IV, 165. - Synops. Fil. p. 320. - Grammitis tenella, Kaulf. - P. Kaulfussii, Presl \& Metten. Polyp. p. 35.

Very common on trees. Not known from other countries. Nat. name: "Kolokolo". 
2. P. serrulatum, Metten. Polyp. p. 32. - Stip. tufted on very short rhizomes which bear only a few dark and stiff ovate long acuminate scalelets, short $\left(1-6^{\prime \prime}\right)$, naked, dark, Fronds linear-spathulate, $1^{1 / 2}-5^{\prime} \times$ $1-2^{\prime \prime}$, obtuse, the upper fourth or third subentire and broadest, the rest notched or cut to near the rhachis into blunt triangular or ovate lobules, gradually narrowing into the winged stem, naked, thick chartaceous. Veins simple, slightly curved, terminating with a clavate apex, one to a segment. Sori confined to the subentire portion of the frond, oblong on the veinlets from their base to near the apex, adpressed to the costule and filling the under surface. - Sp. Fil. IV, 174. - Synops. Fil. p. 323. - Xiphopteris serrulata, Kaulf. - X. Jamesonii, Hook. Second Cent. tab. 14. - Grammitis serrulata, Sw. - P. myosuroides, Sw. - P. minimum, Brack. Fil. U. S. E. E. p. 5, pl. 1. - Exceptionally a few of the upper segments are found soriferous. Sterile fronds are notched throughout.

Rare, on trees at heights of $3000-6000 \mathrm{ft}$. on Konahuanui, Oahu! Eeka, Maui! Waialeale, Ka uai! - This pretty little fern is found on the Andes from Mexico to Chili, in the W. Indies, Juan Fernandez, Mauritius, Madagascar, and on the Guinea coast. The W. Indian fern has a rather different look, but Hooker's figure of Xiphopteris Jamesonii corresponds well with our form, only that the nerves are less spreading and somewhat arehed in the latter. Nat name: "Kihe".

†Chaetothecae. - Sporangia armed with $2-5$ setae. Nos. $3-4$.

3. P. Hookeri, Brack. Fil. U. S. E. E. p. 4. - Rhizome short and rather thick $\left(1^{\prime \prime}\right)$, the scales small and thin, ovate or lanceolate, obtuse, pale brown or yellow. Stip. crowded near the end of the rhizome, ${ }^{1 / 4}-1^{1}$ long, dark, eiliate with stiff spreading reddish single-celled hairlets. Frond chartaceous, dark, ciliate or hispid, linear-laneeolate, $3-9^{\prime} \times{ }^{1} / 4-3 / 8^{\prime}$, acute or bluntish, entire, gradually narrowing at the base, occasionally bifid. Veins simple or once or twice forking, only the simple ones near the apex terminating with a swollen end, the others running out acutely. Sori dark brown, large, round or somewhat oblong, seated at the beginning of the upper branch near the bifurcation, forming two rows elose to the midrib. Sporangia mostly echinate with 2 or 3 stiff purple setae near the apex and 1 or 2 near the base of the annulus. - Sp. Fil. IV, 171. Synops. Fil. p. 319. - P. setigerum, Hook. \& Arn. in Bot. Beech. p. 103, tab. 21. - Luerssen, Fil. Graeff. p. 100.

$\beta$ var. - Frond subcoriaceous, less hispid with purplish hairs. Veins hidden. Sori rather oblong and often impressed, dorsal on the middle of the anterior branches, terminal on the apical ones, forming two rows midway between rib and edge.

On trees in all islands, but not common; the variety from the highest parts of Molok ai. Woula seem to propagate by budding of the root in the same manner as nos. 5 and 6 , but my specimens do not afford a elear proof. - Probably the Tahitian P. subspathulatum, Brack, and the Vitian $P$. conforme of the same author belong here, for their sporangia are given as echinate, but the position of the sori with regard to the veinlets is not adverted to in the description. The Queensland, Bourbon and Philippine forms which 
Baker refers to our species need to be reexamined as to capsules and position of sori, so also the Javanese $P$. setigerum, Bl., with which Luerssen has reunited all these forms in Fil. Graeffeanae, p. 102.

4. P. Samoense, Baker, Synops. Fil. p. 321. - Var. glabra. - Rhizome and scales as before. Frond subcoriaceous, pale, quite glabrous, linear-

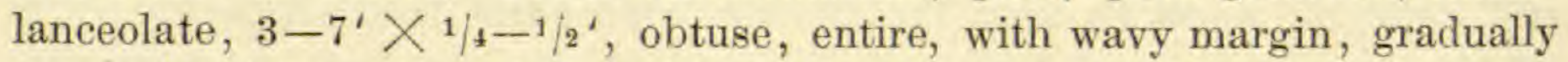
narrowing into a short dull darkish puberulous or naked stipes, the costa green. Veins obscure, simple, or forking at open angles into two or three branches, all ending in punctiform apices. Sori apical on the simple, subapical on branching veinlets, sometimes on two of the same group, large, round or oblong, in a single row near the margin. Receptacle always elongate. Sporangia and spores as in P. Hookeri. - Luerssen, in Flora, 1875 , p. 422 .

Kauai, on the highest summit of Pohakupili, $4000 \mathrm{ft}$. (Wawra); Halemanu, $5000 \mathrm{ft}$. (Knudsen, Baldwin). - Occurs also on Samoa. - In referring, as does Luerssen, our plant to the above species it needs to be stated that Baker's description does not make mention of the sporangia nor of the elongate receptacle, which latter would assign to our plant a fair place in the subsection Grammitis. Its close connexion with $P$. Hookeri through the var. $\beta$ is evident, and it could be regarded as an extreme variety of the same, notwithstanding the great diversity in position of sori as compared with the thin-leaved form.

† Adenophori. - Clavate, stipitate, resinous glands on the frond and similar paraphyses in the sori. Nos. 5-10.

5. P. Haalilioanum, Brack. l. c. p. 5, pl. 1. - Stip, in short tufts which rise at considerable distances from root-like wiry proliferous surculi. Scales few, short, lanceolate, rather obtuse, light brown. Fronds chartaceous, naked, pale, linear-lanceolate, $2-4^{\prime} \times 2-3^{\prime \prime}$, rather obtuse, narrowing below into the winged stem, either sinuato-crenate throughout, or subentire near apex and base, for the rest notched or cut to $1 / 3-2 / 3$ into rather obtusely deltoid lobes with the upper edge horizontal. Veins at acute angles, all simple in the narrow crenate fronds, in the broader ones those of the middle once or twice forking, with obtuse apices. Sori apical on the simple veins or the short anterior branches of forking veins, in two rows midway between rib and edge. Sporangia not setose, intermixed with few thick elavate reddish paraphyses. - P. subpinnatifidum, Hook. Sp. Fil. IV, 177. - Synops. Fil. p. 324. - Mann, Enum. no. 619.

On moss-covered trees, not common, Oahu! Konahuanui; Ka uai! - It passes by gradual transitions into the following species. The proliferous sureuli resemble the dark and naked filiform rootlets in every respect. First appears a sealy bud, from which arise in succession 1 to 4 or 6 fronds. - Blume's $P$. subpinnatifidum is assuredly not the same fern. It has long ferruginons hairs, dorsal sori which are often oblong and impressed, and according to Mettenius (Polyp. p. 39) setose sporongia, while the same aceurate author makes no mention of paraphyses or glands - all characters which assign it a place in the group Chaetothecae.

6. P. sarmentosum, Brack. 7 . c. p. $8, p l .2$. - - Rhizomes more dereloped than in the former species, sometimes $1 / 2^{\prime}$ long, rising at distances of $1-4$ inches from filiform root-like naked surculi. Scales pale 
reddish-brown, linear-lanceolate, somewhat obtuse. Stip. tufted, less than $1^{\prime}$ long, margined, pubescent when young with glandular hairlets. Frond subcoriaceous, naked, elliptico-lanceolate, $3-6^{\prime} \times{ }^{1 / 2}-2^{\prime}$, broadest at the middle, narrowing suddenly toward both ends, the apex mostly subentire and often produced into a long caudate acumination, the middle cut to near the concolorous or darker rachis into erecto-patent, bluntish, entire or crenate segments which are $2-3^{\prime \prime}$ broad at the base. Veins pinnate in the segments, with a flexuose costule, the veinlets very oblique, simple, or forking near their ends, terminating in punctiform apices. Sori apical, round, rather irregular, $2-7$ to a segment. Numerous paraphyses, shining yellow, intermixed with the sporangia. - Sp. Fil. IV, 195. - Synops. Fil. p. 327.

Common on mossgrown trees and rocks. - Not reported from elsewhere. One of my specimens has the deeply cut pinnaeform segments strongly notched, so as to resemble the New Zealand $P$. grammitidis, Br., which however does not seem to have the glandular paraphyses. These peculiar organs, which occur in all the species belonging to the present group, consist of a series of $3-5$ cells, the last one transformed into a clavate shining resinous gland, the walls of which often exhibit faint transverse markings as of an annulus. The glandular hairlets of the stipes show the same structure, but the gland is always straight cylindrical and often sessile. - The gemmiferous surculi run to great leugths, forming intricate convolutions between the moss. There are some indications that this vegetative mode of increase also takes place in the following two species.

7. P. Adenophorus, Hook. \& Arn. Bot. Beech. p. 104, tab. 22. - Rhizome short and oblique, rather thick. Scales small, lanceolate, obtuse, dark and stiff, transparent at the base. Stip. closely set, but not tufted, very short, pale, marginate, pubescent with resino-glandular, often bifid hairlets. Frond pale, thin chartaceous, scantily pubescent, linear-lanceelate, attenuate at both ends, $6-12^{\prime} \times{ }^{3} / 4-1^{\prime}$, cut down nearly to the pale rachis into alternate, patent, blunt or rather acute, deltoid or ovato-lanceolate entire segments which are $2-3 "$ broad at the base. Veins obscure, pinnate in the segments, the veinlets running into the margin, the lower ones emitting a very short anterior branchlet. Sori round, terminal at the apex of the segment, the others apparently dorsal, but probably at the end of the anterior branchlet, $6-14$ on a segment, elosely set in two rows between rib and edge or nearer the former. Paraphyses deepred, large and often incurved. - Sp. Fil. IV, 195. - Synops. Fil. p. 328. Brack, 1. e. p. 8. - P. pendulum, Gaud. Bot. Freyc. p. 349. - Adenophorus pinnatifidus, Gaud. ibid. p. 365.

Not uncommon in forests above $2000 \mathrm{ft}$., hanging in graceful festoons from the trunks of trees. - Reported also from Peru, Samoa and Sumatra. The species resembles greatly the American P. pendulum, Sw., and the Malayo-Polynesian P. decorum, Brack., both of which lack the resino-glandular hairlets and elavate paraphyses. $P$. decorum, indeed, is eredited to the Hawaiian islands in the Synopsis, but I consider it very likely that a reexamination of the specimen in question will reveal the presence of paraphyses.

8. P. hymenophylloides, Kaulf. Enum. Fil. p. 118. - Rhizome short and thick, oblique, almost creeping, covered with thin dark brown lan- 
ceolate scales which end in a single row of cells, the last cell transformed into a clavate or subglobose resinous gland. Stip. slender filiform, dark brown, ${ }^{1 / 2}-1^{i}$, closely crowded. Frond thin membraneous, linear, $2-5^{i}$ $\times 2-4^{\prime \prime}$, obtuse, gradually attenuate toward the base, pubescent with stipitate and sessile glistening yellow glands, pinnate, the rhachis weak flexuose and dark. Pinnae trapezoid in outline, cut more or less deeply into $2-10$ obtuse triangular or obovate segments. Veins one to a segment. Sori large, on the punctiform ends of the veins, $1-5$ to a pinna. Paraphyses pale yellow. - Sp. Fil. IV, 228. - Synops. Fil. p. 337. - Metten. Polyp. p. 31. - Adenophorus hymenophylloides, Hook, \& Gr. Ic. Fil. tab. 176. - A. minutus, Gaud. in Bot. Freyc. p. 365. tab. 8. - Amphoradenium minutum, Desv.

Rare, on trees at elevations of $3000-5000 \mathrm{ft}$.: Oahu! Konahuanui; Maui! Eeka; Hawail! Kohala range, and elsewhere. Nat. name: "Pai*.

9. P. tamariscinum, Kaulf. l. c. p. 11\%. - Rhizome creeping, 1" thick, covered with dark brown shining lanceolate scales which end in a clavate terminal gland and often bear a few smaller ones on their margins. Stip. at distances of $2-3^{\prime \prime}$, brown, stiff, slightly marginate, $1-4^{\prime}$. Frond chartaceous, opaque, dark-green, brownish when dry, pubescent with minute adpressed hairlets and resinous in the same manner as the precering species, elliptico-lanceolate, $4-15^{\prime} \times 1-3^{\prime}$, broadest at the middle, often caudate, gradually narrowing below, bipinnate. Pinnae close, $25-30$ on a side, lanceolate, broadest at the base, subsessile. Pinnules $10-16$ on a side, linear-spathulate, obtuse, the lowest $2-3$ "long and less than $1 / 2 "$ broad. Sori one to a pinnule, at the swollen end of the solitary vein. Paraphyses reddish-brown, thick clavate, mostly curved. - Sp. Fil. IV, 228. - Synops. Fil. p. 338. - Metten. Polyp. p. 31. Adenophorus tamarisci, Hook. \& Gr. Ic. Fil. tab. 175. - A. bipinnatus, Gaud. Bot. Freyc. p. 365, tab. 8. - Fée, Gen. Fil. p. 99, tab. 10. Amphoradenium australe, Desv.

Common on trees and on the ground. Nat. name: "Wahine noho mauna" (the mistress of the mountain). - Is reported also as a native of Tahiti, Samoa, Java and Sumatra, but neither Guillemin in the Zephyr. Taitens. nor Nadéaud in his Enum. Pl. Tah. mentions it, and its presence in Java rests upon the authority of Teschemaker. Carruthers in Seeman's Flora Vitiens. only knows it as coming from the Hawaiian Islds.

$\beta$ var. tripinnatifidum. - One or more, sometimes all pinnules again pinnatifid with rather acute segments, the lowest ones much the largest, $5-6^{\prime \prime}$ long with 5-10 segments. - Sp. Fil. 1. c. - Adenoph. tripinnatifidus, Gaud. Bot. Freyc. tab. 8. - Metten. Polyp. p. 32. - Amphoradenium Gaudichaudii, Desv.

Hawaii! Kohala range; Kauai! Halemanu; Maui! Haleakala (6000 ft.).

$\gamma$ var. montanum. - Rhizome shorter. Stip. more crowded and shorter. Frond dark brown, fragile, narrower and smaller, $2-5^{\prime} \times{ }^{1 / 2}-1^{\prime}$, copiously dotted with resinous glands and viscid, the rhachis sometimes bifid, 
even trifid. Pinnules less numerous and shorter, linear or linear-clavate, even acerose, reduced to the vein; the broad sori projecting much beyond them.

In swampy ground on the top of Mt. Eeka, Maui! high plateau of Kauai! also Molokai (Baldwin).

¿ var. abietinum. - Frond short and broad, oblong, scarcely narrowing below, $1^{1 / 2}-3^{\prime}$ Jong with the stipes and $1 / 2-3 / 4^{\prime}$ broad, the stipes and rhachis filiform, flexuose. Otherwise as in $\%-P$. abietinum, Eaton, in Mann, Enum. no. 626. - A diminutive form, with 10-12 pairs of pinnae and $5-7$ pairs of linear pinnules to each.

Rare, on trees, Oahu! Konahuanui; Hawaii! Kohala range; Kauai! (Kn.).

10. P. Hillebrandii, Hook. Sp. Fil. IV, 228, tab. 279. - Rhizome as thick as a crow's quill, creeping, sparsely paleaceous. Scales pale brown, long acuminate, with 1,2 or 3 stipitate glands at the apex, and a few scattered over the surface. Stip. at distances of $9-12^{\prime \prime}$, stiff, pale brown, naked, 4-5' long, margined or winged. Frond subcoriaceous, rather transparent, pale, sparsely resinous but glabrate, ovato-lanceolate, $8-12^{t}$ $\times 2^{1 / 2}-4^{\prime}$, not contracting below, abruptly ending in a long drawn out pinnatifid apex, bi-, tripinnatifid. Pinnae $12-20$ on each side, rather distant, decurrent along the rhachis, cut deeply, but always leaving a margin to the rib, into narrow oblanceolate or acutely spathulate segments which are $3-6$ " long and 1 " or more broad below the acuminate forward pointing apex; the basal segments always and generally more or most segments notched or cut into $5-2$ pointed serratures, with one acute veinlet to each. Sori subapical, the acute apex of the vein projecting beyond. Paraphyses paler than in no. 9. - P. tripinnatifidum, Mann, Enum. no. 625 (not Presl nor Gaud.).

With the first form of $P$. tamariscinum, in the lower forests, but much rarer. Although not marked by strong characters, it is easily distinguished in its fresh state by the pale and stouter open frond, which does not contract below, and by the broader and acute segments. One of my fronds is simply bipinnate throughout.

b. - Spores ovoid-reniform, with one dorsal line.

11. P. pellucidum, Kaulf. l. c. p. 101. - Rhizome creeping, of the size of a goose-quill, covered with ferruginous, ovate-lanceolate, long acuminate, thin margined, dentate scales. Stip. distant, rigid, pale, naked, $3-6^{\prime}$ long. Frond coriaceous, pale, glabrous, ovate-oblong, $6-15^{\prime} \times$ $3-8^{\prime}$, pinnatifid to near the rhachis, with a pinnatifid apex. Segments or decurrent pinnae $12-30$ on a side, separated by broad sinuses, linearoblong and obtuse, even rounded, entire or erenate or coarsely serrate, $5-6$ " broad, generally with a marginal series of white dots on the back. Veins transparent, close and oblique, with $3-5$ branchlets, all with clavate apices, the various groups and generally also the single veinlets 
separated by pellucid streaks which extend from the margin inward. Sori at the apex of the first anterior branch, large and round, in two straight rows between rib and margins or nearer the former. Sporangia with $13-16$ joints. Spores verrucose or reticulate. Fib. vas. fasc. $3-6$. Bot. Beech. p. 103. - Sp. Fil. IV, 206. -- Synops. Fil. p. 334. - Hook. Ic. Pl, tab. 944. - Gaud. Bot. Freyc. p. 356. - Brack. 1. c. p. 10. - Luerssen, in Flora, 1875, p. 423.

Common on the mountains of Hawaii! Maui! Kauai! from $5000 \mathrm{ft}$. npward. The pellucid streaks, owing to a thinning of the frond, indicate a tendency to split in these directions, which is realized to an eminent degree in var. $\delta$.

$\beta$ var. opacum. - Segments as before, entire, broadest near the round top, but with a tendency to form an auricle at the upper base. Veins opaque, excepting the clavate apex. Pellucid streaks wanting or reduced to a small dot at the crenature. Stipes longer than the frond. Fib. vas. fasc. 8 in a semicircle, the two lowest largest.

Molokai! pali of Waikolu; a single specimen, scarcely differing from $P$, vulgare.

$\gamma$ var. - Segments acute, entire or crenate or coarsely serrate, the frond of thinner texture and often narrowing below. Occasionally two anterior or two posterior branches of veins anastomose so as to form an elliptical ansa; more frequently the first anterior branch splits into two branchlets which unite again below the sorus. Fib. vas. fasc. $3-6$.

With $\alpha$. Of this var., too, I have a Ka ua i specimen in which the transparency of the veins and striae is quite indistinct.

$\delta$ var. bi-pinnatifidum, Hook. Ic. Pl. tab. 945. - Stip. 6-12'. Frond thick, $16-20^{\prime}$, narrowing below, pinnate, its middle pinnae $5-8^{\prime}$ long, shortly decurrent and again deeply pinnatifid in oblong or linear, crenate or serrate, rather obtuse segments, of which those about the middle are again much the longest and sometimes attain $1^{1} / 2^{4}$ in length; their veins pinnate with veinlets again branching. Sori large and numerous over the whole frond. Fib, vas, fasc. 4-6. - P. myriocarpum, Hook. Ic. Pl. tab. 84 .

Rare. My few specimens come from Haleakala on Maui! and from Kauai! The outline of the frond is quite irregular, as only one or another pinna here and there in creases to larger dimensions and splits deeper, while the others remain short and simply serrate or laciniate. - Analogous to var. cambricum of $P$. vulgare.

The species is peculiar to the Hawaiian Islands, but altogether resembles $P$. vulgare and repeats its varieties. The difference consists in the transparent veins and pellucid streaks between them, in the greater number of fib. vas. fascicles, and in the occasional anastomoses between veinlets of the same group.

B. Phymatodes. - Veins anastomosing in fine copious meshes, the sori at the ends of free appendages or at their junctions.

12. P. lineare, Thunb. - Hook. \& Baker, Synops. Fil. p. 354. - Rhizome creeping, woody, of the size of a crow's quill; its deciduous scales small, blackish, stiff, narrow lanceolate, denticulate, rising from a paler orbicular base. Stip. at distances of $1 / 4-1^{1} / 2^{\prime}$, rigid, naked, $1-2^{\prime}$ long. Frond 
thick coriaceous, quite opaque, sometimes with black dots on the back, naked on both faces, rarely with a few scattering scalelets along the rhachis, linear-lanceolate, entire, $6-12^{\prime} \times{ }^{1 / 4}-3^{3} 4^{\prime}$, gradually tapering at both ends, sometimes forking at the apex. Veins hidden, anastomosing, forming 3 oblique sets of angular meshes on each side, the first two with ap pendages. Sori confined to the upper portion of the frond, on projecting angles or inner anastomoses of the second set of meshes, large, round or oblong, $1^{1 / 2}-2^{1 / 2} 2^{\prime \prime}$ in the longest diameter, immersed, with corresponding protuberances on the back, forming a single line between rib and edge, a little nearer to the former, covered when young with $12--20$ dark peltate scales with concentrically radiating cells. Sporangia with $11-13$ joints. Spores ovoid-reniform, laterally compressed, verruculose. Two fib. vas. fascicles. - Pleopeltis elongata, Kaulf. - Drynaria elongata, Brack. - Polyp. atro-punctatum, Gaud. in Bot. Freyc. p. 346. - Hook. \& Arn. in Bot. Beech. - Metten. Polyp. p. 90. - P. loriforme, Wall. - Hook. Sp. Fil. V, 57. - P. leiopteris, Kze. - Metten. Fil. Hort. Lips. tab. 25.

A common fern, on trees and rocks. Nat, name: "Ekaha akolea". - Widely distributed from Japan and China over all India to southeastern Africa. - The black dots correspond to the swollen apices of the appendages.

13. P. lanceolatum, L. - Synops. Fil. p. 356. - Rhizome wiry, clothed with bright ferruginous scales. Frond on both sides, especially the under one, coated with fine peltate scales, otherwise as in no. 12. - P. lepidotum, Willd. - Hook. Sp. Fil. V, 56. - Pleopeltis ensifolia, Hook.

Collected only by Nuttall (probably on Kauai), according to the Species Fil. - Widely spread over America and Africa. In the Synopsis Fil. the Hawaiian Islds, are also credited, in all probability erroneously, with P. lycopodioides, L., a fern ranging through tropical America and Africa, also parts of India. It is easily recognized by the wide trailing rhizome, shaggy throughout with pale brownish hairlike scales, and by the dimorphous naked fronds, the sterile ones being much broader than the fertile ones and obtuse. Veins and sori nearly as in $P$. lineare.

14. P. spectrum, Kaulf. l. c. p. 94. - Rhizome wide trailing and branching, bearing at the end some stiff subulate blackish deciduous scales. Stip. $1-4^{\prime}$ distant, pale, naked, $3-8^{\prime}$ long. Frond thin chartaceous, naked, hastately 3 -lobed, with a deeply sinuose-cordate or shallow reniform base, $6-12^{\prime} \times 5-14^{\prime}$, the lobes long acuminate, the lateral ones rounded at the base and sometimes overlapping, or produced into acute auricles. Veins very prominent, a costa to each lobe, anastomosing (nervatio Drynariae). Main veins at oblique angles to the costa, subparallel, pinnate, their perpendicular branches forming rectangular meshes which are again subdivided into 2,3 or more rectangular areoles with divaricately branching appendages. Sori pale, small, very numerous, often one at the swollen end of each appendicular branch or at their junctions. Sporangia few, with $12-14$ joints. Spores ovoid-reniform, with one dorsal line which bifurcates at one or both ends. Five fib. vas. fascicles. - 
Hook. \& Arn. 1. c. - Sp. Fil. V, 74. - Synops. Fil. p. 361. - Drynaria spectrum, Brack. - Colysis spectrum, J. Sm. - Polyp. Thouinianum, Gaud. Bot. Freyc. p. 348, tab. 5.

$\beta$ var. ovatum. - Frond simply ovate, with a rounded or cordate base. $\gamma$ var. pentadactylum. - Frond deeply 5 -lobed, with long acute or rather obtuse lobes, the base horizontal, not cordate or sinuose.

Not uncommon on trees and rocks. Nat. name: «Peahiv. - Credited also to Sumatra on Teschemaker's authority.

\section{PHEGOPTERIS, Fée.}

Sori dorsal, round, rarely oblong, without indusium, and not covered by the reflected margin of the frond. Stipes continuous with the rhizome.

Veinlets straight and simple, uniting with the corresponding ones of the next groups as in Nephrodium; frond pinnate (Goniopteris)

Veinlets all free as in Lastrea (Euphegopteris):

Frond bipinnate to tripinnatifid, oblong, with opposite pinnae 2. P. Keraudreniana.

Frond bi-, tripinnate, deltoid or ovate-oblong:

Frond polystichoid, fibrillose with glandular scalelets . 4. P. crinalis.

Frond cyatheoid, sprinkled underneath with resinous dots 8. P. Hillebrandi.

Frond tri-, quadripinnate:

Ultimate segments sharply toothed or spinulose

7. $P$, spinulosa.

Ultimate segments obtuse:

Rhachis dull dusky, naked, or paleaceous with ovate scales; frond dark, firm

5. P. unidentata.

Rhachis whitish, naked and glossy; frond bright-green, herbaceous

6. P. Sandwicensis.

Rhachis pale brown or purplish, naked or covered with viscous hairs; tertiary pinnules mostly opposite

3. P. punctata.

The present genus only differs in the absence of an indusium from the sections Nephro. dium and Lastrea of the genus Aspidium, and many of its species resemble to such a degree species of the latter that they can be distinguished by no other eharacter. Moreover, in some species of Nephrodium and Lastrea the indusium is so fugacious that it ean be made out only in the young frond, and not few are those which have long passed for Phegopteris, until the accidental discovery of an indusium caused them to be transferred to Aspidium. Indeed some pteridologists go so far as to unite in one both genera, and to consider Phegopteris as naked forms of Aspidium. For this reason it is of great importance to pay attention to young fronds in all species of Phegopteris.

1. P. polycarpa, Hillebr. - (Polypodium polycarpum), Hook. \& Arn. in Bot. Beech. p. 104. - Caudex erect, attaining as much as $3 \mathrm{ft}$. in height and $4-5^{4}$ in thickness. Stip. $1 \frac{1 / 2}{2}-2 \mathrm{ft}$., light brown, paleaceous at the base with scattering dark ovate-lanceolate puberulous scales, and pubescent besides with single-celled stiff hairlets. Frond subcoriaceous, dark, pubescent on both faces or glabrate, ovate-lanceolate, $1^{1 / 2}-3 \mathrm{ft}$. long, pinnate with pinnatifid apex, cyatheoid; the rhachis pale brown, pubescent. Pinnae $20-30$ on a side, horizontal, lanceolate-acute, $5-8^{\prime} \times 1-1^{1 / 2} 2^{\prime}$, subsessile with a truncate equilateral base, the lower half overlapping the rhachis, the upper auriculate, the edges subentire or bluntly serrate or undulato-lobulate. Veins prominent, pinnate with $5-10$ pairs of straight oblique parallel veinlets, all except the upper ones joining with the corresponding veinlets 
of contiguous groups to form a spurious costule which runs into the sinus, the upper ones excurrent. Sori on the middle of each veinlet, generally somewhat oblong, rarely the lowest much elongate, so as to unite with the sori of the contiguous groups. Sporangia dark, ciliate, with about 20 joints. Spores tetraedrous (?) with projecting ridges or protuberances, subglobose when mature. Two large and broad fib. vas. bands, curving toward each other or folded in M shape. - P. microdendrom, Eaton, in Mann, Enum. no. 615. - Stegnogramme Sandwicensis, Brack. Fil. U. S. E. E. p. 26, pl. 4. - Polypodium (Goniopteris) Sandwic. Hook. Sp. Fil. V, 5. Polyp. stegnogrammoides, Baker, Synops. Fil. p. 317.

Not uneommon. A peculiarly Hawaiian fern which bears much resemblanee to Aspidium cyatheoides, but differs in the pubescence of the frond and sporangia, the pinnatifid apex and the elongate or loose sori, besides wanting an indusium.

$\beta$ var. Kauaiensis. - Sori close to the costules of the lobes, the sporangia loosely agglomerate and irregularly scattered besides. Pinnae only $1 / 2^{\prime}$ broad and very acute, falcate, obtusely serrate.

Ka ua i! Halemanu (Kn.).

$\gamma$ var. depauperata. - Frond with stipes $10^{\prime}$ long, pubescent throughout, pinnatifid in the upper half, only $2-4$ pairs of veinlets anastomosing.

On bare rocks in the bed of Wailuku river, Hilo, Hawaii! where it grew with the corresponding variety of Aspid. cyatheoides, while full sized plants of the form $\%$ of both species were scattered through the woods near by.

2. P. Keraudreniana, Mann, Enum. no.613. - (Polypodium Keraudrenianum), Gaud. Bot. Voy. Freyc. p. 362, tab. 7. - Rhizome underground, long creeping and branching, over $1 / 2^{\prime}$ thick. Stip. at distances of 2 or 3 inches, $3-6 \mathrm{ft}$. long, pale brown or stramineous, glossy, sparingly covered at the base only with pale fleshy deciduous scales. Frond phegopteroid, oblong, narrowing below, 6-12 ft. in length, thin chartaceous, pale, glabrous above, but generally pubescent below with sparse whitish single-celled ciliae, open, bipinnate, terminating rather abruptly with a short fleshy circinnate prolongation of the rhachis, which continues to grow after the lower pinnae have become covered with mature sori. Primary pinnae opposite, horizontal, at distances of $3-5$ inches, $9-20^{\prime}$ long, shortly stipitate with an even-sided truneate base, oblong-lanceolate. Pinnules (the first ones mostly opposite, shortened in the lower pinnae) perpendicular, lanceolate, $1-4^{\prime} \times^{3 / 4^{\prime}}$, broadly sessile and decurrent, or with a cuneate base, cut to $1 / 2$ or $2 / 3$ into triangular or oblong rather obtuse lobes, which are separated by narrow sinuses. Veins distinet, transparent, excurrent, simple or forking at open angles. Sori pale and flat, rather small, subapical and near the margin when on simple or once forking veinlets, dorsal and at a distance from the margin when on the first branch of repeatedly forking veins. Sporangia mostly ciliate, with 13 or 14 joints. Spores ovoid-reniform, pale yellow. - Two broad fib. vas. Hillebrand, Flora of the Hawailan Islands. 
bands, folded in M shape and uniting toward the rhachis. - Hook. Sp. Fil. IV, 268. - Synops. Fil. p. 313. - Brack. 1. c. p. 15.

$\beta$ var. procera. - Frond herbaceous, ciliate on both faces. Pinnae $1^{1 / 2}-2 \mathrm{ft}$. long. Pinnules $3-4^{\prime}$, substipitate with a truncate base, deeply cut into oblong rounded bluntly crenate lobes, which are separated by broad sinuses. Veins repeatedly forking and generally several branches soriferous, therefore the sori irregular on both lobes and undivided lamina. Sporangia always ciliate. - Polypod. procerum, Brack. I. c. p. 14, pl. 3. Sp. Fil. IV, 269.

ivar. tripinnata. - Frond chartaceous, almost glabrous. Pinnae $2-2^{1} / 2 \mathrm{ft}$. long; longest pinnules $8-10^{4}$, distinctly stipitate, cut down to the rhachis near the base into lanceolate acute segments of $3 / 4-1^{1} / 2^{4} \times 2-5^{\prime \prime}$, those of the upper pinnae subentire, with once forking veinlets, the lowest often again crenate or lobed, with pinnulate veinlets. Sori rather oblong when on the anterior branch of once forking veins only and placed in two converging submarginal rows, or round, smaller and irregular when occupying several branches of pinnate veins. Sporangia always ciliate. - Sp. Fil. IV, 269.

A peculiar Hawaiian fern of indefinite growth, with the habitus of some species of Pteris, the "Akolea and Waimakanui of the natives. It sustains its extraordinary length by the circinnate tips which twine round the branches of neighboring shrubs or trees. Occurs on all islands, but is common only in the woods of Hamakua, Hawaii! the var. $\beta$ on the southern slope of Haleakala, Maui! $\gamma$ on Mt. Kaala, Oahu! and Halemanu, Kauai!

3. P. punctata, Hillebr. (Polypodium punctatum), Thunb. - Synops. Fil.p. 312. - Var. glabra. - Rhizome underground, wide creeping, about ${ }^{1 / 2}{ }^{\prime}$ thick, with scanty hairlets. Stip. at distances of about $1 \mathrm{ft}$., stout, $2-3 \mathrm{ft}$. long, mahogany-brown, roughish at the base and sparingly hairy or flocculose, but quite glabrous above and polished. Frond chartaceous, glabrous, deltoid or ovato-oblong, $2-5 \mathrm{ft}$. long, quadripinnate, the rhachides pale. Stipitate pinnae about 10 , patent, the lowest rather remote from the next pair, on stalks of $1-3^{\prime}$, deltoid or ovate-lanceolate, almost even-sided, $1^{1 / 2}-2 \mathrm{ft}$. long. Secondary pinnae perpendicular, ovate-lanceolate, the lowest $6-10^{\prime}$ long on stalks of $1 / 2^{\prime}$. Pinnae of the third and fourth order mostly opposite and perpendicular, the latter oblong, $4-8^{\prime \prime} \times 2-4^{\prime \prime}$, rather obtuse, symmetrically notehed or eut, even to the rhachis, into $3-6$ pairs of generally opposite, spreading but forward curving, obtuse lobules, which are subentire at the lower margin but bluntly dentate anteriorly and at the apex. Veinlets distinct, not excurrent, $1-4$ to a lobule. Sori apical, rather large, one to each sinus or notch. Sporangia pale, with $14-16$ joints. Spores pale, ovoid-reniform. - Fib. vas. bands 3, two broad lateral ones, curving externally, their upper horns united by a broad semilunar dorsal one.

Top of Mt. Kaala, Oahu! heights of Kanalo, Molokai! in swampy ground. The rhachides are naked and polished, but what little of pubescence there exists in the ultimate divisions is viscid. The Kaala plants are herbaceous, with prominent teeth to 
the lobules, those from Molokai have firmer brownish fronds, which at the base are truly quintupli-pinnate, with shorter and blunter teeth to the lobules. Nat. name: cOluan.

$\beta$ var. Mauiensis. - Frond thicker, pale, deltoid, small, only 11' long and as broad at the base, bi-, tripinnate, the tertiary segments sessile. The pale brownish stipes, the stramineous rhachides and the whole underside of the frond pubescent with thin hairlets which consist of a single series of cells, many ending in a globose viscid gland.

W. slope of Eeka at Kaanapali, Maui!

i var. rugulosa. - Stipes and rhachis dark purplish-brown, rough, viscoso-pubescent throughout, the former $1 \mathrm{ft}$. long. Frond subcoriacous, $1 \mathrm{ft}$. long, pubescent over both surfaces. Youngest sori partly covered by the reflected tooth, but soon free and open. All hairlets of one row of cells and ending in a globose, shining gland, - Polypod. rugulosum, Labill. - Sp. Fil. IV, 272, with synonyms. - Metten. Phegopt. p. 12.

Only one specimen in Mr. D. Baldwin's collection, without indication of habitat. Very much like the Australian plant.

5 var. flaceida. - Frond quite flaccid and pale, oblong or lanceolate, $1 \mathrm{ft}$. long, bipinnate, the lower pinnae remote. Stipes and main rhachis deep purplish-red, as in $\%$, and viscoso-pubescent, the rhacheoles stramineous. Sori free and open.

Likewise from Mr. Baldwin's colleetion, without assignment of locality. Perhaps only a. young state of $\gamma$. In texture like the S. American Pol. Poeppigianum, Kze., and in outline like the figure of Hypolepis tenuifolia, Sp. Fil. II, tab. 90 A.

The less divided varieties are polystichoid, or rather subphegopteroid, but in the highly divided form $\alpha$ this character is obscured. While the primary pinnae, barring a few irregularities at the base, and the ultimate segments are generally auadromous, in the intermediate divisions homodromy prevails, and what deviation from this rule takes place goes as often in one as in the opposite direction.

The species extends over S. Ameriea, Australia, N. Zealand and N. Caledonia, Malay Islds. to Japan, India, Bourbon, St. Helena and Tristan d'Acunha. A Hypolepis in every respect but the naked sori, and perhaps not even specifically distinct from $H$. tenuifolia, Bernh., which occurs on the Society, Navigator and New Hebrides Islands.

4. P. crinalis, Mann, Enum. no. 610. - (Polypodium crinale), Hook. \& Arn. Bot. Beech. p. 105. - Caudex short, erect. Stip. dusky-stramineous or purplish-black, $1^{1 / 2}-2 \mathrm{ft}$. long, clothed throughout with long linear, dark brown or blackish, glandular scales which rise from a tuberculate base, the glands globose, sessile or raised. Frond subcoriaceous, dark-green, polystichoid, ovate or oblong-lanceolate, truncate below, $10-18^{\prime}$ long, bipinnate, tripinnatifid; the rhachides and costules fibrillose with stiff dark hairlets. Stipitate pinnae $9-15$ on a side, subascending, ovate-lanceolate, the lowest $3-5^{\prime}$ long on stalks of $1^{1 / 2}-3^{\prime \prime}$, uneven-sided, ovate-lanceolate. Pinnules oblong, obtuse, even rounded at the subentire apex, below notched or cut into subopposite, deltoid or oblong, obtuse or truncate, almost entire lobes or segments, the lowest basal pinnules $1^{1 / 2}-2^{4} \times 4-8^{11}$ and rather acute. Veinlets ending with an obtuse apex within the margin, simple or once 
or twice forking, their costule sinuate. Sori large, seated near the apex of the first veinlet, one to a lobule about its middle or near the sinus, Annulus with 16 joints. Spores ovoid-reniform, pale. Fib. vas, fascicles 5, the 2 lower ones largest. - Sp. Fil. IV, 266. - Synops. Fil. p. 311. Brack. 1. c. p. 16.

Not uncommon in forests from $1000-4000 \mathrm{ft}$. Simply bipinnate forms from Nuиanu Oahu. Small pinnate fronds in my possession, herbaceous, the entire frond with stipes not more than $5^{\prime}$ high, with only a few sori, probably represent the young state.

$\beta$ var. tripinnata. - Frond $1-2 \mathrm{ft}$. long, subphegopteroid, the rhachides nearly glabrate. Lowest pinnae $6-8^{\prime}$ long on stalks of $3-4^{\prime \prime}$. Tertiary pinnules or segments with simple veinlets and $2-6$ sori near the edge or sinus.

Oahu! Hawaii! The upper pinnae, as often occurs in the more compound forms of polystichoid ferns, are catadromous at the base, but soon anadromous from the second or third pinnule onward. Brackenridge's statement, "plant from 4-6 ft. high", undoubte edly refers to $P$. unidentata. Nat. name: "Palapalai aumakua".

5. P. unidentata, Mann, Enum no.611. - (Polypodium unidentatum), Hook, \& Arn. l.c. p. 105. - Caudex erect, 1-2 ft. high and about $10^{\circ}$ thick. Stip. 1-3 ft. long, stramineous or dusky, always densely clothed below with narrow lanceolate reddish-brown glandless scales ${ }^{1} / 2-1^{1} / 2^{t}$ long, which rise from rough protuberances, the scales falling off in size and number toward the upper portion. Frond firm membranous, dark green, close, deltoid-oblong, subcyatheoid, $1-3 \mathrm{ft}$. long, ${ }^{3 / 4}-2^{1 / 2} \mathrm{ft}$. broad at the base, tri-, quadripinnate, the rhachides sparingly fibrillose or naked. Stipitate pinnae $10-16$ on a side, the lowest deltoid- or ovate-oblong, 6-18' long, shortly stalked on stipites of $1^{1 / 2} 2^{\prime \prime}$, long-acuminate, more or less uneven-sided. Lowest secondary pinnae the largest, $3-6^{\prime}$, oblong-lanceolate, caudato-acuminate, projecting downward. Tertiary pinnae $1 / 3-1^{1} / 2^{\prime} \times 1-3^{\prime \prime}$, stipitate or sessile, ovateoblong, with a generally cuneate base, obtuse, crenate or lobed or again pinnate, the lobes broad, obtuse, curved upward and provided with 1 or 2 toothlets, one generally near the sinus. Veinlets not excurrent, simple or once or twice forking. Sori one to each lobe below the apex of the first upper fork-branch, in much compound forms close to the sinus, in narrow pinnules filling the entire surface. Receptacle flat. Sporangia dark red, with $13-17$ joints; no paraphyses. Spores ovoid-reniform, warty. Two large fib. vas. fascicles along the sulcus, with $4-8$ smaller ones along the convexity of the stipes. - Sp. Fil. IV, 267. - Synops. Fil. p. 310. - Brack. 1. e. p. 17.

In all forests from $2000-4000 \mathrm{ft}$. Not known from elsewhere. Nat. name: Akole*. Only the oue or two lowest pairs of pinnae, rarely 3 or 4 , are anadromous at the base, all others catadromous until the second to fifth pinnule; likewise the pinnules are homodromous at the base or catadromous until the second or fifth segment. The under surface is often whitish from a waxy secretion.

$\beta$ var. paleacea. - Caudex subarboreseent, $2-3 \mathrm{ft}$. high. Stip. $2-3 \mathrm{ft}$, long, rough, densely paleaceous throughout with long and dark linear 
scales. Frond large, quadripinnate, $3-4 \mathrm{ft}$. long, with often $20-23$ pairs of stipitate pinnae, the lowest $1^{1 / 2}-2 \mathrm{ft}$. in length. Rhachis and rhacheoles paleaceous throughout with scattering, stiff and blackish, ovate-lanceolate scales of about $3^{\prime \prime}$ in length. Ultimate segments ${ }^{1 / 2}-1^{\prime \prime}$ broad, with mostly simple veinlets, their margins wavy-crenulate and toothless, the mature sori covering the entire surface. Fib. vas. fascicles $8-13$ in a semicircle. Occasionally even one or both lowest pinnae are found catadromous at the base.

Maui! and Hawaii! from $4000 \mathrm{ft}$. upward; Kauai! (carborescent, the stem and frond $10 \mathrm{ft}$. high , Kn.).

The resemblance of var. $\varepsilon$ of Aspidium glabrum to $\alpha$ of the present Phegopteris is very puzzling. In especial, specimens from the hills of Kahuku and Kahana, Oahu, which are also of thicker texture and exhibit rather large raised sori, seem at first sight to differ only in the want of an indusium. The specific differences between typical representatives are, however, neither few nor unimportant, independently of the presence or absence of an indusium:

Aspid. glabrum. A smaller plant with a short rhizome, the stipes smooth and containing only 4-6 fib. vas. ducts; scales of the rhachis glandular. Sori dorsal on a raised receptacle; the veinlets excurrent. Pinnae long-stipitate, the first lowest pinnule much the largest and deflected outward.

Phegopt. unidentata. Plant larger, with a stout erect caudex, the stipes often rough and scaly throughout, holding 6-13 fib. vas. ducts. Scales of rhachis glandless. Sori subapical on a flat receptacle; the veins not excurrent. Pinnae shortly stipitate, the first lowest pinnule scarcely longer than its neighbor and not deflected.

6. P. Sandwicensis, Mann, Enum. no.612. - (Polypodium Sandwicense), Hook. \& Arn. l. c. p. 104. - Caudex 2-6 ft. high, 3-6' thick, erect or prostrate. Stip. $1^{1 / 2}-4^{1 / 2} \mathrm{ft}$. long, stout, with a ventral and a dorsal groove, stramineous or mahogany-brown, polished, furfuraceous with soft and pale russetcolored soon deciduous scales, densely so at the base, less in the upper portion, which is often naked. Rhachides furfuraceous or naked and glossy, quite pale, even whitish. Frond herbaceous, bright green, glabrous, subcyatheoid, ovateoblong, $2^{1 / 2}-8 \mathrm{ft}$. in length, bi-, tripinnate. Stipitate pinnae $12-17$ on a side, horizontal, the lowest oblong-lanceolate, not much uneven-sided, $15-28^{\prime}$ long, on stalks of $1 / 3-1^{1 / 2}$. Secondary pinnae almost perpendicular, stipitate, with a broad truncate even-sided base, lanceolate, $3-8^{\prime}$ $\times 1-3^{\prime}$, deeply pinnatifid or again pinnate with tertiary pinnules which are $3-2^{\prime \prime}$ broad, sessile or stipitate with a cuneate or truncate base, oblong-obtuse or lanceolate-subacute, erenate or lobed, the lobes deltoid or oblong, subentire, obtuse or truncate, often with a tooth in the sinus. Veins semitransparent, not excurrent, with a clavate apex. Sori subapical, pale, on flat receptacles. Sporangia with $15-18$ joints, not setose. Spores pale yellow, ovoid or subglobose. Two large and broad fib. vas, fasc. along the ventral sulcus and 9-11 smaller ones on the back. - Sp. Fil. IV, 267. - Synops. Fil. p. 312. - Brack. 1. c. p. 17.

A tall fern, found in the forests of all islands, but much less frequent than the preceding one. Occurs also on the Society and Viti Islands and on Piteairn's Island. The relative position of the sori varies with the degree of division in the frond. Subentire 
segments with simple pinuate veinlets, as are found in the highest degrees of division or near the apex of less cut up fronds, have all sori almost apical and submarginal. In erenate or lobed segments with 2 or 3 forking veinlets and one sorus to each group the latter stands midway between costa and margin, generally at the base of the segment, but near the sinus when a greater number of branches enter the deeper lobe.

As to habit, the one or two lowest pairs of pinnae are anadromous from the base, all others catadromous until the fourth to seventh pinnule; here and there one eatadromous throughout. Tertiary nerves also catadromous or homodromous until the second or third, but quaternary nerves, where they occur, anadromous. Bipinnate forms from Halemanu, Kauai, Waipio, Hawaii, and Kaanapali, Maui; most divided ones from the southern slope of Haleakala, Maui. - The furfuraceous covering is made up of thin scales with transparent cell-walls, long dentate and laciniate at the base. The species is easily recognized by the bright green frond and whitish rhachides. In $P$. Keraudreniana, which also has white rhachides, these are setose and the frond is much more open, elongate and less divided.

7. P. spinulosa, sp. n. - A smaller fern than the last. Stipes and rhachides dark stramineous or pale brownish, sparsely paleaceous to their last divisions with seattering linear-lanceolate long-acuminate entire dark scales or fibrils, the cell-walls thickened. Frond $1^{1 / 2}-2 \mathrm{ft}$. long, ovate to ovate-oblong, rather dark, firm membranous, tripinnate, sub. phegopteroid. Stipitate pinnae about 12 on a side, patent, the lowest $6-10^{\prime}$ long, on stalks of $4-1^{\prime \prime}$, ovate-oblong, scarcely uneven-sided. Secondary pinnae perpendicular, on stalks of $1-1^{1} / 2^{\prime \prime}$, oblong-lanceolate, with an even-sided truncate base, $2-2^{1} / 2^{\prime}$ long. Tertiary pinnae or segments oblong, $6^{\prime \prime} \times 1^{1 / 2}-2^{\prime \prime}$, sessile with a broad or cuneate base, obtuse, with $2-4$ sharp teeth at the broad top, their margins notched into 3 or 4 subopposite curving crenatures, each with $1-3$ forward pointing teeth. Veinlets converging, mostly excurrent. Sori dark, sub= apical and marginal, one close to each sinus. Sporangia with $16-18$ joints. Spores slightly margined or crested, reniform. Two broader fib. vas. fasc. near the sulcus and $4-6$ along the convexity of the stipes.

Southern slope of Haleakala, Maui! and Hamakua, Hawaii! Two or three middle. pinnae catadromous only with regard to the basal pinnules; the lower ones anadromons and the upper homodromous. The opposition of the two, three or four lowest tertiary segments imparts to the frond somewhat of the aspect of $P$. rugulosa. Distinet from $P$. Sandwicensis not only in the sharply toothed segments but also in the habit of the frond, the character of the scales, and the number of fib. vas. ducts. In all these respects it agrees with Aspid. spinulosum, Sw.

8. P. Hillebrandi, Hillebr. - (Polypodium Hillebrandi), Hook. Sp. Fil. IV, 254. - Rhizome thick, woody, subterraneous, shortly branching. Stip. tufted, 4-6 ft. long, dusky-brownish, clothed below with linear curly dark-brown scales. Frond as in Aspidium latifrons, but darker and larger, 4-5 ft. long and $2-3 \mathrm{ft}$. broad at the base, often tripinnate, the rhachis thinly clothed with dark linear sealelets or hairs. Lowest primary pinnae $15-20^{\prime}$ long, sometimes catadromous like all others. Veins and marginal sori as in A. latifrons, but the latter naked. Sporangia yery large and stout, dark, with $14-20$ (mostly $14-16$ ) joints to the annulus. Spores pale, plano globose, with a single dorsal line. Fib. vas. fascicles 6-8. - Synops, 
Fil. p. 311. - Polypod. Honolulense, Hook. Sp. Fil. IV, 288 (foot note).

Oahu! Kalihi, Kaala, Kahuku, Kahana; Molokai! Kamalo, Pelekunu; Lanai! Maui! Hawaii (Baldwin). - Nat. name: "Akoleas. The great resemblance of this fern to Asp. latifrons was adverted to by Mr. Baker in the Synopsis Fil, and I have long felt doubtful whether it should not be united with the latter; but careful observation of many living plants always revealed naked sori even in the earliest stage of development. It has to be borne in mind, too, that the involucre of $A$. latifrons is large, firm and permanent.

\section{ASPIDIUM, Sw.}

Sori on distinct receptacles, globose, dorsal, rarely apical, or at first apical but by prolongation of the anastomosing veinlets soon dorsal. Involucre orbicular and peltate, attached by the centre, entire or slit, or cordate-reniform, attached by the sinus. Veins free or anastomosing, the sterile ones ending in an acute apex. Stipes exarticulate. Spores ovoidreniform, marked with a single dorsal line.

A large genus, spread over the entire globe.

Frond pinnate:

Pinnae subentire or serrate:

Pinnae ovate or ovato-lanceolate . . . . . . 4. A. caryotideum.

Pimae linear-lanceolate . . . . . . 6. A. cyatheoides.

Pinnae moderately cut; the lower veins of adjoining lobes anastomosing :

Pinnae eut about $1 / 3$ their width into triangular lobes; lowest sori not marginal .

Pinnae eut to $1 / 2$ their width; the sori confined to the lanceolate lobes and all marginal .

Pinnae cut deeper; the sori not confined to the truncate lobes and not marginal .

Pinnae deeply eut; veins of adjoining lobes not uniting:

Sori marginal; rhachis and stipes naked

Sori not marginal; rhachis and stipes paleaceous

Frond bipinnate:

Frond large, stiff, brownish; segments awnless

Frond small, herbaceous; segments awned

Frond tri-, quadripinnate; veins free:

Sori close to the costule

Sori submarginal

Sori midway between costule and margin:

Stip. and rhachis covered with pale diaphanous ovate scales

Stip. and rhachis covered with blackish hair-like scales

Upper portion of stipes naked or scantily fibrillose:

Segments mueronate or awned: invol. peltate. . . 3. A. aristatum.

Segments rather obtuse, with $1-3$ toothlets; invol. netched 13. A. glabrum.

Frond decompound; veins anastomosing 5 5. A, apiifolium.

9. A. unitum.

\section{S. A. terminans.}

7. A. truncatum.

10, A, globuliferum.

11. A. filix-mas.

1. A. Hillebrandi.

2. A, aculeatum.

14. A. rubiginosum.

16. A. latifrons.

15. A. squamigerum.

12. A. Havaiiense.

Polystichoid: A. Hillebrandi, aculeatum, aristatum, caryotideum, filix-mas, Hawailense, glabrum.

Subphegopteroid: A. glabrum, var, rubiginosum.

Cyatheoid: A. cyatheoides, truncatum, terminans, unitum, globuliferum, squamigerum, latifrons, apiifolium.

A. Polystichum, Schott. - Involucre peltate. Veins all free. Teeth of pinnules or segments usually sharp or awned. Frond polystichoid. 
1. A. Hillebrandi, Carruthers, in Seem. Fl. Vit. p. 358. - Caudex stout, erect, $6-12^{\prime}$ high. Stip. 4-8', light brown, glossy, densely clothed throughout with large, ovate to lanceolate, retrorsely laciniate and dentate, pale brown or reddish, diaphanous scales, which when fallen leave a sharp ridge or tubercle. Frond lanceolate, narrowing at the base, $1^{1 / 2}-2 \mathrm{ft}$. long, $3-6^{\prime}$ broad, coriaceous, shining above, dark green, olivaceous when dry, bipinnate, with pinnatifid apex; the rhachis paleaceous, ribs and veins fibrillose underneath. Pinnae $20-40$ on a side, subsessile, erectopatent, lanceolate, falcate, acute, the longest $3^{\prime}$, the upper basal pinnule parallel to the rhachis and little exceeding its neighbor. Outer segments obovate, with cuneate base, entire, shortly toothed at the apex, the inner pinnules shortly stipitate, ovate-rhomboidal, $4-6^{\prime \prime} \times 2-3^{\prime \prime}$, with an entire or subauriculate rounded upper base, muticous or with a cartilaginous toothlet at the apex and auricle only. Veins hidden. Sori 7-9 to a pinnule, halfway between midrib and edge, dorsal on the anterior fork-branch or almost terminal on a short lateral branch of the same. Invol. peltate, entire, stiff, permanent, upturned when dry, rather small.

$\beta$ var. - Pinnules larger, $6-10^{\prime \prime} \times 3-4^{\prime \prime}$, truncate, with several toothed but not awned crenatures on each side.-A. Haleakalense, Mann, Enum. no 594.

$\gamma$ var. - Frond less stiff, chartaceous. Pinnae $4-5^{\prime}$ long. Pinnules as in $\beta$, but the upper basal one much the largest and deeply lobed, all the crenatures and lobules blunt, excepting one short tooth at the apex and auricle. Fib. vas. fascicles 5 .

Southern slope of Haleakala, Ma i i! Kohala range and Mauna Kea, Ha waii! in forests at altitudes of $3000-5000 \mathrm{ft}$. - A near relative of $A$. aculeatum, the form $\alpha$ corresponding to its var. lobatum, Kze., and $\gamma$ to var. angulare, Sm., or aculeatum, Sw. It differs from all the genuine forms of that variable species in the absence of awns, and in its simplest state $\alpha$ in the entire segments or pinnules. The frond is thicker than that of any form of A. aculeatum; in the dried state the sori form prominences on the back of the pinnae. Nat, name: "Papaoi".

2. A. aculeatum, Sw. var. Braunii, Doell. - A weak and low fern with a very short caudex. Stipes stramineous, $2-7 *$ long, paleaceous. Scales concolorous, pale, diaphanous, lanceolate below, retrorsely dentate above, intermixed with soft denticulate fibrils which closely invest the rhachides and midribs. Frond linear-lanceolate, narrowing below, occasionally very small, $4^{\prime} \times 1^{\prime}$, in the larger forms $9-15^{+} \times 2^{1 / 2}-4^{1 / 2^{t}}$, herbaceous, dull, hispid on both faces, bipinnate. Pinnae $20-28$ on a side, lanceolate, spreading, ${ }^{3} / 4-2^{1} / 4^{4} l o n g$, the shorter ones rather obtuse, the upper basal pinnule not much longer than its neighbor. Pinnules obliquely ovate-lanceolate, with the subtruncate upper base rounded and receding from the rhachis, deeply cut into ovate lobules, each with $1-3$ sharp awns. Sori between costa and margin, $5-9$ to a pinnule, more than one to the basal lobe, at last covering the whole under side. Invol. thin, peltate, denticulate, fugacious. - Mann, Enum. no. 593. - Polystichum 
Haleakalense, Brack. in Fil. U. S. E. E. p. 204, pl. 28. - Sporangia globose, with a ring of about 20 joints. Spores ovoid, runcinate. Fib. vas. fascicles 3 .

Rare. Hawaii, Mauna Loa (Mann), Mauna Kea (Braek.); Ma ui! northern slope and crater of Haleakala (Lydg. and Baldw.) at heights of 6000-9000 ft. Nat. name: "Kaupus, This fern agrees in every respect with the var, $\gamma$ of $A$. aculeatum, Milde, Fil. Eur. et Atlant. p. 108, A. Gray, Man. Bot. p. 599, A. Braunii, Spenner, Luerssen, in Crypt. Fl. Germ. III, 320. Rather rare and intermixed with the other forms of A. aculeatum in Central Europe and the Caucasus; it is the only representative of the species in the United States and Canada east and west. No intermediate form between it and $A$. Hillebrandi has been found. A. Prescottianum, Wall., from the higher Himalayas seems to be a simply pinnate state of it.

3. A. aristatum, Sw. var. coniifolium, Wall. - Hook. Sp. Fil. IV, 2r. -Caudex prostrate, rooting. Stip. at short intervals of $2-4^{\prime \prime}$, rather slender, $1^{1 / 2}-2 \mathrm{ft}$. long, pale brown or stramineous, glossy, clothed below with large ovate-lanceolate long-acuminate $\left(1-1^{1 / 2^{\prime}}\right)$ pale diaphanous scales, with matted deciduous fibrils above. Frond dark-green, thin chartaceous, deltoid-ovate, gradually acuminate, $1^{1 / 2}-3 \mathrm{ft}$. long and $1^{1 / 4}-2^{1 / 2} \mathrm{ft}$. broad below, with a fibrillose, soon glabrate rhachis, open, quadripinnate. Pinnae (at least 9-10 bipinnate ones on a side) ovate-lanceolate, ascending; the basal ones on stipites of $6-9^{\prime \prime}$, very broad, $12-14^{\prime} \times 6-7^{\prime}$, their lower half much the broadest, with its first pinnule twice the size of the first upper one, but not deflected. Ultimate pinnules stipitate, rhomboidal, about 6 " long, with cuneate base and 3-5 sharply awned serratures or lobes on each side, besides the awned apex. Sori $5-7$ to a pinnule, in two rows between midrib and edges. Veins strigose. Invol, dark, thin and flat, peltate, denticulate, occasionally slit on one side. Ring of sporangia with 18-22 articulations. - Synops. Fil. p. 255. - A. coniifolium, Wall., Metten. Aspid, p. 67. - Thwaites and Wallich, in Catalogue of Ceylon Ferns.

Not before reported from the Hawaiian Islds. High ridge of Lanai! W. Ma ui above Lahaina! high plateau of Kauai! (Kn.). - The species occurs in Tahiti, the Samoa, Viti and N. Hebrides gronps, Norfolk Isld., Malaysia, Australia, China, Japan, India, Natal. Our variety is said to possess an erect caudex in Ceylon, on which account Thwaites and others separate it as a species from $A$. aristatum, which has a creeping rhizome. In our plant the rhizome is intermediate between both.

B. Cyrtomium, Presl. - Involucre peltate. Veins anastomosing, the secondary branches of parallel veins uniting to form series of obliquely oblong areoles with free veinlets. Nervatio Cyrtophlebii.

4. A. caryotideum, Wall. - Hook. Sp. Fìl. IV, 40. - Caudex short, prostrate, rooting. Stip. crowded, $6-12^{4}$ long, stramineous, scantily clothed with ovate or lanceolate $\left(2-3^{\prime \prime}\right)$ dentate scales, dark and opaque at the base of the stipes, pale and transparent higher up and soon caducous. Frond chartaceous, pale, oblong, throughout of even breadth, $9-14^{\prime} X$ $5-7$, pinnate with a terminal pinna, polystichoid, the rhachis scantily fibrillose. Pinnae $3-9$ on a side, stipitate, broadly ovate-lanceolate, 
falcate, $4-5^{\prime} \times 1^{1} / 2-3^{1} / 2^{\prime}$, finely, often spinosely serrate, rounded at the base, with the upper half dilating into an obtuse or acute lobe or auricle; the two or more lowest pinnae biauriculate, the terminal one tricuspid, Primary veins scarcely prominent, straight, with a single series of 5 or 6 oblique areoles between them, each areole with 1, 2 or 3 free acute veinlets or rays. Sori copious and large, dorsal on nearly every free veinlet. Invol. peltate, umbonate, thin, flat. Ring of sporangium with 16 joints or less. - Brack. 1. c. p. 184. - Hook. \& Gr. Ic. Fil. tab. 69. - Cyrtomium caryotideum, Presl, Tent. Pterid. tab. 2, fig. 26. - Metten. Aspid. p. 35.-A. falcatum, var. caryotideum, Baker, in Synops. Fil. p. 257.

Sometimes the inferior border of the lowest pinnae is irregularly notched into a few deltoid lobules. In one specimen the auricles of the lowest pinnae are entirely separated by deep slits, so as to form palmate pinuas. Another specimen exhibits a bifid rhachis.

In the forests of all islands. Nat.name: "Kaapeape". The species occurs also in the Himalaya and Neilgherry mountains, in Caffraria and Natal. In India it is said to pass into forms like A. falcatum, Sw., a native of China and Japan, in which all pinnae are entire, without auricles. On the Hawaiian Islands no such transition has been observed, and besides there exists an additional difference in the non-erect rhizome and the sharp serratures of our plant,

C. Sagenia, Presl. - Involucre cordate or reniform. Veins anastomosing copiously and irregularly, usually with free included veinlets, the areoles along the rib and main veins elongate. Frond cyatheoid, with ample pinnae and segments.

5. A. apiifolium, Schluhr, Fit. Germ. p. 128, tab. 36 B. - Caudex thick, prostrate. Stip. crowded, $1 \mathrm{ft}$. or more long, deep mahogany-brown or purple, glossy, with a few stiff and dark lanceolate scales $\left(1 / 2^{\prime}\right)$ at the base, otherwise naked. Frond deltoid, 1-4 ft. long and as broad, dark green, membranous, the apex deeply pinnatifid with sinuate lanceolate lobes which are separated by broad angular sinuses, the broad wing on each side receiving a secondary nerve from the rhachis; below this $2-6$ nearly opposite pairs of pinnae. Lowest pinnae stipitate, deltoid, $4-16^{\prime}$ broad at the base, - the lower half much the largest - , pinnatifid in the smaller forms, pinnate with several stipitate pinnules in the larger ones, the largest pinnules $1-5^{\prime}$ broad, more or less deeply cut into oblong or falcate pointed seg. ments with crenate or obtusely lobed margins. Main veins rather prominent, sinuately excurrent to the apex of a lobe, including between them an indefinite number of faintly marked irregular areoles with few or no free veinlets. Sori large, in two nearly regular lines, about halfway between the costule and the margins. Sporangia with about 16 ring-joints. Fib. vas. ducts usually 10 in a circle near the circumference. - Brack. 1. c. p. 182. - Metten. Aspid. p. 120. - Nephrodium apiifolium, Hook. \& Arn. in Bot. Beech. - A. sinuatum, Gaud, in Bot. Freyc. - Microbrochys apiifolia, Presl, Epimel. p. 52. - Nephrod. cicutarium, var. apiifolium, Hook. in Sp. Fil. IV, 49, and Synops. Fil. p. 299.

Common in the lower woods and gulches. Nat, name: -Iwaiwa lau nuip, 
$\beta$ var. pubescens. - Frond smaller, ovate, the lowest pinnae not exceeding the next ones; the rhachis, ribs and margins of the frond shortly pubescent. Pinnae and segments obtuse.

Southern slope of Haleakala, Maui!

In all my specimens the stipes is as above described, while the American plants of A. cicutarium, Sw., have it pale stramineous, and since the elimination of the truly distinct $A$. simulans, Baker, I believe there remain only forms with pale stipites among the Asiatic and African representatives of that species. It seems to be doubtful if Schkuhr's original plant derived from the Hawaiian Islands, but all the other quotations refer to our plant.

D. Nephrodium, Schott. - Involucre cordate or reniform. Veinlets simple and straight, in less divided pinnae the lower corresponding ones of contiguous groups uniting to form a single ray or a spurious costule which runs out at the sinus (nervatio Goniopteridis); in deeper divided pinnae all veinlets free. Sporangia with $16-18$ ring-joints. Spores bilateral, ovoid, smooth. At the base of the stipes 2 lateral oblong fib. vas. bands, which unite in horseshoe shape higher up. Frond cyatheoid, with a tendency to opposition in the median pinnae and secondary and tertiary nerves. (Character modified.) - Lastrea \& 1 Dryopteris, Presl.

\section{A. cyatheoides, Kaulf. Enum. Fil.p.234. - Caudex short and stout, erect} or prostrate. Stip. $1^{1 / 2}-2 \mathrm{ft}$. long, stout, deeply grooved, dark stramineous, sparingly furfuraceous or naked. Frond cyatheoid, chartaceous, dark, oblong, truncate below, $2-4 \mathrm{ft}$. in length, pinnate throughout, with a stipitate terminal pinna, rarely proliferous near the apex. Pinnae $18-26$ on a side, closely set, horizontal, linear-lanceolate, long-acuminate, 6-15 $X^{1 / 2}-1^{1} / 2^{\prime}$, very shortly stipitate, with an even-sided truncate or cordate base, the margin crenate or coarsely serrate into numerous (60-90) rather obtuse, forward pointing teeth or lobules. Primary veins almost perpendicular to the midrib, pinnate with 10-12 distinct veinlets on each side, $7-10$ uniting with the corresponding ones of the next groups. Sori dark, one at the base of each veinlet, forming two straight lines parallel with and contiguous to the costule, confluent with age. Invol. cordate, with narrow sinus, fugacious, dark, entire. - Metten. Aspid. p. 110. - Nephrodium cyatheoides, Presl, Tent. Pterid. tab. 2, fig. 5. - Sp. Fil. IV, 76, tab. 241. - Synops. Fil. p. 293. - Polystichum Dubreuilleanum, Gaud. in Bot. Freye. p. 333, tab. 9. - Nephrodium Dubreuilleanum, Hook \& Arn. Bot. Beech. p. 105.

Common in the lower woods and gulches; the Kikawaeos of the natives, who eat the young shoots as a vegetable, cooked with meat and taro. - The fern resembles greatly the Malayan A. ferox, Bl, which has a rough and hairy stipes and rhachis. Oecasionally only the lowest pair of veinlets bears sori, in which case the pinna has only two lines of them closely contiguous to the midrib, with perhaps a few sori sprinkled irregularly over the sides. The $2-4$ lowest pinnae are anadromous, then follow $1-3$ opposite ones with homodromous bases, while all the rest are catadromous from the base onward. Tertiary veins eatadromous from the base. 
$\beta$ var. exaltatum. - Frond pale, with a very broad and flat rhachis. Pinnae slightly crenate, narrowing at the base. Sori only in two rows along the midrib, as in Oleandra, almost black.

Kauai, woods of Waimea. Of this plant Mr. Knudsen writes that it grows to the height of $12 \mathrm{ft}$., without indicating, however, what proportion of the measure falls to the eaudex.

$\gamma$ var. depauperatum. - Whole frond with stipes only $3-15^{\prime}$ high. Pinnae ${ }^{3 / 4}-2^{\prime}$ long, entire or slightly crenate, truncate. Main veins in small fronds with $2-4$ pairs of veinlets, only one or two branches anastomosing irregularly, almost in the manner of Cyrtomium, in larger fronds the venation distinctly goniopteroid. Sori scattering, chiefly near the midribs of the pinnae. - A. Boydiae, Eaton, in Bull. Torrey Club, N. Y. VI, $\$ 361$.

On bare rocks in the bed of the Wailuku river, Hilo, Hawaii, where the ordinarysized form grows along the banks. If it were not for this circumstance it would be difficult to recognize the affiliation. Found also by Baldwin under the same conditions by the side of a stream in Koolau, Oahu! A larger proportion of pinnae are anadromous here than in $\alpha$, with a short auricle to the superior base. The smaller the plant the greater the relative number of anadromous pinnae.

7. A. truncatum, Gaud. Bot. Voy. Freyc. p. 333, tab. 10 (in tabula). Caudex erect. Stip. stramineous, $8-12^{\prime}$ long, slightly scaly at the base only. Frond thin chartaceous, bright green, glabrous or with a few minute pale scales along the rhachides, oblong-lancenlate, $1^{1 / 2}-2^{1 / 2} \mathrm{ft}$. long, pinnate with $16-24$ pinnae and a pinnatifid apex, the 2 or 3 lowest pinnae often shortened, sometimes dwarfed. Pinnae patent, linear-lanceolate, $7-12^{\prime} \times{ }^{3} / 4-1^{1} / 4^{\prime}$, subsessile or shortly stipitate, with an evensided truncate base, cut into broad oblong rounded or truncate lobes with narrow sinuses. Veins inconspicuous, pinnate with $7-10$ pairs of veinlets, only the one or two lowest uniting with the corresponding ones of the next lobes. Sori on the middle of nearly every veinlet except the apical ones, $5-8$ on a side, forming two rows which are equidistant from each other and from those of the next lobules. Invol. pale, thin, evanescent, cordate. - Metten. Aspid. p. 106. - Polystichum truncatum, Gaud. 1. c. in the text. - Nephrodium truncatum, Presl. - Synops. Fil. p. 294. - N. Hudsonianum, Brack. 1. c. p. 189, pl. 25. - Aspidium Hudsonianum, Mann, Enum. no. 597.

In the lower and middle forests of all islands, not uncommon, Nat. name: -Laukahis. The range of the species, as given in the Synopsis - Polynesia, Australia, Malaysia, Ceylon, N. India - is probably too large. Polynesian forms from Upolu only differ in having the sori a little nearer to the costule. $N$. ensorum, Thw., from Ceylon is also much like ours $-2-3$ anastomosing veinlets and a greater number of dwarfed pinnae -; but $N$, abruptum. Pr., with a darker, pubeseent frond and $5-7$ uniting veinlets against 3 or 4 free ones, would not appear to belong here. Forms of the present species are referred to in the Sp. Fil. under Nephrod. patens and $N$. extensum. - Only the lowest short pinnae are subopposite; $4-5$ pinnae anadromous, all others catadromous from the base to the apex. Tertiary veins nearly all opposite, except at the apex.

8. A. terminans, Wall. - Stip. dark stramineous. Frond thin chartaceous, glabrous, bright green, oblong, 1-2 ft., long, pinnate throughout, 
truncate below. Pinnae about 20 on a side, spreading, linear, $6-7^{\prime} \times$ $7-10^{\prime \prime}$, shortly stipitate, the lower ones narrowing toward their bases, the upper ones truncate and even-sided below, cut halfway to the rhachis into numerous lanceolate pointed subfalcate crenulate lobes, $1^{1 / 2}{ }^{\prime \prime}$ broad, with a space between them. Veins distinct, pinnate, with $10-12$ pairs of simple veinlets, only the lowest one (always sterile) uniting with the corresponding one of the next segments. Sori confined to the lobes and marginal, 5-7 on each side. Invol, thin, reniform, entire, not setose. Fib. vas. band at the middle of the stipes in shape of an arch around the sulcus, or with a short break in the middle. - Nephrodium terminans, J. Sm. - Sp. Fil. IV, 73. - N. pteroides, J. Sm. - Synops. Fil. p. 289.

In Mr. Baldwin's colletion, without assignment of station. The rhizome, wanting in my specimens, is ereeping in the species. Nearly related to A. extensum, Bl. Occurs also in India, S. China, the Philipines, Queensland and Samoa. Lowest pinnae auadromous, all others catadromous from the base. Tertiary veins mostly opposite.

9. A. unitum, Siv. Syn. Fil. p. 4\%. - Rhizome creeping, naked. Stip. distant, 8-20' long, slender, dark stramineous, naked. Frond chartaceous, glabrous, with scattering resinous dots underneath and the costa of the pinnae minutely paleaceous when young (not pubescent), oblong-lanceolate, truncate at the base, $1^{1 / 2}-2 \mathrm{ft}$. long, pinnate throughout, with a stalked terminal pinna. Pinnae $15-20$ on a side, close, ascending, linear, $4-6^{\prime} \times 4-6^{\prime \prime}$, shortly stipitate, slightly narrowing toward the subcordate or rounded base, cut to $1 / 3$ or $1 / 2$ into broad triangular pointed lobes. Veins prominent, the primary ones at open angles, pinnate, with 6-10 simple, rather curved veins on each side, the one or two lowest anastomosing in an excurrent ray. Sori small, on the middle of the free veinlets, rarely also on the connected ones, $4-6$ on each side in two converging rows. Invol. reniform, setose, evanescent. - Mann, Enum, no. 599. - Polypodium unitum, L. - Nephrodium unitum, R. Br. - Synops. Fil. p. 289 . - N. propinquum, R. Br. - Sp. Fil. p. 79. - A. resiniferum, Kaulf. - N. resiniferum, Hook. \& Arn. in Bot. Beech. p. 105. - Polystichum propinquum, Gaud.

Very common in swamps and deserted staros-patches. Nat. name: $n$ Neke*. - Oceurs in the tropical zones of all continents and Polynesia. - Lowest 12-16 pinnae anadromous and mostly subopposite, only $3-4$ catadromous. Tertiary veins mostly opposite, but on the whole catadromous. Two broad fib, vas. bands along the sides of the suleus with a. tendeney to unite.

10. A. globuliferum, Mann, Enum. no. 601. - Rhizome short, oblique. Stip. tufted, short, 3-6', pale to mahogany-brown or purplish, naked and glossy. Frond membranous, firm, dark green, lanceolate, $1^{1 / 2}-3^{1 / 2} \mathrm{ft}$. long, $6-16^{4}$ broad at the middle, gradually narrowing below, dotted with glistening resinous glands, pinnate, with pinnatifid apex, the rhachis stramineous. Pinnae (32-42 free ones on a side) patent, mostly opposite, the lowest $6-10$ dwindling down to mere auricles, 
the middle ones linear-lanceolate, $3-8^{\prime} \times{ }^{1 / 2}-3^{3} / 4^{\prime}$, subsessile with a broadly truncate even-sided base, cut down almost to the rhachis into patent closely set oblong obtuse faintly crenate segments or lobes of $1^{1 / 2}-2^{\prime \prime}$ in breadth, one or both basal segments larger, auriculate and generally deflected over the main rhachis. Veins pinnate with $5-11$ pairs of simple veinlets, all free. Sori marginal, one to nearly every veinlet. Sporangia dark brown, glistening. Invol. thin and small, reniform, setose with mostly glandular hairlets. - The stipes holds a single central broad arcuate fibro-vasal band. - Lastrea globulifera, Brack 1. c. p. 194. - Nephrodium globutiferum, Hook. Sp. Fil. IV, 96. - Synops. Fil. p. 269.

Hawaii! Kohala range and Mauna Kea; Maui! Kaanapali; Ka uai! Halemanu (Kn.); at elevations of $4000--5000 \mathrm{ft}$. Nat. name: "Palapalai o Kaumaapua”. - The largest forms, almost bipinnate with rather acute pinnules or segments, the pinnae $12-16^{\prime \prime}$ broad, come from the last named locality. The cyatheoid character, always manifest at the apex of the frond and of the pinnae, is less so at the base of the latter and their segments, the basal secondary and tertiary veins being generally opposite, as are the majority of the pinnae; but even the second or third inferior nerves or veins stand nearer the costa or costule than their mates of the upper half.

E. Lastrea, Bory. - Involucre cordate or reniform. Veinlets always free, the lower ones forking or pinnate. Two larger, round or oblong fib. vas. fase. along the suleus and $1-5$ smaller round ones along the convex part of the stipes. - Thelypteris and Arthrobotrys, Presl.

11. A. filix-mas, $S w$. var parallelogrammum, Kze. - Caudex erect, $1^{1 / 2} \mathrm{ft}$. high and several inches thick. Stip. 8-18' long, pale brown, densely clothed below, as are the young shoots throughout, with thin dark brown narrow-lanceolate long-acuminate entire scales of $1-1^{1 / 2} 2^{\prime}$, which change higher up and on the rhachis to remotely dentate concolorous fibrils, the teeth longer and two- to several-pronged near the base. Frond polystichoid, stiff, coriaceous to chartaceous, dark green, oblong-lanceolate, narrowing below, $1^{1 / 2}-3 \mathrm{ft}$. long, broadest at the middle, $8-12^{\prime}$, pinnate, with pinnatifid apex, the rhachis densely fibrillose or hirsute. Pinnae close, $20-30$ on each side, horizontal, linear-lanceolate, $5-10^{4} \times^{3 / 4}-1^{1}$, subsessile with an abruptly truncate, almost even-sided base, cut deeply, to the rhachis near the base, at angles of $90-80^{\circ}$ into closely set oblong angular lobes which are $1 \frac{1 / 2-2^{1} / 2^{\prime \prime}}{\text { broad, entire at the margins }}$ and denticulate at the broad truncate apex, the lower basal one mostly auriculate and deflected over the rhachis. Veins distinct, most of them with 2-5 fork-branches. Sori rather small and close, on the upper basal veinlet of each group, $4-6$ on each side of the costule and nearer to it than to the margin. Invol. orbicular-incised, firm, convex, not glandular, its cells wary, Sporangia with $13-15$ ring joints. Spores ovoid, verrucose. Fib. vas, bands 7 . - Nephrodium filix-mas, var. $\beta$, Hook. in Sp. Fil. IV, 116. - Lastrea filix-mas, var. paleacea, Moore and Metten. - L. truncata, Brack. 1. c. p. 195 , pl. 27. 
Rather common on the highlands of E. Ma ui ! Haw aji! and Ka u a i! Nat. name: Laukahis. - The growing plant is readily distinguished from the following variety by its stiff erect habit, in shape like a shuttle-cock. In many fronds the greater number of pinnae stand opposite, as are also the segments in the lower portion of the pinnae; only the two lowest pairs of pinnae are distinctly anadromous at the base. - Among the numerous varieties of the widely spread species those from tropical America, viz., A. parallelogrammum, Kze. and A. crinitum, Mart. \& Gal,, are nearest akin to the present form. Pinnae and segments stand very close, so as to touch each other, while in $\beta$ the fewer pinnae leave a space between them, and the lanceolate segments recede from each other toward the apex.

\& var. fusco-atrum. - Stip. dark stramineous. Scales discolorous, those of the rhachis blackish, but otherwise as before. Frond pale, rather open, straggling, not stiff, ovate-oblong, $1^{1 / 2}-2 \mathrm{ft}$. long and $10-22^{\prime}$ broad, not narrowing below. Free pinnae $16-20$ on a side, ascending, lanceolate, the lowest not shorter than those next to them, 6-10' long, 1-2' broad at the base, distinctly stipitate, their margins cut ${ }^{2 / 3}$ or more at angles of $70^{\circ}$ into obtuse, lanceolate or subfaleate, wavy-crenate segments of $4^{\prime \prime}$ in breadth, the inferior basal segment only being mostly free with a sub. auriculate base. Veins indistinct, flexuose, simple or once forking. Sori large and distant, sometimes midway between costule and edge, but mostly nearer the former.

Highlands of Hawaii, Maui! Molokai! Kauai! Like the European forms in color and habit, but differing in the truncate shape of the frond and the discolorous scales. Specimens from Ceylon agree in both respects, but have differently eut segments. Few pinnae are opposite, but the segments and veins generally are.

The species with its numerous modifications extends over four continents from the Aretic circle to the mountainous regions of many tropical countries. It is however absent from Australia, and in Polynesia is confined to the Hawailan group.

12. A. Hawaiiense, $s p, n$. - Caudex erect, $4-8^{\prime}$ high. Stip. slender, $8-18^{\prime}$ long, dusky-stramineous, brownish below, sparingly covered throughout with thin entire linear-lanceolate brown scales which change to remotely dentate dark fibrils on the rhachis and rhacheoles. Frond polystichoid, chartaceous, dark green, oblong or ovate oblong, not narrowing below, $1-2 \mathrm{ft}$. long and $10-12^{\prime}$ broad, bi-, tripinnate. Pinnae $(12-16$ stipitate ones on a side) patent, close, overlapping, oblong to ovate-lanceolate, $2^{1} / 2-3^{\prime}$ broad at the truncate base, shortly stipitate and partly covering the rhachis, the lowest very little uneven-sided on stalks of $1-1^{1 / 2} 2^{\prime \prime}$. Pinnules close, lanceolate, $1^{1 / 2}-2^{1 / 2^{\prime}} \times{ }^{3 / 4}-1^{4}$, the lower ones shortly stipitate, deeply cut into broad oblong subentire rounded or truncate lobes $2-3$ " broad with $1-3$ short toothlets at the apex. Veinlets indistinct, flexuose, simple or once forking. Sori $4-6$ in each lobe, dorsal, halfway between midrib and edge. Invol. dark, thin and flat, orbicularincised, sometimes peltate, with a few sessile ovoid glands, its cells not wavy. Sporangia with about 18 articulations. Spores ovoid-reniform, verrucose. Fib. vas. bands $5-7$.

Hawaii! northern slope of Mauna Kea, 4000-5000 ft., in the woods near Parker's kanch, where it was collected by the writer in 1862 . - M. \& B's no. 284 is from the same 
region. - The lowest 3 or 4 pinnae are anadromous from the base; in the others the basal pinnules are opposite and anadromy only commences with the second to fourth, as is also the case with the tertiary segments or pinnules. A singular circumstance is observed in the spores. While the majority of capsules eontain small and pale yellow ones, 6-10 each, not few are found with spores of many times the ordinary size and quite dark. Two or three, and often a single one fill the entire capsule. The plant is probably a derivate from var. $\beta$ of no. 11 , and has some analogy with $A$. Canariense, A. Br, but is too distinet to be united with it.

$\beta$ var. - Upper stipes and rhachis glabrate. Frond subcoriaceous, the pinnules stipitate with a broad and mostly decurrent stipes; their seg. ments wavy-crenate and rounded at top. Sori submarginal.

Ka uai! high fog-swept plateau between Waimea and Hanalei (Kn. and E. Johnson).

13. A. glabrum, Metten. Aspid. p. 59. - Rhizome short, oblique. Stip. tufted, slender, 6-15' long, stramineous or brownish, glossy, paleaceous below with dark brown lanceolate long-acuminate sparingly glandular scales of $4-6^{\prime \prime}$ in length. Frond open, thin chartaceous, rather pale, glossy, deltoid-ovate, polystichoid, $8-15^{\prime}$ long, with a naked or fibrillose rhachis, bi-, tripinnate. Stipitate pinnae $7-11$ on a side, all anadromous from the base, subascending; the lowest on stalks of $3-12^{\prime \prime}$, deltoid, much broader in the lower half, 5-8' long. Lowest secondary pinnae the largest, 3-4' long, deflected outward. Tertiary segments or pinnules ${ }^{1} / 2-1^{\prime}$ long, sessile and decurrent or shortly stipitate with a cuneate or unevenly truncate base, obtuse or bluntly pointed, notched or deeply cut into ovate or oblong lobes which point toward the apex and are mucronate with $1-3$ elosely approximate teeth. Veinlets at acute angles, simple or forked, the upper basal branch ending in a sinal tooth. Sori subterminal on raised receptacles, copious, large, in less divided forms at a distance from the sinus, in deeper cut ones close to them. Invol. firm, reniform, lined with sessile, transversely oblong glands. Sporangia with $12-16$ ring-joints, intermixed with glandular paraphyses. Spores dark red, ovoid-reniform, rough or muricate. Fib. ras. bands 4 or 5, rarely 6. - Lastrea glabra, Brack. 1. c. p. 100. - Nephrodium glabrum, Synops. Fil.. p. 278.

Not uncommon in the lower and middle forests of all islands. Nat. name: "Kilau". - The less divided forms, as they come from Kaala, Oah u, are open, with longer stalks to their pinnae than the more compound ones. This form ean hardly be distinguished from A. atmulum, Sw., from the Atlantic islands, in the involucre of which the glands are not always stipitate, and I should not have hesitated to unite our plant with the older species if it had not been for the numerous varieties, which are wanting in the latter. Differential characters of minor importance may be found in the shape of the glands, which are globose or ovoid in $A$. aemulum, the smaller number of fib. vas. fascicles, $2-4$, and the peculiar hay-scent of the latter, which is wanting in our plant.

B var. quadripinnatum. - A large form. Stip. deep brown, naked, glossy, $18^{\prime}$ long. Frond rather thick, chartaceous, $2 \mathrm{ft}$. or more long, quadripinnate; the lowest pinnae $10-12^{\prime}$. Lowest ultimate segments $4-6^{\prime \prime}$ $\times 1^{1 / 2} 2^{\prime \prime}$, substipitate with a broad cuneate base, each side with 3 mucronate crenatures and as many sori at a distance from the sinus. - In 
some fronds all pinnae, except perhaps the fourth, are anadromous at the base or at least homodromous; in others from the same locality 4-7 of the middle ones are catadromous until the second to fifth pinnule.

Hawaii! Hamakua, $5000 \mathrm{ft}$; W. Maui! Molokai!

$\gamma$ var. pusillum. - Frond herbaceous, ovate-oblong, 5-8` long, on a slender stipes of $3^{\prime}$, bi-, tripinnate, the lowest pinnule scarcely deflected. Pinnae all anadromous from the base. Invol, thin, fugacious. Fib. vas. ducts 3 or 4 .

Ka uai! 5000-6000 ft. (Kn. and E. Johnson).

Formae subphegopteroideae. - In the two following varieties all stipitate pinnae, except the one, two, or rarely three lowest, are catadromous from the base to the second or fifth pinnule; they are shortly stipitate on stalks of only $2-4$ ", and the lowest basal pinnule points straight downward, not outward. Glands more copious.

o var. soripes. - A small bipinnate, open form; the herbaceous frond $9-12^{\prime}$ long, with a slender stramineous stipes of the same length. Pinnae and pinnules narrow, the tertiary segments connected by a narrow border. Sori at a distance from the sinus on a much raised receptacle. Invol. very glandular. Many glandular paraphyses between the sporangia. Fib. vas. fascicles 4 .

In the living plant the sori and involucres appear almost stipitate, the receptacle $1^{1 / 2}$ " long; in the pressed specimens, of course, this character becomes obliterated. - Molok ai! Maunahui, at the head of the pali of Waikolu.

ع. var. ambiguum. - Frond large, 1-2 ft. long, tripinnate. Rhachis glabrous, or fibrillose with laciniate glandular scalelets, mostly brownish. Invol. glandular. Fib. vas. fascicles 4 or 5 .

E. and W. Ma ui! Large forms, quite like glabrate Phegopteris unidentata, $\alpha$, in appearance. One specimen from Kauai copiously sprinkled with resinous dots on both faces of the frond.

14. A. rubiginosum, Mann, Enum. no. 604. - Rhizome? Stip. with a sweeping curve at the base, brownish, densely paleaceous below with dark chocolate colored linear long-acuminate curly scales of $1 / 2-1$ ', hirsute above with concolorous viscid but glandless hairs., Frond stiff membranous, dark green, subcyatheoid, large, ovate or deltoid, $1-3 \mathrm{ft}$. long, $10-30^{\prime}$ broad, tri-, quadripinnate; primary and secondary rhachides, as well as the costules, densely covered with the same kind of hair. Pinnae patent, shortly stipitate, $12-15$ on a side, the lowest deltoid with very unequal sides, $6-16^{\prime} \times 4-9^{\prime}$, on stalks of $4-10^{\prime \prime}$. Secondary pinnae perpendicular, the lower basal $2^{1 / 2}-5^{4}$, not longer than the second. Ultimate pinnules patent, narrow oblong, $5-9^{\prime \prime} \times 1^{1 / 2}-4^{\prime \prime}$, shortly stipitate or sessile with a cuneate base, obtuse or rounded, notched or deeply cut into suboblong truncate or rounded segments. Sori dorsal on slightly raised receptacles, close to the midrib, one to a lobe, at Hillebrand, Flora of the Hawaiian Islands. 
or close to the bifurcation when on forked veins. Invol. orbicular-incised, dark, entire, glandless, not ciliate, soon evanescent, its cell-walls not wavy. Sporangia with 14 joints. Spores reniform, slightly muricate. Two broad fib. vas. fascicles along the sulcus, their ends recurved in opposite directions, and 2 or 3 smaller ones. - Lastrea rubiginosa, Brack. 1. c. p. 201. - Nephrodium rubiginosum, Hook. Sp. Fil. IV, 143. - Synops. Fil. p. 280. - Luerssen, in Fil. Graeff., p. 190, who unites with it not only N. Fijiense, Hook., but also Lastrea tenuifolia, Brack, both from the Viti Islds.

On all islands at elevations of $3000-4000 \mathrm{ft}$ : Oahul top of Mt. Kaala; Molokail palis of Waikolu and Pelekunu; Hawaii! Kohala range; Kauai! Waiawa. - The specimens from the different localities are remarkably uniform. A variety nudicaule, Sp. Fil, 1. e., is unknown to me. Only the lowest pair of pinnae are anadromous from the base, all others catadromous from the first to the third or fifth pinnule, from which onward the upper pinnules precede their inferior mates; and in the same manner the pinnules are catadromous with regard to their first segments. The hairs of the rhachis, like the acuminate points of the lower scales, consist of a single series of thin cells.

15. A. squamigerum, Mann, Enum. no. 605. - Rhizome $1^{\prime}$ thick, short, creeping above ground. Stip. at distances of ${ }^{1 / 2}-1$ inch, $9-18^{4}$ long, pale-brown, elothed throughout with thin transparent linearlanceolate pale-brown scales which are covered with clavate glands. Frond membranous, dark green, brownish when dry, open, cyatheoid, deltoid to ovate-oblong, $3 / 4-2^{1 / 2} \mathrm{ft}$. long, $1 / 2-1 \mathrm{ft}$. broad, bi-, tripinnate; all rhachides and costules densely paleaceous. Primary pinnae subopposite, distant in the large forms, falcate, ascending, only $1-6$ stipitate, the others decurrent. Lowest pinnae on stalks of $2-9^{\prime \prime}$, almost even-sided, ovate-lanceolate, $5-8^{\prime} \times 3^{1 / 2}-6^{\prime}$. Ultimate segments lanceolate, acute, ${ }^{1 / 2}-1^{\prime} \times 2-3^{\prime \prime}$, sessile with a broad base, subfalcate, cut into broad triangular forward pointing entire lobes. Veinlets inconspicuous, excurrent, simple or once forking. Sori dorsal on the middle of the veinlets, flat, in 2 rows midway between the costule and edge, sometimes one to each fork-branch and then confluent. Invol. thin, cordate, eiliate with clavate glands. Annulus broad, with $16-20$ joints. Spores papillose. Fib. vas. fascicles 4 , the two lowest the largest. - Nephrodium squamigerum, Hook. \& Arn. Bot. Beech. p. 106. - Hook. Sp. Fil. IV, tab. 270. - Synops. Fil. p. 280. - Luerssen, Fil. Graeff. p. 191. Lastrea squamigera, Brack. 1. c. p. 198. - Carruthers in Fl. Vit. p. 359.

Rather rare. Oahu! Nuramu; Lanai! Maui! Also found on the Society and Viti Islands. The plant is typically cyatheoid, like the following speeies, all pinnae, except the lowest, and all pinnules being catadromous throughout. Nat. name: ‘Paunoan.

16. A. latifrons, Brack. l. c. p.196. - Rhizome $2-3^{\prime}$ thick, prostrate, rooting. Stip. tufted, $1^{1 / 2}-2 \mathrm{ft}$. long, dusky-stramineous, paleaceous at the base with shining deep-brown linear-lanceolate not glandular scales of ${ }^{1} / 2-1$, which run out into curled hair-like points, flocculose or furfuraceous above. Frond chartaceous, olive-green when dry, dotted underneath 
with minute glistening glands, cyatheoid, ovate, $1^{1 / 2}-3 \mathrm{ft}$. long, $1^{1 / 4}-2^{1 / 2} \mathrm{ft}$. broad, decompoundly bipinnate, tripinnatifid, ending in a pinnatifid apex; the rhachides sparsely flocculose or naked. Primary pinnae, 4-6 stipitate ones on a side, distant, falciform, ascending, the lowest on stalks of $3-12^{\prime \prime}$, ovate or deltoid, not much uneven-sided, $10-16^{\prime}$ long. Lowest secondary pinnae lanceolate, $4-9^{\prime} \times 1^{1} / 2-3^{\prime}$, shortly stipitate, deeply cut near the base into broadly sessile or decurrent oblong-obtuse segments, $4-5$ " broad, which are subentire near the apex and base but notched about the middle into deltoid antrorse lobes. Veinlets distinct, single, forking or subpinnate. Sori subapical, generally one to each simple veinlet and then submarginal, as also in once forking ones, or one to a group of forking veins and then at a distance from the margin. Invol, cordate, rarely reniform, very large, flat or convex and stiff, crenulate, reddish when dry. Sporangia large, with $21-24$ joints. Spores smooth subglobose. Four fib. vas. fascicles. - Only 1 pair of pinnae anadromous. - Nephrodium latifrons, Hook. Sp. Fil. IV, 138. - Synops. Fil. p. 282.

At heights of 2000-3000 ft. on all islands, but not common. Not known from elsewhere.

\section{NEPHROLEPIS, Schott.}

Sori round, at the apex of the first anterior branches of the veins, generally near the edge. Involucre reniform or orbicular-incised. Veins free, ending inside the margin with a punctiform apex which secretes a calcareous scalelet on the upper surface. Frond simply pinnate, with indefinite growth, the pinnae articulate at the base and deciduous in the dried plant. Spores ovoid, with a single dorsal line.

Tropical and subtropical ferns; about 7 species.

1. N. exaltata, Schott. - Hook. Sp. Fil. IV, 152. - Rhizome creeping, covered with linear ferruginous scales. Stip. tufted, $2-6^{\prime}$ long, strawcolored or light brown, sparingly fibrillose or naked. Frond pale, chartaceous, glabrous, linear-lanceolate, $1-3 \mathrm{ft}$. long, $2-6^{\prime}$ broad, narrowing below. Pinnae close, horizontal, $25-60$ on each side, the lowest often dwarfed, oblong and obtuse or somewhat acutely lanceolate falcate, $1 / 4-^{3} / 4^{\prime}$ broad, subsessile, entire or crenate, the base truncate on both sides in the lower pinnae, but sharply auricled above and rounded below in the upper pinnae. Veins hidden, close, simple or once or several times forking, the upper basal one pinnate. Sori in a line near the margin. Invol. firm, cordate or orbicular-incised. Fib. vas. fascicles 3. - Synops. Fil. p. 301. - N. cultrifolia, Presl, Epimel, p. 44. - Polypodium exaltatum, Forst. - Nephrodium exaltatum, Gaud.

Very common on trunks of trees. Nat, names: ekupukupu», "Pamohos, - Occurs in most tropical countries. - I have two forms; one small and narrow, with fibrillose rhachis and oblong obtuse pinnae, the lowest gradually dwarfing; the other larger and broader. with naked rhachis, the frond almost truncate at the base or only slightly narrowing, 
the pinnae falcate, acute. A few very short paleaceous surculi, similar to those which occur in $N$. tuberosa, but without buds or tubers, are to be seen in a specimen of the smaller sort.

\section{CYSTOPTERIS, Bernh.}

Sori globose, placed on the back of the veins. Involucre thin, hood-like, attached with its broad base below the sorus, free laterally and externally, soon reflexed. - Fronds small, herbaceous, two or three times divided. Veins free. Stipes continuous with the rhizome, holding 2 fib. vas. fascicles. Spores bilateral.

A small genus, inhabiting the temperate zones of both hemispheres.

1. C. Douglasii, Hook. Sp. Fil. I, 200. - Rhizome short, horizontal, the apex covered with curly ferruginous hairs, each consisting of a single series of elongate cells, several rising from a common base. Stip. crowded at the ends of short branches, 3-8' long, weak, compressed, stramineous, naked, glossy. Frond dark, herbaceous, oblong, rather obtuse, $4-12^{\prime}$ long, nearly as broad at the base as at the middle, pinnate, with pinnatifid apex, sometimes the lowest pinnae shorter and more distant; the rhachis slightly margined. Lower and middle pinnae on short margined stipites, $3 / 4-2^{1} / 2^{\prime}$ long, subentire near the blunt apex, the lower portion cut into. ovate-oblong and obovate-obtuse crenate or incised lobes of $3-6^{\prime \prime}$ in length. Sori irregular, placed across the trunk, at the fork or on one or both branches of a bifurcation, or on the lower half of simple veinlets. Invol. semiorbicular when young, with an emarginate base, almost as in Nephrodium, dentate but glandless, very delicate. Annulus of 14-16 cells. Spores muricate. - C. fragilis, Synops. Fil. p. 103.

Leeward side of Mauna Kea, near Waihu, Haw a ii! $6000 \mathrm{ft}$; Haleakala above Makawao, Maui!

$\beta$ var. - Frond brighter and more tender, ovate-lanceolate, acute, more. open; the rhachis margined only in the upper portion. Lowest pinnae. longest, $1-2^{1} / 2^{t}$, ovate-lanceolate, acuminate, cut deeply into narrow-oblong or linear-oblong obtuse segments or pinnules. Sori on the outer halves of simple veinlets or fork-branches, nearer the margin. Some veins exeurrent in the sinus of an emarginate tooth, as in C. alpina. - C. Sandwicensis, Brack. Fil. U. S. E. E. p. 234.

Oahu! Makaleha of the Kaala range; W. Maui! Distinct from C. fragilis not so much on aecount of the less division of the frond as of the hairy covering of the rhizome and the suborbicular indusium. It is true that such hairs occur also on some specimens. of C. fragilis, but only accompanied by the broad transparent scales fringing their base, and apparently owing their appearance to a disruption of the scales; but here the scales. are altogether wanting.

\section{SADLERIA, Kaulf.}

Sori linear, continuous on each side of the costa, parallel and close to it. Involucre firm, linear, attached to the outside of the receptacle and 
opening toward the costa. Veins forking close to their bases, the forks uniting for the reception of the receptacle into a continuous series of arches next to the costa, which give off one or more free parallel rays toward the margin (nerv. Doodyae). Annulus of sporangium with 18-28 cells. Spores bilateral, ovoid-reniform to subglobose. - Erect, mostly arbores. cent ferns, with bipinnatifid to bipinnate fronds. Sterile fronds like the fertile ones, but without costal arches. Two large lateral fib. vas. ducts close to the sides of the ventral sulcus, 1 circular one at the head of it, and in the larger species $9-10$ smaller ones which form an arch concentric with the back of the stipes.

According to the disposition of the fib. vas. ducts the genus stands nearer to Blechnum than to Woodwardia, with which Mettenius has united it. Interrupted sori only occur near the apex, where pinnatifid pinnae pass into entire ones, and in the tripinnatifid variety of no. 4 . The anastomosis for the soriferous arch is almost entirely formed by the anterior fork-branch of the vein, a short recurrent branch of the next upper being only observable in no. 4 .

A Hawaiian genus, scarcely distinct from Blechnum. Nat. name: eAmamau s.

Stipes paleaceous with soft scales at the base only, sori long:

Scales ovate or ovate-lanceolate, pale; pinnules or segments $1-1^{1 / 2^{\prime}}$ long, the middle and basal ones often pectinate

1. S. Souleytiana.

Scales linear-lanceolate, reddish; segments ${ }^{1 / 2}-1^{\prime}$ long, all entire

Stipes and rhachis paleaceous throughout with stiff scales; sori

2. S. cyatheoides.

shorter:

Frond bipinnatifid, with entire linear-oblong segments; veins prominent:

Frond bipinnate, with oblique ovate crenate or lobed pinnules; veins obscure

\section{S. pallida.}

4. S. squarrosa.

1. S. Souleytiana, Hillebr. - Trunk $3-5 \mathrm{ft}$. high, $8-10^{\prime}$ thick. Stip. $2-3 \mathrm{ft}$. long, $1-1^{1} / 2^{\prime}$ thick at the base, deeply sulcate, pale, thickly clothed in the lower third with bright cinnamon-colored thin diaphanous ovate or lanceolate long-pointed scales of about $2^{\prime}$ in length, furfuraceous or glabrate above. Frond cbartaceous, oblong-lanceolate, $4-6 \mathrm{ft}$. long, slightly furfuraceous underneath or glabrate and pale, bipinnate. Pinnae closely set, subsessile, linear, $1-2 \mathrm{ft}$. long, $2-3^{\prime}$ broad, broadest at the middle, pointed. Pinnules or segments (55-75 on each side) falcate, $2^{1 / 2}-4^{\prime \prime}$ broad, bluntly pointed, entire, or in well developed forms pectinately cut, at least the larger middle ones and the basal pair, the latter deflected over the rhachis. Veins visible, forked or again pinnate in the pectinate pinnules. Sori extending to near the apex, narrow, not filling the under face. - Spores unevenly margined. - Blechnum Souleytianum, Gaud. Bot. Bon. tab. 2 and 134 .

Rare, in forests at elevations of $2000 \mathrm{ft}$ : Oahu! Pauoa; Lanai! Frond larger than that of any other species. With the uppermost scales of the stipes generally a few narrow 
ones are intermixed which have a spurious rib. The pectinate pinnules carry at nearly right angles to the primary sorus a series of converging smaller sori, which recall in a measure the picture presented by the variety of Lomaria punctulata, Kze., formerly called Scolopendrium Krebsii.

2. S. cyatheoides, Kaulf. Enum. Fil. p. 162, - Trunk generally $3-5 \mathrm{ft}$., but sometimes more than twice that height. Stip. 1-2 ft. long, smooth, brownish, densely covered at the base with brown or reddish soft ribless linear-lanceolate scales of about $2^{\prime}$, which run out to a hair-like point, otherwise naked. Frond dark, coriaceous, $2-3 \mathrm{ft}$. long, glabrate, oblong or ovate-oblong, bipinnatifid. Pinnae $30-40$ on a side, $6-10^{\prime} \times^{1 / 2}-1^{\prime}$, acute, deeply cut, often pinnately at the base, into numerous (about 40) narrow subfalcate entire pointed segments with revolute margins, $1-1^{1 / 2}{ }^{\prime \prime}$ broad at the base. Veins hidden. Sori extending to near the apex, at maturity covering the entire lower surface. - Hook. \& Arn. Bot. Beech. p. 107. - Hook. Sp. Fil. III, 65 (in part.). - Synops. Fil. p. 187. - Blechnum Kaulfussianum, Gaud. Bot. Bon, tab. 78. - B. Fontanesianum, Gaud. Bot. Freyc. p. 397, tab. 15. - Brack. Fil. U. S. E. E. p. 133. - Woodwardia cyatheoides, Metten. Fil. Hort. Lips. p. 65.

Common on all islands at lower elevations. The highest trunks have been observed in Kona, Hawaii! and in Waimea, Kauai. - The soft, curly, hair-like seales are gathered for the same purpose as the hairs of Cibotium and are called pulu amamau. In former times the stipites, macerated in water, were beaten together with the bast of "mamake" or "Wauke", to serve as a sizing, perhaps also to impart a reddish dye, in the manufacture of kkapa or native cloth.

3. S. pallida, Hook. \& Arn. Bot. Beech. pp. 75 and 107. - Trunk 2-3 ft. high. Stip. 8--18' long, rough below, clothed throughout, as are also main and secondary rhachides, with stiff linear long-acuminate brownish scales of about $1^{\prime}$ in length, which consist of a broad and dark spurious rib with a narrow fringe of diaphanous cells, the uppermost scales ribless. Frond stiff chartaceous, light-green, oblong, $1^{1 / 2}-2 \mathrm{ft}$. $\times^{3 / 4}-1^{1 / 4} \mathrm{ft}$., bipinnatifid. Pinnae $18-28$ on a side, ${ }^{3 / 4^{\prime}}$ broad, close, acute. Segments $22-28$ on a side, oblong, obtuse, entire. Veins prominent. Sori much short of the apex, broad, filling the entire width when mature. - Mann, Enum. no. 559. - Blechnum pallidum, Brack. 1. c. p. 133. - Mettenius fide Baker.

Hawaii! Kilauea; Mani! Specimens with naked frond and rhachis from $\mathrm{Oahu}$ and, Kanai! In restoring here a species repudiated by its author himself in later works, I believe I am borne out by the general characters and the habit of the plant. Northeast of Kilauea, where it grows in great abundance and to all appearance undisturbed by beast or man (for its scales are too harsh for pulu), I have not seen trunks higher than the limit given above. Mr. Knudsen reports the same from Kauai.

4. S. squarrosa, Mann, Enum. no. 560. - Caudex erect or oblique, $2-6^{\prime}$ high, $1 / 2-3 / 4^{\prime}$ thick. Stip. $6-10^{\prime}$ long, dark-brown, almost black, tuberculate, densely paleaceous, as are also the rhachides and ribs, with lanceolate and linear auriculate harsh dark-brown opaque scales. Frond $10-20^{\prime}$, oblong-lanceolate, slightly narrowing below, chartaceous to coriaceous, rather distantly bipinnate. Pinnae $12-24$ on a side, 
$2-4^{\prime} \times{ }^{1 / 2}-1^{\prime}$, lanceolate, falcate. Pinnules (about 12 pairs) obliquely ovate to trapeziform, $3-6^{\prime \prime} \times 1^{1 / 2}-3^{\prime \prime}$, obtuse, with the base contracted and often subauriculate in the upper half, the lowest opposite, notched or lobulate. Veins obscure, with few and broad costal arches. Sori short, about ${ }^{1 / 2}$ the length of the pinnule, not close to the costa, rarely interrupted. Invol. dark, soon evanescent. Sporangia large, with 24-28 ringcells. Spores pale, at first enveloped by a dense layer of soft elavate papillae which disappear with age, leaving only a rough surface. Fib. vas. fascicles 3. - Synops. Fil. p. 187. - Blechnum squarrosum, Gaud. Bot. Bon. tab. 2. - B. polystichoides, Brack. 1. c. p. 134.

Not frequent, in deep forests: Hawaii! Kohala range; Molokai! Kalae; Oahu!

$\beta$ var. tripinnatifida. - Pinnules $(6-7$ ' long) again deeply eut into 2 or 3 pairs of rounded oblong lobes, with the apex entire. Sori interrupted and short, so as to appear like rounded glomerules at the base of each lobe, which soon lose their involucres by shrinkage. In this state a pinnule resembles exceedingly an entire frond of the smallest size of $\delta$. Molokail

\%.var. intermedia. - Pinnules (12-20 pairs) sessile with a broad base, oblong, rounded, entire, $2-3^{\prime \prime}$ long. Pinnae less than ${ }^{1 / 2}{ }^{\prime}$ broad.

High mountains of W. Maui and Kauai; pali of Kalae, Molokai! A form intermediate between this and the preceding species.

¿ var. depauperata. - Dwarfed. Stipes $1-1^{1 / 2^{\prime}}$, filiform, purplish or dark-brown, paleaceous with ferruginous lanceolate subentire scales auriculate at the base, those of the rhachis dentate with spreading anc! reflexed teeth and sparingly glandular. Frond thick coriaceous, opaque, brownish when dry, $2-3^{\prime} \times 1^{\prime}$, pinnate with $5-7$ pinnae on a side, besides the subentire apex. Pinnae horizontal, subsessile, the upper ovate or suborbicular, the lower with a similar terminal lobe and 1 or 2 pairs of smaller sessile lateral lobules. Veins hidden, the costule even scarcely traceable at the base of the round lobe. Sori large, roundish or oblong, one at the base of each lateral lobe, two along the midrib of the simple pinnae or terminal lobes on elongate receptacles, apparently naked. Sporangia large, brown, shining, their ring with 18 - 26 cells. Spores transparent, semiglobose, surrounded by a dense layer of elongate papillae, appearing under the microscope like a circular wing. Fib. vas. fascicles 3 , with 1 or 2 very faint ones near the circumference. - Polypodium (Phegopteris) unisorum, Baker. Synops. Fil. p. 307.

Kauai! on the high platean between Hanalei and Waimea, where it was collected by the late Mr. E. Johnson. Although the sori appear naked and the anastomosis cannot be traced on account of the thickness of the frond, yet I have no doubt that the plant sent by me to Kew belongs here. Especially the peculiar character of the spores unobserved by me in any other Hawaitan fern, which, however, entirely agrees with that of the immature spores of $S$, squarrosa, supports this view. 


\section{DOODYA*, R. Br.}

Sori short oblong or slightly curved, placed severally in one or more rows parallel with and between the midrib and margins of the pinnae. Invol. membranous, of the same shape as the sorus and opening toward the midrib. Veins forming one or more series of arches between the midrib and edge, on which the sori are placed, - Low ferns, with a short oblique caudex and pinnate or pinnatifid, spinuloso-dentate, harsh fronds. - Woodwardia, Metten. and Fée (in part.).

A small genus, confined to the island world of Polynesia and Australasia as far as Ceylon.

1. D. media, R. Br. Prod. Nov. Holl. p. 151. - Caudex short, suberect. Stip. tufted, 5-10' long, rough, dull stramineous but quite dark below, scantily clothed throughout with stiff linear denticulate blackish scales or fibrils. Frond dark'-green, scabrous, lanceolate, $12-18^{\prime} \times 2-5^{\prime}$, narrowing below, with $30-50$ pairs of spreading segments, pinnatifid above with segments gradually confluent in a subentire apex, pinnate below, broadest about the middle. Upper segments sessile, with a broad base $\left(2-4^{\prime \prime}\right)$, linear-lanceolate, falcate, bluntish, the cartilaginous edge irregularly serrulate, the lower pinnae shortly stipitate, broadest at the base and subcordate, generally biauriculate, the lowest gradually diminishing and more distant. Veins distinct, with 1 or 2 , rarely 3 series of arches. Sori oblong (about $1^{\prime \prime}$ ), in 1 or 2 rows, rarely with an incomplete third one, the inner row at some distance from the rib. Veins of the upper pinnae catadromous, the first lower veinlet rising from the rhachis or the adnate ascending face of the midrib. Sporangium sharply curved at the apex. Spores subglobose. Two larger lateral fibro-vasal bundles and one or two smaller dorsal ones. - Hook. Sp. Fil. III, 74, and Synops. Fil. p. 190. - D. Kunthiana, Gaud. Bot. Freyc. p. 401, tab. 14. - Hook. \& Arn. Bot. Beech. p. 107. - Brack. Fil. U. S. E. E. p. 137. - D. caudata, var. media, Benth. Fl. Austral. VII, 742.

Not uncommon on all islands. Frequent in Makaleha valley, Oahu! - Nat. name: "Pamoho". The species occurs also in N. and E. Australia and in N. Zealand.

\section{ASPLENIUM, L.}

Sori lateral to the vein, linear and generally straight, or less commonly short and curved, single on the anterior side of the vein, or (in Diplazium) double on the first anterior or primary veinlet, one on each side of it, or (in Athyrium) curved, uncinate, kidney- or horeshoe-shaped on the

* The description of Doodya and its species was missing in the final manuseript left by Dr. Hillebrand, although from a pencil note it was evident that he was aware of this and intended that it should oceupy its present position in the order. The deseription here given was taken from an older draft of the manuscript, and is therefore possibly not in the preeise form which the author would have chosen had he lived to supply the omission himself. W. F. H. 
primary veinlet, crossing it at the upper end. Involucre shaped like the sorus, attached to the back of the vein, in single sori opening toward the costule and apex, in double sori opening also toward costa and margin. Spores bilateral. Stipes continuous with the root-stock, holding at its base two flattened fibro-vasal fascicles which unite in various ways in their ascent.

A large genus, spread over the whole globe.

Veins comnected by an intramarginal nerve; frond simple (Thamnopteris).

Veiris free:

Sori single, straight, with a simple involucre (Euasplenium):

Frond pinnate, pinnae subentire:

Pinnae not much longer than broad:

Stipes black:

Pinnae suborbicular

2. A. trichomanes.

Pinnae rhomboidal:

Pinnae with a not excurrent deliquescent midrib; sori often single on a pinna; frond narrowing below

Pinnae with an excurrent midrib or costule; frond truncate at the base

1. A, nidus.

stipes green or pale brown:

Pinnae rhomboidal, with a deliqnescent rib; the sori flabellate

Pinnae ovate-lanceolate, with an excurrent rib; the sori pinnate on both sides

Pinnae lanceolate:

Stipes green when fresh, dull gray when dry:

Frond pinnate to the apex; sori at uniform angles of $30-40^{\circ}$ :

Pinnae $1 / 2-11 / 2^{\prime}$ broad:

Frond dark-green, fleshy: pinnae more than 12 on a side.

Frond pale, thin; pinnae less than 9 on a side

Pinnae less than $1 / 2$, broad, serrate

Frond pinnatifid at the apex; angles of sori gradually opening toward the auricular base

Stipes dark-brown, glossy; pinnae inciso-serrate at acute

angles:

Pinnae linear-Ianceolate, less than $1 / 2^{\prime}$ broad; sori elongate, closely contiguous to the midrib; frond dark-green

Pinnae oblong-lanceolate, $1 / 2-1$ ' broad; sori imbricate, diverging; frond olivaceous

Pinnae ovate-lanceolate; upper basal sori irradiating toward the margin .

Pinnae ovate-lanceolate; sori short and few in one line at equal distances between rib and margin Stipes purplish-black, glossy .

Frond pinnate; pinnae pinnatifid:

Sori dareoid, marginal when only one on a segment:

Pinnae not longer than $1^{1 / 2^{\prime}}$.

Pinnae $4-7^{\circ}$ long - dareoid varieties of nos. 9, 10, 11 .

Sori not marginal:

Lobes or segments short, truncate, subequal; sori along the midrib:

Stipes hairy

Stipes naked

19. A. contiguum.

22. A. caudatum.

21. A. nitidulum.

20. A. Knudsenii.

5. A. resectum.

7. A. erectum, var. $\beta, \gamma$.

23. A. horridum.

22. A. caudatum, var. 
Lobes or segments increasing toward the base, obovate: Stipes livid-gray; sori pinnate in the largest lobes Stipes dark-brown; sori flabellate in the largest lobes Frond bipinnate:

Sori dareoid, pinnules pinnatisect:

Pinnae not exceeding $1^{1 / 2}$

Pinnae more than $3^{\prime}$ long

Sori not dareoid:

Stipes green or grayish when dry:

Pinnae short; pinnules few, cuneate-truncate, with flabellate veins and sori; frond $3-4^{\prime}$ long .

Pinnae longer:

Pinnules rhomboidal or obovate-obtuse

Pinnules lanceolate, acute, entire

Pinnules ovate-lanceolate, inciso-crenate or pinnatifia

Stipes dark-brown, glossy:

Frond not exceeding $1 \mathrm{ft}$. in length, both species also tripinnate:

Ultimate segments cuneate-truncate, with flabellate sori.

Ultimate segments ovate, obovate or spathulate; sori contiguous to a deliquescent costule

Frond $1-3 \mathrm{ft}$. long; pinnae nearly ventral on the rhachis:

Pinnules rhomboidal, with straight inner and lower edge

Pinnules rhomboid-ovate to lanceolate, notehed into bluntish lobules, with connivent veins

Pinnules cuneate-lanceolate, with deep-obovate to obovate segments, serrate at the apex (also tripinnate) .

Frond tripinnate:

Stipes gray; frond deltoid, thick, pale; ultimate segments truncate

Stipes brown; frond oblong, thin, dark; ultimate segments cuneate or pointed

Sori of primary veinlets (first anterior branches) double and straight, the involucre opening on both sides and often forking (Diplazium):

Frond pinnate:

Frond truncate below, polystichoid; pinnae alternate, abscisso-truncate at the base:

Lobes of pinnae obtuse or somewhat acute

Lobes truncate, the first upper one much elongate .

Frond narrowing below, phegopteroid; pinnae mostly opposite, pinnatifid, with an even-sided truncate base: Pinnae stipitate; sori equidistant from rib and edge Pinnae sessile; sori short, close to the margin .

Frond bipinnate to tripinnate:

Frond pale-green; sori $1-3$ " long, mostly reaching from the costule to near the edge

Frond dark-green; sori 1 " or less, contiguous to the costule Sori short and often eurved, with a vaulted involucre, those of the primary veinlets hooked, or kidney- or horseshoeshaped (Athyrium):

Frond bipinnate to tripinnate. Pinnae mostly opposite. Sori intramarginal and straight, or marginal and oblique or curved, or extramarginal and curved or transverse
16. A. lobulatum.

24. A. spathulinum (also bipinnate).

7. A. erectum, var. $\delta, \varepsilon$. 14. A. meiotomum.

8. A. varians.

17. A. insititium.

12. A. bipinnatum.

13. A. Lydgatei.

25. A. furcatum.

27. A. Adiantum nigrum.

29. A. acuminatum.

28. A. polyphyllum.

30. A. patens.

18. A. sphenotomum.

26. A. dissectum.

31. A. arboreum.

32. A. Sandwichense.

35. 4. Fenzlianum.

36. A. marginale.

33. A. Arnotti.

34. A. Sandwichianum.

37. A. deparioides. 
Frond tri-, quadripinnate; sori at the base of the ultimate

Frond tri-, quadripinnate; sori near the apex of the ultimate segments

38. A. aspidioides.

39. A. Baldwini.

A. Thamnopteris. No. 1.

1. A. nidus, L. - Hook. Sp. Fil. III, 77. - Caudex short and thick, erect. Frond coriaceous, broad lanceolate, $2-4 \mathrm{ft}$. long, $3-8^{\prime}$ broad, entire, sessile or tapering to a short stipes; the midrib rounded at the back. Veins quite straight and very close, $1 / 3^{\prime \prime}$ apart, all parallel, at angles of $65-75^{\circ}$ with the rib, simple, or once forking before reaching the margin, and there connected by a distinct transverse intramarginal nerve. Sori linear, on nearly every vein in the upper half or two thirds of the frond, extending from near the rib to ${ }^{1 / 2}$ or $2 / 3$ the distance between rib and edge. Invol, thin, narrow. - Synops. Fil. p. 190. - Thamnopteris nidus, Presl. - Neottopteris nidus, J. Sm.

Common on trunks of trees in the lower forests. The Birds-nest fern, "Ekahas of the natives. - The species extends from Polynesia through tropical Australia and Asia to Mauritius and Madagasear.

B. Euasplenium. Nos. 2-30.

2. A. trichomanes, L. - Hook. Sp. Fil. III, 136. - Caudex short and thick, ${ }^{1} / 2-1^{1} / 2^{\prime}$ long, erect. Stip. densely tufted, $1-4^{\prime}$ long, dark-brown, polished, wiry, naked, flatly grooved. Frond subcoriaceous, linear, narrowing below, $3-8^{\prime} \times 2-6^{\prime \prime}$, pinnate. Pinnae $15-45$ on a side, horizontal, subsessile, suborbicular or ovate, uneven-sided, the upper half the broadest, and truncate at the base, obtusely crenate. Lowest pinnae distant and small, stipitate in the middle of an even-sided truncate base. Veins pinnate, ineonspicuous. Sori linear-oblong, $2-4$ on each side, confluent with age. - A. densum, Brack. Fil. U. S. E. E. p. 151, pl. 20.

Ma ai! Hawail! on the high mountains from $5000 \mathrm{ft}$. upward. Nat. name: "Owalii", - Spread over both temperate zones of nearly the whole world and the high mountain regions of many tropical countries. - The Hawaiian plants have an unusually strong root-stock,

3. A. monanthemum, L. - Hook. Sp. Fil. III, 140. - Caudex as before. Stip. tufted, purple-ebeneous, as well as the rhachis, $2-6^{\prime}$ long, naked, glossy. Frond firm membranous, linear, $10-15^{\prime} \times \times^{1 / 2}-3^{3} / 4^{\prime}$, pinnate; the rhachis often gemmiferous at the height of the first pinnae or near the apex. Pinnae $20-60$ on a side, horizontal, close, subsessile, stipitate at the lower angle, dimidiato-rhomboidal, $2-3^{\prime \prime}$ deep, the inferior and inner sides cut straight, the latter parallel to the rhachis with sharp upper angle, the upper and outer sides crenate with rounded upper outer angle. Lowest pinnae distant and shorter, semicircular, with the base truncate on both sides and stipitate at the middle. Veins not excurrent, ending 
with a punctiform apex, flabellate without or with a leading vein, which verges toward the upper and outer angle but disappears about the middle. Sori, generally one on the first lower vein, parallel and close to the lower edge, but not unfrequently more, the others oblique. Invol. pale and broad, that of the single or lowest sorus (rarely a second one) opening upward, those of the upper, when present, downward. - Brack. 1. c. p. 151, pl. 20, fig. 2. - A. Menziesii, Hook. \& Grev. Ic. Fil. tab. 100, the plurisorous form, in which the lowest sorus is much the largest.

\section{E. Ma ui! on Haleakala from 3000-6000 ft.; W. Maui! Kauai!}

Occurs also in the Azores, Madeira, the Canaries, in Abyssinia and S. Afriea and on the American Andes from Mexico to Chile, generally associated with luxuriant forms of A. trichomanes. - The gemmae on the rhachis are also observed occasionally in plants from Madeira. The lower gemmae often grow into fronds of the size of the mother plant, which remain connected with it.

4. A. normale, Don, Prod. Fl. Nepal. p. 7. - Caudex as before. Stip. black-ebeneous, polished, stiff, naked, $4-5^{\prime}$ long. Frond subcoriaceous, opaque, dark-green, fuscescent when dry, linear-lanceolate, $8-12^{\prime} \times 1-1^{1} / 2^{\prime}$, pinnate, the rhachis not margined and frequently proliferous. Pinnae $30-40$ on a side, close, all uniform, the lower ones deflected but neither smaller nor more distant, in shape like those of $A$. monanthemum, but more oblong, $6-9^{\prime \prime} \times 2-3^{\prime \prime}$, with the lower side less extensively cut, the inner upper angle sharp and produced, the upper and outer edges less deeply crenate. Veins pinnate along a costule which runs into the upper outer angle or apex, those in the basal half forked. Sori in two rows, at angles of $20-60^{\circ}$ to the costule, 3 or 4 in the lower and $6-8$ in the upper row, on the anterior branches of forking veins and therefore at a distance from the rib. Invol. pale, broad and rather obtuse at both ends. - A. pavonicum, Brack. 1. c. p. 150, pl. 20. - A. multijugum, Wall. Hook. Sp. Fil. III, p. 139, tab. 188.

The fern is remarkable for its tendency to produce gemmae. I have one specimen with 11 young plants starting from the rhachis, all frondlets soriferous and with pinnae cut exactly as in A. monanthemum, several of them with a single sorus along the lower edge.

Less rare than the preceding species, to which it is closely related. Oahu! Nuuanu; Kauai! and probably elsewhere. - Occurs also in Hindostan, Ceylon and southern China.

5. A. resectum, Smith. - Hook. Sp. Fit. III, 130. - Rhizome ereeping, slender, the involute fronds sparsely covered with short lanceolate blackish scales. Stip. scattering, naked, dark purplish-brown, polished, $3-8^{\prime}$ long. Frond herbaceous, oblong-acuminate, not contracting below, $10-18^{\prime} \times$ $2-5^{\prime}$, pinnate with $15-30$ pinnae on each side. Pinnae patent, $1^{1 / 2}-3^{\prime}$, $\times^{1 / 2}-3 / 4^{1}$, stipitate at the lower angle, dimidiato-oblong or lanceolate, one half or more of the lower side being cut away, obtuse or somewhat acute, 
the upper base truncate at right angles and not auriculate, the upper edge and the outer half of the lower edge biserrulate or faintly incisocrenate. Veins not close, excurrent, pinnately arranged, nearly all forked, but only one or two nearest the base repeatedly so. Sori on the anterior fork-branches, distant from each other, at angles of $20-60^{\circ}$ with the midrib and at some distance from it and the margin, 10-13 on the upper half (wanting near the base) and $6-9$ on the lower. - Hook. \& Grev. Ic. Fil, tab. 114. - Metten. Asplen. p. 132. - Carruth. in Fl. Vit. p. 354.

Common on trees and rocks. - Widely spread over tropical Polynesia, Asia and Africa. - Nat. name: "Pamoho".

6. A. fragile, Presl, Tent. Pterid. p. 108. - Stip. tufted on a short suberect caudex, $2-6^{\prime}$ long, weak, flexuose, dull, lurid-green, darker below. Frond herbaceous, flaccid, bright-green, linear, $9-16^{\prime}$ long, $9-10^{\prime \prime}$ broad above the middle, pinnate with $20-30$ distant pinnae on each side, which gradually decrease in size and gain in distance toward the base, and are here often 3 -lobed with an even-sided cuneate base. Pinnae dimidiate or rhomboidal, $3-4^{\prime \prime}$ broad, notched into 4 or 5 obtuse lobules and auriculate, with the upper basal angle quite obtuse, the auricle sometimes separated by a deep slit. Veins distant, flexuose, not excurrent, with a leading vein toward the upper outer angle, simple, forked in the auricle or pinnate when it is free. Sori close to the costule or leading vein, short, oblique, $1-2$ on the lower, $2-4$ on the upper side. - Hook. Sp. Fil. III, 144. - Metten. Asplen. p. 125. - A. rhomboideum, Brack. 1. c. p. 156 , pl. 21 , fig. 2 .

Very proliferous; as many as $8-10$ young plants from the rhachis of the frond at various heights.

Only found on the northern slope of Haleakala, Ma ui! at an elevation of $4000-6000 \mathrm{ft}$. - Also inhabits the Andes from Mexico to Peru.

7. A. erectum, Bory, in Willd. Sp. Pl. p. 510. - Caudex suberect, thick, $1-3^{\prime}$ long, with few scattering short lanceolate blackish seales
at the end. Stip. tufted, $2-3^{\prime}$ long, greenish or light brown, dull, naked, not margined. Frond not proliferous, firm membranous, linear-lanceolate, $10-24^{4} \times{ }^{3} / 4-1^{3} / 4^{4}$, pinnate with pinnatifid apex and $20-40$ pinnae on each side, the lowest more distant, gradually reduced in size and almost even-sided at the base. Pinnae horizontal, shortly but distinctly stipitate, rhomboidal or obliquely ovate-obtuse, crenate, subauriculate, the upper half of the base truncate parallel to the rhachis with obtuse angle, the lower cut obliquely with a short sweep. Veins not excurrent, opaque, pinnate at angles of $30-40^{\circ}$ with a distinct midrib, mostly simple, one or two forked and that of the auricle again pinnate. Sori in two rows, 8 in the upper, 5 in the lower, falling short of edge and midrib, on the anterior forks of furcate veins. Invol. pale. - Hook. Sp. Fil. III, 126. - 
Synops. Fil. p. 202. - Is by many recent writers united with A. Tunulatum, Sw.

Not uncommon in woods of the lower region on all islands! - The species is distributed over many parts of tropical and subtropical America and Africa with intermediate and adjacent islands, also Ceylon and India, but seems to be absent from Australia, and in Polynesia is only known from the Hawaiian group. Our plants come nearest to those from Ceylon and India, which are not reported to be proliferous, while those from all African and Ameriean stations are. With the Ceylon plants they also have this in common that the sori occupy the anterior branches of forked veins and are at some distance from the costule, while in the others they descend from the anterior branches to the trunk of the vein and touch the costule.

$\beta$ var. mierophyllum. -- Whole plant only $4-6^{\prime}$ long, on a caudex of $2^{1 / 2}$. Pinnules $3^{\prime \prime} \times 2^{\prime \prime}$, the upper ones almost dimidiate, as in $A$. normale, but with a greenish margin to the pale rhachis and stipes.

$\gamma$ var. subbipinnatum. - Size of $\alpha$. Frond chartaceous, darker. Pinnae longer and more or less deeply cut into oblong, or cuneate-oblong, or bi-, tridentate segments and an almost free auricle, which is cuneate-obovate and obtusely 3-7-toothed. Sori single and marginal in the simple and bidentate segments, $2-3-5$ in the larger segments. - Of this too we have a smallleaved form, the largest pinnae only $3^{n}$ long.

Oahu! Makaleha; Kauai! Waimea and Halemanu(Kn.). - In some Ka ua i specimens several other segments besides the basal one are obovate, with pinnate veins, thus forming a close approach to $A$. gracile, Pappe and Rawson, from S. Africa.

¿ var. Macraei. - Caudex, stipes and shape of frond as before, the latter $10-16^{\prime} \times 1^{1 / 2}-3^{\prime}$, subchartaceous, bipinnate. Pinnae $20-30$ on a side, patent, on stalks of ${ }^{1 / 2}-1^{\prime \prime}$, obliquely ovate to ovate-lanceolate, somewhat obtuse, cut down to a margined rhachis on each side into $7-10$ oblong cuneate and obovate pinnules, of which the upper basal one is the largest and $4-5$-cleft, the following being $3-2$-cleft to entire and falcate; the lower basal pinnule opposite the second upper one. Veins pinnate in the inner, repeatedly forking to simple in the outer pinnules. Sori $3-5$ pinnate in the auricle, $3-1$ in the following, and marginal (dareoid) in the entire pinnules, here touching the midrib and often curved. Invol. thin, white. - A. patens, Hook. \& Arn. in Bot. Beech. p. 106. - A. strictum, Brack. 1. e. p. 168, pl. 23, fig. 1. - Hook. Sp. Fil. III, 200. - A. Macraei, Hook. \& Grev. Ic. Fil. tab. 217. - A. rhisophyllum, Baker, in Synops. Fil. p. 220 (as to our plant).

Oahu! Pauoa; Hawail! Kauai! No gemma on any one of my specimens. Proliferous A. rhizophyllum, Kze., inhabits tropical America and Natal, conjointly with proliferous forms of $A$. erectum or lunulatum, and probably will be found to have the same relationship to this species as our var. $\delta$ has to $\alpha$; but a reasonable doubt arises about the specific indentity of proliferous and non-proliferous $A$. erectum.*

* Its reported occurence on the Viti Islands is not acknowledged either by Carruthers in the Flora Vitiens. or by Luerssen in Fil. Graeffeanae. 
\& var. myriophyllum. - Pinnules again deeply cut into linear segments, and sometimes one or more on each side pinnate, besides the basal ones, thus approaching A. myriophyllum, Presl.

Kauai! (Kn.).

A curious feature in many $\mathrm{Kauai}$ specimens of this and the preceding var. is the development of an empty indusium on the ventral face of the frond, corresponding to a sorus on the dorsal face, which in such case is generally sterile. Particularly the dareoid sori have such companions.

8. A. varians, Hook. \& Grev. Ic. Fil. tab. 172. - Stip. tufted on a very short root-stock, with a few short capillary semitransparent reddish scales at the base, otherwise glabrous, slender, green, $3 / 4-1^{1 / 2}$ long. Frond herbaceous, pale green, oblong to lanceolate, not narrowing at the base, $1^{1 / 2}-3^{\prime} \times{ }^{1 / 2}-3 / 4^{\prime}$, bipinnate with a pinnatifid apex and $7-8$ pinnae on a side. Pinnae stipitate $\left(1^{\prime \prime}\right)$, patent, rhomboidal, obtuse to obliquely lanceolate in outline, and cut at acute angles near the base into 2 or 3 cuneate and truncate pinnules or segments, which are $4-6$-toothed at the apex or cut again into 2 or 3 truncate segments. Veins and sori flabellate; the invol, acute at both ends, very delicate, opening irregularly. Spores smooth. - Hook. Sp. Fil. III, 192. - Synops. Fil. p. 216.

Maui! (Baldwin). - Known from India, Ceylon and S. Africa.

\section{Group of A. Kaulfussii. Nos. 9-14.}

The three following species are ciosely connected and cannot without violence be torn from each other to be separately joined to geographically remote forms. They have in common a short and thick prostrate rooting rhizome with green stipites crowded near the end, which are covered at their bases only with few short and ovate dark stiff entire seales of $2-6^{\prime \prime}$ in length. These consist in their basal portion of 2 or 3 layers of short hexagonal opaque cells with thick warty dividing walls, the cells elongating toward the apex and enclosing a dark-yellow granular mass. The veins proceed from their ribs at angles of not less than $30^{\circ}$, generally $30-40^{\circ}$, and continue at this inclination in nearly a straight line, or in the broadest pinnae of no. 9 they may sometimes deflect to angles of $50^{\circ}$ and even $60^{\circ}$. Together with the derivative forms of nos. 12-14 they constitute a group which in its totality is unknown elsewhere,

For these reasons I deem myself bound to keep these three species, which in turn have been assigned to $A$. obliquum and $A$. lucidum, Forst., A. compressum, Sw., A. gemmiferum and A. flexuosum, Schr., A. persicifolium, Sm., A. oligophyllum, Kaulf., A. salignum and $A$. paradoxum, BI., distinct, at least until it shall please pteridologists to unite in one species all those named (except the last, which belongs to a different section), together with a few others not mentioned here; for our forms, although separately resembling on a superficial view one or another of those above named, differ from them in various ways.

To unite the six following species in one did not seem advisable on account of the great diversity of the extreme forms on one hand, and because the material collected until now leaves some gaps yet in the succession of forms. Should such a step, however, become necessary in future, the name A. Kaulfussii, Schl., which was substituted for the older but untenable one $A$. protensum, Kaulf., would have the precedence.

Some forms of no. 9 approach most closely to A. obtusatum, Forst., or rather to its varieties $A$, obliquum and lucidum; but good distinctive characters exist in the scales, the nervature, and to some extent also in the paler color. The scales in A. obtusatum are indeed peculiar, "sphagnum-like", as pointed out by Sir W. Hooker, transparent, cancellate, as if the cell-membrane had disappeared, the bright ebony and smooth network remaining visible to the naked eye. The cells are quite empty, have no contents at all, and their membranes, where they exist, transmit light without hindrance. The 
scales which cover the rhizome and base of the stipes are large, ovate-lanceolate, long and gradually acuminate, measuring $12^{\prime \prime}$ in length, and have even at the base only one layer of cells. Those which in the young plant and often also in the adult cover the stipes and rhachis are furfuraceous, matted, quite narrow, and end in a long filiform point. The nerves, again, start from the midrib at a sharp angle of $10-20^{\circ}$ and form a slight curve, so as to be in their latter half at an inclination of $20-30^{\circ}$, rarely in the largest forms of $35-400$.

9. A. Kaulfussii, Schlecht. Adumbrat. Fi7. Cap. p. 29. - Stip. curved at the base, stout, $3-6^{\prime \prime}$ thick and occasionally muricate below, with a few broad ovate scales of $3-4^{\prime \prime}, 12-20^{\prime}$ long, dark-green, purplish below; the rhachis compressed and margined in its upper portion. Frond darkgreen, fleshy, glossy on the upper face, oblong, 18-24', pinnate with $12-16$ pairs of pinnae, which are $1^{1 / 2}-2^{1 / 2^{\prime}}$ apart below and gradually decrease to a small terminal one. Pinnae on short stalks of $2-4$ ", the uppermost somewhat decurrent, lanceolate, $4-9^{\prime} \times{ }^{3} / 4-1^{1} / 2^{\prime}$, very acute, irregularly denticulate or crenate, abscisso-truncate at the base, with the upper half parallel to the rhachis and the upper angle acute or rounded. Veins sunk, indistinct, at angles of $30-40^{\circ}$, once or twice forked, excurrent in the margin. Sori linear along the trunk and anterior branch of the forks, straight, reaching from the midrib to the edge or falling little short of both, but often also on a posterior branch, then very close and the alternate ones shorter. Invol. pale and firm. - A. protensum, Kaulf. Enum. Fil. p. 167 (not Schrad.) - A. obtusatum and A. lucidum of authors. - A. compressum, Ettingshausen, in Skelete der Farnkr. II, 44.

In the higher forest regions of Oahu, Hawaii and probably also of Maui; the largest on Mts. Kaala and Konahuanui, Oahu! and in the woods of Kohala and Hilo, Hawaii! Nat. name: Kuau. - The upper base of the pinnae is in some specimens broadly auriculate, often so as to overlap the rhachis. In one this auricle is eompletely separated in the lowest pair and forms a narrow lanceolate pinnule of $2^{1 / 2^{\prime}}$ in length, which bears 11 sori on each side, reaching from rib to margin, and represents exactly a pinnule of A. bipinnatum. A stout frond from Konahuanui, in which the upper basal angle is somewhat rounded off, resembles entirely in outline of pinnae the larger forms of A. obliquum from N. Zealand, but has the veins diverging to angles of $40-55^{\circ}$; while another very broad and fleshy specimen from $\mathrm{Haw}$ a ii, with broad auriculate upper base and shorter sori than usual, can hardly be distinguished from the St. Helena A. compressum.

$\beta$ var. membranaceum. - Texture of frond and involucre thinner; upper basal angle of pinnae rounded off. - A. protensum, Kaulf, in herb. Berolin.

One of my specimens is faintly paleaceous along the rhachis, but the small scales do not differ from the basal ones.

$\gamma$ var. gemmiparum. - Pinnae $11-12$ on each side, the terminal one small, all abscisso-truncate; sori and texture as in $\alpha$. Numerous gemmae on the upper face of the frond, $2-4$ to a pinna, each with $6-8$ frondlets which are shortly stipitate, ovate, obtuse, subentire with cuneate base, about 6" long.

Lanai! 
o var. dareoides. - Fronds oblong, $1-1^{1 / 2} \mathrm{ft}$, dark-green but thin, as in $\beta$. Pinnae $12-16$ on each side, patent, rather suddenly decreasing to a small terminal one, either pinnatifid to half the width or eut deeply (but always leaving a disk along the rhachis) into oblong cuneate and obovate segments, the outer ones entire or $2-3$-cleft, but the two, three or four first upper ones always obovate, with 5-11 notches in the upper half, the first segment inclined toward the main rhachis. Veins at angles of $40^{\circ}$, forked in the outer but pinnate with a leading nerve in the obovate segments. Sori single and marginal, $4-6^{\prime \prime}$ long in the outer segments, but more numerous, 5-9, in the obovate ones. - A. flaccidum, Forst., in Synops. Fil. p. 222, as regards the Hawaiian plant. - Darea flaccida, Hook. \& Arn. in Bot. Beech. p. 107.

Oahu! Manoa, Palolo. - A. flaccidum, Forst., differs in the pale color, coriaceous texture, suberect and narrow pinnae with appressed segments, short and thick sori, and the long lanceolate transparent scales.

10. A. enatum, Brack Fil. U. S. E. E. p. 153, pl. 21. - Stip. 6-10' long, rather slender. Frond $12-18^{\prime}$ long, oblong, sometimes narrowing toward the base, generally thin membranous, bright green and scarcely shining, the rhachis margined in the upper portion. Pinnae $7-9$ on each side besides the terminal one, which is longer stipitate and larger than those next below, the lowest stipitate, suberect, distant, lanceolate-acute, $3-6^{\prime}$ long, with an obtiquely cuneate base, $3 / 4-1^{1 / 4^{\prime}}$ broad at the lower third, unequally serrulate or crenate. Veins at angles of $35-40^{\circ}$, close as before, once or twice forking, generally soriferous only along the anterior branch, therefore the sori equal and parallel and more remote from each other than in the preceding species, but variable in length, mostly falling short of rib and edge, but occasionally reaching both, as in A. Kaulfussii. - Scales of rhizome lanceolate, about $5^{\prime \prime}$. - A. persicifolium, Luerssen, in Flora, 1875, p. 427.

Maui! Oahu! - The figure of A. salignum, Bl., in Metten. Fil. Hort. Lips. tab. VII, would well render the larger forms of the present species if the margins of the pinnae were not entire; again, the figure of A. Sumatranum, Hook. in Spec. Fil. III, tab. 168, fits so well to a young state of our plant as to awaken a suspicion of another one of those mistakes with which the name of Teschemaker has become associated.

$\beta$ var. caudatum. - Pinnae 6 on each side, all on longer stalks than in $\alpha$, long-acuminate, wavy-crenulate, rounded off at the base. Veins at angles of $40-45^{\circ}$, mostly once forked and therefore not much erowded. Texture rather firm.

Probably this, or a form close to it, was Luerssen's A. oligophyllum, 1. e., from K a ua i,

$\gamma$ var. gemmiparum. - Frond membranous, with 6 or 7 pinnae on each side at intervals of $2^{\prime}$, the terminal one on a stipes of $8^{\prime \prime}$, the upper half of the base in the lateral ones semi-truncate but well rounded off. Veins rather distant, only the anterior branch soriferous, the sori 
falling considerably short of midrib and edge. Invol. thin. Numerous gemmae on the upper face, mostly rising from the veins, each with 3 or 4 frondlets which are very shortly stipitate, ovate-obtuse with cuneate base, and more or less deeply lobed.

The typical form of A. enatum Brack., whose plant came from Kaala, Oa hu. Míne and Mr. Baldwin's are from E. and W. Maui.

$\delta$ var. dareoides. - Frond ovate-oblong, 9-12' long, on a stipes of the same length. Pinnae $6-9$ on a side, ovate-lanceolate, long- and gradually acuminate, the terminal one exceeding in size those next below it, all eut throughout (but leaving a narrow margin to the rhachis) into oblong and cuneate, not falcate, segments, which are either simple or deeply and unequally 2-4-cleft at the truncate apex; the first segment on the upper side shorter than that next following, the first lower about midway between the two first upper. Sori rather broad and short, single and marginal on the narrow segments, $2-4$ on those with forking veins. Scales, color and texture as in o. - Very much like A. flexuosum, Schrad., or A. gemmiferum, var. $\beta$, Hook.

Oahu! Paloto and Wailupe.

\& var. appendiculatum. - Like $\delta$, but the first upper segment of the 3 lowest pairs of pinnae much longer than the others and obovate to lanceolate in shape, with lateral incisures and pinnate veins from a leading nerve, thus suggesting a parent form with auriculate pinnae. - Analogous to A. appendiculatum, Labill., in its relation to $A$. flaccidum.

Oahu! Wailupe. Placed under this species with some doubt; may belong to A. Kaulfussii.

11. A. Mannii, Hillebr. - Rhizome about $3^{\prime \prime}$ thick, short, creeping, the rootlets densely covered with a short dark-brown fur (single-celled tubes). Stip. 5-10' long, with a few short $\left(2^{\prime \prime}\right)$ scales at the base, slender. Frond oblong-lanceolate, $8-12^{\prime} \times 2-6^{\prime}$, closely pinnate with $10-20$ pairs, the pinnae gradually decreasing from the middle to the smallest terminal one, thin chartaceous, pale, the rhachis compressed and margined to a great extent, often gemmiferous near the apex. Pinnae erecto-patent, 5-8" apart, petiolate $\left(1-2^{\prime \prime}\right)$, lanceolate, $2-3^{\prime} \times 3-6^{\prime \prime}$, mostly uneven-sided and abscisso-truncate at the base, with the upper angle obtuse or rounded off, crenate or bluntly serrate. Veins distinct, at angles of $35-40^{\circ}$, simple throughout in the narrow pinnae and ending at the margin, or once (rarely twice) forking in the broader pinnae. Sori straight, in regular parallel rows, in forked veins only on the anterior branches, almost reaching midrib and edge. Invol. firm. - A. Kaulfussii. Mann, Enum. no. 569 (M. \& B. no. 571).

Oahu! Waianae range and Kaala. - The upper half of the base of the pinnae is ent away in some forms almost as mueh as the lower half, so as to become narrowly cuneate. In this state a pinna looks exactly like one of $A$. Wightianum, Wall, from 
Ceylon, from which species, however, our plant differs in the great number and close proximity of its pinnae. It probably stands in nearer relation to A. prionurus, J. Sm., from the Philipines. Specimens of this which I have seen in Luerssen's herbarium approach it very closely. - Soriferous fronds of young plants have a very different appearance, showing $6-8$ decurrent, mostly bluntish pairs of pinnae and a large termina] one half as long again or longer.

$\beta$ var. dareoides. - Fronds of the same texture, color and outline, but larger in size, from $1-2 \mathrm{ft}$. long, on slender stipites of $8-12^{\prime}$. Pinnae $15-20$ on each side, linear-lanceolate, $3-6^{\prime}$ long, ${ }^{1 / 2}-3 / 4^{\prime}$ broad, pinnatifid near the apex, but otherwise deeply cut, nearly to the rhachis, into numerous suberect and falcate, oblong and cuneate segments, which are entire or 2-, 3- or 4-toothed at the truncate apex, the largest ones separated by broad sinuses or intervals; the first upper segment parallel or inclined to the rhachis and not shorter than those following; the first lower nearly opposite the second upper. Sori single and then marginal, $4-6$ "long or $2-4$ to a segment. - Scales small as in $\alpha, 2^{\prime \prime}$ long. A small specimen in my collection, which has the pinnae simply serrate in the outer portion and segmented only near the base, removes all doubt concerning the relation of this form to $\alpha$.

Oahu! Kaala, on the ridges of Makaleha valley.

$\gamma$ var.? Kauaiense. - Frond larger, $20^{\prime}$ long, fleshy but flaccid, darkgreen, with a flat compressed rhachis and 16-22 pinnae on a side, ending with a smaller terminal one. Pinnae patent, close, quite narrow, the longest $5-7^{\prime} \times 5-7^{\prime \prime}$, entire or faintly denticulate, the upper base receding from the rhachis with an obtuse or rounded angle. Veins mostly once forking close to the base; the sori on the anterior branches, $3-1^{1 / 2^{2}}$ long, never reaching midrib or edge, most of them very short and not close.

Kauai! (Kn. 103).

o var. gemmiparum. - Texture thinner and the pinnae finely serrulate, otherwise entirely as in $\gamma$. Numerous gemmae $(2-4$ to a pinna) on the upper face of the frond, covered at the base with ovate dark scales $2-3^{\prime \prime}$ long, and bearing two frondlets with stipes of $1-1^{1 / 2} 2^{\prime}$ and a cuneateovate entire but serrulate lamina of nearly the same length.

Kauai! (Kn. 104, 105).

12. A. bipinnatum, Hillebr. - Stipes stout, $26^{\prime}$ long, green, with a few lanceolate scales $\left(3-4^{\prime \prime}\right.$ long) at the base, and slightly furfuraceous above. Frond dark-green, glossy, rather fleshy, oblong, $20^{\prime}$ in length, bipinnate with about 15 pinnae on a side, the lowest as long as the next or slightly longer, about 7 , the uppermost ones gradually decreasing to the apex and pinnatisect to entire. Rhachis angular, slightly margined near the apex. Pinnae ovate-lanceolate in outline - the first upper pinnule longer, but the first lower shorter than the next one -, patent, on petioles of 
about $6 "$, their rhachis compressed in the upper half. Pinnules, 7 or 8 on a side besides a terminal one, at angles of $40-45^{\circ}$, the inferior basal one opposite the second upper, narrow-lanceolate, long-acuminate, entire or faintly denticulate, the cuneate base running into a short margined stipes; the first inner pinnules $2^{1 / 2^{\prime}} \times 3^{d \prime}$. Veins indistinct, pinnate at angles of about $20^{\circ}$, simple or once forking. Sori $12-26$ on a pinnule, extending from near the costule to the margin. Invol. firm, pale. -

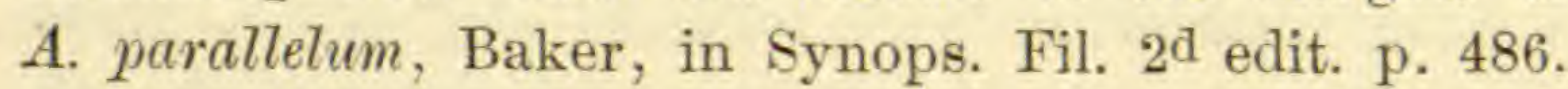

Oahu! Niu. - A large and handsome fern, evidently connected with A. Kaulfussii, The change of my manuscript name was uncalled for, as the A. bipinnatum of Brackenridge (not even admitted in the Synopsis) is a synonym of A. bipinnatifidum of the same author, of $A$. dichotomum, Hook,, and of other names, which are all united under the oldest A. Dregeanum, Kunze, by Luerssen in Fil. Graeff. p. 161.

13. A. Lydgatei, sp. $n$. - Stipes $7-18^{\prime}$ long, scaly at the base. Frond ovate, $7-10^{\prime}$ long, obtuse, chartaceous, pale, bipinnate, with $8-10$ pinnae on each side, which decrease abruptly, the terminal pinna pinnatifid. Rhachis flat and margined in the upper half. Pinnae patent on stipites of $2-3^{\prime \prime}$, ovate in outline, the middle ones longest, $3^{1 / 2}-4^{1} / 2^{\prime}$ long, with pinnatifid apex, the superior basal pinnule shorter than the two next following, the inferior basal one at half the distance between the two first upper ones; their rhachis flat and slightly margined. Pinnules 5 or 6 to a pinna at angles of $35^{0}$, rhomboidal or lanceolate, $1^{1} / 2^{2}-2^{1} / 4^{\prime} \times 4-6^{\prime \prime}$, long-acuminate, the cuneate base running into a margined stipes, the edges crenate-serrate to deeply incised with subfalcate or cuneate-oblong, simple or bidentate lobes. Veins distinct, pinnate at angles of about $20^{\circ}$, simple or forking at the middle. Sori broad, on the anterior branches of the forking veins, 2-4" long, rather distant from each other, in two parallel rows, but marginal, dareoid, in deeply incised pinnules. Invol. firm. - The middle pinnae are largest and their pinnules more deeply cut than those of the lower ones. Scales $11^{1 / 2}{ }^{\mu}$, dark and stiff, the dividing walls of the short hexagonal cells as thick as the opening.

Oahu! Niu and Wailupe. Probably eonnected with no. 10 or 11, or rather with their dareoid varieties. Somewhat analogous to $A$. difforme, $\mathrm{R}$. Br., in its relation to A. obtusatum, but quite distinet from that species.

14. A. meiotomum, sp. $n$. - Caudex short and prostrate, $I^{\prime}$ thick, the rootlets covered with a rufous fur. Stipes crowded, slender, with a few black lanceolate long-acuminate entire scales at the base, green, $6-8^{4}$ long, flat in front. Frond ovate-oblong, 9-12' $\times 5-6^{\prime}$, obtuse, thin chartaceous, bipinnate, tripinnatisect, with about 12 pinnae on either side, which decrease abruptly at the apex. Rhachis not margined. Pinnae erecto-patent, on petioles of 2 ", subopposite, oblong, the middle ones $3^{1 / 2}-4^{\prime}$ long, the lowest pair a little shorter, with pinnules less deeply cut. Pinnules 6 or 7 on either side at angles of $40^{\circ}$, alternate, narrow 
lanceolate, with cuneate base, $1-1^{3 / 4^{\prime}} \times 2-2^{1 / 2^{n}}$, cut to the middle or more into linear-or cuneate-oblong subtruncate ascending lobes; the superior basal pinnule shorter than the one or two next following and less deeply cut; the inferior basal at half the distance between the first and second upper. Veins faint, at angles of $20^{\circ}$, simple or forking at the middle. Sori dareoid, one to a segment, 1-1 $1 / 2^{\prime \prime}$ long. Invol, thin. - Scales 5-6" long.

Oahu! Wailupe. Only one plant found. - On first sight it would appear to be a reduced or less compound form of the South Polynesian A. multifidum, Brack., a species which has been connected with the New Zealand and Australian A. bulbiferum, Forst., by Luerssen. A. multifidum differs, however, not only in its much ampler size but also in the paleaceous rhachis and the upper basal pinnules, which are the largest of their order. Its scales are also quite different, broad ovate, and fringed on each side with 2 or 3 long spreading laciniae.

A small frond which rises from a short lateral spur of the rhizome is bipinnate, with very distant obovate pinnules, which are dentate at the rounded apex, and in the lowest pinnae of a larger frond some of the pinnules are of the same shape.

\section{Group of A. pseudofalcatum. Nos. 15-18.}

Rhizome short and thick, prostrate but scarcely creeping, sparingly paleaceous with narrow lanceolate blackish lustreless scales of $2-4$ " in length. Stipites crowded, green when fresh, grayish or of a livid lead-color when dry. Fronds polystichoid, dull-green, paler underneath when fresh, brownish when dry, brittle when thick coriaceous and striate or impressed on the upper face, not narrowing below, with pinnatifid apex; the pinnae patent, straight and bluntish, at least never caudate, rather even-sided except at the abscisso-truncate and subauriculate base. Ultimate segments patent, ovate or rhomboidal, often auricùlate, obtuse, with broadly cuneate base, and bluntly notched. Veins not close, less eurved than in the group of A. contigurm, at angles of 10 to 50 or $60^{\circ}$ with the midrib (the trunk of the compound veins lying in the prolongation of the next lower sinus), simple and parallel, or forked, or in the largest lobes pinnate. Primary sori oblique to the midrib, not contiguous, $1-2^{\prime \prime}$ distant from each other, oceupying the first anterior fork-branch and nearly reaching the margin, but in broad pinnae extending elso along the trunk of the veins and then curved and nearly touching the midrib besides; secondary sori pinnate in the larger lobes and pinnules, opening face to face. Involuere thin or firm, broad, rather obtuse at both ends. - All the species are apt to produce a single gemma on the main or secondary rhachides below the apex.

15. A. pseudofalcatum, $s p$. $n$. - Stipites crowded, 6-18' long, sparsely paleaceous only at the base, the scales $2-4^{\prime \prime}$ in length. Frond $9-18^{\prime}$ long, oblong-lanceolate, chartaceous to coriaceous and brittle, pinnate, the rhachis often gemmiferous near the apex. Pinnae $12-20$ on each side, patent, stipitate $\left(2^{\prime \prime}\right)$, rhomboido-ovate to obliquely ovato-lanceolate, $11 / 2-5^{\prime} \times{ }^{3 / 4}-1^{1 / 2} 2^{\prime}$, rather obtuse or acute, bluntly and remotely serrate or serrato-incised, abscisso-truncate at the base; the upper half parallel to the rhachis, or even overlapping it, and rounded off, the auricle often detached as a broad obovate segment. Veins opaque, at angles of $10-45^{\circ}$ in the narrower, of $10-60^{\circ}$ in the broader pinnae, subpinnate in the auricle; forking at the middle and simple near the apex of the pinnae. Sori elongate, in the typical specimens covering the anterior branch and trunk from midrib to edge, $6-12^{\prime \prime}$ long and $1^{1 / 2}-2^{\prime \prime}$ apart, straight and parallel near the apex, curved lower down and subpinnate in the auricle, 
but often confined to the anterior fork-branch and then shorter, distant from rib and edge, rarely also on secondary fork-branches. Invol. broad, obtuse at both ends. - A. falcatum? Mann, Enum. no. 578.

Hawail! Hamakua; Oahu! Nuuanu, Pauoa, Kaala; Molokait Halawa. The fern is generally mistaken for $A$. falcatum, Lam., from which however it is assuredly distinct. - A. auritum, Nadéaud, from Tahiti, in all probability belongs here.

$\beta$ var. obtusum. - Much smaller; whole plant $6-12^{\prime}$ long. Pinnae $1-1^{1 / 2} 2^{k}$ long, mostly very obtuse and subentire, but more or less distinetly auricled.

Maui! Pumelei, Kaanapali; Hawaii! In shape of pinnae very much like small forms of $A$. marinum and $A$, obtusatum.

16. A. lobulatum, Metten. in Linnaea, 1869, p. 100. - Stip. sparsely paleaceous when young, $10-20^{\prime}$ long. Frond thick chartaceous, ovatelanceolate, 12-24' long, gradually acuminate, bipinnatisect below, pinnatifid at the often gemmiferous apex. Pinnae stipitate $\left(2^{\prime \prime}\right), 10-20$ on a side, patent, ovate to ovate-lanceolate, $2-5^{\prime}$ long and $2^{\prime}$ broad at the base, notched and gradually eut more deeply at angles of $10-60^{\circ}$ into oblong bi-, tridentate and cuneate-obovate lobes, segments or pinnules, the upper basal segment suberect, all segments bluntly and not closely notched. Primary sori at distances of $11 / 2-2^{\prime \prime}$, extending from costa to sinus, about $6^{\prime \prime}$ long, at angles of $10-40^{\circ}$, but shorter sori on secondary branches in deeper lobes, and on pinnate veins extending from costule to edge. Invol. broad, thin. - Diplazium lobulatum, Meyen. - Only one or two pairs of segments stipitate in the lower pinnae.

Oahu! In shape very near no. 24, but distinguishable at first sight by the distant sori. The upper, less divided pinnae are exactly like those of no, 15 .

17. A. insititium, Brack. Fil. U. S. E. E. p. 161, pl. 22, fig. 2. - A weaker plant than the last. Stip, rather slender, $8-18^{\prime}$ long, generally fibrillose. Frond chartaceous, oblong-lanceolate, $10-20^{\prime}$ long, bipinnate except at the apex; the rhachis fibrillose, compressed and generally proliferous below the apex, as are also often the rhacheoles. Pinnae $10-16$ on a side, patent, the lowest $3-5^{\prime} \times 1-1^{1 / 2^{2}}$, pinnulate in the inner, pinnatifid in the outer half, the upper basal pinnule parallel to the main rhachis. Stipitate pinnules $3-5$ on a side, ovate-rhomboidal or oblong, $8-10^{\prime \prime} \times$ $4-7^{\prime \prime}$, with a broadly cuneate or abscisso-truncate base, the obtuse apex and both sides bluntly dentate or serrate, the upper face striately impressed between the veins. Veins in the pinnules pinnate with a leading nerve or costule at angles of $10-30^{\circ}$. Sori 6 or 7 to a pinnule, reaching from costule to edge; in the pinnatifid portion of the pinnae and in the apical portion of the frond as in A. pseudofalcatum. - A. spathulinum, Hook. Sp. Fil. III, 170, and Mann, Enum. no. 581. - A. affine and A. cuneatum of writers as to the Hawaiian Islds.

Oahu! Pauoa, Nuuanu, Kahana and elsewhere. - The specifie name of Brackenridge is by Mettenius and Carruthers referred to my no. 24 ; but the original description attributes to it gemmae, a dingy stipes, compressed rhachides and striate pinnules with a costule - all characters peeuliar to the present group. Probabiy specimens of both 
no, 17 and no. 24 have been distributed under the above name by the U. S. E. E. It is indeed very similar to A. affine from Mauritius, but that ferm does not seem to be proliferous.

$\beta$ var. grandipinna. - Frond larger and coriaceous, brittle. Lowest pinnules $1^{1} / 2-2^{\prime} \times{ }^{3} / 4-1^{\prime}$, obliquely ovate-lanceolate, obtuse to somewhat acute, the edges bluntly serrate and often more deeply notched. Sori as in small forms of A. pseudofalcatum. Most pinnae gemmiferous below the apex.

Oahu! Kaala; Molokai or W. Maui!

$\gamma$ var. pseudonitidum. - A large fern like $\beta$, but chartaceous, the lowest pinnae $5^{\prime}$ long and $2^{1} / 4^{\prime}$ broad at the base, rather long-acuminate, the lowest pinnules $1-1^{1 / 2^{\prime}}$ long, inciso-lobate as in $A$. nitidum, Sw., but at more open angles, ohtuse, costulate. Sori pinnate, oblique and straight from costule to edge, discreet, not close and crowded at the middle as in genuine $A$. nitidum.

Oahu! Kahana. - Apparently the same fern comes from Ceylon as A. nitidum, which species, however, belongs to the group of $A$. contiguum. All our fronds bear the characteristic gemma near the apex of the main rhachis. The least cut pinnules are exactly like the pinnae of $A$. pseudofalcatum, var. $\beta$.

18. A. sphenotomum, $s p \cdot n$. - Scales dark-brown, ovate, with a short capillary acumination, $1-1^{1} / 2^{\prime \prime}$ long. Stip. stout, 8-16' long, Iurid-gray, deeply grooved, naked except at the base, or sparingly fibrillose. Frond dull-green, fleshy when fresh, thick chartaceous when dry, ovate- or deltoid-lanceslate, commonly $1-2 \mathrm{ft}$. long and $8-12^{\prime}$ or more broad at the base, gradually decreasing from the basal pinna to the acute pinnatifid apex, tri-, quadripinnate with the pinnae closely set, the lowest $11^{1 / 2-2^{\prime}}$ apart. Rhachis deeply grooved, fibrillose or naked, compressed above and in the smaller forms generally bearing a single gemma below the apex. Pinnae $16-20$ on a side, patent, deltoid-lanceolate, with a sharp acumination, $4-8^{\prime}$ long and $1^{1 / 2}-4^{\prime}$ broad at the base, petiolate $\left(2-3^{\prime \prime}\right)$, the upper basal pinnule parallel with the main rhachis, the lower in the first pinna as long as the upper, or longer and pedately deflected; the secondary rhachides compressed, even marginate, and in larger forms mostly gemmiferous below the apex. Lowest secondary pinnae $1-3^{\prime}$ long, cut to the flat or marginate and generally paler rhachis at angles of $30-50^{\circ}$ into cuneate-oblong obovate and rhomboidal truncate segments or pinnules of $3-9^{\prime \prime} \times 2-5^{\prime \prime}$, the lowest generally cut again into 2 or 3 spreading cuneate-oblong truncate lobes which are faintly and obtusely dentate at top (or in some Hawaiian forms deeper cut). Veins not close, flabellate, with a leading nerve in the larger ultimate pinnules. Sori copious, $1-4$ to a segment or lobe, rather broad, $1^{1 / 2}-2^{\prime \prime}$ long, always opening face to face when more than one. Invol. pale, obtuse at both ends. 
Hawaii! Kohala range at Kawaihae iuka, 4000-5000 ft. elevation (Hbd.); E. Ma ui! (Baldwin); Kauai! high mountains of Waimea (Kn.).

$\beta$ var. connectens. - Much smaller. Frond $9^{\prime}$ long, deltoid-lanceolate, bipinnate to tripinnatisect, the main rhachis in its upper portion and the secondary rhachides throughout strongly compressed. Pinnules cuneateobovate as in $A$. insititium, or rather in its var. $\gamma$, but smaller, $4-8^{\prime \prime}$ long, and only the two basal ones, which are much the largest, pinnatisect into 2 or 3 cuneate-obovate truncate segments resembling those in $\%$ of the present species. The leading nerve is marked externally by a prominence and paler color, but vanishes in the upper half of the pinnules. All specimens bear the gemma below the apex.

Kauai! Maui! Haleakala; with the first form. - Serves to connect the present species with $A$. insititium, a relationship which without it would hardly be suspected. It cannot be denied that in eutting of pinnae this variety bears a great resemblance to the $A$. cuneatum from St. Vincent in the W. Indies, which is, I believe, the original of Lamark's species. It differs, however, in being, although of the same size, a much stouter plant with thicker texture, in the deltoid outline of the frond, the compressed rhachides and constant development of the subapical gemma. Moreover, a compound form like $a$ is not known of $A$. cuneatum. As to the A. cuneatum which comes from Natal, I have no hesitation in plaeing it with Luerssen and others next to A. laserpitiifolium, which belongs to the group of $A$. contigurm.

\section{Group of $A$. contiguum. Nos. 19-26.}

Rhizome wide-creeping, covered at the end with short dark-brown glossy lanceolate scales of $2-4^{\prime \prime}$ in length, which generally end in a capillary acumination. Stipites distant, dark-brown, glossy, paleaceous at the base. Frond polystichoid, dark-green, shining, often of a bronze-color when dry, oblong, narrowing below and ending, as do the pinnae, in an acute or caudate pinnatifid apex. Pinnae more or less falcate, mostly with a cuneate base which is largely cut in the lower half. Ultimate segments oblongtruncate or cuneate-obovate, with close and sharp adpressed teeth or serratures. Veins very close, simple, forking or flabellate; the simple veins (near the apex) and the anterior branches of the compound systems rising from the costa (under the seeond lower sinus) at acute angles of about $5^{\circ}$, and subparallel to the costa until they reach their own lobe or segment, when they deflect to angles of $10-50^{\circ}$; the compound systems never with a midrib or leading nerve in the ultimate segments or pinnules. Primary sori on the simple veins and the basal portions of the anterior branches, contiguous to the midrib, very close and more or less imbricate, confluent with age; secondary sori in the larger lobes and segments flabellate. Involucre narrow, pointed at both ends. No tendency to proliferation.

19. A. contiguum, Kaulf. Enum. Fil. p. 172. - Rhizome creeping, 2-3" thick, the scales $1^{1 / 2}-3^{\prime \prime}$ long, linear-lanceolate, with a capillary point. Stip. at distances of $3-4^{\prime \prime}$, paleaceous only at the base, seldom sparingly fibrillose, glossy, brown, slender, 6-18' long. Frond chartaceous, darkgreen with satiny gloss, oblong-lanceolate, slightly narrowing below, $9-36^{\prime}$ in length, pinnate, with pinnatifid apex. Pinnae $14-36$ on each side, shortly stipitate, patent, linear-lanceolate, often falcate and recurved, $2-5^{\prime} \times 1 / 4-1 / 2^{\prime}$, acutely pointed or more frequently long-acuminate; the base very little dilated, obliquely cut in the lower half to a great extent, the upper half receding from the main rhachis, often cuneate; the edge sharply and acutely notched or incised and closely dentate or serrate with 
sharp adpressed teeth. Veins rising at angles of $5^{0}$ and deflecting to 10 and $20^{\circ}$ at the middle and base of the pinnae. Primary sori in two crowded rows, subparallel and close to the costa, confluent with age, $3-8$ "long, imbricate with their distal ends and scarcely reaching the middle of the lamina; only few secondary sori on the upper base, at angles of $20-30^{\circ}$. Invol. narrow, thin, pointed at both ends. - Metten. Asplen. p. 152. - Hook. Sp. Fil. III, p. 156, tab. 194. - Brack., Mann. 11. ec.

$\beta$ var. fitiforme. - Pinnae narrow and long, 6' and upwards, drawn out into a long slender tail. - A. filiforme, Kaulf.

$\gamma$ var. laciniatum. - A large form. All or most pinnae narrowly slit in one or several places to near the rhachis, thus giving to the frond a torn, ragged appearance.

¿ var. pumitum. - Frond linear-lanceolate, considerably narrowing below, with fibrillose rhachis, the patent pinnae not exceeding $1^{\prime}$ in length by 4 " in breadth, the upper base parallel to the rhachis but rounded. - Kauai! Knudsen. - Soriferous fronds of quite young plants with rhizomes $3-4^{\prime \prime}$ long measure only $2^{\prime}$ and bear $8-10$ pinnae on a side, which are $3-6^{\prime \prime}$ long, cuneate-obovate to obliquely ovate, their veins flabellate without leading nerve or costule, or one only reaching $1 / 3-1 / 2$ of the length; the sori few and flabellate, but most in the median line.

On all islands in forests of medium elevation. - The species was first collected on the Hawaiian group by Chamisso, but has since been found on Lord Howe's Isld, Luzon, Ceylon, and in the Neilgherry Hills. In its typical form of a dark satiny green, with linear long-acuminate pinnae which are not auriculate at the base and are excised below to nearly $1 / 3$ their length in often a straight line, the sori close to the costa, the species is very distinct indeed, yet it passes by gradual transitions into A. falcatum, Lam., and A. caudatum, Forst. - A hairy rhachis, as figured in no. 2 of the plate in the Sp. Fil., I have never met with.

20. A. Knudsenii, sp. n. - A small fern, with the rhizome scales and color of $A$. contiguum. Stip. brown, slender, 6-7' long. Frond thin chartaceous, 5-7' long, with $10-20$ pinnae on each side, which are obliquely ovate or ovate-lanceolate, $1-1^{1 / 2^{4}} \times{ }^{1 / 3}-^{-1 / 2^{4}}$, acute, slightly incisoserrate, the upper half of the base parallel to the main rhachis and rounded. Veins as before. Sori very short, $1-11 / 2$ ", distant in a row on each side of the costa, neither contiguous to it nor to each other, seated on the middle portion of the anterior branch or at one of the last bifureations. Invol. thin, pointed at both ends.

Kauai! Waimea (Kn.).

21. A. nitidulum, sp. n. - Rhizome and scales as before. Stip. distant $\left(3-4^{i \prime}\right)$, dark-brown or almost black, $4-6^{\prime}$ long, fibrillose or naked. Frond thick chartaceous, olive-green, lanceolate, $5-15^{\prime}$ long and $2^{1 / 2}-4^{\prime}$ broad at the middle and thence gradually narrowing to apex and base, pinnate, the lowest pinnae $6-15$ "long. Pinnae $12-16$ on a side, patent, 
shortly stipitate, the longest $1-2^{1} / 2^{4} \times{ }^{1 / 2}-1^{\prime}$, ovate-lanceolate, finely acuminate, the base cut in the lower and subtruncate with rounded angle in the upper half, the edge subentire or sharply cut at angles of $5-50^{\circ}$ on each side into $5-8$ serratures and lobules or segments, the largest segments being oblong and sharply serrulate at the rounded apex, the auricular one often cut to near the rhachis and obovate-oblong, with 10-11 flabellate veinlets. Veins very close. Primary sori through the entire length of the pinnae, subparallel and contiguous to the costa in the outer half, deflecting to angles of $10-20^{\circ}$ but always short of the edge in the inner half, $2-6$ "long; secondary sori radiating in the inner half of the subentire pinnae and in the larger segments of the incised forms, all falling short of the edge. Invol. rather firm, obtuse at both ends.

Molokai! W. Maui! woods of Hilo, Hawaii! Rare. - The Hawaiian representative of $A$. falcatum, Lam., the genuine form of which does not seem to exist in the Hawaiian group. At the pinnatifid apex of the frond the soti are crowded close to the rhachis as in the pinnae of $A$. contiguum. The pinnae of the smaller incised forms can hardly be distinguished from a pinnule of a moderately incised $A$. patens, unless by the firmer texture.

22. A. caudatum, Forst. - Hook. Sp. Fil. III, 152. - Rhizome creeping, stout, $1 / 2-3 / 4^{\prime}$ thick, densely clothed with dark-brown linear-lanceolate scales of $3-5$ " which run out into a long, not capillary, acumination. Stip. about 6 " apart, stout, $8-14^{\prime}$ long, $1^{1} / 2-3^{\prime \prime}$ thick, dark-brown, sparingly fibrillose or naked. Frond chartaceous, olive-green when thin, of a deeper bronze color when thicker, with satiny lustre on both sides, oblong, narrowing below, $1-3 \mathrm{ft}$. long, pinnate, with pinnatifid apex. Yinnae $20-40$ on a side, shortly stipitate, oblong-lanceolate, $2-5^{\prime} \times{ }^{1 / 2}-1^{\prime}$, the larger ones gradually enlarging toward the little dilated base, which is abscissotruncate with the upper half receding from the rhachis and rounded off, acute or eaudate-acuminate, subentire, or serrate-incised, sometimes deeply near the base, by narrow slits at angles of $20-50^{\circ}$ into oblong and obliquely truncate to rounded lobes. Veins semitransparent with reddish light, repeatedly and closely forking, except near the apex. Primary sori $4-10^{\prime \prime}$ long on the anterior branches at angles of $10-20^{\circ}$, imbricate and close to the costa, slightly curved, all short of the margin; in the simple pinnae these only, in the deeper lobed ones also a few secondary sori irregularly flabellate on the disks of the Jobes, but never reaching the margin. Invol. thin, narrow, pointed at both ends. - Synops. Fil. p. 209. - Metten. Fil. Hort. Lips. p. 76. - Schkuhr, Fil. Germ. p. 72, tab. 77. Tarachia caudata, Presl, Epimel. p. 79.

Oahu! west end of the main range and Kaala; Ka uai! (Kn.). - Occurs also on Lord Howe's Isld., Sunday Isld., Aneitum, Java, Luzon, Ceylon, in Hindostan, N. W. Australia and E. Africa. - Short and subentire pinnae are broadest at the base, but in the larger pinnae the base is searcely broader than the middle, owing to the extensive cut of the Jower half. In the uppermost pinnae this eut proceeds in almost a straight line, as in A. contiguum, so as to give them a trapezoid outline, but lower down it shortens, and 
in the lowest pinnae assumes a short downward sweep, as is common in A. faleatum. Some of the semi-incised forms could hardly be distinguished from Natal forms of $A$, serra, Fisch. \& Langsd., if it were not for the short auricular and distant lower pinnae in the latter, for in our species the lowest pinnae are only slightly shorter than those next a bove and not more remote. Through the deeply lobed forms it passes directly into no, 24.

$\beta$ var. sectum. - Frond large, about $3 \mathrm{ft}$. long and stout, with a fibrillose rhachis, the pinnae $3-4^{\prime} \times{ }^{1 / 2}-3 / 4^{\prime}$, linear-oblong, broadest at the base, deeply cut, except at the apex, into oblong and obovate segments which are rounded at the top and sharply many-toothed.

Oahu! E. Maui! - This var. approaches A, horridum, but the primary sori overlap each other and there are secondary sori on most lobes, which are not truncate as in that species.

In adopting for the present species Forster's old name I am not unaware that recent writers believe themselves justified in transferring the same to A. horridum, Kaulf., and that Forster's short description applies quite well to the glabrous variety of that species. The supposition would still gain in strength if Forster's plant derived from Tahiti, where only $A$. horridum exists. As, however, Hooker's and Mettenius's descriptions of A, caudatum, which have been followed since by most writers, apply entirely to our plant, I have preferred to abide by their nomenclature, A. Aneitense, Carruth., if not the same plant, stands next to it.

23. A. horridum, Kaulf. Enum. Fil. p. 173. - Rhizome shorter. Stip. dark-brown, stout, 6-12' long, shaggy with dark-brown paleaceous hair $(2-3 ")$, which toward the base changes to larger scales with hair-like points. Frond coriaceous, dark-green, lanceolate-oblong, broadest at the middle, $18-36^{\prime} \times 4-10^{\prime}$, pinnate, with pinnatifid apex; the rhachis hairy. Pinnae $24-48$ on each side, closely set, stipitate $\left(1-1^{1 / 2} 2^{\prime \prime}\right)$, abscissotruncate at the base, the middle ones $2-6^{\prime} \times 4-9^{\prime \prime}$, linear-lanceolate, gradually acuminate, cut at angles of $30-40^{\circ}$ to one half or more into numerous nearly equal oblong obliquely truncate lobes which are subentire or obtusely dentate at the top. Veins obscure, repeatedly forking, but not very close, the trunk of each system rising in the prolongation of the preceding sinus, and the first branch parallel to the costa as far as the outer margin of its lobe, where it suddenly deflects. Primary sori (and these only in typical specimens) on the parallel portion of the main branch, $2-3$ " long, not imbricate, forming a straight row on each side of the costa and contiguous to it; secondary sori at angles of $30^{\circ}$ only in deeper cut pinnae and few $(1-3)$ to a lobe. Invol. narrow, pointed at both ends. - Hook. Sp. Fil. III, 153, tab. 193. - Hook. \& Arn. Bot. Beech. p. 106. - Synops. Fil. p. 211. - Brack. Fil. U. S. E. E. p. 158. - Metten. Asplen. p. 150. - A. truncatum, Bl.

Oahu! Pauoa and elsewhere; Kauai! Molokai! Maui! Nat, name: ‘Iwas. Occurs also in Tahiti and Java. - Of this same form my collection holds also two specimens with naked stipes and rhachis, but it is uncertain whether they derive from the Hawaiian group or Java. In these the sori are also somewhat longer, so as to overlap slightly, and not strietly parallel to the eosta as in the typical form of the Hawailan Islands. The same is observable in shaggy specimens from Tahiti, in which the longer sori $\left(4^{\prime \prime}\right)$ deflect so as nearly to reach the next upper sinus. 
$\beta$ var. - Less robust. Stipes and rhachis naked. Pinnae cut more deeply into mostly obovate, spreading, even recurved lobes having a broader many toothed apex. Veins more divided, but the anterior branch quite close and parallel to the costa. Secondary sori on most lobes besides the primary ones.

Woods of Kahuku and Kahana, Oahu!

24. A. spathulinum, Hook. Sp. Fil. III, 170 (not J. Smith?). - Rhizome creeping, 3 "thick, the scales $3-4$ " long, from an ovate base gradually acuminate and falcate, ending in a hair-Jike point. Stip. 3-4" apart, naked or fibrillose, dark-brown, $10-15^{\prime}$ long. Frond chartaceous to coriaceous, olive-green in the thinner forms, of a dark bronze color when thick and dry, lustrous on both sides, $12-36^{\prime}$ in length, oblong-lanceolate, slightly narrowing below, or at least the lowest pinnae not longer than those next above, bipinnate, with pinnatifid apex. Pinnae $12-30$ on each side, lanceolate, $3-6^{\prime} \times 1-1^{3} / 4^{\prime}$, shortly stipitate, caudate-acuminate, deeply cut, mostly to the rhachis, at angles as in A. caudatum, into oblong spathulate and broadly obovate segments which are rounded or pointed, dentate or serrate at the top, the innermost tapering into narrow cuneate bases; the apex inciso-serrate as in A. caudatum. Veins as in that species, even the largest pinnules without a leading nerve. Sori flabellate on nearly all segments and soon confluent, the narrow disk along the costa having room for primary sori only near the apex. A. insititium, Carruthers and Metten.

In the middle forest region of all islands. - Occurs also in Aneitum, Luzon, Borneo, Ceylon. - A very graceful fern, larger than A. insititium, and may be considered as a more divided form of $A$. caudatum, the shape of which it repeats at the apices of frond and pinnae. The pinnae vary much in shape and cutting, their bases being mostly as large, sometimes even narrower, but often much broader than the portions next above. The pinnules are not properly stipitate, but leave a very narrow margin to the rhachis. In the most divided forms from $\mathrm{E}$. Maui and $\mathrm{Haw}$ aii they are lengthened to a point and their lower half is cut in a straight line, so as to give them a trapezoid shape.

$\beta$ var. furcellatum. - Rhizome creeping. Stip. distant, naked except at the base, dark-brown, $7-14^{\prime}$ long. Frond oblong-lanceolate, $1-2 \mathrm{ft}$., of the same color and texture as before, and naked. Pinnae $12-18$ on a side, $2^{1} / 2-4^{\prime}$ long, eut as before; but the inner segments truncate at the top, with 2 or 3 deeper slits besides the serratures, the next segments obliquely truncate and serrate ( $\mathrm{Kauai}$ ); or the inner segments cuneateobovate, rounded at top, with several deeper slits and serratures, the next cuneate-oblong and semi-truncate (Kaala).

Oahu! Kaala; E. Maui! Ulupalakua; Kauai! In all places associated with forms of $\alpha$. - In shape and cutting of pinnae agreeing with $A$. furcatum, but the ereeping rhizome, the color and size of the naked frond do not admit of separation from the present species. It will serve to etablish the close relationship between these two species.

25. A. furcatum, Thunb. - Hook. Sp. Fil. III, 165. - Caudex short and stout, clothed at the apex with dark-brown and glossy acuminate 
scales of $2-3^{\prime \prime}$. Stip. close, $3-6^{\prime}$ long, more or less fibrillose with ferruginous hair-like scales which are often laciniate at the base. Frond coriaceous, rigid, dark-green, ovate-lanceolate, 4-12' long, bipinnate rarely tripinnate with a pinnatifid apex, the rhachis fibrillose. Pinnae $7-12$ on each side, shortly stalked, $1^{1 / 2}-2^{1 / 2^{4}} \times{ }^{1 / 2}-1^{\prime}$, rhomboidal or trapezoid in the simplest subentire forms, obliquely ovate-lanceolate when longer, and often caudate, with abscisso truncate base, eut at the same angles as in the preceding species into oblong and cuneate segments or pinnules, which are truncate and slit from the top downward into $2-4$ oblong lobes or pinnules which are again serrate or dentate above. Veins as before, flabellate without leading vein in the segments and pinnules. Secondary sori numerous, straight, covering the segments from the base to near the top and soon confluent; primary sori only in the less divided pinnae, near the apex, 3-4" long. Invol, pointed at both ends.

Oahu! frequent on the Waianae Mts.; Kauai! Molokai! E. Maui! Hawaii; at elevations of 2000-6000 ft., generally in open, exposed places. - Nat. name: swaiwa o kanes. Widely distributed through the tropical and subtropical regions of the whole world.

26. A. dissectum, Brack. Fil. U. S. E. E. p. 170, pl. 24. - Rhizome short prostrate, with few short lanceolate dark-brown scales at the end. Stip. rather close, long and slender, purplish brown, shining, sparingly fibrillose with deciduous short reddish hair-like scales which are fimbriate near the base. Frond dark green, opaque when dry, thin chartaceous, open, oblong-lanceolate in outline, not narrowing below, $12-26^{\prime}$ long, $8-18^{\prime}$ broad, tri-, quadripinnate, ending in a short pinnatifid apex, the lowest pinnae not longer than the next upper and 2-4' apart from them. Pinnae about 20 on a side, alternate, erecto-patent, long-stipitate $\left(4-10^{4}\right)$, ovate-lanceolate, finely acuminate, with a slender, not compressed, fibrillose rhachis; the upper basal pinnule parallel to the main rhachis, the lower at nearly half the distance between the two upper and deflected outward; the incisures below the apex at angles of $5^{\circ}$ or less. Secondary pinnae $1^{1 / 2}-3^{\prime}$ long, cut in the manner of A. furcatum. Tertiary pinnae cuneate-obovate, $3-5$ "long, stipitate, pointed or subtruncate and twoto several-toothed at the top, the largest more or less deeply cut into 2 or 3 pointed or cuneate and bi-, trifid segments. Veins obscure, forking without a leading nerve, excurrent to the apex, generally 2 to an ultimate segment. Sori short $\left(1^{\prime \prime}\right)$, on the ultimate branchlets, one to a lacinia or segment, or 3-10 to a pinnule, not opening face to face. Invol. firm, rather vaulted. Spores tuberculate and margined or winged, - No gemmae. - Hook. Sp. Fil. III, 189. - Synops. Fil. p. 214.

Hawail! Kohala range and Mauna Kea; Kauai! mountains of Waimea (Kn. and Baldwin). If in the Sp. Fil. a coriaceous frond and involucres opening toward each other are attributed to this species, I apprehend that specimens of $A$. sphenotomum were 
mixed up with the true $A$, dissectum. There are two forms, both on Hawaii and $\mathrm{Ka}$ ua $\mathrm{i}$; one as above deseribed, the frond dark green and narrow, oblong-lanceolate; the other paler, with the frond broadly ovate-lanceolate.

$\beta$ var. Kauaiense. - Ultimate segments very narrow, less than $1 / 2$ " broad, pointed or truncate, with only one vein and a sorus which fills its entire width. Fronds of variable dimensions, one of the largest size and others only $8^{\prime}$ long by $4^{\prime}$ broar.

Kauai! with the preceding (Kn.).

The species is not reported from elsewhere. Its position is not quite clear, but probably it is connected with $A$. furcatum, although it cannot be denied that a gap exists between the two species. It would furnish the natural complement of the group of A. contigurm, as $A$. sphenotomum does to that of $A$. subfalcatum.

27. A. Adiantum nigrum, L. - Hook. Sp. Fil. III, 18\%. - Rhizome short, stout, horizontal, rising at the end, thickly studded with the remnants of old stalks. Stip. crowded, chestnut-brown, polished, 6-12 long, clothed at the base with dark-brown glossy linear hair-pointed scales of about 3 " in length. Rhachis compressed, greenish in its upper portion. Frond stiff chartaceous, shining above, deltoid or ovate, or rarely ovate-lanceolate, $4-8^{\prime} \times 3-7^{\prime}$, bi-, tripinnate. Pinnae alternate, $8-11$ stipitate ones on a side, subascending, the lowest ovate to ovatelanceolate, on stalks of $2-6 "$, with an abscisso-truncate base and a margined rhachis. Secondary pinnae lanceolate, the largest $1-1^{1} / 2^{\prime}$ long, stipitate with an obliquely cuneate base, and cut down to a mostly winged rhachis into euneate-obovate and oblong-obtuse or subacute segments or pinnules which are $11 / 4-2$ " broad and sharply dentate, often almost spinulose, or again incised. Veins close, at very acute angles $\left(5-30^{\circ}\right)$, with a deliquescent midrib. Sori copious, $1^{\prime \prime}$ and less in length, closely imbricate in 2 rows next to the costule, occupying about two thirds of the width of the pinnule, confluent at last. Invol. firm, broad, rather acute at the ends. - Milde, Fil. Eur. et Atlant. p. 85.

Hawail! Maui! Kauai! from $4000-7000 \mathrm{ft}$, above the sea. Nat. name: "Iwaiwas. Those forms with narrow acute segments are like broad-segmented $A$. acutum, Bory; in others the segments resemble those of $A$. argutum, Kaulf. and $A$. obtusum, Kitaib.

$\beta$ var. - Frond ovate, small, much shorter than the stipes, stiff-coriaceous, dark-brown when dry, tripinnate. Pinnae patent. Teeth of segments short or wanting. Sori very close. Invol, rigid. - A. patens, Gaud, in Bot. Freyc. p. 320. - The segments much like those of the var. Silesiacum, Milde, in Luerssen's Crypt. Fl, tab. 127.

Hawail! Maui! from $7000-10000 \mathrm{ft}$. above the sea.

The species extends over W. and S. Europe, the Atlantic islands, Algiers, Abyssinia, 8. Africa, Asia Minor and the mountain regions of central and southern Asia.

\section{Group of A. polyphyllum. Nos. 28-30.}

Large glabrous ferns. Rhizome short and thick, creeping, with few small, ovateacuminate, dark but transparent, eystopterojd seales at the end. Stipes lurid-brown, deeply grooved, naked. Frond polystichoid, never proliferous, of delicate texture, dark- 
green, oblong, narrowing at both ends, bipinnate to near the pinnatifid end, the pinnae rather ventral on the rhachis, very shortly stipitate, almost sessile; the lower ones subopposite. Pinnules with a leading nerve or costule which loses itself before the apex. Sori on both sides of the costule, the involucres opening toward it. Two broad fib. vas. fascicles in the stipes. Spores smooth.

A most intricate group, not only on account of the difficulty in assigning the different forms to a prototype, but still more in finding a leading clue to their affiliation, in as much as the various characters which suggest themselves for classification cross each other in a puzzling manner instead of running parallel.

28. A. polyphyllum, Presl, Tent. Pterid. p. 108, and Epimel. p. 83 . Rhizome short, creeping, 3-4" thick. Stip. rather close, stout but of loose texture, 8-14' long, paleaceous at the base with a few short scales, lurid-brown; the rhachis furfuraceous with deciduous fibrils, of the same color in its lower portion but green near the apex, as are the rhacheoles of the pinnae. Frond dark-green, thin chartaceous and shining above, or membranous, oblong-lanceolate, narrowing below, $12-36^{\prime} \times 6-12^{\prime}$, bipinnate, with a sharp pinnate apex. Pinnae $15-28$ on a side, subsessile (the lower pairs almost opposite), patent, linear-lanceolate, $3-8^{\prime}$ long and $10-24$ " broad, pinnatifid at the finely acuminate apex; the upper basal pinnule not larger than its neighbor, close to and overlapping the rhachis; the lower but little more remote, almost opposite to it. Pinnules numerous (12 pairs or more) obliquely trapezoid-ovate to lanceolate, $4-10^{\prime \prime} \times 3-6^{\prime \prime}$, shortly stipitate, with the base arcuately cut in the lower and truncate with rounded angle in the upper half, obtuse to acute at the apex and bluntly notched at angles of $20-50^{\circ}$ into $5-6$ bulging serratures or subtruncate and pointed lobules, all obtuse and bluntly dentate at the top, the auricle with 5-9 flabellate veinlets. Costule flexuose, evanescent before the apex. Sori both primary and secondary on most lobules, $1-2$ "long, many reaching the margin; the foremost ones of the auricle sometimes apparently (not really) diplazoid in consequence of the close approximation of the anterior fork-branches. - Goldmann, in Nova Act. Nat. Cur. XIX, Suppl. I, 462. - Metten. Asplen. p. 168 , tab. V, fig. 23. - Carruth. in Fl. Vit. p. 353. - The basal pinnules are not, or scarcely, larger than those next to them, and often the greatest width of the pinnae is about the middle.

Eastern half of the main range of Oahu! First collected by Chamisso. Occurs also on Luzon. - A very graceful and delicate fern. The teeth of the lobules are short, bluntish, and generally less in number than the veinlets in consequence of the convergence of the outer veinlets. This character will generally suffice to distinguish the fern from moderately incised small forms of $\beta$ of the next species.

$\beta$ var. - Frond rather firm. Pinnules very small and crowded, sharply inciso-serrate and auriculate, the angles of the lobules acute, most veins running out into a tooth.

$\gamma$ var. subintegrum. - Pinnae shorter, $3-5^{\prime}$, and narrower. Pinnules rhomboido-ovate, pointed, with a cuneate base, subentire or slightly denticulate. Invol. firm. 
Oahu! Pauoa. - A still less developed form from the same locality has the pinnae pinnatifid in the outer half and the pinnules cuneate-obovate or rhomboido-ovate and quite obtuse, with the costule evanescent before the middle and the sori subflabellate.

29. A. acuminatum, Hook. \& Arn. in Bot. Beech. p. 106. - "Rhizome creeping, nearly as thick as a goose-quill. Stip. subaggregate», lurid-brown, slightly furfuraceous, $6-9^{\prime}$ high. Frond thin chartaceous to membranous, dark-green, oblong-lanceolate, broadest near the middle, $18-30^{\prime} \times 8-10^{\prime}$, bipinnate, pinnate near the apex. Pinnae close, $18-28$ on a side, subsessile, erecto-patent, the lower ones subopposite, the longest $5-7^{\prime} \times 1^{1 / 2^{\prime}}$, lanceolate, broadest at the base, pinnatifid with closely appressed segments at the acuminate apex. Pinnules $10-12$ on a side, rhomboidal to obliquely lanceolate, $16-12^{\prime \prime} \times 4-6$ ", rather acute, slightly incised but strongly serrate with acute teeth, the inferior base cut straight, the superior truncate, the auricular lobule, when present, with 4 or 5 straight veinlets. Costule weak, flexuose, deliquescent. Sori $2-3^{\prime \prime}$ long, at angles of $20-30^{\circ}$, on the anterior fork-branches, with sometimes 1 or 2 secondary ones in the auricular Iobule. - Hook. Sp. Fil. III, 183, tab. 206. - Synops. Fil. p. 218. - Brack. 1. e. p. 164.

Oahu! Nuranu and Pauoa; Maui! Ulupalakua. - Not known from elsewhere. Nat. name: "Lola".

$\beta$ var. - Pinnules elongate, lanceolate-acute, with the upper half of the base receding from the rhachis, incised more or less deeply into truncate lobules which are 4 - or 5 -toothed at the apex, nearly as in $\beta$ of the preceding species, all veinlets running into teeth, the auricle not much larger than the next lobule. Upper basal pinnule $1-1^{1 / 2^{\prime}}$ long.

Oa hu! top of Mt. Kaala. The pinnules cut exactly as in some forms of A. nitidum, Sw.

$\gamma$ var, subintegrum. - Pinnules narrow lanceolate as in $\beta$, but subentire except the larger basal ones, which are cut; those of the upper half $1-1 \frac{1}{2}+$ long.

Maui! Haleakala.

30. A. patens, Kaulf. Enum. Fil. p. 175 (non Hooker nec Gaudichaud). - Stip. crowded on a short creeping rhizome, 1-2 ft. long, of a deep chocolate-brown, sparingly furfuraceous above with deciduous fibrils, but soon naked and glossy. Frond dark-green, either chartaceous and shining on the upper face, or dull and almost black when thinner, open, broad oblong, $18-36^{\prime} \times 9-20^{\prime}$, the one or two lowest pinnae shortening a little, bipinnate to tripinnate. Pinnae about 18 on a side, mostly subopposite, ventral along the deep groove of the rhachis, on stalks of $3-4^{\prime \prime}$, broad lanceolate, the largest $9-12^{\prime} \times 2-4^{\prime}$, slightly narrowing at the base, pinnatifid at the finely acuminate apex with linear appressed segments. Stipitate pinnules $12-16$ on a side, obliquely ovate-lanceolate, the largest $1^{1 / 2}-2^{3} / 4^{t}$ long, cuneate at the base, gradually and finely acuminate; 
those of the upper portion of the frond inciso-serrate and auriculate as in $\beta$ of the preceding species; those of the lower pinnae deeply cut, even to the rhachis, at angles of $5-40^{\circ}$, into 5-10 lobes or segments, the latter being oblong, with $2-5$ serratures at the apex, to cuneate-obovate and inciso-serrate in the upper third. Veins close and straight, excurrent in the serratures, flabellate in all larger lobes, 6-11 in the upper basal one, the anterior branches at angles of less than $10^{\circ}$ until the last bifurcation. Sori $2-4$ " long; in the larger pinnules both primary ones subparallel to the costule, and secondary ones irradiating in the larger segments; the anterior sorus of the larger segment often apparently diplazoid on account of the close approximation of the two first veinlets. - Carruthers, in Fl. Vit. p. 353. - A. laserpitiifolium, Hook. in Sp. Fil. III, 171. - In one of my specimens the frond is truly tripinnate at the base.

$\beta$ var. - Frond smaller, bipinnate, the pinnules almost entire, $1^{1 /} / 2^{\prime}$ or more in length.

The var. $\beta$ from the southern slope of Mt. Háleakala, Ma ui! the typical form from the top of Mt. Kaala, Oahu! and from Kaanapali, Maui! the tripinnate form from Halona, Maui! (Lydg.). - This fern, little understood hitherto from Kaulfuss's meagre description, is not known from elsewhere, but fragments of it have been assigned by competent pteridologists to $A$. nitidum, Sw., and to A. laserpitiifolium, Lam. In the largest specimen from W. Ma ui the pinnules near the apex are rhombeo-ovate, 6 "long, and subentire like those of the Himalaya form of A. nitidum; lower down they assume an auricle and lengthen to the dimension and shape of Mettenius's figure of that species in Asplen. tab. V, only that the segments are more deeply cut and dentate or serrate; while in the largest pinnae the pinnules are exactly like those of $A$. laserpitiifolium as figured in Hooker's Sp. Fil. III, tab. 203, or like shortened pinnae of forms intermediate between $A$. caudatum and A. spathulinum. Color and gloss of the firmer specimen are as in $A$. contigurm or $A$. caudatum, and I should have added this species to the group of $A$. contigurm if it were not for its elose affinity with $A$. acuminatum. The var. $\beta$ of that speeies might almost with equal right be transferred to the present one.

C. Diplazium. Nos. 31-36.

a. Polystichoid. Nos. 31-32.

31. A. arboreum, Willd. - Hook. Sp. Fil. III, 246. - Rhizome very short, prostrate, with few dark lanceolate seales on the involute fronds. Stip. crowded, weak, lurid-green or stramineous, naked, 6-8' long. Frond polystichoid, membranous, almost flaccid, ovate-oblong, 6-12' $\times 4-6^{\prime}$, truncate at the base, pinnate, with pinnatifid apex. Pinnae patent, 9-12 on each side, all alternate or only the one or two lowest opposite, long stipitate $\left(3^{\prime \prime}\right)$, oblong-lanceolate, subfalcate, acute, $2-3^{1 / 2^{\prime}} \times{ }^{1 / 2}-1^{\prime}$, shortly and obliquely cut at the lower base, the upper half truncate, parallel with or verging on the rhachis, the edge notched or cut into 9-12 subequal, broad-ovate or deltoid, obtuse or somewhat acute lobules, the first upper one more deeply separated and protruding; all lobules sharply dentate. Nervatio Neuropteridis. Veins excurrent, rather prominent, only 
few simple or furcate near the apex of the pinnae, the great majority subpinnate, with a flexuose leading vein and $3-8$ alternate lateral veinlets which run nearly parallel to it, those in the auricle again forking; the leading veins excurrent, at angles of $40-80^{\circ}$, the first anterior branches strongly eurved in the broader pinnae. Primary sori on all first anterior branches, $3-6^{\prime \prime}$ long, covering them from the first fork near the midrib to the sinus, curved, generally diplazoid in their upper halves; but shorter asplenoid sori also scattered irregularly over the distal portions of other veinlets, thus imparting a complex appearance to the fructification. Spores winged and crested in various directions. - Synops. Fil. p. 233. - Diplazium arboreum, Pr. - A. auriculatum, Metten. Asplen. p. 164. - Diplasium auriculatum, Kaulf. - No gemmae.

Very rare. In a narrow guleh of Mopulehu, Molokai! Ka uai! (Kn.) - The Ka uai specimens differ only in the sharper, almost spinulose teeth. Not known before from the Hawailan Islands, - The species also inhabits the West Indies, Venezuela, New Grenada and Brazil; it was named by. Willdenow on the erroneous information that the root-stock was arborescent.

$\beta$ var. - Pinnae deeply eut into oblong obovate and ovate, mostly pointed lobes. Primary sori few and shorter, only in the outer half of the pinnae.

Oahu and Molokai! (Baldw.).

32. A. Sandwichense, Hillebr. - «Stipes and rhachis lurid-brown. Frond polystichoid, coriaceous, glabrous, ovate-oblong, $15^{\prime}$ in length, pinnate, the upper pinnae coadunate in a pinnatifid terminal one. Pinnae alternate, patent, stipitate, the lowest on stalks of $3^{\prime \prime}$, oblong-lanceolate, $4^{\prime}$ long, rotundato-truncate in the upper half of the base, sharply cut in the lower, narrowing to the somewhat obtuse apex, the edges cut into unequal lobes, which are 2-5-toothed at the truncate apex; the upper basal lobe twice as long as the others and more deeply separated, almost pinnulate in the lowest pinnae. Veins dark. Sori elongate, rather thick, straight and curved, the lower diplazoid, the upper asplenoid. Fib. vas. band horseshoe-shaped in the stipes. - The frond bears a gemma below the apex which is densely covered with dark scales. \#-Diplazium Sandwichense, Presl, Tent. Pterid. p. 114, and Epimel. p. 85. -

Oahu (Meyen). - Not known to me. Differs from A. arboreum in greater size, in the truncate lobes, the great length of the auricle and a proliferous rhachis; from A. Fenzlianum in the polystichoid habitus.

b. Subphegopteroid. Nòs. 33-34.

33. A. Arnottii, Baker, Synops. Fi7. p. 240. - Rhizome creeping on the ground and branching, 1-2' thick, covered with the remnants of old stalks. Stip. close, pale brown or stramineous, sparsely paleaceous in the lower portion with ovate to linear-lanceolate thin translucent palebrown dentato-laciniate glandular scales of about $6^{\prime \prime}$ in length, but 
glabrate with age; the rhachis with few scattering scalelets or fibrils. Frond large, open, light green, membranous to chartaceous, deltoid or ovate, $2-4 \mathrm{ft}$. long, bipinnate, with a pinnatifid apex, subphegopteroid. Pinnae alternate, $9-11$ stipitate ones on a side, the lower $2-3^{\prime}$ apart, $10-18^{\prime}$ long, on stalks of $1 / 2-2^{1 / 2^{\prime}}$, anadromous; the middle and upper ones homodromous or even catadromous at the base, but gradually anadromous, oblong-lanceolate, broadest below the middle. Pinnules at distances of $1-1^{1 / 2^{\prime}}$, the lowest on stalks of $1-2^{\prime \prime}$, oblong-lanceolate, $1^{1 / 2}-3^{\prime} \times{ }^{1 / 2}-1^{\prime}$, acute, with even-sided truncate base, eut deeply into oblong, obtuse or subtruncate lobes or segments which are $1^{1 / 2}-2^{1} / 2^{\prime \prime}$ broad, subentire or adpressedly dentate. Veins pinnate, $4-7$ pairs to a segment. Sori copious, one on every veinlet at angles of $20-30^{\circ}$, straight, $1-1^{1 / 2}$ " long, mostly reaching from costule to edge, but often falling short of the latter; the first anterior sorus mostly diplazoid or forking. Invol, thin. Spores margined. - Diplazium Arnottii, Brack. - A. diplazioides and A. ambiguum, Hook. \& Arn. in Bot. Beech. - A. polypodioides and $A$. arborescens of Hook. Sp. Fil. (as to the Hawaiian Islds.) and of Mann's Enumeration.

A common fern in the woods of the lower regions, the sHoios of the natives, generally oecurring in patches of some extent.

$\beta$ var. - Frond coriaceous, larger. Largest pinnae 16-24'; largest pinnules 3-6" long; segments $3-4^{\prime \prime}$ broad. Sori mostly extending from rib to edge, 3 " long, but in specimens from Kaala only half the length.

Molokai! Mopulehu; Ma ui! Oloalu; Oahu! Kaala.

$\gamma$ var. - Frond chartaceous. Lowest pinnules $5^{1} \times 1^{1 / 3^{\prime}}$, cut to near the rhachis into narrow subfalcate segments $2^{\prime \prime}$ across, which are separated by broad sinuses. Veinlets once forking; the sori on the anterior forkbranches, $1-1^{1} / 2^{\prime \prime}$, not touching either rib or edge.

Molokai! Kalae.

o var. - Tripinnate. Frond thin chartaceous. Lowest pinnae on stalks of $2^{1} / 2^{\prime}$. Lower pinnules of the first pinnae longer than the upper ones, $5-6^{\prime}$ long, $2^{1 / 2}-3^{\prime}$ broad at the middle. Tertiary pinnae $1^{1 / 2^{1}} \times{ }^{1 / 2^{\prime}}$, subsessile with an evenly truncate base, cut to the middle and more into oblong subfalcate appressedly denticulate segments $1 \frac{1}{2}$ " broad, each segment with 4 or 5 pairs of pinnate simple veins. Sori short, about $1^{\prime \prime}$, contiguous to the rib of the pinnule and sometimes from $4-6$ on the segments also. - A. polyanthes, Sol.; Luerssen, in Flora, 1875, p. 435.

Oa hu! eastern flank of Kaala, near Lihue; Molokai! Kalae.

The anadromous and long-stipitate pinnae, as also the light color of the frond, assign this fern to the present species, although in shortness of sori it agrees with the next. -

The species is not reported from other countries. A. polypodioides, Bl, which resembles it much, has an erect caudex and the veins are at a more open angle. Specimens of that fern from Tahiti and Ceylon in my herbarium differ besides in having the lower 
pinnae catadromons. Whether its scales are glandular or not I have no opportunity for ascertaining. These marginal glands of the scales seem to have escaped observation hitherto, yet they are quite peculiar and never absent in this or the next species. In shape they are transverse-oblong or roundish, elongate-papillaeform, even eup-shaped. The cells of the scales are flexuose. The stipes has two lateral furrows besides the ventral one, and the otherwise horseshoe-shaped fib, vas, band is constricted or inflected by them.

34. A. Sandwichianum, Metten. Asplen. p. 197. - Caudex thick, prostrate and rooting, rising at the end, the involute frondlets thickly covered with darkish ovate-lanceolate translucent thin-walled dentate or laciniate glandular scales. Stip. tufted, $1^{1 / 2}-2^{1 / 2} \mathrm{ft}$. long, paleaceous at the base but soon naked, pale brown; the rhachis stramineous, sparingly fibrillose. Frond subphegopteroid, membranous, dark-green, ovate-oblong, 3-4 ft. in length, bi-, tripinnate. Pinnae alternate or the lowest pair opposed, subascending, $12-15$ stipitate ones on a side, the lowest $5-6$ ' apart, 18-24' long, even-sided, oblong, broadest about the middle, shortly $(1 / 2-1)$ stipitate, the upper ones homodromous at the base or even catadromous, but gradually anadromous. Secondary pinnae oblong-lanceolate, $3^{1} / 2-5^{\prime} \times 1^{1} / 4-1^{1} / 2^{\prime}$, the first ones slightly contracting at the evenly truncate base, shortly stipitate $\left(1-1^{1 /} / 2^{\prime \prime}\right)$, eut to a bare or narrow-winged rhachis into about 10 pinnules of $6-8^{\prime \prime}$ in length, which are oblong, obtuse or somewhat pointed, sessile with a broad or cuneate base, slightly notched or cut into 6 or 7 pointed segments. Veins anadromous, 2-7 to each segment, forking or subpinnate, their trunk and anterior branch at uniform angles of $20-25^{\circ}$. Sori straight, short, $1^{\prime \prime}$ or less and broad, in 2 regular lines of 5-8 each along the costa of the pinnule and contiguous to it, occupying the trunk of the vein and part of its first anterior branch and not reaching the sinus; only in much developed forms sori also on secondary branches and then confluent; the primary sori diplazoid or forking. Invol. thin and narrow, soon evanescent. Spores winged and crested in various directions. - Hook. Sp. Fil. III, 225? - Synops. Fil.p. 242? - Luerssen, 1. c. p. 435. - A. brevisorum, Baker, in Synops. Fil. p. 228. A. Gaudichaudii, Fée, Gen. Fil. p. 188? - Athyrium Sandwichianum, Presl, Tent. Pterid. p. 98, and Epimel. p. 67 ?

Oahu! Paroa and Kaala; Molokai! Kalae, Halawa; Maui! Pumelei; Hawaii! Waimea; Ka uai, Hanalei and Waimea (Wawra and $\mathrm{Kn}$.).

ß. var. - First pinnules of third order stipitate, with an even-sided truncate base.

Ma ui! Waihee.

Placed under this name chiefly for the reason that no other Hawaían Asplenium with short sori agrees better with Presl's most unsatisfactory deseription. An Athyrium it is not, nor does it appear that Presl's plant, "with sori straight linear, $2 / 3-3 / 4$ " long ", was one. Certainly Presl's plant was much smaller, but quite glabrous, and for this and various other reasons it must have been distinct from A. fusco-pubescens, Hook., and A. alienum, Metten., which are united with it in the Synops. Fil. In all probability the specimens referred to by Sir $\mathrm{W}^{\text {m }}$ Hooker as having been received from Mr. Lambert were not of Hawailan origin, for not one of our large compound Asplenia is tomentose. How far the present species agrees with $A$. brevisorum, Wall., I am unable to judge; it is not unlikely that it has some relationship with $A$, coriaceum, Carruth. in Fl. Vit. p. 357. 
c. Phegopteroid, proliferous. Spores papillate. Nos. $35-36$.

35. A. Fenzlianum, Luerssen, in Flora, 1875, p. 434. - Rhizome "short creeping 》. Stip. crowded, stramineous or pale brown when dry, 9-12 long, thickly clothed at the base with dark, opaque, almost black, linearlanceolate, not capillary, scales of $5-9^{\prime \prime}$ in length (paleae clathratae). Frond phegopteroid, thin chartaceous, oblong-lanceolate, moderately contracting below, broadest near the middle, $1^{1 / 2}-2^{1 / 2} \mathrm{ft}$. long, pinnate, pinnatifid at the apex with falcate segments; the rhachis fibrillose or naked and often proliferous near the apex with one or two gemmae. Pinnae $18-30$ on a side, often all opposite, the lower ones always so, shortly but distinetly stipitate $\left(3 / 4-1^{\prime \prime}\right)$, linear-lanceolate, $3-7^{\prime} \times{ }^{1 / 2}-1^{1} / 2^{\prime}$, the lower ones slightly narrowing toward the even-sided truncate base, cut from one to two thirds of their width into obtuse deltoid or oblong, faintly denticulate, nearly equal lobes of $2-4^{\prime \prime}$ in breadth. Veins excurrent, pinnate with $3-8$ pairs of simple veinlets to a lobe, the lowest slightly curving, at angles of $30^{\circ}$ with their costule, the costule at $60-70^{\circ}$ with the midrib. Sori generally on all veins, equidistant from costule and edge, the first anterior diplazoid and $1^{1 / 2}-3^{\prime \prime}$ long. Invol. thin, broad and flat, obtuse at both ends. Spores minutely papillate. - Wawra's plant was a small form with only the diplazoid primary sori. - The base of the pinnae, squarely truncate about the middle of the frond, becomes subcordate in the lowest shortening pinnae, but recedes slightly in both halves on the upper ones.

Oahu! Nuranu, Makaleha; Ka uai! Hanalei, Waimea; Molokai! Lanai! W. Mani! Only found in isolated individuals. It is the fern referred to by Baker in the Synops. Fil. under A. sylvaticum, Pr., and A. Japonicum, Thunb., and by Carruthers in the Fl. Vit. under Diplazium decussatum, J. Sm. (D. congruum, Brack.). To every one of these species it bears a considerable resemblance, and I should not hesitate to unite it with $A$. sylvaticum, as a deeper-cut variety, if it were not for the reported difference in the rhizome. The above given character for this is from Wawra's notes. My own collection is without rhizome, but it contains the apical portion of one in which the involute frondlets, completely hidden by the large black seales, emit a number of roots from their bases. This partly confirms Wawra, but the thickness of it, 4", and the presence of two closely set frondlets would be compatible with a decumbent caudex, and certainly speaks against a wide-creeping rhizome. From A. Japonicum it differs in the character of the seales, also in the rhizome, number of pinnae, and their uniformly even-sided base, from Dipl. decussatum, J. Sm., in the stipitate pinnae. - Extreme forms differ greatly in appearance. Specimens from Makaleha with linear pinnae $1 / 2^{\prime}$ broad and only slightly narrower at the base, the lobes short deltoid, with 3-4 pairs of veinlets in a nervatio Taeniopteridis, would hardly pass on first sight for the same species as those from Lanai, in which the pinnae are $1^{1 / 2^{\prime}}$ broad near the middle and only $1^{\prime}$ at the base, while their largest segments are linear-oblong, with 8 pairs of veinlets at much more open angles in a nervatio Pecopteridis.

36. A. marginale, $s p . n$. - Caudex erect, about $6^{\prime}$ high and $1-2^{\prime}$ thiek. Stip. $1-2 \mathrm{ft}$. long, stout, dull, lurid-brown when dry, sparingly paleaceous in the lower portion with a few thin light-brown lanceolate finely acuminate scales of $5-8^{\prime \prime}$, or furfuraceous (paleae cystopteroideae). Frond 
phegopteroid, membranous, dull-green, pinnate, oblong-lanceolate, $1^{1 / 2}-3^{1 / 2}$ ft. long, narrowing below into a set of much reduced pinnae, the lowest auriculaeform, ${ }^{2} / 2-1^{\prime}$ long and $1-2^{\prime}$ distant from the one next above; the rhachis commonly proliferous with one or several gemmae in its upper portion. Pinnae mostly opposite in $20-40$ pairs, horizontally patent, linear-lanceolate, acute, none contracting toward the base, the middle ones $5-6^{1} \times{ }^{1 / 2}-1^{1} / 2^{\prime}$, all subsessile with a truncate even-sided base and eut to $1 / 2$ or $3 / 4$ or more into oblong obtuse subfalcate denticulate nearly equal lobes, which are $2-3^{\prime \prime}$ broad, with narrow sinuses between them. Nervatio Pecopteridis. Veins excurrent, prominent and straight, pinnate with 5-8 pairs to a segment, all veinlets simple at angles of $40-50^{\circ}$, the costules at angles of $60-90^{\circ}$ with the midrib. Sori one on each veinlet, short, less than $1 "$, all confined to the marginal half of the veinlet and touching the margin; the first anterior generally diplazoid. Invol. thin, fugacious. Spores tuberculate or echinate.

Molokail Kalae and gulch of Halawa; Hawail! Kohala range (lower pinnae less shortened); Maui! Hamakua (very narrow but deeply divided pinnae, only $4-5$ " broad). In many specimens the pinnae, segments and nerves are so regularly opposite in pairs that the phegopteroid habitus of the frond can hardly be made out. The prineipal characters by which to distinguish this - a much stouter plant - from the preceding species must rest on the caudex and the scales; as to all the other characters, they are subject to so much variation that it would be difficult to assign some specimens to one or the other species on their strength alone. The typical form was collected on Molokai,

B var. depauperata. - Rhizome short. Stip. crowded, about 2' Iong, lurid-brown, paleaceous at the base with few thin reddish almost transparent capillary dentate or laciniate scales about $2^{\prime \prime}$ in length. Frond phegopteroid, membranous, dark green, oblong-lanceolate, scarcely narrowing below, $5-7^{\prime} \times 2-2^{1} /^{\prime}$, pinnate with $9-11$ pairs of pinnae besides the pinnatifid apex, the lower ones on stalks of less than $1^{\text {" }}$ and generally opposite, linear-lanceolate, with even-sided truncate base, only $2-3^{\prime \prime}$ broad, cut into obtuse or obtusely falcate segments. Sori short, confined to the first anterior veinlets and nearly all diplazoid. Spores papillate. A gemma near the apex of one frond. - A. grammitoides, Hook. in Sp. Fil. III, 228, as to the Hawaiian plant.

Hawaii! in rocky beds of streams near Hilo (Baldw.) and Laupahoehoe (Lydg.). A starved form of $\alpha$, parallel to starved forms of Aspidium cyatheoideum and Phegopteris polycarpa.

D. Athyrium. Nos. 37-39.

a. Cyatheoid, proliferous. Spores tuberculate. No. 37 .

37. A. deparioides, Brack. Fil. U. S. E. E. p. 172.

Formae pinnatae.

Rhizome short, creeping. Stip. loosely crowded, $1 \mathrm{ft}$. long, sparsely paleaceous at the base with linear-lanceolate denticulate brown opaque scales of $4-6^{\prime \prime}$, their cells all rectangular, prosenchymatous with thick dark walls and narrow cavities (paleae clathratae), but soon naked, grooved, 
pale brown or stramineous; the rhachis mostly proliferous near the apex with 1-3 gemmae. Frond eyatheoid, membranous or flaccid, open, ovate to ovate-oblong, $1^{1 / 2}-2 \mathrm{ft}$. long by $10-16^{\prime}$ broad at the base, pinnate, with pinnatifid apex, the lowest pinnae neither shorter nor more distant than those next above. Pinnae mostly opposite in $14-18$ pairs, spreading, the lowest $6-9^{\prime}$ long, shortly stipitate ( ${ }^{3} / 4^{\prime \prime}$ or less), often broadest near the middle $\left(1-1^{3} / 4^{\prime}\right)$, cut to near the costa into oblong, obtuse or subfalcate, subentire or sinuato-dentate lobes or segments which are $2-4$ " broad and separated by broad rounded sinuses. Nervatio Pecopteridis. Veins excurrent, pinnate with simple veinlets at angles of $30-40^{\circ}$ (their costule at $\left.60-70^{\circ}\right)$, in $6-9$ pairs. Sori short, $1^{\prime \prime}$ or less, straight asplenoid on the marginal half of the veinlet and generally, but not always, touching the edge, the first anterior often diplazoid, rarely uncinate or didymochlaenoid. Invol. thin fugacious, opening toward the apex of the segment.

The form described by Brackenridge. Oahu! woods of Waialua, Halemano, Niu; Kauai! Lihue (Baldw., rhachis furfuraceous).

$\beta$. - Sori shorter, ${ }^{1} / 2^{\prime \prime}$ and less, all marginal, straight or curved on the slightly reflected tips of the veinlets, or obligue or transverse across the veinlets; those of the anterior branches in forked veins near the apex of the pinnae uncinate, their upper end stretching over the veinlet, or even running down the opposite side also, didymochlaenoid. Invol. in all cases free at the sides.

Oahn! Nuиanu. A few oblique sori on dentate projections of the segment in one specimen prepare the transition to the following form, while on another pinna of the same frond a long empty involucre which stretches along the whole vein from the costule to the foot of the marginal fertile sorus reminds of $\alpha$.

\%. - Segments of pinnae shortly dentato-lacinjate. Sori extramarginal, oblique or transverse, the receptacle very short subglobose, near the end of the projecting vein, not at the end. Invol. sometimes free at both ends, sometimes its sides partly adnate to the projecting lacinia or its bare tooth. - Dicksonia prolifera, Kaulf. Enum. Fil. p. 225. - Cibotium proliferum, Presl, Tent. Pterid. p. 69, tab. 11, fig. 10. - Deparia Macraei, Hook, \& Grev. Ic. Fil. tab. 154. -- Deparia prolifera, Hook. Gen. Fil. tab. 44, B. - Fil. Exot. tab. 82. - Sp. Fil. I, 85. - Hook. \& Arn. Bot. Beech. p. 108. - Hook. \& Baker Synops. Fil. p. 55, tab. II, fig. 14. - Brack. Fil. U. S. E. E. p: 240

Oahu! Nuuanu, Pauod; Hawaii (Maerne). - In the broadly stipitate sori the involucres generally have free sides and the posterior covering of the sorus is distinctly seen to be supplied by the parenchymatous lacinia of the frond; in the dentato-stipitate sori, however, where the tooth is destitute of parenchyma, the involuere is puzzling indeed and approaches somewhat to the figure given in the Synopsis Fil., for its short sides seem to be adherent to the veinlet which still forms the back of the sortus. Its true character is, however, always indicated by a gap or emargination behind; it never forms a complete eup. Most speeimens exhibit also a few oblique or transverse or reniform marginal and even intramarginal sori of the character of $\beta$. In one frond the sori and their involucres are straight asplenoid, intra- and extra-marginal, the sorus following the protruding nerve beyond the margin, both the intra- and extra-marginal portion being 
fertile. In other fronds only isolated sori are of this character, but then the intramarginal portion is sterile. It has to be noted also that the distinctly stipitate extramarginal sori are generally sterile, with the involucre incompletely developed, so that the precise nature of the latter cannot be made out.

\section{Formae bipinnatae.}

万. - Stip. more dusky or brownish, $16-20^{\prime}$ long. Frond flaccid, $30-36^{\prime}$ long, the rhachis gemmate near the apex. Pinnae subopposite in 20-22 pairs, $8-10^{\prime}$ long, broadest below the middle, pinnatisect in the onter half; the pinnules separated by broad round sinuses, sessile with a broad entire decurrent base, the longest $1-1^{1} / 2^{\prime}$, oblong, obtuse or somewhat acute, notched in the middle portion, faintly crenate near the apex. Veinlets pinnate in 9 pairs at angles of $40-50^{\circ}$, mostly all simple. Sori $1-1^{1} / 2^{\prime \prime}$, straight, touching the sinus or falling short of it, sometimes the first anterior ones diplazoid. Involucres all asplenoid, opening toward the apex of the segment.

Oahu! valleys of Makaleha and Makaha of the Kaala range.

ع. - Pinnae $8-10^{\prime}$ long and $2-2^{1 / 2^{\prime}}$ broad in the lower third. Pinnules subacute, their lobules often sharply truncate. Veinlets mostly forking. Sori all marginal and shorter, straightish, curved and reniform in the pinnules, or oblique, uncinate, even didymochlaenoid in the pinnatifid portion of the pinnae. Here and there a stipitate sorus as in $\zeta .-$ Gaud. Bot. Voy. Bon. tab. 80 ?

Oahu! Kaala; Kauai! Koloa (Baldwin).

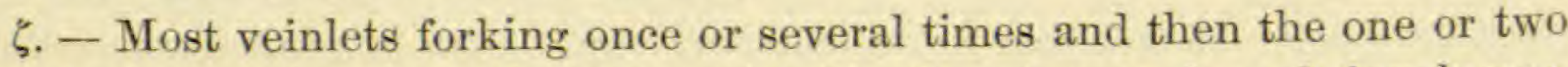
terminal ones bearing stipitate sori with almost cup-shaped involucres, while the lateral ones bear short marginal athyroid sori; other lobes carry only athyroid sori.

Oahu! woods of Waialua and Kahana.

$\eta$.- Largest pinnae $10-13^{\prime}$ long, the largest pinnules $2-3^{\prime}$, cut about the middle deeply into oblong sinuato-dentate segments, exch with 9-14 pinnate veinlets and short sori touching the margin, their involucres curved athyroid; while nearer the apices of the pinnules the furcate veins form truneate lobules with sharply projecting posterior angle, and bear reniform or didymochlaenoid sori.

Oahu! Kaala, Waialua, Nuuamu.

In uniting here Deparia prolifera, Hook., with Asplenium deparioides, Brack., I give the result of repeated and careful examination, and hope to have afforded a satisfactory issue from the intricate perplexities which have troubled other collectors besides myself. However unacceptable such a protean species may appear to many, I have seen no other solution of the difficulty. In all other characters, except the shape and position of the sori and involncres, there is no difference between the athyroid and deparoid forms of the species, In common with all genuine Athyria the stipes holds two separate fibro-vasal fascicles at its base, which flatten as they rise and unite near the frond in a more or less irregular horseshoe form. The sporangia stand on long stalks and have perpendicular rings with $16-20$ joints. The spores are ovoid, with one dorsal line, or slightly reniform and hispid when young, ovoid to subglobose and faintly tubereulate when mature. 
The above described forms can hardly be considered as varieties. Truly deparoid forms which do not exhibit here and there also athyroid sori are rare, while in $\zeta$ it is the rule to see both combined. The species is also conneeted with nos. 35 and 36 , forms of which often touch closely upon $\alpha$ of the present.

Mettenius (Asplen. p. 63) seems to have been struck by the extraordinary resemblance of the two species in question; but if he attributed an inferior involucre even to the elongate sori, and was inclined to place Deparia under Woodsia, he certainly was in error; that the receptacle is never truly terminal, but always placed a little inside of the toothlet, is stated quite correctly. The figure of Deparia prolifera in the Genera Filicum is defective, inasmuch as it does not exhibit the posterior side with the toothlet to which the indusium is only partly attached, leaving a gap above.

The way in which an athyroid involucre is changed into a cup-shaped one, corresponding to that of Microlepia or Dennstaedtia, finds its explanation in an occasional peculiarity of the veinlets as observed in the form $\zeta$. These form a backward curve in the truncate lobules just before reaching the margin. A sorus occupying the curve itself is reniform, one seated on the costal side is straight, opening toward the apex of the segment, while one oceupying the portion beyond the curve is athyroid, opening outward, but has only one free lateral border, that over the curve. The next step is, that from the angle of curvature, which is the natural place for an eventual bifureation, rises a short fibro-vasal spur over which the last form of athyroid sorus extends and to which its involucre becomes attached likewise, thereby assuming a semilunar shape. In this form the sorus is marginal and often bicornute, with a toothlet running out at each horn; but even in the extramarginal and stipitate forms the triangular dilatation of the apex of the nerve, which under transmitted light can often be seen to contain two distinct fib. vas. strandlets, would seem to point to an origin similar to the one described. The uncinate and didymochlaenoid sori occur only on first anterior forkbranches and represent the diplazoid character of the fern.

The habit of the fern is cyatheoid, viz., the lower pinnae anadromous, the upper catadromous, the nerves of pinnules and their segments catadromous, excepting those in the two first pairs of the uppermost pinnae. Its station is therefore near $A$. decur tatum, Link, one of the few eyatheoid species in the genus Asplenium, next to which it has very properly been placed in the Synopsis Fil.

As the genus Deparia was originally built upon our species, the removal of the same must invalidate the genus; for the other species united under it, $D$. concinna and D. Moorei, Hook., have already for good reasons been assigned to the genus Dennstaedtia, Bernh., by various writers.

b. Polystichoid. Spores smooth. Nos. 38-39.

38. A. aspidioides, Schlecht. Adumbrat. Fil. Cap. p. 24, tab. 13. Caudex stout, erect, ${ }^{1 / 2}-2 \mathrm{ft}$. high. Stip. $6-18^{\prime}$ long, pale brown or stramineous, paleaceous at the base with linear-lanceolate entire thin reddish-brown scales of $6^{\prime \prime}$ in length, their cells much elongate and straight (paleae cystopteroideae). Rhachis fibrillose, compressed. Frond herbaceous, dark-green, shining, ovate or ovate-oblong, $3 / 4-2^{1 / 2} \mathrm{ft}$. long, $8-18^{\prime}$ broad, tripinnate, polystichoid, not proliferous. Pinnae alternate, 16-20 stipitate ones on a side, ascending, oblong-lanceolate, 5-10'long, shortly $\left(1-3^{\prime \prime}\right)$ stipitate, the lower ones anadromous, the upper with opposite basal pinnules, but the inferior pinnule receding from the main rhachis. Secondary pinnae ovate-lanceolate, $1-3^{4} \times{ }^{1 / 2}-1^{4}$, on stipites of $1 / 2 "$, anadromous. Tertiary pinnae $3-6^{\prime \prime}$ long, subsessile or shortly stipitate, with an uneven-sided cuneate base and cut to near the rhachis at acute angles on each side into $2-6$ narrow oblong to linear, simple or sharply two- to several-toothed or cleft segments, the first upper one 
often pinnatifid. Veins simple, or forking at very acute angles, subpinnate in the pinnatifid segment. Sori short, ${ }^{1 / 2}-1^{\prime \prime}$, one at the base of a segment, close to the midrib of the pinnule; the first ones generally curved or horseshoe-shaped. Invol. firm, vaulted, brownish, entire or denticulate. Spores smooth. - A. Poiretianum, Gaud. Bot. Freyc. p. 327, tab. 13. A. multisectum, Brack. 1. c. p. 174. - Metten. Asplen. p. 197. - Allantodia Scandicina, Kaulf. Enum. Fil. p. 179. - Athyrium Scandicinum, Presl, Epimel. p. 67.

Common on all lands from 1000-6000 ft. upward. One of my numerous specimens is bipinnate. In another the ultimate segments and laciniae appear almost subulate, but in the plants from the higher regions the same are shorter and more obtuse, while their pinnules contract, thus imparting an open appearance to the frond.

\$ var. - Quadripinnate. Rhachis darker, compressed, flaccid. Pinnae and pinnules narrower. Ultimate pinnules with several veins and shorter rather obtuse segments. Sori at the base of the ultimate pinnules, or near their middle when pinnately cut.

High monntains of Ka uai! (Kn.); a very handsome fern.

The species is widely spread over Central and Southern Africa, Madagascar, Bourbon, Ceylon with Southern India, and the Andes of South America. - In uniting this fern with A. aspidioides I follow the lead of Hooker and Baker in the Sp. Fil. and Synops. Fil. It has to be remarked, though, that it is much more divided and larger than the plants from Natal and Ceylon, and that it remains to be ascertained yet if the caudex of the latter, given as eascending by schlechtendahl, really agrees with that of our plant, which in the higher forests at altitudes of $4000 \mathrm{ft}$. becomes almost arborescent.

39. A. Baldwini, sp. n. - Stip. stramineous, slender, naked in the upper portion. Frond herbaceous, dark-green, ovate-oblong, $6-18^{\prime} \times 7-10^{\prime}$, tri-, quadripinnate, polystichoid, not proliferous. Primary pinnae alternate, 18 stipitate ones on a side, erecto-patent, ovate-oblong, finely acuminate, $5-6^{\prime}$ long, shortly $\left(2-3^{\prime \prime}\right)$ stipitate, with a slender fibrillose rhachis, all even-sided, the upper base parallel to the rhachis, the lower receding from it. Secondary pinnae lanceolate, ${ }^{3} / 4-1^{1} / 2^{\prime}$ long, stipitate, with an obliquely cuneate base. Tertiary pinnae ascending, rhomboidal or obliquely lanceolate in outline, cut at very acute angles to the rhachis into $2-9$ linear or filiform segments of $1-1^{1 / 2} / 2^{\prime \prime}$, most of them cleft again into 2 or 3 subulate teeth. Veins caenopteroid or dareoid, one to each segment or tooth. Sori quite short, ${ }^{1} / 2$ " or less, one to an ultimate segment and near its apex, exceeding it in width. Invol. athyroid, vaulted, firm, eroso-dentate. Spores nearly smooth.

High motuntains of Kauai! First discovered by the late Mr. E. Johnson of Hanalei, and of late Mr. D. Baldwin has sent me two nearly perfect fronds from the same loeality under the name A. multisectum, Brack. It is quite distinet from A. dissectum. Habit of frond, texture, color and nervation, also the charaeter of the spores, place it near A. aspidioides, with which also the fibrillose scalelets of the rhachis agree in strueture, although they are darker and have thicker cell-walls. These fibrils are minute and subulate, generally one near the base of each secondary pinna. 


\section{LINDSAYA, Dryand.}

Sori intra - or submarginal, laterally elongate, interrupted or continuous, mostly linear, placed on the laterally expanding apices of veins or - these expansions unitin - on the marginal anastomoses of two or more otherwise free or anastomosing veins. Involucre transverse on the apex of the vein or on the marginal nerve, its external margin free and mostly even with the often scarious margin of the frond, the sides free or slightly adnate. - Tropical or subtropical ferns, with exarticulate stipes and a tendency to form dimidiate cultrate or cuneate segments. - Areoles of anastomosing veins hexagonal, without free veinlets (nervatio Doodyae).

The Hawaiian species are all endemic and form a connected group, highly interesting inasmuch as it exhibits a twofold line of development from a simple almost evensided pinna with sphenopteroid areolate veins, on the one side to compound forms with the cuneate flabellately veined segments of Lindsaya Catherinae and the linear single-veined segments of Stenoloma, Fée, or Loxoseaphe, Moore, and on the other side to a bipinnate form in which the pinnules are shaped like the pinnae.

All have a short erect or prostrate caudex and dark, chocolate-brown to purplish, glossy, almost terete stipites, the broad anterior groove being so shallow as to become effaced. Fib. vas. fascicle single, nearly central, in shape of an oblique cross with two arms shorter. Pinuae very numerous. The veins start at an acute angle from the midrib, which in the short obtuse pinnae of no. 1 loses itself before the apex. In the broad entire pinnae of nos. $1-3$, and whenever a disk oceurs in nos. $5-7$, the veins anastomose to one or two sets of oblique elongate areoles, the apices of which send out veins which either unite again near the margin with those of the next areoles, or cease before reaching them, and serve for the reeption of the sori. As areoles at the given angle can only form in broad disks they disappear in the narrow pinnae of no. 4 and the pinnules of nos. 5-7, which have only a marginal anastomosis, and this latter also becomes impossible where the segment contains only a single nerve, as in var. $\partial$ of no. 6 and in no. 8. But even here the apex of the single nerve expands laterally, and When exceptionally it forks in the segment the two veinlets unite again with their apices.

The transition of $L$. Alexandri with cuneate truncate segments into $L$. Knudsenii with cuneate-lanceolate segments is quite evident by the gradual elongation of the median vein of the former species, which here becomes a kind of deliquescent costule a transition the more remarkable as there exists besides a bipinnate variety of the former with cuneate-truncate pinnules or segments.

The evolution finally of a bipinnate form with pinnules isomorphous to the pinnae finds its explanation in the change of a simple nervatio Spenopteridis to a nerv. Nenropteridis in the very broad disks of $L$. laciniata. The leading vein becomes an excurrent costule with pinnate veinlets in the almost vertical pectinate laciniae, which gradually grow to pinnules with in distinct auricle in the monstrous var. $\beta$.

The sori are interrupted and distinct intra-marginal, sometimes at a distance from the frondal edge, so that the free margin of the involueres falls short of the Tatter, which throughout remains unaltered, never loses the green color nor becomes scarious, Sporangia on long stalks with about 20 artieulations to the ring. Spores in all species dark, subglobose but apparently bilateral, papillate or muricate, slightly margined.

The habitus of the frond in the compound species is faintly polystichoid from the base of the pinnue. In the simple forms with sessile pinnae the first veins or segments at the base are homodromous or opposite, but the second upper vein already stands nearer the main rhachis than the second lower. The upper half of the base is sharply truncate and parallel to or arcuate toward the rhachis; the lower, parallel to the rhachis at the start, soon recedes from it.

Frond pinnate; pinnae entire:

Frond truneate at the base; sori distant from the margin.

3. L. erecta.

Frond narrowing below; sori submarginal:

Pinnae ovate-rhomboidal, obtuse, less than $1^{+}$Iong

1. L. pumila. 
Pinnae linear, numerous, crowded with imbricate bases Pinnae lanceolate-acute, $1-3$ ' long

Frond pinnate; pinnae pinnatifid:

Segments linear, with pinnate veins

Segments oblong or cuneate, truncate; veins flabellate

Frond bipinnate:

Pinnules cuneate or linear-truncate

Pinnules pointed or lanceolate-obtuse

Frond tri-, quadripinnate; ultimate segments linear, with a transversely expanded apex
4. L. centifolia.

2. L. falcata.

5. L. laciniata.

6. L. Alexandri.

6. L. Alexandri.

7. L. Knudsenii.

8. L. Mannii.

1. L. pumila, Hook. Synops. Fi7. p. 112. - Caudex less than $1 / 2^{\prime}$ long, the rootlets covered with a rufous fur. Stip. slender, wiry, dark-brown, glossy, ${ }^{1 / 2}-3^{\prime}$ long, sparsely paleaceous at the base with stiff lanceolate dark scales of $1-1^{1 / 2}$ " in length and dark ferruginous fibrils. Frond chartaceous, linear-lanceolate, $4-9^{\prime}$ long, narrowing below, pinnate. Pinnae $20-30$ on a side, horizontal, sessile at the lower angle, rhombeoovate to trapezoidal, $4-8^{\prime \prime} \times 2-3^{\prime \prime}$, rounded or obtuse, slightly undulating, truncate and often auriculate at the upper base, moderately cut at the lower; the lowest pinnae orbicular. Veins indistinct, anastomosing in one or two sets of areoles on each side of the deliquescent rib; those near the apex free. Sori submarginal, $1 / 2$ " long, $5-8$ to a pinna, seldom two confluent and then broader. Invol. thin, pale, whitish, even with the frondal margin or falling short of it, - Diellia pumila, Brack. Fil. U. S. E. E. p. 219. - The scales have two layers of cells at the base, with thick dark walls and narrow lumen; the fibrils consist of a single nerve with a membranous margin.

Oahu! exposed cliffs of Nuuanu, Pauoa, and other regions of the main range. Small fronds look almost like Asplenium Trichomanes. Nat. name: "Palapalai laulii".

2. L. falcata, Hook. l. c. p. 113. - Caudex ${ }^{1 / 2}-1^{\prime}$ long. Stip. 1-4' long, of a dull dark-brown, paleaceous with thin pale-brown scales which are broad ovate and 3 " Jong at the base, but gradually become narrow-lanceolate and acuminate toward the rhachis, which generally carries reddish fibrils. Frond chartaceous, lanceolate, $12-16^{\prime}$ long, tapering at both ends, pinnate, the pinnatifid apex with cultrate to cuneate segments. Pinnae $32-50$ on a side, the middle ones $1-3^{\prime}$ long, $2-6^{\prime \prime}$ broad at the base, patent, substipitate, lanceolate, acute, generally falcate, wavy at the margins, the upper base broader than the lower, truncate with a sharp angle and often auriculate, the lower base narrow and rounded off; the lower pinnae deflected and gradually decreasing to ovate-obtuse auricles with subequal truncate bases, Veins obscure in two sets of hexagonal areoles on each side of the costa. Sori $10-24$ on a pinna, $1^{\prime \prime}$ long, submarginal, the upper basal ones often confluent. Invol. thin, straight or semilunar, even with the margin of the frond. - Diellia falcata, Brack. 1. c. pl. 31, fig. 1. - The scales have two layers of cells with pale thin walls and broad open lumen.

Oahu! Kaala and Waimea. 
$\beta$ var. - Sori intra-marginal.

Oahu! Makaleha; W. Maui! Kaanapati.

3. L. erecta, Hook. l. c. - Caudex as before. Stip. sparingly paleaceous at the base with a few thin and pale scales, otherwise naked, 5-8' long, purplish-brown, glossy. Frond membranous, lanceolate, $12-14^{\prime}$ long, pinnate, the lowest pinnae as long as the middle ones or a little shorter. Pinnae $15-25$, rather distant, lanceolate as in no. 2, sharply auriculate, somewhat obtuse. Veins prominent in two sets of areoles along a flexuose costa. Sori $10-20$ to a pinna, distinctly intra-marginal, transverse or oblique, $1^{1 / 2}-2^{\prime \prime}$ long, but near the base often confluent and $4-5^{\prime \prime}$ long. Invol. straightish, oblong, its free margin falling considerably short of the edge of the frond. - Diellia erecta, Brack. 1. c. pl. 31, fig. 2.

E. and W. Maui! 3000-4000 ft.

The distinctive characters of the three preceding species mark extreme forms which gradually approach each other.

4. L. centifolia, sp. n. - Frond lanceolate, narrowing below, $8-12^{4}$ long, $3-4^{\prime}$ broad at the middle, herbaceous, with a dark-purple glossy rhachis, simply pinnate. Pinnae very numerous, $70-90$ on a side, closely imbricate with their bases and concealing the rhachis in front, linear, horizontal, $1^{1} / 2^{\prime \prime}$ across at the base, ${ }^{1 / 2}$ " at the middle, subentire at the apex, shallowly notched with deltoid or obliquely truncate crenatures, sessile, the middle ones with a cordate nearly equilateral base, the upper ones with an auriculate superior and narrow inferior base. Veins at very acute angles, simple, expanding at the apex into one or two transverse horns for a receptacle, those of the upper auricle and next crenature only forking, and two fertile fork-branches sometimes anastomosing with their horns. Sori submarginal, $1 / 2^{\prime \prime}$, in the auricle often confluent. Invol. even with the margin of the crenature. - Lower stipes wanting.

Kauai! Halemanu (Kn.).

5. L. laciniata, $s p \cdot n$. - Frond lanceolate, narrowing below, $2-2^{1 / 2} \mathrm{ft}$. long, 4-9' broad, light green, membranous, sprinkled underneath with short scattering blackish hairlets, pinnate, the lowest pinnae deflected. Rhachis dark purplish, fibrillose. Pinnae $30-40$, the middle ones deltoidlanceolate, caudate, $2-4^{\prime}$ long and $1 / 2-1^{1 / 2^{\prime}}$ broad at the base, sessile with a subcordate, in both halves truncate base, the upper half strongly and arcuately aurieled, subparallel to the rhachis, the lower rounded off and receding (cut in the upper pinnae), both sides irregularly cut from $1 / 3-2 / 3$ of their depth at angles of $60-80^{\circ}$ into deltoid to lanceolate, rather obtuse, wavy laciniae - those of the middle portion and lower half longest - which are separated by broad sinuses. Veins distinct, starting from the rib at acute angles and entering the segments with a sweeping curve (nervatio Neuropteridis), anastomosing on the disk, the leading vein of the 
segments subpinnate, with an interrupted marginal nerve. Sori submarginal, discreet, elongate or curved, those of the sinus mostly confluent and semilunar, supported by $2-4$ veins. Invol. thin, often protruding beyond the margin, rarely opening inside of it.

$\mathrm{K}$ a uail Halemanu (Kn.).

$\beta$ var. subbipinnata. - Pinnae substipitate, broader, cut throughout to the purplish rhachis near the base at angles of $30-60^{\circ}$ into linear-lanceolate undulato-crenate segments, the lowest narrowing to a cuneate or cultrate base, the longest measuring $1^{\prime}$ or more. Veins anastomosing only in the disk of the outer portion of the pinna, those of the pinnules free and simple. Sori small and narrow, mostly curved and often oblique to the segments, corresponding to their crenatures.

With a. - Like Davallia Luzonica, Hook. Sp. Fil. I, tab. 60, the bipinnate form of D. pinnata, Cav.

$\gamma$ var. - In a monstrous frond, sent by Mr. Knudsen, the upper pinnae exhibit the shape and character of $L$. falcata or $L$. erecta, the middle ones are obliquely lobed in cuneate-truncate segments, as is the case in $L$. Alexandri, and the lower much elongate pinnae are in their middle portion pectinately cut to a bare rhachis into subsessile cultrate and narrow cultrate-lanceolate pinnules, while the base and apex remain entire. It is an analogon of the var. $\delta$ of Polypodium pellucidum, and shows in its different parts the characters of nos. 2 or 3 , of 7 and 6 , only the last species in a more advanced form, the upper half of the base of the pinnules free from the rhachis. The most developed pinnules repeat the shape of the pinnae of $L$. falcata.

6. L. Alexandri, sp. n. - Stip. 3-6' long, of a dark chocolate color, glossy, bearing at the base a few dark and stiff lanceolate scales and fibrils, as in no. 1. Frond thin chartaceous, $1^{1 / 2}-3 \mathrm{ft}$. long, linear-lanceolate, tapering at both ends, pinnate; the pinnatifid apex cut into cultrate and obeuneate segments; the lowest pinnae short deltoid and blunt. Rhachis fibrillose. Pinnae $30-40$ on a side, the middle ones $2^{\prime}$ long and $3-5$ " deep at the base, sessile with an almost equilateral cuneate base, caudato-acuminate, and deeply cut by acute slits at angles of $10-30^{\circ}$ (but often leaving a broad disk along the costa) into oblong and oblongcuneate, obliquely truncate segments, $5-7$ on each side besides the notched end. Veins indistinct, mostly free, forking once or twice in each segment, the soriferous ones expanding at the apex and often anastomosing. Sori confined to the truncate apices of the segments, reniform or semilunar, mostly discreet, $1-3$ to a segment, but sometimes confluent. Invol. even with the frondal margin or short of it. - Darker lines of sclerenchyma (spurious veins) descend from the sinus, but not quite to the midrib, and accompany the edges of the segments for some distance 
(nervi recurrentes of Presl), vid. Metten. Fil. Hort. Lips. p. 101, sub Davallia elegans. Similar streaks between the veins, dark in Trichomanes and light transparent of thinner-walled cells in Polypodium pellucidum. They occur also in the following species.

Maui! northern slope of Haleakala (Prof. Alexander and Mr. Lydgate); Kauai! Halemanu (Kn.).

$\beta$ var. bipinnata. - Middle pinnae substipitate, linear, with a subentire apex, the sides cut to an immarginate purple rhachis into $7-9$ broadly obcuneate pinnules with narrow bases, their apices $1-1^{1 / 2} 2^{\prime \prime}$ broad, obliquely truncate or rounded, sometimes notched, rarely produced at the middle. Veins single or once or twice forking, the soriferous ones anastomosing. Sori one or two to a segment, semilunar, often occupying the entire outer margin. Involucres even with the frondal margin or those of the lower pinnules short of it.

Ka uai! Halemanu (Kn.).

$\gamma$ var. - The opposite hasal pinnules cut again from the apex into 2 or 3 cuneate or linear and again bifid truncate segments, the first of these deflected on the rhachis.

Maui! N. flank of Haleakala, 3000-4000 ft. (Lydg.).

ò var. - Tripimatisect. Rhachis fibrillose. Pinnae more elongate, $2^{1} / 2-3^{\prime}$ long and $3-4^{\prime \prime}$ broad at the base; most pinnules cut from the apex into $2-4$ segments, one or two of which are cuneate with a broad apex and soriferous, the others linear-truncate and sterile.

Haleakala (Lydg.).

7. L. Knudsenii, sp. n. - Stip. and rhachis as before. Frond herbaceous, lanceolate, $1-1^{1 / 2} \mathrm{ft}$. long, narrowing below, bipinnate. Pinnae $20-30$ on a side, the middle ones $2^{1 / 2}-4^{\prime}$ long, ${ }^{1 / 2}-1^{\prime}$ broad at the base, subsessile with an equilateral cuneate base, undulato-crenate near the apex. Pinnules 6 or 7 , obliquely cuneate-obovate or cultrate, pointed, entire or notched, the basal ones opposite. Veins repeatedly forking, with a leading nerve, or subpinnate with deliquescent costule in the larger pinnules, generally free, rarely two soriferous ones anastomosing. Sori submarginal, mostly discreet, $2-6$ to a pinnule, straight or curved, ${ }^{1 / 2}-1^{1} / 2^{1}$ broad. Invol. even with the margin.

Ka uai! Halemanu (Kn.). - Here I also refer a less developed sterile frond, apparently of a young plant, with shorter and broader deeply cut pinnae, the broad segments of which are drawn out to a short obtuse point. In this areolar anastomoses are to be seen.

$\beta$ var. - Frond larger, $1^{1 / 2}-2 \mathrm{ft}$. long, with $30-40$ pinnae, the middle ones with $8-9$ pinnules on a side, of which the upper basal one is parallel and nearest to the rhachis. Pinnules cuneate-lanceolate, notched at acute angles into $3-7$ cuneate-oblong obliquely truncate segments, each segment bearing one submarginal almost straight sorus at the apex of a 
free vein, rarely the vein anastomosing with a second mostly marginal one.

Occurs with $\alpha$. Much divided forms have not more than one vein to a segment and exhibit altogether the appearance of Microlepia tenuifolia in the cut of the pinnules, which gradually are more deeply segmented with contracting lobes, thus simplifying the transition to the following species. Here already the sorus fills the entire apex and is curved or reniform.

8. L. Mannii, Hillebr. - Stipes stout, 3-6' long, dark purplish-brown, glossy, sparsely paleaceous at the base only with dark and stiff lanceolate scales. Frond oblong-lanceolate, narrowing at the base, $2-3^{1 / 2} \mathrm{ft}$. long, $6-12^{\prime}$ broad at the middle, herbaceous, dark-green, tri-, quadripinnate. Pinnae $40-50$ on a side, all anadromous, the middle ones $3-7^{\prime}$ long, $3 / 4-1^{1} / 2^{\prime}$ broad at the base, shortly $\left(1 / 2^{\prime \prime}\right)$ stipitate, the upper basal pinnule parallel to the main rhachis and covering it; the secondary rhachis greenish in the outer portion. Secondary pinnae lanceolate, shortly stipitate, unevenly cuneate at the base. Tertiary pinnules simple linear near the apex of the pinnae, the others cut to the rhachis into $2-7$ linear segments which dilate into a clavate apex. Veins single in each segment, the fertile ones expanding at the apex into one or two transverse horns to form a straight or semilunar receptacle, which is exceptionally also supported by a small fork-branch issuing from near the apex. Sorus filling the entire width of the apex. Invol, even with the margin, straight or reniform, open at the sides. Sporangia and spores as before. - Microlepia Mannii, Eaton, in Mann's Enum. no. 548. - Davallia Mannii, Baker, in Synops. Fil. $2^{\text {nd }}$ edition.

Ka uai! Waimea, Halemanu, 2000-3000 ft. (Mann, Kn., Baldw.). - The apical appendages of the vein are sometimes turned slightly upward, almost as is the case in some species of the Stenoloma section of Davallia (vid. D. aculeata, in Hook. Sp. Fil. I, tab. 54, fig. B.), but the involucre is always free at the sides, never cup-shaped. When one of the appendages elongates and enters a lateral projection of the segment, the form of Loxoscaphe arises.

\section{ODONTOLOMA, J. Sm.}

Sori terminal on the thickened apices of the veins, discreet, rarely a few confluent. Invol. inferior, adnate with a broad base, free on the sides and outer margin, which is even with the frondal margin or falls a little short of it. Veins free. Frond herbaceous; pinnae dimidiate. Stipes continuous, with a creeping rhizome. - Ferns, all but one inhabitants of southeastern Asia and Polynesia, one being S. American. Differs from Lindsaya only in the absence of an intramarginal nerve, of which however there are often traces.

1. 0. repens, Desv. - Hook. \& Bak. Synops. Fil. p. 93. - Rhizome stout, wide-creeping on trees, sparingly covered with short ovate stiff blackish scales (with elongate cells and thick cell walls). Stip. distant, straw-colored, sparingly paleaceous below, 1-4' long. Frond linear- 
lanceolate, $12-18^{\prime}$ long, attenuate at both ends, herbaceous, pinnate. Pinnae $50-60$ on a side, close, shortly $\left(1 / \mathrm{s}^{\prime \prime}\right)$ stipitate, $4-12^{\prime \prime} \times 3-4^{\prime \prime}$, dimidiate, patent, the lower and inner margin straight or slightly curved, the latter paraliel to the rhachis, the upper and outer confluent, rounded off, closely crenate. Veins forking once or twice, the costule close to the lower margin. Sori numerous, intramarginal, discreet, in a line along the upper edge, one for each erenature. Invol. small, curved or reniform, its outer margin falling short of the edge. Annulus with 12 joints. Spores triquetro-globose, smooth. - Davallia repens Desv. - Dicksonia repens, Bory. - O. Boryanum, J. Sm. - Davallia Macraeana, Hook. \& Ärn. in Bot. Beech. p. 108.

Rather common on all islands. Nat. name: Laukahi». - Occurs in the Viti and New Hebrides groups, Malaysian islands, India and Mauritius.

\section{MICROLEPIA, Presl.}

Sori terminal, discreet, on the thickened apices of free veins, or apparently lateral by the production of a lateral veinlet from the apex (Loxoscaphe). Invol, inferior, dimidiate, adnate with the semicircular base, intra- or submarginal, its free outer margin truncate or produced, the sides not confluent with the margins of the lobule. Stipes continuous with the rhizome. - A genus of mostly tropical ferns, with head-quarters in Polynesia and southeastern Asia, only few species being American and African. Differs from Davallia chiefly in the non-articulate stipes.

Bi-, tripinnate; ultimate segments oblong or obovate:

Frond firm; invol. adnate with the sides.

1. M. strigosa.

Frond flaccid; invol. open at the sides

2. M. Jamaicensis.

Tripinnate, ultimate segments linear, cuneato-truncate

3. M. tenuifolia.

1. M. strigosa, Presl, Epimel. p. 95. - Rhizome stout, ereeping, covered with pale yellowish hairs which consist of a single row of cells. Stip. straw-colored or brownish, 12-18' long, pubescent throughout. Frond ovate-lanceolate, $1-2 \mathrm{ft}$. long, of firm texture, pale, pubescent or ciliate underneath, particularly along ribs and veins, bipinnate. Pinnae ovatelanceolate, ascending, the lowest $4-8^{\prime}$ long, stipitate $\left(2-3^{\prime \prime}\right)$, with lowest pinnules $1-2^{\prime}$, these deeply cut into rhomboidal or oblong suboblique, obtuse notched segments. Veins quite prominent, subpinnate in the segments, with a flexuose costule. Sori globose, generally one to a seg. ment, at the apex of the first anterior veinlet or of its first fork-branch. Invol. semiorbicular or broad cup-shaped, adnate with the sides, firm, brown, ciliate, its free margin not quite even with that of the crenature. Annulus with 24 joints. Spores smooth, tetraedrous, with convex back and grooved faces. - Davallia strigosa, Sw. - Synops. Fil. p. 98. - D. Khasyana, Hook. Sp. Fil. I, tab. 47 \& 57. - Dicksonia strigosa, Thunbg.

B. var. hirta. - Frond taller, $2-3 \mathrm{ft}$. long, tripinnate, less pubescent, sometimes subglabrate. Pinnae lanceolate, the lowest $8-16^{\prime}$ long; ultimate 
segments or pinnules deeply notched into 5 or more truncato-dentate lobules, each lobule with 1-3 sori. - Davallia hirta, Kaulf, - Hook. Sp. Fil. I, 181. - Synops. Fil. p. 100. - Dicksonia Kaulfussiana, Gaud. in Bot. Freyc. p. 368. - Hook. Sp. Fil. I, 71.

A common fern on all islands, growing on the outskirts and in open glades of the lower woods. Nat. name: «Palapalai». The epidermoidal cells of the indusium are not flexuose, and each is marked in $\beta$ with a papillose thickening, the probable base of a hairlet. The species is spread over India, Ceylon, Malaysia, New Hebrides, Viti, Japan and Formosa.

2. M. Jamaicensis, Fée. - Stip. stramineous or brownish, stout, naked, glossy, $1^{1 / 2}-2 \mathrm{ft}$. long. Frond flaccid, dark-green, glabrous, deltoid, $2^{2} / 2-3 \mathrm{ft}$. long, open, tripinnate. Rhachis faintly fibrillose. Lowest pinnae at distances of $4-5^{\prime}$, oblong-lanceolate, often exceeding $2 \mathrm{ft}$. in length. Lowest secondary pinnae $4-5^{\prime}$, again pinnate with largest pinnules measuring $1^{\prime} \times{ }^{1 / 3^{\prime}}$, ovate, obtuse, suboblique, cut deeply into obovate inciso-crenate lobes. Veins obseure. Sori very small, inside the margin, each at or near the base of a sinus. Invol. thin and whitish, quite low, often reniform with open sides, evanescent. Sporangia with 30 articles. Spores globose, without any lines, pale, minutely papillate. Cells of indusium flexuose. - Davallia Jamaicensis, Hook. Sp. Fil. I, 183. - Griseb. Fl. W. Ind. p. 661. - Dicksonia flaccida, Hook. \& Arn. in Bot. Beech. p. 108. - Davallia speluncae, Bak. in Synops. Fil. p. 100 (as to the Hawaiian plant).

Rare, found by me on the Waianae Mts., Oahu! and near Hilo, Hawail! only. The species occurs also in Cuba, Jamaica, New Granada and Brazil, and in tropical Aus. tralia. The above given character of the indusium is constant and would for itself alone suffice to distinguish the plant from Davallia (Microl.) speluncae, Bak., which it otherwise resembles greatly; but more distinctive eharacters are supplied by the sporangium and spores, for Mettenius, in Fil. Hort. Lips. p. 103, attributes to M. trichosticha, J. Sm., a form of $D$. spelunede, an elastic ring of 12 articles only and smooth 3 -lobed spores as in M. strigosa. The Australian fern, described under $D$. speluncae in the Flora of Australia by Bentham, agrees with ours, but not that of the Flora of Mauritius by Baker nor the $D$. polypodioides in Hooker's Sp. Fil, nor the Javanese M. trichosticha in Fil. Hort. Lips.

3. M. tenuifolia, Metten. Fit. Hort. Lips. p. 104, tab. 27, fig. 14. - Rhizome creeping, densely covered with short and stiff ferruginous fibrils which consist of a single row of cells, of two rows only at the base. Stip. $1 / 2-1$ ft. long, light brown, naked, glossy. Frond ovate-lanceolate, $1 / 2-1^{1 / 2}$ ft. long, glabrous, chartaceous, brownish when dry, open, tripinnate. Pinnae ovate-lanceolate, ascending, the lowest $3-6$ ' long, stipitate $\left(2^{\prime \prime}\right)$. Tertiary pinnules $1 / 4^{-1} / 2^{\prime}$, rhomboidal in outline, cut to near the rhachis into $3-6$ ascending narrow cuneate-oblong truncate segments, $1-1 / 3^{\prime \prime}$ broad, one or more commonly incised at the apex. Veins inconspicuous, forking, generally one to a segment, but often acutely forking near the apex. Sori submarginal, one or two at the truncate apex of the segment, discreet or rarely confluent and then supported by two veinlets. Invol. dark and firm, half cup-shaped, shallow, 
with the sides adnate, the free external margin truncate or excised and even with the apex of the segment. Annulus with 26 joints. Spores smooth, ovoid, bilateral. - Davallia tenuifolia, Sw. - Hook. Sp. Fil. I, 186. - Synops. Fil. p. 102. - Brack. 1. c. - D. remota, Kaulf, - Bot. Beech. 1. c. - Lindsaya Chinensis, Kuhn et al.

The most common of all Hawailan ferns. Nat. name: "Palaa”. From the leaves the natives used to extract a red dye. The species is spread over all tropical Polynesia and Asia, extending as far east as Madagascar and north to Japan. D. Chinensis, Sw., only differs in the rounded apex of the segments and the produced indusium. From analogy with Lindsaya Knudsenii it is fair to infer that the species has been evolved from a simpler form of Lindsaya, perhaps L. elongata, Lab.; in that case it would have to be transferred to that genus, but I am not aware that this has been proved. For the present the truly cup-shaped indusia with adnate sides consign the fern to Microlepia.

\section{PTERIS, L.}

Sori linear, mostly continuous, on an intramarginal anastomotic nerve which only exists in the fertile portion of the frond, covered by the reflected and usually membranous margin of the frond. In the last species also a thin and short true indusium on the inner side of the sorus which is hidden by the reflected margin or spurious involucre. A large cosmopolitan genus, including species of various forms and modes of vegetation.

Inner or true indusium wanting:

Veins free:

Frond pinnate; pinnae entire, the lowest bi-, tripartite . 1. P. Cretica.

Frond pinnate, all pinnae pinnatifid . . 3. P. excelsa.

Frond tri-, quadripinnatifid, with winged rhachis + . 2. P. irregularis.

Veins anastomosing:

Frond less than 1 foot long; rhachis winged in the upper portion:

Ultimate segments deltoid or lanceolate

Ulimate segments linear

Frond several feet in length; rhachis free

Inner or true indusium present; frond bi., tripinnate

4. $P$, decipiens.

5. P. decora.

6. P. incisa.

7. P. aquîlina.

Eupteris. - Veins free; involucre single; spores tetraedro-globose.

1. P. Cretica, L. - Hook. Sp. Fit. II, 159. - Rhizome short creeping, thick. Stip. elosely set, $8-18^{\prime}$ long, stramineous or pale brown, with a few short and dark scales at the base only. Frond phegopteroid, chartaceous, glabrous, shining, ovate or ovate-oblong in outline, $7-12^{\prime} \times 6-10^{4}$, pinnate. Pinnae opposite in $4-6$ pairs, linear-lanceolate, entire, subsessile with a cuneate base, $5-8^{1} \times{ }^{1 / 2}-3 / 4^{\prime}$, the upper pair mostly confluent with the terminal pinna and decurrent, the one or two lowest pairs cleft nearly to the base into 2 , rarely 3 , subequal pinnules with the stipes winged in the upper half. Sterile pinnae broader and spinulososerrate. Veins (nerv. Taeniopterid.) perpendicular to the rib, fine and close, simple or once forked and parallel. Invol. thin, continuous along the entire pinna excepting the apex. Annulus with $17-20$ articles. In 
the stipes two broad lateral fib. vas. bands, which curve outward and are united above by a transverse one.

Maui! abundant in Kula and Ulupalakua, but occurs also on Oahu! Makaleha, Kauai! Waimea, Molokai! and Hawaii. Nat. name: sowalii. - The species ranges over the eastern Mediterranean countries, eastern Africa and adjoining islands, temperate and tropical Asia, Japan, the Philipines, Viti Islands, and in America from Florida to Guatemala.

3. var. decurrens. - The two or three uppermost pairs of pinnae decurrent and confluent, with sori continued on the wings; the lowest 2 pairs bi- or tripartite as before, but the middle and often also the lower segment of the first pair pectinately cleft on the inferior side into 2 or 3 long segments, also the terminal segment of the frond with 1 or 2 lateral lobes.

Oahu! Makaleha; W. Maui! - Touches elosely on the Australian P. umbrosa, R. Br., and facilitates the transition to var. $\beta$ of the next species.

2. P. irregularis, Kaulf. Enum. Fil. p. 189. - Caudex short oblique, scantily covered with dark and stiff, linear-lanceolate and hairlike scales less than $1 / 2^{\prime}$ in length. Stip. $1-2 \mathrm{ft}$. long, angular, naked, pale-brown or yellow, glossy. Frond thin chartaceous, bright green, ovate or ovateoblong in outline, with a pedate base, $10-24^{\prime} \times 8-14^{\prime}$, irregularly tri-, quadripinnatisect, cyatheoid. Primary segments mostly opposite, at least, the lower ones, in $4-7$ pairs besides the pinnatifid apex, ovate-lanceolate, ascending, subfalcate, with a long-acuminate subentire apex, decurrent at the base so as to form a wing of $2-8^{\prime \prime}$ in width along the rhachis; the wing continuous or interrupted, rarely absent in the lowest internode; the inferior basal segment of the lowest pinnae much the largest. Secondary segments separated by broad angular intervals, entire in their basal portion. Ultimate segments deltoid or oblong-lanceolate, ascending. Veins distinct, nearly vertical, simple and once forking. Invol. continuous along margins and wing. Sporangia and fib. vas. fasc. as before. Agardh, Pterid. p. 18. - Hook. Sp. Fil. II, 173. - Synops. Fil. p. 158. Brack. Fil. U. S. E. E. p. 116. - P. alata, Gaud. in Bot. Freyc. p. 391, tab. 19, - Bot. Beech. p. 107. - In young sterile fronds, which are bipinnatisect, the fork-branches of the veins which run to the fundus of the sinuses unite again with their apices.

In woods and deep gulches of all islands from 1000-3000 ft. Nat, name: «Mana. Doubtfully reported from Sumatra.

$\beta$ var. linearis. - Frond $10-18^{\prime}$ long, bi-, tripinnatisect, the main rhachis narrowly margined or winged in the upper, wingless in the one or two lowest internodes. Lowest pinnae stipitate. Secondary segments narrow linear, entire, $2-3^{\prime \prime}$ broad and $3-4^{\prime}$ long, patent, leaving interrupted wings along their rhachis, the very lowest ones again cleft in their lower half into similar tertiary segments. 
E. Maui! Ulupalakua. In the simplest forms only the two lowest pairs of pinnae are segmented.

3. P. excelsa, Gaud. Bot. Voy. Freyc. p. 388. - Caudex short and thick, prostrate, clothed at the end with narrow lanceolate, light brownish, thin hyaline scales of about ${ }^{1 / 2} 2^{\prime}$. Stip. $1^{1 / 2}-4 \mathrm{ft}$. long, pale brown or purplish, naked, glossy. Frond thin chartaceous, bright green, broad oblong, 3-6 ft. in length, bipinnatifid throughout, with a terminal pinna, cyatheoid. Lateral pinnae 10-12, slightly ascending, subsessile, ovatelanceolate, long acuminate, the lowest shortly stipitate and often bipartite, $8-14^{\prime}$ long and $3-6^{\prime}$ broad at the base, all cut down to the rhachis into oblong subfalcate segments or pinnules, which are $2-5$ " broad, subacute, entire, the fertile ones often contracting from above the broadly sessile base. Veins rather distant, once or twice forking. Sori continuous from the base to near the denticulate apex. Invol. broad, thin. Sporangia and fib. vas. fase, as before. - Agardh, Pterid. p. 21. - Hook. Sp. Fil. II, 183, tab. 136. - Synops. Fil. p. 159. - Brack. I. c. - P. terminalis, Wall. - In young fronds only the lowest pair of pinnae is pinnatisect.

On all islands, with the preceding speeies. Nat. name: "Waimakanui. - Is found also in the Himalayas, Ava, the Philipines, Java, New Guinea, New Hebrides, and the Viti Islds. The largest species of the quadriaurita group. The lowest pinnae are not always bipartite, and the segments, although separated by narrow acute sinuses in the immature and sterile fronds, enclose broader ones between them when fertile and contracted, so that the difference between our species and P. patens, Hook., becomes very slight, considering that in the deeply cut plants of the latter species the costal arches are wanting likewise.

Doryopteris. - Frond short and broad, pedate, cyatheoid, with blackish stipes. Veins anastomosing. Involucre single. Spores tetraedroglobose.

4. P. decipiens, Hook. Sp. Fil. II, 209. - Caudex very short and thick, its scales curved, stiff and narrow, $1^{1 / 2}-2^{\prime \prime}$ long, consisting of a distinct black rib and hyaline transparent border which is dentate or eroded near the apex. Stip. closely set, 6-10' long, terete, deep-purple or black, naked and polished. Frond subcoriaceous, glabrous, cordate in outline, measuring usually $3-6^{\prime}$ each way, bi-, tripinnatisect, with the main rhachis interruptedly (cuneately) winged, the lowest interval sometimes wingless. Primary segments opposite in $3-6$ pairs besides the pinnatifid apex, lanceolate, falcate, long-acuminate, the lowest ones deltoid, uneven-sided, their inferior segments longer and again pinnatisect, the basal one much the longest; ultimate segments triangular obtuse or falcate, ascending, 1/4-1'long. Veins hidden, anastomosing (nerv. Sageniae). Sori broad, continuous along the acute sinus and apices. Invol. narrow, soon reflexed. Annulus with about 20 joints. Spores muricate. One small central crescent-shaped fib. vas. fasc. - Synops. Fil. p. $167 .-P$. pedata, Gaud. Bot. Freyc. - Bot. Beech. p.107. - Pellaea geraniaefolia, Hook. 
Sp. Fil. as regards the Hawaiian Islds. - Doryopteris pedata, Brack. P. Beecheyana, Hook.

On rocks and along watercourses; all islands. - Not known from elsewhere. In shape altogether like the Brazilian Pellaea geraniaefolia, Fée, though quite distinct. - From Kauai (Halemanu) Mr. Knudsen sends unusually large specimens which measure 12 inches each way, the ultimate segments $1-2$ inches, and resemble small fronds of $P$. irregularis. - Nat. names: "Iwaiwas and "Kumuniu".

5. P. decora, Hook. Sp. Fit. II, 210. - Caudex and scales as before. Stip. densely tufted, 4-9' long, slender, dark-brown to purple, polished, naked. Frond chartaceous, glabrous, ovato-cordate, $2-6^{\prime} \times 3-5^{\prime}$, tripinnatifid, with 2-4 pairs of cut pinnae or segments, besides the pinnatifid apex, the rhachis narrowly margined only in the upper internodes. Pinnae or segments opposite, sessile, all, or only the lower ones, cut down to the base into 3 principal divisions of nearly equal length, the middle one, and in the lower pinnae also the lateral ones, or at least the inferior, again deeply pinnatisect; the segments distant, separated by angular intervals, linear, the lowest $1-2^{\prime}$ long and less than 1" broad, decurrent in a winged rhacheole of about the same width. Veins (nerv. Doodyae) indistinct, anastomosing in two series of areoles. Sori continuous along the entire margins and winged rhachis, often filling the whole under surface. Invol, crenulate. Annulus with 15-16 joints. Spores and fib. vas. fasc. as in no. 4. - Synops. Fil. p. 167. - Doryopteris decora, Brack, 1. c. p. 103, tab. 13. - In the lowest ornithopoid pinnae the upper of the three divisions is quite as long as the middle and lower, but in the others it is shorter.

Hawail on dry lava fields of Kona and Kau; Molokai! heights of Kamalo; Lanai! Kauai! Halemanu (Kn.).

Histiopteris. - Frond elongate, the opposite pinnae all even-sided and narrowing toward the base. Spores ovoid, with one dorsal line. Veins anastomosing. Invol. single.

6. P. incisa, Thunb. - Hook. Sp. Fil. II, 230. - Rhizome subterraneous, long creeping. Stip. distant, pale brown. Frond subcoriaceous, pale, glabrous, glaucous underneath, oblong, several ft. in length, tripinnate below. Pinnae opposite, horizontal, broad lanceolate, all sessile, even-sided and narrower at the base. Pinnules opposite, perpendicular, sessile, lanceolate from a broad base, the basal pair shorter and less divided than the next one, but neither auriculaeform nor more remote in our specimens. Ultimate segments or pinnules separated by acute or narrow angular sinuses, lanceolate from a broad sessile base, the largest $10^{\prime \prime} \times 2-3^{\prime \prime}$ and sinuously incised about the middle into 3 or 4 round lobules. Veins (nerv. Doodyae) obscure, anastomosing in one series of costal arches. Sori on the sides only, interrupted and unequal, the longest 2 " in length in our specimens. Invol. firm, scarious. Annulus 
with 14 or 15 joints. Spores ovoid, compressed. - Two broad lateral fib. vas. fasc. curved outward and joined above by a transverse one. Synops. Fil. p. 172. - P. Vespertitionis, Labill. - Metten. Fil. Hort. Lips. p. 59 , tab. 15 .

Only two fragments, each holding a pair of pinnae, were found mixed up with specimens of $P$. aquilina, without indication of locality, but it is probable that they came from the western end of $\mathrm{Oahu}$. Although the material is so scanty there can hardly be a doubt about the diagnosis, confirmed as it is by the ovoid spores, which are not found in any other group of Pteris. The pinnae in our specimens are only 8 inches in length. The shape of the segments, the interrupted sori and sparingly anastomosing veins coincide with New Zealand and Australian forms. - The species has a wide range over the tropical regions of four continents and portions of the southern temperate zone. In Polynesia it oceurs on the Society, Viti and Samoa Islds.; from the Hawailan group it is reported here for the first time.

Pteridium, - Involucre double. Veins free. Rhizome creeping. Spores tetraedro-globose.

7. P. aquilina, L. - Hook. Sp. Fil. II, 196. - Rhizome subterraneous, wide creeping, branching. Stip. distant, $1 \mathrm{ft}$. or more long, pale brown,
hairy at the base only. Frond reclinate, coriaceous, dull green, shortly pubescent underneath, deltoid, 2-6 ft. long, $2-3 \mathrm{ft}$. broad, tripinnate below, simply pinnate above and ending in a pinnatifid apex, the rhachis subterete. Pinnae opposite, spreading, ovate-lanceolate to lanceolate, with a slender flexuose rhachis, most of them stipitate; the lowest anadromous, the middle ones catadromous, the upper homodromous; all ending in a pinnatifid apex with linear entire segments. Pinnules lanceolate, patent, the larger ones stipitate, $3-4^{\prime} \times 1-1^{1} / 2^{\prime}$, ending in a short entire linear apex, pinnatisect externally into remote linear segments which are confluent with broad or auriculate bases, but pinnate nearer the rhachis with free linear pinnules having 2 or 3 auricles or segments above the broad or contracted base. Veins impressed, once or twice forked. Sori broad, continuous along margins and sinus. External and internal invol, ciliate, the latter hidden by the former, very delicate and soon evanescent. Fib. vas. fasc. numerous. - P. decomposita, Gaud.

Common on all islands from $800 \mathrm{ft}$. to $8000 \mathrm{ft}$. Nat. name: "Kilau». The common Brake, which in several varieties is diffused over the whole world from the aretic to the torrid zone Our plant is intermediate between the var. caudata and esculenta, the secondary pinnae near the apex and the tertiary near the base of the frond entire or with one or few pairs of segments near the base, separated by broad intervals, the round sinus between entire pinnules lined by the continuous sori. In shady and protected places the more compound forms also oceur, in which the tertiary pinnules are pectinately segmented in nearly their entire length, as in $\%$ of the Synopsis Fil. The Hawaiians do not seem to have eaten the root, like the New Zealanders, but the wild pigs dig up the ground extensively in search of it.

\section{SCHIZOSTEGE, Gen. nov.}

Sori intramarginal, linear, interrupted, on prominent receptacles which are formed by intramarginal anastomoses of two fork-branches or by $T$ 
shaped expansions of simple veins. Invol. marginal, reflected, interrupted, but closely contiguous, one to each sorus, scarious, oblong, almost square. Sporangia stipitate, with an incomplete vertical ring. Spores tetraedrous, mostly angular, with 3 radiating lines.

1. S. Lydgatei, Hillebr. - Caudex short. Stip. not much crowded, 10-16' long, deeply furrowed, stramineous, glossy, paleaceous at the base with dark-brown shining linear scales of $5-6^{\prime \prime}$ in length. Frond subcoriaceous, harsh and brittle when dry, pale, glabrous, ovate-lanceolate, $1-2 \mathrm{ft}$. long and $8-20^{\prime}$ broad below, bipinnate at the base, cyatheoid. Pinnae subopposite, subsessile, $8-10$ on a side, besides a long terminal one, those of the lowest pair nearly $1 \mathrm{ft}$. long and each with 2 or 3 pedately deflected long pinnules on the lower side only, all others and the pinnules linear-lanceolate, $2-1^{1} / 2^{\prime}$ broad and deeply pinnatifid to near the rhachis in oblong subfalcate obtuse lobes which are about 4 " broad, crenato-dentate near the sterile apex, otherwise entire in both fertile and sterile fronds. Veins (nerv. Eupteridis) once forking, the last ones only simple; the sterile ones free and ending in a prominent clavate apex, the branches of forked fertile ones united at their apices by intramarginal veinlets, the simple fertile ones expanding in $T$ shape. Sori $5-10$ on each side, their involucres $1-1^{1 / 2} / 2^{\prime \prime}$ broad and nearly as deep, closely contiguous but disereet to the base, rarely several united completely or partially. Sporangia large, the annulus broad, with $15-20$ cells. Spores large and dark. - Fib. vas. fasc. large omega-shaped, its ends extending into the anterior angles. - Cheilanthes, Baker, Synops. Fil. 2nd Edit. p. 475.

First discovered by the author in a sterile state at a waterfall near the head of the guleh of Waihee, W. Ma ui! and subsequently found fertile by his son and J. Lydgate in the valley of Wailupe, Oahu.

A fern of the habit and size of Pteris biaurita, more akin to Pteris than to Cheilanthes. In fact, it might be considered as a Pteris with interrupted sori and involucres - the interruption not occasioned by a lobulation of the segment. The above given description of the receptacle is not easy to ascertain in the dried plant, but may be satisfactorily verified by boiling a fragment in caustic potash, soaking in glycerine, and careful preparation. Scalariform ducts with some sclerenchyma constitute the anastomosing veinlet as well as the $T$ shaped expansion of the simple veins. In the rare instances where several involucres coalesce there seems also to exist a tendeney of the intramarginal veinlets to unite with each other, but a complete junction I could not discover.

Exceptional anastomoses occur also occasionally in sterile fronds of young plants; thus in one specimen the fork-branches of the first upper vein unite again with their apices, forming elliptical loops, and junetions of the first upper and lower veinlets of contiguous segments at the sinus, either directly in the manner of Goniopteris, or by short recurrent veinlets, are not rare.

The cyatheoid character of the frond is strongly marked. In some fronds of young plants all primary pinuae are eatadromous, and in fully developed fertile specimens only the lowest pair have the first upper segment nearest to the rhachis, while in the upper pinnae and all segments the first inferior segment or vein rises from the rhachis of the preceding order.

The scarious and colorless involucre consists almost entirely of sinuous epidermoidal cells, two layers near the base and a single one only in the outer portion, without any stomata, 
and thus presents itself as an indusium verum in the sense of Presl. The transition or thinning of the green frond in the involucre is quite sudden and indicated outwardly by a straight line.

The youngest fronds bear only one pair of lobulate falcate pinnae besides the long and much broader terminal one. In the measure as more pinnae develop on the fronds the terminal one decreases in relative size.

In fronds of young plants the stipes exhibits three fib. vas. fascicles, two lateral ones which unite with a transverse dorsal one under obtuse angles, as is the case with the smaller species of Eupteris. In the larger fronds the lateral shanks curve outward, while their angles of union with the transverse portion become rounded off, so as to produce the omega shape.

\section{PELlaeA, Link.}

Sori on the upper portions of the veins, at first dot-like or decurrent, but soon confluent into an apparently continuous intramarginal line. Involucre formed of the more or less changed edge of the frond, quite continuous, sometimes very narrow and soon spread open so as to expose the entire fructification. - Fronds with generally dark and glossy stipites, harsh and rigid, olive-green when dry. Veins generally free and indistinct, seldom anastomosing. - Allosorus, Presl.

Inhabitants of dry rocky regions in the tropical and temperate zones, chiefly of S. Africa, Australia and the west coast of America. The genus is distinguished from Pteris by the want of an intramarginal receptacle, from Cheilanthes by the continuity of the involucre, and from Notholuena by the covered sori.

1. P. ternifolia, Fée, Gen. Fil. p. 129. - Caudex short and thick, branching. Scales brown, linear-falcate, stiff, 3 "long, consisting of a thick black rib and a narrow transparent border, dentate at the apex. Stip. close, subterete, 2-4' long, dark purplish-brown, naked and glossy. Frond coriaceous, rigid, glabrous, linear-lanceolate, $4-8^{\prime} \times 1-1^{1} / 2^{\prime}$, with $8-16$ mostly opposite pairs of subsessile pinnae which are cleft to the base into 3 subequal linear mucronate segments with rolled up edges; the terminal pinna simple. Veins hidden, simple or once forking. Invol. rolled over the sori till full maturity. Sporangia subsessile, the annulus of $18-24$ cells. Spores tetraedro-globose. One central semilunar fib. vas. duct. - Hook. Sp. Fil. II, 142. - Fil. Exot. tab. 15. - Synops. Fil. p. 148. - Platyloma ternifolium, Brack. - Allosorus ternifolius, Kze. Pteris termifolia, Cav. - Pteris verticillata, Sw.

Maui! Hawaii! Kauai! at altitudes of 5000-8000 ft. Nat. name: kaukahis. The Kauai specimens are larger, with pinnae not opposed and all shortly stalked, their divisions not rolled up, $2^{\prime \prime}$ broad and more. - The species extends over the high Andes from Chili to Mexico, and further north passes through $P$. Wrightiana, Hook., into P. mucronata, Eaton, and P. ornithopus, Hook.

\section{ADIANTUM, L.}

Sori on the upper portions of the veins, globose, oblong or linear, often confluent, marginal, covered by an involucre which is formed of the reflexed margin of the frond itself, into which the fertile veins extend, the 
sori being seated on its under side. Spores tetraedro-globose. - Fronds usually delicate, with dark glossy stalks, their ultimate segments reniform, cuneate or dimidiate, rarely even-sided. Veins flabellately forking, mostly free.

A large genus, chiefly inhabiting the tropies of both Worlds, but prevailing in America. Segments glabrous, euneate Segments hairy underneath, suborbicular or cordate

1. A. capillus Veneris.

2. A. Bennettii.

1. A. capillus Veneris, L. - Hook. Sp. Fil. II, 36. - Rhizome creeping above ground, covered with ferruginous linear scales or fibrils of $1-2^{\prime \prime}$ in length. Stip. distant, wiry, dark-purple, naked, glossy, 4-9' long. Frond pellucid-herbaceous, quite glabrous, ovate or ovate-lanceolate, $7-9^{\prime}$ long, bi-, tripinnate with a terminal and $3-5$ lateral pinnae, the lowest often again divided, all long-stipitate, with a filiform 'flexuose rhachis and few pinnules. Ultimate pinnules on slender stalks, $1 / 2-1$ ' broad, the base cuneate, uneven-sided, the outer edge truncate or rounded, cut from the circumference to the centre into $2-7$ cuneate-oblong lobes with flabellate veins; the sterile lobes toothed or serrulate, the fertile ones entire and their contracted apex reflexed in a transversely oblong scarious involucre, which is either straight at the base or slightly semilunar.

Common in wet gulches on all islands. Nat name: "Iwaiwa". The segments vary much in cutting; those most developed are as deeply cut as in Hooker's forma $\beta$ dissecta. In Hakalau and other gulches of the Hilo district, Haw aii, a small, simply pinnate form eovers the rock-walls, measuring not more than $2-4$ inches including the stipes. - The black glossy stalks of this fern, as well as of Pteris decipiens, are worked by native women into ornamental baskets and hats. - The Maiden-hair fern oceurs in tropical and temperate regions of all continents, excepting Australia. In Polynesia it is confined to the Hawaiian group and New Caledonia.

2. A. Bennettii, Carruthers, in Fl. Vit. p. 346. -- «Stip. and rhachis black, naked. Frond $1 \mathrm{ft}$. long, deltoid, bi-, tripinnate, membranous, glabrous above, hairy underneath. Ultimate pinnules on petioles of $3-4^{\prime \prime}$, broader than deep, ${ }^{1} / 4-3 / 4^{\prime}$ broad, entire, even-sided, cuneate at the base or rounded-reniform with a broad sinus. Veins flabellate. Sori reniform, $6-10$ on a pinnule, crowded round the outer border, $1 / 2-2^{\mu}$ broad, - Baker, in Synops. Fil. 2nd Edit. p. 473.

Sandwich Islands (Lieut. Strickland, in herbar. Mus. Brit.). Very near to or perhaps identical with A. seabrum, Kze. (according to Baker). - I know nothing of this plant and suspect that the habitat assigned is not correet. A. scabrum, Kze., is a hairy form of A. Aethiopicum, L., from the west const of N. America.

\section{TRICHOMANES, L.}

Involucre marginal or extramarginal, tubular or cup-shaped, the lateral nerves extending to its mouth. Columella exserted, bearing the sporangia at its base. Veins free, often accompanied or apparently united by ducts of prosenchymatic sclerenchyma - spurious veins, spores tetraedro- 
globose. Rhizome with a single fibro-vasal duct, bearing hairs instead of scales.

A large genus, chiefly of the tropical zone and of damp localities in the southern temperate zone.

Frond orbicular in outline, very small .

1. T. parvulum.

Frond lanceolate or oblong :

Stipes and rhachis fibrillose; rhizome erect

Stipes and rhachis naked or nearly so; rhizome creeping:

Frond small, 2-3' long

Frond large, 5-12' long:

Frond narrowing below, dark-green

Frond broad below, brownish when dry

5. T. meifolium.

2. T. Draytonianum.

3. T. davallioides.

4. T. cyrtotheca.

1. T. parvulum, Poir. - Hook. Sp. Fil. I, 118, tab. 39, A. - Rhizome slender, creeping, densely matted, tomentose with dark-brown fibrils. Stip. scattering, filiform, fibrillose at the base, ${ }^{1} / 4-1 / 2^{1}$ long. Frond orbicular in outline, $3-4$ " each way, cuneate or truncate or cordate at the base, flabellately eut more than halfway down from the outer edge in the direction of the base into narrow unequal segments. Veins dichotomous, close, prominent, so that the frond when dry appears channelled, with some spurious veins parallel to them. Sori $2-6$ to a frond, terminating the central segments, the tube quite sunk in the frond, slender, with dilated mouth. - Synops. Fil. p. 75. - Brack. Fil. U. S. E. E. p. 250. T. sibthorpioides, Gaud. - T. saxifragoides, Presl. - More rarely the frond lengthens out and is cut in a subpinnatifid manner.

On trees and rocks. A delicate moss-like fern, rather rare, but in some ravines of the Hilo district, Hawaii, eovering entire rock-walls. Occurs also in Tahiti, Samoa, Viti, tropieal Australia, Japan, China, Java, Ceylon, Mauritius and Madagasear.

2. T. Draytonianum, Brack. Fil. U. S. E. E. p. 252, pl. 36. Rhizome creeping, densely matted, rather slender and tomentose with short articulate dark-brown fibrils. Stip. scattering, slender, green, winged above, ${ }^{1 / 4}-1$ ' long. Frond flaceid, bright-green, lanceolate, broadest at the middle, $2-3^{\prime} \times^{1 / 2}-1^{\prime}$, bipinnatisect, with the main rhachis margined throughout. Primary segments patent, rhomboidal to ovate-lanceolate, obtuse, broadly adnate with the upper base, horizontally cut at the lower, deeply notched into deltoid oblong and cuneate lobes, rarely again pinnatisect, the lobes entire, or notched at the truncate apex into $2-4$ blunt teeth. Costa thin, flexuose; veins at open angles to it, once or twice forking in each lobe, subpinnate in the deeper segments. Spurious veins wanting. Sori, one to each primary segment, partly immersed in the upper basal lobe, rarely 2 or 3 to a segment. Invol. green, broad-campanulate, laterally winged, its mouth dilated but scarcely 2-lipped. Columella short, little or not exserted. - Luerssen, in Flora, 1875, p. 418.

- Didymoglossum Draytonianum, Van d. Bosch.

On rocks; rare. Kauai! W. Maui! Molokai! Kalae. In the Synopsis Fllicum this fern is joined with $T$. filicula, Bory, but without good reason. The entire mouth of the in- 
volucre and the shape and texture of the frond bring it nearer to $T$. pyxidiferum, L., from which it differs, however, in the broad tube of the semiimmersed involucre and in the absence of spurious veins. In both $T$. filicula and $T$. pyxidiferum the frond is also much deeper divided, with the rhachis free below.

3. T. davallioides, Gaud. Bot. Voy. Freyc.p.3\%8. - Rhizome wide-creeping, of the size of a crow's quill, fibrillose with stiff dark opaque hairlets of few articulations. Stip. distichous on the rhizome, distant $\left(1-3^{\prime}\right)$, naked or pubescent at the base, $1 / 4-5^{\prime}$ long, marginate. Frond rather flaccid, dark-green, lanceolate, broadest at the middle, tripinnatifid, the main rhachis narrowly winged. Pinnae $18-24$ on a side, anadromous, linearlanceolate, $2-5^{\prime}$ long and $3 / 4-1^{1} / 2^{\prime}$ broad about the middle, cut at open angles into rhomboido-oblong, rather obtuse segments of $4-9$ " in length, which are again divided into spreading oblong and cuneate lobes, those of the lower segments notched at the subtruncate apex into $2-6$ short obtuse teeth. Sori in the axils of the tertiary lobes, $1-6$ to a secondary segment. Invol. thick, brownish, over 1 " long, tubular, with entire spreading mouth, free or slightly margined. Columella often several times longer than the involucre. - Hook. Sp. Fil. I, 143. - Carruth. in Fl. Vit. p. 342. - T. radicans, Hook. Sp. Fil. 1, 125, and Synops. Fil. p. 81, as to the Hawaiian plant; also Brackenr. and Luerssen, ll. cc. - T. Sandwicense, Van d. Bosch.

Quite common in damp forests of above $2000 \mathrm{ft}$. elevation, festooning nearly every tree. Nat. name: Kilau. - Our specimens are quite uniform and cannot well be combined with the $T$. radicans, Sw, from the Atlantic islands or Jamaica, in which the shorter but more divided frond is broadest at the base, as well as the pinnae, and the angles of division much sharper, so that secondary and tertiary segments point toward their respective apices, while in our fern they spread out, and, being less eut up, impart an open appearance to the frond. The involnere also I never find bilabiate, but as above described, and only in one specimen from Kauai simply truneate. The var. $\gamma$ of $T$. radicans - T. Luschnatianum, Presl - has indeed the lowest pinnae dwarfed and distant, but is in all other respects a true $T$. radicans and cannot be confounded with our plant.

4. T. cyrtotheca, $s p . n$. - Rhizome climbing as in no, 3 , woolly with crisp reddish-brown thin translucent hairs of many articulations. Stip. at distances of $1-3^{\prime}$, terete or most faintly margined, $2-4^{\prime}$ long, fibrillose in the lower portion. Frond polystichoid, ovate to ovate-lanceolate, $5-9^{\prime} \times 3-7 ;$, broadest at the base, firm chartaceous, dull brownish when dry, bi-, tripinnatifid, the rhachis very narrowly margined, often only in the axils, and faintly fibrillose. Primary pinnae $10-14$ on a side, stipitate, ascending, ovate to ovate-lanceolate, the longest $2-4^{1 / 2} / 2^{t}$ long with a short acumination, pinnatifid at acute angles in the upper portion, but pinnate to a faintly margined rhachis nearer the base. Secondary segments or pinnules ascending, narrow ovate-oblong, obtuse, the lowest with a cuneate base and substipitate, their margins cut halfway or more into narrow oblong or obovate lobes which are sharply $2-5$-toothed at the top. Veins close, forking, each lobe or segment with 2-9 branches, a 
few dark striae in the intervals between them. Invol. tubular, slender, about 1 "long, with an expanded bilabiate mouth, curved, truly axillary, terminating the first superior veinlet of a lobe, rarely 2 or 3 to a lobe, quite free, stipitate, the thickened tube brown, the lips green. Columella about the length of the tube.

Oahn! in the woods of Kahuku and Kahana. Quite peculiar in the curvature of the slender involucres, at least all those which are raised on a distinct stipes. The deflection is owing in some to a curvature of the stipes, but in others the axis of the tube itself is concerned. In size, shape and cutting the frond resembles forms of the $T$. rigi. dum group, in which the involucres also occasionally deviate from the straight line, $T$. obscurum, B1., from Ceylon, T. elongatum, Cunningh., from New Zealand, and T. dentatum, Van d. Bosch, from New Caledonia, coming nearest to it; but it is less rigid, and the character of the rhizome forbirls altogether associating our fern with that species. It has the climbing habit of $T$. davallioides and when growing is apt to be mistaken for it. It is the $T$, radicans, $\operatorname{var} \beta$, of Mr. Baldwin's sale-collections. The involucre is distinctly bilabiate and the tubular portion has two layers of cells, while in the lips there is only a single one, as in the frond itself. In $T$. davallioides the thickening of the tubular portion is owing to the development of ducts of prosenchymatic sclerenchyma, which is not present here.

5. T. meifolium, Bory in Willd. Sp. Pl. (not Kaulf.). - Caudex suberect, $2-3^{\prime}$ long, stout. Stip. fibrillose with patent rufous hair, $4-8^{\prime}$ long. Frond dark-green, rigid, lanceolate, attenuate below, rarely the lowest pinnae nearly as long as the next upper ones, $6-12^{\prime} \times 3-5^{\prime}$, polystichoid, tri-, quadripinnatifid, with the primary and secondary rhachides fibrillose and the former always, the latter commonly, without margin. Pinnae $20-26$ on a side, ascending, shortly stipitate, linear-lanceolate, the longest $2-4^{\prime}$ long. Ultimate segments linear, holding a single vein with more or less of cellular tissue. Sori $2-8$ to a pinnule, in the axils of the tertiary segments. Invol. small, $1 / 2-3 / 4$, green, turbinate or cupshaped, entire, free or partly immersed, according to the division of the frond. Columella short, generally not protruding. - Hook. Sp. Fil. I, 137. - Ic. Pl. tab. 703. - Synops. Fil. p. 86. - T. apiifolium, Presl. - T. Bauerianum, Endl. - T. exaltatum, Brack. - In one of my specimens the segments consist of the vein only, with a border of tissue in the axils.

Terrestrial; in shady woods of all islands, but not common. Oecurs also in the Samoa and Viti Islands, on Norfolk Isld., Java and Luzon.

\section{HYMENOPHYLLUM, J. Sm.}

Involucre bilabiate. Columella short, enclosed, bearing the sporangia at its apex. Otherwise as in Trichomanes and with the same geographical range,

Pinnae flabellately divided or dimidiate; rhizome long-creeping:

Frond lanceolate, acuminate:

Frond glabrous throughout .

Frond ciliate on the margins and nerves of the segments and

at the apices of the involucres
Frond ovate or obovate or deltoid, obtuse, hispid throughout Pinnae pinnately divided; fronds tufted on a short rhizome, the stipites hispid

1. H. recurvum.

2. H. lanceolatum.

3. H. obtusum.

4. H. Baldwini. 
1. H. recurvum, Gaud. in Bot. Voy. Freyc. p. 376. - Rhizome ereeping, slender, naked. Stipites distant, slender, $2-3^{\prime}$ long, winged above. Frond flaccid, olivaceous, glabrous, lanceolate, acuminate, narrowing below, $4-12^{\prime} \times 2-3^{\prime}$, tripinnatisect, the apices of the frond and pinnae generally recurved, the main rhachis narrowly winged throughout. Pinnae rather distant, erect-patent, lanceolate, abscisso-truncate, long acuminate, divided nearly to the rhachis into simple or forked or dimidiately compound segments or pinnules, the ultimate segments linear, $1 / 2$ " broad, each with a single vein. Sori $2-6$ to a pinna, on both sides, axillary or on very short lateral segments. Invol. large, not immersed, ovate, divided about halfway; the valves rounded, entire, as broad as their segments or broader. - Bot. Beech. p. 109. - Hook. Sp. Fil. I, 104, tab. 37. - Synops. Fil. p. 61. - Brack. Fil. U. S. E. E. p. 269.

Pendent on trees, common, not known from elsewhere, but a fern from the Samoa Islds. (Graeffe, 1105), named $H$. dilatatum by Luerssen, although larger, is much like it. Nat. name: "Ohiaku ".

2. H. lanceolatum, Hook. \& Arn. in Bot. Beech. p. 109. - Rhizome slender, creeping, fibrillose. Stip. distant, slender, fibrillose when young, $1-2^{\prime}$ long. Frond olivaceous or brownish when dry, lanceolate, $2-6^{\prime} \times 1-2^{\prime}$, bi-, tripinnatifid, with the rhachis flexuose and sparingly fibrillose, winged only in its upper portion. Pinnae rhomboido-oblong, rather obtuse, cut on both sides to near the rhachis into linear bifid and subrhomboidal segments, the latter deeply incised in a flabellate manner; the linear segments $1 / 3$. broad and ciliate only on the margins and vein, the simple rufous hairlets single or two from a common basis. Sori small, $2-8$ to a pinna, terminal on the segments, immersed. Invol. about ${ }^{1 / 2}{ }^{\prime \prime}$, rounded or ovate, divided halfway, the valves ciliate, entire.-Sp. Fil. I, 94, tab. 34. - Synops. Fil. p. 69. - Brack. 1. c. p. 263.

On trees; rare, but on all islands! In appearance like the preceding species, but smaller and less acuminate.

3. H. obtusum, Hook. \& Arn. in Bot. Beech. p. 109. - Rhizome filiform, much entangled, pubescent. Stip. ${ }^{1} / 2-2^{\prime}$ long, capillaceous, ciliate with stellate articulate hairs which mostly divide into 2 or 3 branches. Frond $1-2^{1 / 2} 2^{4} \times{ }^{1 / 4}-1^{1} / 2^{4}$, ovate-obtuse, or oblong narrowing below, or cuneate with truncate apex, reddish-brown when dry, densely hispid, the main rhachis winged (except the lowest internode) in the elongate form, tripinnatifid. Pinnae ascending, close, the longest $1 / 2-1^{1} / 2^{\prime}$, deltoid or dimidiate-rhomboidal, obtuse, with a cuneate base, cleft in a sub-flabellate manner to near the rhachis into long linear or bifid segments, the ultimate fork-branches of equal length, $1 / 3^{\prime \prime}$ broad, the outer ones all soriferous at the apex. Sori $2-11$ to a pinna. Invol. small, ${ }^{1} / 2{ }^{\prime \prime}$, orbicular, with a broad base, deeply cleft, densely hispid. - Hook. Sp. Fil. I, 93, tab. 33. - Synops. Fil.p. 63. - Brack, 1.c. p.263. - Fronds of young plants are sub- 
orbicular, with a cuneate base. The sori border, as it were, the outline of the frond.

Rather rare, on trees! Is reported also from Table Mountain at the Cape of Good Hope.

4. H. Baldwini, Eaton, in Bull. Torrey Club, New York, Vol. VI (1879), no. 50. - Fronds tufted at the end of a short and rather thick rhizome. Stip. ${ }^{1 / 2}-1^{\prime}$ long, pale-brown or greenish, densely hispid with long rufous spreading hairs which rise from a wart-like base. Fronds bright green, pellucid, linear-lanceolate, $2^{1} / 2-5^{\prime} X^{3} / 4-1^{\prime}$, narrowing below, bi-, tripinnatifid with more than 20 closely set erecto-patent pinnae on each side, the rhachis margined, except between the lowest pinnae, and hispid in the lower half or two thirds. Pinnae glabrous, about $1^{1 / 2}$ " broad, linear-oblong, with a rather cuneate base, cut on both sides into short oblong-obtuse emarginate or bifid (not toothed) segments. Veins simple or once forking in a segment. Sori $5-7$ in the larger pinnae, on both sides, terminal on the simple segments or on the anterior lobes of the bifid segments. Invol. very small, less than ${ }^{1 / 2}{ }^{\prime \prime}$, suborbicular, shortly bilabiate, the margins entire and glabrous, the columella nearly as long as the involucre.

Oahu! in the lateral valley of Nuranu which leads up to Konahuanui, at an elevation of $2500 \mathrm{ft}$. (Baldwin). A well marked species, and singular in the genus for the short rhizome with tufted fronds and for the regularly pinnate division of the latter, also for the bright green color. The frond has a single layer of cells and the sporangia are those of the genus.

\section{ORDER XCVII. OPHIOGLOSSACEAE.}

Sporangia formed by lobes of the frond itself, ringless, free or partly united, splitting deeply in a transverse or longitudinal line. Spores of one kind, yellow, tetraedro-globose. - Frond sheathing at the base, erect or bent in the bud (not circinnate), quite naked, divided into two portions, the posterior expanded, sterile, the anterior contracted, fertile. Rhizome short, mostly subterraneous, generally with a single frond which ensheaths with its base the buds of future fronds. The prothallium develops under ground, is pale, tuberous, and carries both archegonia and antheridia, the latter sunk in the substance.

Sterile and fertile portion of the frond entire

1. Ophioglossum. Both portions of the frond divided

2. Botrychium.

\section{OPHIOGLOSSUM, L.}

Fertile portion entire, presenting a distichous, pedunculate spike. Sporangia connate in one row on each side of the rib, opening and at last two-valved by a slit vertical to the latter. Sterile frond entire, with areolate veins.

A small genus, spread over ail zones and continents. 
Root-stock under ground; fertile spike rising from the base of the sterile division of the frond:

Sterile division at or near the base of the frond, narrow and short

Sterile division at or near the middle of the frond, larger and broader

Root-stock above ground; fertile spike rising from the face of the sterile division

1. 0. nudicaule.

2. O. vulgatum.

3. O. pendulum.

1. 0. nudicaule, L. fil. - Hook. \& Bak. Synops. Fil. p. 445. - Rhizome under ground, slightly tuberous. Frond $3-5^{\prime}$ long, the sterile division placed at the base or at least below the middle, narrow-oblong or oblanceolate, obtuse, ${ }^{1 / 3}-1^{1} /^{\prime} \times 2-5^{\prime \prime}$, narrowing at the base but without haft, ribless, the veins distinct, the median areoles elongate only in the narrow fronds and many of the two outermost rows with free included veinlets. Epidermoidal cells sinuous. Fertile spike $1 / 2-1^{\prime}$ long, on a peduncle of $1^{1 / 2}-3^{\prime}$, with $20-34$ pairs of spore-cases. Fib. vas. ducts 3-5. - O. concinnum, Brack. Fil. U. S. E. E. p. 315, pl. 44.

On grassy plains of the isthmus of Ma ui! Waituku, Waiehu, also Lahainaluna near a watercourse (Lydg.), and near the Rainbow Falls of Hilo, Hawaii! (Dr. Whitmore). Nat. name: * Pololei . Appears only in spring after the first rains. - The species is credited to tropical and subtropical America, New Caledonia, Malacca, India and the West Coast of Africa.

2. 0. vulgatum, L. - Hook. \& Bak. 7. e. p. 445. - Rhizome under ground. Plant with sometimes several fronds, the sterile division placed at or near the middle, broadly ovate to elliptical, rather acute, $1-2^{4}$ $\times 3-9^{\prime \prime}$, rather thick with less distinct veins, but areolate as in no. 1 , without a midrib. Fertile spike $1-1^{1 / 2} 2^{2}$. A broad dark band extends along the middle of one barren frond for some distance, but it is owing to a deeper color of the parenchyma, not to the presence of a rib. O. ellipticum, Brack. 1. c. p. 314 .

Maui! Haleakala (6000 ft.) and Hamakua; Kauai! pastures of Koloa (U. S. E. E.). - We have two forms which fall under this species, one from Haleakala with large ovate frond, in no way distinguishable from the European, the other with smaller, elliptical, rather acute fronds about $1^{\prime}$ long, which corresponds to 0 . ellipticum, Hook. \& Grev. It is very doubtful if this species is really distinct from the preceding one. The position of the sterile frond seems to depend upon the depth at which the rhizome lies buried under gronnd: the deeper this, the more remote from it the sterile frond. - The species has a wide range over the Old World, Australia and temperate N. America.

3. 0. pendulum, L. - Hook. \& Bak. l. c. p. 446. - Rhizome above ground, emitting several fronds, which are fleshy, oblanceolate, ribbonlike, mostly falcate, $1-2 \mathrm{ft}$. long, $1-1^{1} / 2^{\prime}$ broad near the obtuse apex and thence gradually narrowing to the base, opaque, without midrib, the indistinct veins anastomosing in elongate areoles without free veinlets. Fertile spike rising from the anterior face of the frond, $2-4^{\prime}$ long, on a peduncle of ${ }^{1} / 2-1^{\prime}$. - Bot. Beech. p. 102. - Brack. 1. c. p. 316. Ophioderma pendulum, Endl. 
Common on trees. The "Laukahi " of the natives, who employ an infusion of the herb as a remedy against cough. - Extends from Polynesia through tropical Asia and Australia to Madagasear.

\section{BOTRYCHIUM, Sw.}

Fertile portion divided, paniculaeform. Sporangia free, sessile, arranged in a row on each side of the rib of the leaf-segments, splitting transversely into two valves. Sterile frond pinnate or ternately dissected, with free veins. Rhizome under ground.

Geographical range as before.

1. B. subbifoliatum, Brack.Fil. U.S.E.E.p.317,tab.44. - Rhizome fleshy, ovoid, carrying one or two fronds. Frond $10-20^{\prime}$ high, the fertile portion separating from the sterile $1-2^{1} / 2^{\prime}$ above the rhizome. Sterile frond on a stalk of $4-7^{\prime}$, fleshy, quite flaccid when dry, deltoid in outline, $4-6^{\prime}$ $\times 6-8^{\prime}$, tripinnatifid, obtuse. Pinnae and pinnules catadromous and always alternate, only the three or four lowest pinnae stipitate on stalks of $1^{1 / 4}-1 / 4^{\prime}$ and ovate or ovate-oblong, the few upper ones suddenly shorter and decurrent in a winged rhachis; the ultimate segments large, cuneate, oblong or obovate, $3-5^{\prime \prime}$ broad, dentato-serrate near the apex or incised in the largest forms. Stalk of fertile frond longer than the whole sterile frond, the panicle $3-5^{\prime}$, tripinnate, open. Spores whitish, subglobose, finely granular. - A small central horseshoe-shaped fib. vas. fascicle in the stipes of the frond. Epidermoidal cells with straight walls. - B. daucifolium, Hook. Synops. Fil. p. 448. - B. ternatum, var. Australasiaticum, Milde, Fil. Eur. et Atlant.

Rare, in deep forests: Oahu! Pauoa, Palolo, Kahuku; Molokai! W. Maui! Kauail Combines the leaf of $B$. daucifolium (only more compound) with the deep separation of both frondal portions which prevails in B. ternatum. The basal pinnae are never opposite, and the lowest has a longer stalk than the first one on the other side. Nat. name: "Makoun.

\section{ORDER XCVIII. LYCOPODIACEAE.}

Spore-cases or eapsules (sporangia) sessile or nearly so at the base of ordinary leaves (apparently axillary) or of changed bractlike leaves which form a terminal spike. The sporangia are either of two kinds on the same plant: microsporangia, which contain a fine powder of 3-or 1-lineate spores (microspores), producing the male prothallia, and macrosporangia, which hold only $4(3-1)$ larger spores or globules (macrospores), producing the female prothallia; or of one kind only, and then microsporangia, the spores of which produce monoecious prothallia. - Low plants, often moss-like, with a dichotomous stem. Leaves simple, persistent, sessile, 1 -nerved, sometimes reduced to minute seales.

Hillebrand, Flora of the Hawaiian Islands. 
Only microsporangia present:

Capsules 1 -celled; spores with sै radiating lines; leaves developed, generally all alike

Capsules 3-celled, 3-valved; spores marked with 1 line only; leaves rudimentary, scale-like.

1. Lycopodium.

2. Psilotum.

3. Selaginella.

Microsporangia and macrosporangia present; spores with 3 radiating lines; leaves generally of two kinds.

\section{LYCOPODIUM, L.}

Spore-cases of one kind only - microsporangia -, sessile on the base of stem-leaves or of bracts in a terminal spike, 1-celled, kidney-shaped, opening transversely with 2 valves. Spores minute, sulphur-colored, marked with 3 converging lines. - Perennial plants, with a terete stem, the leaves mostly even-sided, rigid, imbricate or crowded in 4-16 ranks. - The spores develop a monoecious prothallium, which is either tuberous and colorless, or chlorophyllaceous and provided with foliaceous appendices on its summit.

A large genus, widely spread over every part of the globe.

Sterile leaves of one kind, homomorphous :

Fertile leaves similar to the sterile ones; stems erect:

Leaves spreading or reflexed, membranous:

Leaves broadly spathulate, mostly serrate, green

Leaves linear-lanceolate, entire, often reddish

Leaves imbricate, coriaceous, entire, pale .

1. L. serratum.

2. L. erubescens.

3. L. Haleakalae.

Fertile leaves gradually smaller; plant much divided, pendulous .

Fertile leaves bract-like in terminal spikes:

Spikes sessile:

Leaves acerose, awl-shaped, curved

4. L. polytrichoides.

Leaves flat, lanceolate:

Spikes thicker at the base, simple or onee or twice forking

Spikes cylindrical, repeatedly forking:

Ultimate leaves in 4 ranks

Ultimate leaves in $3-2$ ranks

Spikes pedunculate or on distantly leaved branchlets

Leaves of sterile branches dimorphous as in Selaginella; plant climbing

8. L. eеrnuит.

5. L. nutans.

6. L. pachystachyon.

7. L. phlegmaria, var. Mannii.

9. L. venustulum.

10. L. volubile.

1. L. serratum, Thunb. Fl. Japon. p. 341, tab. 38. - Stems erect, or decumbent at the base, $4-6^{\prime}$ high, $3-4$ times forking, foliose throughout, fructiferous in the one or two last divisions. Leaves rather thin, all alike, in 6-4 ranks, horizontally patent or reflexed, spathulate, $3-6^{\prime \prime} \times$ $1 / 2-1^{1} / 2^{\prime \prime}$, very acute, irregularly eroso-serrate, contracted at the base, even petiolate, with the midrib often impressed underneath. Sporangia broad reniform, not apiculate. Spores pale whitish. - Luerssen, in Flora, 1875 , p. 440. - L. sulcinervium, Spring, Monogr. Lycop. I, 39. Brack. Fil. U. S. E. E. p. 322. - L. varium, Mann, Enum. no. 653.

Not uncommon on $\mathrm{Oahu}$ (west ridge of Nuranu), Kanai, and probably all islands. The different seasons' growths are often (but not always) indicated by shorter leaves; also sets of full-sized fertile leaves are occasionally interrupted by sterile ones. - The 
species extends over Japan, various parts of India, Ceylon and Java; or, if the too nearly allied $L$. lucidulum be united with it, also over the North American Continent. The weak differential eharacter relied upon by Spring to distinguish his L. sulcinervium, viz., the faint rib, sulcate underneath, is only observed in very thin-leaved forms.

$\beta$ var. dentatum. - Stem ${ }^{1 / 2}-1^{1 / 2} \mathrm{ft}$. long, only one to three times forking at variable heights, rarely undivided. Leaves crowded, harsher, narrow-lanceolate, finely denticulate, less contracted at the base.

Highest mountains of Kauai, Maui and Lanai. Almost like L. lucidulum, and probably the Hawaiian plant referred to $L$. varium, $\mathrm{R}$. Br. (Owhyhee, Menzies), in Spring's Monogr. II, p. 24, finds its true place here.

$\gamma$ var: subintegrum. - Stem redidish, $6-8^{\prime}$ long. Leaves subentire, patent and reflexed, broad-lanceolate, $3-4$ " long.

High mountains of Kauail

2. L. erubescens, Brack. Fil. U. S. E. E. p. 320, tab. 45. - «The whole plant brown or reddish, $4-8^{\prime}$ long. Stems tufted, erect, forking. Branches obtuse. Leaves all alike, in about 8 ranks, spreading, plane, linear-lanceolate, acute, quite entire, $1^{1 / 2^{\prime \prime}} \times{ }^{1 / 2^{\prime \prime}}$. Capsules compressed, reniform, pale yellow, persistent, those of the preceding years as low as the primary divisions of the stem.»

"Haleakala, Maui, in wet lands, $6000 \mathrm{ft}$. ; high plateau of Kauai! (Mr. Johnson) Waialeale, Kauai, on rocks (Wawra).

3. L. Haleakalae, Brack. l. c. p. 321, tab. 45. - «Stems tufted, stiff, erect, $4-6^{\prime}$ high, forking. Branches thick, crowded, obtuse, their summits of about equal height. Leaves pale, in about 6 ranks, all alike, $2^{\prime \prime} \times 1$ ", ovate-lanceolate, acute, entire, but with 2 or 3 minute teeth near the point, nearly imbricate with recurved apex, the thick base decurrent on the stem. Capsules yellow, only in part concealed by the leaves, the old ones persistent on the stem to within a few inches from the ground,» «Haleakala, in wet lands, $7000 \mathrm{ft}$. elev. The species is closely allied to L. compactum, Hook. (from the Andes of Ecuador), but this latter has obtuse and distinctly serrate leaves with an incurved point and a manifest keel on the outer side.»

I have a few plants from the top of Eeka, W. Maui! in which the leaves are stiff coriaceous, pale straw-colored, rather obovate with a broad base, entire, densely imbrieate in the upper but patent in the lower portion of the stem, all distinetly carinate and some transversely wavy.

4. L. polytrichoides, Kaulf. Enum. Fil.p. 6. - Stem $6-12^{\prime}$ high, erect or pendulous, repeatedly dividing at open angles from the very base, often 9-12 times, thereby appearing densely tufted, the branches very slender flaccid and terete, leafy throughout, fructiferous through several of the last divisions. Leaves of the young plant and sterile branches very dense, linear acerose, erecto-patent, about $2^{\prime \prime}$ long, those of the main divisions in 6 or more ranks, subulate, incurved, with gradually dilating base. Fertile leaves in 4 or 3 ranks, shorter, lanceolate to broadly ovate, 
strongly carinate, mucronate, entire, always longer than the sporangia, which are small, orbicular-cordate with a narrow basal slit. Spores whitish, smooth. - Spring, Monogr. Lycop.I, 73, II, 32. - Brack. 1. c. p. 323. - Mann, Enum. no. 652. - L. verticillatum, var. $\beta$, filiforme, Spring, l. c. I, 47, as to the Hawaiian Islds. and Carruthers, in Fl. Vit. p. 327.

On trees, not frequent. - The species, not found elsewhere yet, is nearly related to $L$. verticillatum, L., which occurs in tropical America and southeastern Africa with adjacent islands. The transition from subulate to ovate leaves is quite gradual but well marked, so that in old plants the ultimate divisions often appear like catkins. In $L$. verticillatum the leaves of the first and last divisions are conformous and nearly equal in length.

5. L. nutans, Brack. l. c. p. 32\% - Stem stout and stiff, 10-16' long, $2-3^{\prime \prime}$ thick at the base, erect or pendulous, simple, or once or twice forking at acute angles in the upper portion, leafy from the base, passing rather abruptly into a thick terminal spike which is $3-5^{\prime}$ long and simple or once or twice forked. Leaves crowded, in 6 ranks, flat, linear-lanceolate, $6-10^{\prime \prime} \times 1-1^{1} / 2^{\prime \prime}$, broadly sessile, acute, entire, stiff coriaceous, with faint rib, horizontally patent, reflected below, suberect above, passing gradually but quickly into the lanceolate bracts, which are not ampliate at the base, and from $3-4^{\prime \prime}$ in length at the base of the spike decrease to $1^{1 / 2}-1^{\prime \prime}$ at its apex. Sporangia several times shorter than their bracts, suborbicular, with a deep open sinus. - The spikes are $3-4^{\prime \prime}$ thick at the base and taper toward the apex.

On trees, not common. - Not known from elsewhere, but nearly allied to $L$. squar. rosum, Forst., a species common to Polynesia and Malaysia. In this latter there is hardly any difference in length between leaves and bracts, and the sterile divisions pass gradually into the fertile ones, which are also much longer and more divided than in our species. Besides, in $L$, nutans the leaves are larger and stiffer.

6. L. pachystachyon, Spring, Monogr. Lycop. I, 66. - Stem stiff, erect or pendulous, $1-2 \mathrm{ft}$. long, $2-3$ " thick, once to three times forking at open angles, leafy throughout, the fruiting portion in terminal spikes. Leaves in $6-4$ ranks, lanceolate, $6-12^{\prime \prime} \times 2^{1 / 2}-3^{\prime \prime}$, very acute, entire, contracted at the base but not petiolate, stiff coriaceous, with prominent rib, horizontally patent, suberect above, decurrent with two marginal lines. Spikes $1-1^{1} / 2^{\prime \prime}$ thick, $2-10^{4}$ long, twice to four times forking. Bracts broadly ovate, pointed, subcarinate, $1-1 / 2^{\prime \prime}$, as long as the sporangia or longer. Sporangia subglobose, with a deep and close sinus. Spores pale yellow. - Gaud. Bot. Bon. tab. 34. - Brack. 1. c. p. 326. - Mann, Enum. no. 654 .

$\beta$ var. phyllanthum. - Stem weaker. Bracts longer than the spore-cases, ovate-lanceolate, acute, the upper and sometimes also the middle ones becoming foliaceous and sterile. - L. phyllanthum, Hook. \& Arn. Bot. Beech. p. 102. - Spring, 1. c. I, 73.

On trees, rather common. The species is only known from the Hawailun Islds., but stands near the widely spread $L$. phlegmaria, L. 
7. L. phlegmaria, L. - Spring, 7. c. I, 63, II, 28. - Var. Mannii. Stem slender, flexuose, less than $1^{\prime \prime}$ thick, reddish. . Leaves distant, 3 -ranked in the last branches, elliptical, $4-6^{\prime \prime} \times 1^{1 / 2}{ }^{\prime \prime}$, contracting at the base but sessile, rather obtuse, entire, thin. Spikes filiform, 5-6' long, ${ }^{1 / 2} 2^{\prime \prime}$ in thickness, about 4 times forking, the bracts in 4,3 , or 2 ranks, smaller, distant and empty in the lower divisions, ovate, acute and faintly carinate, little longer than the capsules. - L. phlegmaria? Mann, Enum. no. 656 (in herb. Cornell Univ.).

On the mountain above Maalaea bay, Maui. Only collected by Mann. One of the most slender forms of the species. Leaves and bracts differ somewhat from the type, the former not being ovate and the latter being pointed as in $L$. pachystachyon and exceeding slightly the capsules. The leaves are also thinner and more distant than in typical L. phlegmaria.

8. L. cernuum, L. - Spring, l. c. I, 79, II, 3\%. - Stem erect, stiff, terete, $2-5 \mathrm{ft}$. high, excurrent to the apex, with numerous spreading flexuose repeatedly forking branches, each branchlet at last terminating in a sessile cylindrical mostly nodding spike of $3-10^{\mu}$ in length. Leaves subulate, $1-2^{\prime \prime}$ long, those of the stem irregular in 8 ranks, rather distant, decurrent with 2 lateral lines, erect and appressed in the lower portion, those of the branches crowded, patent, incurved or uncinate. Bracts in 8 ranks, appressed, ovate, 1" long, contracting below, denticulate, cuspidate, much longer than the capsules; these minute, globular, without a basal incisure. Spores smooth. - L. curvatum, Gaud. in Bot. Freye.

Common in open glades and on the outskirts of forests, forming dense thickets in the manner of Gleichenia dichotoma - the * Wawae iole" (rats foot) of the natives. The species is widely spread over the tropical countries of nearly the whole globe. It occurs on the Islands, as elsewhere, under two forms: crassifolium, leaves thick and stiff ( $L$. curvatum, B1.), and capillaceum, leaves slender, filiform (L. capillaceum, Willd.),

9. L. venustulum, Gaud. Bot. Voy. Freyc. p. 285, tab. 22. - Stem trailing and sparsely rooting, $1^{1 / 2}-2^{\prime \prime}$ thick, several feet in length, the ascending divisions $4-8^{\prime}$ high, repeatedly forking into branches of the same shape and size as the stem, one or several of the leading divisions running out into an exserted distantly foliose spike-bearing peduncle of $1-4^{\prime}$ ' in length. Leaves of stem and branches subulate, acerose, $2-3^{\prime \prime}$ long, the former distant and irregular in $9-7$ ranks, straight, appressed, the latter crowded, patent, strongly incurved, mostly ending in a soft whitish soon evanescent hair. Leaves of the peduncles few, in irregular whorls, straight, appressed, $6-3^{\prime \prime}$ long including the hair-like point. Spikes $3-6$ on a peduncle, dichotomously or racemosely arranged, $1^{1 / 2}-2^{\prime}$ long, rather thick. Bracts ovate or ovate-lanceolate, patent or recurved, with ciliate or jagged margins, terminating in a hair-like appendage, thin and pale, darker in the middle. Sporangia less than half the length of the bracts, stipitate, roundish, cordate. Spores pale yellow, reticulate, muricate. 
- spring, 1. c. I, 84. - Brack. 1. c. p. 329. - L. heterophyllum, Hook. \& Grev. Ic. Fil. tab. 113. - L. fastigiatum, Spring, 1. c. II, 41, as to the Hawaiian plant.

$\beta$ var. herpeticum. - Stem far trailing. Branches distant, shorter and sparingly divided, but each with $3-5$ peduncles which are long-exserted $\left(4-5^{\prime}\right)$ and bear $4-7$ spikes each. Cauline and branch-leaves also ending in short hairs, those of the peduncular leaves very long.

Rare. Eastern slope of Kaala, Oahu! the palis of Waikolu and Pelekunu, Moloka i! Mauna Loa, Hawaii! Kauai! the variety on Haleakala and the top of Eeka, Maui! Differs from the widely spread $L$. clavatum, L., in the rigid and subulate incurved leaves, The whitish filiform point, so characteristic in all the leaves of the latter species, is seen here in the bracts, peduncular and youngest rameal leaves; the older rameal leaves throw it off; but in the variety it remains. The stem of the high-mountain form $\beta$ trails as far as the European plant, which it also resembles in the reduced fastigiate branches,

10. L. volubile, Forst. - Spring, l. c. I, 105, II, 49. - Stem slender, long-trailing, even twining, its branches 8-10' long, distichous (branches and branchlets lying in one plane), subexcurrent. Leaves pale, those of the stem and fertile branches or peduncles of one kind, small, subulate, appressed, distant; the branch-leaves in 5 ranks of two kinds: the two lateral ones distichous, larger, $1^{1 / 2} "$, oblong-falcate, uneven-sided, patent, decurrent from a sessile base, acute, entire; the intermediate ones small, appressed, two anterior subulate, one posterior, minute, mucroniform. Spikes numerous on repeatedly forking subpaniculate often recurved branches, slender, terete, ${ }^{1 / 2}-2^{\prime}$ long. Bracts ovate, mucronate, serrulate, ${ }^{1 / 2} "$ long. - Hook. \& Grev. Ic. Fil. tab. 170. - Hook. Fl. N. Zeal. I, 391. - Carruth. in Fl. Vit. p. 329. - Benth. Fl. Austral. VII, 677 .

Hawaii. Collected only by Menzies, probably on Mauna Loa. The species inhabits also the Society and Viti Islands. New Zealand, Australia and Java.

\section{PSILOTUM, Sw.}

Spore-cases of one kind only - microsporangia -, sessile on minute bifid leaflets, 3 -lobed, 3 -celled, opening loculicidally with 3 valves, containing a yellowish powder of minute spores which are marked with a single line. - Stems angular, dichotomous, with few minute distant scale-like leaves, the sterile ones simple, subulate. No roots proper.

A smail tropical and subtropical genus, common to the New and the Old World. Stems triangular below and in the fertile branches Branches all flattened

1. P. triquetrum.

2. P, complanatum,

1. P. triquetrum, Sw. Syn. Fil. p. 18\% - Rhizome short, thick and intricately branched. Stems $3-12$ high, repeatedly forking, triangular below and in the fertile branches, the barren ones often flattened. Leaves minute, subulate, the fertile ones bifid. Capsules globular, about $1^{\text {" in }}$ diameter. - Hook. Gen. Fil. tab. 84. - Bot. Beech. p. 102. - P. dicho 
tomum, Lk. - Bernhardia dichotoma, Willd. - Spring, Monogr. Lycop. II, 269.

Common on the ground and on trees, from the plains up to 3000 or $4000 \mathrm{ft}$., the (Pipis of the natives, with whom the yellowish spore-powder is a favorite remedy against diarrhoea in children, also as an external application in intertrigo. On grassy plains the plant grows low and tufted, only $3-4$ high, with thick and stiff branches, while the epidendrous forms have elongate slender branches (var. gracile of authors). The species inhabits most tropical countries.

2. P. complanatum, Sw. l. c. pp. 188 \& 414, tab. 4. - Stems 6-12' long, repeatedly dichotomous, the branches all flattened, linear, $1-2^{\prime \prime}$ broad, mostly falcate, obtuse, deeply notched at the margins. Leaves at the notches, distant, minute, obtuse, inflexed, the fertile ones bifid. Bot. Beech. p. 102. - Spring, 1. c. p. 271. - Bernhardia complanata, Willd.

On trees, much less frequent. - Found also in tropical America, the Society and Philippine Islds.

\section{SELAGINELLA, Spring.}

Spore-cases 1-celled, of two kinds, the microsporangia opening with 2 valves, the macrosporangia with $2-4$; the latter either intermixed with the microsporangia and then scarcely larger, or solitary or few at the base of spikes and then larger. Microspores reddish or orange, tetraedrous with 3 radiating lines; macrospores 4 or 3 in a case, white, globular. Prostrate-erect plants with angular stems; the sterile leaves either all alike and equally distributed round the stem, or dimorphous in 4 ranks, two of them lateral with larger uneven-sided patent leaves, two anterior small appressed. Spikes quadrangular. - The male microspore produces a rudimentary prothallium consisting of a single cell and a single antheridium; the larger prothallium of the female macrospore bears several archegonia. Both kinds of prothallium derelop while enclosed within the spore.

In all our species the stem is goniotropous (its 4 planes oblique, the anterior angle facing the observer), and the leaves are cathedrous (affixed to the planes),

A large genus, spread over all tropical and most subtropieal regions, which also sends a few outrunners into the colder zones.

Sterile leaves all alike, homomorphous

1. S. deflexa.

Sterile leaves of 2 kinds, dimorphous:

Stem- and branch-leaves nearly equal in size; plant small, tufted, moss-like

Stem-leaves larger than those of the branches; plants erect:

Lateral branch-leaves imbricate; spikes long

Lateral branch-leaves not imbricate:

Frond dark-green, obtuse, the stem losing itself before the end, the branches dichotomous, sinuose; intermediate or anterior leaves at last in 2 ranks

Frond pale, lanceolate, narrow at the base, pinnate, as are the branches; anterior leaves at last in 1 row . . 5. S. Springii.

The $S$. lepidophylla found by Lnerssen among Wawra's plants (Flora, 1875, p. 440) was not of Hawaiian origin. 
1. S. deflexa, Brack. Fil. U. S. E. E. p. 332, tab. 45. - Stems slender, dividing near the base into several erect branches, $4-7^{\prime}$ high, leafy throughout. Leaves all of one kind in opposite decussate pairs, forming 4 ranks; the sterile ones green, patent or reflected, ovate-lanceolate, $1-1^{1 / 2} "$, long - and sharply acuminate, serrate in the broader portion; the upper fertile ones paler, straw-colored, patent-erect, larger, $1^{1 / 2}-2^{1} / 2^{\prime \prime}$, broad deltoid or orbieular, suddenly narrowing to a long point, spinososerrate. Macrosporangia numerous and large, opening with 3 or 4 valves, their globules white, papillate. Microsporangia broadly transverse, subreniform, 2-valved; their spores muricate.

In the turfy swamps on the top of Mt. Eeka, Maui! of Waialeale and the high plateau of Kauai; on trees of Konahuanui, Oahu, and of the pali of Wailau, Molo$\mathrm{kai}$ ! The species, peculiar to our group, differs from the alpine $S$. spinosa of Europe and $\mathrm{N}$. America only in the smaller, reflexed, sterile leaves. My speeimens offer two forms. One is subspicate, in which the erect fertile leaves are crowded at the apex; these mostly hold microsporangia with only a few macrosporangia at the base. In the other form the fertile leaves, chiefly with macrosporangia, occupy loosely the upper half and more of the upright stem and branches.

2. S. parvula, $s p . n$. - Stems filiform, trigonous, the posterior face with a median line; the sterile branches regularly dichotomous and entangled, forming a densely matted moss-like tuft; the fertile branches or stems erect, $1-2^{\prime}$ high, dividing from near the base, but excurrent to the apex. Cauline and branch-leaves alike in shape, but the former smaller; the lateral leaves all horizontally patent and distant, most so in the sterile branches, broadly and obliquely obovate or oblong, $1 / 3-2^{2}, 3^{\prime \prime}$, obtuse, quite entire on both margins, with a rounded base, conchoid. Intermediate leaves ${ }^{1 / 3}-1 / 4$ as large, scarcely projecting beyond the rhachis, almost in one row, ovate or obovate, obliquely mucronate, rounded at the base, entire, or faintly dentieulate on the onter margin. Spikes 2-4" long, scarcely narrower than the branches, the bracts rather patent, ovate, acute, keeled, entire or faintly denticulate. Macrosporangia numerous, with 3 or 4 white and smooth globules in each; the microsporangia few, confined to the apex of the spikelet; spores reddish, smooth.

Found in the seeond lateral valley of Nuuanu, Oahu! by my son. - Small as those of the pusillae group. Distinet as it appears from all other Hawaiian species, I have long been in doubt if it be not a young state of $s$. arbuscula, which grew in close proximity to it. The uniformly obtuse and entire leaves, together with the presence of well developed, though short, spikes have seemed to me safe grounds for separating it.

3. S. arbuscula, Spring, Monogr. Lycop. II, 183. - Stems erect from a rooting base, $3-8^{\prime}$ high, copiously branching from the middle upward in a dense pyramidal frond of a dark and dull green, often broad above by shortening of the axis, the branches erect, with stiff appressed branchlets. Stem-leaves close, more or less dimorphous, the posterior ones ovate, conchoid, about $1^{\prime \prime}$ long. Lateral branch-leaves erecto-patent, 
closely imbricate, ovate or ovate-oblong, $1 / 2-3 / 4^{\prime \prime}$, subcordate, shortly and obliquely acuminate, serrato-dentate on the upper margin, deepest near the base, entire below or denticulate near the apex. Intermediate leaves $1 / 2$ or $1 / 3$ as long, ovate to obovate, erect and appressed in 2 parallel ranks, keeled and mucronate, denticulate on both edges. Spikes very numerous, one to each branchlet, sharply tetragonous, slender and long, 6-20", often curved. Bracts closely imbricate, keeled and mucronate, minutely denticulate. Macrosporangia little larger than the microsporangia, 2-valved, each with 3 or 4 smooth globules. Microsporangia confined to the apex, the spores smooth, reddish. - Brack. l, c. p. 332. - Lycopodium arbuscula, Kaulf, Enum. Fil. p. 19. - Bot. Beech. p. 102. - L. pennigerum, Gaud. Bot. Freyc. p. 288.

Oahu! in damp gulches of Nuranu and Kahana (smaller forms); Haw ail! (Kilauea) and Kauai! (larger forms). - Reported also from the islands Bolabola, Ualan and Vanikoro (according to Spring).

4. S. Menziesii, Spring, 1. c. II, 185. - Stem rooting below, the erect portion $8-16^{\prime}$ high, flabellately dividing in the young plant with stem-and branch-leaves equal; the older plants with a nearly excurrent axis, but generally broad at the top and the branches flexuose, dichotomous. Stem-leaves not close; the larger ones covering the back, erect, ovate, subcordate, shortly acuminate, 2 "long, denticulate or serrate on the upper or inner margin, ciliate at the base; the smaller ones about ${ }^{1 / 2}$ as large, ovate, mucronate, denticulate on both sides. Lateral branchleaves horizontally patent, oblong to falcate, close but not imbricate, gradually decreasing to $11 / 2^{\prime \prime}$ and less; the intermediate ones $1 / 3-1 / 4$ of their size, ovate-lanceolate, carinate and mucronate, in 2 ranks. Spikes on the peripheric branchlets only, 4-6" long, thickest at the base, the bracts keeled and long-acuminate, denticulate, the lowest rather patent. Macrosporangia few, with $1-3$ globules; microsporangia rather large. Lycopodium Menziesii, Hook. \& Grev. Enum. Fil. no. 131. - Bot, Beech. p. 102. - L. arbuscula, Hook. \& Grev. Ic. Fil. tab. 200 (not Kaulf.). L. flabellatum, Forst. (not L.).

All islands, in the middle forest region. - Occurs also on Tahiti, the Viti Islds. and Aneitum. The transition in size and shape of leaves from stem to branchlets is less abrupt than in any other speeies. The serrature of the upper edge of the lateral leaves varies in depth, but is always deepest near the base, which is much broader than that of the lower half.

5. S. Springii, Gaud. Bot. Voy. Bon. tab. 12. - Stem erect, rooting below, compressed, whitish, 1-2 ft. long or more, pinnately dividing (even in the young plant) in an oblong, lanceolate, open frond which is quite flaccid, pale underneath and lustreless, the rhachis excurrent to the caudate apex, the branches suberect, long-acuminate or caudate with appressed short branchlets, the lowest branches generally shortest. Leaves 
distant, with intervals of nearly their own width, and shorter, more obtuse than in S. Menz. and less patent; the posterior stem-leaves $2-2^{1 / 2} 2^{\prime \prime}$ long broad-ovate, subcordate, obtuse, spinuloso-serrate and ciliate on the inner margin; the anterior ones little shorter, obliquely mucronate, dentate on both sides. Lateral branch-leaves nearly even-sided, decreasing visibly, the ultimate ones only ${ }^{3} / 4^{\prime}$ long and twisted when dry; the intermediate leaves $1 / 3-1 / 2$ of their size, suborbicular, obliquely mucronate, at last in a single file. Spikes on most branchlets, $4-10^{\prime \prime}$ long, the bracts ovate-lanceolate, acute, serrulate, patent, those of the apex often sterile and foliaceous. Macrosporangia few, with a single white verruculose globule; the spores of the microsporangia reddish. - Spring, 1. c. II, 184 .

Molokai! pali of Kalaupapa and Wailau; W. Maui! Waihee and Kaanapali; Hawail! (Gaud, Douglas, Carmichael). - Typieal forms distinct enough from those of S. Menziesii, but they are conneeted by many intermediate ones which it would be difficult to define properly as varieties. In fact there exists a gradual transition between S. arbuscula, Menziesii and Springii.

\section{ORdER XCIX. RHIZOCARPEAE.}

Sporangia of two kinds, united in one conceptacle or spore fruit, or in separate conceptacles. Macrosporangia with a single mamillate macrospore producing a small green prothallium with female archegonia which remains connected with the spore. Microsporangia with 64 minute microspores, which produce a rudimentary prothallium consisting of one cell and one antheridium. - Plants floating on the water or rooting in mud. Leaves with or without a blade, in the latter case filiform.

\section{MARSILIA, L.}

Conceptacles on simple or forking pedicels which rise from near the base of the petiole, opening with two valves. Macrosporangia and microsporangia consociated in oblong or linear sori on transverse veins proceeding from the upper side or midrib of the conceptacle, two sets of sori in a conceptacle, surrounded by a gelatinous indusium; the conceptacle thus apparently multilocular. - Leaves distichous, petiolate, circinnate in the bud, the blade with 4 cuneate ribless leaflets and forking veins, resembling the leaf of a clover or oxalis. Rhizome ereeping.

A genus of $40-50$ species, distributed over the warmer regions of the whole world. Leaflets entire; conceptacle single, woolly .

Leaflets emarginate: conceptacles several, pubescent

1. M. villosa.

2. M. crenulata.

1. M. villosa, Kaulf. - A. Braun, in Monatsber. k. Akad. Wiss. Berl. 1870, p. 653 , - Rhizome villous with reddish hairs. Leaflets broad, entire; the petiole $4-6$ ' long. Only one conceptacle from the base of the leafstalk on a peduncle shorter than its own length, both villous 
with spreading hairs and hidden in the wool of the rhizome; the conceptacle compressed, convex on one side, with lateral veins free (not anastomosing) and with two closely approximate teeth near the attachment of the peduncle, the upper tooth longer, sometimes uncinate. Sori 7 on each side. - M. quadrifolia, Kaulf. Enum. Fil. p. 271.

Old "taro"-patches in Nuuanu and elsewhere. Collected by Chanisso, Gaudichaud, Remy and Mann. - Its nearest relative according to A. Braun is the M. vestita, Hook. and Grev., from Oregon and California.

2. M. crenulata, Desv. Prod. Fil. - Leaflets emarginate, many times shorter than their petioles. Conceptacles several from near the base of the leafstalk, the peduncles free and $1^{1 / 2}-2$ times as long as the fruit, which is pubescent with appressed hairlets, not ribbed; the forked lateral veins free and the upper tooth longer than the lower. - A. Braun, l. c. and in Kuhn, Fil. Afric. - Baker, Fl. Maur. p. 525. - M. crenata, Presl, in Rel. Haenk. p. 84, tab. 4. - M. minuta, Blanco.

Oahu (in herb. Godet). - Occurs also in the Loochoo islands, Luzon, Mauritius and Bourbon, and stands next to the African M. ditfusa, Lepr. 


\section{GENERAL INDEX.}

\section{Aalii, 88.}

Abacá, 434.

Abroma augusta, 52.

Abrus, L., 98 , precatorins, L., 98.

Abutilon, Gaertn., 45. incanum, Don, 46 . Indieum, Dom, 46. Menziesii, Seem., 46. periplocifolium, 46 . venosum. 46.

Acacia, Willd., 112.

Arabiea, 114.

Catechn, 114.

cornigera, 114.

dealbata, 114.

Farnesiana, Willd., 113.

glauca, Willd., 114.

heterophylla, Hook. \& Am., 113.

Kataiensis, Hbd., 113.

Koa, Gray, 112.

Koaia, Hbd., 113.

leucocephala, Lk., 114.

longifolia, 114.

lophantha, 114.

mollissima, 114.

pennats, 114.

Acaens, L., 118. exigna, Gray, 118.

Aealypha Indiea, 393.

Aesnthospermum, Schr. 203.

Bravilum, Schr., 203.

hirqutum, $\mathrm{DC}_{\mathrm{r}}, 203$.

zenthoides, DC., 203.

Aebras Sapota, L., 275.

Achyrantluns, L. 370.

aspers, L., 370 .

bfdentata, $.5 l$. 371.

matica, Gray, 371.

spleadens, Mrrt., 371.

Aconsopteris, Presl. 548. obtura, Fée, 550.

\section{(Synonyms in italics.)}

Acotyledonous

Plants, 539.

Acronychia, 61.

Acrostichum, L., 548.

cemulum, Kaulf., 549.

eonforme, $8 w_{v,} 549$.

crassifolium, Gand., 550. gorgoneum, Kaulf., 550. micradeninm, Fle, 548. pellucidum, Gavd., 548. reticulatam, Koulf., 550. splendens, Bory, 549. squamosum, $S w, 549$. Wawrae, Luer88., 549.

Adenanthera pavonina, 115.

Adenolepis, 211. pulchella, Less., 212.

Adenophori, 554.

Adenophorus bipiunatus, Gaud., 556 .

hymenophylloides, Hook. \& Grev., 556.

minutus, Gaud., 556. pinnatifidus, Gaud., 555. tamariscinus, Hook.\& Grev., 556 .

tripinndifidus, Gand., 556.

Adenostemma, Forst., 192. viseosnm, Forst, 192.

Adiantum, L., 633. Bennettii, Carruth., 634. capillng Veneris, L., 634 .

Leae, 309.

Aechmea fulgens, 435.

Aerva, Forsk. 374. sericen, Maq., 374.

Aeschynomene coccinea, Forst., 95.

AgalmaKauaiense, Seem.,151.

Agapanthns nmbellata8, 439.

Agatea, Gray, 15.

Agati coecinea, Desv., 95. grandiflora, Desv, 95. tomentosa, Nutt., 95.
Agave Americana, L., 436.

Ageratum, L., 192.

eonyzoides, L., 198.

Agrostideae, 515.

Agrostis, L., 515.

aemula, R. Br., 519.

fallax, Hbd., 516.

flliformis, Spr., 519 .

Forsteri, R. \& S., 519.

Kanaiensis, $T_{h d .,} 516$.

littoralis, With., 518 .

radiata, L., 524.

retrofracta, Willd, 519.

Sandwieensis, $H b d$., 515.

Virginica, L., 517.

Ahakea, 173.

Ahia, 128.

Ahinahina, 219.

Ahnha, 94.

Aiea, 307.

Ainakea, 512.

Mir-plant, 122.

Akaakaswa, 142.

Akaakai, 475.

Akala, 116.

Akea, 385.

Akia, 385.

Akilolo, 512.

Akiobala, 47.

Akoko, 396.

Akole, 564.

Akolea, 562, 567.

Akn, 262.

Ataalawainui, 418.

Alani, 61.

Albizzia Lebbek, 114.

procera, 114.

stipulats, 114.

A16. 363.

Alenrites, Forst., 399 ,

Moluceana, Willd. 400.

triloba, Forst., 400.

Algaroba, 115. 
Aliipoe, 435.

Alismaceae, 429, 456 .

Allamanda cathartiea, L., 294. Allantodia Scandicina, Kaulf., 618.

Alligator Pear, 382.

Allium Cepa, 439.

Allosorus, Presl, 633. ternifolius, Kze., 633.

Almond tree, 119.

Alocasia, Schott, 456. macrorrhiza, Schott, 456.

Aloe, 439.

Alpinia Galanga, Sw., 433. nutans, Rosc., 433.

Alphitonia, Reiss., 81. excelsa, Mann, 82. franguloides, Gray, 82. ponderosa, $\mathrm{Hbd}$., 81. zizyphoides, Gray, 82.

Alsinidendron, Mann, 36. trinerve, Mann, 37.

Alsodeia, Thouar $8,15$.

Alstonia scholaris, R. Br., 294

Alyxia, $R . B r ., 298$. olivaeformis, Gaud, 298. Bulcata, Hook. \& Aru., 299. Amaman, 581.

Amarantaceae, 4, 370.

Amarantrs Blitum, Waw,, 375. lineatus, R. Br., 375. melancholicus, 370. panieulatns, 370.

Amaryllidaceae, 436. Amomum Curcuma, Jacq., 435 . Amphoradenium Australe, Desv., 556.

Gaudichaudii, Desv., ธ็์6. minutum, Desv., 556.

Amygdalas Persica, 119.

Anacardiaceae, 2, 89.

Anacardium occidentale, 89.

Ananassa sativa, Lindl., 495.

Anapanapa, 80.

Andropogon, $L$, 508. aciculatus, Retz., 510. annulatus, Forsk., 508, Byronis, Stend., 509. contortus, L., 508. saceharatus, anet., 511. vulgaris, anct., 511.

Anethum graveotens, L., 145. Anisophyllum, 394. nodosum, K1. \& Gar., 394. Anoda ovata, Meyen, 44. Anoectochilus, $B l$. 430 . Jauberti, Gaud., 431. Sandwicensis, Lindl., 431.
Anona Cherimolia, Mill., 8. muricata, L., 8. Squamosa, L., 8.

Anonaceae, 8.

Anounou, 10.

Anthemideae, 229.

Antidesma, L., 402. platyphyllum, Mann, 402. pulvinatum, Hbd., 403.

Antigonon leptopus, Hook. \& Arn., 377.

Anuna, 135.

Apé, 124, 456.

Aphanopappus, Endl., 210.

Apii, 456.

Apionema obovatum, Nutt., 179.

pendulifiorum, Nutt., 179. sulcatum, Nutt., 179.

Apiri, 88.

Apocynaceae, 4, 293.

Apple tree, 119.

Apricot tree, 119.

Araceae, 429, 454.

Arachis hypogaea, L., 96. Aralia trigyna, Gand., 148. Araliaceae, 3, 146.

Ardisia, 282.

Argemone, L., 9. Mexicana, $L, 9$.

Argyreia, Lour, 312. argentea, Chois., 312. speciosa, Sw., 312. tiliaefolia, Wight, 312.

Argyrophyton Douglasii, Hook., 219.

Argyroxiphium, DC., 218. macrocephalum, Gray, 219. Sandwicense, DC., 218, virescens, $H b d ., 219$.

Arnot to tree, 19.

Arrowroot plant, 438.

Artemisia, L., 230. australis, Less., 230. australis, var. mierocephala, Gray, 230.

Eschschollziana, Bess., 230. microcephala, Hbd., 230.

Arthrobotrys, Presl, 574.

Arthrodactylis spinosa, Forst., 453.

Artocarpeae, 404.

Artocarpus, L., 407. incisa, L. f., 407. integrifolia, 408.

Arum Colocasia, L., 455. esculentum, L. \& Forst., 455.
Arum.

macrorrhizum, Forst., 450. macrorrhizum maximum, Herm., 456.

mucronatum, Lam., 456.

Arundinella, Raddi, 514. agrostioides, Trin., 514.

Arundo, L., 536. Donax, L., 536.

Asclepiadaceae, 4, 299.

Asclepias, L., 300.

Curassaviea, L., 300.

Asparagus officinalis, 439.

Aspidistra Japonica, 439.

Aspidium, Sw., 567 .

aculeatum, $S w$, var. Brannii, Doell., 568.

apiifolium, Schkr., 570.

aristatum, Sw., var. coniifolinm, Wall., 569.

Boydiae, Eaton, 572. caryotidenm, Wall., 569. coniifolium, Wall., 569. eyatheoides, Kaulf., 5̃71. falcatum, var. caryotideum, Baker, 570.

filix-mas, $S w$, var. parallelogrammum, Kze., 574. glabrum, Metten., 576. globuliferum, Mann, 573. Haleakalense, Mann, 568. Hawaiiense, Hbd., 575.

Hillebrandi, Carruth., 588. Hudsonianum, Mann, 572. latifrons, Brack., 578. resiniferum, Kanlf., 573. rubiginosum, Mann, 577. sinuatum, Gand., 570. squamigerum, Mann, 578. terminans, Wall., 572. truncatam, Gaud., 572. unitum, Sw, 573.

Asplenium, L., 584. acuminatum, Hook. \& Arn., 608.

Adiantam nigram, L., 606. affine, auct., 598 .

ambiguum, Hook. \& Arn.,611. Aneitense? Carruth, 603. arborescens, Hook., Manm, 611.

arboreum, Willd., 609 , Arnottii, Baker, 610. aspidioides, $S c h l$., 617. auriculatum, Metten., 610. auritum? Nad., 598. Baldwini, Hbd., 618. bipinnatum, $\mathrm{Hbd.,} 595$. brevisorum, Baker, 612. 
Aspleniam.

candatum, Forst., 602.

compressum, Ettingsh., 592. contiguum, Kaulf., 600. cuneatum, auct., 598. densum, Brack., 587. deparioides, Brack., 614. diplazioides, Hook. \& Arn., 611.

dissectnm, Brack., 605. enatum, Brack., 593. erectum, Bory, 589. faleatum? Mann, 598. Fenzlianum, Luerss., 613 , filiforme, Kanlf., 601. flaccidum, Forst,, 593. fragile, Presl, 589. fureatum, Thbg., 604. Gaudichaudii, Fée, 612. grammitoides, Hook., 614. horridum, Kaulf., 603. insititium, Brack., 588. insititium, Carruth, Metten., 604.

Japonicum, Baker, 613. Kanlfussii, Schl., 592. Kaulfugsii, Mann, 594. Knudsenii, Hbd., 601. Iaserpitiifolium, Hook, 609. lobulatum, Metten., 598. lucidum, auct., 592. lunulatum, \$w., 590. Lydgatei, Hod., 596. Macraei, Hook. \& Grev., 590. Mannii, $H b d ., 594$. marginale, Hbd., 613. meiotomnm, Hbd., 596. Menziesii, Hook. \& Grev., 588. monanthemum, L., 587. multijugum, Wall., 588. multisectum, Brack., 618. nidns, $L ., 587$. nitidnlum, $H b d$, , 601. normale, Don, 588. obtusatum, anet., 592. oligophyllum? Luerss., 593. parallelum, Baker, 596. patens, Kaulf., 608. patens, Hook. \& Aru., 590. patens, Gaud., 608. pavonicum, Brack., 588. persicifolium, Luers8_ 593. Poiretianum, Gand., 618. polyanthes, Lnerss., 611. polyphyllnm, Preal, 607. polyportioides, Hook., Mann, 611.

protensum, Kanlf., 592. psendofalestum, $\mathrm{Hbd}$., 597. resectum, Sm., 588 .
Asplenium.

rhizophyllum, Baker, 590. rhomboideum, Brack., 589. Sandwichense, Preal, 610. Sandwichiannm, Metten., 612. spathulinnm, Hook., 604. spathutinum, Hook., 598. sphenotomum, $\mathrm{Hbd}$., 599. strictum, Brack., 590. sylvaticum, Baker, 613. Trichomanes, L., 587. truncatum, Bl., 603. varians, Hook. \& Grev., 591.

Astelia, Banks of Sol., 443. Menziesiana, Sm., 444. veratroides, Gaud., 443. Waialeale, Waw., 444.

Aster, $L_{\text {. }} 195$.

divarieatus, Torr. \& Gray, var. Sandwicensis, Gray, 195.

subulatus, Less., 195.

tenerrimus. Less., 198.

Asteroideae, 193.

Athyrium, 586, 614.

Sandwichianum, Presl, 612.

Scandicinum, Presl, 618.

Atriplex Oahuensis, Meyen, 380.

Auhola, 94.

Aulu, 86, 276.

Aupaka, 18.

Aurantiaceae, 77.

Auti, 407.

Avena, L., 522.

fliformis, Forst., 519. sativa, $L$., 522.

Avenaceae, 519 .

Avocado, 382.

Awa, 417.

Awapnhi, 434.

Aweoweo, 380.

Awikiwiki, 103.

Awiwi, 166, 287.

Bamboo, 537, 5338.

Bambnsa, Schreb., 537. glaucifolia, Rupr., 538. vulgaris, Sehr. \&Wendl., 537.

Bambuseae, 587.

Banana, 433.

Banana, Brazil, 433.

Banana, Chinese, 433.

Barringtonia speciosa, 124.

Bastard Sandalwood, 339.

Basella, L., 380. rubra, L., 381.

Batatas acetosaejolia, Chois., 314.
Batatas.

edulis, Chois., 314.

pentaphylla, Chois., 314.

Batideae, 5, 381.

Batis, L.. 381.

maritima, L., 381.

Banhinia acuminata, 109. corymbosa, 109.

diphylla, 109.

tomentosa, 109.

variegata, 109.

Banmea, Gaud, 479. glomerata, Nees, 480. Meyenii, Kth., 479.

Beaumontia grandiflora, Wall., 294.

Begoniaceae, 3, 141.

Bernhardia complanata, Willd., 647.

dichotoma, Willd., 647.

Beta, 434.

Betel Pepper, 417.

Beythea bifida, Endl., 53.

Bidens, L., 216. angustifolia, Nutt., 214. chrysanthemoides, Michx., 217.

gracilis, Nntt., 215.

Hawaiiensis, Gray, 214.

helianthoides, H. B. K., 217.

hirsuta, Nntt., 217.

leucantha, Willd., 217.

mierantha, Gaud., 216.

mutica, Nutt., 215.

peduncularis, Gaud.? 217.

pilosa, L., 217.

Sandwicensis, Less., 214.

Sandwicensis, Gray, 215.

Sandwicensis, $\beta$, Gray, 216. Sandwicensis, var. ovati. folia, Gray, 215.

Bilbergia, 435.

Bin, 451.

Bixa, L., 19. Orellana, L., 19.

Bixaceae, 1, 19

Black Molberry, 406.

Black Mustard, 13.

Blackburnia, Forst., 77.

Blechnum Fontanesianum, Gand., 582.

Каulfussianum, Gand., 582. pallidum, Brack., 582. polystichoider, Brack., 583. Souleytianum, Gand, 581. squarrosum, Gaud., 583. 
Bobea, Gaud., 172.

brevipes, Gray, 173.

elatior, Gaud., 173.

Hookeri, $H b d ., 175$.

Mannii, Hbd., 173.

Sandwicensis, Hbd., 174.

timonioides, $H b d ., 174$.

Boehmeria, Jacq., 412. albida, Hook. \& Arn., 413. glabra, Stend, 416. melastomaefolia, Hook. \& Arn., 416.

mollis, Wedd., 414.

Moluccana, Bl., 414.

nivea, Hook. \& Arn., 413.

stipularis, Wedd., 412.

tenacissima. Boxb., 413.

Boerhaavia, L., 366.

diffusa, $L ., 366$.

hirsuta, Hook. \& Arn., 367. tetrandra, Forst., 367.

Bombaceae, 51

Bombax Ceiba, L., 51.

Bonamia, Thouars, 318.

Bonamia, Gray, 318.

Menziesii, Gray, 319.

Boraginaceae, 4, 320.

Boro, 304.

Bothriospermnm, Fisch. d Mey., 322.

tenellum, Fisch. \&Mey., 322.

Botrychinm, Sw., 641.

daucifolium, Hook., 641.

subbifolatinm, Brack., 641.

ternatum, var. Australasia. ticum, Milde, 641.

Bottle-gourd, 134.

Bougainvillea spectabilis, 366 .

Bonvardia, 157.

Brake, 631.

Brambles, 116.

Brassica, L, 12. nigra, Koch, 12.

Brazil Banana, 433.

Breadfruit tree, 408.

Breweria, R. Br., 318. Menziesii,Benth.d Hook.,318.

Brighamia, Gray, 235. insignis, Gray, 235.

Briza, L., 536. minor, $L ., 536$.

Bromeliaceae, 435.

Bromus, $L_{n}, 535$. sqnarrosus, L., 585. tectorum, L., 535 . unioloides, 536 .

Bronssaisia, Gaud., 120. arguta, Goud., 120. pellucida, Gaud., 121.
Broussonetia, Vent,, 406. papyrifera, Vent., 407.

Brunellia Sandwicensis, Gaud., 66.

Brunfelsia Americana, Sw., 303. Hopeana, Benth., 303.

Bryophyllum, Salisb., 121. calycinnm, Salisb., 122.

Buettneriaceae, 2, 52.

Bumelia, 27 .

Burneya Gaudichaudii, Ch. $\&$ Schl. . 173.

Byronia, Endl., 78. Sandwicensis, Endl., 78.

Cactaceae, 3, 140.

Cactus Tuna, L., 140.

Caesalpinia, L., 109.

Bonducella, Flem., 109.

coriaria, 110.

Gillesii, 110.

Kauaiensi., Mann, 111.

Mexicana, 110.

pulcherrima, 110.

Sappan, 110.

sepiaria, 110.

Caesalpinieae, 91, 109.

Cago, 435.

Cajanns, $D C ., 107$. bicolor, DC, 108. Indieus, Spr., 108.

Calabash, 134.

Caladium bicolor, Vent., 455. esculentum, Vent., 455 .

Calcyflorae, 2.

Calliandra haematoma, 115.

Callicarpa, 340.

Calodracon terminalis, Planch., 442.

Calonyction speciosum, var. vulgare, Chois., 315 .

Calophyllum, L., 40. Inophyllum, L., 40.

Calotropis gigantea, 299.

Camellia, 41.

Camphor tree, 382.

Camphora, 382.

Camphusia glabra, De Vriese, 269.

Campylotheca, 213.

Campylotbeca, Cass., 210. australis, Less., 216. cosmoides, $H b d ., 213$. dichotoma, Hbd., 212. grandiffora, $D C, 215$. Hawaiiensis, Hbd, 214. macrocarpa, $H b d ., 214$. Matiensis, Hbd., 213. Menziesii, $\mathrm{Hbd}, 216$.
Campylotheea.

micrantha, Cass, 216.

Molokaiensis, Hbd., 212.

pulehella, $\mathrm{Hb}$., 212.

Remyi, Hbd., 212.

Sandwicensis, $H b d$., 214.

Canavalia, Adans., 103. galeata, Gaud., 103.

Gaudichaudii, Endl., 103.

pubescens, Hook. \& Arn., 104

Candle-nut tree, 400.

Canna, L., 435.

glanea, L., 435.

Jndica, $L ., 435$.

Warszewiczii, Dietr., 435.

Canthium lucidum, Hook. \& Arn., 175.

odoratum, Seem., 175.

Cape Gooseberry, 310.

Capparidaceae, 1, 13.

Capparis, L., 14.

Sandwichiana, $D C$, 14.

Capsicum baceatum, L., 302. frutescens, L., 302.

Cardamine, L, 11. hirsuta, $L,, 12$. sarmentosa, Forst,, 12.

Cardiospermum, L., 84 . Halicacabum, $L_{1}, 85$. microcarpum, Kth., 85.

Carex, L., 485.

brunnea, Thbg., 488.

Commersonia, Kth., 488.

festiva, Dewey, 489.

gracilis, R. Br., 489

Meyenii, Nees, 488.

montis Eeka, Hod., 486.

nuptialis, Boot, 486.

Oahuensis, C. A. Meyer, 487.

Prescottiana, Boot, 488.

propinqua, Nees, 489.

Remyi, Beklr., 488.

Sandwicensis, Bcklr., 487.

Carica, L., 139.

Papaya, L., 139.

Cariceae, 460.

Carpopogon giganteum,

Roxb., 101.

Carrot, 146.

Carthamus tinctorins, 231.

Caryophyllaceae, 1,4 , 27.

Cashew nut, 89.

Cassia, L., 111.

alata, 112.

aurieulata, 112.

florida, 112.

Fistula, 112 
Cassia.

Gaudichandii, Hook. \& Arn., 111.

glauea, 112.

grandis, 112.

Javanica, 112.

laevigata, 112

marginata, 112.

mimosioides, 112.

nodosa, 112.

oecidentalis, L., 111.

Parahyba, 112.

viminea, 112.

Cassytha, L., 383.

filiformis, L., 383.

Castor-oil plant, 399.

Catharanthus roseus, G. Don, 294.

Cancalis, L., 146. daucoides, L., 146.

Ceanothus Asiaticus, L., 80. capsularis, Forst., 80.

Celastraceae, 2, 78.

Celastrinea,? Waw., 86.

Celosia eristata, 370 .

Celtideae, 404.

Celtis Amboinensis, Willd., 405 .

Cenchras, Beauv, 505. agrimonioides, Trin., 505. anomoplexis, Labill., 505. calyeulatus, Cav., 505. echinatus, L., 506. fusiformis, Nees, 505. Taitensis, Steud., 505.

Centanrea, L., 231. Melitensis, L., 231.

\section{Centrospermeae, 4.}

Centary plant, 436.

Ceodes umbellifera, Forst., 368.

Cerastium, L., 37.

triviale, Lk., 37.

viscosum, L., 38.

Cerbera Odollam, Gaertn., 294. parviflora, Hook. \& Arn., 295.

Cerens, 141.

triangularis, 141.

Cestrom aurantiacum, Lindl., 303.

diurnum, L., 303.

nocturnum, L., 303.

Chaetocalyces, 325.

Chaetothecae, 553.

Charpentiera, Gaud., 374. obovata, Guud, 375. ovata, Gaud., 374.

Cheilanthes, Baker, 632.

Cheirodendron, Nult., Seem., 147.
Cheirodendron.

Gaudichandii, Seem., 148. platyphyllum, Seem., 149.

\section{Chenopodiaceae, 5,} 378.

Chenopodinm, L, 379. album, $L ., 380$. ambrosioides, L., 380. hybridum, L., 380. murale, L., 380. Sandwicheum, Moq., 379.

Cherry tree, 119.

Chestnut, Tahitian, 109.

Chili Clover, 96.

Chinese Banana, 433. Guava, 128.

Plum, 130.

Chlorideae, 523.

Chloris, Sw., 523. radiata, Sw., 523.

Chomelia? Waw., 174.

Sandwicensis, Gray, 174.

Chrysodium, Fée, 548.

Chrysophyllum, L., 277. Polynesicum, Hbd., 277.

Chrysopogon, Trin., 510. aciculatus, Trin., 510.

Cibotium, Kaulf., 545. Chamissoi, Kaulf., 547. Chamissoi, Brack., 546. glancum, Hook. \& Arn, 547. Menziesii, Hook., 546. proliferum, Presl, 615. pruinatum, Metten. \& Kuhn, $5 \pm 6$.

Cichorieae, 233.

Cinehona succirabra, 157.

Cinnamomum Zeylanieum, 382.

Cinnamon tree, 382.

Citrus, L., 77.

Aurantiacnm, 77.

Deeumana, 77.

Japonica, 77.

Limetta, 77.

medica, 77 .

Citta nigricans, Lour., 101.

Cladium, P. Br., 478.

leptostachyum, Meyen, 478.

Mariscus, Kth., 479.

quadrangulare, Nees, 481.

Claoxylon, A. Jus8. , 398. Sandwicense, Müll. Arg., 398.

Cleome, L., 13.

Sandwicensis, Gray, 13. spinosa, Hook. \& Arn., 14.

Clermontia, Gaud., 239. arborescens, $\mathrm{Hbd}, 242$. coerulea, $\mathrm{Hbd}$., 248.
Clermontia.

Gaudiehaudii, Hbd., 243.

grandiflora, Gaud., 240.

grandiflora, var.brevifolia,

Gray, 240.

grandiflora, var.longifolia,

Gray, 240.

Kakeana, Meyen, 240.

macrocarpa, Gaud., 240.

macrophylla, Nutt., 240.

multiflora, Hbd., 242.

oblongifolia, Gaud., 241.

pallida, $H b d ., 241$.

parviflora, Gaud., 242.

parviftora, Waw., 241.

persicaefolia, Gaud., 241.

pyrnlaria, $\mathrm{Hbd}, 243$.

Clermontiae genninae, 239.

Clermontioideae, 240.

Clerodendron, $L_{*}, 342$.

fallax, Lindl., 343.

fragrans, Vent., 343.

inerme, $R, B r, 343$.

Siphonanthus, R. Br., 343.

Clitoria, L., 98.

Ternatea, L., 98.

Clover, Spanish, 96.

Clusia sessilis, Hook.\& Arn., 62.

Coceulus, $D C$., 7.

Ferrandianus, Gaud., 7.

integer, Hbd., 7.

lonchophyllus, $\mathrm{Hbd}$., 7.

virgatus, $\mathrm{Hbd}$., 8.

Cocklebur, 202.

Cockscomb, 370.

Cocoanut Palm, 452.

Cocos, L., 451. nucifera, $L ., 452$.

CodiaeumMoluccaneum, Desne., 393.

Coffea, L., 176.

Arabiea, L., 176.

Chamissouis, Hook. \& Arn., 179.

Kaduana, Ch. \& Sehl., 179.

Mariniana, Ch. \& Sehl., 179. odorata, Forst., 175.

Coffee tree, 176.

Coix lacryma, 512.

Colocasia, Schott, 455. antiquorum, var. esculenta, Sehott, 455.

esculenta, Schott, 455. macrorrhiza, Sehott, 456. odora, Brongn., 456.

Colubrina, L. C. Rich., 80. Asiatica, Brongn., 80. oppositifolia, Brongn., 80.

Colysis spectrum, J. Sm., 560 . 
Commelina, L., 446. agraria, Kth., 446. Cayennensis, Rich., 446. nudiflora, L., 446.

Pacifica, Vahl, 446.

Virginica, Forst., 446.

Commelinaceae, 428, 445.

Commersonia echinata, 52.

Combretaceae, 130.

Compositae, 3, 189.

Coniogramme Javanica, Fée, 551.

Connarus? Kauaiensis, Mann, 77.

Convolvulaceae, 4,311 .

Convolvuleae, 312.

Convolvulus acetosaefolius, Vahl, 314.

Batatas, L., 314.

Cairicus, Hook. \& Arn,, 315. ovalifolius, Hook.\& Arn, 318. pentaphyllus, L., 315. pes-caprae, L., 313. purpureus, Hook, \& Arn., 317. repens, Sw., 314. reptans, L., 314. tiliaefolius, Desv., 312.

Conyza albida, Willd., 196. chenopodioides, DC., 196. diversifolia, Weinm., 196. erigeroides, DC., 196. floribunda, H.B.K., 196.

Coprosma, Forst, 183. eymosa, Hbd., 186. emodioides, Gray, 185. foliosa, Gray, 186. longifolia, Gray, 188. Menziesii, $\alpha, \beta$, Gray, 185. Menziesii, $\gamma$, Gray, 185. Menziesii, Ү, Waw., 185. montana, $H b d ., 185$. pubens, Gray, 188. pubens, var. Kauaiensis, Gray, 187.

rhynehocarpa, Gray, 187. stephanoearpa, Hbd., 187. Waimeae, Waw., 186.

Cordia, Plum, 320.

Sebestena, Forst., 321. subeordata, Lam., 321.

Cordyline, Com., 442. Eschscholaiana, Mart., 442. terminalis, Kth, 442. $T i$, Sehott, 442.

Coreopsis cosmoides, Gray, 213.
Coreopsis.

Macraei, Gray, 215.

macrocarpa, Gray, 214.

Mauiensis, Gray, 213.

Menziesii, Gray, 216.

micrantha, Gray, 216.

Cosmos, Cav., 217.

candatus, H.B.K., 218.

Costus speciosus, Sm., 433.

Coulteria Mexicana, 110.

Cow-itch plant, 102.

Crape Myrtle, 132.

Crassulaceae, 2, 121.

Creole Cane, 512.

Crepis, L., 233.

Japonica, Benth., 233.

Cressa, L., 319.

Cretica, L., 319.

Cresseae, 312.

Crinum Asiatieum, 436.

australe, 436.

giganteum, 436.

Crotalaria, L., 91.

Assamica, Hook., 92.

longirostrata, Hook: \& Arn., 92.

Sericea, Retz., 92.

Crotoneae, 393.

Crotonocalyces, 324.

Cruciferae, 1, 9

Cryptocarya, R.Br., 382.

Mannii, Hbd., 382.

Cryptogams, Vascular, 539.

\section{Cryptogamous}

$$
\text { Plants, } 539 .
$$

Cryptostegia grandiflora, 299.

Cucumber, 134.

Cueumis Citrullus, 134.

Melo, 134.

sativus, 134.

Cucurbita, $L, 134$.

Lagenaria, L., 134.

maxima, Duch., 134.

Melopepo, 134.

ovifera, 134.

Pepo, 134.

Potiro, 134.

Cucurbitaceae, 3, 133.

Cumar, 314.

Cuphea, P.Br., 131. Balsamona, Ch. \& Schl., 132. hyssopifolia, H.B.K., 131. platycentra, 132.

Cureuma, L., 434. longa, L., 435.
Cuseuta, L., 319.

Sandwichiana, Chois., 319.

Cuscuteae, 312.

Custard-Apples, 8.

Cyanea, Gaud., 251.

acuminata, Hbd., 254.

angustifolia, $\mathrm{Hbd}$., 253.

arborea, Hbd., 261.

arborescens, Mann, 243.

aspera, Gray, Mann, 245.

asplenifolia, $H b d$., 260.

atra, $H b d ., 263$.

comata, Hbd., 256.

coriacea, Hbd., 254.

ferox, $H b d ., 259$.

fissa, Hbd., 255.

Gibsonii, Hbd., 263.

Grimesiana, Gaud., 257.

Grimesiana, var. citrullifolia, Gray, 258.

hirtella, Hbd., 255.

holophylla, Hbd., 257.

humilis, Waw., 255.

Kunthiana? Hbd., 264.

leptostegia, Gray, 261.

lobata, Mann, 257.

macrostegia, $\mathrm{Hbd..} 263$.

Mannii, Hbd., 253.

obtusa, Hbd., 254.

pilosa, Gray, 255.

platyphylla, $\mathrm{Hbd}$., 264.

procera, Hbd., 262.

recta, Hbd., 255.

seabra, Hbd., 256.

solenacea, $H b d ., 259$.

solenocalyx, $\mathrm{Hbd}$., 258.

superba, Gray, 260.

tritomantha, Gray, 26:2.

Cyaneae delisseoideae, 252.

genninae, 256.

palmaeformes, 260.

Cyatheae, 540.

Cyathodes, R.Br., 272.

Banksii, Gaud., 273.

Douglasii, Gray, 273.

imbrieata, Stschegleew, 273.

Macreana, DC., 273.

Tameiameise, Cham., 272.

Tameiameiae, var. Brownii, Gray, 273.

Cylindrocalyces, 325 .

Cynaroideae, 231.

Cynodon, Pers., 523.

dactylon, Pers., 523.

Cyperaceae, 429, 459 .

Cypereae, 460.

Cyperus, L., 461.

anriculatus, Nees, 465 . 
Cyperus.

brunneus, Hook. \& Arn., 463. caespitosus, Hook.\&Am.,463. canescens, Vahl, 464.

caricifolius, Hook. \& Arn., 464.

caricifolius, var, , Hbd., 464. cylindrostaehy/s, Bcklr., 470. decipiens, $\mathrm{Hbd}$., 467.

(Marisens) Hawaiiensis,

Mann, 470.

Hillebrandi, Beklr., 464.

hypoehloras, $\mathrm{Hbd}$, 468.

(Marisens) Kunthianus,

Gaud., 468.

laevigatus, L., 462.

Maniensis, Hbd, 469.

mucronatus, a, Rottb., 462.

multiceps, Hook. \& Arn., 462.

odoratus, Sol., 467.

paniculatus, Rottb., 463.

pennatus, Lam., 463.

(Mariscas) phleoides, Nees, 469.

polystachyns, Rottb., 462.

Preseottianus, Hook, \& Arn., 466.

rotundns, L., 468.

strigosus, L, , 467.

trachysanthus, Hook.\&Arn., 465.

(Mariseus) umbellatus, Vahl, 470.

viscosus, Mann, 465.

Cypholophus, Wedd, 414.

macrocephalus, Wedd., 414.

macrocephalus, var. mollis, Wedd., 414.

Cyrtandra, Forst., 324.

begoniaefolia, $\mathrm{Hbd}$.. 328.

biserrata, $\mathrm{Hbd}_{\text {. }} 329$.

cordifolia, Gand., 329.

Enalicheriana, Nees, 336.

filipes, $H b d$., 836.

Garnotiana, Gaud, 332.

gracilis, $H b d ., 333$.

grandiflora, Gaud., 335.

Grayana, $H b d ., 330$.

Hillebrandi, Oliv, 331.

Hillebrandi, Vatke, 334.

hirsuta, Hbd., 334.

Honolulensis, Waw, 334.

Kalihii, Waw., 384.

Kanaiensis, Waw., 332.

Kealiae, Waw., 326.

latebrosa, Hbd., 337.

laxiflora, Mann, 393.

Lessoniana, Gaud, 331.

Lydgatei, $\mathrm{HbQ}$, , 335.

lysiosepala, Hod., 330.
Cyrtandra.

Maeraei, Gray, 333.

macrocalyx, Hbd., 329.

Menziesii, Hook.d Arn., 335.

oenobarba, Mann, 338.

paludosa, Gaud., 336.

paludosa, var. degenerans,

Waw., 337.

paritiffolia, $H b d ., 328$.

peltata, Waw., 328.

Pickeringii, Gray, 327.

platyphylla, Gray, 328.

procera, Hbd., 329.

Ruckiana, Meyen, 336. -

triflora, Gaud., 332.

triflora, Waw., 330.

triftora, var. ly/siosepala, Gray, 330.

trístis, Hbd., 334.

Wawrae, IIba., 328.

Waiolanii, Waw., 334.

Cyrtomium, Presl, 569.

caryatideum, Presl, 570.

Cystopteris, Bernh., 580.

Douglasii, Hook., 580.

fragilis, Bernh., 580.

Sandwicensis, Brack., 580.

Cytisus Cajan, L., 108.

Daphne foetida, Forst., 3855.

Darea flaccida, Hook. \& Arn., 593.

Date Palm, 449.

Datura, L., 311.

(Brugmansia) arborea, $L, 311$.

Stramonium, L., 311.

Danens, Tourn., 145.

Carota, 146.

pusillus, Michx., 146.

Davallia hirta, Kanlf., 626 .

Jamaicensis, Hook., 626.

Khasyana, Hook., 625.

Macreana, Hook. \& Arn., 625.

Mannii, Eaton, 624.

remota, Kanlf., 627 .

repens, Desv., 625.

speluncae, Baker, 626.

strigosa, 8w., 625.

tenuifalia, Sw, 627.

Delissea, Gaud., 248. acnminata, Gaud, 254. acuminata, var. angusti. folia, Gray, 253.

ambigua, Pr., 246.

angustifolia, Presl, 253.

arborea, Mann, 261.

asplenifotia, Mann, 260.

calycina, Presl, Mann, 245.

clermontioides, Gand., 243.

coriacea, Gray, 254.

coriacea, $\beta$, Gray, 262.
Delissea.

fallax, Hbd., 251.

filigera, Waw., 240.

fissa, Mann, 255.

hirtella, Mann, 25 ต̃.

Homolulensis, Waw., 20 3.

Kealiae, Waw., 250.

Kunthiana, Gaud., 264.

laciniata, Hbd., 249.

lanceolata, Gray, 247.

Mannit, Brigham, 253.

obtusa, Gray, 254.

parviflora, Hbd., 251.

platyphylla, Gray, 284.

pilosa, Mann, 256.

racemosa, Mann, 246.

recta, Waw., 255.

reginae, Waw., 261.

rhytidosperma, Mann, 250.

sinuata, $\mathrm{Hbd}$., 250.

subcordata, Gaud, 249.

andulata, Gaud., 250.

undulata, Gray, 249.

Waihiue, Waw., 243.

Deparia Macraei, Hook. \& Grev., 615.

prolifera, Hook., 615.

Deschampsia, Beauv., 519.

anstralis, Nees, 520.

nubigena, $H b d$., 521.

pallens, $H_{b d}$, 520.

Desmodinm, $D C$., 96.

Sandwicense, E. Meyer, 96.

triflorum, DC., 97.

trigonum, DC., 97.

ancinatum, DC., 96.

Deyeuxia, Beauv., 518.

expansa, Munro, 519.

Forsteri, Kth., 518.

Hillebrandi, Yunro, 519.

Dhal, 108.

Dianella, Lam., 444.

odorata, Bl., 445 .

Sandwicensis, Hook. \& Arz., 445.

Dichrostachys cinerea, 115.

Dicksonia flaccida, Hook. \& Arn., 626.

glauea, J. Sm,, 548.

prolifera, Kanlf., 615.

repens, Bory, 625.

strigosa, Thbg., 625े.

Diclidium, 462.

\section{Dicotyledonous}

\section{Plants, 1.}

Didymoglosgum Draytonia. num, van d. Boseh, 635.

Diellia crecta. Brack., 621. falcala, Brack., 620. 
Diellia.

pumila, Brack., 620.

Digitaria, 495 .

eiliaris, Hook. \& Arn., 495. consanguinea, Gaud., 495.

filiformis, Muehl,, 496. pruriens, Bŭse, 495 .

Dill, 145.

Dioclea, H.B.K., 102. violacea, Mart., 102.

Dioscorea, L., 438. bulbifera, Wight, 439. pentaphylla, L., 439. sativa, $L_{.}, 438$.

\section{Dioscoreaceae, 428,438.}

Dipanax Mannii, Seem., 150.

Diplazinm, 586, 609.

arboreum, Presl, 610.

Arnottii, Brack., 611.

auriculatum, Kaulf., 610.

decussatum, Carruth., 613.

lobulatum, Meyen, 598.

Sandwichense, Presl, 610.

Disemma coecinea, 139.

Dissochondrus, Hbd., 503.

Dodonaea, L., 87.

Burmanniana, DC., 88.

eriocarpa, $\mathrm{Sm}$., 88.

spathulata, Sm., 88 ,

stenoptera, $\mathrm{Hbd}$., 88.

viseosa, $L$., 87.

Dolichos, L., 107.

altissimus, Velloz., 103.

galeatus, Gaud., 102.

giganteus, Willd., 102.

Lablab, L., 107.

luteus, Sw., 106.

luteolu\&, Forst., 106.

urens, L., 102.

Donax arundinaceus, Beanv., 536.

Doodya, R.Br., 584.

caudata, var. media, Benth. 584.

Kunthiana, Gand., 584. media, $R . B r ., 584$.

Doryopteris, 629.

decota, Brack., 630. pedata, Brack., 630 .

Dracaena, Vand., 442. aurea, Mann, 443. terminalis, Reich., 442.

Drann, $45 \overline{6}$.

Drosera, L., 122. longifolia, $L, 122$.

Droseraceae, 3, 122.

Drynaria elongata, Brack., ธ็9.

spectrum, Brack., 560.
Dubautia, Gaud., 221.

Knudsenii, Hbd., 223.

laevigata, Gray, 222.

laxa, Hook. \& Arn., 223.

paleata, Gray, 223.

plantaginea, Gaud., 222.

raillardioides, $H b d$., 224.

Dubreuilia peploides, Gaud., 412.

Duranta Plumieri, Jacq., 340.

Eai, 389.

Ebenaceae, 3, 274.

Echinocactus, 141.

Echinochloa, 496.

Eelipta, L., 203.

alba, Hassk., 203.

erecta, L., 203.

prostrata, L., 203.

Edwardsia chrysophylla, Salisb., 109.

Egg-Plant, 303.

Ehitoa, 129.

Ehnawa, 462.

Ekaha, 548, 587.

Ekaha akolea, 559.

Elaeocarpus, L., 53.

bifidus, Hook. \& Arn., 53.

Elaphoglossum aemulum, Brack., 549.

nitidum, Brack., อ4 49 .

reticulatum, Gand., 550.

squamosum, Brack., $5+9$.

Eleocharis, R.Br., 474.

obtusa, Sch., 474.

palustris, R.Br., 474 .

Elettaria speciosa, $B l ., 433$. coceinea, Bl., 433.

Eleusine, Gaertn., 524.

Indiea, Gaertn., 524.

Embelia, Burm., 281.

Pacifica, Hbd., 282.

Emoloa, 529.

Enaena, 201.

Endogenous Plants, 428.

Enuhe, 543.

Epacridaceae, 3, 272.

Eragrostis, Beauv., 527.

atropioides, Hbd., 531.

coerulescens Hbd., 531.

equitans, Trin., 529.

faleata, Gaud, 532.

grandis, $\mathrm{Hbd}$, 528.

Hawaiiensis, Hbd., 530.

Mexicana, $L k$, 530.

monticola, Hbd., 531 .

nana, Munro, 533.
Eragrostis.

phleoides, Hbd., 530.

plumosa, $L k$, 533.

poaeoides, Beauv., 532.

thyrsoidea, Hbd., 529.

unioloides, Nees, 532.

variabilis, Gaud., 528.

Wahowensis, Trin., 529.

Erigeron, L., 196.

albidus, Gray, 196.

Canadensis, L., 196.

lepidotus, Less., 199.

multiflorus, Hook. \& Arn., 195.

pauciflorus, Hook. \& Arn., 199.

solidaginoides, Sehl., 196.

Eriobotrya Japonica, 119.

Erodinm, L'Herit., 57. cicntarinm, L'Herit., 57.

Erythraea, Pers., 287. sabaeoides, Gray, 287.

Erythrina, L., 99. monosperma, Gaud., 99.

Tahitensis, Nad., 99.

Euarthronia foliosa, Nutt., 186.

Enasplenium, 585, 587.

Encalyptus globulus, 124.

Eucladus suffruticosus, Nutt., 31.

Encyperus, 461.

Eueclypta, DC., 203.

Eugenia, L., 128.

Jambolana, 128.

Malaccensis, L., 128.

Michelii, Lam,, 128.

rariflora, Benth., 129.

(Syzyginm) Sand wicensis,

Gray, 129.

uniflora, $L ., 128$.

vulgaris, 128.

Eupanieum, 497.

Eupatorieae, 192.

Euphegopteris, 560.

Enphorbia, L., 393.

celastroides, Boiss., 395.

clusiaefolia, Hook. \& Arn.

394.

cordata, Meyen, 397.

genicnlata, Ort., 398.

helioscopia, Mann, 398.

heterophylla, $L_{\text {. }}, 398$.

hirta, Hook. \& Arn., 398.

Hookeri, Steud., 396.

lorifolia, Hbd., 395.

moltiformis, Hook. \& Arn.,

396.

multiformis, Gaud.? 396. 
Euphorbia. multiformis, forma angustifolia, Boiss., 396.

multiformis, $\gamma$, Gray, 396. multiformis, var. celastroides, Gray, 395.

multiformis, var. lorifolia, Gray, 396.

multiformis, var. tenuior,

Waw., 396.

myrtifolia, Hook, \& Arn., 397.

Peplus, L., 398.

pilnlifera, $L$., 397.

pulcherrima, Willd,, 398.

Remyi, Gray, 395.

thymifolia, L., 398.

Euphorbieae, 393.

Euphorbiaceae, 5, 393.

Enpolypodium, 5็อ2.

Enpteris, 627.

Eurya, Thbg., 41.

Sandwicensis, Gray, 41.

Eurybiopsis, Gray, 197.

Euschiedea, Mann, 30.

Euxolus, Raf., 375.

lineatns, Moq., 375.

viridis, Moq., 375 .

Evodia, 60.

Exocarpus, Labill., 390.

brachystachys, Hbd., 391.

cupressiformis, Hook.\&Arn., 391.

Gandichaudii, A.DC., 391.

Gaudichaudii, var. foliosa, Gray, 391.

\section{Exogenous Plants, 1.}

Feejee Tomato, 305.

Fei, 433.

Ferns, 539.

Ferraria tigridia, 436 .

Ferula, 145.

Festuca, L., 583.

bromoides, var. monandra, Parl., 534.

drymeia, Mert. \& Koeh., 534. myarus, $L$., 534.

Sandwicensis, Reich., 533.

sylvatica, Host., 535.

Festucaceae, 525.

\section{Ficoideae, 3, 139.}

Ficus Cariea, 408. elastica, 408.

Indica, 408.

religiosa, 408.

retusa, 408.

Wightiana, 408.
Fig, Banyan, 408.

Fig, Common, 408.

Filices, 539.

Filices Genuinae, 539.

Fimbristylis, Vahl, 471.

annua, R. \& S., 472.

communis, Kth., 472.

cymosa, K.Br., 473.

diphylla, Vahl, 472.

Hawaiiensis, Hbd., 472.

laxa, Vahl, 472.

polymorpha, Bcklr., 472.

pyenocephala, Hbd., 473.

umbello-capitata, Mann, 473 .

Flagellariaceae, 428, 447.

Flax, New Zealand, 439.

Flenrya, Gaud., 409. interrupta, Gaud., 409.

Flor aroma, 114.

Floripondio, 311.

Flowering Plants, 1.

Four o'elock flower, 366.

Foureroya gigantea, Vent., 436.

Fragaria, Tourn., 117.

Chilensis, Ehrh., 118.

grandiflora, 118.

vesca, 118.

Franseria, Cav, 202. tenuifolia, Gray, 202.

Freyeinetia, Gaud, 453. arborea, Gand., 454. Arnotti, Gaud., 453.

Fuchsia, 132.

Gahnia, Forst., 480.

Beecheyi, Mann, 481. congesta, Bcklr., 483 . Gaudichandii, Steud., 481. globosa, Mann, 482. leptostachya, Bcklr., 483. Mannii, Hbd., 482. mucronata, Beklr., 482.

Galega littoralis, Forst., 94. piscatoria, Sol., 94.

Galegeae, 93.

Gamochaeta Americana, Wedd., 201.

Gardenia, L., 171. Brighamii, Mann, 171.

florida, 171.

lueida, 171.

radieans, 171.

Remyi, Mann, 172.

Tahitensis, 171.

Garnotia, Brongn., 513.

patula, Munro, 514.

Sandwicensis, Hbd., 513.
Gastonia Oahuensis, Gray, 153.

Geniostomoideae, 289.

Genisteae, 91.

Gentianaceae, 4, 286.

Geraniaceae, 2, ธ̌ .

Geranium, L., 54.

arborenm, Gray, 57.

Carolinianum, $L$., 57.

cuneatum, Hook., 55.

cuneatum, var. hololeucum,

Gray, 55, 56.

cuneatum, var. hypoleucum, Gray, 55.

cuneatum, var. Menziesii,

Gray, 55 .

dissectum, L., 57.

humile, Hbd., 56.

multiflorum, Gray, 56.

ovatifolinm, Gray, 56.

tridens, $H b d$., 55.

Gesneriaceae, 4, 324 .

Gladiolus, 436.

Gleichenia, J.Sm, 543.

Baneroftii, Hook., 544.

dichotoma, Hook., 545 .

excelsa, J.Sm., 544.

gigantea, Wall., 544.

glauca, Hook., 544.

Hawaiiensis, Hook., 544.

Hermanni, R.Br., 545.

longissima, $B l$., 544 .

Owhyhensis, Hook., 544.

pinnata, Carruth., 544.

Gleichenieae, 540.

Gloriosa Plantii, 439. superba, 439.

Glycine lucida, Forst., 100.

Gmelina Asiatica, L, 289.

Gnaphalium, L., 200.

luteo-album, L., 201.

purpurenm, $L_{*}, 201$.

Sandwicensium, Gaud.,201.

Gombo, 47 .

Gomphrena globosa, 370 .

Goniopteris, 560.

Goodeniaceae, 3, 264.

Gossypinm, L., 50.

Barbadense, L., 50.

drynarioides, Seem., 51.

Peruvianum, Cav., 50.

religiosum, $L$., 51 .

religiosum, Gray, 51.

religiosum, Roxb., 51.

Sandwicense, Parl., 51.

Tahitense, Parl., 51.

tomentosum, Nutt., ธ̃o. 
Gonania, L., 82.

Bishopii, Hbd., 83.

Hillebrandi, Oliv., 83.

integrifolia, Meyen, 83.

orbienlaris, Walp., 82.

vitifolia, Gray, 84.

Gouldia, Gray, 167.

axillaris, Waw., 170.

coriacea, Hbd., 168.

hirtella, Hbd., 169.

macrocarpa, Hbd., 170.

Romanzoffiensis, Gray, 167.

Sandwicensis, var.coriacea, Gray, 168.

Sandwicensis, var. hirtella, Gray, 170.

Sandwicensis, var. terminalis, Gray, 169.

Sandwicensis, var. ce? Waw., 171.

Sandwicensis, var. hirtella, $\beta$, Waw., 170.

Sandwicensis, var. $d$, cordata, Waw., 169.

Sandwicensis, var. f, terminalis, and $\ell$, ovata, Waw., 169.

Sandwicensis, var. $g$, form $\alpha$, and $c$, lanceolata, Waw., 168.

Sandwicensis, var. $g$, form ß, Waw., 168.

Sandwicensis, var. $i$, parvifolia, Waw., 170.

terminalis, $\mathrm{Hbd}$., 169.

Gonrd, Large, 134.

Gourd, Squash, 134.

Graminaceae, 429, 489.

Grammitis sermulata, Sw., ธ็ธิ. tenella, Kaulf., อ๊ร2.

Grass, Lemon-, 508.

Grenadilla, 139.

Grislea tomentosa, 132.

Ground-nnt, 96.

Guava, 130.

Guava, Chinese, 130.

Guazuma tomentosa, 52.

Guinea Corn, 511.

Guineo, 433.

Guettardella Sandwicensis, Mann, 174.

Guilandina Bondue, Hook. \& Arn., Gray, Mann, 110.

Bonducella, L., 110.

Gunnera, L., 123. petaloidea, Gaud., 123.

Guttiferae, 2, 40.

Gymnogramme, Desv., 550. Javaniea, Bl., 550 .
Gymnogramme.

pilosa, Brack., 551.

Gymnotheca Douglasii, T. Moore, 543.

Gynandropsis, DC., 14. pentaphylla, $D C$. 14 .

Haa, 403.

Habenaria, Willd., 431. holochila, Hbd., 432.

Habrothamnus cyanens, 303. elegans, 303.

Haematoxylon Campechianum, 109.

Hahanni, 260.

Hala, 453.

Halapepe, 443.

Haloragaceae, 3, 123.

Hao, 295.

Haplostachya, Gray, 346.

Haplostachys, $\mathrm{Hbd}$., 346.

Grayana, Hbd., $3 \pm 6$.

rosmarinifolia, $\mathrm{Hbd}$., 347 . truneata, Hbd., 347.

Hарт, 547.

Hapu Iii, 546.

Hau, 49.

Hauhele, 48.

Hawane, 451.

Heaë, 73.

Hean, 391.

Hedera Gaudichaudii, Gray, 148.

platyphylla, Gray, 149.

Hedychium coronarium, Koen., 433.

Hedyotis conostyla, Gand., 164.

coriacea, Sm., 164.

Hedysareae, 96.

Hedysarum triflorum, L., 97. uncinatum, Jacq., 96.

Heii, 546.

Helianthoideae, 201.

Helíconia psittacornm, L., 434.

Heliotropinm, $L_{*}, 321$. anomalum, Hook. \&:Arn, 322. Carassavicum, L., 321. Peravianum, L., 321.

Hellenia scabra, 433.

Helmia bulbifera, Kth., 439.

Hemerocallis fulva, 439 .

Heptapleurum, Gaertn., 147, 149.

dipyrenum, Mann, 150.

Kaudiense, Mann, 151.

Waimeae, Wawt, 152.

Herpestis, Gaertn. f., 323. Monnieria, H.B.K., 323.
Hesperocnide, Torr. \& Gray, 408.

Sandwicensis, Wedd., 408.

Hesperomannia, Gray, 231.

arborescens, Gray, 232.

arborescens, Waw., 232.

arbusenla, Hbd., 232.

Heteropogon, Pers., 507. contortus, R. \& Sch., 507. glaber, Hook. \& Arm., 508. hirsutus, Pers., 508. polystachyus, anet., 508.

Henhinhi, 111.

Hialoa, 52.

Hibiseus, L., 47.

Arnottianus, Gray, 48.

baceiferus, Forst., 50.

Boryanus, Hook. \& Arn., 48.

Brackenridgei, Gray, 47.

cannabinus, 47.

esculentus, 47.

Kokio, Hbd., 48.

Manihot, 47.

moschatus, 47.

mutabilis, 47.

phoeniceus, 47.

populneus, L., 50 .

Rosa-sinensis, 47.

Sabdariffa, 47.

tiliaceus, L., 49.

vitifolins, 47 .

Youngianus, Gaud., 47.

Hillebrandia, Oliv., 141.

Sandwicensis, Oliv., 141.

Hilo Grass, 493.

Hinahina, 56.

Hippeastrum, 436 .

Histiopteris, 630.

Hoawa, 22.

Hoea Maui, 548.

Hoi, 439.

Hoio, 611.

Hola, 94.

Holcus saccharatus, L., 511.

Sorghum, L., 511.

Holopeira lonchophylla, Miers, 8.

Honohino, 14.

Honohono, 347, 503.

Honuanla, 512.

Hoolei, 297.

Hordeineae, อ̃25.

Hoya carnosa, 299.

Hue, 134.

Huehre, 7 .

Hueie, 7.

Huluhula, 51.

Hunakai, 314.

Hura erepitans, L., 393.

Hydrangea Japonica, 120. 
Hydrocotyle, L., 143.

Asiatica, L., 143.

interrupta, Muehl., 143.

verticillata, Thbg., 143.

Hydrophyllaceae, 4, 300.

Hymenaea Courbaril, 109.

Hymenodium crassifolium, Feé, 550.

reticulatum, Presl, ธ็๊o.

Hymenophylleae, 540.

Hymenophyllum, J. Sm., 637. Baldwini, Eaton, 639.

lanceolatum, Hook. \& Arn., 638.

obtusum, Hook. \& Arn., 638. recurvum, Gaud., 638.

Hypolepis tenuifolia? Bernh., 563.

Hypolytreae, 460.

Hypolytrum, Rich., 475. dissitiflorum, Steud., 476.

Teie, 454.

Ihi, 39.

Thimakole, 40 .

Ilex anomala, Hook. \& Arn., 78.

Iliahi, 389.

Ilicineae, 2, 78 .

Ilieo, 286.

Ilima, 43 .

Nliohe, 196.

Iliohu, 14.

India-rubber tree, 408.

India-rubber tree, American, 393.

Indigo, 94.

Indigofera, $L$., 93.

Anil, $L ., 93$.

tinetoria, 94.

Inika, 381.

Inoearpas ednlis, 109.

Inuloideae, 200.

Ipecac, Wild, 300.

Ipomoea, L., 313.

acetosaefolia, Roem. \& Sch., 314.

Batatas, Lam., 314.

bonn-nox, $L$., 314.

carnea, Forst., 316.

coecinea, 313.

denticulata, Chois, 316.

dissecta, Willd. \& R.Br., 316.

diversifolia, R.Br., 316.

fastigiata, $\$ w$., 314.

Forsteri, Gray, 316.

insularis, Steud., 317.
Ipomoea.

littoralis, Bl., 316.

maritima, R.Br., 313.

Nil, 313.

obscura, Guillem, 316. ovalifolia, $\beta, \gamma$, Chois., 318.

palmata, Mann, 315.

pentaphylla, Jacq., 315.

pes caprae, Sw., 313.

purpurea, 313.

Quamoclit, 313.

sepiaria, seem, 316.

sidaefolia, Waw., 316.

tuberculata, Roem. \& Sch., 315.

Turpethum, Mann, 312.

nmbellata, 313.

Ipu, 134.

Ipu nui, 134.

Iridaceae, 428,436 .

Isachne, R.Br., 504. distichophylla, Munro, 504. myosotis, Nees, 504. pallens, Hbd., 504.

Ischaemum murinum, Forst., 510.

Isodendrion, Gray, 18. laurifolium, Gray, 19. longifolium, Gray, 18. pyrifolium, Gray, 18.

Ivi, 109.

Iwa, 603.

Iwaiwa, 606, 630, 634.

Iwaiwa lan nui, 570 .

Iwaiwa o kane, 605.

Ixora, 157.

Jack-fruit tree, 408.

Jacquemontia, Chois., 317.

Sandwicensis, Gray, 317.

Jaequinia aurantiaca, Ait., 282.

Jambosa domestica, Rumph., 128.

Malaceensis, DC:, 128.

purpuraseens, DC., 128.

vulgaris, 128.

Japanese Wax-tree, 393.

Jatropha, $L_{-,}, 400$.

Cureas, Li, 401.

Moluccana, L, 400.

Job's tears, 512.

Joinvillea, Gaud., 447. adscendens, Gaud., 447.

Gaudichaudiana, Brongn. \& Gr., 448.

Jossinia eotinifolia, Hook. \& Arn., 129.

Juncaceae, 429, 448.
Juncellns, 461.

Jussiaea, L., 132.

angustifolia, Lam., 133.

octofila, DC., 133.

octonervia, Lam., 133.

suffruticosa, L., 133.

villosa, Lam., 132.

Kaapeape, 570.

Kaawan, 78.

Kadua, Ch. \& Schl., 157. acuminata, Ch. \& Schl., 159. affinis, Ch. \& Schl, 168. centranthoides, Hook. \& Arn., 160.

Cookiana, Ch. \& Schl., 166. cordata, Ch. \& Schl., 161. cordata, $\gamma$, Waw., 162. cordata, a, $\beta$, Waw., 162. foliosa, Hbd., 164.

formosa, $H b d$., 165. glaucifolia, Gray, 163. glomerata, Hook.\& Arn., 160 , grandis, Gray, 159.

Kaulae, Waw, 160.

Knudsenii, Hbd., 162.

laxiflora, Mann, 161.

littoralis, Hbd., 166.

Menziesiana, Ch. \& Sehl.. 164.

parvula, Gray, 165.

petiolata, $\alpha$, Gray, 159.

petiolata, $\beta$, Gray, 159.

Remyi, Hbd., 162.

Romanzoffiensis, Ch. \& Schl., 167.

Smithii, Hook. \& Arn, 164.

Waimeae, Waw., 163.

Каеёё, 101.

Kaiwi, 100.

Kakonakona, 500 .

Kakalaioa, 110.

Kalamalo, 529.

Kalamona, 111.

Kalia, oิ4.

Kalo, 455 .

Kaluha, 471.

Kamakahala, 291.

Kamanamana, 192.

Kamanomano, 505.

Kamani, 40, 130.

Kamann, 40.

Kamole, 133, 378.

Kanawan, 121.

Kapana, 349.

Kaulu, 86, 276, 298 ,

Катри, 569.

Kanwila, 81, 82.

Kawika, 128.

Kea, 111. 
Keahi, 278.

Kenikeni, 512.

Ki, 442.

Kidney-Bean, 104.

Kihe, อ5ร.

Kikania, 311.

Kikawaeo, 571.

Kilau, 576, 631, 636 .

Kilika, 406.

Kilioopn, 466.

Kioele, 164.

Kiponapona, 353.

Kleinhovia hospita, 52.

Ko, 512.

Ko pake, ถั12.

Koa, 113.

Koaia, 113.

Koali, 315, 317.

Koali ai, 315 .

Koali awahia, 317.

Koeleria, Pers., 522. alomerata, Kth., 522. vestita, Nees, 522.

Koffo, 434.

Kohekohe, 474.

Kokea, 512 .

Kolkio, 49, 51.

Ḱokio keokeo, 48.

Koko, 396.

Kokolau, 211.

Kolokolo, 552.

Kolokolo, kuahiwi, $285 \overline{.}$

Konakona, 497.

Koolea, 280.

Kopiko, 178.

Kou, 321.

Kuau, 592.

Kukai neenee, 185.

Kukai puaa, 495.

Kukni, 400.

Kuknkn, 80.

Kului, 373.

Kumara, 314.

Kumunia, 630.

Kuolohia, 477.

Kupana, 225.

Kyllingia, Rottb., 470. monocephala, Rottb., 471. jumilu, $\beta$, Kth., 471 .

Labiatae, 4, 343.

Lablab vulgaris, Savi, 107.

Labordea, Gaud., 288. fagraeoidea, Gaud., 290. fagraeoidea, Gray, 291. glabra, $H b d$, , 291. Grayana, Hbd., 290. hirtella, Mann, 292. lophocarpa, Hbd, 289. membranacea, Mann, 292.
Labordea.

pallida, Mann, 290. pullida, var, alpina, Waw., 290.

sessilis, Gray, 290.

tinifolia, Gray, 292.

triflora, Hbd., 293.

Waialealae, Waw., 292.

Waiolani, Waw., 290.

Labordeae verae, 288.

Lachnagrostis Forsteri, Trin. 519.

Lagenaria, Ser, , 133. vulgaris, ser., 134.

Lagenophora, Cass., 194. Mauiensis, Mann, 195.

Lagerstroemia Indiea, 132. reginae, 132.

Lahaina Cane, 512.

Lahi, 512.

Lama, 275.

Lampocarya Gaudichaudii, Brongn., 481.

leptostachya, Schrad., 483.

Lantana, $L_{*}, 341$.

Camara, L., 342.

trifolia, $L,, 342$.

Lastrea, Bory, 074.

Lastrea, \$1 Dryopteris Presl, 571.

filix-mas, var. paleacea, Moore \& Metten., 57t. glabra, Brack., 576. globulifera, Brack., 574. rubiginosa, Brack., 578. squamigera, Brack., 578. tenuifolia, Brack., 578. truncata, Brack., 574.

Lanala, 453.

Lauhala, 453.

Laukahi, 572, 575, 625, 633, 641 . Laukono, 512.

Lauraceae, 5, 382.

Lavenia glutinosa, Gand., 192. Lawsonia alba, 132.

Leguminosae, 2, 90.

Lehua, 125.

Lehna ahihi, 127.

Lehua makanoe, 285.

Lemon-grass, 508.

Lentil, 97.

Lepeocercis annulatus, Mtunro, 509.

Lepidium, L., 10. arbusenla, $\mathrm{Hbd}$., 10. didymus, L., 11. Oahuense, Ch. I Sehl., 10. Owahiense, Ch. of Schl., 10. serra, Mann, 11.
Lepidium.

Virginienm, L., 11.

Leptospermum collinum, J. R. Forst., 125.

Leneaena, Benth., 114 glanea, Benth., 114.

Lima Bean, 104.

Liparis, L.C.Rich., 430. Hawaiiensis, Mann, 430.

Liliaceae, 428, 439 .

Lindsaya, Dryand., 619. Alexandri, $H b d ., 622$. centifolia, $H b d ., 621$.

Chinensis, Kuhn et al., 627. erecta, Hook., 621.

faleata, Hook., 620.

Knudsenii, Hbd., 623.

laciniata, $H b d ., 621$

Mannii, $I J b d ., 624$.

pumila, Hook., 620.

Lipochaeta, DC., 205. australis, \%., Gray, 206. australis, $\beta$, Gray, 206. australis. $\gamma$, Gray, 209. calyeosa, Gray, 206. connata, DC., 206. hastata, $H b d ., 208$. heterophylla, Gray, 209. integrifolia, Gray, 208.

Lahainae, Waw., 208.

lavarnm, DC., 207.

lobata, DC., 208.

micrantha, Gray, 210.

Remyi, Gray, 209.

subcordata, Gray, 207.

sucenlenta, $D C ., 207$.

tenuifolia, Gray, 210.

Lipotriche australis. Less., 209.

Lippia citriodora, H. B. K., 340.

Lithospermum incanum, Forst., 322.

Litshi, 84.

Livistonia Gaudichaudii, Mart., 4ão.

Martii, Gand, 451.

Lobelia, $L$, 235.

acuminata, Cham., 254.

ambigua, Cham., 246.

angustifolia, Cham., 253.

calycina, Cham., 245.

Gandiehandii, DC., 236.

hypoleaca, Hbd., 238.

macrostachys, Hook, \& Arn., 237.

neriffolia, Gray, 238.

pinnatifida, Cham., 246 .

superba, Cham., 260.

yuecoides, $H b d ., 237$. 
Lobeliaceae, 3, 234.

Lochnera rosea, Reiehenb., 294.

Loganiaceae, 4, 287.

Logwood tree, 109.

Lols, 608.

Lolium, L., 525. temulentum, $L$. 525.

Loętrat, 119.

Loranthaceae, $5,391$.

Lotas flower. 8.

Loulu, 451, 554 .

Loulu hiwa. 451.

Lonln lelo, 450.

Lubinia epathulata, Vent. 255.

Ltzala, $D C$ i, 449. eampestrik, $D C .449$.

Lyeinm, $L$, 309. Bandwicense, Gray, 302.

Lyeoperilemm ercolentum, MFII, 302.

\section{Lycopodiaceae, en1.}

Lycopodium, I., 642. arbuscula, Hook. \& Grev. 649 .

arbuscula, Kaulf., 649. capillacrum, Willd., 645. cernasm, L., 645. curvatum, Gasi., 645 . curvatum, Bl., 645. erabescens, Brack., 643. fartigiatum, Spr., 648, flabellafum, Porst., 649. Haleskalse, Brack. 643 . heterophyllum, Hook. \& Grev., 646.

Mensiesil, Hook, \& Greq.,645. untans, Brack. 644.

pachystaehyon, $8 p r_{i}, 644$. pernigerum, Gand, 649. phlegmaria, Spr., 645. phlegmaria? Manm, 645. phyllanthum, Hook. \& Arn., 644.

polytrieboides, Kavlf, B43. gerratum, Thog., 662. sulcinervitsm, 8pr, 662. varium, Mann, 642. varium, Bpr.? 648. renastulum, Gaud., 645. verticillatum, vax, fliforme, Spr. 644. velubile, Forst., 645.

Iynimachis, L, 282 daphasiles, Hbd. 265. Hillehrandi, Hook., 269.
Lysimachia.

IIIlebrandi, var. angurti. folia, Gray, 285.

Hillebrandi, var. daplinoides, Gray, Waw., 285.

linearlloba, Hook. \& Arn. 285.

lubinioides, Bieb. \& Zuce. 285.

Lydgatei, Hbd., 284.

Remyi, Hbd., 284.

rotundifolia, $\mathrm{Hbd}$., 284.

spathulata, Benth. of Hook, 2855.

Lythraceae, 2, 130.

Lythrom, $L_{-,}, 131$. maritimum, $H, B, K, 131$.

Maba, Forst., 274.

Hillebrandit, Seem., 275.

Bandwicensia, A.DC., 874 .

Maeranthae, 249.

Macrochilus superbis, Pr. 260.

Maerophyllae, 360.

Macropiper latifolium, Miq. 417.

Madieae, 218.

Mahne, 88.

Mahoe, Hhd., 86.

Mahm, 148.

Maiapile, 15.

Maiden-hair fern, 634.

Maieli, 273.

Maile, 289.

Maire, 299.

Mairi, 389.

Makon, 6, 145, 641 .

Malo, 407.

Malva, $I_{,}, 42$.

Americana, Cav., 43.

Coromandeliana, 1., 48. rotandifolia, $L, 42$. subliastata, Car, 42. tricurpidata, Nit., 43. vulgaris, Fries, 42

Malvaceae, 2, 41.

Malvastram, Gray, 43. trieuepidatwm, Gray, 43.

Mamake, 414.

Mamani, 109.

Matnillaria, 141.

Mammen Americana, L., 40.

Mammee-A pple, 40.

Mana, 628.

Mangifers Indiea, 8X.

Mango, 89

Manienie, 507, 523.

Manibot atillesima. Pohl, 393.
Manila hemp. 434.

Manono, 168.

Manulele, 512.

Mao, 46, 51.

Mashiohi, 356.

Maoloa, 416.

Mape, 109.

Maranta diehotoma, 483.

Marattia, J.Sm., 542. alata, Hook. \& Arn., 543, Donglasii, Baker, 542.

Marattieae, 539.

Mariscns, 462. albescens, Gand. 464. glutinosus, Bchrad. 465. Kunthianus, Gasd., 488. phleoiden, Nees, 469. umbellatus, Vahl, 470.

Marvilia, $L$, 650. erenata, Preul, 651. crenulata, Desv., 651. minuta, Blanco, 651. quadrifolla, Kaulf, 651. villoas, $\mathrm{Kaulf}, 650$.

Mati, 385

Mana, 20.

Mannaloa, 103.

Maydeae, 512.

Mazns, Leur., 823, rngosus, Lour., 324.

Medieago, L., 93. Iupulina, L., 93.

Melaleuca aentunea, 6. Forst., 125.

Melia, L., 77.

Azedarach, $L ., 77$. sempervirens, Sve., 77.

Meliaceae, 2, 77 .

Melieope, 60, 61. barbigera, Gray, 70. cinerea, 6ray, 68. elliptica, Gray, 69 grandifolia, Gray, 72. grandifolia, Waw., 72. spathulata, Gray, 72.

Melon, 134.

Menispermaceae, 1 , 6 . Mertennia dichotoma. Willd. Gaud., Brack. 545.

emarginata, Brack 545.

glabra, Brack., 544. glauca, Brack., 544. Havoilensis, Irsek., 544. pinnate, Kze., 54.

Meryta, 147. laseeolata, Forkt, 156.

Meacmbryanthemum, 140. Mctagonia penduliftora. Nutt, 270. 
Metrosideros, Banks, 124. collina, Gray, 125. difusa, Hook. \& Arn., 125. Zuted, Gray, 125, 127. macropes, Hook. \& Arn., 127. polymorphs, Gaud., 125. rugasa, Gray, 127. xpectablits, Gaertn., 125. rlllosa, 8m., 125.

Meanenen, Desf, 110. Kanaiense, $\mathrm{Hbd}, 110$.

Mieranthae, 249.

Microbrochys apiifolia, Presl. 570.

Mieroealyces, 325.

Mieroekacta integrifolia, Nutt., 208.

Ianccolata, Nutt., 206.

Miemlepia, Prexl, 625. Jamaicensin, Fée, 626. Maunil, Eaton, 684. atrigosa, Prest, 625. tenaifolia, Metten., 626.

Mierophyllae, 361.

Milo, 50.

Mimosa, $L ., 114$. pndica, $I ., 114$.

Mimoseae, 91, 112.

Minabilis, L.. 366.

Jalapa, L., 366.

Mohihi, 358.

Mokehana, 64.

Monkey-pod tree, 115 .

Monochlamydeae, 4. Monocotyledonous Plants, 428.

\section{Monopetalae, 3.}

Monsteradeliciosa, Liebm., 455.

Moreae, 404.

Morelotia gatuincformis, Hook. \& Arn., 483. gahmiacformis, Gand., 481.

Morinda, $L_{\text {.. }}$ 176.

eitrifolla, $L, 177$.

trimera, $H o d, 177$.

Moras, $L$. 406.

Brunoniana, Exdl. 406.

nigra, $I_{\text {.. }}, 406$.

papyrifera, I., 407. perdulinn, Baner, 496.

Mremna, Jelans., 101. altivalmn, II0ok. \& ArB., 100 . giganter, DC., 101. nrene, $D C, 101$.

Mnlberry, Black, 406 .

Malo, 50.

Marrays exotica, L., 7 .
Musa, $I . ., 433$.

Cavendishii, Paxt, 433.

Mindanansis, Rumph., 434. sapientam, $L, 433$.

textilis, Nees, 434.

Mrassaenda, 157.

Mnstard, Black, 13.

Mutisieae, 231.

Myonima umbellata, Hook. \& Arn., 176.

Myoporaceae, 4, 338.

Myoporum, Banke \& Sol., 339. Sandwicense, Gray, 339. tenuifolium, Hook. \& Arn., 339.

Myroxylon, Forst., 20.

Myrsinacea $\theta, 3,278$.

Iyrsine, $L_{1}, 279$.

Gaudichandii, DC., 280.

Gaudickavdii, forma acuminata, Waw., 280.

Gaudichaudil, var. hirsuta, Waw., 280.

Kanaiensis, Hbd., 280.

Lamaiensis, IIbd., 281.

Lewertiana, A. DC. 279.

Bandwicensis, A.DC., 281.

Myrtaceae, 2, 124.

Myrtle, 124,

Myrtle, Crape, 132.

Myrtas communis, 124.

Naenae, 222.

Naeo, 339.

Naiadaceae, 429, 457 .

Naias, $L_{.}, 451$. fuvintilis, Lam., 458. major, All., var. angustifolia, Braun, 458.

marina, $\alpha$, L., 458.

Naieo, 339

Nama, $L, 300$. Bandwieensis, Gray, 301.

Nanes, 106.

Nand, 172.

Nastnrtiom, R. Br, 12. offieinale, $R . B r, 12$.

Nunpaka, 265.

Nehe, 805.

Neke, 573 .

Nelumbiaceae, 8.

Nelumbinm speciosum, Willd., 8.

Nenelean, 90.

Neotlopter is nidus, J.Sm., 587.

Xephelium Litahi, 84.

Nephrodinm, Schott, 571.
Nephrodium apiifolium,

Hook. \& Arn., 570.

cicutarium, var. apiifolium,

Hook., 570.

cyatheoides, Presl, 571.

Dubreuilleanum, Hook. \& Arn., 571.

exaltatum, Gaud., 579.

exten sum, Hook., 572.

Fijiense, Hook., 578.

filix-mas, $\beta$, Hook., 574.

glabrum, Hook., 576.

globutiferum, Hook., 574.

Hudsonianum, Brack., 572.

latifrons, Hook., 579.

patens, Hook., 572.

propinquum, R.Br., 573.

pteroides, J.Sm., 573.

resiniferum, Hook, \& Arn., 573.

rubiginosum, Hook., 578 .

squamigerum, Hook, \& Arn., 578.

terminans, J.Sm., 573.

truncatum, PresI, 572.

unitum, R.Br, 573.

Nephroica Ferrandiana,

Miers, 8.

Nephrolepis, Schott, 579. cultrifolia, Presl, 579.

exaltata, Schott, 579 .

Nerandia, Gaud., 415. glabra, Meyen, 416. Kahoolawensis, $\mathrm{Hbd}, 416$. melastomaefolia, Gaud., 416. ovata, Gand., 416.

sericea, Gand., 416.

Nerium Oleander, L., 294.

Nertera, Banks of Sol., 183. depressa, Banks, 183.

Nesaea salieifolia, 132.

Netto, 512.

Neurachne montana, Gaud. 499.

Neurophyllodes, Gray, 54.

New Zealand Flax, 439.

Nicandra, Gaertn., 310. physaloides, Gaertn., 310.

Nicotiana, $L$., 311. glanea, Grah., 311.

Tabacum, $L_{n}, 311$.

Nin, 452.

Nohn, 59.

Nohmanu, 56 ,

Neni, 178.

Nothocestrum, Gray, 307. breviflorum, Gray. 308. latifoliam, Gray, 308. longifolium, Grayl, 308. subeordatum, Mann, 302. 
Nothopanax, 147.

Nothosehiedes, Mann, 30.

Nototrichium, Gray, 372.

Nototrichimm, IIhd., 372. hamile, Hbd., 373.

Sandwicente, Hbd, 373 . viride, $\mathrm{Hbd}$, 373.

Nokniwi, 100.

Nyetaginaceae, 4, 360 .

Oalii makalii, 543.

Oats, 528.

Obbea tímonioides, Hook., 174.

Oehra, 47.

Oehroma lagopns, Sw, 51.

Oehrosia, Juns., 296.

Bandwicensis, Gray, 296.

Sondrolcensis, A.DC., 295.

Odontoloma, J.8m., 624.

Boryonum, J.Sim, 625.

repens, Desv. 624.

Ofal, 95.

Ofe, 156.

Oha wai, 239.

0 hail, 95 .

Ohe, 156, 504, 537.

Ohelo, 272.

Ohelo kai, 349.

Ohelo papa, 118.

Ohenanpaka, 259.

Oheobe, 551.

Ohia, 128 .

Ohia ai, 128.

Ohia ha, 129.

Obia lebran, 125.

Ohiakn, 639 .

$0 i, 340,341$.

Okupukapu, ธ79.

Olapa, 148.

Oldentendia conostylo, DC.. 164.

Otea, L., 301.

Basiwienasis, Gray, 301.

Olenceac, 4, 301.

oléna, 495.

olfersia gorgonea, Preal, 550.

Oliana, 512.

Oloa, 415.

Olobes, 307.

Olosnea, 79 .

Oloะล่, 415.

Oles, 563.

Onagracene, $3,132$.

ophioderma pendulum, Bndl., 8469.

Ophioglossaceae, 639.

Ophioglonsam, I, 639.

conicknoum, Krackn 640

ellipticam, Iraek, 640 .
Ophioglossum.

ellipticum, Hook.\& Girev.,640.

nudieanle, L. $f ., 640$.

pendulnm, $L ., 640$.

valgatam, L., 640.

Oplismenus, Becux., 502.

colonus, Kth., 496.

compositas, R. d. Sch., var. sylvatiens, Trin., 502.

cris-galli, Kth., 496.

Ochuensis, Nees, 503.

Oporo, 304.

Opnhi, 484.

Opuntia, Tourn,, 140.

tomentosa, 141.

Tuna, Mill, 140.

Orchidaceae, 428, 429.

Oreobelus, R. Br., 4R3.

fureates, Mawn, 483.

Oreodaphine? Mamn, 383.

Oreodoxa regia, 449.

Orthopogons componitus, B. $\mathrm{Br}_{n}, 503$.

Oryza, Li, 518.

sativa, $L ., 513$.

Oryzeae, 513.

Osteomeles, I.Rndl., 112. anthyllidifolia, Lindl., 119.

Ovaò, 385.

Orwalii, 587, 628 .

Oxalidaceae, 2, 59.

Oxalis, L. 59. corniculata, $L ., 59$. Martiana, Zuce., 80.

Paederia, L., 182. foetsda, L., 182.

Pai, 556.

Painin, 444.

Pakahs, 345.

Pala, 543.

Palaa, 627.

Palani, 512.

Palapalai, 626.

Palapalai aumakna, 564.

Palapalai Janlii, 620.

Palapalal o kanmanpua, 574.

Paim, Cocoannt, 452.

Palm, Date, 449.

Pulm, Huyal, 449.

Palmaceae, 429, 49.

Palini", 449.

Painakani, 829, 401.

Pamohis, 579, 584, 589.

Panax, 147. GoudichaudII, Ilook. \& Arn. 148.

voctum, Hook, \& Arn., 148, platyphyllwin, Hook. \& Arn., 149.
Paneratiom maritimum, 436.

Pandanaceae, 429, 452.

Pandamus, $L_{\text {n }}, 452$.

Chamissomis, Gand., 453.

Douglasii, Gand., 453.

fascieularis, Lam., $453 .$.

Menzievii, Gand., 458.

odoratissimus, L. J., 458.

verus, Rumph., 453.

Panicaceae, 492.

Paniceae, 492.

Panicam, L., 493.

aftine, Hook. \& Arn., 498.

Beecheyi, Hook. d Arn., 498.

ciliare, Hook. \& Am, 497.

cinerenm, Hbd., 500.

colentum, L., 496.

compositum, L., 503 .

conchoidenm, Hbel. 502.

erus-kalli, var. longiveta,

Trin., 496.

cruispaconis, Nees, 498.

cryptanthum, Natt., 498.

vynoton, Keich, 498.

dactylom, L.., 523.

cchinatum, Wild., 436.

filiforme, $L_{n}, 495$.

gовяурімим, Hook. \& Arn., 499.

fmbricatam, IJbol., 501.

ixacbnoilen, Minzo, 501.

maximum, Jacq, 494.

montieols, Hbd., 500.

montonum, Gaud, 499.

nephelophilam, Geus., 497 .

nephelophilum, Hook.\& Am., 498.

nobigenum, Kth., 499.

pellitum, Trin., 499.

plieatum, Lam., 494.

prostratam, Lam., 494.

pruriens, Trin., 495.

sanguinale, Beem., 495.

tenulfolium, Hook. \& Ara., 497.

torridum, Gaud, 500.

Papar, 512.

Payala, 368, 375.

Papauk, 568.

Papaveraceae, 1,9

Papaya, 139.

Papriya velgaris, DC, 189.

Papayaceae, 3, 139.

Papilionaceat, 90, 91.

Pamyrixs, Lam; 407.

Parapara, 368.

Pardanthos Chiseneis, 436.

Paritiem, St. HOt, 40. 
Paritium.

elatum, 49.

tiliacenm, St. Hil., 49.

Parkia Africana, 115.

Parpalom, L., 492.

eonjogatum, Berge, 493 .

consenguineum, Kth., 495.

filiforme, Finegge, 496.

orbienlare, Forst., 492.

serobiculatum, $\beta$, Kth, 493.

Pasifilora coerulea, 189.

edalis, 132.

foetida, 139.

inearnata, 139.

lamrifolia, 189.

minizua, 139.

quadrangularis, 139.

Passifloreae, 139

Tamohilaka, 318.

Pamooa, 578.

Pavetta, 157.

Pawale, 57.

Pra., \$8.

Pea-nut, 96.

Peach tree, 119.

Peahl, 560.

Pear tree, 119.

Peepal tree, 408.

Pelargonínm, L'Her., 57. sonale, withd, 58.

Pelea, Gray, 60. anisata, Mеид, 64. auriculaefolia, Gray, 73. barbigera, Hbd., 70. cinerea, $H b d ., 68$. elwsiacfolia, Gray, 62. elliptica, HbC., 69. Havailensis, Waw., 69. Kadine, Waw, 69. Kamaiessis, Mann, 64. Knndsenii, $H b d, 70$. Lydgatei, Hbd., 65. marropus, IIbd., 65. Manni, Hbd, 66. Molokaiensis, IJbd, 65. oblongrifolia, Groy, 64. orbieviaris, $I 1 b u t, 67$. pallyda, $I I b d, 68$. parvifolia, IJbd., 65. rotundifolia, Gray, 68. Bandwicensin, Groy. 66. sapotaefotia, Mann, 63. voleasiea, Groy, 67. Walalealse, Waie, 63.

Pullasea, Lik, 683. Deraniarjolia, Hook., 629. ternifolia, Fèe, 683.

Pexnistinm calyculatum, Spr., B05.
Pentacurya heliotropioides, DC.. 322.

Pentapetes phoenicea, 52.

Pentas carnea, 107.

Pejeromia, Ruiz a Pav, 417. Cookiana, C. DC., 427.

Fernandeziana, Miq., 420.

Gaudichaudii, Miq., 422.

Hesperomannii, Waw., 421. hypolenca, Miq., 422. insularum, Miq., 420 . insularum, Waw ? 423. latifolia, Miq., 423. latifolia, var. alternifolia, Waw.? 419.

leptostachya, Hook: \& Arn., 428.

ligustrima, $H b d ., 425$.

Macreana, C.DC., 420.

Mauienais, Waथ., 425. mexobranacea, Hook, d'Arn., 122.

Oahuenis, C.DC., 419. pachyphylla, Miq., 424. pallida, A. Dietr. 419. pallida, Dietr.? 419. jarvula, Hbd., 428. pleistostachya, Hod., 427. purparaseens, Nutt., 419. reflexa, A. Dietr., 426. Aandwicensis, Miq., 424. guberenata, Klotzseh, 424. tetrophylta, Hook. \& Arn. 426.

verticillata, Hook. \& Arn. 424.

Pepper, Red. 302.

Peppergrass, 11.

Pepper tree, 89.

Pereskia, 141.

Perottetia, H.B.K., 79. Sandwicensis, Gray, 79.

Persea gratissima, 382.

Petesia carnosa, Hook. \& Arn., 167. coriacea, Hook. \& Arn., 168. terminalis, Hook, \& Arn. 169.

Petrea volnbllis, Jneq., 340.

Pencedanum, L., 144. graveolens, Benth. of Hook., 145.

Kuvaiense, $I I b d, 145$. Sandwicense. Mbd., 144.

\section{Phanerogamous} Plants, 1.

Pharbitis insularis, Chois. 317.
Phaseoleae, 98.

Phaseolus, L., 104.

amoenus, Sol, 104.

Cumingii, Benth., 104.

lathyroides, L., 105.

Innatus, 106.

rostratus, Wall., 104.

semierectus, $L ., 104$.

Truxillensis, H.B.K., 104.

vulgaris, 104.

Phegopteris, Fée, 560. crinalis, Mann, 563. Hillebrandi, $\mathrm{Hbd}$., 566.

Keretudreniana, Mann, 561.

microdendron, Eaton, 561. polyearpa, $H b d$., 560. punctata, Hbd., 562. Sandwicensis, Mann, 565. spinulosa, $H b d ., 566$. unidentata, Mann, 564 .

Phoenix dactylifera, 449.

Phormium tenax, 439.

Phyllantheae, 393.

Phyllanthus, $L, 401$.

distichus, Hook. \& Arn., 401.

Nirnri, L., 402.

Niruri, var. genuinus, Muell. Arg 402.

Sandwicensis, Muell. Arg., 401.

Sandwicensis, $\beta, \gamma, \hat{0}$, Muell. Arg., $40^{\circ}$.

Phyllocactns, 141.

Phyllostegia, Benth, 347 .

ambigua, $H b d, 350$.

brevidens, Gray, 349.

brevidene, var. ambigun. Gray, 350.

Chamissonis, Benth., 351.

clavata, Benth., 349.

dentata, Benth., 349.

floribunda, Benth., 353. glabra, Benth., 351. grandiflora, Benth., 349. haplostachya, Gray, 347. Hillebrandi, Mann, 350. hirsuta, Benth., 352. hispida, Hbd., 353. Honolutensis, Waw., 351. Knndsenii, $H b d$., 354. leptostachya, Benth., 351. Macraei, Benth., 351. macrophylla, Bentb.? 352. mollis, Beuth., 352. parviflora, Benth., 351. parviftora, var. Gaudi. chaudil, Gray, 351. parviftoro, var, mollis, Gray, 352. racemosa, Eenth., 353. 
Phyllostegis.

stachyoides, Gray, 350 .

truncate, Giny, 347.

vestita, Benth., 348.

Waimeae, Waw., 352.

Phyllostegia, sect. Haplostachye, Gray, 346.

Phymatodes, 558 .

Physalis, L., 310.

eriulks, Sims, 310.

Pernviana, L., 310.

pubercent, R.Br., 810.

Phytolacea, I., 376.

Abyesinien, Hook. \& Arn., 875.

Bogotenais, Mann, 376.

brachystachyo, Moq. 876.

Phytolaccaceae, 4, 376.

Pia, 438.

Pigweed, 39.

Fie-melon, 134.

Pila, 498.

Piipit, 511.

Pilea, Lindll, 411.

peplniles, Hook. \& Arn., 411.

pygmaten, Mį̧, 412

Pili, 508.

Pilikai, 312.

Pilo, 161, 184.

Pine-apple, 495.

Pinomia, Gand. 546. oplendens, Gasd. 547.

Pioi. 441.

Piper. I. 417.

Betle, L., 417.

methystiem, Forst, 417.

pallidum, Forst. \& Willa. 419

reffexum, L. f. 428 .

tetraphyllam, Pornt., 426.

Piperaceae, 5, 417.

Pipi, B47.

Pipional, 474.

Piptarns, Wedd., 413.

albidas, Groy, 418.

albidwe, rar. Govelichandic, Weita. 414.

Tahitenris, Wed4, 414.

Pisang railjak, 4:3.

Piennia, Plum., 367 .

Brunowitwa, Esd!.? BE9.

excelva, B1, 369

Forsteriana, Endi. 369.

grand in, R.13r.7 289.

inernill, Forst, 369

macrucarpa. Pr. 589.

Arooreana, F,Muell. Bes.

procera, Eert., 369.
Pisonia.

Sandwicensis, IIbd., 869.

Sinelairit, Hook, 362.

nmbellifera, Seem., 368.

Pitheeolobism dnlee, Benth. 115.

Samang. 115.

Pittosporaceae, 1, 21.

Pittesporam, Banks, 21. acuminatam, Mann, 22. caslifloram, Mann, 24. eoufertifloram, Gray, 26. glabram, Irook. \& Arn., 23. glomeratsm, Irbd., 23. Hawailense, Hod, 26. insigne, $H b d, 25$.

Kanaiense, HbI, 25. epsthulatom, Monn, 24. gpathulatum, Mann, 23. terminaloides, Planch., 24. terminaloides, 8, Gray, 25. terwinaloidey, \%, Gray, 28.

Plantaginaceae, $4,362$.

Plantago, L., 363.

Brongniartil, Barn.? 365. major, $L$., 386.

pachyphylla, Groy, 264.

prineeps, Ch, of Schl, 363.

prinecps, rar. clata, WaW.s 363.

princeps, var. aquatilis, Waw., 365.

Queleniana, Gand., 363.

Plantain, 306.

Platydesma, Mann, 70. axrieslaefolia, $\mathrm{Hbd}$, 72. eampaxulata, Mann, 71. cornata, Hbol, 72. reatrata, Bhd, 72.

Platylometernifolium, Rraek. 683.

Plestranthts, L'Her., 843. euatrally, Hank. \& Am., 344. parvillorn., Willd., 34 .

Plectroaia, L., 175. odornta, Boith. \& Hook., 175.

Pleiosmilax, Scem., 440. Mensiewil, Besem., 441.

Sinnduricensin, 8eem- 441.

Pteopeltis clongrata, Kaulf.. BS:

rmsifolía, Hook 6559.

Plerabdra, 147.

Mirm, Chines4, 130.

Pam tres, 119.

Plumbaginaceae, 3 , 2986.

Pisabago, Toirn., 296.
Plumbago.

Capensis, 286.

coerulea, 286.

ceccinea, 286.

Zeylanies, L., 286.

Plumieria acntifolia, Poir. 294.

Poa, L., 525.

amnna, L.., 526 .

Eragrostis, Ley, 532.

fatenta, Gatsd., 5133

longe-radiata, $H b d, 526$.

Mannii, Munro, 528.

Mexicana, Lag. 531.

monticola, Gasd., 531.

plumasa, Retz, 583.

unloloides, Retz, 538.

Poaceae, 515.

Poha, 310.

Pohnsban, 313.

Poinciana Gillenil, 110.

Poke, 376 .

Polianthes tuberosa, 436.

Polimalina, 34\%.

Pololex, 640.

Pololo, 320

Polycoelium Sandvicense. A.DC, 389.

Polygonaceae, 4, 876 .

Polygonum, I., ส78. glabrum, Willd., B78.

Polypodieae, 540.

Polypodism, L., 152.

Adenophorns, Hook. \& $A r n$, 555.

atro-punctatum, Gasd., 559. conforme ?, Iraeky 558. crimale, Hook. \& Arn- 563. diefotomum. Thlig., Forst. 545 .

exalloficm, Porst, 579.

Haalilioanum, Brack, 554.

Hillebrasili, Hook., 557.

Hillebrandi, Hook. 566.

Hemolulense, Hook., 567.

Hookeri, Brack, 063.

bymenopibyllolites, Kaulf., ถธ5็.

Konifusril, Presl \& Metten. biv2.

Kernudreniasum, Gaud. bet1.

Lamenolatnm, L., BS9.

Leiopteria, Kzक्, 1899.

lepidotum, Willd, 552.

liseare, Thboy, 604.

forlforme, Wall., 559.

lycopodiedidea, L., 569.

minimum, Braek-, 5 s.8.

myonuroides, Bw., 508 . 
Polypodium

myriocarpem, Hook., 558. pellecidum, Kantfe, 557. pendutum, Gand., 655. polyeerpam, Hook, a Am., 560.

procernem, Brack., 562. peendo-grassmitis, Geud., b52.

pructatuw, Thbg, 562. rugutorum, Labill., 563. Bameense, Baker, 564 .

Sandwiccuse, Hook. \& Am., 565.

(Guniopteris)Sandwicense. Hook., 861 .

sarmentesam, Brack., 554. serralatass, Metten., b5is.

setigerem, Hook. \& Ara, 558. spoctram, KauU., 659.

ategnogrammoides, Baker, b61.

aubbiplnnatifdum, ITookn, BSA.

subepatfulatum? Braek., 638.

tamariseinsm, Kaslf, 556.

Thosinianxim, Gavil, 560.

tripinnatifidum, Mana, 057.

unidentafism, Hook. \& Arm., b64.

unitum, Ja., 578.

(Phegopt.) uminorim, Baker, 58.

Polypogon, Desf, 517.

litzoralis, Sin., 518.

Polysticham, Schott, 567.

Diubreufllecnutm, Hook. \& Aru., 871.

Haleakalense, Brack, s68. propinquиm, Gasd., 578. truseafum, Qand, 572.

Pomegnanate, 124.

Poslasai, 214.

Popolo, 250, 304, 307, 376.

Portulaca, Tourn., 39. Iutea, Sol., 39. sleracea, L., 39. sclemearpa, 6ray, 39. villoea, Cham., 39.

Portudacacea, liowk \& Arm, 38 .

Portulacaceae, $1_{4} 4,8 s$.

Potaumogeten, L, 458. fluitans, Roth, 409. Gasdichaudii, Cham., 459. vatans, var. anguatatus, Kth., 469.

Oheaihlensis, Cham., 459. pasciflerus, Pursh, 459.

Potato, wos.
Potato, Sweet, 314.

Prasium glabrum, Gand., 351. grandiftorum, Gaud., 349. parvifurum, Gazd., 351.

Prenanther Japonica, L., 233.

Pride of Barbadoes, 110.

Pride of India, 77.

Primulaceae, 3, 282.

Pritehardia, Seem, \& Wendl., 450.

Gandichandii , H.Wendl. 450.

Martil, H.Wendl., 451 .

Priva, Adans, 341.

aspera, H.B.K., 341.

Procris glabra, Hook. \& Arn., 410.

Prosopia duleis, Kth, 115. juliflora, DC., 115.

Pacudonerus, Bur, 405. Brunoniana, Bur., 405.

Pvidium, L., 130. Cattleyanum, 180. Geayava, L., 130. powiferum, L., 180. pyriferum, Liv, 180.

Puilorhegza, Vog., 111.

Psilotrichium Bandwicense, Beem. 378.

Psilotum, sie., 646. complanainm, Sw, 647 . dichotomum, L.k., 646. triquetrum, $S w ., 646$.

Psychotria, L., 180. grandiffora, Marn, 181. hexandra, Mani, 181.

Pteridinm, 631.

Pteris, L., 627. alata, Gand., 628. aq̣uilian, L., 631. Beccheyana, Hook., 630. Cretica, L., 627 . decipiens, Hook., 629. decomposita, Gatud., 631. decora, Hook, 690. excelsa, Gaud, 629. incisa, Thog., 630. irregalaris, Kaulf., 628. pedete, Gaud., 629. terminalls, Wall, 629 ternifolius, Cav., 633. vertielliata, Bw., 638. Veopertilionie, Labill., 631. Pterotropia, Hod., 149, 151. dipyrena, IIbd., 150. grmsocarpa, Hbd., 154. Kanaienais, IIDC, 150.

Ptilotus, seet. Nototrichium, Gray, 372. Sandwiensis, Gray, 373 .
Pua, 302.

Puaainaka, 361

Puaala, 235.

Puahanai, 121.

Pushekili, 283.

Puakala, 9, 258.

Puakuuhi, 103.

Puakeawe, 273.

Paalele, 233.

Pualolo, 49.

Puamakanui, 142.

Puaole, 512.

Puapilo, 15.

Puarata, 125.

Pumpkin, 134.

Pulihilihi, 106.

Punica Granatum, 124.

Puukoa, 477.

Pycrens, 461.

Owahuensis, Nees, 464.

Radish, 13.

Raillardia, Gaud., 224.

arborea, Gray, 228.

ciliolata, $D C ., 226$.

Hillebrandi, Mann, 227.

latifolia, Gray, 225.

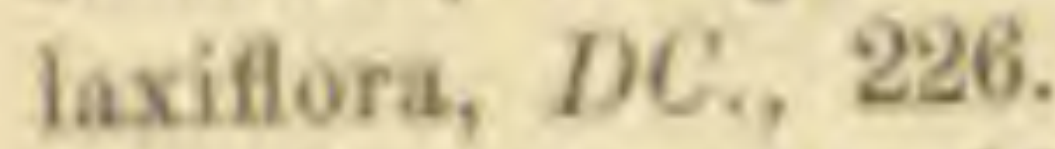

linearis, Gaud., 227.

Menziesii, Gray, 228.

Menziesii, Gray, 226.

montana, Maun, 227.

platyphylla, Gray, 227.

seabra, $D C$, 225.

scabra, var. hispidula. Gray, 225.

struthioloides, Gray, 228.

Ramee plant, 413.

Ranunculaceae, 1, 5.

Rannoenlus, L., 5.

Hawailensis, Gray, 6.

Mauiensis, Gray, 6.

Raphanns sativus, 13.

Raspberries, 116.

Rauwolfia, L., 295.

Sandwicensis, A.DC., 295.

Ravenala Madagascariensis, Adans, 434.

Rea, 435.

Reamoernurn, 434.

Red Pepper, 302.

Remya, Hbd., 193.

Kauaiensis, Hbd., 194.

Maniensis, Hbd, 194.

Reynoldsia, Groy, 150, 155.

Sandwicensis, Gray, 156.

Rhamnaceae, 2, 4, 79 .

Rhamanus, 80.

Rhaphiolepis Indies, 119.

Rhaphis trivialis, Lour, 510 . 
Rhizocarpeae, 650.

Rhns, L. 89.

Sandwicengis, Gray, 90. semialata, Marray, 89. semialata, vat. Sandwieenris, Engl, 89.

succedaneum, 89.

vernix, 89.

Rhynebosia Itecida, DC., 100.

Rhynehospermam jaswinoides, Lindl. 294.

Blyynehoepora, Vahl, 476.

lavarum, Goud, 477.

laxa, R.Br , 476 .

eclerioldes, Heok. \& Am. 478.

spicapformis, Hod., 477.

thyrovidea, Nees \& Meycn, 477.

Rhynchosporeae, 460.

Rhytidotuy Sandwicensis, Hook, 175.

Rice plant, 513.

Richardia Afrieana, $K t h$, 455. ncabra, 1., 189.

Bichardsonia, $K t h,, 189$. seabra, St. Ifit., 189.

Ricinns, L., 399. commonis, L., 398.

Rivaea tiliaefollia, Chois., 312.

Rivins laevis, $L$, 376.

Rocon tree, 19.

Rollandia, Goud, 244. ambigua, G.Don, 246. calycina, G.Don, 245. crikpa, Gaud., 247. erispa, Mann, 245. crispa, Meyea, 245. Delesertíana, Gaud., 247. grandifolia, $\mathrm{Hbd}_{2}, 245$. Humboldtiana, Gaud., 248. Kaalac, Waw, 248. lanceolata, Gaud., 246. lancoolata, var.grandifolia, De., 245.

longiflora, Wase, 24 h. pedunculoea, Waw, 246. racemosa, $H$ bd. 246. angisinea, Hbd., 246. ncabra, Wawn, 247.

Busa Damascena, 120. multiflera; 120.

Rosaceae, 2, 115.

Bose Apple, 128.

Rotiboellle dimidicto, Thbs. 507. atolonifera, Polt. son.

Royal Palm, 449.

Rubiacene, 3, 156.
Rubus, L., 115.

Hawailensis, frey, 116.

Macraei, Groy, 116.

g्र. n. IIbd., 117.

Rumex, L., 377.

albescens, $H b d ., 378$.

gigantens, Alt., 377 .

Longifolius? Gray, 378.

Ruppia, $L$, 458.

maritima, $L$., 458.

Rutaceae, 2, 60.

Sacchareae, 507 .

Baccharum, $L$, 511. officinaram, $L$., Б12.

Badjeria, Kaulf., 590. cyatheoides, Kaulf., 582. pallida, Hook. of Arm., 582. Bonleytiana, $I B b d ., 581$. squarrosa, Mann, 582.

Bafflower, 231.

Sagenia, Presl, 570.

Bagina, $L, 38$. snbulata, Wimm., 88.

Bagittaria, $L ., 457$. sagittifolia, L., 457.

Sagotia triflora, Walp. 97 .

Salvia, L., 345. eoceinea, 345.

oceidentalis, Sw., 345.

Bamang tree, 115.

Sandalwoed, 359.

Sandbox tree, 393.

Sanienla, L., 143. Bandwicensis, Gray, 143.

Santalaceae, 5, 398.

Santalnm, I.., 388. cllipticum, Gand., 390.

Freyeinetianum, Gaud., 389. Healeakalae, Hbd., 390. paniculatum, Hook. \& Arn., 389.

pyrularimm, Groy, 390. pyrularium, $\beta$, Gray, 390.

Sapindaceae, 2, 4, 84 . Sapindus, L., 85.

Oahnensis, $H b d$, 85.

Sapote Sandwicensis, Gray, 276.

Sandwicensis, $\beta$, Gray, 277 .

Sapotaceae, 3, 275.

Bapetilla Plum, 275.

Sarmentosae, 355.

Saxifragaceae, 3,120 . Beaevola, L., 265.

Chamissoniana, Gand., 267.

ciliata, Don, 267.

coriacea, Nutt., 266.
Seavola.

coriacea, i, Gray, 267. cylindrocarpa, $\boldsymbol{H} b d, 268$.

Dicliana, Gand., 268.

Gandichudai, Hook. \& Arn. 266.

glabra, Hook. is Arn., 269.

Koenigii, Vabl, 266.

ligustrifolia, Nutt, 267.

Lobelia, $L<, 265$.

Mensiesiena, Cham., 267.

Mensicsiana, var. glabra, Cham., 267.

mollis, Hook. \& $A$ rm., 269. montana, Gand., 267. plumierioides, Nutt., 286. procera, Hbd., 268. pubercons, Nutt, 267. serieen, Font., 266.

Seandentes, 360.

Schefflera, 147.

Sclienkia sabecoides, Griseb., 287.

Behiedea, Ch, d: Seht, 29. amplexteaulia, MAnn, 32. diffusa, Gray, 31. globesa, Mann, 35. Hawailensis, IIbd, 33. Hookeri, Gray, 34. Kaalae, Waw, 32. ligustrina, Ch. de Schl., 33. ligustrina, Hook., 34. Iyehnoides, Hbd., 36, 37. Lydgatei, Hbd., 34. Menziesti, Hook., 35. Nuttallii, Hook, 30. Nuttallic, Gray, 31. Orhuensis, Waw., 31. plantaginea, Hbd., 32. pubeseeus, Hbd., 31. Temyi, Waw, 34. saliearia, Hbd., 33. spergulina, Groy, 33. stellarioides, Mann, 32. viseosa, $\operatorname{Mann}, 36,97$.

Behinns molle, 89.

Behizaea, J.Sm., 543. australis, Arack , 543. robusta, Boker, 548.

Schizaceae, 540.

Behizocalyeice, 320 .

Schisophyllum micranthum, Nutt, 210.

Sehiznstachymm, Nees, 537. glaneifolinm, Munro, 538.

Behizosterge, Hbd., 681. Lydgatei, IIbd., 682.

Bcirpeae, 460.

Beirpus, 1., 474. lacustrik, L, 475. 
Seirpas.

maritímus, L., 475.

obtuxus, Willd., 474 .

palustris, 1sy 474.

riparies, Mann, 475.

validus, Vahl, 475.

Scitaminaceae, $428,432$.

Bcleria, Berg., 484.

testacea, Nece, 484.

Sclerieate, 460 .

Scoparia duleis, L., 324.

Scrophulariaceae, 4 , 323.

Scytalis anomala, Vog., 106.

Belaginella, $s p r_{r}, 647$.

arbuscula, $8 p r ., 648$.

deflexa, Brack., 648.

lepidophylla, 647.

Menxiesi, Spr., 649.

parrula, Hbd., 648.

Bpringii, Gaud., 649.

Senehiera, Poir., 11.

didyma, Pers., 11.

pinnatifida, $\mathrm{DC}, \mathrm{1L}$.

Seneein, I., 289,

eapillarin, Gaud., 229.

Bandwieensis, Lesy, 229.

Senecionideae, 221.

Sensitive plant, 115 .

Berisaa foetida, 157.

Seshania, Pery., 94. coccinea, Poir., 95. grandiflora, Poir., 95. tomentosa, Hook. \& Arm., 95.

Sesnvium, L., 140.

Portulacastrum, L., 140.

Setaria, Beauv., 503.

triflora, $\mathrm{Hbd}$., 503.

verticillata, 503 .

Sicyos, L., 134.

euenmerrinus, Gray, 136.

hispidas, IIbd., 136.

laciniatns, $H b d ., 138$.

macrophyllns, Gray, 137.

Maximewiczii, Cogm., 135.

microearpns, Mann, 138.

waebyearpas, Ilook, d Arm., 187.

Remyants, Cogn., 138.

Bida, L., 43.

anguatfolio, Lam., 45.

corpinoides, DC. 43.

cordifolia, L., 43.

Diellil, Gray, 44.

fallax, Wolp., 44.

incasa, Lk., 46.

Menzlesiana, Walp, 45.

rhombifolia, L., 49.

rotundVfolia, Gand., 44.
Sida.

Sertum, Nutt., 44.

spinosa, L., 45.

ulmifolia, Hook. \& Arn., 45.

Sideroxylon, L., 276.

Sandwicense, Benth. \&

Hook., 276.

spathulatum, Hbd., 277.

Siegesbeckia, L., 204.

orientalis, L., 204.

silene, L.. 27.

Alexandri, $H b d, 28$.

cryptopetala, Hbd., 29.

Gallica, $L, 29$.

lanceolata, Gray, 28.

struthioloides, Gray, 28.

Siliculosae, 10.

Siliquosae, 10.

silversword, 219.

Sinapis nigra, L., 13.

Siphonia elastica, Pers., 393.

Siri, 417.

Bisyrynehium, L., 436. aero, Mann, 436.

Smilax, L., 440. anceps, Kth., 441.

Hawailensis, Seem., 441. melastomaefolia, Sm., 441. pecudo-China, Hook. \& Arn., 441.

Sandwicensis, Kth., 440.

Smythea, 80.

Soap-trees, 85.

Solanaceae, 4, 302.

Solanam, L., 303. aculeatissimum, Jacq., 303. anthropophagorum, Seem., 305.

incompletum, Dun., 305.

Kanaiense, Hbd., 305.

Melongena, L., 303.

Nelsoni, Dun., 304.

nodiflorum, Jacq., 306.

oleraceum, Dun., 306.

psendo-eapsicum, L., 307.

puberniam, Nutt, 306.

puberulum, Natt., 306.

pulverulentum, Nutt., 306.

repandum, Forst., 305.

rotundifolium, Natt., 304.

Sandwicense, Hook. \& Arn., 304.

Sandwicense, var. Kauaiense, Gray, 305.

tuberosum, L., 303.

vestitum, Nutt., 304.

viride, Sol., 305.

Woahense, Dum, 304.

xanthocarpum, Seem., 304.
Sonchus, $L_{+}, 233$.

asper, L., 233.

oleracens, $L, 233$.

Sophora; L., 108.

elurysophylla, Seem., 108.

tomentosa, 109.

Sophoreae, 108.

Sorghnm, 511.

Sorghum, Sugar, 511.

Sorghum, Pers., 511.

saceharatum, Pers., 511.

vulgare, Pers., on11.

Sotursop, 8.

Spanish Clover, 96.

Spergula, L., 38.

arvensis, $L$. 38.

Sphacele, Benth., 344.

hastata, Gray, 344.

Spodiopogon, Trin., 509. anrens, Hook \& Amn., 510. B̈yronis, Trin., 509.

Spondias dnleis, 89.

Sponia, Lam., 404.

Amboinensis, Desne., 405.

argentea, Benth., 405.

Tahitensis, Nad.? 405.

velutina, Planch., 405.

Sporobolus, R.Br., 517.

Virginieus, Kth., 517.

Sprekelia formosissima, 436.

Squash-gourd, 134.

Stachys, L., 340 .

arvensis, $L$, 346.

Stachytarpheta, Vahl, 341.

dichotoma, Vahl, 341.

mntabilis, Vahl, 341.

Stapelia, 299.

Stegnogramme Sandwicensis, Brack., 561.

Stenogyne, Benth., 354 . angastifolia, Gray, 357.

bifida, $H b d ., 358$.

calaminthoides, Gray, 355.

cinerea, $H b d$, 361.

cordata, Benth., 359.

erenata, Gray, 362.

diffusa, Gray, 362.

Haleakalae, Waw, 360.

Kaalae, IIaw., 358.

Kamehamehae, Waw., 356.

Kealiae, Waw., 357.

macrantha, Benth., 360.

macrantha, M. \& B., 360.

microphylla, Benth. 361.

Nelsoni, Benth., 358.

parvifiora, Mamn, Waw., 353.

purpurea, Mann, 357.

rotundifolia, Gray, 360.

rotundifolia, Gray, 361.

rugosa, Benth., 356. 
Stenogyne.

serophularioides, Benth., 358. serophularioides, $\uparrow$, Mann, 360.

serpens, Hbd., 362.

sessilis, Benth., 359.

vagans, $H b d ., 362$.

viridis, $H b d$, 361.

Stenotaphrum, Trin., 506.

Americanum, Schrank, 506. glabrum, Trin., 507.

Stephanotis floribunda, 299.

Sterculiaceae, 52.

Stibasia Donglasii, Presl, 543.

Stillingia sebifera, Michx., 393.

Straussia, Gray, 178.

Hawaiiensis, Gray, 180.

Kaduana, Gray, 179.

leptocarpa, Hbd., 180.

Mariniana, Gray, 179. oneocarpa, Hbd., 180.

Strawberry, 118.

Strelitzia augusta, 434. Reginae, 434.

Strongylodon, Vog., 100. lueidnm, Seem., 100. ruber, Vog., 100.

Strophanthus dichotomns, $D C$., 294.

Stylocoryne sambneina, 168.

Sugar-Cane, 512.

Sugar-Sorghum, 511.

Sumach, 89.

Sweet Potato, 314.

Syzygium Jambolana, 128.

Tabernaemontana eoronaria, R.Br., 294.

Tacamahaca resin, 40.

Tacea, Forst., 437. littorea, Rumph., 437. oceanica, Nutt., 437. pinnatifida, Forst., 437.

Taccaceae, 428, 437.

Tahitian Cane, 512.

Tahitian Chestnut, 109.

Tamarind tree, 109.

Tamarindus Indica, 109.

Tapioea plant, 393.

Tarachia caudata, Presl,602.

Tea plant, 41.

Teak tree, 340.

Tectonia grandis, 340.

Temminekia Chamissoniana, De Vriese, 267.

Gaudichaudii, De Vriese, 267.

mollis, De Vriese, 269.
Tephrosia, Pers., 94. piscatoria, Pers., 94. purpurea, Pers., 94. toxicaria, Gaud., 94.

Terminalia Catappa, L., 130.

Ternstroemiaceae, 2, 40.

Tetramolopium, Nees, 196. arenarium, IIbd., 199.

Chamissonis, Hbd., 199. consanguineam, IIbd., 199. conyzoides, Hbd., 200. humile, $H b d_{*}, 197$. Remyi, Hbd., 196. tenerrimum, Nee8, 197.

Tetraplasandra, Gray, 151, 154 . Hawaiiensis, Gray, 154. Waimeae, Waw., 15 .

Thalamiflorae, 1.

Thamnopteris, 585, 587. nidus, Presl, 587.

Thelypteris, Pres1, 574.

Theobroma Cacao, 52.

Thespesia, Corr., 49. populnea, Corr., 49.

Thevetia neriifolia, Juss, 294.

Thymeleaceae, 5, 383. Ti, 442.

Tiara, 171.

Tiliaceae, 2, 53.

Timonius Gaudichaudii, DC., 173.

Tithymalus, 398.

To, 512.

Tobaceo, 311.

Tomato, 302.

Tomato, Feejee, 305.

Totoe, 129.

Tou, 321.

Touchardia, Gaud., 414. Iatifolia, Gaud., 415.

Tournefortia argentea, L., 321. heliotropioides, Hook, 321.

Trachyrhynchium iridifolium, Nees, 480.

Tradescantia Jaeq, 446. effusa, Mart., 447. floribunda, Kth., 447. genienlata, Jacq., 446.

Trapa bicornis, 132.

Trema Amboinensis, Bl., 405. Trevesia, 156.

Tribulus, L., 58. cistoides, $L_{\text {., }} 59$.

Triehomanes, L., 634 . Bauerianum, Endl., 637. eyrtotheca, Hbd., 636. davallioides, Gaud., 636. Draytonianum, Braek., 635.
Trichomanes.

exaltatum, Brack., 637

filicula, Hook., 635 .

meifolium, Bory, 637.

opiifolium, Presl, 637.

parvulum, Poir., 635.

radicans, Hook., 636.

radicans, $\beta$, Baldwin, 637 .

Sandwiçense, Van d.Boseh, 636.

saxifragoides, Presl, 635.

Sibthorpioides, Gaud., 635.

Trifolieae, 92.

Triplasandra, Seem., 151.

Kaalae, Hbd., 154.

Lydgatei, Hbd., 153.

meiandra, Hbd., 152.

Oahuensis, Seem., 153.

Tripolium divaricatum, Nutt., 195.

subulatum, Nees, var. DC., 195.

Trisetum, Pers., 521. glomeratum, Trin., 522.

Tristegineae, 513.

Triticum vulgare, Vill., 525.

Tropaeolum, L., 58. majus, L., 58.

Turmeric, 435 .

Turnera trioniflora, 139. ulmifolia, 139.

Turneraceae, 139.

Tuta, 80.

Tutai, 400.

Uala, 314, 512.

Ubi, 314.

Ufi, 314.

Uhaobako, 377.

Uhi, 314, 441.

Uki, 445 .

Ulehihi, 441.

Ula, 408.

Uluhi, 543.

Ulnpua, 302.

Umara, 314.

Umbelliferae, 3, 142.

Uncinia, Pers., 485. australis, Hook., 485.

Lindleyana, Kth., 485.

Unuhi, 543.

Urena lobata, 42.

Urera, Gaud., 409. glabra, var. mollis, Waw., 411.

Kaalae, Waw., 411.

Sandwicensis, Wedd., 410.

Sandwicensis, var.glabella, Wedd., 410. 
Uiera.

Sandwicensis, var. glabra, Wedd., 410.

Sandwicensis, var. mollis, Wedd., 410.

Urtica grandis, Hook. \& Arn., 412.

Sandwicensis, Wedd., 409.

Urticaceae, 5, 403.

Urticeae, 404.

Uru, 408.

Uto, 408.

Unlei, 119.

Uwiwi, 166.

Vacciniaceae, 3, 269.

Vaecininm, L., 270.

calycinum, Sm., 271.

cereum, Ch. \& Schl., 271.

dentatum, Sm., 271.

Macreanum, Klotzsch, 271.

Meyenianum, Klotzseh, 271. penduliflorum, Gaud., 270. penduliflorum, var. berberifolium, Gray, 270.

retienlatum, $S m ., 271$.

reticulatum,. , Waw., 271. reticulatum, $\beta$, Waw., 270.

Vachellia Farnesiana, Wight \& Arn., 114.

Vallesia, Ruiz \& Pav., 297. macrocarpa, Hbd., 297.

\section{Vascular Crypto-} gams, 539.

Vegetable Marrow, 134.

Ventilago, 80.

Verbena, L., 340. Bonariensis, L., 340. officinalis, L., 340 .

Verbenaceae, 4, 339 .

Verbesina, L., 204.

alba, L., 203.

connata, Gaud., 206. encelioides, Benth. \& Hook. 204.

hastulata, Hook. \& Arn., 209. lavarum, Gand., 207.

lobata, Gand., 209. succulenta, Hook.\& Arn., 207.

Vernonia, Schreb., 191. cinerea, Less., 191.

Vernonieae, 191.

Via, 456.

Vicia, L., 97. grandiflora, Sm., 98. Menziesii, Spr., 97.

Vicieae, 97.

Vieillardia, Brongn., 368.
Vigna, Savi, 105.

anomala, Walp., 106.

Iutea, Gray, 105.

Oahnensis, Vog., 106.

Sandwicensis, Gray, 106.

villosa, Hook. \&Arn., 107.

Vilfa Virginica, Beauv., 517.

Villebrunea crenulata, Gand., 410.

Vinea, L., 294. rosea, L., 294.

Vineentia, Gaud., 480. angustifolia, Gaud., 480.

Viola, L., 1 . .

Chamissoniana, Ging., 17. helioseopia, Hbd., 17.

Kauaiensis, Gray, 15.

Mauiensis, Mann, 16.

robusta, $\mathrm{Hbd}$., 16.

trachelifolia, Ging., 17.

Violaceae, 1, 15 .

Virgilia anrea, 109.

Viscum, L., 392. articulatum, Burm., 392. moniliforme, BI., 392.

Visenia Indica, 52.

Vitex, $L_{r}, 342$. ovata, Thbg., 342. trifolia, L., 342.

Vittadinia arenaria, Gray, 199.

Chamissonis, Gray, 199.

consanguinea, Gray, 199.

conyzoides, Gray, 200.

humilis, Gray, 198.

Remyi, Gray, 197.

tenerrima, Gray, 198.

Vittaria, Sm., 551.

elongata, $S w ., 551$.

plantaginea, Bory, 551.

rigida, Kanlf., 551.

zosteraefolia, Bory, 551.

Vin, 451.

Vuga, 125.

Wahane, 451.

Wahine nohe manna, 5 วั6.

Waimakanui, 562, 629.

Walahee, 17.

Waltheria, $L_{+}, 52$.

Americana, L., 52.

Indica, L., 52.

pyrolaefolia, Gray, 52.

Water-Cress, 12.

Water-lemon, 139.

Watermelon, 134.

Watsonia, 436.

Wanke, 407.

Wawae jole, 640.

Wax-tree, Japanese, 393.
Wheat, 525.

Wi-fruit, 89.

Wiegmannia glauca, Mejen, 161.

Wikstroemia, Endl., 384.

bicornuta, Hbd., 387.

buxifolia, Gray, 387.

elongata, Gray, 385.

foetida, Gray, 385.

foetida, var. glauca, Waw.? 386.

Forsteri, Desne., 385

Hanalei, Waw., 386.

Indica, C.A.Meyer, 385.

phillyreaefolia, Gray, 388.

Sandwicensis, Meisn., 386.

tuva-ursi, Gray, 387.

villosa, Hbd., 386.

Wild Ipecac, 300.

Wiliwili, 100.

Wilkesia, Gray, 219. Grayana, Hbd., 220. gymnoxiphium, Gray, 220.

Wissadnla periplocifolia, 46 .

Woodwardia,Metten.,Fée, 584 . cyatheoides, Metten., 582.

Xanthim, Tourn., 201. echinatum, Murr., 202. macrocarpum, DC., 202. strumarimm, L., 202.

Ximenesia encelioides, Cav., 204.

Xiphopteris Jamesonii, Hook., 553 .

serrulata, Kanlf., ธ็ริ3.

Xylosma, Forst., 20.

Hawaiiense, Seem., 20.

Hillebrandi, Waw., 20.

orbiculatum, Forst., 20.

Yabia, 438.

Yasi, 389.

Youngia Japonica, DC., 233.

Yneea gloriosa, 439.

Zanthoxylum, L., 73. dipetalnm, Mann, 76. glandulosam, $\mathrm{Hbd}$., 74 . Hawaiiense, Hbd., 76. Kanaiense, Gray, 73. Mauiense, Mann, 74. Oahuense, $H b d ., 75$.

Zea, L., 512 . Mays, $L$., 512.

Zephyranthes, 436.

Zingiber, L., 434. offieinale, L., 434. Zernmbet, Rose., 434.

Zygophyllaceae, 2, 58 . 
Frintel los C. P. Wiater, Darmitadt.

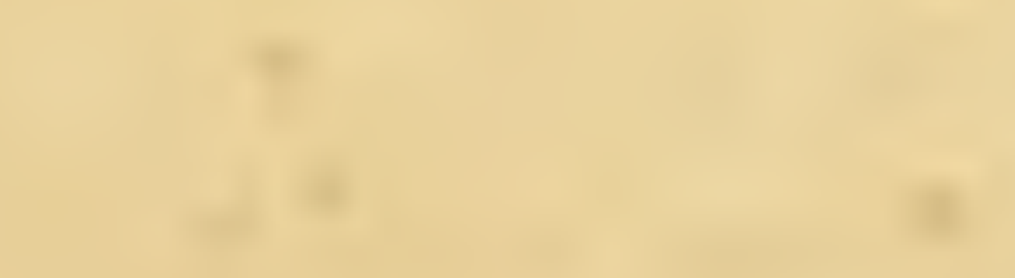




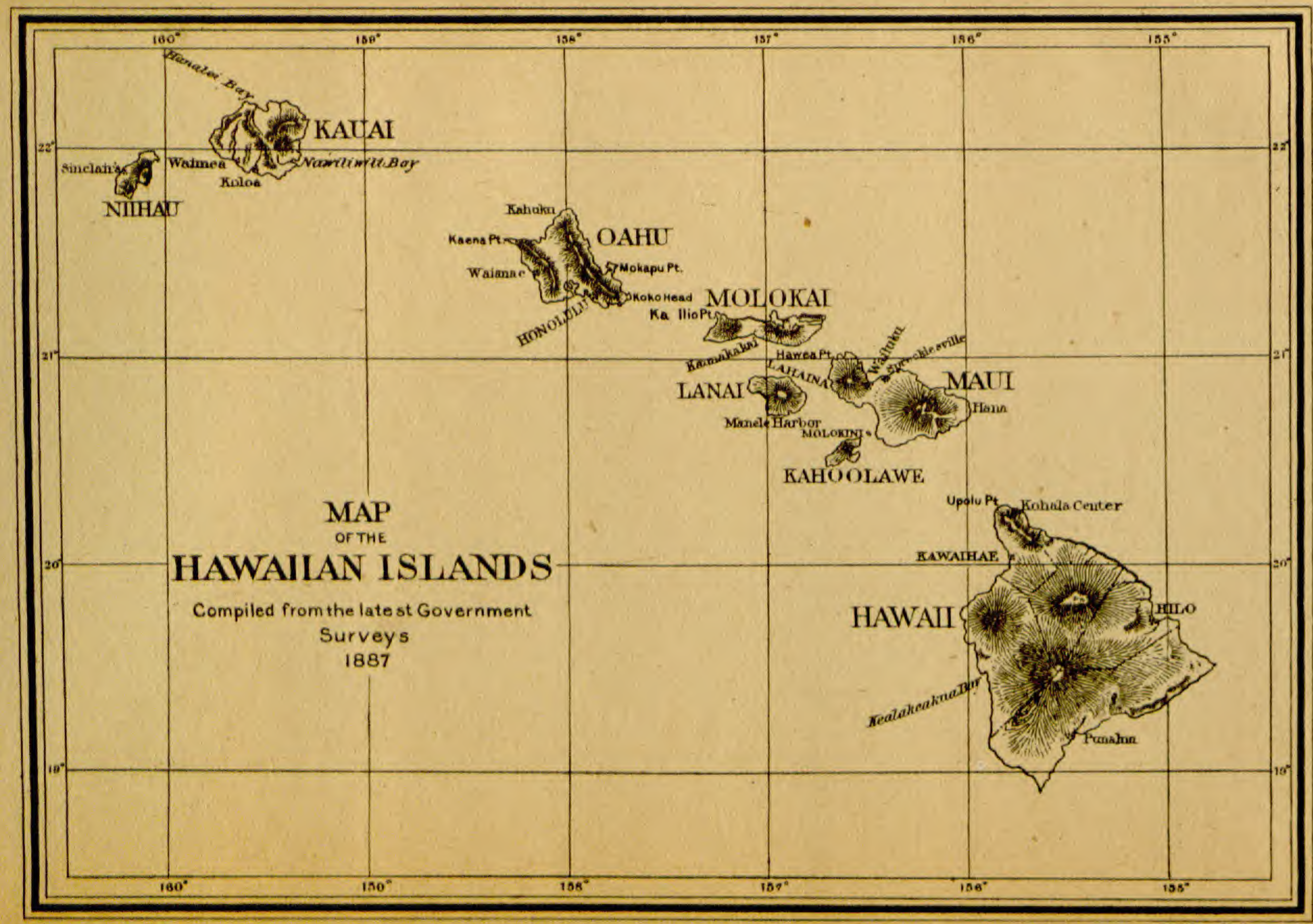




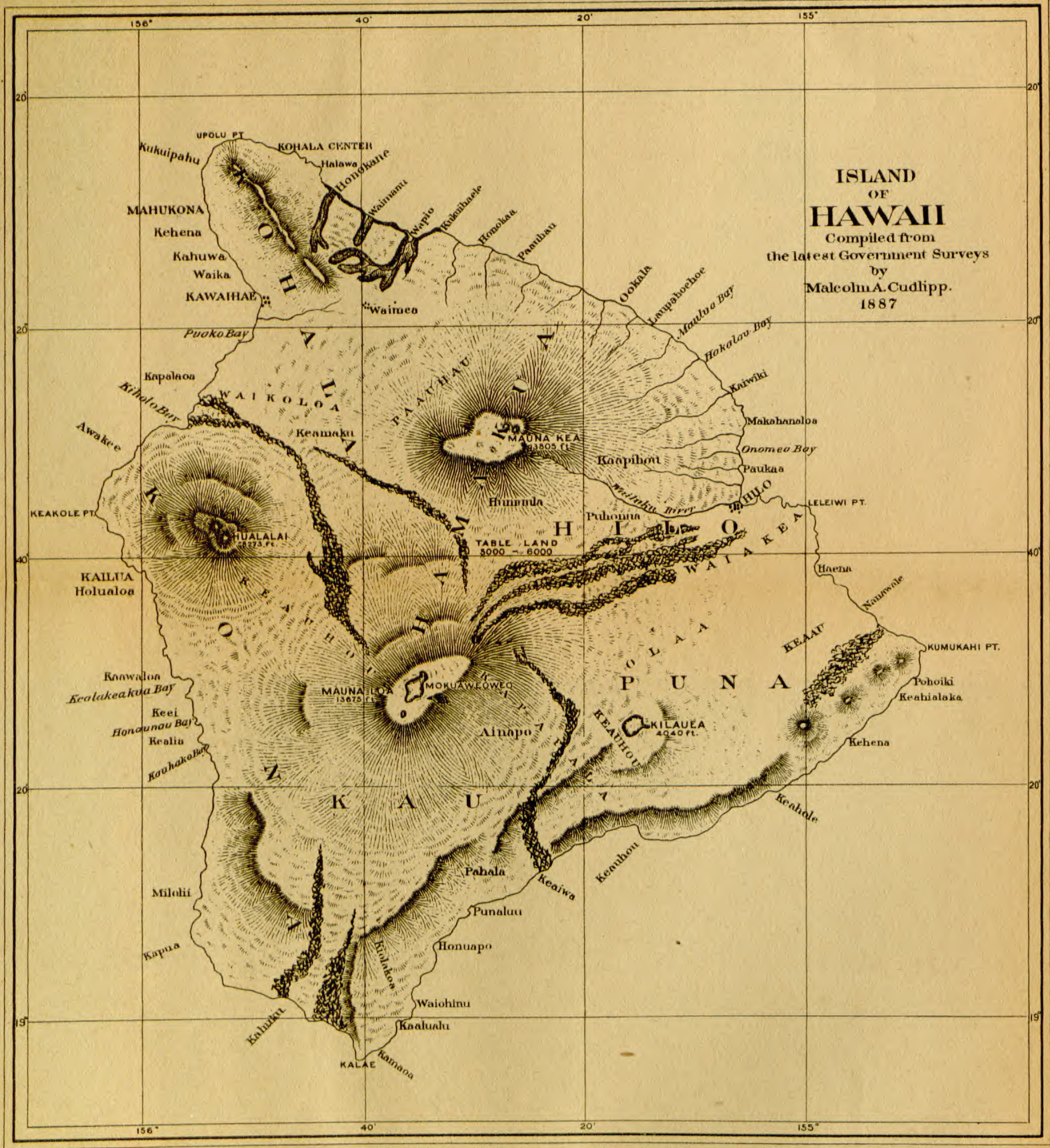











